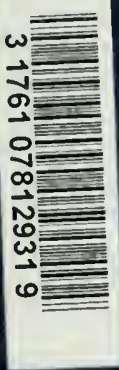

45

The

W. W.6. H.

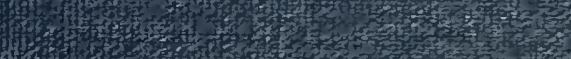

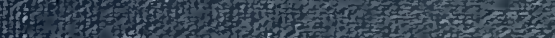

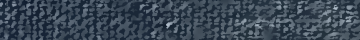
ontry $1+1950$. 15.

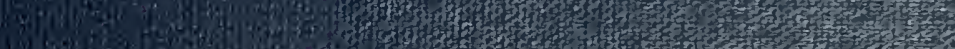

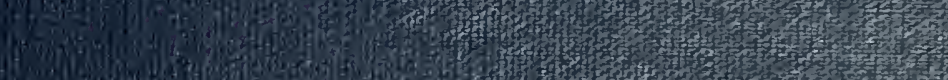

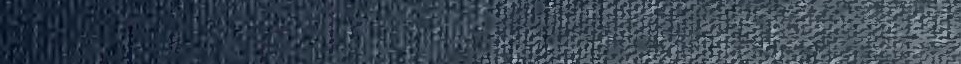

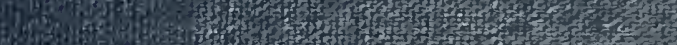

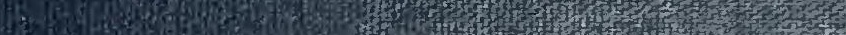
N.6. 6. 20 .

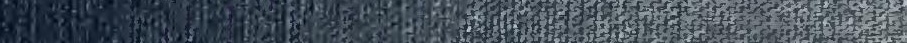
1.

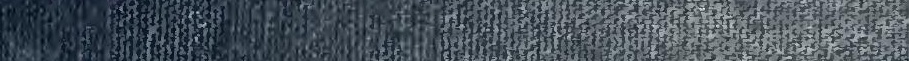

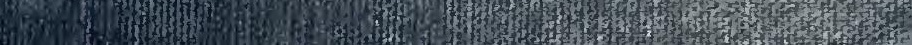


Digitized by the Internet Archive in 2010 with funding from University of Toronto 



($$
\text { ( }
$$

$$
\text { F, }
$$

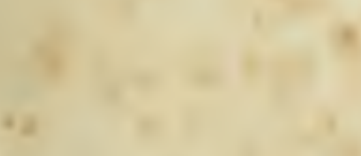




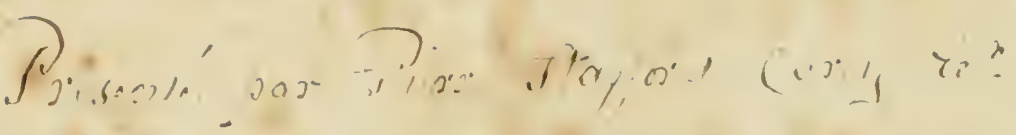

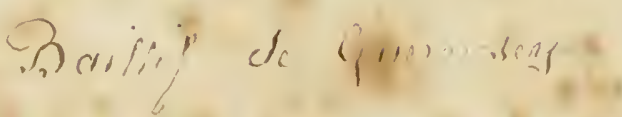

is $P$ c.

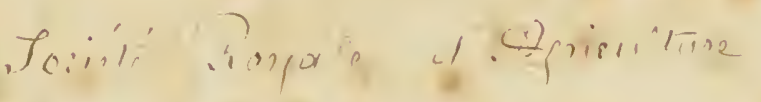

de. Guenmides.

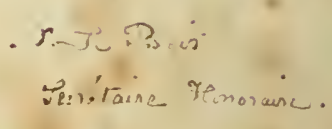

A + is 
Brought from the Lords, 6th March 1897.

\section{$\begin{array}{llllll}\mathbf{R} & \mathbf{E} & \mathbf{P} & \mathbf{O} & \mathbf{R} & \mathbf{T}\end{array}$}

FIOM THE

SELECT COMMITTEE

OF

THE HOUSE OF LORDS

A PPOINTED TO INQUIRE. INTO

\section{THE STATE OF AGRICULTURE}

IN

\section{ENGLAND AND WALES;}

WITH

THE MINUTES OF EVIDENCE,

APPENDIX AND INDEX.

Ordered, by The House of Commons, to be Printed, 30 June 18.37. 

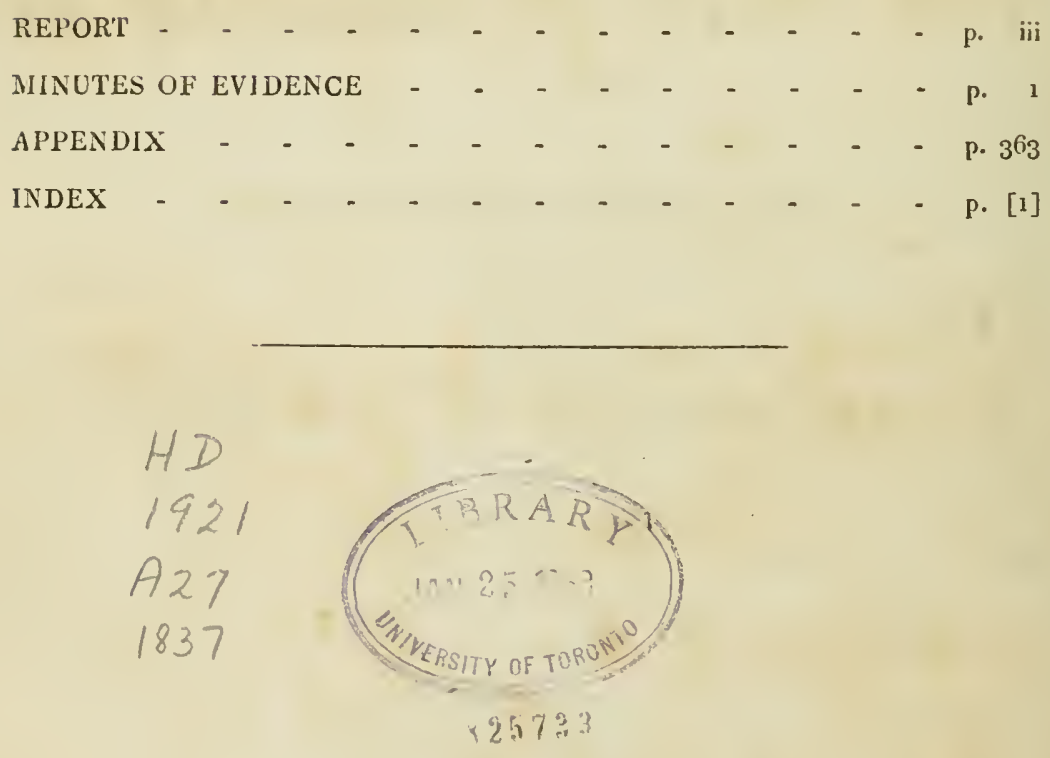


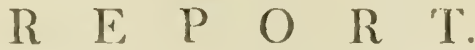

\section{BY THE LORDS COMMITTEES appointed a SELECT Com-} artese to inquire into the State of AgRICULTURE, and into the Causes and Extent of the Distress which still presses upon some important Branches thereof, and to report thcir Obser-

- vations and Opinions thereupon to The House; and to whom leave was given to report from time to time to The House; and to whom were referred certain Petitions and Papers relating to the Matters under the Consideration of the Committee ;-

ORDERED TO REPORT,

THAT the Committee have met in pursuance of your Lordships' Order of Reference, and have examined a great Number of Witnesses, and collected a great mary very important Documents relating to the extent and causes of Agricultural Distress; but they have not agreed on any Report on such Evidence to be submitted to your Lordships.

And the Committee have directed the Evidesce taken before them, together with an APPENDIX and INDEx thereto, to be laid before your Lordships. 


\section{I S T O F W I T N E S E S.}

Die Luna, 22 $2^{\circ}$ Februarii, 1836 .

Thomas Waring, Esq.

John Green, Esq

William Jacob, Esq. -

\section{Die Jovis, $25^{\circ}$ Februarii, 1836.}

John Rickman, Esq.

Mr. William Bennett

Mr. John Thomas Twynam

Die Veneris, $26^{\circ}$ Februarii, 1836.

Mr. Jolın Mockett Cramp - $\quad$ - $\quad$ - 39

Mr. John Joseph Allnatt - $\quad$ - $\quad$ - 40

Mr. Joln Lewin - $\quad$ - $\quad$ - 50

Die Luna, $29^{\circ}$ Fcbruarii, $183^{6}$.

Mr. Samuel Kendall - $\quad$ - $\quad$ - $\quad$ - 59

Mr. Evan David - _ $\quad$ - 64

Die Marlis, $1^{\circ}$ Martii, 1836.

Mr. George William Firclsild _ $\quad-77$

Mr. John Nearne - $\quad$ - $\quad$ - $\quad$ - 80

Mr. Richard Peyton - _ _ $\quad$ - 83

Die Jovis, $3^{\circ}$ Martii, 1836 .

James Bernard Bernard, Esq. - $\quad$ - 86

Henry William Wilson, Esq. - $\quad-9^{2}$

Die Veneris, $4^{\circ}$ Martii, 1836.

lavid Hodgson, Esq. _ - - $\quad$ - 101 Charles Howard, Esq. _ _ - $\quad$ - 114

Mr. William Thurnall _ $\quad$ - $\quad$ - 121

Die Lunc, $7^{\circ}$ Martii, 1836 .

Mr. Edward Bradley - $\quad$ - $\quad$ - $\quad$ - 133

Mr. James Grinling Cooper $\quad-\quad-140$

Mr. Richard Hoare Dowling - $\quad$ - 146

IIenry William Wilson, Esq. - $\quad$ - 154

Die Martis, $8^{\circ}$ Martii, 1836.

Mr. Jolnn Thomas Carter

Mr. Rober Hughes -

Mr. George Trumper - $\quad$ - $\quad-\quad-165$

Mr. James Taylor

Mr. James IIudson - - $\quad-\quad-176$
Die Juvis, $10^{\circ}$ Martii, 1836.

Edward S. Cayley, Esq., M. P. - - $\quad$ 181

Die Veneris, $11^{\circ}$ Martii, 1836.

John Langhorne, Esq. _ _ $\quad$ - $\quad-215$

Mr. Abcl Sharpe - - $\quad$ - $\quad-224$

Joseph Sandars, Esq. $\quad$ _ $\quad \ldots \quad$ _ $\quad$ - 228

John Beresford Turner, Esq. - $\quad$ - 236

Die Luna, $14^{\circ}$ Martii, 1836 .

Edward S. Cayley, Esq., M.P. - $\quad-236$

Michael Comport, Esq. - $\quad$ - $\quad-248$

Richard Spooner, Esq. $\quad$ - $\quad$ - $\quad-252$

Die Martis, $15^{\circ}$ Martii, 1836 .

Richard Spooner, Esq. $\quad$ - 259

Die Veneris, $18^{\circ}$ Martii, 1836.

Mr. George Frederick Muntz - $\quad-275$

John Grey, Esq. - $\quad$ - $\quad$ - $\quad$ - 286

Mr. Matthew Sherborne - - $\quad-293$

Die Lunce, $21^{\circ}$ Martii, 1836 .

Bickham S. Escott, Esq. - _ - $\quad$ - 295

Die Veneris, $25^{\circ}$ Martii, 1836 .

Bickham S. Escott, Esq. - - $\quad-309$

IVilliam Blamire, Esq. - $\quad$ - $\quad-315$

Mr. WVilliam Summers - $\quad-\quad-318$

Die Luna, $9^{\circ}$ Maii, 1836.

James Patison, Esq., M. P. - $\quad-326$

Die Jovis, $2^{\circ}$ Junii, 1836 .

Matthias Attwond, Esq., M.P. - $\quad-338$

Die Luna, $13^{\circ}$ Junii, 1836 .

Mr. William Blacker - $\quad$ - $\quad-356$

Mr. Carter Fairbrother - _ $\quad-361$ 


\title{
MINUTES OF EVIDENCE.
}

\author{
Dic Luna, 22 Februarii, 1836.
}

The Lord WYNFORD ix the Chair.

Thomas Waring, Esq., is called in; and Examined as follows.

1. WHERE do you live?-At Chelsfield, in the county of Kent.

2. You are a considerable occupier of land ?-To some considerable extent; about 1,000 to 1,100 acres.

3. Is it your own?-A great part is mine; about 1,000, acres of it is my own, and the rest I lire of Mrs. Waring's sister.

4. Is it freehold?-Yes.

5. Is it arable:-I have some of all sorts; arable, fruit, hops, meadow and wood.

6. How long have you been an occupier of land?--I think about 45 years; I was very young when I first took the farm.

7. What is the state of agriculture in your part of the country, in your district? - Exceedingly bad.

8. Do you think, from your own observation with respect to the management of your own farm and wliat you see of others, that it is impossible that a farmer can make by the cultivation of lands for corn any thing like a profit:-Certainly not, at present.

9. How much rent could he make :--I should say very little, if any.

10. Did you, in company with any other respectable farmers, make a calculation lately of the expense of cultivation of land for four years, and the value of the produce of those lands:-I did.

11. How much, upon that occasion, did it appear there would be reserved for rent:- On the calculation of one acre of land on the hills sown with corn, we could not make more than $2 s$. and about $1 \frac{1}{2} d$. for rent; land which is supposed to be worth $15 s$. an acre.

12. Was that through the whole course for the four years?-Yes.

13. Will you be so good as to state the rota of crops; you begin with a fallow? -Certainly; I begin with a fallow the first year; then sow with wheat, which is the regular system on the hills, then with clover, then with oats, and then with tares; that is generally the system on the hill farms; it is not exactly my system of farming, but the general system on the stiff lands.

14. According to your system, on the whole of the four years is there any thing more than this $2 s$. I $\frac{1}{2} d$. for rent:-No.

15. Is there any thing for the interest of the capital of the farmer?-According to our calculation, there is not a shilling.

16. Is it possible that the farmer can longer go on cultivating land?-I should say, upon those hills it is quite impossible.

17. Of what description of land do you speak; strong clay?-Mostly clay, where they use that system of farming; i do not use it mysclf.

18. What quantity per acre of wheat, in the first year, would be produced ?I should say about three cuarters, on the average of land of that description; the second year we should sow with clover.

19. What would your clover be worth the second year :-That rery much depends upon the season; there is a probability of its being spoiled; but a load an acre would be about the mark; that is 56 trusses of 56 pounds per truss.

20. At what do you take the value of wheat; how inuch per quarter?-In this calculation I should take it this year. If I was to put it at $40 \mathrm{~s}$. that would be quite the extent.

21. Would it not lue a great deal above ?--That would certainly be the extent. 464 . 
T. Waring, Esq.

22 February 1836

22. Did you make the calculation at the price of $40 s$. a quarter?-We put it down at that.

23. Calculating the expense of the first year, the three quarters of wheat to be sold at $40 \mathrm{~s}$. a quarter, was there any profit at all:-No, not on the first year; a loss of $4 l$. or $5 l$.

24. Is it possible, in your opinion, to cultivate this sort of land in any way to produce any profit?-I should think not; it is generally supposed to be the best system of farming on the hills.

25. What was the value of your crop the second year?-I think the value of it, deducting the expense of making and carrying, was about $2 l$. odd.

20. What were the expenses? - I can hardly say within a trifle; there is the tithe to be deducted; I think the expense of making we reckoned about $1 l$.

27 . Was there any profit in that year?-Yes, I think about $2 j s$. or $26 s$. in favour of the farmer.

28. That would not fetch up the wheat ?-O dear no.

29. What did you cultivate it with the third year?-With oats, according to that manner of farming.

30. What would be your expenses that year?-I cannot say exactly; I was not prepared with these particulars.

3. Can you supply that another day :-Yes; I did not receive my order till Saturday night; I know, on the whole calculation, there was about $2 s .1 d$. or 2 s. $2 d$. per year for rent.

32. That is all which there would be for payment of rent; there would be nothing for the farmer's profit or his capital?-No, only $2 s$. a year for the landlord.

33. As you have been a farmer for 45 years, what is the difference of the rate of expense in cultivating a farm now and when you first began :- I do not think there is a great deal, except in the taxes; the men's wages are pretty much the same; even now we give them as much as we used to do then; we gire them $2 s$. a day; we gave them no more when wheat was $24 l$. or $25 l$. a load.

34. What proportion do the wages of labour bear to the rent generally?I think that the labour is beyond the present rent, clearly.

35. Is it possible that you can go on employing men, paying them at the rate at which you now employ them, at the present prices?-I should think it quite impossible long to do it.

36 . What is the state of the poor in your county now ; are they satisfied or dissatisfied :-I think they are tolerably satisfied.

37. If this system of husbandry goes on at the rate at which it goes on now, must there not be a great number turned out of employment?-There must be. Speaking of my own local knowledge, we have now a new turnpike-road going on, which has taken off all our surplus poor; there are not a great many out of employment.

38 . Before that new turnpike-road was begun, what was the state of your poor? ?-Very bad.

39. How many men have been out of employment? - In our small parish from 10 to 15 .

40. What is your population:-About 700 .

41. Those men were not in a good state?-Certainly not.

42. In what condition were they? - We were obliged to employ them on the roads, and some received $8 \mathrm{~s}$. or $9 s$. a week, and we made it up $2 s$. per head a week, according to the family.

43. You state that the average was about three quarters of wheat the acre; does that apply to land after a dead fallow:-Yes, taking four or five years together.

44. If you went down to the ralleys, what would the difference be?-In the valleys it might be a little more; perhaps three quarters and a half.

45 . Is it your opinion that even in the valleys land ean be cultivated with any thing like a profit?-Not at the present price of corn; not even my own farm.

46. Do you attend the markets :-Very little indeed.

47. You do not know whether the market is glutted with corn or not?-No;

I very seldom go there.

48. You take your rent at $15 s$. an acre?-About $15 s$. an acre.

49. How much a year should you say was the amount of the expenses per 
acre for labour?-That depends upon what the field would be for one year; if fallow it would be increased considerably.

50. Will you give it year by year on your average of four years?-I can hardly speak to it for the four years.

51. What would be the expense on the year of fallow :-I cannot recollect that particularly, in the manner we have stated it.

52. It depends a good deal upon the season?-Ycs; I am speaking, not for one year, but four or five years.

53. Even the fallowing of land depends upon the state of the weather very much?-Yes; it may make a difference of five or six bushels an acre, whethes it was fine weather, and whether it was a kind season or not.

54. How many ploughings do you reckon?-Four for a fallow; it cannot be done for less.

55. How many ploughings between the wheat and clover?-None for the clover.

56. How many ploughings between the clover and the oats?-Only one.

57. What do you reckon the charge for the manure?-We did not reckon any thing; we reckoned the straw, and only the carting it out; that the straw was to be trodden to pieces to make the manure the first time, and what might be wanted afterwards.

58. You did not reckon for the purchase of artificial manure?-No; there is very little fetched in this part of the county; it is too far, and it is too much expense; I fetch a good deal of sugar scum.

59. What is the expense of poor-rates per acre?-I think we pay about $4 s$. per acre, or $5 s$. ; we pay nearly $6 s$, in the pound.

60. Are there any other taxes on the land beside poor-rates?-Church-rate and highway-rate.

61. At what do you calculate those:-Generally from $6 d$. to $9 d$. in the pound; we are generally rated at $3 s .4 d$; that would be $15 \mathrm{~s}$. for land worth $1 l$. an acre.

62. Land-tax?-My land-tax is all redeemed; I paid 233l. 2s. 6d. poor-rate last year, and highway-rate.

63. If the land-tax had not been purchased, what would it have been?-About $1 s$. in the pound, as we are rated; we are rated at about two-thirds of our value; it would be about $8 d$. in the pound.

64. Do you pay tithe in kind?-No, we compound for it; in one parish they take it in kind; I have land in five different parishes.

65. You say that the state of agriculture now is very much depressed; do you impute that chiefly to the prices, or to what causes?-I think to the prices; the expenses are so much more in comparison to the prices.

66 . When the prices were bigher had the farmers greater facilities in any way for carrying on their business than they have now? - No, I think not.

67 . Have the three last seasons been favourable to you or not:-Yes; the two last particularly; I should say there has been rather more than an average crop.

68. Do you think that the last year there has been a fair average?-Rather more, I should say.

69. Of all sorts of grain as well as wheat?-Yes, just in our neighbourhood; but 1 know in other places they have been a great deal worse; in Sussex their lent corn is much worse.

70. The greatest depression is upon wheat?-Yes.

71. Do you find that your county-rates come heavy upon you?-Yes.

72 . You were understood to say that the prices were the only thing that pressed upon you as a farmer?-No, not the only thing.

73. Since what time has farming become so much more depressed?-Only since the fall in prices; I should think the last two or three years; before they were very fair.

74. You remember occasionally low prices 12 or 15 years ago ?-Yes; they were not so low then as they are now; not the wheat; I think I never sold wheat at $38 \mathrm{~s}$. before till this year.

75. You do not happen to have the account by you of the prices of wheat in 1822 and 1823 ? -No; in 1822 they were very low, I know.

76. Was the price lower than 40 s. in 1822 ?-No ; I never sold any wheat at 40 s. till this year, I think, since I have been a farmer.

464. 
T. Waring, Esq. 22 February $1 s_{3} 6$. so lieavy.
77. Did the lowness of price in those two years affect the farmer or not?No; I think there were not so many out of employment; the poor-rates were not

75. It appears by the Report made to Parliament that the price of wheat in 18.2 .2 was $42 \mathrm{~s} .11 \mathrm{~d}$., and in 1823 was $40 \mathrm{~s}$. $7 \mathrm{~d}$; how do you account for it that the farmers did not feel the same distress then as they do now $:$ - I have no doubt they must have felt the distress then, but it was not so permanent; it has been now two years.

79. Is the capital very much reduced?-Yes; I know many little farmers that cannot pay their rents; the small farmers suffer the most; they are obliged to bring their corn to market; others who are better off can keep back a little; I have threshed very little new wheat yet.

So. Does the poor state of the small farmer press down the price of wheat?-I should think that very probable.

81. What was the state of the crops in 1822 and 1823 ; have you any recollection whether they were good or not?- $\mathrm{No}$, I have not a recollection at this moment; I think they were not very good then, to the best of my recollection.

S2. What do you suppose is the difference between the poor-rates in 1822 and 1823 , and those at present?-I should think probably they are $1 s$. in the pound more now than they were then.

83. That will make a considerable difference :-Yes; I am speaking off-hand; I do not know that I am quite correct.

$S_{4}$. The price of wheat has got up with in the last few weeks?-It has, a little.

85. Do you think any number of the farmers will be able to avail themselves of that?-A good many farmers, I have no doubt, have considerable quantities on hand; but the small farmers have been obliged to sell.

86. The last two years the crop has been above an average crop?-Rather more than an average, $I$ think.

87. Are you of opmion that the farmers' difficulties arise principally from the low price of wheat?-Yes.

SS. Do you keep sheep?-Yes, a large flock.

S9. Do you consider the sheep beneficial to the farm in keeping it in good heart $:-$ Yes.

90. They save you in manure?-Yes; it is the chief advantage we have at a distance, for they serve to manure the land.

91. Do you think the alteration of the currency had any thing to do with the distress of the agricultural interests?-I cannot say that in my opinion it had; it may have had some; I never in my life had any thing to do with the country banks.

92. How far from London do you reside ?-Seventeen miles.

93. Have you had many fires in your neighbourhood lately? - We had one last Friday week ; that is one great reason why we cannot reduce our labour.

94. Should you otherwise have reduced your labour? - I should, certainly.

95. Can you go on paying the present wages?-No.

96. You would decrease them but for the fear of fires? - I think we should do so, certainly, from the necessity of the case.

97. How do you account for the price of wheat getting up rapidly lately ?I think the markets are not so well supplied as they were; one reason is, I apprehend, that the farmers are engaged in threshing their seeds, in threshing their lent corn.

98. Have you ever been in the habit of employing other men than your own population in agricultural labour $-\mathrm{No}$.

99. Have any of your agricultural population emigrated?-None; in fact, if it were not for my own property (I employ near half the parish, a grcat part of them in what I call improvements) our rates would have been exceedingly higher than they are; and we have a great many of our poor on the new road, which has relieved us very much this winter.

100. What is the acreage of your parish - -As near 3,000 acres as possible.

101. Have you any considerable landlord who does not live in the parish? None; we have one gentleman who has lately got his farm in his own hands because he cannot let it, and he himself is one of the proprietors in the parish.

102. Have rents been very much reduced :- They have been reduced, but not very much.

103. What has been the highest rent per acre on the hill lands?-I do not think 
think there has been much alteration in the hill lands; it is more in the low lands.

104. Is it the practice there to rent some of the low lands with the high lands?

-Yes, in some instances; several farms are entirely hill farms; they could not put any low land with them.

105. Yon reckon the average value for the hill and dale land at $15 s$. an acre? -Yes: that is about a fair average; but the hill land will not bring now $15 \mathrm{~s}$.

10 . What do you consider the average of value, hill and dale?-A bout $15 \mathrm{~s}$.

107. What proportion of each? - I should think there is rather more of the low land; I do not think there is half hill land in the hundred.

108. At what do you reckon the produce of wheat in the low land?-Taking the average of the one and the other, I do not think that it will be more than I mentioned; they frequently grow not more than two quarters on the hill land.

109. What is the most you liave known on the low land?-We reckon from four quarters to four quarters and a balf a very good crop.

110. What should you consider the average produce of low land?-Three quarters and a half is a full average, I sloould think.

111. IIow much seed do you sow ? - Three bushels.

112. Will the low lands pay the expense of cultivation?- Certainly not, at those prices.

113. Can the farmer go on many years without being ruined ?-I should think not; I know I can save no rent myself; I am astonished how people pay rent.

114. Do you know the state of the poor in Mary's Cray and Paul's Cray? No; I have land niyself in Orpington.

115. What is the state of the poor there; I have understood by report that they are very badly off; in fact, but for the turnpike-road our part would have been very badly off.

116. Do you not know that there is a very unpleasant feeling amungst the poor there?--There certainly is a very unpleasant feeling.

117. How many fires have you had within five miles within the last twelre months?-Five or six ; they have been all very recently.

11\&. It is your opinion that the present price of wheat is out of proportion to the price of the rent of land?-Yes.

119. And that the rents are paid out of eapital, and not out of profits?They must be now; and in my opinion it is impossible they can go on under the present system.

120. What quantity of sheep do you keep on your farm?-I keep about 600 .

121. Do you breed them?-No, I generally buy them; but many have sold their sheep, though mutton is rising now.

12. How came they to sell them?-I suppose because they wanted the money, or had no food for them.

123. Did they sell them when it was not profitable to sell them?-Yes, some, on account of the short feed.

124. You conceive that they were sold because of the distressed state of the tenantry?-Yes; and some of them the want of food.

125. Have any sheep been fed upon wheat this year?-Some have been, but not in our neighbourhood. I have fed them myself on oil-cakes, and I have been very fortunate in my droves.

126. What may be the average of sheep in proportion to the acres?-We generally reckon that we keep a sheep to an acre of land; that is about the mark, taking the farm all through.

12\%. Have you any practical acquaintance with the feeding them with malt? - No; I was going to try barley, but $\mathbf{I}$ was persuaded that it was dearer than oilcakc, and I pursued that.

128. Your land is not adapted for barley :-No; I sow very little barley.

129. How many acres of wheat had you last year? - I think six or eight-andforty. I grow very little corn now, and have very much less expenses in consequence.

130. The farmers are reducing the quantity of corn, in conseriuence of the expense of cultivation, and the low price of the produce?-I think they are, certainly.

131. How have you reduced your expenses? - I have put a team away, and 464. 
T. IIaring, Esq. shall put another away; I have laid down some in grass; and reduced my expenses in that way.

22 February $1 \$ 36$. 132. If that goes on must it not be attended with the consequence of a great many poor being turned out of employment?-Certainly; it will increase the poor-rates.

133. You employ fewer labourers than you did?-Yes, I certainly do.

134. How many fewer?-Not many; it is chiefly the team-men and the expense of the team of horses.

135. How many men have you discharged?-Only the team-men, a man and his mate, and the team of horses; saving about $100 l$. a year.

136. Have you not reduced the wages?-No.

137. You mean that four horses and two men cost you $100 \mathrm{l}$. a year?-Yes.

13S. Though you have not been obliged to reduce your number of men so much, what has been the case with the poor farmers?-They have been obliged to reduce them. I have been obliged to take some of them myself, being a large landed proprietor.

139. You have not had so many labouring men employed upon your land as formerly? -I think I have had very little difference, for I have been planting a good deal of forest wood; I have planted 50,000 lately, merely to employ the poor; and I have a good deal of hops and fruit, which I keep up to employ the labourers.

140. What effect has your ploughing less had upon your power of keeping sheep?-I do not think it can make much difference in that, for I keep that land down; I do not buy quite so many sheep.

141. Shall you be able to keep more sheep upon it in consequence?-I do not know that that will make much difference; I am obliged to use more artificial food in the winter.

[The Witness is directed to withdraw.

John Green, Esq., is called in, and Examined, as follows.

J. Green, Esq. 142. YOU live at Eltham?-Yes.

143. How long have you been an occupier of land?-All my life; I have been a farmer, perhaps, two or three-and-forty years.

144. Do you occupy a large quantity :- Now I do not occupy above 900 acres; my son has about 200 acres, making 1,100 acres.

145. You farm a considerable estate under the Crown?-I do.

146. Is that in your own occupation?-Entirely.

147. Have you any land of your own in your occupation?-About 300 acres.

148. Is that included in the 900 ? - Yes.

149. Have you a good deal of arable land?-About half; about 400, or between 400 and 450 acres.

150. What is the state of agriculture in that part of the country?-Certainly in a very distressed state. I have made out a statement; I was not summoned till Saturday; but I believe it is correct.

151. Of what is that a statement:- It is a five years' course.

[The same is delirered in, and read; and is as follows:]

A STATEMENT of the Expenditure and Receipts of Corn Crops for Five Years :

One ploughing; five horses - -

Four times ploughed, at $15 \mathrm{~s}$. per acre

Three times ox-harrowed, at $2 s .8 d$.

Rolling

Labour, for carting dung and spreading

Taxes

Rent

$\begin{array}{ll}\text { Fallow: } \\ - & - \\ - & - \\ - & - \\ - & - \\ - & - \\ - & - \\ - & -\end{array}$

\begin{tabular}{rrrr|rrr}
- & - & - & - & f. & $s$. & $d$. \\
- & - & - & - & - & - \\
- & - & - & - & - & - & - \\
- & - & - & - & - & 7 & - \\
- & - & - & - & 1 & 5 & - \\
- & - & - & - & - & 6 & - \\
- & - & - & - & 110 & - \\
\hline
\end{tabular} 


\section{Brought forward - Wheat:}

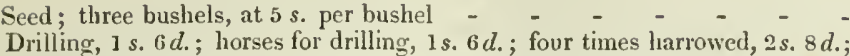
striking furrows, $1 \mathrm{~s}$.

Hoeing

Hand-weeding

Harrowing, sowing, and rolling secds

Reaping

Carting to barn

Threshing four quarters, at $5 \mathrm{~s}$. per quarter

Delivery

Rent

Taxes

Tithe of four quarters, at $40 \mathrm{~s}$.

By four quarters of wheat, at $40 s$. -

Loss on the two first years

One peck of clover seed -

Rolling for mowing

Mowing twice

Turning and making clover

Carting $2 \frac{1}{2}$ loads, stacking and thacking

Rent

Taxes

Tithe on $2 \frac{1}{2}$ loads, at $4 l$.

Binding $2 \frac{1}{2}$ loads, at $2 s$; commission at market, $12 s .3 \frac{1}{2} d$.; delivery, $10 \mathrm{~s}$. per load

By $2 \frac{1}{2}$ loads of clover, at $4 l$. -

Loss on the third year

One ploughing

Seed, five bushels per acre, at $1 l$. -
Harrowing, $2 s .8 d$.; striking furrows, $8 d$. ; rolling, $10 d$. ; sowing, $6 \bar{d}$.

Mowing and binding

Carting and stacking

Threshing eight quarters, at 1 s. 6 d.

Delivery

Taxes

Rent

Tithe on eight quarters, at $1 l$.

By eight quarters of oats, at $1 l$. per quarter

Loss on the fourth year -

One ploughing

Three bushels of seeds, at 1 l. $16 \mathrm{~s}$. per quarter -

Sowing and drilling, $1 \mathrm{s.} 6 \mathrm{~d}$.; four horses, $1 \mathrm{s.} 6 \mathrm{~d}$. -

Harrowing, 2 s. $8 d$.; striking furrows, $10 d$.

Horse-hoeing, three times, at $4 s$.

Reaping

Carting and stacking

Threshing four quarters, at 1 s. 6 d. -

Delivery

Taxes

Tithe on four quarters, at $36 \mathrm{~s}$. per quarter

Rent

By four quarters of beans, at $1 l .16 s$. per quarter

Profit on five years

No charge for hedging, ditching, bird-keeping, loss of crops, interest on capital 464 . employed, and the farmer's labour, and housekeeping.
J. Green, Esq.

22 February 1836. 
152. Are you quite sure that that is an accurate statement?-I am.

153. That $19 s .9 \frac{1}{d}$. is the whole profit for the five years on an acre of ground 22 February 1836 . - Y es.

154. There is no allowance for your capital, for your trouble, or for risk:-No.

155. How long have the prices of agricultural produce been in so very depressed a state - $-A$ bout seven or eight years ago wheat was as low as it has been this year, but not last year; last year the price was about $43 \mathrm{~s}$. or $44 \mathrm{~s}$.; now it has been $40 \mathrm{~s}$. for some time; there is a little advance in the market just now.

156. Is it possible the arable farmers can carry on their farms with their present expense, and at the present low prices of produce?-No, it is perfectly impossible. I am certain that I am correct in my statement.

157. How do you explain that there is this profit; you say that the loss for the two first ycars was $6 l$. $1 \mathrm{~s}$. $8 d$., the loss of the clover year $2 l .6 s .2 \frac{1}{2} d$, the loss on oats $2 s .10 \frac{1}{2} \mathrm{~d}$, the profits on the fifth year $7 l$. odd; how then can there be a profit, inasinuch as the loss on the first, second, third and fourth year amounts to between $8 l$. and $9 l$. ? -1 think you will find I am correct in my statement.

$15 \mathrm{~S}$. What is the state of the poor in your parish -We are not so heavily burthened as in some other parishes; our rates are about $4 \mathrm{~s} .6 \mathrm{~d}$. in the pound; but we are rated on only two-thirds.

159. Have you many out of employment :-Not a great many now; we do employ them; they may be said to be out of employ when they throw themselves on the parish, but we have a method of employing them making pimps; we make pimps for lighting fires.

160. Is that a profitable employment :- We just make them earn their living by it ; it keeps them employed.

161. Can you go on long to pay the present wages ?-We cannot go on, certainly, in the state we are in; we are sacrificing every thing.

162. Are you sacrificing your capital now in paying the wages and other expenses you have to pay? - No doubt of it. This paper is perfectly correct. If I may be allowed to say, there are some things I liave not charged; for instance, water furrowing; that is, drains to let off the water.

163. Does the $6 s$. burthen include the county-rates?-That includes the whole.

164. The church-rates, highway-rates, and poor-rates - Yes; but within the last few years we have had a very heavy gaol-rate, and a lunatic-asylum rate also.

165. Do you mean to say, from the statement you have given in, which is decidedly an expensive way of farming, you have liad every one of those years the very good crop referred to, or that that is an average crop for the years referred to?-No; I do not make allowances for the failure of crop; I am taking four quarters on the acre; we scarcely ever exceed that; the year before the last we did not exceed two and a lialf; I have put it at the highest.

166. Do you farm your own land ?-I do.

167. Have you made any attempt to reduce wages:- We have reduced them to $12 s$. a week; we used to pay $15 s$.

168. Have you made any attempt to reduce them lower than $12 \mathrm{~s} . ?-\mathrm{No}^{\circ}$; in fact we are going to raise them about Lady-day to $15 \mathrm{~s}$. again.

169 . For what reason?-It adds to the comfort of the poor, I think, and it keeps them more quiet.

170. What do you mean by keeping them more quict; are you apprehensive of fires :- ITe are desirous of attending to the comfort of the poor; they are not altogether very desperate with us, but they are not far off, I believe.

171 . Do not you think $12 s$. a week wages for the labouring classes, at the present price of wheat, high wages?-Yes, it is; but it is what is generally given with us; near town the wages are generally rather higher.

172. How far are you from London?-Nine miles.

173. What are the highest labourers' wages you ever remember?-Eightcen shillings.

$r \rightarrow 4$. How long is it since they were reduced below the $18 s$. ?-I should think 18 or 20 years; when coun was at an extraragant price, we thought it necessary to increase the wages.

175. Can you recollect what the wages were in 1828 and $1829:-N o$, I cannot, without reference to my books; but it was when the corn was so extravagantly dear we adsanced the wages to $18 \mathrm{~s}$, and continued them till it decreased in price 
again; then they were at $15 \mathrm{~s}$. for some years; we have only lowered them within the last two years to $12 s$.

176. Do you farm under lease ?-Part of it is belonging to the Crown, and part is my own; that I rent under the Crown is under lease, which lease expires in three years.

177. What was the length of the lease?-Twenty-eight years.

178 . Have you paid your rent the last few years out of capital or out of profit? -Out of capital.

179. What rent do you pay?-We pay a very high rent. That was sold, soon after the grant was made, to Sir John Sliaw.

180. What rent does Sir John Shaw pay the Crown :-I cannot say; but my farm is about $34 \mathrm{~s}$. an acre, and $\mathbf{I}$ gave a premium at the same time for that farm of $1,800 l$.

181. It is underlet to you ?-Yes.

182. You calculate the value at $1 l .10 \mathrm{~s}$. an acre; do you conceive that about the rent now?-That is more that the avcrage rent given in the parish now ; the rent of the Crown land is higher.

183. Have you a lease from Sir John Shaw ?-Yes, I have; that lease expires at three years from last Michaelmas.

184. It is not co-extensive with his lease from the Crown?-No; he reserves a year.

185. Your market for your clover is the London market?-Yes.

1 \$6. Do you get your manure from London?--Yes, and some from Woolwich ; they bring it back as back carriage.

187. You make no charge for manure?-No; I have given the straw for manure.

1 $\$$ S. How much have your poor-rates, highway-rates, and church-rates increased within the last five years?-I do not think they have increased much; we have adopted the plan of keeping the men emploved, and have agreed sometimes among ourselves. I take so many to keep them off the parish.

189. What is the state of the small farmer?-Very bad indeed; but I do not know that it is worse than the large, for the large is sinking lis capital.

190. Is it not the case that the large are sinking their capital, and the small have sunk theirs?-Yes.

191. How much have you charged for drilling?-We drill with the Suffolk machine; $1 s .6 d$. an acre is the usual price. My bailiff keeps two of those machines to drill for the farmers when they are in small business. They cost $40 l$; it does not answer for them to keep them; the $1 s .6 \mathrm{~d}$. is his charge to every one.

192. Do you mean that the practice of drilling increases the produce so much as to make it advantageous to adopt it:- - If it were not drilled we should not get it hoed for $5 s$. an acre, when it is broad cast; I have given from $10 \mathrm{~s}$. to a guinea an acre formerly.

193. Have you many sheep?--1 generally keep from 1,400 to 1,500 sheep.

194. Do you not reckon, according to the late price of wool, that you make a good deal by them?-The price of the wool is good, but the price of mutton has been very bad.

195. Have you fed any sheep this year on wheat ?-No.

196. Do you feed many bullocks on your farm ?-I do not keep many bullocls ; I keep a large stock of cows.

197. Do you ever give them grown barley ?-No.

198. How long do you keep your sheep?-Two years.

199. What do you reckon a fair profit on the sale of the carcass of each sheep?-I did not breed them. My profit depends on the rate at which they are bought; last year we bought them at a most enormous price, and there was little profit; this year we bought them at a low price, and anticipate a fair profit: I always buy my sheep at Romney fair.

200. How much a head profit do you think you ought to have upon a sheep, independent of the wool :- I ought to get $1 l$. a head on the two years.

201. You buy them as lambs?-Yes.

202. You do not feed any bullocks but mine are principally of the cow kind; I keep nearly 100 cows.

203. Would you be able to afford fat bullocks at much less money if the price of hides and tallow were higher?-The price of tallow reduces the price of the 464. 
J. Green, Esq. meat very muclı per stone, for tallow is fetching only $3 \frac{1}{2} d$. a pound, when it used 2.2 February $18_{3} 6$.

to be fetching $8 d$. or $9 d$.

204. The higher price of tallow would consequently make up for the price of the meat? - Y es.

205. To what time do you refer when you say that the price for tallow was $8 d$. or $9 d .-$ Ten or twelve years ago it used to be a common price, from $8 d$. to $10 d$. for the tallow; now it is $3 d$. and $3 \frac{1}{3} d$.

206. Do you refer to the time of war, or not?-I think since the war.

207. What is the quality of your land generally ? - Strong land; clay.

20S. Not favourable to the breeding of sheep, then?-No.

200. If it were you would not breed them on your land? - There are certain soils where they can breed them better than we can.

210. You consider yourself to pay a very high rent :-Certainly, at $34 \mathrm{~s}$. an acre; I am speaking of the Crown lands; it costs me more than $40 \mathrm{~s}$. an acre, and I an convinced nobody can live at the present time on two farms I have under the Crown at $20 s$. an acre.

211. Did you take those farms yourself?-I purchased the lease.

212. Did you consider it was then a high rent $\mathrm{r}$-It was at the time corn was selling at $z l$. or $\mathrm{S} l$. a quarter.

213. When was that :-It was during the war; it is 25 years since.

214. You considered it a high rent then?-It was a high rent then; but we were obliged to purchase, almost; we were taken so much by surprise. We understood, if Sir John Sliaw renewed we should have new leases; but, instead of that, it was put up to auction; we were therefore buying our improvensents.

215. If there had not been other circumstances you would not have taken it then at that rent?-No; on one small farm, 150 acres, I made considerable improvements; I have made a great sacrifice.

216. Have you laid down any part of this lately, to cover the high rent? - No.

217. Why do you go on cultivating it?-Strong land of that description would not answer my purpose to lay down, under a lease; the first 10 or 12 years it produces very little, after the first year or two has expired, till a bottom is formed.

218. It would be sacrificing the land for 10 or 12 years? - Yes.

219. Therefore you are obliged to occupy the land in this way ?-Yes.

220. How many pounds of wool do your sheep produce?-The old sheep from seven to eight, and they are the long-woolled sheep; and the younger sheep, of a year old, about five.

221. How much a pound do you get?-This year I sold it at $1 \mathrm{~s} .7 \mathrm{~d}$. a pound.

222. Is it the same price for the older and the younger sheep :-It is all sold together.

223. Was that a higher price than the year before?-The year before it was sold at $1 s .6 d$., I think.

224. Do you consider those high prices?-Yes; three or four years before it was selling at $7 d$. and $\mathrm{S} d$. a pound.

225. What rent can you afford to give for this land now?-At the present prices it would not be worth any rent at all, if things were to go on as they are.

226. It has been a losing concern to you for the last few years?-Yes, certainly, almost from the commencement of my liaving it, when the war ceased, almost immediately afterwards; I could not have farmed now if I had not farmed in those better days.

227. You are melting down what you gathered at that time?-Yes.

[The Witness is directed to withdraw.

William Jacob, Esq., is called in, and Examined as follows :

W. Jacob, Esq.

$22 \mathrm{~S}$. YOU are in the office of the Board of Trade?-I am Comptroller of Corn Returns.

229. You have been so a good many years?-About 14 or 15 years.

230. You were for some time a practical farmer, were you not :-I was.

231. You have not been a practical farmer for a great many years ? -No.

232. From your situation of Comptroller of Corn Returns, can you form any opinion as to what is the present state of agriculture in this country ?-Certainly not from my official situation as Comptroller of Corn Returns; but, having travelled about both in England and in foreign countries during the leisure that my 
office sometimes affords me, I have paid particular attention to the state of agriculture.

233. From such observations as you have had an opportunity of making, what do you consider the present state of the farmers in this country; are they in a thriving state, or otherwise ?-It is extremely difficult to look at such a number of people in the mass, and to give a definite or tolerably accurate description of the whole people in the mass.

234. Have you any means of forming any opinion whether the quantity of corn grown in this country has increased or diminished :- I apprehend the system of agriculture has very much improved within the last 20 years, and that on the same space of land a larger proportion is now grown than was 20 years ago, from such improved system of agriculture.

235. Are there as many acres of land cultivated for wheat and corn now as there were five years ago :-I cannot answer that question.

236. Is it as well cultivated now as it was five ycars ago?-Supposing the number of acres to be the same, which I cannot ascertain, then I should say there was a larger quantity produced now than then; and I should perhaps say that the increase of population is very rapid ; but I believe the increased productions of agriculture, especially of coln, liave kept pace with it.

237. That is your opinion?-It is.

238 . That is a mere opinion; you have no facts to go on ?-There are no statistical facts upon the subject; I wish there were.

239. Is it your opinion that the quantity of corn grown in this country can with safety be reduced to any considerable extent? - Certainly not.

240. Suppose it was diminished one-tenth, what would be the consequence? -That we should pay to the foreigner double as much as we now pay to the English farmer.

241. Could we get it from abroad :-I do not believe we could.

242. Do you mean to say you do not think there is corn enough to be sent from abroad?-There is corn enough, provided you will pay the price of it, but it must be drawn from such a distance, with land carriage, and a profit to those through whose hands it passed, that it would arrive here at a higher cost price, and would obtain a higher selling price than if it were grown at home.

243. Can you form any opinion of the state of the harvest the last two years? -The reports are so very various, it is impossible for any human being to generalize them. I judge, from the facts which I have investigated, that we have not, during a long average of years, produced wheat enough to feed our population by about $1,000,000$ of quarters.

244. That is your opinion?-That is the fact, drawn from the importations from foreign ports.

245. Do you think, with the quantity of corn which comes from Ireland, we cannot do entirely without foreign corn?-The quantity of wheat which comes from Ireland is very inconsiderable.

246. What do you consider the quantity of corn which comes from Ireland ?-Supposing we import $2,000,000$ of quarters in the year, not above 200,000 come from Ireland.

247. Do you not know that in the year $1814,814,000$ quarters came from Ireland?-I have not seen the account of that.

248. Do you mean to say that much more corn cannot be imported from abroad than is now imported?-Much more may be imported; the quantity must depend entirely upon the price paid for it.

249. Supposing it were necessary to import much more corn, would the price abroad be a great deal higher, in your opinion:-Without stating opinions, I think I could say, that in every year when the demand in this country has been such that we have imported $1,000,000$ quarters of corn, the corn in all foreign countries has risen at least 100 per cent.

250. If that is the case, do you not think that the present restrictions on the importation of corn are of very little or no use?-That is matter of opinion; I should rather say that I think them of very great use; I think that, by means of those restrictions, our farmers are induced to cultivate almost as much as will supply us, but if they were more deficient, we should then collect it from foreigners, but at a higher price than we can raise it.

251. Supposing the restrictions to be taken from the corn, do you not think the price of corn, whether imported or grown in this country, would be much the 464 . 
II. Jacob, Esq. same?-It would be nearly the same, and under the operation of the present law, it has been found that the variations of the seasons have effected variations in the 22 February $1 \mathrm{~S}_{3} 6$. price to a less extent than formerly.

252. Is there an inclination lately to speculate in foreign or in English corn ?-I cannot answer that question.

253. You gave evidence upon that subject a few years ago :-A few years ago I thought the state of the market was such that there was no disposition to speculate in English corn at that time.

254. Do you think there is now?-I do not know; I rather think not, to any extent.

255. You think that they get more by speculating in foreign corn; that there is a chance of greater profit?-I Yes, but of course the loss also may be greater.

256 . You consider speculation in foreign corn injurious to the agriculturist of this country ?-Yes.

257. Would not speculation in English corn be promoted by not allowing foreign corn to be warehoused in this country? - I do not know how that would operate, but $I$ think it would not be safe, considering the years of scarcity we sometimes have.

258. Supposing it to be safe, would it not be greatly adrantageous to the English corn-grower, by directing the course of speculation to his corn rather than the foreign? - Yes, and to the public also.

259. Are you to be understood to say, that if foreign corn were allowed to. come in, it would raise the price of corn abroad a hundred-fold :-I do not say what wonld be the effect, but what has been the effect.

260. To what time do you refer?-I forget the number of years now, but I published that in a volume of tracts on the subject, and showed what the effect each year was.

261. Are you not aware that corn is almost a drug abroad now ?-No; corn is certainly not a drug; wheat is. The inhabitants on the Continent eat scarcely any wheat.

262. The houses are full of it?-I believe they are not overloaded with the corn they mostly consume, which is rye; they were not five or six months ago, when I was in Germany and Switzerland.

263. Are you not aware that there is a general complaint on the Continent of the low price of agricultural produce?-There is a complaint generally of low price every where.

264. Are you not aware of the Report of the French Minister?-Yes.

265. Is there not a complaint also by the Dutch Minister:- Ies.

266. Is the agricultural interest in France in any thing like the state the agricultural interest in England is? - I do not think they can be compared together; they are in a different state of society.

267. Is not the state of opulence and comfort of the farmer far greater in France than it is in England?-I have not seen very much of France lately, but I should say not; the farmers in France are to be compared to our little farmers, who are generally in a state of great distress, if they are bad farmers especially.

268. Unless the system is altered, is it possible they can ever be in any other state:-I do not know.

269. What is your opinion of the cause of the present low price of wheat?There are several causes to be assigned for it ; in the first place, in many parts of the kingdom the lower class of people have changed their food from wheat to potatoes, to a certain extent.

270. Do you mean in England :- Yes.

271. You were examined before the Committce in the year 1833, and you then stated that you thought the consumption of wheat in this country was about $13,000,000$ of quarters? - I think I did.

272. It appears that in the period between 1821 and 1831 there was an increase of $3,000,000$ in our population; taking it that there would be about $4,000,000$ increase since that time, thcre must be a much greater demand for and consumption of wheat than there was in 1821; therefore the increased demand would meet the increased amount which you state, supposing your opinion is correct as to the improvement of agriculture:-In my former answer I stated my opinion that the increase of population and the increase of the growth of corn upon the same portion of land had been going on together. 
273. The manufacturing interest has been now for some years in a state of W. Jacub, Esq. comparative ease :-I think so.

274 . Has that led to a greater consumption on the part of manufacturers of 22 February $18{ }_{3} 6$. butchers' meat?-Certainly.

275. Has that had any effect in reducing the consumption of wheat P-It is possible it may.

276. Are you aware of the improved cultivation of wheat in any part of the country, particularly in the fen lands? - I have not turned my attention to that; I am aware that there have been in some parts.

277. When you take into consideration the vast increase of the manufacturing population, do you conceive there is a less consumption of wheat in the manufacturing districts than there was five, ten, or twenty years ago?-No; I do not believe there is a less consumption, but a less comparative consumption in proportion to the population.

278. Do you not conceive that many of the population eat more wheaten bread than they used to do?-I think that they eat more potatoes.

279. Do you think that there has been an increase in the consumption of wheaten bread among the agricultural population?-- I should think that there is, in proportion to their numbers.

280. Are you aware that in many districts there used to be oats, or barley, or rye consumed to a much greater extent formerly, and that wheat has been substituted ?-Yes; but that has ceased, to a great extent, particularly the eating of rye and barley bread, I believe entirely, in my time. I recollect when nothing else was eaten by the labourers but barley bread; now, in those parts of the country, they eat no barley bread.

281 . Is not a good deal of the bread called wheaten bread made of potato flour?-I believe that it is, and very good bread too.

282. Do you remember when there was scarcely any thing but potatoes eaten in the west of England ?-No, I do not recollect their being so much eaten in the west of England as they have been of late, and on the noble Chairman's estate in Dorsetshire there are more than ten times the potatoes grown now than formerly.

283. What do you conceive to be the average consumption of wheat in the British islands? - I have looked at the subject ; formerly, five or six years ago, I calculated it "as about six bushels per head for the population.

284 . What is your opinion of the average produce of wheat in the British islands?-It must be the quantity minus that quantity we have imported for any series of years.

285 . How much of that $1,000,000$ do you reckon comes from the Continent of Europe?-It is a very hard thing to carry figures in one's head; almost the whole of it comes from the Continent of Europe, for I believe our imports from Canada have been very insignificant; the impression upon my mind is, that for a series of years we have not imported from Ireland as much as 200,000 quarters a year, on the average.

286. Is there any year in which we have imported so little as $2,000,000$ quarters a year? - I have not looked at that lately, but I did some years ago, very accurately. I deducted what had been exported to Ireland; in some vears I found there was a very large quantity sent from Ireland to England in the beginning of the year, and at the end of the year a larger quantity had been sent from England to Ireland. In the year 1817, though in the beginning of the year Ireland sent wheat to England, in the latter end of the same year England sent more than that to Ireland.

287 . Did Ireland send, in the year 1817 , one quarter of what she sends now? -I cannot recollect figures; I know that Ireland has been gradually inereasing in her exportation.

288. In the course of this winter has any quantity of wheat been sent from England to the United States :- I have not heard of any; I have seen in the papers that some flour has been sent, but I know nothing of it.

289 . You have travelled in most of the corn-growing countries of the Continent? -I have.

290. Will you state to the Committee what is the relative quality of French as compared with English wheat. generally ; is it better or worse?-I think it is worse, generally ; it does not weigh so much as the English.

291. Is the French bread, as it is commonly sold in Paris, as compared to the 464. 
$W$. Jacos, Esq. London bread, better or worse?-It is inferior, the common bread; but if we were there we should not eat the common bread; we should have rolls, or something of 22 February 1836 . that kind.

292. The common bread of Paris, as compared with the common bread of London, is inferior?-Certainly.

293. Do you ever look at the returns constantly put into the public papers here. particularly the "Times" newspaper, as to the relative prices in England and France of bread ?-Yes.

204. Do you consider those statements erroneous?-Very erroneous as to the relative goodness of English and French wheat; for they say that French wheat is 20 per cent. better; the price is higher in France than in England, which cannot be denied; they then assume to show that in England it is dearer; that French wheat is 20 per cent. superior in quality than English; whereas the reverse is the fact.

295. You consider those statements to be erroneous? - Yes, I do.

396. In point of fact, how much higher is the price of wheat in France, calculating the same quality of wheat, than it is in England?-I have this morning received the account of the markets in France for the preceding week; I see it has risen there; I think it is above $2 s$. a quarter higher, upon the average.

297. Have you any materials in your office by which you could furnish the Committee with any thing of an estimate of the relative qualities and prices between the two countries?-No, I think I could not find it in my office; but inquiries might be made among the importers, perhaps.

298. Can you state as to the averages in the two countries; the average is taken by law in this country, and the average is taken by law in France, for the purpose of regulating the importation of corn; which is the fairest of the two?-Ours is the most correct; it comes the nearest to the actual truth ; for in France they take the average of the markets, and add them together, the same as we unfortunately did, till the year 1821 ; therefore they do not give the average of quantities and prices according to the quantity; but in a market where there are 1,000 quarters of corn sold it teils as much in their average as if there were 10,000. It will be recollected that some of the little counties in Wales, where scarcely 50 bushels of wheat were sold, used, before 1821, to bear the same proportion to the whole as the 100,000 quarters sold in London; and in some such way as that the accounts are made up in France. They are correct as to the places, but not as to the general prices of the country.

299. Have you not made some observations on the connexion between the prices at which the averages are published and the prices at which public contracts have been published in France?--Yes, I have made examination into that matter ; the public contracts, if I do not mistake, have been by weight; the hectometre is to make so many killogrammes.

300 . Was not the result of that examination to satisfy you that the averages, as published by law, were rather below than above the real prices in the country?Yes, they were so.

301. Does your observation as to the relative value of the wheat in the two countries apply generally to the two countries, or to particular districts?-To the whole of the country.

302. There are particular districts in England where wheat fetches a considerably higher price?-Yes, and in France also ; the variations of price in France are vastly greater than they are in England. I could, with a little trouble, have shown this, if I had been aware of the question, the contrast of the highest and the lowest prices; I think, at Marseilles, wheat is near 100 per cent. higher than it is at Verdun or Metz.

303. At the present moment, taking France and England as two countries, do you think that bread, supposing it of equal quality in both countries, is much cheaper in France than it is in England?-It is cheaper in Paris than it is in London taking quality for quality, it is somewhat cheaper; there are reasons for that ; first of all, the flour trade in London is a sort of monopoly.

304. Is it not still more a monopoly in Paris ?-That is a monopoly of a different kind; the corporation of Paris, the municipality, have been bound to keep a certain quantity of corn always in store, and the public establishments also, the army and the hospitals, which is a very important feature in Paris, are bound to lay in a stock at certain periods, and to have always that stock; that influences the price of bread, and I have no doubt keeps it a little below ours.

305. You 
305. You stated that one ground for the low price of wheat at the present moment, in your opinion, was the increased cultivation of potatoes; to what district in England do you particularly allude?-That was one cause to which I referred; 22 February 1836 .

I have observed that in every part of England.

306. Do you mean among the farmers? - Yes, in every part of the country.

307 . You are aware that the cultivation of potatoes requires a good deal of capital in the way of manure?-Yes, but it does not require more capital than turnips or mangel-wurzel, for feeding cattle; and, those cattle making dung, a larger quantity of wheat will be grown upon each acre, which, I believe, is the case.

308. What soils, do you say, are suitable to the growth of potatoes?-Any tolerably loamy soil; either clay loam or chalky loam, or sandy loam.

309. You consider potatoes a very exhausting crop, do you not?-I do not consider it so; some persons do.

310. That is the general opinion of people, is it not? - It is found in Ireland to be the reverse.

311. You mentioned that there was a monopoly of the flour trade in London; will you have the goodness to describe that?-It is a monopoly which the large millers create; the bakers are poor and the millers are rich, and they compel the poor bakers, by giving them credit, or something or other, to buy their flour of them.

312. Is the mealing trade in few hands in London?-Yes.

313. You cannot state in how many hands?-O no.

314. It is in so few hands they can influence the price of the article they deal in?-Yes.

315. How comes it that this mealing trade is not influenced, like all other trades, by competition? - In the first place, the few mill-streams there are in the vicinity of London, and the more valuable purposes to which those mill-streams can be put in manufactures, causes a scarcity.

316. There can be no competition by one who has not got a grinding power?No, and a large grinding power.

317. Are there no steam-mills for grinding corn near London ?-Yes, there are some; one at Wandsworth. The man who built it had a single mill, in my memory; he died a short time ago worth half a million of money; he had a small windmill when I first knew him.

318. Do you suppose he made that money in the mealing trade?-I suppose so. When I was in Poland, ten years ago, one of his sons was there inquiring the price of wheat, and I believe buying it; at that time they must have been able to import.

319. The averages of corn are made up from returns from certain towns in different parts of England; there are no averages taken from any of the towns in Ireland? - No.

320. Would not averages taken from the towns in Ireland, if they were included in the average return, show a very different rate of price?-I do not know how that could be done; there was, in an Act of Parliament, passed, I think, in the year 1828, power given to the Board of Trade to establish inspectors of corn returns in towns, both in Ireland and Scotland; but those were not to be placed in the averages; but they were merely experimental things; there were a number of them appointed in different parts of Ireland and in different parts of Scotland, and they made their returns. About five years ago, when Lord Auckland first came to the Board of Trade, he asked me whether there was any expense in my department that could be spared; I told him I thought those returns from Ireland and Scotland exhibited nothing; there was nothing to be gathered from them, and it cost some hundreds a year, and I thought that might be as well saved to the public, and they ceased.

321 . Was the whole expense $300 l$. or $400 l$. a year?-Yes, about that sum; the returns were so very small in amount they produced no effect on English averages.

$32 \overline{2}$. Supposing the growth of corn to have very much increased of late in Ireland and Scotland, is it not very material we should have returns from those countries?-I do not know what use it would be.

323. If the prices of corn in Scotland and Ireland are considerably lower, would it not lower the average in this country ?-Perhaps it might, but the quantity brought to market is very small; if it is brought into the English market it comes into the averages.

404 . 
324. That comes with all the cxpenses of carriage and so on?-Yes.

325. How much a quarter does that make?-I cannot tell; it depends on the 22 February $18_{3} 6$. part of Ircland from which it comes.

326 . If it came from the west of Ireland would it not be $5 s$. a quarter? - I think not; it is $1 s$. or $1 s, 6 d$. on oats, which is the principal thing.

327 . If the averages are taken at Bristol or Liverpool, it is with the addition of those charges, and not what the farmer gets for it?--Yes; but the object of the law, I apprehend, is, not to determine what the price is the farmer gets for it, but what the consumer pays for it.

328. Then we might as well be governed by the London market?-We take it from all the places where it is consumed.

320. Taking the average as returned for England, and comparing them, what should you say is the average price of corn in London; is the average as collccted by the existing law a fair average and a fair price?-I have no doubt it is, as far as it is attainable; you cannot enter more into particulars without cramping all the operations of trade.

330. You have no reason to suppose that the mode prescribed by the Act of Parliament for taking the averages does not give, upon the whole, the fair price of corn?-I have no apprehension that it is not a fair price, as fair a price as can be obtained.

331. Would it not be as well to ask the seller what he sold at as well as the buyer?-No; I think that would not do at all, because, though the millers are not very good accountants, they are much better accountants than the little farmers.

332. It is the interest of the millers to keep the average as low as they can?No; when they have a large stock of corn by them they wish to get up the price; as millers, in general, they have no interest in the question; and my returns are very numerous, coming from millers and brewers, and persons of that description; they would be ten times as numerous if they came from little farmers, every man who brought his two bushels or his sack upon his back, as they do in the Welch murkets; it would be a labour beyond any thing.

333. Have you any reason to doubt that the farmers are as good accountants as the millers? - They are much worse book-keepers.

334. You say you have no means of ascertaining the quantity of corn grown in this country, distinct from the quantity annually imported ?-By calculation of what each person eats, and adding to that the quantity annually imported.

335. Have you any means, by such process, or any other, of showing the annual consumption for a certain number of years, reckoning backwards? Only by referring to the imports and exports of corn, and seeing how much we have wanted to feed the population, dividing that by the number of years.

336 . Whatever alteration there may be in the population, you have no means of ascertaining it by any other means than that?-No.

337 . Would not the returns you have of sales enable you to do that :No, I think not; every one of my clerks has been at work, with the assistance of extra clerks, in consequence of a motion made by Mr. Dillwyn in the House of Commons; and after six months' hard labour it produces no result at all.

338. Supposing you were to go back for 30 years, and to have no other means of judging of the quantity of corn that is consumed in this country except by the amount of importation, what would your conclusion be, when you take into your consideration the immense increase of population of this country? - Supposing our soil feeds 13 or 15 millious of people as well as it formerly did 10 millions, our soil is so much more productive, minus the quantity we inport from foreign countries; I have no doubt our soil is more productive of food.

339. We have had no importation from foreign countries within the last two years :-No.

340. If the soil is more productive, and the consumption is increased, that increased production and consumption must show itself in the quantity of wheat sold in the different markets?-No, it will not; for this simple reason:-there is an abstract of the paper I have mentioned as having taken so much labour, which has been printed, being laid before the House of Commons ; it will appear that in some inarkets, in some years, there liave been three times as much sold as in another; the quantity sold is no criterion for consumption; when the trade 
is brisk there is a great deal of speculation; a man will buy 500 quarters of wheat one day; if he can make $6 \%$. the next he will sell it again; and so it passes through the market again.

34 . If there is a high price, the supposition will be there is a much larger quantity of wheat:-No, it is not; the standard is fixed with reference to the highest and the lowest; it is the comparison between the two which produces the greatest number of returns.

342. Is there not the greatest speculation when the price is at the highest?No; there is a great deal of speculation as it rises and as it falls; they are anxious then to get rid of it, at any loss; the speculator will buy it to keep it, in hopes that it 1 ill rise again.

343. Although there may be a gond deal of corn sold two or three times over, yet probably that upon the average of years would be pretty much the same; if the consumption of the country had increased one-tenth or one-fifth, or any certain amount, it must show itself in the increased quantity brought to market in the different markets? - I do not think any inference can be drawn from that.

344. Your observation leads you to think that any calculation founded on that would not be accurate :-That it would not deserve any confidence at all.

345. You say, that when prices are falling, people are glad to get rid of it at any price?-Yes; then there will be others who buy it with a view of holding it for a time.

346. If there is a fall of price it will frequently fall rapidly?-Yes.

347. If there are none who want it for consumption in the market, it will fall very rapidly indeed ?-Yes; I believe imagination acts more upon the market of corn than on any other market in the world.

348. Supposing the English supply were not equal to the consumption, and there came in $1,000,000$ quarters in the year, would not that knock down the market very much?-Certainly; it appears to me that the present Corn Law relieves us, as it supplies us at a time of scarcity at a cheaper rate than we could be supplied withont it ; but at the same time it prevents, in times of great abundance, the price going down so low as it would otherwise go.

349. You say it would go down much lower than it ought to do if the market once feels a sort of panic -Yes; and it is better for the public to pay a little more when it is very cheap, than a great deal more when it is very dear; I consider the present Corn Law not so much a protection to the farmer, though it is so, as it is a protection to the consumer.

350 . It keeps the prices at an equilibrium?-Ies; or as near at an equilibrium as they can be.

351 . Have you turned your attention to the question whether what is called the allotment system, the disposition to which has been increasing through the country, of increasing the cottage gardens every year, has had a tendency to throw agricultural labourers for their food more on garden produce, and less on bread? -It may be so, and I suppose it is so, so far as I have seen it; but I have seen it so little, compared with the whole face of the land in the country, it is impossible to measure its extent.

352. Do not you think the cottage system has induced the cottagers to be more in the habit of keeping pigs, or perhaps cows, than they used to be?-It may have done; but I have not had an opportunity of measuring the extent to which it has gone.

[The Witness is directed to withdraw.

Ordered, That this Committee be adjourned to Thursday next, Twelve o'clock.

Die Jovis, $25^{\circ}$ Februarii, 1836.

The Lord WYNFORD in THE CHAlk.

John Rickman, Esq., is called in; and having been sworn, is Examined as follows:

353. YOU made out a table, when the Reform Bill was before Parliament, of the population of this country, did you not?-I am not certain it was at that time; there is in the preface to the population volumes a table of the population, divided into the agricultural and manufacturing classes.

464 . 
J. Rickman, Esq. 354. You having distinguished the total number of families engaged in agriculture, those in trade, and all other families, be so good as to state what you 25 February 1836 . include in the class engaged in agriculture?-It is not by any choice of mine that I include or exclude, but merely according to the answers of the overseers of the parishes.

355. This was taken from the answers of the overseers of the parishes? - The total is collected from the answers of the overseers of the several parishes.

356. Do you recollect whom they described as agriculturists; what sort of persons?-If we conceive an agricultural village, they would include every family, except probably the minister, the blacksmith, the shoemaker, the carpenter, and other such village occupations.

357. Then, in a parish purely agricultural, the minister, the blacksmith, the shoemaker, the carpenter, and so on, are excluded from the total?-Yes; those employed in trade would be placed in the second column.

358 . You would exclude from agriculture, even in an agricultural village, the mechanics employed by the agriculturists?-Yes; I take the agriculturists to be the persons actually employed on the land as occupiers of the land, and the labourers under them; in the course of the inquiry many questions of this kind were asked of me, and so answered.

359. Then the carpenter, the tailor, the shoemaker, and the wheelwright, and so on, are all included under the head of mechanics?-Yes.

360 . What do you include under "all other families?"-It is impossible, in inquiries which attempt classification, to make a consistent total, unless there is a waste or negative column (so to speak) in which to enter all those who are not included in the attempted classification; if I am asked who the majority of such persons are, I believe them to be chiefly superannuated persons; and in asking questions as to families, there are many individuals who have no families, such as old women in the Highlands, living in small black huts made of turf, living quite alone; and there are many similar cases in which an individual is unavoidably deemed to be a family.

361 . Supposing a beneficed clergyman residing in a country village, which class should you put him in?-He, that is, his family, would be put in the column of " all other classes."

362. So would a landlord?-Yes.

363. Where do you put the master tradesmen? - As employed in trade.

364. Every sort of mechanic is classed as employed in trade?-Yes; the village shoemaker, and other artisans.

365. Does that arrangement give any thing like an accurate idea of the families dependent on agriculture?-Not at all; if the investigation were to be pursued, such a computation would be a task of much labour ; but it may be pursued as far as any person wishes to pursue it; for in the population volumes of 1831, at the end of every county, persons in retail trade or in handicraft are distinctly classed in a hundred classes or more; and where a large town exists, in two or three hundred classes; five or six hundred species of trade and handicraft are thus distinctly specified in the metropolis. All these are subdivisions of the column of those employed in retail trade or handicraft, as masters or workmen; the total of such column being 404,000 persons upwards of 20 years of age.

366 . Is this page of the pamplilet now shown to you copied from the population volume?-I have no doubt that is an extract from it.

367 . Do you consider the classification to be accurate? - I think it is sufficiently accurate for all general purposes; not completely accurate, of course; but we may venture to suppose, that if one individual makes an error on one side, another makes an crror on the other side; and therefore, taking it upon the whole, that it is sufficiently accurate for general purposes.

368 . In the comparative statement of the occupation of families in Great Britain in the years 1811,1821 and 1831, it would appear that the proportion of persons employed in agriculture was in the proportion of 35 per cent. in 1811 , of 33 per cent. in 1821 , and of 28 per cent. in 1831 ; is this extraordinary reduction in the apparent amount of persons employed in agriculture, in your opinion, real, or does it arise merely from a difference-from a different mode-of stating the several classes of the population? - I conceive it to arise entirely from a different manner of understanding the inquiry; and this was caused by the collateral questions asked at the same time concerning persons 
upwards of 20 years of age, as is attempted to be explained in the preface to the population volume [pp. xi, xii.] at some length.

369 . Have you any reason, from any thing known to you, to believe that there is a real diminution of the number of persons employed in agriculture?-Certainly not; and I can point out, in corroboration of that opinion, the proportion of persons in trade, which lessened just as much, from 47 per cent. in 1821 to 42 in the. year 1831 ; and 1 conceive, from the same cause, that the agricultural population has lessened, the surplus being thrown upon the class of "other families."

370. Are clergymen and mechanics differently disposed of in the one calculation and in the other?-I cannot answer that question briefly, and must refer to the before-mentioned preface.

371. You having stated, that in parts of the country purely agricultural those persons who are not immediately employed in the cultivation of land are set down either under the head of manufacturers, or of others; is not, in truth, the whole of that population employed, if not in the actual cultivation of the land, still in the manufacture of such instruments of machinery as are necessary to the cultivation of land, or the supply of such wants as are felt by persons who cultivate it? 'Taking, for instance, the county of Rutland, which may be said to be purely agricultural, should not you say that the whole of that population, in fairness, should be considered as a population devoted to and dependent on agriculture?-Yes, certainly; and if the question be put in general terms, I will endeavour to answer it from a paper to that effect, prepared some years since, for some purpose which I have now forgotten.

372. In what proportion was the population of Great Britain in the year 1831 absolutely dependent upon agriculture, in the largest sense of the word ; upon the produce of land?-For the most satisfactory solution of this question it will be convenient to rely on the number of males 20 years of age, the per centage on which number cannot vary materially from that on the number of the families, or of the entire population.

Then select the seven following counties, as being unquestionably dependent on agriculture, their market towns containing no manufacture, commerce, or other means of extraneous profit or expenditure.

$\begin{array}{llllllllr} & & & & & & \begin{array}{c}\text { upwards of Twenty } \\ \text { Years of } A \text { ge. }\end{array} & \begin{array}{c}\text { Three Agricultural } \\ \text { Classes. }\end{array} \\ \text { 1. Bedfordshire - } & - & - & - & - & - & 22,571 & 13,392 \\ \text { 2. Bucks - } & - & - & - & - & - & - & 35,504 & 19,348 \\ \text { 3. Essex - } & - & - & - & - & - & - & 79,023 & 43,683 \\ \text { 4. Herefordshire - } & - & - & - & - & - & 29,342 & 16,397 \\ \text { 5. Huntingdonshire } & - & - & - & - & - & 13,001 & 7,221 \\ \text { 6. Rutland - - } & - & - & - & - & - & 4,940 & 2,763 \\ \text { 7. Suffolk - } & - & - & - & - & - & 71,376 & 38,687 \\ & & & & & & -255,757 & & 141,491\end{array}$

Add five other counties, after due deductions made, as follows:

8. Cambridgeshire (the town of Cambridge) - 30,357

9. Lincolnshire (Boston) - - - - 76,983

10. Norfolk (Norwich, Yarmouth and Lynn) - $\quad 72,299 \quad 44,629$

11. Oxfordshire (the city of Oxford) - - $33,232 \quad 18,393$

12. Sussex (Brighton and Hastings) - _ _ $\quad 54,955 \quad 30,408$

Totals - $\overline{523,583} \quad \overline{299,041}$

The first seven counties propuce 80 per cent. additional to the three columns of actual agricultural population; but, lest these should not be deemed of weight enough to establish the solution sought, five other counties have thus been added, which lessens, rather unfairly, the agricultural preponderance of population, because the cities of Norwich and Oxford, and the towns of Cambridge, Boston, Great Yarmouth, Lynn, Brighton and Hastings, contain a numerous market-town population, intermixed with their manufacturing, commercial and other peculiar population, not agricultural; and this is more than equivalent to the seafaring population of Harwich, in Essex, Ipswich, in Suffolk, and the expiring 464 . 
J. Riçmax, Esq. domestic manufactures of lace in Bucks, and of gloves in Oxfordshire, which have not been deducted from the agricultural population of those three counties.

25 February 1836 . Referring, therefore, to the foregoing totals of 12 counties-

$$
\begin{array}{cc}
\text { Actual } & \text { Apricultural } \\
\text { Agriculturists. } & \text { 1'opulation. }
\end{array}
$$

Say, If 299,000 produce 523,000 , what is the per centage addition?

If $299,000: 100:: 523,000$ gives 174 .

Therefore, add 74 per cent. Further: The three columus of agricultural population
in Great Britain stand thus:

Males Twenty Years of age. 187,075

168,815

887,167

\section{Total - - $\quad-\overline{1,243,057}$}

Say, then, if $100: 174:: 1,243,057$ gives $2,162,920$ directly and indirectly dependent on agriculture:-and all the males 20 years of age in Great Britain being in number $3,944,000$, - say further, if $3,944,000: 100:: 2,162,920$ gives 55 per cent. on the entire population.

Add to this 55 per cent. a proportion of the persons who do not indeed cultivate the land, but subsist on income derived from it in the form of rent, tithe and the like, assuming herein the following approximation:-

The taxable amount (not the actual amount) of such rental, tithe and the like, was 44,000,000/. in the year 1814-15 (see Property Tax Account, printed 26th February 1823); - and the now actual amount at least equals the then taxable amount, although the publication of every deficiency and reduction of rent, and the non-publication of any increase, has led to much fallacy in comparing the rental of 1815 with the present income derived from land. Such rental, \&c., is therefore estimated at - _ - - - $\$$. $44,000,000$

Deduct one-fifth (more accurately 19 per cent.), being) the proportion of all real property occupied by the owner thereof (see Property Tax Account of 1820, p. 97 of Papers printed 26th February 1813), already reckoned as an agricultural occupier

Remains rental expended by non-agriculturists - - -

Suppose, further, each individual in the family of those expending such rental to create an expenditure of $100 \mathrm{l}$. per annum, and one male of 20 years of age to be found among four persons; therefore divide $35,200,000 \%$. by $400 l$., and the result is 88,000 such inales; and as the expenditure of such families is not entirely among the artisans and tradesmen dependent on agriculture, it cannot produce less than 50 per cent. additional persons on that consideration :and the agricultural population stands thus :--

Males of 20 years, directly and indirectly employed in agriculture Males of 20 years, subsisting on rental of land directly Males of 20 years, subsisting on rental of land indirectly - - 44,000

$$
\text { Total - - } \quad \underline{2,294,000}
$$

And if the total of such males in Great Britain be in number 3,944,000, and those dependent on agriculture be $2,294,000$, the solution of the question at issue $(3,944,000: 100:: 2,294,000$ gives 58$)$ is, that so 58 per cent. or 3 per cent. additional to 55 per cent. But this addition of 3 per cent. supposes all the proprietors of income arising from rent, tithe and the like, to be absentees from the 12 counties on which the first part of the calculation proceeds; and in sn far as this supposition is unfounded, the additional 3 per cent. disappears, and the population of Great Britain, dependent on agriculture for subsistencc, is nearer to 55 than 58 per cent. 
373. It is the case on many large farms, that instead of employing the village blacksmith or carpenter, they keep a blicksmith and carpenter of their own to do that work? - It is so on very large farms; I lave known instances.

374. Yet, according to your table, those would be included as manufucturers? -I should rather cail them artisans or persons cmployed in handicraft, who are distinguished from manufacturers in the return of 1831 , the manufacturer being deemed of a higher class; and upon inquiry, for accurate definition, the answer always was, that he only should be so called who did not usually sell to the immediate consumer. Hence it occurred unavoidably that persons in the same kind of business might be placed in a different column, according to the extent of their capital, and the consumption of their commodities in the same town, or exported for consumption elsewhere.

375. In the population abstract you divide those employed in agriculture into three classes; be so good as to explain the use and result of such distinction?I deem that question to have been the most successful of any of the new questions applicable to all males 20 years old; there being no uncertainty in the answers, except in the doubtful case of the son of a small occupier working on the land cultivated by his fatler; and the doubt was solved by recommending a distinction, as whether he did or did not receive wages, or some stated reward in money, beyond the actual cost of his maintenance? If he did not, his father was not deemed to employ a labourer, and was placed, accordingly, in the second class. This premised, I will take the liberty to read a paper prepared yesterday, in expectation that an explanation of the three agricultural columns might be required of me be this Committee.

The number of males in Great Britain above 20 years old is 3,945,000, and of these are employed in agriculture $1,243,000$, about 31 per cent., who are thus divided in classes :-

1st. Those who employ labourers are - -

2d. Those who do not employ labourers -

3d. Labourers employed by the first class

\begin{tabular}{l}
$-187,000$ \\
$-169,000$ \\
$-887,000$ \\
\hline $1,243,000$
\end{tabular}$\left\{\begin{array}{c}\text { per cent } \\
\text { among } \\
\text { the Three } \\
\text { classes. }\end{array}\right\} \begin{gathered}15 \\
14 \\
71 \\
\mathbf{1 0 0}\end{gathered}$

2.5 February $183^{6}$.

(1) 
Mr. Willian Bennett is called in; and Examined as follows:

Mr. $W$. Bennett.

25 February 1836 .

378 . YOU are concerned in the cultivation of land? - I am.

379. How long have you been so ? -I was bred and born a farmer; I have been employed on my own account as a farmer ever since the year 1813 .

3 So. In what part of the country do you live? - I live now in Bedfordshire.

$3 S_{1}$. How long liave you lived in Bedfordshire?-I was bred and born in Bedfordshire, but I cummenced farming in Norfolk in 1813.

3 S2. What quantity of land do you occupy?-I now occupy about 350 acres.

$3 S_{3}$. Is that your own, or do you rent it ? - I rent it. land.

$3 s_{4}$. Of what does the land consist?-Three hundred acres of it is arable

3 35 . What is the state of the farming interest of those who cultivate arable land at this time, as far as you know ?-As it regards those upon arable land, I consider it to be in a state of extreme depression, but more especially on the strong lands.

$3 \delta 6$. With respect to the strong lands, do you think, by any mode of cultivation, however skilful, by any attention to economy, however strict, the tenant can make it answer at the present prices ?-Most certainly not, at the present prices.

$38 \%$. Is it worse now than it was in the year 1833 ? - Decidedly worse.

388. Prices are lower?-They are.

389 . Are the expenses of cultivation as high now as they were in $1833:-$ The expenses of cultivation, as it regards iny own farm, vary nothing, except $1 s$. a week in the price of labour; $1 s$. a week to an able-bodied man is taken off since 1833.

390 . What are the wages of labour now?--The wages of day labour now are $s s$. a week, but most of our labourers have piece-work; they earn about $9 s$. or $10 \mathrm{~s}$.

391 . Is that price more than is sufficient to support a labourer and his family? -O dear no, 1 think not; the bare expenses of the labourer have not lowered, except in the article of bread food; his rent and firing, and so on, are the same.

392. Do you think you shall be able to continue to pay them that rate of wages if prices continue the same?-No; I see no chance of it.

393. Have rents been lowered in your neighbourhood?-I believe, in most instances, they have been lowered.

394. Has your own been lowered?-The farm I at present occupy I have occupied four years, and took under a lease; that has not been lowered.

395. You took it at the low rent of the times?-I took it on a lease at the commencement of the year 1832 .

396. You took it, of course, at the rent of that time?-Yes; I hired it, calculating wheat at $64 s$. and barley at about $37 s$., the average price of 1831 ; indeed I think wheat was then making $66 s$. per quarter.

$39 \%$. Will it bear that rent? -No, it will not.

398. Must there be a considerable deduction from that rent?-Yes; I consider that there is a difference between the time I hired and the price of wheat and barley, in wheat and barley alone, nearly to the whole amount of my rental, and $I$ am prepared to prove it.

399. You say there is a difference in the price of wheat and barley nearly to the whole amount of your rent?-Yes; upon my farm the difference in the value of my wheat and barley between the year 1835, which has just ended, and the year 1831 , the year preceding my hiring, will amount to the whole rental of my land, taking the amount of produce to be the same.

400. Are the Committee to understand that you cannot afford to pay any rent at all for your wheat and barley land ?-- I mean to say, as far as those crops are concerned, I should be as well off to have paid the rent I contracted for as I should now to live rent-free; and I can prove that by figures, in the produce of my own farm.

401. On wheat and barley land can you afford to pay any rent at all? - Not much on land of that quality.

402. What is the quality of your land?-It is a chalk-bottomed soil.

403. What is the rent? - About 18s. an acre rent.

404. Paying tithes? - We are subject to small tithes on a part of the farm, and free from great tithes altogether; $18 s .6 \mathrm{~d}$. being clear of tithes. 
405. That you camot pay from your agricultural produce?-No.

406. What is to become of your poor if the land should be thrown into

grass?-Our land would not grass; it will grow more mutton and wool under 25 February 1836 . present management than if attempted to be laid down to grass.

407. If it could, must the poor be turned adrift?- Yes; and I employ generally from $\mathbf{1 5}$ to 20 labourers, men and boys.

408. Your sub-soil is chalk; what is your surface?-It partakes of it ; but it

is rather a convertible soil ; it will move casily.

409. Loamy soil? - It can hardly be considered a loam; it is a mixed soil.

410. Is it clay?-No.

411. What is the depth of your soil before you come to chalk?-It varics

much; in some fields seven or eight inches ; some more, and some less.

412. Do you break it up by the plough?-No; I do not break up the chalk generally with the plough.

413. Do you recollect the year 1823 ?-I do.

414. Which is the worst year, 1823 or the present year 1836 ? We considered 1822 worse than 1823 .

415. Wheat was the lowest in 1823 , was it not?-I think not; it was as low as $43 s$. in 1822 .

416. Was not it $40 s$. in 1823 ? -No, not according to the returns; it began to advance in 1823.

417. One thousand eight hundred and twenty-two and 1823 were very bad years?-Yes; but wheat was not so low, nor any thing like it, in 1823 as in the last year.

418. In what part of Bedfordshire do you live?-I live at Lucy farm, near Dunstable.

419. Do you know whether rents about you have been lowered?-I believe they have been.

420. To a great extent?-They have been lowered very materially on the strong lands. I have five brothers who are farmers, and their rents are all lower than they were.

421. Though their rents are lower, still can they go on on their present rent? -No, decidedly not; I know many farmers are sinking; very many I am acquainted with cannot possibly meet their engagements.

422. Are the farmers in your country, notwithstanding these reductions of rent, in great distress?-Yes, they are. I wish to make one exception; that on some of the better convertible lands the system that has been adopted of late years, of feeding sheep and cattle with oil-cake, and corn on the four-course system of husbandry, which has been adopted on the convertible soils, has so improved them that the farmers under those circumstances are much better able to stand the brunt, though they do not get a fair remuneration for their capital ; but rents have been paid largely from their improvements.

423. Are you better off than you were in 1831 ? - No, by no means.

424. Are you worse?-Yes.

425. Do you remember the year 1824 ?-In 1824 and 1825 things mended, and we hoped we were getting into a healthy state.

426. Do you remember the cause ?-We generally attribute it to an issue of paper. Parliament agreed to issue one pound notes; for two or three years money was more plentiful.

427. When money became more plentiful did prices rise?-Yes; the improvement commenced in 1823 .

428. When those notes were called in did the prices fall again?--Yes; we began to get worse again in 1826 , very much, and in 1827 .

429. Did you ever get better again after that?-No; prices rather improved up to 1832 , about 1830 and 1831 ; but we considered that owing to bad harvests in some parts of the country.

430. Then the fall returned, and has continued erer since till now ?-Yes.

431. To what do you attribute the present rise?-I find it very difficult to account for the present rise; I have rather thought the circumstance of there being Committees of both Houses of Parliament agreed to, and the question of agriculture being to be considered, had some influence upon the markets.

432. Do you know whether there have been any importations from Ireland this year?-I rather think that the importations from Ireland have been less this year. 
Mr. IF. Eenrett. 433. You state generally that the improved agriculture in your neighhourhood has made farms bear a better rent than they otherwise would bear?--Yes, I think the rent has been paid from the improvements of late.

434. Then it is the fact that there has been a great improvement in agriculture?--An improvement on eertain descriptions of land. The farmers have had to struggle with difliculties, and have looked round to endeavour to live, if possible. That there has been a great improvement on the convertible land I have no doubt.

435. The distress of the farmer has forced him to great exertion for the improvement of his land?-Yes; those that have the means of doing it.

436 . Looking to the general extent of your neighbourhood, should you say that the improvement is considerable withiu the last four or five years? -No, certainly not, on the clay lands; but on convertible soils there is improvement.

437. Since when should you date that improvement?-Farmers who have had the means have improved cultivation some years. There was an impetus given in 1825, when things got a little better; the farmers then found that stock paid them better, and when attempting to grow mutton and wool they have almost imperceptibly improved their land.

438. Do you use bone dust in your county :- It is used partially, not much on light land. I use rape cake.

439. The improvement is progressive up to the present time? - Not upon the poor land; it is retrograding on the poor clay lands.

440. Should you say that that improvement has gone to the extent of increasing the produce of corn in the district; is there more corn produced within the circle with which you are acquainted than there was?-Upon the whole there is more.

441. The improved cultivation of the ground has given you an additional quantity of corn?-Yes.

442. Have you not, as far as wheat is concerned, also, had very good crops the last three or four years ?--On some descriptions of land we have; I do not consider, however, that the difference in the produce has at all made up to the farmer any thing like for the difference in price we have had.

443. For how many years back do you consider that you have had a full average produce of wheat?-I think the harvests of 1833 and 1834 were the greatest produce of wheat on our land; they were not wet summers, they were both dry summers, and we always find that they serve for the growth of wheat; but I think, though we have more wheat stacks this year, that the produce is less this last year than either of those two years.

444. The harvest does not yield well :-No; we do not get near so much out. 44.5. You are not asked as to the produce of your own or any particular farm; but looking round your neighbourhood generally, should you say that the produce of wheat last year has been under what you would consider an average? - I should think ahout erpual to an averag'c.

446. So that, according to your experience, the last year would be about an average crop, and the two years preceling rather above an average crop? Yes; I would not say greatly above it, bitt rather above an average crop.

447. Is there a large stock of wheat with the farmers in the county now ?-

Not with the farmers; the poor clay-land farmers have pretty much sent theirs to market; they were obliged to do so; the great bulk of it has gone to market. 448 . Should you say there was less in the farmers' hands now than there was this time last year, or two years ago ? - I think there is rather less.

449. Is your own farm cultivated on what you call the four-course systcm ?Yes; I grow scarcely any corn but wheat and birley; I prefer the four-course system; I fallow for turnips; then we sow barley after turnips, and clover sceds; after that wheat; that makes the four years.

450. Your seeds are only one year down? - No.

451. Do not you keep those seeds down two years in the poorer soils? - No; we find that we cannot grow wheat if we do; the four-course system will do better than the other; we are subjeet to great expenditure for artificial manure; I lay out above $100 l$. a year on manures.

4.52. What stock of sheep do you kecp on your furm ?-When we have a good turnip year (but this year turnips have failed) we keep albout 200 breeding ewes on 300 acres of land. 
453. The corn you grow is divided equally between wheat and barley?-Yes.

454. In making up your account, can you state what the money return for your farm consists of ; in what proportions it consists of barley, wheat, and of 25 February $183_{3} 6$. stock sold? - No, I have not made that distinct calculation.

45.5. You lave stated the general depreciation of prices which lias affected you; the price of barley is not lower than it was?-It is lower than when I enterch, by $7 s$. a quarter, and indeed more than that; in the year 1831 the average price of barley was abont $37 \mathrm{s.} 11 \mathrm{~d}$.; that was just at the time I entered in Jannary 1832 wheat was $66 s$. a quarter; in 1831 the barley was $37 s$. and some odd pence, and last year's barley pays only $30 s$., or barely $30 s$.

4.56. This is a good year for barley? -A tolerably good year.

4.57. Can you state at wliat you sold your own barley those different years? I have not got that account with me. Many individuals are misled as to the price of barley now, there is so much difference between the fine kinds of barley and the common barley; though there is chevalier barley that makes in the market a good price, the average of the kingdom is not more than $\mathbf{2 7} \mathrm{s.8d}$. or $28 s . ;$ a fortnight ago it was only $27 s$.

458. You are speaking of the average as returned by the inspectors?-Yes ; I believe the average of the county of Bedford was only $28 \mathrm{~s}$. a few weeks back, and it is not much more now.

459. Can you state what you sold your own barley for, the average price?The average price of my own sale this year will be about $32 s$. for the bright barley, for mine is all chevalier barley, the whole of it; but that which is stained is much lower.

460. Does the chevalier barley produce as good a crop as the common barley? - We do not consider that it yields so large ; we get more weight per bushel, but fewer bushels.

461. You do not recollect how you sold your own barley the year you took to your farm? - - No, I do not exactly.

462. Do you think you sold it higher than $32 s$. ?-I know it made more previous to 1832, when I commenced. I am speaking of the calculation that I as a farmer had a right to act upon in taking to the farm under the last legislative enactment relative to corn ; for the four years preceding wheat made an average of $64 \mathrm{~s} .3 \mathrm{~d}$. per quarter, and barley an average of $33 \mathrm{~s} .10 \mathrm{~d}$. per quarter, for the years $1828,1829,1830$ and 1831. I take four years. If I take the price of one year only, the year 1831, admitting that we had the same quantity, I say there is the difference of the whole rent of my own farm. If I take four year's there is still a ruinous difference.

463. Admitting that the price of wheat is very much lower than when you took your farm, as far as barley is concerned, the present prices are not prices of which you would eomplain as being low ?-I shonld, inasmuch as they are less than I calculated on, or had a right to calculate on; there is a difference of $8 s$. a quarter even in barley from 1831 to 1835 inclusive.

464. Do you mean to say that in these times you took your farm on a calculation of getting $34 \mathrm{~s}$. a quarter for barley? - I cannot conceive that the landlord and tenant can possibly go upon a fairer scale than taking the price of four years previous, and taking the present four years it makes a very material difference to me.

465. Do you recollect what you sold your wool for last year?-I am not sure whether I can speak with confidence to that.

466. Is not wool now nearly double the price it was when you took your farm ?-No, nothing like double the price it was.

467 . What is the price of wool in your neighbourhood now?-Some wool is worth two guineas per tod.

468. Do you speak of hogget wool?-I am speaking of regular lots, mixed lots; we have not all hogget wool. I was with the greatest wool-buyer in Bedfordshire on Munday, with a seller of wool, and he offered him no more than $42 s$., taking ewes and hoggets togetlier.

469. Of what description of sheep?-Long-woollcd sheep.

470. Are your's all long wool? - Part long wool, and part short.

471 . How much does a Heece weigh, commonly, of your own? - Some of mine are remarkably light; they are half-bred Norfolk, rather fine wool; they make very little in point of weight; I have lad as many in laalf breeds as nine to a torl.

$4 ! i 4$. 
Mr. W. Bennett. 472. You say that at present the price given by the wool-staplers in Bedfordshire is about $42 s$. ?-Yes.

473. Do you not remember prices in that county little exceeding one guinea or $25 s$. ?-Yes, but that is farther back, about the year 1822, when agricultural produce was exceedingly depressed.

474. You cannot state the prices of wool, from your own experience, in former years?-No, I cannot; but I have no hesitation in admitting that the price of wool is something better, and that in that department we have some relief.

475. Has not the price of wool very considerably increased ? - Yes, it may be perhaps improved, something like one-third, since the time I entered.

$4 ; 6$. As to the price of your lambs; do you sell them?-We feed part of them for the London market; those which do not get fat I keep on and clip.

477. You sell a certain number every year?-Yes.

478 . How is the price you get for them now as compared with the period at which you took your farm?-I do not think that there is any improvement since that time; I made quite as good of my fat lambs the first year as I do now; I think rather more money.

479. You have nothing to complain of at present as to the price of stock, and as to the price of wool you are better off than you were; are the Committee to understand that the whole of your complaint applies to the present price of wheat?-No; I consider that it applies to all grain; that all corn is lower than we can afford to grow it at, at the present rent and burthens which we have to sustain.

480. Do you grow any beans?--I do not myself; there are a good many grown in Bedfordshire.

481 . Are they now selling dearer or cheaper than formerly ?-I believe there is not much difference; the best beans will bring $4 s .6 d$. a bushel.

482 . Is not that a high price? - No, certainly not.

483 . Is it not a high price compared with three or four years back :-No, I think not; but it is easily to be accounted for, beans making a better price than common this year; from the great failure of turnips, farmers are confined to beans; we have no other means of keeping the sheep, in many instances.

484. Are there beans in Bedfordshire selling at what are considered a high price?-I do not consider it a high price at all.

485 . And you think not high as compared with three or four years back? I think not.

486. But not at prices which, applying merely to the article of beans, the farmer would complain of? - I think they are not remunerating prices, decidedly not; that is my conviction. They grow on strong land, land that is most heavy in the tillage, particularly so. I have been a strong-land farmer 12 years, though I am not now.

487. How are you as to poor-rates in your parish? - In the poor-rates in my parish, I think there is a very trifling difference; the new Poor Law has just come into operation, and, if any thing, they will be a trifle lower this year Whether that is to be attributed to the Poor Law, or to the great bulk of straw that was grown this year requiring more threshers a great deal, or to the convenience of getting labour on the railroad, I cannot sily; an immense number of our labourers are employed on the railway. I think the rates will be somewhat lower.

488. Generally speaking, your agricultural labourers have more easily found employment this year than last?-Yes, they have, within the last 12 months, since the railway has been preparing through Buckinghamshire.

489 . Can you state what your rates were?-- My rates vary so much; my farm is situate in three parishes: one a pretty good parish, the parish of Luton; another in the parish of Toddington, a very heavy parish; and another, the parish of Hougtston Regis, rather a bad parish than not.

490. Is there an improvement as to rates in all those parishes within the last year? - I am hardly prepared to answer that; I think there is improvement in general; perhaps some little improvement in all of them.

491. Your wages, you state, are reduced about a shilling a week?-Yes.

492. How many men do you employ, on an average?-Labour is a rery heary outgoing 
outgoing on my farm, and manure also ; we have from 15 to 20 men and boys, on all average.

493. That makes from $15 s$. to $20 s$. a week difference in wages?-No; for it

will be fair to calculate only $6 d$. on the boys; it will make a difference, perhaps, of about $12 s .6 d$. per week; that is about the saving in point of wages.

494. Is there a competition for farms?-Yes, I confess there has been, and still is, some competition for good farms.

495. As a farmer, how do you account for that?-I account for it because we increase, as well as all other classes of the community. It is well known that the education and habits of farmers are generally such, they are not disposed, and in many instances not fit, to go into other engagements in life for employnent; then it becomes a question with them whether they shall hire a farm, under the hope of better times, or emigrate to a foreign land.

496. What wonld you consider a remunerating priee, under the present rates, taxes and rents ?-I think that, under the present burthens that more particularly press upon the land, wheat ought, on an average, not to be under $8 s$. a bushel, or $64 s$. a quarter, and barley not under $5 s$. a bushel, or $40 s$, a quarter.

497. You say under the present burthens; what are the burthens which you consider press particularly on the agricultural interest?-As regards the local burthens, I consider that the assessment to the poor-rates is exceedingly unfair ; it presses very much upon the land, from the inequality of it; in my own parish I can prove there are gentlemen that return from $30,000 l$. to $40,000 l$. a year in manufactures that do not pay half so much to the poor-rates as I do on little more than 300 acres of land.

498. Their stock in trade is not assessed? - No.

499. Do you mean manufactures within your parish ?-Yes.

500. You say there is not so much corn now in the farmer's' hands; do you consider that they have been obliged to part with it?-Yes.

501. What has obliged them to part with it ? - I believe poverty has compelled the needy farmers, those that are the most distressed of them.

502. Has not that affected the prices in the market, their being obliged to force the corn on the market, from their distress?-I have no doubt of that.

503. You have had some relief from wool, and also from the price of stock; can you account for the price of wool getting up or keeping up, and also the price of stock ; is it from a permanent or a temporary cause?-I find a difficulty in accounting for the improvement in the price of wool, except from the rot in sheep. As regards stock, I do not think there has been any improvement.

504. Has there not been a great rise in sheep? - There was last year, but they were lower in the autumn.

505. Would that account for the improvement in the price of wool?-It will, perhaps, in some measure.

506. When the stock of sheep gets upon the land, will not that be improved? -It will, no doubt, in some measure.

507. You have said that lately there have not been many poor out of employment, and that, you say, is accounted for by the railroads; does that affect all the parishes of which you have spoken?-More or less it affects the whole county.

508. How were your poor employed before these railroads began?-In many parishes we had 50 or 60 labourers out of work; in some I have known more than that.

509. Were you relieved from this pressure on the poor-rate till the railroads began?-Not inaterially, at all.

510 . Then, of course, there is reason to presume that when the railroads are finished or given up, there will be the same pressure again?-I should say so, unless the poor are employed in other parts of the country, or agriculture is more prosperous.

511. Have you any flax or liemp in your neighbourhood?-No.

512. Your land is not strong enough for them?-No.

513. What, in your opinion, would be the effect of a repeal or diminution of the nalt tax? - I think the total repeal of it would be a very essential benefit to the agriculturists.

464 .

D 2

514. Do 
Mr. W. Bennett. February 1836 . grow barley?-Yes; I think the wheat farmers would receive an equal benefit 25 February 1836. by giving a stimulus to the growth of barley on barley land; that would lessen the quantity of wheat grown; and I think the repeal of the malt tax wonld benefit the unkind barley lands more than the very fine barley lands.

515. Are you acquainted with the chevalier barley ?-Yes.

516. That will grow on any land?-It will grow a better quality on all lands.

517. Can that be used for purposes of malting? - Yes; it makes the rery best malt.

518. Do you think with this clevalier barley a sufficient quantity of barley might be obtained in this country for making any fuantity of malt it may be desirable to make?-Ycs, I have no doubt of that. I conceive the clay lands, wherever they drain them, and grow tares upon them for sheep in the summer season, that land will be so porous it would grow barley that would make good bcer, and for all useful purposes, but not the fine quality to bear a tax.

519. With respect to the chevalicr barley there has not been sufficient time to try it whether it will fail in a wet season?-It is supposed it will germinate sooner, and of course will be more difficult to harvest.

520. You say you do not grow any flax or hemp in your county; if that was increased in the counties where it conld be grown, would you not consider that that would relieve agriculture by taking off some of the land now used for wheat? - I am not sufficiently versed in that to speak to that question. On the subject of malt there is one observation I would beg to make, which is not generally taken into the calculation, and that is, as to the relief that farmers would derive from the repeal of the tax, that the consumption of malt for their cattle would be of incalculable benefit; I have no doubt it is the most fattening of any food we can give to cattle.

521. If you could have it without duty?-Yes; I conceive that would render the importation of oil-cake quite unnecessary; I should never think of spending money in oil-cake if I could have the bencfit of making malt without duty.

522. What do you consider the present arerage of beans in Bedfordshire?-I should say not above $4 s .3 d$.

523. Are yoll aware that in the year 1832 the average price of barley was $33 s .1 d$. ?-Yes, it might be, but it will be impossible for us to calculate upon what it was in any particular year; I speak of what it was in the year 1831 ; it will appear that in 1831 , even the last week of 1831 , or the first week in 1832 , when I hired my farm, it was higher.

524. Is it not true that in the years 1828,1829 and 1830 the price of barley was under $33 \mathrm{~s}$.; in 1828 it was $32 \mathrm{~s} .10 \mathrm{~d}$., in $1829,32 \mathrm{~s} .6 \mathrm{~d}$., in $1830,32 \mathrm{~s} .7 \mathrm{~d}$, although in 1831 it was $38 s$.; should you have thouglit, as an agent maniging a farm, that you should take the price in 1831 without reference to its having been so much lower in the three years preceding ?-No, I consider it was fair to take the average of four years from the time of the Duke of W'ellington's Corn Bill, the last Corn Bill, and I made my calculations accordingly in taking my farm; something like $33 \mathrm{~s}$. a quarter, or rather above that, was the averige of the kinglom.

5:5. Upon the whole, are the present prices of barley, prices of which the farmer has a reason to complain?-Not so much as wheat, but still barley is not at a remunerating price; the last two years in our part of the country we were exceedingly dried up ; the barley was a very bad crop; I mean the harvest of 1833 and 1834. I consider the present price to have been in consequence of the deficiency the two last years.

526. Supposing you had known the present price of barley this year, would that have deterred you from taking your lease upon the terms you took it? I certainly could not afford to have given so much money for it, according to the present price of barley.

527. Therefore when you took your farm you anticipated a better price for barley than it at present brings?-Yes.

528 . Is not the wheat crop, generally considered, that to which the farmer most looks:-Y ${ }^{\top}$ es; that is the staple article of the farmer, but more especially so upon clay-land farms.

529. If 
520. If wheat is rlepresserl to the extent it is now, will good crops of other deseriptions of coln make that up to the farmer?-No; hut we have nothing else to make it up.

530. What are the manufactures in your neiglibonrhood?-Straw-plait; no other.

531. Do they employ many hands?-They employ a great many women ; it has been very beneficial to the poor in our neighbourhood, all the southern side of Bedfordshire.

532. Is the manufucture liable to much fuctuation in its employment of labour?-The farmers do not feel that so much; the poor themselves feel it most, because it is women and children, and not agricultural labourers, who are employed in it.

533. Do they do it to the extent of injuring your rates?-Yes; whenever the trade is bad in the plait business it affects onr poor-rates decidedly.

534. In fact, the land is obliged to support the labour thrown back upon it by the manufacturer?- $-A$ lmost entirely so.

535. You said there were a great many labourers now employed on the railroad; have you reason to know what price they get for being so employed on the rail road?-I should think they vary from about $2 s$. $3 \dot{d}$. to $2 s$. $6 \dot{d}$. a day.

536 . Yet a labourer employed in agriculture has only $8 \mathrm{~s}$. a week?-No; but the railroad labourers liare great ontgoings ont of those wages for beer and other expenses; it would not answer their purpose to go from home if they could not get more thim agricultural wages; and when I speak of $8 s$., it is the regular day's pay in most parts of the country; but a great deal is done by piece-work, and the men earn about $10 \mathrm{~s}$.

537. When the railroads no longer employ those people, they will fall back, of course, on the parishes? - Yes.

538 . Then if it remains the case, infortunately, that the farmers cannot employ them, they will fall back upon the parishes, and increase the poor'-rates? -Of course they will.

539. Can you state why the price of wheat suffered so much more depression than that of any other corn? - I think it is to be accounted for partly from this, that there have been two or three full years of wheat, and that the barley were not full years the two last years; I think that makes the difference; there lias been a greater demand for barley than wheat ; upon that ground the stock of malt was cleared, while there was a quantity of wheat on hand.

540. You attribute the ligh price of barley at present to the deficiency in the crop ?-I do not call the price of $28 s$. (the present average price) at all a high price; it would be reckoned low but for the extreme depression of wheat.

541. Is there no other circumstance to which you can attribute the fall in the price of wheat; nothing affecting the consumption of the poor, the use of potatoes, for instance?-Yes; I believe the growtl of potatoes inas increased very considerably, and that that has, imperceptibly, lessened the consumption of wheat.

542. May it have affeeted the price:-Yes, in some measure.

543. Has it affected it to any great extent, in your opinion?--I do not know that; the manufacturers have been in very good circumstances; they consume a great deal of meat, and when they consume a great deal of meat they consume less bread; that is invariably the case.

544. That may tend to keep up the price of meat?-Yes; but the present advance is more to be attributed to the failure of the tumip crop.

54.5. Has the allotment system prevailed among you?-Y Yes; I have felt a great interest in that some years; I lived for 12 years under the late Mr. Foster, of Brickhill, who was a very worthy gentleman, and felt a great interest in the welfare of the poor. I let part of my farm ont in cottage allotments to the poor, and it benefited them, I have no doubt; but while the Poor Law was in operation we could get no benefit in the parochial rate, for if we took any thing off from their parochial allowances, they would turn round and say, "It is no use my cultivating my garden if it is to be taken off in another shape ;" but, I think, under the new system, it is most desirable that poor people should everywhere have a good extensive garden.

546 . In your opinion, has not the system of increasing the cottage garden a tendency to throw the agricultural labourer more on his garden produce for his food, and less on the consumption of bread ?-Some little. 
Mr.W. Bennett. $\quad 54 \%$. You do not think to a great extent?- $N_{0}$, I think not.

$54^{8}$. Is not the price of bread much higher than it ought to be, according to ${ }_{25}$ February 1836 . the price of corn?-We have thought it so.

549. Can you account for that? - In many instances the poor have paid the bakers so badly, they have been obliged to charge a high price for their loss in debts where they have given them credit.

550. Is there much fuel in Bedfordshire?-No; fuel is an expensive article in the upper part of Bedfordshire.

551 . Have you been in the habit of selling to your labourers corn for their own consumption? - It is not a general habit; we occasionally do it; we find, unfortunately, so many of the labourers who have got a delst standing at the bakers, that many of them camnot very well leave their old shops.

552. Is it the baker or the miller they are more indebted to?-More to the bakers than the millers.

[The Witness is directed to withdraw.

Mr. John Thomas Twynam is called in ; and Examined as follows :

Mr. J. T. Twynam.

553. WHERE do you live?-At Whitchurch, in Hampshire.

554. Are you a farmer or a steward ?-I am a farmer.

555. Are you steward for any one?-No.

556 . What quantity of land do yon occupy ?-About 800 acres.

557 . Is that your own, or do you rent it - - Partly my own, and part I rent.

55 . What proportion do you rent? - About 600 acres are my own ; 200 acres I rent.

559. How long have you been a farmer? - On my own account, about 10 years.

560 . What situation were yon in hefore?-With my father, who had been a farmer for years previously to those 10 years.

561. You have been yourself in the farming business all your life?-I have been bred to it ever since I left school.

562. What is the state of agriculture in that part of Hampshire? - It is clistressed in some parts, but more in some parts than others.

563. What parts are particularly distressed?-The clayey soils and the land, I should observe, that is peculiarly adapted for the growth of wheat, nore than the others.

564. That is the strong clays?-Yes.

565. You say it is peculiarly distressed; have not rents been lowered in your neighbourhood? - Not permanently; there have been reductions at different rental days, but they have merely been acts of charity; they are merely' gratuitous reductions, and have been invariably put on when wheat has risen; there have been reductions this year to a greater amount than previously. The greatest reduction has amounted to 15 per cent. at one time, upon the half year's rental.

566 . Have other reductions been made upon that again, so as to bring it still lower? - No.

567 . The whole reduction has been 15 per cent. ?-Yes.

568 . With that reduction, in your opinion, can the farmer go on to cultivate his land?-I do not believe he can, even in Hampshire; and I am willing to confess that Hampshire is a favoured county.

569. You think the situation of the farmer in Hampshire better than it is in other places ?-Yes, I do ; in our part of Hainpshire particularly.

570. That is no great distance from Audover? - No.

571. You consider that it is more favourable to the farmer than in other parts of Hampshire?-No, not than other parts of Hampshire, but other parts of England.

572 . In your former answer do you refer to the prices of wheat, or of corn generally?-I confine myself to wheat; I think if wheat bore a remunerating price, all other produce would be satisfactory.

573. Are the prices of other articles sufficient to compensate the farmer for his luss on the price of wheat?-No.

574. In what state are the poor $r$-They are generally in employ.

575. Hare they been so continually? - Since the year 1831 .

576. Were they in employ hefore 1831 ? $-\mathrm{No}$, not so generilly employed. 
577. To what do you attribute their being better employed since 1831, than Mr. J. T. Twynam. hefore that?-One thousand eight hundred and thirty was the time of the riots. We e'une to an arrangement with the labourers in our neighbourhood, without 25 February $18_{3} 6$. any difficulty; then, when we found that the great cause of disturbance was the want of employ, we agreed roluntarily among ourselves to take each so many of the surplus labourers, and by that we set all to work who had nothing to do.

578 . Had the riots been occasioned by men being out of employ ? - I fancied at that time that that was the case.

579. Had you rick-burnings in your neighbourhood? - Yes, we had a considerable number of fires.

580. Did the rick-burnings and riots cease on the men being well employed? -Yes.

581. Can you afford, according to the present prices, to employ your labourers and pay them the same wages you are now paying?- We make it our first object to pay them the amount we think them entitled to, to ensure them necessaries and comforts; but, certainly, we cannot afford to pay our rents or tithes and our labour at the present price for the produce of our farms.

582. How much must your rent be redueed to enable you to pay the labourers? - That is a question I scarcely can answer, perhaps, properly. Wheat being now $9 l$. a load, we calculate in Hampshire a remunerating price would be $15 l$., or $60 \mathrm{~s}$. a quarter. I do not think wheat can be cultivated, even in Hampshire, under $15 l$. a load.

583. Not at the present wages?-No.

584 . What proportion do the wages on your farm bear to the rent?-Nearly equal.

585. Suppose you pay a pound an acre rent, you think the labour employed to cultivate that acre wonld cost about another pound? - Yes, as near as possible.

586. How is the price of stock ?--The price of stock is good.

$58 \%$. How do you account for the price of stock being good, while the price of wheat is so low ?-I attribute it entirely to the demand.

5 58. By what has that demand been occasioned ?- By the greater consumption going on, in my opinion, in the kingdom, on account of the manufacturing prosperity. I consider that the manufacturing labourer, from the great wages he is now receiving in proportion to the agricultural labourer, is enabled to consume more than double the quantity of provisions.

589 . He eats more meat, and of course less bread ? - Yes.

590. Is that equally advantageous to the farmer?-It would be; but for that prosperity we should lie worse off than we are now.

591. Supposing that prosperity to continue, will that enable you to employ the labourer?--No, unless the stock they consume should be raised still higher.

592. Do you employ as many labourers about a stock farm as you would about a farm that produces corn? - Not quite so great a proportion, certainly.

593. If the price of wheat is so diminished that the farmer cannot grow wheat, but may remumerate himself by selling his stock at a fair price, still that will affect the state of the poor?-Yes.

594. Do you know any thing further which you can state to the Committee, which will communicate any useful information on the subject of this inquiry? -I have taken the liberty to put a few ideas of my own on paper, thinking the question would be put to me, what I considered to be the chief causes of agricultural distress. If I am asked what I considered the occasion of the depressed price of wheat, I should refer to the imports for the five years beginning with 1822 and ending with 1826 , both inclusive, and to the imports for the five years beginning with 1827 and ending with 1831, in which I include the general imports from abroad and from the colonies and from Ireland. The increase of general imports during the last five years over the imports for the preceding five years are 11,998,246 quarters, two-thirds of which will be found of wheat, taking from 1826 to 1831 .

595. From whence do you take that ?-From the "Farmers' Magazine."

596. That includes the whole import from the foreign colonies, the channel islands, and Ireland?-Yes.

59\%. What do you make the amount of imports the previous five years?-The first five years, $12,219,209$; the second five years, $24,217,455$; which two 464 . 
Mr. J. T. Tuynam. periods will make an annual increase of $2,399,649$. I go on doeuments I have read in the books, whieh onght to be anthentic, and I believe generally are. By a reference to the monthly returns of the arrivals of wheat and flour in Mark-lane it will be found that the produce of wheat in England is also very much increased during the last five years, more particularly in the counties of Cambridge, Lincoln, and the northern counties; I have not the document to show how much, but I recolleet that the increase in the arrivals at Mark-lane is immense. I consider that the produce of the kingdom generally will be found to be greatly inereased during the same period.

598. What do you mean by the kingdom generally?-England and Ireland; and the whole extra supply derived from importations and home growth will be found for the last five years to exceed that of the first five years by two-fifths annually more than the supply amounted to in the previous five years.

599. How do you proceed after 1831 ? - The aceounts are not made up after 1833.

600 . The quantity taken altogether of home growth and of importations is more than the kingdom consumes in the year:- No, not on the ammual consumption; but I believe the annual consumption is generally estimated at twelve millions in England, so that it would not amount annually to twelve montlss' consumption.

601. Does what you estimate the produce of the kingdom, and the importations, exceed the home consumption? - Y es, by two-fifths.

602 . Will an exeess of two-fifths account for the depressed state of the market?

-I should think that, to a certain extent, on every principle of reason, it will.

603. Do you often frequent the markets yourself?-I attend weekly; sometimes twice a week.

604. When there is more corn in the market than you think the corn-buyers in your neighbourhood will require, does not corn fall?-Yes, certainly.

605 . You are bidding against each other, who can get rid of his corn first :Yes; the more is supplied the more rapidly it falls.

606. Would a little increased quantity more than the demand, if it is continued for several weeks, clepress the market in an inereased ratio?-Yes; becanse the dealers' minds are operated on by the eonvietion that there is a great deal to come; or, in the absence of that, that there is none to eome.

607 . Does not it operate also on the seller, being desirous to get rid of it? -Yes.

608 . What is the state of the farmers in your neighlourhood?-I consider their capital very much diminished within the last 15 years.

6og. Can you give any opinion what the efiect of the state of the farmers' capital is upon the markets; are they obliged to bring their corn to market sooner, in eonsequence of distress ?-That is generally the case in Hampshire; I should say the ease of four-fifths of them.

610 . They are obliged to bring their corn to a falling market:-Yes; they are obliged to realize the money by selling it.

611. Cannot they get accommodation from the country banks ?-I think they have got to the extent they can; there may be some capital left, but it is so far clepressed that the whole security they have to give for money is given already. I think that a great deal of business is now carried on in borrowed capital.

612. That you consider a cause of the depression of the prices? - Not entirely; that assists in keeping the prices down.

613. Of course, if the farmer were in a condition to keep it back till he should think it prudent to sell, the prices would be more equipoiserl?-Yes; but then the knowledge that there is a certain cuantity of wheat in the comntry, over and above the anmul consumption, will keep the people who buy wheat from buying any large quantity.

614. Do the corn-factors speculate in English corn now?-Within the last fortnight or three weeks they have done so, but before they did not at all.

615 . Do you know what corn they speculate in?-Wheat chiefly.

616. What country com?-The speeulation appears now to be directed towards English wheat.

61 7 . What has it been the last two or three years? - I do not think they have speculated much in foreign corn since 1833 .

618 . Then they have not speeulated at all?-I cannot give an opinion upon that.

619. Caminot 
619. Cannot you give an opinion upon it from what you have seen pass in the Mr. J.T. Twynam. market :- I have not scen a disposition to speculate till of lite.

620. Before this time, when have you observed it lately; how lately have 25 February 1836. yon observed any disposition to speculate in English corn?-I have net observed it till these two years, and then not to any great extent.

621. Must it not he an injury to the English farmer?-Yes; I think the absence of speculation is.

622. Your poor are well employed? - Yes; they have been well employed since 1830 . As another cause of the depreciation of wheat, I consider the very great increase in the enlture of the potato. In the parish where I reside there is a population of about 1,500 souls; within ny memory, perlaps 16 or 17 ycars, the quantity of ground then planted in that parish might lave been about three acres, the produce of which might have been about 300 sacks; during the last three or four years the average quantity of ground planted las been about 20 acres; upon the same ratio of calculation the produce has been 2,000 sacks.

623. Do you think that potatoes are consumed there, or sent to market? $-A$ great many are consmmed there; hut a great quantity of them are made up in hread mixed with wheat flour, as I believe is almost invariably the custom in all the bakers' shops, except those years in which potatoes are scarce, and it is not worth their while to do it.

624. Generally speaking, do not the people eat more wheaten bread now than they did formerly ? - $\mathrm{N}_{0}$, I think not, especially in the counties where the allotment system has becn introduced; and that I consider as one cause for reducing the price of wheat; though it has been very beneficial to the labourer, it certainly has liad an eflect in reducing the price of wheat, in my opinion.

62.5. Is there any thing else which it occurs to you to state?-No funther than that I think the first great blow we received was on the change of currency, if we may judge from effects; the first we felt of it was in 1822, from which we have never recovered; all I judge from is the consequences; our produce fell, from 1819 to 1822,100 per cent. suddenly.

626. Did it rise afterwards?-After two years, or not quite so much, there was a trifling improvement; but it never attained to the height it was previously.

627 . When was that improvement? -In the latter end of 1823 .

628. Did it fall off again?-There has been a falling ofl, but I cannot cliarge my memory to the date.

629. Has it ever got up since that?-No; it has been gradually getting down since the year 1831 .

630. It is your opinion that something which took place respceting the currency in the year 1822 is at the foundation of the difficultics which the farmers experience?-I conceive it is, that so great a shock was then experienced by the agriculturists, they have never recovered it, by the sudden fall of their commodities, equal to 100 per cent. in the three years.

631. Does that arise merely from the fact that, looking about you, you can assign no other reasonable cause, and therefore you conclude it must come from the currency; or can you point out to the Committee in what way you conceive the currency has operated in that way?-The way in which I conceive of it, speaking in general terms, was this, the withdrawal from the narket of a vast dcal of money in paper, which paper enabled, during previous years, speculators to come into the market, and there was consequently a demand, but this great amount of money being withdrawn, the means by which the speculators carried on their business was taken away, and the demand was affected by that.

632. Are the Committee to unrlerstand that you do not aseribe this difficulty which the alteration of the currency brought npon you to the stanclard of currency, but that you attribute it to the faet of country bankers having their small notes drawn in? - I attribute it to the withdrawal of a vast deal of circulation, in consequence of which the means of purchasing were withdrawn from the pcople who bought our corn.

633. You think that began to show itself in the year 1822 ? - - It showed itself very decidedly then, not only in wheat but in every article of farm produce.

634. One thousand eight hundred and twenty-two and 1823 were bad years? -One thousand eight lnumdred and twenty-two and the early part of 1823; there was a slight improvement in the latter part of the year $18: 23$. 
Mr J. T. Trynam. 635. Are you aware that from 1823 up to 1832 the prices were rather high; that they were ahove that which you yourself name as being what you call a remunerating price for wheat, namely, $15 \%$. a load ?-During that period they were; but it must be recollected that most of the farmers had leases existing at thrit time, which were taken at the close of the war, when the Corn Bill was passed; but that is almost beyond ny recollection. I think there was a Corn Bill passed in 1815, which guarantced that no importation of wheat should take place unless our prices exceeded $80 \mathrm{~s}$. a quarter; so that if the wheat did rise to $15 l$. a load after the shock of 1822 , and the great loss then experienced, the low price compared with our rents was the cause of a vast deal of eapital being annihilated.

${ }_{6} 6$. Do you suppose that the rate at which you took your farms gave any guarantee of Parliament, or any promise of price, or liad any effeet on the market price of corn ?-We have taken many leases on the faith of Parliament, as we did in 1815 and 1816 , on the faith of the Act which passed at that time, and which we had reason to suppose would be final.

637 . From 1825 to 1832 , a period of seven years, we have had what you call remunerating prices, under a system of restrieted issues; how do you account for the opinion you give, that the alteration of prices is owing to the state of the currency?-I believe I observed, in the first place, it was a very great shock we experienced in 1822, and which caused great difficulties. I do not think I intimated that prices did not recover in some measure without saying that a temporary issue of notes, which I think was four millions, had not some effect; but I admit that prices did after a time rally, and that the farmer was somewhat relieved; but it must be taken into consideration that in the period from 1825 to 1832 , namely, in 1828 , we had one of the most deficient harvests experienced since 1817 .

638 . In what year, according to your notion of the operation of the currency upon your prices, do you consider that operation to have ceased; in what year did the effect of the circulation of small notes to which you have referred cease? - The effect of the alteration of the currency has not ceased.

639. Do you mean to say you are now under the operation of the existence of small notes? - No.

640. You state that the withdrawal of the small notes has been partly the cause of the distress?-It has heen the canse of diminishing, or rather annihilating, a great quantity of agricultural capital.

64: When were those withdrawn in your district?-In 1822.

642. Have they ever re-appeared in your district?--No.

643. You have had none of those small notes since 1822 ? - I do not think in Andover we have had any small notes out.

644. Do you mean country bank notes or Bank of England notes?-Country bank notes; I have seen Bank of England notes very often since that.

645. In your district, Whitchurch, those country bank notes ceased to circulate ahout the year 182:2 ? -Yes.

646. If froni 1822 to 1832 you have had, upon the average, good remunerating prices for wheat, how do you reconcile that fact with the opinion that the depressed state of agriculture is owing to the cessation of the circulation?-To this $\mathrm{I}$ must beg to be understood, when I allude to $\mathbf{1 5} l$. as being a remunerating price, to apply that to all contracts entered into since 1822 ; not to the contracts entered into before 1822

647. The contracts entered into can have no effect upon the price of wheat, can they; whether you have taken your farm at one price or another, can have no effect upon the price of produce?-So far as regards a remuncrating price, if I took my farm previously to 1822 at a great deal higher rent than I should now give, $15 l$. is not a remunerating price to me.

048. May it not affect the question whether the price you get is a remunerating price, though it may not affect the question what that price shall be?No; but I was asked how I could account for $15 \mathrm{l}$. not being now a remunerating price, admitting that $15 \mathrm{l}$. was a remunerating price at that period.

649. The question is, if from 1822 to 1832 prices have been by the returns above $60 \mathrm{~s}$. or $15 \mathrm{l}$. a load, is not that a proof that the state of the currency of the country has not prevented a fair remunerating price for wheat during that period ? - I think one great thing to be taken into consideration is the year 1828 , in which we sold wheat, solely owing to the deficient harvests, at from $20 l$. to 
25l. a loarl; I think the average was $66 \mathrm{~s}$, and in Iampshire our produce did Mr. I. T. Trunum. not exced three-fifths of the average.

6.50. Would not that bring you to this conchision, that the price of wheat was governed in that year by the fact of a deficient harvest, and that your price of wheat is now governed by two or three years of abundant harvest? - To a great extent; for in the year 1828 the harvest was worse than in 1815,1816 , or 1817 , or any year previous to the change of the currency; and, lust for that change, instead of $66 \mathrm{~s}$. a quarter it would have averaged perhilps $100 \mathrm{s.}$, or more than that.

651. Does not your notion of the operation of the currency relate to the farmer when he comes into the market finding a less facility for obtaining: money for what he sells ? - Finding less buyers; that is, less means of ljuying.

652. Supposing that to be the effect of something which hiss taken place in the currency, how do you account for the circumstance that barley, that beans, that sheep stock, that wool and oats, in fact all other produce of the farm, should sell at what you admit to be reasonable prices, and that the wheat alone should be affected; if the cause be something connected with the currency, would not that catse affect every article of produce in the same manner?-I do not wish to be understood as attributing the whole effect to the currency, but a part; I believe I began by stating my opinion that a great deal is attributalbe to the quantity that came in; but I consider that barley, wool, sheep, beans and oats, for which there has been a much greater demand than for wheat, would have partaken of a still greater rise had Sir Robert Peel's Bill not been passed. I cannot help thinking that the currency has in a great measure affected it.

653. This detrimental effect of the currency has not gone the length of giving unremunerating prices for any article but wheat?- Wheat chiefly.

654. The currency will certainly equally affect all articles, unless there is some countervailing cause?-Yes.

655. Was there any countervailing cause which prevented the currency depressing the prices of other articles, though it did depress the price of wheat? -It did for a time; they were all depressed for a certain time.

656. You have been asked ahout the year 1822 ; what was the price of wheat that year?-I speak from Hampshire prices; it was from $28 \mathrm{~s}$. to $36 \mathrm{~s}$. a quarter. $65 \%$. Was that a remunerating price?-By no means.

$6{ }_{5} \mathrm{~S}$. That was the year when the country one-pound notes were called in?Yes. Perhaps I should observe, we had some of the produce of the previous harvest left, which was not of so good a quality; but I think the average of 1822 was not above $36 s$.

659. You are speaking of the average of your own market?-Within the circuit of 15 or 20 miles round.

660 . You say that wheat in that year was only $36 \mathrm{~s}$; when did it rise again?

-I cannot speak to the exact time, but I think at the end of 1823 .

661 . There were no country bank notes out then ?- None whatever.

662. Was there a great plenty of money in the market at that time? -1 cannot speak to that decidedly.

663. Though there were no country bank notes out, were not there one and two pound Bank of England notes out till 1829 ? - To the best of my recollection there were.

664. Since those have been withdrawn have the prices recovered?-I think it will appear that they have gradually gone down from that time.

665. Another circumstance which, in your opinion, has operater to produce the present very low prices, has been the increased importations from foreign countries and from Ireland, of which you have given your idea of the quantities; are you aware of the great importations of wheat from abroad in the years 1829,1830 and 1831 ? - Yes.

666. And that since that the quantities have been very inconsiderable?-Yes, I am aware of that.

667. As the foreign importations ended in 1831, and we are now in the year 1836, should yon, reconsidering that subject, ascribe the present low prices to the effect of any considerable foreign importation, leaving out Ireland?-Yes; so far as this, that the country was then filled with a quantity of wheat, which has been dealt out to our markets as it suited the convenience of purchasers; we have in the mean time reaped three abundant harvests, the vast proportion of which wonld have been required for immediate consumption but for that wheat which came in in 1829,1830 and 1831 .

464 . 
Mr. J. T. Twynam. 66S. Are you not aware that the importation takes place in bond, and it is not taken ont for consumption until it is actually wanted for consumption?25 February 1836 . Yes; but still I submit that the question is, whether it las been taken out for consumption or not.

669 . If it should turn out that since 1831 no considerable portion has been taken out for consumption, should you not from that infer that the foreign supply has not been the main cause of the depression of the present prices of wheat?-If any material quantity has been taken out since 1830 , taking the two years, not just one year.

670 . In 1831, there was a million and a half?-I think the better way of getting at the facts, would be to take out the whole ruantity taken out in the three years when the large importations arrived; I think we have had an ample sufficiency of wheat since that, and a superabundance in 1833,1834 and 1835 , from our own growth.

671 . Supposing that we have had a superabundance of our own growth in those years, would not that sufficiently account for the prices? -1 think not. Supposing that a great part of this foreign wheat was brought into the English market by degrees during that time, for a great deal of that might have constituted the superabundance, for that would have been consumed bnt for the foreign wheat which is now left over; if the foreign wheat had not been consumed in preference to it, I do not think we should have had that superabundance.

672. You state vourself to farm about 800 acres of land; of what quality?The quality I hold myself is tolerably good.

673. On chalk? - On a chalk sub-soil; what we call in Hampshire a good farm; not capable of growing what many farms would, but a good stock farm.

674. What is the value of the rent of land of that description in your neighbourhood - The rent, separate from tithe, would be, perhaps, about $1 l$. an acre, which with tithe, would bring it to $25 \mathrm{~s}$.

67.5. What is the general course of cultivation?-The five-course system.

676. You leave your seeds down two years?-Yes, before we break up for wheat; I do myself, in consequence of my own farm being well situate for manure, adopt in some parts of it the four-field system ; but the general system in Hampshire, is the five-field system.

677. You adopt the four-field system with your better lands, and the five-field system with the lands which are not equally good?-Yes; and there are others who do so too.

678 . Is the land in your neighbourhood improved :-Yes, I think it is greatly improving, where there are any means left; we have made great improvements within the last five or six years.

679 . In what does the improvement consist?-The encouragement given to breeding sheep; we are stocking our land harder on account of the great prices sheep bring.

680 . Should you say that the improvements in agriculture have led to a greater production of corn?-Yes, on a certain quantity of land; I should say more generally, taking the whole into account, of a greater average of corn.

681 . Taking your own farm, the quantity of corn you produce upon it has been rather increasing?-Yes; I do not say my own farm has increased the quantity of wheat, but taking all corn together, we grow more on a certain number of acres.

682. Your wool is selling very well ?-Yes, at a satisfactory price.

$68_{3}$. What is the price with you? -Our wool has gone for the last year; but they varied from $35 \mathrm{~s}$. to $40 \mathrm{~s}$. a tod, from $15 \mathrm{~d}$. to $17 \frac{1}{2} d$.

684. That you can get for it? - I think I could get $17 d$. now.

685. That is an improvement?-Yes, so far it is.

686. The price of your sheep is rather higher ?--It is very fair in Hampshire, as regards us, and I admit barley as well.

$68 \%$. What do yon make your price of barley ? - I beg to be understood, under leases taken of late years, the price of barley has varied from $28 \mathrm{~s}$. to $29 \mathrm{~s}$.

688. That you consicler a fair price?-I do, provided we take our leases on the calculation of wheat at $15 \mathrm{l}$. per load, as the corresponding price to wheat at $15 l$.

689 . How is your rate of labour?-We give $8 s$. per week.

69o. Have 
6no. Ilave you lately redueed to $8 s$. ? - At Mieliaelmas last we reduced from Mr. J. T. Truynam. $9 s$. to 8. .

Ggl. How are your rates? - They are lower than they were last year, but we were always pretty well situate as to rates; I do not think our saring this year, since the new Poor Law Bill has been in operation, will be above $6 d$. in the pounil.

692. What is your poor-rate?- $\Lambda$ bove $3 s$. in the pound, on the frir raekrent.

693. Are you in a union?-Yes, we are.

694. Is this the first year?-Yes; it began in June last.

69.5 . Is it liked by the firmers in your neighhourhood ? - It is liked by the farmers pretty generally; I think it will be found it will work very well in my neighbourhood ; but it all depends upon the quantity of labour to be obtained. This has heen a particularly lavourable year for bringing the Bill into operation.

696. You say that you do not think it will make more than $6 d$. in the pound difference; do not you eonsider that the first year you bring it into operation it is likely to he more expensive than in any future years?-It may be a little, but we shall have the same expenses to pay of officers.

697 . You have nothing to do with providing a poor-house?- - We harl one poor-house and one assistant-overseer in our parish previously; I speak of my own parish. I think the union will benefit more than $6 d$. in the pound; perliaps $1 s$,

698 . If the benefit is $1 s$. on $3 s$, that is a third of the whole rate?-Yes; but it must be taken into consideration that provisions have been much cheaper during a great part of the year than they have been for a long time past; and also the farmers have been compelled, on account of the bulk of straw they grew last year, to employ one man at least to 150 aeres more than the usual quantity, to thresh out the eorn; we do not use machines in our neighbourlıood, unless on pressing occasions.

6ig9. Is there much corn in hand in the hands of the farmer?--Yes; they have been threshing every thing they had, rather than thresh the wheat. Thie quantity of wheat is rather greater in stock than I have known it for many years.

700. The prices have improved?-Yes, to the extent of 15 per cent.

7ot. What do you eall them now?-I should say the average price of whent of fine quality in our country would be $42 s$, at Anclover and Newbury markets.

702. Do you pay tithes in your parish?-Yes, under composition.

703. When was that composition made?-It was made about four years since.

704. How do you consider it with referenee to the present value?-I eertainly eonsider it higher than we fairly ought to pay; it is higher than the present value of the tithes.

705. Do you mean to say, if the tithes were strietly valued?-I do not mean to say it would not amount to the sum, taking the gross value, but taking the expenses of threshing and going to market it would not amount to the sum.

706. You had rather pay your present emposition? - We had rather pay our tithes, on account of the trouble; we shall prefer paying our present amount of tithes to having them taken; but the proprietor, if he did take, would not get so mueh, on account of the expenses.

707. Supposing there was no corn introduced from foreign parts in 1834 , but $\$ 14,000$ quarters introduced from Ireland, and a ensiderable quantity from the ehannel islands, making that introdueed something above 1,000,000 quarters; adding that to an abundant produce in England, would that depress the prices? -I think it wonld, to a certain extent.

708. Would that amount to a depression equal to that which you find?-I think not.

709. You say the prices of barley and some other articles are good; is the price of barley suffieiently high to eompensate you for the loss on the wheat? -By no means; my own farm would be a very good exemplification of that.

7 io. You say you have reduced your wages from $9 \mathrm{~s}$. a week to $8 \mathrm{~s}$.; can you maintain the present wages at those prices:-Certainly not, without loss of eapital.

711. You say the Poor Law has done good, and will do good if work ean be 464 . 
Mr. J. T. Truynom. found; was not the great complaint of the expense of the Poor Law the poor being ont of enployment? - Yes, it was, at one time.

25 Febuary 1836 . 712. Has the Poor Law done any thing to remedy thit ? - I think it has, because people have been driven to such extremities, that if there was work to he had they must take it at any price.

713 . It is the pressure on the poor which has accomplished the object?-Yes, 110 donbt, so far as it made them seek after work, which they did not nuder the old law.

714. Can any thing relieve you withont raising the price of produce, though the poor may be employed? - Nothing for a permanency, unless our outgoings are vastly reduced.

715. Are you of opinion that the poor wonld be all employed if there were remunerating prices for agriculture? - In my own inmediate neighbourhood they would.

716. When they were out of employment was that occasioned by the furmers not being able to pay them their wages? - I think so.

717 . How should you estimate the last crop of wheat; very mucli above the average? -. We hare not threshed enough of it at present to determine; but from what we have threshed I should say not so much above the arerage as was at first expected; it is above the average. Ours is a light soil, and affected by dry summers; the produce will not correspond in the case of the produce of heary wet lands.

718. What should you say of the year 1834 ? - I should say it was a better average in Hampshire than the year 1835.

719. Therefore 1834 was a very good year?-Y Yes, for the produce.

720. One thousand eight hundred and thirty-three?-One thousand eight hundred and thirty-three was about the arerage.

721. One thousand eight humdred and thirty-two?-One thousand eight hundred and thirty-two was not quite so good; but we have nothing to complain materially of the average of wheat since 1828 .

722. Do you recollect so many years of good wheat coming together?-No, never since I was a child. I have noticed the seasons, my father being a farmer before me; I never recollcet such a succession of seasons, nor any thing like it.

723. You said that you thought that the men not being employed was owing. to the farmers not being able to pay them; do not you think that the new Poor Law has made labourers in your parish or your neighbourhood seek for work who might have got work before if they had been obliged to do it?-In some instances, 1 believe.

724. To a considerable extent? - Not in $\mathrm{m}$ y parish to a considerable extent; since the union there are cases where there were people thrown on the parishes previously, who have been driven by the working of the new Poor Law Bill to seek work on their own account; but $I$ think if we had not the railroads and other works going on that we should still have many deserring people in the country generally out of employment who are willing to work.

725. Do not you think you will be better under the new Poor Law than you were before, as to work; not public works?-I cannot say that I have that opinion, in the absence of public works.

726. What railway have you near you ?-The Southampton; it comes witkin five miles of us ; they are at work on that.

727 . Have they been at work in that neighbourhood as much since last rear as the year before?-They are at the present moment; but I do not think they have been very busily employed upon it till within the last month again.

728. Do you think the passing of the Great Western Railway Bill affected their works? - There was a sort of suspension of operations, from some cause; I cannot say from what.

729. Do you know when that took place?-I think some time about list November.

730. The Committee are to understand that the poor in your neighbourhood have not had the benefit of the Southampton railway during the last winter?No, certainly not; but they had previously, in the autumn.

731. Do not you consider that that part of the alteration of the poor laws which takes away the settlement on hiring has operated very beneficially on th: $t^{2}$ country? 
country?--I think that a very beneficial elause; one of the best that could be Mr. J. T. Truymom. eflectril. 732 . And that it does promote the circulation of labour in the country?-
Yes; and that when a man has a place he endeavours to keep it; breause, under 25 February 1836 the old law, the man knew at the beginning of his contratet that at the end of his year he mist leave it, and he was careless.

733. Yon are not now deterred from taking a good labourer and an industrions man by the fear of settling him on the parish? - No.

734. You have not felt the effect of labourers being returned on your parish that have been working their lives ont in manufaeturing towns? - No; nor have we a great surplus in our neighlbourhood.

735. You found that when you came to divide them among you, you had in

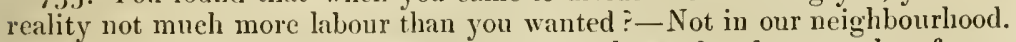

$73^{\circ}$. In the active portion of the year you have abundant employ for your lands? - Yes, during the summer six inonths.

737. Your parish charge for labour is mainly for want of employment during the dead season of persons that work during the active season?- T'he main constant charge upon us is for the old people.

[The Witness is directed to withdraw.

Ordered, That this Committee be adjourned till To-morrow, One oclock.

Die Veneris, $26^{\circ}$ Februarii, $18_{3} 6$.

The Lord WYNFORD in the Chair.

Mr. John Mockett Cramp is ealled in; and Examined as follows.

73S. YOU occupy land in the parish of St. Peter's in the Isle of Thanet? -I do.

739. What quantity of land do you oecupy?-One hundred and twenty acres.

740. Is yours arable land?-Arable land entirely.

741. What is the state of farming in that county; can a farmer at the present prices farm to advantage, or any thing like it?-Certainly not.

742. You are quite sure of that?-Yes.

743. Have you examined into the matter ?-I have; and my father is a proprietor and cultivates his own land, about 130 acres. I am acquainted with his affairs as well as my own; I am also chairman of the board of guardians of the Isle of Thanet Union, under the new Poor Law Act.

;44. What do you consider the present prices ?-The average price of wheat for the six months now ending has been $38 s$.

745. What is the lowest price at which you think a farmer can eultivate with advantage at the present rates?-We have been always aceustomed among us to say that we cannot remunerate ourselves at less than $60 \mathrm{~s}$. for wheat, and other grain in proportion.

746. Is that according to the present expenses?-Yes

747. What are your wages? - We give our able-bodied men from $10 \mathrm{~s}$. to $12 \mathrm{~s}$. a week.

748. Can you sustain that rate of wages if those prices continue the same?Certainly not.

749. What will be the effect of lowering the wages?-Other things must lower in proportion, or the poor will not be able to maintain themselves; for instance, cottage rents.

750. In what state are your poor? - They are in a better state than they are in many districts of the kingdom; their wages are higher.

751. Have you been over-burdened by surplus population?-Not to a great extent.

752. Have you many beer-shops in your neighbourhood? - I am very sorry to say we have.

464 . 
Mr. J. M. Cramp. $26 \overline{\text { February } 1836}$ ffect.

754. Are your poor contented at this time, or otherwise?-- That is a question that cannot be answered generally; some are, and some are not.

755. You have had no fires there, have you? - The only instance of fire for the last year or two was a mill destroyed last weck.

756. Was that by aceident? - I fear not, for it belonged to a gentleman who could not be supposed to be obnoxious to any man.

757. The prices, except of wheat, are not very low ?-No, but they are lower than when 1 took the farm I occupy.

758. Are the prices of other articles such as to remunerate you for the low price of wheat?-No, they are not.

759. How is stock selling?-I have nothing to do with sheep.

760. Have you sheep?-No; very few farmers in our neighbourhood have sheep.

761 . What is the food of the people chiefly; bread or potatoes? - Chiefly bread.

;62. Have there been many garden allotments in your neighbourhood? $-\mathrm{No}_{0}$; many of the cottages have land belonging to them, but $I$ do not know an instance in the Isle of Thanet of allotment.

763 . Has the cultivation of potatoes increased in the Isle of Thanet within the last few years? - The growth of potatoes has diminished.

764 . How long should you say? - Particularly within the last two or three years, on account of the defieieney of crops. Our seasons have been very dry ; in fact, we have not made lialf a crop of potatocs.

765 . There is a less breadth of land sown with potatoes now than formerly? - Yes.

766 . It cannot be the potatoes which have depressed the price of wheat? -No.

[The Witness is direc!ed to withdraw.

Mr. John Joseph Allnatt is called in ; and Examined as follows.

Mr. J. J. Allnatt.

767 . WHERE do you reside?-I live in Berkshire, in the town of Wallingford.

768. Do you occupy any land? -I do not now; I have occupied land, but not for the last few years.

769 . How are you connected with land?-Latterly I have commenced business as a land surveyor and agent, but I have not yet lad an extensive experience in that business, having so recently commeneed; but I live upon a farm which my father occupies, and have been in the constant habit of attending to agricultural pursuits for the last 20 years.

770. What is the state of agrieulture in your county?--The state of the farmers is exceedingly depressed at the present time. I know that, because I have an extensive acquaintance with farmers, and from the cireumstance of attending the markets always to sell corn and transace other business for my father. I have done so for the last 20 years, and an conneeted in that manner with the farmers, and therefore enabled to speak confidently of their condition.

771. From your connexion with the farmers, are they in a depressed state, or are they flourishing ?-- Decidedly distressed, and so badly so, that I know perfeetly well that taking them as a body they eannot exist from the profits of their farms, or perform their engagements to their landlords and other creditors.

772. What do you mean by "taking them as a body"?-I mean taking them as a class engaged in a particular branch of business; and that those who ought to live by agriculture cannot make a profit on their farms, and consequently they are in a very distressed situation.

773. How long have they been in that state?-I should say it has been gradually getting towards that state, at all events, for the last 10 years; that I can prove by a table I have taken from the accounts of a farm. I have examined the book from which it has been extracted.

774. From what book? - From this account book. I should premise, these accounts and papers have been entrusted to me in confidence, and the parties would not wish to have their names made public.

775 . Do you know the faets contained in that statement; do you know that the books are correct? - I know the furm occupied by the party who kept this 
account; I know that his manner of keeping accounts is exceedingly clear and explicit; and I lave been through the account.

776. Are you able to form an opinion as to the information contained in it? - So much so, that I have myself sold almost every article introduced into this account. The proceeds of the farm have passed through my hands, but I did not keep the account.

777. According to your memory, having acted in the sale of the produce of this farm, are you satisfied that this account is correct?-I am positive it is ; very few farmers keep a correct account, but this I believe to be a perfectly correct account.

[The same is delivered in, and read, and is as follows :]

Statement, extracted from a correct Account, exhibiting the annual Gain or Loss, for Ten Years, ending September 1835 , upon a Farm of 163 acres, 34 acres of which are meadow or pasture land; the arable land of superior quality for corn, and generally excellent stock land; near a market town; fully stocked with sheep and cows, and highly cultivated and productive.

Annual rent $263 l$., being just over $32 s$. $3 d$. per acre; titheable, a composition amounting to $8 \mathrm{~s} .10 \mathrm{~d}$. per acre for great and small tithes having been usually paid by the tenant ; poor-rates, 7 s. $6 \mathrm{~d}$. per acre.

$N B$. In the following Table four per cent. interest is allowed for capital employed, which is taken at $1,500 \mathrm{l}$. and $15 \mathrm{l}$. per annum for casualties, wear and tear of stock, and other contingencies. Both these items are supposed to be considerably under their real amount and value.

STATEMENT.

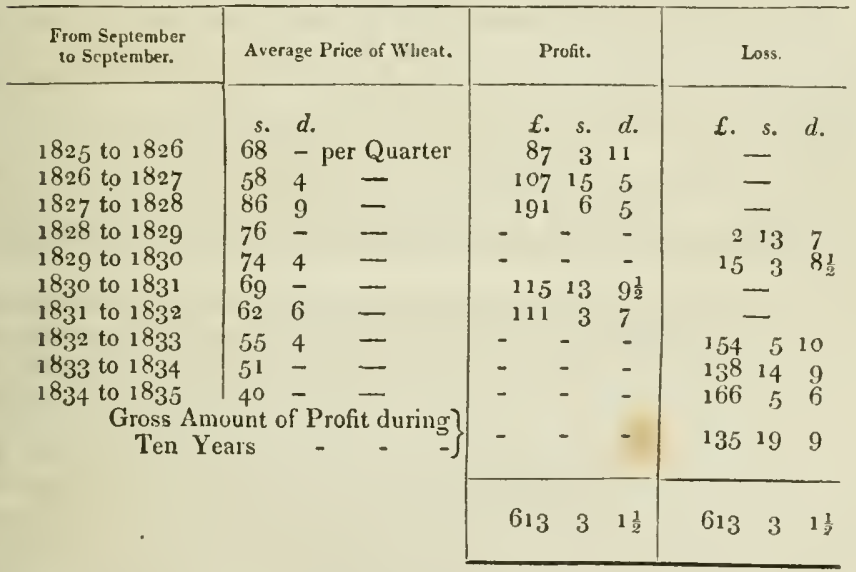

It must be remarked, that the quantity of wheat sold last year included 66 qrs. 4 bush. of wheat of the preceding year's growth, which areraged $49 \mathrm{~s} .9 \mathrm{~d}$. per qr., and amounted to $165 \% .8 \mathrm{~s} .4 \frac{1}{2} \mathrm{~d}$; ; but, inclusive of this, the average price during the year was only $40 \mathrm{~s}$. per quarter, and the loss upon the year's account, as appears by the Table, was $1661.5 \mathrm{~s} .6 \mathrm{~d}$. None of last year's wheat or other corn was kept over to be brought into this year's account, except $26 \frac{1}{2}$ quarters of wheat, which produced $43 l .13 \mathrm{~s}$. ; so that the difference between the two sums of $165 l .8 \mathrm{~s} .4 \frac{1}{2} \mathrm{~d}$. and $43 \mathrm{l} .13 \mathrm{~s}$, , viz. $121 \mathrm{l} .15 \mathrm{~s} .4 \frac{1}{2} \mathrm{~d}$., being added to the amount of loss above stated, the actual loss upon the last year's account was $288 \mathrm{l}$. $-s .10 \frac{1}{2} \mathrm{~d}$.; being $25 \mathrm{l}$. $-s .10 \frac{1}{2} \mathrm{~d}$. more than the rent.

The average loss per annum for the last three years, $153 l .2$ s. $-\frac{1}{4} \mathrm{~d}$.

The whole of the above and following calculations liave been prcpared with considerable attention, and from authentic documents.

$25^{\text {th }}$ February 1836 .

John Jos Allnatt.

778. What do you mean by casualties?-Accidental losses; depreciation in the dead stock as well as the live stock, and which is very considerable.

779. Is the farm referred to well managed?-Exceedingly well.

780. Could it be better managed? - I think it is impossible for a farm to be in a higher state of cultivation.

$40{ }^{\circ}$. 
Mr. J.J. Allnatt. $\quad 781$. Is there sufficient capital employed upon it?-Yes, for the person is not 26 February $18_{3} 6$. at all dependent upon the farm; and the produce, in my opinion, excceds any thing I have ever secn from so small a farm.

7 S2. How do you account for the loss being so great in some years when the corn was so high? - In some of these years corn has been kept over till the next year.

$7 \delta_{3}$. Look to the year when you state that corn was so high, and when you state there was a considerable rise?-I attribute that, in a great measure, to the corn being kept over; there was a large produce of corn, and it was customary to keep two or three ricks to sell at the next harvest, or just after the next harvest; or that there was a shorter crop of barley that year.

$7 S_{4}$. It does not appear what was the quantity of corn sold each year?-No. $I$ have not had time to complete the Table in that particular; all the proceeds of the farm are however included in my abstract.

785. What was the average amount of labour each year?-Last year the labour was $430 \mathrm{l}$. $15 \mathrm{~s}$.

786. That is double the rent?-Nearly so, the labour is high in the parish, for this reason; it is a parish principally of land, there are but few houses to be rated, and we found that unless we employed the labourers they came on the poor-rates and were paid for idleness; and if they are employed in the farm we have as a set-off the increased produce; but the labour is certainly high in proportion to other farms.

787. What are the poor-rates?-The poor-rates on the parish amount to $6 s$. an acre.

788. You state them at $7 s .6 d$. for this farm? - Yes; part of this farm is in a neighbouring parish which is within the town, and the town itself is rated much higher, and the rates come much oftener than in this hamlet in which the principal part of the farm is situate. Here is another farm in the same parish of 180 acres, which paid only $45 l$. to the poor-rates last year, while this 163 acres paid $59 \mathrm{l} .19 \mathrm{~s} .6 \mathrm{~d}$.; the reason of that was the difference of rating in the town. I have another statement which I have drawn ont, to prove that last year the price of wheat being so very low, our labourers and the poor-rates not only took the whole of the wheat crop of the whole parish, but $578 l .2 s .7 \frac{1}{2} d$. besides.

789. Do you suppose the $430 l$. expended in labour could be beneficially expended? - 1 should observe that one reason the amount of labour is so high upon this farm is, the extraordinary amount of produce; the extra labour increases the produce, and then again the increased produce creates a demand for more labour. At this time, for instance, there are four men enployed on this farm constantly in threshing, which is a very great proportion to a farm of this extent; but the produce bcing so great it is absolutely necessary. I consider this land superior to most I have ever seen, and it is also good stock land.

790. Have you taken at all into your account the produce of stock?-Yes.

791. Then, whatever the produce of stock, they are swallowed up by the small price of corn?-Yes. Sheep are bought in in the autumn; they are always introduced in the yearly account, and that they sell for is brought in before the year closes; therefore the whole amount of the profit of stock, the wool, and fat sheep, or whatever they may be, is included in the year's account.

792. Are these different prices of wheat you have given in the different years the average prices that are published, or the actual prices?-The actual prices realized upon the produce of the farm; it is very probable that in some of these years the average price stated may be ligher thau the general average price of the country, because a portion of old wheat was included in the account; for instance, last year the average is stated at $40 \mathrm{~s}$., but a quantity of old wheat, which sold for about $50 \mathrm{~s}$. is included in that average; the real average of last year was under $35 \mathrm{~s}$. I have here a statement showing the produce of wheat after the harvest of 1834 .

[The same is delivered in, and read, and is as follows :] 
Statement, showing the Produce of Wineat at the harvest of 1834 in a whole parish, of land of great fertility and in high condition (including fifty acres in an adjoining parish connected with one of the farms of the said parish), calculated at five quarters per acre, and at $36 \mathrm{~s}$. per quarter, both items being above the actual amount; also the Sums paid by the Occupiers for Poor-liates and Labour alone, from Michaelmas 1834 to Michaelmas 1835 .

Total number of acres, 793 ; average of poor-rates, 6 s. per acre.

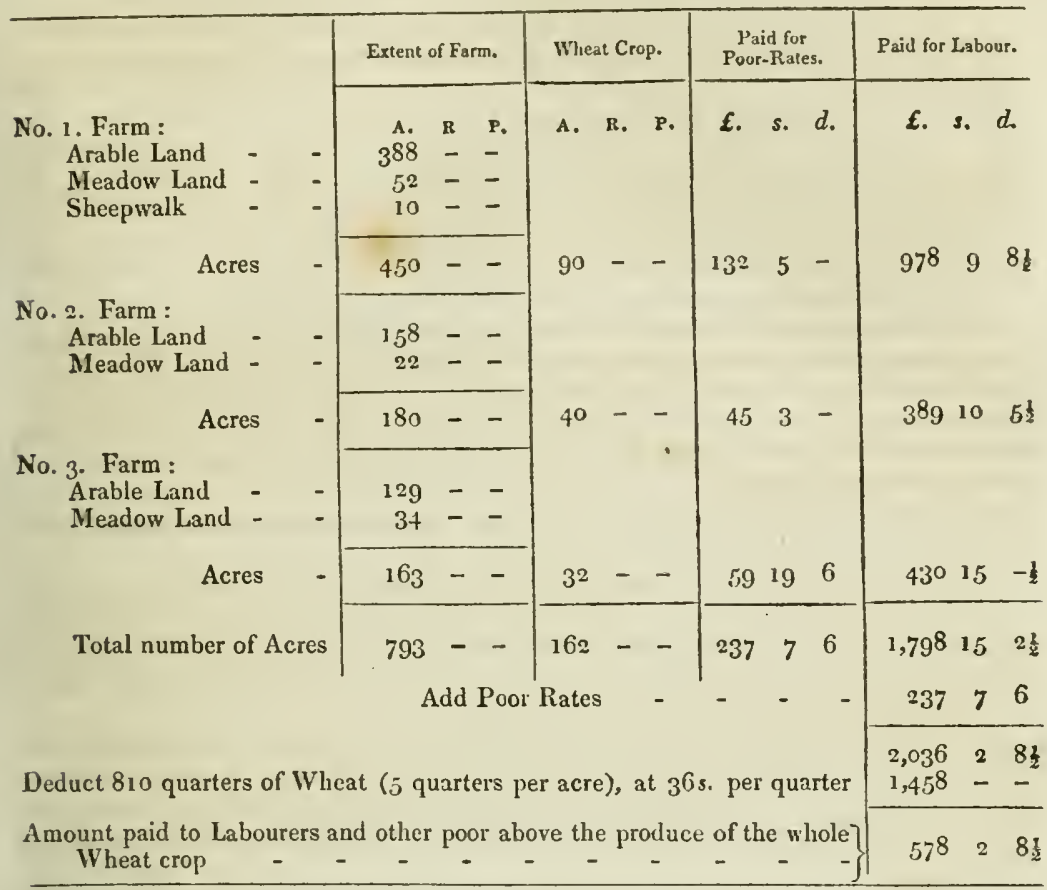

N.B.-The item of poor-rates includes the county assessments, which have been usually paid by the overseer. They have been comparatively trifling in amount.

I consider the produce stated in this account much higher than will be found to have been produced.

793. Was $36 s$. the price that the wheat sold at in the market ?-It is higher than it sold for, but ours was one of the wet districts; we had an immense deal of rain; the wheat was much injured. A great part of our wheat was sold for $7 l$. $10 s$. or $8 l$. instead of $9 l$., as I have put it here; but it would have been worth more if we had been as fortunate as our neighbours; I have therefore put it at that sum, that the case might be fairly stated. I have no doubt but that, in point of fact, the wheat crop did not rcalize the sum stated by $150 l$. and upwards, which would swell the balance paid to the labourers and poor to above $\mathbf{7 0 0 l}$., but $I$ would rather be under the facts than attempt to prove more than the truth.

794. What was the rental on the farm you have referred to of 450 acres?It is worth about the same as the other farm I have referred to, $32 s .3 d$.; but it is occupied by the proprietor, therefore there is no means of ascertaining the rent.

795. What is the tithe?-The tithe of that parish is under $8 s$. The farm of 163 acres is that to which I referred in the other account.

796. Do you account for the profit on the stock?-No; this is a separate thing, showing that the wheat crop is of no consequence as it regards the payment of the labourers and the poor-rates.

797. The whole of the other produce is included in the general account?I have included that in the first account, which gives a statement of profit and loss on one of the farms for ten years. The farms are pretty much the same as regards their fertility.

464 . 
Mr. J.J. Alinatt. 798. As a surveyor, have you the means of knowing what is the state of the other farms in your neighbourhood; whether the farmers are in the same con26 February 1836 . dition :-They are all complaining.

799. Does it appear to you, from the observations you have made, that they complain with reason?-I should say, certainly; I have no question but that they are exceedingly poor and embarrassed, where they depend exclusively upon their farms.

80o. Do you think they had been paying the expenses of their farms out of capital, and not out of the produce of the farm?-Yes, I should say so, in almost all cases.

801. Are they getting worse each year?-Yes; for the last three years they have been doing very badly; for though barley has brought a much better price than wheat, it must he recollected that there has been a-decided deficiency, not only of barley, but of beans and peas, up to the harvest of 1834 inclusive.

S02. Taking their advantages and disadvantages, are they making a profit by their farming? - It is impossible.

8o3. Stock has sold well ?-Yes, it has sold tolerably well; but last year I think there was some misapprehension with respect to that. I bought some sheep myself for this very farm in the autumn twelvemonth, and those sheep were kept during the whole winter for fatting, and they were fatted, but they did not make the stock price; when they were sold out there was a positive loss upon them, independent of their keep and other expenses attending them.

804. Is there a profit on stock, or not?-I should say, in a farmer's stock farm there must be a profit on the stock, but not sufficient, when brought into the general account, to sare the farmer from loss.

805. You have stated the result of the calculation upon this farm for different years, from 1825 down to the present period; when you speak of the profit of different years, do you suppose that is after the tenant has lived off his farm; does he make any charge for his own living, or does he feed limself off the farm? $-\mathrm{N}_{0}$; this farm is not situated as many others.

8o6. Is that calculation, after the farmer has lived on his own produce, then that he finds himself in the result with a profit or loss; or for the purpose of establishing profit and loss, has he charged himself with any thing for his living $\mathrm{r}-\mathrm{No}$; he lives in the house, but he does not live upon the produce of the farm. All is introduced into this book, with the exception of a few eggs or small things; but it is not like most farms; he does not bake his own bread from the farm ; it is independent of his living; the money which supports his family does not come out of the farm, and he lives as he pleases; he is not supported by the produce of his farm.

807. The farmer does not live upon his farm produce, consuming some of the produce of his farm? - Very trifling; with respect to the number of chickens or ducks, there are a few kept, but all the barley which that number consumes during the year is given eredit for in this book as so much barley.

808. Does he provide his own farming or the board of any of his labourers? $-\mathrm{No}_{0}$

Sog. That is not done in your part of the country?-No; living as this gentleman does, in the town, it would be inconvenient, and probably no saring; it is done in some cases, but not so often as it was some vears ago.

810. He has had to feed himself and take care of himself out of the profits of his farm, whether he has made any; his own living is not included in the expense of the farm?-No; it is quite a distinct thing, for he has not lived upon the produce of the farm.

811. He would charge to himself any thing he took for use?-Yes; for instance, if a pig were killed its value would have been entered in this account; every item is introduced on the proper side; if the pig was worth $5 l$. that would be put down, if it was consumed.

812. With farmers generally, they live aud pay their rent, and pay their charges, and then the farmer reckons with himself, according as he has gone backwards or advanced and gained, $100 l$. or $150 l$. ?-Then perhaps he has not kept a correct account.

813. Your account supposes he has charged himself with all his living off his farm? - I have no douht that whatever he has taken off of the farm las been charged in the manner before stated.

814. By the statement you have given you have shown that this tenant has at different 
different periods found his furm a profitable or a losing one, without immediate reference to the price of corn; beeause in some years, although the items of produce of one year may be carried over to another year, here are two years together where the price of wheat was $76 s$. and $74 s .4 d$., with still a loss upon the farm; therefore the Committee are to understand from that statement that it lias been frequently a losing concern, even with very good prices for wheat? - Yes, so it appears; but it must be recollected that in some of those years stock was a ruinous thing; sheep have been fattened upon this farm, and after fattening they would not make the stock price; then the whole of the turnip crop, and the expense of cultivating abont a fourth part of the arable land, have been thrown away; and in other years, when stock has brought a better price, it lias not been sufficient to alter the balance in his favour.

815. Are there other circumstances which make it impossible to draw any conclusion as to the success of the farmer merely from the price of wheat alone? - It camnot be done entirely fom the price of wheat, unless other things coulbine.

816. Have you had in your county any rot among the sheep?-Yes, we have had a considerable number of slseep rotten during the last ten years; but that does not affect us so much, because we buy the sheep in, and it is seldom that we buy a rotten lot of sheep; it must have lessenerl the supply of store sheep, and consequently raised prices; but that has been against the farmer who fed them, the price of mutton having been for some years ruinously low.

817. Yours are not breeding farms:-On some of the farms they breed lambs, but they do not generally breed largely for stock; many of the lannbs are fatted and killed in the spring.

818 . When was this farm taken at the rent of 2031 .? - The farm was taken, I think, first in the year 1800, or thereabonts; the rent was ligher, and so it is now, nominally; but 10 per eent. lhas Ireen thrown off of late years, for which 1 have accounted; I have taken it at the actual rent pail.

819. Ten per ecnt. lias been taken off since 1800? - Yes, within the last few years; perhaps eight or nine years since.

820. IIas it had no other reduction but that? $-\mathrm{No}$ further reduction.

821. Taking into consideration that this farm has given but very moderate profit at any time, and in many years has given a loss, even with good prices of corn, should not you, upon the whole, say, from your knowledge of the country, that that farm is over-rented? - Not so, when compared with other rents; it is overrented according to the present times; but I say if any land will bear any thing like a fair rent this is not over-rented, according to a comparison with other farms; for this farm has, in better times, produced a profit of $400 l$. a year.

822 . When did it pay $400 \mathrm{l}$. a year?-- From 1823 to 1824 ; immediately before my account begins it paid a clear profit of $396 \mathrm{l}$. 12s., after allowing $67 \mathrm{l}$. $10 \mathrm{~s}$. for employ of eapital at $4 \frac{1}{2}$ per cent.; I have no doubt that for many years it paid something like that sum.

823. What rent did the tenant give the year before that, in 1800 ? - I am not prepared to state, but I think not much more than the present rental, with the addition of 10 per cent.; but I cannot speak positively.

824. What does he pay with the 10 per cent. taken off? - T'wo hundred and sixty-three pounds, being $32 \mathrm{~s}$. $3 d$. per acre; what I meant was, that the profit not the rent, was $400 l$ : in the year $1823-4$.

825. Was the profit $400 \mathrm{l}$., after allowing rent? - Yes, after allowing every thing; and it was then farmed in exactly the same way as it has been of late years.

826. Was that owing to the state of prices in that year, or to the goodness of the crop? - I see there are several parcels of wheat which sold at 18l. a loal, and another parcel of wheat at $17 \mathrm{l} .8 \mathrm{~s} .6 \mathrm{~d}$; barley appeared to be about $35 \mathrm{~s}$; this was the produce of 1823 , sold in March 1824; but I have not been through the whole account of that year.

827. You have stated that you do not think this fam over-rented?--Compared with land which will bear any rent, I mean; all land, in my opinion, is decidedly over-rented; but compared with land worth $20 \mathrm{~s}$. an acre, this is not high; but I consider that all land is over-rented.

828 . It is your opinion that that is the general state of land; that it is overrented? - I should say the land $\mathbf{l}$ an acquainted with is over-rented; supposing the prices are to remain as they are now, it is a greater rent than the farmer can afford to pay; in fact they can make no rent at present, and ought rather to receive a bonus for oceupying their farms. 
Mr. J.J. Allnatt.

26 February 1836.

829. As you sell for the farmers, and deal in the town for them, what do you consider about the price of wheat which would justify the existing rents in your neighbourhood ; is it $50 s .60 \mathrm{~s} ., 70 \mathrm{~s}$., or what rate for the price of wheat, supposing other things to be in proportion?-Does the question mean the other burthens remaining as they are; for rent is only one feature in the calculation? I do not sell for farmers, or deal in the town for them. I said that I had been in the habit of transacting the market and other farming business for my father.

$\$_{30}$. If you were called upon to value a farm, you would value on some certain price for the produce; what is about the sale of wheat you would consider a justification for the rents as they now stand; should you think $15 l$. a Ioad, or 16l.?I should think, that supposing the other com to sell as it does now, and calculating upon fair average erops, wheat ought to be at or above $16 l$. a load to make any thing like profit on the farm.

831. At the present rents?-Yes; if the labour and rates and other expenses are to remain on agriculture, I think it should be at least 16l. to make a fair remunerating profit.

832. Do you grow inuch barley?-Zes, we grow barley.

833 . What is your course of husbandry?-The four-course; wheat, turnips, barley or oats; a portion of that barley land grass, and sometimes a portion of it beans, preparatory to the next wheat crop.

834. You have not in your neighbourhood any lighter lands," where they breed sheep; no breeding farms? - They breed sheep on many of the farms in our neighbourhood, but not to a large extent, for stock.

83.5. What is the common price of day-labour with you? - We give $9 s$. a week to a common labourer; but many of them work by the piece, in threshing, and cutting chaff, and other things, which enables them to earn from $10 s$. to $12 \mathrm{~s} .6 \mathrm{~d}$.

836 . Is that the common price in the neighbourhood?-I should say that in the neighbourhood they are rather lower than that; $8 s$., I believe, is given in the villages near us; but we generally give $1 s$. more in the town and the immediate neighbourhood of the town.

837. You have stated upon this farm $430 \mathrm{l}$. expended in labour this last year; what proportion of it was labour really wanted for the farm, and not expenderl for the purpose of supporting the people?-I know there has been a strict examination upon this farm, to know in what way labour could be reduced; but it was thought advisable not to reduce it more.

838 . You conceive the whole of the labour went for the farm?--Yes, certainly; and it was the impression, when it was examined into, that it could not be reduced to any considerable extent, with propriety.

\$39. And was beneficially employed?-Yes. I think I can explain. With respect to this lalnur, there are at this present moment three men, for instance, employed in cutting chaff; that might be considered an extravagant outlay upon so small a farm, but it is in fact a gain, as by this means the consumption of hay is lessened: so in other matters the amount paid for labour, although comparatively high, may not be an evil, if the labour itself has been properly and profitably directed.

840 . Was this labour employed for the purpose of maintaining the people, or labour necessary for the good of the farm?-It is considered that every man employed on this farm is beneficially employed.

841 . Do they thresh by hand?-Yes, every thing; and they have done so since the unfortunate riots in the rural districts.

842. Has the cultivation of the land been improved?-This land has been for some years past in such a state of fertility, I do not know that it can be much improved; the produce has been great, in consequence of the state of cultivation; it is in a very high state of cultivation; in as high a state of cultivation as a farm need be.

843. Is the cultivation about you improved generally of late years?-No, I should say not.

844. Do you think they have more wheat for the acre than they used to do ?I believe, for the last three years, there has been a great crop of wheat; not from the improved cultivation, but from the seasons being favourable to wheat; but harley las been deficient.

845 . What is your opinion of the last year; was it a large crop, or more than an average crop? - In our neighbourliood the liarvest of 1834 was decidedly a good crop.

846. What 
846. What was it in 1833 ? - I should say an average crop; 1834 was above nn average crop for our immediate neighbourhoor. In my ealculation $I$ liave given five quarters an acre, which may be considered a prodigious crop, in 1835. I have had something to do with valuing crops for tithes, and other matters, and I should say the wheat $I$ have been over in our immediate neighbourhood was defieient, when compared with the year 1834, about one fifth; at least one fifth; and in fact, from tlureshing the wheat, I know that is the fact, witl regard to our own experience.

847. Is it, upon the whole, what you should call an average crop?-I should say a fair average crop, but not a large crop.

848. Do you know any thing of the produce in 1832 ? - I do not so well remember the produce of 1832 .

849. You stated that you do not conceive the rent of this farm so high; you lave estimated on the rent bearing a certain proportion to the value of the produce?-I think I explained that loy slowing that in proportion as other lands were now let it was not, but that $\mathbf{I}$ thought all the land in our neighbourhood was let too high, according to the present price of produce.

$8_{50}$. Can you state what was your opinion as to the value of this farm, in the year 1819, per acre; how much it was worth ?-I cannot at this moment refer to prices in 1819.

851. What price, as a land surveyor, should you have put on that farm in the year 1819 ? - I have no doubt, if a farm situate as this farm is, were to be let by a landlord, it would have brought as high and perhaps a higher rent than has been paid for it.

852. The question is, what rate of interest the present rental bears to the value of that land in 1819 ? - Not being able to refer to the price in 1819 , I cannot answer that question; but I should say that the farm was worth the sum given at that period.

853. How much was given for it?--Ten per cent. more than is paid at this time.

854. You have been asked what the prices should be to sustain the present rent; what rent ought to be paid for it, according to the present prices?-None at all, and a person should have a bonus to occupy it.

855. You think at the present prices he eannot afford to pay any rent for this excellent tract of land? - Just so.

856 . That being land of the best quality, and in the best state of cultivation? -Yes. I do not mean to say that if a man pays no rent he would not get a single farthing during any one year, but he could not maintain himself upon it by any cultivation, with present prices.

857. You state that the loss in the year $1834-5$ was $166 \mathrm{l} .5 \mathrm{~s} .6 \mathrm{~d}$., the rent being $263 \mathrm{l}$.; supposing he had been there without rent, his profit would have been about 100l.?-Yes; but by subtracting the amount of corn sold in the year of the preceding year's growth he would have lost more than the rent paid.

858 . If that farm were now out of lease would it fetch its present rent from any substantial farmer?-Yes, I have no doubt it would; and this is an extraordinary fact, that land of this character, and so eligibly situate, would bring, not only very nearly the rent which is paid for it, but, perhaps, entirely. But, in point of fact, we know that near a town many men would be glad to procure such land; they fancy that they could benefit themselves, though their predecessors did not; but I am very well convinced that it would be impossible to farm it better, or for any occupier to prevent a loss upon it, under present circumstances.

859. Then they must lose, of course?-Certainly.

860. Therefore you consider the disposition of men of substance to take good farms at a given rent no criterion always that they can fairly afford to do so?Certainly not.

861. Farmers must have some occupation?-Yes; the fact is, as to the farmers in our neighbourhood, that is, in Berkshire, and elsewhere probably, they are generally a race of plodding and industrious men, who had have a limited education, and who are fit only to remain on the soil they have been brought up on. 1

862. Therefore they would take farms on very disadvantageous terms? Yes; but always under the delusion that times would mend, and that if they could take a farm under the present reduction they might eventually. get on.

464.

F 4

863. There 
Mr. J. J. Allnatt.

863. There is rather more eagerness to take good farms at a high rent than bad farms at almost no rent, is there not?-Yes. I know many farms in our 26 February $18{ }_{3} 6$. nicighbourhood where there has been great difficulty in proeuring tenants. I know a gentleman, who farms his own estate, six miles from us, who assured me he has been throwing many acres of his estate out of cultivation, and suffering it to go back into its primitive barrenness.

864. Can you convert arable into pasture with benefit?--No, not for many years; and it must be properly laid down, with a decided expense; besides, much land is not suitable for pasturage.

86.5. Is it your opinion that there would be more land taken from under the plough, if you could, with readiness, convert it into pasture?-Yes, certainly.

866 . What is the stock of wheat now in the hands of the farmers; is it large? -No, not particularly large; but there is one reason why it appears larger than it really is, and that is the great bulk of the straw, and the great difficulty in getting it to market; otherwise the farmers would have been desirous to bring it to market to pay their expenses.

\$67. Are there a great many wheat-stacks in the farmers' yards? - Not in my immediate neighbourhood; perhaps above the average bulk, but not more corm.

S6is. What as compared with last year?-There was, perhaps, about the same ; but I have no immediate means of ascertaining. About the same as regards the number of ricks; but I should say, if there are more ricks this year there is not more corn, because the wheat yields badly from the rick; there is much straw, and consequently less wheat per rick by several loads, in mauy cases, than there was last year.

869. Do you attend the markets much?-Yes, every week.

870. Have you observed whether there is a glut of wheat in the market? -There has been a very bad sale of late, consequently we may call it a glut.

871. Has it appeared to you that there is more corn in the market than the market has required?-Yes, considerably more; and when there is much corn in the market the farmers are compelled to force a sale, and to find buyers, but it is at depreciated prices.

872. The prices will fall greatly when there is more in the market than the country requires? - Yes, certainly.

873. Do you think it is from corn produced in England that the markets are over-stocked?-Our wheat markets are supplied principally with our own produce. We have Irish oats brought occasionally by dealers, and sometimes I have seen samples of foreign wheat, but not frequently.

874. You have not seen any foreign wheat for the last year or two? -No.

875. Do you send corn away to distant markets?-No.

876. Do you go, at times, to the London market, or other markets? - No, the farmers do not, but the dealers who come from Reading or Henley or other places do, I liave no doubt, occasionally. have.

877 . Have those dealers come so frequently as in times past? $-I$ believe they

878 . And have bought freely?-I would not say they bought freely, for during reduced prices there is always an indisposition to buy freely, which adds to the depression.

879. You state the expense of labour to have been $430 l$. in late years; can you state what the expense of labour was in 1828 or $1829 ?-\mathrm{No}$, I have no means of doing that, without looking through this account before me.

880. The reduction in the price of labour has borne no proportion to the reduction in the price of wheat?-Certainly not. That will be proved from this fact: when wheat was $20 l$. a load the wages were $10 \mathrm{~s}$. for a man, which was one bushel of wheat; last year the wheat was under $4 s .6 \mathrm{~d}$. a bushel, and we gave them $9 s$, which was two bushels of wheat instead of one.

881. Have you had quiet and peace anong the labourers in your part of the comutry?- We have, lately.

882 . Is the farmer now, with respect to his labourers, in a state to be equal to regulate his price of labour according to the price of corn, or are the people in any state of excitement which renders it impossible or difficult to do that?If we were to reduce them to the extent that wheat would warrant us 
in doing, giving them a hushel of wheat a man, they would be starved, independent of the excitement produced; no farmer would act so crucl a part.

$88_{3}$. Setting aside the question whether it would be fair to do it, is there any thing in the temper of the people which makes it impossible to regulate the price of wages according to the price of food? - I can only speak from what has ocenrred in our parts, which were part of the disturbed districts; I should say it would not he safe to do it.

8S4. An impression still remains which would make it difficult for the farmer to regulate the price of labour as he would think it equitable to do it?-I think it would indispose the farmer to attempt it to that point. If there was something egregiously wrong, or wages were exorbitant, he would probably reduce them.

885 . Ilas the alteration in the price of corn enabled the farmer to get his work, such as that of blacksmiths and wheclwrights, and different tradesmen, at all relueed?-They have been very little reduced; and that is an extraordinary fact. Last year I was remarking on the blacksmith's bill; it came to very nearly as much as some years ago.

S86. Then the farmer has to contend with the low price of his produce, and no reduction of the charges which press upon him in that respect? - Very little indeed.

S57. What does that arise from ?-I do not know; they bave been spoken to on the subject, but their reply is, that they cannot do it for less. Whether there is combination among them I do not know, but they all cliarge the same.

8S8. It has been the custom to give a certain price for shoeing a horse or making a cart-wheel, which it is difficult to alter?-Yes; I think they have altered, but very little. Now the high price of iron will be an argument in their favour.

S89. IJas the new Poor Law done you any good? - The union has lately been establisherl. The guardians meet in our town at present. It is an experiment; but $I$ believe there will be a decided reduction in the amount expended upon the poor the first year.

Sgo. The farmers think well of the measure?-Generally; they think well of the principle, but they are not very much enamoured, in my opinion, with the operation of the law; they fancy that there is too great cruelty exercised towards the poor: not absolute cruelty, but that their allowance is not so liberal as it ought to be.

891. The objection of the farmers is, that they think it presses hard upon the poor?-Yes, but they do not object to the principle.

S92. Can you state whether there is any particular part of the Act which they consider to be offensive? - No, I do not know that there is. I am not a guardian myself, but I have frequent communication with them.

893. What is the principle which you say they approve? - The prineiple of being able to coerce an idle and disorderly person; but the objection I lave heard started, and I think justly, is, that there is no discrinination allowed to the guardians or the parishes in case a man of good character and industrious habits should apply for relief; that le is treated as a pauper, and degraded in the same way as the idle and dissolute.

894. They think they should have relief at their own houses, instead of being sent to the workhouse?-Yes. Many have stated that they th ink that the ratepayers should have an opportunity to recommend persons whose tonesty they can depend on, to be assisted by the guardians.

895. Do not the guardians institute inquiry into the character of those persons? -They were disposed, I believe, to take this matter into consideration; but the Commissioners in London replied to them, and stated that they were too liberal.

$S_{90}$. You have stated that the farmer's are rather afraid to lower the rages; do you not think there is equal danger from the application of this Poor Law system in exciting disturhances?-I think, unless they alter the manner in which the poor are treated in some plnces, they will be exciter; I have no donbt of it, eventually.

S97. Are the Committee to understand there is no relief given at their own houses? - That will be the operation of the system, and that, I understant, is the ultimate intention in our union. At present we have not completed the poorhouse, nor brought the system into complete operation.

S98. Where there is a workhouse are not the guardians cmpowered to relieve 464. 
Mr. J. J. Allnatt. the poor in their own houses?-It is at present diseretionary; but I believe the intention is eventually to relieve none in their own houses.

$2 f_{\text {February }} 8_{3} 6$. S99. Have the becr-shops been beneficial or prejudicial to the lower class?Decidedly prejudicial, in our neighbourhood.

9oo. They liave tended to demoralize ?-Yes, to an alarming extent.

901. Do you think it wonld be benefieial if the duty was taken off malt and put on beer? - In a moral point of view, deeidedly beneficial.

902. You think that the lower class would then be enabled to brew at home? - Yes.

903. Has any wheat been consumed in feeding cattle in your neighbourlood? - Yes, a considerable quantity; we are giving wheat to sheep ourselves just now.

904. IIave you had any experience as to feeding cattle witl malt or grown corn?-Never; I have never known the result of that.

905 . Is it your opinion that it would be beneficial to the agricultural body if they could malt their own barley for their cattle?-I have no doubt, from what I have heard, that would have a very good effect, and as good to the farmer as the application of oil-eake.

906 . Have you malted any wheat in your neighbourhood? - Not in our immediate neighbourhood; it was used in the city of Oxford; a considerable quantity was malted by a brewer there, and it produced very exeellent beer; the ale was very much approved of.

907 . You eannot state at what proportion of the price between wheat and barley it answers to malt wheat for brewing?-No, I cannot; for the increased quantity of saccharine principle must be brought into the ealeulation, which I do not understand sufficiently to enable me to state the proportion with aceuracy.

908 . What is your present price of barley?-From $30 \mathrm{~s}$. to about $32 \mathrm{~s}$, generally.

909. You consider that a fair price?-It is a fair price for barley; but the crop has been short of late years.

910. Do you grow barley?-Yes.

911. Would it be beneficial to you to have the malt tax removed?-It would be a relief generally.

912. Would it be a great relief?-I should say it would be a great relief; it would be a stimulus to the barley trade, by inereasing the consumption.

913 . What is the proportion of produce between a bushel of wheat and of barley when malted? - I do not know what the exact inerease is; I have not been aceustomed to the process of malting.

[The Witness is directed to withdraw.

Mr. John Lewin, is called in ; and Examined as follows:

Mr. Juhn Lewin

914. WIIERE do you live?-At Wiekham Market, in the county of Sulfolk.

915. What quantity of land do you oeenpy?-My son and imyself oceupy between 400 and 500 aeres of land between us. I am a miller, (I have two water-mills and two wind-mills,) and a buyer of corn to a considerable extent. I can speak as to the produce of 50,000 or 60,000 acres of land around me.

916. How long have you been a farmer?--I have been concerned in farming all my life, ever since 1795 or $1796 ; 40$ years.

917. Is the land your own, or do you rent it?-I rent it principally; the mill I live in is my own, and a certain portion of land.

918 . You purchase a consiclerable quantity of corn more than you grow? - Yes, 10 times as much as I grow.

919. From the experience you have, both as a miller and a farmer, what is the state of agriculture in that part of the country? - Very distressed indeed.

920. When do you consider the distress to have begun?-In 1815.

921. Did it then improve again?-Yes, it did; it improved from the wet harvest of 1816.

922. How long did it continue improved?--The short crop and the wet harvest of 1816 brought high priees; they did not go down very low till after the Act (Peel's Bill) of 1819.

923. When did it go down?-In 1820 ; in 1821 lower still; in 1822 very low; in 1821 it was of a bad quality.

924. In 1823 it rose again!-It did. I bonglit a great deal in 1822, from a great 
great many firms ubout my neighbourhoml; every hushel of wheat, before Nichachnas, from the failne and the low price. I bought a great deal of the finest wheat from 4. . $(\mathrm{d} d$. to $5 s$. a bushel.

925. When diel it full again, after it rose in 182:) ?-It fell, in some measure, in 1825) anc 1826. From Oetober 1825 to March 1826 (during the panic) wheat fell from $8 s$. $(j d$. and $9 s$. per bushel to $6 s$. (id. and $7 s$. In $18.2: 3$ the surplus was expenderl, and the prices rose from $4 s$. 6 d. and 5s.; in 182:2, from $7 \mathrm{~s}$. to $9 \mathrm{~s}$; and continued varying between 1824 and $18: 28$ from $7 \mathrm{~s}$. to $9 \mathrm{~s}$. generally, exeept the time of the panic, as before statel.

926. lighteen hundrerl and twenty-eight was a bal harvest?-It was a wet summer and a short crop, but not a very had liarrest.

927. Did eoln rise or full then?-It rose then; it continued from $7 \mathrm{~s}$. to $9 \mathrm{~s}$. during the four wet summers of $1828,18: 9,1830$, and 1831 .

928 . Were those gool or bad seasons? - They were barl, generally spreaking; barl for wheat on lieavy lands.

929. What priees were they in those years? - They varied from $9 s$. to $11 s$; they averaged in three years from $6 s .6 d$. to $10 s .6 d$.; averaging abont $8 s .(j d$. for the four years.

930. Those are fair prices?-Yes, with good seasons and good crops.

931. When dirl they fall again?-In 1832 and 1833 they began falling.

932. And did not rise again till this year?-No; they have gone down in 1834 and 1835 still lower.

9.33. What sort of year was 1832 ? - A pretty good year of wheat. In 1833 , 1834, and 1835 we harl four dry summers; the erops of wheat have been better; but all onr crops of other corn have been very short, on the average of the last four years.

934. What sort of crops had you in 1834 and 1835 ?-Very good crops of wheat; but almost all other corn was very short indeed in 1834.

935. In your opinion, did that contribute to keep up the prices of barley and other kinds of corn while wheat was depressed?-Certainly, there was no other reason; the crops of beans and peas were nearly a failure in 1833 and 1834 .

936.- What markets do you attend?-Woodbridge and Framlingham markets. I live just half-way between them.

937. Those two markets, which are the two great corn-markets of the county, are supplied from your distriet?-Yes, from that district of the connty where they are situated; perhaps from 100,000 acres of land.

938. Were those markets overstocked with corn?-Certainly not, in those jears.

939. In what years?-Eighteen hnndred and twenty-cight, 1829, 1830, and 1631.

940. They were understocked, perhaps, then?-Yes, they were; they were overstocked the first part of the last four years.

941. How were they in 1834 and 1835.- Overstocked the first part of the year, and continued a drug the whole year.

942. Was the drug such as to press down the prices?-Yes.

943. What is the state of the farmers in your neighbourhood?-Drearlful.

944. Do you think that the pressure of their distress drove them to take their corn to market when they otherwise would not have carried it there?-I am sure it did.

945. That also contributed to foree down the prices?-It dir.

946. Have rents been lowered in your neighbourhoorl?-Yes.

947. To what extent?-Depending upon the quxlity of the land; I know one farm lowered from $1,200 l$. a year to $700 l$. a year.

948. To what extent, in your neighbourhood, have farms been lowered? -I should say from 20 to 40 per cent. Very few farms produce any rent at the present prices of eorn.

949. Within what time? - The last 15 or 20 years.

9.50. IInw much are they above what they were before the year 1793 ? - Some of the good lands are alove, but some of them are as low, in my opinion; as many farms, I know, have ruined the tenants, who have pair no rent.

951. Taking into consideration the improvements whieh love heen made with the capital of the landlords, are they generally higher now than they were then? -I shoulil say they are not.

952. Is it possible that the tenant ean pay the present rent and the present rate of wages at tle present prices?-It is quite impossible they ean either pay 4 (14. 
Mr. John Lcwin. rent or wages, or half the present rent or half the present wages, at the present prices.

26 February 1836 . 953. Which is the largest item in the account, wages or rent?-The wages, generally speaking; ny labour is considerably more than my rent.

954. You say that the wages cannot be sustained at the present prices of produce?-It is impossible.

955. In what condition will your poor be, if that is the ease?--They are in a most dreadful state now. In 1822 there were two fine jolly farmers riding through the village $I$ live in to complain of their distress to a public meeting in the neighbourliood, and they were joked and jeered about their being in distress; but in two years afterwards they were paupers on the parishes, where they now remain.

956. Have many passed from being rate-payers to paupers?-Yes, a very great number; there is a poor wirlow (73 years of age), whose husband ocenpied the largest farm in the parish; her lieart and purse were always open to the distress of others; but she is now dependent on parisl relief, and under this new Poor Law is allowed only a pound of flour and $3 d$. per day.

957. Is the distress confined to the tenants, or does it extend itself to the peasants? - On the part of the peasantry it is dreadful. There is one poor widow in another adjoining parish to the last-mentioned (aged 75), whose hushand occupied one farm of his own for which Lorrl Huntingfield oflered him 5,000 guineas. IIe has now, from circumstances orer which he had no control, becone distressed, died broken-hearted, and he has left his widow dependent on the parish, and she receives a pound of flour and $3 d$. per day, same as last mentioner.

95 $\mathrm{S}$. Was that the effect of improvidence, or the effect of the times?-The effect of the times; there could not be a more steady respectable man; his son is now a policeman in the City of London; I met him in Fleet-street yesterday, when lie informed me that two other young men, farmer's' sons, whose names I have, and whose fathers were living one on the right and the other on the left of me, were just in the same situation; each of the fathers had a fam of their own, and rented another. The father of one of the young men is at this moment in prison for debt; the other is left without a shilling. The two eldest sons hare come to Lendon, and they are in hopes of getting employment in the eity police.

959. Are those cases exceptions to the general rule?-No, there are hundreds of other instances who have been reduced to distress by the state of the times.

960 . Have you many poor out of employ? $-A$ great number around me. I have contracted for flour for 14 parishes under the new system; I have a mill two miles from where I live, where the paupers cone from three of the parishes. for their flour; I see the men, and to hear their complaints is dreadful. One good labourer, whom I have known for years, who worked in a barn opposite my nill, said he was discharged last April, and had but two weeks' employment siuce; receives only two stone of flour, $2 s .8 d$. and $2 s .6 d$. for four of them, he having a wife and two children. The farmers do not hesitate, if a man has a large family, to say, "I eannot afford to keep him, he wants more wages than I can afford to pay;" consequently many men with large families are turned upon the parish ; and if the farmers can give but $6 s$. per week, they must either reduce the quantity of labour on the farm, or they must have the same number of men at a less price. They are getting now into the habit of hiring men at reduced wages; and as young healthy men have no resource, from the new Poor Law, they are offering their services at less money.

961. What is the rate of wages now ?--Eight or nine shillings is about the regular rate of wages; but when men have large families we generally give them an opportunity of earning $1 s$, $2 s$. or $3 s$. more, making $10 s$. or 12s. a week.

962. Can that rate of wages be sustained at the present prices?-Certainly not. 963 . You say there are a great number of instances of this in your county ?Yes, I can mention many other instances.

964. To what do you attribute this depression of prices?-To the want of moncy.

965 . Does there appear to be a want of money in the market?--Yes; as to all kinds of produce; we have always had better prices when the currency has been expanded, and when it is contracted they are lower.

966. It is your opinion, that if there lad been a greater circulating medium it would have tended to relieve the agricultural interest from a part of the depression? - Certainly. 
967. What other remedies would yon propose?-Perhaps some alteration in the corn laws; I contend the present corn laws do not give us that protection which they profess to give. 'There wats a frand practised in the ealeulation of the expense of bringing wheat from Dantzic to London of $6 s$. to $8 \mathrm{~s}$. a quarter; instead of our average being ( $j 4 s$. our average comes to $56 s$. or $58 s$, in consequence.

968. What is the nature of that fraul to which you refer?-I suppose the improper information furnisher to Govermment; but that I cannot speak to; but the freight and expenses were calculated at $12 \mathrm{~s}$., aml several of my friends proved it was to be obtained for ( $s$. Then the foreign corn, I conceive, should pay a duty on its arrival, and never be under $20 \mathrm{~s}$; , the average should be taken from the grower only. We consider that as soon as the wheat gets at a fair price the farmer has no protection; we think that the sliding seale should never go below $20 \mathrm{~s}$. I mean to say, in short, that Government might as well have had $20 \mathrm{~s}$. duty as $1 s$. duty ever since the law was passed, and not increase the price of corn.

969. You mean that there should never be a less duty than $20 s$., let the price be what it will ?-Yes, at any rate it should stand at $20 \mathrm{~s}$. duty; from $64 \mathrm{~s}$. to $80 \mathrm{~s}$. or $74 s$. at any rate. Whenerer it comes to a fair price the farmer is stripped of his protection, and stands on just the same ground as men in Poland, or in other foreign countries.

97\%. The moment the corn begins to rise, down go the duties; is not the fall too rapid? - A great deal too rapid.

971. Is not the effect of that fall to give to the country the benefit of good harrests, and to throw the loss upon the farmer of the bad ones? - Yes; I consider that if the $20 s$. was not always continued, it should stand a certain time, say from $60 \mathrm{~s}$. to $80 s$, or from $64 s$. to $74 s$.; but what we complain of is, that it goes up to a certain height, then it tumbles down immediately; that is a very serious injury, that it draws away the capital from our market to the foreign corn. Foreign corn is allowed to go into Jersey and Guemsey, and even into Canada, and they ean practise this fraud to a great extent; I do not know whether it is practised, but the whole growtl of those places may be sent into the British market, and they may turn round and buy any quantity of corn where they please, and then send the whole of their growth to this country; this very corn may be transferred into our market, where it is now chargeable with about $40 \mathrm{~s}$. duty. If it is carried across the Atlantic it may be unloaded and loaded again, and brought in here at $5 \mathrm{~s}$.; I have no means of knowing if this is practised, but I mention it to show the defect in the law.

97.2 . Is there an idea prevailing that that is the ease?-We suppose something like it, for we had flour from Ireland at one time of a better quality than the Irish eould be made; we never harl any difficulty in competing with the Irish flour till one season; the thing was looked into by Govermment, and it has not occurred since.

97\%. In what year was that?-I have not got the date of the year.

974. Is Irish flour in general as good as English?-Certainly not.

975. This flour was better than the Irish flour?-Yes.

976 . Is the American flour better?-Yes; but not so much better as flour from the Dantzic wheat.

977. Have you any other complaint to make of the corn laws?-Only that flour is not protected as it ought to be; there is no protection for the manufacturer of flour.

978. The American flour is much higher dried than the English?-Yes; the wheat undergoes the process of kin-drying before it is ground.

979. IIow does that answer?-It is stronger, and suits the bakers better.

9So. The speculation being in foreign corn is an injury to the English corngrower?-It is.

$9 \$ 1$. Would not that be prevented if the warehousing system was knocked up? - Yes.

982. Do not you think it would be beneficial if the arerages were taken in Ireland as well as in this country?-Yes, and from the farmer. Some say it is not possible to take it from the farmer, but I can see no difficulty in it; I lave been in the habit of purchasing from farmers, and sometimes from merchants who buy often, and then they will sell to us again; if that is the best corn it happens perhaps to be sold five times over, that is, returned five times into the Government accounts, and carries the amount very far beyond what the farmer receives.

$9 S_{3}$. All that the firmer wants is, that the foreign corn should be totally exchded, is not it?-No; I do not ask that in my proposition.

464.

ci 3

${ }_{9} 94$. Your 
Mr. John Lewin. 6 February 1836

984 . Your complaint is, that the foreign corn is received in that manncr which ron think prejudicial to the English farmer? - Yes.

$9_{9} S_{5}$. If it ean he shown to yon that it is not let in at all, then all the objections you make against the corn laws would fall to the ground, wonld they not? - No.

980 . Can the Legislature do more tlian not let it in at all? - I apprehend it camot prevent what I lave mentioned, that it is not in the power of the Legislature to do it.

$9 \$ 7$. If it was proved to your satisfaction that the forcign corn is not let in at all, then all your difficulty abont the different averages, whether they are taken in one manner or another, falls to the ground, if it does not come in at all ?I apprehend that is impossible; how can any one satisfy me, when it is quite impossible that corn never was returned nor bought in any way to be ascertained.

988. Is it possible yon could be injured by the state of the corn laws, if it were shown to yon that for several years past the foreign corn has not come in at all ; is it not then immaterial in what manner the arcrages are regulated ?-I do not clearly understand the question. I mean to contend, that the corn that was brought into this country in 1828 and in 1831 has an effect upon the market at this moment, and that the quantity of corn bronght in at those particular times drove so mneh of our English corn out of the market; a good deal of that has to come in the third or fourth following year.

$9^{8} 9$. Yon think that the importations in 1828 and 1831 are the canses; do you mean that in those years the very good prices occasioned corn to be sent over, and which comes now into our markets?- - No, I say it comes in and prevents so much of ours being consumed; consequently ours is kept back and comes from time to time to market, and thus corn is kept in liand; but that the farmer, instead of bringing ont his corn in September, brings it out in the next July; it goes step by step.

990. Do you recollect the years 1829, 1830 and 1831 ?-Yes.

991. Those were years of bad crops?-Yes.

9.12. Was there any consilerable stock remaining in hand at the end of those years?-We lave no means of ascertaining how much.

993. Cannot you, as a miller and farmer, recollect whether there was or not a considerable stock in hand at the expiration of those years?-There was not a great stock in either of those years.

994. If there was no considerable stock in either of those years, and it can be shown there is no foreign wheat now selling in the market, and has not been for years past, low do you make out that it is the foreign wheat which has come into the market? - $A$ great deal has come in, in the way I have before described, that has never come into the market at all.

99.5. If there is foreign wheat which is now coming into the market, can you state where it is?--No ; I lo not say that any man can; we can only speak from the circumstanees.

996. Can you give information of any person who conld show if foreign corn really comes from Ireland clandestinely?- $\mathrm{No}$, if I could I should take some trouble to ascertain it.

997. There is a suspicion that it does, Is there not?-Yes, to a certain extent; I do not think there is any suspicion now, but that there was at the time I speak of.

998. From what point do yon suppose the foreign corn came to Ireland ?-We supposed it to be Dantzic, becanse the quality was so superio:.

999. You seem to think that injmy is done to the English grower by the fact of foreign corn being warehoused in this conntry; is not the injury done when foreign corn is bronght into actual consumption ; supposing the com to he warehoused, is there a difference between its being warehoused in London, or its being warehoused at Calais, or any where on the opposite coast of France, provided it can at any time be brought into the market; is it not the same thing where it is warehoused? - No, I do not consider that; the duty can be paid, and it can be taken out of the granary to-morrow; and if it were at IIamburgh or otlier places it would require a month.

1000. Are you aware that it can come over from the coast of IIolland in one tide?- Not quite so quick; they have to send vessels over for it.

1001. Are you aware that it can be brought from the coast of JJolland to the London market as cheaply and as rapidly as from your market at Wondlbridge?- 
I should think not quite so quick as that; I have a vessel goes backwards and forwarls.

1002. How near do you make it from Woollbridge to the port of London? - It seldom goes in less thain four days, but the ressels in general come once a month, taking the year.

1003. What time does it take, upon the average? - The traders keep regular voyages; one loads this week, another the next week, and so on, and that weekmonth they are ready to load again; they come up in a fortnight and go back in a fortnight.

1004. If it can be proved that it can come from Flushing in half that time, can there be any difference as to the market in London, from whence the wheat is to come in the one case and the other, whether it cemes from Flushing or from Woodbridge?-Yes, because there is an order to send a vessel to fetch it ; if corn is bought ont of warehouse here, it can be had the day after; if it is bought at Hamburgh, it cannot be had for a month; and a great portion of foreign corn is speculated for in Hamburgh.

1005. Supposing that you were not to warehouse it in London, but could warehouse it on the opposite coast just as cheap, can there be any difference to the English grower of corn, whether it is lodged in one place or the other?-I apprehend that is impossible; if a speculator brings it to Holland, he must ship it again to London; if he brings it into a London warehouse, it is here, and it must come into this port.

1006. There would be a considerable risk fron stormy weather in bringing orer corn in those ressels, would there not?-Yes, there is a risk attending that; there are 24 ressels now lying wrecked within four miles of Lowestoft.

1007 . If the corn was warehoused at IIamburgh, it would not so readily get into consumption as if it were warehoused in the river Thames?-No, it would not.

1008 . Would the English corn-merehant so readily speculate in corn warehoused on the Continent as he would in corn warehoused in this country?-No, certainly not.

1009. You have stated that the last four years have been years of good crops? - Crops of wheat alone. I do not consider them so good as to reduce the price to the level at which it is without other causes.

1cı. The farmer has been distressed?-He has.

1011 . The years 1829,1830 and 1831 , were all of them bad crops?-They were.

1012. Was the condition of the farmer better or worse then?-Not better, but the same; they were sinking and falling fast for eight years.

1013. Do you think that his condition is worse now than it was in 1829,1830 and 1831 ? - About the same, on the arerage.

1014. You do not think he is in a worse condition now than he was from 1828 to 1831 ?-Yes, I think he has been gradually sinking; the seasons have been all gradually sinking ones to the farmer for the last eight years; he las been sinking from crops the first four, and bad prices the last four.

1015. Taking the whole into vour view, has it been a more losing coneern to you during the years of good crops, or during the four anterior ones of bad crops? -I have lost more; my soil is rather dry, and has been seriously injured by the last warm seasons, which have benefited some others.

1016. Woodbridge is your town?-Yes, the nearest.

1017. Have you country banks in that town? - I's.

1018 . Since when have they ceased to issue any small notes?-In 1829, I think.

1019. Did they issue up to 1829 ? - I lo not think there were many; the last three or four years they began to draw them in.

1020. You said that when the currency was expanded one year, that you thought your condition was better; what expansion of the curreney took place to which you refer?-I did not mention one in particular, but every expansion of the currency from 1796 alwars raised the price of our corn.

1021. You attribute such an altered price of corn to the altered state of the currency?-I consider that one of the causes.

1022. How comes it that in 1829,1830 and 1831 you had the prices of whent, which you say areragerl at about $8 s .6 d$. a bushel, and those have fallen to $4 s .6 d$. a bushel; was that owing to any corresponding alteration in the state of the currency in your neighbourhood ?--I do not know that it was. The former price of the four years, $1828,1829,1830$ and 1831 , was in consequence of a short quantity of corn coming to narket.

46.

G 4

1023. So 
1023. So that the reduction of price has been influenced by the more or less supply of the article, and not by the state of the circulation?-No, I do not say

36 February 1836. that; it was for part of this winter. There has been no cajital working to take off the extra com that comes in. As millers, we want a certain quantity of corn, but if there is twice as much wheat in the market, there is no speculation to any extent with eapital to take it off, which there used to be in former years, when the circulating medium went to a greater extent.

1024. Do you not find that whenever there is a fall in prices, there is always capital for speculation?-Yes, there is always a time, as lately, when a great deal of money is locked up. In large towns, like London and Liverpool, as soon as those parties who are great speculators consider that it has got to its lowest price, they begin to speculate, but unless they find that small streams of money are flowing into the small channels as well as others, they turn round, and, finding there is no one speculating to take it off their hands, they stop.

1025. In the last three or four weeks, there has been something of a disposition to speculate, has there not?-Yes.

1026. When there is in your neighbourhood an opinion that prices are about to rise, is there any difficulty in getting capital for the purposes of buying?-Yes, I should say there is, generally speaking.

1027. Does not that want of capital arise rather from the impression that the article is not a good one to speculate in than any thing else?-No, there is always money to be had by the large speculators, but small buyers have not the means.

1028. When you speak of the contraction and expansion of the curreney, do you apply that to the more or less issue of country notes?- No, I apply it to all paper currency; the extension of the Bank of England regulates that and all others.

1029. Have yout watched the alteration of the Bank circulation?-I have, at many different times.

1030. You think that the alteration of prices in your neighbourhood has had something to do with the Bank circulation?-I am quite satisfied of that fact; when they have been extended our prices hare got up, and when they have been contracted our prices have gone down; it is not that alone, but that has in some measure regulated it.

1031. The extension of bank notes and of other notes?-Yes; if the Bank of England extends, the country banks do the same; and if the Bank of England contracts, the country banks do the same.

1032. Do you mean that you have looked to the prices of corn and the extent of the Bank of England circulation, and that you have found a corresponding connexion between the one and the other?-Just so. I have watched for 20 years past,- before the end of the war, and from the end of the war. Whenever the operation has arisen, I have always said things must be guided by it; and I have been complimented years afterwards by its being said, "You said, such a year, such and such must be the case, and it has been the case."

1033. You have been complimented upon your sagacity upon those occasions? -Yes.

1034. Supposing that to be the moving cause, we should infer that when the prices lave been very low there lias been on the part of the Bank of England and the country bankers a contraction of paper?-Gencrally speaking.

1035. Do you ascribe the prices to that as being the sole cause?-No, by no means.

1036. If there is more wheat in the market than is wanted, that will be a cause?-Certainly.

1037 . What are your prices of barley?-Our prices of barley have varied from $18 s$. to $32 s$. a quarter.

1038. Have you had it as low as $9 s$. a coomb?-Yes; in the month of November there were several samples shown me by farmers that could not get more than $9 \mathrm{~s}$., in Woodbridge Market.

1039 . Barley of last year?-Yes.

1040. Not barley of good quality?-No. The farmers in the county of Suffolk supposed they had got a very excellent quality of barley, but when they came to liave it threshed, they did not find it so generally.

1041 . What is now the price of gond malting barley?-Thirty-two shillings a quarter; I dare say from $28 s$. to $32 \mathrm{~s}$. prime samples; the clievalier barley is the favourito barley with us now. 
1042. As a farmer you consider that a fair price, do not you?-No, at the end of four years' bad crops I reckon that any thing less than $40 \mathrm{~s}$. would be low.

Mr. John Lewin.

1043. Any thing under $40 s$. you consider not a fair price for barley?-Yes, 26 February 1836. after four years' bad crops.

1044. How do you consider meat at present ?-I am sorry to say I am fattening beef now for the London market that will cost me $1 s$. a pound, and mutton must cost as much, for we lost our feed in the marshes last sunmer, and all our white turnip crop, most part of our swedish turnips, and a portion of our mangelwurzel.

1045. Are not the prices of meat, on the whole, fair average prices?-Certainly not, according to the feed; if we had had full crops of vegetable food, the present prices would have been high.

1046. Neither the prices of barley nor meat satisfy you as a farmer?-They do not pay me; I am out of pocket with both; I should be satisfied if I had a profit.

1047. Is the price of wool satisfactory?-Yes, I consider that very fair.

1048. How do you conceive the currency to operate upon prices, that it should touch the price of wheat and not at the same time the price of other articles?It touches every other article, as far as I see..

1049. If the price of produce is, as you suppose, affected by something taking place in the currency, how is it it affects wheat and not other articles?-Because wheat has been a fuil crop and the others have not.

1050. It is the crop, if that is the case, and money does not affect it? -No, I do not admit that; one affects it in one way and the other in the other.

1051. The currency will affect all articles, unless there is some countervailing cause in respect to particular articles?--Yes, it will.

1052. You have been asked as to corn coming from the Continent; supposing I. corn to have come from the Continent and to have been brought into consumption for the last two years, if there has been a great increase of corn from Ireland will not that do the same mischief here?-Certainly. I have always contended that if the poor of Ireland have not the means of consuning their produce, and living better, our poor must be reduced to the same level. We both grow corn for the same narket; and I consider the allotment system and the Poor Law to be two steps to bring our poor down to their state. The allotment grows the potatoes; the man is obliged to sell his corn to pay his expenses, and he has his potatoes left; the Poor Law gives him no relief, and he consequently must live upon his potatoes, as they do in Ireland.

1053. Are you speaking of the allotment system in Ireland ?--No, here.

1054. If corn be considerably cheaper in Ireland than it is here, and if it has free access to the English markets, will not that bring down the English corn to the Irish price? - It has done so for the last 20 years, in some measure.

1055. Have you watched the effect of the beer-shop system in your part of the country?--Not much; our poor hare not been in a state to encourage the beer-shops of late.

1056. If the allotment system is only carried to the extent of sending the garden produce to market, or the feed of a cow, in that case should you think that it was injurious either to the labourer or to the farmer?-No ; the allotment system enables the poor men to grow their own potatoes, whereas they used to buy then. All respectable persons in country villages grow their own vegetables, and they, the poor, have no means of selling any regetables; they grow half wheat and half potatoes, and sell the wheat.

105\%. You think one of the effects of the allotment system is, that the labouring classes have grown more potatoes and consumed less corn?-Yes.

105S. Do they keep pigs ?---Yes, in some instances.

1059. According to your experience have freeholders, occupying their own land, or farmers generally, suffered most in these bad times? - I think the freeholders occupying their own land; where they have been owners and occupiers both, they have had the landlords' losses and suffering as well as the tenants'. I happen to have been the humble instrument of disincorporating one of those houses, such 464 . 
Mr. Joh Lcwin. as are now about to be set up and built all over the country, and my roing so was for the benefit of the country. I was working ten years at it, after trying tle 26 February $18{ }_{3} 6$. experiment of the incorporation of the house for 60 years. It was tried under $\Lambda$ ct of Parliament for 25 years, and failed, and another 25 years, and failed, and 15 mole years it was tried, making altogether 60 years; and at the end of that time I slıwed clearly, that (from 1800 to 1824) to maintain 271 paupers in that house, on the average of the 24 years, it cost $6 s .6 d$. each per week, when upwards of 1,200 cost only $1 s .9 \mathrm{~d}$. on the average out of the, house; and above $60,000 l$. was spent, in fact it was $78,000 l$. that was expended, more than if all these poor had been in liealth and strength, and in full employment the whole time, out of that house instead of being in the louse; and in spite of all classifying, and chaplain and schoolmaster, the morals of the poor were much injured by the system.

1060. You are of opinion the present system of poor laws is working injuriously to the poor?-Dreadfully. The poor have their eyes upon me, and they have been making all inquiries of me about this law. I think it very injurious, as injuring the labourer very seriously in society, depressing lim down, lowering his wages; in fact all agricultural labour, I consider, must affect this question, inasmuch as if the farmer has the means of paying but $6 s$. a week instead of $12 s$. a week, he must have men at $6 s$. a week, if it is possible to get them, and he can get them; because I can take my horse and find 100 men at $1 s$. a day, when many men with large families are working and getting $10 \mathrm{~s}$. to $12 \mathrm{~s}$. a week: consequently farmers in general say, "If others do, I must resort to the cheapest labour, in the same manner." I consider that the Poor Law Bill deprives a man of any resource but the prison, as the men call it; they say, that if they are to be sent to a prison, they will do something to be sent to a prison for.

1061. Is that the general opinion of your neighbours, or a peculiar opinion of your own?-There are many in my situation that say that it is working well by saving their pocket, without regard to the condition of the men.

1062. Setting aside the consideration of hardship to the poor, and looking at it as a question of fact, is it working beneficially as to any saving ?-- It must be saving money to some persons; but I am certain it will, after a time, work the other way; that it is impossible it can be done on this principle without increasing the expense ultimately.

1063. Is it, in point of fact, within your knowlerge that there is a saving?The report is so; but $I$ believe the fact is not so. There are some parishes where the expense is increasing very materially; all the best managed parishes that kept their poor in a proper manner before will be increased in their expenses; some people desire to get the system that they may save by it.

1 064 . Can you mention any parish which has increased in its expenditure by the operation of the Bill?-I should say we have, to begin with. I am told that the board is saving money in the village I live in; but instead of being called on for less, I am compelled to pay $3 s$. in the pound as a quarter's rate, instead of $2 s .6 d$.

1065. Is that for building? - No; the building is not yet fixed on.

1066 . Do you pay $12 s$. a year?-Yes, I have paid $20 s$; and since I took up the parish matters I reduced them to $8 s$, with the assistance of my brother parishioners. We reduced them from $20 s$. to $12 s$, and then to $8 s$.; but they have since been from $10 s$. to $12 s$.

1067 . Is that upon a fair rating?-Yes.

i 068 . Upon a fair valuation of your rent?-Yes.

1069. Is that on the actual value?-On about two-thirds of the value. The farm I now have paid $1 l$. an acre for rates, and almost every labourer in the parish was a pauper. Before we had undertaken the parish seven years there was not an able-bodied labourer a pauper: but, under the old law, we remedied ourselves, and set the poor free, and they all earned their bread before they ate it.

1070. What was the rental ?-Thirty shillings an acre.

1071 . What conrse did you pursue to reduce the sum?-Constant attention and constant employment.

ro72. Did the farmers employ more people than they used ? - Yes.

1073. Were they beneficially employed?-No; not to pay them. I employ 20 men, women and boys and girls, on 100 acres of land, when I might have done with five.

1074. How 
1074. How many men shoult you employ on 100 acres, according to the usual system? $-\Lambda$ bout five; I have had 20 many times; but could not liave employed so many if I had not the millering business, in addition to $\mathrm{my}$ farm, in that parish.

[The Witness is directed to withdraz.

Ordered, That this Committee be adjourned to Monday next, One o'clock.

Die Lunœ, $29^{\circ}$ Februarii, 1836.

The Lord WYNFORD in THE ChaIR.

[The following Paper is delivered in by the Lord in the Chair, and read:]

A Statement showing the respective Quantities of Hemp, Flax, Tallow, and Bristles, of Foreign Production, consumed in the United Kingdom during the last Three Years.

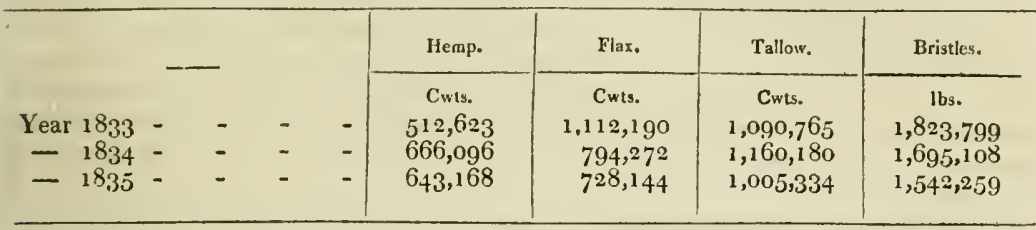

Inspector General's Office, Custom House, London, 27 February 1836 .

W. Irving.

Mr. Samuel Kendall is then called in, and Examined as follows:

1075. YOU manage His Majesty's farms?-Yes.

1076. You are not a farmer on your own account?-No, not at all.

1077. Therefore you have no interest whatever in the question now before the Committee?-No, not any.

1078. To what extent do you farm?- We have two distinct farms; one we call the Flemish farm, and the other the Norfolk.

1079. What quantity altogether?-A bout 1,300 acres.

1080. Cultivating that quantity of land, you have had an opportunity of knowing whether farming is now a profitable occupation, or not?-I am extremely sorry to say I give very bad accounts to His Majesty as to profits.

1081 . To what is that owing?-From the low prices of corn.

1082. Are they farmed with a view to profit, or experimentally? - Not at all for experiment, nor have I attempted any thing of the kiud while I have been with His Majesty.

1083. It is in the regular course of farming?-Yes.

1084. You would farm as well for the King as for any other individual?-Yes.

1085. You do not render it profitable?-No; the farms were in a very wretched state when His present Majesty took to them; he has had them now some few years; they are now getting into a better state of cultivation.

1086. Will it pay any thing like a profit now?-I hardly think it will.

1087. Would it pay any rent?-No, we could not pay any rent.

1088. That is owing to the depreciated price of produce?-Yes.

1089 . What do you take to be the prices in WVindsor market?-The wheat fluctuated in, that market from $8 l$. to $12 l$., the present year's crop.

1090. Other articles have borne better prices?-Oats and barley have borne better prices.

1091 . How is cattle? -I do not think cattle has done much this year, the keep has been so high.

1092. Do the prices you receive for oats and barley compensate for the loss on wheat?-Not at all.

1093. Do you think you could pay any rent?-I do not think, at the present prices, rent can be paid.

1094. Do you know the state of the farmers round the country?-Deveral of them I know.

464 . 
Mr: S. Kendall.

29 February 1836 .

1095. What is their condition?-I think they are in a very bad state, generally speaking.

1096. Do you think they are able to pay their rents out of their profits?-Not many of them, I think.

1097. What proportion should you say?-I should think perhaps they might make up two-thirds of the rent.

1098. Is that generally the case, that they can only make up two-thirds of the rent? - I think, except in individual instances, it is impossible to do more, under present prices.

1099. Do you think the capital of the farmers in your neighbourhood, so far as you have the means of knowing, is diminished?--There is no doubt of that.

1100 . Have they, in your opinion, been paying rent and other out-goings ont of their capital?-They have paid a great deal out of their capital.

1101 . They have been sacrificing property every year?-Yes, they have been losing their property.

1102. Do you conceive that to be generally the case?-I think that is generally the case round the country.

1103. What is the state of the poor in your county out of employ?-There have been a great number out of employ.

1104. Do you think those persons would be employed if the produce of agriculture fetched a remunerating price? - I have no doubt they would; there is a want of labour on the farms thronghout the county, but, from the want of money, they are not enployed.

1105. How far does your knowledge extend?-I am a Norfolk man.

1106. Are you acquainted with Norfolk as well as with Windsor?-I am.

1107. Do the observations you have been making apply to Norfolk as well as to Windsor?-To Windsor and the neighbourhood round. I have left Norfolk 30 years.

1108. How many miles round are you acquainted with the state of things?Twenty miles round.

1109. Do you apply those observations to 20 miles round Windsor?-Nearly that.

1110. On what description of land? - The land is very various indeed; there is very light gravelly land and stiff clay.

1111. Have you good land?-There is some good land.

1112. Do you make a distinction between the good land and the bad?-The good land is much better to manage; the tenant will do much better in managing that, though he pays a ligher rent.

1113. Even upon good land, with present prices, can he pay the present rent?I think not.

1114. Are the poor dissatisfied in that country?--They have been much.

1115. What rate of wages do they receive?-Two shillings a day.

1116. Have you been obliged to lower them? - No; we think it dangerous to reduce them.

1117. From what reason?-The fear of damage to the property.

11 18 . Have there been many incendiary fires?-There have been two fires in our place within the last five months; in the neighbourhood of Maidenhead.

11 19. What do you think is the occasion of the incendiary fires?-From the dissatisfaction among the labourers. They have no interest towards their employers at all; they have no energy to work an lour longer without being paid for it, which used to be the case formerly.

1120. Are the labourers in a much worse condition now than they were formerly?-I think not; their wages were high.

1121. Can the farmers possibly continue the payment of the present rate of wages?-Not from the present price of corn.

1122. Would the lowering of the rate of wages produce the consequence you refer to, of more general dissatisfaction among the labourers?-I think it would.

1123. Have you at all turned your mind to a consideration of what is the cause of the depression?--I feel, in my own mind, that the produce of Ireland is a great injury to this country; both stock and corn too.

1124. Have 
1124. Iave you the means of knowing how much more cheaply corn can be produced in Ireland than it can in England?-No.

1125. You know that there are great importations of corn from Ireland; and you consider that these affect prices in England?-Yes; I have been looking at the account of the year 1830. The prodice from that country was $13,000,000 l$. taking eattle, linen, grain and butter; all the produce from Ireland.

1126. Do you know what it was last year? - No ; the duty upon that, if imported from another country, would be $4,000,000 \mathrm{l}$.

1127. But, coming from Ireland, it pays no duty?-No, none at all.

1128. What is the state of banking in your county? - There is very little doing in our neighbourhood.

1129. Can the farmers get the accommodation the farmers in former days were in the habit of obtaining? - -Certainly not; confidence is totally lost.

1130. The bankers will not trust the farmers?-No; they know they are needy, and will not trust them.

1131. Are there any other circumstances you can state material to this inquiry?There is one thing, with respect to labour; I am convinced the farmers are very much injured in consequence of the men not doing the work they formorly used to do ; three men will not do the work two used to do.

1132. What is that from?-From a disinclination towards their employers.

1133. Is that from idleness, or their not being fed?-I think it is more from their disposition than any thing else.

1134. Have the beer-shops done good or harm?-A very great deal of harm.

1135. Do you think that this arises, in a great measure, from the demoralized state produced by the beer-shops?-Yes.

1136. Has a bad feeling arisen, also, from their being turned out and badly fed while they were out of employ? - Yes, in part.

1137. Is the barl feeling increasing or decreasing?-I think it is not diminished; there is a great deal of petty thieving going on.

1138. Do you think that the contraction of the circulating medium of the country, by the Bill, of 1829 has had an effect?-It has had some effect.

1139. Is it your opinion that the extension of the circulating medium of the country would have been for the benefit of the agricultural interest ?-I can hardly tell that; because the farmers are so short of money, confidence is so much lost they could not obtain that credit they otherwise would have done.

1140. Can you give any opinion why the wheat is so much lower than other grain on the farm? - About 10 or 12 years ago all the fen country grew nothing but oats; in Cambridgeshire, Lincolnshire and part of Norfolk, and so on; and in consequence of the immense importations from Ireland they were not able to get any price for oats; in consequence of that all this land has been drained, and they are now growing wheat equal to that in any part of England.

1141. They were driven to grow wheat, because the Irish drove them out of the oat market?--Yes; that country is now producing wheat.

1142. You think a greater breadth of wheat is grown than used to be grown formerly?-Yes.

1143. That is owing to the quantity of Irish oats that come into this country?

-Yes. The drainage was assisted in their doing it.

1144. Do you think they would have continued to grow oats if the Irish oats had not driven them out of the market?-They would have done it, most probably.

1145. Is it your opinion that there is a considerable increase in the consumption of potatoes?-I think the allotment system has done away with a great deal of the use of corn; they eat more potatoes and meat. In going down to Sussex last year, at one of the houses at Cranley where the coach stopped, I did not see a piece of bread on the table; and the landlord told me that lower down in the country I should not see any bread at all.

1146. What is the substitute?-Potatoes.

1147 Are you of opinion that there are a great many more potatoes grown now than formerly? - There are a great many grown by the labourers; I do not 464 . 
Mr. S. Kendall. know that there is that quantity grown for sale there used to be, but in consequence of the allotment system there is a great deal more grown by the labourers.

29 February 1836 . $114 \mathrm{~S}$. Are those potatoes grown by the plough or the spade?--By the spade, those grown by the labourers.

1149. Do they generally consume them in their cottages, or send them to market, or feed cattle or pigs with them?-They feed on some, and the offal goes to the pigs.

1150. Does that system prevail to a great extent?-I think it does.

$11 j 1$. Was it ever the habit for the labourers to have part of a farmer's field, and grow potatoes upon it? - No; it night be the practice where a liedge was grubbed to let the men grow potatoes upon it.

1152. The allotment system never extends to more than a quarter of an acre, does it?-I do not exactly know the quantity to which the allotment system extends; in respect of the produce of wheat there is sometining very puzzling to my mind.

1153. Hare yon any idea whether there is still a great deal of wheat in the farmers' hands?-There is a great deal in Sussex; a great deal of old wheat; some men are keeping three-year-old wheat in the neighbourhood of Lewes.

1 154. Those are considerable farmers?-Yes.

11 55. The smaller farmers cannot keep back in that way? - No.

1156. They are obliged to take it to market to pay their rent and taxes? --Yes.

1157 . Does not the necessity of the smaller farmers tend to depress the prices? - There is no doubt of that; the same has been the case as to hay this year; hay has been selling at $\mathrm{W}$ indsor as low as $3 l$. a load to the Barracks. :

1158 . Wheat is rising now?-Yes, and barley going down, which is very extraordinary.

1159 . What is the reason of that?-The maltsters say they have all done malting; they generally malt till the middle of May.

1160 . What do you say to the malt tax; suppose that were repealed, would that increase the consumption of barley :-I think it might, in some instances; but I think that the better plan would be to let the malt be free and bonded, and to pay no duty till it is taken out of bond; to throw the trade completely open, let it be malted free and bonded, and then to pay suty when it is taken out for use.

1161. They pay the duty now inmediately upon its being made?-Yes; but I would do away with the excise, and all the vexations of it.

1162. Would your plan diminish the revenue?-No; I think it would increase it.

1163 . But you would do a way with the vexations of the excise :-Yes.

1164. Have you any thing else to state?-We all know that we have got an immense increase of the population in this country, and an overburthened produce of wheat; and to my knowlerge the cultivation is deficient; I cannot account for that.

1165. To what ought the consumption to be inereased, supposing it $10,000,000$ of quarters some 20 years ago ? - I am not prepared to answer that distinctly. 1166 . Is there more or less wheat grown in your neighbourhood than there used to be?-It is much about the same; we go on one regular system.

1167. But the produce is less? - I think all over the kingdom that there is not the same produce, in consequence of not going to the same expense of cultivation.

$116 \mathrm{~S}$. Is there the same labour employed in its cultivation? - I think not.

1169 . That arises from a surplus population being out of employment? - Yes.

$11 ; 0$. Would there be a necessity for emigration if the labourers were well employed?-There is employment now for them, if the prices will permit.

1171. According to your observation does distress prevail most among the tenantry, or among the freeholders who occupy their own land?-I think it is pressing very hard on those who are occupying their own land.

11;2. Are there many of those who have been much distressed, and have been obliged to alienate their land? - I do not know that there are many in my neighbourloud; but I know that the distress presses on many. 
117.3. Has the new I'oor Law Bill had an effect in benefiting the farmers?-It hats reduced the rates in many places.

1174. In what state has it left the labourers; has it enforeed from them an equal quantity of work ? - I an fearful the labourers have abandoned the place, and many who are turned out of work must lave loread, and they go to thieving. In the first quota of the Windsor district there is nearly $500 \%$. saved in the quota.

1175. Have any unions of parishes taken place?-Yes; and there is one in Sussex I know very well, the parish of Pulborough, where, under the new Poor Law, they lave been saving, comparing the month of January 1835 and the month of January $1836,146 l$. in the montl.

1176. How has the saving been effected? - From the poor having been driven away.

$11 ; 7$. When that system is equally established all over the country, where must the poor go to? - They must come back.

1178 . Are there not some distriets in England where there is a seareity of hands, such as Lineolnshire? - I know nothing of that district; the railroads have taken up a good many, but that is only a temporary thing.

1179. Is it not the case in your neighbonrhood that many are on the Great Western Railway?-No; it has not, commenced in our neighbourhood yet.

1180. Do you believe there will be an alteration in the qrantity of wheat sown, from the low prices?-I think it is very probable persons may tum their attention to that which pays better.

1181. Have any experiments been made in the introduction of other corn on the land on which wheat has been used to be grown ?-- I am trying the experiment on our Flemish farm, and making a fallow for barley; it is very stiff land.

1182 . What sort of barley shall you sow? - The common barley.

1183. Have you had many bankrupteies among the farmers in your neighbourhood? - Not many in the neighbourhood of Windsor.

1 184. Have many farmers been totally ruined already, owing to the present state of things ?-There is no doubt many have ; many lave left the country, and gone to America. A man from Norfolk came to my place the other day; he is going to America, with his family, being driven by distress.

1185. When you say that many of the labourers now eat meat and potatoes instead of bread, do you suppose an equal quantity of land is exhausted in providing that kind of food as when they eat more bread?-No ; that is one thing which I consider has reduced the price of wheat, for there is not that quantity of wheat consumed which there was formerly, by those who used to eat only bread.

1186 . In those gardens which produce potatoes, a part of which were applied to the sustenance of pigs, which become the food of the labourcrs, will an equal quantity of land be exhausted by producing that food as there would if they had been fed more largely with wheat?-.No; those persons will have manure, and dress that land, and raise their potatoes.

1187 . Do you think one effect of this different mode of their being fed is that there will be less manure for the wheat land or the farmers' land ?- I do not think it will have any effect upon that, it is in so small a compass.

1188. In so far as that goes that system will produce more manure than the wheat-growing system?-However that would be it must go to the general eultivation.

1189. Do you think that the allotment system has tended very much to improve the situation and condition of the labouring classes, by giving them more comfort? -I think it has; I think that the labouring man is now exceedingly well off.

3190. Do not you think that half an acre of potatoes would last a family much longer as food than half an acre of whent?-Yes.

1191. As long again?-I should think it would.

[The Witness is directed to withdraw. 
Mr. S. Kendall. The following Paper, prepared by Mr. Jaeob, by the direetion of the Committee, 29 February $188_{3} 6$. is delivered in by the Lord in the Chair, and read:

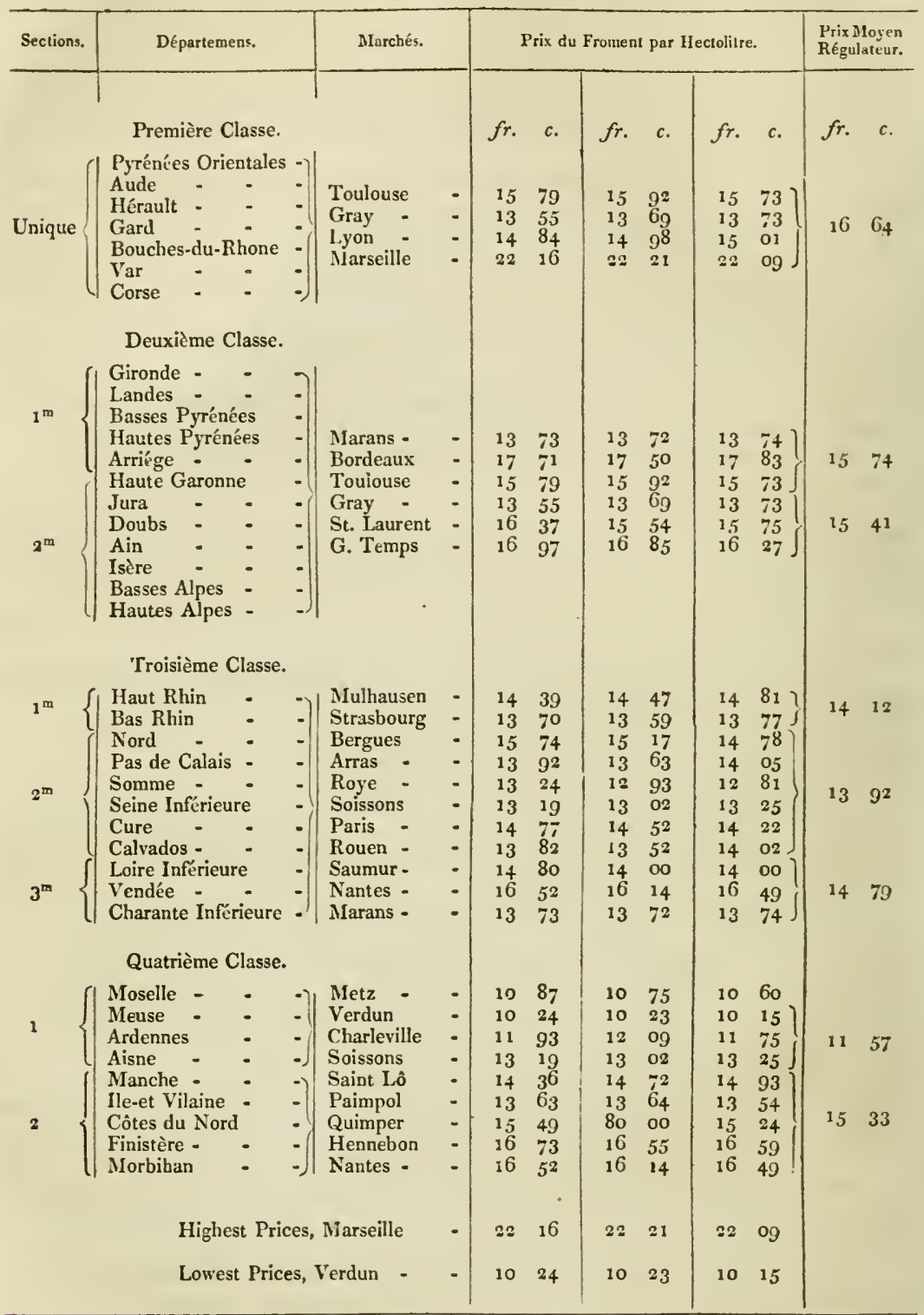

Mr. Evan David is called in ; and Examined, as follows: 1192. WHERE do you live?-In Radyr Court, Glamorganshire. 1193. You are a farmer?-I am.

1194. What quantity of land do you farm?--About 730 acres.

1195. That is in the Vale of Glamorgan?--Yes.

1196. Are you employed by any gentleman in managing his estate? - Not to any great extent.

1 197 . To what extent? - I have at present a farm of 1,200 acres, which I superintend for the purposo of letting or selling it; it is in the hands of the proprietor. I have valued other property. 
1198. Are you a director of a joint-stock bank in that county?-I am.

1199. How long have you been a farmer? - I have been a farmer since 1812 oll my own account.

1200. Were you employed in agriculture before you were engaged on your own account?--I was; my father farmed before me; I was brought up to it.

1201. How long can you speak to the state of agriculture in this country?I have a statement of the profits and expenses of farming a farm of 650 acres at present, in 1813, and from my father's accounts I am enabled to give it in $\mathbf{1 7 9 0 .}$

1202. From that time to the present?-From 1812 I can speak of my own knowledge.

1203. What is the state of farming in your county?-Very much distressed; the capital of the tenantry has been gradually reducing for the last 10,12 , or 15 years.

1204. Have those farmers of whom you have been speaking, whose capitals you say liave been reduced, managed their estates well?-They have not, from want of means.

1205. Have they been skilful industrious persons?-Decidedly so, generally speaking.

1206. Their estates were not well managed only in eonsequence of their diminished means ?- Just so.

1207. To what district of country do you speak?-The Vale of Glamorgan, an extent of about 40 miles long and 15 or 20 wide.

1208. That includes a great deal of good land, and perhaps some bad?-The chief part of the Vale of Glamorgan is considered as good land.

1209. Though good land, do you find the tenants distressed as well as those on the bad? - They are; and rather more so in the vale than in the hill district.

1210. For what is the hill used? - Chiefly for grazing land; for sheep pastures.

1211. You do not think that the cattle farmers are suffering so much as the corn farmers?-They are not.

1212. Will that induce farmers to cease cultivating the land for agricultural purposes, and use it for sheep farms? - I believe it will.

1213 . What effect will that have upon the employment of labour?-It will no doubt diminish the employment of labour.

. 1214. How are your labourers off for present employment?--They are at present better employed than they have been, in consequence of the improved price of corn.

1215. Before the price of corn was improved, what was the state of the employment of labour in your county? - We had in many cases a surplus, which was a burthen to the parishes.

1216. Were they in a good condition and well disp osed?- They were not ill disposed in Glamorgan.

1217. Have you had many fires? - No.

1218 . What is the rate of wages in your county? - Abut $10 \mathrm{~s}$. a week.

1219. Do you consider that, at the present prices, your farmers can pay those wages?-I do not.

1220. What would be the effect upon the labourers of reducing the price of wages; would they be so well disposed ?-I think not; it would have an injurious effect.

1221. Would it be dangerous to do it ? - Yes, in some degree.

1222. Whether dangerous or not, the rate of labour must be reduced, unless the prices can be raised?-It is impossible to cultivate corn at the present rate of prices and expense, and pay a fair rent to the landlord.

1223. Have the rents of land in your county been reduced?-Very much, in some instances.

1224. How much should you say? - There are two farms in my own parish which were formerly let for $240 l$., thiey are now let for $110 l$. Another instance of reduction in rent in an adjoining parish, on two farms, from $800 \mathrm{l}$. to $500 \mathrm{l}$. Another farm purchased some years ago for $8,000 \mathrm{l}$., it was formerly let at $350 \mathrm{l}$, and now it is offered for $250 \%$; it is at present in the lands of the proprietor. Another estate, which was purchased about 1811 for $42,000 l$., the proprietor has laid out $30,000 \mathrm{l}$. in building, farm-yards and other agricultural improvements, and it is now offered for sale at $37,000 l$.

464. 
Mr. Evan David. 1225. Do you know any other lands in that eountry which have been sold at 29 February 1836 . the

the same rate?-There are other eases, but I cannot at present recal to my mind

1226. What is the state of the small gentry in the eountry; are they in as much distress as farmers?-They suffer from the low price of produce, and complain that they are not paid their rents regularly.

1227. Can the tenants pay those reduced rents?-There has been so great a loss of capital among the tenantry they cannot. I could enumerate the names of 25 farmers within 10 miles or 12 miles of me, whose losses have been upwards of $40,000 \mathrm{l}$; farmers from 200 to 500 acres of land.

122S. In how many years lave they been contracting that loss? - Within the last 12 or 15 years; a great proportion of them are insolvent, from one-third to half; and these losses altogether amount to that sum or upwards.

1229. In what condition are gentlemen who have settlements on their estates made on families?-They are in a very unpleasant situation; where properties were charged with payments during the high rents and the high prices of provisions, the rents are now barely sufficient to pay those charges.

1230. When they are charged with payment for the younger branches of families?-Yes.

1231. The farms are not now equal to the payment of those eharges?-No, in some instances they are not.

1232. You have, you say, an account of the management of a farm for a certain number of years; will you have the goodness to produce that account?-I have here a statement of the comparative expense attending cultivation in 1790,1813 and 1835 , on a farm in Glamorganshire.

1233. What is the size of the farm? - Six hundred and fifty acres.

1234. Did you make out that account yourself ?-I did; I have taken the average of three years preceding 1790 , three years preceding 1813 , and three years preceding 1835. I have enumerated the different items of expense, which I will read, if the Committee wishes. In 1813 labour was 44 per cent higher than in 1835 , and in 1790 , lower by 33 per cent. than in 1835 ; carpenters' work was 66 per cent. higher in 1813 than in $\mathbf{1 8 3 5}$, and 43 per cent. lower in $\mathbf{1 7 9 0}$; smiths' work 26 per cent. higher in 1813, 43 per cent. lower in 1790 ; saddlers' work, 26 per cent. higher in 1813 than in 1835 , and 36 per cent. lower in 1790 ; thatchers' work 57 per cent. higher in 1813 , and 73 per cent. lower in 1790 than in 1835. They are the different expenses to which the farmer is liable, and the proportions they bore at different periods; the difference in parochial rates is still greater, as my accounts will show. did.

1235. You made out that account from your own books and your father's? --I

[The same is delivered in, and read, and is as follows:]

T A B L E, No. 1 .

A Statement of the Comparative Expenses attending Cultivation in the Years 1790, 1813 and 1835, on a Farm in Glamorganshire.

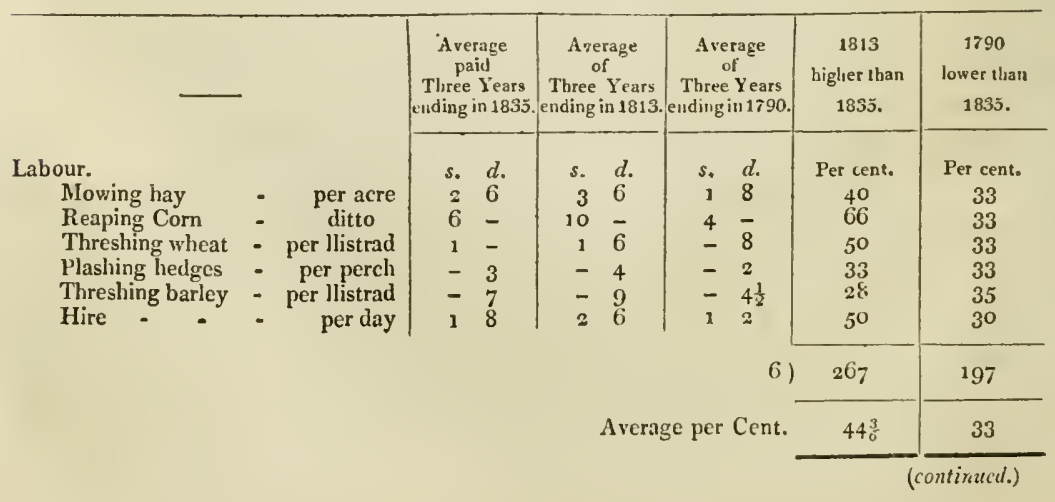


ON TIIE STATE OF AGICULTURE. (Brought from the Lords.) 67

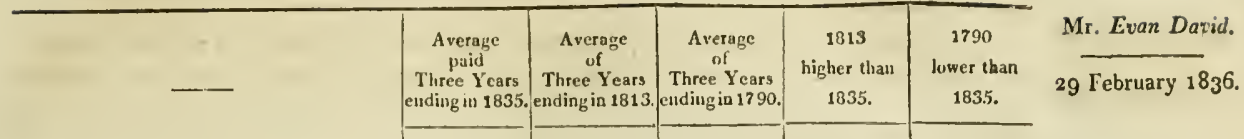

Carpenters' work.

Oak timber

- per foot 2

Ash and clus - - ditto 16

Hire -

- per day

$3-$

$\begin{array}{ll}\text { s. } & d . \\ 4 & - \\ 2 & 6 \\ 4 & -\end{array}$

$\begin{array}{rr}\text { s. } & d \\ 1 & 2 \\ - & 10 \\ 1 & 8\end{array}$

Average

3)

\begin{tabular}{c|c} 
Per cent. & Per cent. \\
100 & 42 \\
66 & 44 \\
33 & 44
\end{tabular}

Sniths' work.

Horse-shoes - - - each -

Removing ditto - $\quad-\quad$ -

Repairing ploughshares - $\quad 16$

Journeymen - - per day

$3-$

Set of harness

Horse collars

Mules' bridles

Hire and dict

$3-1$

$4-16$

Average

4)

\begin{tabular}{r|c}
199 & 130 \\
\hline $66 \frac{1}{3}$ & $43 \frac{1}{3}$ \\
\hline
\end{tabular}
\begin{tabular}{rr|rr}
60 & - & 32 & - \\
7 & - & 3 & 3 \\
7 & 6 & 4 & 0 \\
3 & 6 & 1 & 6
\end{tabular}

$\begin{array}{r}106 \\ \hline 26 \frac{1}{2} \\ \hline\end{array}$

4)

4)

\begin{tabular}{r|l}
\hline 40 & 40 \\
- & 50 \\
33 & 33 \\
33 & 50
\end{tabular}

Thatchers' work.

Thatcling - - per square

Hire

per day

$\begin{array}{ll}3 & \overline{6}\end{array}$

Average -

\begin{tabular}{c|c}
107 & 151 \\
\hline $26 \frac{3}{4}$ & $37 \frac{3}{4}$ \\
\hline & \\
17 & 33 \\
40 & 40
\end{tabular}

\begin{tabular}{l|ll}
36 & 1 & 6
\end{tabular}

Average

Masons' work

Walling - - - per perch

Pitching - - per yard

Hire - - per day

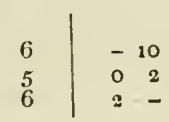

Average

\begin{tabular}{llll|ll|ll|l} 
Hurdles & - & - & - & per dozen & $16-$ & $24-$ & 10 & - \\
Sacks - & - & - & ditto & $40-$ & $57-$ & - & 30 & -
\end{tabular}

3)

\begin{tabular}{c|c}
\hline 57 & 73 \\
\hline $28 \frac{1}{2}$ & $36 \frac{1}{2}$ \\
\hline 20 & 33 \\
\hline
\end{tabular}

$3-5$
-3

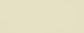

\begin{tabular}{l|l}
20 \\
25 & $\begin{array}{l}33 \\
50 \\
17\end{array}$ \\
\hline 62 & 33 \\
\hline & 116 \\
\hline
\end{tabular}

\begin{tabular}{|l|l|}
\hline $20 \frac{2}{3}$ & $3^{8 \frac{2}{3}}$ \\
\hline 31 & $37^{\frac{1}{2}}$ \\
35 & 25 \\
\hline 66 & $62 \frac{1}{2}$ \\
\hline
\end{tabular}

Rates and taxes.

Poor-rates

Highway-rates

Assessed taxes

Land-tax

County-rates

Agistments -

Church-rates

Property-tax

Household expenses.

Sundries

Shoemaker.

Men's shoes - - per pair

Paupers' dit

Men's boots - - ditto 7 -

Journeymen's wages - per day

\begin{tabular}{l|cc|} 
per acre & 4 & 4 \\
ditto & - & 9 \\
ditto & - & 3 \\
ditto & $-10 \frac{1}{2}$ \\
ditto & $-6 \frac{1}{2}$ \\
ditto & -11 \\
ditto & $-2 \frac{1}{2}$ \\
ditto & - & -
\end{tabular}

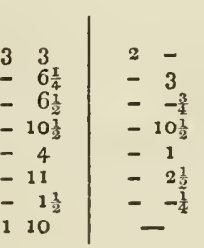

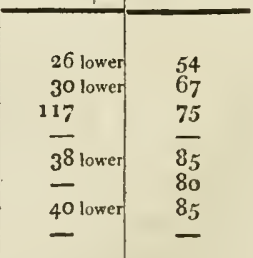

Average 
Mr. Evan David.

29 February 1836 .

Tailors.

s.

\begin{tabular}{lllr|ll} 
Making a coat - & - & - & - & 9 & $\overline{6}$ \\
Making trowsers & - & - & - & 3 & 6 \\
Journeymen & - & per day & 3 & 6
\end{tabular}

\begin{tabular}{|c|c|}
$\begin{array}{c}\text { Average } \\
\text { paid } \\
\text { Three Years } \\
\text { ending in 1835. }\end{array}$ \\
\hline s. & d. \\
9 & $\overline{6}$ \\
3 & 6 \\
3 & 6
\end{tabular}

\begin{tabular}{|c|}
\hline $\begin{array}{c}\text { Average } \\
\text { of } \\
\text { Three Years, } \\
\text { ending 1813. }\end{array}$ \\
\hline e
\end{tabular}

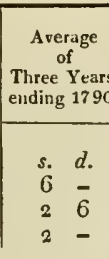

\begin{tabular}{rr|rr} 
s. & $d$. & s. & $d$. \\
10 & 6 & 6 & $\overline{6}$ \\
4 & 6 & 2 & 6 \\
4 & - & 2 & -
\end{tabular}

\begin{tabular}{c|c}
1813 & 1790 \\
higher than & lower than \\
183.5. & 1835.
\end{tabular}

Coo pers.

Small hoops - - - each

Casks - - . - ditto

Hire - - - per day

\begin{tabular}{|c|c}
\hline Per cent. & Per cent. \\
16 & 33 \\
28 & 29
\end{tabular}

\begin{tabular}{l|l}
16 & 33 \\
$28 \frac{1}{2}$ & 29 \\
14 & 43
\end{tabular}

3)

Average -

\begin{tabular}{c|c}
$5^{8}$ & 105 \\
\hline $19 \frac{1}{3}$ & 35
\end{tabular}

Dairy-maid, wages Maid servants, ditto

Education and board Day school

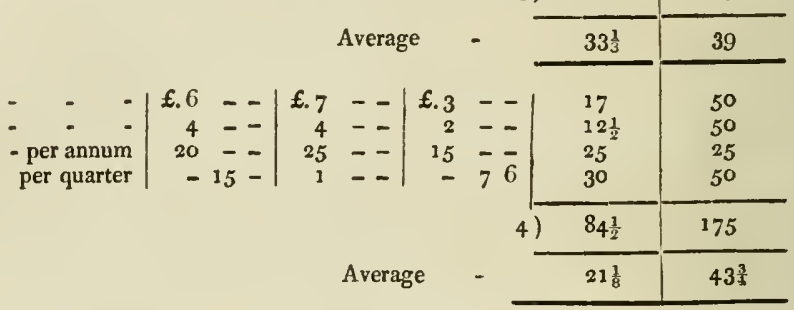

TABLE, No. 2.

Annual Expenses of Cultivating 650 Acres of Land, (450 Arable and 200 Pasture,) at the following periods, according to the foregoing Table, in Glamorganshire.

\begin{tabular}{|c|c|c|c|c|c|c|c|c|}
\hline \multirow{2}{*}{ Labour } & \multirow{2}{*}{ - } & \multirow{2}{*}{ - } & & $\begin{array}{c}\text { Amount paid } \\
\text { in } \\
1835 .\end{array}$ & $\begin{array}{c}1813 \\
\text { higher than } \\
1835 .\end{array}$ & $\begin{array}{c}\text { Amount paid } \\
\text { in } \\
1813 .\end{array}$ & $\begin{array}{c}\text { Amount paid } \\
\text { in } \\
1790 .\end{array}$ & \multirow{2}{*}{$\begin{array}{c}\begin{array}{c}1790 \\
\text { lower than } \\
1835 .\end{array} \\
\begin{array}{c}\text { Per cent. } \\
33\end{array}\end{array}$} \\
\hline & & & & f. s. & Per cent. & f. s. & f. s. & \\
\hline \multicolumn{3}{|c|}{ Carpenter, including timber } & $-\quad-$ & $40-$ & $\begin{array}{l}44 \\
66\end{array}$ & 6610 & $\begin{array}{rr}415 & 0 \\
22 & 15\end{array}$ & $\begin{array}{l}33 \\
43\end{array}$ \\
\hline \multicolumn{2}{|l|}{ Smith, and iron } & - & - & $4^{2}-$ & $26 \frac{1}{2}$ & $53-$ & $24-$ & 43 \\
\hline Saddler - - & - & - & - & $16-$ & $26 \frac{1}{2}$ & 2010 & 105 & 37 \\
\hline Assessed taxes & - & - & - & 810 & 117 & $18-$ & 23 & 75 \\
\hline Land-tax & - & - & - & $27-$ & - & $27-$ & $27-$ & - \\
\hline Agistments - & - & - & - & 2912 & - & 2912 & $6-$ & 80 \\
\hline Property-tax - & - & - & - & - $\quad-$ & - & $60-$ & - & - \\
\hline Lime coal & - & - & - & $30-$ & 33 & $40-$ & $24-$ & 20 \\
\hline Dairy maid and & d dairy & tensils & - & $3^{8}-$ & 17 & 4410 & 2216 & 40 \\
\hline Clover, turnip & and $m$ & gel seed & - & $45-$ & 33 & $60-$ & $3^{6}-$ & 20 \\
\hline Hurdles, sacks, & s, sieves & nd rope & -maker & $18-$ & 33 & $24-$ & $12-$ & 33 \\
\hline Druggist and fa & farrier & - & - & $10-$ & 20 & $12-$ & 616 & 33 \\
\hline $\begin{array}{l}\text { Corn tithes, } \\
\text { kind - }\end{array}$ & by com & sition : & and in 7 & $9^{8}-$ & $24 \frac{1}{2}$ & $122-$ & $85-$ & 13 \\
\hline $\begin{array}{l}\text { Bad debts, mar } \\
\text { incidental ex }\end{array}$ & $\begin{array}{l}\text { rketing } \\
\text { xpense }\end{array}$ & tock and & $\begin{array}{l}\text { d other } \\
-\quad-j\end{array}$ & $50-$ & - & $50-$ & $30-$ & 40 \\
\hline Poor-rates & - & - & - & $13^{1}=$ & 26 lower & $g^{6}-$ & $6 o-$ & 54 \\
\hline Highway-rates & - & - & - & $22-$ & 30 lower & 1510 & 75 & 67 \\
\hline Church-rates - & - & - & - & 610 & 40 lower & $4-$ & $1-$ & 85 \\
\hline & Total & penses & - $f$. & $1,231 \quad 12$ & - & $1,635 \quad 2$ & $79^{2} 8$ & \\
\hline
\end{tabular}


TABLE, No. 3.

Mr. Eran David.

Annual Produce of 650 Acres, as per contra.

29 February 1836 .

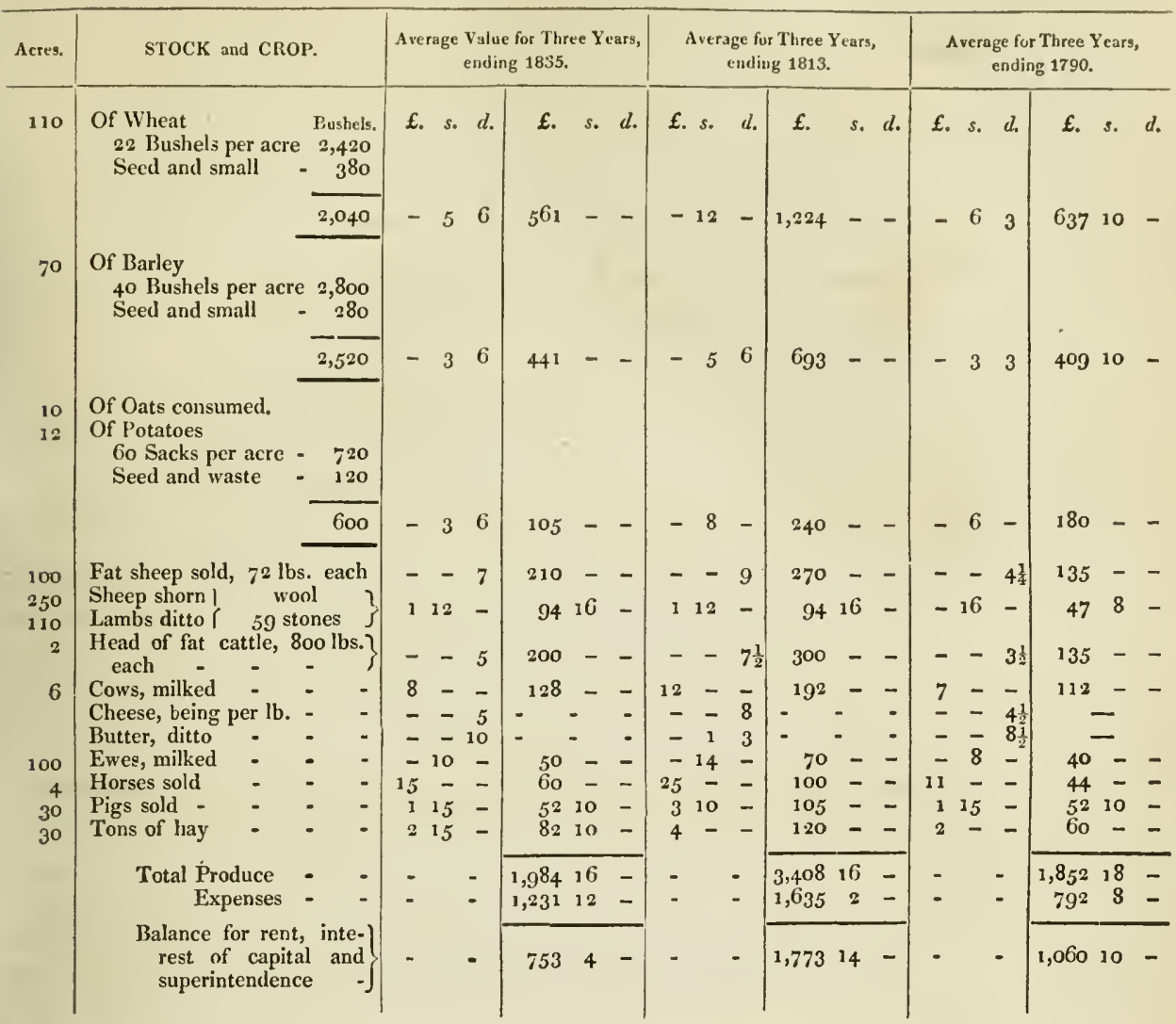

1236. What was the rent at the different periods?-I have said nothing about rent; being desirous only of showing the surplus remaining for rent, interest of eapital, and superintendence, at those different periods.

1237. Do you suppose the same amount of produce in each year?-Yes; I have supposed the farm to be cultivated in the same manner.

1238. You do not allow an increased quantity on the land in consequence of any improvement in cultivation?-No.

1239. How do you account for the depreciation of prices ?- I believe it arises from a combination of causes; all $I$ can say is, that we have been lowering. From about 1820 or 1821 to the present time, prices lave been coming down gradually.

1240. Has there not been a rise during all that period?-In 1825 and 1826 there was a considerable advance for some time, and things were better.

1241. TVere the crops good or bad during that time?-Not much better than usual.

1242. Do you attribute that at all to the extension of the circulating medium in 1825 ? - I do. My opinion is, that the increased circulating medium at that time produced an increase of price.

1243. You attribute part of the present state of agricultural distress to the resumption of cash payments in the year 1819 ?-That is my opinion.

1244. You think that if there is an extension of the circulating medium there will be a rise of prices?-Yes.

1245. State all the causes of the present depressed prices?-Probably another cause is the great import of corn from Ireland, and our unequal competition with the Irish grower.

464 . 
Mr. Evan Durid. 1246. IIas there been a greater importation of corn from Ireland than in former years?-From the information I have obtained, I have no doubt there has been a 29 lebruary 1836 . greater importation from Ireland.

1247. How do you know there has been a greater importation from Ireland? -From published returns; the Custom House returns.

1248. Your account is of the same farm?-Yes; but I occupy more than my father did.

1249. You have not added that, which is an addition to the basis of your comparison; this professing to be a statement of your present out-goings as compared with the former, you liave calculated upon the same surface?-Yes; it is founded on the first statement, or Table, No. 1.

1250. It has reference to the same number of acres being cultivated for the same kind of com? - Supposing the same quantity of labour being bestowed upon it, and producing the same crop.

1251. Since 1790 has there been no increase in the relative quantity of arable land in your neiglibourhood? - That I camnot speak of from my own knowledge; but for the last 10 years I can speak to the quantity of corn produced in our country, generally.

1252. Is it your belief that there is more converted into arable since the year 1790 ? - I believe there is.

1253. You think that since $\mathbf{1 7 9 0}$ there is more land in arable in that farm than there was in the year 1790 ? - I lave no donbt of it.

12.54. Consequently the present expenditure of labour on that farm would exceed that of 1790 , cateris paribus?-Undonbtedly.

1255. Then to make your comparison of the farm a fair comparison, some correction ought to be introduced to that effect?--Yes; probably a small allowance might be made for improved management.

1256. If you have more in arable now than yon had, should not that be stated? -I have supposed that if the farm was managed in the same namner in 1790 as it is now, the same quantity of labour would cost the amount I have stated, the same number of bushels of wheat would produce that amount, and so on. The produce now per acre is something increased, but not to any great degree; but, supposing the same system I now pursue was then pursued, it would produce the result $I$ have stated. If I am asked as to any supposed improvement in the system of husbandry, I shall be haply to give the Committee all the information I call.

1257. You state that there is rather more in arable now than there was in 1790 ? - Yes.

1258 . Is there no improvement in your country in the quality of stock and wool? -There is an improvement in the stock.

1259. The same quantity of sheep will produce more pounds of wool, and of a better quality? - Yes ; there is an improvement in stock, cattle, sheep and pigs.

1260. Is your mode of plonghing and your course of cropping precisely the

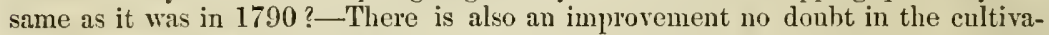
tion of the soil, and I am well aware that there has been effected a very great improvement in the machinery of the country since 1790 ; but it is a very difficult thing in the cultivation of the soil to avail ourselves of that improvement in machinery.

1261. Are you to be understood that in drawing those comparisons from an abstract calculation, when you come to apply it to the same identical surface of land, that land will produce more corn, it will produce more wool, it will produce better wool, being cultivated under a better course of cropping, and therefore, cateris paribus, there must be a greater surplus in the shape of rent than there would be in the year $\mathbf{1 7 9 0 ? - M y ~ b e l i e f ~ i s , ~ a s ~ I ~ s t a t e r l ~ b o f o r e , ~ t h a t ~ t h e r e ~ i s ~ a ~}$ greater produce, but not equal to our increased expenses.

1262. Notwithstanding all these improvements, still they camnot pay rent, and are distressed? - Yes.

1263. At the period of 1790 machinery was not so much introduced generally throughout the country, and the great body of agricultural labourers throughont 
the country and their wives and clildren being employed in spinning, was not there a greater sum received among the family? - These families lave not the same opportunity as they had formerly of earning something. $\Lambda$ s I stated before, on the cultivation of the soil we camnot avail ourselves of that great improvement which has taken place in the machinery of the country. We mow our hay with the same scythe, and reap our corn with the same look as we dicl 40 years ago; and it costs us 30 per ecnt. more, while the inprovement in machinery has enabled the manufacturer to accomplish perhaps filty times as much work with the same number of hands now as he formerly dirl, which enables him to sell his articles at a lower rate with a profit. I might have also arkled that eorn is threshed by the same flail; some improvement las been effected in the plough, but none in the drag and liarrow; our carts and waggons are also much the same.

1264. Whatever the comparative state of agrieulture, with respect to trade or manufacture, what is the comparative state of agriculture in 1836 , compared with what it was in 1790 ? - I would say it was certainly much better in 1790 ; it left a greater surplus for rent.

1265 . Do you mean that, notwithstanding these many improvements, the eircumstanees of the times do not allow you to a vail yourself of those improvements? -Certainly not; the expenses have increased so much, while the price of produce is diminished.

1266. Though sinee $\mathbf{1 7 9 0}$ the course of eultivation has been different, and there has been more arable land than before, has the state of the farmer himself been a more or less prosperous condition?-Decidedly less prosperons.

1267. Are your women so well employed now as they were formerly, before the machinery was employed? - No, they are not.

1268. They used to spin by the road-side?--Yes.

1269. They used to weave the woollen?-Yes; they were in general clothed with clothes of their own making.

1270. That is all made in the towns now ?-Yes.

1271 . Has that been a great injury to the agricultural population?-I believe that it has taken away a great deal of useful labour from them.

1272. Have you mentioned all the causes to which you attribute the depression of agricultural produce?-Those are the chief causes.

1273. From the situation yon are in, as the director of a bank, what do you think would be the effect of an improved system of banking in the country ? - My opinion is, that any measure that would tend to increase the circulation of the country would be of benefit.

1274. Would not any measure which tended to direct the cireulation from London, and to keep it in the comntry, be of benefit?-No doubt; it all rushes up to Iondon; it is in the hands of the few, not of the many.

1275. Would not an improved system of circulation be of benefit to the farmer? -I have no doubt it would, from my short experience on the subject.

1276. Do you mean the joint-stock banks? - I think they are jroducing a good effect; for they have been the means of accommodating the farmers on more moderate terms than they were formerly by private banks.

1277. Were not the farmers suffering much from want of accommodation?I helieve they were; and if your Lordships will allow me to advert to it, although an unpopular opinion, I would state that I believe the savings banks have produced the evil of withdrawing the circulation from the country, by placing it in the public funds.

1275 . They have withdrawn it from the rural districts, and placed in the public funds? - Yes. I have the opinions of some old farmers in the neighbourhood of a town where a savings bank was established, and they tell me, that before its establishment they found it an easy matter to obtain accommodation from their more saving neighbours, by the loan of $20 \%$. or $30 \%$. at harvest or at other times, when they were distressed; since the establislment of the savings banks all that money has been deposited there, and taken out of the neighbourhood.

1279. What do you think of requiring every bank to give security for their issues?-It would be a great improvement upon the old system of private banking.

12 So. At present, if a person beeomes a partner in a bank he is liable for all the debts; would not it be perfectly seeure to the depositors and also to the takers of 464. 
Mr. Evan David. notes, if the responsibility was limited to the sum he subseribed for, provided February 18 paid up or gave security for that sum?-No doubt the paying up the amount 29 February 1836 . or depositing of security would be desirable; in fact any thing that would give confidence to the country; but I must observe that I think the required degree of confidence is equally as well accomplished by the subscribed eapital of a joint stock company, and the depositing of further security is unnecessary.

1281 . Is that accomplished if the eapital is not paid up? - When the names of parties are published and known to be responsible for the sums subseribed, the public must be safe.

1282. In the one case you rely on the well-known credit of the party, and in the other you rely on the eapital brought in ?-No doubt.

$12 S_{3}$. Would there be any objection to $1 l$. and $2 l$. notes if the bank gave security for their issues up to the extent? - None whatever; and I believe they would be very beneficial in England, as they are found to be in Scotland.

$12 S_{4}$. Are you acquainted with Scotland?-I have never been in Scotland.

1285 . Do you think you are competent to give an opinion what effeet they would have as to coin in this country?-Not being sufliciently aequainted with the bullion subject, I would decline giving an opinion.

12S6. Could they have any effect if those notes were immediately convertible into bullion?-They would not have so beneficial an effect if convertible into bullion; but into bank notes, as they are at present, they would be beneficial.

1287 . Do you suppose it would be beneficial if bankers were to issue $1 l$. notes and give security ?--I think it would. I heg not to be understood as recommending an inconvertible issue of $1 l$. notes, but convertible into bank notes in the country, and into bullion at the Bank of England, as at present.

1288. Do you grow much barley in the county? - WV do grow a good deal of barley in the county.

$125 \mathrm{~g}$. What would be the effect of diminishing or taking off the duty on malt?A very beneficial effect.

1290. Would the effect be beneficial not only to the barley countries but to the other countries? - It would be beneficial to all ; because, when the prices of barley increased, more barley would be grown, and less of other produce; it would soon improve the value of all agricultural produce.

1291. Do you find that the duty on malt has prevented the consumption of malt increasing with the population?-Decidedly so. I believe it would have been double what it now is, but for the duty.

1292. Have you manufacturing towns near you?-We have several in Gramorganshire.

1293. Do you find that a great many of the manufacturers have their labourers living in your villages, and not in the towns in which they pay rates?-That is the case, in some instances.

1294. Is it an injury to agriculture, their not being rated?-Ies, it is. I also believe that the manufacturers do not pay the same amount of parochial rates, in proportion to the capital and the amount of men they employ, as the agrieulturists do.

129.5. Do they pay any rates, generally speaking, on their capital?-No; on capital they may not strictly be liable; but there is a great difficulty of rating manufacturing property ; the exemption which iron mines claim from paying parochial rates renders the difficulty greater.

1296. They are rated upon their warehouses and shops, but they pay no rate on their capital?-No; but the property they have locally situated in the parish, I conceive, ought to be rated, and the existence of it ought to be sufficient evidence.

1297. Are the county-rates paid as well in the towns as in the rural villages?I believe not. I happen to know a manufacturing establishment where 600 persons are employed, and a capital of at least $120,000 \mathrm{l}$., and the whole amount paid by this in poor-rates, road-rates, eounty-rates and land-tax is only $90 l$. per ammum, not $1 \mathrm{~s} .6 \mathrm{~d}$. per cent. : while on my present occupation of 730 acres the arerage number of men cmployed is about 25 , and requiring a eapital very little cxeeding 
$4,000 l$., my poor-rate, road-rate, county-rate, and land-tax is $185 l$., or ratler more than $4 l$. $10 \mathrm{~s}$. per cent. on the capital employed, or sixty times as much as that establishment pays.

1298. Have you reason to believe that that is the case all over the kingdom?Yes; from the existing difficulty of properly rating it.

1299. You have not included the tithes in that?-No; that will only make the contrast still greater, because they pay no tithes; in the rceent erection of a new gaol and house of correction in the county my contribution was $40 l$., and on that establishment it was only $20 l$.; if I had paid in the same proportion as they did, it would bave been only $16 s$. $8 d$., by taking the number of hands employed as the criterion, as the county-rates must be increased nearly in the same ratio as the population increases.

1300. Is it not the same with respect to the land-tax in the towns? - I believe it is; there has been no adjustment of land tax for some time.

1301. The property in towns las increased, and the property in the country has diminished; and consequently the land-tax in the country bears a much higher proportion to the value than the land-tax in towns?-Yes; the land only remains liable according to the extent of surface, without reference to the value of the erections on it.

1302. You say that the population employed by manufacturers exceeds the population employed by you; can you ascertain the proportion of wages:-We pay nearly the same; my wages are at present about $10 s .6 d$. a week; their average is from $10 s$. to $12 s$. for day labourers.

1303. The same average would remain if you took the wages given by them as the criterion of their liability to pay, as you think does if you take the labouring people employed by them?-I should say that the proper criterion is the number of men employed, and the capital employed; these jointly produce the additional charge upon the county-rates in the prosecution of felons, \&c.

1304. What description of agriculturists do you think suffer the most, the tenants or the freeholders oceupying their own land?--The freeholders occupying their own land suffer as tenants and as landlords; but I would observe, that as the whole capital of the tenant consists in his stock, crop, \&c., if the value of that is reduced to half, or below his debts or engagements upon it, he becomes insolvent.

1305. Supposing an individual, being a freeholder, occupies all his own land, what do you think will be the comparative state of suffering of that man and a man who is only a tenant?-If the property is at all burthened with any charges, I should say a small freeholder, occupying his own land, would feel it most.

1306. In point of fact, which description do you think has suffered the most in a series of years? - I think the tenants have suffered the most, because the land may still remain, if not previously mortgaged, \&c. ; but the capital of the tenant may have disappeared altogether.

1307 . The person who occupies his own land is more likely to charge it?-Yes; where that has been the ease he will be a greater sufferer.

1308. Has not the distressed state of agriculture had the effect of making people farm badly, by breaking up land which they should not do, and not applying a sufficient quantity of manure to it? - It has.

1309. Do not you think that the land in consequence is in a worse state in respect of its power of producing? - Yes, that has been going on for some years; I find, from recent inquiries, since I have been summoned to attend this Committee, that the quantity of corn grown in our county is diminishing; I have ascertained the quantity grown in 26 parishes in the Vale of Glamorganshire, and I find that the reduction is $13 \frac{1}{2}$ per cent. as compared with what it was six, eight and ten years ago.

[The Statement is delivered in, and read, and is as follou:s:] 
29 February $18{ }_{3} 6$. Glamorgan, at the under-nientioned periods.

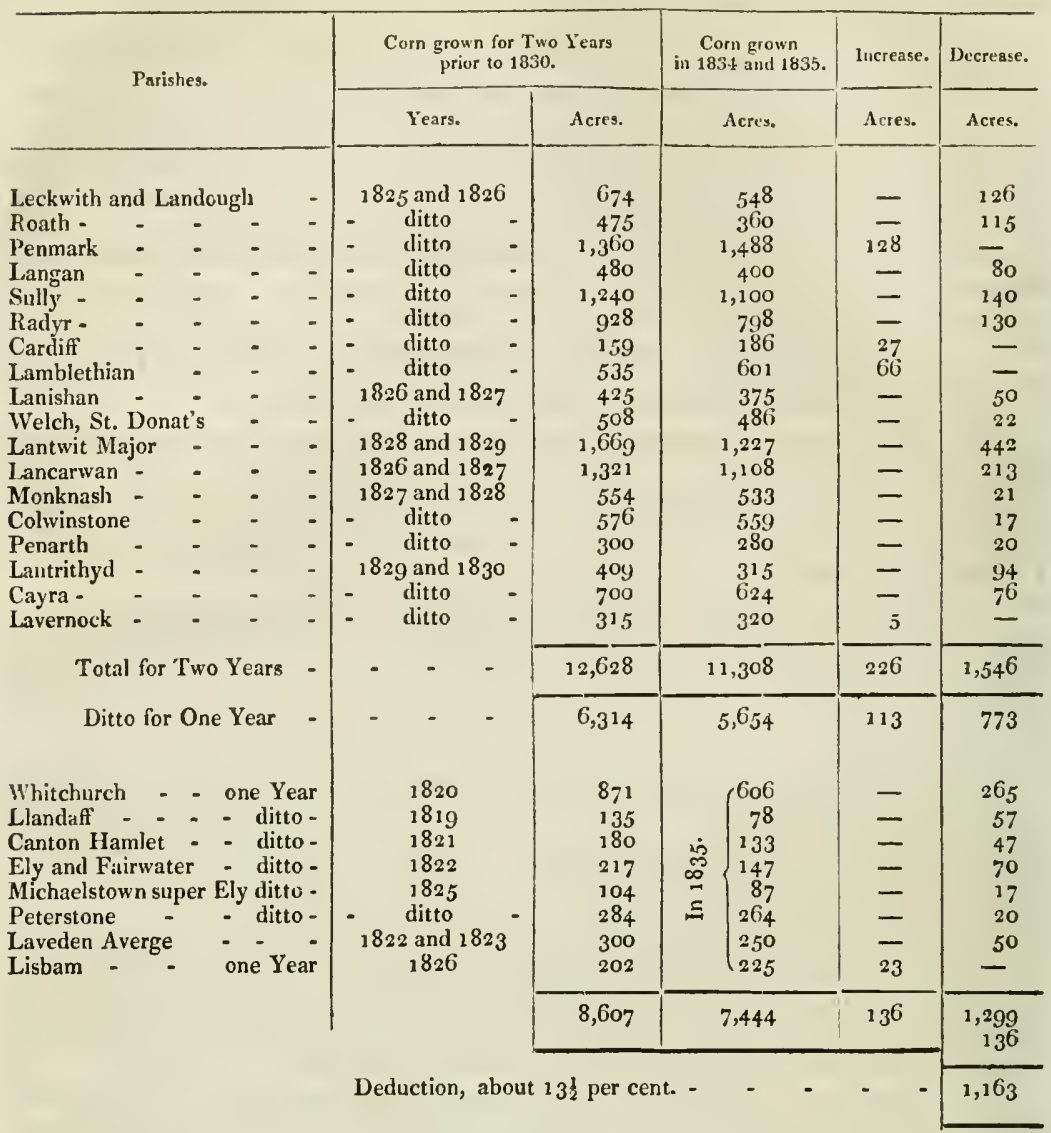

The quantity of wheat in Wenvoe, Porthlnery, Merthyrdovan, and Saint Nicholas in 1834 and 1835 , is reduced to per cent. as compared with 1830 and $183_{1}$. In Flemingstone the reduction is stated to be about 12 or 15 per cert. In Eglioyselan it is also reduced, according to the titheman's account, about five per cent.

1310. What is your opinion as to the state in which land is laid down now?-. In my opinion it is laid down in a very inferior state.

1311. Will not that tend to depress the agricultural interest for some time to come?-Yes; and in my opinion this cause has been in operation for some years, and the results are now beginning to be felt in a reduced quantity of corn grown.

1312. You conceive that to have been caused by the distress, and to have become itself now a cause of the distressed state of agriculture? - Yes.

1313. Do you think the land broken up and laid down as you describe it, is wheat land of a quality that ought never to have been broken up?-The necessities of the country at that period during the war required that it should be broken up.

1314. Do not you think that, looking to the outgoings and the prices of produce in the years preceding 1790 , the land paid the produce of the capital applied to it? -I believe so.

1315. It was not then broken up? - Not so much as at present.

1316. Is much of the corn removed from the neighbourlood, or is the population sufficient to consume their own growth? -The county of Glamorgan altogether consumes more than it grows.

1317. Supposing in 1790 there had been the same demand for it; do you think Jand could have been profitably employed by being broken up? - Yes, the demand existing at the time the land was so broken up. The facilities of conveyance are 
such, that only a small portion of the farmers in Glamorganshire benefit by the Mr. Evan Daved. increased consumption. Irish corn and corn from the opposite coast of Devon, Somersetshire and Cornwall can be conveyed to Merthyr Tydvil, the centre of our 29 February 1836. iron manufactories, at a cheaper rate than half the farmers in Glanorganshire can convey theirs.

13 is. Have you reason to believe that much corn comes to Glamorganshire from the Continent? - No, I have not.

1319. From Ireland?-Yes, very large quantities.

1320. Can you speak to that point? - In Cardiff the quantity imported was 10,000 bushels in 1826 , and in 1835 it was 160,000 bushels.

1321. That includes all sorts of grain?-Yes, it is; although chiefly wheat and flour.

1322. What is the population of your county?-I believe about 126,000 , according to the last returns; since 1826 it has increased, I believe, about 18,000, or 2,000 per annum.

1323. Have your cottages generally land?-No, they have not.

1324. That increased inportation into Glamorganshire has taken place recently; has it not?--Since 1826.

1325. Would not that account of itself for the present deterioration of the arable land in your district?-In some measure, no doubt it does, but as some proportion of our produce is exported to Bristol and other places where they have not the facility of sending it to Nertlyyr, it camnot apply to them.

1326. Was not the exportation to Bristol practised at the period to which you refer before 1826 ? - Probably it might; we have been in the habit of sending from some parts of the county always to Bristol.

1327. Do you send as muclı to Bristol now as you did formerly?-No, we do not.

1328. How do you account for that?-In consequence of the increased population of our own county.

1329. Is there any other reason you can assign for the present low prices?-I believe another cause is the system of warehousing foreign corn, called the bonding system; I believe that has a very injurious tendency.

1330. Have the goodness to state how you conceive that operates to injure the lome trade? - Because when we have a small surplus of English and Irish corn beyond the demand, we have no outlet for it, as the price of corn in England must ever bear a ligher rate than on the Continent; when there is an excess, if ever so small, it sometimes reduces the price to a most ruinous rate.

1331. That being got rid of at a loss renders the depression still greater?Yes, it adds to the distress of the seller. The bonding system encourages speculation in foreign corn rather than in corn the produce of the country, and, I think, should be improved.

1332. How do you suppose it might be improved on? - I think without giving the foreign corn-merchant any serious cause of complaint, that when the arerage price in England gets below $50 \mathrm{~s}$. a quarter, all foreign corn imported after that should be made liable to the present scale of duties; that it should be allowed to be bonded, but charged with that duty as other foreign goods are, the duty to be paid only when the corn is taken out of bond for home consumption.

1333. Have you any suggestions to make of improvements in the present corn laws? - I think the averages might be improved by requiring a greater number of returns.

1334. That there ought to be returns from the sellers as well as the buyers?That would be an improvement, but $I$ think that all the principal millers and nialtsters should be required to make returns as well as the few who attend certain markets.

133.5. Do you think that there would be any difficulty in obtaining returns from all millers and maltsters? - I think not, if it was left to the quarter sessions to determine who should return in cach county; this would double the present quantity returned; they shonld be required to make returns every week to an officer appointed for the purpose in each county.

1336 . Should there be returns made from Ireland of the corn coming in ?-As long as they are allowed to import corn into this country without restriction, they should be put on the same footing in every other respect, more especially their parochial burthens.

1337. Have you any information as to the difference of expense of growing corn in lreland and in England? - I have not been in Irelaud, but I have made myself 464 . 
Mr. Evan David. acquainted with some facts from the evidence before a Committee of the House of Commons, and I find that it is much lower. I find that the expenses of cultivating

29 February ${ }_{18} 86$. a farm of such an extent as I now farm, would be $600 l$. less on two items alone in Ireland than in Glamorganshire, that is, labonr and poor-rate; for I find, from the evidence of a Mr. M'Mahon, a gentleman who appears to be well acquainted with Ireland, that he has often heard the labourers state there, that they wonld be very happy conld they receive $8 d$. a day for six months in the year, which I conceive is not equal to $6 d$. a day all the year round, or $3 s$. a week. My labour is equal to $10 \mathrm{~s} .6 \mathrm{~d}$. a week all the year round, more than three times as much as in Ireland; the total I pay at present is $720 \%$. per annmm, this might be had there for $240 l$. saving $480 l$; my poor-rates amount to $140 l$; in Ireland there are none; total 6207.; besides which the expenses of a farmer's family are mueh lower in Ireland than here. The expenses of bringing Irish corn into our market are extremely low, from our great export of coal into that country.

${ }_{13.3} 8$. Will the proposed railroads increase the facility of bringing corn from Ireland liere? - I do not know that they would ; but the facilities of communication tend to adjust and equalize the prices of corn and other produce all over the kingdom, and all parts should consequently be made subject to the same burthens. I would say that, on the same principle, if the manufacturers of Yorkshire were exempt from taxation to that degree that would enable them to get labour at onethird the expense it is in other parts of England, that the elothiers in the west of England and the corn-growers of the conntry generally would have just cause to complain; what I wish is, that they should be all placed upon the same level, either by a duty on the importation, or the expenses of production equalized.

1339. Is your land barley land? - Yes.

1340. Of good quality?-Yes.

1341. What is your average produce of wheat and barley per acre?--I have averaged as much as 22 bushels of wheat and 40 of barley, but that is a high average of barley.

1342. Are there many farms ont of occupation in your neighbourhood? - There are some farms out of oceupation; there is one close by me which cannot be let except at a great reduction, more than one-third of the rent it formerly let for.

1343. Do you know what the proportion the rent asked for that farm at present would bear to the rent it paid in the year $1790 ?-\mathrm{No}$, I do not; but I know this farm has let at $350 l$, which is now offered at $250 \%$.

1344. Do you imagine that that farm was let for $250 \%$. in the year 1790 ? That I do not happen to know; but the landlord would not be as well off; I conceive, at present with $350 l$. as he would at that period with $250 l$.

1345. You say you employ 25 labourers; how many acres have you in arable land $\%$-Four hundred arable and 250 pasture, in the 650 upon which I have given in the account to the Committee.

1346 . Is that the general proportion of labourers employed on a farm of that extent?-I believe it is. Perhaps that may exceed the average proportion in my neighbourhood, but it does not include the labourers employed in harvest; the difficulty is, that we cannot reduce our expenses to meet the present low prices.

1347. Is it necessary for you to reduce the expenses, or to increase the prices? -It is.

1348. Is it your opinion you cannot go on without that?-In my opinion, we cannot pay any thing like a fair rent to the landlord.

1349. Is your farm on lease?-Not the whole of it; some part of it is.

1350. What is the average rent in your neighbourhood?--About $20 \mathrm{~s}$. an acre, subject to tithe; I oceupy some at a higher rent.

1351. About 25s. tithe-fiee?-Yes.

1352. You have not adverted in your calculation to the difference of tithe in England and in Ireland? - No, I have not.

1353. Are you not aware the tithe paid in Ireland is much less than that you pay? - Yes, much less; but I am taking a view of the advantages they would possess, supposing they would pay those burthens which the laws require them; but they get rid of those burthens by resisting the payment.

1354. They pay no agistment tithe, nor a number of other outgoings?-No, they do not.

[The Witness is directed to withdraw.

Ordered, That this Committee be adjourned till To-morrow, One o'Clock. 
Die Martis, $1^{\circ}$ Martii, 1836.

The Lord WYNFORD in TIIE CHalr.

Mr. Genrge William Firchild is called in ; and Examined, as follows:

1355. WIIERE do you live? - At IIarborne, in Staffordshire.

1356. What quantity do you farm?-About 300 acres.

1357. Are you in any other business? - I an a cow-keejer and a farmer.

1358. On the 300 acres? - Yes.

1359. Do you receive rents for any proprietors? - No, I do not.

1360. Is your's a mantfacturing part of the country? - It is; it is near Birmingham.

1361. Is your land good? - No, not of good quality; my louse is in Staffordshire; my farm is in Worcestershire.

1362. What is the state of agriculture in your country? - In great distress.

1363. Are the tenants able to pay their rents? - - l should imagine not.

1364. Do you know of any who have left their farms?-Yes, a number.

1365. Did they leave their farms because they were not able to pay their rents? -Yes; that is continually the case, that tenants are leaving their farms, and they are sold up, and the produce of the sale is taken by the landlords for arrears of rent; I have known numbers of instances.

1366. Have your rents been lowerer in that county? - Some of them.

1367 . To what extent have they been lowered; how much per cent.?-The reduction has been in this way; it has been a return of 10 or 15 per cent. more than an absolute reduction of rent.

1368. Do you know what the burthens on agricilture are now, and what they were formerly? - The local burthens in my own ease are pretty much the same; they are a little reduced; but the local burthens on my farm amount to about $27 l$. a year, including poor-rate, church-rate, county-rate and constables' accounts.

1369. Not tithes? - No.

1370. Are those rates higher than they were formerly?-They are a little lower; we used to pay about six rates in the year, five or six years ago; they have been reduced since that, and are now about four.

1371. Are they as low now as they were 20 years ago ?-I did not live in the neighibourhood at that time; they are lower this year than they were last.

1372. Do you think that those who do pay rent pay it out of the profits of their farm or out of their eapital? - They must pay their rent out of their capital.

1373. Why do you say that?-Because the produce of the farn is not sufficient to give it at the present prices.

1374. What ought the prices to be to enable them to pay rent out of their produce?-All the proceeds of the land now, I take it, ought to be from $8 s$. to $9 s$. for wheat, to enable them to pay the rents asked.

1375. What is wheat now :-It has been $5 s$. ; it is perhaps now $7 s$.; it has risen very much within the last three or four weeks.

1376. Can you account for that rise?--Yes, I think I can; it is found there is a less quantity of wheat sown than has been in previous years, perhaps full one-third less, and consumption is much increased by the improvement in trade.

1377. Has it also been found that the crop of last year was not so good as was expected ?-I think it has, in some places.

1378 . Is there as much land now sown with wheat as was formerly ?-Certainly not; there is full one-third less this year.

1379. In what state are the labourers?-With us they are in an improved state.

1380. Are there many out of employment :-None; a great many are taken up in my neighbourlood from the improvement in trade.

139 r. That has taken off the surplus labour?-Yes.

$138_{2}$. Has that always been the case, or has the change taken place recently? The change has taken place recently.

464 .

Mr. G. W. Ficchild.

1 March 18,36 . 
Mr.G. $W$. Firchild. 1383. The improved state of trade has lately improved the condition of the labourers?-Yes.

$1 \mathrm{Masch}_{1836 .} \quad{ }_{3} 84$. Before that improvement in manufacture were the labourers in agriculture in employ? - No, not all of them.

1355 . Were there any considerable number out of employ ?-Not a great many in ny district; more or less they are taken up by trade.

1386. To what do you attribute the present depressed state of agricultural produce?-I think low prices, \&c., are owing to the distress of the labourers, and their diminished consumption, but that they always have been in a bad state since 1816.

1387. Agricultural prices have fallen very much within the last two or three years; to what do you attribute that?-I think that may arise from two causes; first, the great crop of wheat the last two or three years; and there was very great distress, and I have no doubt that diminished the consumption of wheat.

1388. Do you attribute it to any other cause?-Not any other cause than the restricted consumption of produce.

1389. Ifave you any means of knowing whether the produce introduced from Ireland has affected you?-There has been a good deal come in, and I have no doubt it lias affected us.

1390. Has there more come in of late than formerly?-Y Yes, but not within the last month or two; I think it lias fallen off a little.

1391. Was the increase to your part of the country sufficient to depress the prices? - Very much to assist in doing that.

1392. Is there any other cause to which you attribute the distress? - No, I am not prepared with any other cause.

1393. Can you suggest any remedy? - I have no doubt a great relief would be given to us by removing the malt-tax.

1394. Why do you think that a great relief would be given to you by removing the malt-tax?-By the increased consumption of barley. I take barley to be a fourth part of the grain produced and consumed by man in the year, and if the tax was taken off the malt the monopoly would go also.

1395. What monopoly? - The monopoly occasioned by the severity of the excise laws; the price of barley, perhaps, is $4 s$., the duty $2 s .7 d$., but we do not get our malt for less than $8 s$; the expense of the operation is little or nothing; if we get the $2 s .7 d$. off the $4 s$. we should be able to make it ourselves, and use it for cattle and other things, and beer would then become the cheapest sustenance for the labourers.

1396. Have you many beer-shops in your part of the country? -1 good many.

1397. Have they not a had tendeney, with regard to the morals of the people? - Yes, and every body eomplains of them.

1398. Have you formed any opinion whether if the duty on malt was taken off the poor would brew their beer at home?-I have no doubt they would, and not only that, but we should have no objection to supply them with beer; at present, if we supply them we pay duty and monopoly; but if we could make our own malt we should have no objection to supply them with beer; if the duty was taken off', the price of beer would be only $I \frac{1}{2} d$., whereas it is now $5 d$.

1399. Would you supply them with beer to drink at home?-Yes; there would not be room for the profit in the $I_{\frac{1}{2}} d$. there is now in $5 d$., nor room for the deleterious infusions they make in their beer at present.

1400. Would the taking off the duty on malt oceasion an increase in the growth of barley?-No doubt it would. If the same money was spent in malt as is now spent in the duty and monopoly, it would huy more than as much again barley from us; that being the ease, it would call on every farmer to produce one quarter more grain than he now grows.

1401. There has been a doubt expressed whether if the consumption of malt was very much increased you could prochuce a sufficient supply of barley; what is your opinion upon that?-There is no loubt that we could.

1402. Could you produce double the present growth of barley? -I have no doubt we could.

1403. How far can you say with certainty you think the growtl of barley could be increased in this country?-Certainly double; I have no doubt of that.

1404. You 
1404. You were understood to say that yon are of opinion if the duty on malt Mr.G.W. Firchild. was lowered or taken off, it wonld do away with the monopoly in the trade of malting? - Yes.

1405. It is your opinion, therefore, that in that case the farmers would generally make their own malt? - Yes, exactly so.

1406. Cim you state, from your recollection, whether many farmers who were in the habit of malting, and had malt-houses ten years ago, bave ceased to use them? - I do not think in that period many farners have had malt-houses; but my father and grandfather had both malt-honses, and used to make their own malt, till the severity of the exeise law beeame so exfessive; in case a man made any mistake, or did any thing that the exeiseman thought wrong, the penalty was so great that they threw it up, and preferred buying their malt to running the risk of a servant leading them into difficulty.

1407. You do not attribute the cause of the farmers giving up keeping their malt-houses to any alteration in the amount of duty on malt ? - No.

1408. Do you remember what the duty on malt was at the period to which you refer?-No; but 1 do not attribute it to the amount of duty, but to the excessive severity of the excise laws to protect that duty.

1409. In what way did that severity show itself? - Supposing a man makes malt, and he is caught doing wrong, the penalties would be such, he had better buy his malt for a year. I would make my own malt now, and have looked out in the last four or five years to see whether I eould not get some remedy; but I have been alarmed, and have given up the idea of making it, because I found that I was exposed to such severe penalties, in case my man did any thing wrong, and on whom I must trust, that we could not help ourselves.

1410. What can you do which subjects you to the penalty?-I do not know; I am not a maltster. If they water at an improper time, or do not comply with the exciseman's directions during the operation, they are exposed to severe penalties, and one penalty would be more than the value of the risk.

1411. Is there a great deal of barley grown in your districts? - There is.

1412. There are a good many counties in the north where no barley is grown, and in Scotland rery little?-They grow some fine barley there, and they grow what they call bigg or bere, which is an inferior barley.

1413. Would not the counties which grow no barley obtain relief in this way, that more barley would be grown in the barley counties, consequently there would not be so much land to apply to the purposes to which it is now applied?-We have been all in distress; they have been trying to grow wheat on land that ought to lrave been in barley, a great deal of it.

1414. Would that be restored to barley if the malt duty was taken off? - I have no doubt of it.

1415 . If the duty was taken off you would get rid of the vexatious proceedings of the excise? - Yes, of course; and I have no doubt it wonld do away with the beer-shops, for there would not be roon for the profit.

1416. Do you think you would get rid of beer-liouses by putting an end to the duty on malt? - Yes; beeause there would not be the room for the adulteration there now is, when the price is $5 d$.

1417. Do not those houses under the name of beer-houses sell other liquors?I have no doubt they do; but that is a question I cannot answer.

141S. Have you any doubt they sell spirits?-I eannot speak to the fact, not knowing how it is.

1419. You state, as one of the good effects to agriculture from taking off the malt duty, that a larger proportion of land would be sown with barley and a smaller with wheat than at present?-Yes, that is my opinion.

1420. You state as a reason for the late rise in the price of wheat, a greater portion of land being sown with other grain which previously had grown wheat?The land is not sown with other grain instead of wheat: it is going into a state of nature, a good deal of it, especially the poorer soils; bnt if we got rid of the malt tax we slould have a steady price, governed by supply and demand: if the country was in a prosperous state there would always be a steady demand for it.

1421. Do you grow any flax or hemp? -No.

1422. Is there any grown in your county?-No; it is not grown in inland counties.

464 .

K 4

1423. Are 
Mr. G.W. Firchild. 1423. Are your county-rates charged upon property in towns as highly as they are upon property in the comntry? - In Woreestershire I believe they are; it has been looked into in Woreestershire.

1424. Is the land-tax equally charged on property in towns as in the agricultural districts? - I am not able to answer that question.

1425. Can you state any thing else which you think important to this inquiry? -No, I do not think I can.

1426. What is the character of the soil of that land which is in your neighbourhood being thrown ont of cultivation? - It is generally poor soils which were going into grass, that will not pay for the cultivation of grain at the present price.

1427. Are the poor lands to which you allude heavily burthened by poor-rates?I should think not; the burthens upon my own are trifling.

1428 . What is the precise rent at which you have heard of this land being let per acre?-I should think those lands I speak of have been let at $10 \mathrm{~s}$. to $15 \mathrm{~s}$. an acre.

1429. At present probably they will not pay any rent at all ?-They cannot, with wheat at $5 s$. a bushel; such lands as those cannot pay rent.

1430. Does not the throwing those lands out of cultivation diminish the stock of labour for the poor?-Unquestionably.

1431. If that goes on will not there be a difficulty in finding employment?Certainly.

1432. Are the lands to which you allude lands supposed to rot sheep, or attended with any unfavourable cireumstances of that kind? - Some part of them would not; I allude to poor soils, those parts of farms not worth cultivating; some sound, some clays and some wet: all of inferior quality.

\section{[The Witness is directed to withdraw.}

Mr. John Ncarne is called in; and Examined, as follows:

Mr. John Nearne, 1433. YOU reside in the county of Kent?-I do.

1434. You are steward to several noblemen and others in the county of Kent? -I have been for some years, but I have just relinquished several.

1435. How many thousand a year have you under your superintendence?Perhaps, speaking generally, upwards of $20,000 l$. a year.

1436. Are you well acquainted with the state of agriculture in that part of the country?-I am.

1437. In what part of the country? - The neighbourhood of Ferersham and Canterbury.

1438. Is that good land?--Some very good land; it varies very much.

1439. In that part of the country, from the means you have of knowing the different farmers, what is the state and condition of the farmers?--Many of them are in a very distressed state; but I think the distress has been lately taken from one part of the agricultural community to another; the agriculturists of the lower part of Kent and at other places where it is rery stiff land were suffering very greatly three years ago; the last three seasons have been more congenial to the growth of corn upon that stiff land, and now they have been recovering themselves; and the parties who have been enltivating good wheat lands where they had a right to expect a good crop of corn, have not realized more than an average crop, and are more in a distressed state in consequence of low prices than they were previously.

1440. Lately the occupier of poor land has been better off than the occupier of good land? - That is my opinion.

1441. Do the farmers pay their rents ?--I cannot say that they do not, for I do not think of all the rents I receive I am $100 \mathrm{l}$. in arrear.

1442. In your opinion, do they pay those rents out of the profits of the estates, or out of capital?-I think they formerly paid them out of their own capital, but lately matters have been better, and for the last year or two they have paid them from the produce of the soil.

1443. From what sort of land?-The poor lands, where the distress did exist most; they lave been able to pay them from the produce of their farms the last two years; and perhaps the good land farners have been obliged to resort to their capital to enable them to pay their rents, and they have generally capital to resort to when others have not.

144. Do you think they have been obliged to resort to their capital ?-Yes; we are peculiarly situated in the county of Kent, by growing hopss which have been profitable on lands congenial to their growth.

1445. Do 
144.) Do you think that the prices of other articles of agricultural produce have comuterbalancel the rexluced price of wheat? - Where they have adopted that xystem of managenent they have, but where they depend on the growth of corn only tles lave suffered materially fom the low prices of wheat.

1446. To what do you attribute the low prices of wheat ? 1 attribute them very unch to the immense produce of the poor land.

144\%. By the poor land you mean the poor stiff land; the poor clay?-Yes; they caunot get muel produce from other descriptions of poor land without extraordinary expense; and it is the oppressive srstem of paynent of tithes in kind which has prevented many of the farmers expending capital on this sort of land.

1448. Generally speaking, in your part of the connty, is the condition of the farners good or bäl?-I slould say bad.

1449. To what do you attribute that?-I attribute it to various causes; one is the want of capital ; many of them have not capital enough to manage the land in the way they used, or in the manuer it ought to be.

14.50. What has become of their capital-It is exhausted, from the former unfortunate bad seasons and low prices of prodnce.

1451. From what time did those scasons begin?-Perhaps ten rears back or more; we had several wet seasons which ruined many farmers.

1452. Do you mean to say that the clergy generally take the tithes in kind?Yes, when they are rectorial tithes many take them in kind; I think I may be a judge of the value of tithes, for I have talien tithes in kind, and I do not hesitate to say they have been formerly profitable to me; but I think the system ought to be altered, for it prevents firmers improving their land as they otherwise would lo; I have had farms oftered to me to cultivate, but I never did, or will, take a farm subject to the parment of tithe in kind.

1453. Do you think on farms where there are sheep and cattle of different descriptions as well as corn, tley can, generally speaking, make a living? - I think, last year, their balance might perhaps come even, but previously I think they have bcen obliged to pay part of their rents out of their eapital; I think sone of them recoverel themselves last rear, and I think the Poor Law Amendment Bill is a very favourable thing to them; it operates very favourably in our district.

1454. Wras the crop good last year? - Very abundant in wheat, in our part of the country.

145.5. You think last year they did rery well?-- I will not say very well, but perhaps they made both ends meet; they had enough to pay their rent and their labour, and perhaps part of the interest upon their capital, unless where they were very nuch involved and incumbered. Men in that situation never can recover at the present prices of corn.

1456. When you said that matters had been better the last two years, you mean with respect to the sheep farms? - Yes, and the abundant erop of wheat; the men who were eultivating stiff heary land then reaped the benefit of the abundant erop?.

145\%. The prices of wheat have been progressively lower? - Yes; and that has operated against the best wheat land; from this description of land they did not get more than an arerage erop.

1458. Could they do well with those low prices?-No, certainly not. They would do better on the stiff land, with an abundant crop, at the present prices, than formerly, when wheat was at a higher price, and the produce small, and the quality inferior, from the bad wheat seasons.

1459. On the estates of which you have had the management have rents been materially reduced since the high prices?-The landlords I have been so fortunate as to be connected with have met the tenants in time to save them, and I am happy to say we have not seen many new faces; they have been able to keep on. Some landlords could not afford to render that assistance to their tenantry.

1460. What do you imagine to be the amount of the reduction of rent upon those estates sinee the war prices?-There is one large estate I am connected with where there has been no reduction whatever; only a temporary reduction of from 10 to 20 per cent.; the rents stand as they did in 1812 .

1461. In the present prospects of agriculture do you find a difficulty in letting farms upon that estate at the present rents? - I cannot say that I do. 
Mr. Jolin Nearne.

1 March $188_{3} 6$.

1462. Do you find that the applieants for farms upon that estate are persons who have been all their lives employed in agrieulture, or do you find any fresh eapitalists eoming into the county? - No; we confine ourselves pretty mueh to men who understand the management of the land, and we take eare to find ont whether they have capital enough to eultivate the land in a proper manner before we suffer them to take it.

1463. You do not find a difficulty in procuring tenants to take a farm? - No, none whaterer; ours is a favourite distriet, and the hops are a great thing with us.

1464. That is a very gambling trade?--Yes; but some of them have done very well with their hops.

1465. What have the reductions been altogether?-From 10 to 20 per cent. with those I have been immediately concerned with.

1466. Since what time?-Since 1822.

$146 \%$. You made none before that? - I think not.

1468. Is the allotment system earried into effeet in your county? - It is not so essential in our part of Kent, for the cottages have been invariably furnished with gardens.

1469 . What are the average wages of your labourers?-We pay now from $10 \mathrm{~s}$. to $12 s$, a week.

1470. Considering the present price of the necessaries of life, do you consider the eondition of agricultural labourers better or worse at this time than it was 30 years ago? - A great deal better; I know it to be so in our own neighbourhood, as regards their condition. I now speak of industrions labourers; those of good character; they are in a better eondition than they were at that time.

1471. Are you aware what the rate of wages was 30 years back?-Yes; I think they were half as muel more as at this time. Some farmers made up their wages at that time by allowing them corn at a reduced price.

1472. Have the other expenses of the farmer increased within the last 30 years? Yes, very materially indeed.

1473. Have they not inereased within the last 20 years? - Yes, certainly.

1474. Within the last 10 ? - No, I think not.

1475. Is not the price of produce lower now than it was 20 years ago?-Yes, certainly.

1476 . Are the farmers in as good a condition now as they were 20 years ago? - Certainly not.

1477. What are the expenses of farning which yon consider higher now than they were 20 years ago ?- The system of farming is improved, and there is more manure bestowed upon the land than there was 20 years ago.

1478 . Without reference to the price, there is of eourse a proportionate profit? - Since the peace there have been so many more labourers thrown upon us that we have been obliged to employ them, which has improved the eultivation. The labourers sinee the new Poor Law Amendment Act are thankful to us for giving them empioyment; before that Act they would nse abusive language, and state that tiney must be kept whether they work or not, and would not do work in a proper manner.

1479. Have you many labourers out of employment now? - We have not, to any great extent, but several are out of employment.

14So. In what condition are they? - They are of course distressed and in bad eondition; but we seleet the best eharacters, and do all we ean to find them work, and they are now grateful for it.

1481. Are they dissatisfied? - Those that are out of employment are dissatisfied.

1482. Have you had many fires in your neighbourhood?-Some years ago they began with us; I had one on my own premises; they were all burned; it was one of the first fires that happened, and we have had several since in the neighbourhood, but none very lately.

1483. Do you think if the state of agriculture were improved, and the farmers could employ them, they would be all employed?-I think they would; I think the farmers are generally inclined to employ all their capital on their land.

1484. Ilave you any doubt that then those labourers would be all employed?-I think there is very little doubt that if the farmers eould see a prospeet of getting a shiling for every shilling they spent they would be indueed to employ them, and assist the poor labourers.

1485 . IIas 
1485. IIas their eapital been got rid of by any improvidence or what circumstances? - It was the sudden cliange from ligh prices to low prices.

1486. When did that take place; was not it in 1822? - Yes; after that time prices recovered again.

1487. Did uot the prices rise again in 1824 and 1825 ? - Yes, from the failure of the crops. In 1822 we had an abundant crop; prices were lower than in any other year.

1488. Then they got up in 1824 or 1825 ?- -They got up in 1826 , I think.

1489 . One thousand eight hundred and twenty-five was the year of what was called the panie; did they get up before the panie? - I think they did.

1490. Did not they keep up again till 1829 ? - I think they kept up till 1831 ; but I cannot speak positively.

1491. They fell then, and have not risen since?-No. The three last years have been very low ; the four years previous to the last seven the wheat would average $70 s$. a quarter.

1492. To what do you attribute the rises and falls at those particular times which have been referred to? -I suppose the question alludes to the currency; that of course had some effect upon the price of produce; I lave no doubt it must certainly have an effect.

\section{[The Witness is directed to withdraw.}

Mr. Richard Peyton is called in; and Examined, as follows:

1493. YOU reside in London?-I do.

1494. You are concerned in the valuation of land, are you not?-I am.

1495. Are you steward for any gentlemen in the country :- I am.

1496. In what part of the eountry?-I have the management of estates in Berkshire, Essex, Middlesex, Surrey, Sussex and Kent.

1497. What is the state of the farmers in those counties? - I should say certainly it depends a great deal npon the land that they oceupy; the occupiers of poor soils are very badly off indeed.

149 S. Can they pay their rent except out of their capitals ? - They do not.

1499. Have there not in those different counties been a great many broken up lately?-Yes; ruined.

1500. And their property sold off?--Yes; quite sunk.

1501. Do you apply that observation to every one of the counties you have named? - Partiaily to every one; I do not apply it to Berkshire.

1502. Prineipally to the poorer soils? - Yes; the heavy soils more than the light soils.

1503. To what do you attribute the breaking up of those different tenants; have they been prudent persons? - Generally speaking, harl-working men.

1504. To what do you attribute their failure?-Principally their expenses; sometimes their want of skill; their adhering to the old process, and the low price of produce.

1505. Is the present price of produce at all a remunerating price?-Not of wheat.

1506. Is it of other grain? - I think it is.

1507 . Is the price of other articles sufficient to counterbalance the low price of wheat?--I do not think it is.

1508. What reduction would you make on a farm of a certain size on account of the low price of grain? - It is impossible to say. The men who lave real good land and cultivate it at less expense, and liave been generally able to pay, they are now living.

1509. Are they able to make a profit? - Yes, they do make a profit, but it must be good land.

1510. Do they pay rent? - That good land tithe-free is cheaper at $40 \mathrm{~s}$. an acre than some land $I$ let at $6 s$. and $7 s$.

1511. Have not the occupiers of poor land been better off of late years than the occupiers of rich land?-I should say not.

1512. To what do you attribute the low price of wheat? - A good deal to the excess of cultivation, and a good deal to the importation from Ireland.

1513. Do you know whetler the imports of wheat from Ireland have inereased much the last two or three years? - I do not know the fact, but I believe it is the fact.

464.

L 2

1514. Do 
1514. Do you know whether wheat can he grown eonsiderably cheaper in Ireland than in England? - I ro not know it. except fiom information.

1515. Is there any otlier cause to which rou attribute the depression of wheat? - None, except the excess of cultivation, and the exeess of importation fron Ireland, and from Scotland as well.

1516. Do you think there is a great exeess of cultivation in England :-There has been of late years, certainly.

$151 \%$. You think there is more land cultivated with wheat? - I think that is unquestionably the ease.

1518. In proportion, has wheat borne a low price?-A great deal of that land which has ever been cultivated with wheat is still continued in the cultivation of wheat, particularly in the southern counties.

1519. Is there any other land sown with wheat that was not used for wheat before?-A great deal during the high prices during the war.

1520. That has continued? - Y es, but more particularly in the sonthern counties.

1521. There have been no importations from the Continent within the last three years?-No; I apprehend we have had the monopoly of the home market.

1522. Do you think that England grows enough for her own cultivation ?-I am of opinion that Great Britain and Ireland does; it is generally admitted that England will not grow suffieient witlout ineluding Ireland.

1523. The merely bringing into the market enough would not reduce the prices? -But there has been a great excess.

1524. From whence dirl that come?-I think there has been a great deal of wheat consumed by cattle.

1525. Then the excess must have been still greater if it had not been so consumed?-Of course.

1526. Do you think that excess arises from corn grown in Great Britain and Ireland ?-Certainly, I do; I cannot account for it in any other way whatever.

1527. Do you account for the depression of prices at all in eonsequence of the contraction of the eurrency?-That is a question of politieal eeonomy so far gone by I would say nothing more about it. I have no doubt but for Sir Robert Peel's Bills we should have had more eurrency and more ruin. The eurrency is now settled on a firm basis. I am not a curreney doetor.

$152 \mathrm{~S}$. When you speak of poor lands, do you mean the clay lands or the clialk lands :-The elay lands.

1529. Have not the ehalk lands had a greater produce of wheat the last three years than was ever known before?-They had the same crops some years ago in a dry season.

1530. It was more than an average crop the last year $;-Y e s$.

1531. Do you think the farmers of the South Downs are better or worse off than they were 10 years ago ?-I should say they are better off than they were in the year 1822; that was the worst year I ever remember. The lands of the Sonth Down farmers are very superior lands; the lands skirting the Downs are very fine.

1532. Is it not in eonsequence of the price of wool they are better off than they were in 182:? - The wool is better the last two years.

1533. Are not the elay lands more expensive to eultivate than other land?-They are double the expense, at least, beeause they require a greater number of horses, and they cannot get a crop of wheat without a fallow.

1534. Though the price of wheat has gradnally got lower and lower, have not the farmers been obliged to pay as much for their implements of husbandry and their blacksmiths' bills as they used to do?-There is very little difference.

1535. You state that a man on good land might pay rent and make a profit, if it was tithe free?-I have found that tithe-free land of good quality was better for a farmer at $40 s$. an acre than a great deal of the land which lets for $7 s$. or $8 s$. an aere. The best land is cultirated on the four-course system; wheat, turnips, barley and seeds; then they get wheat after the seeds again, so that there is no blind fallow, no dead year; and, managing that good land at a small expense, of course it is most profitable.

1536. Do you conceive that the outgoings of a farmer are generally higher or lower than they were 20 years ago?-They are higher than they were 20 years ago.

1537. In mhat respect?-In poormates principaily. 
1,538. The question resperets the expense of "ultivation; the chiferent bills the farmer has to pay? - I applohend there is very little diflerence in the tradesmen's and artisans' bills now ; there may be $4 d$. in il round of shoes, and some reduetion in the price of implements; a man may get a waggon for $45 /$. that he used to pay 50\%. for ; but not materially, I apprehend.

1539. To what period are you reforing?-I am speaking to the high prices of the war.

1540. Do you think there has been any material rednction in the counties you speak of in the rate of wages?-Not so much; I think the jrices of provisions would have justified the rate of wages which has been kept up.

1.541. What do you suppose the average rate of wages for a ray labourer to be at this moment in those comuties?-I should say abont $10 \mathrm{~s}$. a weck; $20 \mathrm{~d}$. a day.

1542. What would you say was the average rate in the western division of Sussex?-I do not know so much of the western division as towards the eastern, or rather within 35 or 40 miles of Loindon.

1543. Have not you found tenants throw up their estates very much lately ?An estate I purchased in the county of Surrey; we had a farm there in hand upwards of two years, and I have let that farm now for $10 s$. $2 d$. an acre; good wheat land.

1544. At what did it let before "-I let it for $25 s$, not immediately, but I purchased the estate in the year 1810 , then that farm I let at $25 s$; the same farm I have now let for $10 s, 2 d$.

1545. Have not a great number of farms been thrown up of late? A great number.

1.546. Have you not found a difficulty in getting tenants?- WVe have been obliged to keep them in hand a year or two, and then give up the valuations.

1.547. What has that been owing to?-The tenants have failed and gone, and we could not get others.

1548 . Have the tenants failed in consequence of the prices of produce not being equal to the expenses of cultiration?--Uudoubtedly.

1549. Have the goodness to explain the nature of the valuations you have referred to?-The valuations are of this kind: the custom of the counties of Kent, Sussex and Surrey, and part of Hanpshire, is, that the out-going tenant holds possession of the farm and every thing belonging to it up to the end of his tenancy. Supposing he be a Michaclmas tenant, he fallows the land for wheat. He ploughs it, he hamows it, and if he has time he will sow it; then the incoming tenant pays him for all the labour and seed, and all the manure put mpon the farm, though it was produced upon the estate; for the underwoods, and even the hedge rows. In the month of May, when he gives up his farm, there is another valuation of the hay and straw left unspent, and the nanure made between the 29th of September and the day when he quits possession. Then there are other valuations. We have got rid of as much as we could, the half-dressings; namely, the half of the quantity of manure put on the land the preceding year.

1550. Do not you know that those half-dressings are got rid of in Kent?-Yes; we have got rid of them in many instances. A noble lord was telling ne the other day that he is buying up all his as fast as he can, instear of their having valuations on the next tenant coming in. I believe we have very few half-chessings there now.

1551. Do you know that in the countics you have alluded to a great reduction of rent has taken place within the last 10 years ? - A very great reduction.

1552. Still the fammers have not been able to go on ?-Still they have not gone on.

1553. Do you believe they have been able to go on?-No; they are a class of men not naturally rogues; they would stick to their home, if they conld do it, and if you foree thein they will go out of one farm and will get another in the same parish, if they can.

1554. Notwithstanding they are losing?-Yes.

1555. Have they not for the last six or seven years been losing on the land they have famed? -1 believe they have been losing for almost the last 20 years; ever since the alteration of prices. Hops have oecasionally brought a man rouncl.

1556. They still have been losing, notwithstanding the rents have been reduced? --Yes, they liave been.

464 .

1557. Is 
Mr. R. Peyton. 1557. Is that owing to the pool living more on potatoes than they used to do? - No, I do not think they live more on potatoes : they eat more wheat than they were in the habit of doing; 1 believe oats and barley are nearly exploded.

1558. You have stated that cattle have been fed of lite on wheat?--Yes, this year; I have known it before also; I remember in the year 1822, in Huntingdonshire, a great number of cattle were stalled with wheat meal.

1559. Was not that in consequence of the great drug of wheat in the market? - Yes, and the very low price.

1560. You state that the rents of landed property have very much fallen; do you think the rents of cottages have fallen equally ? - That depends upon whom they belong to. The cottages on gentlemen's estates have been let so low as $\mathbf{I} s$. a week, and so on. They have not fallen where they have belonged to persons who built them on speculation; they have not been able to get their rents. They will generally keep a house over their heads, and their landlords give then some garden or a potato patch, and keep them as part of that establishment.

1561. Is it the practice in the district you are acquainted with to let the cottages with the land?-Generally speaking they let them at so much per year to the labourers, and gire them a $3 s$. dinner once a year, and they come and bring their wives and children, and enjoy themselves.

1562. Wheat is not the only produce imported into this country from Ireland? -Oats have always been imported in great quantities.

1563 . Has not a great quantity of pork and bacon been imported from Ireland? -Yes, and beef; Irish pork, and live pigs have been imported to an immense amount.

1564. Has not that had the effect of lowering the prices of those particular articles?-It did for some time, but I think the prices of meat have rallied; bacon and pork is not equal in price to beef or mutton.

1565. Are you acquainted with Lincolnshire?-I an acquainted with parts of Lineolnshire; but I have not been in that county for four or five years.

1566. Do you not believe the importation of oats from Ireland has driven out the growth of oats in Lincolnshire, and that the land has been eultivated with wheat? - I am not aware of that fact.

[The Witness is directed to withdraw.

Ordered, That this Committee be adjourned to Thursday next, One o'clock.

Die Joris, $3^{\circ}$ Martii, 1836.

'The Lord Wr Y NORD in THE ChaIR.

James Bernard Bernard, Esq., is called in ; and Examined, as follows :

J. B. Bernard, Esq.

1567. YOU live in Deronshire?-I do.

1568. At what part?-Sidmouth.

3 March $188_{36}$.

1569. Are you engaged in agriculture?-No, I am not; but I have for some years past given great attention to these subjects, and $I$ suppose it is in consequence, (I do not know who sent for me,) but in consequence of the works I have published, especially on the "Theory of the Constitution," in which this question was gone into largely, that I attend here.

1570. Are you acquainted with agriculture? - I have taken great pains to ascertain its condition.

1571 . Have you any means of forming an opinion on the condition of agriculture in this country?-I have those means, and in preparing my work for the press I obtained them.

1572 . What are your means of knowing the present state of agriculture? - In consequence of what I have observed generally of the state of the country I have been writing a good deal on the subject, and in 1832 I applied to the farmers in different counties to furnish me with documents, debtor and creditor statements, of the outgoings and produce of farms of an arerage quality in diflerent counties, taking the price of wheat at between $7 s$. and $8 s$, a bushel. 
357.3. What did yon find to be their condition at that time from all the returns J. B. Bernard, Esq. made to you - - That at that time no less than half the average rent of the kingdom was paid ont of capital instead of profits.

1574. You know that from the accounts furnished to you?-I have them here.

1575. They are in print?-Y Yes.

1576. From the accounts then furnished to you, believing them to be genuine accounts, do you know that half the rentals were paid out of eapital ?-That is my opiniol1.

1577. Was that in any particular class of farm, or farms generally?-My request was to farmers of intelligence and superior character, that they would furnish me with these debtor and creditor statements.

1578. Did you find those to be accounts from farms in general, or on 1 y of a particular sort?--Of an average quality; of a fair proportion of arable and pasture.

1579. Throughout the kingdom?-No; certain counties. I had three statements from Somerset, one from Surrey, one from Essex, and one from Hertfordshire, all in different parts, all drawn up in different manners, but all agreeing on the great point of the great loss sustained on agricultural produce according to the then price of produce.

1580. The price of produce then was about $7 \mathrm{~s}$. a bushel, was it not?-It was more; it was put in no case under $7 \mathrm{~s} .6 \mathrm{~d}$., and in some cases at $8 \mathrm{~s}$.

1581. If agriculture was distressed at $7 \mathrm{~s} .6 \mathrm{~d}$. a bushel, would it be distressed now when it is $36 s$. a quarter?-At $5 s$. a bushel it speaks for itself.

1582. It must be more distressed? -Yes.

1583 . Is there much difference with respect to the average amount of crops?-From all the information I have received, yes. I consider $7 s .6 d$. a high price, occasioned by a succession of bad wet seasons. The present price is the natural price; the price of average seasons; not more than average seasons; for as to wheat the crops have been no more than an average; there has been a very good quality, but no more than an average as to quantity.

1584 . How is the stock; is there any profit to be made from stock?-That I will not pretend to speak to; I only speak to the general condition of the agriculturist.

1585. Have you formed any opinion as to the cause of this depression, which you say must be ruinous to the agriculturist?-Yes, I have formed very strong opinions on the subject. There is a variety of causes; but before I could go into them and prescribe the remedies (I think them all capable of being remedied) it would be desirable to ascertain the total extent of the loss.

1586. As far as you have seen of the depression, to what do you attribute it? I consider the alteration in the standard as the great cause; there are many causes combined.

1587. The diminution of the circulation, you mean?--Yes, that is what I mean.

1588. When do you find the prices fell?-The prices fell immediately after the war.

1589. In consequence of the diminished circulation, as you suppose?-They fell in consequence of the Bank of England withdrawing its issues, in expectation of eash payments.

1590. When was that?- Very soon after the war.

1591. May it not be considered that that reduction of prices was in consequence of the falling of the market at that time, those supplies not being required which were required during the war?-I consider the falling of the prices was occasioned by lessening the quantity of circulating medium.

1592. Did the prices fall off in $\mathbf{1 8 2 2}$ lower than in $\mathbf{1 8 2 1}$ ?-I believe it was $\mathbf{1 8 2 1}$ when the prices fell; but they rose again immediately after that little Bill was passed which allowed the further circulation of the one and two pound notes of county banks:

1593. Do you recollect what year that was in?-In 1822; perhaps it was 1823.

1594. Did the prices rise again then?-Yes.

1595. One thousand eight hundred and twenty-two was the year of the greatest distress?-I believe it was either 1821 or 1822 .

1596. On the passing of the Bill did they rise? - They did.

1597. How long did they continue up?-Till the next Bill passed, in consequence of the panic in 1825 , that limited the circulation of the one and two pound notes.

1598 . The one and two pound notes of country bankers?--Yes.
464 .
L 4
1599. Did 
J. B. Bernard, Esq. 1599. Did prices fall again?-Immediately.

1600. When were the bank notes called in; the one and the two pound bank 3 March 1836. notes? - It was immediately after that great panic in 1825.

\section{[The Witness refers to his Papers.]}

1601. Do you remember if the prices fell in 1829 ? - They have been gradually falling ever since that period when the Bill of 1823 was repealed.

1602. You think so?-Yes.

1603. And never lave risen since? - No, I apprehend not.

1604. Have the prices been more depressed the last three years than at any other time?-They have been gradually declining. No.

1605. Did you ever know them so low as they have been for the last year?-

1606 . IIare you any other cause to which you attribute this repression of prices? -Not materially; there are other causes that affect agriculture in various ways. There is the free intercourse with Ireland; that is injurions to the agriculture of this country.

1607. IIave you any means of knowing whether, through the intercourse witl Ireland, there has been a greater quantity of importation of late years than formerly? - Only by what I see from the papers; I apprehend there has been a greater importation. I do not think that is the material cause; it is one, and a very serious one.

1608. Have you any other cause to which you attribute it?-We may consider that the poor laws have been increasing the evil; but that is only a secondary canse.

1609. Are you enough acquainted with the business of farming to say whether, notwithstanding the depression of prices, the expenses of the farmer have increased in the last 20 or 30 years? - Very materially.

1610 . Have they fallen within the last 10 years? - No.

16 и. The blacksmiths' and carpenters' bills remain the same?-Yes; there is nothing to speak of.

1612. How do you account for it that the prices of those articles should continue up when the circumstances of the persons who purchase them are so much depressed ? - I look upon it as a matter of impossibility to force back the working people generally to a condition that will put back the prices to the original state.

1613. Is theie suficient competition as to those little tradesmen to bring down the prices to their proper level; in a village for instance?-I conccive it to be impossible to force back the labourer of the comtry.

1614. Now as to the tradesmen, the blacksmith or the carpenter, and so on, is there a sufficient competition among them in villages to force the labour in the article in which they deal down to the level of the prices of the time? - 'That I conceive to be impossible.

161.5. From the attention you have paid to this subject, do you believe it possible that farmers can go on at this rate?-No; I consider the whole agricultural body are insolvent.

16.6. You do not mean to say, withont a great many exceptions? - I mean to say, that if the lands of the kingdom were taken thronghout, - I put aside the rich land and the poor lands, and set one against the other, and take the avernge of the lands of the kingdom throughout, -I apprehend to this extent it goes, that all the rent, all the tithe, all the rates, and all the taxes are at the prescnt moment paid out of capital, and not out of profits.

1617 . There are many exceptions to that?-Yes.

1618 . Is that the general rule throughout the country? - That I apprehend is the general rule, from all the information I have received, and from documents.

1619. That you have obtained from different parts of the country remote from each other?-Tes.

1620. On your conscience, do you believe that that information is true?-I do ; and consequently my belief is, that the whole agricultural body, including all noblemen as well as farmers, are insolvent; they are virtually insolvent; and the nation is insolvent too; and that a revolution of blood and violence must occur if it be not put a stop to.

1621. Yon stated that you conceive the limitation of the circulating medium to be the main cause of that continual depression of the price of wheat?1 do. 
162.2. Do you consider that the prices of other articles of agricultural produce J. B. Bcrnard, Esq. have also been in a very depressed state during the period to which you are alluding? - As to loarley and oats, the seasons have hecol hal lately, and they are at a higher price than will correspond with the wheat; but I ilprehend, aceording to the rule of all we know of history, that wheat will govern the price of other produce, and all will fall to a level.

1623. Your opinion is generally that the prices of all agricultural produce are at a very depressed rate?-Decidedly so. I eonsider as to harley and oats it is in the same state wheat was a few years amo, after a long succession of wet seasons; the crops of barley and oats hare been short.

1624. Does the contraction of the currency operate unless there is a countervailing eause ; for instance, if it is a bad barley or oat harvest, however the curreney might operate, the barlness of the harvest for barley and oats would countervail that ?-Of course; but the farmers are not the better for having a bad crop.

162.5. Do you think this diminution of the eirculating medium has operated in every case, except where it has been counteracted by a scarcity in the articles?Decidedly sn.

1626. Do you conceive that the effects of that change in the circulating medium are an existing and continuing evil, or that the main part of the evil has already passed ? - l consider that Peel's Bill has not advancerl one single step yet. Although $\mathbf{I}$ consider that the rent of land throughout the kingdom, wherever it was raised during the light prices up to its full value (and in a number of eases it was not), the rental of the kingdom, has been alrearly rednced,--making that allowance no less that 50 per cent, to the destruction of thousands and tens of thousands, ret the whole thing is to be done over again. Fifty pounds per cent. reduction of rents will not save you now : if you reduce it 50 per cent., the national debt, together with all private debts, will be donbled: and we are now in a worse state than the state when that Bill was passed, and every thing is to be done over again ; but I say that jo per cent. reduction of rent is nothing.

1(127. You mean it will not save the famers:-No, not at all; the whole thing las gone, rent, tithe, rates and taxes.

1628. Are you aware that up to 1816 silver was a tender:-Yes.

1629. By diminishing the tender, which they effectually lave done by making gold only a tender, is not the currency more fluetuating than it ever was liefore ?I consider that, in consequence of Peel's Bill, the eurrency is in a more fluctuating state than ever.

1630. Why is it more fluctuating ? are the bankers and the people afraid to issue, for fear they might come back and call for gold, which they liare not got ?-That I will not say; there is a constant depreciation of the emreney going on.

1631. When there has heen a fresh issue of currency, or of bank paper, hare you found the prices immediately rise:-Certainly:

1632. Do you think the expansion of the circulating medium would tend to remove, to a certain extent, the present distress of the agricultural interest?-Of course it would, to a certain extent; but I apprehend a great many other remedies are necessary. I apprehend no extension of circulating medium is calculated at the present moment to prevent a revolution.

1633. Is it your present opinion, with the present price of agricultual produce, unless the expense of the land is reduced, or the prices increased, perfect ruin awaits the agricultural interest? - Unless you can undo the whole of that state of things which I represent; namely, that all the rent, all the tithe, all the rates and all the taxes are at the present moment paid out of eapital, taking the average of the kingdom, putting rich and poor lands on one side. But supposing that to be the real state of the case (which I think is rery easy to be recrified if the evidence were taken in a proper mamner), no alteration of the currency alone, though you alter the standard 50 jer cent., will save the nation.

1634. What remedies would you apply?-I an qnite prepared to go into that; but perhaps before I should dare to state them I should wish to see the fact verified. As I observed, if it be proved: I am only giving my opinion; I say it ean be rerified, if the evidence were taken in al proper mamer, that all those things are paid at the present moment out of the capital, and not out of the profits of farmers.

4 (i)t. 
J.B. Bernaril, Fsq. 1635 . If it were really the ease, how do you account for the fact of the very little difficulty there is in getting tenints for average laud?-For this reason:

3 Narch 1836 . What is the farmer to do? I have no difficulty in getting tenants myself immecliately. This is the reason: suppose a farmer rents a farm of $300 \mathrm{l}$. a year; suppose he has 2,000/. capital in it ; what can he do? Can he give up farming? If he quits business he nust sell off his eapital and stock, "1pon which he would lose perhaps $300 \%$. at least on selling it off, and live on his eapital. He goes on in the hope of times menting, and it is better for his interest to go on losing a considerable portion of eapital ; he will lose much less than if he lived on it altogether.

I 630 . That answer would only apply to tenants quitting; not to fresh tenants entering on fresh agreements? - Yes; another thing is to be considered; farmers do not keep accounts very regularly; very few keep written accounts; very few know the extent of the losses they are snstaining: a former cannot state them; it is necessary to bring him to paper, and make him enter into a regular debtor and ereditor statement, before you are able to tell the whole extent of his losses; even then yon will find it diffienlt to get it from him: I found it execedingly difficult to get the doements $I$ did ; and in the mean time they are going on sustaining those losses; they do not know what thcy arise from; sometimes they are told it is the bad seasons; they hope it will he better; they cannot suppose the Government of the conntry ean have done such a thing as to destroy the whole of its landed property.

1637. Could any thing as to the manner of managing farms be done to lessen the distress of the existing tenants?-No, nothing; I apprehend it is possible to put the whole affair to rights.

1638 . How do you propose to put it to rights? - It is going into a very long question: I should wish to be excused saying that; it night seem absurd, mless the facts were first proved; I think they are very casy to be proverl. I addressed the farmers on the subject, and have endeavoured to prove their case.

1639. Are those farms much clistressed where there is not much arable land :Not so much.

I640. Supposing that the quantity of arable land on different farms was diminished, would not that, for the tine at least, have a tendency to relieve the farmers from their distresses?- No, I appreliend not; the distress of the farmers (if it be true what I say) is so gigantic, every thing is gone;-it is so gigantic, every thing is gone.

1641. When you speak of the readiness of farmers to take farms, you are not understood to mean now that they are realy to give the rents which are asked, but to give diminished rents?-They make the best terms they can; they camnot quit their business, and the landlords cannot reduce their rents. I love already reduced my rents $40 \mathrm{l}$. per cent.; low can I reduce them any more?

1642. Your land is very good in your neighbourhood?-Pretty well; it is good second-rate land; not first-rate. Mine is about second-rate.

1643. What is the produce per acre of wheat:-It is a dairy country; if you were to put the produce of wheat there would not be more than 12 bushels an acre.

1644. Have you been obliged to reduce 40 per cent. in a dairy country? - Yes.

1645. Do you think your tenants are doing well now?-No; my tenantry, all except those who have got capital besides what they have got on their farms, are a year and a half in arrear; and I think I may say, if I were to put it fairly, this property (and I have got between $40,000 \mathrm{l}$. and $50,000 \mathrm{l}$. to pay out of that) has been reduced 50 per cent. It was doubled in value in the year 1806 and following years, and on the faith of that, fanily charges were laid on; some parts of it were let out on lives, and other leases, which did not fall in, and were never raised. If, however, the whole thing were considered, and all put together, I have no doubt the reduction would amount to 50 per cent.

1646. What is the article of produce of your estate in which there has been the greatest depreciation of price?-It is principally butter.

1647. Can you state what is the difference in the price of butter between the present time and 20 years ago :- I think they got as much as $14 l$. or $15 l$. a cow at one time; that would be about $15 \mathrm{~s}$. a dozen pounds: now they get about $9 /$; ; 
they let it to dairy people at 81 . or 97 . a cow, but they do not recover the moncy, J. B. Bernard, Esy. as I understand; so they tell me.

164 S. Fou are not able to state what is the price of huticu, and the depression:- The price of butter has falle'n some time aron: it fell to sixpence a pound.

1649. What was it at the lighest?-Fourteen-pence and fifte n-penec.

16.jo. Is a great deal of butter brought in from Ireland: - I apprehend there is; that I do not know.

1651. You would not have make those reductions to your tenants unless you were satisfied, by yourself and steward, that those reductions were necessary? -- Of course not.

1652. Yon have made a reduction yourself, yon say, and if it haul been male generally over your whole property, it would have been j0 per cent ?-Yes, I think so.

1653. You mentioned some burthens were imposed on the estate during the high prices?-Yes; I have $44,000 l$. to pay, which, supposing the rents to lave been reduced 50 per eent., has been turned into $88,000 l$, and these charges now remain.

1654. The burthens remain the same, though the rents of the estate are diminished 40 per cent.-Yes.

165.j. What stock are you able to keep on your farm in this dairy district?Cows; but very little fatting stock.

1656. How much to an acre?-That I cannot tell; I am not a practical farmer myself, I can only speak as a proprietor.

1657. On an a verage, what do you reckon the rate per acre in your own neighbourhood? - I cannot sjeak to that nyself; I consider mine is fair average land, sceond quality land, good sceond quality land. I suppose one acre with another averages $25 s$.

1658. You cannot tell the produce in corn, or in keeping sheep?-No.

1659. You stated you had reduced your rents 40 per cent.; can you state if that reduction has generally taken place to that extent in the country where you male those inquiries? - In a great number of places; but in many places gentlemen of large fortune, and others who did not look into their affairs, never raised their rents. I consider in all cases where the rents were raised up to the full value of the land during the war they have been lowered 50 per cent.; but in my own district (I am not above 30 niles from the vale of Taunton, the best part of the vale of Taunton). I understand the rich land there, now let for $40 s$. an acre gencrally, did not let during the war for more than 4: $s$. That land is better worth $40 s$. at the present moment than $\mathrm{my}$ land is worth $20 s$. , and therefore if it hat been let up to its full value during the war, instead of being let at $2 l .2 s$. an acre, it ought to have been let for $4 l$. at least.

1660. What was the rental of your estate during the war, or has it gone down to the same price, or how near it - It must have gone down nearly to that extent, It was raised 100 per cent.; it was doubled in value at least, all those estates that foll in, and they did not all fall in. It was doubled in value, and on the faith of that doubled value, which no one ever supfosed would come down, those family charges were laid on. In all those farms that came into hand and were raised, there has been a 40 per eent. reduetion.

1661. How near do you think it is to the former prices? Have you improved this land?-There has been great improvement.

1662. Making allowance for the improvement on your estate, how near do you think it has got to the price before the war?--I should think it is pretty near the seme, allowing for improvement.

1663. So then the whole burthen of the war, as it is the ease generally, fell on the landed proprietors? - Yes.

1664. What quantity of land do you hold in your own hands:- None.

1665. In what state are the poor-rates about you? - Not so high, I apprehend, as in most other parts. I do not know what they are exactly; they are not so high generally in Devonshire as in other parts.

1666. Has there been much difference in their amount during the last 10 or 12 years? - It has been increasing generally; but I apprehend in Devonshire the labouring classes are better off than in miost other parts; you have not heard of the same disturbanees; they live more in the farm-houses.

464. 
J. B. Berrard, Es

$3 \operatorname{March} 1836$.

to67. What aro the weekly wages? - The wages are low, generally speaking. among agricultural labourers, not nole than 6.s. or 7 s. a week; but then they are allowed liquor and other indulgences, so that perhaps they are better off than in other comtics, where 10s. and 1 ? s. are paid ; so 1 am given to understand, and we lave not hearl the sanc complaints. Tre have had no incendiary fires in Deronshire.

[The Vitness is directed to withdraw.

Henry William Wilson, Esq., ealled in ; and Examined, as follows:

1668 . WHERE do you reside?--At Allexton, in the county of Leicester.

1660. That is a grazing county? - Yes.

16 -0. You have not much corn on your lans? ?--None.

1671 . Is grazing a profitable business now?-There are very great complaints among graziers; there are now and have been of late years.

1672 . In that part of the country :-Yes.

1673. Now what is the nature of the complaints generally: state those you know, from your own observation, to be well-grounded complaints? - I believe that one of the great reasons is the difference of the price of fat from the price of meat, which it formerly equalled.

1674 . The tallow was equal to the price of meat?-Yes.

1675. How much has it fallen below it? - About $3 d$. in the pound.

16-6. IIow is the price of hiles; hatre they fallen?-I cannot speak on that point, but they have fallen very considerably.

1677 . Is the effect of this depreciation in tallow to bring distress on the farmers?-No doubt it is.

1678. It takes from the buteher what is called the fifth quarter?-Yes.

1679. Do not you think that keeps up the price of meat as it is kept up, the butcher being deprived of the advantage of selling the fifth quarter? - It prevents the grizier getting the price that he otherwise would clo. I consider that it reduces the price to the grazier something considerable.

16 So. To what do you attribute this depression ?-The importation of foreign tallow:

1681. From Russia?-Principally.

1682. Have you any means of knowing if those importations have lately increased ?-I have not any return by me; I have an aceount which I received from a merchant in the city, in November, of the quantity of tallow.

1683 . Why was that account furnished to you ?-I had been making calculations on this point.

1684. What was the gentleman's name who furnished you with that account?

-Mr. Wilson, of Devonshire-square.

$16 \$_{5}$. Have you any reason to know that that account is correct ? I wished him to give me the most authentic account, and he forwarded this.

1686. He is a man of character?-Yes, he is; it is an account of tallow exported from St. Petersburgh to London.

1687 . Is he a Russian merchant?-No; he is a general merchant.

1688. How far does it go down to?-From 1828 to 1835.

1689. Does it show any great increase of importation for the last four or five years - From 1833 to $\mathbf{1 8 3 4}$ there was no ensiderable inerease.

1690 . What was it in 1835 ? - One thousand eight hundred and thirty-fire there is a decrease.

[The Witness then reads the following Statement:]

Tallow exported from St. Petersiurgh.

\begin{tabular}{|c|c|c|c|c|c|}
\hline \multicolumn{3}{|c|}{ lear. } & Loudon. & Out-ports. & Total Britain. \\
\hline $\begin{array}{l}1828 \\
1829 \\
1830 \\
1831 \\
183^{2} \\
1833 \\
1834 \\
1835\end{array}$ & $\begin{array}{l}- \\
- \\
- \\
- \\
- \\
- \\
-\end{array}$ & $\begin{array}{l}- \\
- \\
- \\
- \\
- \\
- \\
-\end{array}$ & $\begin{array}{c}\text { Casks. } \\
83,698 \\
89,921 \\
85,929 \\
91,571 \\
91,251 \\
105,783 \\
102,478 \\
71,074\end{array}$ & $\begin{array}{c}\text { Casks. } \\
52,518 \\
54,156 \\
35,19^{2} \\
32,965 \\
44,815 \\
46,842 \\
40,426 \\
20,199\end{array}$ & $\begin{array}{c}\text { Casks. } \\
136,216 \\
144,077 \\
121,121 \\
124,526 \\
136,066 \\
152,625 \\
142,904 \\
91,273\end{array}$ \\
\hline
\end{tabular}


But as tallow arrives from Odessa and other places, the total arrivals in London only, H. W. Wilson, Esq. from all parts, in the season, are as follow:

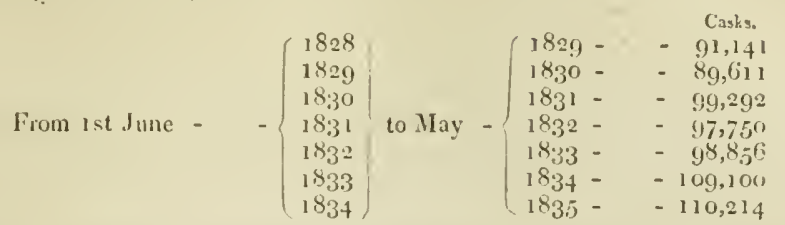

3 March 1836 .

1691 . Is that year 18.55 made up completcly, or only up to the latest periorl Novimber 11$)$ th, $18: \%$.

1602 . Do you know if the frost set in earlier in Russia in $1835 ?-\mathrm{No}$.

1603. Can you state what were the priees in the market for those several years? $-\mathrm{No}$.

1694. Have the prices of the eattle of the same quality and size diminished?-

I should say the priee of neat this year is higher than it was last.

1695. But, on an average of five or six year's how has it been ?-I am not prepared to say.

1696. Can you say whether the tenantry in your part of the country appear to he in a distressed state? - In many particulars in our neighbourlood the tenantry are rather better of now than a tew years sinee, from the increased price of wool.

1697. Comparing their situation a few years ago and now; is their situation now one of prosperity, or the reverse; that is, do you think they are well off now? - Certainly not.

1698. Do they pay their rents? - Pretty well; in Norfolk and Suffolk, with which I am comnected, they pay their rents very badly indeed; and 1 can there state, that in the light lands, in many instances, the produce of the corn for the last few years has not been sufticient to pay labour and poor-rates.

1699. The last you spoke of, where they pay their rent well, are those grazing lands:- Yes, from this eireumstance, that it depends more on the judgment of the grazier in not giring more for his eattle than he thinks he can make when they are fat.

1700. Consequently, then, if he sells eheap he buys eleap? - This does not alwars follow; various causes in the course of the rear may raise or depress the price; but he is in a much better situation than the person who breeds them, and especially than the person who grows eorn.

1701. What is the state of the breeding farms; ean they pay their rents?I eannot sar; where they are connected with grazing they are better off.

1702. Where they are not eonnected with grazing, but depend entirely on breeding, and eonsequently do not buy at all, and are not benefited by the cheap purchase, what state are they in?-I cannot speak to that, from my own olservation; there are few such farms in my neighbourhood.

1 - 03 . From your residence in the country, and eonnexion with persons engaged in agricultural pursuits, what do you consider the state of the farmers in general now? - I consider that in the agrieultural counties they never were in such a state of depression as at present.

r 704 . You say yours is entirely a grazing farm, is it not ?-The neighbourhood I live in is grazing.

1705. There is very little arable?-Very little indeed, and I attribute that to the reason that they are so much better off than others.

jof. You were saring that at the present moment the price of wool has bettered their condition very much indeed ?-- Y es, to a certain degree.

1707 . Since when is that?-I have some memoranda on that point; in $\mathbf{1 8 2 9}$ the price of wool was 1 l. a tod, that is 28 pounds, and now it is about $40 \mathrm{~s}$. to $42 \mathrm{~s}$.

1708 . Ilas it been gradually rising since 1828 ? - It has varied very much; in

1828 it was $22 s$. a tod, in 1829 it was 1 ., in $1830 \mathrm{I}$ have no account.

1709 . It is the long-woolled sheep you have?-Yes.

1710. How many pounds to a fleece generally? - That varies very much, from the quality of the land, and from the skill and eapital of the farmer.

1711 . But the average of your flock, what would be the average of your flock? -I should say, on a good farm, with a skilful grazier, the average would be about four sheep and a quarter to each tod; at least this is the statement from a very superior farmer, that his farm averaged; perhaps five sheep would be nearer the general average. 
H.W. Wilson, Esq. 1712. Be so good as to state what is the course of husbandry with your grazing farm; you buy the lean cattle from the north, fatten them, and send them up to London?-We buy them from all parts of the country.

1713. You fatten them, and send them up to the towns?-Yes.

1714. That is the ordinary course of your business? - Yes.

171.5. Has your lean stock been cheap ? could you state, during the last five or six years, whether there has been that difference between the lean and fat stock, so as to give you a fair remunerating price for your land, because it depends on that, does it not?-Yes.

1716 . The difference between the price of lean and fat stock?-I have heard many instances of farmers who have sold, I am speaking generally of four or five years since, have sold fat stock at hardly any greater advance of price than on what they have given for them.

1717 . That is not the case now ?-This year has been better than the last. I should mention that the price of fat meat getting up at this particular season of the year is the worst thing that could happen to the farmers in Leicestershire, because all those fat beasts and sheep hare been sold for some weeks, and in consequence lean stock has risen about $30 \mathrm{~s}$. a head; that is the case at the present fair.

1718 . At what periods of the year does the fat stock generally rise?-That is rery uncertain; sometimes it has been highest before Christmas, and at others after.

1719. That must depend a good deal on the season?-Yes.

1;20. And on the preceding season?-Yes. I attribute the gross rise in price now to the very great failure of the turnip crop in Norfolk and Suffolk; the consequence has been, that there has not been one bullock fed now where there were eight or ten fed before, and those are now fed on wheat and other artificial food.

1721 . Have they been fed on wheat to a considerable extent?-I believe so. I know many farmers who have done it in Norfolk and Suffolk, and also in Leicestershire, but not to any great extent in the latter county.

172. Have not the markets for meat here in the metropolis for the last two or three years been fair markets, that is, brought fair prices for the grazier?-If you can believe the farmers I should say very far from it.

1723. Judging yourself, looking impartially at the case, not meaning that it quite answers the expectation of the farmers, should you not say that the meat markets in London for the last two or three years have been fair markets, taking $1835,1834,1833$ ? - I should say not ; but I am hardly able to speak off-hand.

1724. You could not state the prices of those three years as compared with any former period, that as for fat beasts generally which come to Smithfield market, whether by the stone or by whatever weight you take it by, whether the price lias not been on the whole, in the last two or three years, a very fair price? - I should not say it was a remunerating price.

1725. But it has been an improving price during the last two or three years, upon what it was before?-I hardly like to give an opinion without having papers or statements before me.

1726. As to what you were saying about the tallow, do you know what the price of English tallow fat has been?-It is about $4 s$. a stone at this time.

1727 . What was it the last year?-It was lower.

1728 . So that is rather better?--Yes.

1729. What was it five or six years ago? - About $2 \frac{1}{3} d$. a pound I sold mine.

1730. Speaking of the same measure, you say $4 s$. the stone; what was it in any one year you could state, in 1830 and 1831 ? - As far as my memory serves me, it was abcut $3 s$; but I really cannot state.

1731. Is it eight or fourteen pounds to the stone?-Fourteen pounds to the stone for fat.

1732. So that in the year 1830 it sold for $3 s$., now it sells for $4 s$.? -To the best of my recollection it was about $3 s$; ; thas risen within these few months.

1733. To $4 s$. ?-Yes.

1734. Can you state what it was last year?-No, I cannot.

1735. Was it under $3 s$. last year? - I think it was between $3 s$. and $4 s$.

1736. If that is the case, that the price of English tallow or English fat being at $3 s$. in the year 1830 , at $3 s .6 \%$. we will say in the last year, and now at $4 s$, is it fair to say that the importation of Russian tallow has matcrially injured 
the sale of English fat in the marlict, or that a grazier has much to complain H.W.W'sor, Esq. of in the present price of that article? - I conceive that the quantity produced in this country has been less in consequence of the great loss of turnips, that the quantity from the English grower has been less of late. I might add, that from the low price of fat, the decrease of capital, and from the great losses the graziers sustained in the dry summer of 1826 , and since that from the rot, a larger portion of ewes, and consequently fewer fat sheep, have been kept.

1737. You mean that his cattle have been less fat?-Yes.

1738. That refers to this year only?-To this last year, and to several preceding.

17.39. If it should appear that there has been no material falling off in the price of tallow or of fat, then would it not be presumable that the markict lias not been improperly damaged by the importation? - I have not been sufficiently acquainted with imports to say exactly the effect upon it ; but it is merely the general opinion that I have formed upon it.

1740. Is it the opinion of your neighbourhood, that you are injured by the iniportation of foreign tallow:- Most decidedly.

1741. There have been importations of foreign tallow at all times, have there not?-Yes, 15 or 16 years ago, before I took any part in agricultural concerns.

1742. Do your tenants complain; have you reduced their rents?-Yes.

1743. How much per cent. in your old rents?-It has varied very much.

1744 . In grazing land now? - In grazing land some have reduced from 10 to 15 to 25 per cent.

1 74.5 . In your neighbourhood?-Yes.

1746 . Do they still complain?-They do not complain so much as they did.

1747. What reductions have you niade yourself, in what proportion?-Our rents were not raised in the same way as other people's in the neighbourhood were, and ours is only reduced 10 per cent., but they were not raised in the high times.

174 S. When were your rents fixed, if that is the case; were they fixed before the war? - I am sorry I have not the paper with me, but I think it was about 1797 or 1798 they were fixed, and then they were raised one-fifth.

1749. And since they have been reduced 10 per cent. ?-Yes.

1750. Do they now complain? - Not near so much as they did.

1751. Do they complain at all ? - Yes, they do.

1752. Do they require still further reductions, as far as you yourself know, or have been advised by those to whom you entrust your concerns; do they require further reductions?- - Some of them do certainly.

17.53. Are the rents well paid or not? - Pretty well ; I am speaking of Leicestershire now ; the Norfolk and Suffolk rents are very badly paid.

1754. Have any farmers in your county failed?-Yes, numbers; in Leicestershire I mean.

1755. A large proportion, a great many?-No, I should think not.

1756 . Have they been prudent persons, or was it in consequence of the times? - Of the times.

1757. Hare you observed any effect upon the poor in that part of the country from the failure of those persons?-We suffer most from the manufacturers pressing upon the poor-rates to a very great extent.

I 758. How do you mean pressing; be so good as to explain?-For instance, in the parish of Wigston, which contains between 2,000 and 3,000 acres, there are 69 agricultural labourers and 301 manufacturers.

1759. For whom do these manufacturers work; where do their masters live? - In Leicester chiefly.

1 760 . Do they contribute any thing to the poor-rates of that parish?-O, hardly any thing; there may be individuals who may happen to have a small cottage, or something of that sort; but we find it, as magistrates, extremely difficult to get any rates from these manufacturers; we have had numbers of them, and we have struck them off, till at last in some parishes they have hardly thought proper to rate them at all.

1701. A manufacturer living in Leicester employs workmen in these parishes? In all the parishes round.

1;62. Do these Leicester manufacturers contribute to the poor-rates of those parishes where their workmen live?-Hardly any thing. From an Abstract of 464 . 
H.W.Wilson, Esq. the Parliamentary Returns, showing the money levied for the poor and the county-rates in each county in England and Wales for 1834, Leicester ${ }_{3}$ March 1836 . 108,330l. $3 s$; of this sum mills and factories contribute only $783 \mathrm{l} .2 \mathrm{~s}$; the dwelling-houses contribute $29,551 l$. $i s$.; manorial profits, navigation, \&c., $6381.14 s$.

$1 ; 63$. Did the land contribute all the rest ?-The land contributed 108,330 $l .3 s$. and the mills and factories only $783 / .2 s$.

$17 i_{4}$. Can you tell the Committee how is the land-tax in that part of the country; how does it bear on agricultural districts and on the towns? --I cannot speak to that; on our own property it is redeemed, and, I believe, generally.

$1,65$. You do not know that it is much lower in the towns?-No.

1,66. How are the county-rates; as a magistrate, can you form an opinion as to the proportion of prisoners sent from the towns to the gaols, and those sent from the villages? - I should say that there was a large proportion of manufacturers of those who are committed; but perhaps I could give a better answer to that to-morrow.

$1 ; 67$. There are a larger portion of manufacturers committed than agriculturists:- I should think so.

$1-08$. What is the rate of wages given to your manufacturing population ?We found great difficulty in ascertaining the rate of wages manufacturers give; and in the adjoining parishes, where the manufacturers were employed, they force the landlords to make up the wages of the labourers; and we found the greatest difficulty possible in ascertaining from the manufacturers what they really received; but the manufacturers at this time are in a state of full employment, that we have not sufiered to that extent we formerly did.

1,69 . Within what ages do they employ them in the manufactories? - I cannot speak to that fact; the stockinger's are all grown-up people, but in the winding and those manufactories $I$ have been in I have seen young children, but not so young as I have heard of in other places.

1770 . On an average, do the agricultural employers or the manufacturing employers find work for a larger proportion out of each family as to age? - The young children in agricultural parishes have little or no employment whatever.

$17 ; 1$. Supposing your labourers were not employed in manufactures, would there be sufficient means of employing them in agriculture?-Not in these particular parishes; they would be useless to the land.

177 . Has not the machinery taken a way the employment of women and children in agricultural parishes? - - To a very large extent.

1773. You are not old enough to remember when they spun by the roadside? - No. An account has been given to me by a respectable person on that point, who had it from an old man in his own parish; he gave me this; I believe it is the statement of what his own wife and family received. He says, "Forty years since the wages of labour was $1 s$. a day; his wife spinning wool or flax was $8 d$. a day; a child 12 years old was $8 d$., of 10 years old $6 d$., of eight years old $4 d$., which is $3 s .2 d$. a day." The wages now of a labourer in that neighbourhood is $1 s .6 \mathrm{~d}$. a day, and his wife and children earn little or nothing.

$17 ; 4$. What they used to do in spinning is now done by machinery?-Yes.

177.5 . Have you turned your attention to the relative value of hides? - I cannot speak to that; I know there is a great reduction; I do not know to what amount.

$17-70$. Would it be fair to take the present market price for meat as the price which the farmer receives for his fat stock :-Certainly not, because the butcher now is not realizing the same sum which he did for his fat; so that he gives the grazier less for his meat.

$1 ;-7$. But although the price of meat in butchers' shops may be no criterion by which to judge of the price the farmer gets, yet the price of the beast, taken together, as sold in Smithfield market now, and as sold at any other time, is a fair criterion to judge, inasmuch as the fat and lean and every thing else is taken together, is it not? - I have made a calculation.

$1,-78$. Is not the question for the grazier, what he gets for the whole animals when fattened?--Certainly.

1779. Although that sum he gets for the whole aninals when fattened may not stand in the same proportion to the price of meat when sold by the butcher to 
the consumers, yet if he gets now the same price for the whole carcase he got before, he is equally well off? - But he does not do that.

1780 . If the price of the hide and the fat was as high as it used to be, he would of course get a larger price for the beast?-Yes.

1781. In whatever way that loss is to be divided between him and the butcher, still it must be a positive loss to the farmer, if the price of the fat and lide is lower?-Yes, it must be a positive loss to him.

${ }_{17} \mathrm{~S}_{2}$. You stated that there had not been a corresponding falling off in the price of lean stock as there had been in the price of fat stock?-I conceive not.

1783. Are you at all able to account for that; have you ever inquired into the causes of that?-One reason for the price of lean stock being ligher than it ought to be for the Leicestershire farmer is, that they are not enabled to keep a great quantity during the winter, and they all want beasts at the same time, therefore they bid for the lean beasts one against the other, and often get a higher price than they ought to do.

1784 . In fact they must have them?-Yes; if not, they say the land is useless to them.

1785 . But is the price of lean stock, though higher in comparison than fat stock, is it lower than it was some years ago? - O yes, certainly, very considerably.

1786. Do you know whether the breeder of lean stock is not in a worse situation a good deal, than the grazier, in consequence of the depression of price?Speaking of Leicestershire, I have had so little to do with breeding farms, I can hardly give an answer.

1787. Are you able to state the condition of the freeholders who occupy their own land in Leicestershire, as compared with the state of the tenants? $-\mathrm{I}$ am not prepared to give the difference between the two.

1788. Can you state, from your own knowledge of the freeholders, if they are in a prosperous or distressed state?-They are certainly in a distressed state, but they are better off than the tenants in many instances, from the circumstance of its being known that they have some property of their own, and they can get accommodation at their bankers for money, which the tenant now cannot do. At the present time the country bankers are willing to give credit to manufacturers, but they are not willing to do so to the farmer, and have not been for many yeats, because it ceases to be a profitable concern; a country banker has stated to me, and a man of some eminence, several times, that if a farmer would bring surety, that then they would advance him money, but that they have not done so for many years, from grazing and farming being an unprofitable concern; in many instances the freeholders are in as bad or worse state than the mere tenants, those who purchased their farms in the high times, and have borrowed part of the money.

$17 \mathrm{~kg}$. There is no difficulty with the banker to make an advance when he considers his security good, but in the case of the farmer he has been so much distressed, he does not think his security is good; is not that what you mean?He has long ceased to think so.

1790. In point of fact, the stock in hand of a farmer in most instances, has ceased to be any security at all in a grazing country ?--Certainly, it is no security whatever; because in some instances, indeed in many, they have sold their fat stock at very little or any profit.

1791. You do not confine your observations to the grazing countries, but you extend it to the arable farmer?-The arable farmer is in a very much worse state.

17y2. As to credit :-Decidedly so, at this very time; I do not know in the county of Norfolk where I could look for a solvent tenant.

1793. You speak to those parts of Norfolk where barley is grown to a very great extent?-Yes.

1794. The country bankers apply their minds a good deal to the consideration as to which is a good security, and which is not?-Yes, certainly.

1795. Then can there be a stronger proof of the wretched state of the agriculturists, than that the bankers will not lend the farmers money? - It is a strong proof, certainly.

1706. In what state are the freeholders in the county of Norfolk? - The remarks before made on the freeholders of Leicestershire, apply with more force here; I lnow many instances where it has caused utter ruin.

+64. 
11.W. Wilsm, Esq. 179\%. Is there any thing in the course of the cultivation of land you could 3 March 18,36 . suggest, likely to relieve the farmers from the distresses, by the introduction of any other article that will be profitable to the farmers; hemp, flax or any other articles? - I am not prepared to say to what extent flax and hemp; what profit it would yield.

1798 . If there is a considerable increased proportion of those articles from abroad, do you not conceive that if the Legislature was to give any assistance that way, it would be beneficial to the farming interests?-Certainly; and rape is a thing that is imported, which yields no profit on certain lands, in consequence of importation; I do not speak from my knowledge; I have understood the duty was $20 s$; ; it is now $1 s$.

179?. You are not aware if there is any decreased quantity of hemp and rape and flax grown of late years? -I conceive so.

1800 . The importation abroad has interfered with the general growth?-Yes.

1801. There used to be formerly a bounty on the growth of flax?-I have heard so ; I am not acquainted with it.

1 So2. There is no bounty now?-I think not.

1So3. Are you aware if flax is grown in this country of an inferior quality than used to be?-No; I have not seen any grown in our neighbourhood for some time.

1804. For how long? - I really can hardly remember.

1So5. Have you any practice of feeding of cattle on malt? - I have fed them on grown barley, and horses too.

iso6. Are you aware that malt is a much stronger food? - I have been told so; I believe it to be the case.

1 So 7 . Do not you think it would be exceedingly advantageous to the agriculturist if the duty on malt was repealed, so far as to allow him to malt his own barley for his own consumption?-There is no question about it ; it would be a very great relief.

1808. Do you know what the duty on the importation of those articles, hemp, flax and tallow, was formerly?-I was told a short time ago it was $20 \mathrm{~s}$.

1 sog. Is there much improvement going on in the cultivation of land with you?-Yes, a good deal.

1810. The cultivation has improved? - Yes.

1811. Has there been much draining? - There has.

1812. Of the grass lands?-Yes; especially for the last three years, from the rot ; the landlords have generally encouraged it.

1813. So there has been a great improvement of cultivation?-Yes.

1814. That improvement has taken place at the expense generally of the landlord, not of the tenant? - I should say, to my own knowledge, greatly.

1S15. Can you say whether the improvements you have been making at your own expense on your own lands have not exceeded the 10 per cent. you reduced your rents since the last war?-Not in Leicestershire ; but we have done all substantial repairs, made new buildings and other allowances, which we should not have been required to do when the times were better; these have amounted to a very considerable sum.

1816. Were you not called on for a reduction in going back, of rent, when the rot took place in the country ?--It so happened that the land I was connected with in Leicestershire was pretty well drained before that; the loss on our own estate was not so great as of our neighbours.

1817 . Do not you know your neighbours were called on for a very large reduction of rent?-Yes.

1818 . As much as 30 per cent. on the rent, or to what amount in that year? -I do not know to what amount.

1819 . Have you understood it was a considerable amount?-Yes.

1820. One advantage, is there not, which the tenants derive from draining, is, that they get a greater produce from the land without any increase of charges on the people whom they employ upon it?-Yes.

$1 \times 21$. Therefore it by no means shows that the landlords are likely to profit much by it, for it is as much a synuptom of distress as any thing else, is it not? - If it had not been for those improvements, and for the tenant using his utmost endeavours to keep as much stock as possible, and improve his land more, they would not have been in so good a state as they are at present.

1822. Have tenants in your part of the country what is called scourged the 
land, that is, by over-cropping or working it out? - In many instances thcy have, II.W. Wilsum, Esil. to a very great extent.

1823. Has not the ruin of the estates in that way been the means of keeping 3 March 1836 . them up in the way they have been kept up?-Yes.

1824. And so saved themselves from ruin? - They have done every thing they could to prop up a bad concern for a year or two, and have sunk at last.

1825. Has not that been one of the means? - It has.

$18_{2} 6$. Has much grass land been ploughed up?-Z Yes.

1827. Broken up and turned into arable?-Yes.

1828. That enabled the tenant to pay his rent out of his landlord's capital?Yes, it has been the means of propping up rents for a few years.

1829. Looking about in your neighbourhood, should you say that there has been more land converted from pasture to arable, than of arable land laid down to grass? - There has been little or none laid down in grass in that country.

1830. There has been a considerable quantity ploughed up?-Yes.

1831. That is with the consent of the landlords, is it not?-Yes, of course.

1832. The leases generally prevent the tenant doing it without consent? -

Certainly; besides it would be against the custom of the country; they would be liable to damages.

1833. That consent given is likewise a proof of the distressed state of the tenant, which induces the landlord to give that consent? - It has been in many instances to prop up the rents.

1834. Looking to the relative value of corn and of meat, should you say there was much temptation to break up grass land?-None now, but there was a few years ago.

1835. Have not tenants and landlords been obliged to consent to this overcropping, to keep up the rents yearly ?-Yes.

1836. In many instances you have known tenants over-crop without the consent of the landlords? - Certainly. that.

1837. Notwithstanding covenants or the custom of the country?-Some do

1838 . Do the tenants now lay down their land in as good a state as they used to do? - There has been little or no land laid down.

1839 . Have you any account which would show the effect of the introduction of foreign tallow on the land of this country?-I submitted the data that this calculation is made upon to many of the graziers and butchers in our neighbourhood, and they agree in the accuracy of it.

\section{[The same is delivered in, and read as follows:]}

Calculations of Loss in the Profits of the Grazier upon Sheep and Bullocks, when the Price of Fat is lower than that of Meat, which it formerly equalled. (The price being $3 d$. per lb. lower, which it has generally averaged of late.)

Upon good grazing land the sheep will average 20 or 22 pounds per quarter. The tallow fat on the kidneys and parings of the neck, chine and loin will average 20 pounds, which, at $3 \mathrm{~d}$. loss, is $5 \mathrm{~s}$. The same description of land will feed beasts of 64 stone (14 pounds to the stone), the fat one-eighth, or eight stone, at $3 d$., is $28 s$.

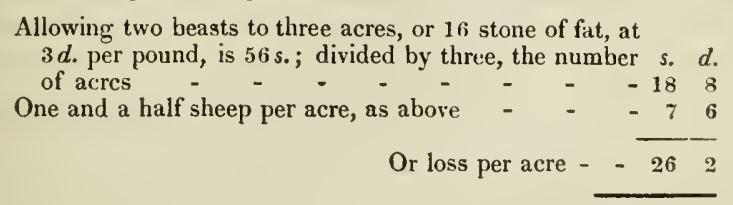

If it be allowed the grazier ought to make three rents, one for himself, one for expenses and one for the landlord, divided by three, it would give $8 \mathrm{~s} .8 d$., or from 20 to 25 per cent., which now would be about $40 \mathrm{~s}$. per acre.

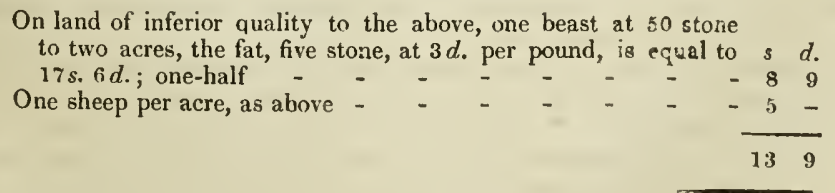




\section{H. Wr.Wilson, Esq.}

3 March 1836 .

Or divided by three, as before, would amount to seven per cent. on the rental of $32 s$; price $2 \frac{1}{2} d$. lower.

s. $d$.

Two beasts, as in the first instance, 16 stone of fat, at $2 \frac{1}{2} d$ per pound, is $46 s .8 d$, divided by three - $-{ }_{-}-{ }_{-}-1564$

One and a half sheep per acre, 30 pounds of fat at $2 \frac{1}{2} d$. $\quad-\quad 63$

$$
\text { Loss per acre } \quad-\quad-21 \quad 9 \frac{1}{4}
$$

N.B.-The tallow will weigh from 10 to 14 pounds; the fat on the kidneys not less than five pounds. The parings are small in the country, but in London often $10 \mathrm{or}$ 12 pounds; therefore the calculation is a moderate one. Sheep which have been fed on artificial food will average a larger quantity.

An eminent land surveyor reported to me he considered the averagre price of mutton to the grazier $5 d$. per pound, the fat, about 12 pounds, at $3 d$., the difference of price, $2 d$.; amounting to $2 \mathrm{~s}$. each sheep. Here the parings are not taken into account, being sold with the meat at a reduced price, which takes from the average price received by the grower. The average weight of a beast eight score and ten pounds per quarter, $\mathbf{8 5}$ stone London weight, or between 48 and 49 stone, 14 pounds to the stone; average of fat, seven stone of 14 pounds. The difference at $2 d$. per pound is equal to $16 s .4 d$. On the average of feeding and stone land, one beast and one sheep to an acre, rent $30 s$. Therefore,

\begin{tabular}{|c|c|c|c|c|c|c|c|c|c|c|}
\hline Half a sheep & - & - & - & - & - & - & - & - & $\begin{array}{l}s . \\
-\quad 1\end{array}$ & d. \\
\hline Half a beast & - & - & - & - & - & - & - & - & -8 & 2 \\
\hline Loss per acre & - & - & - & - & - & - & - & - & -9 & 2 \\
\hline Or when the $p$ & $s$ & less & - & & - & - & - & - & -13 & 3 \\
\hline
\end{tabular}

That is what the grazier would directly gain if the fat was advanced to the price of the meat; but his gain would not rest here; indirectly he would gain more.

It is a well-known fact that sheep which are made thoroughly fat, and weigh from 25 to 40 pounds per quarter, are not so valuable per pound as one less fat, and weighing from 16 to 20 pounds per quarter; not that there is a difference in the quality, but because it is too fat, and not so saleable; in consequence of which the grazier (under existing prices) prefers selling his sheep when they are half fed, which it would not be his interest to do if tallow and meat were at the same price; because he could make his sheep thoroughly fat upon good feeding land at less expense than he could make a young or lean one marketable, as fat animals, whether beast or sheep, eat less and gain more weight in proportion than lean ones. The quantity of two-shear heavy sheep has much decreased of late years, in consequence of this difference of price.

1840. You have stated that the price of fat and of tallow which you have been speaking of, was $3 s$. in 1830 per stone, and that it is $4 s$. at present; is it possible to reconcile to that state of things the opinion that the lowering the price of tallow or fat is any material cause of the present distress of the farmer? - I hardly know if I can make myself clearly understood, but I conceive that the price of meat has at this time fallen off in quantity.

$18_{4}$. But speaking of the price of fat or tallow, to which you seem to attach considerable importance; first, you have given details of the importations of foreign tallow, which, taking London and the outports together, did not show any material increase of importation; and secondly, you have stated that the prices are considerably better than they were six years ago; can you state how you reconcile to these facts the opinion that the alteration in the price of tallow or fat is at the bottom of the present distress of the farmer?-I forget the date, but I can remember the time when fat and meat made the same price; that was when there was no importation, as I am told.

1842. You remember the fact of fat and meat being the same price? - Yes.

1843. You do not remember when the fat was still higher than the meat?I have been told so.

1844. What was the highest price you remember fat and meat were at?-It was before I looked at accounts myself.

1845. Have you seen any accounts, included in authentic returns, on which you can state fat to have been as high as $9 d$. a pound?-No, I have not.

1846. You were asked if during the war the value of the fifth quarter was not considered generally to cover the rent on the grazing ground?-I have not made that calculation; I have heard it was considered sufficient "for the butcher's profit. 
1847. If that is withdrawn, the farmer might get it out of the carcase?-Yes.

1848 . The seller must give it out of the carcase?-Yes.

1849. Have you any further observations to make to the Committee?-As to the state of the Norfolk and Suffolk farms, I have examined the accounts and memorandums I have with me, and regret I had not a few more days' notice, that I might have collected others, and have been better prepared to answer the various and important questions that Noble Lords have put to me." I take as an example three farms of good and of light land; the former contains 611 acres; the land tax is $45 l .4 s .8 d$, about $1 s .6 d$. per acre; the rent in 1820 was $1,010 l$., which was not set upon the high prices of the years 1810,1812 or 1813. In 1821, 20 per cent. was taken off and continued. In 1827 or 1828 the tenants required a further abatement, but stated their rents were not too high when the average price of wheat and barley together was $100 \mathrm{~s}$. per quarter; it reached this price the following two years, when the tenants declared they were worse off than ever, and that the great increase of poor-rate was the cause; upon which I made an arrangement, instead of further reduction in money, to allow on the three farms $86 l$., or rather more than another $10 l$. per cent., for claying and draining; this has been continued, with a trifling increase, to the present time; and if the prices of produce do not improve the tenants cannot pay their rents, and I believe have not done so lately from the annual produce of their farms. Timber and bark have fallen one-half in value; the cause, importations. Underwood in the same parish about 200 acres, formerly considered low let at $220 l$., tenant paying all outgoings except the land-tax, $9 \mathrm{l}$. $10 \mathrm{~s}$.; now reduced to $160 \mathrm{l}$., landlord paying the tithes, rates, \&c., which amounted to $86 l$. last year. For three light-land farms, containing $2,398 \mathrm{~A}, 2 \mathrm{R} .5 \mathrm{P}$. , the rents were formerly $1,140 \mathrm{l}$. the land-tax on two of them $49 l .11 s .8 d$.; in 1831 the net rent was $709 l .6 s .9 d$.; in 1833 , only 595l. 5s. $7 \frac{1}{2} d$., after deducting repairs, \&c. Further reductions have been made this and last year. One tenant declares he has paid his rent out of his capital each year of his occupancy (three years); that his corn will not pay the labour this year. Last year one tenant left ; the third purposes doing so this year.

[The Witness is directed to withdraw.

Ordered, That this Committee be adjourned 'till to-morrow, One o'clock.

Die Veneris, $4^{\circ}$ Martii, 1836.

The Lord WYNFORD in the ChalR.

David Hodgson, Esq. is called in ; and Examined, as follows :

1850. YOU are a merchant at Liverpool?--Yes.

1851 . You were examined before a Committee of the House of Commons in 1833 ? - I was.

1852. Are you acquainted with Ireland?-I am generally acquainted with

D. Hodgson, Esq.

4 March 1836. Ireland.

1853. From your situation, do you know much about the quantities of corn imported into Liverpool lately from Ireland?-Yes.

1854. Has it increased, or diminished ?-It has been increasing and varying.

185.5. Has it increased lately? - With reference to what period?

1856. Within three or four years?-I think it has; but there is an account regularly delivered to Parliament. I have got the particulars up to the present time.

1857 . What quantity was imported in 1833 ? - Eight hundred and forty-four thousand two hundred and one quarters.

1858. Was that of all descriptions of grain?-No; of wheat and flour.

1 $\$ 59$. Do you know the expense of cultivating corn in Ireland?-No.

1960 . Do you know whether it has increased? - It has been on the increase for a great length of time.

$1 \$ 61$. For how many years?-I cannot state the period; but for a great length of time; in the list of imports since $1 S 20$ it has been constantly on the increase, but varying according to particular circumstances; I mean in the proportion of 464 . 

D. Hodgson, Esq. wheat and oats respectively, according to the encouragement given to one or the
other.

4 March 1836 . 1862 . Have they broken up grass land, and sowed it into corn?-I am not in the possession of facts as to that.

$1 \$ 63$. Do you know if the quantity of land cultivated for corn in this country has increased or diminished?-l do not know if there has been any material change.

1864. Do you know any thing-if any foreign corn has come in?-For home consumption, clandestinely-none whatever.

$1 \$ 65$. You have no reason to think any foreign flour has come in the shape of Irish flour to this country? -No.

1866 . What is your particular business?-I am in the corn trade, and a general merchant.

1 867 . And connected with Ireland?-Yes; and with other parts of the world occasionally.

$1 \mathrm{~S} 68$. Receiving consignments of corn?-Yes, and in the purchase of corn. I have an opinion with regard to the present depression in the price of wheat, and of the prospect of a change in the value, which, if permitted, I would state.

1869 . What is your opinion?-The present depression in agricultural produce I apprehend to be confined to wheat ; there is not any other article, of which I am aware, of agricultural produce, that is not maintaining either an average price or above it, or nearly the average of the last 15 years; the depression of price is confined to wheat only.

1870 . What, in your opinion, is the occasion of that ?-A superabundant production for three or four years.

1871 . Where have you a superabundant production, in England or Ireland? Partly in both, but especially in a particular portion of England.

1872 . What is the part of England?--The great wheat-growing districts, embracing the counties of Essex, Norfolk, Suffolk, and Lincolnshire, \&c. There were three crops in succession, 1832, 1833, and 1834, but in particular 1834, which in that district was the largest in point of acreable produce I have known.

1873 . Have you the means of knowing if the increase of wheat has not been occasioned in those counties by its being grown on that land on which they used to cultivate oats?-I think not ; the crops of wheat for 1832 and 1833 I compute as having been crops yielding a supply sufficient for the consumption of the country.

1874 . From England and Ireland?-Yes; 1834 the crop greatly exceeded the consumption.

1875. What do you say of 1835 ? - It was an average, and not producing what I should think would be equal to the consumption of the year.

${ }_{18} ; 6$. Are the Committee to understand you as speaking of the whole United Kingdom all the way through ?-Yes; the commercial estabiishment, of which I am a partner, have been in the habit many years of making annual examinations of the wheat crop in England,- since, I think, 1809, and of forming each year their opinion of its productiveness. The crop of 1834 was one of the largest and best crops, especially in the great wheat-growing district, to which I have already referred, that has come under their notice. Independently of season, there were causes tending to increase the growth of wheat in this country; for instance, the price of oats in 1832 and 1833 , and of barley, was singularly low, whence there was inducement to convert to wheat tillage every soil that could be converted.

1877. That is from oats and barley ?-Yes, and from cattle; cattle maintained lower prices in 1830 and 1831 than the relative proportions of wheat; wheat being high in $1828,1829,1830$, and 1831 .

1878 . Are you aware whether that inducement to produce wheat was not in consequence of a great importation of oats from Ireland?--I have no reason to think so.

1879 . Was not an immense quantity of oats imported from Ireland in those years? - The difference in the importation of oats, by the returns, does not appear very large.

1880. It is above $1,000,000$ quarters a year, is it not?-Yes; the aggregate importation is always above that; the importation last year was $1,300,000$ quarters, the jear before $1,700,000$, and the year before $1,600,000$; and the 
largest import appearing in the list was in the year 1828, being 2,000,000 quarters.

1881. Was not that sufficient, added to the English crop, very much to overstock the English market:-The market subsequently to the year 1828 was overstocked with oats, so that the price fell greatly, relatively to the price of wheat.

1882. Do you not know that the lands that used to be cultivated for oats were cultivated for wheat? - I should infer it.

1583. Do you infer it from general reasoning, or from the report of the person you sent to examine?-No. The person's business is with wheat alone.

1884. It is almost a necessary inference :-Yes, 1 think so.

1885. You stated that the other grain has averaged about the price it has done the last 15 or 20 years; are you aware if the crops of other grain have been very defective the last three years, - barley and beans particularly ?-I think beans may have been; 1 am not aware of it as to oats and barley.

1886. Your reporter only reports on the wheat crop - -Only.

1887. Does he on the others? - Ie makes general observations; but his mode of examining the wheat crop is peculiar, and is what alone is relied on ; the rest is merely conmon observation.

1888. At what period of the year do you send your examiner round?-According to the season; immediately preceding the harvest, when the grain is very nearly fit for the sickle.

1889 . You have reason to think the reports you get are accurate?-Yes.

1890 . How many persons do you send round the kingdom? - Two.

1891. Are other merchants at Liverpool in the same practice?-None.

1892. You are the gentleman who stated that before the Committee in 1833 ? -Yes, I am.

1893 . You were going on to give your view ?-If I understand the object of inquiry with your Lordship's Committee, it is to ascertain the causes of depression in the price of wheat, and the prospect there may be of improvement.

1894 . Can you refer to the present prosperous condition of the manufacturing districts? - I was going to say I think there is no agricultural produce whatever that is low, with the exception of wheat; none.

1 19.5. There is no distress except that which is caused by the low price of wheat?-I am not aware of any.

18y6. What do you consider to be a fair remunerating price for the different sorts of grain? - I think the best mode of ascertaining that would be the average prices of the last 20 or 30 years.

1897. The Committee would rather you gave a distinct answer to that question?-It is the only way which occurs to me of answering it.

1898 . You are not practically acquainted with the subject?-No, I am not practically acquainted with it.

1899. The remunerating price to the farmer must depend on the rent lie pays.? - If a merchant is asked the price of any commodity that he is dealing in, and were shown an account of the price for the last 20 years, and he says the constant price is so and so, my inference would be that that person must of necessity cease to produce it, or else it is not a remunerating price. If you take 20 years as an average, or any given period that you may please, and still find the article produced and the quantity is still sutficient for the supply of the consumption for which it is appointed, I should, with submission, think that is the best mode you have of arriving at the remunerating price.

1900. You say you conceive there is no article of agricultural produce too low to afford a fair remunerating price to the farmer, except wheat?-Yes.

1901. Be so kind as to state what you consider now are those prices with respect to other articles which give a sufficient remunerating price for the farmer? - Oats, barley and beans are nearly at average prices; wheat alone is the article very much below the average. Wheat is about $42 \mathrm{~s}$. a quarter, whilst the average of the last 16 years would be about $60 \mathrm{~s}$. Oats are now about $21 \mathrm{~s}$. or $22 s . ;$ and in the average price for the same period there is a difference only of about $2 s$. ; the same with barley and beans.

1902. In taking the present price of those different articles, before you can make up your mind if it is a fair price to remunerate-not a farmer who pays his rent, but a freeholder cultivating his own land-must you not take into consideration the produce of the preceding year, and the sale of the articles produced, $4^{6} 4_{4}$. 
D. Hodgson, Esq. which is to gire a return to the farmer?-The quantity of produce affects the price materially, of course.

1903. Can you make an estimate of the fair remunerating price to the freeholder cultivating his own land, without considering what is the crop from which he obtains that price?-No, I cannot offer an opinion; the circumstances under which his produce are raised must be so varied.

1904. Must it not be a most important ingredient as to the sufficiency of the price, the quantity of the article which is produced?-Unquestionably; but the fluctuations from year to year, as so affected, influence the aggregate price in the series of years.

1905. But the question is this: whether at the present moment, under the present circumstances of the farmers, - not the tenants but the freeholderswhether the prices themselves are such as to leave the freehold farmer in a depressed or a prosperous state?-I should think in a prosperous state; the interchangeable value of wheat is probably as high now,-I ought rather to say of erery thing but wheat,-as at any given period.

1906. You think the condition of the farmers at present is prosperous?There may be some abatement, occasioned by the pressure of peculiar circumstances, as the price of wheat.

$190 \%$. Have you any doubt that they have been in a state of great distress for at least five years ? - I really mould rather not give an opinion upon that to which I am not competent to speak.

19o\$. Can you give any opinion on the subject without knowing what is the quantity of produce contrasted with the price; is it possible?-The quantity of produce of wheat is very large.

1909. Is not the difference between the price of wheat and of other articles this, that of wheat there has been a large quantity produced, whereas, everybody knows, of the other articles there has not been any thing like an average crop. Do not you know that occasions the difference between the price of wheat and the price of oats and barley, that of wheat there have been fair crops, and barley and oats have been much under the quantity?-From the failure of the season or less cultivation?

1910. From any source; has there not been from failure of seasons?-I think not; I think there has been from a variation in the cultivation, and that variation is in the course of correcting itself now.

1911. Has not that variation in the cultivation been from an inundation of Irish oats, in a great measure? - I cannot say that.

1912. Your reason for thinking the farmers are getting a remunerating price is, that they have gone on for several years? - Yes, I think so.

1913. Is not the high price of other articles occasioned by their scarcity in the markets? -By the relative scarcity, no doubt.

1914. And that from bad seasons?- - No; I should not so conclude; I should think it is from the preference that has been given to the cultivation of wheat, but more especially to an extraordinary natural production of wheat in the year 1834 ; that there was a greater acreable produce of wheat in the great wheat-groming districts of England than had been for a great many years; and that though the farmer of England generally may not be remunerated in wheat because of the low price, he however would be in the east of England on account of the rery unusual acreable produce of wheat.

1915. Are you prepared to state that the price of other articles remunerated him for his loss in wheat?-I am not prepared to state that, but I am of opinion that he is now in a situation of improvement, from the rise in price of wheat ; and that we shall hare, in the course of the ensuing year or two, a further great improvement in the price of wheat.

1916. On what grounds do you form that opinion?-On these grounds: the years 1832, 1833 and 1834, but especially 1834, gare from natural causes an unusual superabundance; 1835 was merely an arerage crop, and hence the accumulation of stock, resulting from 1834 particularly, is now in the course of being consumed, as the crop of last year was not a crop of supply; an average crop, according to my mode of computing, would not suffice for the consumption of the country; hence the load which pressed on the previous year is now in the course of diminution; the price is already manifesting that; since the commencement of the year, it has risen $10 s .6 d$. a quarter for wheat. I am of opinion, that in the years 1832 and 1833 , crops were upon a large scale of cultivation, 
because oats and barley harl not paid as well as wheat had in previous years; cattle likewise had not paid as well; that there was a concentration of inducement to prefer the cultivation of wheat.

1917. What year was that?-I should say for the crops of 1832,1833 , and, in a lessening proportion, for 1834 ; but that in 1832 and 1833 , there was an extent of cultivation for wheat, not merely from the importation of oats from Ireland, as has been suggested, but from the circumstance that wheat had previously paid better than all those things I have enumerated, and that there was a decided tendency to cultivate wheat in preference to every thing else. Concurrently with this preferrence, there came a very extraordinary season in 1834 that gave the largest produce in the wheat-growing crops of England. Those accumulations brought down the price of wheat to the lowest point known in the history of agriculture almost; I do not know whether we ever had it so low ; that was at the close of last year, when it was down to $36 \mathrm{~s}$. a quarter. Now, wheat last year paid worse than any other agricultural produce; and if one course will produce an increase of wheat, the opposite course will produce a decrease. I am under an impression that last year the cultivation of wheat was on the wane. A less quantity was sown for the crop of $\mathbf{1 8 3 5}$ than for 1834, and I am under the rather strong impression that there is now, for the present crop, a less quantity of wheat sown than for any year for the last 40 years.

1918. Do you derive that information from what was given you; from your traveller? -No, that is impossible ; the survey was made last year; I have been engaged in making inquiries on this subject; it is now almost a common opinion, that there is a less quantity of wheat sown than there has been for very many years; but I was very desirous of establishing this by fact, not leaving a subject of such importance to mere matter of inference; and I had set on foot some inquiry, but it is rather early in counties where they sow spring wheat to get a document of that kind complete; and at the distance of four or five weeks, a very complete return, I think, might be obtained. It is very much to be regretted that the country should be left in uncertainty on a statistical question of such deep practical importance; if it should be found to be interesting and important, and your Lordships took it up in that light, your Lordships might have the return made from some of the great estates, from different parts of the kingdom, and from your land agents and stewards; this would leave it no longer a matter of question, but of fact, and which, according to my view, would do more than all the discussions that can be had on the subject, to give the relief you are now seeking. There is a common feeling in the country, that there is a small quantity of wheat sown; I have no doubt the facts will completely bear it out ; and it may be there is a fifth, a third, or a fourth (there are various opinions on that subject); but if facts were before your Lordships' Committee to establish that point, and you were to promulgate it to the country as from your Lordships' Agricultural Committee, I have not the least hesitation in saying it would raise the price of wheat $20 \mathrm{~s}$. a quarter; it seems a bold assertion, but we are now at this present moment nearly $20 \mathrm{~s}$. below the average price of the last 20 years; if we could show (and no doubt it could be shown) that we are about to resume our average position, there is no reason why we should not resume our average prices; the manufacturing districts of England at present are in a high state of prosperity ; they were never known to be equally so; there is a great superabundance of capital, as your Lordships perceive from the various railroads and other schemes afloat in every part of the empire; and there is a great inclination to invest capital in wheat at the present time, from the knowledge that the price is so extremely low ; and all that can be calculated upon for the ensuing crop, as regards the season, would be an average; more cannot be calculated on. If you have an average season with a diminished cultivation, to such an extent as I believe in, you cannot look forward to another year passing without realizing considerably above an average price, for I apprehend we shall not be in an average position.

1919. What do you call average prices?-Fifty-nine shillings a quarter.

1920. You take the average upon 20 years? - In the return to Parliament, the average of England, from 1820 to I 833 , is $59 s$.

1921 . What is the average price of wheat in Ireland, how much a quarter, to sell in the markets of Ireland!--I should think it will be just the difference of transportation.

1922. Do you mean to say, that wheat sells in the market of Dublin for any thing like the price it sells for in the market of London?-In proportion to the 464 . quality

\section{Hodgson, Esq.}

4 March $183^{6 .}$ 
D. Hodgson, Esq. quality, just the difference of transportation; not indeed the difference, for snch quality of wheat cannot be brought to London to be sold ; it finds other markets nearer, to which it is more suited; the only difference between any part of Ireland and England must be the expense of transportation.

1923. What was the price of wheat in Waterford market the year before last? -I do not remember.

1924. Was it more than $35 s$. a quarter?-I cannot recollect.

1025. Can you take on you to say the price of wheat in Waterford market the year before last was more than $35 \mathrm{~s}$.? - I do not remember the price.

1026. What was its price here at that time?-I cannot recollect actual prices, but I will take upon me to say that there can be no price in Waterford market differing from the price in London, quality considered, more than the difference in transport. The common interest of buyer and seller would not allow the price to be very much lower there than in London.

1927. If there was any rery great difference in the price berond the expense of transport would you not conclude that there must be a difference in the quality? - Unquestionably.

1928 . You state, you ground the present low price of wheat on the very superabundant harvest we had in 1834 ? - Y Yes.

1929. You also think the probability of wheat rising in price arises from the diminution in the growth of wheat?-Yes; and to the probability that the superabundance yielded by the seasons will not continue.

1930. Suppose the next season should be as abundant a harvest as me had in 1834 , and suppose an inquiry instituted, and it were proved, instead of your opinion being correct as to a less quantity of land being sown with wheat, a very considerable increase in quantity has taken place, especially in Lincolnshire, with the superabundant harvest, if we have one, what would then be the state of the agricultural interest? - Prices would be very low.

1931. Are you of opinion that at the present moment among agriculturists who have got capitals, they have more wheat in hand than they have had for some years? - I think they probably have. I believe a more than usual proportion of stock is in the hands of the agriculturist, not of the merchant; and if you could raise the price $20 s$. a quarter in four or fire or six reeks, as the legitimate consequence of the facts you might be possessed of, you would confer a very large proportion of benefit on the agricultural interest, perhaps $4,000,000 \mathrm{l}$. or $5,000,000 \mathrm{l}$. at once.

1932. You think the crop of wheat last year remains in the hands of the great body of the agriculturists, not in the hands of those who have capital ? - I think there must be a very considerable stock of wheat remaining in the country. I believe it is not in the hands of the merchants; what class of farmer may hold it I am not able to say.

1933. When you send your travellers round to ascertain the state of the crops once a year, prior to harvest, do not you desire them at the same time to make you returns of whether the stack-yards are well or ill stocked with old corn; is not that an important part of your calculation as to the probabilities of future prices? - No, it is not; we do desire it, and obtain it; but it has generally appeared to me to be so uncertain, I have not wished to take away their attention from considering themselves as machines. There is no estimate on the part of the men whom we send round; they go with a measuring machine, and give the result of the dimensions accurately taken. I am afraid of giving them much discretionary power, showing them that I should rely much on what they gave as matter of opinion. I should be afraid of diverting their attention.

1934. What do you mean by a measuring machine?-We have a regular mode of examining all fields in different districts.

1935. Do you mean they have any machine by which to measure if it is a good, middling, or bad crop?-Yes.

1936. What sort of a machine is it ?-It is a very simple machine.

1937. He does use a machine?-Yes.

1938. How can he go into different fields?-He possibly commits a trespass. He decides to examine, we will say, alternate fields, and takes them as he proceeds, without consulting any judgment at all, merely going into every alternate field; or when starting in the morning resolves to take every thirl field, or every second; and whether large or small, whether clay or gravel, makes no subsequent 
selection; so that out of 40 stages in the course of the survey I form the average result.

1939. Might not different portions of the same field show very different results from the application of this machine? - No doubt, and there is no possibility of reducing any plan of the kind to certainty, but in a matter of uncertainty it is the least objectionable of any with which I am acquainted.

1040. Does he judge with his eye about what is the average portion of the fields, and then apply lis machine to measure that average portion, and thence draw his conclusions? - On entering a field he looks at it, goes to a particular part of it, according to the size of it, and goes to a particular part of the ridge, takes his dimensions and does not use any judgment beyond that; and by that means arrives at as fair a result as can be expected from the process.

1941. Does he ascertain the quantity?-Yes; suppose a square yard, he ascertains what it contains, and this may be done through 1,000 fields.

1942. Then his judgment might be according to the bulk of straw, he cannot tcll if it is well eared? - No; he makes up a given-number of ears, taken indiscriminately, and sends them down to me, and 1 have them threshed.

1943. He takes a given surface, and cuts off the ear, and sends them to you? -Yes.

1944. Does he pay no attention to the quantity grown, whether it is more or less than another year? - The survey is very incomplete, in consequence of that deficiency, but it would take too much time and expense. I recommended it to Mr. Huskisson, and he was very much disposed to do it; and it is very much to be regretted that there is so little certain information on a subject of such deep practical importance. If your Lordships saw it in the light I do,-I have been attending to it for 20 years, - and if you saw the importance of it in the way $I$ do, I think Government might have an anmual statement that would be of the utmost practical importance. If the parishes throughout the kingdom were required by the overseers to make a return of all the land and its occupation in each parish, and the result be published in the Gazette every June, your Lordships would know, the farmer would know, the merchant would know, the extent of land under crop and grass, and the question be one of acreable produce.

194.5. You say that your messenger you send about makes no inquiry as to the stock remaining in the farmers' liands? - I did not mean to say he made no inquiry, but it is not charged on him as part of his duty ; I think he has enough to do in what he is required to perform. I am rather afraid of his opinions; my object is facts; and if I exalted his opinion too much I should fear to divert his attention from his duty, which is more mechanical than the exercise of judgment.

1946 . The fact of the quantity remaining in the hands of the farmer, as well as that in the stack, must be a matter of importance to enable the person to judge what would be the probable price next year; should it not?-Y Yes; but I think you come best at that information by knowing what the produce was; for you are not to suppose the consumption to vary materially. I wish to ascertain that by a particular figure which gives me the crop and consumption, and if I find it much below or above, I draw my inference of what will be the stock. If I had the means of accurately knowing what was the stock, it would be better than those figures; but I consider the figure to offer me a better datum on which to proceed than gencral notion derived from servants or general inquiry. In the line of road you might find a good many ricks in one place, and a few in the other; it would be a very operose and uncertain business.

1947. At the time of the year when your man goes round, what is your opinion as to the comparison of the actual quantity then remaining in the farmers' hands, and the actual quantity in the warchouses? - I do not think $I$ have endeavoured to settle that.

1948 . What is the impression on your mind as to where the largest quantity is likely to be found of these two? - I have never endeavoured to make that out.

1949. You cannot form any opinion as to that question? - No.

19.5. You were saying, some time ago, you thought the situation of the farmers was not distressed, taking into consideration the circumstances of the times, without reference to their condition? - I meant to say, that in agricultural 464. 
D. Hodgson, Esq. produce generally, with the exception of the price of wheat, which I have shown to be much below the arerage of the last 20 years, there is not that variation in other produce that will not retain (as compared with all other commodities) the exchangeable value it possessed 40 years ago; therefore I do not see why the farmer is in a worse condition. It is not a question of mere money, but what all the other necessaries he has to deal in can be had for ; the change of currency in 1819 brought down the price of every thing, but it has preserved this juxta-position.

1951. Is that the case as to articles most in demand by farmers, such as leather and iron and woollen articles ?-Leather is perhaps an exception ; and I think there may be a reason given why that should be an exception; the increase of luxury and wealth may greatly extend its use.

1952. All these articles are required by the farmers to carry on their concerns ; can you say there has been any considerable diminution in the price of those articles?-A great diminution.

1953. Do you state that from information, or as a general impression on your mind ?-I think, as to the means of subsistence, as conspicuous in the conveniences of living, we see in every direction better clothing and better appearance, and a better condition of the country, go where we will.

1954. What do you say as to iron; do you consider it is more or less in demand than formerly?- Until the rise occasioned by the sudden demand for railroads it was never so low; iron now is worth $10 l$. or $12 l$. a ton, which, if my recollection be correct, was worth only $5 l$. about 18 months ago.

1955. Have you particular information to enable you to come to the conclusion, except those general reasonings, that the farmers do pay less for the implements of husbandry than other matters necessary for carrying on their business, such as are retailed to them ?-I have no doubt they must; I cannot say why it should be different with them from any other class.

1956. As to wages, do you suppose the farmers are better off as to wages and poor-rates than they used to be?-As to poor-rates, I am not at home, also as to wages; but they probably have not fallen in proportion to other things.

1957. You were speaking of the quantify of spring wheat that you thought was likely to come into the market; have you any knowledge at all as to the quantity of spring wheat usually sown?-No, I hare not.

1958. Have you any reason to believe that it is sown to any considerable extent?-I do not know the proportion; and perhaps some reason why this year the extent may more depend on the price of wheat, is, that the turnip crop was a failure last year, and also the sowing season was unfavourable, it was very wet. It is possible land may yet be unappropriated, and be sown either with wheat or other grain, according to the state of the prices.

1959. What is the impression on your mind as to the result that probably would follow by the substitution of spring wheat for autumn wheat, as to the quantity, or as to the price?-I have no opinion at all about it.

1960. Have you a knowledge as to whether the produce of the spring or autumn wheat is larger?-By the acre? I suppose that depends very much on the season.

1961. Supposing land is in a proper state to sow autumn wheat and spring wheat? - I am not sufficiently conversant with the subject.

1962. Your impression is, that the general practice being to sow it in the autumn, it produces a more productive crop than sown in the spring ?-Yes.

1963. Do you know any parts of the country where they are in the practice of cultivating any extensive quantity of wheat by spring sowing?-I am not able to answer that question; I have an impression that it is considerably cultivated in some parts of the kingdom, in the north of England; but I would really rather not speak as to facts of that kind, for a knowledge of them is very much out of my province. I alluded at all to spring-sown wheat on the ground that I wanted to have information; and, as to the extent of this year's crop, I deferred applying for it until, the period for sowing being passed, I might have a more accurate return.

1964. You have taken your calculation of the remunerating price for farmers, beginning in 1820 ; is that a fair series of years to enable you to come to that conclusion? - I see no reason why it should not; I have no reason to suppose it otherwise. 
196.5. You think, taking a series of years from 1820 to 1836 , on the whole you regard that as a fair criterion as to the years that have produced a remunerating price for tenants ?-I think so.

1966. You have said you thought the condition of the people better in general than it was?-Yes, I think so.

1967. Do you apply that observation to the farmers? - I should say, in passing through the country at large, in every direction, the manifestation of greater comfort is visible; I think the olservation forced on every hand.

1968. You think the condition of the farmers is better?-Yes; I see no exception.

1969. Do you not know in the neighbourhood of Liverpool, where you live, that a great number of farmers have broken up lately?-I think there has been a very considerable change of farmers, not a great many broken up. I think there was a great deal of distress, arising from the change in the value of money, and as a consequence of that change a great many farmers were broken up ; and I think there is a great deal of distress, not with the tenant, but with the landowner, and that the tenant is now very frequently availing himself of that circumstance with his landlord, and the distress that did prevail, to make advantageous bargains for himself.

1970. Are there not several gone out of business lately in your neighbourhood? - Out of the farming business?

1971. Yes; and have been obliged to give up their farms?-There may; I did not know it; I am not aware of a farm without a tenant.

1972. You have said you think their condition good; in order to ascertain what their condition is, it is fit to inquire what is the price of the different articles they have to purchase?-Yes.

1973. Do you know the price at which the various implements of husbandry are sold to the farmers?-No, I do not.

1974. Do you not know that the price of the implements of husbandry, their shoes, their clothes, and every thing, is the same as in the time of the highest prices ?-No; I should think not.

1975. Do you know it? - I know clothing is not, for I can buy it cheaper for myself, and I cannot see why a farmer cannot. As to the implements of husbandry, I do not know; I have not had occasion to buy them.

1976. Are the Committee to understand you to say the condition of the farmers is good?-I can only speak generally on that subject; I am not aware of clistress.

1977. You have spoken of your information on other subjects; is the information you have collected round the country, that the condition of the farmers is good, or otherwise? - I should say, with the exception of the depression in the price of wheat, for which he has been partly compensated by quantity, I cannot see why he should suffer by distress.

1978 . What is the fact; what have you heard in the country as to the condition of the farmers? - I have heard a good deal said about the distress of farmers; every one who reads must notice that; my observation has not coincided with the statement; I am not persuaded of it; but at the same time I have not been searching to establish that fact ; it is no part of my employment. 1979. You attend more to the state of towns than the country?-Yes; I take a general interest in the question.

1980 . Your business is that of dealing in corn in the town of Liverpool?Yes, generally, and other things.

1981. You have no practical information as to the state and condition of the country; your habits do not lead you particularly to examine into the condition of the farmers in the country? - I am a small land-owner myself, and always have been; I know a little of it; but I do not wish to be giving an opinion on a subject so foreign to me.

1982. To return to your own particular business; what advance has taken place in the market of Liverpool in the price of wheat since the rise?-About $10 s .6 d$. a quarter.

1983. From what price to what price?-The price in Liverpool was about $35 s$., and now the same quality of wheat would bring $45 s .6 \mathrm{~d}$.

1984. So that there has been an advance of from $35 s$. to $45 s .6 \mathrm{~d}$. ?-Yes.

1985. There has been an advance in the market at Liverpool from the lowest price, which you think to lave been as low as $35 s$, up to $45 s .6 d$.? - Yes.

464.

03

1986. When

D. IIsdgson, Erq.

4 March 1836 . 
D. Hodgson, Esq. $\quad$ 1986. When you say $35 s$. was the lowest price, was that the price of good corn; was it ever so low as that for good wheat?-Yes, good Irish; not the finest quality of wheat, such as is used in London, but good useable wheat, such as excellent houschold bread could be made from.

1957. How do you rate good Irish wheat as English?-Five shillings to $6 s$. per quarter inferior.

10\$S. How would you rate good English wheat as compared with good Dantzic wheat?-Good English and good Dantzic wheat are very nearly on a par; perliaps Dantzic is rather superior.

1980 . The considerab! adrance which has taken place in the market, do you ascribe it, as a dealer, to the short supply, or to an increased disposition to speculate on the article?--It is from a conviction that the supply is not likely to be so large; and the purchasers are both those who are buying as suppliers of the immediate consumption, and other purchasers for investment on speculation of a rise.

1990. Do you think there is more disposition to purchase on speculation?Yes, and to hold grain generally; not only in those clisposed to buy, but in those who have it to sell, from the conviction with the holder that he has less to sell, and the other of less stock to purchase from; and that the time approaches when there will be some corresponding inprovement.

1991. You suppose that the disposition to speculate arises in a considerable degree from the opinion you have before given, that the quantity grown or growing for the present year is very much diminished as compared with the production of antecedent years? - I think that a contingency which may enter into the account; but the very low prices and the circumstance I have mentioned enter more into the calculation than the contingency of the diminished growth, for I think there is not yet (though there is a common opinion) a sufficient basis of fact on which to establish it; it was therefore I mentioned, that if the facts obtained-obtained by the great land-owners of your Lordships' House-should they bear out what I state, would give the relief, the only relief, that can be given by Government or any power whatever; for it is clear nothing can be done as to foreign grain, for you have had none admitted since 1831 ; the agriculturist has had the whole market to himself.

1992. As the rise has taken place, has it brought any great quantity of corn to the market, has it induced the growers to bring largely to the market ? - They are supplying the market fairly, not indicating any particular satisfaction with the advance, nor yet holding it back as if afraid to meet the demand. I think the market is just in that situation as to wheat that it either may go, without any other stimulus than what is on it, a few shillings higher, or it may recede a few shillings; but if there was a conviction convered to the country that the common opinion was a right one, of less being sown for the crop of the present year, with the probabilities that there will be no more than an average yield, the price of wheat would rise very considerably, probably nearly equal to $20 \mathrm{~s}$. a quarter.

1993. Has the Irish wheat since the rise been pressing into the market?-No, rather otherwise.

1994. Will Irish wheat for speculators keep as well as our own corn?--Not so well.

1995. Can you, as a dealer in corn, say how long you reckon that whent well harvested can lieep without deterioration?--It suffers deterioration, however well harrested, from keeping, unless kept in the straw, where I should think it would not deteriorate; it would lose in quantity, but not much in quality ; there is a freshness in new grain which is lost in old, but it will retain its valuable property for making sound bread indefinitely; I have some now by me, which I have kept in sacks or small bags, average samples of England, for the last 14 or 15 jears, perhaps 20 years, and I do not think there is any material change; I am quite satisfied if you could keep wheat in bags, so as to exclude the atmosphere from it, you might keep it a century.

1996. Is it not the usual mode of keeping wheat, for the purpose of keeping it in order, to turn it over and expose it to the air generally?-Yes, it is the general practice; the grand desideratum must be to have your wheat in a very fine condition when you place it in store, and then you must not admit the air partially; if you admit the air partially you will be obliged to turn it in the 
way alluded to; if you could exclude the air wholly, it will be better so to keep it.

1997. In the course of your experience as a merchant at Liverpool, have you any reason to suppose; you have probably heard the suspicions that foreign corn was fraudulently imported; have you any reason to believe that there is any truth in that? -I think it is impossible, quite impossible ; first, I cannot understand what the inducement to a person could be to attempt the illegal importation of an article that would yield him so little profit, and expose him to so great a risk : if willing to forfeit his principle, he contrives to do it by concealment, so as to escape the chance of a detection, and make a great profit. I cannot see what can be the inducement to smuggle corn.

1998. Having no inducement to smuggle at the prices which have lately existed, would there not be a great inducement to him to smuggle, in the average prices of the last eight or ten years?--None whatever; if the price is high he will get it in at a small duty; there is no inducement to smuggle where there is no duty.

1999. Is there not always a great difference, or lias there not been, between the price of the foreign corn not admitted for consumption and English grain admitted for consumption?-Certainly.

2000. Is there not sufficient difference, supposing it practicable to do so, for persons fraudulently to import the one for the other?-I think the freight and the charges, and the lumber of so bulky an article, the number of persons who must be privy to the fraud, renders it impossible; it must be an importation made for the express purpose of smuggling; we know a ressel cannot go into a creek and discharge corn without its being known throughout the country; the people too who would see it landed would have the greatest interest in opposing it ; that is, the farmers.

$20(11$. It would not in your opinion, from your experience as a merchant, be practicable for a vessel to clear out partially loaded with corn from Ireland, and to take in the complement of her cargo at sea from a vessel from a foreign port, and bring it to Liverpool as Irish corn?-She could not; the Irish wheat is so easily discovered; I should know it as well as I know oats from wheat. If foreign corn was introduced, any man who knows the quality of grain would say at once, "This is foreign corn."

2002. You think you could discover it immediately? - Yes.

2003. You feel convinced no such practice exists?-Yes, I hold it to be impracticable. I do not mean to say it is a thing impossible ; some person might be fool-hardy enough to make the attempt; but to speak of it as a system, involving any national consequences, is perfectly out of the question.

2004. Are you aware that it was proved last year foreign corn was imported from the Isle of Man to Liverpool in that manner?-I am not sure that it was imported; I think it is not very improbable that it was; but the situation is somewhat different as to Manx and foreign corn. From the extraordinary position in which the Isle of Man was as to the corn laws, foreign wheat had for years been sown there; therefore the wheat of the island assimilated a good deal to foreign, in consequence.

2005. That has now been put an end to :-Yes, it has.

2006. You, the purchaser at Liverpool, would immediately detect the mixture of Irish from foreign corn if it was tendered to you to purchase?-Yes. It would not do to mix it for concealment; you cannot make a mixture of two opposite qualities of corn without its being inanifest.

$200 \%$. But supposing the purchaser at Liverpool to be combined with the seller from Ireland, in what manner is that to be detected:-But the purchaser at Liverpool must sell it again.

2008. But if he tenders it for sale in the market, and says, "It is mixed wheat, I mixed it ?"--If he comes to me, and says, "I want to sell you a given quantity of mixed wheat," and he says, "It is Irish ;" I should say, "It is not; where does this come from?" "Why, from Waterford;" then I should say, "There is a mixture of foreign whent."

200y. That is, if you are inclined to inform; but if you, being a miller, choose to buy that mixed wheat, and get $25 s$. a quarter by the bargain, which you may, a fraudulent purchaser or a miller might casily put it into his mill, and pocket the difference? - I think practically it could not be managed.

2010 . Could rou detect it when it in the shape of flour:-No. 464. 
D. Hudgson, Esq.

4 March $183^{6}$.

2011. Then if the miller purchases from the mixing importer, and grinds it in his mill, there is 110 possible means, as it is to be collected from you, of detection?-But we must first ascertain how he would get possession of it ; if it is to be taken from Waterford some one would know it was there; the people there are as anxious as any class of persons to prevent that which will injure the sale of their own produce; and you must find some point through which you can introduce the wheat without detection, which I take to be impossible.

2012. Why would it be impossible to do it in the way mentioned, of meeting a ship at sea, a vessel coming out from Waterford, and you may suppose it took only half a cargo, and met a vessel coming from Guernsey or a part of France, and transferred that wheat, and came into port?-Supposing a vessel leaves Waterford with half a cargo; there would be a letter from Waterford by the day she clears out, saying, "There is a remarkable circumstance of a vessel having left this port where there is plenty of wheat, and sailed with half a cargo ; watch her when she comes to Liverpool." It is quite impossible.

2013. You think they would denounce it?--Yes.

2014. Who would?-The merchants; everybody ; the collector of Waterford; the clearing out would attract attention.

2015. Do you mean the Government officer, or some person of his own free will? - It would appear so extraordinary to take part of a cargo.

2016 . It would be to the interest of the merchants to detect it :-It would not be to the interest of the rogue who engaged in it, but of every merchant. Suppose I wanted to sell to a miller, and that I was in treaty to sell him a quantity of wheat, of which I was in possession in a legitimate way, and that I find him supplied by another, who got it in an improper way, it can be no part of my interest to allow such a one to supplant me.

2017. Can you get a search warrant to search his mill :-They cannot get it to the mill without the agency of many hands.

2018 . With an organization of the kind, is it not possible at a higher price of wheat, and therefore at the greater profit, to induce a person to incur that risk, if it could be done?-I will not say that one of the deepest laid schemes you can imagine, might not by possibility accomplish the introduction of a cargo of wheat. I will not say it is impossible, but it is perfectly impossible, if applied to any national object, or to any question that would really affect the marketable value of property.

2019. Do you mean to say, all foreign wheat is of such a particular quality that it can always be detected from Irish, or any other wheat but itself? - Y es; foreign wheat is of a character by which you can designate the country where it is produced from.

2020. Has the quality of English wheat improved of late years?-I should say it had rather improved, but much depends on the seasons; it is difficult to judge; except as through a series of years; there is such an effect on quality by season, it is not very easy to speak with regard to the fact; I think it lias probably improved, but not in a very marked manner.

2021. The Dantzic has not deteriorated?-No ; I fancy there is a finer wheat in Dantzic now than they ever had, but that is not attributable to the improved cultivation, but to season; they have had fine seasons, and a superior quality of wheat is the consequence.

2022. You said the Dantzic and English best wheat are of an equal quality?Not the same in appearance, but of equal value; you can know one from the other with perfect ease.

2023. Was that always held to be the case within the last 20 years? - I think they have kept a juxta-position very nearly; the Dantzic wheat was sometimes better, sometimes not.

2024. You said that the recent rise in the price of wheat was a great deal owing to a greater disposition to speculate? - I think it is, in part.

2025. Has there not been an extraordinary consumption of wheat for farming purposes this year, to which it never was applied before, namely, to the feeding of cattle of all descriptions :-Yes; it has been cheaper than oats.

2026. And also from the want of turnips?-Yes, I believe that was the case; the latter part of last year there was an unusual consumption of wheat as a substitute for other things.

202\%. That application of wheat to different purposes arose, in a great measure, from the low price of wheat itself?-Yes, no doubt. 
2028. Do you know any thing about Talavera wheat? - Not any thing that I would venture to give an opinion on.

2029. Not so as to compare it with any thing in the country?-No; I do not know it.

2030. Is there much American wheat introduced from the United States? None ; it is prohibited by duty ; in short, the price in America is higher than in England.

2031. Has there been any wheat exported last season to the United States? Yes; not English whent, but wheat out of bond, remaining in bond here; American wheat returned, the old States' wheat, remaining ever since the years 1830 , 1831 , and 1832 .

2032. What is the description of English wheat that is most common in Jiverpool market? -The Irish is in most general use.

2033. What is the description of the English? - There is not much; the great supply is from Ireland, and occasionally from Norfolk and other counties.

2034. Have you hardly ever any white wheat in the Liverpool market?-White wheat is more used in London; red wheat is the general character of that used in Liverpool; it is preferred there.

2035. You speak of wheat that has been here since 1830 and 1831 ? - I should say it came here just after the periods the ports closed-in 1831 .

2036. Suppose it had been here from 1831 and 1832 , and you had held it as a dealer, slould you consider that now, in 1836 , it very much deteriorated in value from keeping, supposing it had been well kept and well taken care of :- It would be deteriorated in value; but it rather depends on circumstances ; it depends on the quality of the wheat at home; if you have very fresh sound dry wheat for the season, it would not bring the same value as if your own was what is called tender, not got in a good season, so that it would make good bread; the admixture of the old wheat, when much used, gives it a value quite as much, though kept that time, as if it were new wheat.

2037. So that, under the latter circunstances, though it were six years old, it would sell for as good a price as if it were the wheat of this year? - Under given circumstances it would, and under other circumstances perhaps $3 s$. or $4 s$. more or less, according to the way in which it is kept.

$20.3 \mathrm{~S}$. Would the price in the Liverpool market be likely to produce a large quantity from the United States? - The United States of America never export any considerable quantity of wheat; it is exported, but it is only when prices are high. The export is generally confined to flour.

2039. At what price could you introduce a large quantity of American flour? -I should think $80 s$. a quarter would give occasion for a supply.

2040. Has there been a large quantity of supply of American flour since the price lias been lower than $80 \mathrm{~s}$. ?-I think not; no American flour can come for home consumption, except on payment of a duty. Until the price shall get up to be very near $70 \mathrm{~s}$. there would be no chance of American flour coming at all, for the average price of American wheat is higher than in the Baltic ; therefore any small quantity we should want at a comparatively low price, would be supplied from the Baltic, not from America; the Baltic would have the first preference, and we could derive supply of American when the prices have taken a higher range.

2041. You mean the Liverpool merchants would apply to the Baltic before they applied to America?-Yes, for a moderate quantity would be obtained cheaper from the Baltic, therefore they would not have recourse to America.

2042. But if the prices were such as to make it worth while for the Americans to import it, though that might be the practice of the Liverpool merchants, still the Americans would import it if it answered their purpose?-Yes.

2043. But you think there would be no chance of importing it to any extent, unless the price were at $70 \mathrm{~s}$. a quarter?-No, not to any extent, nationally speaking, important.

2044. Is there not a good deal comes in from Canada to America?-I think it probable that some does, but the whole exports from Canada show that the extent cannot be very great. I thing the largest export made from Canada was 120,000 quarters in the year.

2045. Have you not the means of knowing that a considerable part of that comes from the United States?-I lave not the means of knowing, but I suspect some of it does.

464 . 
2046. There is nothing to prevent a person bringing it from the United States, and landing it at Canada, and bringing it thence?-No; a good quantity of wheat is bought at Liverpool to go out to Canada; I do not know that the Canadians have had flour from America. The Canadians this year have no wheat of their own to spare; wheat about to be sent to Quebee may have to come to Quebec and Montreal, and may have to cross the lines and be introduced to America; I have no doubt of it.

2047. Do you consicler that has prevailed to any extent, that surreptitiously wheat has been introduced to Canada? - I think, as a matter of inferenee, it may have been, but it is too grave a charge for me to make without faets, the whole quantity of flour that arrives from America is not to any very great extent.

2048 . It has not been so sincc what period? - For any period; it has perhaps nerer exceeded at any period a quantity equal to 300,000 to 400,000 quarters of wheat.

2049. What do you reckon is the annual produce of wheat in Great Britain? -I suppose the consumption.

20.50. No, the annual produce?-I can hardly say what it is.

20.51. How many parts of the field does this measurer you have been speaking of go to?-Only one.

20.52. Of 100 acres?-He only takes one; he goes to a given place in any field he may come to.

[The Witness is directed to vithdraw.

Charles Howard, Esq., is called in ; and Examined, as follows :

2053. WHERE do you live, Mr. Howard ? -At Melbourne, in the East Riding of Yorkshire.

2054. You are the receiver of an estate there ?-Yes.

2055. What is the size of the estate?-I am the manager of two estates in that neighbourhood; one of about 1,500 acres, another about 2,000 acres.

2056 . Do you attend to the management of them?-Yes.

2057 . You are the steward?-Yes.

2058. Whom do those estates belong to?-One to Mr. Wood, of Liverpool, the other to Colonel Hare.

2059. Have you made up any account of the produce of those estates lately? $-\mathrm{No}$, I have not.

2060. Has the produee of those estates increased or diminished lately?-On one it has much diminished.

2061. To how many years do you speak:- - The farming produce of the Sutton estate (Colonel Hare's estate) has been diminishing considerably for the last 12 year's.

2062. How long has the other been dininishing, or has it been diminishing? -I would wish to explain that; the other estate (Scoreby) has been more thrown into grass.

2063. Why was it?-Because it was not profitable to cultivate for corn; they could no longer be at the expense of the cultivation of grain.

2064. Was that in eonsequence of the diminished price of corn? - Yes.

2065 . How many acres were thrown out of eultivation? - I should think about 200 acres.

2066. Because it would not produce a remunerating price for the corn :- Yes. 2067. Do you apply that observation to corn generally, or to any particular description of eorn?--To corn generally.

2068. Were the seasons bad for any particular kind of corn? - Not latterly;

I think it was four years since; we had a succession of wet seasons, which were unfavourable to the production of corn.

2060 . That would be from 1828 to $1831 ?$-Yes.

2070 . When was it thrown out of cultivation?-It was reduced from cultivation in $1829,1 \times 30$ and 1831 .

2071. Two hundred ac'es out of how many?-One thousand three hundred.

$20 ; 2$. What is the state of the tenants on that estate?-The tenants are decidedly, poorer than they were; much poorer; but they have been greatly assisted by their landlords, both by improvements made on the estate and by the great reduetion of their rents.

2073. To what extent have their rents been reduced; how much per cent.? 
If you have no objection to state, low much per cent. on the whole?-About 30 per cent.; but 1 wish to explain, that the landlords, reducing at the same time the rents, incurred great expense in improving the drainage and in the purchase of manure, and in different ways, by fencing and every thing of that sort; the reduction would otherwise liave been something like 45 per cent.

2074. But they reduced 30 per cent. and improved the estates besides?-Yes.

2075. Can the tenants pay that reduced rent, with the adrantage of improvements?-No.

2076 . Do they complain, or pay up regularly :-They do not pay up regularly; and prior to last Michaelmas every tenant gave a notice to quit. I have been speaking latterly of Mr. Wood's estate, in the East Riding of Yorkshire; every tenant gave notice to quit.

2077. Were those men prudent men, generally speaking, or otherwise?Exceedingly prudent men.

2078 . Were they extravagant in any respect? - Not at all.

2070. Yet they could not cultivate those farms at the reduced rent?-No.

2080. Do you know the state of any other farms in your neighbourhood?-I would now revert to the Sutton estate, Colonel Hare's.

2081 . What state is that in with regard to the condition of the tenants?-May I be permitted to explain. I was asked a question whether I had the management of any estates. I named Colonel Hare's estate at Sutton. I believe it was named with the property; but I do not receive the rents. The management of the estate has only very recently been put in my hands. I occupied a considerable portion of the estate several years ago, therefore it has always been immediately under my eye.

20\$2. Has that estate improved or fallen back? - Fallen back very much.

$20 \$_{3}$. Have the rents been reduced upon that? - The rents have been reduced upon that, I believe, nearly 50 per cent.

2084. Can the tenants afford to pay even the reduced rent?-The rents, I believe, have been tolerably well paid, but the estate was in high condition, and it has been deteriorated and run out; the rents have been paid out of the landlord's capital, if I may use the expression.

208.5. Have they been over-cropping $;-Y$ Yes.

20\$6. Can they go on at that rate many years:- It has been going on for 10 year's past.

$208 \%$. Is the estate now in as good a condition as it was? - Not by a great deal.

2088. So that the landlord has in fact paid his own rent?-I should conceive so.

2089. What is the state of the tenants of the farmers around you in your neighbourhood?-The part of the East Riding in which I live may be termed poor land; the tenants generally are very much depressed. The estate of which I just now spoke as belonging to Colonel Hare, Sutton upon Derwent, is not poor, it is valuable land; but the country round is poor land; and the tenants are very much distressed.

2090. Have a great many been broken up?-A great number indeed.

2091. All round you - A great number all round me.

2092. Have the rents all round you been very inuch reduced :- Very much.

2093. Have those who have taken them at reduced rents been broken up?-

They have failed, tenant after tenant.

2094. What is the average produce of wheat, of Colonel Hare's land, per acre?

-I should state it at three quarters.

2095. Twenty-four bushels?-Yes.

2096. Is it a barley-growing land:-It is bean and oat-growing land more than a barley land.

209 - You have no objection to state what it was let for. per acre previous to the reduction?-The farm that I occupied was let directly for more than $40 \mathrm{~s}$. per acre, but indirectly for more than $50 \mathrm{~s}$. an acre.

$20 \mathrm{~g}$. You mean by indirectly including tithe?-No, it was free from tithe; but $I$, as tenant, stipulated in the outset to advance $2,000 \mathrm{l}$. for the improvement of the estate.

2099 . Then, if you are understood rightly, you were paying $50 \mathrm{~s}$. per acre for land which did not produced above 24 bushels of wheat?-I was. Allow me to explain; it was not good wheat land, it was not good barley land, but it was 464 . 
c. Howard, Esq. highly productive land; its great excellence was in keeping stock. On the average the seeds have liept eight ewes and eight lambs per acre; it was that 4 March 1836 . kind of land. It grew too much straw ; it was not productive in point of grain, of wheat.

2100. As it is not good wheat land, and produced mostly beans and so on, how do you account for the necessity of the great reduction that was made; why was that great reduction made in the rent, if it was chiefly that sort of produce? -Because when corn generally fell below the price at which the farmers could afford it, they began to crop their land more and more with corn, to make less fallows, to sow a less quantity of seeds, to reduce the condition of the soil.

2101 . How did that affect the property of which you are immediately speaking; how did it affect that property; why was it necessary to reduce the rents of that property which you state is not usually cropped with wheat, or, in short, with those articles of agricultural produce that have been so much deteriorated? -I have stated that the management of that estate has only just now been put in my hands. I was formerly a tenant of one-fourth part of the estate.

2102. Are the farms large?-Rather large farms, I should fancy; they were about $300 l$. a year.

2103. What proportion of pasture is there to them?-There is now a very small proportion of pasture; the pastures have been progressively ploughed up and cropped.

2104. Do you consider that a good managing of property to let them do so ?-No.

2105. Then why do you do it?-I said the estate was not in my hands. When I gave up farming a fourth of the estate I left a large quantity of land in pasture ; it never was my practice; I consider it bad management.

2106 . What is the course of cropping upon the ploughed land?-Wheat and oats, often wheat again, and sometimes beans.

2107. Then do you begin with wheat?-Yes.

2108 . Is it surprising that land cropped in that manner, unless a very rich quality indeed, should be exbausted ?-It is not.

2109 . In short though, these are farms that have been very ill used?-They have, in consequence of the poverty of the tenants.

2110. Has not that a little been owing to the fact that the tenants have been paying rents which they have been obliged to rack the land, for the purpose of paying? - The rents have been reduced at rather an early period.

2111. In what year?-The first reduction that took place on that estate was in 1816.

2112. What was the year in which it was let for $40 \mathrm{~s}$. an acre?-Eighteen hundred and nine.

2113. You state $40 s$ which you as a tenant were to pay, to make a great outlay, which you considered as equivalent to $50 s$.? - Fully.

2114 . Having taken that in 1809 at that rent, when was the reduction made; the first reduction?-One thousand eight hundred and sixteen.

2115. How much was then reduced?-I must speak. from memory, but I think 10 per cent.

2116 . When was the second reduction made?-I believe in 1822 or 1823 .

2117. Do you recollect what the reduction was then?-I fancy that was a reduction of full 20 per cent.

2118 . Upon the remaining rent?-Yes.

2119. When was the last reduction?--Reductions have since been made, year after year; the last reduction was in 1832 .

2120 . Were the intermediate rents pretty well paid ?-I think they have been pretty well paid.

2121. Do you consider the lands as very much deteriorated in quality from what they were 10 years ago ?-Very much deteriorated.

2122. And now all the tenants on one of those estates have given notice to quit ? - I beg pardon; I wish to make a clear division of estates; the latter estate on which we are now calculating has been very much deteriorated, not the former one, of which I spoke.

2123. But the one which has been so much deteriorated; it is on that the tenants have now given notice to quit?-No; it is on the other, in the former one, which has not been deteriorated.

2124. It has not been deteriorated?-It has not. 
2125. Is that the same description of soil ?-It is an inferior soil, and more variable.

2126 . Is it an inferior soil of the same description, fit for the cultivation of wheat and beans?-It is rather lighter land; I should not say for the cultivation of beans generally.

2127. Pray can you tell if the country bankers are now ready to advance money to farmers? - I think that country bankers would advance money as readily to farmers as to any set of men, if they could have any security ; but they will not do as they used to do, they will not advance money without a security.

2128. Why is that; why will not they do now as they did formerly?-They have not so much confidence in farmers; they were formerly making money; and if they were persons of tolerable prudence, they would advance on their personal security ; that is, they would allow them to overdraw accounts.

2129. It is now because they suppose they have got poorer?-Yes.

2130. Have they, or have they not, in your opinion, paid their rents out of capital? - Certainly; the rents have been paid out of capital for many years.

2131. Of course that must have diminished their capital and their credit with the bankers? - Of course.

2132. What is the condition of the poor?-I do not think the poor are in a worse state; I think the situation of the poor has been rather improved latterly.

2133. Are there many out of employ?-Not many.

2134. How are they employed?-Great numbers have emigrated from the East Riding of Yorkshire to America.

2135. Has that increased the market price of labour?--Yes, it has.

2136 . Are there any other causes for their being employed?-The young men who have found a difficulty in obtaining agricultural employ have left the country and gone to the manufacturing districts.

2137. Have any of those been returned upon you?--Not many.

2138 . Some have?-Yes; but not to any serious extent.

2139. How are the rates; have they increased or diminished?-The rates during the last 10 years have rather diminished, and a good deal the last year.

2140. To what extent?-I do not know whether I shall go too much into detail.

2141. How many shillings in the pound?-I should state, that if land is let for $20 \mathrm{~s}$. an acre, the rate in the East Riding is seldom more than $15 \mathrm{~s}$. an acre, and then the rates that were about $1 s$. in the pound, as we term it, prior to 1800 , had got up to about $3 s$.; now they are fallen generally about $6 d$. or $9 d$. in the pound.

2142. Which are they now at?-The average, I am much inclined to think, would be $2 s .6 d$.

2143. On a three-fourth rating?-Yes.

2144. Has the new Poor Law been put in execution with you at all?-It has operated without being put in execution; it has operated by the understanding generally, that if a man applied for relief, he would only have a sum of money lent to him, and it must be returned again to the overseers when work could be obtained; that has checked the application to the overseer.

2145 . Is it thought to work well, on the whole, in your part of the country? -Extremely well ; it is popular, with the exception of one clause.

2146. Which clause is that?-The bastardy; that is thought to incur great expense to the parishes.

2147 . Otherwise it is very popular?-Yes.

2148 . With the labourer as well as with the farmer?-I think it is very popular with the more respectable labourer.

2149. You say that clause is supposed to be expensive to the parishes; do you speak of its having been so, or is it your impression that it will be so?-It has been so ; it is actually found so.

2150. It is more expensive to go to the sessions than to go before a single magistrate?-Yes.

2151. Do they employ counsel to go before the sessions?-Yes.

2152. What is the average rate of wages of an agricultural labourer on the estates you have mentioned at the present time?-What I should consider a yearly rate? I think a respectable labourer will obtain from $10 \mathrm{~s}$. to $12 \mathrm{~s}$. a week throughout the rear.

2153. Not more?-No.

464. 
C. Honard, Esq. 4 Mirch 1830 .

2154. You stated that on the estate which you first gave an account of, Mr. Wood's, that you had the management of, you considered the tenants, generally' speaking, prudent men, and they are now reduced to rery great distress; are you able to say whether the greater part of those men undertook their different occupations with sufficient capital to enable them to go on farming properly?-I know that they did.

2155. You staied in 1809 this land was let at $40 \mathrm{~s}$. an acre :-The Sutton estate was.

2150 . Do you recollect what was the price of wheat at that time?-I am afraid to state it.

2157. Probably abont $8 l$. a quarter?-Yes, or higher.

215 . And all other agricultural produce in proportion?-Yes.

2159. You said the labourer wonld earn l2s. a week; but what is the common price you give to a lahourer who comes, without task-work; would you at once give him $10 s$, or $12 s$. a week ?-Yes.

2160 . You are not speaking of your carter or shepherd, a superior man, but a common labourer?--Yes.

2161 . What were the wages that you gave to the same description of labourer 15 years ago ? - I have been in the habit of employing men by the week, and of paying the same sum through the year. I now pay $2 s$, a day to such men as I used to pay $3 s$. a day to.

2162. Iou have reduced it then?-Yes; I used to pay $18 \mathrm{~s}$. a week, generally, a little more or a little less, according to the value of the man.

2163 . Is it generally the case throughout that district that agricultural wages are reduced $1 s .3 d$. ?-I think it is.

$210_{4}$. Bearing that reduction in mind, do you think that the diminution of the cost, the diminution in the price of the common necessaries of life which a labourer has to procure, renders his position as good as it was when they earned 18s. a meek? - I think it is.

2165 . It is your opinion that the price of the common necessaries of life, or money value, is reduced one-third?-Fully that; more; but I wish to state that when I gave $18 s$. a week it was at the time corn was high, when it was ranging at something like $90 \mathrm{~s}$.

216ii. What do your labourers usually pay for their cottage rent? - In the East Riding there are very few cottages without gardens attached to them, larger or smaller; those rents are generally about $50 \mathrm{~s}$. a year, including the garden.

2167 . And generally a pretty good cottage garden?-Generally so.

2168. Now, has what is called the allotment sistem, the system of increasing their cottage gardens and giving them bits of land, prevailed at all with you?Upon the larger estates, and especially where there are resident landlords, that has been done to a considerable extent; it has not been done much except in cases where the landlords reside.

2160 . Could you state whether, in your opinion, the cottage labourer is in the habit of living nore from his garden prodice or less from wheat bread than formerly; do you think he feed himself less from wheaten bread and more from his garden produce than he used to do?- He certainly eats more regetables than he used to do, and of course less bread.

2170 . Should you think that had gone to any extent as to account for the greater diminution of wheat?-No, I cannot think that the quantity reduced is such as to affect the price of wheat.

$21 ;$. If that had heen pervading pretty generally throughout the lingdom, should you not think it might have influenced in diminishing the use of wheat bread?-Another circumstance would operate against that at the same time, and in an equal degree, that whenever corn or any article is cheap a much larger quantity is consumed.

2172 . And when you take into consideration the great increase of the population, do you suppose, on the whole, there is less consumption of corn? - I fancy the consumption of corn wheat (but I state it as a mere matter of opjinion) must be very much increased; much has been given to the farmers' cattle. Our labouring population has considerably decreased.

2173 . As to the cottage gardens, is a considerable quantity of produce, do you think, employed in feeding pigs? - A considerable quantity is employed in feeding pigs. 
2174. If the cottage lahourers eat less of bread, do you think they eat more of meat ? - I think they eat more of meat than they used to do.

2175. Then their habits of living are not worse than they used to be?--Certain!y not; I think they live better now than before, when corn was of a higher price, where they can obtain employ.

2176 . To what do you attribute the depression of the price of wheat and corn? -I can only give it as a matter of opinion.

2177. What is your opinion? - I think it must arise from something which we farmers do not at all comprehend; 1 fancy that the corn has diminished in price by the alteration which has taken place in the eurrency.

2178 . Have you observed that the prices of corn have fluctuated with the currency ; with any circumstances regarding the currency? - That will be found decidedly the case.

2179. Tell us when you have observed any particular fluctuation or any rise or fall in the prices?-P'ersons in my situation never thought nor heard any thing of the currency question formerly, and it is only since it has a become a matter of discussion we have looked back to see if it can have lad that effect. In the years $1823,182+$ and $1825,-1$ think 1824 and 1825 , - there was a very considerable advance in the price of all agricultural produce.

2180 . Was there any depression before that, and when?-There was a very great depression in 1815 and 1816 .

218 . When again? - In 1818 and 1819 , and I think that continued until 1822 ; there was a very great depression in 1821 and 1822 ; then they rose again in 1823 and 1824 and 1825 , beginning in 1823 and ending in 1825 .

2182 . It came down again in 1825 ? - Just at the very last.

2183. At the close of the year 1825? - Yes. There is a period universally known under the term "the panic ;" that was at the close of the year ; after that there was a very rapid fall.

$21 \%$. When did it rise again?-We have not had any considerable advance since.

2185. Can you state at all what the diminution has been in the prices of agricultural produce generally, from the highest period you recollect ; the period you alluded to when you said the labourer's' wages were $18 \mathrm{~s}$. a week?--I cannot go on with my memory at all as to the current prices; if you ask simply at what price I have myself sold in the country, I can.

2186. Generally, has it fallen a third or a fourth; what do you remember the highest price of wheat or oats?-I have sold at $8 l$. a quarter.

2187 . You cannot give a general answer, though you have made a general calculation, which would show what is the difference between the present price and the highest price of agricultural produce?-No.

21 Ss. The highest price at which you have sold wheat was at $8 l$. a quarter? -Yes.

$21 \mathrm{Sg}$. Well, what has been the barley?-I do not recollect.

2190 . Do you use any artificial manure :-Yes, bones, to a considerable extent.

2191. Was that of late introduction?-Yes.

2192. Has it been profitable?-Very profitable. I think that in those farms where cultivation has been kept up, it has been kept up solely from the introduction of bones, and a better system of agriculture. I think the intelligent farmers with us now farm better than at any former period.

2193. Yet, notwithstanding that, you state your land on one estate to have been very much deteriorated?-Yes.

2194. Notwithstanding that?-Yes; it had not been applied there to any considerable extent.

210.5. That those artificial manures had not been applied? - The East Riding of Yorkshire, of which I speak particularly, is divided ; there is nearly a third of it that is termed wold land, that is, a high lime-stone soil, and there the bone dust is very valuable.

2196 . What is that? - Lime-stone.

2107 . You never applied lime dust on bean land?-It is not found to answer at all; it does no good whatever; only on chalk land and warm sand soils.

2198. Have you turned your attention to the state of the bee1-shops in your neighbourhood?--They are unvopular.

404 . 

have.

2199. Have they produced much mischief among the labouring class?-They

4 March $188_{3} 6$.

2200. And tended to demoralize them?-The respectable labourers are never seen in then, but they do mischief by a certain set who meet there, and get intoxicated.

2201. You have spoken more particularly of the condition of the two estates that you have now the management of. Looking round your neighbourhood generally, is the land generally much of the same condition as that you have described? - There is a large district in my neighbourhood termed Howdenshire, which is generally a clay soil; it has been in cultivation from time immemorial, and is particularly applicable to wheat and beans. Perhaps the greatest possible reduction that has taken place in the rental, and the greatest deterioration in the cultivation, has been in that extensive district. The rents have very greatly fallen, and a very large quantity of that land has been entirely thrown out of cultivation, and is absolutely now lying waste.

2202 . When was it thrown out of cultivation?--It seems to have been gradually thrown out of cultivation, particularly after the year 1826 .

2203 . Has it been more particularly so within the last two or three years? - It has much more increased.

2204. In cultivation?-In waste; the throwing out has increased.

2205. Being thrown out of cultivation, it is laid down to some sort of grass; a feed of pasture? - I know a considerable quantity of land of that description used to let at $20 s$. an acre, now let at $1 s .6 d$. and $2 s$., to allow stock to pick up what they can on it. It is not grass; it is nothing that resembles grass.

2206. Which used to let at $20 \mathrm{~s}$. ? - It has not covered itself with any herbage.

2207 . Should you, from your own experience, say, that in consequence of the discouragement of wheat-growing, less wheat has been sown this year than usual? -To me it appears certain than much less wheat has been sown; the two last years much less has been sown.

2208. Your beans, which seem to be a considerable produce with you, bear good prices?-Yes, because we have had very failing crops; we certainly have had very bad crops.

2209. Has not that led you rather to put some land into beans, that you otherwise would put into wheat?-I think it has been put more into oats; there has been an alarm from the almost total failure of the bean crop.

2210 . You are of opinion there is a considerable diminished breadth of wheat sown in your part of the country last season from former seasons? - A very considerable quantity ; my impression is, that not more than three-fourths of the acres of wheat have been sown last year that have usually been sown. I an now not speaking of the land thrown out of cultivation, but of that which is in cultiration, and has been made fallowed. It has been the habit of the country to sow all the fallows with wheat; many will now be sown with barley and oats, or beans in the spring.

2211. You said that cultivation is very much improved in your part of the country? - I did not mean to say that; I said the cultivation by our best farmers, who still retain capital, has very much improved; their knowledge has increased.

2212. Notwithstanding their cultivation has improved, is their condition as good as it ought to be?-I beg pardon; I wish clearly to be understood, that I speak at different times of very different soils. On wold land, the sheep land, the dry high land, the condition of the farmers is not bad.

2213 . They are sheep farmers?-Yes.

2214. This land, being high and dry, they have escaped the rot?-Yes; that has increased the value of their sheep.

2215. Therefore they have done pretty well ?--Yes.

2216 . But wheat farmers, whether cultivators, well or ill, have they done well ? -IIl; the best cultivators of the clayey lands and strong lands have lost the most money.

2217 . Is your opinion of this cold clayey land of which you have been speaking, that you can get no rent at all ?-I think it is of no value whatever.

2218 . Laying aside all consideration of the rent, it would not bear the expense of cultivation with other burthens; it would not be the remunerating any person to hold it without rent:- -There are near to me 10,000 acres that were let at as much as $10,000 l$, that would be an average of $l l$. an acre; I believe that land could not be let to be cultivated; I would not take that land myself, and I think 
a tenant could not be found who would take it rent-free, and be bound to keep it in good cultivation, on the understanding that he should sell his grain at the late prices.

2219. Does it pay tithes?-Not generally; I speak of it as tithe-free.

2220. Does that clayey land prevail very much over the kingdom; what proportion does it bear to the other land of the lingrlom? - I have seen it stated so differently that $I$ am afraid to state it from iny own report; there is certainly a great quantity; I cannot state what is the extent of it.

2221. What proportion does this clayey land bear to the other lands of the kingdom?-I am spealing of the cultivated lands, putting the others out of the question; it is a matter of opinion and without any grounds, but it may be one fourth of the kingdom.

2222. You stated on one estate the landlord has been paying his own rent by the improper cultivation by the tenant; has that prevailed to any great extent? - To a very melancholy extent.

2.223. Your opinion is, that would be found to be the case in many parts of England, from your own observation? - It would; I believe the first measure, generally, when the rents were required to be reduced, was to allow privileges; and instead of reducing rents the grass land was allowed to be taken up.

22:4. Two or three wheat crops were taken instead of that ?-To let the farms the agents were too apt to allow the tenants to go on in any way whaterer, hoping that in another year they might be better able to let them.

222.5. At what price of wheat should you say that those lands would come back into cultivation :-I think at $7 s$. or $8 s$. a bushel they rould be cultivated, that is, from $56 \mathrm{~s}$. to $64 \mathrm{~s}$. the quarter.

2226. And gire what rent?-I think they would give $17 \mathrm{~s}$. an acre.

2227. Tithe-free? -Yes.

22.28 . You would consider, if you could get back to the average price of about $60 \mathrm{~s}$. for wheat, and other produce in proportion, you would consider that agriculture would be doing fairly in your neighbourhood? - I think it would, and other things in proportion.

2229. But other things are now in a good proportion, are they not?-When $J$ speak of wheat, meslin, which is largely sown, that is, a mixture of wheat and rye, that must come up again; the fall in that deseription of grain has been more considerable than the fall in the best wheats.

2230. You do not keep many sheep; it is not a sheep country, is it?-There is only one-third of the East Riding of York which is a sheep country ; large quantities of sheep were kept in the remaining two-thirds, but since they were destroyed by the rot in 1831 they have not been fully replaced.

2231. Are those districts where they do keep flocks of sheep, are they as much distressed as the other part?--Decidedly not.

2232. What is the price of wool and mutton; that has been tolerably remunerating, has it not?-It has been good.

2233. So that the distress has been heaviest on the wheat and bean land?I am still confining myself to the East Riding of Yorkshire, the extensive parts of it, Holderness, which is a good heavy soil, and Howdenshire, which is a poorer heavy soil, the distress has been very severe.

2234. Is it all equally heavy in both? - I think it has not been so equally heavy in Holderness as it is in Howdenshire, the soil is richer.

2235. You know the Holderness country? - Perfectly.

2236. Then what is the rent; how is the rent of the wheat land, of the good arable land?-The rents averaged full $30 \mathrm{~s}$.; now they average below $20 \mathrm{~s}$. per acre.

$2: 37$. How comes it that if they were only at $30 \mathrm{~s}$. for this very good land, you paid $40 \mathrm{~s}$. or $50 \mathrm{~s}$. for comparatively indifferent land?--I did not state it was indifferent land; I stated it was good land, but only indifferent wheat land; that the crop of wheat it grew was not equal to those of beans, barley, and grass.

\section{[The Vitness is directed to withdraw.}

Mr. William Thurnall is called in; and Examined, as follows :

2238 . YOU have been connected with land in some way, eitler as owner or occupier?-As occupier.

2239. What quantity of land do you occupy?-Abore 400 acres.

464. 
2240. Are you chaiman of the Agricultural Association of Cambridge? -Yes.

4 March $1 \mathrm{~S}_{3} 6$.

2241. What do you say as to the state of the farmers in your country?Ther are in a most deplorable state; I have not only an opportunity of knowing in what situation they are, as an occupier myself, losing an enormous sum of money, but in the way of my business in selling things to them, being a cornmerchant and miller, and generally in the malt trade, and I find the greatest difficulty in the world of getting payments for what I sell to them.

2242. You think they are greatly in distress?-They are in a most dreadful state of distress.

2243. Is that owing to imprudence, or the state of the times? - It is owing to the state of the times; I believe they are men as prudent as any class of men in the community.

2244. Have the rents been reduced in your part of the country? - In some instances.

2245. Are they over-rented; do they pay too much? -I know of no farm that is worth any rent at all; I have one of 400 acres, for which I pay $400 \mathrm{l}$. a year; I told my landlord, "If you let me have it for nothing I would not farm it, unless corn realized a better price."

2246. How long have you had it ?-Fifteen or sixteen years.

$224 \%$. When did the prices get so low that you were disposed to have nothing to do with it?-About four or five years since.

2248 . Is that owing to the low price of produce?-Yes.

, 2249. Have you a lease?-Yes.

2250. In what part of Cambridge is your farm? - At Duxford.

2251. You have offered to give that lease up? -I have not offered to give it up, other property being connected with it; but if there was nothing but the farm I should be most anxious to give it up.-I lost last year more than the whole rent of the farm.

2252. To what do you attribute that?-To the state of the times. I am one of those who firmly believe that the abridgment of the circulating medium is the great cause.

2253. When did you find the first material fall in price?--Six or seven or eight years since.

2254. Do you remember whether it was in 1822 ? - Yes, it was a dreadful fall indeed.

22.55. Did it get up after that?-Eighteen liundred and twenty-three, 1824 and 1825 were the years of prosperity, to the best of $\mathrm{my}$ recollection; I am confining myself to agriculture.

2256 . Did it go down at the end of 1825 ? - I can speak to the date if I refer.

$225 \%$. It rose in 1825 ; when was the next fall?--The average price of wheat in July 1825 was $68 s .3 d$; in $1826,56 s .5 d$; in $1827,58 s$. ; in $1828,73 s$. ; in $1829,75 s$; in $1830,78 s$; in $1831,72 s$. ; in $1832,62 s .8 d$.; in 1833 , $53 \mathrm{~s} .11 \mathrm{~d}$; in $1834,48 \mathrm{~s}$; and in $1835,39 \mathrm{~s} .8 d$.

$225 \mathrm{~S}$. Where did you get that from?-This is taling the average of the price of the country.

2259. Not the Parliamentary averages?-Those are what have been published in the different papers.

2260. From 18:8 to 1832 , were they bad crops :- - Two or three years were very deficient.

2261. Were those years bad from 1829 downwards? - I think 1828 and 1829 were bad, to the best of my recollection.

2262. From where did you take those arerages?-Those were published from our agricultural reports.

2263 . Are they taken from the returns? - Yes.

2264. Are they taken from the returns of the markets in that country, or London?-From the returns of England.

2265 . To what do you attribute this, besides the fluctuation in the currency?

-I think the competition of the Irish produce against us is very great, while we pay labourers more than they do in that country.

2266. Do you know what they paid in Ireland?-I think $\delta d$. a day.

2267 . Do you know it of your own knowledge? - No.

2268. What do you pay here?-About $1 s$. $4 d$., or $8 s$. a week, and we gire 
them small beer, which makes it about $9 s .6 d$. a week; that is where they work Mr. W. Thurnall. by the day.

2269. Is that the common agricultural labourer, or are jou spcaking of the carter and shepherd?-No, of the common labourer; the sheplierd is paid more.

2270 . Do you know if the farmers in general in your country pay their debts?-They are in a most deplorable state; I dread opening every letter, expecting to hear of the insolvency of the farmer. I had several bad debts last month.

2271 . Is that a frequent occurrence?-Very common.

22,2 . Will the country bankers trust them?- Not if they are men of any dis. cretion or prudence they will not trust a farmer now ; they know he is verging on insolvency.

2273. What is the state of the labourer?- When they are employed I do not think it can be said to be very bad, but we are paying them double the money we can afford.

2274 . Can you keep up the present rate of wages? - It is totally impossible. We do, fearing if we did not we should be burnt down; it is a sort of insurance on property. I am paying 40 per cent. more than I can afford, but not more than I conceive the labourer ought to have.

2275. Has there been any apparent uneasiness among the labouring people who are out of employment?-They are in a most feverish state. I have two men employed for no other reason than that they should not rob on the highway, they having declared to me, that rather than go to the poorhouse they would rob. I do not believe there are two more honest men in the village.

$22-6$. They are driven to a state of great distress? - Yes, they are.

2277. Do the present Corn Laws afford you that protection you think they ought to have done?-Certainly not.

2278 . Where are they defective?-In the first place, the importer is allowed to bond his corn without paying his duty upon it ; he would not be able to import half as much as he does if he paid his duty on the day of arrival.

2279. Does that turn the speculation to foreign corn; is the consequence of foreign corn being bonded here that your corn factor speculates in that rather than in English corn?-They could not, generally speaking, purchase much more than half the quantity of English they can of foreign, the foreign is so much lower in price.

2280. They are more ready to speculate in foreign than English corn? -Yes.

2281 . Would that be the case if it was kept out of the country till the duty was paid?-Certainly not; but the duty, I conceive, is not a protecting duty, it is not sufficiently high; I would have it at such a price that the English farmer should have $7 s .6 d$. or $8 s$. a bushel on his wheat. It is impossible to get a fair remuneration unless he gets $7 s .6 d$. or $8 s$. a bushel.

22S.2. Do you know of farmers living on their own property? - Several.

$22 \$ 3$. How are they doing? - We have three farmers who reside in the village in which I live, farming their own property, and at this moment they are not able to pay the poor-rates of the parish, neither have they done it for some time past.

2284. What are your poor-rates in the parish now?-I think about $6 s$. an acre; mine are; that is as near as I can state it.

2285. What is the state of the farmers; how do they feel; are they living in the expectation of any thing being done for them?-The farmer is looking with great anxiety upon the Committee of your Lordships' House, and of the House of Commons.

2286. Do you think the expectation he has of something being done for him keeps them going on with their property? - I think it does at present ; I believe there will be a complete state of despondency and desperation if nothing is done for them.

2287 . When the farmer began to hire land in your country, he was then possessed of capital?-Yes.

2288. Is that melted down; is it gone?-I should think a man whose capital was $4,000 l$. ten years since is reduced very nearly to $2,000 l$.

464 .

Q 2 2289. Has 
Mi. W. Thurnall. 2289 . Has that taken place in consequence of the bad state of farming? Exactiy so; from the low price of produce.

$2=90$. What is your soil ? - Light soil.

2291 . Very light? - It is a gravelly soil.

2292. Upon chalk? - Yes.

2293 . What is your conrse of cultivation? - Four course.

2294. That is what?-Wheat, turnips, barley and seeds.

224.5. Will the whole of the land bear that four courses:-I have some grass land, but it is very poor.

2296. Your plough land will bear the four courses still? - That is the general course of farming.

2297. You are not obliged to leave your seeds down the second year? - We have tried that plan, but do not find it answer.

2298. What number of sheep do you keep on your farm?-The allotments are not divided exactly equally, and some years we are obliged to have more than others; generally speaking about 400.

2299. Are yours open field? - It is an inclosed parish.

2300. About a sheep to an acre?-Yes.

2301 . Is it a breeding flock? - Part breeding.

2302. How many breeding ewes do you keep? - Sometines 300, sometimes 400 ; it depends on the state of the market.

2303 . Could you state on your farm what the gross produce consists of; in what proportion the wheat, the barley, the wool, and the stock contribute to the gross produce of your farm?-I can state it for the last year, but it would vary sometimes; there are a greater number of acres of one description "of corn, because the farm is not divided into allotments of equal size.

2304. Have you any reason to presume it is not about the average rate of it? -No; I should think some were about an average rate.

2305. Be so good as to state what it consists of ? - Of barley, wheat and oats ; I am speaking of the harvest from 1834 to 1835 , for the present crop was not threshed off.

2306. What is your barley?-Two hundred and thirty-seven quarters seven bushels of barley; a miserable crop; we had not half a crop.

2307. What did that sell for?-Four hundred and twelve pounds and sixpence.

2308. Now the next?-One hundred and ninety-three quarters and seren bushels of wheat.

2309. What did that sell for? - Three hundred and eighty-two pounds fifteen shillings.

2310 . Be so good as to say at what price that was sold at; at about what price? - I have not got the price down, but I should think it was under $40 s$.; something under $40 \mathrm{~s}$.

2311. Now the next?- One hundred and twenty-six quarters four bushels of oats.

2312. What did they produce?-About $23 \mathrm{~s}$, a quarter; about $145 \mathrm{l}$. $15 \mathrm{~s}$.

2313. Now the next? - Twenty-three quarters two bushels of rye, sold for $34 l$. $17 s .6 d$.; I say $34 l .17 s .6 d$., because I know the amount.

2314. Now the next? - That is sheep and wool, 376 l. 14s. $6 \mathrm{~d}$.

2315. Not more for the two together?-No; I keep the short-wool sheep; they cut very little.

2316 . Do you sell wool for a good price? - A very good price.

2317 . Is there any thing else comes into the gross produce? - The remainder of the farm consists of turnips and grass; very inferior grass.

2318. How much altogether did your gross produce amount to last year? One thousand three hundred and fifty-two pounds sixteen shillings and sixpence.

2319. Now had you a large crop of wheat; was it a good one in the year you gave?-The year I am giving you an account of it was a very good crop of wheat ; it was the produce of the harvest of 1834 .

2320 . The barley was a very bad one?-Very bad one; that accounts for the disproportion of the price of barley to wheat; barley was a very deficient crop both last year and this year.

2321. So that notwithstanding your barley was a very bad crop, and your 
wheat a very good one, your barley produced $412 l$. and your wheat $382 l$.?

Mr. II'. Thurnall.

-Yes; then I had a much greater number of acres of barley than of wheat.

2322. How much? - Thirty-two acres of barley more than wheat.

2323. Your wheat, was it much over an average?-Not a great deal; it 4 March 1836. was over an average, certainly.

2324. Do you think it was 25 per cent, orer; was it a quarter? - I should think there was never an instance of such a thing; it was considerably more than an average.

232.5. You have stated, that from $7 s .6 d$. to $8 s$. is the price that the farmer would want for a remunerating price for wheat? - To average that; yes.

2326. Instead of which he has now, what do you call the price? - The price is very much on the decline; it has been advancing lately; this week it has gone down rapidly again; a greater part of which wheat was sold till lately $4 s .6 d$. a bushel; the last month we have been giving more.

2327 . What, should you say that you were at $1 s$. $6 a$. a bushel lower than what you conceive a fair price? - Much more than that.

2328 . Two shillings and sixpence a bushel ?- J have stated to your Lordships that nothing would remunerate the farmer less than $7 \mathrm{~s}$. $6 \mathrm{~d}$. to $8 \mathrm{~s}$. the bushel, and the price lately, till last month, was only $4 s .6 \mathrm{~d}$.

2320. You say, in the year of which you have been giving the particulars, it was above 5s.?-I think it was.

2330. What is wanted to be understood is, how it comes that out of $1,352 l$. which is the gross produce of your farm, the part which consists of wheat only being 382 l., that that wheat was a very full crop ; how it comes that the diminution in the price of that wheat should so distort and disarrange your whole calculation as to make your land not worth cultivating? - I have told you that I only had half a crop of barley that year; there are many other causes besides that; I am not confining the depreciation to that only; I have suffered loss by feeding beasts and pigs.

2331. Are the Committee to understand that it is not only the price of wheat? -Agricultural produce generally.

2332. Do you consider barley, oats, sheep and wool to be at very low prices? I think barley has been at an extremely low price in proportion to the crop grown; if you had had an average crop; that is the sole cause of barley bearing a disproportion to wheat. In 1834 I did not grow three quarters of barley an acre; In 1835 I was amazingly deceived in my crop; I fully expected I should have had, after my last harvest, 12 bushels per acre more than I had.

2333. It ought to have borne a greater proportion?-I never sold any so cheap as in 1834 , in proportion to the growth.

2334. What did you sell it for? - Thirty-two shillings a quarter; if I had had an average crop, I should have made as much if it had been only $16 s$. per quarter.

2335. What crop did you have last year? - Of 1834? Of 1835 I have only four bushels more than half of an average crop ; I am speaking of the present harvest; 1 have threshed nine-tenths of my barley.

2336. You have not more than half of the average crop?-I say that of the harrest of 1835 , I shall have a coomb an acre more than half an average; but of the preceding year, 1834, I have not half an average crop; not more than that.

2337. Then are the Committee to understand it is not only the price of wheat you think the farmer has to complain of, but of the other articles of agricultural produce?-Exactly so.

2338. Do you think the sheep sell unfairly?-- Sheep have declined an immense deal since this time twelvemonth; store sheep 30 and 40 per cent.

2339. Have your lambs sold?-No; I am speaking of store sheep; the lambs we have not sold yet.

2340. Speaking generally of sheep, such as your farm enables you to say? - Last autumn the lambs declined enormously indeed, store lambs.

2341. How is wool?-That is bearing a tolerably fair price?-I have not lieard the price.

2342. Did you ever make an estimate of how many rents should be made for the gross produce?-The general opinion is about four rents; but I think it is a very poor criterion; you can judge nothing from that.

464 . 
Mr. W. Thurnall.

4 March 1836 .

2343. You have never made that estimate as applied to your own case?-1 have, but it is very vague; it is no criterion at all.

2344. Now you have given an opinion that the circulation, the currency, has something to do with the prices, have you followed that up, so as to state to the Committee in what way it has worked?-I can speak to that in a inercantile point of view as well as that of a farmer; your Lordships will not confine me to any particular dates; I have no document before me; but I have always observed when there was a contraction of the currency, there has been a declension of prices, and when an extension has taken place, prices have as invariably adranced.

2345. How do you calculate as to the currency; is it the account you see in the newspapers as to the circulation?-Dince the passing of Sir Robert Peel's Bill, in 1819, we have seen the miserable effect of it upon the country; the country bankers do not circulate half the number of notes they did; I have heard them say so.

2346 . Are you aware that the prices, as you have stated them to us, though not quite accurately, the prices of $1824,1825,1826,1827,1829,1830,1831$, have, upon an arerage, been equal (speaking now of the prices of wheat) to the prices you have named as a fair price for farmers, and yet that in those years the same law in respect to the currency existed that exists now?-I'lie onepound notes were withdrawn in 1829 .

2347. Not taking it from 1824 , but in 1825 , there was an end to the circulation of country bank notes? - It was in 1829 .

2348 . Can you speak, from your own knowledge, if country bank notes were in circulation in your district ip to 1829 , the one-pound and two-pound notes? - To the best of my belief.

2349. Were the one-pound and two-pound notes ont till 1829 ? -Yes.

2350. But not Bank of England notes?-Yes, as far as my recollection goes, the one-pound Bank of England notes were withdrawn in 1829.

2351. Do you attribute the difficulties arising from the currency question to the fact of the Bank of England small notes being out, not the country bank small notes? - We have experienced. difficulties from the country bankers one-pound notes not being in circulation as well as the Bank of England, for the principal circulation was country bank notes; very few Bank of England notes were circulating in the country.

2352. You have no small notes of the Bank of England in circulation?-Not now.

2353. Had you at any period since 1825 any Bank of England small notes in circulation? - I believe up to $1829 ; 1$ am not positive.

23.54. You mean the Bank of England notes?-Yes.

2355. What effect would the issue of one-pound and two-pound notes now have? - A most beneficial one.

2356 . What are your neighbouring towns:--Cambridge and Saffron Walden.

2357. Of course there are country banks there? - Yes.

2358. Can you state, from your own knowledge, up to what period the small notes of the country banks were in circulation in your own neighbourhood :- - I cannot do that.

2359. Can you state whether, since they have ceased to exist, you have not had some years a fair price for your produce? - Nerer, except in case of deficient harvests.

2360. Have you not had fair prices for your produce since the period when these country notes were in circulation in your neighbourhood:--I think it is very likely we have had scarce harvests during that period; that was the cause of the advance in corn.

2361. Were 1830 and 1831 all bad?--Yes; that would produce a higher price.

2362 . But in point of fact you have had fair prices subsequent to the period of the suppression of these notes?-Certainly not, with arerage crops.

2363. You ascribe that fact to deficient crops? - Certainly.

2364. If these higher prices har not continued up to the present time, should you not ascribe the cause to the crops from 1832, 1833, 1834 and 1835 having been full crops? - Erery ycar our prices are getting less. 
$23^{6} 5$. Is it not a fact, that the last year but one has been the most productive harvest you have known for many years? - The last year, in wheat only; barley was a deficient crop.

2366 . You think the duty on importation is still too low?-I do, certainly.

2367 . All that can be done for you by any duty or Parliamentary enactment is to kecp out the foreign corn altogether; nothing more can be done than that, can it?-That rests with your Lordships.

2368 . But in your opinion, when you state you think the seale of duty on foreign corn is too low, the Committee wish to know if it is possible to do more than give you the complete monopoly of your home market?-That is as far as it relates to the importation of foreign corn; that would not do alone.

2369 . Have you not, as far as wheat is concerned, at present the entire monopoly of the home market?-Yes, certainly.

2370 . Are you aware that foreign wheat has come to this country for the last two or three years?-There has been wheat the last two or three years, certainly; but it operates very forcibly on the purchasers of corn ; I know how it has operated on myself. Whenever wheat advances to about $6 . s$ a bushel, or $6 s .6 \mathrm{~d}$., I, as a buyer of corn, dare not go on with my purchase; I know a higher price than that lets out the foreign corn, with a small duty, so that it prevents all speculation in corn.

2371 . So that the injury you consider you derive from foreign corn is, not that it comes into consumption, but that it is rearly to come into consumption the moment the price turns, the importing price?-Certainly it has a very great effect, and operates on the minds of the purchasers of corn.

2372. That arises, you think, from that foreign corn being permitted to be bonded in warehouses? - In a great measure ; they do not pay duty on arrival ; it would make a great difference.

2373. But if you were to refuse permission to bond it in the river Thames, in the warehouses, and instead of that the speculator was to bond his corn at Flushing, or any where on the opposite coast, would he not be almost as ready to make use of .it as if it were bonded in England? - It would militate then against the farmer, but not so much as at present; the freights are very low ; I have been offered freight from Hamburgh to London at l $s$. per quarter, to bring wheat in ballast, instead of coming empty. I do not mean that that is the general freight ; but frequently captains of vessels have offered me freight at that.

2374. If it would come as cheap as that, it would come still cheaper from Flushing or Rotterdam?-About $2 s$. or $2 s .6 d$. a quarter is the usual freight.

2375. What is the port you ship your corn to London from?- From Lynn.

$23 ; 6$. Is it not as ready for the London markets from Rotterdam or Flushing as if it were shipped from Lynn?-Certainly.

2377. Therefore, what is the reason you think the fact of being committed to bond in England exposes you to less danger from foreign corn than if it were bonded in Flushing or Rotterdam? - I speak of this as a slight assistance to the farmer. If that were the only relief you gave him, it would amount to but little ; but I am sure any English merchant would prefer having his corn bonded at Liverpool or Hull, or any English port, than from a foreign granary.

237 S. Would they not more readily speculate on it if the foreign corn were excluded till it was to pay duty?-Yes.

2379. Is it not the practice, in a great many parts, that the money of the English capitalist is employed in speculating in foreign corn?-Undoubtedly.

2380 . Would not that be prevented by requiring a duty to be paid on foreign corn on being brought to England?-It would be a means, to a certain extent.

$238 \mathrm{r}$. From your experience and knowledge of the corn trade of this country, do not you consider the protection, such as it is, that is given by the corn laws to the corn grower of the country, is made much more acceptable and tolerable to other parts of the community from the fact of their having ready at hand a certain portion of foreign corn, which may be brought in in periods of distress? - Probably it might; but it is an extremely hard case that the capital of the English farmer should be wasted for that particular purpose, merely to serve another branch of the community. It is a very hard case that the whole of my capital should be wasted to support the rest of the community.

2382. Reasoning the matter simply for the interest of the farmer in England; 464 . 
Mr. $W$. Thurnall. supposing there were to come several cases of a totally deficient harvest, and there was a want of a foreign supply, do not you think that that might make a portion of the population of this country so impatient under the system of the corn laws as to endanger for the farmer the maintenance of that system which is now for his protection? - The present system is much more prejudicial ; for now you are driving the land all out of cultivation to a much greater extent than all the foreign corn ever imported in one year; I think you are injuring the community now ; and one of these days the country will be put in a dreadful state of starvation, as the land goes out of cultivation, and no foreign supply will be able to meet your wants.

2383 . Is the cultivation improving, or deteriorating, or going backwards, in your neighbourhood?-There is a great desire to inprove the cultivation; but the farmers are deprived of the means of doing that. I am in the oil trade, and an oil-crusher, and sell a vast quantity of manure; I do not sell a fourth of the quantity of oil-cakes to the farmers as I used. There is a great deal more skill; I never saw such an ardent desire for improvement as of late; and the best reasons for that, a man, with all his industry, can scarcely keep himself afloat.

$23 S_{4}$. Is the land less cultivated than it was?-Yes; I have two farms adjoining the one I occupy; the land is overrun with weeds, and in a most dreadful state; and the other tenant has paid little or no rent; and he told me the other day he could not pay any.

2385 . Looking back to some years of your own experience, should you say that the acre of wheat is less productive than it was; that the produce per acre is diminished?-It will keep diminishing rapidly; for the farmers cannot afford to purchase manure as they did.

2386. Has it diminished?-Within the last three or four years; the land is not so well cultivated; there is not so much manure purchased.

2387 . You stated the profit and expense; you did not draw the balance?-My rent is about $432 l$.

238s. Was the whole rent lost? - My whole loss is $432 l .10 s^{\circ} 9 d$.; here is my account:

STATEMENT, showing the Recerpts and Oetgorngs upon a Farm of 400 Arres, at Duxforl,

Cambridgeslire, in the Occupation of Willial ThukNaLL, from Michaehmas 1834 to Michaeluas $18: 35$.

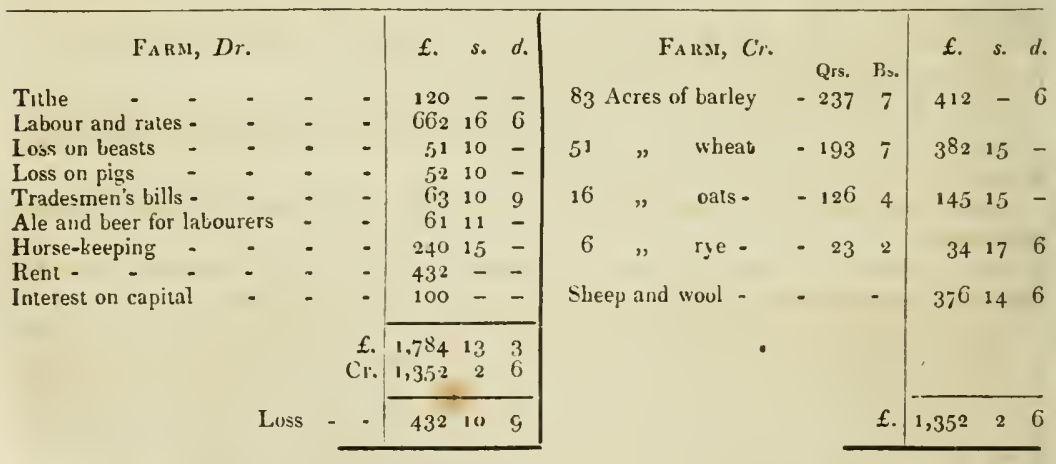

The remainder of the farm consists of turnips, grass, and meaduw land; the produce of which was consumed by the sheep, \&.c. in the above statement.

2385*. You have told their Lordships that wheat can be brought from ports opposite to England as quickly as from your coast?-As quickly as they can from Lynn; that was in reference to Flushing.

2389 . Therefore there would be no greater danger of starvation from its being kept there than bringing it here?-No.

2390. Consequently the English farmer would receive the benefit, without continuing to suffer a loss?-Yes.

2391. You have stated, from observations, that you have arrived at the conclusion, that the price of agricultural produce is much affected by the state of the currency rising or falling, as the currency has been expanded or contracted? -Yes. 
2392. Have you cone to this conclusion, that if there should be expansion of the currency by any wholesome course, are you persuaded it would be a considerable relief to the agricultural interest ?-I believe of the greatest relief; all the others amount to a mere nothing.

2393. Do you think the repeal of the malt-tax would not be an advantage ? It would benefit the farmer to a certain degree.

2394. Or if the whole were not taken off, if the farmer were allowed to malt his own barley for his own consumption, or his cattle or family?-Yes, considerably.

2395. Has wheat been malted at all in your neighbourhood?--Yes; a considerable quantity last year.

2396. Has grown wheat been used at all for feeding cattle?-In a few instances the plan has been adopted; but they were fearful of the excise laws.

2397. Do you know any thing as to the state of the beer-shops in your neighbourhood; are they productive of good or injury to the agricultural population?-In some instances they have been very much abused, but I do not think they have done injury to the morals of the people in the manner described.

2398. What acreable produce of wheat and barley did you calculate upon when you took your farm? - I should calculate I should grow five quarters of barley and 25 bushels of wheat; I know a less quantity than that would not remunerate me; and then the wheat should make from $7 s .6 d$. to $8 s$. per bushel upon an average crop.

2399. You have said that they purchase a less quantity of manure; that you sold oil-cake, and they purchase a small quantity?-I do not sell one-fourth.

240(. How are the country shopkeepers off, do you think?-They are getting into a very deplorable state.

2401. Do they sell as much?--Nothing like it.

2402. A farmer makes his coat do two years instead of one ?-And every thing else; they cannot pay the country shopkeeper.

2403. Does he pay his debts?-A farner pays scarcely any body but his landlord; my book debts will show that; I have heard the landlords state, they could not suppose the farmers were so distressed, for they got their rents.

2404. You do not get your bills paid?-I do, in some instances. The master of a college said, "I cannot conceive how the farmers can be so distressed as you represent them ; for we have had the college rent and tithes tolerably paid." I said, "Yes; that has been paid out of my capital ; three of your tenants came and told me I must wait if they paid you."

240.5. In the last two years you have not produced nearly the quantity of wheat and barley jointly that you anticipated when you took your farm?--Of wheat I have.

2406. But jointly? -I have had little more than half a crop of barley the last two years.

2407. Then in the two last years the quarter of your entire rent was lost by the want of productiveness in your barley crops?-Not altogether.

2408 . Is it not adequately met by a higher price?--No; and it is not confined to that, but to all descriptions of agricultural produce. Within the last three months I have sent nearly 200 pigs to London, and, on an average, I have lost $3 s$. in every $20 s$. for which they have sold, 15 per cent. The small London pork did not make so much as I gave for it lean, in many instances.

2409 . In your answer relative to the profit of the flock, it does not appear you made $1 l$. a head, one with another, in the course of the year?-Probably not, as that would vary according to the number sold; some years it would be more, others less. I must sell part of my flock this year, as the slreep have become what is termed broken-mouthed; and if all were sold at a particular time, that year there would appear to be a greater profit.

2410. In the year you have been giving an account of, you have stated the profit of your flock at $400 l$ ? - No ; the gross produce.

$24: 1$. That is not above $1 l$. a head?-Yes.

2412. Does not your flock generally yield more than $1 l$. a head all round? - No.

2413. Never?-I do not mean that there lave been years when it has not; if the wool is included, I should say certainly.

404 . 
Mr. W. Thurnall.

4 March 1836 .

2414. Are your sheep South Down?-Between the Norfolk and South Down; a half-breed.

2415. Do you fatten any for London?-Yes.

2416. Do you send them to town:-Yes. I sent very few last year.

2417 . What did the fat ones average?-The average was from $2 l .2 s$. to $46 s .6 d$.

2418 . When do you sell your store lambs?-Prices were so low I would not part with them; I have them by me now; the price of sheep and lambs has declined, and I was unwilling to part with them.

2419. What do you generally estimate the average price of lambs at Michaelmas; what do you estimate them at?-Last year?

2420. No; you have taken your farm on some calculation?-I should think, generally speaking, about $1 l$.

2421. Those lambs you sent to town at $25 \mathrm{~s}$. you sell at Michaelmas, store lambs, or thereabouts, at $\mathrm{l} l$.; that takes all the produce of your ewes, at averaging about $l l$., then you add to that the profit of the wool?-All that will depend on circumstances; a number of them die. It is a very rare thing for a man to rear as many lambs as ewes. I think last year I had not any thing like two-thirds of lambs to the flock. I had 50 ewes died in lambing last year. I would beg leave to put in here the statement of a neighbouring farmer [the Witness produces a paper]. I know the person, and I will swear to the handwriting.

2422. Have you any means of knowing whether it is correct?-I know Mr. Grain; it is his own handwriting, and I am ready to swear it is his handwriting; and he gives it as a true and correct account.

2423. Do you believe it is a true account? -I have no doubt of it whatever. It is the statemenit of a farm in the same village as I live myself; a regular account of every item in the farm; it is for two or three years. But your Lordships will understand there will be some sort of appearance of discrepancy between his statement and mine; his farm is on a corn-rent; he pays a bushel of wheat and a bushel of barley per acre, being about $8 s .6 \mathrm{~d}$.; I am paying $22 s$. an acre for my land, besides tithes, and the tithes are very high. This farmer takes it at a bushel of barley and a bushel of wheat, so that he pays only $8 s .6 \mathrm{~d}$. an acre, that being about the price of a bushel of wheat and a bushcl of barley at the time the rent was decided.

2424. Is his land of the same quality as yours? - In the course of a few years it will be very nearly; it is not very different now. The village was inclosed 14 or 15 years since, and now this farm is getting to the same state as my own. This was one of the distant farms.

2425. If this farmer was to get a very bad year for his produce, he would be caught with his corn-rent, would he not; suppose he got a very deficient crop and a very high price, he would be caught? - If it was a deficient crop generally, it would be a higher price, and he would be no loser.

2426. He would have to pay a rent proportionate to the price, without a consideration of the crop :-If it was a partial deficiency, affecting him only, he would pay a higher rent.

[The Witness delivers in the following paper, which is read:] 
Statenfaxt, showing the actual Proceeds and Expenses attending the Cuitivation of an off-luand Farm of 65, Acres, in the Parish of Doxford, in the County wf Cambridge, fron Michaelmas 1831 to the same period 1835 , in the occupation of Mr. Peter Grais.

This farm is held at a corn-rent of one bushel of wheat and one bushel of bartey per acre, Wiuchester measure. The yearly average upun which such rent is calculated not being regulated hy any corn returns, but by the nccupier's books. 'I he land is farmed upon the four-score system, and is favourable for the keeping of sheep, of wlich there have beell, during all the above period, from 25 to 30 score kept upon the furm.

From August 1831 to August 1832.

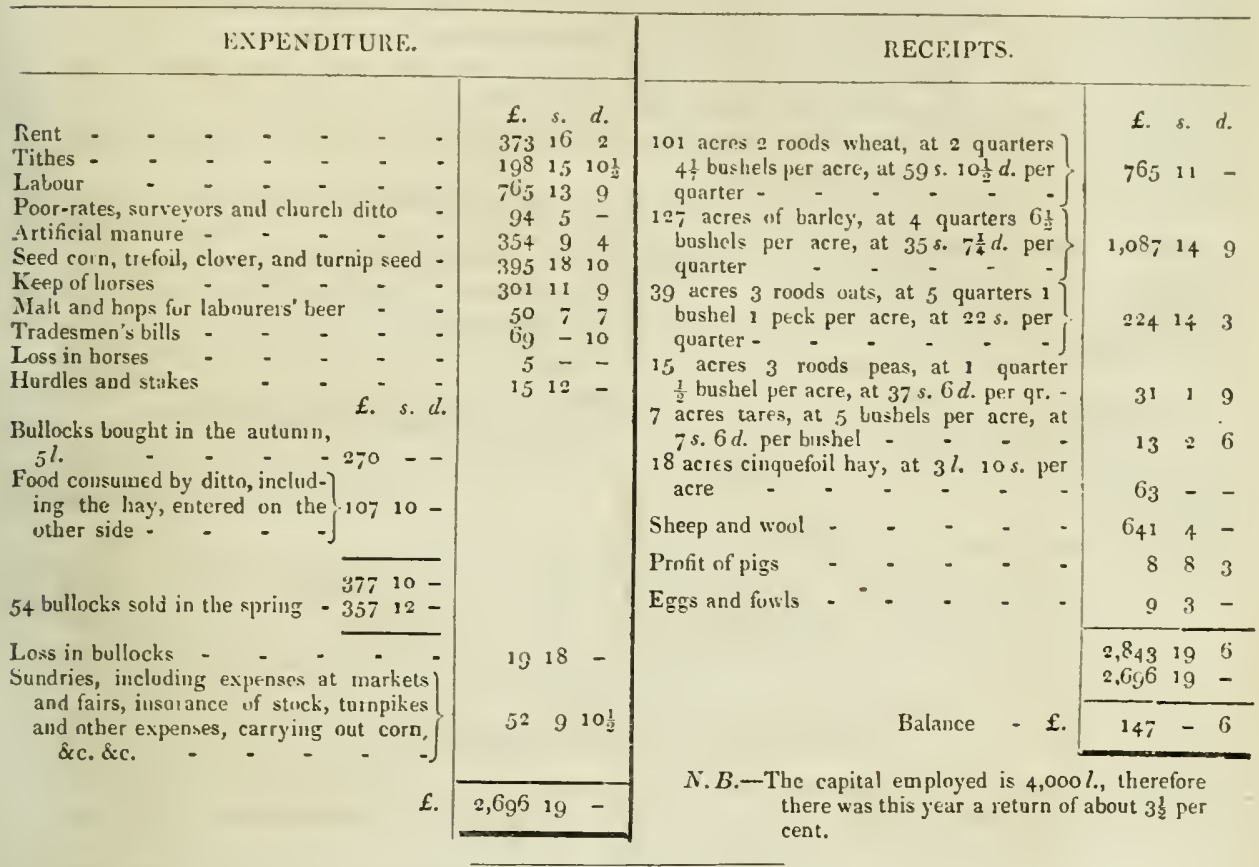

From August 1832 to August 1833.

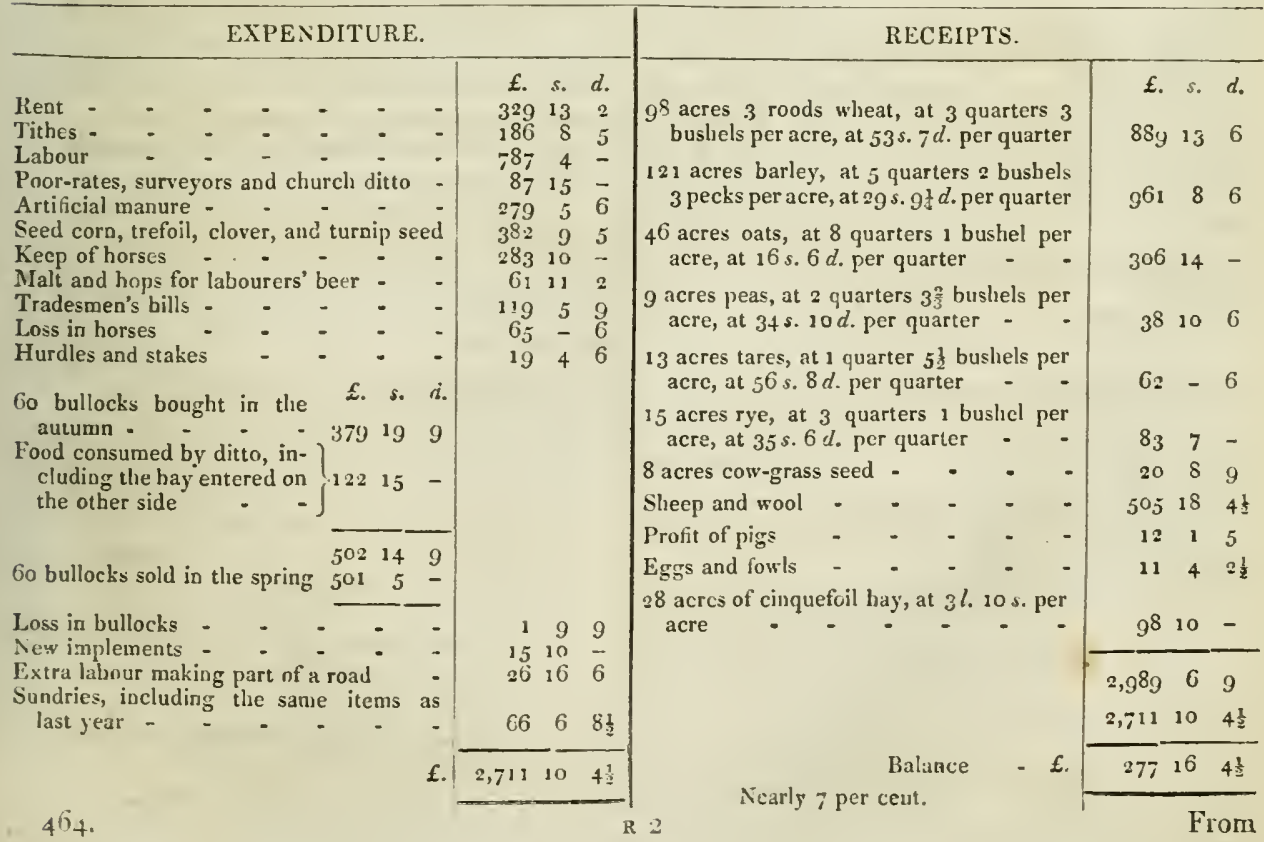




\section{From August 1833 to August 1834.}

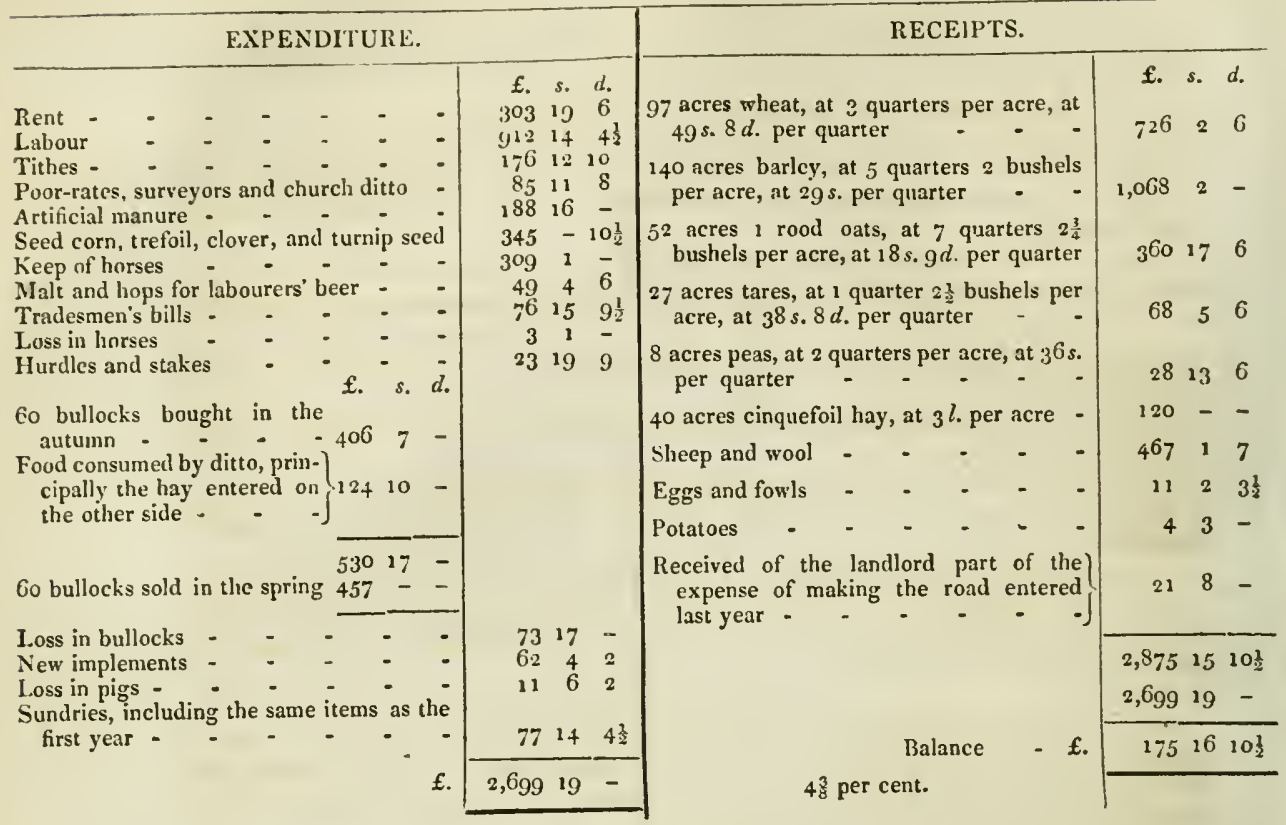

From August 1834 to August 1835.

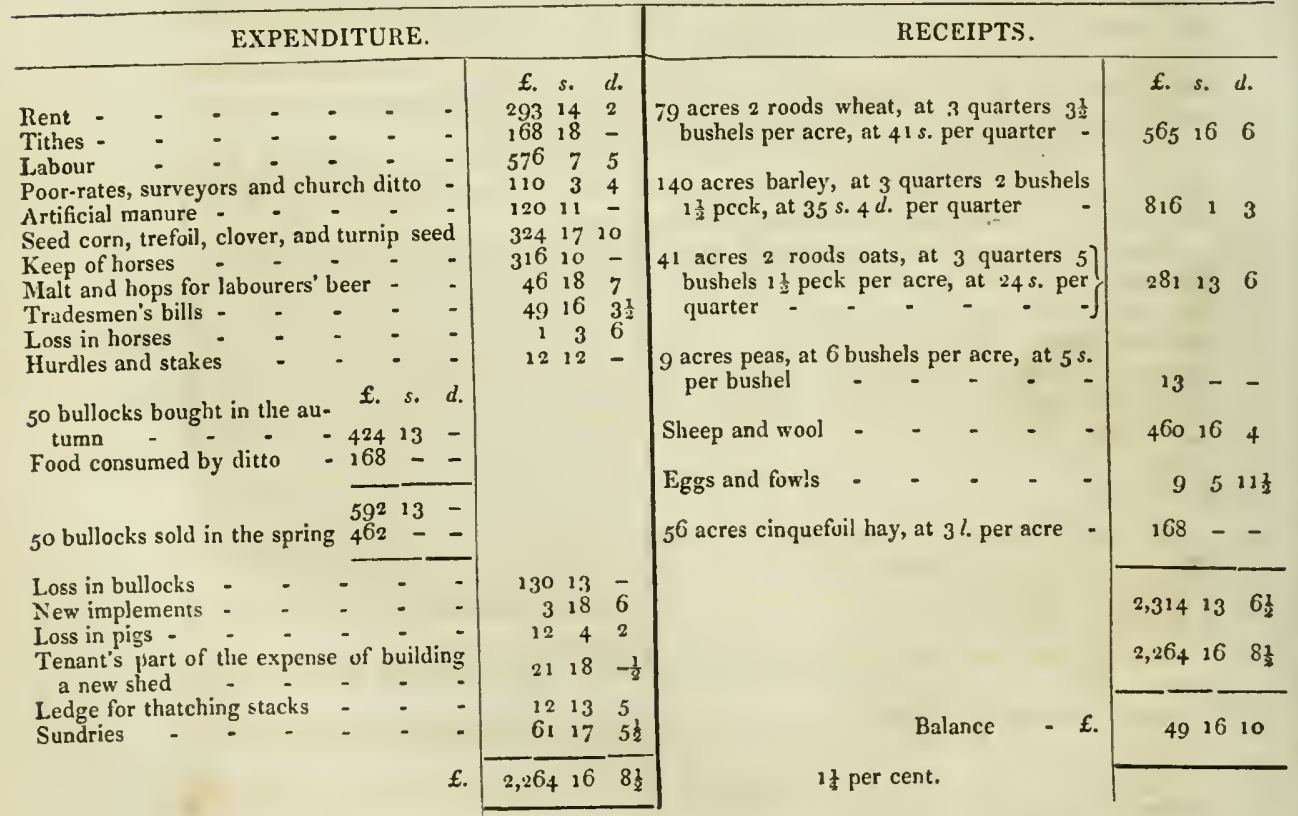

[The Witness is dirccted to withdraw.

Ordered, That this Committee be adjourned to Monday next, One o'clock. 
Die Lunæ, $7^{\bullet}$ Martii, 1836.

\section{The Lord WYNFORD in the Chair.}

Mr. Edward Bradley is called in ; and Examined as follows :

2427. WHERE do you live? - I live at Cowbridge, in Glamorganshire.

2428 . You are steward for some gentlemen in that neighbourhood, are you not?-I am.

2429. What quantity of land have you under your care?-It would be difficult to say; a great many thousand acres in Glamorganshire, Brecknockshire and Herefordshire.

24.30. How long have you had the management of it?-I suppose from 15 to 20 years ; perhaps 18 years.

2431. Does it extend itself over a considerable part of those counties?-Yes ; north, south, east and west.

2432. Have you any concern in country banks? - I have not.

2433. What is the state of the farmers in that district?-Very much depressed.

2434. Do they pay their rents? - They are very backward.

2435. Do you think they have any means of paying rent out of the profits made on their lands?- No, nor have they had for some time; many have been paying from their principal.

2436. Have any been broken up ?-A great number.

2437. What number in your neighbourhood?-The changes have been so great I cannot pretend to say, so many have been obliged to quit their farms, and others have been distrained; I do not think there are a great many really solvent at this moment, taking the country through.

2438. You live near the coast?-I do, within about five miles.

2439. That distress arises from the depression of prices ?--Exactly so.

2440. Particularly wheat?-Yes.

2441. Are the other articles that they sell than wheat as high as they ought to be, considering the state of the tenants?-No, I think not.

2442. How long have they been depressed?--They have been more particularly depressed for the last four or five years; but before that time the price of corn was extremely low; it was not a remunerating price.

2443. To what do you attribute that ?-My own opinion has been for some time that the importation of Irish corn has tended very much to reduce the price of corn in Glamorganshire, for the imports have been very great indeed.

2444. Can you state the importations from Ireland into Glamorganshire for the years 1833, 1834 and 1835 ?-Yes; I have it from the Custom-house ; in the year 1833 the Custom-house returns from Swansea and Cardiff were 168,080 bushels of wheat and flour. I have made the calculation according to the average; that is rather high in Glamorganshire; the average produce of an acre would be about 20 bushels. I have reduced that into acreage. It would take 8,404 acres to produce that quantity.

2445. What were the average prices per bushel that year?-Six shillings and ninepence.

2446. How many were imported in 1834 ? - Two hundred and seventy thousand nine hundred and sixty bushels of wheat and flour.

2447. How many acres would that take?-Thirteen thousand five hundred and forty-eight acres.

2448. What was the price per bushel then?-Five shillings and tenpence halfpenny.

2449. So that the prices appear to have fallen as the quantity of importation increased?-Just so.

2450. What were the importations in 1835 ? - Three hundred and eleven thousand two hundred bushels.

2451. That would cover how many acres?-Fifteen thousand five hundred and sixty acres.

2452. What was wheat a bushel that year?-Four shillings and fourpence halfpenny.

464 .

R 3

2453. Was

Mr. E. Bradley.

7 March 1836 
Mr. E. Bradley.

$7 \operatorname{March~} 1836$.

2453. Was $4 s$. $4 \frac{1}{2} d$. the average of the year in your county?-Yes, it was.

2454. Have you attended the markets, or do you know any thing of the state of the markets? -The markets are extremely dull; we cannot sell the produce of the country.

2455. Is the Glamorganshire farmer able to compete with the Irish farmer in his own markets? - No.

2456. Was the produce of Glamorganshire in those years sufficient for its cultivation?-No, I should think not, from this circumstance, that the state of the farmers has not allowed them to cultivate their land properly, and it has been very much deteriorated.

2457. Have they not very good land there?--Very good.

245 . Would it have been sufficient, if the land had been properly cultivated? -I should think it would; and before the importations were so great from Ireland, we were in the habit of sending considerable quantities to Bristol.

2459. Has agriculture been depressed by the introduction of Irish corn? Yes, very much. I have known corn sent to Bristol, and kept there for some time, and returned because they could not get the sale of it.

2460 . Has there been, in consequence of the importations from Ireland, less corn grown in Glamorganshire than formerly? - No, I cannot say there has; I should think not less.

2461 . In consequence of the glut, has it been saleable?-We have not been able to effect sales.

2462. Did it ever, in any time you can remember, grow enough for its own consumption? - I think it has.

2463 . For how many years has it ceased to grow enough for its own consumption?-Four or five or six years, I think.

2464. During all that time have there been those importations from Ireland? -There have.

2465 . How do you reconcile that with your former statement, that the quantity grown has not fallen off?-They have been taking a quantity of land not properly cultivated.

2466. You say that 20 bushels is the average per acre; is that the average now, according to the present course of cultivation?-No; I think the crops are very deficient now.

$246 \%$. The population has much increased ? - It has.

2468. Those two circumstances of deteriorated cultivation and of increased population have operated together?-Yes.

2469. You say that the Welch are not able to compete with the Irish in your markets; to what do you attribute that?-I should think that arises in part from the liabilities of the farmers in Glamorganshire being very much greater than those of the Irish, and their local taxes are not equal to ours.

2470 . Have you been in Ireland?-I have been there twice.

2471. Does their not paying poor-rates make a considerable difference in the expense of producing corn? - I should think it does.

$24 ; 2$. What other taxes do they not pay? - I believe they do not pay assessed taxes.

2473. What is the rate of labour in Ireland?-I have understood from $6 d$. to $10 \mathrm{~d}$. or $1 \mathrm{~s}$. a day.

2474. What is the rate of labour in Glamorganshire a week? -I do not think we have any labourers under $9 \mathrm{~s}$; ; great many at $11 \mathrm{~s}$. and $12 \mathrm{~s}$.

2475 . Is not the price of labour a most material ingredient in the cost of grain? -Certainly, in Glamorganshire.

2476 . Does that exceed the rent of the farm?-It does, in my farm.

2477. Is it possible for a man who pays $11 s$. a week for his labour to compete with a man who has his corn grown by labour at $6 d$. a day?-Certainly not.

2478 . In consequence of their not having been able to compete, are there great losses in the management of farms in Glamorganshire?-There are.

2479. Have those produced the ruin of the farmers? - A great many.

2480 . Is it possible for them to go on, unless something is done to diminish the expenses or raise the prices?-Quite impossible.

2481. Do you know whether the farmers are holding on their farms in hopes of something being done for them?-I know many; I have induced a good many to go on, in the hope of something being done for them. 
2482. What have you induced them to hope may be done? - One great point I have laboured to induce them to expect is, that the Irish agriculturist would in justice be subjeçt to the same imposts as the English; and they have been induced, in some instances, to hold on.

${ }_{24} S_{3}$. Do you think if they were to find that Parliament had said that they could not do any thing for them, they would hold on any longer? - No, I think not. I had a farmer with me last week, who holds under ___ _ who wished to give up his farm, but I induced him to wait till it was seen what would be done.

2484 . Are you acquainted with the country banks at all:-No, not as regards their mode of doing business with the country farmers.

248.5 . Do you know whether the farmers were, in previous years, in the habit of being accommodated by country banks? - Yes, and are now.

2486 . Will the country banks afford them assistance with that facility they would formerly?-No. We have some joint-stock banks established, and I do really believe the farmers have been accommodated lately; I do not know what security they give; for many of them, I know, have nothing beyond what they have upon their farms; and many of those very persons who had money, if their stock and crops were taken, would not have any thing beyond the payment of their rent.

$248 \%$. Have those persons reduced themselves to this state of things by any imprudence of theirs, or is it entirely owing to the times ?-Not by any imprudence, many of them living harder than their labourers.

2488. Notwithstanding that they are, in that part of the country, many of them in a state of ruin?-Yes.

$24 \mathrm{Sg}$. What is the average rent of lands on the estates to which you are alluding? - I should think from $16 s$. to $18 s$.

2490 . Has rent been reduced materially since the reduction of the prices?Very much ; I have known reductions of 25 per cent.; it varied from 10 to 25 ; but I do not think the farms in Glamorganshire have been highly rented in proportion to the produce of corn.

2491. You state that the chief advantage the Irish farmer has over the English or Welch grower is, that he does not suffer under the pressure of the same taxation, and particularly the taxation for the poor; what is the highest amount of poor-rate on the estate of which you have the management?-It would be difficult for me to say; I was not aware of being called here when I left home; I cannot give particulars as to the charges of the poor, but they are very low, comparatively, to what they are in many other parts of the kingdom.

2492. Are the prices in the immediate markets materially lower than in the other markets in the kingdom? - - I do not know as to other markets.

2493. Can you state as compared with London; is there a great difference between Cardiff or Swansea and Mark-lane?-They are certainly lower, from many of the returns I have seen.

2494. What is the price now in Swansea market?-I think that wheat may be worth $4 s .9 \mathrm{~d}$. or $5 s$., probably $5 s$; there has been a change within the last three or four weeks in the price.

2495. Do you know that the price has gone back again within the last few days? - I was not aware of that. But the averages are very inaccurate at Marklane. I recollect travelling by the mail into Glamorganshire; there was a person seated on the roof of the coach, who got into conversation about the prices of corn; he had been to Abergarenny market; he went to Cowbridge, and bought a quantity of oats, for which he gave $3 s .6 \mathrm{~d}$.; I was purchasing at $2 s .4 d$. and $2 s .6 d$.; he returned, and then wrote to the person of whom he bought the oats that it did not suit his purpose to take them, and hoped he would not insist upon the purchase, but it was too good a bargain not to hold him to it, and it was compromised. The actual return from Cowbridge was from what he had bought that day, but which he refused to accept.

2496. If the sales actually made were returned, that would furnish a proper arerage? - Not those small sales; I think the millers or the large contractors would be the persons from whom the return ought to be made.

2497 . Do you mean that the return sent up that day was founded on that sale?-Yes.

464.

R 4 249S. The

Mr. E. Bradlicy.

7 March 1836 . 
Mr. E. Bradley. 2498. The price in London is charged with the expense of bringing it there? - Certainly.

7 Marcl 1836 . 2499. Is it fair that those should be mixed with the prices in the country where the corn is grown?-Certainly not.

2500. Do you know what it costs to bring a quarter of corn to London?-I do not. I think the fair averages of corn, where they are stated in the different markets, would be the price which should be given by the corn-buyer. A person may find it an object to come into the market and buy a few bushels, giving an extra price, to suit his purpose at Mark-lane.

2501. Are there many freeholders who cultivate their own land? - - There are.

2502. In what state are they?-They are in a very distressed state. I know one lamentable instance of a farmer who had some property from his father, and within the first four or five years, I believe, he has mortgaged it up to the hilt.

2503. Is that the case with many?-Yes, with a great many.

2504. In what state are the smaller gentry in South Wales?-Their situations are very much reduced.

2505. Have they contracted engagements in better times which they are now unable to discharge ?-Certainly they have.

2506. Have you any thing to suggest to the Committee which would be likely to give relief to the agriculturist?-It is very difficult for me to do that; we only know how we are depressed. If it were possible that the three kingdoms should be subject to the same liabilities, we might all compete and start fairly together.

2507. Do you think it is occasioned principally by the production of wheat grown at low taxes in Ireland?--Certainly.

2508 . Is your opinion confirmed by the circumstance, that as the Irish grain has come in, our grain has gone down in price?-Yes; and the farmers in Glamorganshire are very peculiarly situated for those large importations. The large works in the country take a great number of the labourers; if we do not give them the price they demand, they will go up to the works, where they get full employment. The general complaint in Glamorganshire is the importation of Irish corn, which is consumed by the labourers at the works; and we are in fact paying, in consequence, greater wages in the lower part of the county, and they do not consume the produce of the county.

2509. With regard to the prices of other agricultural produce, have they been very low ; the price of stock, for instance?-Very low.

2510. Fat stock?-Fat stock have been very low; they have risen very much within the last month or six weeks.

2511. Do you think that is materially affected by the imports from Ireland?No; we have not any fat stock from Ireland; we have had a great quantity of Irish stock, but not so much as formerly.

2512. Have you a great deal of Irish pork consumed?--It does not come into our part of the country ; there is a great deal goes to Bristol.

2.513 . You think the only part of your produce which is affected is the corn?

-Yes, more particularly the wheat and the oats; there is a great quantity of oats imported; but we do not complain so much of the price of oats.

2514. You think that the prices in Swansea and Cardiff markets are not materially lower than the prices in London?-No, I do not say that.

2515. Take Bristol; are they materially lower than they are at Bristol ? - No, they have not been; corn has been very heavy at Bristol.

2516. And there have been great importations from Wales into Bristol?Yes, from Glamorganshire, and some has been returned there again.

2517. Do you know whether the Irish breed less cattle, and break up their lands?-I understand that they produce less cattle, and that they are breaking up their lands, which they do not want for grazing, to cultivate.

2518 . You know they have imported less cattle into your neighbourhood of late?-Yes, I know that.

2519. Do not you recollect when the fat and the hide of cattle sold for much less than they do now?-Yes; but I do not know what the difference was; I have nothing to do in that way. I breed a great many cattle myself.

2520. It is your conviction, that in consequence of the distressed state of the farmers the land is much worse cultivated, and produces much less than it did? Very much so. 
2521. In consequence of the high prices, they broke up land they ought not to do, and farmed it improperly?-Yes; and they have not now the means of purchasing lime, which is the great manure in our country.

2522. Have those means been exhausted in eonsequence of the unsuccessful returns in prosecuting their business?-Yes.

2523. If this process goes on, must the quantity produced be decreased? - No doubt of it.

2524. Do you grow much barley?-Yes.

252.5. Any oats? - Not a great quantity, except in the mountainous districts; we draw the line between the mountain and the vale districts.

2526. What do you conceive would be a fair remunerating price to the farmer for wheat?-I should think they could not cultivate wheat under about $7 \mathrm{~s}$.; and there is one system in Glamorganshire which is a very expensive one, and where practised they could not cultivate for that price; that is what is called the fallowing system. They work their land for a whole year, and manure it with lime very heavily. That is rather an expensive system; I do not think they can possibly cultivate an acre of land and pay rent for a year under $10 l$.; and I do not think a remunerating price could be less than $9 s$. a bushel, or perhaps a little more than that. Then they do not get much profit upon that; they are looking to subsequent crops.

2527. Do you think that peculiar and very expensive mode of cultivation is the result of a want of skill and knowledge on the part of the farmers, or owing to some peculiar circumstances of soil?-Circumstances of soil more than any thing else ; the soil is very prone to grass in the county of Glamorgan, and unless they have a summer's fallow, and put lime on the land, they cannot get a crop. They do not adopt the hoe system so frequently as they ought.

2528 . What would be a remunerating price for barley upon the same system of fallows? - I have never known a crop of barley to be so produced.

2529. What is the produce per acre of barley?-Perhaps about 30 Winchester bushels, where it has been well cultivated.

2530. You make this calculation, supposing there is a fair harvest every year? -I take that, conceiving they might have fair harvests; and perhaps the same quantity of oats would be about the average crop, about 30 bushels. I am speaking of the farmers generally. Formerly the lands produced very much heavier crops than they do now; I have grown on my farm upwards of 50 bushels an acre of barley, but that was under particular circumstances of culture.

2531. Has the quantity of barley grown in your neighbourhood decreased?Very much; and in fact all the grain has decreased; every person travelling through the country sees a very great difference.

2532. You attribute the present price of barley, as compared with wheat, to the decreased quantity produced? - I do not know what to attribute it to ; there are so many circumstances connected with the agricultural interest. I do not know how far the consumption operates upon it, for we have no barkey from Ireland, that I know of, in any quantity that can affect us at all.

2533. What is the course of cropping on your farm? - The general course of the country is fallow, wheat, barley and clover, and wheat again; but in some parts of the country they used to have an extraordinary system of growing nothing but wheat in fallow; a most expensive system where it prevailed.

2534. Was that particularly rich land?-No; but the expense was enormous, and it is ruinous besides; for we know that lime properly used is a very fine manure, but if an extra quantity is put, there is nothing runs the land out so much. 2535. It destroys the vegetable principle? - Yes.

2536 . Is the land improved, or gone backward?-Gone backward very much. 2537. So much so as to affect the crop of wheat?-Yes, certainly, all crops.

2538 . What do you call an average crop now ? - I have calculated the averages at 20 Winchester bushels, but I think that is rather high, taking the country generally.

2539. How much of your own farm is in wheat; is it one-fourth every year? -No, not one-fourth.

2540. One-fifth?-Perhaps there may be nearly one-fifth on my own farm; but I should not speak of my own farm, putting it in competition with any other farms in the country.

2541 . Speaking of the generality of farms, the general custom is, that about $4_{14}$. 
Mr. E. Bradlcy. one-fifth is in wheat:-Yes, I fancy it may be as much as that ; one-fifth of the arable. They have been in the habit of growing a great deal too much wheat; and the mischief is, they have grown so much, their land will not produce any wheat hardly now ; in some of the parishes which I have to do with, they average lower, about 12 or 13 Winchester bushels an acre; I think many of the wheat crops last year did not exceed 12 bushels an acre.

2542. Do they hold under leases ?- Many of them.

2543. Long leases? - There are some old leases existing, but not many.

2544. Are they not restricted as to their crops?-Not restricted generally in old leases.

2545. Are the properties large properties or small?-Generally small; there are some 5,000 or 6,000 or 7,000 a year; but they are nostly small.

2546 . You have no green crop except clover?-Yes, vetches.

2547. Have you any beans?-Not a great many; I do not know above four or five farmers who cultivate them; I cultivate them myself, after turnips; I have a great resource in the shape of manure; I grow a great quantity of turnips, and $I$ have beans after turnips myself, after beans wheat, and on stiff land it is very likely turnips again, but on light land barley and clover; I sow my wheat with an implement called a presser, a very useful implement, and the very best way of sowing wheat; there are two cast-iron wheels that follow two ploughs; the pressure indents the land, and in the case of clover or hay presses down the top grasses, and in a fortnight after the land is ploughed; I merely sow the wheat, and it falls into the drills.

$254 \mathrm{~S}$. Is your own land deteriorated?-No, not at all; but the only mischief is, that within four years I lave got to look for $2,000 \mathrm{l}$. or $3,000 \mathrm{l}$. somewhere, which I cannot find; I have very great resources; I have a great quantity of land in water meadow.

2549. Have you a large flock of sheep upon them?-Yes; my cattle since Christmas have been feeding on the water meadows, and in April I always have plenty of grass for all my stock, and I grow retches.

2.550. Do you keep a breeding flock of sheep?-Yes.

2551. You can feed your ewes and lambs upon those meadows in April ? -Yes.

2552. You state that of all the articles of farm produce, with the exception of wheat, there is a fair price?-No; barley is low; oats are at a fair price.

2553. Did you not state $32 s$. is a fair price for barley? - Yes, $4 s$. a bushel.

2554 . Is it not at $4 s$. a bushel now? - No; I do not know that there has been a sale effected for more than $3 s .3 d$. and $3 s .6 d$. for a very great length of time; $4 s$. would be a fair average price if there was a proper return as to quantity, but they do not get a fair return as to quantity.

25.5.5. Has it never been $4 s$. a bushel in the course of this last winter?-No, not to my linowledge.

2556. You say that the farmers have been very much distressed; have they, in consequence of that distress, overworked their land?-Yes; they have not been able to pay their rents. Last Friday se'nnight I was in Brecknockshire, and I was unfortunately obliged to distrain one of our own tenants there, and, taking the whole, he had not one half enough to pay his arrears; but he had a friend that came forward and settled his arrears, and he is going on; that man's ancestors have been on the farm for generations; the land was in the most wretched state.

2557 . Is that the case with many of them?-Yes, many.

$255^{8}$. Have those persons, for the purpose of keeping themselves up, overcropped their farms? - Very much.

2559. Has that harl the effect of decreasing the produce in subsequent years? -Yes; there are many farms I would not have rent-free.

2560. In what state were those farms before they were so over-cropped?Many of them in a flourishing state.

2561. Do you grow a fair sample of barley ?-Yes, a very good sample; I have between 700 and 800 acres, and on the lighter soils I get as good barley as can be grown.

2562. Was your crop a bad one last year?-No; I do not complain myself of the crops, only of the prices.

2563 . You attribute your crop being so much better than your neighbours' to their 
their bad state of cultivation?-Yes, for my land is not better than my neighbours'.

2564. It is your opinion that the landlords received their rents by the land having been run out? - Yes, in many instances they will not receive their rents at all.

256. You say that barley is not at a fair price now? - No.

2566 . What other article of farming produce is there that you consider to be at a price low enough to account for the distress? - Wheat most particularly ; the farmers generally cultivate only barley, wheat and oats in that county.

2567 . Do not you cultivate beans?-I do, and some one or two others; but those are exceptions.

2568. Do not the beans sell well?--No; I conceive if the system was introduced, it would be a good one; and 1 did on one occasion, where I had authority from the landlord, offer a farmer the bean seed to put in the land; I drill mine; and if the crop was productive I engaged to take it, because $I$ can consume it ; I am a mail contractor; and if the tenant did not succeed, that he should not pay any rent to his landlord; but he was so fearful he would not try it; he said he knew it would be ruin to him if it did not succeed; he had no inclination to try it, and did not try it.

2569 . Does not your stock sell pretty well? - Lately it has been paying very badly; but we have had an increase in price within the last three weeks or a month.

2.57 . Otherwise your stock has been at rates of which the farmers justly complain?-Yes, certainly.

2571. Do you complain of wool? -No; that has been at a very good price.

2572 . If the farms in your neighbourhood have been overcropped and injured in the way you have stated, so that the wheat crop is not expected to produce, on an average, above 20 bushels an acre, is there any state of prices that may reasonably be expected that would not leave farmers so situate in a state of distress? - I do not know; I cannot tell what the price would be; but if they get small produce and a high price, that might remunerate them; for that crop I think about $7 s$. a bushel would be a remunerating price, if a farmer had an average crop.

2.573. What do you mean by an average crop?-Thirty bushels an acre; he ought to have that, if he crops his land properly.

2574. A farmer, if he could get remunerating prices, would be able to get credit, and to help himself on?-Yes; and I believe that has been the case with some, where they have that to offer; a man can have assistance from a banker for a month or two when the prices are very low, and perhaps there may be a change in price at the expiration of that time.

2575. Are you to be understood that a man has refused to take a farm at any rent? - No ; but there are farms I would not take myself.

$25 ; 6$. You spoke of wool bearing a remunerating price; have you had any great loss of sheep?-No, I do not know that I have lost one sheep myself, but many farmers have had considerable losses in 1831 , and the last year too.

2577. From rot?-Yes.

2.578 . You say barley is not at a fair price ; when you make use of that expression, do you mean with reference to the state of the crops?-A good average crop at present prices is not remunerating.

2579. What is the present price?-Three shillings and sixpence to $3 s .4 d$. in our part of the country.

258 o. What should be the price on an average crop in your country?--It should be $4 s$.

2581 . What do you say, according to the present course of cultivation and the present state of land, you consider as an average crop per acre?-Under 20 bushels, I think, taking the country through.

$25 \mathrm{~S}:$. Yet the farmers cultivate land not producing more than 20 bushels an acre with two wheat crops in four years?-Yes.

2583 . That is the custom of the country? - Yes, it has been during the times of depression.

2.58. Are you aware how many years that land has been under plough; is it land which has been recently broken up?-No; we prevent that as much as possible; there are very few cases where men have old leases and new ones not having covenants to protect the landlord.

464 . 
Mr. E. Bradley.

7 March 1836 .

$25 \mathrm{~S} 5$. You say they are in the practice of liming their lands to a great extent; how often do they lime them?-On what they called their fallowing system they lime very heavily, and take a crop of wheat; the next year they allowed their land to lie in stubble; and the year after, breaking it up, take off another crop of wheat; this practice liad been adopted in a particular district only, and is now alınost, if not entirely, extinct.

2.5 \$6. Do they lime it then?-No; they do not lime it for the next crop; that is in one particular part of the country; the best arable farms we have near the coast; but that is a system they are getting very much out of ; the system is expensive, and there is one year's rent to pay without the use of the land.

2587 . They have two fallows? - Yes; what is called the bastard fallow for the second crop.

[The Witness is directed to withdraw.

Mr. James Grinling Cooper is called in, and Examined as follows:

25 S8. WHERE do you live? -I live at Blythburgh, in Suffolk.

2589 . Are you a farmer yourself? $-\mathrm{I}$ am.

2590. Are you steward for anybody? - I am not.

2591. Are you a tenant of Sir Charles Blois? - I am.

2592. What quantity of land do you hold?-Upwards of 1,600 acres.

2593. How long have you been in the occupation of that land?-Since Michaelmas 1823.

2594. What is the state of farming in your country? - We generally think that farming is on the decline.

2595. Are the farmers in a good condition round you, or otherwise?-The farmers are generally spending their capital ; that is my own opinion, from my own experience.

2596. Are you yourself? - I cannot boast of a great deal of profit.

2597. Have your expenses increased in the cultivation of a farm? - Our outgoings, our parochial expenses, are increased materially.

259\%. Since when? - Since 1823.

2599. Can you state what they have been in the several years of 1789,1804 , 1814,1824 and 1834 ? - I can give the gross expenses of the parish in which my farm is situate, for the years referred to.

2600. What rates does that include?-The poor, county and clurch rates.

2601. All the rates in the parish?-Yes.

2602. Can you state what has been the price of wheat at those different times?-I can state the price which $I$ have realized, and which my father realized in his time; not from the year 1789; my father did not take business till the vear 1793.

2603. Will you give the rates and expenses for the several periods ? - In the year 1789 , the whole expenditure was $107 \mathrm{l} .0 \mathrm{~s} .7 \mathrm{~d}$.; in the year 1804 , it was $210 l .16 s .6 d$; in the year 1814 , it was $333 l .17 s .3 d$. ; in the year 1824 , it was $714 l .7 \mathrm{~s} .11 \mathrm{~d}$; ; in the year 1834 , it was $1,213 l .2 s .5 \frac{1}{2} d$.

2604. You have not got the account for 1835 ? - I have not.

260.5 . Can you state what was the price of wheat in those different periods? Not the price of wheat in 1789. I have a list of my father's prices in 1793, $46 s .8 \frac{1}{2} d$. per quarter; we keep our accounts in combs; that is the produce of the year 1793 ; it was sold in 1793 and 1794.

2606 . What is the next date to which you can give the price?-In 1804 , it was $78 s .10 d$. ; in 1814 , it was $64 s .8 d$.; in 1824 , it was $65 \mathrm{~s} .4 d$; in 1834 , it was $41 \mathrm{~s}$.; and, as far as I can give the present year's produce, my average is $39 s, 2 \frac{1}{2} d$.

2607 . In each year how many labourers were employed upon your farm? -I was not in possession of the farm in the early years.

2608. When are you first in possession of an account of the number of labourers employed either in the parish or on your own farm:--In 1832 we had a. great many men out of employment, and an arrangement was made in the parish to see whether we could find some means for getting the men into regular employment; the first step we took was to allot to each occupier such a number of labourers to be employed by him as would keep his land in a good state; and after apportioning the labourers in that manner, it left upwards of 50 men unemployed. 
2600. How long had your parish been in a state to have a number of labourers; for we know you could not get employment?-I cannot say the number regularly every year, but there have been a number of labourers out of employment for 12 or 14 years.

2610. Arc there more or less out of enployment now than there were when you first took an account?- More than there were when I first took the farm.

2611 . Would those people be employed if your lands were properly cultivated ?-I do not think we could find profitable employment for all the labourers in that parish.

2612. Could you find proper employment for a larger number than are now employed, if your produce was at proper prices?-I think we could.

2613. Was that sort of voluntary rate you speak of done by consent of all the inhabitants? - Yes.

579.

2614. What is the population of your parish?-By the last census, in 1831 ,

2615. What was it in 1789 or 1793 ? - I cannot speak to that.

2616. Can rou speak to it for any earlier year?-No.

2617 . What is the acreage of the whole parish? - This parish has two hamlets attached to it; there are 3,711 acres in the parish. Yes.

2618. You take the parish with the same boundaries as the population?-

2619. Are the lands in your parish so well cultivated as they were formerly?

-The lands in our particular parish are as well cultivated as they were in 1823;

I was not resident in the parish till that jear.

2620. Are they in as good a state now as they were in 1823 ? - I should be apprehensive hardly so good, but there is very little difference.

2621. Your stock has not been so much diminished in price?-I do not think

the quantity of stock upon farms is much altered; but there is a system grown up in consequence of the necessity of the times, where stock is sent on to different occupations by dealers at their own prices, and afterwards taken again when fat.

2622. Do the farmers go on cultivating their land in the expectation that something will be done, and that times will be mended? - That is the impression on farmers generally.

2623. Do you think that they would go on cultivating, if they did not entertain such an expectation? - If they did not entertain an expectation of prices mending, they would not go on.

2624. Do they expect any thing to be done by Parliament?-Yes.

2625. If that expectation were disappointed, would they, in your opinion, throw up their farms? - They must throw up their farms, or have their expenses reduced in some manner.

2626 . In the country around you, are the farmers in a prosperous or ruinous state?-They are bordering on a ruinous state.

2627 . Is that the case with the greatest number?--I should say it is the case with the majority.

2628 . For how many miles round are you acquainted with it ?-My observation would apply not far round me; I am skirting on the coast; but perhaps 20 miles each way.

2629. You think that the farmers generally are in a ruinous state?-Yes.

2630. Has it been the habit to make up the rate of wages out of the poorrate? - Never, to those who were in regular work; they have received full wages when they were regularly employed on the land.

2631 . What wages do you give?-By the day, $\pi$ e are now at $8 s$. a week; but the earnings of men employed on land generally would average with us abore $9 s$. a week.

2632. How do you account for the great increase of expenditure of the parish between 1824 and 1834 ? - I cannot account for that, except from the increased population of our parish, and the inability of the farmers to employ; we are so situated that we have not houses for them; we have a great number of poor belonging to the parish who are not resident.

2633. A large proportion of the 3,711 acres probably is not in cultivation?I can give the different quantities of each description of land; arable land, 2,380 $\frac{1}{2}$ acres. I should beg to observe, there is a very great disparity in the value of our lands; from $5 \mathrm{~s}$. to $22 \mathrm{~s}$. and $23 \mathrm{~s}$. an acre; a great part is of the worst descrip464 . 
M1. J.G. Cooper. tion of land; there are 707 acres of marsh and pasture; a great part of them are very ordinary; $27 \frac{1}{2}$ of marsh walls; $9 \frac{1}{2}$ acres of reed lands; 363 acres of 7 March 1836 . heath land, sheepwalks, and so on; 224 acres and 1 rood of woods, very ordinary; no underwood in then; they are mere fir plantations.

2634. What market town are you near?-Halesworth, in Suffolk.

2635. The land is stiff, cold land generally, is it not?--The principal part of this parish consists of mixed soil ; poor light land, and some poor heavy land.

2636. What are the poor-rates in the pound ?-Taking out the heath land and woods, the rates will average $7 s .9 d$. an acre, and this is exclusively of statute duty ; I take the money actually paid.

2637. You regulate your rates by so much in the pound on a valuation; how much in the pound is it?-I am not prepared to answer that question.

2638. What is the proportion of your poor-rate to your rent?-It is in the same proportion as $254 \mathrm{l}$. $10 \mathrm{~s}$. is to $1,100 \mathrm{l}$; I live in Blythburgh, but about two-thirds of my farm is in an adjoining parish, where the rates are very low.

2639. How many rates do you collect in the year?-Generally four.

2640. What per-centage in the pound in Blythburgh? - I should say not less than $12 s$. in the pound for the year ending March 1834, and our best lands assessed at $17 \mathrm{~s}$. per acre ; then, graduated according to the quality of the land that we assumed at the time of the valuation to be two-thirds of the annual value, that would make our best land tithe-free $25 s .6 d$. an acre.

2641. Does the tithe belong to the landlord?-The tithe of the whole parish belongs to my landlord.

2642. So that he lets it tithe-free?-He lets the estates he owns tithe-free.

2643. Have the rents about you been reduced much? - I believe in all cases I know, where the farms have been re-let, they have been reduced.

2644. To what extent? - I will take the case of a farmer in my own parish ; a farm containing 379 acres of land.

2645. What was the rent?-The rent in 1804 was $350 l$. ; the rates of the parish for that farm that year, $10 \mathrm{l}$. $11 \mathrm{~s} .4 \mathrm{~d}$.; the same farm, in 1814 , rent $350 \mathrm{l}$., rates $23 \mathrm{l} .10 \mathrm{~s}$; in 1824 , the same farm, the rent $250 \mathrm{l}$., the rates in that year $51 \mathrm{l} .14 \mathrm{~s} . ;$ in 1834 , the rent $200 \mathrm{l}$, the rates $84 \mathrm{l} .12 \mathrm{~s}$; and, out of the annual rent, the land-tax, repairs, and the expense of keeping up a considerable marsh wall, were $42 l .16 s$. per annum.

2646. Do you mean out of the $200 l$ ? ?-Yes. farm.

2647. Was that deducted also out of the $350 l$ ? - Yes; this is a light land

2648. Have the farms in your neighbourhood been all reduced in the same proportion? - I should consider not; I should consider this rather an extreme case; but they have been generally reduced when they have been re-let.

2649. How much per cent. have they been reduced?-I should say the difference in the last 12 years would vary from 12 to 15 and 18 per cent., and beyond that in some instances.

2650. Can they go on at this reduced rent?-I should say certainly not; I have a statement of a heavy land farm, a stiff soil.

2651 . What was the reduction on that?-The farm consists of 101 acres of grass land, 80 acres of arable, and 13 pasture, and 8 acres of waste; it has been regularly farmed in the four-course system of husbandry; this farm in 1813 was purchased at 4,000l., and was mortgaged to a $\mathrm{Mr}$. Capron for 2,000l. at that time; his executors at the present time would be very glad to sell the farm at $2,000 l$.

2652. Was it thought a good purchase at the time it was made? - That I cannot say; it would be something under $40 \mathrm{l}$. an acre; that I consider a full price at the time.

26.5.3. Was it thought a high price at that time?-I should conceive it was only the market price at that time; the executors, who are offering it at 2,000 l., cannot obtain a purchaser for it.

2654. Is there any very material difference in the condition of the land between the time of the purchase and the present time? - The farm, 1 believe, has been regularly farmed in the four-course system of husbandry.

265.5. Is the land now in as good condition as it was then?-Perhaps not in quite so good a state of culture.

$265^{\circ}$. Has the land about you generally gone back in cultivation, or been improved? - I apprehend it has gone back. 
$265 \%$. For some time back? - It has regularly gone back since the present price of farming produce. back.

2655. It will produce less corn to the acre? - Yes, in consequence of going

Mr. J.G. Cooper,

7 March $: 836$.

26.59. Your own farm, you say, you took in 1823; what was the price of wheat then?-Whe price of the produce of 1824 I can state; taking from Michaelmas 1823 , the first year would be 1824 ; that was $65 s .4 d$. per quarter.

2660. When you agreed with your landlord to take the farm, what was the price of wheat in your contemplation?--Sixty-one shillings and twopence was the average price the preceding Michaelmas to my taking the farm.

2661 . When you took it, about $60 \mathrm{~s}$. was in your contenplation as the probable price of wheat?-Yes.

2662. Do you suppose that at $60 \mathrm{~s}$. for wheat, with other things in proportion, your rent was a fair rent at the time? - I thought so.

2663. Do you think it would be so now? - I think it would be such a price that I could pay my rent, with other produce in proportion.

2664. What should you consider a corresponding price for barley, taking $60 \mathrm{~s}$. for wheat?-I think barley about $34 s$.

266.5. Thirty-four shillings for barley is about equivalent to that?-I think it will appear so on the average of years.

2666. Have you had any reduction of rent since 1823 ? - I have taken a fresh hiring since that.

2667. Have you any objection to state when your last hiring was?-About a twelvemonth back.

2668. What reduction then took piace?-Nearly $12 \frac{1}{2}$ per cent. reduction; but mine is a stock farm, as well as grain; a reduction of that sort might be fair on my farm that will not apply to many; I have a large quantity of marshes and sheepwalk in my farm, that I am not dependent on corn only.

2669. What is your course of lusbandry?-The four-shift course; one-fourth fallow, one-fourth barley, one-fourth layer or beans or peas; the remaining fourth of wheat, on such land as it is good enough to grow it, or rye on the poor land.

2670. What do you call a fallow ?-We put turnips on the light lands.

2671. You do not mean seed?-No; the land lies clormant, turnips excepted, for a year, for the purpose of cleaning it, and getting it into a proper state.

26 2 . What does your barley sell for now? - The average produce of $\mathrm{my}$ barley of the last harvest, up to this time, is $24 s .6 \frac{1}{2} d$. per quarter; our lands are poor, and from the excessive drought we had an inferior quality.

2673 . Is your barley generally of an average quality?-Yes.

2674. What is the price of average qualities of barley?-I cannot give any opinion of the average quality; I have known barley sold by us as low as $22 s$. this year, and up to $35 s$.

20675. Does not fair malting barley at Halesworth sell at $36 \mathrm{~s}$. ?-Fair malting barley will not average with us $30 \mathrm{~s}$, , unless it is the chevalier barley ; I have sold good malting barley last November at $26 \mathrm{~s}$. per quarter, and cannot now make more.

2676 . What flock of sheep have you? - I keep about 45 score and upwards.

2677. Nearly 1,000 sheep? - Yes.

2678 . Have they sold pretty well? - Lambs have sold better, in consequence of the improved price of wool.

2679. Have you had for your stock pretty much as good a return as, when you first took your lease, you had reason to expect?-No, I do not conceive I had during the last lease; as to the present, I cannot give an opinion; I have not taken any produce to market since that.

268 o. Your wool is selling well?-Yes; it was selling at $36 s .6 \mathrm{~d}$. a tod

when I first took my farm ; it has been selling at $36 s$. since that.

2681. It was much lower formerly?-I sold at $14 s$. a tod in 1829 , and it was very low in $1826,1827,1828$ and 1830 .

2682. The present price of wool you consider a good price?-Yes; other circumstances corresponding, it would be a remunerating price for wool of that description; the same observation would not apply to hogget wool.

2683. You have spoken to the case of a particular farm; is the cultivation generally going backwards in your county? - I conceive it is. 
Mr. J. G. Cooper.

7 March 1836 .

$208_{4}$. That the lands are deteriorating ? - They are deteriorating in point of cultiration.

2685. Do you use artificial manure ; bone-dust, and so on? - There is a great deal used in some places, but not as a general system.

2686. Is there less used now than there used to be ?-I think there is.

2687 . The farmer cannot afford it ?-He cannot.

2688. Does your land require draining?-No.

2680 . You conceive the cultivation is going back generally; to what do you attribute that?--To the low price, and the inability of the farmer to employ more labour on the land.

269o. What do you consider the average per acre? - I can give the average crop on my own farm, and on the farm I lave alluded to, which was reduced one-half in the fee-simple value; I have grown, on an average of 10 years, six coombs and a half per acre, that is, three quarters and two bushels per acre, that is, 26 bushels ; barley about 28 bushels per acre ; oats I do not grow. farm.

2691. Beans?-I do not grow oats, beans or peas; mine is a light land

2692. How was it last year; was it more than an average crop, or less, with you?-The harvest of 1835 we have not threshed; the harvest of 1834 barley was decidedly below an average crop.

2693. How was wheat?-Wheat was nearly an avernge produce.

2694. You do not know how much it yielded an acre of wheat in 1834 ? Twenty-three bushels per acre.

2695. You stated 26 to be the average?-That was the average of 10 years. The question asked me was as to my farm; what I considered the average ; and I considered 26 the average.

2696. Eighteen hundred and thirty-four cannot have been an average crop with you?-No, it would not, compared with the 10 preceding years.

2697. Generally speaking, it was a productive year, was it not?-Generally speaking, I think it was; there was a greater deficiency of barley than of wheat.

2698. You have stated that the crop of barley in 1834 was below the average crop; did the price compensate for the smallness of the quantity? - Not any thing like it.

269y. Will you give the average of the other farm to which you alluded ?I cannot give the average of 10 years on that farm; I can only speak to each particular year.

2700 . Can you give the average quantity on that for the last year? -Yes; the average quantity of wheat on the heavy land farm for 1834 would be 21 bushels per acre; barley 29 bushels per acre. On the light land farm for 1834 it would be 23 bushels of wheat per acre, and 19 bushels of barley.

2701 . Is that usually the average as to crops between those two farms; that the heavy land is more productive in barley, and less in wheat? - I have not examined that particular point; but $I$ can state the quantity in any one year. The barley of 1834 was very unproductive with us.

2702. Take any one year when barley has made a good crop on the light lands? -I will take the year 1831 . The barley on the light land farm in that year would be 32 bushels per acre; the barley in 1831, on the heavy land farm, would be 36 bushels per acre; on the light land the wheat would be 26 bushels per acre, and for the year 1831, on the heavy land, only 12 bushels per acre.

2703. What sort of a year was that; a dry year or a wet year?-The year 1831 was neither excessively dry nor wet.

2704. Have the turnip crops failed you this year?-Yes.

2705. Is there much oil-cake used with you in feeding cattle?-Yes, and corn.

2706 . Has wheat been so used?-Yes, to a much larger extent than formerly,

2707 . Have you much practical experience in feeding beasts with grown wheat?-No.

2708. Or with malt? - I have had experience of feeding horses with malt.

2709. Do not you think it would be advantageous to the farmer if the malttax was repealed, and he could malt his own barley? - I think it would, and it would have a great effect in bettering the condition of the lower class. 
2710. What effect have the beer-houses in your nëighbourhood?-Generally a very bad effect.

$27 i 1$. You were mentioning that your father farmed before you; was that on the same farm? - He was with me three or four years in this farm; but he was on a heavy land farm previous to Michaelmas 1823 .

2712. Can you state, from what you collect from the old farmers of the county, what proportion the present rents bear to those in 1789 ? - It was in the year $1793 \mathrm{my}$ father took the business; the same farm now lets for more money than it did in 1793.

2713. Looking about at individual farms, not stating who holds them, can you state in what proportion any given farm is higher now than it was then?- $\mathrm{N}_{0}$, I cannot do that.

2714. Has the new Poor Law been in operation with you?--Nearly 12 months.

2715. Do you belong to an union?-Yes.

2716. Have you built your workhouse, or are you building one?-We have one.

2717. Did you form part of an union before?-We were incorporated with the hundred ever since the year 1767 .

2718 . Those unions are not uncommon in the county of Suffolk?-No, they are not.

2719. How are they considered to have worked; have the parishes belonging to the old unions been better off than those which managed their own poor?Before the operation of the new Poor Act, it was considered that the rates were generally lower in the incorporated than in the unincorporated hundreds.

2720 . Do you anticipate any reduction of the present poor rates from the present system?-We are expecting some reduction.

2721. As far as the present year has gone, has any actual reduction taken place? - There has.

272. To a considerable extent? - We have not had more than half a rear's experience, as it took some time to get the system into work; we have not paid more than two rates under the new system; as far as those two rates go, we are lower than we have been. I think the two rates together would amount to $4 s .6 d$. in the pound; I think they would have been from $5 s .6 d$. to $6 s$. under the old system.

2723 . Is the new system popular with you? - It is generally supposed that it will have the effect of reducing our rates to some extent, but it is not popular with the lower orders.

2724. You do not consider that the labourers really suffer under the alteration much? - They are suffering in our particular parish; for this reason, because we have an excess beyond that we can employ, and the out-door allowance being cut off, the labourer is compelled to go into the house for relief; they have been gradually enforcing that; and I think, with the exception of the very old and the widows, there is no out-door relief to be continued.

2725. Do you find that that makes them shift for thenselves more than they have been used to do?-It drives some of them to that, but some are spending any little furniture they have, to keep out of the bouse as long as they can.

2726. Can you state how many able bodied labourers were out of employment last winter? - The number of labourers belonging to the parish in 1832 was 171 men, and 18 boys between the ages of 12 and 15 , exclusive of paupers in the workhouse.

2727. What proportion of them were out of work? -From the 10th of October to the 27 th of December inclusive, 1834 , we averaged $31_{11}^{2}$ men per week out of work the whole of that time, and from 27 th of December to the 4th day of April following, 1835, we averaged $64 \frac{13}{14}$ men per week unemployed.

2728 . You stated that rents are higher now than in 1793 ? - I think they are.

2729. Do you think that may be owing in any measure to the capital laid out on the land in more prosperous times:-I consider that to be from the increase of competition for land, and caused in many cases by the farmer being obliged to leave his farm, from inability. There are many who have diminished capital who go and hire the land at a higher rent than it is worth, who keep the price of land up, in expectation of being able to draw out of the land the unexhausted improvements left by the previous ruined tenant, and trusting to the return of 464. 
Mr. J. G. Cooper. better times; but they cannot long continue to pay their rents if corn remains at the present low price.

7 March 1836 .

2730 . Were not great improvements carried on in the farms, in draining, fencing, and so forth, when prices were higher ?-Certainly there were improvements made; but I should not conceire the lands now to be in the improved state they were at the time referred to by the question.

2731. Have the landlords in general expended any capital upon the lands since that time, in drainage or otherwise? - In all cases of draining with us, the tenant does the whole.

2732. Have the landlords expended any capital in substantial improvements? -In improving the buildings, perhaps.

2733. Has the rent increased above what it was in 1793, exceeding proper interest on the amount of money expended by the landlord?-I do not know that I could answer that question without going into some calculation.

2734. Do you think that the state of the land is better now than it was in 1793 , so as to justify an improved rent ?-I think the land is decidedly improved since 1793 .

2735. Either from the actual state of the land being better, or their being able to cultivate it with more skill, do you think a larger rent might be fairly expected? I think it would be reasonable to expect an increased rent now, provided agricultural produce was at the same price, and outgoings on land not increased.

2736. You speak of labourers who are forced to go into the workhouse; does that apply to able-bodied workmen ?-Yes.

2737 . Does it apply to people of good character ; steady and industrious people?-Yes.

$273 \mathrm{~S}$. They had been used before to have assistance on the poor-rates without going into the house ?-Yes, by working on the road, or any other work which was ordered by the overseers.

3739. They have no such assistance now ?-No.

2740. Who are the persons who have the management of the poor in your neighbourhood?-The guardians, under the direction of the Poor Law Conmissioners.

2741. Have the guardians any discretion upon that subject?-Not being a guardian, I cannot answer that question.

2742. Have many of those respectable labourers with their families been sent to the workhouse?-I believe in many cases they have been offered the workhouse, and almost universally refused it until after several weeks.

[The Witness is directed to withdraw.

Mr. Richard Hoare Dowling is called in ; and Examined as follows :

M.

R. H. Durwling.

2743. YOU are a corn-factor, farmer, and miller at Bexley, in Kent?-I am. 2744. You occupy an estate under Lord Bexley?-I do.

274.5. How many acres :- I occupy and farm my own estate; I also hold under Lord Bexley, at a little distance, a farm called Hurst, which contains 210 acres; added to which, I have 26 acres of marsh land. I occupy about 400 acres, my own and that together.

2746 . What is the state of the farmers in your country? - In a very bad state.

2747. Can they pay their rents?-The landlords are best able to judge of that?-I should say very partially so.

2748 . If they do pay their rents, have they any particular mode of paying those rents; can they raise it out of the land in any way? - If they pay their rents, they must pay them out of their own capital, generally speaking.

2749 . Do they pay it by over-cropping the lands?-They are compelled to force their land.

2750. Are they compelled to force their land in consequence of the difficulty of paying the rent:-No doubt they are.

2751 . That is injurious to the land?-Certainly it is.

2752. From your situation as a corn-factor, can you form a better idea of the state of the farmers than as a farmer?-I can.

27.53. Are they, round your neighbourhood, very much distressed?-They are; I know many instances where they have applied to me for advice; they are sinking fast the little capital they have, and must inevitably come to the workhouse in two or three years, unless they get some relief. 
2754. Docs that apply to any great number?-1t is not a solitary instance; in several instances I have been applied to.

275. Are they holding out in expectation that something will be done for them?-They cannot leave the little property they have in the land without sus. taining a great loss; they have been holding on with the expectation of recovering themselves.

2756. Have you found, in your situation of a corn-factor, that they can pay their debts?-No; I am sorry to say I have been a great loser by them.

2757. Were the people you speak of, who have stated to you they must give up their farms, respectable men?-They were, and highly industrious and holnourable characters.

2758 . Is their distress owing to the depression of prices?-Yes.

2759. To what do you attribute that depression?-I think there are several causes to which it may be attributed; as far as my own knowledge goes, I should say from improvements in agriculture in Ireland. I speak from my own experience as to the great importations we of late years have received from them as compared with former years.

2760 . Is there more Irish corn imported into this country than there was formerly? - Considerably. When first I went to live where I now do, and I have been there 22 years, for the first 10 years I was in the habit of shipping oats from Kent to London; but for the last 10 or 12 years it has been quite the reverse; I am continually in the habit of shipping the other way, for the farmers seldom grow sufficient for themselves.

2761 . What has prevented the farmers growing sufficient for themselves?I should say the great increased growing of wheat, oats having been at so low a price.

2762 . Has the importation of oats from Ireland prevented your sending oats to London?-Yes; the Kentish farmers have been the users of them, instead of growing them themselves.

2763. Are you acquainted with Ireland:-No. I have very recently had some conversation with a gentleman who has been looking at a farm, with a view to taking it, in Ireland. I have been inquiring the expense, and I find we have no chance of competing with them, under the mass of burthens we have, and which they have not.

2764. What are those burthens?-This gentleman tells me he can get a good labourer at $8 d$. a day; I am paying $2 s$. to $2 s .6 d$. ; they have no poor-rates; and as to tithe I will say nothing, your Lordships being better able to judge of that than myself; the church-rates and many other contingencies we have; and our poor cannot live as they do; I venture to say three Irishmen would live where one Englishman would live.

2765. To what other cause do you attribute that depression of prices?-The currency question I should be very sorry to go into, but the farmers say that when the $1 l$. notes were in vogue they were much better off.

2766 . Have you remarked the fluctuation of prices in particular years? - Yes, but my memory will not serve me; the year 1822 I perfectly recollect; that was the worst season I ever saw for the farmer and the trader also; from 1821 to 1822.

2767. Did the prices fall greatly in those two years?-Most materially from 1821 to 1822 .

2768 . When did they rise again ?-I think they turned before the year 1822 was out, and they rose again in 1823 and 1824 .

2769 . They got up to a better price?-Yes; they got up to a prosperity price.

2770. Have you observed that the prices of agricultural produce have risen or fallen in proportion to the largeness of the circulating medium?-Yes, that is my observation.

2771 . Have you made any observation on the bonding system which prevails in this country?-Yes, I have.

2772. What do you think is the effect of the bonding system on the price of produce? - I think the present Corn Laws are very injurious to the farmer; and that the bonding of foreign corn is the cause of that injury. If the corn was paid for at a protecting duty when it is imported, that would be a great protection, 464 . 
Mr. R. H. Dowling

7 March 1836.

and would benefit the Government, which now are great losers thereby, as also the farmers.

2773. Has the bonding system the effect of diverting speculation to foreign corn instead of English corn?-Decidedly.

2774. But for that would English corn be treasured up in our own warehouses, and the produce kept over?--There is half a million of foreign corn in bond, and I would go and buy English corn but for this corn lianging over our heads, and so would others.

2775 . Would those warehouses be filled with the surplus of good seasons, if it were not for this foreign corn? - They would not be filled, but there would be a great portion in them.

$27 ; 6$. You are of opinion that the warehousing of foreign corn in this country is attended with injury to the farmer and to the merchant in English corn? -Yes.

$277 \%$. Have you considered what would be the effect of a partial or total repeal of the malt-duty; whether it would tend to relieve the farmer?-I think a partial remission of the duty would be useless to him ; that if we do not get a total repeal it may as well remain, as they would not thank you for it.

2778 . What would be the effect of a total repeal?-The farmer has in all seasons a quantity of barley he cannot sell to the maltster, but he could make very good beer of it for his family and people round him, if it was not for the excise.

2779. Would there be much more consumed ?-Certainly there would.

2780 . That would relieve the wheat land?-Decidedly so.

2781 . Suppose there were more flax and hemp grown in this country, what would be the effect of that on the farmer ?-I do not understand those articles.

2782 . Is there any other information you have to give?-Seven years ago I took a farm, which Lord Bexley has since purchased, at what I then considered a very low rental. I have kept a balance-slieet; it is about a mile from my own house; I balance every Michaelmas; this is a copy of it, and not made up for the purpose of producing here. I took the farm at $1 l .1 s$. an acre, 210 acres; I thought it a very low rent.

2783 . Is it tithe-free?-No. That farm had at a former period been let at nearly double the rent; I took it, therefore, because I thought it a very low rental.

$27 \$_{4}$. You took it in 1828 ?-Yes; I commenced it from Michaelmas 1828. $I$ also added 26 acres of marsh land to it, which I came into at a very low rental of $70 l$. a year, the previous tenant paying $170 \mathrm{l}$. I' attached that to this Hurst Farm, as it is called. It took 2,000l. to enter and to stock it. My expenditure for the seven years ending Michaelmas 1835 was 16,862l.; my returns for the same seven years, including valuation of live and dead stock, to Michaelmas 1835 , were $16,731 \mathrm{l}$. $6 \mathrm{~s}$.

2785 . Was that upon this farm only? - Including the 26 acres of marsh land. I keep no account of my own farm on which I reside.

2786 . Your outgoings include rent:-Yes, there is a balance of $130 l$. 14s.

$278 ;$. Have you any objection to deliver that in?-No. The $130 \%$ would leave me about a balance as when I commenced, leaving me no interest for my capital, nor $1 s$. profit for the seven years' farming, although I think I must have the credit of supposing that I have great advantage in selling my produce better, as also in seeding the land at a cheaper rate than most persons could do, and did not stand still for capital. I could make a better return of produce than a common farmer could, from the advantages I possess, being in trade.

2788 . You have paid attention to this farm?-I have; I have farmed it well. The ploughing-match was on that farm this season, which proves it is in a good state of husbandry.

2789 . Notwithstanding that, the result is as you have stated?-Yes; I have not had $\mathrm{l} s$. interest or reward for my undertaking.

27 yo. How many years is that? - Seven years previous to Michaelmas last.

[The following paper is delivered in and read:] 
In occupation of R. H. Dowling, at Bexley, Kent. 236 acres.-Rent $290 l$. - Rent previous to 1822 was $610 l$.

\begin{tabular}{|c|c|c|c|c|c|c|}
\hline Seven years' expenditure, e & nding Michaclmas & 1835 & - & - & $\begin{array}{c}£ . \\
16,862\end{array}$ & s. \\
\hline By returns and valuation to & Michaelmas 1835 & - & - & - & 16,731 & 6 \\
\hline
\end{tabular}

A capital of 2,000l. employed, which neither bears interest nor $1 \mathrm{~s}$. profit for the last seven years.

2791. You say your expenses were $16,862 l$, and you had from 2,000l. to $3,000 l$. capital employed; in what state is that capital now ?-It comes into my returns of $16,731 \%$. $6 \mathrm{~s}$.

2792. But there is no profit upon it?-No, nor $1 s$. of interest, though it is farmed as high as any farm in the county of Kent.

2793. What is the rent of the marsh land?-Seventy pounds.

2794. It is $220 l$. for the farm, and $70 l$. for the marsh land?-Yes; which marsh was previously let for $170 l$.

2795. Are your tithes ligh?-The great tithes are taken in kind, which is very much against us.

2796 . You state the returns to have amounted to $16,731 \mathrm{l} .6 \mathrm{~s}$. in seven years? -The returns and valuation at Michaelmas last.

2797. Do you know what the valuation at Michaelmas last was?-No.

2798 . The return appears a very large one for so small a farm? - I am very fond of stock; I am a great stock-farmer.

2799. Do you suppose the valuation to have been $3,000 l$. ?-Oh no; 2,000l. I should say.

2800 . Supposing it to be $2,000 l$., leaving $14,731 \mathrm{l}$., that would make upwards of $2,000 l$. a year return upon your farm? - Yes.

2 So1. Is not that a very large return upon a rent of $290 l$. ?-Yes, a very large return; but I am very fond of stock-farming, and perhaps rather overstock.

2802. If it is stocked, and it makes a return, does not that increase the expense of cultivating a farm?-No; it very much increases the return.

2803. Two thousand pounds a year would make something like seven or eight rents?-Yes; it is no criterion of the mode in which others farm. I perhaps fatten 100 bullocks in the year on that farm, and in the marsh I fattened 70 bullocks last year; another would not perhaps fatten half the number.

$2 \mathrm{So4}$. Your land is improved?-Yes.

280.5 . Is that the case with the land about you generally?-No, decidedly not. I think when the farmer is needy, his land is going behind hand; if a farm is in a good state of cultivation, I should say the farmer is not a needy man.

2806 . You think the bonding system is injurious to the farmer, because you say that bonded corn hangs over his head in the warehouses, and prevents people speculating in English corn?-Yes; and bonded corn is particularly injurious to the farmer, because it usually comes out about harvest. Our prices generally get up higher during the harvest, or the months just after the harvest. When the ports open for a short period, they depress the marliet from that till Christmas, when the needy farmer must be getting his corn out, and he is the great sufferer.

2807 . The article the farmer suffers from the low price of at present is the article of wheat?-Yes, particularly ; but I think all prices of corn are low.

$280 S$. You do not think barley is at a low price, do you?-Yes, I do.

2809 . At what is it selling now ?-At $29 s$. or thereabouts, the average.

28 i 0 . Do you not get a better price for barley of the best quality?-Yes; but there is more inferior than of best barley.

2811. Do you grow inferior barley in your neighbourhood? - I do not grow either barley or oats; when I can buy Irish oats at $15 \mathrm{~s}$. and $16 \mathrm{~s}$. a quarter, as I have done, I should never think of growing any.

2812. You do not grow any barley?-No; but where there is one sample good for the maltster, there are two of a secondary quality.

2813 . Is that owing to the dryness of the season?-Yes, it is.

2814 . Do you consider your other prices bad; the prices for stock and for wool :-No; for stock, decidedly not. The prices of stock are good, but that is 464. 
Mr.

R. H. Douling

7 March $18{ }_{3} 6$.

owing to having no turnips; the price of meat is dearer this day in Smithfield; but the want of turnips is against the farmer.

$2 \$ 15$. You consider the prices of stock as good for the farmer :--The stock of fat meat.

2810 . Is the lean stock low:- It has been low this last season.

$2 \$ 17$. That is better for you, is not it ?-If we had any thing to fatten them on.

281 S. You do not suffer by the low price of lean meat?-No; it would be a benefit if we had turnips to fatten them on.

2819 . Have you any fat stock to sell?-Yes; but my neighbours have not.

There is not any one in my immediate neighbourhood who fats so many as I do.

2820. Speaking of your orn individual case, the state and price of stock, lean stock being rather low, and fat stock being at good prices, is rather a favourable state of things for you?-I must put something against that. I have been compelled to fatten them on artificial food, on oil-cake and corn; that rather turns the balance against me.

2821 . Have you a flock of sheep? - Yes, a very large flock.

2822. Your wool is selling very well?-Yes, at very fair prices.

2S23. Taking the average of the other things you sell, your wool, your stock and your barley altogether, should not you say, as a farmer, you have nothing materially to complain of but the price of your wheat?-I think that wheat is the main cause, but I think that barley is not fetching a remunerating price.

2S24. You would rather see that a little higher?-Certainly; but the price would be better if we could malt ourselves, for there is a great proportion we grow which we cannot sell to the maltster.

$22_{25}$. If you could malt it yourselves, you would use it more in fattening stock :- - I have not turned my attention to that particularly; but we should find our workmen in beer, which we do very sparingly now.

2826 . That would materially improve the condition of the agricultural labourers?-Very materially; but I conceive that taking a portion of that duty off would give us but a very trifling relief.

$2 S_{27}$. You would like to have the manufacturing of the article?-Yes.

2828 . You state your returns to come to pretty nearly the amount of your outgoings. In the early part of the seren years you have spoken of the state of your account as better, and it is in the last two years it has become so bad?It was better two years ago, but not remunerating then.

2829 . It has been getting worse the last two years?-A little worse each year.

$2 S_{30}$. You say that foreign corn comes into the market in the manner you have spoken. At about what price of wheat do you suppose foreign wheat to interfere with you?-It comes in, I think, at about $4 s$; that is the average amount of duty usually paid on foreign wheat.

$2 S_{31}$. When the prices get up, at about what do you find the foreigner coming and interfering with you ; is it when you get to $60 \mathrm{~s}$., or $65 \mathrm{~s}$, , or $70 \mathrm{~s}$, , or what rate?-Perhaps I can hardly answer that question; I should think we inust be at $65 s$. to $70 s$.

2S32. The price has been down under $40 s$, has it not ?-It has.

2833 . Must it not get up to $65 s$. or $66 s$. before the foreign corn can enter the market in quantities to interfere with you? - That must depend on circumstances; it must depend on the prospect of the ensuing harvest; if that is expected to be good they will pay the duty upon it, and take it out at a high rate of duty. They do not usually pay the heavy duty under those Corn Laws; I have taken a great deal out myself at $i s$. duty.

2834 . There must be for a time a great price:--Yes; and when they fancy that the next harrest is a bad prospect, they would wait and pay a low duty.

2835 . Are you aware it was the intention of the Legislature, when the price became very high, to let in corn at $1 s .6 d$., that the country might be relieved from too high a price of bread?-I am aware of that.

2836 . Should you say, if the law is so poised as that no considerable importation can take place till it comes to $65 s$. or $66 s$., that the English farmer, having the command of his home market up to that rate, has not a fair protection by those laws? - He has no protection by them, because the ports usually open about July and August; generally the highest prices range at about that pericd, at the time of our harvest ; then we are glutted with corn, perhaps at a low duty, for they scldom pay the high duty on much, if they have a prospect of 
bad harvests; corn gets down to a very low price ; then the needy farmer must bring all his corn between that time and Christmas; he therefore reaps no benefit from the Corn Law, but a serious injury, for he is sclling while that foreign corn is having its full effect.

2837 . If it comes into the market at a time when the English grower is obliged to bring his corn into the market, must not the state of the market, notwithstanding the English grower is forced into it in the manner you mention, be such as to afford a remunerating price, if, under those circumstances, his stock fetches a price which shall let in the foreign grower?-It is high only for a few weeks, and during that time we have this 500,000 quarters all poured in upon us, and we have, in addition to that, consignments from all quarters.

2838 . Are you aware that the Bill is so calculated that it is not the high price of a very short time which will let it in?-Yes; the average of six weeks.

2839 . Therefore there must be an average of six weeks of this price before it can come in? - That six weeks happens at a time when the needy farmer has not a grain of corn to bring in; the moment it gets up to this price this quantity of wheat is poured upon him, and he is obliged to sell it to great disadvantage, to pay his rent and bills, and so on, and he must inevitably be ruined.

2840 . He is coming into market simultaneously with the foreign corn? - Yes, immediately the foreign corn has been poured in; from harvest time till the following Christmas is the time he has a glut of foreign corn to encounter, consequently the prices are very much depreciated.

2841. The foreigner has not brought in his corn for the last two or three years at all ?-The ports have not been open for the last three years.

2842. If it should appear that for six or seven years before those three years the prices had been on an average above $60 s$, and since they have been so very low the foreigner has not imported at all, could you, under those circumstances, impute the present depressed state of the market to any interference of foreigners? - I should not at this moment, with the exception, that a speculating man will say, as I would myself say, let us see the quantity of corn we have in bond before I speculate in the English corn; he sees 500,000 quarters in bond, that of course is a great bar to his speculating in English corn.

2843 . The Committee are to understand you do not think the manner in which the Corn Laws generally exist in this country exposes the British grower to danger; you do not impute to the state of those laws the very low price which for the last two years has existed ? - No, I do not ; I impute it to the great glut of oats from Ireland which has been poured in upon us.

2844. You state that you have remarked that corn has generally got up a few weeks previous to the harvest, and that owing to foreign corn being enabled to come into the market, the small farmers have no means of making a good price in consequence of that competition?-Yes; I am a practical man; I have been in it all my life, and have invariably experienced it.

2845. When you speak of the high price of com just on the eve of a harvest, and consider the short period during which the average is taken, do you think that can be considered a high price?-No; it is a high price, considering the state of averages.

2846 . Should you think that the English farmer would consider that a price at which he could get remunerated :-No; we should not be very prosperous at those prices.

2S47. Do you live in your farm-house :--No, I let it; that is an advantage I have not before stated to you.

2848 . Do you include the rent of the farm-house in the account you have given in $\mathrm{F}-\mathrm{Yes}$, I do; I let that to an advantage.

2849. At how much a year do you let the house :-The average is $26 l$. a year.

2850 . You say there is no advantage to the fattening farmer, the farmer who fattens the sheep, in consequence of the artificial food; how is the breeding farmer off, has it been a very good year for him :-It is a seriously bad year for breeding lambs.

2851 . He has sold his lean stock very low - - Yes, it has been sold very low in the autumn; I never knew it so low since 1822 .

2852. Do you speak of sheep?-Of sheep and beasts.

2853. You say it is necessary to have the whole of the malt-tax off; unless you got off the whole, you do not take the farmer out of the jurisdiction of the Excise?-Yes.

464.

T 4

2854. At 
Mr. R. H. Dowling. 7 March $183_{6}$.
$2 S_{54}$. At what rate of duty does the foreign corn-grower generally introduce his corn into home consumption here?-I have stated about $4 \mathrm{~s}$.

$2 S_{5.5}$. He watches his opportunity, and gets it in at $4 s .-Y e s$.

$2 S_{56}$. Which opportunity has not been presented these two years, but it is generally presented about the time of harvest?-Yes; I have paid on large quantities less than that.

2857. Then comes in a great glut, which depresses the market for a considerable time?-Yes.

$2 S_{5}$ S. Are you aware what must be the price of English corn when the foreign corn comes in at $4 \mathrm{~s}$. duty? - It appears that it must get up to $70 \mathrm{~s}$. to pay $10 \mathrm{~s} .8 \mathrm{~d}$., at from $73 s$. to $74 s$. it comes in at $1 s$. duty.

$2 S_{5}$. Do you not think that, taking the large population of this metropolis for instance, it is a great blessing for them if the price of wheat passes $70 \mathrm{~s}$. to find a supply somewhere?-Yes.

2860 . Do not you think that the farmer himself would be in danger of his whole protection being taken away, if it were not that the law does provide that remedy in the case of very high prices; do you think that the farmer would be able to maintain any protection of corn laws if it were not guarded so as to give the large population of the country a supply when the prices passed from $70 s$. to $80 s$.? - My opinion is, that if we had a stipulated corn-duty payable when corn is imported, and not housed, then the farmer would be more satisfied, the community better off, and the Government meet a liberal reward, for they would get this excellent duty on the whole amount, whereas a great deal comes in now at a very low duty.

2361. Your objection is, not to its coming in when corn is high, but to its being warehoused in the country when prices are low $?$-Yes.

2S62. Your mill is near the Thames?-Three miles from the Thames.

$2 \mathrm{~S}_{3}$. Do you grind for the London market?-Yes.

2864. Do you communicate by the river?-Partially so ; more by land.

2865 . You have ground foreign corn $\dot{r}$-Yes.

2\$66. Have you got that from the docks?-Yes, or from on board ship.

2867. Supposing you were to prevent the importer from warehousing in those docks, and you were to oblige him to warehouse on the opposite coast, at Flushing or Rotterdam, could not he equally pour it into our market in a manner calculated to produce that effect, almost with the same facility he could from the docks? We have no objection to his pouring it in, paying the duty; a great proportion would be paid duty on and then warehoused.

$286 \mathrm{~S}$. He imports it at present, bonds it in the warehouse, and takes it out when he wants it for home consumption; if he were, instead of that, to bond it on the other side of the water, where he can do it without duty, and pour it into the market and pay duty upon it when he chooses to import it, is not that quite the same as if he brought it in, paying the duty at another time ?-Yes, quite the same; but I think a large quantity would be duty paid, housed here.

2869. Would the English merchant speculate upon it when it was lying on the other side the water?-I should say not; I think he would speculate in our own.

2870 . What difference is there between the price of our own corn and the others?-There is not above $12 s$. a quarter now.

$2 S_{71}$. Do you suppose that there is so little communication between the kingdoms of England and Holland, and so little communication with the merchants of the two countries, that the English corn-dealer would not feel it as convenient to speculate by deposits on the other side as in the river Thames? - No; very few of us would like to advance our money on that which was abroad.

28;2. You like to see the warchouse where it is?- We like to know that it is near us, within reach.

2873. You think that would more than counterbalance the difference of paying the duty on importation and taking out of bond?-Yes.

2874. What do you contemplate as the duty which ought to be paid, if it is a fixed duty? - I think any farner would not be safe at less than $20 s$., letting the ports be open at all times.

2875 . What do you contemplate would be the annual profit to the country?That would depend upon the harvests; I think it is probable there would be $1,000,000$ quarters per annum on the average. 
2876 . Yours is not a grist mill, but you grind for the market generally ?-I do.

2877. Do you suppose a labourer gets lis bread cheaper in proportion to the price of wheat since the reduction of prices? - They do; but more so in London than in the country.

2878. The prices of flour liave yielded more in London than in the country?Yes, from the great competition betwecn the millers and the bakers.

2879. The labourer in the country has not the full benefit of the great fall of price?-No.

2880. The small millers' profits have been good ?-Yes, in a retail trade.

2881 . You do not mean to say that the wages have fallen to a greater extent than the price the labourer pays for his flour?--No, I do not think the wages have fallen to a proportionate extent.

2882. Then, as far as flour is concerned, he is better off? - I think the labourer who is in constant employ is better off than he ever was; it is the tenant who is the sufferer; the agriculturist.

2883. You have stated the opinion in your neighbourhood that the distress must in some measure be owing to the state of the currency; can you state any facts or any calculations you have made which bring you to that conclusion?I have said before I would rather not enter into that, because my memory would not perhaps serve me; I only say, that when the one-pound notes were in vogue the farmers had more money, and were better off; we liad a country bank at Dartford.

2884. When you speak of the altered state of the currency, you refer merely to the circulation at that time of the country one-pound notes, which do not now circulate?-I do.

2885. You have no other notion of any injury done to the farmer by the state of the currency?-No; I am not sufficiently acquainted with the subject to speak to that.

2886. How lately were the one-pound notes in circulation?-I do not recollect.

2887 . How do you reconcile the fact of the state of the currency being the cause of the great depression in one article when it does not act in the same manner on other articles; why should the state of the currency be the cause of great depression in the price of wheat when it does not affect the price of wool or the price of stock, and not very much the price of barley?-I have said that barley is too low, and that when the pound notes were in vogue the farmers could get better accommodation from the bankers, and were better off. There has been a great breadth of wheat sown in our neighbourhood, because of the quantity of oats from Ireland.

2888 . In that case the cause of depression in your neighbourlood was the greater production in one year than another of some of those articles :-There has been a greater breadth of wheat sown.

2880 . In the last five or six years prior to the depression there were no onepound notes in circulation in your neighbourhood?-No; but we had good harvests.

289 . Would you not rather look to the difference of harvests than to any alteration in the state of money ?-That the season had an effect on prices there is no doubt; a bad harvest would affect the prices.

289 1. Can you carry your observation back to 1826 , when there was an increase in the circulating medium of the country ?-After 1822 we increased progressively, as far as my memory takes me, up to 1825 .

2892. It is very much the impression of persons in your neighbourhood, that the alteration of the state of the currency has something to do with the depression of agricultural produce ?-Yes.

2S93. You always observe that the price of agricultural produce hias risen and fallen with the demand, and that demand must be regulated by the means of satisfying it?-.Yes; a man cannot buy without money.

2894. There may be countervailing causes which may prevent the contraction

of the currency from bringing it down?-Yes, if there was a bad harvest.

2895 . There is sometimes money for an article, though not in one-pound notes? -Yes.

2896 . Do you find the woolstaplers extremely eager to buy your wool of you, though they lave no one-pound notes?-There is a great demand.

2897. That is on account of the prosperity of trade? - Yes.

2898 . You say that the tithes are taken in kind; they are not taken by the clergyman?-No, we have a lay impropriator; I could always manage with the clergyman for the small tithes satisfactorily. 
Mr.

R. H. Dowling.

7 March 1836 .

2899. Do you say this season has been a good one with you in breeding cattle?-No; the question was put to me, whether it was beneficial to me; I say, no; not so beneficial as it wonld have been to me if I had had turnips.

2900. It has not been beneficial, in consequence of the shortness of the green crops?-No.

2901. Do not you think it would have been very advantageous to you if you could have fattened with malt without the duty?-Yes; malt half made, I think, would have been very beneficial.

2902. What is the effect of the beer-shops in your neighbourhood?-I should say there is no good in them, decidedly.

2903. Have they tended to demoralize the labourers?-Decidedly so.

2yo4. And the small public-houses as much as the beer-shops?-Yes.

2905. You think that the relieving you from the malt-tax would benefit the farmer, but that would occasion a larger quantity of barley being sown; in what way do you conceive there would be a larger quantity consumed?We should find our men in beer, which we cannot now do; I can speak to facts ; a few miles below me, the farming man seldom gets beer-the honest industrious man-from the harvest-time till till the next hay-time again.

2906. Would not that increase in consumption be to a very limited extent, unless the price of barley was so low as to prevent the remunerating price you suppose to the farmer? - No, for we always have a quantity that we can sell; but we should increase the growth of barley.

2907. Are you aware that if you were to raise barley above $35 \mathrm{~s}$, according to the present corn laws, you would have all the barley from the Continent poured in upon you?-Ycs; but I should say an alteration of the corn laws is a great desideratum.

2908 . If there was more grown, it could be afforded at a lower price than $35 \mathrm{~s}$.? -Yes; we should be happy to grow it at $35 s$. The average at $34 s$. and under $35 s$. they must pay $10 s .10 d$. duty; then $9 s .4 d$.; every shilling varies $1 s .6 d$.; but the top price of barley must be a good price to nuake the average $36 s$., it would be $40 s$. to bring us down to $9 s$. $4 d$. duty.

2909. Is not $4 s$. a bushel a fair price for barley ?-Yes, such barley as we should malt for our own use.

2910 . Would $32 s$. a quarter be a fair average price?-No; I think $35 s$.

2911. Can you state from any account what has been the largest amount of barley that ever has come in ?--I have no account with me.

\section{[The Witness is directed to withdraw.}

Henry William Wilson, Esq., is called in ; and further Examined, as follows :

H. W. Wilsom, Esq.

Report of Commissioners, County liale, 1835 .
2912. THE Committee understand you wish to put in this account?- $[A$ paper being shown to the $\mathrm{Witness.]-I}$ do.

$29^{13}$. Did you make it yourself $:-Y e s$.

\section{[The same is delivered in, and read, and is as follows :]}

Total money levied for poor and county rate throughout England and Wales -

\section{$8,606,501 l .9 \mathrm{~s}$.}

Leicestershire is a manufacturing as well as an agricultural county. The number of manufacturing labourers exceeds that of agricultural, and the former have been more generally the objects of parochial relief than the latter.

By the Abstract of Returns laid before the House of Commons, however, the proportionate sums levied by assessment on different descriptions of property in the year ending 5th March 1833 , are as under:-

\begin{tabular}{|c|c|c|c|c|c|c|}
\hline Lant. & & Dxelling.houses. & Mills and Faclories. & Manorial Property, \&c. & Total. & \\
\hline${ }_{108,330}^{f .}$ & $\begin{array}{l}\text { s. } \\
3\end{array}$ & $\begin{array}{cc}\boldsymbol{\varepsilon} . & s . \\
29,551 & 7\end{array}$ & $\begin{array}{cc}f . & s . \\
783 & 2\end{array}$ & $\begin{array}{cc}f . & s . \\
638 & 14\end{array}$ & $\begin{array}{c}£ . \\
139,303\end{array}$ & $\begin{array}{l}s . \\
6\end{array}$ \\
\hline
\end{tabular}

Whence it appears that of a total sum of $139,303 l .6 s$. levied in that year ly parochial assessment, no more than $783 t$. $2 \mathrm{~s}$. were contributed by mills and factories, the ouly species of manufacturing property amenable to the rate.

From the Return of $i_{2} 6$, as under, it appears the sum levied on lands and houses has increased, while that on mills and factories remains the same; the value of land has very much fallen, while the number and value of factories has considerably increased. 
This increase is proved by population returns, and by returns of British manufactured woollens exported.

This increase is to be accountcd for in Leicestershire by the great decrease in the price of coal, which since the opening of the railway between the Leicestershire collieries and the town of Leicester has been lowered frum $17 \mathrm{~s}$. or $18 \mathrm{~s}$. to $8 \mathrm{~s}$. or $10 \mathrm{~s}$. Hence the vast increase of steam power applied to the Leicestershire manufactories, and consequently their numbers have increased.

\begin{tabular}{c|c|c|c|c}
\hline Land. & Houses. & Nills and Factories. & Manorial L'roperly. & Tolal. \\
\cline { 1 - 2 } $\boldsymbol{f .}$ & $\boldsymbol{f}$ & $\boldsymbol{f}$ & $\boldsymbol{f}$ & $\boldsymbol{f}$. \\
93,882 & 17,634 & 782 & 310 & 112,608 \\
\hline
\end{tabular}

There are few counties in England furnishing instances of individual parishes where the burthen upon land for the support of pauperism has approached more nearly to confiscation than Leicestershire. In all these instances the demand has bcen occasioned by the pressure of a manufacturing population upon a rate levied exclusively on the land.

This statement is confirmed by reference to the Report of the Assistant Comnissioner of Inquiry into Poor Laws (Mr. Pilkington), who visited the county in 1833 .

He observes, " in most of the parishes throughout Leicestershire the poor-rate is very Appendix, part 2, high; in many places it is equal to $10 \mathrm{~s}$. in the pound; in some to $12 \mathrm{~s} ., 14 \mathrm{~s}$, , and $20 \mathrm{~s}$.; page 83. and even the land itself has become insufficient for the demands of the pauper."

With respect to Hinckley, is the following statement:-

"Mr. Preston, yeoman, occupies of his own land 110 acres ; rents of T. Grundy, Esq., page 95 . 45 acres; total, 155 acies. Paid last year for poor-rates, $165 l .5 s$.

"Mr. Bonner, yeoman, occupies of his own 60 acres. Paid last year for poorrates, $60 l$.

"Mr. Sanson occupies $7^{\circ}$ acres of land. Paid last year, $108 \mathrm{l}$. $15 \mathrm{~s}$.

"Mr. Checkland occupies 36 acres. Paid last year, $42 l$. $7 \mathrm{~s} .6 \mathrm{~d}$."

Number of mannfacturing labourers in Hinckley, as shown by Population Returns, 692 ; number of agricultural ditto, 119 ; number of acres, 3,190; rates on land (1832), $2,351 l$; ; rates on liouses, $1,411 l$.

"Wigston contains 2,944* acres of good land, capable, under proper cultivation, of Page 98. growing four quarters of wheat to the acre, four or five quarters of heans, and five quarters and a half of oats; one acre and a half of grass would feed a good beast, and would carry from five to seven ewes and followers; the rates upon land in $183_{2}$ were $2,692 l$., upon houses, $233 l_{\text {. }}$; the number of manufacturing labourers, 301 ; of agricultural ditto, 69 . This PopulationReturns. parish presents the monstrous anomaly of land of excellent quality being thrown out of cultivation because unequal to the demands made upon it for poor-rates."

Other instances of almost equal injustice might be adduced. The following calculation See that of Ansty. with regard to 24 parishes has been made:-They comprise 44,590 acres; 1,121 agricultural labourers, 3,513 manufacturing ditto: rates on land, $21,698 \mathrm{l}$. $13 \mathrm{~s}$.; rates on houses $1,411 l$. $19 s$; ; total rates, $23,110 l$. $2 s$.

Such was the state of things in $183^{2}$; matters have no doubt much improved since then, partly from a better condition of trade, attended with better wages, and partly owing to more careful parochial management; but depression may again occur; the last resource of the manufacturing poor is still upon the land, and there is no security that the same, demand may not again be made, and to the same extent. +

The manufacture is that of worsted stockings; the labourers engaged in it are many of them settled by apprenticeship to masters who were themselves not rate-pravers, or ratepayers to a very small amount to the country parishes, where they work for the capitalists residing in the large towns, su long as thcir labour yields a profitable return to the employer, but liable at any moment to be turned adrift, to be maintained by the occupier of laind, who in no case can claim advantage from theii exertions, and has no work for which they are fit; while those who have made a fortune, perhaps by their labour, remain exempt from all contribution to their necessities.

The practice of making up wages from the poor-rates has prevailed to a great extent among this class of operatives, and necessarily so while they were unable to earn sufficient for their maintenance and that of their families. It is discontinued now, rather in consequence of the better profits of the trade than because discountenanced by the I'oor Law Commissioners. The new principles of Poor Law administration could not be maintained in this county during a stagnation of trade.

The looms upon which stockings are made are, for the most part, the property of the employer; their value may be from $5 l$. to $12 l$, and they yield a clear annual rent to the owner of about $2 l$. on the average; being thus a local visible property yielding a profit; there are those who think these frames are a legal subject of assessment. Be this as it may, there are great practical difficulties in the way of such assessment.

- By another account 2,780 acres.

4 Pressure to a great, though not to so large an amount, is felt by all country parishes in the neighbourhood of large manufacturing towns; Norwich for iustance.

464 . 
H. Wr.Wilson, Esq. If the frames could be taxed while trade was prosperous and active, in order that a fund miglit be provided for the support of the weaver in a different condition of .things, 7 March 1836 . there could be no qucstion as to tlie justice and expediency of such a tax; but the contribution from them would unfortunately be most necessary during a depression, when many of them perhaps would be unemployed, and the wages to be earned at them reduced to the lowest point.

Parish of Ansty :-Population, 850 ; manufacturing labourers, 148; agricultural ditto, 27;

Page 414 .

Re. \& p. 20 to 33 ,

part 3 . containing 1,400 acres, of which 700 are extra-parochial ; 700 acres assessed at $5081 . ; 170$ houses assessed at 54 l. $17 \mathrm{~s}$. $6 d$.; total assessment, $562 l .17 \mathrm{~s} .6 d$.

f. s. $d$.

Amount collected in $1826 \quad-\quad 1,01336$ equal to 180 per cent. or $36 s$. in the pound. Ditto - $1829-1,12515-" 200$ per cent. or $40 \mathrm{~s}$. ditto. Ditto - 1830 - $90012-, \quad 160$ per cent. or $32 \mathrm{~s}$. ditto. Ditto - 1831 - 675 - $" 120$ per cent. or $24 \mathrm{~s}$. ditto.

Statement showing the whole Number of Machines engaged in the Hosiery and Glove Trade in Leicester and Leicestershire; also the Number of Persons employed, and their average clear Earnings, if in full work, as from July 1832 to 1833 .

Number of Machines - $\quad$ - _ 14,000

\begin{tabular}{l|c|c|c}
\hline & $\begin{array}{c}\text { Above 18 Years } \\
\text { of Age. }\end{array}$ & $\begin{array}{c}\text { Under 18 Years } \\
\text { of Age. }\end{array}$ & Total. \\
\cline { 2 - 4 } $\begin{array}{c}\text { Number of Persons directly and indi- } \\
\text { rectly employed }-\end{array}$ & 15,076 & 12,924 & 28,000 \\
\hline
\end{tabular}

Appendix I. Poor Law Keport A. Part II. page 96. Mr. Pilkington.

Mr. Pilkington.

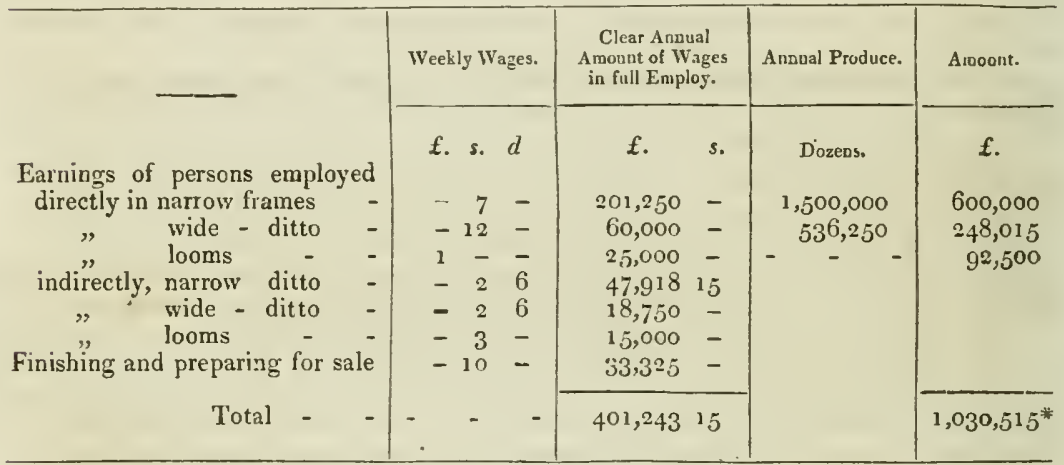

* Of which there was exported $159,400 l$.

Mr. May stated, "Trade doing very ill; wages so low, from the most laborious exertions our workmen can hardly procure a subsistence; $6 \mathrm{~s}$. to $7 \mathrm{~s}$. outside of which an industrious man can earn per week, working 14 hours per day; have known the time they could earn $1 l$.; industrious and steady men 14 to 16 hours per day, $6 \mathrm{~s}$. $6 \mathrm{~d}$.; women same, if no housebold or children to attend to; a child eight years old $6 d$. to $9 d$. per week; child 11 ditto, $1 \mathrm{~s}$.; child 14 ditto, $2 s$. $6 \mathrm{~d}$.; clear earnings, independent of outgoings, as such of frame, about $1 \mathrm{~s}$; winding, which is $6 \mathrm{~d}$. a frame, 8 c. In these times their wages are made up by the rates on the land."

Average wages per week of 10,000 in 1831,7 s. $8 \frac{1}{2}$ per week.

Ditto - ditto - of 4,000 higher, sometimes 20 to 50 per cent.

2914. Is there any thing you have to add ?-I wish very much to be allowed to call yourLordships' attention to so large a portion of the county and parochial assessments being charged on the land almost exclusively. Since the sums levied are not expended for the exclusive advantage of one class, but for the benefit of all his Majesty's subjects, I would most earnestly but humbly entreat your Lordships that that principle, which is founded upon the broad, equitable and imperishable basis of equal liability and equal ccntribution and equal rights, may be established, whereby the fundholder, the merchant and the manufacturer may be made to bear their share in proportion to the advantages which they receive; I would also beg that those fiscal regulations which 
admit the produce of foreign nations, such as tallow, hides, \&c., as they are H.W.Wilson, Esq. admitted at such low dutics as completcly to annihilate the profits of the home grower, might reccive the attention of your Lordships, in order to their revision.

[The Witness is directed to withdraw.

Ordered, That this Committce be adjourned till to-morrow, One o'clock.

Die Martis, $8^{\circ}$ Martii, 1836.

The Lord WYNFORD in the Chair.

Mr. John Thomas Carter is called in; and Examined, as follows:

2915. WHERE do you reside?-At Hunstanton, in Norfolk.

2916. You are a farmer?-I occupy a farm of about 600 acres.

2917. Are you steward to any gentleman?-I am agent to Henry Le Strange

Mr. J. T. Carter. Styleman, esq.

2918. What quantity of land do you manage for him?-His estate consists of about 10,000 acres.

2919. That is under your care?-It is under my care; but we have about 1,000 acres of it now in occupation, for want of tenants.

2920. Who occupies that? - That is entirely under my management for Mr. Styleman; the rest is let out to tenants.

2921. Do you superintend Mr. Styleman's property?-I do. I have been resident there about 25 years; eight years under the late Mr. Styleman, and 17 under the present.

2922. What is the present state of the tenants in that country?-Their present state is ruinous.

2923. Do you mean to say that is generally the case?-Yes; in my district of Norfolk.

29:24. On this property under your care $:-Y$ es.

2925. Have the rents of that land been reduced:-They have been reduced the last year.

2926. Had they never been reduced before?-Very trifling.

2y27. Were the rents low before?-They were let at molerate rents, but a great part of the estate was let on corn-rents, consequently they reduce themselves.

2928. You say they are in a ruinous state; can they pay even their reduced rents?-My private opinion is, that they cannot; not off the farms.

2929. Have they paid them regularly up to this time? - We have none in arrears now. The reason we have been particularly urgent in pressing the payment of the rents up to this period is, that the present gentleman is just of age, and his property has been in the Court of Chancery, therefore, with a view to get all the accounts settled, we have urged the tenants particularly to pay up all arrears to Michaelmas last.

2930. Have you any means of knowing whether they have paid them out of their profits or out of their capital?-I believe they have reduced their capitals very much.

2931. Have any of them been broken up ?- - No.

2932. Have any in your neighbourhood been broken up?-No.

2933. Can you form any opinion of what is the occasion of this depression of prices?-I really cannot; they are ruinously low at this period; the immense supply at market appears to have an effect upon it.

2934. You have occupied a farm yourself of 700 acres, have you not?-I occupy one myself of 600 acres, and one of 700 for Mr. Styleman. He bas now indeed 1,000 acres in hand; 300 of the 1,000 acres came into hand last Michaelmas; I had previously occupied the 700 acres three years.

2935. Had you made any profit by it?-Not the last five years; but I occupied the same farm from Michaelmas 1822 to Michaelmas 1825, when I obtained a profit; and the accounts of those three years, which have been verified in the Court of Chancery, are now in London.

2936. You made a profit from 1823 to 1825 ? - I did.

2037. Have you made any since? - No; but there has been a gradual increase of debt.

2938. Has it been managed in as good a manner since 1830 as it was before? -I have managed it precisely in the same manner.

464 . 
Mr. J. T. Carter. 2939. Though it produced a profit before, it has occasioned a loss since?-A regularly gradual annual loss.

8 March 1836. 2940. Have you the accounts here?-I have the current accounts.

2941. Can you deliver them in?-I can state the result from a general statement I have made. From Michaelmas 1830 to Michaelmas 1831, I paid, on taking this farm, $6,219 \mathrm{l}$. $15 \mathrm{~s} .8 \mathrm{~d}$.

2942. For what did you pay that?-For stock, implements, seed-corn, \&c., for carrying the farm round one year; I received within that year $1,487 l .2 s .3 \mathrm{~d}$.; leaving a debt to carry forward at the end of the first year of $4,732 l .13 s .5 d$,, which was the amount of capital engaged in the farm.

2943. Have you made up the balance each year?-Yes; this estate having been in Chancery, the annual receipts of the rents have been regularly paid into the court every year; the court would not allow us to take money out to carry on this farm, but we were obliged to borrow the money from the bankers to carry it on. From Michaelmas 1831 to Michaelmas 1832 I paid, interest included, $2,526 l .0 s .6 d$; the receipts of that year were $2,190 l .8 s .4 d$.

2944. Is rent charged in that?-No. It adds an increased debt, the second year, of $335 \mathrm{l}$. $12 \mathrm{~s} .2 \mathrm{~d}$. I paid from Michaelmas 1832 to Michaelmas 1833, interest included, $2,872 l .12 s .3 d$.

2945. Had you any additional land in that year?-No. I received in that year $2,720 \mathrm{l} .14 \mathrm{~s} .5 \mathrm{~d}$.; the debt was increased the third year $151 \mathrm{l} .17 \mathrm{~s} .10 \mathrm{~d}$. From Michaelmas 1833 to Michaelmas 1834 I paid, interest included, 2,368l. $1 \mathrm{~s} .11 \mathrm{~d}$; I received 1,706 l. $16 \mathrm{~s} .4 \mathrm{~d}$; making an increased debt the fourth year, of 661 l. $5 s .7 d$. From Michaelmas 1834 to Michaelmas $1835 \mathrm{I}$ paid, interest included, $1,889 \mathrm{l}$. $1 \mathrm{~s} .3 \mathrm{~d}$.; I received $1,485 \mathrm{l} .17 \mathrm{~s} .7 \mathrm{~d}$., the debt was increased the fifth year $403 \mathrm{l}$. $3 \mathrm{~s} .8 \mathrm{~d}$. That makes an increased debt since the occupation of the farm from the first year, besides all the rents of the five years, of $1,551 l .19 s .3 d$.

2946. Do you mean to say that the rent is all swept away, and still there is that loss?-Yes.

2947. You have stated that your farm was managed as well as in those years in which it produced a profit?--Precisely in the same way; but I would make one observation, that may account for the rent accumulating during the three years from Michaelmas 1822 to Michaelmas 1825; I account for that, in some measure, by having bought in my stock, implements, seed, corn, \&c., at very reduced prices; and in 1825 they were sold out at high prices, which materially contributed to the accumulation of the rent in those three years. In $1830 \mathrm{I}$ bought in at high prices, and have had to contend with bad crops and reduction in prices since.

2948. There have been bad crops since? - Very bad, indeed.

2949. But notwithstanding that the prices have been reduced?-Yes.

2950. Have the prices been bad on barley as well as wheat?-On wheat particularly.

2951. The prices of barley have been higher than wheat?-Yes, in comparison.

2952. But you attribute the difference in the prices to there being a better crop of wheat than of barley - Y'es.

2953. Can you give the average prices of your crops for 1823, 1824 and 1825 ? -In 1823-24, at Lynn market, wheat $54 s$, a quarter; in the year 1824-25 it was $63 s .8 d$, and in 1825-26, it was $56 s$.

2954. Will you state the prices of barley in those years?-Barley in 1823-24, $31 \mathrm{~s} .8 \mathrm{~d}$.; in 1824-25, $36 \mathrm{~s} .6 \mathrm{~d}$.; in 1825-26, $32 \mathrm{~s}$. $10 \mathrm{~d}$.

2955. Will you explain what was the cause which led to the great difference in the receipts and expenditure in 1833 ?-The expenses, I think, were increased materially in 1833 by the advance in the price of stock, and the receipts in 1833 were enhanced by a good crop of corn, which was the only good crop of corn I have had since 1830 .

2956. What was the average price of wheat in 1833 ? - Fifty-one shillings.

2957. What was it in 1834 ? - Forty-three shillings and tenpence.

2958. One thousand eight hundred and thirty-three and one thousand eight hundred and thirty-five liave been failing harvests?-Very much; so much so, that in the year 18331 had but three coombs and two bushels of wheat per acre.

2959. Have the poor-rates increased in your parish?-No, not materially; the parishes where Mr. Styleman's estate lies being all together and principally con- 
fined to four parishes, I have endeavoured to kcep the poor employod, and the rates in consequence have varied very little.

2960. Are the poor employed generally throughout the country?-No; there are a great many out of employ in' some districts.

2061 . Are they much distressed? - They have been greatly distressed, and are now, some of them.

2962. If those prices go on they will be more distressed, will they not?-Yes, they will.

2963 . Has there been mucl, difference in the rate of wages ?-No; we used to give $10 s .6 d$. per week; now we are giving $9 s$.

2964. Should you have employed so many if you had not desired to prevent the ponr-rate increasing? - No.

2965. Even supposing the times had been better, should you have employed so many :-I think I should.

2966. In that case it would have answered if prices had been higher?-Yes.

2967. Would they all be employed now if prices were higher?-Confining myself to Mr. Styleman's property, I should say so.

2968 . Would other farmers employ more labourers if they could afford to employ them?-Yes.

2969. What is the feeling of the poor ; are they contented ?-I am sorry to say in our district they have been very much otherwise; but I think they are becoming more reconciled to the alteration of the poor law.

2970. What would be the effect of lowering wages upon them?-They would rebel against a reduction in wages; in fact $\mathbf{I}$ believe at this very instant the porters at Lynn are stopping for wages, because the merchants will not increase the porterage.

2971. Can you keep up this rate of wages at the present prices?-No.

2972. Then you must lower? - Yes; but the farmers are fearful of lowering.

2973. What are they afraid of ?-They are afraid that the labourers will set fire to their premises, or annoy them in going about.

2974. Still ultimately they must come to that, or raise the prices? - They must; but till the union house is erected we can do nothing with the men.

2975. What effect have the beer-houses had in your neighbourhood? - Very prejudicial indeed; and I would beg to be allowed to make an observation on the good effect in our neighbourhood produced by the employment of some policemen from London. At the first coming down of the Poor Law Commissioners we had several turbulent meetings, and but for the union having consented to send up to London, and get three policemen down, we should have had very great disturbances. Those policemen have been engaged for 12 months, and have done an infinity of goud, by rooting out the becr-houses, and improving, very materially, the morals of the poor. I think the poor, since the policemen have becn employed, have been very much better in their general conduct.

2976 . Do not you think that the repeal of the malt-tax would be a great benefit to the farmers and agricultural labourers?-Yes, undoubtedly.

2977. Would there be much more barley brewed at home?-I have no doubt of that.

2978. Would it become more the practice of the farmers to give it to their labourers at home?-Yes.

2979. Would not an increase of the growth of barley take place upon that ?Materially.

2980. That would occupy some of the land now employed in wheat?-Yes.

2981 . Have you any practical acquaintance with the practice of feeding with grown barley?-No.

2982. Is there any feeding of cattle with wheat in your country?-A great quantity.

2983 . Is the land as well farmed in your neighbourhood as it used to be? -No; they are exhausting it, for want of capital to keep it up.

$29 S_{4}$. Do they plough up land they ought not to do?-No; but they do not manure it as they ought to do ; they do not clean it so well, nor manure it so well.

2985 . The land has become deteriorated in point of value?-Yes.

2986. Have they got into the practice of scourging the land?-Where they can do it they will; but I keep a strict eye over the tenants, and keep them to their 464 . 
Mr. J.T. Carter. covenants; but I cannot compel the tenants to buy manure for their land when really they have not the money.

8 March 1836. 2987 . Do you find that the land wants manure in consequence of the want of money to buy it? - Certainly.

29SS. Is not that a great injury to the conntry :-Uudoubtedly it is.

[The Witness is direcled to withdraw:

Mr. Robert Hughes is called in; and Examined, as follows:

Mr. R. Hughes. 29S9. WHERE do you live?-At Woodford, near Salisbury.

2990. You are steward for gentlemen in that part of the country :- I am, for several in the county.

2991. A rental to what amount have you under your care? - I think somewhere about $15,000 l$. a year.

2992. Are you steward to one nobleman or gentleman, or to different:-The re are three large proprietors; and I am also agent for tithe property to a smaller amount.

2993. On which side of Salisbury is the property - The Amesbury property is under my care ; but $I$ have lived the greatest part of my life in North Wiltshire, near Swindon.

2994. You have been connected with farming for many years :-I have been; I was a practical farmer from a boy to the year 1829 .

2995. What is the present state of agriculture, as compared with its state some years ago? - I think it was as bad in the year 1822 as it has been this year; but, with that exception, I never knew it any thing like so bad as this last year.

2996. Are the farmers who occupy land under you distressed, or otherwise?Where they are not men of capital they are very much distressed.

2997. Do you recollect the year 1815 ?-Perfectly.

2998. Was it as bad in that period? - Corn was then at a very high price, consequently the farmers did not complain; there were no complaints then.

2999. When did your complaints begin :-The complaints began, I think, to be seriously made in the year 1822 , and in the year 1823 and 1824 things rallied very much; 1824 was rather a good year, and the farmers were in higher spirits, and that continued till the year 1826 ; then, in the year 1826 , a certain thing took place which I will not venture to allude to; that depreciated the property immediately.

3000. Iou mean the panic:-I mean the alteration of the currency; then the panic came at the sanje time the one-pound notes were withdrawn.

3001. You refer to the one-pound country bank notes?-Yes; that had a very serious effect.

3002. Did that reduce the prices very much :-Yes; it prevented country bankers giving that accommodation to the farmers which they had been in the habit of doing before.

3003. Have the prices ever risen since that time:-They went down in the year 1827; and then we had three wet seasons, 1828, 1829 and 1830, and in consequence of those wet seasons, the crops not being so good and the harvests bad, the prices rallied a little; then in the year 1832 we had a very bountiful crop, and have had excellent crops of wheat ever since, with fine harvests.

3004. Have your other crops, barley and oats, been equally good?-Not equally good; they have been partially so.

3005. Has the difference in the crops occasioned a difference in the price between barley, oats and wheat? - There is no doubt of that.

3006 . From the observation you have had an opportunity of making, can the farmers go on at this rate in your part of the country ?-I think they cannot, at the present price of wheat; that they must be ultimately ruined; some of them, I am sorry to say, are already.

3007. Are there many in your neighbourhood already ruined :-I do not think there are a great many in my neighbourhood, for in Wiltshire the farmers are men of more property than they are in any other county in England, particularly the south farmers; they are men of large farms, and many of them of considerable property, and I believe they have been paying part of their rents lately out of capital, and not out of profits.

3008. They stand upon the strength of their purses :- Yes. 
3009. But if things go on as they are going on now, must their fate be the same as that of the small farmers?-Yes; if wheat continues at the same rate it has been for the last twelvemonth, I think they must be ruined altogether.

3010. To what do you attribute this depression of prices?-To various causes.

3011. Have the goodness to state them? - I think, in the first place, the immense importations lowered the price in the commencement.

3012. Of what time do you speak?-live or six years since, or four or five; there were immense quantities of foreign corn brought into the market, which depreciated the value of wheat in this country very materially; since that there have been a great many causes which have operated very powerfully; one is the very great supplies we have had from Ireland; those have had a very serious effect upon our markets; the next is the four extraordinary good crops of wheat and extraordinary good seasons.

3013. Have the importations from Ireland affected other things besides corn; have they affected cattle, pigs and so on ?-Quite as much.

3014. Are you acquainted with Ireland at all ?-I am not.

3015. You do not know what amount in quarters of wheat has been imported from Ireland of late years :-No; but I know that Bristol, which has great influence in the Wiltshire markets, has been very considerably supplied till the last month frem Ireland; the supplies have fallen off the last month, and the market has rallied in consequence; I understand there is scarcely a sack of Irish wheat in the Bristol market now; the Bristol dealers are obliged to come to Devizes and $W$ arminster markets for English wheat.

3016. Since that has been the case, the prices have risen ?- Yes, they have risen considerably. There is one circumstance which I know has had a very considerable effect; I know it from experience; the allotment system is very much encouraged, and which, I think, has had a very excellent effect for the poor, but it is astonishing how that has reduced the consumption of wheat beyond any thing which can be conceived.

3017. Is there any other cause?-Those are the principal causes, and the last certainly not the least.

3018. In what state are the poor; are they suffering with the farmers?-The poor have been suffering very much, but I am very glad to say that under the new system they are recovering very much indeed; the expenditure is lowered, and their comforts are increased. I have taken a very active part in it, and can speak from practical knowledge.

3019. Have they been turbulent in your county?-Not in South Wiltshire at all; they have in North Wiltshire.

3'120. They are not so now:-No; their great objection was to receive the allowance in kind, namely, bread; they wanted money to take to the beer-houses.

3021 . What are your wages now?-The amount of wages varies from $7 s$. to $9 s$. and $10 s$. a week.

3022. Can you keep up those wages?-They are increasing since the new Poor Law system has been introduced; the labourers are now better employed and paid more liberally; the wages, I am glad to say, are still increasing.

3023. Can the farmers afford to pay those wages unless the prices of produce are increased :- I am afraid they cannot.

3024. What will be the effect of a great reduction of wages? - Of course the poor-rates must be increased.

3025. What wonld be the effect of that on the tranquillity of the poor :-I think it would injure their morals and make them riotous, and their comforts would be diminished.

3026. Would they submit to it?-Not quietly; they are now, I an very glad to say, in a very peaceable, quiet state.

3027. Have you had any rick-burnings there? - Not in South Wiltshire, but in North Wiltshire there have been three or four not more than a month ago, and it was all in consequence, I believe, of the bread allowance instead of money.

$302 \mathrm{~S}$. What is the extent of the union of parishes to which you belong ?-It embraces 23 parishes.

3029. What is the population :-Between 7,000 and 8,000 .

3030. Your land about Amesbury is good, is it not?-Very kind soil.

3031. At what does it let per acre ?-There is a variety of soil, and considerable proportion of down and water meadows; the arable land and water meadows and all together average about $1 l$. an acre, tithe-free, and poor rates moderate.

464 . 
Mr. R. Hughes.

8 March 1836.

3032. What do you reckon the fair produce of wheat per acre of that land?-I should say about three quarters.

3033. How much of barley? - They grow, on an average, about four quarters and a half.

3034. How much of oats? - There are not very many sown, but five quarters at least. The land of all the cottage tenants lets, in one parish, at $l l$. an acre, and in another parish $2 l$. per acre; they have some of the best land in the parish.

3035. You state that the allotments have produced a less demand for wheat among the labourers; how is that occasioned?-They live now upon the produce of their little garderss.

3036 . You think it has tended very much to their comfort?--Very much; but then certainly it has reduced the consumption of wheat to a considerable extent.

3037. They have more comfort in having more pig-meat, and so on?-Yes. When first I had the management of that estate, there were about 130 cottagers, and there were but very few pigs among them; now there are hardly any without pigs.

3038 . What are the poor-rates? - I think, at rack-rent, this year they will not be more than $2 s$.

3039. What difference is there in the rate of wages from what it used to be?They are very much the same as they have been the last two or three years.

3040. Taking the present time as compared with 15 years back, what is the difference in the prices of labour?-They are about $2 s$. to $3 s$. less when they are employed; they are better paid now than they have ever been in my recollection, according to the price of provisions.

3041. You consider the allotment system a very good one?-Yes, where they are allowed good land at a fair price.

3042. Can you recollect the state of things before 1793 ? - I cannot.

3043. Do the labourers bake at home, or do they send to the baker?--We allow them ovens as much as possible. The great advantage that the poor have in this new system is, that they are not now at the mercy of the bakers and little shopkeepers, as they used to be ; they used to pay, to my knowledge, 20 to 25 per cent. more for every article they consumed than the higher ranks; now, under the new system, that is in a great measure destroyed.

3044. You state that about 10 or 15 years ago you think the wages were from $2 s$. to $3 s$. ligher than they are now ? - I must go rather further back, about 20 years, I think, for that difference.

3045. Going back to the year 1820 , which is 16 years ago, do you think the wages were higher than they are now - - Yes, about $2 s$., I should say, on an average.

3046. Do you remember what the poor-rates were at that period on the average ; were they higher or lower than they are now? - They were lower than they have been lately; the poor-rates till the last twelvemonth have been increasing, notwithstanding every thing else has been reduced in valuc.

3047. Taking this year, compared with the year 1820, when you say wages were about $2 s$. a week higher, were the poor-rates higher or lower than they are now ?-The new system has not been introduced into Wiltshire more than from four to six months; the first half year was high. I find that we have invariably decreased the expenditure 20 per cent., and increased the comforts of all the old and infirm.

3048. With that reduction of 20 per cent., do you think the poor-rates will be higher or lower?-I think they will be lower the half-year since the new system was introduced, but higher the former half-year.

3049. Can you state what reduction has taken place in rent since 1820 ? - I think it varies from 10 to 20 or 25 per cent., according as the farms were let; a deduction of 10 per cent. on some is equal to 20 or 25 per cent. on others.

3050. You do not think there has been, on an average, a greater reduction than 25 per cent?-Certainly not.

3051. You say you think that the cottagers consume less bread-corn than they used to do ? - Very considerably less.

3052. Considering the general increase of population, do you think there is less bread-corn consumed in the county of Wilts than there used to be?-Yes. I remember, in the year 1822, I had the honour of being summoned before the House of Cornmons on a similar inquiry; I had lived in the parish where I had resided for 20 years; the population had increased one-third during the 20 years, 
and I lad ascertained very accurately the consumption of wheat had not increased one sack, even so long ago as that.

305.3. That was before the allotment system began?-It was before it was so general.

3054. The allotment system has been carried to a greater extent in Wiltshire than any other county :-1 believe it has.

305.5. What is the extent in point of quantity of land ?- My rule is never to go beyond a quarter of an acre, if the family be cver so large; that will be sufficient to maintain the largest family in vegetables.

3056. Do you include potatoes in vegetables?-They grow potatoes principally; if they had more it would spoil the character of the inan, and make a sort of gardener of him.

3057. What quantity of corn do you suppose each of those labourers used to consume before the allotment system was introduced?-The calculation used to be about a quarter in the twelvemonth.

$305 \mathrm{~S}$. What quantity do they consume now ?-According to my calculation, the consumption is reduced one-third.

3059. That, you think, applies pretty much to the agricultural population?Yes; I think it has had a considerable effect upon the price of wheat.

3060 . Is that the case with respect to the labourers in agriculture, where the allotment system does not prevail, on account of potatoes being grown in farmers' fields? - - It is the case in every county, more or less, but more strongly where the allotment system is introduced.

3061 . What quantity of potatoes do you conceive a labourer can grow in a quarter of an acre ?-Twenty sacks ; that is 60 bushels.

3062. Are 60 bushels of potatoes any thing equal to the support of the family of an agricultural labourer?-Quite sufficient ; they tell me they have always plenty if they can grow 20 sacks; that will keep them, and they fatten their pigs with the small potatoes.

3063. You do not suppose them to live entirely on potatoes :-No, certainly not.

3064. Do you think the potatoes grown in farmers' fields have diminished the consumption of wheat?-No doubt of it ; they are so commonly grown by farmers, they are very cheap.

3065. Then they have no cause of complaint, if the price of wheat has been diminished by the growth of potatoes by themselves?-We know it applies in that way, but then the comforts of the poor are increased.

3066. Has the farmer any cause of complaint, if his land produces him as great a profit in potatoes as wheat?-It is not in general the farmers who grow the potatoes, but other persons who have taken land to grow them.

3067 . Do not you think that the introduction of Irish bacon among the labourers has tended to decrease the quantity of wheat eaten? - Yes; the quantities of Irish bacon brought through Wiltshire to the London market and other, markets are beyond any thing which can be conceived.

$306 \mathrm{~S}$. You allude to that having tended to diminish the profits of the farmer? -Yes.

3069. Do you grow any flax or hemp in your county ?-Very little indeed; the farmers in general do not understand it ; it has not succeeded among them.

$30 \%$. If flax and hemp could becultivated in this country, that would diminish the quantity of land applied to wheat and barley?-I do not think it can ever be cultivated to any great extent; the farmers do not well understand it.

3071. Is not there more grown in Somersetshire and Dorsetshire?-Yes, there is.

3072 . Is there any district in your county where the labouring classes generally have their bread from the bakers? - Some of them have it in all districts; there is no general custom.

3073. Do you think there is a greater breadth of wheat sown in Wiltshire at the present time than there was 10 years ago ?-Very considerably more; there bas been more wheat in consequence of the fine seasons and the low price. Farmers have been trying to make up in quantity what they lost in price, and there has been more wheat sown and better crops the last four years than the oldest 'farmer'ever remembers.

3074. Have you not observed any exception to that statement during the last wheat season :- The last wheat sowing has been unfarourable; they have not been able to put in so large a quantity as they did in previous years.

464 . 
Mr. R. Hughes.

$8 \operatorname{March}_{1} 8_{3} 6$

3075. Do you think that is owing to the season?-Yes; the season was very wet; the lands were not in a state to receive it.

3076 . Do you sow your wheat in the autumn or in the spring?-We take from a month before Michaelmas and go on till after Christmas, according to the situation of the sqil.

3077. You do not grow any spring wheat?-No; when the prices were very high, the farmers did it ; but it is very inferior wheat.

3078 . Then they would have preferred the autumn wheat, if they had the land ready :-Yes; but they were in the habit of sowing spring wheat on land that ought to have been sown with barley.

3079. Is the land as well cultivated as it was formerly? -With regard to large farms, where the farmers have capital, I think the farming is still kept up; but where the farm is nearly ruined, wherever there is a poor farmer there is generally a poor farm.

3080. Do you see many poor farms?-I see more in other counties than in our own, but we have some.

3oS1. When you say that the season was unfavourable for wheat, do you confine that to the north of Wiltshire, or include South Wiltshire?-I allude to the claywet soils.

3082. Do you refer to the vale of Pusey ?-There is not so much clay there; it is further north.

3083. Was the season unfavourable for that? - It was too wet for it; but near Swindon it is worse.

3084. In the Salisbury plain country the season was good? - Yes; it was good for that sort of land.

3085. Do you consider that the North Wiltshire farmers are more distressed than the South Wiltshire? - No doubt of it ; for they have not had, generally speaking, the advantages of the sheep.

3086. The South Wiltshire farmers, in general, are sheep farmers?-Yes; and the price of sheep and the price of wool have been of great service to them.

3087. Do you not think that the high price of sheep and wool, and the fair price of barley, have pretty nearly brought the down farmer home?-The barley crop has been so very partial; upon so many farms there have been very light crops, and perhaps on another farm not very far distant there has been a failure of the crop for the last two or three seasons.

3088. Do you consider the price of barley, supposing your crop to be an average one, a pretty fair one ?-Quite high enough ; indeed every thing is fair enough except wheat.

3089. Do you mean that it is high enough in proportion to the quantity grown?I apply that to cattle, meat, butter, cheese, and indeed every thing the land produces, except wheat. I think if the wheat bore a proportionate price, the farmers would not complain.

3090. Are the prices of those other things sufficient to counterbalance the loss upon the wheat?-I do not think they are, for the wheat is what they calculate so much on.

3091. Are you to be understood that the price of barley has been a remunerating price, considering the sinall quantity of produce ?-I think the price of barley the last two year's has been remunerating, and as high as ever I wish to see it.

3092. What do you call a remunerating price? - I have always stated $30 s$. a quarter for barley.

3093. In the same proportion, what should you say was a fair price for wheat? -I stated before your Lordships, two years ago, $56 s$., and $1 l$. for oats.

3094. You would consider those prices, supposing average crops to rise a little in the case of a deficient crop, and to fall in case of a very abundant crop, would be about fair prices for the farmers under present rates? - I thiuk, under present rents, if the farmers had those prices, they would not complain, and I should say they would have no reason to complain.

3095. You calculate upon having an average crop?-Yes.

3096. Do you suppose the price of barley would have been what it is, if they had had an abundant crop?-No, not so high; but I still think, if they had had a good crop of barley, the barley would make a good price.

3097. When you state what would be remunerating prices, do you take the produce per acre; you have beforc stated three quarters for wheat, four quarters 
and a lialf for barley, and five quarters for oats, at the rent of $1 l$. an acre?-The rent I stated in one parish ; the rent must vary according to the soil, and according to the soil the produce will vary.

3098 . Did you reckon upon such produce per acre when you stated those prices? -I would rather say generally; but I think those prices with the present rents would class altogether.

3099. At what prices do you reckon the produce would answer?-That statement I gave was from land in my own neighbourhood; where there is that different proportion of land, I think the average is very much about $l l$. an acre.

3100. You stated that you calculated the produce per acre of wheat at three quarters, the produce of barley at four quarters and a half, and the produce of oats at five quarters; that, you say, at the prices you have just stated now, would be remunerating? - It would be quite remunerating to every farm that did not exceed $1 l$. an acre.

3101 . How many rents ought a tenant to make?--That depends on local circumstances; there are some where two are as good as three to others.

3102. Do you mean to say, that according to present crops of barley and oats you have had lately, the prices are remunerating?-I think they are.

3103. Are they more than remunerating? - No; I think with the partial crops the prices have been rather beyond my calculation; I think they have not been more than remunerating, but $I$ think there is no reason to complain of the prices of spring corn.

3104. Have the crops in your neighbourhood been below the average? - Just in my neighbourhood they have been rather below the average, but in other instances they are a full average. I speak of the best barley land in Wiltshire.

3105. What effect has the Beer Bill had in your neighbourhood?-A very bad one; nothing can be worse.

3106. Do you think it would be advantageous if the malt-tax were repealed; that that would tend to improve the lower class? - I think it would; I should be very glad to see them brew their beer at home, as they did when I was a boy, and it would promote their comfort.

3107 . Have any cattle been fed on wheat these late years:-The quantity of wheat consumed this year, instead of oil-cake, by cattle, is immense.

3108 . It would be exceedingly advantageous to the farmer to malt his own barley for consumption on his farm ?-Certainly.

3109. Did the poor brew beer for their families when you were a young man?Invariably.

3110 . Do you think that they would do so again if the malt-tax were taken off? - I think they would be some time before they got to that, but that they would go back step by step till they got into that plan.

3111. Would that increase the consumption of barley very much?-No doubt it would.

3112. Is yours a cheese county? - No, there is no cheese made in the neighbourhood of Salisbury; I am perfectly acquainted with the north of Wiltshire, where it is made.

[The Witness is directed to withdraw.

Mr. George Trumper is called in, and Examined as follows :

3113. WHERE do you live?-At Norwood, in Middlesex, near Southall.

3114. You are a land-surveyor:-I am.

3115. How long have you been so?--Five-and-twenty years or more.

3116 . In what part of the country do you practise generally?-In most parts of the kingdom.

3117. You have for some years?-For many years.

3118. Can you speak to the state of the farmers in different parts of the kingdom?-In many parts.

3119. In what part?-Where I have the management of property in Oxfordshire, Northamptonshire, Middlesex, Kent, Essex, Norfolk, Cambridgeshire, Surrey, Sussex ; in short, almost every county in the soutbern part of the kingdom.

3120. What do you find to be the state of agriculture in all those different counties that you have had occasion to visit? - Generally speaking, it is very much depressed.

464 . 
3121. In what condition are the farmers?-The farmers who have capital, and on intermediate soils and bettermost kinds of land, are better off certainly than those on the cold and heary lands, when they have capital sufficient to manage.

3122. Are they increasing their capital or improving it?-On the good lands, where they are fairly rented, I do not think they are wasting their capitals much ; but I think they are depressed upon those ; it depends upon how they are rented; in inferior cold lands they are very badly off.

3123. Are they distressed?-They are distressed; they are farming without capital, and have hardly any means of paying rent.

3124. Do you think that the rents that they do pay, they pay out of their capital? - I am certain of it, to some extent.

3125. What proportion do those heavy lands bear to the rest of the lands of the kingdom? - I have not turned my attention to that, but I should think they are quite equal to the others; I cannot speak to it positively, but I think about half; a considerable portion of these heavy lands should not be classed with the cold clays.

3126. Do they pay their rents?-They have managed, in many instances, to pay them, but I know many instances where they do not.

3127. Have a great many of them failed ?-Yes, on the worst heavy lands.

3128. In all the different parts of which you have been speaking? - In some more and some less.

3129. Can they, in your opinion, go on, unless prices can be raised above their present level?-The heavy clay land cannot pay rent with wheat at $10 l$. a load.

3130. At what rent are those lands? - The intermediate lands are letting from $15 s$. to $20 s$. and $25 s$, tithe-free; the very best land as high as $40 s$.; we had tenants ready for them on good mellow soils at those rents.

3131. Can they pay rent?--They do manage to pay rent.

3132. Do you find they can do it with advantage to themselves?-I do not think they can, without infringing upon their capital, which must ultimately reduce it below what is sufficient to manage the land.

3133. When the capital is sweated down, how will it be ?-It goes away very fast on the poor lands to what it does on good lands.

3134. Do they employ so many labourers?-I think labourers have been better employed of late years than they used to be.

3135. What do you call of late years?-The last three or four years.

3136. How do you account for that? - I think there has been a great deal of draining done in the country.

3137. By whom has that been done?-By the landlords; on several estates the landlords have contributed a certain per centage to give employment to the poor.

3138. When those improvements are finished, what will be the state of the poor then?-If the land gets into a better state, we are looking forward to be better able to employ them than we have been.

3139. Suppose it continues in its present state, what will be the condition of the poor? - They cannot be cultivated if the price is not better; and if they are laid down, of course that will deprive the poor of their labour.

3140. When did you observe this depression of price - It has been a long time taking place; I think the last seven years on the heavy land, because the seasons were so much against them the early part of that period.

3141. You recollect the period of 1824 ? - Yes, the seasons were wet; a quantity of land got very much out of condition; I allude to the wet season of 1828 , and not 1824 .

3142. Is it better or worse since that time?-The land, from the late dry summers, has improved in its state; but the farmers are still very much behind, both as to capital and the means of carrying on their farms; nevertheless the land is certainly in a better state than it was three years ago, from the dry summers and the opportunities of making fallows.

3143. Is there as much labour employed upon it as there was six or seven years ago ? - I think not.

3144. Is there so much manure? - No, for there is not so much produce raised upon the poor lands.

3145. There is consequently a diminution ing the quantity of manure and labour also?-Yes. 
3146. To what do you attribute this depression of prices?-There has certainly been a larger growth of wheat the last four years; a very large growth.

3147. Do you mean larger crops, or more extensive cultivation?-I think extensive cultivation, as well as large wheat crops. The land has been foreed beyond what it ought to be, and the late dry summers have given facility to that. The people have forced their land into cultivation beyoud what they ought to have done.

3148. How long back? - That has taken place only the last three years; since the land has been in a better state; some was so bad they could not do that.

3149. Has that continued down to the last crop, the greater cxtent of wheatsowing than usual ?-I think it has rather fallen off this year.

$315^{\circ}$. Has this extension of cropping been occasioned in any measure by the distress of the farmers ?- No doubt they have been pushing their land too far.

3151. They have endeavoured to make up by increased quantity to pay their rents?-Yes.

3152. Must not that be, in the cvent, highly injurious to the land itself?-Yes, certainly.

3153. Has it begun to have that effect?-Yes, to a very great extent.

3154. What has been the effect of this?-It has produced a great deal more wheat.

3155. What occasioned that distress which occasioned over-cropping?-The great pressure on the heavy lands, and from the expensive cultivation they require, and the low price of produce.

3156. What occasioned the ruinous price first, six or seven years ago?-I have no idea what occasioned it altogether; we have grown large wheat crops within the last three years certainly.

3157. Have the importations from Ireland had any effect?-Yes; we have received the whole produce of Ireland into this country.

3158. They do not eat their corn in that country?-No, nor their pork neither, I should think.

3159. There are great quantities of pork and corn from Ireland coming to this country? - Immense quantities.

3160 . Do those diminish the prices of corn and pork in this country?-Certainly, to a great extent.

3161. Do you think that is one cause of the depression of agriculture in this country?-I think that is the main cause.

3162. Is there any other canse to which you attribute it? - The loss of capital, the capital of the farmer, in many instances, being nearly exhausted.

3163. Was that owing to the imprudence of the farmers, or to the depression of prices?-I do not think it is owing to the imprudence of farmers of late years; they are a different class of men to what they were.

3164. They have been taught prudence?-Yes.

3165 . The present race of farmers are living very economically?-It is distressing to see how some of them are living.

3166 . Do you think less comfortably than some of them are entitled to live?I think so.

3167. They have not luxuries, and some of them hardly comforts?-Many, I know, have not comforts.

3168. What is the case with the labourer?-The labourer, where he is employed, is well off.

3169. Do you think he ts as well off as you remember him to have been?-He was never better off, when he is regularly employed and fairly paid.

3170. Is his ability to get employment as good as it was, or is it gone back?I think there is a great facility given to employment by the great works going on in the country; we do not find, when those works are going on in the immediate neighbourhood, that there is that surplus of labour there has been.

3171 . Are you a ware that there are a great many men going out of the country at the present time?-There are a great many emigrating, I understand.

3172 . In the different parts of the country you visit, in the active period of the year for work upon the lands, is there much superabuidant population at the present time? - There is a superabundant population to a greater extent than there would be if the farmers had the means of employing them.

3173. Does not that principally show itself in the dead time of the year, and not the active periods of farming work? - It is generally shown in the winter time.

464.

$\times 4$

3174 . Would 
Mr.G. Trumper.

8 March $18_{3} 6$.

3174. Would there be that superabundant population if agriculture was in a better state?-I think there would still be a superabundant population, but not to its present extent.

3175. You speak of labourers being fairly paid; what did you mean by that? -'There is a great deal of difference in the scale of payment; in some parishes they are paid low; in others very fairly; $9 s$. a week I should call, generally speaking, fair; that was the price I paid my father's labourers when I first left school in 1799.

3176. You would consider that fair wages at a distance from London?-Yes. We give our labourers $12 s$. a week, some $2 s$. $6 d$. a day, in Middlesex. We have not a superabundance of labourers in our parish. The high price of our cottage rents requires at least $1 s$. per week more to be paid to our iabourers.

3177 . You act as agent in different counties in England; is there much difference of payment of the daily labourers? -A great deal.

3178. Where are the highest, and where are the lowest?-I think where the population is thin, such as Lincolushire, the labourer is generally paid higher.

3179. What are the wages there?-They generally give $2 s$. a day for good labourers.

3180 . Where are they lower?-They are lower in some parts of Essex and Suffolk.

3181 . Where are the lowest in the different parts you are agent for?-In some parts of Hampshire they are lower; some parts of Oxfordshire and Berkshire.

3182 . What are they in Hampshire?-I understand about $9 s$. a week.

3183. To what part of Hampshire do you speak?-I speak of the New Forest; in short, generally.

3184. Are you aware that in the Down part of Hampshire they are lower than that :-They are from $7 s$. to $8 s$., I believe.

3185 . In Lincolnshire, where you say the labourer is paid $12 s$, does he pay dear for his cottage? - No, he does not; he has a cottage at a moderate rate; perhaps, on the average, $1 s$. a week, or $3 l$. a year.

3186. In some parts the cottages are much cheaper?-In some places much cheaper than others; in some places they do not pay more than $1 \%$. or $30 s$. for their cottage.

3187 . Is it the small farmer or the large farmer who is the most distressed ?I think the small farmer is more distressed than the large one; he has not the means of making that profit of his labour that formerly he used to do ; when population was smaller he had the benefit of his own labour; and the smaller farmer in populous districts, where he has high rates to pay and the surplus labourers to cmploy, cannot make that market of his own and his family's labour he could formerly.

3188. Though he and his family work partly on the land?-Yes. A small farmer would, with his family, probably do nearly the whole of the labour; now they have to pay surplus labourers if they do not employ them.

$3^{189}$. Is there a tendency in farms to become larger than formerly?-I think there is a tendency to become smaller; to subdivide them.

3190 . Is that in particular places?- No; I think it is rather a general feeling to have smaller farms.

3191 . You do not see many snall farm-houses pulled down, and farms thrown together into larger farms?-No; lately that was the case.

3192. Do you see small farms broken up into large ones :-No; there has not much alteration taken place of late.

3193. What alteration has generally taken place in your experience as to rents? -I have made a considerable alteration ; I might say from 30 to 40 per cent.

3194. Since what time? - Since 1812 ; and in many instances 50 per cent. for the heary lands; full 50 where I have had the management; I do not mean to say that is generally the case; a great alteration must take place where there has not been any yet.

3195. Generally speaking, where you have managed, about what prices of wheat, barley and oats do you look to for setting your rents?-We have been obliged to vary our calculation alnost every year; I should say that, according as the rents have been set by me, except valuations recently made, the generality of them about $24 s$. a quarter for oats would be a fair price, probably $34 s$. for barley, and from $50 \mathrm{~s}$. to $60 \mathrm{~s}$. for wheat.

$319^{6}$. 'Those are about the prices you calculate on in setting rents :-Yes, that has been the case till recently. 
3197. Those rents, as so set, cannot hold at the present prices? - At the present prices they cannot, certainly.

3198 . What do you mean by the present price for wheat?-It is now gone a little back; our best white wheat has been $50 \mathrm{~s}$. a quarter at Uxbridgc, but there has been a great deal sold for less; $10 l$. a load would be about as much as the whole country would average, $40 s$. a quarter or $42 s$.

3199. What liave been your prices for barley?-There is a great difference in barley; there is a vast deal not fit for malting that is selling at about $24 s$. or $25 s$. a quarter; that is nsed for feeding stock; malting barley is worth $34 \mathrm{~s}$. and $35 s$., the first-rate qualities.

3200. Supposingwheat, barley, and oats and wool, to stand at the present prices, and you had now to re-let your farm, what reduction, on the avcrage, would generally be necessary? - That would depend entirely upon the nature of the farm; the reduction on the poor lands would be greater than on the good lands; there the cropping is more certain; the thin poor soils and burning gravels would require a larger reduction.

3201. Would not the cold clays require more?-I hardly know what to say about them; they are cultivated nearly as they were 100 years ago; all intermediate lands have very much improved, and received a value they did not before possess; the clays and heavy lands still are pretty much as they were; nothing but a better price, in my opinion, can give any value to them.

3202. Setting those lands aside, taking the average of the property under your management, supposing present prices to continue, what reduction should you think the land would require :- I think a reduction, perhaps, of 15 per cent. on the rent as it stands would probably meet it. I have nothing under my hands but what bas had very serious reductions made upon it, the consequence of which is, that there has been a confidence created between landlords and tenants, and they have been better able to pay their rents.

3203. You state that a great deal of drainage has been going on; has not that improved the lands? - Yes, very much.

3204. Has not that increased the quantity of corn?-Yes, and also the value of pasture for the sheep.

3205. Looking at the improvements by draining, and comparing what your county produced 10 or 15 years ago, do not you think that your county produces more corn now ?-It would produce a great deal more if it could be well managed; the county is capable of producing a great deal more.

3206 . Would your county produce enough, if well managed, to supply its population with food? - I think it would.

3207 . Without including Ireland?-Ireland ought, I think, to be considered the same, if they were brought under the same laws and the same regulations as ourselves, and rendered liable to the same burthens.

$32 n 8$. The rent, you say, of the property you manage, has been reduced as much as 50 per cent. ?-Some parts of it.

3209. With the present price of agricultural produce you think that a still further reduction of 15 per cent. would be required?-Some very heavy lands, with wheat at $10 l$. a load, will not pay rent at all.

3210 . You would make a reduction of 50 per cent. on some land?-Yes; nearly 100 per cent. on some of the very heavy clay lands of the poorest description.

3211. Those are lands that have been cultivated in all times?-i es; they were lands in very good repute 100 years ago.

3212. They were not taken into cultivation in consequence of high prices?No. I recollect a great many of them growing an immensity of corn in former years, after their inclosure, until they were over-cropped.

3213. With all the improvements in cultiration they cannot cultivate them now? - No; there has been little or no improvement made in the cultivation of them.

3214. Do you state that that applies to half the lands in the kingdom?-To a great portion of what is considered heavy land.

3215. Till the turnip system was introduced, were nut those the only lands that grew corn?-They were the only lands that prodnced wheat in any quantities, except the loarns and intermediate soils.

3216. What would bring rents to the prices they were at before the year 1793 ; how much per cent. ?-A great many of them, that is, the heary lands, were letting for more money in 1793 than they are now.

464 . 
A)r. G. Trumper.

8. March 1836 .

3217. 'Taking into consideration what the landlord las expended in improvements, are there not a quantity of lands in this country now which do not produce more than they did in $1793:-$ - There are some that will not produce so much.

3218. You say, in some parts of Essex labour is low ; in what part of Essex is that?-The Hertfordshire side of Essex; towards Hertfordshire the wages are about $8 s$.

3219. You were understood to say, that on lands where the rent was already reduced, you thought a still further reduction of 15 per cent. was necessary to pay, at the present prices; did you mean that observation to apply to the bad lands merely, or to the land of intermediate quality? - To lands of intermediate quality, where I have fixed the rents some time ago, not recently.

3220. You fixed those rents on the prices you gave at the beginning of your examination:-Yes.

3221 . Has not the want or supply of fuel had some influence on the wages?Certainly; if a man gets his fuel readily and cheap, that must have an effect.

3222. You are aware that where the pricc does not exceed $7 s$., $8 s$. or $9 s$. a week, where those labourers are well supplied with fuel you can get them cheaper? - There are many parts where they cannot get it, and many parts where they can. A man living near New Forest gets his firing very cheap.

3223 . He does not purchase it? $-\mathrm{No}$, he does not; he gets it for his labour bestowed in collecting it.

3224. Are you aware that any quantity of wheat has been consumed in feeding cattle?-Immense quantities of all descriptions of corn.

32.25. Do you think that the repeal of the malt-tax would be very beneficial to the agriculturist? - There is no doubt of that.

3226. Do you think that the use of malt would supersede oil-cake ?-There would be more of it used in that way as wetted barley, and more go to the labouring man. I doubt whether taking off the malt-tax would benefit the farmers to the full extent some persons expect.

3227. Would it be a benefit to the agricultural labourers?-Yes, no doubt it would, and to the agriculturist himself.

3228 . Is there any article in this country taxed so high as that article, the produce of the farmer?-No.

3229. Or half so high?-No. The maltster will not now look at a sample of inferior barley, because he has to pay a duty of $20 \mathrm{~s}$. per quarter; therefore he buys only the finest samples for malting.

3230. Ilave you practised in any counties where hemp and flax are grown?I have seen a little flax.

3231. Can you state whether it would be for the benefit of the country to encourage the growth of flax?--I cannot say; it would impoverish the land.

3232. Would it be of any benefit to this country to inerease the price of tallow? - No doubt of it.

3233. By putting a higher duty on the importation of foreign tallow ?-It would occasion a better price to be given for our own produce.

3234. Would it diminish the price of meat at all?-I do not think it would.

3235. That would encourage the grazing part of the farming interest?-Yes.

3236. Do you know how that is affected?-The grazing interest varies so much, there is always something to be done by the grazier.

3237. He buys his fatting cattle cheap if he sells cheap :- Sometimes better, sometimes worse; they are not like the farmer, who is looking seven years forward in the proper management of his land.

3238 . What is the highest price you recollect tallow bearing?-I think $6 s$. a stone; $9 \mathrm{~d}$. a pound; but I cannot speak positively to that.

3239. How longr is it since it bore so high a price as $9 d$. a pound?- I think about 1812 .

3240. Do you recollect hides bearing a much higher price?-Yes; and calfskins $18 s$. and $19 s$. a piece; they are now worth about $7 s$, and cow-skins in the same proportion.

3241. How mucl a pound?-I have not studied that much, but I think they have been as high as $6 \mathrm{~d}$. per pound, or more.

3242. What is the present price of tallow? - I do not know; but the price of fat is low ; $2 \mathrm{~s} .4 \mathrm{~d}$. a stone; about the price of butchers' fat, I believe.

324.3. That is not $3 \boldsymbol{l}$. a pound? - Threepence-halfpenny per pound, calculating eight pounds to the stone. 
3244. You speak of the state of the farmers as much below that which the state of the English farmer ought to be, but that the condition of the labourer has improved; do you thiuk that can continue?-No, l think not; it is not a proper stiate of things.

324.;. The farmers cannot afford to pay those wages under these circumstancer?- No.

3246. Whatever the danger of doing it, at no distant period the wages of the labourers must fall :-They must fall according to the means of cmplorment; the wages of the labourers must fall if there are not better prices, certuinly.

3247 . Do you suppose thcre is a good deal of wheat in the farmers hands at present? - I think there is in some places.

3248 . More than usual at this scason of the year? $-N_{0}$, I do not think there is.

3249. Do you think there is more than there was this time last year:- $-\mathrm{No}, 1$ think not; the inferior wheat has been bought up at a low price to feed stock, and other purposes than that of making flour.

3250 . Has the produce of wheat in 1835 been equitl to the produce of wheat in 1834 :- - I think not quite; generally spcaking, the produce of 1834 was very great; so was that of 1832 .

32.51. How was 1833 :- Not so great, but altogether, I believe, good; since 1832 we have had good years of wheat; the last year and the year before were too dry for the barley on the thin lands.

3252. One thousand eight hundred and thirty-two, 1833, 1834 and 1835 have all been good years for wheat?--Yes, they have.

\section{The IV itness is directed to withdraw.}

Mr. James Taylor is called in; and Examined, as follows:

3253. YOU reside in Dorsetshire:-Yes.

Mr. J. Tayior.

3254. In what part of Dorsetshire?-About seven miles below Dorchester, at Littlebury.

325.5. Are you a large farmer?-Yes.

3256. To what exteat:- Upwards of 1,500 acres; not more than 300 of arable land.

3257. What is the rest? - Down and meadow pasture.

3258 . Is part of the pasture water-meadow:-Very little; there is some of it.

3259. What is the state of farming in Dorsetshire?-In the agricultural districts I think it is very bad; it is bad every $w$ here. In Dorsetshire there has been less distress than in almost any county in England, from our poor-rates not being so heavy ; and I think the system of Dorsetshire, allowing the men their cottages, and giving them their potato ground in a field, where we plough and manure it, according to the size of their families, and they get their fuel from the lown, the furze (they have an allowance of wheat as well), though we pay them but $7 \mathrm{~s}$. a week, I consider these make it equal to $11 s$. to them.

3260. You include in that a cottage with a piece of garden?-Yes.

3261. Do you mean to say they pay nothing for their cottages? - No.

3262. They have wood from the copses?-No, we have no copse in some of the parishes; furze is the principal with us.

326.3. You think that keeps your poor in a better state than in the neighbouring counties?-Yes.

3264 . Is there any thing got by the cultiration of land for corn?-No, but a los.s.

320.5. You cultivate according to the four-course husbandry? - Yes.

3266 . What is the course:- Turnips, barley, or oats; then clover and wheat.

3267 . Upon that four-course husbandry is the loss upon the whole, or only on the wheat?-I think principally upon the wheat.

326s. During the other years do the profits on the other produce bring up the loss on wheat? -No.

3269 . With respect to sheep - I do not think there has been much the matter about the price of stock till the last season, and that was only a casual thing, from the failure of turuips.

$32 \%$. Does the advantage derived from the good price of stock bring up the farmer? - No.

3271 . It docs not compensate him for the loss on the wheat?-No, our dairies have sunk about $1 l$. a cow within the last two years. 


\section{MINUTES OF EVIDENCE BEFORE SELECT COMMITTEE}

isr. J. Taylor.

8 March 1836 .

3272. Have rents been reduced in that part of the country?-I have not heard much of rents being reduced in that part; I do know some instances, but not to any amount.

3273 . Since what period? - I have been in Dorsetshire only about six years.

3274. Where were you before?-I lived at Moor Farm, by Rickmansworth.

327.5. You rent under Mr. Williams?-Yes.

3276. You came from Moor Farm to Mr. Williams's farm in Littlebury?-Yes, about two or three years after Mr. Williams left I took this farm.

3277 . The poor, you say, are well off; can you pay them their present wages and give them their present advantages, unless there is an increase in the price of corn?-No.

3278 . What will be the effect of any reduction of wages? - I hardly know what to say to that.

3279. In what state are the poor now? - In a tolerably good state.

3280 . You do not see any disposition to riot or disorder?-No.

3281 . Had you riots two or three years ago? - Yes, but they did not reach us within about 14 miles, I think.

3282 . Would there be any danger of riots if their wages were much reduced now? - I should doubt it; I do not think they could live with less wages.

3283. Can the farmers, unless the prices of produce are raised, afford to pay them their present wages?-No.

$32 \mathrm{~S}_{4}$. The allotment system does not prevail much with you?-No, not in the parishes I have referred to, except a garden and land for potatoes, and that we give them. I think that preferable to the allotment system, for we manure their land; and if they got any quantity in the allotment, they have a difficulty in procuring manure, and it takes them away too much from their masters' work.

3285 . Do you give them a bit of fresh land every year? - Yes, wherever we make our fallow for turnips.

3286 . They have gardens generally annexed to their cottages?-Yes.

3287 . Are not the gardens in Dorsetshire very productive; do not they grow many apples :- They have tolerably good-sized gardens, with perhaps a tree or two, but not more.

3288 . Have you made a calculation as to the expense of cultivation, and the amount of produce? -I have.

3289 . Are you prepared to say from that, whether the expenses exceed or fall below the value of the produce of the land?-This is a calculation for several different parishes just around us; Winterbourn Stapleton, Winterbourn Abbas, Portisham, Abbotsbury, Swyre, Puncknowle, Litton Cheney, Longbredy, Kingston Russell, and Littlebredy. I have a calculation for those parishes as far as the arable land goes.

\section{[The same is delivered in, and read, and is as follows :]}

The Average Rent, Tithes, Wages, Rates and Taxes, and all other Outgoings, for each Year, for Four Years, of an Acre of Land farmed.

On the Four-field System :

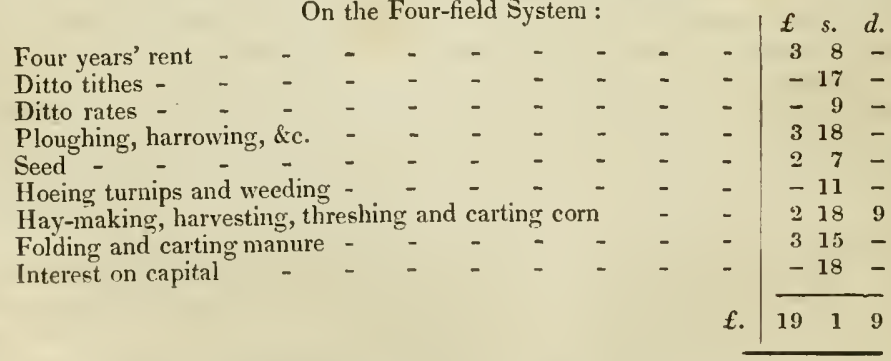

The Value of the Produce of each Year for Four Years.

Produce of One Acre of Land in Four Years:

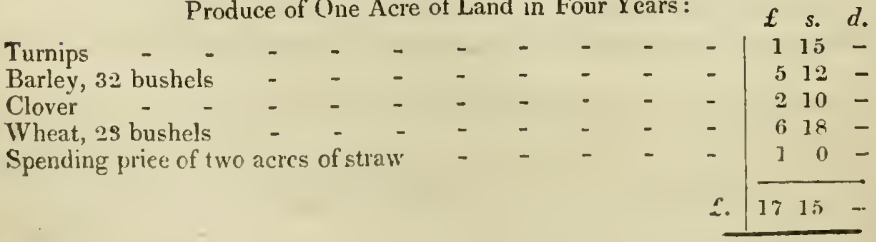


3290. You do not allow any thing for the purchase of manure?-Not in my statement; most of those farms liave green ground enough for the sheep, which, the folding and the straw together, make sufficient; I should state that these farms are what we call sour farms; the barley is not very good; I take the average of barley that goes from the maltsters in the neiglibourhood; they have proved it to be rather lower than I have put it down at.

3291 . There is a loss upon the corm of $1 l .6 s .9 d . ?-$ There is.

3292. You derive some advantage from the keep of sheep upon this land? -Yes.

3293. Have you given credit for that? - No; there is very little feed upon this land; the turnips. I have cliarged, in fact, $6 d$. an acre for the stubbling for the sheep running, but I should think that would be quite as much as it would be.

3294. What is this land; is it of any one given farm, or generally ;-No; I have taken it as the average of the country; the farms I have stated lying just round me, in the parishes I have just named.

3295. You state them to be sour lands; is that the general character of that land?-Yes; I have taken in those farms that lie round us.

3296. What distance does that embrace; how far round? - Four or five miles, I should think.

3297. Have you taken them indiscriminately ?-I have taken them as nearly as I could at the average rents; some of the rents I know.

3298 . You have not selected the worst?-No; I have taken them within the circle.

3299. You say you have done very well with your cattle?-Yes, till the three last years and this year; there has been a temporary loss with turnips.

3300. You had a temporary loss three years ago with your sheep ?-Some of those farmers had.

3301. Do the advantages you derive from your wool and sheep, and other produce, at all counterbalance the loss upon the corn? - No, there is a loss upon every thing but wool.

3302. You state this as the result of four years average?-Yes.

3303. To what do you attribute the depression; is it the Irish butter brought in which keeps down your dairies?-Yes, and .rom Holland.

3304. In any quantities?-I know that from hearsay generally.

3305. Has your butter fallen?-Yes, it has.

3306. When did the fall in butter take place?-Butter fell about three years ago, and it has kept getting down; now it is going up again, from the short supply last year; but the dairymen have been losing a great deal.

3307 . State what it was, what it fell to, and to what it has risen? - We let our cows at so much a piece, and the dairymen can best state what they get.

3308. At how much a cow did you let your cows three years ago?-At $9 l$. ;

I let them last year at $8 \mathrm{l} .10 \mathrm{~s}$, , and I was obliged to throw back again $7 \mathrm{~s}$.

3309. At what did you let them this year - Eight pounds ten shillings, with a promise, if the season should not be good, I should throw that back again; but they are let in several places with that sum taken off at onee.

3310. Where does the butter go to? - A great deal of it to London; there are butter factors, and they buy it of the dairymen.

3311. Do they make butter altogether, or some clieese?-They make some cheese; the butter is very good, the cheese very bad.

3312. It is a famous county for butter-Yes; it is the best butter that can be got.

3313. Will you explain what you mean by letting your cows; the farmer, you say, lets to the dairyman? - Yes. We find the cows in February in calf, and the dairyman takes to them, and gives us so much for each cow; and when they cease to yield we take the cows back till they calve again, and if there is one that will not answer his purpose we give him another; we breed some every year to make up for the deficiencies.

3314. Who keeps the cows?-The cows are kept on my land all the year through.

331.5. Do you deduct the price for the feed?-No; he gives me so much for the cow, and I find lim the feed.

3316 . He has a house also to live in ?-Yes.

3317 . Who has the calf :-The dairyman has the calf.

464.

Mr. J. Taylur.

8 March 1836 . 
Mr. J. Taylur.

8 March 18,3 .

3318. Suppose the cow does not turn out a good milch cow; what is done then ?-Then we take her back, or take that cow out of the account.

3319 . How often in the course of a season las he the power to object to a cow?-Not after May-day. It is optional whether we do it; if wc find it is a hard case, if the cow should go dry, or any thing of that kind, we take it off. We live in a good understanding with each other, but I do not think they can compel us to do it after the bargain. The time of entering on the dairies is generally in May; he takes them as they come in, and those that calve later will give longer.

3320 . Who pays for any expenses of milking those cows or making the butter?-The dairyman.

3321. You give them food? - Yes, their food entirely.

3322. He takes the cow from February, and pays for it through the year, whether in milk or dry?-Yes, unless we choose to let him off. Whatever cows he dislikes at old May-day he points them out, and says, they are not good milkers, or something, and we take them away, and give him others from the heifers that come in.

3323. At what age has he the disposal of the calf? - He has it at once.

3324 . He either raises the calf or sells it at once, as he pleases:-Yes; generally they part with it in a few weeks.

3325. Are there other things which come in from Ireland?--Yes; pigs and corn, and every thing comes from Ireland, to the injury of the farmers in this country.

3326. Does it come to Weymouth:-I cannot say; the greatest quantity of wheat which has come to Weymouth has come from Lincolnshire.

$332 \%$. Has the quantity of land used for the purpose of growing corn been increased lately :-I cannot say that it has; there have been some instances where land has been broken up; but the poor land has generally been let out, on account of the price of corn.

3328 . Has there been a great deal thrown out:-Not a great deal, perhaps, generally.

3329. In what state are the farmers:-Mostly in a good state; I do not see much distress among them; they are all men of opulence to begin with, with large farms.

$333^{\circ}$. What is about the average size of the farms - From 500 to 1,200 acres, and up to 1,500 or 1,600 ; I think mine is about 1,550 acres.

3331. A great deal of that is down land? - Yes.

3332. There are not many of them all arable?-No; there are good farms about Bridport and Beaminster ; they have not much down.

3333. What is the quality of the down land about you; what does it let at where it is alone? - From $8 s$. an acre to $l l$.

3334. Mo you mean for down pasture?-Yes; it is quite different from the Wiltshire downs.

3335. The generality of down in Dorsetshire is not worth that, is it?-Yes, I think it is.

3336. It is very superior to the Wiltshire or the Hampshire downs?-Yes; there is more staple to the land.

3337. It will feed cows:- Yes; on some of it we feed cur cows quite on the top of the hills, it lies so high; it is the climate that hurts us.

3338 . What do you mean by the climate?-Its lying so high; that does so much mischief to our corn; if we had a wet season we should grow but little. I never knew so many good seasons for corn as there have been these last four years. I do not think I should state it on the average of eight or ten years at more than 20 bushels an acre as the produce.

3339. Is the land on the farms there as nell cultivated as it used to be?-Yes, I think it is.

3340. There is no want of management in the cultivation of the land?-No; I think it is quite different from the corn districts in England; I think there is a great deal more distress there than in Dorsetshire.

3341 . You speak of the generality of the country?-Yes.

3342. How many sheep do you keep on your farm?-I lave now something like 2,000 .

3343. Is that since the lambing:-No; before the lambing. 
33.4. How many breeding ewes have you?-About 960 I had when I began lambing.

334.5. Do you reckon that they will protuce you as many lambs?-No; I have never had above 700 ; that was last year; and I lost 100 just after the shearing time. If we ean bring 600 to the shearing place that is as much as we generally do. That is from climate; we do not lose them from their lambing, but the weather will sometimes brcak in upon them; I had 26 brought home one night killed.

$334^{6}$. Camnot you shelter them? -No; when we bring them down it is like a gateway between the hills.

3347 . Beside the 2,000 sheep, how many cows have you? - 1 have had 100 corrs.

3348 . Which are let to these dairymen?-Yes; and they produced to me last year a little more than $800 l$.

3349. Do you consider your stock, the produce of your cons and your sheep, as your most important returns from your farm, or is corn a large portion of it :- ()ur stock is what we reckon on most in that quarter.

3350. Your sheep stock have been selling pretty well, have they not:-Till this year ; they have sold very badly this year.

3351. The early fairs this year were good, were not they - No; they were better than they were later, but there has been a great loss upon them.

$335 \%$. The conntry fairs were good till it turned out that the turnip crop had failed :- Y es; we did not begin to sell till Wilton fair; they kept sinking every fair.

3353. Was not Wilton a good fair ?-No.

3354. Your wool sells well ?---That is at a great price.

3.355. Have you sold your barley so low as $28 s$. - Yes, and less than that;

I have not had more than $26 \mathrm{~s}$. for my barley this year.

3356 . It has been a bad sample?-No; a middling sample. I did not grow more than 24 bushels an acre; mine is one of the poorest farms to grow barley in the parish I am situated in.

3357. Taking into consideration the price of wool and the price of stock, has it been altogether a worse year for you than the last year :-Yes, a very bad year.

$335^{8}$. How was the year before this:-A loss; I should say a loss every year.

I bey I may not be understood, when I say the distress is not so great in Dorsetshire as in other counties, to say that there is no distress here; but it is getting serious now with every coln farmer.

3359. Is not that serious state of things with every corn farmer mainly from the low price of wheat? - Yes; I think the price is not enough according to the crop, because in the dry lands the lent corn has not been quite an average crop, and the other has been more.

3360. Supposing the present price is held, even with the price of $40 \mathrm{~s}$. for wheat; that the prices of sheep, barley and wonl held where they are at present; taking the chance of average crops, would not you feel satisfied that you could pay the rent of your farm? - No.

3361 . What prices are there at present existing in the market, whether of sheep or of stock generally, or of barley, or of wool, which you would say was so low as to injure you?-The price of the sheep and the wheat; sheep are selling very fair at Smithfield as fat sheep, but that is on account of our loss from our not laving turnips; we lose from not having turnips, and being obliged to use artificial food.

3362. Taking your ordinary chance of turnips or no turnips, and looking at the price of sheep, you have nothing to complain of in the price of sheep, have you? - Yes; we have a great many ewes which did not fetch so much by $1 l$. a piece as they did the year before.

3363. What did they fetch ?-They fetched $26 \mathrm{~s}$., and last year they fetched $46 s .6 d$. with us.

$33^{64}$. What is the highest price at which you recollect cows to have been let by the year?-I have heard my neighbours speak of $14 \mathrm{l}$. and $15 \mathrm{l}$, but I cannot go back so far myself.

3365. What does butter sell for? - I forget whether it is $9 d$. or $10 d$. the dairymen are making now.

3366. In what way do you think relief could be best afforded to the agriculturists?- If the duty should be taken off malt, that would give us as great relief as any thing; the beer-houses, I think, have been a very great evil in the country. 


\section{MINUTES OF EVIDENCE BEFORE SELECT COMMITTEE}

Mr. J. Taylor.

8 March $283_{3}$.

3367 . In what way would that be a benefit?-I think it would benefit landlord and tenant and the public too; I think the poor would get a little wholesome beverage at home.

3368 . Would the farmer be able to give lower wages to his labourers, in consequence of being able to give them beer in their farm-houses?-I think the poor labourers would get it in their own cottages. The generality of pesple round us speak of lowering rents; there is no doubt, if something is not done, rents inust be lowered; but I an doubtful whether that would have a good effect in the country; from what I know of other counties, I believe that the rent has been taken down within these few years one-third, which must take away from the expenditure of noblemen and gentlemen who are the landed interest; there will be only more poor and less means of assisting them.

3369 . If the rent was lower it wonld deprive the landlord of the means of assisting in the improvement of the land?-Yes.

3370 . Have you many freeholders about you occupying their own land? - No ; Mr. Farquharson farms some of his own land; I think several thousand acres.

3371. Do you think he gains a profit by his farm? - I should doubt that very much.

[The Witness is directed to withdraw.

Mr. James Hudson is called in ; and Examined, as follows :

3372. WHERE do you reside? - In Sussex.

3373. How long have you been a farmer?-About 35 years.

3374. What is the present state of farming in that part of the country?-It is in a very bad state.

3375. Are the farmers in a bad state? - I think they are.

3376 . Is that the case in any considerable district of country there? -I think it is in the Weald of Sussex.

3377. To what is that attributable; to their misconduct or the times?-To the times, I think.

3378. Are the prices sufficient to afford them a remuneration?-Decidedly not.

3379. Do you think they must pay rent out of their capital ? - They must, at the present prices.

3380. The opinion you have given has been given confined to the growing of corn?-Yes.

3381. What is the state of stock?--They are in a very peculiar state with respect to stock; on account of the great drought we had last summer, the provision for stock is very short; it has not been a profitable concern at all, so far as grazing has gone. thing.

3382. Was it profitable before that?-I think it paid its way as well as any

$33^{8} 3$. Within the last four or five years, has the profit on the stock made up for the loss on corn?-Decidedly not.

3384 . What is the state of the poor in your county ?-In some situations they are very well off; in some others they have been very badly off.

3385 . Has there been disturbance in your county ? - Not any in my neighbourhood.

3386. Are there many persons out of employ ?--Not in my neighbourhood exactly.

3387 . Are they employed on the farms?-Generally.

3388. If the farmers are so distressed as you represent, how do they afford to employ the labourers :-They give them employment because they have no other means of subsistence.

3389. Do they employ them profitably to themsclves?-Certainly not, at the present price of corn.

3390. Is it impossible the farmers can, at the present price of corn, pay the expenses of agriculture?-It is impossible.

3391. What do you consider as the cause of the present depression?-I think that the cause of the present depression of wheat is the great crops we have had the last three years.

3392. If you grow two ears of corn where you formerly grew one, that would increase the quantity of corn, but would not distress you -It lowered the price. 
3393. If you had double the quantity to sell? - The expense of cultivation is not paid by the produce; the present crop will not pay it. Taking the present crops all together, the crop of barley and oats is very deficient, and the crop of hay is very deficient.

3394. Are you speaking of your own neighbourlood, or the country generally of which you have experience as a valuer?-I think that is the case generally.

3395. The account you have been giving is applicable to that whole district of country? - I think it is.

3396. Can the farmers go on at the present rate?-No, not at the present prices.

3397 . Has any cheaper corn than that grown in England been introduced among you :-We always have the Irish corn in the market against us; the importation of Irish oats is very great to Brighton.

3398 . Has not Ireland sent a great many oats to Brighton :-Yes; they have met our own produce to a great extent.

3399. Are you shut out of your market by the Irish importations :-We are not shut out, but our prices are very much lowered by them.

3400 . Is there any other cause to which you attribute your difficulties?-Our local taxation.

3401 . How is your poor-rate?-It is very heavy in some places.

3402. Has it been mended by the Poor Law?--Very much.

3403. Notwithstanding that amendment, is your condition much better than it was?-Our prospect is much better in this respect, for we expect we shall not have so much to pay to maintain the poor.

3404. Will any benefit you have from the Poor Law relieve you from your present distress?-I think not.

3405. What are the wages of your labourers?-From $10 \mathrm{~s}$. to $13 \mathrm{~s}$., and a shepherd at $16 s$., where they have 600 or 800 in a flock together.

3406 . Do you mean generally throughout the district?- No; from $10 s$. to $12 s$.

3407 . In the Weald district what do you reckon the produce per acre?-From 20 bushels to 28 bushels of wheat.

3408. Of barley? - They grow very little in the Weaid.

3409. Oats?-From 28 bushels to 40 bushels.

3410. Beans?-From 20 bushels to 28 bushels.

3411 . What may be the produce in the Down country? - Wheat about 7 sacks, or 28 bushels; barley about 36 bushels; oats about 44 bushels, upon the best lands.

3412. In the Weald, what prices for corn, according to the produce you have reckoned, would be remunerating for the farmer?-I think, unless he gets $56 \mathrm{~s}$. a quarter for wheat, and $1 \%$. for oats, and about $30 \mathrm{~s}$. or $32 \mathrm{~s}$. for barley, he cannot pay his way.

3413 . Would those be the prices required for the Down district as well as for the Weald :-Yes, I think they would.

3414. What has been the extent of the crops of barley and oats during the last two or three years? - They have been very deficient; where I have been in the habit of growing ten sacks of barley I have not grown above seven, and in some instances not more than six, and that of very inferior quality.

3415. Does the present price of barley at all compensate for the deficiency of crop:-Certainly not.

3416 . What do you call the present price of barley?--From $29 s$, to $33 \mathrm{~s}$.; there is inferior barley sold as low as $27 \mathrm{~s}$.

3417 . Oats? - Seed oats are selling at $23 \mathrm{~s}$.; from $18 \mathrm{~s}$. to $23 \mathrm{~s}$.

3418 . The prices of oats and barley are, as near as possible, what you consider fair prices?-Yes; but then there is a deficiency in the crop.

3419. Supposing you had an average crop, those are about the prices you would consider fair prices?-Yes.

3420. What do you call the present price of wheat?-From $11 \%$ a load to $12 l .5 s . ;$ that is about $44 s$. to $49 s$. a quarter.

3421 . The price you consider a fair price would be $56 s$, therefore you are about $12 s$. under the fair price.-Yes.

3422. Do not you conceive there have been very large crops of wheat the last two or three years? - Ies.

3423. To what extent does the largeness of the harvest compensate for the 464.

lowness 
Mr. J. Hudson. lowness of price?-We have been selling wheat from $81.10 \mathrm{~s}$. to $9 \mathrm{l}$. a long time ; that is $5 l$. off from $14 l$.; the price is reduced more than one-third; I think we 8 Narch 1836. have about one-fourth more than the average produce.

3424. Supposing the prices to be at present, as you state, $44 s$., add one-fourth to the $44 \mathrm{~s}$., which would be $11 \mathrm{~s}$., that would bring you up to $55 \mathrm{~s}$.-Yes.

3425. So that the present price, supposing you had kept all your wheat, and had not sold it at the low prices, taking into consideration the largeness of the harvest, is not very much under the fair price?-Then we have been selling at this price only last month; we have disposed of a great deal of our produce at an inferior price.

3426. Is it not generaily the case that the farmers dispose of their produce of corn at a low price ; that it is bought by the corn-factors, and then prices rise?Yes; but we are compelled to sell, having our payments to make.

$342 \%$. The small farmers are more distressed than the large ones, are they not? - No; I think they are more benefited by the greater produce of wheat, because, with a short crop, their seed and their own families consume the greater part of their growth; with a good crop, if they sell at a low price, they make more money.

$342 \mathrm{~S}$. That is because the low farmers cultivate a different description of land? -Yes.

3429. What description of land is that? - The heavy clay.

3430 . You have stated that the increased growth of corn was, in your opinion, one of the causes of the distress of the farmer:-The cause of low price.

3431. You have stated that you consider that as the main cause of the distress of the farmer?-Yes.

3432. Since when has this increased growth of corn taken place :-The last three years; we have had three following years of good crops of wheat.

3433. Do you recollect the years 1828, 1829, 1830 and 1831?-I do not recollect particularly the growth of those years, but about that time I know there were some very deficient years as to the produce of wheat.

3434. Were the farmers in a flourishing condition in those years?-No, I think not.

3435. In those years the small quantity of produce was against the farmers?Their produce was of a very inferior quality at that time.

3436 . Neither abundance appears to agree with you nor scarcity; how is that? -On account of the heavy expense there is in cultivation.

3437. What occasions that heavy expense :-The labour and the rates and the tithes we have to pay.

$343^{8}$. Is it not generally the case that the farmer is better off with moderate crops and good prices than with great crops and low prices?-With average crops and good prices.

3439. The price generaliy bears a proportion to the benefit he derives from the increased quantity? - Yes.

3440. Is your own farm in the Weald?-No; it is on the Hill.

3441. Are you agent or steward for properties in both?-No; I am employed in valuing farms and farming stock and implements.

3442. The Hills are chalk Hills ?-Yes.

3443. Is it in the Weald or on the Hills the farmer is most distressed now ?Occupations in the Weald are very different from the Hill; their capitals are not in proportion to those on the Downs; I think that the Weald farmers are more distressed than those on the Hills.

3444. The Down farmers have had some compensation in the price of their sheep and their wool, have they not?-The price of sheep last year was very inferior; the expense we are put to in maintaining our flocks will take off a great deal of our return; I am keeping part of my flock on oats, and my working oxen on oil-cake.

3445. Has not the straw been remarkably abundant the last year?-No; I never knew it worse with us.

3446 . The price of your sheep stock is good, is it not?-No; it was very bad last year.

3447 How is your wool? - The wool has improved since the fair last year; it is now worth $53 s$. a tod.

3448. Is that a considerable iten in the produce of a Down farmer?-Yes, it is.

3449. Have 
3449. Ilave the rents in your part of the conntry, taking first of all the Weald, been reduced considerably of late years? - Yes, they have.

$345^{\circ}$. To what extent? - In many instances to half.

3451 . Since what tine? - Since the year 1814 .

34.52. From the highest time?-Yes; I know in some instances they have been reduced more than half.

345. Are you of opinion you still cannot farm at the present prices?-Cer. tainly we cannot.

3454. Are there considerable portions of the stiffer land that will hardly pay any rent at those prices?-Yes.

3455. Have the rents upon the Down farms fallen in the same proportion?-I think that the falling off lias been one-third instead of one-half.

3456 . Would the stock farmers fare better, at present prices, taking wool and sheep and every thing into consideration, than the Weald farmers? - If they get an average crop; but the crops of barley and oats were so deficient last year.

345\%. Taking your chance of crops, suppose you had to give an opinion according to the present prices as to what the rent of a farm should be to the farmer, taking his chance of seasons, would the Down farms be able to hold their present rents? - They would, better than the Weald, certainly; but I do not think they would be able to go on for any great time.

$345 \mathrm{~S}$. You do not think, at the present rents, the farmers are making a profit even on the Downs ?-No, I think not.

3459. Has there been much reduction in the expense of farming utensils or the expense of artisan's labour?-No; the charge is nearly as high as ever for the carpenters', wheelers' and the smith's work.

3460 . Have not wages been reduced?-The day-men we employ by day-work we have got down to i0s. a week; but I am paying the same for task-work; I am paying $22 d$. for threshing barley.

3461 . You value farmers in and out?-Yes.

3462. Are you much employed in that-Yes.

3463 . Have a great many farms been given up lately ? - Yes, there have been some, but not a great number; when they do give up, the dividend is generally very small.

3464 . There is not a good dividend?-No; a very bad one; there is a man on the Downs, within the last two months, compounded with his creditors at $7 \mathrm{~s}$. in the pound.

3465 . In instances in which that has occurred, has it been from the imprudence of the farmer or the state of the times?-The state of the times, undoubtedly.

3466. Have they been skilful, prudent, industrious farmers?-- Generally they have; not perhaps the most skilful, but they have been industrious persons.

$346 \%$. Generally speaking, the farmer is not living very extravagantly?-No; that is altered very much for the better within the last ten years.

$346 \mathrm{~S}$. There is no cause of reproving him upon that ground?-No.

3469 . Are the wages you mention given on fair competition, or is it found prudent to give that rate of wages to satisfy the people?-I think the probability is, we might get it done at a less price if we were to select our people in the market; but the persons we employ are those who have lived in the parish, and worked on the farm, and we think they cannot live for less.

3470 . Does it arise from any fear on the part of the farmers of any acts of outrage?-Decidedly not.

3471 . You would have no fear of refusing those wages; you do not give them merely because you thought it prudent to do so?-Decidedly not.

3472 . There is none of that apprehension in your part of the country?-No.

3473. Have you had any fires of late?-No.

3474. What do they pay for their cottages? - About $3 l$. a year.

3475 . Do you think cottage rents in the east of Sussex are generally as low as that? - That is what I pay at East Dean.

3476 . Have most of them gardens?-Yes, small gardens; we hire them of one person at $3 l$; but $1 s .6 d$. a week is a very common rent, with a garden.

3477. Do you think the labourers live as well as they used to do?-They never lived so well.

3478 . Do they eat as fine bread as they used to do ?-They eat as fine bread as 1 do; finer than they used to do.

464 .

z 2

3479. Do 
Mr. J. Hudson.

8 March $188_{3} 6$.

3479. Do the farmers live as well as they used to do? - They live very well, but not so extravagantly as they used to do.

34 So. You do not know any instances of farmers who live very closely :-I think they live closely; they raise their subsistence principally within themselves; they kill the sheep, pigs and poultry they feed; I do not think their butchers' bills are great.

3481 . Do they live as well, in proportion to their condition, as the labourers ?I think so.

3482 . It is your opinion that the farmers in the district with which you are acquainted have reduced their expenses very much ?-Decidedly.

3483 . What do you reckon the average value of the shearing of your own sheep - About $4 s$. a fleece, if the wool is $1 s .6 d$. a pound.

$34 S_{4}$. To what age do you keep your sheep:-We generally turn them off at four years old.

3485 . What do your sheep generally sell for?-Upon the average of years, our best shcep will fetch about $24 \mathrm{~s}$. each.

$34 \$ 6$. How many sheep do you keep on an acre of ground?-I cannot state that, because we stock in large flocks, 600 or 700 , and they go over certain quantities of ground, and we feed them also on artificial food.

3487 . Supposing a person had 100 acres of inclosed land, and a suitable portion of down, how many sheep would he keep?-I have 450 acres of arable land, and about the same quantity of down, and I keep 700 breeding ewes; 900 sheep altogether.

$34 \mathrm{SS}$. Should you say that there was, during the last three years, more or less wheat grown in the country than latterly :-I think there has been more grown till last year; this last autumn, I think, not so much; because the summers have been so favourable for the preparation of it, people are anxious to sow that which they calculate they shall make most of.

$34 \mathrm{~S} 9$. It is your opinion that, with the exception of the last wheat season, there has been a greater breadth of wheat sown, and a greater crop produced, than before that period?-Yes.

3490. Taking those two circumstances together, do not you think that in a great degree accounts for the low price of wheat?-I think it does.

3491. Do not you think that the farms are as well cultivated now as they uscd to be? - I think, on the Downs, they are, generally.

3492. The men on the Downs are generally well off for capital ? - I think that they cultivate their farms well, where they have sufficient capital to carry it on.

3493. Are your poor-rates very much reduced?-I think they will be this year, when the new Poor Law is brought into operation.

3494. To what extent? - We think it will be in some instances one-third, and in some instances one-half reduced.

349.5 . And that without any severity on the poor man:-I think so; without any severity.

3496 . Do you ascribe that effect to the alteration of the law, or that the parisles have looked after their rates more carefully?-I think that they have looked after their rates more carefully, and that the law has assisted them.

3497 . You think the new system has worked well, both to the labourers and the rate-payers? - Yes.

3498 . The labourers are contented with it $?-$ Yes; I think the best men are contented with it, but not the worthless.

3499. What are the cases in which the poor men with large families have assistance from the poor-rates? - Where a man has more than three children, they give them the option of taking them into the house.

3500 . Supposing he is not willing to part with them?-In many instances, formerly, their children have been kept at home in idleness, and not put to any employment whatever; now they are willing to let them get parish work on alt occasions.

3501. Would they not be willing, if they got something for their children's work?-They are now willing their children should be employed.

3502. Do you mean to say that assistance was used to be given to labourers if they would not employ their children?-Yes; they used to have a certain stipend allowed them weekly; if we wanted one of their children they would not let thom come.

3503. What were your poor-rates:-1 think $4 s .6 \mathrm{~d}$. in the pound, and $5 s$. 
3504. You think they will come down to $2 s . \hat{r}-$ Not this year, perhaps.

3505 . How arc the children removed from their parents taken care of in the poorhouse?-Very well indeed; there is a governor and a matron in each house.

3506. Are they taught? - We have not had a schoulmaster in the Newhaven Union until last week; he commenced his business, and they will be taught to read and writc.

3507 . In general, in the unions you are acquainted with, where the children are placed separately in the poorhousc, you understand that provision is made for their education? - Yes; we appointed a schoolmaster and a schoolmistress last week for one.

3508. Do you find that those who are in work and have so many children that they cannot provide for them with the earnings of their work are contented to part with some of their children? - In most instances they are not.

3509. In point of fact, you are not acquainted with a great many instances where that has taken place?-No; I do not hnow of many.

3510. In those instances where it has not taken place has it been found that the parents have chosen rather to go without the relief than part with their children :- Yes; but in some instances where the parents have sent their children to us at Newhaven they have been to see them, and they say they are much better off than they were at home.

3511. Are not the greater number of the children in the workhouse orplans or illegitimate children?-Yes.

3512. At what age do you keep the children :-- To any age at which they can be provided for.

3513. Supposing there were orphans or illegitimate children, at how early an age do you take them in :-I take it the earliest we have are two and three years of age.

3514. Do they give them any employ in the house:- We have not established any employment yet.

3515. Up to what age do they keep them in the house:-If they can be provided for in no other way, till they can get into a service.

3516. At what age do you suppose that will be? - Twelve or thirteen or fourteen years of age.

3517 . Are there many in your workhouse at that age?-There is only one boy of 14 , and others 10 or 11 .

[The II iness is directed to uithdraw.

Ordered, That this Committee be adjourned to Thursday next, One o'clock.

Die Joris, $10^{\circ}$.Martii, 1836.

The Lord WYNFORD in the Chair.

Filward Stillingfleet Cayley, Esq., a Member of the House of Commons, attending; is Examined, as follows :

3518. YOU sit for the North Riding of Yorkshire?-I do.

3519. Have you made agriculture, and that which is connected with it, the subject of your study :- For some years I have, before I had a seat in Parliament, since that I have thought it my duty, not only to make especial inquiries as to the state of the farming interests in my own county, but also as extensively as I have been able, in every part of the United Kingdom.

3520. Have you considered every species of soil? - I cannot say that I am practically acquainted with the chemical analysis of soils, but I have made inquiries of farmers occupying every species of soil.

3521. You were a Member of the Committee of the House of Commons on Agriculture, in 1833 ? - I was.

3522. Of course you know pretty well what was the state of agriculture and the condition of the farmers at that time?-I do.

3523. Do you think the farmers were in a prosperous condition in 1833 , or the reverse?-I think very much the rererse.

3524. You think they were distressed at that time?-Yes, deeply so.

$4^{6} 4$.

23

3525. Were

Mr. J. Hudson。

8 March $18_{3} 6$. 


\section{MINITES OF EVIDENCE BEFORE SELECT COMMITEE}

E. S. Cayley, Esq. 10 March 18,36 .

352.5. Were they then suffering from their losses?--They were.

3520 . The question is hardly necessary,-are they better off now?-I would state, that in 1833, although the low-land farmers were suffering very much from low prices, they were suffering almost as much for two or three years consecutively from a series of wet harvests, that so far diminished their crops that they had scarcely any produce to bring to market. At the same time, however, that the wet harvests were so destructive to the crops on the low lands, the high-land or upland farmer, who did not suffer from the wet harvests, reaped the advantage of an abundant crop, whilst he received what may be termed the scarcity price resulting from the injury done by those seasons to the clay lands. Since 1833 the harvests have been entirely of a contrary description; the seasons have been dry, the low-land farmers have had better crops than have existed on such soils, I believe, within the memory of man, and thus, by the bounty of Providence, they have been rescued from the full effects of the great depression of price.

3527 . What has been the state of the upland farmer since that time?-For the first year subsequent to I 833 his condition was improved, in consequence of the high price of wool, a high price caused by the great pestilence called the rot, which began four or five years ago. There has been rather a decline in the price of wool and of meat down to the last autumn; therefore, the last two years the upland farmer has been rather worse off, compared with the period about 1833; and the low-land farmer is in some degree better off; but that in fairness is to be attributed, not to any increased expense which he has been able to afford in cultivation, or to any inclease of his own exertion, but rather, and in my opinion solely, to the bounty of Providence.

3528. Taking all these circumstances into consideration, advantage and disadvantage, considering the state of the farmer now, do you think he can go on at present prices?-I should say that it is impossible that he can go on at present prices on half the arable soils in the kingdom.

3529. Can he pay any rent at all on half the arable soils ?-In my opinion, he cannot, excluding their connexion with grass land. My opinion is, that an acre of arable, from time immemorial, has paid, and that it ought now to pay, its expenses from its own produce. The advantage which the upland farmer has had has been chiefly derived from his flocks; those have been connected with the grass part of his farm; the profits on the grass have gone in some degree to meet the losses on his arable; and it is only in consequence of his sheep flock that there has not been an entire loss even upon upland farms.

3530. He could not have gat on so long but for the advantage of his grass land?-Yes, that is my opinion; in conjunction with his turnips.

3531. Do you think the profit he has derived from his grass has gone to counterbalance the loss upon his corn?-I think on the upland farms they have gone in some degree to counteract the losses, in consequence of the adventitious circumstance of the scarcity of sheep from the rot, which did not occur on the upland farms; and that having had the advantage both of crop and of flock upon those farms, together with the circumstance of a scarcity price, 1 think the upland farmers have been preserved up to a late period, to a considerable extent, from the ill effects of really low price; a state of things which will only continue for them until the deficiency in the sheep flocks is supplied.

3532. What has been the effect on low-land farms with respect to setting off the profits on stock against the loss in corn?-Nothing but the good seasons,extraordinary good seasons for him.

3533. Has that enabled him to meet the loss on his corn, being assisted by the good seasons, and the profits on his cattle?-In my opinion they have made his condition rather better than it was about 1833 ; but I think his prospects now are worse than they were in 1833 , because he cannot expect the continuance of extraordinarily favourahle harvests, and the price of wheat has lately been nearly $20 \mathrm{~s}$. lower than in 1833 .

3534. Have you any account of the cost of growing wheat in different sorts of soils? - Since your Lordships have done me the honour to invite me to appear before this Committee, 1 have written for the account of my own farm; l have written also to three or four persons in the North Riding, with whom I am well acquainted, and in whose honour and respectability $\mathrm{I}$ have the fullost confidence.

3535. Are you disposed to deliver in those accounts?-I am. 
$353^{6}$. What is the state of the farm in your own occupation:- It is on a small farm of my father's, which 1 pay rent for'; the size is about 260 or 270 acres; two-thirds of it is grass land; it is entirely a sheep farm, a farm of that description which ought to have derived benefit from the scasons that have taken place within the last six or seven years, taking into consideration the rot, from which my flock did not suffer; therefore I have had the advantage of good prices for my wool and guod prices for my sheep flock, which is the main Hock I keep.

3537. Is that light land?-It is what we call in Yorkshire a limestone height, not a very productive soil, but one which will bear, under good cultivation, about four quarters of harley and three quarters of wheat per acre, but peculiarly sensitive to every change of weatlier; it can scarcely have too wet a season.

3538 . Will you have the goodness to produce the account of that farm; is it taken under your direction?-It is taken from the books kept by my bailiff. I do not mean to give this as a specimen; for it is often said, on the one hand, that a gentleman farmer has advantages which a greater capital will give him; and, on the other, if he loses, that he is not so careful as a common farmer; therefore I do not think a gentleman's farm is any criterion of the state of the farming interest, and I do not give it as such: at the same time, I may state that I have never indulged in fancy farming, and that I do not believe the expenses on my farm to be greater than usual. The account gives me the amount of $17 l .2 s .2 d$. to meet my rent in 1833 .

3539. What is the rent?-One liundred and fifty pounds a year ; in 1834 there was a loss of $39 l .11 s .5 \frac{1}{2} d$. besides the rent; in 1835 a loss of $49 l .11 \mathrm{~s}$. without reckoning rent.

3540. It has been getting gradually worse :- So it appears.

[The Account is delivered in, and read, and is as followes :]

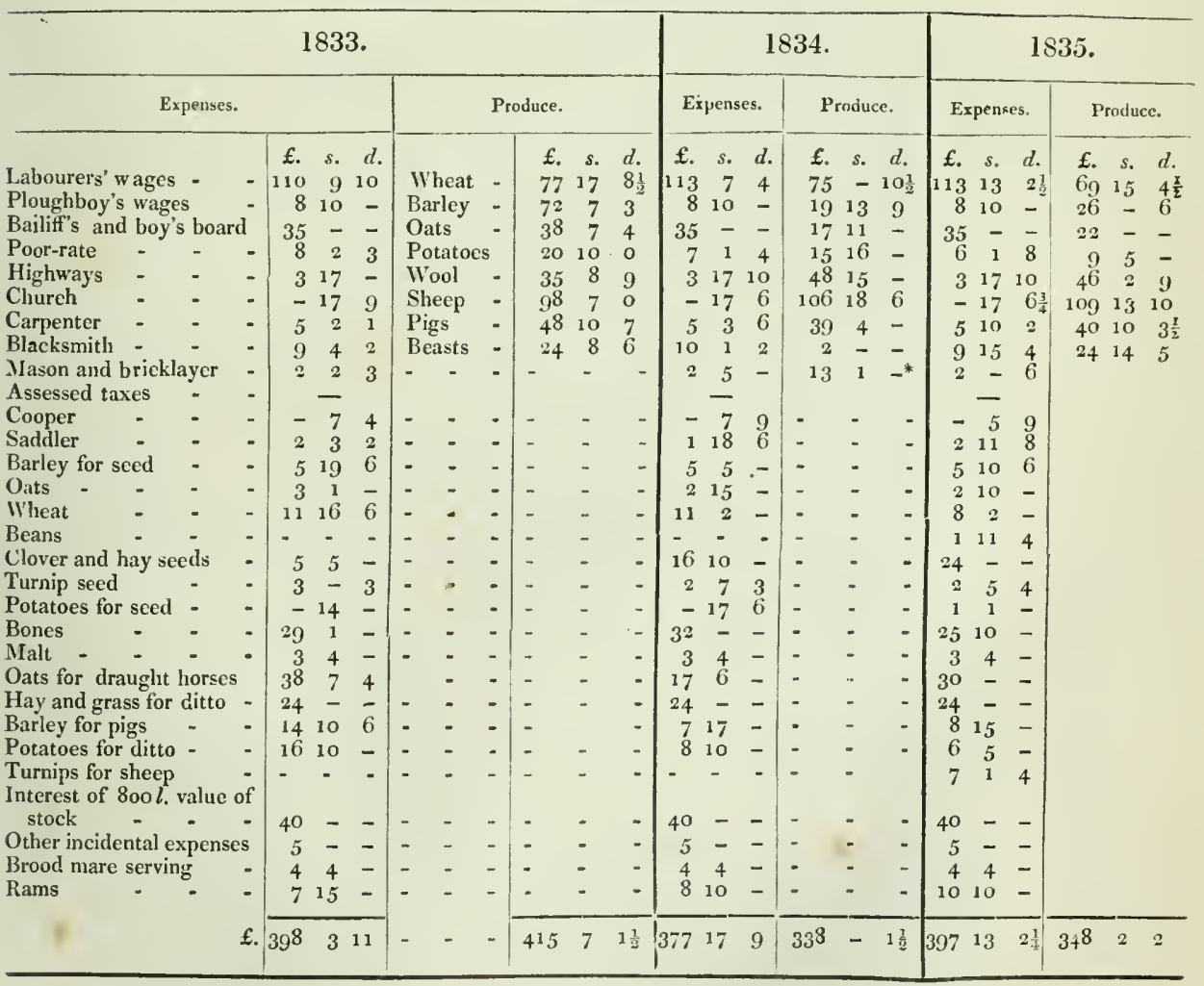

* Turnips sold. 


\section{MINUTES OF EVIDENCE BEFORE SELECT COMMITTEE}

F. S. Cayley, Esq 10 March 1836 .

About six cows are kept for the use of the house, but the produce of the dairy could be bought at a cheaper rate, so they are not entered into the account, although perhaps they ought. I would repeat, that I give this account as no exact criterion. All I can answer for undoubtedly is, that it has been a losing concern to full the extent here shown.

$354 \%$. Have you an account of the other farms :- Here are two accounts, one only of which I should propose to deliver in; the first I find is not the usual course of cropping: the usual course of cropping on land of that kind is turnips, barley, seeds and wheat; I find the first given to me is turnips, wheat, seeds, and either oats or barley; that is not the common course.

$354^{2}$. Is that the account of a common farmer?-It is.

3543. What sized farm did he rent ? - I should think he farms about $300 l$. a year.

3544. Will you state the result of that you are about to geliver in?-The result is stated at the close of the estimate. The prices are those of the last year. The system of cultivation the four-shift.

3545. Do they use artificial manure?-Yes. If it had not been for artificial manure, the whole of this district would have been thrown out of cultivation long ago ; that is, on the Wolds of Yorkshire, where bones have been brought into most extensive use : and I do not hesitate to say, the use of bones since 1820 has raised the value of limestone land in that district from $7 s$. or $8 s$. an acre up to $20 s$.

\section{[The Account is delivered in, and read, and is as follows:]}

Detalled Statemext of the Mode of working One Acre of Land cultivated on the Improved or Four course System:

\section{EXPEN D 1 T URE.}

1st Year.-FALLOW for TuRNips.

Nov. First plonghing - - -

Apr. Harrowing, two times, at 1 s. Second ploughing -

May. Harrowing, four times, at $1 s$. -

Rolling, two times, at $9 d$.

Harrowing, two times, at $1 \mathrm{~s}$.

Third ploughing - - -

Harrowing, three times, at 1 s.

$\mathrm{R}$ olling, one time, at $9 \mathrm{~d}$.

Three chaldron of lime, $10 \mathrm{~s}$.

Leading and spreading ditto, 1 s. $6 \mathrm{~d}$.

Harrowing, one time, at $1 s$.

Fourth ploughing - - -

Harrowing, two times, at 1 s. -

Rolling, one time, at $9 d$.

Harrowing, one time, at 1 s.

Fifth ploughing for seed firrow

Seed, two times, at $1 s$.

Bones, 12 bushels, $2 \mathrm{~s}$.

Harrowing, one time, at $1 \mathrm{~s}$.

Gathering quicks or couch grass after each ploughing, $1 s$ -

Gripping, 1 s. . - . -

Hoeing, first time, at 5 s. -

Ditto, second time, at 2 s. $6 d$.

Poor-rate, 1 s. $6 \mathrm{~d}$. - -

Constable rate, $1 d$. - -

County rate, $4 d$. - _ -

Highway rate, $9 d$. -

Church rate, $2 d$.

2d. Year.-Barley after Turnips.

Mar. First ploughing

Apr. Harrowing, three times, at $1 \mathrm{~s}$.

Rolling, one time, at $9 d$.

Harrowing, one time, at $1 s$.

Rolling, one time, at $9 d$.

Harrowing, one time, at 1 s.

Second ploughing - -

Harrowing, two times, at $\downarrow s$.

Sowing with clorer seed, $16 \mathrm{lbs}, 7 d$.

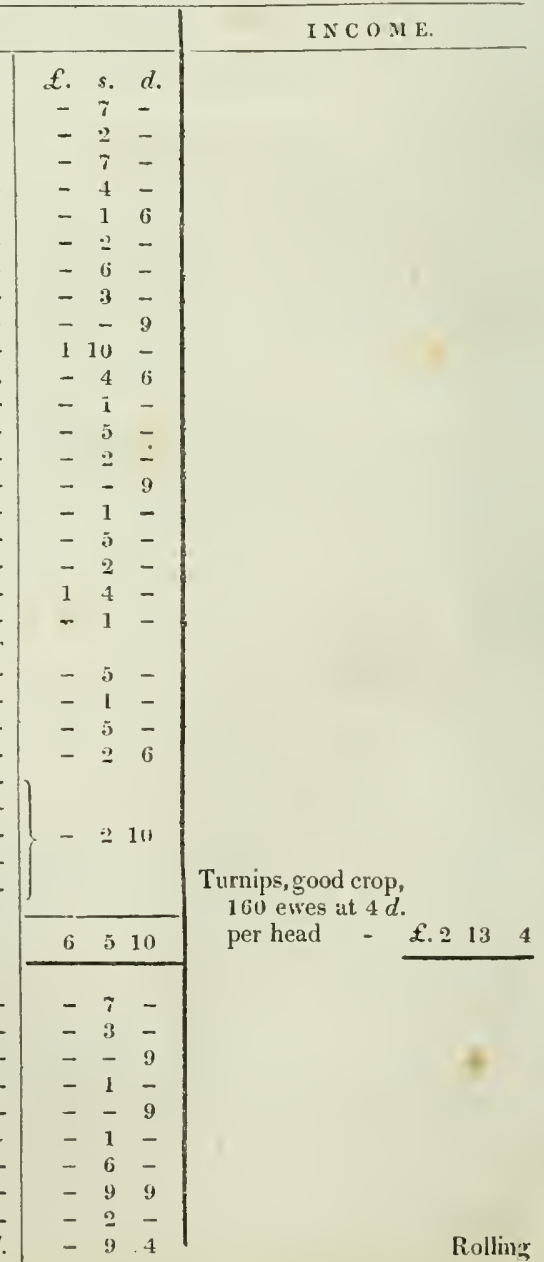


ON THE STATE OF AGRICULTURE. (Brought from the Lords.) 185

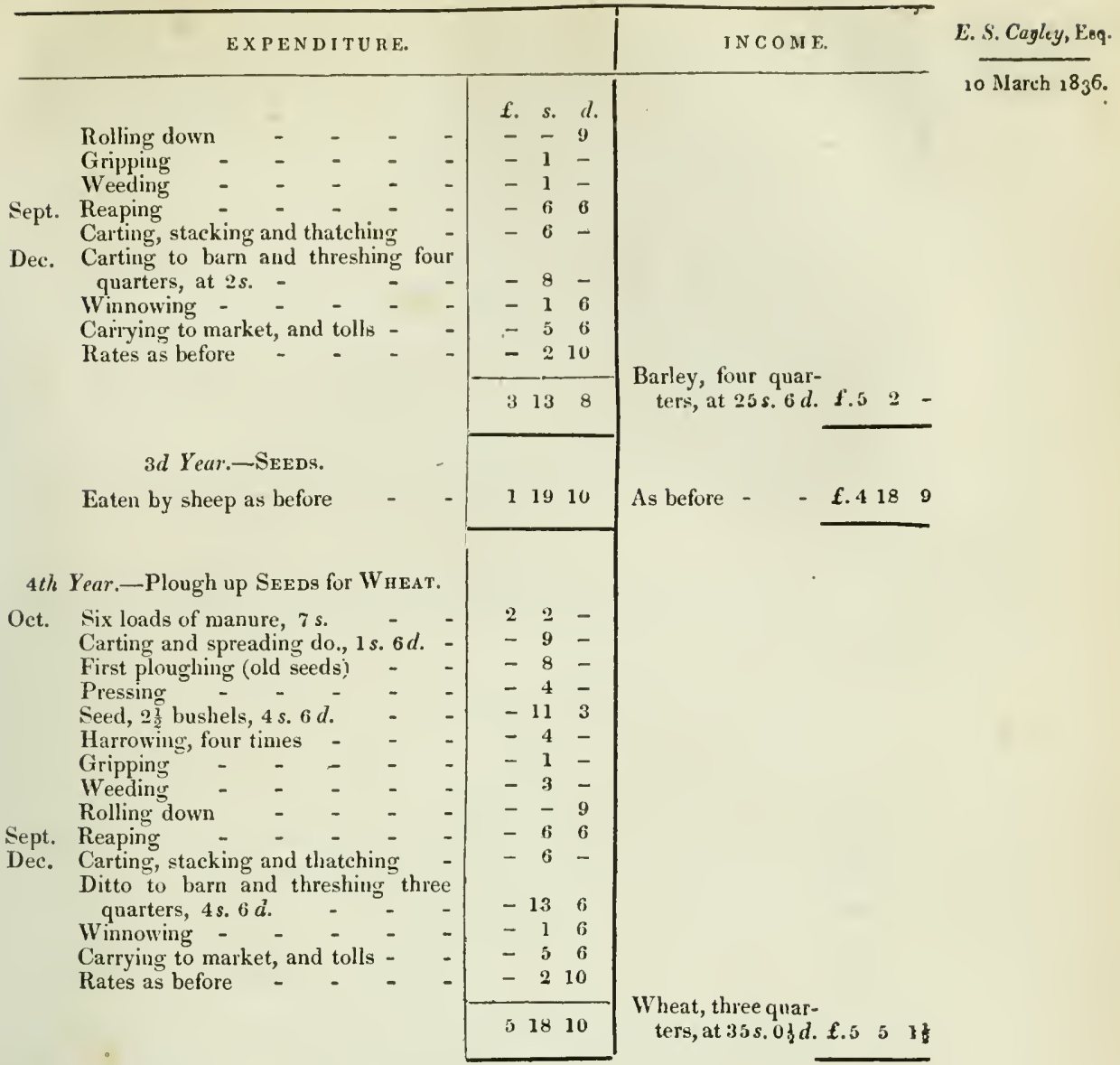

Recapitulation.

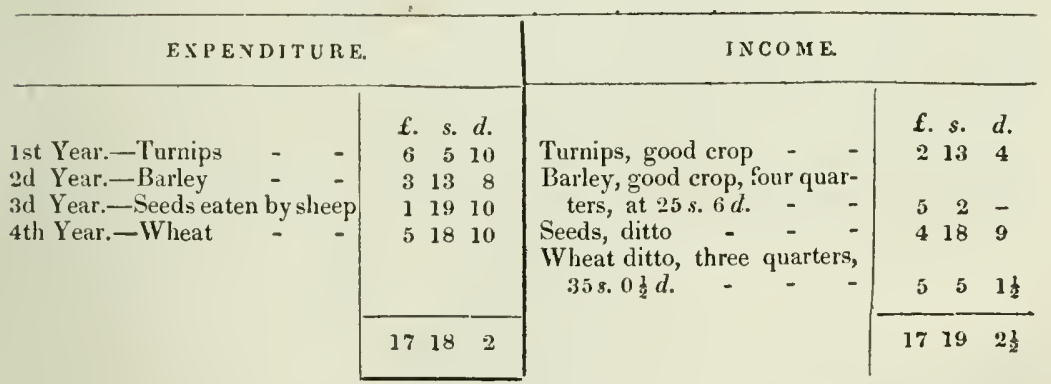

Showing a surplus of $1 \mathrm{s.} 0 \frac{1}{2} \mathrm{~d}$., withont rent or interest of capital.

The farmer sending me this account states, that the present rent of the above land has lately been estimated at from $20 s$. to $22 s$. per acre; a few years since it was worth $30 s$. There must not, he continues, be a great abatement of the working or manuring, or it will not produce such crops. Nevertheless, through the farmer's poverty, he does actually manure less, larrow less, \&c., and thus is compelled to hasten his own ruin, and to deteriorate the land. The farmer sending me the above resides in my own parish. 
E. S. Cayley, E:q. 3546. That does not include rent or interest of capital?- No, neither; the prices were the actual selling prices.

3547 . Have you any other account? - I have also an account, which I consider a very interesting one, from the principal tenant of a nobleman in the North Riding. He gives the receipts and expenses for six years; and this farm is on a corn-rent, which of course varies with the price of corn.

3548 . Is that in an agricultural district? - Purely so ; it is about eight or nine miles from York.

3549. What is the acreage of the farm?-One liundred and four acres of tillage, and 155 of sward. It is an account for six years; the arable land is very good, and the sward is much better than ordinary. In the township (which is a small one) in which this farm is situated, there used to be kept, 20 years ago, upwards of 300 cows; now there are only $45 \mathrm{kept}$, in consequence of butter and cheese and such articles selling so low.

$355 \mathrm{c}$. Is not there a demand for those articles in the city of York? -Of conrse there is a demand for butter, but there was equally a demand many years ago. I compare the present with the former time, when 300 were kept, and there was a profit on keeping them. 'I he account gives the gross incomings and outgoings of each year.

[The Account is delivered in, and read, and is as follows:]

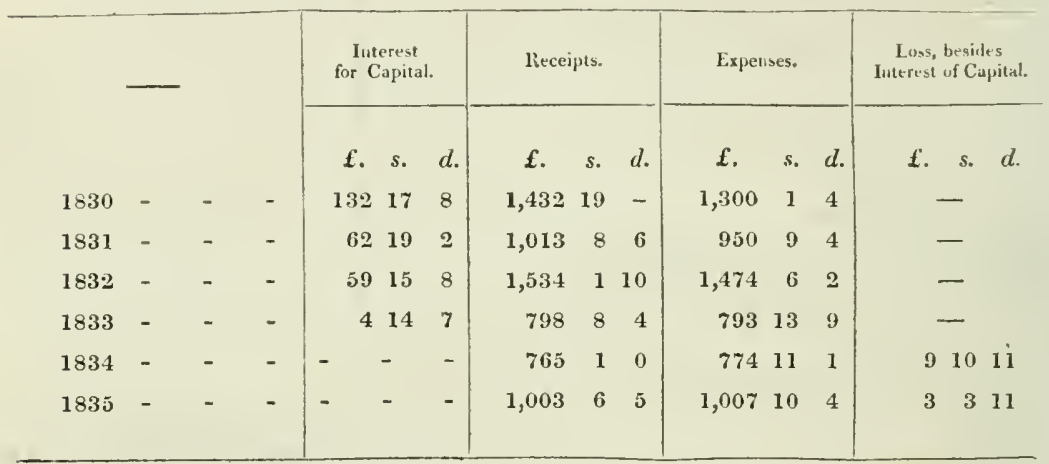

This farm requires a capital of $2,500 l$. to carry it on. By the statement it appears that for the last three years there is nothing left as interest for capital. The receipts include all that has been receired for corn, sheep, horses, beasts, pigs, butter, cheese, bacon, and in fact every thing which the farm produced in each year. The expenditure includes houschold expenses, rent, taxes, cesses, and every other incidental expense.

The following is the standing rent and the rent actually paid, showing a sacrifice of $514 l .8 s$. in six years for rent.

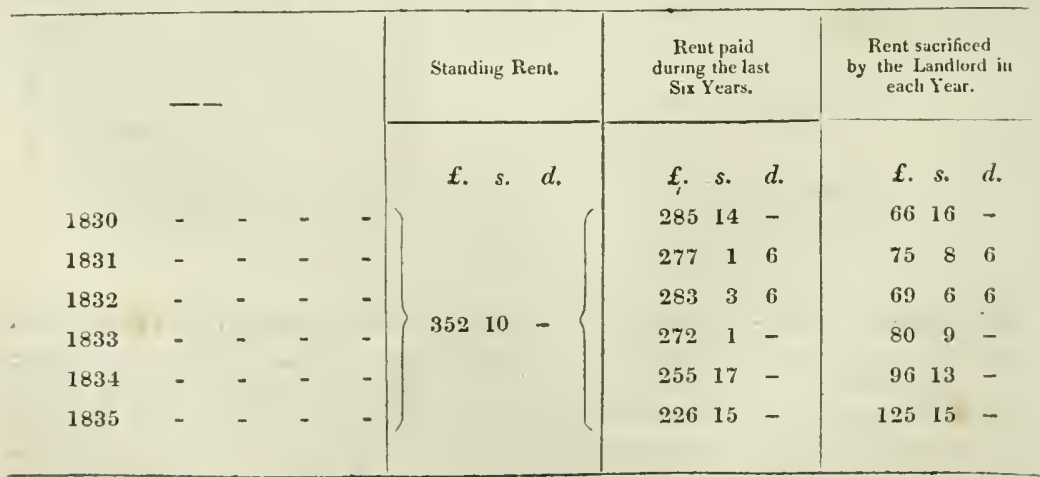


It is also ptain that the loss on the interest of capital, reckouing four per cent. only, during the last six years, is no less a sum than $3 ., 2 l$. $16 \mathrm{~s} .11 \mathrm{~d}$., besides $514 l .8 \mathrm{~s}$. sacrificed by the landlord; altogether a loss of $867 l .4 s .11 d$.

E. S. Cayley, lisq. 16 Masch 1836 .

If you take the last three year's only, it is much worse, showing a loss of $308 \mathrm{l} .19 \mathrm{~s} .8 \mathrm{~d}$. besides the landlord's sacrifice of $302 \%$. $17 \mathrm{~s}$; ; altogether a loss of $612 l .16 s .8 d$.

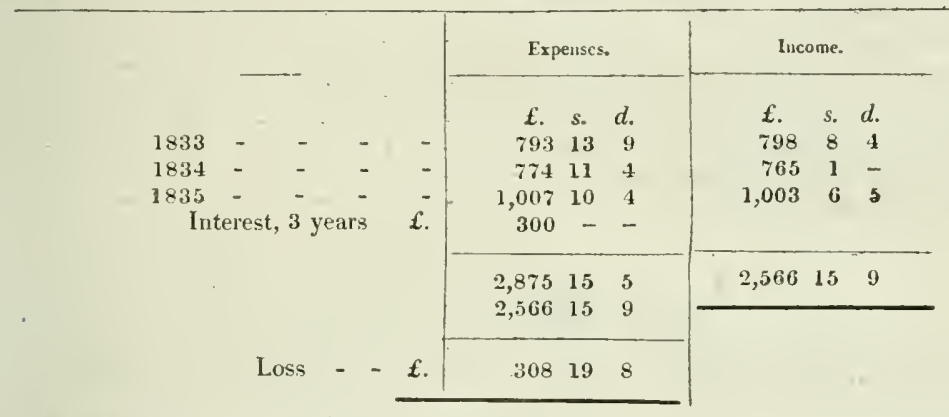

This too on a farm considered of good quality, a loamy clay. The sward, with the exception of 18 acres (laid down 30 years ago), has not any of it been in tillage in the memory of man, and at least three-fourths of it of excellent quality, and on a rental of less than $1 l$. per acre.

3551. That the account of receipts from produce should vary is intelligible, but can you account for the fact tliat the expenditure should be, in one year, $774 l$, and at another $1,474 l$. ? - In light lands the expenses of cultivation are almost the same every year; but in heavy lands, where every thing depends upon the season, and the time of putting in the seed, it may be increased in an immense ratio; but probably there was some extra-incurred expenditnre to account for that great difference. It does not appear, however, to have been paid for in the receipts.

3552 . There does occur that variety in the expenditure? - Yes.

3553. Has there been a quantity of grass land broken up on that farm? - No; it is stated not; and the tenant has the advantage of 155 acres of grass to 104 tillage, a much larger proportion than usual, which I consider a great advantage to a farmer in these times, when cultivation is so expensive.

3554. Is the parish burthened with poor? - No; the poor's-rates in the North Riding are, generally speaking, compared with the south, perfectly trifling; in the township in which I reside, I do not think they are more than $15 d$. in the pound.

3555. Have you any other account to give in?-This is one from extremely good land, the farm of the tenant of another nobleman in the Nortl Riding; this, I conceive, to be the finest species of land that can be cultivated; it is a beautiful loam, that produces upwards of four quarters of wheat an acre, and is as well adapted to, a turnip cultivation as the lightest land; it is situated a few miles 464 . 


\section{MINUTES OF EVIDENCE BEFORE SELECT COMMITTEE}

E. S. Cayley, Esq. beyond Boroughbridge, on the Leeming-lane road, which is a celebrated tract of land for fertility; I wrote to the occupier to send me the cost of growing wheat so March $188_{3} 6$. and other crops on an acre, according to the four-course system.

[The Account is delivered in, and read, and is as follows:]

Cost of growing $W_{\text {HEAT }}$ and other Crops upon good Soils by the Four-course System of Husbandry.

1st Year.-Turnips.

1st Ploughing, three horses and two men

Five other ploughings, two horses and one man, at $6 s$.

Large harrows, twice, at 1 s. $3 d$.

Small harrow, four times over for each ploughing, twenty times, at $9 \bar{d}$.

Raking and gathering couch, four times, at $1 s .6 d$.

Ploughing for seed furrow, and sowing, 7 s. $6 d$., seed $2 s$.

Ten loads of manure, at $8 s$.

Carting manure to the heap, and afterwards carting upon the land and

spreading

Hoeing twice over

Statute labour, rates and land tax

2d Year.-BARLEY.

Twice ploughing, at $7 s$. and $6 s$.

Five times harrowing, at $9 d$.

Seed, three bushels per acre, at $3 s .9 \mathrm{~d}$. -

Drilling, $2 s . ;$ sowing clover seeds, rolling and weeding, $2 s .6 \mathrm{~d}$.

Reaping $8 s$. ; carting, stacking, \&c., $5 s$. -

Threshing, five quarters, at $2 s$.

Winnowing, marketing, and delivery

Statute labour, rates and land tax

White clover and other small seeds

Statute labour, rates and land tax .

f. s. $d$.

$-10-$

$110-$

$-26$

$-6-$

$-150$

$-6-$

$-96$

$4--$

$1--$

$-8-$

$-36$

£. 9106

E. s. d.

-13 -

-39
-113

$-46$

$-13-$

$-10-$

$-10-$

$-36$

f. $39-$

f.

f. s. $d$.

$-10-$

$-136$

4th Year.-WHEAT.

Ploughing - - -

Drilling, $2 s$, barrowing $3 s$.

Rolling, $6 d$; harrowng, $3 s$. - - - -

Reaping

Carrying, stacking and thatching -

Threshing 30 bushels, at $3 s .6 d$.

Winnowing, marketing, and delivering -

Statute labour, rates and land tax
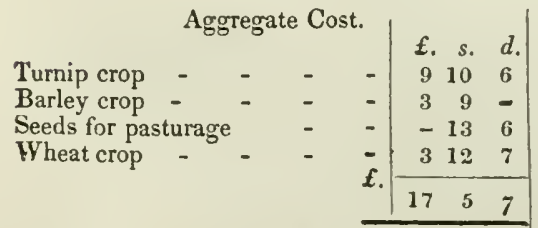

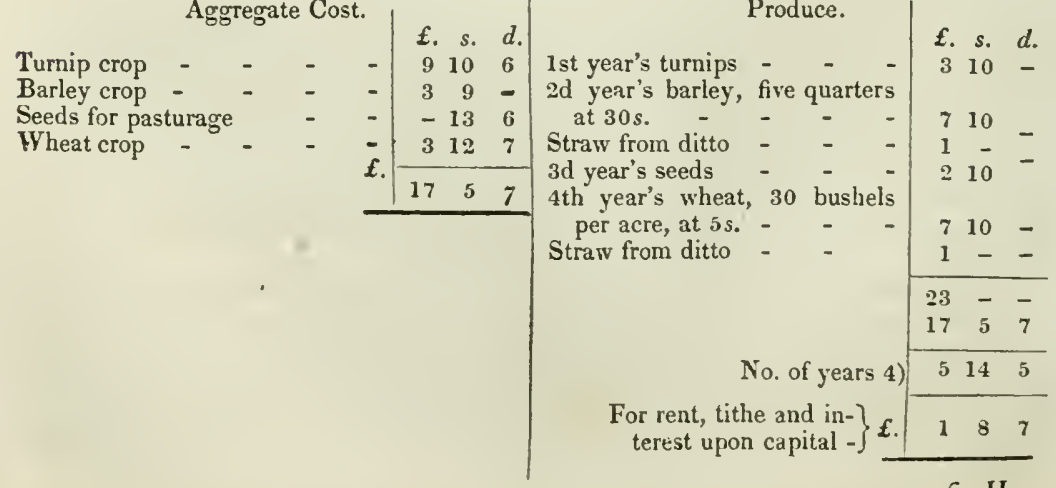

Produce.

f. s. d.

- 9 -

$-15-$

- $5-$

$-26$

$-10-$

$-56$

$-131$

- 9 -

- 36

f.

$\begin{array}{lll}3 & 12 & 7\end{array}$

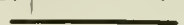


$355^{\circ}$. How much per acre rent is paid for that farm ?-1 should say, that if half the lands were thrown out of cultivation by wheat remaining at $5 \mathrm{~s}$. a bushel, this land would still be able to pay probably $20 s$. an acre; it is land that las been usually estimated, I suppose, at about $40 \mathrm{~s}$. an acre.

3557. Whereabouts is his rent now? - He does not state that; I told him to make the estimate without rent.

3558 . One pound eight shillings and sevenpence a year remain for each year? -Yes; for tithe, interest on capital, and rent.

3559. Have you another account?-Yes, from the same occupier; the soil is rather heavier, and not so well adapted for turuips; it is cultivated aecording to the three-course system.

\section{[The Account is delivered in, and read, and is as follows:]}

Cost of growing W IIEAT and other CRors upon good Soils by the Three-course System of Husbandry.

\section{1st Year.-F Fllow.}

1st ploughing, four horses and two men -

Four other ploughings, at $10 s ., 9 s .8 s$, and $7 s$. -

Drag harrow, once

Large or ox harrows, once

Small harrows, twice, at $9 d$.

Seven loads of manure, at $8 s$.

Carting and spreading -

Ploughing for seed furrow

Seed, $2 \frac{1}{2}$ bushels, at $5 s$.

Drilling, $2 s$. ; harrowing, $1 \mathrm{s.} 6 \mathrm{~d}$.

Gripping, twice

Statute labour, rates and land-tax -

\section{$2 d$ Year.-Wheat.}

Rolling and weeding

Reaping, $10 \mathrm{~s}$; ; carting, stacking, thatching, \&c. $5 \mathrm{~s}$.

Threshing, 30 bushels, at $3 s$. fid. -

Winnowing, marketing and delivering -

Statute labour, rates and land-tax -

\section{3d Year.-Gats.}

Ploughing

Seed, four bushels, at $2 s .6 \mathrm{~d}$.

Sowing and harrowing -

Gripping (twice)

Reaping, $6 s$.; carting and thatching, $5 s$.

Threshing, five quarters, at $1 s .4 d$.

Winnowing, marketing and delivering -

Statute labour, rates and land-tax -

\section{Aggregate Cost. gregate Cost.}

1st year's fallow $2 \mathrm{~d}$ year's wheat 3 d year's oats -

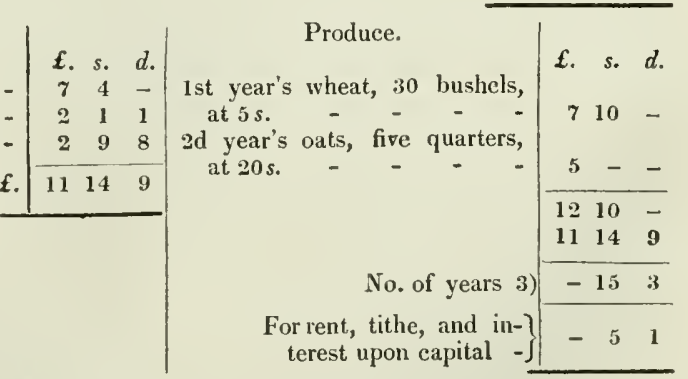

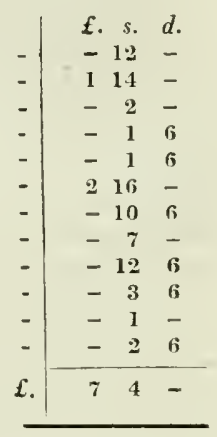

\begin{tabular}{r|rrr} 
& E. & $s$. & $d$. \\
- & - & 1 & 6 \\
- & - & 15 & - \\
- & - & 13 & 1 \\
- & - & 9 & 0 \\
- & - & 2 & 6 \\
\hline f. & 2 & 1 & 1 \\
\hline
\end{tabular}

\begin{tabular}{l|rrr}
- & $f$. & $s$. & $d$. \\
- & 9 & - \\
- & 10 & - \\
- & - & 3 & - \\
- & - & 6 \\
- & -11 & - \\
- & - & 6 & 8 \\
- & - & 6 & - \\
- & - & 2 & 6 \\
\hline $\mathcal{L}$. & 2 & 9 & 8 \\
\hline
\end{tabular}

3560. Is that heavy tillage land?-It is land that would grow turnips very well; but the mischief of that kind of land is, that they cannot eat the turnips off at the back end of the year.

464 .

A $\mathrm{A} 3$

3561. You 
E. S. Caylcy, Esq.

10 March $18_{3} 6$.
3561. You stated that the low-lands were much better off than the up-lands?$\mathrm{No}$; I only meant, in comparing their condition at the end of 1835 , and when the Committee of the Honse of Commons sat in 1833, I think the up-land farmer's prospect is not so good as it was then ; whilst, in consequence of the most abundant harvests which have taken place within the last three or four years, generally on the low-land farms ( 1 wonld guard myself from saying abundant on all soils and in all districts), the low-land farmer s condition is better comparatively than in 1833 .

3562. You state that you think that their prospects are not so good; on what account :-Because I think that three such years in succession as we have had are not to be calculated upom in the ordinary course of things, and that with average crops they will be totally unable to meet the difficulties arising from the decline in price, amounting to $20 \mathrm{~s}$. per quarter since 1833 .

3563 . Ilave you ever made an estimate of what proportion that description of heavy land bore to the lighter land in this kingdom?-That is a question I put often to witnesses in 1833, and I have put it to witnesses in the Committee of the House of Commons now sitting; I think it very difticult to offer, from any data I have seen, even an approach to an accurate estimate; but in many counties the average of the one species is quite as great as the other, and in some greater.

3564. The wheat lands formerly were, a very large proportion of them, of the heary description, were they not?-Until very lately those soils were peculiarly the wheat lands; they were anciently considered and described as wheat lands; in consequence of the bone husbandry in a great part of the wolds of Yorkshire and of Lincolnshire, and in consequence of the drill system and the artificial manure used in Norfolk and Suffolk, a great deal of land has been applied to the growth of wheat which was not formerly; but this has been going on from 15 to 20 years, and in some cases more.

3565 . It is generally considered that the product of the heavy soils determines the abundance or scarcity of the supply of wheat; if it is a favourable year for the heavy soils, it is generally a year of abundant wheat?-Yes, generally speaking. but depending at any given period on the proportion of the up-land soils growing wheat; if the proportion of them growing wheat has been increased, that will tend to affect the conclusion to be drawn from a dry summer, that the harvest will be abundant. There is this peculiarity on the dry soils, the limestone soils in particular, if we can get straw we are sure to get corn; that is not the case on the low-land farms. I should say, rather, that this might be laid down as a rule, that the failure of the crop on the low-land farms, from a wet season, would be in some degree compensated for by the benefit which the up-land soils derive from such a season; and vice versî, that the abundance in a dry season on the heavy soils wonld be in some degree counteracted by the difficulty of growing straw on the very light soils in such a season.

3566. If the wheat crop in England depends mainly on the heary soils, notwithstanding the great improvements lately made in the lighter, which has made them produce more wheat than before, and we have had for the last three or four years seasons peculiarly favourable to those heavy soils, does not that, in your mind, account very much for the prices of wheat being low, as compared with other articles?-No. I have been a very attentive observer of the state of crops as reported by the corn-factors from Liverpool and other places, and I have taken pains to ascertain the state of the crops from private individuals in various parts of the country; I have had opportunities, not only of consulting farmers and seeing them in many districts of the country, but of meeting them from every part of the kingdom in the metropolis; and I should say, taking the last three crops into consideration, 1833, 1834 and 1835, and taking Ireland and Scotland into the calculation (for though I believe the low-lands of this country had a most abundant crop on the average of the three last years, the harvests in the west of Scotland and in Ireland were on one or two occasions very adverse), I should state, with respect to the crops generally of the United Kingdom, so far as I have been able to ascertain them, 1833 was scarcely an average, 1834 was a very abundant harvest, and 1835 was rather deficient. In consequence of the lowness of price (which farmers may not be able to account for, and which perhaps many of us may be mistaken in our ways of accounting for), the price of wheat at the harvest of 1835 remaining depressed, it led to a most improvident consumption of wheat; it was used for pigs, it was used for beasts and for lorses,

a practice 
a practice which began to a trifling extent about two years ago. In this country there has been an antipathy, for a long series of years, to use wheat for any other purpose but the food of man; but the low prices continuing, and it being necessary for the farmer to look to any source of profit, or any means, if possible, to prevent a loss, he has resorted very generally, withm the fast six months, to the use of it for other purposes than the toorl of man. I should, therefore, attribute the late rise in the price of wheat partly to the deficient harvest of 1835, partly to the improvident consumption of it for other purposes than the food of man, and partly to it very general feeling, a feeling supported by every witness brought before the Comnittee now sitting in the House of Commons, that there is a much less breadth of wheat sown for the coming crop than there has been in previous years; and taking all these circumstances into consideration, I believe they will mainly account fur the late rise in the price of wheat, which rise of price I should say has received a check and undergone a fall for tile last two weeks.

$356 \%$. Which was the bad season you spoke of in Ireland:-1 think the last; last vear was a very bad harvest, and in the west of Scotland also.

3568 . In the last year was it not the opinion of farmers that the crop promised much better than it turned out on reaping ?--Yes; there are two circumstances that operated against the yield of this year; the one was a very violent storm which occurred in June, and laid a great deal of the wheat, from which it never recovered, in many instances; the damage done was immense. In the north I do not believe that the storm did so much harm, but the season was rather late before the corn was fit for iipening, in consequence of continued bleak weather during the summer; then came a sudden fit of very fine weather, which tended to ripen the corn prematurely, and consequently the sample is shrunk, so that in most lands, except those very particularly situated in the north, I believe about five bushels will go into four of the year preceding.

3569 . Is it not the fact also, that on threshing out in a shrunk state, not only there is less in quantity, but that the same quantity in measure produces less wheat and a less quantity of flour?-- Yes, I should say so; but I have heard, nevertheless, although I do not exactly know on what grounds, that this year, generally, is not a bad one for millers.

3570 . Do you mean to say that a bushel of wheat, partially shrivelled and weighing comparatively light, will produce as much flour as a bushel of plunip wheat:- -No, I do not say that, nor do I give my own anthority upon the subject; doistless, as a general rule, the quantity of bran is greater and the quantity of flour smaller produced from a bushel of shrivelled wheat than from a bushel of plump well-filled wheat.

3571 . Should not you rather conclude from that, that if a sample of wheat is called a good one, the wheat is not much shrunk?--Yes; but the sample has not been generally good; I spoke of a larger quantity of ears being necessary to fill the bushel in some districts; and this I cannot speak of as attending markets, but partly from the information of others, and also having gone into my own barn and asking the men who have been threshing; and I take it the thresher is the best authority upon this subject, particularly when he threshes for so much a bushel.

$357^{2}$. How are rents paid now in the north? - In my opinion they are much better paid than they ought to be.

3573. Why do you say they are much better paid than they ought to be?Because a great deal of rent must come out of the tenant's capital; and hesides, I understand from tradesmen of agricultural towns, that farmers leave their bills unpaid in order to scrape together the rent.

3574. Are the tradesmen in the towns badly off in consequence?-I have made that a particular subject of inquiry, and I find wherever I go, tradesmen, who were perhaps seven, eight or ten years ago anxious to have the corn laws taken off to rednce the price of corn, are now anxious to sustain the price of corn, because of the disastrous condition of the farmer, produced by a decline of price.

3575. You say rents are better paid than they ought to be; have any of the tenants been broken up?-As far as I can hear, and I have made very extensive inquiries upon that point, I should say, if the landlords were to press for all their arrears, there are very few tenants that could stand up against the demand. There has been a great change of tenantry.

$3.5 \div 6$. Have rents been reduced rery much?-That depends so much upon the quality of the land; if you conpare some of the up-land soil with the rent 
E. S. Cayley, Esq. it bore 15 or 20 years ago, before the improvements were made in consequence of bone husbandry, the rent has perbaps not been much reduced, nor required to be so much reduced. The rents upon those farms, however, have been reduced within the last six or seven years, although they have been sustained likewise by the scarcity price of wool and sheep; but the rents on cold clay farms are, in many instances, reduced from $400 \%$. a year to $150 \%$; and I have heard of instances where landlords have even offered a certain sum to a tenant to take a farm, paying no rent.

3577 . Has that been frequent? - Not yet perhaps very frequent, on account of the good crops of the last three years; but I have frequently heard of instances of a reduction of from $400 \%$. to $100 \%$. per annum, and that not on the cold clays only.

3578 . Can you give any opinion what proportion of the country those form?No; but the heavy lands form a very large portion; and, as I stated before, they are the ancient wheat lands.

3579. In what condition are the poor?-In my own immediate district, the state of the poor, those who are in employment, ought to be very good, because I am not aware that in any of the parishes immediately in my own district we pay less than from $12 s$. to $14 s$. a week throughout the year; but I believe that high rate of wages arises in a great degree from a very extensive drainage under Act of Parliament having been undertaken 15 or 20 years ago; the land which was drained having been before almost uncultivatable; the population, therefore, would be small compared with the present demand for labour, in consequence of a new district being brought into cultivation. This deficiency has tended to raise and to sustain the price of labour in that particular district.

3580 . What is the state of the labourers in general where they have not that advantage?-I should say, generally speaking, the state of the labourers who are in employment is or ought to be good; but there are various circumstances to be taken into consideration with respect to the labourers' present condition. I feel confident that the rate of wages is not that which the farmer can afford to give, but rather what he thinks the labourer ought to have, to keep body and soul together. There was in our country a system of roundsmen. The farmers knew if they did not employ the labourers, they should have to pay for them in their rates, therefore they chose rather to take the labourers. But if the capital of the tenant be trenched upon, and he be paying rent out of capital, I take it, a part of his expenses must come out of capital also, and that the labourers' wages are just as much out of the capital of the farmer as the rent is out of his capital: thus the legitimate fund for the employment of lahour is gradually wasting away; and I cannot conceive a more dangerous notion to prevail, than that the labourer is to be congratulated on account of an apparent prosperity which he is enjoying at the expense of his master's capital. It is the doctrine of the spendthrift, who draws on his principal instead of his interest. The welfare of the nuaster cannot decline without his labourer eventually suffering with him. So strongly do I feel this, that if I wished to produce discord where harmony existed, or to sow the seeds of discontent and disorganization where a happy and well-affected state of society prevailed, I could not conceive or contrive a plan so eminently suited to my purpose as establishing a state of things which should have, in the first instance, the appearance of separating the interest of employer and employed, thus engendering a distance and enmity between them, a state of things ending in the min of the master, and the disemployment of the labourer.

3581 . If the employer is deprived of his proper remuneration, the necessary consequence is, that the labourer must in time be deprived of his employment ; must he not?--Certainly. There may be an apparent discrepancy for a time in their interests, but it is transitory and fallacious; there must, in the long-run, be a complete identity of interest between the employer and the employed.

3582 . Is the country in that state that you think the present wages must be reduced, if things go on in their present course?-I think, if the present prices remain, not only wages must be reduced, but that the agricultural labourer must be thrown altogether out of employ; for though the tenants will, for a number of years together, in consequence of their attachment to their homes, remain on their farms when they are occupying them at a loss, that state of things must come to an end. First of all, they exhaust their own capital to pay rent; then they borrow of their friends, and run bills with their tradesmen; but that kind of system cannot last for ever; the fund being at last eutirely exhausted, the labourer must 
must be thrown out of employment, and when he is thrown out of employment he must either emigrate, or he probably will set himself to some mischief or other at home.

3.583 . What has been the effect of the Poor Law in your country?-The effect of the Poor Law in my own district is next to nothing; from the poor-rates being so low, we may imagine that the management of the poor has been better than it has been in the south. So far as the north of England is concerned, the Poor Law Amendment $A$ ct can hardly be said to have come into operation.

3584. There is nothing in the Poor Law Bill which can prevent the evils to which you allude?-No. I have inquired what the effect of the Poor Law has' been in different places where it has come into operation, and I find that it has tended very much to reduce the rates. The question I have put to agricultural witnesses before the House of Commons and to other parties has been this: In what way has the rate been reduced ? and I think the greatest part of the answers has becn, that a labourer prefers leaving his parish to going into the workhouse, but that the reduction has not arisen from any greater capacity on the part of the farmer to employ the labourer. The truth is, the great amount of poor's-rate (except where the management has been wantonly extravagant) is a symptom of the distress, not a cause of it.

358.5 . What will be its effect when the new law is in full operation all over the kingdom, and there is no parish to which they can go where it is not in operation? - My opinion is, that it never can come into full operation whle the present prices and profits, or rather losses, remain. I was a supporter of this Bill in Parliament; but I took the liberty of telling Lord Althorp, the proposer of it, in my place at the time, that although I was favourable to an amendment in the administration of the poor law, I was perfectly convinced it never could come into full operation while there was a want of employ for the labourer; that his first step should be to make agrieultural produce remunerating; that I did not believe there was one labourer too many in the United Kingdom; that all might be brought into employ under prices that would remunerate the farmer; that he might then, under the blind of a state of prosperity and full employment, gradually introduce a more economical system, which, however beneficial to the landlord and farmer, no one could doulit would be, for a time at least, unpopular among the labourers.

3586 . Do not you think the alteration of the law of settlement may have opened a new market for the employment of agricultural labourers - - In the north no great change is perceptible from the alteration in the law of settlement. I understand that the factory commissioners have induced agricultural labourers from the south to emigrate to the north; but I conceive, that although that is very advantageous to the labourer for a time, yet, in consequence of the fluctuations in trade, he may very likely be ultimately in a worse condition than he is now.

3587 . In what state generally are the tradesmen in the towns surrounded by agricultural districts :- Many of them have been bankrupt, and the complaints of those which remain have been loud for some few years, that the farmers, who were their best customers, are gone.

3588. Have you found that in many instances?-Wherever I have inquired; and $I$ have made that a particular subject of inquiry, for I connect them entirely with the agricultural interest; I look upon the persons making the plough and other articles for the farmer, as much part and parcel of the agricultural interest as the soil and the seed.

3589 . Have you found, in examining witnesses in the Committee of the House of Commons, that it has been very common for labourers, where unions have been formed, to go into other parishes where there were not unions :- They had been generally sent to railroads, or emigrated to some other places: the lowering of the rate was not in consequence of a greater capacity on the part of the farmers to employ them.

3590. Did you find, from the evidence, that they had left the unions, or only that they were supposed to be likely to do it?-That they had done it.

3591. You are aware that some parts of the country are quite under the operation of the unions, while they have not equally extended to the north Some of them state, that in a few instances the factory commissioners have induced some of them to emigrate to the north, but that, generally speaking, they had left the parish from a dread of the workhouse system; and where they are 
E. S. Cayley, Esq. gone I do not know, whether to the immediately adjoining parishes or to the factories, or seeking their livelihood in some other way.

10 March 1836 . 3592. From the statement you have made respecting the rate of wages and the employment of labourers, it may be fairly supposed that the demand for labour generally through the country has been gradually increasing, including manufacturers and that description of labour?-Within the last year or so, according to the best information I have received, the manufacturers have been doing better; they call for more labourers, and railroads take oft a great many.

3593. Do not you apprehend, under those circumstances, the farmer, instead of being able to reduce his wages, will be obliged to keep up a rate of wages which he cannot afford to pay, in order to secure having any labourers at all :- Undoubtedly it will have that effect; and that is one of the worst effects of an unremunerating state of prices, that it tends to separate the interest of the labourcr and the occupier of the farm.

3594. Have you, in point of fact, heard any apprehension of the kind expressed by the farmers in Yorkshire?-I have heard something very similar to it in principle expressed. There is a very general desire throughout England for a poor law for Ireland, with a view to keeping the poor of that kingdom in their own country, and to prevent their interference with the labourers in this country. Now, though that might operate extremely well in the populous districts in the southern counties, where there is a surplus of labour, yet in Lincolnshire and the East Riding of Yorkshire they depend frequently for their harvest work on reapers from Ireland, and consequently the position of those farmers, without reference to the general question of the identity of interest between the occupier and labourer, might throw a doubt, so far as their immediate interest is concerned, as to the expediency of a poor law for Ireland, if that effect (which I am inclined to dispute) of retaining the labourers in Ireland were to follow; because then labour at harvest time would be scarcer, and a higher price have to be paid for it.

3595. Are you of opinion there are persons who have been induced to work for less wages than formerly, rather than go into the workhouse?-With respect to the lowering of wages hitherto, in consequence of the Poor Law Amendment Act, I can hardly speak; but that it must be the result, unless counteracted by extraneous sources of demand for agricultural labour, is evident. With respect to the general fall of wages, I would say, that though the rate of wages has gradually gone on declining, I look upon this as the most difficult part of our position at present; there has been an impossibility to reduce the expenses of cultivation compared with the prices of produce; and the main difficulty is the impossibility and the danger of reducing the national rate of wages after they have once been raised.

3596. You have not heard in your part of the world of labourers, instead of receiving $8 \mathrm{~s}$. in some places and $10 \mathrm{~s}$. in others, working at a reduced rate of $6 \mathrm{~s}$. a week, for instance?-The result of my inquiries has been what I stated before, that up to the present time the tendency has been for the labourers to emigrate from their own parishes to avoid being sent to the workhouse under the new system. This is in the sonth. In the north, enigration lias taken place most extensively to America, in consequence of deficient employment in agriculture.

3597 . The high wages given by the manufacturers and speculators in railroads are prejudicial to the farmer ?--I can hardly say that they will be prejudicial in the long-run; but for the time being they do prevent the general adjustment of the rate of agricultural wages.

359 . They prevent his bringing wages to the level he can afford to pay:Yes. But I would guard myself from being supposed favourable to such a reduction of wages as would be unequal to the decent and comfortable support of the labourer and his family; it is mainly because I saw the difficulty of adjusting a high rate of wages to a low rate of prices, so as in the end to be just or beneficial to either the payer or receiver of wages, that $I$ have been favourable to a system which would sustain prices higher than their present level.

3599. How are the artisans paid; do they charge the same prices they did?To a great extent they do; there is another difficulty in the condition of the farmer; the blacksmith, the carpenter, the wheelwright, who used to cliarge in proportion to the state of prices 15 ur 20 years ago, are now compelled to charge the same or nearly the same prices. It is a very natural question to put, "Why are those people receiving such high prices for their work? Why is not there competition 
competition for this apparently good trade, which can charge high prices out of E.S. Cayley, Esq. low-priced matcrials?" Yet the fact is, these parties become ruined almost as much as the farmers.

3600. How do they become ruined? - They are obliged to charge a high price to their good customers, to meet the bad debts of their other customers. Now and then a farmer of very large capital may beat down the prices charged by these artisans by a threat of withdrawing his custom, which they cannot afford to lose; so he gets, individually, his work done lower, while his poorer brethren are obliged to pay the old rate; they are not in the position to command the same terms; and this dispreportionate power of capital in a declining state of things is, I fear, not confined to agriculture alone.

3601 . - Do you find that their bad debts are very frequent ?-Yes, very frequent. The best judges, perhaps, of the real condition of the farmers' welfare is the country doctor or the country apothecary. Whenever I have an opportunity of seeing those people, particularly if they have lived in the neighbourhood for years, I ask them the question respecting the farmers' condition; they see the farmer at all times, and often under trying circumstances, under domestic affliction, or themselves, perhaps, on their dying bed; they then communicate to those men what they may not have communicated to others; and they know, from sad experience, the wretched state of the farming interest; they also know from their own receipts; and I have frequently heard from those men it is almost impossible to get in their debts ; one says, I luave $2,000 l$. to get in, and I cannot get it ; and another $1,500 \mathrm{l}$., and I cannot get it in ; the farmers cannot pay me; and I think the condition of the country apothecary is almost as bad as that of the farmer himself.

3602. That applies to persons having farmers for their debtors:-Any person who depends for payment on a farmer, except it be a landlord whose estate is peculiarly situated, or unless he have had a pinching steward, or unless he have other independent resources, must be in a depressed state.

3603 . The manufacturers are apparently very prosperous now?-They are said to be very prosperous. I confess having made the manufäcturing interest a matter of study, and their condition a matter of inrestigation, although not to the same extent as the agricultural; I believe their present prosperity in a great measure owing to the enlarged issues of a number of joint stock banks, especially in Lancashire, which I understand push out their notes in a most imprudent manner; the only prudence they seem to show is in refusing accommodation to farmers.

3604. Do they afford an assistance which the other banks do not?-I put this question to a Liverpool man lately, well acquainted with the state of Lancashire, having been 40 years in trade- " Do these joint-stock banks accommodate farmers as well as the manufacturers?" "No," he said, "they will not trust farmers." I said, "Do you remember the country bankers, previous to the resumption of cash payments in 1819 , when they accommodated farmers pretty freely?" He said lie did. I said, "Do you think the joint stock banks lately brought into operation in Lancashire accommodate the manufacturers now as freely as the country banks used to accommodate the farmers during the paper system?" He said, "I think they accommodate them much more freely." That being the case, I, for one, would say,-though my name is connected in some measure with the desire for an enlarged paper currency, I have never wished to see a paper currency without a substantial basis on which to rest,-I think if these joint-stock banks proceed in this manner, and especially if we have them established also in the agricultural districts, and they there act on the same principle, that there will be a crash, as there was in 1825 , which was the necessary consequence of issuing so much paper money on a contracted standard of value. To increase paper money securely, and to raise prices permanently, you must have a standard adapted to the prices and circulation you require.

3005. Do you say you think the bankers are more disposed to give accommodation to the farmers now $:-N o$; to the manufacturing interest, and not to the farmer.

3606. You say that agriculture is to be considered as distressed, and manufactures in a state of prosperity; can that state of things go on long; is not there an identity of interest between the two?-It used formerly to be considered that there was a complete identity of interest between the manufacturer and the agriculturist, and so long as an interchange of commodities took place between the home manufacturer and the agriculturist, and the interchange was confined to these parties, the principle of the complete identity of interest could not be well 
E. S. Cayley, Esq. doubted: but when there is a great export trade, the party with whom the merchants conduct business is not the farmer at home, but a person living abroad ; I 10 March 1836. conceive, therefore, that there may not be at all times an identity of interest between the manufacturer and the home agriculturist; and $\mathbf{l}$ think that they are mistaken who make the prosperity of the manufacturers always a criterion that agriculture is or ought to be in a prosperous condition. I remember it being stated by Mr. Huskisson, I think in 1822, that though agriculture was in a very adverse state, exports had very much increased within the last three years; I think he made the same statement about 1828; Mr. Poulett Thomson made the same remark in 1833. I find at each of those different periods, when the opinion was expressed that agriculture ought to be prosperous, or at least ought not to be cast down, because there had been a large export for two or three years preceding, in each of those periods agriculture was in a state of woful depression; so indeed was the manufacturing interest; so that the amount of exports appears to be no criterion either of agricultural or manufacturing prosperity.

3607 . Do you find that after agriculture has been in distress for two or three years, thougl at first manufactures have been prospering, they have in turn participated in the distress ?--Up to a very late period I think that has been the case; but of late our foreign trade has increased so much that it may in some degree modify opinion on that point; but if I were asked the question, which is the best state of things for the manufacturer? I should say that the greater quantity of demand coming from the home trade, which is a much more certain source of custom to him than the foreign demand, by way of putting the manufacturing interest into the best possible state, the first thing to do would be to improve the condition of the home market, the main part of which consists of the agricultural interest; for the return of prosperity to the agricultural interest and the home narket would, I have no doubt, far more than connterbalance any loss the export manufacturer might be supposed to experience from any rise of price tending to decrease the foreign denand; a rise of price, however, from the source which I wish it to proceed from, would increase rather than diminish our foreign trade.

3608 . The home market is considered the best and most extensive, is it not ?-It is very extensive; I made, two or three years ago, a comparison between the extent of the manufacturing and the agricultural interest, and I expressed the opinion as follows, in the House of Comnons:- "My opinion is, that the numbers connected directly and indirectly with the agricultural interest is very much underrated, and purposely underrated, in order to give undue importance to the export trade. I contend that $20,000,000$ out of $25,000,000$ of the pecple of these islands are directly interested in the well-being of agriculture, and in its relief from its present depressed state in consequence of the fall in prices. I do it on these grounds, taken from the Population Returns of England, Scotland and Wales :

\begin{tabular}{|c|c|c|c|c|c|c|c|c|}
\hline \multirow{2}{*}{\multicolumn{2}{|c|}{$\begin{array}{l}\text { Agricultural occupiers } \\
\text { Agricultural labourers }\end{array}$}} & - & . & - & - & - & - & $1,500,000$ \\
\hline & & - & - & - & - & - & - & $4,800,000$ \\
\hline \multirow[t]{2}{*}{ Mining interest } & - & - & - & - & - & - & - & 600,000 \\
\hline & & & & & & & & $6,900,000$ \\
\hline Manufacturers & - & - & - & - & - & - & - & $2,400,000$ \\
\hline \multicolumn{3}{|c|}{ Millers, bakers and butchers } & - & - & - & - & - & 900,000 \\
\hline \multirow{2}{*}{\multicolumn{4}{|c|}{$\begin{array}{l}\text { Artificers, builders, Sc. } \\
\text { Tailors, shoemakers and hatters }\end{array}$}} & - & - & - & - & 650,000 \\
\hline & & & & - & - & - & - & $\mathrm{J}, 080,000$ \\
\hline Shopkcepers & - & - & - & - & - & - & - & $2,100,000$ \\
\hline \multicolumn{3}{|c|}{ Clerical, legal and medical } & - & - & - & - & - & 450,000 \\
\hline \multirow{2}{*}{\multicolumn{2}{|c|}{$\begin{array}{l}\text { Disabled paupers } \\
\text { Proprietors, aunuitants }\end{array}$}} & - & - & - & - & - & - & 110,000 \\
\hline & & - & - & - & - & - & - & $\mathbf{1}, 1 \mathbf{1 6} 6,398$ \\
\hline
\end{tabular}

Now, taking the mannfacturers at $2,400,000$, in round numbers, as one-third of the $6,900,000$ agriculturists and miners, I apportion the $6,406,398$ individuals last mentioned as interested in or employed, two-thirds by the agriculturists, and onethird by manufacturers. This will add $4,077,000$ to the agriculturists, and $2,316,000$ to the manufacturers, making $10,977,000$ agriculturists, and $4,716,000$ manufacturers. But of this number of manufacturers half at least are employed 
(it is generally said four-fifths) by the agricultural body and its dependencies. 'This will deduet 2,358,000 from the aggregate Inanufacturing interest, and leave only $2,358,000$ as the purely or rather export manufacturing body, whilst it makes the agricultural body and its dependencies amount to $13,3355,000$. But here Ireland is left out of the question, which may be called a strictly agricultural country-Ireland, whose very existence almost depends on supplying us with corn. Add 8,000,000, the population of lieland, to the above $13,335,000$, you have a total of $21,335,000$ as the real agricultural interest of Great britain and Ireland, compared with not more than $3,000,000$, at the outside, of the export trade. And the whole of this body of $21,000,000$ is interested in a remunerating price for agricultural produce."

3609. Taking your figures, supposing them to be correct, on a subject evidently on which absolute precision is impossible, that $21,000,000$ are comnected with agrieulture, and $3,000,000$ arc connected with the foreign trade, is not the other state of the case true, that the $21,000,000$ engaged in agriculture depend very much for those remunerating prices they so much desire upon the success of the labours of $3,000,000$ employed in what you call foreign trade?-There is no doubt that our agriculture is dependent in part, for the prices of its produce, on the demand of those who may be considered as belonging to the foreign trade; yet, as the home market is far the largest for our manufactures, it follows, I think, that more manufacturers are identified with the home than the foreign trade. I know it is very difficult to distinguisl between what is manufactured for one market and for the other; but still the position, in the way of argument, is not less correct on that account. Now agriculture being connected with this larger portion of the manufacturing hody, so its prices will have reference to the eondition of this part of the manufacturing class; and since this class had its first origin in the wants and demands of the cultivators of the soil, and continues to look to the agricultural body (which in fact forms the basis of the home market) as its richest customer, so the measures which may conduce to the prosperity of that richest customer are beneficial to the interests of that manufacturing class. Thus agriculture is the first link in the chain of those mutual dependencies which constitute that solid and inseparable identity of interest between the manufacturers and agriculturists of our home market. Doubtless any addition to the manufacturing class which works for foreign parties, and yet spends money at home, so far tends to increase the demand for agricultural produce ; and to this extent, and the extent is limited, the agriculturists are interested in the prosperity of the foreign trade. What I contend for is, that the comparatively smaller advantages which agriculture derives from the export trade will not counterbalance or make up for any general dislocation of home industry; we ought not, therefore, to be prevented remedying any such dislocation by the objection that it may possibly tend to check the increase of our foreign trade; for the home trade is our mainstay, the foreign an adjunct ; and the larger market should not be sacrificed to the smaller, supposing the case of a collision of interest existing between them.

3610 . If this were a country in which this mass of wealthy persons and the active capital employed in what you call foreign trade did not exist, would not the cultivator of land in England be like the cultivator of land in Poland and Germany, without the means of having those comparatively high prices which now prevent this country receiving foreign corn $;-I$ have not stated, that $I$ am aware, any thing against the advantage which the agriculturists derive from the custom of that body; but that their interests cannot always be said to be entirely identified, because their transactions are not reciprocal; the exporter is obliged to consult the wishes and capacities of parties abroad, rather than the necessities of the agriculturist here; his selling interest, which is his chief one, is foreign; his buying interest only, home.

3611 . In that view of the ease, does it not instantly follow that the interests of the whole are identified; that it is desirable for the commercial interests that the agriculturists of the country should be fairly remunerated; and that it is, on the other hand, for the interest of the agriculturist not to push that remuneration beyond what will enable the merchant and manufacturer to carry on his beneficial trade, without which, again, the farmer cannot maintain his prices:-That is undoubtedly true; but there is a much greater danger which threatens us; viz. that the export manufacturer, being perhaps compelled to sell very low in the foreign market, may be able to induce the Lenislature to deprive agriculture of its protection, by which means its prices would be reduced by much more than 464. 


\section{MINUTES OF EVIDENCE BEFORE SELECT COMMITTEE}

E. S. Cayley, Esq. the custom of the export trade tends to raise them ; thus an export trade may have a diametrically opposite interest to the great body of the agriculturists of this comitry. It has always appeared to me that the principles I have here ventured to lay down may be illustrated by supposing Manchester and Liverpool cut off from the rest of the kingdom; Manchester being the cotton manufactory for the world, and Liverpool its carricr. I can easily conceive Manchester thriving under that state of things, as I can conceive of Liverpool also thriving after the fashion of places in ancient times, such as Tyre, Carthage, Venice, Genoa, and others; but I think their interest would not then appear to be connected with the other parts of the kinglom from which they had been cut off; they might thrive, indeed, for a time, perhaps for a long time; but stiil I think they would be iiable to all those transitions of trade to which others have been subject, and would not have a large home market to fall back upon. Their prosperity would not be so permanent, in my opinion, as if they remained connected with a rich country, where a large amount of capital was invested in the soil, which must create an abiding interest in the soil, and the wealth continually springing from which must increase the only source of demand which can be considered secure or permanent. I have no objection, very much the reverse, to the export trade as an adjunct, but I object to it in the light of the great base on which we are to found legislative enactments.

3612. It is clearly for the interest of the surrounding cultivators of the soil that the manufacturers should thrive?-Undoubtedly.

3613. Do not you consider it, therefore, the duty of the Legislature so to regulate the laws which affect the important interests of the country, that both interests should be fairly protected?- Yes, there is no doubt of that ; but when it is said that the agricultural interest is benefited by the prosperity of the manufacturing, I say there may be a state of things in which the larger number may not be benefited by what I should consider the peculiar or temporary interest of the smaller part of the population, the $3,000,000$ of manufacturing exporters; what I protest against is, the doctrine that the condition of the manufacturing interest, in connexion with the export trade, should be always taken as a criterion of the condition of the agricultural interest.

3614 . Though the manufacturer may be so isolated, and having the benefit of machinery and his steam power, he might be fed from abroad, would not his being so fed from abroad, and not having the power of supplying himself from the growth of his own country, expose him to occasional dearth and famines, arising from the possible uncertainty of foreign supply, from the uncertainty of seasons, as well as political causes which might impede his supply; would it not be to him a most dangerous position to exist in a country, although he might for some time be fed from abroad, if that country had not the power of supplying food for itself? - That is certainly my opinion; the export manufacturer, however, does not always look upon this matter in that point of view.

3615. Do not you consider, upon the whole, the present system of Corn Laws, as they exist in this country, to operate fairly between those interests, as fairly as any artificial system which can be introduced - In my opinion the present corn law is wearly perfect; it might, perhaps, be improved in a few of its details ; for instance, the graduated scale should never fall, perhaps, below $6 s$., hecause the falling so low as $1 s$. gives rise to great speculations; I do not believe the consumer would pay any dearer for his corn, and the revenue would materially benefit by such an alteration. I am against meddling, however, with the corn laws; they have given the farmer, of late years, every advantage he can derive from a corn law; and it is just possible that if we begin altering we may end by having a much worse.

3616 . Have you turned your attention to ascertaining what is the value of the produce of the land in a year?-Of late years the usual estinate of the gross produce has been about $200,000,000$, but I hardly know on what ground; I should be inclined to think it exaggerated.

3617 . The greatest portion of that must be exchanged for manufactures?-For labour and manufactures.

3618 . So that if the farmer is benefited by the manufacturer, the manufacturer is benefited in an equal if not a greater degrce by the farmer Certainly.

$3^{619}$. To what do you attribute the distress whicn lias taken place in agriculture:-I attribute the distress to the fall of prices. 
$3^{620}$. Of all produce, or of some articles?-That is rather a broad question; I should say that the prices of all agricultural produce are really low; there is a distinction to be made between wheat and other grain, and meat and wool; my opinion of wheat is, that it has been lately perhaps rather lower than was to be expected, in consequence of the resumption of cash payments; I believe that barley, and oats, and beans, and meat and wool, are higher in consequence of scarcity. The two years preceding this, as I said before, were dry years; those dry years operated very disadvantageously for barley, and in many districts for oats; the drought during the last summer operated very much against the growth of hay and of turnips; stock fell last autumn in the south 30 per cent. in conseyuence of the failure of the turnip crop, which much prevailed. There has been since Christmas a rise in the price of meat, wholly in consequence of the deficiency of winter food; and therefore the present price of meat I consider a scarcity price. The price of wool was operated on, I believe, entirely, three or four years ago, by the rot which took place among the sheep flocks; during the years 1830 and 1831 it was estimated that one-fourth part of the flocks was cut off by that pestilence; parishes which had 2,000 or 3,000 sheep were left without one.

3621. Did that prevail in the north as well as in the south?-All over the kingdom; land that had never given the rot within the memory of man produced it in those years; one year of wet will not produce rot generally; it requires a succession of wet seasons, as we had in $1828,1829,1830,1831$, to produce it generally. The sheep flocks of this country have, I believe, been estimated at about $32,000,000 ; 8,000,000$ of sheep had to be supplied. The price of wool immediately before those wet seasons was $8 s$. or $9 s$. a stone; it rose, in consequence of the scarcity, in a short time to $30 s$. and $32 \mathrm{~s}$. a stone; that price being sustained for about two years, it had rather a tendency to decline up to a few months ago. I think probably the stimulus in the manufacturing districts may have tended to prevent a great fall since that time. The flocks, however, are not yet made up. Besides, we were given to understand the other day, in our Committee, by Mr. Smallpiece, who is the largest sheep-dealer, I believe, in the kingdon, purchasing to the extent of 40,000 sheep in a year, that there was a short clip last year; and a short clip is anticipated also this year, in consequence of the deficiency of turnips. Wool is affected entirely in the same way as the produce of the land; if you do not feed the sheep well, you will have a short crop. Taking the circumstances, therefore, into consideration, I conceive the high price of wool has been almost entirely produced by the scarcity consequent on the rot. That rot, however, while it did such havoc with the low-land farmers, conferred a great advantage on the up-land farmer; for the up-land soils never suffer from rot. The consequence was, they have had the benefit of all this amazingly high price of wool, and the accompanying scarcity price of mutton and beef; for when there is a failure of mitton, the deficiency will have to be filled up by other meat. The up-land farmers have had the advantage of all this adventitious rise of price. The wool has been higher, compared with meat, for this reason, that the high-land flocks of Scotland and the north, and of other districts, do not supply the same sort of wool as was afforded by the low-land sheep, and this sort is in great demand for our manufactures. The carcass has been supplied, to a considerable extent, from those sources, but not the wool.

3622. You think that the higher prices paid for those articles have been occusioned by scarcity? - Yes.

3623. Would they have been as low as the price of wheat but for that scarcity? -I think so; I base that opinion upon this fact, that before those wet seosons, begimning with 1828, wool, meat and other articles of agricultural produce had fallen quite as low as wheat, if not lower.

36.24 . Is not all rise in price owing to comparative abundance, and all fall in price owing to comparative scarcity; is there any other circumstance which tends to raise or depress the price but that of comparative abundance or scarcity, as proportioned to the abundance or scarcity of demand ?-There are two circunstances which operate upon prices, the one is the supply of the commodity, the other the supply of money; but in order to come to a just estimate of whether high prices are affected by a scarcity of commodities or by a plentifulness of money, we must take into the account a longish series of years, or see whether all prices have risen simultaneously. If all prices have risen simultaneously, the probability is, unless there be extraordinary circumstances of counteraction at work. that some operation in currency is going ou. If the rise be partial, then

464.

B. $\mathrm{L} 4$

tlie 
E. S. Cayley, Esq. the presumption is, that the rise is from the scarcity of the particular commodity. The converse of this is true with respect to a fall in price. Now, as far as I have 10 March $18_{3}$. been able to ascertain, and I have inquired of great numbers, the last six or seven seasons have been very extraordinary ones; there have been crops on some lands such as had not existed for a length of time before; and there was a pestilence, which perhaps was unequalled in history.

3625 . If, the state of agriculture in the country being that you have described, wheat is low, and some other articles are at fair prices and some at high prices, is it not the fact that wheat was considered abundant, compared with the demand for it, and that other articles have been scarce; and if, as you state, there is a tendency very lately to some rise in the price of wheat, is it not from the circumstance that people lave begun to find out or suspect there is not that abundance of wheat they at first calculated upon: is not the whole regulated upon that principle of the comparative scarcity and abundance of articles?-I was asked that question, with respect to wheat, in the early part of my examination, and I stated that, from the best information I had been able to obtain, there had not been an over supply; indeed, my view is, that instead of wheat having to rise, except temporarily, to other articles, other articles have to fall to a level with wheat.

3626. You stated that there were two causes of the rise, the scarcity of money and the want of produce; is it your opinion that the scarcity of money has lowered wheat, and the scarcity of produce has raised other articles ?-It is.

3627. It is your opinion that money has made a whimsical selection of one article, in preference to others, to show itself:-My opinion is, that nature is much more whimsical in her operations than money; by which 1 would be understood to mean, that, from the capriciousness of the seasons, we can much less calculate on the result, than we can of the effects to be produced by an increase or diminution of money. The seasons and money may indeed play, as it were, counteracting games. Such an occurrence took place in 1811. There was a bad season that year, and there was also, in consequence of the Bullion Committee sitting, a prospect of a speedier return to cash payments than had been contemplated. This caused many failures among the bankers, and a corresponding diminution of currency ; so that, notwithstanding the deficiency of the harvest, prices fell, compared witl what they had been the year before.

3628 . As you state the condition of the farmer has not been good for many years, to what do you attribute that; continued adverse seasons, or any other cause; and if so, what is that other cause?-I do not attribute the depression in the farming interest to adverse seasons continued for 20 years, because nature, in the long-run, is much more equable in her operations than such a conclusion would infer. A pretty certain average of seasons may be calculated on for a long series of years. Mr. Scott, the corn-factor, of Liverpool, who had kept an account from 1809, informed the House of Commons the other day that there had been, for the whole of the period up to the present time, about an average crop, taking one harvest with another. I have myself very little doubt, though it is a subject on which no one ought to speak confidently after so many mistakes have been made (the mistakes, however, have been all the other way), that the cause of the fall in price has been the preparation for and final consummation of the Act commonly called Mr. Peel's Bill of 1819.

3629. Do you think that Bill continues to operate now ?-My opinion is, that it never has been in full perceptible operation on the price of wheat until about two years ago; and it is scarcity alone that prevents its effects being now perceived on other articles of agricultural produce than wheat. The wet seasons of 1828 and the following years concealed its effect on wheat; after 1832 whent began to fall to its currency level at the rate of about $10 \mathrm{~s}$. per quarter each year, down to the winter of 1834 . I will state, with the permission of your Lordships, the grounds of my opinion, that it is the change in the currency which has caused the fall in price. In 1814 , at the close of the war, in consequence of the Acts of Parliament that had been passed, and in consequence of the Report of the Bullion Committee, there was an expectation that cash payments would take place within six months after the return of peace; there was, consequently, when the war ceased, a great withdrawing of the Bank of England's issues, which of course operated upon the country bank circulation, which became very much reduced. With respect to that withdrawal of circulation by the Bank of England, according to $\mathrm{Mr}$. Muschett, a great authority with those who difier with me, and 
therefore I prefer it on this occasion, there was a diminution of $23 \frac{1}{2}$ per cent. in their circulation between the end of 1814 and 1816. This was followed by a great adversity, both among the manufacturers and agriculturists; it, in fact, produced a great fall in prices in 1815 and 1816 . There was an abundant wheat liarvest in 1813, which commenced the fall in wheat; but that would not affect other prices.

3630. That reduced the price of wheat very much?-Yes; in 1816 such was the state of distress, that the resumption of cash payments was put off till 1818, and subsequently to 1819 ; measures were tluen taken by the Government and the Bank in conjunction to increase the circulation; it was increased $3,000,000$ or $4,000,000$ between the end of 1816 and the ycar 1818; and higher prices followed that increase of the paper issue. It is very true 1816 was a bad harvest, which tended to raise wheat in 1817 to a higher price than it would have been, unaccompanied by a scarcity of wheat; but all other prices, manufacturing as well as agricultural, rose along with wheat, which showed that an action on the currency was going on. To prove that this really took place, there is a very interesting memorandum in the Appendix to the Lords' Report on the Expediency of the Resumption of Cash Payments in 1819, page 7, I think, which states,and evidently states it on authority, although there is no signature to it, but it bears internal evidence of having come either from the Government or the Bank,which states the whole progress of the actions on the currency from the end of the war up to 1819. Mr. Jeremiah Harmon, then deputy governor of the Bank, was also summoned before the House of Commons' Committee in 1819, and he was asked whether he recollected a state of great distress anong the agriculturists and manufacturcrs in 1815 and 1816 , and he replied in the affirmative. He was then asked whether he remembered how that distress was removed; he stated, that in consequence of communications with Government an increased issue took place of $3,000,000$ or $4,000,000$ of bank notes. He was asked whether that had the effect of removing the distress, and lie stated it had; at the same time there was an increase of the country bank issues. I would quote, in confirmation of this view, which however needs none, but it may show the opinion of contemporaries, part of a speech of Mr. Tierney in 1819; he is describing the condition of the country in January 1817 ; he says, "The right honourable gentleman, in the month of June 1817, had come down to Parliament with a smile of triumph, and told the House that cvery thing was now restored to the very condition in which he had long hoped to see it; that it would be soon found that the revenue was increasing, that stocks were rising, public confidence flourishing, \&c.; and when every body was looking for the realization of these gay promises, three or four months afterwards down came a number of returns from the Bank that explained the whole mystery; the secret of the triumph of the Chancellor of the Exchequer was exposed at once; for it appeared that the Bank had been increasing its issues, that country banks had followed its example, and that, in truth, the state of prosperity was nothing more than an increased paper currency." And I shall not be very much surprised to see the same smile on the face of the present Chancellor of the Exchequer when he opens his budget this year; the increasing issues of the joint-stock banks, and the speculations consequent on the plenty of money proceeding from the payment of the West India Loan, will be sure to help the revenue very much. It will, however, be a temporary triumph, as the other was, unless accompanied by other measures. Then, taking it for granted that the prosperity of 1817 and 1818 and the begrinning of 1819 was produced by the circumstance of an increased issue, I come to the year 1819, when Mr. Peel's Bill passed ; that Bill was not to come into full operation, I thiuk, till 18:23. Immediately after the passing of that Bill, and in preparation of what was to come in 1823, the Bank of England withdrew its notes, and the country bankers followed its example, and to a much greater extent. Mr. Ward, a bank director, stated before the Bank Committee of 1832, that "the country bank notes had been in a most extraordinary manner reduced shortly after Mr. Peel's Bill of 1819 . In 1820 they had become reduced to about $11,000,000 \mathrm{l}$, having becn $16,000,000 \mathrm{l}$. the previous year, and $20,000,000 l$. the year before; that in 1821 they were reduced to as low as $7,000,000 \mathrm{l}$; then the effect of that would be produced about the year 1822 ; for the effect does not follow the alteration immediately ; therefore $I$ cannot help thinking there was a great increase in the country bank circulation in the intermediate time between 1822 and 1824." "These were Mr. 464 . 
E.S. Cayley, Esq. Ward's recollections in 1832 . Thus did the reduced issues cause the adverse years of 1820,1821 , and 1822 .

10. March 1836. 3631 . What do you mean by the adverse years of 1820,1821 , and 1822 ?The low prices.

3632. Not bad crops?-No; I believe they were, on the whole, ordinary seasons; but bad years both for the manufacturer and for the agriculturist, for there was a fall in price in manufactures as well as agriculture; and the manufacturer suffered from the depression equally with the agriculturist. In 1822 Lord Londonderry, on the part of the Government, of which he was a member, seeing that the Bill of 1819 was producing such disastrous effects, and that it could not be allowed to come so suddenly into operation, came down to the House of Comruons, and proposed that the one-pound notes wlich were to be extinguished (I think) in 1826, should be continued to the year 1833, the year of the expiration of the Bank Charter, which virtually meant that they were not to be put an end to. I quote the following from Sir James Graham's pamphlet on "Corn and Currency."-"In April 1822, Lord Londonderry, then the colleague of Mr. Huskisson, introduces his measures intended for the relief of the agricultural interest, and he dwells on the extension of the currency of the Bank of England, and the consequent increase of the country bank paper, as a principal source of mitigation of the distress, admitting distinctly the contraction of the currency caused by Mr. Peel's Bill to have occasioned the fall in the price of agricultural produce; and in this very speech he gives notice of the introduction of the Small Note Act." That larger issue did take place, as we learn from the evidence of Mr. Norman (also a bank director) before the Bank Committee of 1832 : "It appears,' says he, "by the returns made by the Bank, that on the 26th of February 1822 the notes of the Bank (taking out one-pound notes) were $16,700,000 \mathrm{l}$; ; on the same day in 1823 they appear to have been $17,400,000 l$.; on the same day in $1824,19,300,000 l$; and in $1825,20,600,000 l . "$

3633. In what year was that:-Between the years 1822 and 1825 ; that increased circulation was followed by what was generally considered among the farmers and the manufacturing interest, the prosperous years of 1823, 1824 and 1825 .

3634. Those years you consider prosperous :- Yes; those years 1 consider prosperous as regards prices; but I would add, that those best acquainted with the operations of currency, at least what I esteem authorities, predicted some such crisis as the panic in 1825, as the necessary consequence of an over-issue of paper on the existing standard of value; they affirmed that the exchanges must go against us; that gold would go out of the country; that the Bank of England issues must suddenly be contracted, and that a crash must ensue; and it did come at the end of 1S25. The prosperity I conceive to have been owing to higher prices, in consequence of increased issue; the panic I attribute to the standard of value being upon too contracted a base for the paper to rest upon; but $\mathrm{I}$ have no hesitation in saying, that if at the same time that the Government stimulated the Bank to push out a greater number of notes, with a view to effecting a certain rise in prices, it had also altered the standard to adapt it to the increased issues, the panic would never have come, and that the state of prices of 1824-5 would have been as permanent as the present prices will be on the present standard of value. To proceed with the history of these operations on currency : in consequence of the panic, a law was passed to put down the onepound notes in the year 1829, four years before they would have come to their termination according to the law.

3635. Was that the first time they were put an end to?-Yes.

3636 . They were simultaneously put an end to at that date?-Yes.

36.37 . In 1829 they were to cease to exist:- - I do not think they would cease to exist; I think there was some provision in the Act preventing the issuing of stamps after a certain time previous to 1829 ; they were not to issue after that time.

3638 . In what year was the speech made by Lord Ripon, called the Prosperity Speech? - In the year 1824; all the interests of the country were prosperous, if the speech were true, and one can hardly suppose the Chancellor of the Exchequer states such matters without some ground, though sometimes prosperity has been proclaimed by mistake; but there is no doubt that all the productive parties in the country then felt in what may be termed an easy.and comfortable state. 
3639. You have watched the fluctuations of currency since $1819 ?-\mathrm{I}$ have.

3 ti. 0 . Have you found that when the currency was increased by an issue of onepound notes, or any other financial project which lias been introduced, prices have risen, and that when it has been contracted they have fallen?-Invariably; the first instance was from the distress of 1815 and 1816 to the prosperity of 1817-18; the second from the prosperity of $1817-18$ to the general distress of 1820,1821 and 182:2 and next the increased issues of 1823,1824 and 1825 , which produced the prosperity of those years; subsequent to 1825 the Bank of England notes were reduced, and country notes reduced also; prices declined gradually till the year 1828; then there began that series of wet harvests which raised the price of wheat from about $50 s$. or $54 s$. to $60 s$. and $66 s$. for three or four years. Under the influence of those wet scasons, and a higher price resulting from scarcity, the one-pound notes were finally extinguished, $i . e$. in 1829 ; therefore it was not till those wet seasons came fully to an end that we saw the full effect of $\mathrm{Mr}$. Peel's Bill of 1819. Since that time, i. e. from 1832, there has been a gradual diminution in the price of wheat, with no extraordinary seasons (except one, viz. in 1834), from $66 s$., down, in my own market, as low as $29 s$. a quarter, the Winchester measure; and though a part of that fall, perhaps from $5 \mathrm{~s}$. to $8 \mathrm{~s}$., may be accounted for by the harvest of 1834 , my firm conviction is, that the necessary consequence of Mr. Peel's Bill was to reduce the price of wheat in this country from $80 s$. (which had been the average for 90 years previous to 1819) to at least $40 s$. a quarter, whenever it came into full and stringent operation.

$364 \mathrm{I}$. Do you consider that the effect of Mr. Peel's Bill was disguised by the bad harvests which have taken place?-I do.

3642. Whenever there happens to be a rise, you look out for some justification in the state of the harvest, and whenever there is a fall, you look out for some justification in the state of currency, abandoning any argument to be drawn from wet harvests or the operation of the weather ?-I would state, as I stated before, that in order to pass a just judgment upon the operation of seasons or of money, you must take a longish series of years. The fact is undeniable, that subsequent to the Bank Restriction Act in 1797, there followed a general increase of prices up to the year 1819, which, including the years 1815 and 1816 , and taking wheat as the test, amounted to at least $80 \mathrm{~s}$. a quarter, the price having been previously somewhere between $40 s$. and $50 s$; ; but that price had been only brought on latterly, in consequence, I believe, of some banking regulations which took place in 1775 , and, I think, in 1791. The old standard price was about $40 \mathrm{~s}$. the quarter. We find, then, by the increased issue consequent on the bank restriction, there was a general rise of prices, and since 1819 a great reduction of issue, and a consequent decline of prices, a decline which has only lately come into full apparent operation, beeause the effect has been concealed or interfered with both by the seasons and by law; and I see no escape from the conclusion, that the increase of the circulation produced, during the first period mentioned, an increase of price, and during the second period, that a reduction of currency has produced a diminution of price. This conclusion induces me to say, that throngh an increased circulation alone can we look for any permanent rise of prices from the present level of price. That an increased currency does necessarily increase prices we know from the fact, that, previous to the opening of the American mines, for 100 years, the price of wheat had ranged about $10 \mathrm{~s}$. a quarter, and when the supply from those mines came fully into operation, wheat for 200 years succeeding bore the average price of $40 s$. a quarter, the supply from the mines having been, it was supposed, about quadrupled. If it was wished that I should go into an explanation of the precise mode in which prices are affected by the increase of money, I am ready to go into it.

3643. You have stated that which it is impossible to contradict, that the variations of that in which every thing is measured must affect the price, though not the real value of the thing measured; have not alterations taken place in the value of money, first of all by the diseovery of the richer mines of America, subsequently by the introduetion of the paper system, and lastly by the introduction of the irredeemable paper system; have not the great alterations which took place at those different periods in the value of money affected the price of commodities?-YYes.

3644. What reason have you to suppose that they affected the value of agricultural produce further than this change in money affected the price of other things?-They operated equally on manufactures and on agriculture, and on all 
E. S. Cayley, Esq. commodities. In the last instance, which is the one in question, it appears by the prices of the different periods of distress, since the preparation for and fulfilment of the Bill of 1819 , that the manufacturing prices fell equally with the agricultural prices.

3645. Do you not believe in the general statement which is made through the country, that all the interests of the country, with the exception of the agricultural interest, never were in a state of greater prospcrity than at the present moment?-I am led to believe that they are in a state of prosperity at this moment, but that began only a few months ago; and, as I stated before, their prosperity, in my belief, rests alone, or to a great extent, on a considerable increase of issue by the joint-stock banks: this being on the present contracted standard of value, for the reasons before given, I do not think their prosperity can be considered permanent. My opinion, which is the result of not an inconsiderable degree of inquiry among manufacturers, and particularly those who are not the largest capitalists, is, that up to a very late period little or no profit has been making in the manufacturing districts. I separate the large and smaller manufacturers, because, although the contraction of the circulating medium operated against the manufacturing and commercial interests generally, $\hat{I}$ am not quite sure it has not given some countervailing advantages to the large capitalist; for while the smaller capitalists are swept away with great rapidity, the larger ones are benefited by a greater monopoly in the market. I always observe that the great capitalists in the House of Commons are the foremnst to affirm the existence of prosperity; and it is to these alone generally that the ear of Government is lent; but $I$ have found that the persons connected with the smaller branches of manufacture have at the same time stated that there was no profit-making so far as they were concerned; and this up to six months or a year ago.

3646. Do you not believe, though in all departments of the country there must be varieties of condition, and all cannot be exactly prosperous at the same time, that the great bulk of the manufacturing and other interests of the country may be said to be in a state of great prosperity?-My opinion of the state of the manufacturing interest up to a year ago was, that it was, as a body, making little or no profit; that its state might be likened to the state of the low-land districts, which was produced by the rot among sheep. I look on Peel's Bill to have acted as a sort of pestilence, a scourge among the productive classes generally, as the rot did on the sheep flocks. At the same time the large manufacturers may have benefited in some degree by that state of things, as the up-land farmers have benefited by the adversity of thcir low-land brethren. The great men, if they can stand the shock, are greater still after the shock is over, because their competitors are swept away. The prosperity, as it is called, of the last few months of the manufacturing interest, particularly in Lancashire, is to be attributed, I stated before, I believe, mainly to the over-issues of joint-stock banks, and, so far as the iron trade is concerned, to the greater demand for iron for railway purposes in America and this country.

3647 . You have informed the Committee that the prosperity of the woollen manufacture did not cause the rise in price of wool ; is it not true that the woollen manufacture, as well as the iron trade, and the cotton manufacture of Lancashire, are in a state of work that obliges the master manufacturers to refuse a large portion of the orders sent to them?-As I stated before, up to about a year ago, my opinion was that the woollen manufacturers as a body were not making a profit; I believe now the manufacturing interest of Yorkshire and Lancashire has had a great impulse given to it from the operation of the joint-stock banks; I will state why I conceive the prosperity of the manufacturing interest did not cause a rise in the price of wool ; I hold in my hand an account taken from the Parliamentary Returns of woollen manufactured goods exported from the year 1820 to the year 1834; I have also got the importation of the sheep and lamb's wool for the same years; the result is, up to the year 1834, previous to which there had been a great rise in the price of wool, the export of woollen manufactured goods was not in fact increased from what it had been in the year 1820; there is an average of about $5,500,000 \mathrm{l}$. or nearly $6,000,000 \mathrm{l}$; but immediately after the year 1829 there began an amazing increase in the importation of foreign wool; it increased from $21,000,000 \mathrm{lbs}$. in the year 1829 to $46,000,000 \mathrm{lbs}$. in the year 1834. Now the argument I would draw from that is this: if there had been up to that time no increased export, and there had been that amazing increase of at least 100 per cent. in the import of raw wool, one of two circumstances must have 
happened, cither a great increase of consumption of woollen gaods at home (which I do not believe to be the case, because the principal consumers of the home market have been greatly distressed), or therc lias been a great scarcity of home wool, because that increase of foreign wool must have found a vent somewhere; with respect to woollen and worsted yarn, it has been nearly the same for the last four years; at the same time, from the late fillip in our manufactures, I shall not be surprised to see that the export of woollen goods for the last year has increased.

[The Account is delivered in and read, and is as follows:]

\begin{tabular}{|c|c|c|c|c|c|c|c|}
\hline \multirow[b]{3}{*}{1820} & \multirow[b]{3}{*}{-} & \multirow[b]{3}{*}{ - } & \multirow[b]{3}{*}{ - } & \multirow{3}{*}{$\begin{array}{c}\begin{array}{c}\text { Sheep ond Lainlis' Wool } \\
\text { Impurted. }\end{array} \\
\text { Lbs. } \\
9,775,605\end{array}$} & \multicolumn{2}{|c|}{$\begin{array}{l}\text { Declared Values of } \\
\text { Woullen Mlanufactured Goorls } \\
\text { Exported. }\end{array}$} & \multirow{3}{*}{$\begin{array}{l}\text { Quantities of } \\
\text { Woulien and Worsted Yara } \\
\text { Exported. } \\
\text { Yards. }\end{array}$} \\
\hline & & & & & f. & s. $\quad d$. & \\
\hline & & & & & $5,586,000$ & $-\quad-$ & \\
\hline 1821 & - & - & - & $16,000,000$ & $6,462,000$ & $-\quad-$ & $\longrightarrow$ \\
\hline 1822 & - & - & - & $19,000,000$ & $6,488,000$ & $-\quad-$ & - \\
\hline 1823 & - & - & - & $19,000,000$ & $5,636,000$ & $-\quad-$ & - \\
\hline 1824 & - & - & - & $22,000,000$ & $6,043,000$ & $-\quad-$ & - \\
\hline 1825 & - & - & - & $43,000,000$ & $6,18,5,000$ & $-\quad-$ & - \\
\hline 1826 & - & - & - & $25,000,000$ & 4,966,000 & $-\quad-$ & - \\
\hline $\mathrm{IS}_{2} \mathrm{~T}$ & - & - & - & $29,000,000$ & $5,245,000$ & $-\quad-$ & - \\
\hline 1828 & - & - & - & $30,000,000$ & $5,069,000$ & $-\quad-$ & - \\
\hline 1829 & - & - & - & $21,000,000$ & $4,587,000$ & $-\quad-$ & - \\
\hline $183^{\circ}$ & - & - & - & $3^{2,000,000}$ & $4,728,000$ & $-\quad-$ & - \\
\hline 1831 & - & - & - & $31,000,000$ & $5,23^{2}, 000$ & $-\quad-$ & $1,592,455$ \\
\hline 183.2 & - & - & - & $28,000,000$ & $5,244,000$ & $-\quad-$ & $2,204,464$ \\
\hline 1833 & - & - & - & $38,000,000$ & $6,294,000$ & $-\quad-$ & $2,207,47^{8}$ \\
\hline 1834 & - & - & - & $46,455,23^{2}$ & $5,568,000$ & $-\quad-$ & $1,861,81+$ \\
\hline
\end{tabular}

* Declared Values are the only ones given.

3648. Taking all the circumstances into consideration which guide your own opinion, do you think that the general opinion as to the present prosperity of the manufacturing interest is a mistake?- No ; so long as it lasts as it has been for the last two or three months, it is a state of prosperity; but I do not believe it to be on a permanent basis.

3649. While, on the contrary, the state of the agriculturist is very much depressed?-Yes.

3650 . Have not those two interests, dealing with the same currency and the same money, the one risen to a state of prosperity, and the other fallen into a state of depression; and if so, how can the state of the currency be called in aid as a proof of the depression on the one hand, if it did not act in the same manner on the other?-As I stated before, the state of the currency at two or three periods subsequent to the preparation for Mr. Peel's Bill affected the manufacturing interest equally with the agricultural; but the manufacturer recovered from the effect of the change earlier than the agriculturist; there is a continuity in the operations of agriculture which does not exist in manufactures; there are leases, there is capital invested, which takes often many year's to realize a return for; there is a greater attachment to localities among the yeomen, which makes them hold longer by a losing trade; then there is the landlord yielding to the pressure of the times, and so affording a partial relief; whereas the operations of manufacture extend to very little more, perlıaps, than a year; and it is only the hope of better times, and the difficulty of parting with a concern under an adverse trade, that prevents a inanufacturer giving up his business almost immediately, or being ruined at once, and then a new set of capitalists start; then, again, the export manufacturers have an extraneous source of demand beyond the home market, and the export trade has prodigiously increased (so far as the quantity of goods is concerned); within a few years the South American markets have been called into existence; then, about the year 1832, when the full operation of Mr. Peel's Bill began to be perceived on the price of grain, there was a cessation of hostilities in Europe, there was a deliverance from cholera, the opening of the East India market and the China market to our manufacturing interests; all those circumstances would affect the manufacturing interest, and indirectly, but at a great $46 \overline{6}$. 
E. S. Cayley, Esq. distance, would affect the agricultural interests also. New markets having been open to the manufacturers after the operation of the scourge of 1819 upon them, joint-stock banks having been instituted to a great extent in Lancashire for the last four or five years, where no private banks had issued notes before; and to show the extent to which this matter is proceeding, there are at this very moment, I understand, two new joint-stock banks about to start in Manchester, and another at Liverpool, and another at Storkport. Taking all things into consideration, and that money is lent to manufacturers more rashly than it was to the farmer previously to the bill of $1 \$ 19$; taking all these things conjointly, I think they prove that circumstances lave been in operation to affect the condition advantageously of the manufacturing interest, which have not been in operation to produce the same effect on the agricultural interests.

3 t51. Of the joint-stock banks none of them issue notes under $5 l$. ? - No.

3652 . When you say that the issues of those banks will contribute to aid this state of things, and to improve the condition of the manufacturer, you do not consider it is necessary that the issue should consist of small notes for that purpose? - My opinion is, that a general increase of circulation will, at all events, operate so as to increase prices; but the difficulty at present is to effect an increase in the agricultural districts, for the five and ten-pound notes are too large to pay wages with, so they revert shortly again to the banker, to be changed for sovereigns; if a banker accommodates a farmer with $50 \%$. or $100 \%$. in large notes, they quickly flow back again on the bank for smaller change; the bankers cannot, of course, afford to accommodate in the same manner with gold as they can with paper, and that is the reason I would advocate the issue of one-pound notes; I have no objection, if it be required, to their being secured, considering it as the money of the labouring class, and that the labouring class have suffered from the failure of banks and local one-pound notes, though I believe they have suffered very much more from the want of one-pound notes than from the failure of bankers; I believe it is generally understood in the banking world that the country bankers find a great difficulty, if not an impossibility, in rapidly increasing their issues, because the notes of one banker are paid on the counter of a rival banker, and that banker immediately returns them to the banker who issued them; therefore, though the Bank of England has the power of issuing notes at discretion, and increasing its circulating medium, it is generally understuod that in the long-run there is a natural check to the over-issue of country banks; an alteration of the standard, or the Bank of England giving them their notes on more advantageous terms, certainly may and will increase their issues; the great failures of country banks in $1793,1811,1815$ and 1825 arose from no fault of theirs, but from a tampering with the currency by the Government, in conjunction with the Bank of England.

3653. You are understood to be of opinion that the operation on prices of this issue or contraction of bank notes does not depend on the amount of the notes issued, but on the quantity altogether; then if the prosperity is to be ascribed, as you ascribe it, in some degree to these joint-stock banks, which cannot issue small notes, you must be of opinion, that, provided there is a quantity of paper out, it is not essential for the purpose of producing prosperity that that paper should be in suall notes?-It is not necessary, because if the country bankers have the power of issuing their five-pound notes on exceedingly advantageous terms, that might counterbalance the advastage they might utherwise derive from having the power of issuing one-pound notes; but I would guard myself from stating that the Bank of England issues are always an exact tes of the amount of currency in circulation. The last paragraph, I believe, of the Report of 1819 states the very same opinion, that though on a long series of years they may, on a large scale, be taken as a criterion, yet that it is difficult to ascertain the proportion of bills or of country circulation that may arise out of any given increased issue of the Bank of England. That Report concludes as follows :- "Your Committee have forborne from entering into any reasoning upon the effect produced upon the value of our currency by variations in the numerical amount of the notes issued by the Bank of England; so many circumstances contribute to affect that value, such, for instance, as the varying effect of commercial credit and confidence; the fluctuations in the amount of country bank paper; the different degrees of rapidity with which the same amount of currency circulates at different periods; that your Committee are of opinion that no satisfactory conclusions can be drawn from a 
mere reference to the numerical amount of the issues of the Bank of England outstanding at any given time."

3654 . In speaking of the state of agricultural prosperity at the periods when paper was irredeemable, are you aware that a great portion of that must be ascribable to the state of war at the timc, and for a great portion of the time our being cut off from the Continent, and the fact that Ireland, then supplying our large navy with its salted provisions, had not turned so much to agriculture as it has since done, and that till 1814, Ireland, which supplied us only 967,000 quarters of all descriptions of grain, supplied us, in the year 1832, with 2,600,000 quarters ; are there not sufficient reasons in the facts of supply from Ireland, and of our being shut out from the Continent, and other circumstances connected with war and high prices, without reference to simply the question of paper :- I apprehend the circumstances mentioned are not sufficient to account for the change, for these reasons, that all prices universally rose during the war, of every description, whether they were imported from abroad or raised at home ; in the first place, it is not necessarily consequent on a state of war that there should be a rise of price; perhaps I might state the fact, which is pretty well known, that in the wars of the last century the prices always fell, except in one instance, during the war, and rose again at the return of peace. The following is a statement from 1698 to 1793 :

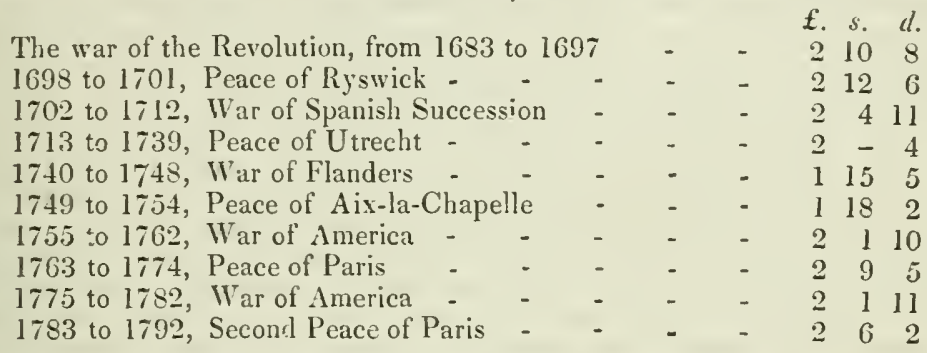

In addition to these strong facts, plain reason will, I think, assure us that it does not necessarily follow from the state of war that there should be an increase of prices; there is generally during war an increase of taxation; that increase of taxation, unaccompanied by measures to raise prices, falls either on production or consumption; if it fall on the producer, and he cannot charge it in the price on the consumer, he may thus be compelled to cease producing the article, and at all events is a poorer man; if it fall on consumption, that is, if the taxation be added to the original price of commodities generally, the consumer must take his choice between one set of commodities and another; taxation certainly does not increase his income; and if his money income remain the same while the prices of commodities rise, lie cannot purchase so many as before; he will abide by his consumption of articles of necessity, and give up the consumption of a portion of his luxuries; this diminished consumption of luxuries at least will canse a fall in the price of such luxuries; in the case of an article of first necessity, which men must lave at all events, the producer may take advantage of this necessity, and charge the taxation in the price; nay, I would say he will always do so whenever he is able ; but the more he can do this on one article of necessary consumption, the less ability he leaves on the part of consumers to purchase other things; those other things therefore will fall in price; but the price of all articles rose during the late war, which proves that some other cause was in operation; that cause was the depreciation in money, in consequence of which there was a more plentiful supply of money, and thus more of it would be given for each cornmodity; consequently a state of war, bringing with it an increase of taxation to the whole community, without increasing at the same time its money income, unless such is accompanied by a depreciation in the value of money, does not necessarily increase prices, but has, on the contrary, an opposite tendency; that a depreciation of the currency tends necessarily to produce an increase of price is not only demonstrable, but, to save the trouble of the argument, the principle is acknowledged by every great authority upon the subject; it has been a matter of dispute, indeed, whether a depreciation shall be measured by the price of gold, or by the prices of commodities generally. I myself, though I state the opinion very humbly, have always considered that a general rise of prices indicates the extent of any depreciation that might be going on much better than the price of gold, 404. 
E. S. Cuylcy, Esq. which might temporarily be operated on by an absence of supply or demand; March $183_{3}$. I all supported in that opinion by various authorities; among others, I am not sure that Mr. Horner does not go in principle to that; Sir James Graham holds the same opinion; Mr. Thornton also lield the same; Mr. Alexander Baring also. To my mind, it is very obvious why it should liave been so during the last war; for in consequence of the Bank Restriction we gave up our gold circulation; at the same moment other countries did the same; Austria, Russia, and others betook themselves to a paper circulation; their circulation of gold, then, and our circulation of gold, would be thrown into the general market; that would tend to depress the value of gold in the same way as an increased supply or a falling demand would cause a decline in the price of any other commodity. Suppose that, in consequence of a depreciation of the currency, wheat rose to $100 \mathrm{~s}$. from $50 s$. per quarter, and there was immediately to cease half the demand for wheat; notwithstanding the effect of the depreciation, the obvious consequence of the reduction of demand would be to reduce the price to $50 \mathrm{~s}$. again; exactly the same circumstance in effect took place with respect to gold during the earlier and middle periods of the war. I apprehend, therefore, that the mere price of gold was no criterion as to the extent of the depreciation during the war. Wheat (and wheat was not higher in proportion than other articles) that bore a price of $80 \mathrm{~s}$. during the war, at one period $100 \mathrm{~s}$, must now fall to $40 \mathrm{~s}$. a quarter or thereabouts; and other articles, unless operated on by extraneous circumstances, have in fact fallen half. I am quite aware there are two ways of estimating per centage; when it falls it is considered 50 per cent., when it rises it is called 100 per cent.; I state this to prevent misconception. These principles arc illustrated by circumstances which took place even very early in history. Mr. James, in his "State of the Nation," a most interesting publication, quotes from Montesquieu what took place in Rome, on the subject of money, at the time of the Punic war. He says, "During the first Punic war the $a s$, which ought to weigh 12 ounces of copper, was reduced to two; and in the second Punic war it only weighed one ounce. This answers to what we call the augmentation of money. Take from a crown of six livres the lialf of the silver to make two of it, or make it pass for 12 livres, is precisely the same thing;" and he adds, "They did this, not during the time of a corrupt republic or a state of anarchy, but at a time when, with the vigour of their institutions, by their wisdom as by their courage, they disputed empire with the Carthaginians. The Romans," he says, "conducted themselves better than we, who, in our operations, hare swallowed up as well the public as private revenues. Examine the Romans, you never find them so superior as in the choice of circumstances between good and evil." Montesquieu here refers, I suppose, to what took place in France under Louis XIV. Sir James Graham also thus refers to it: "Nor are the fatal effects of the sudden contraction of the currency peculiar to our time or country; for in France, under Louis XIV., when the currency had been depreciated $2 \tau$ per cent., and when an attempt was made to restore its value by reducing its amount, we find that the remedy was worse than the disease; that universal distress was the consequence; that all pecuniary contracts which had been previously made were raised one-third against the party who had to pay the money; that the restoration of full value was a death-blow to the debtor; that the people were reduced to despair by the efforts of the Gorernment to draw all the money to themselves; and that there was scarcely a proprietor of land who did not see his patrimony melt away, without possessing the slightest means of prevention." Montesquieu goes on on the same subject of money :"Money is the price of merchandise or commodities. But how will that price be fixed; that is to say, by what portion of money shall each thing be represented?' If you compare the mass of gold and silver which is in the world with the quantity of merchandise which is in it also, it is certain that eacl commodity or merchandise in particular will be compared with a certain quantity of the entire mass of gold and silver." And there can be no doubt, as far as human reason can remove the doubt, that the effect of depreciation, whether that takes place through the medium of paper, or through the medium of an increase in the supply of the precious metals, or through the medium of clipping the coin, the invariable consequence, unless it be counteracted by other circumstances, nust be to raise prices. The reason I am anxious to press this consideration, which to your Lordships is probably familiar, is, that the full effects of the changes in the currency since 1797 have been attempted to be concealed from the public view. 
The public, not taking the trouble to reflect on the causes of high prices, at a time.when difficulties did not stimulate them to do so, were deceived in respect to the currency by resolutions in the Honse of Commons in 1811, when it was stated that there was no depreciation; that the paper guinea and the gold guinea were of equal value, although one was selling for $8 s$. or $9 s$. more than the other. $\Lambda$ gain, the effect of Mr. Peel's Bill has been studionsly concealed from the view of the public lyy every cffort l'arliament has been able to make. I wish to put the matter upon its right basis; I wish the truth to be proclaimed to the public, that it may no longer be deluded with the vague notion that prices will be raised, without the steps being taken which can produce higher prices. The conclusion I would inake to my observations on the depreciation of paper is, that instead of coming, as we did, to all antiquated standard, a standard which was no standard of justice, or of the engagements that had been entered into for 20 years, we ought to have measured our metal standard at the rate of the depreciation of paper; then we should have kept faith with both creditor and debtor; whereas we dealt out double faith to the creditor, and not even half faith to the debtor, which debtor is, in fact, the public. This doctrine is held now, not only by persons of the first authority in this country, but it was held by M. Say, the great political economist of France, who declared that the obvious and just mode of proceeding for us in 1819 was to have struck the standard at the rate of the depreciation; and with respect to the other mode, viz., the one pursued by Mr. Peel's Bill of 1819 , he goes on to say, - "The privileged classes, the official persons, the pensioners of the state, the clergy and the annuitants, have profited by the restored value of the paper currency; but it has been a scourge to the mass of the nation and to industry, - a scourge which would alone have been endured by a nation like England, rich in capital, so pre-eminently industrious, and in every other respect so admirably well governed." This was the unprejudiced language of the greatest political economist, perhaps, of his day, living in another country, with respect to Mr. Peel's Bill of 1819 . Lord John Russell declares the same, or very much the same opinion in his chapter on the national debt, in his work on the English Constitution. He says, "In order to avoid the evils attendant upon a restoration of the currency, Lord Lauderdale recommenderl, in 1814, that we should coin guineas of the value of $21 s$. of paper currency. This would have depreciated the standard more than 30 per cent. Had this advice been adoptec!," Lord John proceeds, "we should have avoided the misery that we have since suffered, and that too with a very small breach of the national faith. Perlıaps, indeed," the noble lord adds, "the fund-holders would have had reason to bless the day on which such a measure was adopted, for it would have retarded the period which some time or other will in all probability arrive, when the payment of the full dividend and the safety of the state shall be found to be incompatible." But the authorities supporting the principle that depreciation does affect prices, and that after a long period of depreciation the restoration of a former standard is unjust, are without number; amongst them I may mention Mr. Ricardo, Mr. Mlalthus, Lord Althorp, Mr. Alexander Baring, and so on; Mr. Horner, Mr. Henry Thornton, Montesquieu, the historian Niebuhr, and many others.

365.5. Nobody doubted it?-It is quite true that no one of any reflection and of unbiassed mind could have a doubt upon the subject; but the noble lord will remember that the mass of the people are not given to great reflection, especially on a subject like the operation of money, which appears to them difficult and abstruse. The people, therefore, were liable to be exposed to the ingenious sophistry of interested parties, who, ever since the passing of MIr. Peel's Bill, have taken pains to throw dust in the eyes of the public on the subject, aud have led them a wild-goose chace after any thing but the real cause of their sufferings. It is high time, in my opinion, that the country should know the truth upon the subject; and it is therefore that $I$ have ventured to quote authorities in which the public will have confidence. We might indeed, at the termination of the contest in 1814, have taken a valuable lesson from other countries; Austria, France and America all acted virtually upon the principle I have maintained to be the just one; their debts, which had been contracted in depreciated money, they paid in depreciated money. And if I do not very much mistake, a gentleman of high authority upon this subject in this country was honoured, along with two other gentlemen (one of America, the other of France), by a request from the Einperor of Russia that they would act as unbiassed umpires in a question of this very nature. Russia had contracted a debt in depreciated paper; the emperor wish464. 
E. S. Cayley, Esq. ing to do equal justice by both debtor and creditor, and distrusting the impartiality of his own subjects, who might have an interest or bias on the question, 10 March 1836. applied to Mr. Alexander Baring (now Lord Ashburton) of England, Mr. Gallatin of America, and, I think, M. Dupin of France. They were unanimous in their decision, that the only equitable mode of settling the question was, that the depreciated debt should be repaid in depreciated money. These instances will, I think, be sufficient to establish my position, that Mr. Peel's Bill ought never to have passed. The concluding part of the question put to me, I believe, referred to the importations of grain from Ireland, and whether they had not bad a tendency to reduce the price in this country. The state of the importations from Ireland to this country bas been in this wise:-they increased up to 1833 ; they have decreased ever since; that is particularly referring to flour and wheat. When any one looks at the returns, they see that a certain number of quarters of wheat hare been imported; they then look at the flour column, which will show an apparently large increase, in consequence of the establishment of large flour-mills in Ireland; but if the hundred weights of flour are reduced into quarters, which is done by some such divisor as four, the apparent increase is very much diminished according to the usual estimate, which is in quarters of wheat. Taking the flour and wheat together, reduced into quarters, for the last three years, there were about 800,000 quarters imported in 1833; about 700,000 in 1834; and about 600,000 imported in 1835 . The decline in the price of wheat has been very considerable since 1833 , about $20 \mathrm{~s}$. per quarter; but in the face of this great fall in price, and contemporaneously with it, there has been a considerable diminution in the import of wheat from Ireland.

3656 . Ireland, notoriously in the face of paper money, has sent us a comparatively small supply. The general impression in the country is, that the Irish supply bas materially affected the prices. Do not you consider that the difference in the short supply in times of paper money, as compared with the larger supply in present times, accounts in a great measure for the depressed price of agricultural produce in England, without having reference to the subject of paper? -No, I do not think that acconnts for it in the least degree. If we take the increase of the population even only since 1821 into the account, the increase of population since 1821 is upwards of $5,000,000$; I conceive it to be impossible that any ostensible increase, within that period, of production in England or of supply from Ireland, can have been more than adequate to meet the demand of such increase of population, unless, indeed, distress has caused a great falling-off in consumption. Then I take a later period, 1824 and 1825 , when wheat ranged abont $66 s$. a quarter; and I find, so far as the fall in price is concerned, scarcely a perceptible difference in the importation of wheat from Ireland between that time and the present. I attribute, therefore, no part of the fall in the price of agricultural produce since the peace, other things being equal, to increased importation from Ireland. I would say further, that the effect of Mr. Peel's Bill had been, if it were possible, even more stringent on Ireland than on England.

3657 . But you think that the great fall in this country has checked the importation from Ireland this last year?-I am not aware that the depreciation of price has the effect of checking the import from Ireland, unless the fall be very great indeed. I have always understood that the effect of a diminished price on Irish produce is this, that rent being in a great measure fixed in Ireland, the niddleman screws it out of the tenant, whatever be the price of produce; of course exceptions to this are numerous. If, then, prices fall, it is quite evident that the tenant or the labourer must part with more of his produce to raise the rent, even to the extent of depriving himself of his pig; the landlord may also be induced, to prevent a fall in rent, to give permission that old grass land should be broken up : these circumstances will increase the quantity of corn brought to market, and of pigs, and cause a larger export of both to England; and we have nsually seen this effect follow a fall in price. Indeed, in a debate which I took the liberty of raising in the House of Commons last year on the state of agriculture, Mr. O'Connell promulgated the same doctrine, that when the prices are iow in Ireland there is the greatest export to England.

$3_{5} \sigma_{5}$. When prices are low here, will there not be little import from Ireland? -The principle I have just stated I believe to be perfectly true; and the limit to it is the inordinate fall in this market, so as to prevent any remuneration to the exporter. 
3659. Was not there such an inordinate fall last year?-There was.

3660 . Could the import of whent from Ireland into England at sucl a price pay the freight for it? - I am not aware of the exact difference of price in England and Ireland last year, and therefore cannot answer that question.

3661. You say that the joint-stock banks accommodated very rashly; do you apply that observation to the farmers, or only to the manufacturers?-Only to the manufacturers. The information I have received, and it has been from many quarters, assures me that it is with the greatest possible difficulty that even farmers of character and apparent stability can obtain accommodation from the bankers.

3662. Has that been from the well-known distress of the farmers?-Yes. It is contrary to the very nature of credit that it should be given to what is known to be a failing trade; and none know the state of the farmers better than the country bankers.

3663. You have said something about trade being advantageous to the great capitalists; low is trade at present advantageous to the great capitalist more than to others? - Where there is a scarcity of money, and there has been a decline in prices, that will of course operate most on the parties who are the least wealthy; " the weakest go to the wall ;" a sudden and violent change will smite them to the earth. Those capitalists, however, who have a large surplus capital beyond what is immediately invested in their trade,--and these have hitherto been but a fraction in point of numbers compared with the great mass of producers,- these gentlemen, having survived the shock, have the opportunity of going to a market inordinately depressed as to prices ; they take advantage of the sales of bankrupts, and sales which are pressed on by the adversity of the parties, and then they can buy those goods and retail them at a much greater rate of profit than usual, in proportion to the wholesale prices.

3664. You think that the great manufacturer has beat the smaller?-I think that the great man is beating the smaller, not only in manufactures but in agriculture also. The lord of $100,000 l$. a year, supposing him to have $25,000 l$. per annum incumbrance on his estate, if his estate fall in value to $50,000 \mathrm{l}$. a year, has still $25,000 \mathrm{l}$. a year left. But take a similar case of a small proprietor of $1,000 \mathrm{l}$. a year; his rental falls to $500 l$.; he lias $250 l$. per annum incumbrance, and he has $250 \mathrm{l}$. a year left to contend against retail prices fallen only one-fourth, when wholesale prices have fallen one-half.

3665 . Is not that the worst possible thing for a country; does not it depress the energies of a country? - Yes; we must never forget that it was by the united energies of the men of small means, but persevering industry, that this country became great. I think it has not only produced political consequences of great magnitude, but that it threatens everw worse.

3666 . That is the tendency of the present state of things?-Yes; the distress breeding dissatisfaction and discontent consequent on Mr. Peel's Bill of 1819. If my opinion is desired as to the political consequences of that fatal measure, I will give it freely and without disguise: perhaps my testimony, on this point at least, may be the less exposed to a charge of partiality, because my votes have, for the most part, been on the side of reform. It is my firm conviction that Mr. Peel's Bill of 1819 (together with the preparation for it) was the great instrument in securing the Reform Bill; the pressure it caused on industry produced a disposition in men's minds for a change. 1 would guard myself from being supposed to think that the principles of that measure were untrue or unjust; but $I$ say they were as true when they were brought forward thirty years before, and that if the people had not been in comfortable circumstances in consequence of a remuneration for industry, they would have been brought to join before in the cry for change. It is in human nature not to rest content under circumstances of great privation. This tendency, after the distress began, was first evinced by the blanketeers and coal-men thrown out of work in 1816. The prosperity of $1817-18$, proclaimed in the King's speeches of that day, was accompanied, according to one of those speeches, by return of contentment among the working population. After 1819 , and during tive c'istress, the King's speeches, up to 1823 , generally contained allusions to the spirit of disaffection and insubordination which had lately sprung up. Then after this distress was removed in 1823,1824 and 1825 , the King's speeches of 1824-25 stated, that "content and satisfaction were now widely diffused throughout all classes of the British people." After 1825 distress again began, and the speeches from the throne acknowledged it in 1830, remarking on "the spirit of discontent and dissatisfaction among the people, breaking of 464.

D $D 2$ machinery," 
E. S. Cayley, Esq. machinery," Sc. Distress was the giant power in the hands of the reform party. - I need not say I do not recrret the passing of that great measure, but I bitterly $10 \mathrm{March} 1836$. deplore the price which it was necessary to pay for it; and my foreboding is, that distress, if allowed to continue, may lead to changes much greater than the Reform Bill, - so great as to be subversive of our ancient form of Government.

3667 . Has there been a tendency for the land of the country to get into fewer hands, or to get into a greater number of hands, in your neighbourhood? - The sale of land is very various: when there happens to be a retired manufacturer or person connected with the monied interest, who fortunately wants land in the neighbourhood, of course he will buy it : where such are wanting, land is often put up to sale without an offer. In former days, when land was to be sold, especially small estates, there was much competition among the smaller proprietors and the yeomany to purchase; their powers to do this are now paralyzed. $I_{t}$ is on this class of proprietors of land that the change in the value of money has operated the most grievonsly; and on the moral independence of this ancient and numerous class, the high character of this country had, in my opinion, its sccurest base.

3668. Have not many of thcse been ruined?-They have been. I believe that I have the honour of representing as large a body of the old estates men as any member of the House of Commons; the havoc and the struggle has been dreadful amongst them; the dales of the North liding of I orkshire were filled with the ancient yeomanry.

3669. You do not think the driving out the old yeomanry by new people has been the effect of the paper system?-No; but the result of the depreciated paper system was to raise prices. Lnder the blind of high prices we contracted debts, public and private, entered into engagements, and increased expenditure, and founded settlements which never would have been dreamt of, except in the faith of those prices remaining. The depreciated paper was put an end to by Mr. Peel's Bill; the prices (allowing for temporary counteractions from opposite causes) have been gradually tending to the ancient standard level; and although the estates men had, as a body, formed no larger engagements than they and their ancestors had been accustomed to form from time immemorial in proportion to their nominal incomes, they have been unable to withstand double debts and double expenses of cultivation, with halved prices, consequent on Mr. Peel's Bill. The change has swept many of them away like a pestilence.

36\%. Do not you think that the principles on which the cash payments were resumed were very unjust towards the public? - As I stated before, I can conceive nothing so analogous to it as the rot which a few years ago swept away the sheep flocks. It was unjust, because during 20 years which had preceded cash payments, all the taxation, the engagements, and expenditure had been entered upon on the footing of a higher range of prices. And when we talk of taxation, for instance, men do not contract for sounds and denominations, but for intrinsic values: a farmer, when he consents to be taxed, considers how much his wheat (and other producers make the same calculation with respect to their commodities) will sell for; two bushels of wheat, during the war, would raise a pound; the nominal pound of $20 \mathrm{~s}$. remains the same, although national and private debts (and the private debts are supposed to be quite equal to, if not greater than, the public debts, )-although all these debts and engagements have to be paid under a system which has latterly taken five bushels of wheat instead of two to raise the nominal pound. The reason little rent can be paid is, that the fariner is obliged to take so much more of his produce to pay the expenses of cultivation, after paying which, little of the produce, often none at all, is left either for rent to the Jandlord or profit to the tenant; this is the way in which the fall in prices affects the landed interest, and, as I suspect, all other interests; and these were the circumstances which ought to have been considered at the close of the war. At the same time, although I should have wished to have returned to a very different state of things than was adopted in 1819 , I am far from wishing to return to that precise state now, after such a length of time has elapsed. My impression is, that all we can look to now is, a return to the old standard of value, which was gold and silver conjointly. The price of wheat has fallen in this country beyond what it was immediately preceding the war, because we have not bad the old standard of value. It was stated in 1819 that we were not intending to return to the old standard; we have only returned to the gold standard. If we had 
returned to the silver, a higher rate of prices would, in my opinion, have been the consequence. The measure 1 should propose would be to add silver as an optional standard, at its present coinage price; not $5 s .2 d$. , the old standard price,
but $5 s .6 \mathrm{l}$.; and I cousider that not much, if at all, more than equivalent to the old standard before the war; because before 1819 there was a law to prevent the export of the coin ; that operated to the extent, I believe, of two and a half or three per cent. in kecping it at lome.

$36 \%$. How does that appear? - I think it was so stated by Mr. Alexander Baring before the Privy Council Committee on Coins in 1828. That would atford a loroatder base on which to found a paper circulation than the present standard, and would enable the bank to increase their issues with safety. There is this advantage in silver as a standard, that there is a physical obstacle in procuring it rapidly from the bank upon any sudden panic, so that ultimate convertibility is secured; the more the bank is protected against a general and sudden run, the safer it is for property itself, because, with all the eredit transactions of this comntry, no anount of bullion that is attainable could protect the bank. l'anics are commonly only of short duration; it is wise, therefore, whilst you concede to the principle of convertibility, to place a difficulty in the way until confidence be restored. This was done in the rebellion of 1745. By paying in sixpences, the bauk leeld out till the panic was over. The same sort of thing took place in the three days of July in Paris; a run was mate on the bank; the slow payments in silver prevented the bank coffers being exhausted, until the crisis was over. Silver thus creating a physical obstacle in the way of that rapid convertibility demanded in a political panic, which all authorities agree no bank can withstand if continued long enougl, tlee bank would be encouraged to increase its circulation. Taking the present market price of silver into the account, together with the physical advantages of silver, its adoption as a standard would produce a rise in prices, in my opinion, of from 10 to 15 per cent. I hnow there is an objection to altering the standard, but we must recollect that a great difficulty has to be overcome; and if the United States have lately, with no such difficulty pressing upon them, depreciated their gold standard six per cent. to bring it on a par with their silver (which I understand to have been the case), while no complaints have been made against the measure, I do not see why we should scruple in doing it. In addition to the adoption of silver as a standard, I would allow the country bankers, at least, to issue one and two pound notes; and I sliould have no objection to the one and two pound notes being sccured, if it be thought requisite to protect the labouring class from the failure of banks; though, as I said before, my own opinion is, that the working class have lost 20 times more for want of one-pound notes than ever they did by the failure of banks. Then there was a clause in the last Bank Cliarter $\Lambda$ ct which prevents the public demanding gold from country bankers, which is a great security against internal panics. With these adjuncts to a silver standard, prices might be permanently and securely sustained, full 20 per cent., I believe, above their present level; the effect of which would be, that $40,000,000 \mathrm{l}$. annually would be given to the agricultural interest. Supposing $200,000,000 \mathrm{l}$. to be the gross value of agricultural produce at this time, 20 per cent. on that is $40,000,000 l$. Then, as to rents, at the present prices certainly there must be an immense reduction of rent; a great change has taken place already in the rental, but probably as much more remains to be made, if $40 \mathrm{~s}$. is to be the standard for wheat; the landlords up to this time bave staved off the evil day by obtaining rent out of the capital of the farmer; but the day of reckoning will come, because the land cannot be cultivated at the price I have named. Now supposing rent to be one-fifth part of the gross produce of the land (and on an average of present prices I do not think it is more), if this modification of Mr. Peel's Bill, which I propose, were to take place, it would save at least a reduction of $8,000,000 \mathrm{l}$. of rental; $8,000,000 \mathrm{l}$. being the fifth part of the $40,000,000 l$. increase, which I have assumed would be effected in the price of the gross produce. By the same means I should hope that, together with further improvement in husbandry, the land might remain in cultivation.

3672 . Supposing the landlord's rent to be $1,000 \%$. a year, if he continued to reccive that $1,000 l$. a year, which you say he cannot do under the present state of things, if he was enabled to do that in consequence of a depreciation of currency, would not his money go less far in any thing he had to apply it to, except the payment of his debts; if he desired, which of course he would, to apply that $40_{4}$. D D 3

money 
E. S. Cayley, Esq. money to procure him commodities of any description for his own use, would he not, from that increased price of every thing, find that he gained nothing by the 10 March $1 \varepsilon_{3} 6$. depreciation :- He would gain by the depreciation in all his fixed payments. That is no small thing with the landed interest generally, for we are not to consider one individual landlord, but the whole together. Then the retail prices have not fallen nearly so much as wholesale prices in consequence of the bad debts of the customers of tradesmen, and any increase in the wholesale price would not necessarily entail an increase of price on the retail ; for the retail trade becoming prosperous, competition would prevent more than the profitable charge being made; whereas the retail trade, notwithstanding its comparatively high charges, having been lately ruinous, competition has not come into operation with respect to it. But the same argument will apply to the expenditure of the labourers as to that of the landlords; their wages, it is true, not liaving been reduced in proportion to the fall of prices, those who get employed and get money are in as apparently a prosperous state as they were, or at least in a good state; but this prosperity is filched from the capital, not taken out of the profits, of the farmer; it therefore cannot last. Many are unemployed, and wages and prices must ultimately fall to the same level. When that takes place, agriculture remaining unprofitable, what will be the condition of the labourer? The case of a rise of prices and a rise of wages is extremely well put by Mr. James; he is taking in his argument another ratio of depreciation; he says, "The farmers and other first producers, manufacturers, ship-owners, \&c., would have, after paying their fixed charges, a larger amount of money left for themselves, their labourers and workmen. An agricultural or manufacturing lahourer would then receive $20 d$, where he now receives $12 d$. Taxes remaining the same, beer would rise, say from $4 d$. to $5 d$. the pot; sugar from $7 d$. to $9 d$. the pound; tobacco, first cost, from $5 d$. to $8 d$. the pound ; the tax $3 s$. remaining the same, the total cost would rise from $3 s .5 d$. to $3 s .8 d$. the pound, which would make but little increased cost in the price of the ounce, say $4 d$.; other things would rise much in the same proportion; some more, some less, as taxes and fixed charges operated upon them. Suppose a workman, now receiving $1 s$, to purchase a pot of porter, $4 d$., a pound of sugar, $7 d$., and a quarter of an ounce of tobacco, $1 d$., such would take his shilling; but at the rate of depreciation supposed (and one rate is as good as another for the argument), he would then receive $20 d$. instead of $12 d$; and having then to pay $5 d$. for his pot of porter, $9 d$. for his pound of sugar, and $1 d$. for his quarter of an ounce of tobacco, making together $1 s .3 d$., the labourer would be a clear gainer of $5 d$. by the operation, which $5 d$. would remain with him to purchase any other necessary or comfort he might desire. Its operation upon a larger scale would be to give the labourers $20 \mathrm{~s}$. where they now only receive $12 \mathrm{~s}$.; but as they, as consumers, would. have to pay only in the proportion of from 12 to 15 , they would be benefited as clear gainers of $5 \mathrm{~s}$. in every $20 \mathrm{~s}$. they earned." In this way the labourers and all the productive classes would be beneited by the change I propose.

36\%3. For how maluy years do you consider the present state of currency, as it now exists, and as you think it has existed to the injury of the community, has now continued?-It has now continued more or less, with certain interruptions, from the year 1814; but the full operation of it has not been perceptible more than the last two years.

$3^{6} 74$. So that you conceive the operation of the transition from the paper currency to the present system, begun in 1814, has been going on gradually, with different variations in different years, but has not been in full operation until the last two years? - Yes.

3675 . It is to its coming into that full operation the last two years that you ascribe a considerable portion of the farmers' distress which has existed the last two years - I attribute the increased distress to that.

3676 . Would not the change you advocate be a serious injury to fixed annuitants?-It might be a partial injury, but no injustice to the fixed annuitant; and I say so on these grounds: at the close of the war it was agreed in Parliament, Mr. Huskisson himself supporting the view, that $80 s$. was to be considered the remunerating price for wheat, and other produce in proportion. We passed the Corn Law, apparently making provisions to accomplish the price of $80 \mathrm{~s}$. ; that remained in force till $\mathbf{1} 822$. During that time any operations which bad produced a rise of price to $80 \mathrm{~s}$. would have been no injury to fixed annuitants, because Parliament bad declared that as the basis of price, and calculations would have been made 
made by annuitants accordingly. Between 1822 and 1828 a Corn Law prevailed, proposing for the landed interest $70 \mathrm{~s}$. as the price of wheat. If any change had taken place in the currency to secure that $70 s$., the fixed annuitant and every other class had been led to expect it; they had never contemplated another price; if they did, whilst others were in ignorance of what was going on, then indeed dishonesty may have produced the change that has taken place; but I do not suspect fixed annuitants generally of a knowledge of the cause of their late increase of wealth. Since 1828 a Corn Law has prevailed, declaring $64 s$. as the price, on the average, for wheat ; any change, therefore, in the prices up to $64 s$. a quarter for wheat would not be any injustice to the annuitant, because he has been led to expect it ; and it is only three or four years since (in consequence of scarcity, of which the annuitant knew nothing) that price in fact prevailed.

3677. How do you account for the suspension of the effect to the last few years?-Many changes have taken place in the currency in the interval since 1814, and latterly some extraordinary seasons.

[Mr. Cayley withdraws.

Ordered, That this Committee be adjourned till To-morrow, One o'clock.

Die V'eneris $11^{\circ}$ Martii, 1836.

The Lord WYNFORD in the Chaik.

John Langhorne, Esq., is called in ; and Examined as follows :

3678. WHERE do you reside?-At Berwick-upon-Tweed.

3679. You are a banker there ?-I am.

36 So. You are a banker in an extensive way?-Not very, but tolerably so.

3681 . You are also a steward for one or two noblemen or gentlenten ?-I have

John Langhorne, Esq.

11 March 1836. the management of one large estate.

3682. Of course you are acquainted with the state of the farmers in that country? - - Yes.

$36 S_{3}$. Your land is there generally good, is it not?--There is the finest land in the kingdom. I believe Lord Tankerville has one of the finest farms in the whole kingdom, and generally his estate is the finest I know. farms.

3684. You have more than one farm under your view?-Yes; about 40 large

$368_{5}$. Is the land generally good :- It is.

3686. And their local burthens not high ?-The local burthens are very low indeed.

3687 . What do you include in the local burthens?-I include poor's-rates, statute duty, church-rates, and land-tax.

3688 . Have the goodness to state how much in the pound is paid for landtax? -I have a good deal of tithing over a large district. We always deduct, for all the rates, $2 s$. in the pound; for all those four rates.

3689 . They do not exceed $2 s$. in the pound; the land-tax, the highway-rate, the poor-rate and the church-rate ?-No, they do not exceed that.

3690 . What is the amount of poor's-rate?-The poor's-rate will be perhaps $1 s$. in the pound; the highway-rate $6 d$. generally.

3691. Do you mean on real value?-Yes. The church-rate and the landtax together will be about $4 d$.; probably there will be $2 d$. between the other two.

3692. Is the land-tax grenerally borne by the landlord or the tenant?-By the tenant.

3693. What sort of tenants are they; are they an industrious people?-Highly respectable tenantry, and of large capital also.

3604. Are the men skilful as well as industrious?-Yes; the best farmers in the kingdom.

3695. Notwithstanding they are the best farmers in the kingdom, what is their condition?-Upon the turnip soils they are just making them pay, and upon the strong soils they are losing a great deal of money.

$4^{64} 4$.

1) $\mathrm{D} 4$

3696. Are 
John Langhorne, Esq.

11 March 2836.

3696. Are they paying rent out of capital:-Yes.

3697. That you know ?-Yes; I have heard from several tenants, on strong clay soils particularly, stating that they had lost such a sum, and I might take the farms into my owu liand and plough them, and that they would go away; one even threatened that he would make an assigument, and we might do what we liked with the lands.

3608 . W'as that a farmer of good character?-Yes.

3699. Occupying a very large farm ?-Yes, a very large farm indeed.

3700. As a banker, besides being acquainted witl the circumstances of the tenants of this large estate to which you have alluded, you are acquainted with the tenants of other estates, and know their circumstances?- $Y$ es, I do pretty well, from that sort of experience which we generally have.

3701. Do you advance them money with the same facility you did formerly ?Certaiuly not.

3702. Unless they bring securities with them, do you accommodate them with money at all ?- I never advance a shilling of money to pay rent. I go upon this principle, that it is leading to a false end, for without the landlords do not get the rent, they do not know the distress of their tenants. The thing is, that if I lend money I may get it back as I can, under the present circumstances.

3703. The landlord has a distress for his rent; you have no such distress for your loan? - Just so.

3704 . Do those people, under those circumstances, pay their rents?-No, certainly not.

3705. Are they in arrear?-They are.

3706. Considering what the half-yearly payment is, are they greatly in arrear? -'They are.

3707 . In what proportion to the yearly rent?-About one-fourth is left unpaid.

3708 . How long does that remain over generally?-We get it in from time to time, as we can; I have got some in since the last rent-day, and some very large arrears I have not got at all yet.

3709. There is none in danger?-I think not. I will explain how we deal with the farmers. There is scarcely a farmer in the whole district that has not with me what we call a cash account.

3710 . The same as they have in Scotland?-Yes; and every one of them overdraws me, according to the extent of his farm, from $200 l$. to $300 l$., $400 \%$. $01500 l$, either for rent or any thing else.

3711 . Does lie do that now without any security :- We have a bond in the first place; the man himself, with two securities; we have always three names to the bond before we lend money; he draws as he likes, and pays in as lie likes, and as he pays in, it decreases his interest.

3712. You are acquainted with the mode of Scotch banking? - Yes

3713. Do the Scotch notes come over the Border? - They do, sometimes.

37 14 . Do they do any good?-No, they are of so small an extent that they are not of any consequence.

3715. Do they do good in Scotland? - They do good, not particularly in Scotland, but they do good to the community in general, inasmuch as the increase of circulation in Scotland tends to raise the prices in Scotland, with some contingent benefit for England. I remember being with Mr. Herries once. He told me they were going to take away the one-pound notes from Scotland. I said, that will be very foolish ; they do no harm; they are a general good ; it will only add to the mischief; and they did not take them away.

3716. It is your opinion that they do great good in Scotland?-Not particularly so; they nay be a profit to bankers, but the bankers are so rich in Scotland, that whether they lad them or not, they could give accommodation.

3717. Why are you so anxious to preserve them?-Because they have a tendency to assist the circulation.

3718 . If they do not do so much good to the bankers, they increase the general mass of the circulation of notes, and do good to the public :-Certainly.

3719 . Have you turned your attention at all to the bondiug system in this country :- No, I have not.

3720. lou do not consider these one-pound notes of any particular advantage in consequence of their size, but merely from their swclling the circulation?-Yes; and of course advantagcous to the banks who put then out, and have 
their profits upon them; but as regards Scotland particularly, I do not think they are of advantage.

3721. If the bankers were more secure of not being drawn upon for gold, would they put out more notes?-No; in Scotland they are never liardly called upon for gold.

3722. Do the Scotch banks give security for their deposits or their notes? -O no.

3723. They are like our joint-stock banks here?-Perfectly.

3724. The sceurity consists in the number of the names and the personal responsibility of the parties?-Yes; there are the chartered banks, in which the partners are not liable.

372.5. They are incorporated banks?-Yes. know.

3726. You have only about 30 or 40 banks altogether in Scotland?-I do not

3727. How many of them are like our English banks, with a limited number of partners?-Very few.

3728. Are you aware whether there are more than 16 or 17 out of the number? -I cannot say.

3729. You have described agriculture to be in a very bad condition in Northumberland; can you state any particular instances of the depreciation?- Y es, 1 can; I have before me the names of several farms that I do not personally know, but being in the neighbourhood, I know the statements are pretty correct; there is a farm of the name of Grindon, of 1,400 acres, once let at 2,400l. a year, now let at $1,200 l$. a year.

3730. Within what perind has that deduction taken place?-The last lease was about 22 years ago ; it is just out of lease again.

3731 . What is the usual term of the lease? - Nineteen to 21 years. There is another farm I know perfectly well; Goswick, 900 acres, which was let at 2,100l., and is now let at $1,260 \mathrm{l}$. These are the depreciations in certain farms. There is a farm of Norham Mains, of 1,000 acres, which was let at 2,100 $/$, and is now let at $1,400 l$. or $1,450 l$.; Duddo, 1,100 acres, was let at $1,600 l$. a year, and is now let at $1,100 \mathrm{l}$. a year; then Melkington (I have not the number of acres), which was let at $600 l$., now is let at $300 l$.

3732. How long ago was it let at $600 \mathrm{l}$.? - It will be some time ago; in the high times. Then there is East Lilburn, 800 acres, was let at $1,800 l$, and is now let at $1,200 l$.

3733. How long ago was it let at 1,800 l.? - Four or five-and-twenty years ago. There is Horton, 2,100 acres, was let at 2,300l. a year, is now let at 1,560l.; North Earl, 400 acres, let at $1,000 l$. a year, is now let at $700 l$; Brunton, (I do not know the number of acres,) let at $1,000 l$. a year in the last lease, was a year or two ago let at $600 \mathrm{l}$. Then I have before me the rental of a large estate in Northumberland. This estate, (for I have it very exactly,) produced in the year I815 a yearly rental of $7,448 l$; at present it produces $4,935 l$; a reduction of $2,513 l$., or 33 per cent.

3734. Have you any farms in your fine country thrown out of cultivation? - No.

3735. In all those farms, of which you mention that the rents have been so much reduced, have the tenants been kept strictly to the fulfilment of the terms of their leases?-Yes, I have no doubt of it.

3736. You have no suspicion that the value of those farms has been lessened in consequence of their being badly farmed during the leases?-I am quite clear they have not been deteriorated. I take the leases of 19 and 21 years. In the beginning of the lease they lead lime, and lay out a great deal of money. I have known as much as $2,000 l$. laid out in a few years. Then they lime no more; the lease goes on; and of course they do not lime or buy any manure at the end of the lease, because they say "I am manuring now for the next tenant ;" and therefore, for the last five or six years, they are not at the same expense with it.

3737. Does that, in point of fact, deteriorate the value of the land towards the close of the leases? - It will, to a certain extent; it will make it worse if they do not add the same quantity of manure as they have been putting on before; but still it cannot be considered as much deteriorated in five or six years.

3738 . Can you speak at all to the produce of corn at the time of those leases being first granted ?-I have a paper of the general averages of the kingdon; I can only speak to the kingdom generally.

464 .

Jolın I.anghorne, lisq.

11 March 1836 . 


\section{$21 S$ MINUTES OF EVIDENCE BEFORE SELECT COMMITTEE}

Juhn Langhorne, Esq.

1) March $18,{ }_{3}^{6}$.
3739. The prices were a great deal higher when the leases were taken than they are now?-Yes, three times the amount, I should say.

3740. Can you state what is the produce per acre of different kinds of grain on those lands ? - Yes : on the gravel soils, if we get about four bolls of wheat an acre, we think that very good; that is, 24 bushels; our boll consists of six bushels.

3741 . Can you give the same as to oats, barley, beans and peas?-Oats will run from 36 to 42 bushels on those good lands. If it is a very ury year, they will probably get under six bolls; if it is wet they will perhaps get seven. Barley will run from six to eight bolls; the average may be seven; that is 42 bushels.

3742. Beans :- Beans are very uncertain; from 24 to 36 .

3743. Have you any statement of what has been the profit of an acre of land, taken from the fair average value of the light lands? - I have such statements made by another gentleman.

3744. Can you rely upon them, so as to state them to be in your opinion correct:-Yes; they are made by Mr. Jobson, one of the best agriculturists in the north of England, a tenant of Lord Tankerville.

3745. Have you a statement of the expenditure on farms of a given extent on lands of different quality :- I have a calculation of my own and other persons.

\section{[The same is delivered $i n$, and read, and is as follows:]}

Estimate of the Proceeds of a Farm of 300 Acres of Tuinip Soil, or nearly so, managed under the Fifth Course Rotation of Husbandry, 1835.

Four pair horses, kept with oats, 840 bushels, at $2 s .4 d$. per bushel

One ridincr horse, kept with ont, 120 bushels, at $2 s .4 d$. per bushel

Six servants' wages, corn money, \&c., each at $32 l$.

$\Lambda$ young lad within the house of the farmer

Two strvant maids, 7 . each

Blacksmith's work -

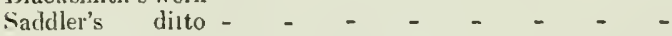

Carpenter's ditto - $\quad-\quad-\quad-\quad-\quad-$

A spademan and corn stacker - $\quad$ - $\quad$ - $\quad$ - $\quad$ -

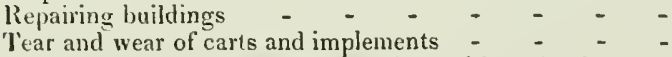

Ditto - ditto, in tlureshing machine and barn implements

Poor-rate, church-rate, highway-rate and county-rate

Grass seeds for 60 acres, at $12 s$. per acre -

Summiel work

llarvest work, 120 acres, at $10 s$. per acre

Threshing the crop

Marketing the produce -

Assessed taxes and window cess - $\quad$ - $\quad-\quad-\quad-$

'Twenty acres of fallow sown with bone dust, at $30 \mathrm{~s}$. per acre

Ditto - - ditto, limed, at 30 s. per acre - -

Sixty acres of tumip seed, $2 \mathrm{lb}$. per acre, at $8 d$. per lb.

Incidental expenses

W' heat for seed, 20 acres, at 3 bushels per acre, and $4 s .8 d$. per bushel

Barley for seed, 60 acres, at 3 bushels per acre, and $3 s .4 d$. per bushel

Oats for seed, 60 acres, at 5 buslieis per acre, and $2 s .8 d$. per bushel -

\section{Produce.}

Twenty acres of wheat, at 24 bushels per acre, at 4 s. $8 d$. prr bushel Forty acres of barley, at 40 bushels per acre, at $3 s .4 d$. per bushel Sixty acres of oats, at 40 bushels per acre, at $2 s .8 d$. per bushel

Ten three year old steers, at $15 l$. each

Thirty old ewes, at $30 \mathrm{~s}$, each .

Fifty-five dimmonts, at $34 \mathrm{~s}$. each -

Thirty gimmers, at $30 \mathrm{~s}$. each - $\quad$ - $\quad$ -

Seventy stones of wool, at $36 s$. per stone -

Profit on 12 steers bought in -

Expenses, as above

Leaving for interest of capital, rent and tithe

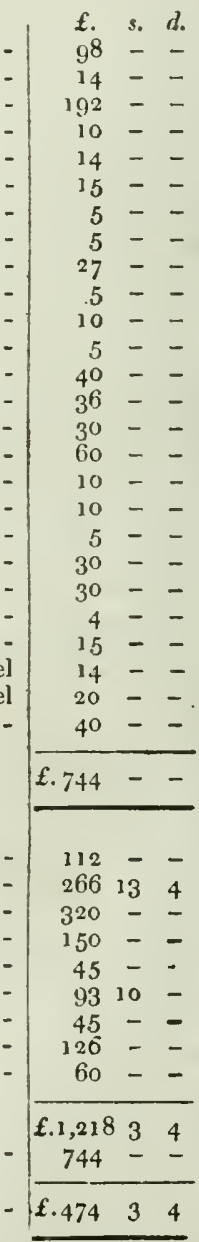

That land is werth at the leart $30 x$. an acre. 
3746. Do you mean with reference to the present prices?-No; it was formerly $40 \mathrm{~s}$. They vary very much; they are very good, and all the turnip soils with us are sloping; sume of the soils at the bottom are worth from $2 l$. to $3 l$ an acre; then when they get up to the top of the hiil they are not worth above $10 \mathrm{~s}$.

3747. How much capital do you calculate? - About $1,400 l$ on the farm.

$374 \$$. Is there any thing calculated for the value of the tenant's living and his family, against this - No.

3749. Is the produce consumed at home taken into the calculation:-No; they consune part of their own produce, and they buy other articles: 1 have put down nothing for that. I did put down $100 l$., and I struck it out, saying, "He has at any rate his family to maintain; I will not put that into the expenses of the farm."

$375^{\circ}$. Is not the calculation you have given of bone dust very small :- Bone dust is of very late introduction; generally the manure of the farm will manure two-thirds of the fallow land; then they always had one-third without any crop. Since the introduction of bone dust, they now grow crops on the whole of the soil. The overplus is $474 l$., the rent is $450 l$.; so that there is just $24 l$. for the tenant.

3751. You do not include the tenant in the previous expenses? -No.

3752. He has $24 l$. for himself :-Yes.

3753. This is land which you consider of the best quality; the turnip land?$Y$ es ; it will grow any thing every year.

3754 . What quantity of turnips per acre would you ronsider an average produce :- Those lands will grow from 20 to 24 tons an acre.

3755. Do you speak of the common turnip?-Yes; I had a calculation made very particularly.

3756 . What is the state of the poor in that part of the country:-We have very few poor; it may be inferred, from what I have stated, the poor are kept very well; there are no complaints, and we never have any difficulty with the servants.

3757. You have not a surplus population in that country $\overline{\text { - }}$-No ; we are much better off.

3758. Notwithstanding you are so well off; can you go on at this rate unless prices are raised ? - I am quite sure not.

3759. To what do you attribute this lowness of price? - To various causes; but I think the leading cause is the contraction of the circulation.

$3 ; 60$. Did you ubserve that the prices fell at that particular time?-Yes; they always fell when the Bank of England were preparing for their cash payments; they have always risen when the Bank of England issued its notes again.

$3 ; 61$. You have found that to be the case in your own experience?--Yes; I can give an instance of a very great decrease of paper circulation with which I am concerned.

3762 . As a banker you attend to this, of course?-Yes. In the year 1814 there were two banks and a branch of Sir William Loraine's bank existing in Berwick. I know the circulation of my own, and from the other bank I have a statement, but I know nothing of the circulation of Sir William Loraine's branch. I have put mine as 8; I put the other as the figure 7; I put the third as the figure 1; those together make 16. My circulation at this time is just 5, and that is the whole circulation of the Berwick Bank. Mine is a much more extended business now than all those three businesses.

3763 . What is that which you put down as $7:--T$ That is the circulation of the other bank which then existed in Berwick; there is now none but my onn, nor has there been for a great many years.

3764 . Instead of 16 there is now only as 5 ? - Yes, just so.

3765 . Have your prices fallen since the circulation has been diminished in the manner you refer to $\%$-There is no doubt of it.

3766 . Of course it would be for your interest, provided you were insured against any inconvenient calls upon you, to increase your circulation? - T'he truth is, we used to be very fond of increasing our circulation, but I do not care about it now ; if a person comes and asks for accommodation, I give it him.

3767 . Is it not the apprehension of being called on suddenly to repay the notes, which makes persons unvilling to increase their circulation?--It makes then careful ; every one says, "I have no wish to put out more pound notes."

$+64$.

E E 2

3,68 . Irould 
John Langhorne, Esq.

11 March 1836 .

3768 . Would they like to put out more one-pound notes ?-We are not fond of increasing our business.

3 ;ig. If the golden days could return again, you would be as glad to put out

your currency now as you were then :- We always followed in the train of the Bank of England.

$37 ; 0$. You have observed that the expansion and contraction of currency has very much affected the prices of agricultural produce?-Yes.

377 . Is it your opinion, that if an expansion took place through a double currency of gold and silver, that would tend to improve the agricultural interest? -Decidedly so.

3772 . Were you a banker at the time of Mr. Mowbray's failure?-Yes, I was a partner with Mr. Mowbray.

3773. It was only a branch bank established in Berwick?-It was a bank separate from the otliers ; I took pretty good care not to involve myself with them, and kept myself out of the scrape.

3774 . One cause of their great failure was their extensive issue of paper, was it not? - No; it was the lending a large sum of money to some speculators in lead mines; I believe they lent to the extent of $240,000 l$. to one house, and that was their ruin.

3775. You say you conceive a great relief would be afforded if silver was made a joint standard with gold; in what way do you conceive a great relief would be afforded?-They might make the standard $5 s .6 d$. instead of $5 s .2 d$. ; that would be an advantage at once, and also it would stop all panics.

$37-6$. How would it do that?-People would not take the silver ; they would not betroubled with it; they would rather run the risk of the bank notes.

3777. Supposing they were to require it, would there be any increased facility of paying in silver except the inconvenience of its great bulk?-Yes; much greater inconvenience. I remember during the three days in Paris, the bankers saved themselves altogether by payments in silver.

377 S. Is there any actual power possessed by bankers in gaining a supply of silver abroad they do not possess in respect of gold? -I do not know the quantity of either; but certainly, as respects gold, it is the circulation of the world. We can retain no more in our kingdom than that; all the other states must share with us; each must have an equal share.

3779. Supposing a person drew a bill for 100 livres on Paris, he would not be entitled to have it paid in gold? - They can pay it either in silver or gold.

37 So. Will they pay it in gold unless they are paid an agio upon it?-No.

3781 . Supposing the standard was a joint standard, and if gold and silver, would not the probability be that there would be a much larger quantity of silver in this country than there is now?--Certainly; three or four times as much.

$37 S_{2}$. Would not that have a tendency to increase the general circulation of the country?-No doubt it would.

$37 \delta_{3}$. Has there been any departure from the Bill of 1819 for the Resumption of Cash Payments?-In the year 1819 they preparcd for cash payments, then they got into a state of very great distress, and in the year 1823 they let loose the bank notes again, and they did it in the most foolish and improper manner possible, for they forced the Bank of England to lend on mortgaye, and do every thing that was improvident.

$37 \$_{4}$. Did it force up the currency ?-Yes.

3785 . Then came the panic in the close of 1825 ? -Yes.

3786 . Then came down the prices again? -Yes, and half the manufacturers in the kingdom were ruined.

$378 \%$. Was any practice had recourse to after 1825 , to raise it again ?-No.

3788 . Do you remember any one-pound notes being issued after that?-During the panic they issued one-pound notes, and saved themselves by them. I had some myself, for on sending for gold, I ordered a box of gold, and, to my great surprise, came a parcel of one-pound notes, which were of no use to me.

$37 S_{9}$. Was any thing done afterwards to raise the currency?-No, not that I recollect; in 1826 they passed a Bill to annihilate the one-pound notes in three years, and they ceased in 1829 .

3790. They continued out till 1829?-Yes.

3791. They were rapidly disappearing during that time?-Yes ? I had a very large payment to make, that requircd, I think, as much as $20,000 \%$ in one-pound 
notes, all among labources, in the very last month before they expired. I put out the whole $20,000 l$. in notes, to save me the expense of getting gold from London.

3792. In the year 1829, when the small notes were called in, were there not bad seasons, that kept up prices for some time?-There were some bad seasons in 1829,1830 , and 1831 .

3793. After they were over, did not the price immediately fall ?-It did.

3794. It continued down for some time?-It did.

3795. Taking 10 or 15 years previous to 1819 , what was the condition of the farmers?--The condition of the farmers in the years 1812, 1813 and 1814 was good.

3796. Some time previous to that, take 10 or 15 years?-In 1815 they began to prepare for cash payments, and prices began to go down in 1816 ; I remember perfectly it was a very bad year, from a wet season and the contraction of the currency; and the wet season placed the farmers in a most dreadful situation.

3797 . In 1817 ? - In 1817, such was the dreadful state of things, that they again put out the currency.

3798. Was it remedied in 1817 ; was it relieved for a time :-Yes; then in 1819 they again commenced the operation of contracting the currency.

3799. Did that lower the prices?-Yes.

3800 . The year 1822 was the worst year of all?-Yes.

3 Sol. The condition of the farmer kept pace, in your opinion, with the contraction and expansion of the currency?-Yes.

3802 . Then previous to 1819 , several years previous to 1819 , with the exception of the years you have mentioned, the condition of the farmer was generally pros. perous? -No; there was great distress in 1816.

3803 . Generally speaking, you did not hear of great agricultural distress in 1819 ? - Not in 1819 .

3804 . Since 1819, with the exception of the years 1824 and 1825 , the years of prosperity, what has been the condition of the farmer since that?-Every year it has been getting worse and worse.

3 So5. There have been a great variety of seasons during that period, some years very productive, others the contrary ; let me ask you, the years 1828, 1829, 1830, I believe, were wet seasons? - Not good years at all.

3806 . Prices, in consequence of the small quantity of produce, increased?Clearly.

$3^{S 07}$. What was the condition of the farmers in those years?-These years were very bad.

3 So8. Then since that year, the years 1833 and 1834 were productive years? Very productive, exceedingly so, that is $\mathbf{1 8 3 4}$; barley and oats were very short.

3809 . Gencrally speaking, they were good seasons; what was the condition of the farmer - Every year worse.

381 . Whether the season was productive or otherwise, the condition of the farmer was equally bad? - Gradually getting worse.

3811 . Therefore you consider there was some cause which occasioned these extraordinary circumstances, that neither a good nor a bad year brought any relief to the farmer?-Yes, and I anticipate myself that the thing will be worse yet.

3812. Do you attribute it to any other causes except the currency ?-I do.

3813. To what; to importations from Ireland ?-I do not think that alters the question at all as to the currency.

3814 . If I understand you right, your opinion is, that, without any importation from Ireland, with a defective currency, we should have low prices? - Yes.

3815 . But will not the great importations from Ireland contribute to increase the depression occasioned by low prices?-Yes.

3816 . If you had ever so good a currency, suppose more was imported from Ireland than England can fairly take, would not that occasion low prices?-Yes, clearly.

3817 . Are there any other causes you attribute it to?-I do not attribute any thing to the corn laws; I think they are a dead letter just now.

$3^{81}$ S. Why do you think they are a dead letter?-Because they cannot operate at all.
464 .
E E 3
3819. What 
John Langhorne, Esq.

11 March $18_{3} 6$.

3819 . What do you think of the warehousing system? - I do not understand it.

3 S2o. With respect to the Bank of England branch banks, do you consider thes have any effect or otherwise? - I consider them injurious to the landed interest, and 1 will give my reason; wherever they are established, the branch banks contract the circulation of the other banks very much; whatever notes they get in, they take them in for cash, when, of course, the other banks withdraw their accommodation.

3821 . The consequence is, they are bcund to keep a certain sum of money to meet those average demands on them, and deprive them of the means of lending money on accommodation to farmers? - Yes; I had better explain how the bankers went on before this took place; they took each other's notes, and exchanged once or twice a week, and paid the balance over to the banker in London.

${ }_{3} S_{22}$. The same as they do here at the clearing houses?-Yes; since the Bank of England have set up branch banks they do not let them do that; they make them pay all the notes in cash and gold on the spot; consequently a banker may have to keep $50,000 l$. by him.

$3^{8} 23$. Do you know any bank which, in point of fact, has been obliged at times to pay large sums?-I know one bank that has, and this I know, that the Bank of England are trying to get all the taxes into their own hands.

$3 \$_{24}$. These Bank of England branch banks only pay the notes specially payable there?-Yes.

$3^{S 25}$. In point of fact, they have a great advantage from having to do with the Bank of England, and being able to give their notes for their own when required? - The Bank of England does not put out any notes of the bankers doing business with them.

$3^{S} \approx 6$. 'They have a great advantage over the country banks, by being able to put out some of the London notes? - It is no advantage to them, because they had that before.

3827 . Do they not do that in such a way as to give them an advantage orer the country notes:-Yes, they do.

$3 S_{2} 3$. And therefore the country bank notes and the branch Bank of England notes are not on a fair equality? - No.

3829 . You say that the Bank of England send their notes to you, and get cash for them?-Yes; or otherwise we pay into the bank beforehand.

3830 . Are not the country bankers now authorized to pay them in Bank of England notes?-Yes; but we never run on each other for gold; we paid in London.

3831 . When you spoke just now about gold, you meant gold or Bank of England paper?-Yes.

3832 . Will the branch banks give any accommodation to the landed interest? -They will not; it is impossible for the farmers to deal with them at all.

$3^{8} 33$. They will not lend money to a farmer, or to the occupier or proprietor of land, on any security that they have the means to offer?-No; they conduct their business on the system of London, where there are bills to discount; we have very few London bills; where I discount 10,000 l. of London bills, I dare say I discount $30,000 \mathrm{l}$. of local bills, which they would not look at.

3834 . Would there be any objection on the part of the country bankers to give security with respect to the amount of their issues from time to time?-I should think there would, because you would secure one class of creditors to rob the others.

3835. Supposing greater facilities were to be given to country bankers for issuing their notes on that condition, do you think they would be inclined to subscribe to that condition? - Certainly not; I would not.

${ }_{3}{ }_{3} 6$. You were stating what you thought the cause of the reduction of bank notes; you stated, as there was an issue to the extent which you expressed by the figure 16 , that now that may be expressed by the figure 5 ; do you think that is at all the fair average in the present reduction of the amount of circulation? - I should think it would be tolerably fair.

3837. Including the Bank of Fingland, country banks and branch banks?That is precisely the fact; I should say that their amount is reduced a third, or at least, I believe, there is not a bank in the kingdom that has not reduced onehalf of its notes. 
38,3 . Then, as you take your local circulation as described by figure 16 , the reciuction being in the proportion that 5 bears to 16 , can you nake any conjecture as to what is the whole amount of circulation, and what is the reduction in that whole amount? - In that period the l3ank of England would have out about $28,000,000$ or $29,000,000$ in round numbers; then I think the country circulation would be as much. Now, the country circulation is $10,000,000$, and the bank circulation is $18,000,000$; so that there wonld then be $60,000,000$ of circulation, and now there is $38,000,000$ of notes in circulation.

3839 . Does the circulation of the Bank of England include notes only, or coin also ?-It includes nothing but the notes.

3840 . Can you state what was the amount of circulation of the prccious metals at one time and the other? - That is a question which I believe no person can answer; it is matter of guess ; some persons would guess $50,000,000$; others $15,000,000$; ny own opinion is, that the circulation of grold is very much overrated.

$3 \& 41$. Do you believe it is $30,000,000$ ? - No, far below that: I received from a variety of persons $12,000 l$, and in that $12,000 l$. I rcceived only $98 l$. in sovereigns.

3842. Within what period ?-Last October.

$3 \$ 43$. You received that in one day? - Yes.

$3 S_{44}$. As a banker or a receiver of rents ? $-A$ s a receiver of rents.

384.5 . Was there a great deal of arrear upon that rent? - Far too much.

3846 . Have you taken notice that at any period of agricultural distress a good deal of old coin lias been brought out of the coffers of the farmers?-I have not seen such a thing in my own experience.

3947 . Have you any thing to suggest that you think would be of use to assist in the relief of agricultural distress ?-- I lave nothing to suggest, except that I mentioned before, the making of a silver standard. I think the Bank of England might be allowed to issue one-pound notes ; and that, instead of issuing my own one-pound notes, which I should not wish to do, 1 should go to the Bank of England and take my choice, whether sovereigns or bank notes; I should take one-pound notes, which would assist the country circulation.

3848 . You think that the country bankers would not wish to issue one-pound notes again, in consequence of their fear of a change?-Yes, lest the country people should run upon them in case of alarm.

3849. You mentioned, that from there not being a large population in your part of the kingdom, the labourers are all employed?--Yes.

3850 . What are the wages which are generally given in your neighbourhood? -I can state that from some papers I have with me; Lord Tankerville has always paid $10 s$. a week for labour; the farmers pay in winter $9 s$, in summer $12 s$. a week, so that they come to the same thing; in fact, then, all the farmers' servants, such as the hinds and the ploughmen, and so on, are not paid in money, but in kind.

3851 . In those large farms in Northumberland, are there not cottages attached to the farms? - Yes, there are; and I have in my hand the very conditions on which Lord Tankerville hires his labourers.

\section{[The Witness then read the paper.]}

"I agree to serve the Eurl of Tankerville as a servant in husbandry or a common labourer, at Chillingham, from the $13^{\text {th }}$ of May 1835 to the $13^{\text {th }}$ of May 1836 , upon the following conditions: to have six bolls of oats (a boll is six bushels), three bushels of wheat, half a stone of cast wool, four bolls of barley, one bushel of rye, one boll four bushels of peas, five bolls of potatoes, one cow kept, $4 l$. in money, six stones in pork, in lieu of keeping a pig, or hens or other poultry; and I further agree that my cow shall stand in the common cowhouse, and that 1 will find a sufficient woman to work, when called on, for 1 s. a day, for 40 days in harvest, and $8 d$. for every day's work the remainder of the year.

" IVitness my hand, this $2 \mathrm{~d}$ of March 1835 .
"Witness, John Jackson.
(signed)
"John Paes." -No.

3852. In point of fact, has there been any discontent among the labourers?

3853. Was the manner in which that was calculated, as the payment of the labourers' wages, intended to be equivalent to about $10 \mathrm{~s}$. a week?-Yes; it is rather under $10 \mathrm{~s}$. a week, considering some additional advantages of potatoes, the 10 s. labourers have. 
Juhit Langhorne, Esq.

11 March 1836 .

Mr. Abel Sharpe.
$3^{8} .54$. Does this mode of payment tend to give an interest to the labourer in the produce of the farm? - It does.

\section{[The Witness is direeted to withdraw.}

Mr. Abel Sharpe is called in ; and Examined, as follows :

$3 \$ .5$. WIIERE do you live?-I live at Maidencroft, near Hitchin, in Hertfordshire.

$3 \$ 5 t^{\circ}$. Are you steward to any gentleman?--I am steward to Mr. Delme Ratcliffe.

$385 \%$. He has large property in that part of the country, has he not?-Yes; a considerable property.

3858 . Do you farm any land yourself? - Yes; I farm about 300 acres.

$3 \$ 59$. How long have you been a farmer and steward to Mr. Delme Ratcliffe?

--I have been steward to Mr. Delme Ratcliffe and his father nearly 20 years.

3860 . Is the condition of the farmers in your county improved much?-Very minch the reverse.

3861 . What is their state now?-Their state is a state of great distress.

$3^{562}$. Do you apply that observation generally to all farmers, or to farmers on a particular kind of land?--To all, in a measure; certainly more to some than others.

3563. What is the "class" you apply that particularly to ?-Those that are occupiers of inferior land are inore oppressed than those who occupy land of a better quality.

3\$64. Do you get your rents satisfactorily?-I do not receive rents for Mr. Ratcliffe.

386.5 . Have you any means of knowing how rents have been paid ?-No.

3866 . Have any farms been given up of late? - Some have given up their farms.

$3^{867}$. Have those who have given up their farms been prudent men ? - Yes.

3868 . Men who would have been likely to thrive, if the times had been prosperous? - Yes; I do not mean to say that a great many farmers in ny neighbourhood have given up their farms.

3869 . Are some of those who have gone on in a bad condition?-Yes.

3870 . Do they pay their rents out of profits or out of capital ?-I have no doubt that they pay their rents out of capital.

3871 : You state that things cannot go on thus? - Certainly not.

$38 ; 2$. What is the state of the poor?-Those regularly employed I conceive to be in as good a condition as ever they were.

3873 . What is the rate of wages paid? - The rate of wages by the day is about $8 s$. or $9 s$. a week.

3874 . Can the farmer, at the present prices, continue to pay them those wages?-Certainly not.

3875 . It is the lowness of the price that occasioned the distress?-Yes.

3876 . Have you any observation to make on the present corn laws?-Yes; 1 should wish to make an observation upon them; my opinion is, that the very great inducement given to speculations in foreign corn, and the immense importations which have taken place, have been the occasion of the great depression in the present prices.

3877 . What are the inducements given to speculations in foreign corn?-I conceive the inducement is much greater to a speculation in foreign corn than in home-grown corn.

3878. Why?-I will state a case which I think will show that; I will suppose that the average price of wheat were to be at $56 \mathrm{~s}$. a quarter in a season of fair supply, a season supposed to be an average; if a person had a wish to enter into speculation to purchase at that price, he would be greatly inferior in the advantage he would have to a person engaging in foreign speculation, because foreign wheat can be imported and laid into bond in this country at about $28 \mathrm{~s}$. or $30 \mathrm{~s}$. the quarter, instead of $56 \mathrm{~s}$., which would be little more than half the price; then supposing a deficient or a bad harvest ensued, and the price were to reach an amount which would bring the duty down to its minimum, which I believe is $1 s$. a quarter, the foreign speculator then would obtain a gain of about $42 \mathrm{~s}$. a quarter, whereas the speculator in home-grown corn would get a 
gain of only about $17 \mathrm{~s}$; the one would get a gain of 130 per cent. upon the capital employed, and the other only a gain of about 30 per cent.

3879 . Are you of opinion that, to prevent this speculation in foreign corn, and to divert speculation towards English corn, it would be desirable to get rid of the bonding system? - I think it would, in a measure; I have no wish entirely to prohibit the importation of foreign corn, but $\mathbf{I}$ think it requires a check to it.

3880 . Should it pay the duty when it comes in?-Yes, in part at least; I have thought the best thing would be to raise the minimum from $1 s$. to $8 s$, and that that proportion shall be paid on its first coming into this country; and that, when released from bond, it should pay what remaining portion of the duty might be required, according to the scale of the present Corn Laws; that it should never get down below $8 s$; ; and 1 think not only the grower but the consumer would be benefited by that, for this reason: now in a season of scarcity, when prices are high, and there is reason to expect it will come to nearly the price, to bring down the duty to its lowest point, the foreign speculators have the markets so completely in their hands they will withhold their supplies, and by every means force up the markets to get the duty at its lowest point; they have a double inducement; they will get an advance in price, and a benefit by the decrease of duty.

3881 . How do you mean that they have the markets in their hands?-By having a large quantity in bond, and thereby a very large capital is locked up, which would otherwise be employed in the purchase of home-grown corn in a plentiful season; it would be far preferable that, in plentiful seasons, the surplus produce should be purchased and stored in our warehouses, as a supply for a deficiency in a scarce one, than that the warehouses should be kept constantly supplied with foreign corn.

$3 S_{2}$. Would not that have the effect of distributing over seasons of scarcity the abundance of years of plenty?-Yes.

$388_{3}$. Should we then be under the necessity of sending to foreign countries for corn? - I think we need scarcely ever do it.

$3 S_{4}$. Is it your opinion that the surplus of abundant seasons hoarded in this manner would supply our necessities in other years? - Yes; and I think that would be a means of keeping prices more on an equality, without those extreme fluctuations to which they are now subject.

388.5 . Have you attended a good deal to this subject ? - I have.

3886 . Have you seen the effect of that which you have referred to in practice? -I have, so far as this, that I believe there is not a cloubt that, in seasons of scarcity, the foreign importers and speculators have used every means they possibly could to get the duty down to the lowest point by forcing up the market, which, I think, occurred in the year 1830 or 1831 , when there were nearly $1,000,000$ ef quarters of foreign corn released at the nominal duty of $1 s$.

3887 . Then they could bring that into consumption when they pleased, on the payment of a nominal duty?-Yes.

3888 . Is there any price you would consider sufficiently high not to justify the imposition of any duty on importing corn from abroad?-It is far from my wish ever to see prices rise to an extravagant height; my opinion is this, that in a fair average season the price of wheat ought not to be more than perhaps $56 \mathrm{~s}$. a quarter, or from $56 s$. to $60 s$. a quarter.

3889 . Less than that, you think, would not be a remunerating price to the grower? - I think not less than $56 \mathrm{~s}$.; but in abundant seasons, of course, it would come lower, and then there would be an encouragement, according to the plan I have taken the liberty of proposing, for speculators in home-grown corn to purchase, in order to make provision for a scarce season; that natural and wholesome speculation, which, I think, ought to be encouraged, would then be resorted to, whereas the present system is neither more nor less than a system of gambiing.

38go. Do you not consider that there is some price of coril so high as to make it fit that any foreign corn imported, when the market price was at such a height, should be imported without duty? - I think the present Corn Law is a sufficient protection against that.

3891 . You say you wish that $8 s$. duty should be always required on importation? - Is there not a certain price in our own market, which would make it improper to require any duty from foreigners on their corn? - I think not.

3892 . Suppose it were to rise to $80 s$. or $120 s$. ? - If that were the case, an 464 . 
Mr. Abel Skarpe. importer of foreign corn, under those circumstances, could very well afford to pay Es. duty upon it.

3893 . Do you think the English consumer would like to pay $8 s$. addition charged on the foreign impost? - I think if he did not pay it in the shape of duty, he would have to pay it in the shape of price; it would only raise the foreign market so much the more; and in a season such as that spoken of, if the $8 s$. duty were to be taken off immediately, the foreign markets would rise proportionably, and the consumer would not get his bread the cheaper.

${ }_{3} 894$. It is the foreign importer that pays the duty, not the consumer, is it not? - The consumer would not have to pay the duty, I imagine.

3895 . Out of whose pocket would that come; out of the consumer's pocket, or the pocket of the foreign grower?-Out of the pocket of the foreign grower.

3896 . Do you believe the people of England would ever be persuaded that if corn was very high, and there was a duty of $8 s$. on the importation, the fact of that duty of $8 s$. would not increase the price to them?-Some might think so; but I believe it would not have that effect.

$3 S_{9}$. Do you think any thing could persuade the people that they did not pay that $8 s$. duty?-I think the generality of the thinking part of the people are quite aware that the duty being taken off only increases the price in the foreign market, and that they have to pay just as much as if the duty remained.

$38 \mathrm{gs}$. There must be some check while there is sufficient corn supplied from England, for the English corn would keep it down? - Of course.

3899. You say that $56 \mathrm{~s}$. per quarter for wheat you conceive to be a fair remunerating price?--In an average season.

3900 . What do you suppose is an average price for barley?--I slould think a remunerating price for barley would be about $32 s$. or $34 s$. a quarter, on an average season.

3901. For oats?-Oats I can scarcely perhaps form an opinion on, because we grow so few oats; we are more oat-purchasers than growers in Hertfordshire; I should think perhaps $22 s$. or $23 s$. a quarter for oats.

3902. Have you attended at all to the malt-tax?-Yes; I think it would be a very great relief to the agriculturist to take that off.

3903. Is there any other article in the country so highly taxed as malt ?-I think not.

3904. Do you think that the consumption would be greatly increased, to the benefit of the owners of all lands?-There is not a doubt of that.

3905. Would it have the effect of enabling the poor to brew in their own houses, instead of going to beer-shops?-Yes.

3906. Are beer-shops numerous in your neighbourhood?-Yes, too numerous.

$390 \%$. Are they attended with the effect of demoralizing the people? - They are.

3908 . Would that be prevented by their drinking their beer at home?-I think it would.

3909. Therefore it is desirable, you think, to repeal the whole duty on malt? -I think it is, because then the farmers would brew a great deal more beer, and supply their labourers with it; they would probably then make some of their inferior barley into malt, which they are now prevented doing; and not only that, but we should have the opportunity of feeding our cattle with inferior barley malted.

3910 . Is the barley, when malted, much more nourishing to the cattle?-I should imagine it is; I never tried it, therefore I cannot speak from experience; but I have understood that to be the case from persons competent to judge.

3911. Have you turned your attention to whether it is likely that there are fraudulent importations of foreign corn?-I only know from what I have seen reported in the newspapers; but it is the general opinion that that has been the case.

3912. Do you conceive that the importations from Ireland tend to produce the depression?-They have been very great, no doubt.

3913. Of what sort?-Of every thing; of corn, of pigs, and grain of every description.

3914. Considering what the state of the crops in England has been for the last two or three years, do you conceive the addition of the Irish importation has depressed the price?-Certainly; with this consideration, of there being also a large quantity of bonded corn in the country, which certainly langs as a dead weight upon our markets. 
391.5. You consider that, together, they occasion this depression?-I do; and I think that would be removed if a check were given to foreign importations, and a greater inducement for speculations in home-grown corn in plentiful seasons.

3016 . If you could find the means to supply the lower orders with becr at home, would that have a beneficial effect here?-Certainly, that would increase their comfort. With reference to the malt-tax, the objection has been urged against its repeal, that it would very materially contract the transactions of maltsters, for this reason, that a great part of the capital which carries on the trade is the duty they receive from consumers before they pay it to the Gorerment, on account of Government giving six months' credit, which is a very erroneous idea. The rluty is always, I believe, charged from the cistern on the first commencement of the operation. Considerable time is taken up in carrying on the operation before it can be ready for the market, and before a sufficient quantity can be had ready to take to market in the wholesale way; then, when it is sold, the regular way in the trade is, that it is sold on three months' credit; therefore the six months will have expired generally ; and I believe more firequently a longer period expires before they receive any money from sales; therefore they are not trading on the capital of duty. Then, with regard to the retail trade, that is carried on under a credit of 12 months, and every person entering into the malt trade is obliged to have two substantial bondsmen to be bound with him, which is a hinderance, in some instances, to persons entering into the trade.

3917. That prevents competition in the malting trade? - I think it has that effect.

3918 . Has the consumption of barley increased in this country as the population has increased?-Most certainly not equal to the increase of population.

3919. Have you formed any calculation upon that ?-No.

3920. Are you aware that several of the counties of England grow a very small quantity of barley? - Yes.

3921 . Therefore, if there were a repeal of the malt-tax, it could not have any material effect in relieving those farmers?-I apprehend they are capable of growing barley.

3922. Does not that depend on the soil ?- Some soils are much more suitable to barley than others, but I apprehend there are very few not suitable; but there would he a greater breadth of barley grown in those soils fit for barley, and less of wheat, and that would assist the wheat part of the kingdom.

3923. Do you conceive that would be the case to any considerable extent? I think it would.

$39: 4$. Is there a kind of barley called the chevalier barley?--Yes.

392.5. Will not that grow in almost any soil?-That I cannot say. It has been much in use in our county, but I am rather inclined to think it is less used than it has been. It does not yield so much per acre as some others, and is more liable to injury in a wet season.

3926. Has any quantity of wheat been used for feeding cattle in your county? -A very considerable quantity. I have myself, this year, consumed more than 30 quarters of wheat in feeding sheep and pigs and bullocks; wheat of rather an inferior quality, which I had taken to market and could not sell. The millers have said, "No, I cannot buy that ; it is not good enough." They have bought only the best qualities; and there have been sacks, brought out week after week and pitched in the market without even a bidding for them, taken back again and given to the pigs.

3927. Is it your opinion that the consumption of wheat in feeding cattle has tended to raise the price in the markets? - No doubt of it.

$392 \mathrm{~S}$. Would there have been that glut if corn had been purchased, as you propose, if the attention of the capitalists were drawn to the speculation in English corn? -I think there would not; I think there would have been a demand for every species of corn.

3929. Aecording to your judgment and observation, have the farms got into a much worse state than they were in ?-Yes, I think, where there has been a want of capital; those farmers who have capital and private property have kept up their farms. There are instances where the land is deteriorated very much for want of the means of cultivating it.

$393^{\circ}$. Are you acquainted with the state of the farms through a large district? -Yes, a very extensive district.

[The Witness directed to withdraw.

464. 


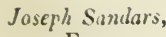
Esq.

11 March 1836 .

Joscph Sandars, Esq., is called in ; and Examined as follors :

3931. YOU were examined by the Committee of the House of Commons on Agriculture in 1833 :- $-\mathrm{I}$ was.

3932. Yon are a corn-merchant at Liverpool ?-I am.

3933. Has there been an increase in the importation of lrish wheat of late years?--There has been no increase, I think, during the last two years; but that does not prove that the cultivation of wheat in Ireland is not extending.

39.34. When did the increase of imports begin to fail? - I think after 1833 ; there has been very little falling off, but there has been nothing like that increase there had been in other years; it is now about stationary, and has been for the last three vears. The quantity is given by Mr. Jacob in his last return.

3935. When was the last large import from Ireland ?-I an not quite sure, but I know it reached 540,000 quarters a few years ago, which was larger than it is now.

$393^{6}$. You are well acquainted with Ireland?-I am.

3937 . Has the quantity of wheat grown in Ireland increased lately?-I have no doubt it las.

3938. Has it greatly increased?-I should think not very greatly.

3939. During what time are you speaking of ? - I think it has gone on increasing for a great many years. I gave the particulars of increase in my answer to the Committee of the House of Commons in the year 1833. I was asked, "When did rou first observe the rapid advance in the amount of imports from Ireland?In 1808 the arerage import of wheat was about 50,000 quarters, including flour; in the vear ending the 5th of January 1833, it amounted to 572,286 quarters, including flour; the import of oats in 1808 and 1809 amounted to about 500,000 quarters per annum, and in the year ending the 5th of January 1833 it amounted to $1,890,321$ quarters, including oatmeal. The total of all kinds of grain imported in the years $1825,1826,1827$ and 1828 , averaged $1,840,422$ quarters ; that of $1829,1830,1831$ and 1832 , areraged $2,445,223$ quarters; showing an increase in the last four years of 30 per cent.; and the total import, ending the 5 th of January 1833, was 2,614,130 quarters, showing a further increase in the average of the last four years; and there is some reason to suppose the import of the present year will be greater still.

3940. That was in 1833 ? - Yes.

4941. Do you happen to know what it was in 1834 ? - I an afraid I have not got the return here.

3942. You have been somewhat acquainted with the state of crops in this country?-Yes.

3943 . With the crops of this country for the last tro or three years, are not the importations from lreland sufficient to depress the prices down to the extent to which they hare been depressed ?-I think the importations from Ireland for the last 10 or 15 years must hare had a very considerable effect in depressing the price of the English agricultural produce.

3944. Of course that effect must have been increased with the increase of importations? - No doubt.

3945. It must have been the greatest up to the time you have referred to? -Yes.

3946. You have said there is a greater quantity of wheat grown in Ireland than formerly ?-Yes.

3947 . Is there any other produce imported?--Yes; cattle and other produce.

394 S. Is the cattle equal in quantity to what it was formerly?-There is certainly an increase of cattle also; a considerable increase.

3949. Would that be still further increased by increased facilities for sending into different parts of this country by railroads and so on ?-There is no question of that.

3950. Can you state the particulars of the increase?-I have an account of the number of bullocks, cows, sheep and so on, imported into Liverpool from 1829 to 1835 .

[The same is delivered in and read, and is as follows:] 
Catti.t. imported into Liverpool.

IRELAND.

\begin{tabular}{|c|c|c|c|c|c|c|c|c|c|}
\hline Yea & ear. & Bullocl:s. & Cows. & Slierp. & Pigs. & Hurses. & Mules. & Calves. & Lambs. \\
\hline 1829 & - & 157 & 53,001 & 99,768 & $178,1-8$ & 526 & 134 & 43,671 & 29,877 \\
\hline 1830 & - & & 24,113 & 107,625 & 166,854 & 433 & 288 & 19,600 & 29,536 \\
\hline 1831 & - & & $90,-15$ & 1334,762 & 156,001 & 306 & 243 & 1,196 & 25,725 \\
\hline $183^{2}$ & - & & 68,728 & 73,622 & 145,917 & 669 & 33 & 1,755 & 12,854 \\
\hline 1833 & - & & 50,999 & 54,636 & $225+353$ & 1,428 & 5 & 2,237 & 19,439 \\
\hline 1834 & - & - & 62,009 & 54,349 & உ88,699 & 1,487 & 137 & 3,974 & 24,995 \\
\hline 1835 & - & -1 & 60,240 & 60,423 & 261,345 & 2,324 & 221 & 5,353 & 32,005 \\
\hline
\end{tabular}

Joseph Sandars, Esq.

11 March 1836.

\section{Constwise.}

\begin{tabular}{|c|c|c|c|c|c|c|c|c|c|}
\hline 1829 & - & 59 & 1,860 & 17,893 & 4,753 & 28 & & 2 & 879 \\
\hline 1830 & - & $-\quad-$ & 1,693 & 15,388 & 4,767 & 17 & - & 1 & 100 \\
\hline 1831 & - & - & 1,229 & 23,943 & 5,481 & $4^{6}$ & - & 18 & 730 \\
\hline 1832 & - & - & 1,204 & 20,951 & $5,8+9$ & 21 & - & 43 & 287 \\
\hline 1833 & - & - & 2,359 & $3^{2}, 384$ & 7,734 & 54 & - & 47 & 3,062 \\
\hline 1834 & - & - & 2,390 & 67,039 & 8,280 & 84 & - & 66 & 2,546 \\
\hline 1835 & - & - & 4,921 & 75,281 & 13,240 & 67 & - & 214 & 3:739 \\
\hline
\end{tabular}

3951. There was $4,000,000 \mathrm{l}$. value imported into Liverpool only in one year, was not there?-I should think twice that; I think the import from Ireland into the port of Liverpool will be found nearer $8,000,000 \mathrm{l}$. in one year. The imports were taken out, in the year 1833 , by a gentleman, with very great care, and the amount of the imports was very nearly $10,000,000 \mathrm{l}$. sterling, including all sorts of produce, linen and agricultural produce, and so on.

3952. About how much was the agricultural produce, of different kinds?I cannot say.

3953. Was there any thing like $2,000,000 l$. of linen?-No, 1 slould think not.

3954. The remainder, then, was agricultural produce?-Yes.

3955. What are the expenses of cultivating a farm in Ireland, as compared with cultivating a farm in England? - Prodigiously less in Ireland than here.

3956. Are they half?--Labour is not more than half, certainly.

3957 . What is the amount of wages for labour there?-The price of labour varies from $4 d$. to $\mathrm{J} 0 d$. a day.

$395 \%$. Besides the price of labour, what other expenses have they?-They have no taxes.

39.59. They have no land-tax? - No, nor assessed taxes nor poor-rates.

3960 . They pay no church-rates now?-I believe not.

3961 . No tithes; or at least they do not pay them?-I believe so.

3962 . How are the highway-rates? - I am not sure how that is.

3963. Are rents as high in Ireland as in England, or the same?-I think they are quite as high.

3964 . What proportion of produce do you think the landlord in Ireland gets out of a farm?-I should think he gets a much larger proportion than an English landlord does.

3965. An Englishman has to pay poor-rates, church-rates and tithes?-Yes. I would not venture to assign the exact difference between the two, but the Irish landlord gets nearly the whole produce. The labour costs little. The labourers are the most miserable class that can be seen; they live upon potatoes and buttermilk.

3966. They do not live as English labourers do?-No.

3967. In what sort of cabins do they live? - In very miserable cabins. But when this fact is taken, that labour is $4 d$. to $10 d$. a day, that they do not get constant employment, that they can also get $14 \mathrm{lbs}$. of potatoes for $1 \frac{1}{2} d$. to $2 d$., and sometimes $3 d$., it is evident their living does not actually cost them more than $l d$. a day. They never eat animal food.

$396 \mathrm{~S}$. What is the price of wheat in an Irish market in ordinary times; what was it three or four years ago, when the price was from $50 \mathrm{~s}$. to $60 \mathrm{~s}$. here?I think from $38 s$. to $45 s$.

3960 . There would be that difference between the two?-Yes. 404. 
Juseph Sandars, Esq.

11 Mlarch 1836 .

3970. What is the expense of transport ; for what can it be brought over to England? - Wheat or corn may be moved as cheap from Ireland to England as from one part of England to another.

3971. Cannot you more it as cheap from Wexford to London as from Yorkshire?-No. The Lincolnshire produce will be moved to Yorkshire for about $1 s$. to $1 s$. $6 d$. a quarter, and you cannot move it from any part of Ireland for so little as that.

3972. At how much can it be moved?-At not less than $2 s$. a quarter

3973. There is still $10 s$. or $12 s$. difference in the price?-Yes, then the quality of the Irish is inferior.

3974 . How much is the quality of the Irish inferior? - The quality of the Irish wheat, the last two or three years, has been worse by $3 s$. or $4 s$. a quarter than it was for some years before; it had been improving before that, but they have had unfarourable seasons.

3975. Are they improving in cultivation?-I think they are; I know they import a greater quantity of culm, which of course is used for burning lime; when I was in Ireland, two years ago, I ascertained that beyond all doubt.

3976 . Have rents fallen in Ireland as they have in England ?-I do not believe they have.

3977. Have they fallen at all? - I know there are many landlords who have never made any reduction at all.

3978. What is the expense of the transport of corn from Ireland to Liverpool?-It varies from about $6 s$. or $8 s$. a ton to $20 s$. a ton from the east or west coast.

3979. What is the proportion of corn consumed at Liverpool which is English, compared with that which is Irish? - The great proportion of that consumed in Liverpool is Irish.

39 So. Liverpool is one of the cheapest places for the transport of corn from Ireland?--Yes.

3981 . They have a most capital market there for their produce?-Yes.

3982 . What is the condition of the farmers in Ireland?-It depends a good deal upon what part of Ireland the observation applies to; in the grazing counties the farmers have not suffered at all in the same degree they have in the corn-growing counties.

$39 \$_{3}$. Is there not, generally speaking, an improvement in the condition of the small growing farmer ?--I think there is; a few years ago it was very bad indeed; very little better than the serfs of Russia.

3984 . Have you observed the condition of the corn-growers in England? I have.

3985 . Has their condition bettered in the same proportion as that of the Irish? -I really do not think it has, of late years.

3986. Have you any doubt that the one is getting worse, and the other getting better?-I have observed, among the Irish farmers who occupy small portions of land, a very considerable increase of domestic animals, pigs, poultry, geese, hens and turkeys; round a most miserable cabin there will be found 50 or 60 heads of poultry; that would not be the case unless they were in rather bettered circumstances; I recollect the time when no such thing could be seen in Ireland as flocks of poultry.

3987. The condition of the Irish farmer is in that respect better?-Yes; I think the condition of the Irish people has improved generally in comforts in the last 20 years.

3988. You mean the agricultural population?--Yes.

3989. Is not the reverse the case with the agricultural population in England? -I do not think they have gone back in their external appearance; I have no doubt they are poorer.

3990. You have no means of knowing from your dealings with them that they are poorer?-No; I have nothing to do with the farmers, but it forms part of $\mathrm{my}$ business to inquire into their condition.

3991. Have there been any emigrations from Ireland -Very extensive ones.

3992. To what do you attribute that ? - A great number of Protestants have emigrated, I have no doubt whatever, from the apprehension of persecution, or a want of safety for their property and lives.

3993. Hare many Irish labourers come to this country?-Yes.

3994. Have you observed whether their condition is different now from what 
what it was formerly? -Yes, much improved; they are better clothed, and so on.

390.5. Is not the appearance of the English peasant worse than it was?-I do not think it is.

3996. With respeet to the Irish peasantry who come over for labour, is their appearance better when they come or when they go back again?- When they come.

3997. What is your opinion with respect to the quantity of corn that Ireland can supply England with :-That depends upon the question whether the present Corn Laws are supported, or whether we are to have any Corn Laws or not; which is a subject on which no one can be sure now-a-days.

3998. Supposing the present English Corn Laws to continue, and Ireland in a state of quiet :- There would then be a prodigious increase.

3999. Have you any doubt Ireland could feed all England?-Certainly she could not; but Ireland will produce enough to depress the value of lands and the price of corn in England.

4000. She will do that as long as she has not the same taxes and rates which England has, will she not?-Exactly so ; it is the most fertile land in the world, and there are tracts into which a spade has never yet been put; so that, with labour so cheap, it amounted to a certainty that she could grow grain lower than England could.

4001 . You consider the absence of local taxation a greater cause of cheapness of production in Ireland than the rate of wages?-No; the rate of wages forms a much more important ingredient in the cost of production.

4002. Would it not follow, that in proportion to the increase of prosperity in Ireland, either from the increase of its agriculture or other causes, the rate of the wages would gradually rise at last as high as the wages of this country, which would be in a less state of prosperity ? -No, I think not; that country is so exceedingly densely populated, and the inducements to marry are so much greater than in this country, that unless Ireland has poor laws, the population will go on increasing just as fast as ever it has done.

4003. Is it your opinion that the increase of population in Ireland has been more rapid than in England?-Much more rapid; your Lordships may not be aware of the fact; but travelling over Ireland, you will see persons extremely young, of the age of 16 , married; and on their being asked, "What could have induced you to marry so young?" the answer is directly-it comes from them all, "What must I do when I am old, if I have not children to maintain me ?" They marly for the purpose of bringing up a progeny which is to maintain them in their old age.

4004. Can you form any opinion whether Ireland can grow cheaper corn than France? - I have no doubt it can grow corn as cheap, or cheaper than France and Holland.

4005. Why do you think so ?-Because the rate of wages is lower in Ireland than it is in France and Holland; the condition of the Irish labourer is such as compels him to submit to a lower diet than either the French or the Dutch do, and then the soil of Ireland is so remarkably productive.

4006. For those reasons, you think that Ireland can compete advantageously with either France or Holland?-I am certain Ireland can grow corn as cheap as either France or Holland.

4007. Of course she can compete most advantageously with England?-No doubt.

4008. She must beat the English corn-grower out of the market?-Yes; and it must affect the rent of land, and must affect the price of labour, and the produce of the land.

4009. If that corn comes untaxed, as it does at present, to the English market, must it not, whatever is the price of growing corn in England, bring down the English corn to the same price?-If England supplies any thing like the quantity necessary for her own consumption, it is quite evident that it will weigh prodigiously in the market.

4010. Where there is a market overstocked, the man who can bring it to market cheapest will bring down the price much below the level which, according to the crop, it ought to be ?-Yes, unquestionably.

4011. Do you conceive the quantity of corn grown has been lately much on the increase in Ireland?-Yes; I think there has been an increase every year, but 464 . 
Joseph Sandars, Esq.

11 March 1836 .

that increase is not apparent in the exports. The fact is, the price of wheat has been so low in Ireland and in England during the two last years, a very considerable quantity of wheat has been consumed by distillers in Ireland, which, but for the low price, would hare come here and shown an increasing export.

4012. Is it your opinion that the late low prices of wheat will interfere with the remunerating price for the exportation of Irish wheat?-I apprehend the price the Irish farmer has been receiving with regard to wheat has not been remunerating lately, - not for the last two years.

4013. Would not that price have been a remunerating price to other foreign growers of wheat? - 1 think it would, for Ireland has not yet got to her condition of growing wheat as cheap as she can, because England takes off her supply at a higher price, and rents have not fallen.

4014. You think the cultiration of wheat in Ireland has not arrived at that perfection of which it is capable?-I think not.

4015. And not at the cheapness of production on which you think you might calculate? - Just so.

4016. Have you formed any opinion of the causes of our distress in 1833 ? There were a great many circuinstances which concurred to bring distress and ruin on the English farmer.

4017 . It was ruinous at that time, was not it? - It was very bad, certainly.

401 S. Must it not be much worse now, when corn is so much lower than it was then?-I am not quite sure, but I think that wheat is the only article that is lower.

4019. Have you any means of knowing whether the others are higher in consequence of the scarcity which has taken place in the crops of those articles:There was no scarcity last year in spring corn; they have borne high prices, but the wheat is much depressed, in consequence of there being so much grown, and having very productive crops.

4020. And the importations from Ireland?-Yes.

4021. Do you believe that observation applies to England generally, with respect to there not being a deficiency in the lent corn? - I am quite aware that in some parts of Scotland there was a deficiency in spring corn.

4022. Do you believe that, generally speaking, it was much below the average produce :-No; barley was above the average produce.

4023. You speak of the county in which you reside, probably?-No; I do not take the counties of Lancaster and Chester; their cultivation and routine of crops are peculiar; but it is my business to acquaint myself with the state of the crops generally.

4024. You think there was an abundant production of spring corn in 1835 ?Yes, with the exception of some parts of Scotland.

4025. You stated, in 1833 , that a reduction of the expense of producing corn was absolutely necessary to enable the farmers to go on!-Yes, I did.

4026. Is it not still more necessary now?---Since 1833, I believe, there have been reductions, and 'I have no doubt there will be still further reductions.

4027. Can the farmers go on at the present prices?-No, not if wheat was to continue so low as it has been; but that has been caused partly by the misdirection of industry. The rot which occurred in sheep in 1831 and 18.32 prevented the farmers replacing their stocks, their losses were so heary; the consequence was, they ploughed up their land, and grew wheat upon it. It is the loss of sheep in 1831 and 1832 that brought him to his present condition.

4028. He was obliged, in consequence of his distress, to grow more wheat:Yes, and that produced the catastrophe we have now met to consider.

4029. Is it not absolutely necessary there should be a great reduction of taxation to enable him to go on ?-I think that there is so great a reduction in the quantity of wheat sown this year, as is certain, let the crop of wheat be what it will next harvest, to give us an average of something like $50 \mathrm{~s}$. We have seen it reduced during the last few months as low as $36 \mathrm{~s}$.

4030. If it gets up to $50 \mathrm{~s}$., do not you think that Irish wheat will come in ?-

There is no doubt it will; there will be no wheat used then in distillation.

4031 . You think that it is kept out only by the lowness of the price?-Yes.

4032. You account for the difference in the importations this year and last year from that cause:-Yes.

4033. When you talk of $50 \mathrm{~s}$, , do you include the quantity which may be expected from Ireland?-Yes.

4034. You stated that there has been a less quantity of wheat imported from 
Ireland the last two ycars? - Yes, much about the same, but previously there had becn a gradual increase.

4035. You attribute that to their not having had two good harvests in Ireland for wheat?-'They were not so productive as they had been two or three years before, but still they produced a large quantity ; if it had been exported, instead of being used by the distillers, there would have been a continued increase.

4036. Do you suppose they will distil less in Ireland if the prices rise in England?-No; they would then take to distilling oats.

$403 \%$. That would have the effect, to a certain extent, of raising the price of oats?-Yes.

41.38 . If the prices are further reduced, will it not have the effect of throwing a considerable quantity of land out of cultivition?-Certainly ; if any thing like the prices of the last four or five months continue, I have no doubt large tracts of land must necessarily go out of cultivation, that. is, of wheat ; I do not mean to say they will be unproductive, but they must expend no labour upon them, and let them go to grass.

4039. What is to become of the labourers in that case?-They will get employment in the manufacturing districts ; it is a remarkable fact that must strike any one, that amidst all this agricultural distress there never was so much labour offered to the labouring classes.

4040. That is in consequence of the railroads, is it not?-I believe there are not less than 20,000 persons employed on the railroads between London and Liverpool.

4041. That, by keeping up the price of wages, is not beneficial to the farmer? -I have no doubt, if the manufacturers had been in a state of distress, and those railways had not been in the course of execution, the condition of the farmers' lajourers must have been wretchedly bad indeed.

404:. Have you attended to the price of warehousing corn? - Yes.

4043. What is the difference in the price of warehousing corn at Hamburgh, Rotterdam, and Liverpool ? - I should think very considerably less at the foreign ports generally than in England.

4044. It costs less to warehouse in a foreign port than in England?-Certainly, the value of property is so much less.

4045. Would men speculate in foreign corn as readily as if it were in England?

-Perhaps not quite so readily, but that would not prevent speculation. 4046. Would it not damp it? - I think not.

4047. Would it not at all indispose them to speculate in foreign corn?-I

think not.

4048. Why do men speculate in foreign corn rather than in English?-Because

it can be purchased at a much lower rate.

4049. And you get the duty? - We take the chance of the duty.

4050. There was a good deal got in at $4 s$, taking the chance, was there not?-

I think I found that the average duty on imports has been about $6 s .8 \mathrm{~d}$.

4051 . There is a great deal got in at $1 s . \hat{:}$-Yes; and a great deal at $12 s$,

$14 s$. , and $16 s$.

4052. That is a temptation to speculate in foreign rather than in English corn, is it not? - That depends upon the price of the English; hardly any one would speculate in foreign, if he could speculate in English wheat at $30 s$, or $40 s$. a quarter.

4053. You would speculate upon it if you could get it in for nothing, and keep it till the price rose so as to let it?-Yes; but that is a very uncertain issue to put it on; if he buys English at $32 s$. or $34 s$, he may get a considerable adyance upon it without its affecting the bonded wheat at all.

4054. Suppose wheat was $50 \mathrm{~s}$. a quarter, would he not rather be disposed to speculate in foreign corn? - - Yes, no doubt.

405\%. What is the lowest price at which you have known foreign corn imported at Liverpool? -I think $3 s .6 d$. per bushel of 70 pounds.

4056. Do you suppose it is practicable for any considerable quantity to be introduced at that price? - That would depend on the time they were required to have it in Liverpool; if the question refers to a year or two years, no doubt a very large quantity could be got at those low prices; but if it were required in five or six weekș, a very great increase of price must be paid; I have known wheat sell at $18 s$. to $20 s$. a quarter, for three or four years together, at the lower jorts of the Baltic, and the freights are but $4 s$. delivered at Liverpool.

464.

Jistph Sandars, lisq.

1. March 1836 . 
Joseph Sandars, Esq.

11 March 1836 ,

4057. Have you attended to the effect of the fluctuations of the currency on the price of corn? - I have not been an inattentive observer.

405S. What, in your opinion, is the eftect of the currency upon it; has it had any thing to do with reducing the prices to the rate that they have been at :1 should think it has had verr little.

40.59. You do not think the Bill of 1819 had any effect? - I think very little indeed.

4060. Were you in business at that time? - I was in business in the year 1800 . 4061. Did not you observe that corn fell in the year 1822? - Materially.

4062. To what do you attribute that fall? - To the very extraordinary crop in the year 1820, and to the very singular crop in the year $1821 ; 1821$ was a crop on the largest scale; I hardly ever knew a larger crop, but it was very much damaged in quality by rain; the quality was injured, and the value was lowered in the market.

$40 n_{3}$. It rose again in 1825 ? - It began to rise in the latter end of 1823 .

4064. To what do you attribute that? - It had fallen unprecedentedly low ; it had never been as low for 30 or 40 years as then; it rose from the spirit of speculation.

4065. Was not that spirit of speculation excited by the issue of money there was at that time? - I have no doubt that had some influence; I think it was in 1823 Lord Castlereagh extended the time for the suppression of one-pound notes; I think from that time it certainly had an influence; and I think, if I recollect rightly, the Bank of England came under some engagement to extend their issues, and that they lent money on mortgages, and brought out $3,000,000 l$. or $4,000,000$ l.

4066. Have yon any doubt that the issuing of those $3,000,000 \mathrm{l}$. or $4,000,000 \mathrm{l}$, and extending the time for calling in the notes, raised the price?-I have no doubt that it assisted speculation, and kept up the price.

4067. Are you to be understood that you consider the condition of the English farmer to be much depressed ?-I said I did not see any external signs of it.

4068. You are of opinion that the Bill of 1819 has had no effect in producing any depression of prices :-I have no doubt it has had an effect.

4069. To what extent; a considerable or an inconsiderable one?-I think much more than the political economists assigned to it.

$40 ; 0$. You have alluded to a variety of causes as depressing the condition of the farmer; are there any others you have in your mind? - - The first deficiency arose from what is generally called Peel's Bili; I have no doubt that had an effect in depressing the prices of commodities.

4071 . Do you consider that the full effect of that Bill has ret taken place?I should think it has had its effect over a very large proportion of the capital and property of the country, but there is still a portion which has not yet passed under the standard.

4072. And that probably they will be operated on still more forcibly? - I bave no doubt that the holders of land who bave entered into contracts 20 or 30 years ago, and whose estates are charged with hereditary charges, must suffer most grievously still; but the farmers have had to contend with difficulties such as perhaps would not be found orer any equal space of time. It is evident that the lowness of prices of 1822 was chiefly the effect of the very bad harvest of 1821 .

4073. You think those low prices were not connected with the reduction of the currencr?-Ther would be, to some extent, but prices are always the effect of supply and demand more than any measure of currency; then came the drought of 1826 ; I have heard it estimated that the loss to the agricultural interest was not less than $10,000,000 \mathrm{l}$. sterling by the destruction of the cattle and the short crops of corn; then there was the rot in the sheep of 1831 and 1832, which I suppose is something like $7,000,000 l$. or $8,000,000 l$. sterling; then the low prices of wheat now ; so that he has had nothing but adversity to contend with.

4074. As many as one-fourth of the sheep of the kingdom died by the pestilence, did they not?- Some state it at one-third, and some one-fourth.

4075. You have stated that the prices of agricultural produce depend a good deal on demand; do not you suppose that is regulated a good deal by the means of payment, the circulating medium of the country; if there were plenty of 
money there would be plenty of demand ; there cannot be a demand without the means of payment?... Certainly not.

4076 . You state that, to a certain extcnt, you believe the state of the currency lad the effect of lowering prices? - I have no doubt of that.

4077. Do you conceive the agricultural interest would now be materially benefited by an extension of the currency?-No, I do not.

$407 \dot{8}$. Will you state your reasons why you think it would not be materially benefited now by an extension of the currency?-It depends upon the extent of the relaxation of the currency.

4079. The question refers to any extension of the currency which would tend to raise the money price of all produce? - If the currency were extended, unless the standard were changed, it could not be permanent ; it would bring on a panic in the course of 9,12 or 18 montlss.

4080 . Suppose you adopted a silver standard, what should you say to it then, extending the standard to $5 s .6 d$. ? That would have an action of about 10 per cent.

4081. That would raise the prices 10 per cent., would it not?--Yes; it would enable some persons to discharge their engagements easily, but it would also fall remarkably heary on persons in different circumstances.

40\$2. In what circumstances?-It would enable all traders to pay their creditors with $18 s$. in the pound.

4083 . Did not most of the traders contract at much less than that? - Yes; but all those transactions have been settled, or most of them, many years ago.

4084. What do you apprehend would be the effect of that state of things upon the agricultural interest, the producers of com; do you think it would have a tendency to raise their profit?-I much doubt whether it would; it would place them all on an equality. One of the great difficulties under which a large class of tillers of land is, that they are tilling bad and unproductive land; in that case I am certain that the currency would not give them an advantage over a man who is tilling good land. The Irish farmers are gradually driving the bad land of this kingdom out of cultivation, and which has brought on a state of things your Lordships are now assembled to consider.

4085. In your opinion, if the effect of extending the currency and the standard were even to raise prices to the extent of 10 per cent., should you think a considerable portion of the worst land of this country must go ont of cultivation?-No; it must be cultivated, and that must be under an exclusive benefit.

4086. Would it go out of cultivaticn quite so fast if the Irish cultivator paid the same taxes?- - No, I think not.

4087. Has there been much Canadian corn imported? - Yes, about 100,000 to 130,000 quarters annually, during one or two years.

4088. Have you reason to believe that there was much corn imported that was not the growth of that colony in that mode?-I have no doubt of that.

4080 . Do you not think much more American corn is likely to come through

Canada? - That would depend on the price of wheat in Canada and America;

the price there is higher than it is here now.

4090 . The prices there are generally lower than they are in this country?-

Generally;

4091 . Is there not reason to suppose that henceforth there may be a consider-

able quantity imported through Canada?-No ; I do not feel any apprehension at all upon that subject, because the price of wheat is generally higher than it is in Europe; with the exception of England, considerably higher.

4092. Is it higher than in France? - It is quite as high, but much higher than

it is in Prussia and Germany.

4093. Have rou reason to believe that no foreign flour has come through

Ireland as Irish flour?-No; I consider that quite impossible.

4094. What is the cause of wheat being grown cheaper in France than in Eng-

land; are the wages much lower there?-I believe the wages are lower, perhaps rents not so high, but I do not know those facts.

4095. With respect to Poland, do you know what the rate of wages is?I think, through the greater part of Poland, there are no wages at all; they are serfs.

4006. They are fed? - Yes. I should like to read an extract I took a few days ago, with reference to the growth of corn in the north of Europe, and the state of 404. 
Joseph sandars, the people ; it is from Dr. Pinkerton's "Past and Present State of Russia," page Esq. 284: "We come now to speak of the condition of the slaves belonging to the nobility, who are estimated at $21,000,000$, male and femele, whereas those belonging to the crown are not above $14,000,000$. The Russian slave has no right, and can possess no property himself; his wife and children, and all that he possesses, are the property of his lord." The question is, whether the landlords of England are prepared to enter into competition with those who are living in this state. I hold that the importation of foreign corn is importing foreign labour; and are the labourers of England to be subjected to a competition such as this?

[The Witness is directed to withdrau.

John Beresford Turner, Esq., is called in ; and Examined, as follows :

J. B. Turncr, Esq.

4007. WHAT are you? - I am farming an estate of my own in Herefordshire. 4098 . What is the state of the farmers in that county?--Very indifferent indeed.

4099. Are they distressed? - Yes, they are, very much.

4100 . Do they pay their rents? - Many of them cannot.

4101. Though the farms are let on fair terms? - They are let at low rents.

4102 . Have the rents been reduced ? - Very considerably.

4103 . Still they cannot pay their rents?-That depends upon the mode of cultivation; those who are very industrious, and have capital, and lay it out judiciously, can pay a great deal more than those who have not.

4104. Have they been able to put any money into their pockets?-None at all, unless some individuals who have been very fortunate as breeders.

4105 . What is the case with those upon cold clay land?-Those on cold clay land must have greatly reduced their capital, so far as agriculture is concerned.

4106 . Is their capital wasting away? - Very much.

4107 . Has it been wasting in consequence of their own imprudence, or the low prices? - In consequence of the low prices; I have three farms now to let, more than I can at present dispose of, at very low rents.

4108 . Are you a letter of farms?-Yes, of my own; I have not this spring been able to get tenants.

4109 . Are they good farms?-Yes.

4110 . You cannot get tenants?-No, I have not at present, and I consider the low price of produce the only cause.

[The Witness is directed to withdraw.

Ordered, That this Committee be adjourned to Monday next, One o'clock.

Die Lunce, 14 Martii, 1836.

The Lord WYNFORD in the ChaIr.

Edward Stillingfeet Cayley, Esq. (a Member of the House of Commons) is further Examined, as follows :

E. S. Cayley, Esq. 4111. HAVE the goodness to state whether contracts and every thing of that kind have not now adjusted themselves to Mr. Peel's Bill of 1819? - It is very 14 March 1836 . true that the greater number of contracts may have adjusted themselves; or I would rather say, that those which have not adjusted themselves may now be exceeded in number by contracts formed since 1819; but all those formed since 1819 have not been entered upon with any such idea as that prices would fall to their present level. I should say, only those formed within the last two or three years have, by the majority of parties, been undertaken with such a conception; for the Bill of 1819 was interrupted in its progress, virtually postponed altogether for three or four years, and never came into full apparent operation till a very short time ago, as I have before observed. On the other hand, those engagements hanging upon the landed interest are of much longer duration than is generally imagined; and it is unquestionable, that a great number of mortgages, and contracts of that nature, made during the war, are still in existence, and still pressing very harl upon the landed interest. 
4112. Such as settlements on younger children?-Yes, and jointures, and things of that kind, which it bas been the habit of the landed proprietors at all times to make, in certain proportions to the value of their estates, and which would not now have pressed more unduly upon them than at former periods, had not those engagenents been virtually doubled by the change of the currency. But, in my opinion, the simple case of debtor and creditor is the least part of the mischief done by Mir. P'cel's Bill, although the loss to the debtor interest (public and private) in this point of view alone, cannot well be estimated at less than $500,000,000$ l. sterling; the naked question of debtor and crcditor will, with a great deal of injustice, adapt itself within a certain period of time; but the effects produced by Mr. Pcel's Bill, the worst cffects, in my opinion, are these: that during the war, under the mask of the paper currency and high prices, we contracted debts and engagements which we should never have dreamed of incurring, except under the conviction that those prices were to be permanent; and Parliament itself lent its sanction to that conviction. Whilst the prices remained, they sufficed to meet the expenditure, which had increased at the same time; which expenditure, under the ancient prices, would have absorbed all the proceeds of industry. When Mr. Peel's Bill came and contracted the currency, and with that contracted the prices, this very effect took place; the land is left with the major part of the incrcased expenditure upon it, and with prices which are in numberless instances alsorbed by the mere expenses of cultivation, leaving nothing for profit or rent. Rent and profit being generally estimated in money, men are apt to forget that they are constituted of some portion of the produce. Now, suppose previous to the resumption of cash payments in 1819 , an acre, after paying its expenses, preduced a surplus of four bushels, for profit to the farmer and rent to the landlord ; in consequence of the prices falling so much, all those bushels are taken up in paying merely the expenses of cultivation, and in extreme cases, perhaps more, perhaps fire or six; in which last cases the cultivator pays money, instead of receiving it, for his trouble ; but in the former case, there is neither rent nor profit; and this I believe to be the case on half the purely arable soils of this country, at the present price of wheat. If nothing be done to alleviate that state of things, all such land must, slowly perhaps, being gradually exhausted by a failing tenantry, yet eventually, cease to be tilled; and if that land goes out of cultivation, that race of tenantry is thrown on the wide world, either beggared, or in want of an occupation, where none, perhaps, is to be found. Then the labourers who depend on that land for emplorment must be thrown out of employment, overstocking the markict of labour; lowering the condition of their brethren in other branches of trade by a grinding competition; many remaining out of work, brooding over their misfortunes, and conspiring against institutions which have ceased to foster and protect their industry. The ultimate consequences of such a state of things as I have here contemplated, are of ten-fold greater moment in a political point of view, than any consideration of the mere case of debtor and creditor; no one can predict the end of them, except in a total change of national feeling, and possibly the uprooting of ail we hold dear. To avert such consequences by a partial modification of the measure that is produeing them, even at the expense of some small injustice to creditors of a recent date, we are, in my opinion, commanded by duty, humanity and sound policy.

4113. The capital of manufacture is a shifting capital, it changes every vear; capital on land remains the same. Is there any variation in its effect in consequence of that difference between the two descriptions of property?-There is this difference between land and nanufactures, there is a greater continuity in all proceedings relating to land; the engagements of the manufacturing interest do not, generally speaking, last, perhaps, beyond a year; then the manufacturers, as I have said before, have the benefit of the export trade; there is a greater scope for the improvement of machinery, and various other things can be applied to manufacture that cannot to land. It was stated by a witness before the Committee on Agriculture in 1833, that the mischief has been done in respect of manufactures; their crop had been destroyed, and there had a new crop grown up; but that process was not yet accomplished with respect to the agriculturist; and that brings me to the consideration of the rent of the landlord. The landlord's rent, up to this time, has been paid a great deal out of the capital of the tenant; if the capital of the tenant has not sutficed, it has been paid out of the property of his creditors. But now the pinching time is come; if 464 . 
E. S. Cayley, Esq. the present prices remain, I do not hesitate to say, that the rent on arable soils must be reduced, on an arerage, at least another 30 per cent. Then comes the day of reckoning for the landlord; he has never reduced fully, compared with the fall in prices : if some nucasure be not passed with a view to increase prices, not only the rent must be reduced, - and that means an extinction of rent on many soils, - but half the tenantry, who, in my opinion, are merely existing at the mercy of the landlords, nust be sold up ; for if the landlord chose to press for the arrears of rent due, I do not beliere half the tenants in this country could stand the test of it; but if the prices be raised to, I will say, from $56 \mathrm{~s}$. to $64 \mathrm{~s}$. for wheat, and other prices in proportion, those tenant farmers will have the opportunity of recovering themselves, and some redress will be made for the injustice which has been done to them; and landlords, for the most part, now aware of how their tenants have suffered, would rather rejoice in this breathingtime given to their tenants than take any advantage in the shape of an increase of rent ; prices would then, in fact, be only brought up to the proper remuneration for the farmer's capital, on the average of soils.

4114 . How do you apply these observations to those freeholders who cultivato their own land? - With respect to those freeholders, the Bill of 1819 operated on them sooner than on the landed proprietors, who were possessed of larger means ; a mortgage or other engagement will al ways press in proportion heavier on a small estate than a large one; those who had not engagements descended in their style of living, and if their land was only of moderate fertility they were very severely pressed, for the expenses of cultivation liad so enormously increased. Their case has been that of living from hand to mouth, but not of saring moner, as was the custom of their forefathers.

411.5. The effect on their obligations is the same?-Yes.

4110. You consider that on frecholders occupying their own land the hardship of Mr. Peel's Bill has pressed more than on any other description of persons ? Yes; and according to my own individual feelings the most valuable portion of the community were the old yeomanry of the country; they were the necessary support of the aristocracy, as I think the aristocracy are of the Crown. The prop being undermined, in either case, endangers the position of what rests upon it.

4117. Hare you considered what the effect of the reduction of interest on money has been?-There the case also presses more on the smaller proprietors than on the larger; in the case of a large mortgage it is quite worth the while of the party to change the mortgage; but in the case, of which there are innumerable instances, of a mortgage for $100 l$. or $200 l$. the very expense of changing the mortgage prevents the party doing it; and, in fact, many a small freeholder who has a mortgage on his bit of land is paving the same five per cent. he was during the war: for the expense of changing the mortgage would be $40 \mathrm{l}$. or $50 \mathrm{l}$., and it is five or six or seven years before he can reap the benefit of the change.

4118. Are you aware of an alteration made last year for the purpose of reducing the expense of the assignment of a mortgage ?-I am not; nor do I think that has yet come into practical operation in regard to such engagements.

4119. Persons with very small mortgages cannot transfer a mortgage orer to another, therefore they still continue to pay the five per cent. ?-- Yes, on account of the expense of the change.

4120. You have ascertained that that is the case:-Yes; I heard the complaint made only just before I came up to the meeting of Parliament; therefore the parties of whom I last heard it are not aware of the new law, or incapable of relieving themselves under it.

4121 . You think that is the case generally, that the small mortgagees still continue to pay the old rate of interest?--Yes, in a great number of instances.

41.22. As you are a member of the House of Commons, you are aware there has been an immense reduction of taxation?-Yes, a nominal reduction; but if the arguments I made use of in $m y$ previous examination, to show the rate of depreciation during the war are correct, it follows that when prices were reduced half, the means of paying taxation were lessened half, therefore the taxation was doubled. The taxation at the end of the war was somewhere about $80,000,000 \mathrm{l}$.; if that is doubled, it was made $160,000,000 l$, virtually; it has been reduced $40,000,000 \mathrm{l}$. since the peace; that $40,000,000 \mathrm{l}$., supposing it to be gold, is equal to $80,000,000 l$. of the paper money, and deducted from $160,000,000 l$. leaves $80,000,000 \mathrm{l}$; therefore the $80,000,000 \mathrm{l}$. remain as at first ; and notwitlstanding all the nominal amount of reduction, we are now paying as heary a tax- 
ation as we did at the close of the war ; and other nominal charges press heavily in the same proportion. The poor rates of $8,000,000 \mathrm{l}$. are at least $16,000,000 \mathrm{l}$, estimated in the money or produce of the war.

4123. From the alteration in the state of the currency, though the quantity paid is nominally less, it is actually as much?-Yes, and with diminished means of paying it.

4124. Have the goodness to explain how you consider the contraction of the currency operates to produce a fall in prices?-The mode on which the currency operates on prices is this:- before the invention of money you exchanged commodity for commodity by barter; but when, for the sake of convenience, money was invented, you compared the quantity of labour necessary to produce, say, an ounce of silver and a bushel of wheat, and exchanged them the one for the other, because they were produced by the same quantity of labour. Now, so long as the bushel and the silver required the same amount of labour to produce them, those two commodities would be exchanged the one for the other, and the price would remain unchanged. But supposing the case, as it was after the discovery of the American mines, of the quantity of silver being quadrupled, or an ounce being procured with one-fourth of the labour it previously took, the expense of raising a bushel of wheat remaining unaltered, you would get four ounces for the bushel of wheat where you before got one; and the silver being the commodity which measured the price, prices would then be raised. Likewise, paper money, having been established for the sake of convenience, operates in its increase and diminution precisely in the same way as has just been stated in the case of the silver. If silver were now our standard, and it was to be suddenly discovered in quadruple the abundance it now is, the denomination of the money remaining the same, four times as much paper would be issued, and prices would increase accordingly. If the paper be convertible into silver (and I am no friend to an inconvertible paper), you can only issue a limited amount of paper, because you are liable to be called upon for the silver in exchange. The reason why, under a depreciated currency, you can issue a larger quantity of paper safely is this:-take the case of the gold sovereign; the $20 s$. in paper, or one-pound note, being convertible into $20 \mathrm{~s}$. in gold, that limits the power of issuing paper; but supposing you were to cut up the sovereign into four pieces, the nominal paper pound remaining the same, you could issue four times as many paper pounds, i. e. nominal paper pounds, as you did before, because each nominal paper pound, although still convertible into gold, would not be convertible into the whole sovereign, as it was previous to the cutting it into four; you would only be required to exchange it for one quarter of the previous sovereign; you could then as safely issue a one-pound note on each quarter of the sovereign as you did previously upon the whole; and therefore four one-pound notes could as securely, so far as convertibility was concerned, be issued, after such depreciation, as one one-pound note could be issued before such depreciation. I am not advocating such depreciation, but only showing the effect of depreciation on prices by the above illustration. The principle is equally true of any less degree of depreciation; and when people say that increased prices on a depreciated standard cannot be permanent, they only show that they do not understand the nature of depreciation.

4125. With reference to the silver currency, would there be more pieces of metal to base the paper currency on?-The mode in which a silver currency would operate, at the price I proposed in my last examination, would be this :the present price of silver is, say $5 s$, and the coinage standard, which was the one, for reasons there shown, that I proposed, being $5 s .6 d$., the operation would be as follows. To make the case clearer, for the sake of illustration, suppose, instead of one-pound notes there were $5 s$. notes; if the standard be depreciated from $5 s$. to $5 s .6 d$., that is one tenth, or 10 per cent., 10 of the additional sixpences making $5 s$.; a banker, therefore, after this change, could as safely issue 11 of these $5 s$. notes as he before could issue 10 , because only the same quantity of silver would be required for the 11 notes as were before for the 10 . The argument applies to five-pound notes and ten-pound notes just the same. Eleven fivepound notes could be issued, and with equal security of convertibility, where 10 were before; and prices would rise, and permanently rise, if the proportion between the market and currency price of silver remained the same, say $5 s$. to $5 \mathrm{~s} .6 \mathrm{~d}$. There is, however, a great practical advantage in silver as a standard, independent of all depreciation, in the physical obstacle it presents in the way of too rapid 464. 
E. S. Cuzley, Esq. convertibility in cases of extreme emergency; all the authorities on this subject are agreed that it is impossible, where there is a great and continued run for gold, that it can be paid. Now it happens that panics are generally temporary. The panic of 1825 , which was stopped by one-pound notes, was temporary; the panic of the three dars of July, in Paris, which was staved off by payments in silver, was only temporary: again, the run for gold in 1832, when Lord Grey went out of office, continued only two or three days; the advantage of silver, therefore, consists in the slow process of paving it, compared with gold, and in the probability that the panic will be over before the silver is exhausted. It is quite evident then that the bankers, or the Bank of England, not being exposed to so much risk from a run upon them as when gold is the only standard, will issue more freely in proportion to the degree of protection they feel from such risk.

4126 . That was the case in the year 1745 , in this country?-Yes; the Cheralier de Jolnston mentions it in his History of the Rebellion; the bank was saved by paying in silver.

4127. Do you recollect an order issued in Lord Liverpool's administration for the regulation of the quantity of silver at the bank, or the price of silver to the bank? - The only thing I recollect with respect to silver, in connexion with Lord Liverpool's name, is the Act of 1816, putting an end to the silver standard.

4128 . Was there not some order issued by the 'Treasury to regulate the price the bank were to pay for silver?-I am not aware of it, unless it were one of the provisions of that Act.

4129. Do you know any instances in other countries in which the raising or contraction of the currency has been attended with any particular consequences? --It has been attended with remarkable efiects, in more countries than one, indeed, I believe, wherever it has been experienced to any considerable extent. Illustrations might be given even out of the early history of our own country. As an instance of depreciation, I quoted, on my last examination, the case of Rome in the Punic war; and there is another from the same history. Montesquieu, in his "Reflections on the Causes of the Rise and Fall of the Roman Empire," observes, "When Augustus had conquered Egypt he conveyed the treasure of the Ptolemies to Rome, and this proceeding occasioned much the same revolution which the discovery of the Indies afterwards effected in Europe, and which some ridiculous schemes have since accomplished in our time; the revenue was doubled at Rome; and as that city continued to absorb all the riches of Alexandria, which was itself the repository of the treasures of Africa and the East, gold and silver by these means became rery common in Europe, and the people were able to pay very considerable taxation, even in money; but when the empire was afterwards divided, all these riches flowed in full tide to Constantinople ; and we may add to this unhappy circumstance, that the mines in Germany had not then been opened, and those of Italy and Gaul were very few and inconsiderable; and that the mines in Spain had not been worked since the Carthaginians lost that country, or at least they were not so productive as formerly; Italy itself was now a continued waste of forsaken gardens, and consequently could not be in any condition to draw money from the east; while the west, at the same time, was drained of all its wealth by the oriental merchants, who supplied the inhabitants with their necessary commodities. Gold and silver, by these means, became extrenely scarce in Europe, and yet the emperors extorted the same pecuniary tributes as formerly, which completed the general destruction."

4130. Do you not know that the standard of this comntry, the old angel and all the different coins in use formerly, were varied in their value according as the scarcity of gold was ascertained? - I am aware that there was a gradual depreciation of the coin, to a considerable extent, each century, up to 1717 .

4131. Have you seen a statement of the manner in which those were regulated in Comyn's Digest?-No; I have seen it, I think, in Ruding's Anmals of the Coinage. Long ago only $20 \mathrm{~s}$. were coined out of a pound of silver; now there are 66. The former shillings were three times as heary as the present. Mr. Peel's Bill of 1819 was in principle the same as making us revert to parments in these old shillings. If we had borrowed 66 of the present shillings, and had to pay them in the ancient shillings, we should have had to pay three times the amount, or 198s. instead of $66 \mathrm{~s}$. There is another instance l would mention of 
the ill effects of a violent contraction of the currency, in a case where this country was greatly concerned. I cannot say I know it of my own knowledge, but I have often heard and seen it in the following shape, and never heard it doubted. The celebrated Dr. Franklin, before the Privy Council of this country, gave the annexed exhibition of the causes which led to the revolt of the American colonies from this country. " $\mathrm{U}_{\mathrm{p}}$ to the year 1761 , the profits, industry and wages of the British colonies in North America had been, as is well known, pre-eminently prosperous. They had enjoyed this condition of unequalled happiness under the operation, and assisted by the stimulus, of an exceedingly abundant paper circulation, which for more than a century the inhabitants themselves, as acting through their different colonial legislatures, had highly fostered, to the extent of making it a legal tender. In that year, however, the English House of Commons took it into its head to raise the value of colonial currency ; and accordingly, by the 4th Geo. III. cap. 34, it did enact, that such paper circulation should no longer be a legal tender, and that any Acts of the colonial legislatures from that time forth to make it so should be null and void. Now mark the issue. The great confusion and disorder introduced into every branch of industry by this frantic raising of the value of money was soon productive of its natural results, that is to say, of obstructed circulation, decayed prosperity, and political discontent. This discontent found vent, as usual, in impatience of taxation. It ended, in 10 years from that date, in the famous declaration of liberty and independence."

4132. As silver is the standard in other countries, all over the Continent and in America, is it not desirable to have the same standard here?-It is so ; for this reason, that whenever there is a run upon the Bank, it is desirable that we should know where to go for the standard metal. Gold, not being the standard of any other country, is not certain of being found in abundance on any emergency. Silver, therefore, is preferable to gold, alone on this account, in addition to other reasons already assigned.

4133. If you now draw a bill on France, or any country on the Continent, you would get no gold for it?-No; unless there were an agio paid upon it.

4134. But if you drew a bill for 1,000 livres on France, you would be entitled to 1,000 pieces of silver coin, and that would be of use to you here if silver coin was made the standard currency?-Yes, certainly, it would be useful to be enabled to obtain that treasure, in case it were adopted as the standard; and I think it would have a great tendency to counteract the danger of panics.

4135. What is the present market price of silver?-About $4 s$. I I d. I may add another instance of the ruinous effect of change from a great depreciation to a state of stringent appreciation, in our own history since the late war. I am no advocate for a depreciated paper currency, in the first instance; the reason I advocate the principles I do on this subject is, in consequence of the disastrous effects which I am convinced must always follow the change from a state of great depreciation to a state of great appreciation; effects, as I have stated before, not immediately perceived, nor confined to the palpable case of debtor and creditor. The case of appreciation, after long depreciation, operates, perhaps, harder on the debtor than a case of depreciation on the creditor; but they are both cases of great injustice, and not to be sanctioned except in extreme cases of national emergency, or where, in consequence of a falling-off or increase of the supply of the standard metal, the spirit and really good faith of contracts is better preserved by a change than by an obstinate adherence to the old standard price. When a country is sinking, or in danger, for want of a depreciation of the standard, I would say, and I think every man ought to say, "Preserve the country ; re-model your standard."

4136 . The extent to which you would go, in addition to the gold, would be to have a silver standard, in order to have a larger basis for paper to rest on ?-Yes, and one-pound notes: at the same time I should have preferred a different plan in 1819. I think, as I said before, depreciation never should be resorted to but as an instrument to work out some great act of national expediency. It was resorted to by the American colonies in their war of emancipation, and was the main weapon which carried them through the struggle. It was resorted to by the French in the first struggle of their revolutionary war; and that measure carried us, in my opinion, successfully through our struggle in our contest with Napoleon; and that measure likewise carried the Romans through their struggle 464. 
E. S. Cayley, Esq. with the Carthaginians; and when it has been in operation some years, it is dangerous and unjust to resort to appreciation.

14 March 1836 .

413i. The utmost change you would be disposed to make now would be to restore the silver standard with one-pound notes?-Yes ; I feel sure that a measure of greater extent would be beneficial to all the productive classes, and, on the whole, just, taking every thing into consideration. A currency that would, on the average, give $64 s$. for wheat, $35 s$. for barley, $24 s$. for oats, $1 s$. a pound for wool and $6 d$. per pound for meat, would do the most good as a national measure; but, such are the prejudices on the subject, I am willing to make the compromise for silver and one-pound notes.

$413 \mathrm{~S}$. Which is, in fact, not making a new standard, but restoring the standard that existed in this country up to the year 1816 ?--Exactly. If I could have my own way, I would add to this some measure to protect the Bank of England under a temporary adversity of the exchange, so as to preserve the currency as equable as possible.

4139. The silver standard was altered a little in 1774 ; but, striking out those two Acts, you would only be bringing it back to the old standard of this country, of which the alteration in 1774 was only that, instead of paying unlimitedly in silver, you could pay a part by weight, at $5 s .2 d$. an ounce?The change took place in 1774 , but I am not sure that it did not come to an end in 1788, and was never renewed again; if that were the case, the old standard was actually in existence up to the Act of 1816 ; but this is not material to the argument, for any sum might be paid in silver at $5 s .2 d$. by weight.

4140. Would not the effect of a rise in prices be to let in foreign corn?-I apprehend not, for this reason: in 1828 the corn laws were made upon the basis that $64 \mathrm{~s}$. was to be the pirot on which the prices were to turn. If the change I propose produced a rise in prices, even to $56 \mathrm{~s}$. or $60 \mathrm{~s}$, , it would still come under the view and operation of the Act of 1828 . When wheat is $64 \mathrm{~s}$, I think, or $60 s$., the duty is still $24 s$. a quarter, and I think that $24 s$. a quarter duty at that point, particularly rising as the price falls, and reaching somewhere about $30 \mathrm{~s}$. duty when the price is $56 \mathrm{~s}$. per quarter, is quite sufficient to protect us.

4141. Do not you think we should have a little more protection in the descending duties? - No: my opinion on the corn laws is, that, although they might be slightly altered for the better in detail, it would be imprudent to call for an alteration, lest by chance there should be a change for the worse.

4142. Is not the effect of the corn laws to give the public the benefit of a good harvest, and to throw upon the farmer the consequences of a bad one?It is very true that, perhaps, after a bad harvest, the farmer has not prices to remunerate him. It is one of the false notions entertained by political economists, that a bad harvest is an advantage. In all periods of history a good harvest was always considered a blessing, good both for man and beast, for then there is plenty in the land. When there is a deficient crop, that increases the price, but not sufficiently to compensate for the loss of produce; but the increase of produce by a good crop, in a proper state of things, more than counterbalances the fall of price.

4143. That would certainly be so, unless a depreciation is still further occasioned by the letting in cheaper corn from cheaper countries?-There is no doubt, if we had a complete prohibition, the price then would rise higher under a deficient supply than the present corn law will allow it; but there is another thing we must look to, viz. the resistance to a high price by a hungry population. The basis of our legislation, in this case, must be the remuneration to the grower on the one hand, and the capacity and necessities of the consumer on the other.

4144. With respect to the accommodation country bankers are disposed to afford; will they now afford accommodation to farmers of known stability? -In most cases they will not; it is a question often asked, whether a person with good security cannot find accommodation? If the security be a substantial man, of independent income, he may not find a difficulty in procuring accommodation; but his difficulty is in finding a security of that nature. Heretofore his neighbour and brother farmer was sufficient; and he was considered so for this reason, that, when a trade is-prosperous, there is a tendency in the 
mind to look to the profits of the trade as enabling the farmer to return the interest or the money lent; but when there is a failing trade, and the bankers see that men of the best character, and most approved mode of cultivation and of the greatest industry are failing all around them, there is no confidence in lending on character, or on stocks which are falling in the market.

4145. Have you turned your attention to the difference in the law as affecting persons in trade and farmers, as it respects pledging their property $?-\mathrm{No}$, I have not.

4146. A tradesman may give security in this way; having goods in a certain warehouse, by an indorsement in the warehousekeeper's books of those goods to the banker; that is a good security. A farmer, you are aware, cannot in that way indorse over the crops while they are on the ground?-Certainly not.

4147. You state, that in many instances the landlords have been receiving their rents out of capital, and not out of profits ; do you not think they have been paying their own rents by the land being run out?-In that point of view they have; in a great many instances, where one tenant is obliged to quit the land before he has succeeded in quite running it out, another tenant has come on the land with a view to running it out still more, and leaving it when it is utterly exliausted.

4148. And by breaking up grass land?-Yes; that has gone to some extent, but it was checked by the better price of wool and meat, caused by the rot. A necessitous landlord, rather than reduce his rent, will allow the tenant the privilege of ploughing up old grass land. This went to a considerable extent in Ireland. In Connaught the con-acre system has prevailed, I have understood, very much within the last 15 years.

4149. Do you think the farmer is likely to obtain any relief from the commutation of tithe?-If it were on an equitable principle, and not to draw more than has hitherto been drawn, it must be a benefit, as giving him the power to enjoy the fruits of his own capital invested henceforward in the soil ; but if the question allude to the Bill now before the House of Commons, my opinion is, that the farmer will be better off by remaining as he is than if that Bill pass into a law.

4150. What do you think of a repeal of the malt-tax?-I think it would be beneficial; it would create a greater demand for barley; more land would be sown with barley and less with wheat, which would tend to increase the price of wheat without diminishing the price of barley; whilst the saccliarine principle of the malt would help the farmer amazingly in the feeding of his cattle.

4151. Would that not give additional employment to the poor?-No doubt, if it caused an additional cultivation of barley, or produced a better price for wheat.

4152. Might not the deficit which would be occasioned by the repeal of the malt-tax be made up by a more equitable extension of the direct taxes?-If the question allude to an income-tax, my opinion is, that it might be put on; but it would not be paid for 15 months in this country, under present circumstanćes.

4153. A more equitable system of the land-tax, for instance?-Yes, that is very much wanted, for much property escapes that ought to pay.

4154. When you say that an income-tax would not be paid for 15 months, what do you mean?-My opinion is, that when there is a tax on consumption, an indigent man may evade that; but when the tax-gatherer knocks at his door for a direct tax, he cannot evade it; and that was the true cause of the objection to the house-tax. The householders of London, with a bad trade, finding they could no longer charge the tax upon their customers, resolved to resist it ; they found that the tax-gatherer came to their doors, and would have his money whether they had it or not; and they could not, as in the case of indirect taxes, deny themselves any luxury by which they might evade it.

4155. An income-tax would be found so heavy, they would not submit to it?-I think so; unless it were very light indeed.

4156 . There is no land-tax in Ireland, nor any direct taxes; would not the extension of the direct taxes to Ireland, and the application of the Poor Law, tend to improve the agricultural interest? - I do not think that they could bear a landtax. I believe that Ireland is much more pressed with fixed engagements than England. A poor law for Ireland is a very popular doctrine, and it might relieve 464 . 
E. S. Caykey, Esq. parishes overburthened with paupers in this country from the direct competition of the Irisl labourers; but it is an experiment I think none of us can see

14 Marcb $18_{3} 6$. the end of at the present moment, although, on the whole, I am favourable to the trial.

4157. Do you see any reason why England should be taxed in this way, and Ireland not?- No, there may be no direct reason for it ; but $I$ think in all countries we ought to endeavour to accommodate our legislation to things as they are. It is stated that an Irish poor law would be a benefit to the farmers : it would be a benefit to the farmers in those parishes where there are heavy poor-rates, in consequence of a surplus population, if that surplus population could go and find employment where at present the Irish labourers do: it would be a relief to that extent. In Lincolnshire and the East Riding of Yorkshire, I believe, they depend a good deal upon the Irish labourers for their harvest work; and if they did not come they would have to pay additional wages in harvest-time; but I have not quite made up my mind whether the effect of an Irish poor law would be to prevent the labourer coming over ; for if his wife and children were supported during his absence by the rate, it is possible that he might still come over, at least for some time to come.

4158. Do you not think the necessary effect of a poor law would be to raise wages, and thus prevent their growing corn so much lower than we can in England, as they do at present?-No, I am not sure of that; supposing additional corn to be grown in Ireland, in consequence of such a law; to be grown profitably the labourer must produce more than he consumes; the effect of that will be to send an additional quantity to this country, which will have a tendency to reduce the price.

4150. If their wages are increased they will eat some of it themselves, will they not?-Yes; but a man is supposed to raise four times as much as he consumes. Even suppose the Irish labourers to eat part of the wheat they produce, it will be a change of habit, and all changes of this kind are gradual : the increased export would be immediate. In the long run, doubtless, when the Irish labourer has ascended to the English scale, there may be more comparatively consumed in Ire. land, and less exported.

4:60. Do you think it is possible for England to go on, Ireland increasing in the cultivation of her lands as she does, and cultivating at so much cheaper a rate than England does :- It is an injury, certainly, to the English landlords; but I think, upon the whole, we can hardly alter that state of things; and if there be any truth in the calculations made by some, who pretend to be authorities, on this subject, that for a length of time before 1833 we have depended, on the average, for 500,000 quarters of wheat from abroad (although I do not think it the fact in ordinary seasons), I had rather we got that supply from Ireland than that we got it from foreign countries. And with respect to Ireland being able to produce it cheaper, I am afraid that is a position we cannot very well relieve ourselves from. I quite agree that any thing that would have the effect of enabling the Irish labourer to consume his own corn would have a beneficial effect; and if the poorrate pressed, corn probably could not be sent so cheap to market.

4161. Would not a poor law in Ireland have that effect immediately?-I cannot think it would immediately.

4162. Whenever the Irish have had the means of purchasing comforts, have they not done it?-In some instances they have, but I believe not in others.

4163 . Are you not aware that where there are public works going on they will live better and clothe themselves better than they have done before; is not their condition immediately changed:-There can be no doubt the natural tendency is that way, and it must have that tendency eventually. The only doubt I have is as to any great change in national character taking place in a short space of time; and the distress of agriculture is much too pressing to wait for that.

4164. Can that distress be effectually removed without some change; must not Ireland bring us down to her level, or we raise her to ours?-I believe it is only in consequence of the distress arising from low prices that we feel the pressure from Ireland. Lower wages will tend to reduce higher wages, that is certain; but the smaller party cannot always pull down the larger to its own level. There is some point in the scale where the smaller party is absorbed, and then the decline of wages stops, possibly mid-way between the higher and the lower rate. 
4165. Will not a small quantity brought in by a person who can sell it cheaper depress the price of the market very greatly, and press it down?-Yes, certainly.

4166 . Do you not think that, supposing the fact to be that there were 115,000 quarters imported in 1834, when we had a great quantity of our own, that would be sufficient to lower our prices? - No, for the prices had fallen, in fact, previous to Christmas 1834; the abundant harvest of 1834 could not, therefore, have produced that fall.

4167 . There were 600,000 quarters brought in in that year?-In 1833 it amounted to 800,000 quarters, wheat and flour together; in 1834, 700,000; and $1835,600,000$; therefore I do not think the Irish import can be considered as the cause of that part of the depression of prices which has taken place within the last two or three years.

4168 . Have you cver made a calculation of the amount of all the Irish produce imported into this country ?-No; but the returns show the amount, I imagine.

4169 . What effect had the repeal of the dity on beer? - I think it had the effect of raising the price of barley $2 s$. or $3 s$. a quarter.

4170 . If the Beer Bill had the effect of raising the price of barley $2 s$. or $3 s$. a quarter, the Malt Bill would raise it a great deal more? - I should think it would. When I say it would raise it a great deal more, I think the natural price of barley would not now, independent of deficient crops, be more than $22 \mathrm{~s}$. a quarter; and I think, in consequence of the Beer Bill, it will range, in ordinary seasons, somewhere about $24 s$.

4171 . You attribute the present high price of barley to a scarcity?-Yes, to a very deficient crop in 1834, and to a crop short of an average in 1833 .

4172. Has drainage taken place to a great extent in this country?-Drainage has taken place to a considerable extent of late years, partly because labourers were out of work and wages low, which rendered draining cheap; and partly because the landlords have been advised to lay out capital in permanent improvements, in preference to reducing their rents. It is, in fact, the same thing as reducing rent, because if rents be not increased on land which has become more valuable, it is an equivalent advantage to the cultivator. But unless prices are altered the draining will not pay itself. It used to pay 10 or 12 per cent. to the landlord, and of course it would pay something to the tenant also. Where 15 or 16 per cent. of rent has been thus reduced in the shape of draining, it has not only been reduced, but hard cash has been laid out, which will be all lost if present prices remain, for the land will not be worth cultivating.

4173. Then if the draining is not carried on we shall go back to a state of morass? - If land of that nature is not drained it will not pay the expenses of cultivation, even at higher prices than the present.

4174. Is land saleable in your part of the country?-I have heard of many instances of lands being put up to sale in the north, where there has been no bịdder. I have heard of an instance where a rich capitalist has gone with $80,000 l$., not in his pocket, but at his command, and has purchased the property at $50,000 \%$. With respect to the number of years' purchase at which land is bought, there is a great misconception on this subject; persons fancy that a decline in prices must necessarily cause a decline in the years' purchase given for land, whereas the years' purchase is reckoned on the rental, whatever it may be. If the rent, for instance, be $30 \mathrm{~s}$. an acre, you reckon 30 years' purchase on that $30 \mathrm{~s}$.; then if it be reduced to $10 \mathrm{~s}$. an acre, you merely make the calculation upon that $10 \mathrm{~s}$. rental: the 30 years' purchase will be the same; the amount on which the calculation is based is different; that is all: I speak of lands under circumstances which are not likely to lead to their being thrown out of cultivation; but if, for want of remunerating prices, there be a prospect of land not being worth cultivating, such land will then have a reduced number of years' purchase given for it ; it may be worth absolutely nothing; and if a man buys it, he does it probably on the speculation of prices rising. 'The number of years' purchase in such a case will not be measured by the rent the land is actually worth, which ought to be the criterion when we speak of the number of years' purcbase given for land.

4175. The number of years' purchase for the existing rent is not reduced:-No; if there be a fair prospect of its remaining in cultivation; if there be an uncertainty, then the years' purchase will be reduced.

4176 . It has been said there is a great increase in the growth of wheat; may not a farmer increase the price by reducing the quantity grown?-If he reduces the quantity grown he must cultivate some other crop, and I do not apprehend 464. 
E. S. Cayliy, Esq. there is a great advantage to be gained by the farmer (except inasmuch as the nature of the soil itself may require it) by chopping and changing from wheat to barley, if at the time that one rises in price by diminished produce, the other falls from increased production. If some fresh produce of a more valuable nature could be substituted, suppose sugar, that would be another thing; but it is a great fallacy to suppose, if you have been in the habit of sowing 60 acres of wheat and 40 of barley, that you will gain an advantage by sowing 60 of barley and 40 of wheat; you get an increased price, it is true, for your wheat, but you liave a diminished quantity; and on an average of years the returns to the farmer's pocket will be the same.

417. Would it not be proper at this time to encourage the growth of flax and lemp in Ireland? - I have always thought that we might encourage the growth of flax in Ireland with advantage; less wheat would then be grown, which might tend to raise the price. At the same time my firm conviction is, not that we grow too much wheat, but merely that there is too little money distributed to buy it. I do not want a high price of wheat from scarcity, but from an increased capacity in the consumers to buy. With regard to encouraging the cultivation of barley in preference to wheat, I may add, that I should be sorry to see it resorted to as a general measure; it is a crop which is very sensitive to a dry season. Wheat will stand almost any weather in the spring and summer; but barley cannot bear a dry May, and two years out of three, in this country, there is a dry May; therefore I slould not wish the farmer permanently to rely on barley instead of wheat.

4178. Do not you think it would be desirable to go back to the old duties on the importation of flax and hemp, so as to encourage the growth of them in such lands in this country as will bear them?-I think it would be a very good thing to encourage them by any legitimate means. The reduction of the duty on the importation of flax has not had the effect, I believe, of materially reducing the price.

4179. Might not that afford some relief for the loss sustained by taking off the malt-tax? - It might.

41 So. And also on tallow?-Yes, the imposition of a duty on tallow.

4181 . Might not those taxes and a moderate land-tax supply the deficiency of the tax on malt? - I have no objection to an equalization of the land-tax, so as to iuclude bouses and other property; but $I$ have a very great objection to an additional tax on the land.

4182 . In some courses of agriculture is not wheat almost necessary as a change? - No doubt of it.

4183 . Take the Norfolk system, the four or the five-course system, the farmers would find it difficult to make the change the land requires unless they grew wheat? - No doubt of it.

$41 \mathrm{~S} 4$. Does any thing else occur to you to be stated more than you have already mentioned? - - In any thing I liave stated, I should wish to be understood, that in any measure I should contemplate for the benefit of the farmer or the land owner, I should equally include the labourer; for no country can be in a state of security unless the welfare and the comfort of the labouring class be secured. My opinion of a rise in prices is, that it would give remuneration to the employer of labour, and whatever gave remuneration to the employer of labour wuuld give security to the condition of the labourer. At present I consider the condition of the labourer to be very insecure; whatever benefit he is now reaping he is reaping at the expense of his employer, he is drawing upon the capital instead of on the profits of the employer; a state of things which it is impossible can last; that fund will soon be exhausted; always taking out and never filling is the simplest of all ways to empty the coffer.

4185 . That fund has always been considered a very slender one?-It has; but until late years the trade of a farmer has not been considered an insecure one; the pursuit was not a very lucrative, but it was not a dangerous one. For centuries before the late war one never heard of the changes of tenantry which have taken place the last 20 years; families remained upon the same farm sometimes for centuries; but we find that state of things has not existed since the conclusion of the war.

4186. You think that state of things began since the war?-Yes; and in consequence of the change of the value of money which tuok place in 1819.

4187. You are understood to say, that one of the great mischiefs you apprehend from the present state of things is the impossibility of long sustaining the wages of labour? - Yes; there is nothing so difficult as to change a national rate 
of wages; it is difficult to convince a large and a dense population that there is a necessity for reducing their wages. During the war we raised the pay of the army ; he would be a very bold man that should now propose to reduce the pay of the army ; yet there is no reason, in justice and in fairness, why the pay of the army should not be reduced; for having becn increased in consequence of the high prices, the return of low prices forfeits their claim to it; but we are in this predicament, - we dare not do it.

4188. Dare they reduce the agriculturists' wages much more?-The wages were kept up in some agricultural districts, in conscquence of a tendency to insubordination in 1830. Just before Lord Grey came into office, incendiarism was very general in the south, in consequence of the farmers commencing a system of reducing wages; they were cliecked in this reduction by fear. The poor cultivators are thus in the dilemma of being able neither to reduce wages nor to raise prices.

4189. Do not you think that the system of Northumberland, paying a man partly in the produce of the land, flour and potatoes, and barley and oats, and so on, would be, in general, a course exceedingly beneficial, and would enable the farmer to reduce the price of wages equivalent to the produce of his farm ? - If he paid in a certain amount of produce, he would not feel the expenses of cultivation so greatly as he does; the mischief is, that money wages require a very long period, perhaps a generation, before they can be reduced to the price of produce; they can be quickly raised, but slowly reduced; therefore the Northumberland system, which is virtually on the principle of a corn rent, must be advantageous to the occupier.

419o. You liave probably paid much attention to the price of labour, as compared with corn, in high times and at the present time?-I have.

4191. Do you think the state of the labourer is better now or formerly, after having made that comparison? - My opinion is, that, taking the whole of the labouring class now and during the war, they were better off during the war; taking the employed labourer alone, now and then, the employed labourer ought to be, perhaps, better off now than then; because a farmer can refuse to employ a labourer much easier than reduce his wages. The present condition even of the employed labourer, however, is, as I said before, on a very insecure foundation ; but taking the employed and unemployed together, I am perfectly confident their condition was much better during the war than now. Whenever I go into any district or county, I make it a point to inquire of an old labourer how he likes the change of prices; the answer invariably is, "We never were so well off as when corn was $10 \mathrm{~s}$. a bushel."

4192. Do not you think that the reason for that was, that there was during the war a much smaller number of hands? - There is no doubt that would have some effect; but in 1817 and 1818 , when there was a rise of prices after the war, the two previous years having been years of distress, the labourer reverted again to full employment, although war had ceased to exist. The truth was, that the profitable state of farming during the war cnabled the farmer to give excellent wages, and the task-work was paid at a higher rate even than the daily wages.

4193. Taking wheat as the standard of the price of labour, do you conceive that where a labourer is employed his pay will not buy more wheat now than it would during the high prices?-Yes; but I question whether he has a greater surplus left to purchase what may be called the luxuries of the labourer.

4194. Do you conceive the labouring classes generally have altered in their habit of expense?-It is the necessary consequence of receiving higher remuneration during the war, that they should have done so. I am not anxious that they should descend to a lower species of food, but the contrary. They must be compelled, however, to descend to a lower grade, if prices are so low as to ruin their employers.

4195. The labourers used to come in former times, and bring their eatables and sit down and eat them; and now in many instances they go to the publichouse to get their dinner?-That is not the case in the north.

4196. You have always considered that the price of human labour forms the greatest part of the expenditure, particularly on arable farms?-Yes. In conclusion, with the permission of the Committee, I would add, that in quoting authorities on a particular point of currency, in a previous part of my examination, I purposely abstained from adducing any now living who are in favour of 464 . 
E. S. Cayley, Esq. my own views for an alteration. Although, of course, I place more confidence in them, it appeared to me that hostile testimony would be considered the most 14 March 183 f. impartial.

[The Witness is directed to wilhdraw.

Michael Comport, Esq., is called in ; and Examined, as follows :

M. Comport, Esq. 4197. YOU are an attorney at Rochford, in Essex?-I am.

4198 . In considerable business ?-I am.

4199. Are you acquainted with the landed proprietors and farmers in your county?-I an.

4200. What is the state and condition of the small proprietors of land?-

I should say very indifferent.

4201. By indifferent, do you mean that they are distressed in their circumstances?-Very much distressed.

4202. Have they contracted engagements in better times, which, under present circumstances, they cannot discharge? - They have, many of them.

4203. They are therefore in great distress? - They are.

4204. Do you apply that observation to a great many, or only to a few in your neighbourhood? - A great many.

4205. How many should you say in the hundred of Rochford?-It is very general.

4206. The hundred of Rochford is very good land, is it not?-Very good.

4207. You have stated what is the condition of the landlords; what is the condition of the tenantry?-The tenantry are worse off.

4208. Are they occupying farms of good land?-Yes.

4209. Have you the means of becoming acquainted with their circumstances by being consulted by the farmers in your profession?-I have.

4210. Have you the means of knowing whether they are paying their rents out of their profits or out of their capital?-They have been paying their rents out of capital.

4211. Is not the capital of most reduced, and of some entirely gone?-O Of most reduced, and of some entirely gene.

4212. Is the number of those whose capitals are entirely gone considerable? -It is.

4213. How many do you think there are in your neighbourhood that have thrown up their farms, and whose farms are in the hands of the landlords? -I have drawn out a statement, from the best of my recollection, and I find there are between '2,000 and 3,000 acres of land in the landlords' hands; about 2,600 acres. 4214. Do you mean of lands where the tenants have thrown up their leases? - Yes, or have failed, in Rochford hundred only.

4215. How many acres does that hundred contain?-I cannot say; I have nothing to guide me.

4216. How many miles long and wide is it?-About 10 miles long and eight miles wide.

4217. There is a good deal of water in it, is not there?-Yes.

4218. The whole area is not filled up by farms?-No; there are several rivers, and a number of small creeks.

4219. What is the state of the poor in that part of the country?-I do not consider that it is worse than it has been several years.

42:20. Are they employed ?-Yes, nearly the whole.

4221. How is employment found for them if the tenantry are broken up?-

The farmers employ their labourers now pretty well, notwithstanding the distress of the country. I do not consider the land has ever been in a better state of cultivation. 4222. That in the hands of the landlords is cultivated better, perhaps?-Yes, that may be the case; they have been generally cultivating their lands well, notwithstanding the pressure upon them.

4223. Have they paid moderate rents, in general ?-About 25s. an acro is the average of the hundred.

4224. Is that a moderate rent for the land in that hundred ?-Yes.

4225. Have they been attentive to their business, generally speaking? - Very.

4226. And skilful in the management of their business?-Y Y s.

4227. To what do you attribute their failure? - To the low price of corn.

4228. Do you apply that answer to every species of corn, or any one in particular? - To wheat in particular. 
4229. Do barley and nats and beans produce remunerating prices?-They have, comparatively. I think it wheat had been at a proportionable price with barley and oats, there would not have been the distress.

4230. Is the price of barley and oats sufficient to compensate the farmer for the

loss on his wheat?-Certainly not.

4231. Is that stiff land, or light land ?-Light land.

4232. Light loamy land? - Yes.

4233. Has the quantity of oats and barley produced been an average crop?-

I think it has.

4234. Does any thing else occur to you to be stated? - I was prepared to state what the average growth had been of Rochford hundred within the last three years.

4235. Have the goodness to deliver it in.

[The statement is delivered in, and read, and is as follows:]

ROCHFORD HUNDRED, ESSEX.

Produce of 100 Acres of Land in 1833 , consisting of 90 Acres of Arable and 10 Acres of Pasture, upon the sis-course system.

30 acres wheat, at $3 \frac{1}{2}$ quarters per acre, and $53 \mathrm{~s}$. per quarter 15 acres oats, at 6 quarters per acre, and $18 \mathrm{~s} .6 \mathrm{~d}$. per quarier 15 acres clover, at $3 l$. per acre

15 acres beans, at 3 quarters per acre, and 33 s. $3 \mathrm{~d}$. per quarter -

10 acres grass, at $50 \mathrm{~s}$. per acre

15 acres fallow.

Profit on pigs and poultry from run of yard

Expexses upon 100 Acres of Land, same year, 1833 .

Rent, at $25 s$. per acre

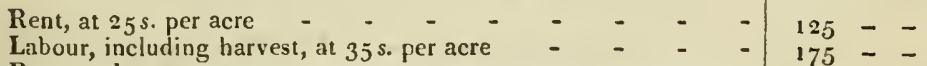

Rates and taxes, at 5 s. per acre - - - - - - $-175-$

Tithe

Seed corn

Horse corn and hay for four horses, at $8 s$. each per week

Wheelwright, blacksmitlı and collar-maker's bills

Average annual loss in horses -

Interest of capital -

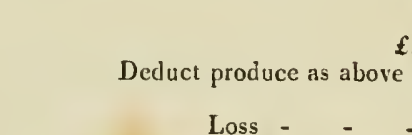

Produce in 1834 .

30 acres of wheat, at $3 \frac{1}{\mathrm{~s}}$ quarters per acre, at $46 \mathrm{~s}$. per quarter 15 acres oats, at 6 quarters per acre, at $21 \mathrm{~s}$. per quarter -

15 acres clover, at $2 l$, per acre

15 acres beans, at 3 quarters per acre, and $35 \mathrm{~s} . \overline{\mathrm{b}} \mathrm{d}$. per quarter 10 acres grass at $40 \mathrm{~s}$.

15 acres fallow.

Profit on pigs and poultry

Expenses.

Rent

Labour, including liarvest

Rates and Taxes

Tithe

Seed corn

Horse corn and hay, suc. -

Wheelwright, blacksmith, and collar-maker

Average annual loss in horses -

Interest of capital 
M. Comport, Esg. 14 March 18,36 .

\section{Produce in 1835 .}

30 acres wheat, at $3 \frac{1}{2}$ quarters per acre, at 40 s. per quarter 15 acres oats, at 6 quarters per acre, at $22 s$. per quarter 15 acres clover, at $3 l$. per acre

15 acres beans, at 4 quarters per acre, and $36 s$. per quarter 10 acres grass, at $50 s$. per acre 15 acres fallow.

Profit on pigs and poultry

-

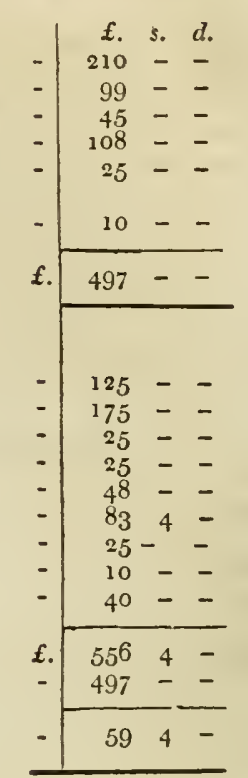

Deduct produce as above

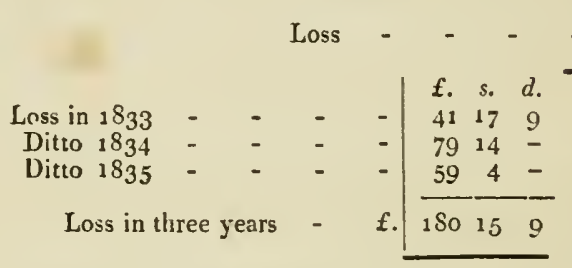

4236. At what rate do you reckon interest on capital?-Five per cent. on $800 l$.

4237. What do you depasture on your grass lands, for which you reckon $40 \mathrm{~s}$. an acre?-Sheep and cows; or if it is mowed, it is the same thing.

4238 . Do the profits of the sheep and cattle make that?-I have calculated the gross produce.

4239. You have allowed nothing for the support of the farmer?-No, unless he should have the interest of his capital to live on; if it is a borrowed capital he will have nothing.

4240. The utmost of that is five per cent. on $800 l$., making $40 l$. a year ?-Yes. 4241. You understand the cultivation of a farm, and have a farm in your own hands? - I have.

4242. You manage other farms?-Yes, I manage several farms.

4243. Is there any other information you can give?-I have before me a list of farmers in Rochford hundred who have failed; there are seven large failures, one to upwards of $40,000 \mathrm{l}$. last year.

4244. Was the land farmed by him his own land?-Great part of it was his own land.

4245. How many acres did he farm?-I should think 1,500 acres.

4246. What was his land worth per annum?-He was an occupier of some; he was an occupier of about 600 acres; the remainder was his own.

4247. What should you suppose was the whole rent for that he occupied?Two thousand pounds a year.

4248. Was there not a failure of a large farmer who was a magistrate for the county :-Yes.

4249. He is now in the King's Bench prison, is not he?-I believe he is. He failed for upwards of $10,000 \%$, , on which not a shilling in the pound will be paid.

4250. Was that from losses in farming :- It was.

4251. Was that failure for 40,000 l. occasioned by farming only?-Yes, by farming entirely.

4252. Is the quality of the land in Rochford hundred as good or better than others?-It has generally been considered the garden of Essex. 
4253. Do you find a want of money there to carry on the ordinary transactions of life between farmers? - Very great.

4254. In what manner do they accomplish their transactions now ?-There are M. Comport, Esq. many obliged to give certain quantities of corn, to which they resort when they want seed corn.

4255. Can they get accommodation at the country banks now?-The way in which they get accommodation is through two bill-brokers whom we have in Rochford town; if it was not for them I do not know how the common transactions of life could be carried on; they discount their bills.

4256 . What security do they require on discounting bills?-They get two or three names upon every bill.

4257. Upon the security of those two or three names they discount the bills? -Yes.

$425^{8}$. When they get into this course of proceeding, is it long before they find their way to Chelmsford gaol ?-It is the forerunner of it, for they are paying nearly 10 per cent.

4259. From your knowledge of the proceedings going on at law, is it not a sure forerunner to the destruction of the farmer, being obliged to take up money in that way? - It is.

4260 . What is the manner of living of those small farmers?-It is scarcely better than that of the well-employed labourers.

4261 . It is not their extravagance which has brought them to distress?- $\mathrm{No}$, certainly not.

4262. Have you any suggestions to offer as to the means of affording relief to the agricultural interest :- No, I am not aware that I have.

4263. What has been the effect of the Beer Bill in your neighbourhood?Very bad, indeed.

4264. What has been the effect of the new Poor Law in your neighbourhood? - That has had very favourable operation in Essex; I think it will reduce the poor-rates very considerably.

4265. That will, of course, be very beneficial to the farmers?-Yes.

4266. How is it liked by the poor?-They do not quite understand it; but generally the labourer who has not been in the habit of receiving relief is pleased with it, because it makes his labour much more valuable than it was.

4267. Are the better disposed poor persons much against it?-I must confess there is a prejudice among the ill disposed, but I think not among the well disposed poor.

4268. How is it liked by able-bodied men, who are good workmen and have large families:-I believe they approve of it.

4269 . In what way has it been administered in your neighbourhood as to the mode in which relief is given in those cases? - Chiefly in kind.

4270. That they are pleased with :-Yes.

4271. Has it been the case at all, that in those instances any children have been taken away from their parents ? - There have been one or two instances of that, but it has been with the consent of their parents and the wish of their parents; the board of guardians, to which I happen to be clerk, have never, to my knowledge, insisted on a child being taken away without the consent of the parents.

4272. You consider that the Poor Law will work well, and be beneficial to the country; do you think that the benefits which can be derived from the Poor Law will remove the distress of the farmer, and raise him to the state in which he ought to be?-No, I do not think it can do that, but $\mathbb{I}$ think the poor-rates will be considerably reduced.

4273. Will the Poor Law give employment to the unemployed poor?-It has one effect in employing the poor; the able-bodied labourer is thrown upon his own resources, and instead of his being an idle disorderly person as he was before, he becomes a useful member of society.

4274. Have you what is called a parish farm? - No.

4275. Does not the Poor Law drive them out of the parish?-No, I have not found that to be the case.

$42 ; 6$. Is your agricultural population sufficient or insufficient for the demand of the farmer ? - I do not think that it is at all more than sufficient for the demands of the farmer.

464 .

I I 2

4277. What 
M. Cemport, Esq. $\quad 4277$. What is the average of the poor-rates in your parish or your union?In the union about $5 s$. an acre.

$14 \mathrm{March} 1836$. 4278 . Taking the acreage, at what value generally ?-I take the acre at $25 \mathrm{~s}$. 4279. So that the poor-rates average one-fifth of the real value :-Yes; the poor-rates levied for the relief of the poor within the last three years have been $10,000 l$., within a fraction.

4280 . Do you anticipate much reduction in consequence of the introduction of the new Poor Law? -I calculate upon a reduction of one-third.

4281 . One-third of $5 \mathrm{~s}$, being one-fifth of $25 \mathrm{~s}$. $?$-Yes.

4282 . What does the union embrace?-Twenty-three parishes.

4283 . You have fisheries in the rivers for your labourers? - Yes.

4284 . That employs your surplus population?-Partly.

$42 S_{5}$. Some of them smuggle a little, do they not ?-Not a little, I believe.

$42 S 6$. You anticipate a reduction of $2 s$. out of $5 s$., by the introduction of the new Poor Law?-Yes.

4287 . And that without any proceedings which are very objectionable to the poor themselves, that is, to the good and well disposed poor?-Yes.

4288 . Do not you think the tendency of this measure will be that of raising the moral character of the labouring classes?-I do; it gives independence to the able-bodied and industrious labourer.

$4^{2} 8 \mathrm{o}$. Have you any produce poured in upon you from other countries, such as Ireland? - No.

4290. To what do you attribute the depression of prices?-It is, I should imagine, from over production in some other parts, but not with us. The seasons have been favourable for heavy lands, but not for Rochford liundred generally.

4291. You have not had over production in your part of the country?-No. 4292. Therefore, if that exists, it exists somewhere else $:-Y e s$.

4293. A farm of $100 l$. a year pays now in your union about $25 l$. poor-rates; and you anticipate a reduction of about one-third of that, being about $8 l$. odd ?Yes, between $8 l$. and $9 l$.

4294. That, on a farm of $300 l$. a year, would make $18 l$. or $20 l$. in favour of the farmer; would that at all tend to compensate the losses he is now suffering, and the difficulties against which he has to contend ?-O dear no; if that relief had been afforded to him for the last three years, according to the statement I have given, it would have made only about $20 l$. against the losses I have put down in my statement.

\section{[The IVitness is directed to withdraw.}

\section{Richard Spooner, Esq., is called in ; and Examined, as follows :}

R. Spooner, Esq. 4295. HAVE the goodness to state to the Committee in what way you think the malt-tax acts prejudicially to the landed interest?-It acts most prejudicially in destroying a very great means of profitably feeding cattle; the relief to the farmer would be considerable, as far as the duty is concerned, by enabling him to give to his labourers a cheap wholesome beverage; but even this advantage is nothing, compared with the benefit he would derive from being able to feed his cattle in the cheapest possible way.

4296. That has been done with grown barley?-Grown barley will not do. That was the great mistake Sir Robert Peel made in his speech in the House of Commons; he there said that every thing was allowed to the farmer he could desire, by allowing him to spirt his corn. He is under a great mistake in two points; first, it is by no means so gond a food, even if it could properly be done, but there is a great difficulty in doing it, because unless it is carried to exactly the right point, it is injured instead of benefited by spirting; it must be stopped at the right point. It can be rendered fit for use only by drying, and that is prohibited. A great proportion of the saccharine matter is lost, unless it is by drying stopped at the right point. Perhaps your Lordships have never had the curiosity to examine a sample of malt, of which there is that which is called flinty malt, that is, malt which is imperfectly made. The acrospire in malt goes up under the skin, on the outside of the meal, in the process of malting it, which is never complete until it bursts the skin. If hy any wrong operation in malting the course of the acrospire is stopped before it comes out at the other end, you will find the saccharine matter generated up to the point to which the acrospire goes, 
but beyond that it is nothing more than mere barley; that shows loow very much the generation of saccharine matter, and the subsequent proper development of it, depend upon the very great nicety with which the process is conducted, and the whole process being permitted.

4297. In order to make it useful for the purpose described, namely, feeding cattle, it is necessary to make it into malt?-Yes.

4298. You would consider it malt when it is dried?-Yes. To a certain degree, no doubt, spirted barley is better than dry barley; but in order to have the full benefit of it, it ouglit to be dried.

4299. One good effect you would anticipate from allowing the farmer to malt his barley would be enabling him more beneficially to himself to feed his cattle with it?-Yes. I have tried experiments on a small scale, and I have no hesitation in saying, if farmers last winter had malted their wheat, which they were selling at $4 s$. to $4 s .6 d$. a bushel, and fed their cattle with it, and their cattle had come to market at the present prices, it would have paid them from $6 s .6 d$. to $7 s$. a bushel.

4300. 'The price of wheat would have been raised in consequence of that additional consumption?--No doubt it would.

4301. Are there any other advantages you consider connected with the repeal of the duty on malt? - Y es; but I wish first to say one or two words with respect to the food of cattle. It is generally supposed it would be the light soils only that would receive benefit from the altering the duty. Now, were I to point out the soils which would receive the most benefit, it would be the clay soils. Every practical farmer knows that the great difficulty attending the proper cultivation of clay soils is the heavy expense he is put to in obtaining a sufficient quantity of winter food for cattle to furnish manure; on such soils he cannot grow turnips or any green food, for winter consumption; but if the farmer could malt his own grain of all sorts duty-free, for the purposes of feeding cattle, he would be able to fatten a large quantity upon his farm; and he would substitute that for that which is now the most expensive food, oil-cake, which comes from abroad; this would give him a very great facility to procure manure for his clay soil farms.

4302. Are you aware of any difficulty this permission would produce in the collection of the revenue?--I have no doubt that the permission to the farmer would be attended with difficulty.

4303. It would be felt to be an opening to fraud?-Yes; but I do not think that is an insuperable difficulty. But I conceive there is a far better way of doing it, and attended, not only with benefit to the farmer, but to the public at large; and that is, taking the duty off the malt, and again placing it on becr. There never was such false legislation, if I may use such an expression, as that of taking off the duty upon beer, and opening beer-houses.

4304. That would get rid of the beer-houses? - It would.

4305. Would not the revenue be increased; for it does not necessarily follow that he who brews would brew malt ? - I conceive it would increase the revenue; for by the operation of the tax at this moment there is an inducement to the brewer of beer to brew from any thing but malt. The duty on beer operated as an inducement to brew from malt; the duty was on the article when finished; therefore it became the interest of the brewer that an article so heavily taxed, when finished, should be of the best possible quality, because he paid the same tax, which formed a very large proportion of his expense, on a bad article as a good one. Now that security for a good article is gone, for there is no duty whatever on beer. The consequence is, in the manufacturing districts there is an opportunity and an inducement to brew frum any thing but malt. I act as a magistrate in a most populuus district round Birmingham, where convictions for the use of grains of Paradise, and other things used in brewing, are very common.

4306. If the duty be transferred from the malt to the beer, would that induce them to brew from malt instead of using those articles ?-No doubt, for malt would be the cheapest article they could get.

4307. That would be a better beer for the lower class?-It would ensure a better description of beer, and it would ensure the protection of the revenue.

4308. Do yon propose that the duty should be paid on beer, though it is never sold? - No, neerely beer brewed for sale by retail. I would still permit the sale of beer, not to be drunk on the premises, duty-free, but I would admit that under certain restrictions which were not properly attended to before. 
R. Spooncr, Esq 4309. You suppose two cases of benefit to the farmer, giving him the use of his barley; the one merely allowing him to malt barley, and consume it in the way in which he is not now permitted to do; the other the transferring of the malt-tax to beer?-Yes, and the very best way of doing it would be to transfer the duty from the malt to the beer.

4310 . You conceive that transfer would be attended with very good effect, and that it might be done with a due regard to revenue?-Yes.

4311. Is there any other article, foreign or domestic, taxed now as barley is when made into malt? - No.

4312. Is tea taxed so highly? - No.

43 เ 3 . Is there any article of manufacture so taxed?-Certainly not.

4314. Is cotton?-No.

4315. The hemp?-No.

4316. The flax? - No.

4317. The tallow?-No.

4318. Is there any article taxed one quarter so high as the malt?-Certainly not.

4319. You are aware that the tax formerly on the importation of raw cotton was higher than it is now, and that the tax on the importation of hemp and flax was higher formerly than it is now?-Yes.

4320. And beer, till very lately?-Yes.

4321 . In your opinion, if the old taxes on those different articles were resorted to, and an equal land-tax distributed all over the country, would not that abundantly supply the deficiency of the malt-tax ?-I have no doubt it would, and that the whole together would be found highly beneficial to the country: and no one can look at the present state of the cotton trade without great alarm. When one sees the immense number of people brought together, and that it is a trade which can be extended to almost any amount by machinery, the tendency of which is to draw together an immense number of people; that it wants the usual limit which checks too rapid an increase in most other trades, namely, the power of getting hands instantly they are wanted, machinery being applied instantly obviating that difficulty; --if any thing should happen to stop their trade, by the glut of the foreign market, which I think must inevitably happen, the frightful effect on the exchanges of this country can scarcely be anticipated. That which we have already once seen I think very likely we shall see again. The great profit on the manufacture of cotton goods leads to an immense speculation in the import of raw cotton. How are the engagements to pay for the import of the raw material to be met, if the export of the manufactured article should be stopped? The exchanges would be deranged; a great demand created for gold ; the bank issues diminished; and one can hardly contemplate the effect of throwing out such a number of hands as must inevitably be thrown out of employment under such circumstances.

4322. Are you of opinion that a sufficient duty might be raised from those articles without injury to the country, a great injury to commerce, which would enable us to take off the malt-tax? -I am decidedly of that opinion.

4323. You have lived near Pirmingham :-I have.

4324. That place has increased enormously?-It has.

4325. Do you know whether Birmingham has felt the effect in any way of agricultural distress?-I know the factors whose trade is among the country trade, in the purely agricultural districts, complain very much of the falling-off in that branch of the trade, and the difficulty of getting paid for those articles they supply.

4320 . Have you seen the resolutions of any meeting a year or two ago at Birmingham respecting the diminution of their home custom?-I have seen them.

4327 . Do not they complain that when the prices were high the farmer bought liberally; that now he uses his worn-out gear, and does not buy new?-That is just the fact.

4328 . Have you the means of knowing that Birmingham and other towns depending on the home trade are suffering from the distress of agriculture?It is more the case in other towns than Birmingham, because Birmingham is so largely connected with the foreign trade, with the iron trade, and the peculiar demand for railways, and so on, it is not felt in Birmingham; but in the small towns, where the whole of the business depends on the consumption of the agriculturists, they do feel that distress very much, not merely in articles of luxury, 
but in articles of nccessity, for the farmer is obliged to do without them, and puts himself to great inconvenience in consequence.

4329. Before the railroad mania began, was not that the case with respect to Birmingham?--To a certain degree; but the trade of Birmingliam has been increasing very rapidly the last three or four years.

4330. Is it in consequence of those speeulations ? - I think it was greatly in consequence of the very low price to which manufactures had been reduced, having forced themselves into the continental market at a low price, and thus created an increased demand. I would wish to turn your Lordships' attention to the question of the beer-houses; that really is a matter that calls loudly for some sort of remedy; the great evil which was found originally in giving permission to certain houses, called private brewers, to sell for consumption, not on their own premises, arose from the licenses being uranted a great deal too indiscriminately; they were granted, in many instances, to persons who had not sufficient station, if I may use the phrase, to men of straw. If you took the duty off malt, and laid it on beer sold for consumption on the premises, and granted permission still to retail beer to be consumed off the premises duty-free, that might be guarded by requiring that the houses occupied by persons to whom such licenses were granted should be rated to a higher amount; they would then be persons occupying a station in life who would not be likely, by the small profit on beer, to be tempted to run the risk of fine or imprisonment; but many licensed under the Act as it originally stood, ran no risk at all; they were induced by brewers and others to become the agents for selling their beer; if they could get a trifling profit by it, it was of little consequence to them if they were brought before the magistrates and convicted; they had nothing to pay, and they went to prison for a short time, and perhaps lived quite as comfortably there as they might have done in their own houses. But if that could be guarded against by taking care that the licenses should be granted only to persons paying a certain amount of taxes, I think they would be kept by persons who would not, for a trifling profit, hazard so great a risk.

4331. Are you not aware that many of the common beer-houses belong, not to the men who give themselves out as occupiers, but to the brewers themselves?That is much more confined to a certain district called the home district; it is not the case in our district; there are very few brewers in the manufacturing districts who are owners of houses.

4332. You are yourself a considerable agriculturist? - I have been a farmer these 30 years.

4333. How much land do you occupy?-Not much land, only about 150 acres; but it is very good land, and farmed in a very high manner.

4334. Are you acquainted with the state of agriculture round your country? Yes; I have been brought into contact during the last month with farmers from all parts of the kingdom; I have gone accuratcly through the statements of farmers from all parts of the conntry.

4335. In your own immediate neighbourhood have you found, even with your good farm and good management, and plenty of capital, that it is a profitable or an unprofitable concern?-It is very unprofitable; it leaves very little for rent, after the expenses of cultivation.

4336 . It does leave something ?-Yes, for it is land of very high quality; it is dairy land, in the neighbourhood of the city of Worcester.

4337. You have a demand for your dairy produce?-Nothing like the demand we used to have; but the first quality land has not gone out so much as others.

4338. As a banker of Birmingham, can you give an opinion of the state of the farmers round the country? - I know them to be in a very bad state.

4339. Are they solvent or insolvent, generally speaking:- A vast number are insolvent; they are all insolvent as it affects their farms, unless they have private property.

4340. You think that the farms do not pay rent?-Not except the very best lands.

4341. What proportion should you consider those?-Through the kingdom I can very safely state that they are under one-fourth.

4342. From your business as a farmer, and from the communications you have had with people in the country, what do you consider to be the state of the farmers generally in that county? - I consider that they are losing their capital very fast.

464 .

I I 4

4343. Do 
4343. Do you think they can go on many years longer?-It is utterly impossible.

14 March 1836. 4344. What will be the effect of this; in what state will they be?-The effect will be, in my opinion, most dreadful, for it will end in a great quantity of the land being thrown out of cultivation, and a great reduction of rents on all lands where there is any rent remaining, and a very great want of employment for agricultural labourers.

4345. Will that produce disturbance in the country ?-Most undoubtedly ; and I am sure, from information I have received, and which I have sifted with very great care, that there is very much cause for alarm in many counties of England at present; I should mention the counties of Norfolk, Suffolk, Cambridge, and some parts of Kent and Sussex, where I have with great care gone through the accounts which farmers, very intelligent men, have shown me; and it is clear that they are carrying on farming now at a loss, without paying any rent at all.

4346. You conceive that the alteration of the tax from malt to beer would be of essential importance; in a certain degree restoring the proper state of things? - I conceive it would be a very great palliative and a great relief; but I cannot look to that alone.

4347 . Do you consider the currency to be one cause?-I consider that to be the chief moving cause; there are other causes.

4348. Have you derived the information respecting other counties from farmers you have scen from different parts of the kingdom? - Yes.

4349. They have satisfied you of the verity of their accounts?-I have seen the accounts, which, on the face of them, were evidently not formed for the purpose.

4350 . They appeared to be accounts they had kept in carrying on their business?-They are the accounts kept in the rough manner in which farmers keep them, proving to me they had been made at the periods to which they refer.

4351. As a banker, is accommodation extended to farmers in the manner it was formerly?-Undoubtedly not. In speaking of labourers, I do not think that the labourers in tlie midland counties are by any means in a bad state at this moment, for they are within the influence of the great increase of manufacturing prosperity, and their wages are much higher than the farmers can afford to pay, and much higher than they are in those parts of the kingdom wholly agricultural; and at the present moment they are better off.

4352. Are they better off in respect of the price of wheat than they were in what were called the high times? - Yes ; the labourers in the neighbourhood of Birmingham, and in a very considerable part of the county, are getting $10 \mathrm{~s}$. a week, which would represent, till within the last month, more than two bushels of wheat; and in the war they were getting about $15 \mathrm{~s}$. a week, which represented a little more than a bushel and a peck; in fact it has been rather an injury to the farmers having the wages thus kept up by the manufacturers in many places; it is in one county peculiarly hard; I have become acquainted with the particulars lately; I allude to Glamorganshire; in that county the iron trade is exceedingly flourishing, and the rate of labour very much raised; but the farmer receives no benefit from this higher rate of wages, because the consumption so created amongst the labourers by the increased rate of wages is supplied from Ireland; and he has actually got the price of labour raised against hinı, and the price of his produce lowered by the immense importation from Ireland: and there is another great difficulty, unfortunately, attached to that; should any thing stop the iron trade, those men who are now engaged in that trade would be sent back to be supported by the poor-rates paid by those very farmers.

4353. To which the manufacturers do not pay in their proportion?-Certainly not.

4354. Suppose a manufacturer lives in a town, has he not workmen working for him in all the villages round, to the support of which he does not contribute a single farthing?-Yes, in a certain degree.

4355. In the districts of which you have been speaking, should you generally consider that the labourer who is employed is better off than he was during the high times?-In the midland counties, and those particularly connected with manufactures. 
4356. Are you well acquainted with the countics of Norfolk and Suffolk, as to the agricultural labourers ?- Merely from the communication with farmers who have been in town. I am the chairnan of the body of agriculturists who are in town seeking relief.

435\%. As far as your informalion gocs, do you conceive that the labourer who is employed is generally better off, with respect to the necessaries of life purchased with his wages, than be was in the high times?-Certainly not, in purely arricultural districts; where they are within the influenec of manufacturing wages they are.

4358. In those agricultural districts, what is the average of the labourcr's pay, so far as rou have ascertained - In many counties they are giving only $7 s$. and $8 s$. a week. In Herefordshire, when I came up to London, they were giving only $6 s$. and in certa:n parts of Woreestershire they were giving only $7 \mathrm{~s}$.

43.59. Would $7 . s$ or 8 s. give more produce in corn now than the former wages of $16 s$. and $17 \mathrm{~s}$. at the high prices of wheat?-Yes, no doubt; but that will not apply in other articles; their rent and their clothing are not reduced to the same degree. Cotton goods are reduced, no doubt.

4300. Is not woollen much reduced :-No, I think not; and their clothes are very bad in many districts. They do not lay out much in new clothes.

4361 . Has not the cotton driven out the old woollen dresses the women used to wear?-Yes, entirely so.

4362. Are not cotton and woollen very much reduced in price with respect to the articles of dress used by labourers :- Iudging from the price of wool, I should say that woollen goods must have risen very much.

4363 . The woollen goods the women and men used to wear formerly were the produce of this country - -Yes, and the product of their own labour in their own cottages, instead of being made by machinery.

4364. The cotton wool is entirely of foreign product, and is manufactured by machinery in distant towns:-Yes.

4365. Have you ever made a calculation of the annual value of Irish produce imported into this country? - No; but the quantity of wheat imported from Ireland has fallen off in the last three years.

$4360^{\circ}$. Do you attribute that falling off of Irish wheat to their using a good deal in distilleries? - I attribute it to the using a good deal in distilleries, and to the low price in England.

$43^{6} 7$. Have you not always found, that when the prices have fallen down here, the importations from Ireland have been stopped; but the moment the prices have revived, the importations from Ireland have revived again?-Yes.

4368. Will not that, in a length of time, continue to keep down the prices here? -I conceive it will.

$436 \mathrm{~g}$. Will not it bring down the rate of English prices to the rate of Irish prices? - If that anomaly is suffered to exist, which does nuw exist, that England is charged with poor-rates before it can bring any part of its corn into the market, and Ireland can come into the market withont any poor-rates at all, the tendency of that must inevitably be to drive down the English labourer to the state of the Irish labourer.

4370 . Have you any means of knowing what the rate of wages in Ireland is? -l do not accurately; but if I rightly understand, it is under $6 d$. a day. But the question in Ireland of the poor laws appears to me to be just the same as if in England there were half a dozen counties totally free from the maintenance of their poor, who might send them about as vagrants, and not be charged with them; it would be impossible for other counties to compete with them; this is the case in Ireland; and as long as that exists, the tendency must be to bring down the state of the English labourer till he comes to the state of the Irish.

4371 . Will not it pull down the English farmer and the English gentleman?Yes, it must.

437:. Do you really think, that supposing poor laws are enacted in Ireland, that would prevent the Irishmen coming over here; if they get only $5 d$. or $6 d$. there, and can get $2 s$. a day here, would they be such blockheads as to stay there?-Certainly not; but that would not be the way it would operate. The nonresident landlords, finding that before they got their rents there must be a charge for poor-rates, would see whether they could not find some way in which those people could be employed at home. 


\section{MINUTES OF EVIDENCE BEFORE SELECT COMMTTEE}

R. Spooner, Esq

14 March 1836 .

4373. Would not they eat a little more of their own corn at home?-Of course ther would.

4374. In cultivating a farm, taking the poor-rate and wages into estimation, those charges make such a difference in the expenses of a farm in England and in Ireland, that it would not be possible for the English farmer to compete with the Irish :- I conceive without poor-rates it is impossible.

4375. Labour is here the great expense of the farmer, and would still be very great:-I conceive that the tendency would be to raise the rate of wages in Ireland.

4376. Would not there be a greater number employed upon the land, and so increase the consumption:-Yes; and though that would increase consumption, we always find that when prices are lowest in Ireland there is starvation, and you see famine in the midst of plenty.

4377. Does that apply particularly to the last famine, for the relief of which a large subscription was raised in this country?--Yes, peculiarly so ; we were subscribing here to send back the very same produce which liad deluged our markets; they would have been starved if we had not done it.

$43 \% 8$. You think that, through the urgent necessity for further employment in Ireland, if there are poor-rates in Ireland, demands would keep pace with the additional supply?-I do ; and that it would put the labourers into a consuming as well as a producing position. He now sends the crop be produces to a market which has already got as much produce as it wants, because, in fact, he is not in a condition to eat it; but by establishing poor laws he would soon, in my opinion, be in a condition to consume it in his own country.

4379. The poor man in Ireland now has merely this alternative, take $5 d$. a day, or go and starve; suppose he had a claim on the poor laws for support, would he not be able to make a better bargain with his landlord? - I think so.

4380. Supposing an Irish land-owner had 1,000 acres of bog, which might be drained; if there were poor-rates in Ireland he would find it necessary to find employment for the people, and would therefore drain his bog; consequently in that district the demand would keep pace with his supply - Y Yes; and that demand for labour would put the labourer into a condition to make his own terms, and he would enjoy the benefit of it, which he does not now.

4381 . Do you know whether in the parts of lreland in which your public works are carried on, they do not, in consequence of getting better wages, live better?-I cannot speak to that particularly.

$438_{2}$. Is there any other cause of the present depression of prices and the consequent depression of agriculture, the removal of which would relieve the agricultural interest, besides those which you have enumerated?-I am not aware of any other that causes the depression of prices.

$43 \delta_{3}$. Is there any thing else which it occurs to you to state?-There is nothing occurs to me particularly, except what has been mentioned elsewhere, the local burthens which press unequally on the agricultural interest. I confess myself, I do not think that great relief can be administered by the alteration of parochial burthens, unless the payment of the whole, including poor-rates, were put on a national assessment; I do not think the local burthens could be beneficially altered by any thing short of this.

4384. Must not that be done in some way or other, unless there be given to the farmers of this country a monopoly, not only against foreign farmers, but also against the Irish, which will enable lim to throw off those charges on the otler part of the population of the country :-There is no doubt of that.

$43_{5}$. There must be equal direct taxation, or there must be given to the person against whom there is unequal direct taxation the power of charging it on his neighbours:-Yes.

4386 . Have you turned your attention to the warehousing system of this country

$438 \%$. What do you think would be the effect of removing that?-I do not myself anticipate any beneficial effect to the agriculturist by removing it.

4388 . Do you not think it would induce the speculators to speculate in home instead of foreign corn? - I do not; I have thought a good deal about it, and my opinion is, that the only direct effect of altering the warehousing system would be, that instead of corn bcing warehoused in this country in English warehouses, and so far with the employ of English capital and labour, it will be warehoused on the other side of the water. 
4389 . Do you think they would speculate in it unless it was within the protection of the English law?-I do; and I know I am supported in that by the opiuion of many persons very conversant with the Englislı corn markct.

R. Sporner, Esq. $14 \mathrm{March}_{1} 8_{3} 6$.

[The Witness is directed to withdraw.

Ordered, That this Committee be adjourned till To-morrow, One o'clock.

Die Martis, $15^{\circ}$ Martii, 1836.

The Lord KENYON in THE Chalk.

Richard Spooner, Esq., is called in ; and further Examined, as follows :

4390. WHAT other circumstances occur to your mind that have tended to the present depressed state of agriculture?-I conceive the main cause to be that of low prices, occasioned by our present monetary system.

4391. By the monetary system you mean the state to which it was reduced in the year 1819?-Yes; it began long before that. I apprehend that I need not state here that which is admitted by every body to be perfectly true as an axiom, that the price of every thing is regulated by the quantity of active circulating medium ; that if yon increase the active circulating medium you will always raise prices; if you decrease it, of course you will have the contrary effect. The present monetary system will not permit the prices of commodities in this country to take that level necessary for a fair remunerating price to the owners and occupiers of land, while the paper currency of the country is liable to be converted into gold at $3 l .17$ s. $10 \mathrm{~d}$. an ounce; that liability must completely regulate the quantity of circulating medium, and which quantity of circulating medium will not be found sufficient to carry on the transactions of the country. I apprehend, if your Lordships will examine, you will find that that is not a mere question of opinion, but it is a case supported by history and by facts; for if you will look back to the Report of the Secret Committee, in the year 1793, on the commercial credit of the country, you will find it distinctly stated there, that the cause of the great failures which had taken place, especially in the north, - at Neweastle almost all the banks stopped, - was to be traced to one, two, or three causes; the one, the very great drain for bullion to pay for imported corn; the other was the alarm which had been occasioned by the war then just breaking out-the apprehension of invasion; the farmers were alarmed, and hoarded what bullion they could possibly get together; that made a very great demand for bullion ; that demand for bullion created a contraction of the curreney, and that brought on a very great and pressing distress; and the committee reported that persons perfectly solvent in their circumstances were rendered unable to pay, not from any acts of their own, but from a diminution of the circulating medium. The committee recommended it should be relieved immediately by the issue of Exchequer bills; that issue took place; the Bank of England advanced upon those Exchequer bills, and great relief followed; increased circulating medium gave the relief; but that followed which always will follow while the circulating medium is liable to be controlled by being brought to the test of gold at $3 l .17 s .10 \frac{x}{2} d$. per ounce, 一 gold left the country; the crisis of 1797 followed, and Mr. Pitt brought in the measure for the suspension of cash payments. This was not made necessary by any thing which happened in that one year, but was occasioned by a long-continued struggle between the then standard of value and the circulating medium necessary to carry on the transactions of the country. I think, if your Lordships turn to Mr. Pitt's evidence, which is a most important evidence, before the Secret Committee in the year 1797, you will see that Mr. Pitt clearly contemplated the necessity of, at some future time, fixing a standard of value which would enable you to build a large superstructure of circulating medium, and better adapted to the circumstances of the country. I think also that the difficulty has again been most materially increased by returning, not to the old standard of value that did actually exist in the year 1797 , but to a standard of value far more against the debtor of the country. The whole standard 46. 
R. Spooner, Esq. previous to 1797 , with the exception of nine years, was a standard conjointly of gold and of silver coin, protected likewise against melting and export.

15 March 1836.

4392. Gold coin to any amount; silver, not as coin, but as bullion? - As coin to any amount, with the exception of nine years. The contrary is a very common opinion, but it is a very erroneous one; and so common an opinion is it, that in the framing one of the Acts of Parliament, I think the Act of the year IS16, the first enacting clause sets out with repealing part of the Act of Parliament alluded to (that for restraining silver coin to $25 l$.), which had expired in the year 1783 . The first limitation to which your Lordship alludes took place in 1784: after the regulation of our currency in the reign of King William III. the first Act that put any limit on silver as a legal tender was in 1773 ; that was only for one year and to the end of the next succeeding session of Parliament; it was continued by one or two other Acts of Parliament, the last of which expired in the year 1783; and in Mr. Vausittart's own words, in the years 1810 and 1811, when he argued against Mr. Horner's proposition for returning to the standard of value, he laid down this very remarkable declaration:- "That there never did exist in this country that invariable standard of value to which the honourable and learned gentleman was then urging the House to return ;" and he said, "that up to the year 1797 you might have paid the whole of the national debt in crooked sixpences, if you could have got them;" and in my Lord Liverpool's Letter to the King, he there states the same fact, that the Act of Parliament had expired in the year 1783 , and yet, notwithstanding that, the subsequent Acts dealt with it as being in existence. What is more astonishing, Lord Ashburton, then Mr. Baring, whose accuracy I should have almost taken for granted, has made the mistake in the evidence he gave before the Committee of the Board of Trade, the 12th of February 1828. (House of Commons Paper, No.31, 1830.) Mr. Alexander Baring says, "Before 1778 silver coin of proper weight was a legal tender for all sums, great or small ;" therefore he appears to have fallen into the same mistake.

4393. In point of fact, in what was it at that period that silver was a legal tender?-In any way in tale to any amount, with the exception of those nine years, without any reference whatever to its weight. If a man owed $10,000 \mathrm{l}$, if that man had got $10,000 \mathrm{l}$. in plain sixpences, he could have paid in them.

4394. He could not pay in the sixpences if they were under weight?-Yes; they were the King's sixpences; the regulation limiting the amount by tale had expired; it lasted only from 1774 to 1783 .

4395. Do not you conceive that the fact of its being ordered that the silver should be of a given weight would of itself put it out of the power of any persons to give it if it was of a deficient weight :-I certainly doubt that, because it was by that $\Lambda$ ct of Parliament that it was limited.

4396. Do you recollect that there is a distinct expression in one of the Acts of Parliament that it is to be paid up to $25 \mathrm{l}$. in coin, and above that by weight? - That was the Act which expired in 1783, having first passed in 1774, the last Act of renewal in 1778 .

4397. That was an Act, you apprehend, rather for restricting than extending the power of paying in silver?-Yes; and that restriction lasted only those nine years. Now we have adopted as a standard the gold standard, only preventing the debtor paying in silver and going to the cheapest market. There is a value also given to coin as a mercantile commodity; formerly, once coin, it must always afterwards be coin; it could not be legally melted and exported; the exporters were subject to very great penalties. I know well that Act was evaded, but it was not evaded without a great risk, and consequently without a corresponding profit; and exactly in proportion as you take away the risk, and the necessity of a corresponding profit, you facilitate the export of the coin; you gave to it a new value and a new character, as an article of merchandize, which it did not possess before, therefore; it is unjust to require from the debtor the same amount of coin as you did before, when it could not be legally melted and exported. So with respect to silver; you prevent silver being the legal standard. Formerly, if a man sent his goods abroad, he might sell for silver or for gold, and having received that he might coin that silver or that gold, and with that he might pay his debt; he is now restricted only to one coin, and that the most inconvenient, gold, because that, as a standard, is rejected by every other nation in Europe. If a merchant sells his goods abroad, he knows when he purchases them here what quantity of gold he is compelled to pay for them, but he cannot form any correct estimate what quantity of gold they may fetch abroad, for the only payment he may demand is silver, 
and he must then go into the market to purchase grold, and there may be circumstances which he could not anticipate, and over which he could not exercise a control, and which may have raised the price of gold; that very circumstance of his being obliged to purchase the gold may absorb the very profit on which he hat exported his goods. The derluction is, that you have returned to a standard of value much more agrainst the debtor,--practically 15 per cent. more against the debtor, - on the standard of value, than the original standard in the year 1797.

4398. It is your opinion that we have returned to a standard of value which never had existed in this country before?-Yes; nor has there been in any other country a single gold standard.

4399. If we had returned to the ancient standard we had in 1797 , a mixed standard of silver and gold, that would lave been an advantage to the public debtor of 15 per cent. :- A mixed standard of silver and gold, and a protection against the export of silver and gold, would have been a protection to at least 15 per cent.

4400. Do you think any attempt to prevent the export of coin has ever been effectual :-No; but the risk of exporting it always made it necessary to have a certain profit to cover that risk; now it goes for the mere carriage, without legal risk. 'There was also another restraint, and a very important one,-a moral restraint; respectable merchants would not break the law; now that moral restraint is removed, and of course they pay in that way which will render them the highest profit.

4401. Have you any data from which you can form an opinion what quantity of gold is in circulation?-No, I do not think we have any data at all. At present there is no doubt gold is coming into the country. Gold coming into the country has occasioned an increase of the circulating medium, not only as far as the yold itself has increased, but, as it always will do, has increased the quantity of paper in circulation, and that has tended to raise the prices of all manufactured goods very materially, and is extending itself to raise the prices of agricultural produce; and, I have no doubt, as long as that continues unchecked by any alteration of the exchanges, the agriculturist will continue to receive the benefit of it. I anticipate an increase of prices; but I anticipate exactly the same result as followed the increase of prices in 1825; the same causes are at work, and, in my opinion, will inevitably produce the same effects; not so rapidly, and for this reason, that before the speculation took a foreign turn, and a great deal of our money was absolutely lost in foreign loans and speculations in mines, but now it is taking a more domestic turn, in improvements, railroads, and domestic commerce; but it will have this effect; it must have the effect of raising the prices of agricultural produce, because it lias given to a very large proportion of our community the power of consuming a great deal more than that portion did before ; the rise of the price of agricultural produce will again act upon labour; an increased price of labour will follow; that will again act on the price of our manufactures, till they come to the point at which gold will be the cheapest article of export; and then, the Bank being compelled to find gold to the holders of its notes at the old rate of prices, and manufacturers having taken a new rate of prices, there will be a profit on the exportation of gold; the liank must meet that, in self-defence, by again withdrawing its notes, and that will produce the effect which was produced in 1825 ; whether that will come quickly or at some distance of time, depends, in my opinion, upon whether we have the continuance of good or of bad harvests; one ol two bad harvests following one another will, in my opinion, break up the whole monetary system; it will be impossible to carry it on under such circumstances.

4402. On account of the necessity of importing a quantity of corn? - Y es; taking out bullion to pay for it; for they who argue that manufactures will pay for that corn come too hastily to that conclusion; that that would be the effect of a long continued course of a free trade in corn I have no doubt; but to suppose that it will suddenly have that effect is a delusion. I can hardly conceive more dreadful events which would occur, if, from famine, we wcre obliged to open our ports : gold nust go out in that case to purchase corn; the Bank must withdraw their notes; market prices must inevitably rise in consequence of the famine; and at that moment the manufacturing labourers would no longer be employed, for want of means to pay them. I do not hesitate to say that the situation in which we are placed, by having the whole system of paper credit based on so narrow a 464 . 
R. Spоoner, Esq. 15 March $18,6$. ground, is very alarming. very liastily at any time.

4403. The foreign importer of corn would not take manufactures in return, unless it $w$; $s$ a more profitable speculation than receiving payment in gold or in any other way? - No; that must be the effect of time. $A$ great part of our corn would come from Poland; we are all aware of the habits of Poland, and they have not the power of paying for, nor the habit of consuming, our manufactures; they conld not take them at present; ultinately, the result of making then rich, by finding for them a market for their corn, would be to make then luxurious, and then they would become the consumers of our manufactures; but to do this we must make them rich by making ourselves poor.

4404. What would you suggest to obviate that danger which you think is to be anticipated?-I should say undoubtedly that the most practicable remedy at the present moment would be to make silver and gold jointly the legal tender, and to make it at the price at which silver coin is now coined, namely, $5 \mathrm{~s}$. $6 \mathrm{~d}$. an ounce; any thing short of that, in my opinion, would be a complete delusion. I for one should be exceedingly sorry, as being one of those who have always said the currency was too limited, to give any sanction to a cliange short of that, for it would be a change attended with all the evils of a change, without any benefit whatever accruing to the country.

4405. The effect of a silver standard at the old mint price, $5 s .2 d$. per ounce, would go only to 10 or 12 per cent. ?-It might go to 10 per cent. ; five per cent. in its monied value, as near as possible; but I think there might be five per cent. in the difference of mechanical protection.

4406. Supposing the Bank were called on to pay its notes, not as it does now, in gold, but in a mixed standard of gold and silver, what benefit would the country derive from that?-If at $5 s .6 d$. an ounce, I think that prices would rise about 15 per cent.

4407. Would that remove from the Bank any risk to which it is now exposed from being called on to pay its notes in gold?-Certainly, because that would make the base wider on which public credit is built. Any alteration that took place in the value of bullion would not lower the prices of commodities to that point to which they are now lowered, and therefore would not inflict so great an injury on the productive classes of society.

4408. When there has been a panic the Bank has been at some difficulty in providing gold; in what way would it be able to get a sufficient quantity of treasure into its possession not to be subject to that risk?-If you change the legal tender to gold and silver jointly, at the rate of $5 s .6 \mathrm{~d}$. an ounce, that would give a tendency to a great quantity of silver to flow into this country; it would be a bounty on the export of manufactures, and an encouragement to the import of silver.

4409. Would the Bank liave the power of commanding a greater quantity of silver than it has of gold in the foreign market? - Just the alteration which would follow from an alteration of prices of 15 per cent.

4410. Would not the Bank be able to do that if it could issue silver, which it cannot do with gold alone?-Not the Bank only, but all debtors.

4411. Would not the Bank, which is the body to which the country looks to afford it the circulating medium, have an opportunity of doing that, if it could issue silver as well as gold, which it does not possess at present with gold alone? -Certainly; it would have more of the two metals in common use.

4412. Would not that give an opportunity to the Bank, and likewise to private banks based on solid security, to issue notes, so far as the public seems to demand it, without being liable to the risk to which they are now exposed?Certainly, to a very great degree; the circulating medium might be increased very considerably, and very safely.

4413. What fair increase of the circulating medium might be expected, based on a system of large treasure, to afford, in case of great urgency, the precious metals instead of notes?-I conceive no numerical account cau be stated of what the positive circulation of the country is, for there are various periods at which the same circulation will not meet the wants of the country which may at other times; but I think we might safely depend on the increase of price 15 per cent. higher being maintained in this country if a paper circulation was based on a conjoined standard, than being based on a mere single gold standard.

4414. Suppose 
4414. Suppose that increased price was to raise the agricultural produce, what effect would that be likely to have on the commercial or manufacturing interests ?-It would have a beneficial effect rather than otherwise; it would not at all raise the price of our manufactures so as to prohibit their export, for the returns for those exports would be measured exactly in the same aitered standard as the exports themselves were measured ; the question with the foreigner being, not what we do with our gold or our silver, whether we coin into sovereigns or lalf-sovereigns, that being a question between the debtor and creditor of the country; the question which regulates foreign trade is, how much weight of gold or silver is required to pay for a given quantity of exports; and that would not be altered by the standard price at which we coin the gold when it comes into this country.

4415. Have you any means of ascertaining what is the average amount of the home consumption with respect to manufactures, compared with the amount of foreign deniand?-No, I have no other than that which is open to your Lordships; the different tables, Marshall's Tables, and other tables, which I think are liable to very great mistakes and errors.

4416. Is it your opinion that the increase in the home market, which would necessarily be produced by a change with respect to the productive value, would be counterbalanced by any loss which might be sustained by the increased expense to which the manufacturer may be put in producing his articles ?-I conceive there would be no increased expense at all; that the increased cost to the foreigner is not regulated at all by our standard of value here; it would be merely a nominal rise of price. Suppose I send over a quantity of iron, that quantity of iron would produce me a certain quantity of gold: it signifies not to the foreigner what $I$ do with that when I get it here, whether I coin it into sovereigns at $15 s$. or sovereigns at $1 l$; the only persons interested are the debtor and creditor of the country: and if, instead of gold, colonial produce or any foreign produce came in return for the iron, that would be measured against the same standard of value as the exported iron.

4417. Do you think that would prevent the home manufacturer selling the goods abroad as cheaply as he does now ?-Not the least.

4418 . Do you think any departure from the Bill of 1819 has taken place ?Very considerable departures have taken place; and that is a very important part of the subject, because it is said universally we admit we were wrong; we did wrong in 1819 , but it is now too late to go back. Now I think that is a more fatal delusion, if possible, than that of the year 1819. You have not been under the effect of that Bill ever since 1819; the first effect felt was in 1815, immediately after the peace, after the battle of Waterloo; every body then expected there would be an alteration in the currency; that created a great deal of distress. In the year 1816 there was great distress; but it will be found that the period of returning to cash payments and the continuance of the propertytax were postponed, if I recollect rightly, for two years; that relieved the distress at that moment; and there was a very considerable increase in the Bank of England notes in the year 1817. In the year 1815 the Bank of England notes had been reduced from $28,000,000 l$. to $26,000,000 l$., and the country notes from $22,000,000 l$. to $19,000,000 l$. In the year 1816 came on the great distress, and in which distress the price of corn did not fall down so low as might have been otherwise expected, bad harvests having operated upon prices. In the year 1815 there was a reduction in bank notes, in the year 1816 the reduction continued, and in the year 1817 they were raised again from $26,000,000 \mathrm{l}$. to $29,000,000 l$., and the price of wheat got up immediately from $75 s$. to $94 s$. In the year 1818 it still continued to rise, and circulation still continued to rise; the circulation was, of the Bank of England, upwards of 26,000,000l., nearly $27,000,000 l$; and, of country bankers, upwards of $20,000,000 l$. In the year 1819 , when they determined that they would return in the course of two years to cash payments, the Bank reduced its circulation down to $24,000,000 \mathrm{l}$., and the country banks were reduced down to $17,000,000 \mathrm{l}$.; and then came on the lamentable distress of 1819,1820 and 1821; and in 1822 Lord Castlereagh came down to the House, and stated that the principle was right upon which thcy had been acting, but that it had been carried too rapidly to work; and he proposed three distinct different measures for the purpose of increasing the quantity of the circulating medium. From that moment the Bank of England notes began to increase, and went on increasing till the year 1825, and then exchanges had 464 . 
R. Syouner, Esq. turned very much against the country; the Bank as rapidly decreased its issnes; the panic of $1 \$ 25$ and the distress of $1 \leqslant 26$ followed, and for two or three years after that all the great interests of the country were suffering, the manulacturing and agriculuural interests. Joint-stock banks were then encouraged by Lord Liverjool and the Government of that day ; they have got into action, and have increased their circulation very largely; that has operated a great deal more on the mercantile and manufacturing interest than on the agricultural, for reasuns which night be explained; and the consequence of that circulation is now beginning to be felt in the rise of agricultural produce, and I fear will end exactly as it did in the rear 1825, unless some step is taken.

4410. Why do those banks give assistance to the manufacturing and not to the agricultural interest:-Because the way in which they conduct their business, the very system on which they proceed, is much more suitable to the manufacturing and commercial interest than the agricultural ; they are formed in large towns; they are composed of gentlemen intimately connected with the manufacturing and commercial interest of the country, and their habit is not to make advances, but to discount bills. Before 1819 country baukers were in the habit of lending money to farmers, but in 1825 , when the money was wanted, they could not get it in; they had not bills they could take into the market and raise money upon, while every body was demanding money from them; and therefore all bankers are extremely unwilling, in the present unsettled state of the monetary system, to part with their money for any thing else than bills, which they can turn into money again when any occasion arises to make them want it ; and there are now large sums of money, it is well known, belonging to bankers lying unemployed, or employed at two and a half or three per cent., which they prefer doing, sooner than lock up the money by lending it to farmers at five per cent., because they know they are liable to those fluctuations arising from our present monetary system, and may want it again; and that is one reason why the system is not working so rapidly as it did.

4420. To what do you attribute the present advance of price to the manufacturer?-To the increased circulation of joint-stock banks and the Bank of England. In March 1835 the joint-stock and the private banks had nearly $10,500,000 \mathrm{l}$. of notes in circulation; on the 19th of February last they had $11,134,000 \mathrm{l}$.

4421. What is the issue of bank notes now :-According to the last return, I think it was $17,000,000 \%$; from Norember 1835 to February I 836 there was an increase of about lialf a million.

4422. Do you think that increase of prices in the manufacturing districts likely to be permanent:- Not permanent; because I conceive that the advance of prices of manufuctured goods will create a greater consumption of agricultural produce, which will raise the price of agricultural produce, and that will raise the price of lahour, which will again operate on manufacturing prices, till gold becomes the cheapest article of export.

4423. On what ground do you conceive the present monetary system acts injuriously on agriculture alone:-I conceive that the increased price of manufactures is only now begiming to operate on agricultural produce; that it will operate even. tually on agricultural produce I have no doubt; it is now operating upon it, and all agricultural produce will rise; when it rises that will create again a corresponding increase in the price of labour; that corresponding increase in the price of labour will again operate upon the price of manufacture, till they come to that point that gold becomes the cheapest article of export; then there will be a profit upon the exportation of gold : the Bank will again be obliged to reduce their issues, which I fully and clearly anticipated, and the very same results will follow the operation now going on which occurred in 1825 .

4424. If you are of opinion that the suffering of the agricultural interest from low prices arises from the present imperfect state of the currency, how do you account for the fact, that all the principal productions of agriculture, namely, wool, cattle, barley, oats, beans, are represented by the farmer to be at present, some of them at high, and, generally speaking, at fair prices, and that the only great ground of complaint they have is the low price of wheat; if the difficulty arises from the state of the currency, will it not slow itself equally over all those various productions of agriculture? - I contend that it does show itself over all those productions, with the exception of wool, and wool tn a great degree. Wool is at a higher price than any thing else, occasioned, in the first place, by the very great rot which took place in sheep) in the yen 1830; and I am decidedly of opinion, if rour Lot dshipw will examine practical mon, when asked upon the subject, they will state 
that that loss by the rot is any thing but compensated for; we have still a very deficient supply of sheep in this country; but I will likewise admit that this rise in the price of wool arises in part from what I call a legitimate and healthy source, which is the increased demand for manufactured goods, and that as long as we can keep the export trade, which I think we slıall not long keep, it will continue to give to the farmer a better price for his wool. With regard to the barley, which has been stated to be at a remunerating price, I am really convinced it is at a very losing price, and that that is the case in many counties. If you take into account the deficiency of the crop, and the price at which they have sold the produce, barley has brought less money than their crop of wheat; barley has been a most failing crop for the last three or four years; but here again I admit there is some increase of price, to be attributed to another cause, which I cannot look upon as permanent, that is, the increased prosperity of manufactures; this has increased the consumption of malt. With regard to beans, we have not had a general good crop of beans these five years, and every practical man will state that it has been a failing crop these five years. The crop of the last year, 1835, has been the best crop; but old beans regulate the price; the new beans of 1835 are not selling high; only old beans, because there are none in the country. In regard to oats, there has been no general good crop for the last three years. Of wheat there has been an unusually good crop for the last four years, and therefore a certain proportion of the low price of wheat is to be attributed to production; but that I attribute also to the unhealthy state of the currency, because if the farmer was in the position he onght to be, he would consider goud crops a blessing rather than an inconvenience; he would be enabled to keep the extra produce of good years till it was wanted in bad years; the farmer's ricks are the best granary for corn; it cannot be better than in his rick-yards; but he is obliged to carry it into the market, to pay old engagements and old burthens which are pressing upon him.

4425. Are you aware that though the barley crop may have been bad in Norfolk, in other parts of the country it has not been bad :- l know, in parts in Worcestershire, in Warwickshire, and great parts of Shropshire, there were failing crops; I speak to my own knowledge, and I have been in the habit, the last three weeks or month, of intercourse with farmers from every part of the kingdom, and I find that to be their universal statement from all parts of the kingdom.

4426. If it is the fact, according to your opinion, that beans and oats and barley have been at fair prices, because the crops have been indifferent, and that the wool has been at a great price because there has been a rot in the sheep, if wheat is at a low price because there have been several years of abundant production, would not that lead you to the conclusion, that those different articles, like every article of commerce, were affected naturally and legitimately by the proportion of their supply to the demand, and that those variations of prices have shown themselves according to the state of the supply and demand, notwithstanding any derangement which may exist in the state of the country :-To a certain degree; but I do not admit any of the articles named to be at a remunerating price, taking the circumstances $I$ have mentioned into consideration. There is one article to which the question alluded, which I forgot to notice,-cattle. I know that though to the consumer beef and mutton are at a very great price, they are to the producer at any thing but a remunerating price. In the month of November last, owing to the failure of the turnips in many parts of the kingdom, and also to the want of money among the farmers, there was a very unusual quantity of sheep and cattle of all sorts pressed into the market in the country; they did not, on an average, sell for more than $4 \frac{1}{2} d$. a pound; they are fetching in some country markets $7 d$. a pound; but though the price is so increased it has cost the farmers more to keep them from the want of turnips, therefore the price must not be taken as remunerating to the farmer; and if there had been a good year of turnips, the prices would have averaged not much more than $5 d$. or $5 \frac{1}{2} d$. a pound, which is completely a losing price to the farmer for winter-fed cattle.

4427. Do not those several articles appear to follow in their prices the ordinary impulse of trade, being high when they are scarce, and being low when they are in great abundance, without having recourse to any reasons deduced from the past and present state of the currency :-Higher or lower, I should say, but not positively high or low, for they are all low, and all ruinously low to the farmer; and whether one is affected more and another less, depends upon the proportion of the supply of that article to the demand for that article, but the whole are kept down by the action of the currency. 
R. Spooner, Esq. 442S. Sliould it have occurred that different persons immediately connected with agriculture have given an opinion before this Committee that the prices of the produce of agriculture, with the exception of wheat, were fair prices, would not that rather lead you to the belief that the farmer had wot been very much injured by any defective state of the currency?-It would not bring me to the belief, because I know the reverse. I have seen farmers' accounts from all parts of the kingdom; there are a great many in London at this moment; I have seen their accounts and their books; and when I look round to my neighbours in my own district, where every farmer without exception has, for the last two or three years, been paying a large proportion of his rent out of his capital, I do not say the whole; I believe they are getting poorer and poorer every day; they are in great and universal distress. I cannot believe any witnesses who come here to state the contrary.

4429. Without doubting the state of distress, the question refers to the manner in which you connect that distress with the question of the currency?--.The way in which I connect it with the question of the currency is, first of all, on the great general principle, that the price of every thing is regulated by the quantity of circulating medium; then, if I see that for a number of years there have been alternations of prosperity and adversity, and if, in looking for the cause, I find there have been at corresponding times great alterations in the amount of the circulating medium, I naturally come to the conclusion that those alternations of prosperity and adversity have been produced, I should say, arguing from general principles, by the increased quantity of the circulating medium at one time, and the decreased quantity of the circulating medium at another tine; and that will be found to be so, with very few exceptinns, and those exceptions may be always traced to a bad harvest and failure of the crop counteracting the action on the currency.

4430. If the opinion stated by some witnesses as to the prices of spring corn being good was with reference to the article produced, it might be a proper answer, but if connected with the failing crop it would not be?-No; the spring corn is not got up to a price to remunerate the farmers.

4431. Was not the last harvest a fair harrest of barley in many parts of England ?-I believe in many parts of England it was so. The barley in 1834 was good in quality, but deficient in quantity.

4432. Is the farmer complaining of the last four years, or of the immediate state of prices as compared with the prices of last year - He is complaining both of the result of former years and of the present year. There is a great tendency to rise, but he is pressed by the difficulties of former years, and that tendency to rise the poorer farmer lias not been able to benefit by, because be has been obliged to sell before the rise took place.

4433. You are of opinion that the effect of the currency is shown on the prices of commodities generally ?-On every thing.

4434. It cannot select one particular article?-If it is currency, it acts universally.

4535. Are you aware that a portion of the produce of agriculture is selling at a fair price?-I do not conceive tliat.

4436 . Are you aware that, setting aside the question of agricultural produce, the metals from the different mines of the kingdom, and articles generally of every description, have risen for some time, and are in a progress of rising at present; and do you think that would be the case if the state of the currency was so defective as to affect injuriously the general interest of the farmer, more especially in the single article of wheat :-I conceive the increased prices of manufactures and commerce are to be traced to the increase of the circulating medium. I should take that as a proof of my argument. I find there has been an increase to the extent of nearly half a million of the Bank of England notes, and an increase of more than half a million considerably of the private bankers and jointstock banks. In March 1835 the circulation of the joint-stock and private banks stood at $10,419,000 l$.; it now stands at $11,134,000 l$, a rise of considerably more than half a million upon that; and the Bank of England has increased since November 1835; the returns show an increase in circulation of $495,000 \mathrm{l}$. up to the account made up in February, very nearly halt a nillion; and then, not only has the increase of circulation been indicated by the quantity of notes, but all persons at all aware of the way in which the joint-stock banks which have been established are now carrying on their business, nust be aware that they give a very 
great impulse to trade, and have tended very much to raise prices; added to which, from the low price to wlich our manufaetures were reduced, they have forced themselves into use upon the Continent, thus oecasioning a very considerable demand, and a consequent tendency to rise, which tendency to rise has been fostered by the operations of the joint-stock banks. 'The alteration of the tariff between Paris and America on iron has given a very great impulse to the export of iron, and, together with the spirit for railroads, has raised that artiele very considerably. I contend that that rise is now extending to agriculture; but I think the country is placeil in peril of a re-action.

4437. Do you attribute that inereased prosperity to the increase of circulation of the Bank of England and the joint-stock banks ?-Yes, and to the alteration of the tariff, and to the stoeks having been reduced to very low rates, whieh has led to great increased demand, and consequent increased speculation.

4438 . Should you not attribute that, in a great degree, to the prevalence of peace all over the world, and the accumulation of wealth, and increased comfort of the great mass of the population? - If that was the case, why was it not so in the year 1825 ? It was not so in 1825 , for it vanished. If there had been an aceumulation of real wealth on the Continent, and the rise oceasioned by solid prosperity, it would not have vanished in 1825 .

4439. Are you aware that the years before 1825 were years of great prosperity; that they were years remarkable for the Chancellor of the Exehequer announcing them as years of partieular prosperity; and that that great prosperity led, as prosperity is apt to do, to over speculation?-Just so; and I believe the same clements that worked then are at work now, and will produee inevitably the same effect.

4440. When you see money subscribed for every adventure, and the eagerness of parties to go into those different adventures, may not that bring on a panic and a derangement, without its being imputable to the state of the curreney?-No. I think the very fact of thosc increased speculations, and the fact of those subscriptions, is clearly to be aseribed to the bad system of our currency. Men are not such fools as to run hastily into speculations, and throw away their property only for the purpose of speculation. They have been led to it by the tendency of our present monetary system, which has been to withdraw capital from the general circulation throughout the country, and draw it into great masses. That capital has been unemployed, or employed at a very low rate of interest. The moment tliere is a tendency in any particular article to rise, persons who have money lying by them, not knowing what to do with it, naturally turn their attention to this ; speculation immediately follows, and up go the prices of cvery thing; and this arises, not because there is too much currency in the country, but because of the uncertain state of our monetary system; a system which has tende!l to accumulate large eapitals in few hands, and to withdraw it from the wholesome eirculation of the country.

4441. You represent the state of the currency to be in a defective state; will you state what you conceive to be that perfeet state of currency to which you wish to bring it back? - I can state what I should certainly wish to see adopted, though I do not think that would be a perfect state of currency. I should advise to return to a joint standard of silver and gold; and the standard of silver taken at the present price at which our silver is coined, $5 \mathrm{~s} .6 \mathrm{~d}$. an ounce; and I think justice is completely on the side of that being the standard of value. It has been said, those who wish for an alteration of the standard of value are not acting justly. I conceive, without going at all into the question of necessity, a sense of justice requires it, and the public faith requires that the standard of value should be at $5 s .6 d$. an ounce on silver. I should be happy to explain why I dwell so muelı on its being a question of justice.

4442. When, in point of fact, did the country eome to a metallic standard?The first effeet of a return to a metallic standard was felt in 1815; varied again between 1815 and 1818 by several eireumstances; then in 1819 it came to a point again from which they were obliged to depart. Upon the question of justice I take this ground, that in the year 1819 you contemplated to return to the old standard of value; you did not return to the old standard of value, but you returned to a standard of value which never lad existed in this country; but to a standard which I think can elearly be proved to be practieally full 15 per eent. more against the debtor interest of the country. The old standard of value, up to the year 1797, was gold and silvẻr conjaintly, without linit; silver without any 464. 
R. Spooner, Esq. limit whatever; for it is a mistaken notion to suppose that in 1797 silver was limited in tale to $25 \%$. In the year 1819 you took a single standard of value, 15 March 1836 . gold; you likcwise took away from coin the protection it had against exportation and melting. Previously to 1797 it could not be melted or exported without incurring heavy penalties. I know that $A$ ct was evaded, and I am not finding fault with the alteration; but when it was made, and a valne thus given to coin in mercantile exchanges which it did not enjoy before, that should have been taken into consideration, and the debtor should not have been required to pay the same amount in coin to which this new value had been given; and in returning to gold only you luave taken the very worst of metals, that which no other nation lias taken for its standard. When you make a bargain here you know you must pay a certain quantity of gold, but when you send the goods abroad you lave no means whatever of kuowing what quantity of gold they will produce, for you cannot compel a person abroad to pay in gold; he may pay in silver; then you must give the market price for that gold before you can discharge your debt in England. When, therefore, we take a gold standard, that is the worst, for that is exclusively our own standard, a standard rejected by all other nations, increasing the difficulty of accommodating our transactions with those of other nations; and there is this disadvantage also, that gold is more liable to be exported, because it is less bulky. Justice required that all these circumstances should have been taken into consideration. The old standard of value was $5 s .2 d$. an ounce; the token coin is $5 s .6 d$. ; and I am quite certain that the additional $4 d$. an ounce will not be sufficient to compensate for the increased value given to coin by the alterations above mentioned.

4443. You state that the alteration of the standard, as compared with what it was before the cash suspension in 1797 , makes, in your opinion, a difference of $\mathbf{1} 5$ per cent.?-Yes, practically, 1 should say.

4444. How do you make out that 10 per cent. difference; the price of silver you state to be rated in the old standard at $62 \mathrm{~s}$; ; are you aware what the price is at present?-The last price I saw was $4 s .11 d$. an ounce; you might have purchased at $4 s .11 d$.

4445. On inquiry, a little while ago, it appeared that it was $5 s .-\frac{1}{4} d . ?-$ It was $4 s .11 d$. a little while ago.

4446. How far is that below the old standard of $62 s$. ?-Rather more than four per cent.

4447. There is four per cent. clearly difference of standard?-Yes.

4448. You reckon something very properly for the difference of coin not being then exportable or meltable, and now liable to be melted and exported; at what do you rate that:- l rate that very high; for you have now given to large houses of great character the power of immediately sending an immense quantity of gold out of the country, which they were restrained morally from doing before. I do not deal with that as a mere question of pounds, shillings and pence; there were always a certain set of men who, for a certain profit to compensate them, would do it; but I am sure the highly honourable houses of the City would not have done it; they may now do it without any check; a very small profit will induce them to send over gold to meet the exchanges.

4449. Would not a money-changer, for from one to two per cent., undertake the risk? - I am not aware what the risk is equal to, but his power of doing it is so small; he has not the power to do it; but it is very different when large houses, with large capital, have the means of doing it without any moral restraint upon them.

$44.5 \mathrm{O}$. Is there any other circumstance beyond the difference of the present price of silver, and the price at which it was then rated, and the circumstance mentioned of the exportation and melting being now permitted which was not then permitted, which goes to make up the difference between the present and former standard -1 consider we are very liable to have our gold standard altered by circumstances which would rarely affect a silver standard. Suppose large armies moving, would they fill their chests with silver? would they not buy gold at any agio rather than transport silver? It would operate upon us immediately.

4451. Are you not aware that that operated upon us before the suspension of cash payments?-Yes; but then we had silver to resort to.

4452. Was not gold the real practical standarl, though silver always existed as the measure of value?-I should say that, practically spcaking, that was not so.

4453. You 
4453. You have no recollection that, within our lives, people have taken silver to the bank to be coined, when according to the old law they might dr so?-1 am not aware that they did, or that they did not.

4454. Having the power to take one metal or the other, if they took gold, was it not that gold was rated, as relative to silver, so as to make gold the most profitable?-I cannot carry back my recollection to that; all this las been closed since the year 1797 .

445.5. Do you not conceive that, at the price of $5 s .2 d$. per ounce, silver would be takien very largely to the bank to he coined :-Yes, certainly.

4456 . That does not amount to 3 out of the 15 per cent?-That is matter of opinion; but I reckion very largely the moral effect.

4457 . Do not you consider that the currency is liable to constant derangement by the fact, that the Bank of England being restricted to one metal, and sometimes not being able to get that metal, it is obliged, more than it otherwise would, to contract its issues on every occasion of distress?-No doubt ; the whole argument is grounded upon that. But I was asked whether that would be a perfect state of currency; 1 always said it would not; and 1 must refer to that which I have put into print,-my view of a perfect state of the currency. 1 think that, considering the present large amount of the national debt, considering that we have to raise amongst ourselves very nearly $50,000,000$ of money yearly, and to spend that $50,000,000$ of money amongst ourselves, we never shall get a really perfect state of currency till we have at least a portion of the currency in national paper not convertible into gold, payable in dividends and receivable in taxes, and legal tender; because without something of that kind we are always liable, by operations over which we can exercise no control whatever, to have the value of thuse taxes very greatly enhanced against the debtor. The very moment any thing draws the gold out of the country, the very small base on which the whole superstructure is built, the value of every thing is deranged; and if it required a certain number of bushels of wheat to pay the taxes one year, it may require double the quantity of bushels the next year.

$44 . \overline{8}$. Should you be of opinion that we could have a currency in the country simply devoted to the payment of the dividends, receivable as taxes, and not applicable to the common business of life?-No; I would make it applicable to all the common business of life. I know it may be said we are going on the system of assignats. I draw a great distinction between the plan I propose and assignats : assignats were issued on a prospective income never realized; the paper I propose represents a debt due from one part of the community to another, and is a mere acknowledgment of the debt, and would be received in payment of taxes.

4459. In what way would you measure the issue of this irredeemable paper; or would you hare no measure at all ; - I certainly would have a measure; the exact amount must be matter of calculation, matter of consideration, but it never should exceed the amount of dividends.

4460 . Would you leave that to the discretion of the bank?-No; I would recommend a certain number of millions of national paper to be put out in dividends, and the remainder in cash.

4461 . Would it be convertible?-No, not at any time; it would be very much similar to Exchequer bills, putting them in the shape of circulating medium.

4462 . The Exchequer bill is first of all a paper at interest, and is redeemable? - By law, but not practically. When is it ever redeemed? It is advertised to be paid off, but then it is always done by exchange of bills. There are a certain number issued, and why should not these go into circulation.

4463 . You would not have these redeemable by law?-No; the Exchequer bills have never been redeemed.

4464 . Would you make it compulsory on the persons to receive them?Certainly.

4465 . Would they then be liable to depreciation or not?-There would be times, I have no doubt, when this would not range with the gold; when the gold would, as against the national paper, be at a premium.

4466. If it were to be compulsory on persons to receive, would you make an allowance with respect to the depreciation on behalf of the receiver?-No, I think not; that would be a trifling evil compared with the benefit accruing from a steady circulating medium, which in my opinion cannot be obtained in any other way.

404.

L L 3

4467 . You 
R. Spooncr, Esq.

15 March $183^{6}$.

4467. You would not care about what relative proportion it might bear at different times to the gold and metallic currency?-I do not see any reason why I should.

4468. You think that circulation would be safe for a great commercial country? -I think it woułd, to a certain amount.

4469 . Would foreign countries have confidence in it? Would they know, when they got $1 /$. sterling, whether it was worth 20 francs or 25 francs? Would that be safe for any country carrying on large commercial operations like those of this country? - We never saw any country carrying on commerce with such paper, but we never saw a country in a similar situation to ours, raising 50,000,000l. anmully to pay to itself, and that based on 7,000,000 l. of gold, which may be withdrawn at any moment. I do look with very great fear on the effect of one or two bad harrests. It has pleased God to bless us with good harvests, and that has averted from us what $\mathrm{l}$ consider almost the inevitable consequence of two or three bad harvests, - a great run for gold, in which case the Bank of England would be obliged to withdraw its paper to an amount that would destroy the whole monetary system at once.

4470 . Thinking there is danger to the circulation of the bank, you would meet that danger by bringing immediately the very thing felt into operation, that of irredeemable paper; the danger, if there is any, is the danger of bringing paper not practically redeemable; and you would remedy that by rendering legal the very thing feared ? - I do not view it in that light. The danger $I$ fear is the having, on the one hand, high fanine prices, and, on the other hand, the whole of our manufacturing population thrown out of employment by the money being withdrawn, the notes being withdrawn from circulation which now afford them that employment. The bank will be obliged to do so in case of famine opening the ports, and the danger would be increased beyond calculation, if obliged to resort to irredeemable paper at a moment of very great excitement, when it must be done instantly, without cue care and due caution. I would do that, seeing it must be done sooner or later, when $l$ had the power to exercise judgment and discretion, rather than drive it off to the last moment.

4471. Do you think that, when this irredeemable paper did exist, the bank was conducted with judgment and discretion?--Totally devoid of judgment from one end of the cliapter to the other; there never was any thing so monstrous.

4472. Taking into consideration the chances of wisdom or folly in the management of banks and of human affairs, is there any probability that they would be conducted with wisdom if you take away the great and only measure by which the circulation can be regulated, that of their liability to specie payment ?-I conceive it would operate exactly differently, that it would put them into a situation to be enabled to act with wisdom and great discretion, which they cannot at the present moment, because the Bank of England has to do that which the very soundest judgment cannot enabłe them to do, exercise a control over uncontrollable events. They are to regulate their issues as much as possible by the wants of the nation, and yet they are at all times to look to a certain point, the quantity of bullion they can command, which may be altered by circuinstances they cannot control. See what was done in America by the President Jackson last year. There was a very great drain of gold to America. Suppose he should be able now to carry into effect his recommendation of substituting a gold coin for all paper under twenty dollars, must not the gold for that purpose be drawn from Europe, and if we have only gold to regulate our circulation, must not that very much affect us?

4473. The amount of national paper, you were understood to say, you would have regulated in some degree by the amonnt of annual dividends and taxes?Yes; I should say dividends rather than taxes.

4474. Would any foreigner be bound to take any of that paper if he did not think fit to do so?-Not unless he holds funded property; he must then take the same general proportion.

447.5. If by his oun acts he naturalizes himself in England, he must be subject to our rules:-Certainly.

4476 . Do you suppose, if this national paper was under the management of Government, it would run the same chance of being mismanaged as if by the bank, which has a pecuniary personal interest to issue, as they gain a profit by it $\bar{i}-\bar{l}$ should certainly have it issued by Government, and for the profit of the country, not the profit of any company whatever. 
$447 \%$. Would not that give the nation a security that it would not be so liable to be improperly extended ? - Ies, undoubtedly, the Government being subject to Parliament. I do not recommend a national paper, as such; but when we have that superstructure of paper founded on gold, depending upon whether we keep $8,000,000 \%$. or $9,000,000 l$. in the bank, that is a position in which this country ought not to be placed; and, as I mentioned before, I think no one can read Mr. Pitt's evidence before the secret committee, in the year 1797, without seeing that he contemplated the necessity of adopting some standard which should be cnabled more adequately to represent the wants of this large community.

4478 . You have stated that we are in this extraordinary situation, that we pay $50,000,000 l$. from this country to this country?-Just so.

4479. That is supposed to include the payment of interest on the national debt and the national expenses?--Yes.

4480 . Is not a very large proportion of the national debt possessed by foreigners: -I do not conceive any very large portion.

4481 . Have you taken the trouble to inquire how large a proportion?-No; I only judge from this, that as there is a lower rate of interest here than they can get by their own funds, there is no temptation left to foreigners to invest in our funds.

4482 . Suppose a very large propurtion of the dividends on the national debt was in the hands of foreigners, and they were bound to receive those dividends in paper, how would that affect the credit of the country :-My own opinion is, that it would render the credit of the country much more stable; we are now liable to such continued and alarming shocks, that 1 think the stability of the country is very liable to be shaken.

4483. Do you conceive any bad effect would be occasioned by the necessity of paying those dividends in paper, which would be worth more or less, as the case might be, in the progress of years? - I luave said before, I recommend this from an absolute conviction that we must come to it ; that it is utterly impossible to continue the present system; it cannot be continued in a bad liarvest, it cannot be continued during a war; and we must resort in either of those cases to an inconvertible paper; and I think it is much better to do it at this time, when it can be done on consideration, than as it was done in 1797 , on the spur of the moment.

4484 . You would look upon it as an evil that the country should be placed in that situation, but you take it only as a preference of two evils, and you would rather do it when the country is in a calm state, and it can be well considered, than under the pressure of necessity on an extraordinary emergency?-I am hardly prepared to go so far as to say it is a positive evil; I doubt whether it would not tend to the real prosperity of the country, as I am quite sure it would enable us to avoid a very great evil that may happen any day, and it may prevent our having to resort in a hurry to an inconvertible paper currency.

4485 . You do not consider that, setting aside the facility of a paper currency, any good is to be done to this country from what is called the depreciation of standard; that is, making the pound $15 \mathrm{~s}$. instead of $20 \mathrm{~s}$.? - No. I consider original clepreciation is bad; that the moment a coin is depreciated, you take away from that coin so much power; it is only a nominal change, and that half-sovereigns will do no more good than the whole; but my opinion is, that that has taken place many years ago, and that we are now suffering from an attempt to do that which is impossible, to return to a standard of value that we have long abandoned, indeed which we never had.

4486 . Setting aside the past sins of the country in respect to its tampering with its currency, taking it as it now stands, you do not conceive any benefit will result to any classes in this country from lowering the value of the pound sterling?-I conceive that done by the plan I recommend, practically, by coining at $5 s .6 \mathrm{~d}$., and by issuing a national paper, and I conceive justice requires we should do it, and necessity requires we should do it, and that is the best and most practical way of doing it.

$448 \%$. You conceive that not only we want a better system of circulation in the shape of paper, but that benefit is to be derived from the positive depreciation of the value of the pound 'sterling as it now stands?-Yes, because it follows the plan I propose. I say we are suffering at this present moment from an attempt not only to return to the old standard of value, but one still more against the debtor; and that we have not accomplished the attempt, and never can accomplish it.

464 .

I. L 4

4488. You

R. Spoener, Esq.

15 March 1836 . 
44SS. You think that a fair measure of justice between debtor and creditor?Yes; and that it is called for by the debtor as a measure of absolute justice, and 15 March 1836. much more cailed for by the creditor as a matter of safety.

$44 \mathrm{Sg}$. The interest on money is lower in this country than in most parts of the Continent?-l believe it is.

4490. Is not the consequence of that, that all the world use the capital of this country and draw on this country? - It has that tendency.

4491. Do not the United States and the different new States of America, and most parts of the world trading with this country, trade mainly with British capital ? - Certainly not the United States of America.

4492. Do not you think the United States draw on this country largely?-I should think not; and I will state my reasons. The system of the United States has changed most rapidly. When first I was a banker at Birmingham, we had a very large number of American merchants; they carried on the whole trade with their own capital, and never thought of turning it more than once in a year and a half; but there is no such thing now. The American cumes over and buys in our market; the American merchant is gone; and the commission agent comes and buys, and pays ready money, almost every Saturday night, for the articles he has purchased.

4493. Setting aside the States of America ; generally speaking, do foreign countries, dealing with this country, use largely the capital of this country ? - Not so much as formerly; the remittances from foreign merchants come much quicker than they did.

4494. Should not you say, if a balance was struck at any time between this country and the rest of the world, the world is in our debt? - I have not knowledge enough to give an answer to that.

4495 . If it should be the case, that from the low rate of interest in this comntry, the interest on the public debts, and the use of capital of the country, the consequence of that should be, that in the course of business the world should be debtors to this country, would not a depreciation of the currency be the most unwise thing a country so situated could do? - It would put foreign debtors in a condition of paying a less amount of debt; but $\mathbf{I}$ think there would be much more than countervailing advantage given to the country by stimulating exports; and I am very doubtful as to the great extent of debt owing to the country.

4496. If this state of things existed, a foreigner being in debt to this country, instead of having any thing to complain of, would be a gainer by it?-No doubt; and I have no doubt, striking a balance between debtor and creditor in France and other countries, there is a balance due to this country, but nothing like what there used to be, and it is every year decreasing.

4497. From your experience of the state of the manufacturing interests of the country, you believe it to be in a prosperous state?-I believe it to be in a highly prosperous state at the present moment; the only exception to that is in those parts peculiarly connected with the purely agricultural districts. The factors who are concerned in trading in the purely agricultural counties find a much less demand for their goods, and not such good payment.

4498. How long has that state of prosperity eontinued :- It has been gradually increasing for these two years, but the great advance has been within the last six months; copper and all the articles liave been most alarmingly adranced in price; so they were, I recollect, in 1825 ; copper has jumped up from about 87 to 100 or 102 within the last month or six weeks.

4499. To what do you attribute that ? - I think, in a great degree, to the specu lation which always follows low prices when they have existed for a considerable time; when they have brought a renewed demand for consumption, that gives a general impulse to price. There has been a great surplus capital. When people think that things are going to rise there is a great rise of opinion, much beyond that which is found to be the real demand, and I believe that is going on very largely.

4500. This prosperity has existed for the last two years?--It has been commencing, but going on much more rapidly the last six months.

4501. That was from the advance of half a million in Bank of England note before March 1835, when the joint-stock and other banks advanced half a million less?-No; there has been a corresponding advance; they have been gradually advancing.

4j02. This 
4502. This great prosperity in every other branch, that has been continued the last two years, has been contemporaneous with the greatest distress known to the British tarmers?- When it is said great prosperity the last two years, that is rather too wide; it has been gradually increasing, and become great prosperity the last six months; that has been contemporaneous with the great distress of the farmer.

4503. The one class has been in a state of at least great prosperity, and the other has been in great adversity ?-No doubt.

4504. Both using the same circulating incdium; would it not be too strong to say that the distresses of one are mainly caused by the circumstances of the circulating medium, and that that did not affect the circumstances of the other?-Not at all; the real fact being, that the way in which the joint-stock banks are established, the persons of whom they consist, their connexions, the places where they are established, their manner of conducting business, are altogether tending to act on manufactures and commerce directly, - on agriculture only indirectly. I will explain the reason why. Country banks before 1825 were in the habit of lending moncy to farmers. without negociable securities; the farmers knew nothing about bills; money was advanced to them for four or five or six months to pay their rents, till their produce was sold; and in 1825 a great many country banks were in that situation; men of great property, but without the means of getting a farthing of it in when they suddenly wanted it. They are very careful not to do it now. The uncertainty of the monetary system makes them careful of lending their money. They lend at two and a half per cent. to the merchant on negociable bills rather than to the farmer at five per cent.

4505. The country banker will lend his money to the farmer when he thinks him a safe person ?-No; because if it is lent to farmers it must be lent for some time; it is no use lending it to discount a bill for two or three months; it must be till the harvest comes round, and he can give no negociable security.

4506. So far as regards the farmer, you think that the only means of amelioration besides those you have stated is the making this alteration in the state of the currency? - Yes.

4507. Will you state to the Committee whether you have considered the project of laying a duty on the importation of tallow, and taking off the duty on soap : and do you think such a thing would be conducive to the interests of agriculture? -Laying the duty on tallow, most undoubtedly, would be very conducive to the interest of agriculture. I have not so accurate a knowledge what the effect might be of taking the duty off soap as to give an opinion upon it ; I believe it is generally held to be likely to be beneficial. I have some donbts upon it, and upon this yround, that at present the duty on soap acts as a guarantee that the soap shall be of a certain quality, because the duty is equal on good and on bad. If you tuke off the duty, the question then is, whether the manufacturer will have so great an inducement to makc the best article, or whether, being able to make a poor article for sale, he may not have recourse to the use of palm oil or rosin, and other things to make it, instead of tallow. This is a very different opinion from that held by many who have turned their attention to this subject, but I own I am not convinced.

4508. You think that, setting aside any difficulties of the nature to which you refer, and supposing the duty placed on the importation of tallow, that would be highly beneficial to the farmer?-Highly beneficial.

4509. You have adverted to the evidence given by Mr. Pitt in 1797; will you point out the particular passage to which you refer?-I conceive the whole of Mr. Pitt's evidence must lead to the conclusion I before mentioned, but particularly the last answer to the last question of Mr. Pitt's evidence, in Commons Report, No. 26, reprinted 13th February 1826.

4510. What is your opinion as to the benefit the agricultural interest would be likely to derive from the proposed Tithe Bill ?-I look upon the Tithe Bill to be an extremely imperfect Bill as it now stands; it would be highly desirable that some plan should be adopted by which the commutation of tithe, with justice to all parties, should be introduced into this country; it is a very inconvenient mode of paying the clergy; but $I$ think this Bill goes on very erroneous principles, in more instances than one.

4511. In what way do you think the commutation of tithe might be carried into eflect so as to benefit the farmer - - It would certainly be very beneficial if 464 .

\section{R. Spooner, Esq.}

15 March $18{ }_{3} 6$. 
R. Spooner, Esq. the commutation of tithe were carried into effect so that they should be enabled to improve the land without being charged additional tithe in consequence of the improvement.

4512. What particular part of the proposed Tithe Bill, as it is framed, do you conceive likely to give that advantage -A great quantity of land is at this moment continually going out of cultivation, and if low prices continue, a great deal must go out of cultivation, and yet the Bill charges the land with an annual payment of tithe calculated on land when it has been in a productive state the last seven years, and not calculated on that quantity which will go out of production. With regard to the tithe on grass land and ploughed land; take the tithe on very rich grass land; that is a low titne compared with the value of ploughed land; the produce is gained at a very great expense, and is much larger; the Bill taxes the very rich grass land with a low rate of tithe, because it is productive of a less amount; the Bill taxes arable with a large rate of tithe, because a large produce is obtained with a large expense of cultivation; but what security is there against the grass land so charged with grass tithe only being converted into arable, and so coming immediately into competition with the farmer who pays the larger corn tithe.

4513. Do you think any clause should be inserted making that land liable in case of change of culture?-If that can be done; but that would break in upon the principle of not charging the land higher in consequence of additional capital laid out. It is a matter which requires a great deal of consideration. There is another very important point; the allowance to be deducted from tithe at present paid in the case of a lay impropriator. He takes tithe over a certain property; in the market that tithe is worth not more than 18 years' purchase, but if you go to give him a rent charge you turn it into a property which will sell for 30 or 32 years' purchase.

4514. Do you mean to say that you think 18 years is any thing like the number of years' purchase given for the lay tithe?-I believe that 18 years' purchase cannot be got for tithe at the present moment; tithe is looked upon by no means an advantageous property to hold; formerly they might have got a great deal more. With regard to small incumbents there will be a difficulty also; you make a deduction from the tithe, upon the very ground that you are going to give them a more stable property; that is very good for the patron of the property, but the poor incumbent, who has only $200 l$. a year, will find that press upon him during the remainder of his life.

4515. You are aware that there are particular burthens that fall on the land; are you of opinion that might be relieved by their being removed -- L Local burthens are talked of, and if the poor-rates are included, great relief would be given, but no real relief could be afforded unless by the adoption of a national instead of a local assessment for all local burthens. The county-rate alone will not be found to come to any thing like $1 s$. an acre all over the kingdom; in many counties it is not equal to $6 d$. It is not proposed to take off more than half of that.

4516. Do not you consider that a great burthen arises to the farmer from the circumstance, that the manufacturer takes up and puts down labour whenever he wants it or wants to get rid of it ; whereas the farmer is obliged to take the surplus population thrown upon him by the will or the interest of the manufacturer? No doubt; therefore, I say, in common justice, if it is practicable, there ought to be a national system for the poor.

4517 . Do you think it would be practicable to put the charges of the poor and also of the county-rate on property:-I do not think it could be done by tax on property; I should recommend it to be paid out of the Exchequer. Personal property cannot be reached except by tax on expenditure.

4518. If it does become necessary to put it on visible and tangible property, or, in other words, on the soil of the country, does not that fully entitle the farmer to that degree of protection which the system of corn laws gives him?-The system of corn laws gives him no protection; it never can be a protection under the present monetary system; the prices never come within the range of it. The landed interest has the odium of monopoly without one iota of protection.

4519. You are not a considerable landed proprietor?-No; I farm my own property.

4520. Have you considered the measure of an equalization of the land-tax?The land-tax is very unjust in its operation now; because we see large towns s

built 
built on property called upon to contribute only the former proportion of the tax, the value of the property being many hundred per cent. larger, in consequence of being built upon; yet it pays no more than it did when it was in a state of land.

[The Witness is directed to withdraw.

Ordered, That this Committee be adjourned to Friday next, One o'clock.

Dic Veneris, $18^{\circ}$ Martii, 1836.

The Lord KENYON in the Chair.

Mr. George Frederick Muntz is called in ; and Examined as follows :

4521. YOU are a merchant in Birmingham ?-I am.

4522. To what part of the world do you trade?-To all parts except the East Indies.

4523. Do you consider trade to be flourishing at this time:-There is a great deal doing; but it is a very extended question, whether it is flourishing. The question is, whether that applies to the artisan, or to the merchant, or to the master manufacturer. It may be very flourishing for one of the parties without being flourishing generally. I am of opinion myself, that the working classes are better off now than ever I have known them, in consequence of the steady demand for labour, and the low price of the necessaries of life; but I have very great doubts whether their masters are obtaining profits at all adequate to their risks or to their outlay in capital; indeed I am confident that, in many instances, they are not doing so. There is a certain price at which manufactured goods can be sold, and there is a certain rate of wages which the manufacturing labourers will obtain, if they can get employment. There is a difference between the merchants and the manufacturers. The manufacturer stands between the artisan and the dealer in the markets to which the manufactured goods are sent, much in the same way as the farmer stands between the landlord and the consumer. So that, though there is as much business doing, and perhaps has been more done, in the last two years than in any previous, I have great doubts whether it has been done with profit to the principal, and whether it is now with profit to the principal. There is indeed the iron trade, which is attended with great profit, from peculiar circumstances; there has been an advance of something like 100 per cent. in the last seven months; but it is not at all known how long the advance may last, or in how short a period it may be reduced to the original price. It is now altogether a speculative trade.

4524. That is the most important trade in Birmingham, is it not?-No; the iron trade is not in Birmingham, but from 8 to 15 miles from it. The trade of Birmingham is in hardware made of iron, copper, brass, silver, gold and so on.

4525. You state the condition of the workmen to be better than you have ever known it, though the master manufacturers are making very moderate profits; have the goodness to state what you consider to be the condition of the merchants? - I am also a merchant and manufacturer. The condition of the merchants who are merely commission merchants, and receive their remittances, like the American merchants generally, to purchase goods, is perhaps as good or better than ever, because there is a large demand for the articles they purchase, and though at a low commission, it is a certain business; but those who take orders in various countries, from patterns and by prices, are in a very disagreeable situation at the present moment. I am in that situation myself; for example, my travellers, in the last two or three weeks, liave sent me orders from Germany, Turkey, Russia, Italy or Spain, for various species of manufactured goods, of which they have had the patterns and prices from me some months. In the mean time the raw material advances very much upon the manufacturer. When the orders come, and are given to the manufacturer, hesays, "Look how the raw material has advanced; it is advanced more than all my profit; I cannot make those goods." Then I say to the manufacturer, "What a situation I am placed in!
464 .
M M 2
I sent

Mr. G. F. Muntz.

18 March 1836. 
Mr. G.F. Munts. I sent ont your patterns and your prices, in the hope of receiving orders; some time must elapse in receiving them, and of course my correspondent expects me $1 \mathrm{~s}$ March $1 \$_{3} 6$. to execute them, and I expect you to execute them." Then what is the result? Either the merchant executes the order at his own loss, or the manufacturer executes the order at his own loss; or, generally speaking, they agree to divide that as well as they can. There are at the present moment very extensive orders executing in Birmingham and its neighbourhood, not only witlout profit, but with a loss upon them. The raw materials have advanced; the advancements of the raw material preventing the manufacturer executing them at his own prices with profit, they, the merchant and manufacturer, divide the loss altogether, in a certain proportion, or, at least, execute the orders at a very little gain.

4526. What has caused the late rise of prices ?-Various circumstances liave caused it. In my opinion it is entirely a speculative advance; and the strongest proof $I$ have felt of that is this, that I know of no instance of any advance taking place in manufactured articles before the advance on the raw material; the advance has uniformly taken place upon the law material. I consider that a very strong proof that it is a speculative advance; but there are other reasons. There has been a constant reduction of prices for some years, and till within the last six months, of manufactured articles generally, in Birmingham and the neighbourhood; and I think I may say, generally speaking, that until within the last month they have been as low or lower than they were ever known. Whenever prices are extremely low, all the shopkeepers in the country keep as small a stock as they can, from the hope that perhaps the prices may be still further reduced; but whenever there comes the least turn in the market they all buy together, and that makes the advance much more serious and sudden than it would be. In the present case there are three causes of action : first, the very serious depression; then the alteration in the money market; there is great facility of discount; a great deal of unemployed money; the facility allowed to every manufacturer of raw material to obtain money very easily, and to hold his stock back better than he had done before.

4527. Do you think that is the present existing state of things ? - I speak of that as the existing state of things three months ago. The facility for obtaining money has been greater in the last two or three years than ever I have known it; the principle of the joint-stock banks is such they will discount paper with any two respectable names upon it. The repeal of the usury laws has also operated, for it has made every man's credit available in the secoud or third rate, and that has acted on prices, and helped to turn the prices, then the moment the turn takes place every man buys his stock who has held back, and all buying together causes an operation upon the market greater than it would under other circumstances; that is, in my opinion, the occasion of the rise in raw materials.

4528 . Is there a rise in the price of iron only, or raw materials generally?All materials generally. Iron is advanced more than any thing else, in consequence of the speculations in railroads; that has operated in addition to other circumstances.

4529. Have all your manufactured articles adianced? - No, not the manufactured articles, but the raw material they are made of.

4530. The articles of manufacture have very much advanced, have they not? - No, not many; there are many that cannot advance; there are many that cannot be sold, because the advance cuts off the sale. I can enumerate some articles which I have exported largely, some of which may appear to you a very common sort of article, of little importance: for instance, simply the article of brass chair-nails; that is a very important article with us; there is an enormous quantity used of them; it is a large trade. Since the late advance upon the price of copper there is not an nunce sold abroad where there was a hundred weight sold; they are made in Westphalia. Nothing but our low prices get us the orders; we lose them if we advance more than two and a half to five per cent. on the foreigners' prices.

4531. The price of manufactured articles was very low between 1825 and 1835 , was it not? - Yes, after the panic, when things settled down; they lave been constantly reducing from that till the last six months. I do not think there is a single article in the way of hardware which was not reduced in price, except some trifing articles, from local circumstances.

4532. At the time when the price of manufactured articles was so low, did the price of provisions fall in proportion?-They bave only lately fallen; but I am sure they

have 
have never fallen in proportion to the price of manufactured articles. The only things which appear to have come near the price of manufactured articles lately are wheat and potatoes, and 1 attribute that to their being consumer by the poorest portion of the working classes, who are the largest consumers of them, and also, the produce of both is ample.

45.3. Do you believe there has been any diminution in the consumption of either of those articles:-No, not latterly, for there is no cause for it. How long it may be so I cannot say. If the high prices should cut off our sale in the continental market, we shall very rapidly have a re-action in the lower classes, for they work from liand to mouth, and if their consumption is cut oft it must reduce the price of the necessaries of life still lower.

4534. You speak of the labourer in manufactures ?-Yes.

4535. Why did the price of corn fall so much below the average intended to be kept up by the corn laws?-- In my opinion it is very easy to explain this. The average intended to be kept up by the corn laws appears to be about $8 s$. a bushel, 64 s. a quarter. At 64 s. our manufacturing labourers cannot live so as to compete with the foreign manufacturers, who consume corn at half that price; therefore, whenever the prices of the necessaries of life are advanced materially and permanently, so as to increase the rate of wages, a re-action takes place, from the impossibility of goods manufactured at high rates of wages selling in competition with the manufacturers on the Continent. The natural consequences, from the want of employinent of the manufacturing population employed on the continental trade (which I cousider to be ahout one-third of the trade of this country), is, that, losing the export trade, they fall on the home trade for employment; thus they reduce the average state of wages to the same ratio that they were before the rise took place, and necessarily the prices of provisions must follow. That I understand to be the reason why the price of wheat did not hold; when the wages were reduced the consumption was reduced in nearly the same ratio. The rise of prices prohibits the sale of the article, that prohibition operates to reduce the workmen's remuneration, and the manufacturer's remuneration being reduced, the necessaries of life are obliged to follow the " ant of their consumption.

4536. Have you any opinion as to what effect would be produced on manufacturing prosperity or agricultural prosperity if the standard were altered so as to be a mixed one of gold and silver?-There would be an alteration by having a silver standard, but it all depends upon the rate of the silver standard. If it was one at the present standard of coinage, I think it would be about 10 per cent., the actual variation; but there would be an additional variation from the relief the Bank would have from paying in silver; they cannot be called upon to supply silver so suddenly; it would make, upon the whole, from $12 \frac{1}{4}$ to 15 per cent.; but all that is matter of surmise; it cannot be stated with perfect accuracy.

4537. What is your opinion as to the advantages of that on the agricultural interest :- The agricultural interest would in that case obtain just the difference; if the advance was 10 per cent. they would get 10 per cent.; if 15 per cent. they would gain 15 per cent.

45.38. Keeping to the standard which exists now, low would that apply as to the manufacturing interest? -lt would make no difference whatever in the manufacturing interest; the reduction of the exchange will exactly counterbalance the advance of 15 per cent. on mannfactures necessary in consequence of the same increase in the price of corru, \&ic.

4539. Suppose the silver and gold were made a concurrent standard, do you think it most advantageous that they should be made according to the present price of silver or another price of silver?-My opinion is, that the standard is too low ; but I think it is a very dificult question how the best standard is to be found. Supposing no standard ever had existed in this country, and that we thought it advisable we should have a standard of gold and silver, the great question would be, on what principle such a standard was to be declared.

4540. In what way do you think the arrangement of a mixed standard of silver and gold would be likely to be beneficial to the agricultural and to the manufacturing interest?-The question refers to a mixed standard of silver and gold. I do not understand the mixed standard; you may have the one or the other, but I do not see any advantage in having the two.

4541. You would take the silver standard alone :-Yes, decidedly.

464.

M : 3

4542. You 
Mr. G. F. Muntz.

18 March 1836
4542. You do not exclude a person from paying in gold? - No; there could be no objection to that, if the debtor and creditor agree.

4543. Giving him the preference of paying in whicherer he liked ?--I see no objection to that, as I think the price of gold and silver would not vary much in the market under a just silver standard.

4544. In what way do you think that could be arranged so as to be most beneficial to the agricultural interest, and not prejudicial to the manufacturing interest? - In my opinion, every elevation of the standard, if it be found to be best for the agricultural interest, will never be injurious to the manufacturing interest in any case; that is my firm opinion.

4545. You think, with respect to foreigners, if the agricultural interest was only kept in a state of prosperity, the exchange with foreigners would right itself?That depends entirely upon how it is done. In my opinion, the great failing is, that we have two laws in existence; one to make wheat at $8 s$. a bushel by a corn law, and the other to make wheat at $4 s$. by a money law. The two are preposterous, acting together. If the corn laws, when established, had been established on another principle, that is, if in keeping up the high price of corn the means of the parties consuming the corn had been kept in the same ratio, we should never have known the inconvenience we have suffered during the last 20 years. The great inconvenience from the corn laws is, they attempt to keep a fixed price of corn in opposition to all other interests besides the agricultural interest, and without indemnifying those otleer interests for the means of consumption; that is, you attempt to keep corn at $8 s$. a bushel, and reduce the means of the consumers to give half that price. It would be highly desirable, in my opinion, for the agricultural iuterests, that means should be applied for making corn $8 s$. a bushel, giving, at the same time, the means of consumption at $8 s$. a bushel, and then the same system may go on from year to year, which it has not done. The price of corn may be kept at exactly the price which the agricultural interest find really necessary for their remuneration, provided it is accompanied by an alteration of the standard in the same proportion. I do not think it signifies whether it is $4 s ., 6 s ., 8 s ., 10 s$., or $12 s$. a bushel; it will exactly counterbalance itself by the operation on the exchanges; the exchanges would be reduced to meet the difference in prices which manufactures must advance to meet the permanent high price of corn.

4546. You consider that the interests of the manufacturers are very much concerned in the prosperity of the agriculturists? - No doubt of it ; for two-thirds of their sale is to the agricultural interest. I do not think any one class can lire on another for a long period; that the commercial can live on the agricultural, or the agricultural on the manufacturing interest.

4.547. How could the workmen in this country compete with foreigners if they paid more for their support:-Exactly on the principle I have just mentioned, that the advance of price is alway's a nominal price, which is the real fact. If there is a price of wheat here above the real price in the rest of the world, that must be a nominal price, because there will be an indirect operation that will reduce that price, if attempted in sterling money, though not so rapidly as if it were in the direct line. The landed interest never had a permanent high sterling price; the high prices during the war were uot sterling prices; they were not realised by sterling money, but were nominal prices valued in paper. In my opinion, the way to look at that subject would be, to see what the circulation of that day would purchase in corn or any other staple article; then it will be found, that as a pound note would only obtain about half the quantity of these articles that it would before the paper system, or does now, the prices of that day were all nominal prices; and if we are to have high prices again we must go to the system of nominal prices.

4548. What advantage can it be to the agriculturist to have $\mathrm{SO} s$., for instance, to pay in a currency depreciated one-half, or in half sovereigns, instead of $40 \mathrm{~s}$. in whole sovereigns; in what manner is he benefited by what you call the high nominal price, if that is in a coin reckoned on only the half value?-It is not the agriculturist himself that is benefited; he can nearly always relieve his distresses by relinquishing his farm; but he throws them upon his landlord, in the same manner as the manufacturer does upon the agriculturist.

4549. The question is not as between landlord and tenant; but take the instance of a proprietor of land, and that lie owes nothing; would he be benefited at all by having $80 \mathrm{~s}$. in pounds that were payable by half-sovereigns, instead of $40 \mathrm{~s}$. 
in poumls payable in whole sovereigns, or in the same proportion for any more or less depreciation of the curreney ?--It will depend on several things : in the first place, what sort of land it is; if it is poor cold land he would not be able to get any rent at all for it, upon the present monetary system; for, when it is worked out, there will be thousands of acres in England, $W$ ales and Seotland not worth a farthing of rent. The end of it will be most decidedly, - and it is not from mere surmise, but from very deep caleulation, reading and consideration,-I am of opinion we shall not liave the average price of wheat, with a fair supply, at more than $3 s .9 d$. per bushel. Then the question comes to this (and there is no secret in it), that there will be no rent left on the land after the expenses of eultivation are paid ; that is speaking of a man who owns his property, not in what is called common land, but in poor land. In land that will afford but small rent in the best of times, at nominally ligh prices, that man cannot exist if we go on at the present currency, for the prices will be reduced below that which will afford any rent at all. If a man has land of good quality, there is no doubt he will be as well off, provided his estate is unincumbered, if he goes to the extreme reduction of prices and taxes, tithes, rates and labour, as he is at the present rate of prices; it will make no difference to lim.

4550. Why should it make a difference between a man having good land and a man having bad land; does not this question of price, in determining the standard, apply to land of every deseription, whether good or bad ?-I do not understand that it does. I understand that good land will produce rent at a certain price, but that bad land will not.

4551 . Whether land produces $100 l$, in whole sovereigns, or $200 l$. in half sovereigns, is it not the same thing ?-Yes, if it does so produce; but I am supposing it did not produce rent at all ; that it is poor land.

4552. Is it not as easy for the owner of this poor land to produce $100 l$. in whole sovereigns as $200 l$. in half sovereigns?-Yes; but it might be shown that he does not produce any rent at all.

4553. The question is, whether his condition to produce or not to produce is at all affected with relation to the standard of value in which his property is valued?-The question is, whether he produces at a rate at which he can pay any rent, after his expenses are paid, or whether they do not take away the whole he gets for his corn.

4.5.54. If he pays in money one-half its value, will not that double the expense of his cultivation; will not all the expenses of cultivation, allowing all his outgoings, be raised or diminished in proportion to the standard of value of the money in which those articles were paid for?-No; his outgoings will not be raised in proportion.

4555. Why would they not?-I do not know the reason exactly why; but, though not a farmer, I am connected with very large farmers, and I find their expenses have not been reduced in any proportion to the reduction of the value of their produce; and it is explained in this way: they say, "My blacksmith charges me almost as much as he did formerly; my saddler cliarges me quite as much, and so do other tradesmen. If I ask him why he cannot shoe my horses for less, when iron is half the price it was, and so on, he says, 'The way in which I get paid, and the less quantity I have to do, makes my general expenditure on my less trade such that I cannot reduce my prices;" and I believe that to be true; the retail dealers do not reduce in a series of years as the wholesale dealers do.

4556. You would reduce those retail dealers by debasing the money in which they were to be paid ; pay them a lighter pound or a lighter shilling?-That is a question it is difficult to understand; it is a question how a man may lay out the money; but I would inerease the price of the coin.

4557. In short, there are abatements of price which do not immediately follow any alteration of the currency? - The alterations of the currency do not enter into all the ramifications of priees immediately; they enter into thelarge general system many years before they enter into ramifications of retail prices.

$455^{\circ}$. You were asked how a certain prineiple would affect the condition of the agriculturist, supposing that he was free from debt; do you believe that to be the condition of any eonsiderable portion of the furming community :-As far as my own immediate knowledge of the parties goes, I should say, that half the landed proprietors have not any real interest in the land at all; that they have just enough to pay the interest of their debts:

464 . 
4559. Was that in consequence of the engagements they may have entered into, and the steps they may have taken, when things were at high prices?$18 \mathrm{March} 183^{6}$. Yes; the liabilities of their estates. I know several men, of large property apparently, who, 1 believe, at present are not worth a shilling; they are merely representatives of the property, and not real holders.

4560 . Does it not appear to you the necessary consequence would be, the debtor would be benefited at the expense of the creditor?-That is not exactly the question. I should say to the creditors, "First, before you can show you would lose so much, show me how you have gained the difference; how you have realized the difference between the heavy sovereign and the light one; how you have made your $10 s .20 s$; whether you have had an advantage in your mode of living or your mode of expenditure, or in any way, save and except on buying your government stock;" and when he has shown me that, I should feel very much at home in asking him how this is produced.

4561 . Do you mean to say that his light sovereign would go as far in purchasing the necessaries of life as a heavy one - - No ; that is going to the full extent of the case. I will take any man's expenditure, 1,000l., 2,000l. 3,000l., 4,000l., or $5,000 \%$. a year, analyze his expenditure before the renewal of the standard and after it was fixed, and show how much further his money goes now. I have done so for several, who have been quite astonished to find how much more the apparent saving was than the real one; a man las saved nothing in his shoes, in his servants' wages, or, I may say, in short, in his general establishment, worthy of notice, except the price of wheat ; there he saves, in his bread, and a little in his meat, which is not reduced in the same proportion; but he cannot show 25 per cent. saving.

4562. Is that true with respect to each class, and is it not true to a greater extent to the agricultural classes?-That is rather a difficult question ; they are placed in so different a situation; they do not depend so much on the luxuries of life, and they are not reduced in proportion to the necessaries; it is obvious the necessaries are regulated by the price of labour; the luxuries are not regulated by the price of labour.

4563. The artisans who are employed by the agriculturists have not reduccd their prices to the same extent as others?-No; the workmen who make the goods thel agriculturists consume lave reduced very much in their prices; the manufacturers of the article have reduced above 50 per cent. in their labour, but the articles themselves, when sold to the farmers, are reduced hardly any thing, and the reason they assign is, that they, the intermediate tradesmen, are reduced in the extent of their business, and therefore must increase their charges in proportion.

4564 . When you speak of the reduction of prices and the currency question, do not you conceive the national debt has a great deal to do with it?-There is no doubt of that; it is that, in fact, and old liabilities, that make the difficulty of the present time. The burthen is greater than we paid at the end of the war; it bears heavier upon the country than the taxation of 1800 to 1813 ; though in the whole there is an apparent reduction of taxation, yet there is a real increase. Considering the circulation at the end of the war to purchase only one-half the quantity of the staple articles it now does, it is very easy to see that the present taxation ought to be doubled to discover what the real amount is, and that taken at $40,000,000 l$. will make $80,000,000 l$. per annum ; but we never had a permanent taxation of $80,000,000 \mathrm{l}$. during the war; therefore there has been a virtual increase of taxation since the peace.

4565. From your experience of the condition of the manufacturer, the master, and the workman, what particular class of taxation should you say presses the heaviest upon them $;$-The taxation that presses the heaviest is the taxation on the necessaries of life generally, which obliges them to endcavour to have a rate of wages above their competitors.

4566. Tea, sugar, soap, and so on ?-The great thing is bread; that tax is nearly 100 per cent. I give the taxes, direct and indirect. The bread tax is the worst tax he pays of that hind, I look upon it; then the tax on malt, the tax on tca, and every article he consumes, adds, of course, to his general expenditure.

4567 . What is the rate of wages at Birmingham at present, taking the differcut classes, the skilful workman, the medium skilful workman, and the ordinary labourer?--That is a very difficult question, though no man is better acquainted 
with the matter than I am; I am proprietor of a very large establishment for rolling metals for the different manufacturers, and I know what many manufacturers are doing; it gives me a vely extensive knowledge of the nature of every manufacture; but the variations of prices in Birmingham are greater than in all the world, for this reason,- - there is such an extraordinary variety of manufactures; and good men get wages out of comparison to those of inferior note; the wages of labour in Birmingham will vary from $10 \mathrm{~s}$. up to five guineas, in a few instances, per week; there are a few men in very particular trades very clever in their trade, who cannot be surpassed or equalled in that trade; then there are also a great many women and boys and girls employed, from $1 s .6 d$. or $2 s$. to $8 s$. or $10 s$. per week.

$456 \mathrm{~s}$. What would you say are the average wages of a moderate skilful workman, laying aside the extremes in one side and the other, in manufacturing labour? -I should say, if he was a man who understood his business perfectly, and of good character (for that is important in those trades when they are working in valuable metals), he can generally get from $23 s$. to $25 s$. a week.

45 fig. 11 as it advanced lately or been stationary?-There has been no advance till lately; they have been reducing gradually, but in consequence of the great variety of trades, wages are never reduced to that low rate which they are where there is only one branch of manufacture; if a man cannot get work at one thing he does frequently at another.

4570 . They have been at that rate for some time?-They have not advanced in proportion to the great advances in the raw materials; but when I came from home, a week ago, I know there was an intention on the part of the colliers in the neighbourhood to make a strike, as they call it, for increase of wages, in consequence of the rise in iron.

4571. For how many years back have wages been about stationary ?-I do not remember wages in the last six-and-twenty years to have been absolutely stationary for any long period, and I have been in active business that number of years.

4572. You said they had not varied much lately ?-No, not materially.

4573. For low many years have they been about stationary, at the average rates you have just stated - I cannot say they have been for many years, for the real fact is, that three years ago the wages were, in some instances, rather lower than they are now.

4574. Cannot you state whether, for the last two, three, four or five years, the average wages of the workmen have advanced or fallen back?-I should say the last three years or 30 months they have advanced rather than fallen back, because there has been an improvement in the quantity of trade, and then there is always a natural improvement in wages.

4575. So that, though for the last 18 months or two years the price of bread has been lower than has ever been known, the wages of Birmingham have rather increased than otherwise ?-Yes, I think so; but it is so small an increase it can hardly be called one; they liave not advanced generally; only in some few instances, and that has arisen in consequence of the advance given for good workmen. The wages have not been advanced generally, but the situation of the artisans has been improved by the reduction in the price of corn.

4576. Are there saving banks at Birmingham?--There is one.

4577. Have deposits increased of late years?-They have increased some thousands within the last few years.

4578 . You consider that as a symptom of the more easy condition of the labouring classes, do you not?-I do not know; that is rather doubtful; it depends on two eircumstances-not what they obtain alone, but how they spend it; there is a considerable difference in our manufacturers as to temperance; I know there is a good deal of that with us. I can say, for the credit of the place and my own interest, drunkenness is not half so common as it was.

4579. The moral condition of the people, upon the whole, is improving?The moral condition of the people of Birmingham is decidedly better than of any other place I know.

4580 . You say, in respect of the facility of money, the circulation of money for the purpose of business and on credit has been greater lately than you have ever recollected it?-It has been greater in our part of the world, from the very great establishment of joint-stock banks, and it is the natural result that 464 . 
Sir. G. F. Muntz. there are more persons doing business; they oppose each other, and do what they can.

$18 \mathrm{March} 1 \$_{3} 6$. $\quad 4581$. That you attribute, in your judgment, to the joint-stock banks ? - I have no doubt of it ; though joint-stock banks are highly respectable, they have not their capital all paid up, and that increases the amount of credit and discount, without the employment of a proportionate quantity of capital.

$45^{\mathrm{S} 2}$. That credit circulates freely with you?-Yes.

$45^{8} 3$. Are you not apprehensive of some check to that system of credit?Yes; I liave not the least doubt of it ; it is the natural result.

$45^{S}$. Is the facility as great as it was in the time of the unredeemable paper? -Yes; much greater.

4585 . There is a greater facility at present?-Yes, beyond comparison; it is not to be named on the same day.

4586 . You attribute some of that facility to the alteration of the usury laws; you are aware the alteration of the usury laws is to permit persons to lend at higher interest than five per cent.; do you suppose, in the present low rate of money, any transactions take place at higher interest than five per cent.?-I cannot say from my own transactions, because I have not occasion to borrow, but I hear they are extensive; it las been lately a very speculative time, and there are opportunities for men realizing money very rapidly, if they have a small sum to lay out in the first cost of shares. I have no doubt, in many instances, friends have agreed to raise money in that manner to purchase shares. It would pay a man very well to give seven and a lialf per cent. per annum to raise money to make 50 per cent., as they have done, in many instances, in three months.

$455 \%$. Is the employment of the manufacturers at Birmingham healthy or not?-Some are unhealthy; but Birmingham, generally speaking, is healthy; the water is good, and it stands on high ground as well as hilly ground.

$45 \mathrm{Ss}$. In point of fact, they live to as advanced periods of life as persons engaged in other pursuits? - Yes; many live to old age. They live in distinct separate houses, which conduces mucli to health; never in flats, as they do in many places; each man has his own house.

$45 \mathrm{Sg}$. What is the rent they usually pay for their dwellings? - That is very various; it will vary from $18 \mathrm{~d}$. a week to 5 s. a week, for the dwellings of the operatives; one or two rooms below and a couple of rooms above; some larger and some smaller; and some run in courts that stand back from the streets.

4590. Families of tive or six :-I never inquired into the number of their families; I canuot speak to that.

4591. Will you state your reasons for thinking some check will, at no distant time, come to the manufacturing prosperity? - I am speaking like a lawyer upon that subject; I would go back to precedents; I would go back to 1823,1824 and 1825 , when I recollect all the circumstances; and I think that our position in the present instance is not very different ; the prices were advanced, every one knows, by the increased circulation of paper, both Bank of England and local ; at present prices are advanced for the same cause, the increased circulation of the joint-stock banks, the increase in the circulation of local banks, and the increase of the Bank of England paper, and there is a greatly increased circulation of bills generally; but there is this great difference between the years 1824 and 1825 and the present time, that then speculations were made to send money out of the country, and now they are to keep the money in the country, which will make this difference, that the re-action will not be so sudden; it will not come with the rapidity it did in 1824 and 1825 , but by an indirect operation, and the advanced price of manufactured produce cutting off the sale in the export market, added to a probable export of gold ; an adrance must take place in all the manufactured produce if the present state of things continues; when this takes place to seven and a half or ten per cent. there will be a suspension of orders, then there will be a reduction of wages for the artisans, an increase in poor-rates, a suspension of demand for the necessaries of life, and we return to the old course of things, low prices.

45.2. Supposing there was a rise in the price of the necessaries of life?It is no consequence, if that be provided for by an alteration of the standard.

4593. Would not an increased price of the necessaries of life produce a corresponding advantage to the manufacturer, by giving an increased power to those who raise agricultural produce of becoming customers to hin? ?-No. If 
we had the trade of this country, and dealt to no other country, the price at which we fix the import of corn would fix the price of every other article; but the export trade, though only one third, is sufficient to fix the price of the whole. It is a thing $I$ have seen over and over again : as soon as there is a general advance in the price of manufactures, within a corresponding time there is a re-action from that advance, destroying the foreign sale, and a suspension of orders, and a corresponding alteration of all prices naturally follows.

4594. The suspension of trade arising from the permanent high price of bread must affect the power of competition in our manufacturers, by eventually affecting the price of wages?-Provided there were a great and permanent increase in the price of corn or bread in times of scarcity, that will advance wages or produce distress; but if there is speculative labour in manufacturing produce you need not wait for an advance of bread, for that will be accompanied with an advance of every other article, and an advance of manufactured articles with it.

4595. Will the prices of wages affect our competition with the foreigner?Yes, if you mean sterling prices, but if it is nominal prices it is merely a home question; we obtain in each case the same quantity in weight of gold and silver in return for a certain quantity of manufactures. It is very often stated, that any alteration of the standard would be an artificial and unsound state of things. I admit that it must be an artificial state of things, and I submit whether every thing is not an artificial state of things that we have had before. We have had a corn law for the purpose of making wheat $8 s$. a bushel, and unless that $8 s$. a bushel will raise the prices of the artisans' labour in the same proportion, it is a very unjust law. If it would raise the price of the artisans' labour in the same proportion, it would be a just one; but, as it is, either it has an object or it has none. If it has the object of making the value of a bushel of wheat $8 s$, without giving the means to the working manufacturer to buy it, it is a very unjust and artificial law ; and if its object is to raise all other prices with wheat, it is equally as artificial as to raise all prices by a money law, or alteration of the standard of value. You are now endeavouring to make corn $8 s$. a bushel, for your own remuneration. You cannot do that on the principle you try to do it. It would make no difference whether you do it by your own plan, or by any other which is effective. One is effective and just to all; the other is very unjust in principle, and it never will be effective, for though the object is to keep the rate of corn at the price required, it never will be obtained; the manufacturer who is affected by it, he shifts the burden from his shoulders by his very wants; the reduction of his consumption of the necessaries of life eventually reduces the price. But a short time is not sufficient to effect this purpose. In the first place, the reduction of the price of the necessaries of life falls upon the farmer; the farmer, while he has any property to enable him to hold, will not sell his produce at a reduced price; he will hold it up as long as he can, and he will, in addition to that, take credit from his landlord, and hold himself up by that ; another period will come and he will lose his farm ; but his next neighbour, who thinks himself cleverer than he has been, will take his farm; then it requires two or three years to get rid of this man; then the landlord at last is the scape goat. How is he to get rid of the liability, with his land thrown on his hands, as in 1822 ? It takes always from seven to ten years to produce this result; and that is the reason why we have come only at this period to the position to which, without com laws, we should have come so much sooner.

4596. What proportion are the expenses of the manufacturer in Birmingham with respect to the rate of wages, compared with other expenses to which he is subject?-They are so various, it is impossible to give an answer to it; there are such varieties in the labour compared with the quantity of stock, I do not see how I can give an answer.

4597. Should you suppose the dead capital vested in stock and in buildings (that is, the interest calculated upon it), is more or less than the expense to which the manufacturer is exposed with regard to the wages of his workmen? There are instances with us where the rental of a man's establishment is equal to his wages; the amount of his dead stock is nothing in comparison (that is, the interest of it); I am sure there camnot be an instance that can be mentioned.

4598. Is the stock of goods on hand large in Birmingham at present with the 460. 
Mr. G. F. . Iuntz. merchants or master manufacturers, or does it go off pretty currently ?-I do not think there are any large stocks on hand; the merchant is not in the habit

$18 \mathrm{March} 1836$. of keeping large stocks; but the manufacturer is obliged, in a bad state of trade, to hold stocks.

4599. In the present state of things is he overburthened with stock, or do the articles of his manufacture go off currently?-They go off currently of late ; there have been a few instances to the contrary, but that has not happened more than a month or six weeks.

4600 . That is a symptom of what you would call a healthy state of trade?A healthy state of trade is a very awkward term; a trade may be very healthy as regards quantity, and not as it regards profit.

4601 . That proves that either the manufacturer is working on orders he is executing, or, if working without orders, that he finds a mart for his goods as far as he could turn them off?-They are working for orders, not for stock.

4602 . That would be a state of things which, barring any loss which may come upon you from any bad management of the banks or the circulation, would rather lead you to infer that the manufacturing trade of the country was in a healthy state? - There is another circumstance which would make and is making a great difference, that is, the advance in the raw material; a great many of our trades may be said to be lost now from the advance of the raw material.

4603 . What particular parts of the Continent are our rivals in manufactures? -Both France and Germany, and even America. I should say no person who has not seen them can form an idea of the perfection of their manufactures; in many places their manufactures quite exceed ours, particularly as regards the application of manual labour; many in Paris are far beyond ours in Birmingham. 4604. In what articles? - In plated articles and some silver articles; also gilt and bronzed work.

4605 . In the finer description of articles or the most bulky?-In the large and heavy articles we have the advantage.

4606. You do not refer to taste?-They are rery tasty; their invention of patterns exceeds any thing we have here; but I mean to say, in the execution also of things long invented, all articles that require a great deal of manual labour, they can underwork us. In the last seven years Birmingham has lost many trades in which I myself have exported thousands of pounds worth per annum, and in which I do nothing now. They have the trade at Westphalia, Vienna and Paris.

4607. Paris is the seat of the manufactures you speak of ?-Yes, of many articles made in France.

4608 . Is St. Etienne?-They manufacture cutlery there.

4609 . Have you ascertained what were the wages of the manufacturers in Paris of articles similar to those made in Birmingham?-Yes, as to many of them.

4610. How did you find them?-Very considerably lower.

4611. Can you state the proportion? - At Paris, in a number of trades, some of them 30 per cent., and in some 50 per cent. lower; but they were decidedly lower.

4612. You have stated generally that you think the state of the circulation at the present moment unsatisfactory; is it your opinion that we should have what is called an irredeemable paper again; are you favourable to that?-I am not at all favourable to that.

4613. You would not send any paper out not payable in gold? - Certainly not; I would have all paper payable either in gold or silver.

4614 . But that there should be a silver currency, not regulated according to the present value of the depreciated silver currency, namely, $66 \mathrm{~s}$. to the pound of silver?-No; that would make a difference of about 15 per cent.; and if the gentlemen of the landed interest can show that that is sufficient for their interest, without corn laws to help, I should be satisfied with it; not that I think they can.

4615. In stating your opinion of the unsatisfactory state of the currency, you would not wish it to be understood that you wish, what some persons wish, a return to irredeemable paper, but a silver instead of a gold currency; how do you think it would be proper to regulate that?-There is only one way I can find to regulate it, and that is, that it should regulate itself. 
4616. Is it possible to have any standard of value which is not a fixed quantity of the precious metals? - If Parlianent choose to fix the standard I have no objection; but it must first be ascertained what the standard ought to be.

4617 . It must be a certain quantity to be a standard? - If I am informed what the price of a bushel of wheat ought to be, I will say at once what the standard of silver ought to be.

4618. Then supposing the wheat were to be $8 s$. ? - Then the standard should be $8 s$. an ounce, and then you get rid of corn laws altogrether, and keep the corn at $8 s$. a bushel.

4619. Why do you suppose those two prices should be commensurate to secure the bushel of wheat selling at $8 \mathrm{~s}$. ? - I find, on searching all the authors that I have looked into, that the average price paid for a century prior to the paper system of the Bank Restriction Act was an ounce of silver to the bushel of wheat; therefore, I say, the price still continuing the same throughout Europe, if it is necessary in this country that wheat should be $8 \mathrm{~s}$. a bushel, and I believe it ought to be so, then you have only to take care that the ounce of silver is regulated by that price; you cannot limit the foreigner's ounee of silver for his bushel of wheat; and you must add to that the expense of transit and insurance, which will make it a remunerating price to the farmer here. You might as well keep your prices at that standard of $8 s$. of silver to the ounce, and then they would be much more fairly reguiated than they are now.

4620. What do you call the price of the circulation now?--Five and sixpence.

4621 . Supposing the price of silver now to be $5 s$, according to your notion, that it should be $8 s$. to justify the price of $64 s$. for corn, you would depreciate the currency in the proportion of eignt to five?-Yes; that is taking the two; one balanced by the exchange reduced thereby against the advanced prices of the other.

4622. You have given that as the rule?-That is not the case now; the present price of silver, under the present limitations, does not regulate the price of corn from indirect operation; it is a free import that makes all the difference; on my plan it would always be a free import.

4623. Your hypothesis of $8 s$. an ounce of silver and $8 s$. a bushel of corn rests on the presumption that there should be no corn laws?-Yes, they will not be required ; they are very odious, and will be got rid of.

4624. Your measure would be to do away with the corn laws, and to change the silver currency from $5 s$. to $8 s$. ?-Parliament need not abolish the corn laws, if they are afraid so to do; they would become nugatory with a silver standard of $8 s$. per ounce.

4625. When you say, that taking into consideration the average price of corn for two years past, that is the consequence of the state of circulation of this country, how can an alteration with respect to paper make a material difference as to the present, compared with the former, state of things ?-It has nothing to do with the paper, but the price of corn on the Continent. Prior to the Bank Restriction Act I see that the average price of corn was $8 s$. a bushel; then the foreigner can never send it in at less price than that, with a standard of $8 \mathrm{~s}$. to the ounce of silver; and manufactures here could advance in the same ratio.

4626. How would that apply to the prosperity of the manufacturing interest? -It would make no difference at all ; the wages will advance to nearly the proportion to which you advance the standard, and the advanced price of our manufactures on the Continent would be counterbalanced by the exchange falling in proportion.

$462 \%$. Then the operation of the change would make it a matter of no injury to any one?-Not the least ; it would make them steady, and allow for the rent being paid; it would be a trifling reserve for the workmen, for the prices of articles of support are not yet reduced to the rate of wages.

4628 . How would that apply to public and private creditors? - There must be some injured, and some will be benefited; but the interest of the many must be attended to, though to the injury of the few. I think they would be 75 out of the 100 . I go back to the year 1824 and the early part of 1825 ; I recollect that all classes were then in a state of prosperity, of which the then Government boasted; all trades were profitable, and no one complained; and all I wish is to place the country in the state it was in 1825 , with one exception-that I would keep it in that position. I can only compare the state of 1825 to the condition of a bridge that a man built, and he left the keystone of the arch out; of course

$$
464 \text {. }
$$$$
\text { N N } 3
$$ 
Mir. G.F. Munis. it fell down when he approached the middle; and that was exactly the condition

18 March 1836. of 1824 and 1825 ; all prices were brought up to the war level except gold and silver, and the price of wheat was higher than the war price; but there was only one thing that could keep it up, that was, the keystone of the arch,- - the alteration of the standard or value of gold and silver. I wish that we shonld arrive at the prosperous state of things as in 1824 and 1825 , and that the same state of things should continue to exist.

4629. Had you not in 1824 and 1825 the same state of standard you have now?-Yes; which was indirectly operated on by the great circulation of paper; and there was, as at present, a very great rise in all prices except gold and silver, and afterwards a great export of gold from the kingdom in consequence. The Bank had but one resource; they had no choice; they were obliged to withdraw their paper from circulation rapidly, being bound to find gold at $3 l .17 \mathrm{~s} .10 \mathrm{~d}$. an ounce, and they were forced, when it left, to look for it again at any cost. 'They had no option; they could not do otherwise than they did; and they will have to do the same again if prices keep rising.

4 (i3o. If you were to make an alteration with respect to the standard, in what way should you recommend it should be done?-I should do it in that sort of way which I consider the only way of finding the true standard; I should give the Bank of England permission to issue one-pound notes, and to pay their notes at the market price of gold instead of a fixed price. If it was thought necessary to limit it it should be limited, lest it should go to excess. Then that would be the natural standard which would be produced thereby, and would keep prices in proportion to taxation.

[The Witness is directed to withdraw.

John Grey, Esq., is called in; and Examined as follows :

John Grey, Esq. $\quad 4631$. YOU live in Northumberland ?-I do.

4632. You are receiver of the Greenwich Hospital estates for the northern counties?-I am.

4633. Of what extent are they? - They are of considerable extent; the rental is above $30,000 l$. a year.

4634 . It was returned $44,000 \mathrm{l}$. a year a few years ago?-Yes; but there liave been many deductions since that.

4635. In what state are the farmers farming that property?-Their circumstances are very much reduced; their capital has been considerably diminished.

4636 . What sized farms do they hold? - The farms vary very inuch throughout the district. The rental of farms in the north part of the county of Northumberland is generally from $500 \mathrm{l}$. to $1,300 \mathrm{l}$. a year.

4637. You are also a considerable occupier of land, are you not ?--I have been till within the last three years an occupier of 2,000 acres, my own and other persons.

4638. Of land of the best quality?--Yes, partly so, on the Tweed.

4639. In what state do you consider the farmers in that district generally to be?-I consider them to be in a state very much below what they were a few years ago, in point of capital; they are distressed; they have been much more so of late years.

4640 . In what manner do they cultivate their land; as high as they used to? -No.

4641. Their farms have been run out, in consequence of their distresses?Yes; they have had recourse to repeating corn crops too frequently, and exhausted the land; and in some instances considerable injury has been done in the country by the high prices dnring the war inducing the farmers to break up the old pasture lands, which is an injury, and a permanent injury, for they cannot be easily restored.

4642. Have reductions taken place in the rents of the hospital lands?-Yes.

464.3. Has that been on the heavier or the lighter lands? - I can tell your Lordships the reductions which have taken place in the Greenwich Hospital estates within the last two years, since I became receiver. Some of them have come to the termination of their leases, but the great majority were given up in consequence of the inability of the farmers to keep them.

4644. How many were thrown upon your hands at one time?-There were upwards of 30 the year before last, 1834 . 
4045. Extending to about how many acres?-I suppose the average of those farms might be from 200 to 300 acres.

4646 . What were the rents, as far back as you can remember them, and the alterations which have been made? - I liave not been in the nanagement of that estate for more than three years, but the average reduction upon the farms that I speak of as being re-let was $22 \frac{1}{2}$ per cent. below the former rental.

4647. When was that re-let?-From the year 1833 to the present time, but that reduction varied very much, according to the quality of the land, and other circumstances. The average reduction on land, chiefly what are called barley soils, was 15 or a fraction less than 15 ; the average reduction upon those which contained a considerable proportion of wheat land on heavy soils was 25 per cent.

4648 . Since 1815 ? - Those reductions have been made in the re-lettings on leases expiring from that time.

4649. Have the managers of the hospital farms met the tenants, by making, from time to time, reductions, without waiting for the expiration of the lease?No; I believe they are not able to do that, in consequence of their Act of Parliament. The leases must be determined or become void, and it was necessary to take them from the hands of the tenants, and make a re-letting.

4650 . There was no application to the Court of Chancery to allow them to do that ?-No, I believe not; there was a reduction, I believe, in the year 1822 .

4651. A great proportion of those farms were thrown up by the tenants? Yes; and if they came to a termination of the leases the greater proportion were re-let to the same tenants.

4652. You let the tenantry go on with burthens they could not afford, sooner than interfere and give them relief?-Yes.

4653. When they threw them up the land was a good deal exhausted and the tenant ruined?-Yes, in some instances.

4654. Has no application been made to the proper authority for power to make any concessions?-No ; it was discussed, but my own opinion was, that that was not the best way to do, because in many cases there were tenants upon those estates that it might be adrisable to get quit of, and by resorting to the other course, of allowing them to give up the farms, we had an opportunity of replacing those with new ones.

46.5. Has not every landed proprietor the same porrer, though he may use the power he has with care, making to a good tenant a certain reduction, if be thinks the state of things requires it ?-Of course every landed proprietor can use his option; but the Greenwich Hospital Commissioners were not so empowered.

4656. Do not you think that an imperfect state of management of the hospital property? - I am not certain that it is; I think there was one difficulty in the management of the hospital property ; the plan acted upon for many years was, that every farm was let by public tender, and that brought on the property tenants who might be rejected by other landlords in the district, who might put in their tenders. In the last two years I have been authorized to treat by private contract with those tenants who have managed their land well, and were considered deserving tenants; but in resorting to a mode of letting by public tender, when the tenants do not wish to occupy a farm again, there is a chance of getting tenants of a character not desirable.

4657 . Are your tenantry, as compared with the tenantry of the surrounding country, of a more or less respectable class? - They are a highly respectable class of tenunts; but they have been on farms at too great rents, and probably were induced to take great liberties with the land; and I think that arose from the system of public tender, and their being induced to give more than they otherwise would do to obtain their farms.

4658. Since 1833 there have been reductions which you estimate 22 per cent. ; do you apprehend there were any deductions prior to 1833 , as compared with the higher prices during the war? - Yes; the farms that had been re-let prior to that had been reduced gradually. I observe the average reduction of the preceding years was 15 or 16 per cent.

4659. During the high prices were those farms let at the lighest rents? - I think they were let at the highest rents, because everybody in the county was bidding for them ; there was the greatest possible competition.

4660. They were let by tender?-Yes.

4661. How much were they above the average of the farms of the tenants 464 . 
John Grey, lisq. round about? - It is difficult to say that, but they were alwars considered to be very high rented farms : and there might be one reason why they would bear rather a higher rent, because Greenwich Hospital, as landlords, were in the habit of doing a good deal in the way of building, draining, and so on, the tenants leading the materials for them.

4662. Nowithstanding the improvenent of the buildings, and moner laid out by the hospital, the condition of land has deteriorated :-Unquestionably.

4663. Do you see a manifest diminution in their crops of corn?-Yes; and I have been introducing a different system, and doing all I can to get them to use it a little more in grass, and not to come so quickly round with their rotation of crops.

4664. What has been the rotation of crops :-Generally that called the fourcourse rotation; two years in corn, with one of green crop and one of fallow.

4665. No turnips?-Turnips instead of fallow. It is called a fallow crop; some part of the land will grow turnips and some not.

4666 . Owing to the distressed state of agriculture, they have been running the land out?--Yes, in some measure.

466\%. How much does that land produce an acre? - - The estate varies much; we have on Alston Moor land which was let for $1 s$. an acre, and on the Tyne, land which last year has let as high as $3 l$. an acre.

4668. Arable land? - Yes.

4669. What is the rent of good average arable land?-About $30 s$. an acre, tithe-free.

$46 \%$. What would be the produce of that per acre in whent, supposing it properly cultivated ? - I should say three quarters.

4671 . Barley ?- Five to six quarters.

4672. Oats?-Probably seven to eight quarters.

4673. Beans? - It is not much a bean country.

4674. Peas? - From three to four quarters.

467.5. When you say that average arable land lets for $30 s$, is that the price since the deduction of $22 \frac{1}{2}$ per cent. ?-Yes, for good arable land, tithe-free.

$46 ; 6$. That land which does not produce better than three quarters of wheat for the acre?-Not on the average of rears; I should say it comes pretty nearly to that; we have in some cases much larger produce.

4677 . Have you any very expensive hind of manure you apply to it?-No; they do not apply any manure not made on the premises, except a little bone manure, and a good deal of lime.

$46-8$. How much an acre do you reckon that bone manure costs? - It costs about $1 l$. or $1 l$. $1 s$. a quarter, and they apply about two quarters or two quarters and a lialf.

4679 . Is it a very enduring manure ?-I am not sure that it is a very enduring manure; it is very good for raising a crop of turnips; and it is also good for the succeeding grasses.

4680 . In the present distress of the farners, do other articles, wheat excepted, sell at reasonable prices?--Yes, I think they do.

4681 . Their barley and their stock? - Their stock has been selling well.

4682. Their wool? - That has been selling very high.

4683 . Have they large flocks of sheep? - No, unfortunately they have not;

I wish they had more; they might pay us better rents if they had. Owing to the poverty of the farmers and the exhaustion of the soil, it is much against them in this respect.

$468_{4}$. The poverty of the farmers and the exhaustion of the soil has prerented their lieeping the sheep stock they should otherwise have kept?-Yes; but I know many farms on the borders where large flocks are kept, almost exclusively in grass, lately let without any reduction of rent, in consequence of the high price of wool.

4685. Are those farms belonging to private individuals? - Yes.

4686. Where the farmer has not been injured by being over-rated?-Yes; and farms which have never been in tillage, except in a small degree.

4687 . How many sheep can they keep on an acre?-I cannot say; they are generally mountainous districts; some of them not more than two sheep an acre, some one sheep, and on the Cheviot Hills much less.

4688. Those lands you speak of which have not been broken up are generally mountain farms?-Yes. 
4689. Valued at about how much an acre?-Five shillings to $8 \mathrm{~s}$. an acre; those, with a mixture of heath, are not above $2 s .6 d$. or $3 s$. an acre.

4690 . At $8 s$. an acre, what number of sheep would they keep?-That ought

o keep during summer from one and a half to two sheep an acre.

4691. What are your wages in that ncighlourhood? - The wages of day labourers are generally from $10 \mathrm{~s}$. to $12 \mathrm{~s}$. a week; $12 \mathrm{~s}$. very much at this season.

4692. Do you pay them the whole in money?-No; in the arable districts of Northumberland the regularly hired servants are paid in kind, and supplied with a house and garden, and receive so much in grain. Generally they have the means of keeping their families comfortably.

4693. The labourers in the district you speak of are pretty comfortably off, though the farmers are in a state of distress?-Yes, for the labourers' gains have not varied; what they received has been continued; with their families, the labourers, I should say, are very well off.

4694. Where the labourer is paid in kind, how much does he stand the farmer in ; how many shillings a week is it equal to?-I should think from $9 \mathrm{~s}$. to $10 \mathrm{~s}$. a week; it varies according to the price of corn, therefore now it is at a very low rate. On a former occasion, when I was asked that question here in the Committee on the poor's-rate, the calculation I made brought it to more; then that was the price of corn brought it to that; it was then $13 \mathrm{~s}$. a week.

4695. Are you much burthened with poor in that neighbourhood?-No, we have never been very much burthened with poor in our neighbourhood.

4696 . Is your population equal to the agricultural want, or beyond it?-It is quite equal to it, except in harvest, when we have an influx of Irish labourers.

4697 . What payment do they receive?-About $2 s .6 \mathrm{~d}$. a day, I think, generally.

4698. With meat and drink?--Yes, they get meat.

4699. They come generally in harvest, and reap it?--Yes.

4700 . What have been the prices of wheat in the course of the last year?The prices of wheat have been very low; as low as $3 s .6 d$. a bushel; from that to $6 s$.

4701. What is your market?-Berwick, in the northern part, and Newcastle and Hexham, in the other part of the hospital estate.

4702. Is there any particular alteration which could be made, which, in your opinion, would tend to relieve this agricultural distress? - I am not aware of any great relief that could be given, except a reduction of rents, which is the first and most important mode of relief. The alteration in the poor-rate is improving the state of the agricultural districts, but we do not feel that so much, for we never experienced so much the abuse of the Poor Laws.

4703. You state the rents to have been already reduced 22 and 15 per cent.? - No; I said that farms which had been re-let previous to that period had experienced a reduction; but they were not the same farms.

4704 . You think the lands belonging to the hospital have been worse managed and more worked out than the general farms in the country?-Yes, I think they have.

4705. What is the description of lease they have under Greenwich Hospital; for years, or for life?-For years.

4706 . Are they strictly bound down as to the course of cultivation?-Yes.

4707. Has that not confined their cultivation, so as to prevent the farms being injured?-The course of cultivation is that which has been in practice very much before; but I think it has a tendency to exhaust the soil, and that it is not the most beneficial to the tenant or the landlord.

4708. They are allowed to grow too much corn? - Yes, and too little in grass. Their leases now, with few exceptions, bind them to let it lie two years in grass.

4709. That would not give them two crops in four years? - No, in five years ; and it gives them two years for sheep, which I contend will pay them better, and with less manuring.

4710 . You remark that the condition of the farmers was very different; to what do you attribute the change? - 'lo the exhaustion of his capital from the course of the seasons, in which he has been called upon to pay more rent than his land was capable of producing.

4711 . Do you attribute that entirely to the seasons; have they been un404. 
John Grey, Esq. favourable?-The seasons have been favourable; the harvests have been good for the last three years.

18 Iarch 1836 . 4712. For all descriptions of corn?-Yes, generally; but not so much for other grain as for wheat.

4713 . To what do you attribute the present low prices?-I apprehend to the great produce.

4714 . Has there been a great produce of barley and oats?-There has been a great produce in that district of barley and of wheat ; oats the worst of any.

471.5 . Was there a great produce in 1829,1830 and 1831 ?-No.

4716 . Was the condition of the farmer better in those years? - No, the condition of the farmer was very bad in those years. The change which took place in prices was owing not so much to the seasons as to the alterations in the monetary system; the change of the currency made it quite apparent what the effect was to be on prices.

4717 . Do any small notes of Scotland reach your country?--They come over the border, but are immediately sent back again; they do not continue in the neighbourhood.

4718 . Do you pay them among you?-Sometimes, but not to any great extent.

4719. How far over the border are they in general circulation?-We do not find them more than 20 miles over; they are generally returned.

4720 . Within the border of Scotland nothing else circulates? - No.

4721 . You see no sovereigns? -Very few, I suspect.

4722 . Is there an ample supply of those notes in Scotland?-- Yes.

4723 . Is there any difficulty in getting a large supply, if persons in credit apply for it ?-I apprehend not.

4724. Does that make any difference of price on the two sides of the border? -Yes; the pressure has been less where those notes were in circulation, and where the Scotch system of banking prevails; I believe the tenants were not immediately swept away, as they have been in some instances in the south, because they can derive accommodation from the banks; the banks have more opportunity of giving them accommodation, and more facility in their operations.

4725 . What is the different system of banking to which you refer?-The issue of notes makes one part of the difference, and there is generally a difference in the banking of the two countries; there are banks circulating throughout all Scotland in the remotest part, and giving abundance of circulation for the business of the country.

4726 . Is there any difference between the condition of the farmers in Scotland and those in England, any further than the circumstance of the Scotch being more accommodated by those banks, and that creating a difference as to their prosperity?-I apprehend that is the great cause of difference; but the tenants in Scotland are generally better off than those in England, from the circumstance that they produce more wool ; that they have more sheep and less cultivation; mutton and wool now are generally remunerating articles; at least the only ones that pay very well.

4727 . What is the condition of the strong lands?-That is the worst; the average reduction was $22 \frac{1}{2}$ per cent.; the reduction upon those lands, chiefly light or barley lands, was 15 per cent., and that of the wheat lands 25 per cent.; there were some instances reaching to 28 and 30 per cent.

4728 . The reduction on good wheat lands was from 22 to 30 per cent., and on some 40 per cent. ?- Thirty per cent., and in some instances further.

4729 . In your neighbourhood would the repeal of the malt-tax be of any considerable advantage? - It would certainly be a relief to those farms producing barley, but they require it less than the heavy soils; any thing which would induce a better market for barley would be of use.

4730. Would it have a tendency to force wheat into use for feeding cattle?Yes ; I have no doubt that it would be used, in some measure, as substitute for other grain.

4731. That wheat would be malted for cattle?-Probably it might, in some cases.

4732. Would not that operate as a relief?-Yes, to the light soils, but not so directly to the wheat soils. 
4733. Will it not have a tendency to prevent the growth of so much wheat, by promoting the growth of barley ?--Y Yes, I think it would.

4734. Have you considered what would be the effect of the Tithe Bill lately proposed?-If the Tithe Bill were settled on just grounds, it would remove the impediment to the employment of capital on agricultural improvements.

4735. Have you looked at the proposed 'Tithe Bill, and do you eoneeive it would have that effect? - I imagine it would have that effect; whatever the principle of the Bill might be, if that were actually settled, it mould withdraw the impediment to the employment of eapital on agricultural improvements; whether it is properly adjusted, or otherwise, makes a difference to the present individuals, of course.

4736. You have said, in the lands belonging to the hospital the cultivation has deteriorated; that the land is in a worse state than it was ?- Unquestionably that is the case.

4737. Looking round the county, is that generally the case :-It is.

473 . Do you think it is in a state of producing less than it did? - I do not know whether it will produce actually less, because I think there is more perhaps in cultivation. There has been an inclination among the tenants to extend their quantity when the value was diminished; I apprehend, therefore, that the quantity produced is perhaps as great as ever it was, but the condition of the land certainly is not so good.

4739. Are there large stocks of wheat at present in the farmers' hands? - No, not generally ; there are a few farmers who have eapital, and the inducement to them has been very great to keep their stocks; but, generally speaking, I should say they have not large stocks; rather the reverse.

4740 . Not so large as usual at this season of the year:-Not so large, I should think.

4i41. Has as much wheat been put in the ground ?-No; much less, I think.

4742. This is the first year there has been a diminution of the quantity sown? -I think it is.

4743. Do you believe, when a larger quantity was sown, probably the produce has not been so great, in consequence of its not being attended to?-The produce of the two last years has been very great.

4744. The land is not generally so well cultivated?-No, nor the crops so good.

4745. What are the prices you get for wheat now ?-At present $6 s$. a bushel, and for barley scarcely $4 s$. ; about $3 s .6 d$.; that is very low for barley.

4746 . Do you grow barley of good quality? - Not so fine in quality as the southern districts; it does not compete with the Norfolk barky.

4747 . What prices for wheat would, with the present rent of land, reduced as it is $22 \frac{1}{3}$ per cent., enable the farmer to live?-I think the wheat lands could bear their present rents if they had $7 s .6 d$. a bushel.

4748 . The rents could not stand at $7 s$., in your opinion?-Yes, perhaps in pretty fair seasons that would be a sufficient price.

4749. What are your poor rates; how much in the pound?-They are from $1 s .6 d$. to $2 s$.: we consider them very high at $2 s .6 d$.

4750 . On the real rental or the nominal rental ?-They are not generally reckoned on the real rent, but I should say $1 s .6 d$. on the real rental would cover almost all the agricultural district of the county.

4751. Does that include the highway-rates and county-rates?-No; probably altogether from $2 s$. to $2 s$. $6 d$.

4752. That is the whole of the tenant's outgoing in the shape of rates and taxation? - -Yes.

4753. What is the customary agreement with tenants in respect of repairs? -

He is bound to keep in repair the things he holds.

4754. To find the materials and labour?-Yes.

4755. You make a distinction between farmers having capital and those having none; has there been any considerable waste of farmers' capital ?- $A$ very great waste; a great many have been entirely ruined. There is a very great difference in the state of the occupiers, for there is a new class which is treading on the heels of the old occupiers; they offer higher rents than they can give, and require less capital; a man entered on a farm 20 years ago with $5,000 l$. capital; now another man will enter upon the same farm with 2,000l, capital, and he will of course be content with a smaller return.

464.

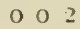

47.56 . Why 
John Grey, Fsq. $\quad$ 4756. Why will he enter with a smaller capital ?-Because he can do it with less outlay for his seed-corn, for instance, and it takes much less for his outlay for stock, and the purchase of all his materials. But there is one other item which is still more important: in that country all the expensive improvements which the high prices of the war gave rise to are now done; the tenant is not now required to lead the materials to a large set of farm-offices, for they have been built, and land has been inclosed and reclaimed. A great many farms, when they were entered upon in former years, required the tenant to lay out $1,000 l$. or more for liming and so on, but he can now enter without that, and therefore he is satisfied with a small return.

$475 \%$. Inclosures were carried on to an immense extent :-Yes, to an immense extent. There is a great change in the state of agricultural occupiers within my knowledge; a change in the character of the people. I can point out thousands of acres now in the occupation of men who were, 30 years ago, shepherds or blacksmiths, or something of that kind, and who are now pressing upon the farmers of old standing in the country, the men whom they used to look to as the most respectable. By industry and economy those men have accumulated sufficient capital to enter, at the present reduced prices, on those lands; their ambition is to be farmers, and a very laudable ambition it is for a man to elevate himself in the scale of society. A man who served as a shepherd to a farmer 30 years ago has now become the farmer himself.

4758. Do not you find that when farms are to be let, persons are disposed to give more than a prudent man will give?-Yes; which is owing to the circumstances I have stated, that the present occupiers, though they may not be doing well, would wish to remain on the spot as long as they can; then persons who come with a less capital are always disposed to bid.

4759 . When a person bids for one of the farms of the hospital, do you make him give any security, or inquire into the state of his capital?-Yes; there is an inquiry into the state of his capital, and a selection made; but that was not thought so necessary when there was large property among them.

4760 . Does land change hands much in your county of late?-There has been a great change of late.

4761 . Has a good deal been on sale?-Yes; but it cannot be sold.

4762 . Who are the people who buy land?-I cannot say. There has been a great deal offered for sale, but very little sold of late years.

4763 . Do you know at how many years' purchase it has been sold of late?Twenty-six years' purchase; it used to be 30 .

$4 ; 64$. Has that which has been sold been sold in large or small lots ;-There have been no large sales.

$475_{5}$. You remember when farming was a good speculation, when every one was disposed to enter into it ; is that the case now?-No. At one period every man of capital was desirous of engaging in farming speculations; now most men of capital are desirous to get out of it.

4766 . If you were to begin life again, you would not probably engage in farming? - No; I am withdrawing from my concerns altogether.

4767 . If it were given as an opinion that the present low prices were the result of greatly improver cultivation, and consequently the greatly increased crops of corn, you would say, as far as your experience goes, that is not the case?-Certainly not, in consequence of increased cultivation; that is not the cause, but the good seasons and large produce in the last three years.

4768 . Then the produce of the last three years has been, so far as your experience of the neighbourhood has gone, the result of favourable seasons, and not of the increased cultivation?-Yes.

4769 . But not from the improved condition of the land?--No.

475 . Their cultivating so much more largely has been symptomatic of the increased distress of the farmers?-Yes.

4771 . You do not apply that to barley, but to wheat? - In that country the average of barley was very good, better than in other parts of the kingdom.

4772 . You speak entirely of 1832,1833 and 1834 ?-Yes.

4773 . Is the condition of the farming labourer good ?-Yes, it has varied very little; I should say it is quite as good now as it was in 1815 .

[The Witness was directed to withdraw. 
Mr. Matthew Sherborne is called in ; and Examined as follows :

4774. YOU are a farmer living near Hounslow?-Yes.

4775. What sized farm do you hold? - About 635 acres.

4776. How long have you held it?-From Michaelmas 1833.

Mr. M. Sherlorne.

4777. What is the rent you pay for it?-From $30 \mathrm{~s}$. to $50 \mathrm{~s}$.; we hold two

$18 \operatorname{March}_{18} 86$.

farms; one the allotment in lieu of the great tithes, and the other is an estate belonging to Mrs. Parsingham.

4778 . Is there a difference in the quality of the land?-Yes, a great difference. A great deal of the tithe allotment was Hounslow Heath, and was under the furze when I took to it.

4779. Is that tithe-free?-The parish is tithe-free in both cases; there was an allotment for the small and for the large tithes.

4780 . Of the bad farm you hold, what has been the produce of wheat per acre?-I have not been there long enough to tell.

4781 . What do you suppose the yield would be?-From 24 to 28 bushels.

4782 . How many bushels of barley per acre?-I cannot speak to that as to that farm, because we have not grown barley upon it yet.

4783 . How much would be the produce of oats?-We are in the same situation; it is full of rubbish; we are farming that farm on a different system.

4784. What system do you pursue?-We are growing mangel wurzel; we are fallowing it.

4785 . Can you give an opinion of the state of the farms in your district?-I

think, as to appearance, much as usual.

4786. Do they appear to be in a flourishing state, or in a reduced state?-Not flourishing.

4787. Have you known many changes among the tenancy?-Yes; but not more so than usual, I think.

4788 . Have any of them been given up ?-No; I think I know of only one case of that kind.

$47 \mathrm{Sg}$. Do the farms in the neighbourhood appear to be well cultivated?--Yes, very well.

4790. Does there appear agricultural distress in the neighbourhood?-Yes, there have been some complaints. I am in conjunction with my brother, and we have other farms besides the two where I am now living.

4791. Where is that other farm?-We have two or three farms at Bedfont, and one in the parish of Harmondsworth, under Mr. George Byng, the member.

4792. What does the other farm consist of ?- Light soil.

4793. Light turnip soil ?-Yes.

4794. Is it better than the land you have before spoken of?-No; different land altogether.

4795. Is it better or worse?-Worse.

4796. About what rent is that?-About $37 s$.

4797. Is that worse land than the other land?-Yes.

479 . What will that land produce of wheat, on an average crop?-About 24

bushels.

4799. Of barley how much?-Thirty-six bushels.

4800. Is that tithe-free?-Yes.

4S01. What is your market?-Uxbridge our principal market.

4802. That is a very good market?-Yes, but not so good as it used to be.

4803 . Do you raise your own manure upon your farm, or get it elsewhere?-

From London chiefly.

4So4. Have you a great deal of manure?-Yes, a good deal.

4805 . Do you send many articles of produce to the London market? - Straw chiefly.

4 So6. Have you any sort of garden produce which you send to London?-We

used to send a great many peas, but now it is not worth while.

4So 7. Did you last season? - No, very few.

$4 \mathrm{Sos}$. What are your daily wages? - Two shillings a day.

4809. What are your rates? -About $5 s$. an acre; altogether I should think

$5 s$. to $6 s$. an acre.

4810 . Ilave they increased lately or not?-No; they have decreased.

4811 . Have you had the new Poor Bill in operation with you? - No.

48 12. They have decreased, under your management, without that?-Yes.

464 .

003

4813. Have 
Mr. M. Sherborne.

$4 \mathrm{~S}_{13}$. Have you a select vestry? - No ; wot either in the parish of Heston or Bedfont; an open restry.

18 March $18_{3} 6$.

$4 \$_{14}$. Haring had this farm for three years, you consider 24 bushels an acre a fair crop of wheat upon land of that description ?-I thiuk the land will not produce more.

$4 S_{1.5}$. Are you satisfied with that as an average crop?-Yes; I am satisfied the land will not grow more.

4816. You pay your rent under the expectation of that crop?-I do ; that is as near as I can tell ; in short, it is correct.

4\$17. How long have you had each farm ?-Mr. Byng's lease expires next year; we have had it 11 years; it was for 13 years.

$481 \mathrm{~S}$. Is it at the same rent now as when you took it?-Precisely; we have had but one lease.

4819 . What price of wheat do you calculate, according to your present rent, you ought to get?-To pay a fair rent, and a fair profit to the farmer, $15 \%$ a load; I think that ought to be the price of the best wheat; that is $7 \mathrm{s.} 6 \mathrm{~d}$. a bushel.

4820. When you took your lease, you did not calculate on so high a price as that, did you?-Yes.

4821 . What are your prices now?-I do not attend the markets now ; my brother attends; yesterday week the average was upwards of $12 l$; rather better than $6 s$.

4822. Yours is a very good sample of wheat?-Very good, generally.

4823 . When you manure your land with the manure from London, how much an acre do you suppose it costs you?--It depends on situation; from $4 l$. $10 \mathrm{~s}$. to $6 l$.

$48_{24}$. Does it soon run through the ground?-On the gravel it does.

4825. On Hounslow Heath ?-That is not so gravelly as some we have.

$4 \mathrm{~S}_{26}$. Is there any old turf remaining on the ground you have upon the tithe allotments ?-None at all; it is all under cultivation.

4827 . And yet you have cultivated nothing but wheat ? - I mean on a portion of what was old common field land, not the common land; on the common land we have grown oats, but not on the other, nor barley, for the reason I have stated.

4828 . Do you keep any sheep there?-Yes.

4829. Do you find them answer? - That depends upon the price.

$4 \delta 30$. Do you keep them for the butcher, or for breeding stock?-We keep for the butchers and stock.

$4 S_{31}$. You buy in the west of England, and fatten for the London market? -Yes.

$4 \$ 32$. What is the order of crops you mean to cultivate there?-Precisely the same as on other land, when we get it into the state we wish; one-third green crop, one-third of wheat, and one-third barley and oats.

4S33. You have two-thirds of your land in corn every year?-Yes.

4834 . Do you consider that a fair mode of managing land ? - I think the more corn the land grows, the better order it is in; the better for the farmer, and the better for the land.

4835 . That is, provided you can get a proper quantity of manure upon it?The land would not do it without that.

4836 . How much a load do you get for your straw ? - That depends upon the time of year; it is worth now about $1 s$. a truss.

$48_{37}$. Do you sell it by contract, or where do you sell it chiefly?-Sometimes we supply two or three barracks; Hounslow, Hampton Court, Knightsbridge, and so on.

4838 . Do you get back the manure cheap?-We agree for the dung of one barrack when we are supplying two.

4839. That makes the carriage of the manure very cheap to you?-Not very cheap; I calculate two days' work for the horses to come to London; they do not lie by in consequence; but they must be a certain description of horses to do that.

4840 . What does your load of manure from London cost you?-From $4 s$. to $10 s$.

4841 . Is there a large stock of corn in the farmers' stack-yards at present?I should say about as usual. 
4842. Not more nor less than is usual ?-No.

4843. Do you think there is more wheat sown this year, or less than usual?I do not lnow that there is any difference; there is no difference with respect to 18 March 1836 . ourselves.

$4{ }^{4} 44$. Do you speak of a waggon load or a cart load? - A waggon load will cost us $8 s$. or $10 s$, and a cart load from $4 s$. to $5 s$.

484.5 . Is there any thing that the farmers in your neighbourhood consider a particular grievance to which they are subjected by way of burthen? - No, I do not think there is.

4846 . Do they think that the repeal of the malt-tax would be a relief?It would be a relief to a certain extent, but not sufficient to give the relief required.

4847. The great relief would be better prices?-Yes, decidedly so.

484 S. Do you hear much complaint among the farmers of the present prices? -Yes.

4849 . Is there much difficulty in obtaining a tenant for a farm when it is out of lease?-No, not if the farm is worth any thing.

[The Witness is directed to withdraw.

Ordered, that this Committee be adjourned to Monday next, One o'clock.

Die Luñ, $21^{\circ}$ Martii, 1836.

The Lord KENYON in THE Chair.

Bickham S. Escott, Esq., is called in, and Examined, as follows :

4850 . WILL you point out what observations you have made with respect to the distress which has existed in agriculture, and suggest any measure having a tendency to relieve that distress?-I should very much have wished I could, before I was examined by your Lordships, have had the opportunity to consider the questions which were to be put to me. I will state, as far as I am able, any opinions I may have formed on the present state of agriculture, and the means of remedy; but I was not aware, until of late, of the intention to examine me, nor have I had any opportunity to consider properly the course which I would propose, because that must depend on what is about to be done by others.

4851. According to the observations you have made, what do you consider to be the present state of agriculture?-I am of opinion that the state of agriculture, as regards landowners, renting farmers, and agricultural labourers, is much more depressed than the condition of any otler class of the subjects of this country. I am of opinion, to begin with landowners, as far as my experience goes, all, except, I should say, in very particular situations (for I think the statement must be taken with this qualification, there being estates, under particular circumstances, that are nearly as well off now as ever), but I think that, generally speaking, the landowners have suffered very great depression in their property ; that their incomes are excecdingly reduced, and that it operates in this way: where a man has a large estate of from $10,000 l$. to $20,000 l$. a Jear, he can reduce his income by $5,000 \mathrm{l}$. or $6,000 \mathrm{l}$. a year, and still live in a splendid style, and he will not feel it in the same way; but where a landowner has an income, I will say $1,000 \%$. a year, or from that to $2,000 l$. or $3,000 \mathrm{l}$. a year, and has maintained a respectable station, which he may do, in good society, even mixing with persons of the highest family, as far as the common intercourse of life goes, he has suffered a dreadful depression, and is obliged to make most enormous sacrifices to keep up his station in society, and that of the various branches of his family dependent upon him, and to burthen his property, so that at last, if the engagements contracted were to be paid off under the present depression, he or his successor would be left without a penny. I know several now who are, I fear, in that state. I think that the tenants are, generally spealing, in a very reduced condition, compared with what they were in when I first knew them; that their condition is low, as 4 (i4.

\section{B. S. Escott, Esq.} 21 March $18_{3} 6$. 
B. S. Escott, Esq. compared with others who are vulgarly called the middle classes, and of the same grade in society. I think they are suffering a very great depression, as 21 March 1836 . compared with the manufacturing and trading persons who set out with the same skill and capital. I think the immediate cause of this must be very obvious, - the reduction of the scale of prices of their produce. But here, again, I must make an exception, for there are some estates which pay pretty nearly as good a rent as ever; there are some farms where the profits are pretty nearly as good as they were, but they are very peculiar farms, very excellent pasture and meadow land, and with a good narket, where there is a very small comparative expense in the culture or management, and in transporting the produce and turning it into money. But those on arable farms, in general, I think, are in a state of very great depression; that the prices have been such they cannot pay any thing like the former rents, or any thing like the rent they are now engaged probably to pay, and meet the expenses to which they hitherto have been accustomed, and to which they are still subject, without a very great declination in the scale of society, which is misery. With respect to labourers, I have a very decided opinion that in my own neighbourhood, and I speak of one large parish in particular, there have been, through the whole of this winter, as many as 16 or 20 labourers constantly out of work, of one sort or another; and I need not tell your Lordships that when they are out of work they must be in a very miserable condition, because they get only the necessaries of life supplied through the medium of the poor-rate. What I think about the state of the labourer is, that, owing to the depressed value of produce and the depressed condition of the farmers, and the reduced state of their incomes, and their capitals, too, in many cases, they are unable to employ a sufficient number of labourers, and there is therefore a great deal of distress among the labourers. I think, at the same time, that where labourers are now in full employment they are full as well off as ever I knew them, as far as money goes; and I should be inclined to think, - though it is rather difficult to ascertain that, for the most honest labourer does not like to admit he is as well off now,-but I am inclined to think that the labourer in full employment is better off than I have ever known him; but then he must be in full employment. I think, on the whole, the labourers in my neighbourhood are worse off, for there are more out of employ than there used to be, for which there are other causes.

48.52 . Where they are too abundant for the demand, there is great want?I think they are too abundant for the present demands of labour; but I do not think they are too abundant for the good of the land.

4853. The fact is, that they are unemployed?-Yes. My own opinion is, that supposing the farmers were more prosperous, the existing number of labourers, speaking from a very limited local knowledge in the west part of Somersetshire, are not too many for the proper cultivation of the land, but that they are unemployed through the poverty of the farmers.

4854. Is not there a good deal of that district in pasture?-It is very much mixed; the greater number of acres in my part is not in pasture. Some of the middle part of Somersetshire is almost entirely in pasture; but in all the western part, where I live, there is a great mixture of land, and far the greater portion of acres is arable, alternately wheat, turnips, barley and grass seeds.

4855. The average farms in Somersetshire, taking the whole, employ less labourers than those of other counties, on account of the very large tracts of pasture there are, do they not?-I cannot answer that question. I should not think they employ less than Devonshire. In all my part of Somersetshire they break up the hay for wheat, and then have turnips after the wheat, and then have barley, and seed it out, as they call it, and let it lie out two years.

4856 . Under the system you mention, what proportion of the whole farming land is arable?-Of the average farms in my neighbourhood three-fourths of the fields, I suppose, are arable.

4857 . How much do you conceive is actually under the plough each particular year?-I think about three-fourths. I cannot speak positively, farms are so very different; some have a great deal more of water meadow with them than others. Water meadow is never broken up.

4858 . Is that a system which, in the present state of the farmers, has any tendency to make the land go out of good condition?-No, I think not; in the opinion 
opinion of the most experienced farmers with whom I am acquainted, it is the best system for our neighbourhood.

4859 . Even in these times, when prices are so low, do they manure it sufficiently to prevent it going out of condition?-They prevent it going out of cultivation, but not in all instances out of condition. I know many farms that I am certain are not so well cultirated as they were some few years a go.

4860 . You conceive, upon the whole, the farms are deteriorating for want of perfect management?-I do not conceive that the farms are generally deteriorating, but that some are, and therefore, taking them in a lump, they are deteriorating; there are some deteriorating, I have no doubt; and some few, I have no doubt, are constantly still improving.

$4 \$ 61$. From what period of time do you think, generally speaking, the farms have been deteriorating in your neighlourhood?-I should say that some farms have been detcriorating ever since 1821 and 1822 .

4862. What, in your opinion, is likely to be the state of those farms a few years hence, if the prices should not improve?-I think the cultivation of wheat must very materially decrease indeed, or cease, upon such farms, if the prices do not improve, and permanently improve.

$4 \$ 63$. In your neighbourhood has the crop of wheat been abundant the last two or three years? - Not extraordinarily ; it has been very good in quality, the last year particularly, but not extraordinarily abundant.

4\$64. Hare you made any observation to enable you to judge whether a larger or a smaller breadth of wheat is sown this year? - 1 am certain there is a much smaller breadth sown; I think that is one of the causes of the present rise of price; I know myself a large farmer, a near neighbour of mine, who has not sown a single acre this year; he is one of the largest farmers in the parish in which he resides; and I know a great number of farmers who have lessened their breadth of wheat this year by six or eight acres a piece.

$4 \$ 6.5$. Is that owing to the low prices? - Entirely to the low prices as compared with the expenses; they have determined that they would not sow that which was not a remunerating crop.

4866. Do you know at all what is the average produce of wheat per acre in that district?-I do not know that, and I think it rather a difficult thing to be ascertained; what will be stated by the farmers will be about 18 or 20 bushels, except in very good land; there is some land I know in Somersetshire that will grow 40 bushels; the common run of the farms in my neighbourhood, which are subject to the course I have mentioned, will, I think, produce about 20 bushels.

4867 . What should you say was the quantity of barley grown per acre?-It is a very uncertain crop in quantity, but I should say 40 bushels; I have known a great deal more, but I do not speak on these matters with any certainty.

4868. Can you state at all what bulk of turnips it produces?-No, I cannot ; it is a very uncertain crop with us, particularly this year; we have lost nearly the whole crop of common turnips; we have nothing but swedes left; the insects, called with us the "black army," destroyed them all on many farms.

4869. Having given those quantities, about what, should you say, on the average, is the rent in those districts per acre? - Fron $1 l$. to $30 s$, but it varies very much.

4870 . What reductions have there been? - The reductions have been so very unequal that I cannot say; I know what I have reduced my own; I have reduced my own exactly 50 per cent.

$4 S_{7}:$. As compared with what year? - With the dearest times.

$48 ; 2$. With the year 1814 or 1815 ? - I cannot state the year in which it was let at double, but it must have been about that time.

$48 ; 3$. Is it your impression that there have been similar reductions with respect to other landlords? - I do not think that there has been a general reduction to that amount; I know there has not.

4874 . In speaking of $25 s$. or $30 \mathrm{~s}$. an acre, do you take that as the average value, or apply it to arable land only, where, in point of fact, the pasture land is at a different rent?-I apply it to the whole farms in that neighbourhood.

4875. Do not pasture farms bear a very different price ?-Very different indeed.

4876 . Much higher?-Yes.

$48 ; i$. What is about the average rent of a pasture farm which grows just sufficient produce to feed the cattle in winter? - I should think, if it is good 464 . 
B. S. Escott, Esq. land, from $2 l$. to $3 l$.; I know a farm in the neighbourhood of Taunton that let 21 March 1836 for $2 l$. an acre; I think that is too high; but I think that is better worth $2 l$. than some farms are worth $l l$.

$487 \mathrm{~S}$. That is principally pasture?-That is not nearly all pasture; I think it is about equally divided ; but the arable land must be very good, and the pasture very fine; but the rent of peculiar farms is a very fallacious thing; I know meadow land in Somersetshire, far from any town, quite among the hills, which lets for $6 l$. or $7 l$. an acre now; but that is no proof of agricultural prosperity.

4879. What gives it that peculiar value?-The quality of the soil, the climate, and facilities for watering; from the moment the snow is off the ground, there is a great crop of grass.

4880. There are streams which can be applied to it during the summer season? - Yes, at all times; it never fails.

$488_{1}$. It is like a water mountain meadow?-Yes, and it never burns.

$488_{2}$. Have you any notion how many head of sheep can be kept on an acre of that sort of land?-No.

$4 \delta 8_{3}$. They keep them without rot?-Yes; there is seldom any rot in our best water meadows; when they get the rot, it is down in the marshes.

4884. Artificial water meadow never gives the rot, does it?-I do not know; but I know those excellent water meadows never do.

$488_{5}$. What is the rate of wages given to the farming labourers?-They give now, I believe, about $7 s$. or $8 s$. a week.

4886. Has there been much alteration in the last ten years in the wages of the labourers?-Not very great; not, I think, in proportion to the different prices of produce; and therefore I think, where they are employed now, they are well off as to money.

4887. What was the price of labour in Somersetshire in high times? - I have not made inquiries into that lately; I do not recollect that it was ever above $9 s$. or $10 \mathrm{~s}$. in my neighbourhood; but I cannot speak positively.

4888. Have you ever seen any tables of labour, comparative as to counties?Not that I remember.

4889 . You do not know whether Somersetshire, as compared with other counties, has been low or ligh ? -I think it has been low.

4890 . There has been very little fall ?-I think only about $2 s$. a week; that they gave them $9 s$. or $10 s$. in the high times, and that they now give them only $7 s$. or $8 s$., and they give them liquor.

4891 . Is that in addition to the wages of $7 s$. or $8 s$. a week?-Yes.

4892 . Is that at all seasons of the year, or only in harvest?-All do it in harvest, but some do at all seasons.

4893 . Do they give them cider or beer?-There is about an equal quantity of each consumed, I think.

4894 . Is the labouring population sufficient to do the labour in harvest-time? -I think it is. No labourers come from a distance, that I am aware of ; no Irish labourers come to us. Some of our labourers migrate in harvest-time; a few of them go up into Gloucestershire, mowing principally.

$4 \mathrm{~S}_{95}$. Is the population in that district considerable?-Yes, there are some villages of a scattered agricultural population, generally a cottage or two attached to a farm, but not enough of that.

4896 . Is the population almost exclusively agricultural ?-In the villages there are a good many small shopkeepers.

4897 . Nothing of manufactures?-We lrave no manufactures in that neighbourhood of any consequence; there are some paper manufactories.

4898 . There is no population in the village but what may be considered as mainly connected with agriculture? - I think not.

4899. Have you any knowledge whether the expenses of the farmers have been much reduced with respect to other necessaries of life, excepting that of food?I think not much, even nominally.

4900. The blacksmiths' bills, and those of different artisans, have not been reduced? - I am not aware of any decrease.

4901 . Are you not aware that, though their prices have not been reduced, they have been improved in respect of some expenses for managing their farms, or for clothing?-I do not say as to clothing; clothing is cheaper.

4902. Do you conceive that, though cheaper, it is of so durable a kind as formerly? -I think so. I believe that the articles of fustian and corduroy, and 
all cotton goods, are all cheaper; and I do not know but that they are as good B. S. Escutt, Esq. now as ever.

4903. Shoes?-Shoes, I think, are not cheaper; I have never known any fall in 21 March 1836 . the price of boots and shoes. I think they are not worse, but rather better, upon the whole; we have very elever shocmakers now in the comtry.

4904. To what do you ascribe the low price of farming produce? - I do not wish to speak with any degree of confidence on any one cause; I ann myself of opinion it is owing to a great many causes.

4905. Have the kindness to enumerate them in their order?-I have not the information which I could wish on any of these subjects; but I think, to enumerate detached causes, that the state of the currency has a great deal to do with it. The quantity of money in circulation must affect the price to be paid.

4906. Do you found that opinion on any observation you have made as to the alterations which have taken place in any particular times?-Yes.

$490 \%$. What are those obscrvations you have made at particular times?-I think that the fall of prices was immediately consequent on the withdrawal of the paper money and the removal of the bank restriction. I think that prices rose again as soon as ever measures were taken to obviate that contraction of the circulating medium. I think that they fell again as soon as ever the Bill of 1825 , for the suppression of country one-pound bank notes, took place; and I think that from that time, with certain exceptions, there has been a gradual progression to the state of things which we have now, and that it was not felt in full operation for several years. I am not aware when that last Bill operated; I rather think the circulation was not contracted at once, but that it took two or three years before that Bill came into full operation as to its effects.

4908. Next to the alteration of the currency, what appears to you the next important cause of the great reduction of prices?-I think there has been a very great deal of evil caused by the price of bread not bearing its proper proportion to the price of wheat; and that if it had borne its proper proportion to the price of wheat, the decrease of price would have caused a great increase of consumption, which would probably have helped to right the evil. I remember it used to be said by persons practically acquainted with these sort of things, that the price of bread should be as many pence per loaf as the wheat was shillings a bushel. Now, through the whole of this winter, I know, in London, while wheat has been $5 s$. a bushel, bread has been $7 \frac{1}{2} d$. a loaf, and of course there has not been the same quantity consumed as if it was $5 d$.; and I think that has operated very much to drive the poorer classes to the consumption of less bread. I think also that potatoes are much used instead of bread.

4909. Do you think that is a practice which prevails to a very great extent in Somersetshire?-Very great indeed.

4910. Do you think there are other causes which tend to that?-Yes; I think that it has encouraged the growth of potatoes very much, where persons have the opportunity, and lately they have had all sorts of facilities aftorded them for growing them, under the allotment system. No doubt larger quantities of corn would have been consumed but for the allotment system.

4911. Unter the allotment system, as practised in Somersetshire, do they generally make use of those allotments for the providing food for themselves, or apply that food for the sustenance of animals?-For both purposes ; principally for their own use, I think. I know that on some large estates there was a good deal of land allotted out to the poor; last year the whole thing entirely failed; the potatoes were scorched up by the heat of the summer; they got a very poor crop ; there was a very large expense incurred in preparing the land for them, and a large number of the poor are totally unable to pay the rent they contracted to pay. The last summer, being a very hot summer, was not a fair year to try it. In other situations, where the ground was not so burnt up, they had a good crop; but the rent comes heavy upon them.

4912 . What was the rent they contracted to pay, and what was the size of the allotments which have been usually made?-They have different sizes, from a quarter to half an acre; I think in no instances more than half an acre; I have directed that they should not have more than that, and I think that too much; they were to pay as much, after the ground was dressed for them, as $4 l$. an acre.

4913 . Is that taking it on a series of years, or only the first year? - I think they were let only for one year. 
4914. Was there a contemplation of its being continued ?-That I do not know, but I think so.

4915. Can you state what was the expense of clearing and manuring the ground? - I cannot state that at this moment. I mean to let them have small quantities of land, as much as I think they can manage, and not more, at the same rent any other farmer pays for the same land, and to do what they like with it, so long as they do not hurt the land.

4916. Have you known any allotments for a longer period than one year?No; I have no doubt myself that the increased growth of potatoes is a thing which has materially contributed to decrease the price of wheat, and that the allotment system has increased the growth of potatoes; but it had been very materially increased before there was any allotment system in my neighbonrhood within my memory.

4917 . In what way was it practised so as to increase the growth of potatoes? -I think that it was a profitable thing to the farmers generally when they were not under a lease or a limitation from growing more potatoes than were necessary for their families and their pigs; and they have been in the habit, where not under lease, of letting a portion to others for the growing potatoes; and others have had permission.

4918 . What is the practice with respect to manuring their land?-They inust manure it well.

4919. Do not those who have the benefit of the allotment system keep pigs :I do not think they do generally; I know that some have pigs, but whether the greatest number have, I cannot say at present.

4920. Is it your opinion that the practice of using potatoes for corn has tended to make the labourer more or less comfortable?-I do not know ; I think it was necessary, under the circumstances in which they were placed.

4921. On what account?-O Owing to their being frequently thrown out of work, and potatoes being a much cheaper food.

4922. Their being reduced to a state of distress made it necessary for them to resort to a different sort of food?-Yes.

4923 . You think that it is an evidence of distress, the labourers resorting to this change of food?--In some instances; I think that they like potatoes, and that there is a great habit of consuming potatoes lately come in, and that it is not only by the poor, but in many instances potatoes are substituted for bread by others.

4024. As far as your experience of the allotment system has gone, in the case where the labourers were not out of employ, would you think it beneficial to carry on that system of small allotments?-I think it would be a good thing to let them have small gardens with their cottages, but not allotments in fields; my present opinion is against the allotment system in fields, as lately introduced.

4925. Has the new Poor Law been put into operation in your neighbourhood? - It is not put into active operation; the Commissioner has just been down there; what measures he has taken I am not yet correctly informed. I have had information from different parts of the country, but have not seen it in operation any where. My own opinion has been exceedingly strong against the new Poor Law Bill, and I have no hesitation in saying, that, from what I have heard of late, I rather feel now in favour of its operation than against it. I am sure there is a general expectation amongst the gentry and the tenantry of the neighbourhood with which I am best acquainted, that it will operate beneficially ; and I do not think that there is any very general feeling among the peasantry against it ; I am not aware that there is.

4926 . When you say that the poor are unemployed at the present moment, you mean that they are unemployed under the old system?-Yes.

4927. Their favourable feelings towards the new system do not arise from their having seen it in operation, but from what they suppose theoretically $:-J u s t$ so, with many; but some gentlemen with whom I am acquainted are very great friends to the new Poor Law, and must have seen it in operation, I think; but I do not speak positively to that. With respect to the new Poor Law, I am very decidedly of opinion, that the abuses of the old Poor Law system have very materially contributed to the present depressed state of agriculture, and, joined with other things, reduced the whole body of agriculturists. When I speak of the abuses under the old law, some persons would say they were not abuses; they would say that they could not help it; but this I doubt. 
4928. Have the goodness to instance the abuses to which you refer?-I think that the mode in which relief and wiges were constantly mixed ujp together, and the mode in which the industrious and well-bchaved labourer, as well as the dissolute, were both treated, very often put the good into a worse situation than the very bad one, and was reducing the payers to the condition of the receivers of relief.

4929. What is about the amount of your poor-rates in the pound:-They vary very much; from $1 s$. up to $5 s$. or $6 s$. on the value.

4930. You cannot state the average? - No; I never saw an average struck.

4931. Do you suppose that it has heen to any thing like the amount of $5 s$. or $6 s$. in the pound on any one district in Somersetshire?-I put that as the very highest; but I know estates which pay as much as $4 s$. in the pound.

4932. You mean the pound actual value, and not the conventional value ? - I mean the actual value.

493.3. Are they now hecome reduced? - I think not much; during the last year they have been very high.

4934. Have any of your agricultural labourers migrated from the parish ?.-No, not to any extent ; I do not know that any have.

4935. That has not been the case, to your knowledge, in Somersetshire ?-Not to any extent, that I an aware of.

4936. You have stated that the labourer's wages have never been in your district, as fiur as your recollection goes, more than $9 s$. or $10 s$, a week in the high times, and that they are now about $7 s$. or $8 s$. Do you conceive that the labourer's daily pay will buy more wheat, which is generally taken as the standard of labour, now, and how much more, than formerly, when he has been employed? -No doubt it will buy double or more than double, nay, treble, what it would in some years.

4937. Then if the labourer has altered his habit of living, that has not arisen from necessity on his part, but from a preference of the food he takes? - I do not think that; I think that where he is in full employment he may do well; but I think there are other causes at work which prevent it.

4938. Do you think that the difference in the mode of living las arisen with respect to labourers fully employed?-Yes, I think that those fully employed consume more potatoes and less bread than formerly.

4939. Do you think that those who consume more potatoes eat more meat than they used to do?-No, I do not think so, though I know it has been said.

4940. Then if they are better off now than they were, considering the small reduction of wages and the decreased price of food, do you think they are laying up money in the sarings' banks; or how are they going on with regard to prosperity? - I know some persons will think that what I an about to say is absurd, but I feel confident that the beer-shops in my neighbourhood swallow up an enormous portion of the earnings of the labourer; my own opinion is, that the present system of the beer-shops is very rumous to the condition of the people.

4941. You conceive that though the labourer is better off in his pay, as compared with the price of wheat, than formerly, he is not better off in fact, because he spends so much money in the beer-shop?-Yes; and that reconciles the difference between their being better off, as far as money is concerned, but not better in condition.

4942. Do you conceive the general habits and expenses of the labourers are much altered in your neighbourhood ?--No, I do not, as regards the good ones.

4943. Do you think that the cottages are furnished with more luxuries or comforts?-No; they appear to be much in the same state I have ever known them, and the farm-houses also.

4944. You attribute the fact of their money not going further, though they are paid more, comparatively to the price of wheat, in a great measure to the beer-shops?-In a great measure.

494.5. Do you think that there are more of the poorer classes who go to the beer-shops than would have gone to the old public-houses? - Yes, a great many.

4946. How do you account for that?-Where there was one public-house, there are, I should guess, at least six or eight beer-shops.

4947 . Are there not beer-shops in many places where public-houses were never thought of, and where no magistrate would lave thought of licensing publichouses?-Yes.

464 .

P P 3

4948. Has

B. S. Fiscott, Esq.

21 March 1836. 
B. S. Escolt, Esq. 494S. Has any advantage accrued from the late Act which passed, enabling the magistrates to regulate their hours ?-I cannot say; I had most grievous complaints made last winter of the disorderly conduct of persons in beer-houses in the district in which I reside.

4940. You do not act as a magistrate?-No, I do not. There is one circumstance I wish to mention, becanse it appears to me to produce similar and co-operative effects to the Beer Bill, that is the present game law; I think that is almost doing as much harm in our neighourhood as the beer-shops; they are acting together. The beer-shops are the meeting places for the persons who engage in poaching; the one makes them poachers, and the other drunkards; and being one makes them the other.

4950. Poaching has increased? - Yes, and, in comparison, almost every body is a poncher; nen who never would have thought of it before. I am certain it has depraved thousands of characters; men who would have been honest hardworking characters.

4951. Are there large preserves in that neighbourhood?-There are very large covers, but it is not a very plentiful country for game.

4952. Do they apply themselves to pheasants principally?-Pheasants and hares.

4953. Do they go in large gangs? - Yes, 20 together, armed.

4954. By night? - Yes ; they do not poach much by day.

495.5. You conceive that the present game laws have done much harm to the agriculturists instead of good?-I am positive they have.

4956 . Is the game more preserved than it used to be?-Not at all ; it is less preserved than it used to be in our neighbourhood. There is one other circumstance I would mention; I think there has been a great deal of evil caused among the agricultural population by the political excitement of the last years. I am very confident, that ever since the Reform Bill was first talked of in the neighbourhood, it has produced a great deal of disorder and immoral state of the population. I think the agitation about the Reform Bill, the Game Bill, and the present state of the Beer Bill, has made the agricultural population think of any thing but what they were most interested to think of, and that it produced for a long time a great stagnation of business, and has ruined many.

4957. Do you think that they do not do so good a day's work as they used?No; a man who has been out poaching all night will not do a good day's work, nor one who has been drinking to excess; and then it operates in reducing the consumption and lowering the price of wheat; I am very confident of that. When a man drinks a quantity of this beer (and more particularly is this true of the gin-drinker), he naturally loses his appetite; and a man who is drinking all night will satisfy himself with a potato the next day; he cannot eat half a loaf, as he would do else.

495 . You do not think he takes down as much barley in his beer as will compensate for that?-No; but that may be so, as far as money will compensate. I think that the Beer Bill has raised the price of barley; there is no doubt of that.

4959. Do they drink gin at all in the beer-shops?-I am afraid there is gin getting into the country; I am not certain of it.

4960 . There is a very great facility for selling gin, by opening those beershops?-Yes; and if there were gin-shops as well as beer-shops scattered throughout the country, it would complete our ruin under this system.

4961 . Have you not strong suspicion that many of them that pass for beershops are gin-shops? - I have heard it mentioned, but I have no personal knowledge of it.

4962. Do you happen to know what hour the magistrates have fixed for shutting up the beer-shops?-No, I do not.

4963. Is there any disinclination on the part of householders to give recommendations to persons desirous of keeping beer-shops?-I do not think that there has been any difficulty in getting recommendations.

4964. No house can be established without a recommendation from a certain number of householders?-Six, I think. I know there is an abunclant quantity of beer-shops all over the country.

496.5. Have you any thing else to state as the causes for the depressed state of agmculture?-I do not think of any other to suggest.

4966 . Have you attended much to the price of iron? - No.

4967. Therefore, 
4967. Therefore, when you say that blacksmiths' charges are not decreased, that is without a minute inquiry into the subject?-Yes; but I am pretty sure they have not.

4968. Are you aware that, within a very short period, iron has risen 100 per cent. ? - I know it has risen very greatly, but 1 cannot say to what extent.

4969 . Will you have the goodness to suggest to the Committee any thing that occurs to you as having a tendency to lessen the distresses of the agriculturists? - The difficulty I feel is this, that it appears to me a person is placed in an absurd position, who would attempt to devise a legislative remedy for the state of the agriculture of this country, without knowing what the Legislature and the Government mean to do. 1 cannot say whether this or that legislative enactment would do it, unless I knew by what other legislative enactment it is to be accompanied, so as to have all the benefit likely to arise from the other.

4970 . Taking into your consideration that the object of establishing a committee of inquiry is first to ascertain the facts, and then to point out the remedy, the Conmittee will be glad to hear any remedies that occur to your mind as likely to lessen the distress which now exists?-It is my opinion that the contraction of the currency consequent on the return to payment in gold, and the termination of the Bank Restriction Act, have very materially reduced the prices of all articles; but then, if it has reduced the price of all articles, how is it, it may be said, that wheat is the only article the farmers produce which is so prodigiously low? I think that the other articles of barley and stock have been raised by peculiar circumstances, which did not operate on the wheat.

4971 . With respect to the barley, when you state that it has been raised, have the crops of barley in the last year or two been such as to make the present price of barley a remunerating price?-I should think that that is a remunerating price, were other things in proportion.

4972. Do you believe the last two crops of barley have been considered very good ones in Somersetshire? - No, not large crops generally; the year before last, or last year, I believe, was a very bad one.

4973. Then the prices were not remunerating in proportion to the quantity? - Unless I was actually aware what the crops have been the last two or three years, I could not certainly give an answer to the question; I think that if the price of wheat bore its old proportion to the price of barley, there would not be the same cause of complaint; that is, if the price of wheat was twice the price of barley.

4974. Do you conceive, if the price of wheat was $60 \mathrm{~s}$, the price of barley being $30 s$, that would afford a complete relief to the agriculturist? -No, I think not.

4975 . Should you say that $7 s .6 d$. a bushel would be a fair remunerating price to farmers, taking the average of farms ?-Not at the present rents, I think; but I think, if it is to remain at $60 \mathrm{~s}$., there must be a further reduction of rent, and a further ruining of a great number of those landowners whom I mentioned just now.

4976. When you say at its present rate, do you mean the poor-rates continuing so high? - I wish particularly to say, I think the new Poor Law is an exceedingly important thing, and if, without starving the poor, it shall be found very much to reduce rates, there is no knowing what good it may do. I am afraid, in some instances, it does pinch the poor a good deal ; but if it will reduce the rates, and enable the labourers to live as well as they have been accustomed to live, it is a benefit. I will just mention one circumstance which appeared to me important; I was talking one day with a very intelligent man, a large farmer and miller, a violent opponent of the Poor Law Bill, as I was till lately; this man, a practical farmer and miller, was talking very violently against it, and he said that he knew a man in his neighbourhood who was a large farmer and a great friend of the Poor Law Bill; he came to him the other day, and said, "Here is this Poor Law you are opposing, it will be the making of me; I have saved $200 l$. a year in rates already ;" my friend continued, "Now this neighbour of mine is fool enough to think he is saving by this Poor Law Bill, because he saved $200 l$. a year in rates; but to my knowledge he has been paying $500 l$. a year more in wages." It seemed to me that this was the very best thing which could be said for the Poor Law, that there should be this money spent on the land in increased hire of labour; so I said, "That is the strongest argument in 464 .

B. S. Escott, Esq.

21 March $183^{6}$. 
B. S. Escott, Esq. favour of the bill; it will make ne a complete convert;" and all he said in answer was, that it might have been done under the old law; but would it?

21 March $1 \varsigma_{3} 6$.

4977 . Did you ascertain how that came to be expended, whether it was a profitable expenditure :- The person who was talking with me seemed to think it was not all profitable; but he could not be aware of the result. Whether the labour is profitable mnst depend on what the produce is, and how it sells; but he stated as a fact, that his friend was employing all these labourers; and a farmer would not lay out $500 l$. a year more in labour, if he did not expect a return.

$49-8$. That $200 \%$. a year he used to pay for poor-rates was not only saved, but he added $300 l$. to it in labour? - Yes.

4979. In consequence of the opinion expressed, and the power given under the Poor Law Bill, is it the fact in your neighbourhood, that the practice, under the Poor Law Bill, has been introduced of giving relief to the poor in different articles, instead of giving it in money ? - I am not aware that it has; I think the general practice has been to give them money.

4950. Do you think it nould be a relief to the farmers if the practice recommended by the Poor Law Bill was introduced, of giving articles of food for the labour performed, instead of paying in money?-Yes, I think it might; but it requires caution.

498 . What other suggestions can you favour the Committee with, of measures which will tend to remove the agricultural distress? - I beg your Lordships will not consider any thing I say about the currency as said with any conficlence; but I think that any measure which tended to increase the amount of money in circulation must have a beneficial effect. I think that where high prices depend on the increasing circulation of money they are good to every body, particularly to the producer, but that they are no loss to the consumer; but where they depend on a scarcity, they are a great evil to all; and that puts me in mind of one thing I wish to state respecting the present price of wheat: I an of opinion, that the present price, as it has been raised within the last fortnight or month, is caused very much by scarcity; that it is caused both by the decreasing quantity of wheat in this country, and by the apprehension that it will be further decreased by so much less being grown. I know that has operated very much, and that the stock in hand is getting, in many cases, very small in the country; I am not aware how it is at the great ports.

$49 S_{2}$. Do you conceive there is less now in the farmers' rick-yards than formerly?-Much less.

4983. Do you speak of Somersetshire?-Yes; all my practical acquaintance with the subject must be confined to the western parts of Somersetshire. With respect to the increasing quantity of money, I have never found any reason that accounted to me satisfactorily why there shonld not be a circulation of notes between $5 l$. and the sovereign, fours, threes and twos; I think there are stronger reasons against one-pound notes.

4984 . On what security would you have those notes of two, three and four pounds founded?--The same security that the fives are now.

4985 . Namely, the general repute and stability of the bank?-Yes; I think credit should be more free.

4986. Do you speak of the Bank of England?-Yes, and country bank notes also, and of notes payable on demand in metal.

4987. Do you think it would be at all safe if those were issued payable in the country?-I think so; I am not aware why it should not be safe.

4988. Do you think there would be any reason to expect that country banks would be able to keep in hand a suficient quantity of cash, such as would probably be required to answer the demands likely to be made upon them ?- Yes, I think they would; I think they would be as likely to keep cash in hand to answer the demands made upon them as they are now; I do not think now that the bankers lieep cash in hand to answer any demands which might be made; if they did, I do not see how the bankers would make any profit; it is the very essence of credit.

4980 . Do you think there is likely to be so close a demand for cash for notes above $5 \mathrm{l}$. as if they issued those small notes?-No; I suppose the danger would be increased somewhat, but it appears to me the increase of danger on that score would not be equal to the advantage to be derived by the agricultural population by the circulation of notes; I speak on that point from the fact that the distress has proceeded with much greater steadiness since the suppression 
of the small notes than under the return to cash payments by Mr. Pecl's Bill, passed in 1819, and which, I think, came into operation in 1821 .

4990. There was an extension of the issue in 1822 ? - Y es, and a cessation of distress.

4991. The whole of the notes were not recalled till 1825 and 1826 ? - No, and for the whole of that time there were generally one-pound notes in circulation, and a rising price. The Bill for the suppression of them did not pass till 182.5; from a year or two after that time the distress has proceeded with greater and less rapidity up to the present time. It appears to me that one of the great objections to a one-pound note circulation is that which I believe originated with Mr. Burke. I renember hearing Mr. Huskisson or Mr. Canning, I now forget which, quote it in the House of Commons, that when very ill at Bath, he (Mr. Burke) sent to Mr. Pitt to say, that if he put out one pound-notes he would not have a guinea left in the country. Now it appears to me, that that which is a good objection to a paper circulation of the same denomination with the gold, would not apply in the same degree to one of a different denomination. We have no gold of the same denomination as these twos, threes and fours. I never could hear any good reason for having the standard of value fixed as it is ; I think the return to gold payments would have caused no difficulties, if the standard of value had been fixed in proportion to the then market value of gold. I think that the return to cash payments, without altering the standard of value in proportion to the depreciation which had affected its market value, has caused the depression. I think there is no satisfactory reason, and I do not know what reason there is, why the standard should have been fixed where it is fixed.

4992. How do you conceive it ought to be fixed so as to be most beneficial to the country? - I will not pretend to say what it might be best to fix it at, unless I know all that is to be done in regard to the circulation; but it was fixed without any regard to the depreciation, if I understand it.

4993. Do you consider it fixed with a view to return to the old standard, or that an alteration has been made in regard to the old standard? - - The present standard is the old standard; when the bank restriction was taken off, we returned to it with a circulation very much depreciated by the enormous issue of paper during the war.

4994. Are you aware that the standard in this country; some years previous to the year 1797 , was not the same as that which existed in that year?-No, I do not recollect it.

4995. Are you aware that in the year 1783 the standard of silver was $5 s .6 d$, instead of being, as it now is, $5 s .2 d$. ?-Yes, I think I remember that, now my attention is called to it.

4996. That having recurred to your mind, what is your opinion as to what would be the fair standard to be adopted, supposing any alteration were made to give general relief to the country ? - I think such a one as would enable the credit circulation to increase without driving out the gold, and having a conjoint standard of silver and gold; making silver a legal tender would be a very great benefit.

4997. Would the advantage from having that conjoint standard be, that we should have a greater facility of being supplied with treasure from abroad? - Yes, I think so ; and less hazard of runs.

4998. Next to that relief, which you consider the primary relief which might be given to agricultural distress, what strikes you as the best relief,- - the repeal of the malt-tax or the Beer Bill, or what other measure? - With respect to the malt$\operatorname{tax}$, I have no doubt in my own mind that the repeal of the malt-tax would afford very substantial relief to agriculture.

4999. Would it afford relief to agriculture in general, or exclusively to the barley districts? - The relief would be more immediately to the barley soils, but the actual expense of the malt-tax to the large farmer is something considerable; a large farmer would gain $20 l$. or $30 l$. a year by it immediately; that, I think, is very much undervalued. I think also it would give a very great stimulus to the sale of barley, and the increased price of the barley would increase the growth of it, and therefore would operate also on the wheat. If the farmer found barley answer so much better, he would grow less wheat, and that would raise the price of wheat too.

5000. Supposing the opinions of some of the witnesses are true, that the larger proportion of land in this country is calculated to produce wheat, would it not 404 . 
B. S. Escott, Esq. have the effect naturally of inducing the farmer to cultivate more barley, where it could be grown, instead of wheat, and thereby enable the farmers who cultivate stiff lands to obtain a better price for their wheat ?-I am of that opinion.

5001. Can you form any opinion whether the bad wheat and bad barley would be likely to be applied to the feeding of cattle?-I have heard that said very lately by practical gentlemen, but I am not aware how that would be; it appears to me that the lower the price of an article is, the more the article is likely to be employed in the feeding animals. I hear that some farmers have of late been in the habit of consuning a good deal of their wheat in that way.

5002. Are you aware that it would be a more profitable application of wheat for animals, if they could malt it ? - I have heard that, but never saw it tried.

5003. Do not you think, if that is so, the taking the duty off malt would be useful as it respects the lower descriptions of wheat?-Yes, I think it would ; but I am not certain that wheat malted is a very good thing for animals.

5004. If such has been the tendency of the evidence of several witnesses who have appeared before the Committee, you know nothing to contradict that ? - No, I know nothing of it.

5005. Is it your opinion, that, supposing the duty was taken off malt, the probability is that farmers in general would be more inclined to provide their labourers with malt liquor in their houses?-I am sure of it.

5006. Do not you think that would have not only a pecuniary but a moral benefit?-Undoubtédly.

5007 . Will you be good enough to farour the Committee with your opinion, how far any benefit would result to the farmers from an alteration of the Tithe Laws?-My present opinion about the Tithe Laws, under the existing circumstances of the country, is, that a very great alteration would be a very great benefit to the agriculturist, but in order to be a benefit it must be such an alteration as I have not heard of lately.

5008. Whether the present Bill, as proposed, is just in its construction or not, how far do you think it will, if passed, tend to give relief to the agricultural interest, or what are the provisions in it which you think not likely to give that assistance? - I think the present Bill, if passed, must give relief to agriculture, if at all, in this way,-where a man has once parted with a certain portion of his estate, and engaged to pay a certain sum per annum to be free of tithe, he might then set about all sorts of expensive improvements in agriculture, knowing he should have to make no increased payments for tithe on account of those various improvements, so far it might benefit agriculture; but I think that, generally speaking, the effect of this Bill would not be for the benefit of the renting farmer at all; I think that the renting farmer would immediately have his rent increased fully in proportion to the tithes which he would not have to pay.

5009. Do you speak of the tenant at rack-rent:-Yes.

5010 . How would that apply to tenants under leases? - I doubt, at the present moment, how the present Bill affects the tenant under lease; I apprehend the landlord would have to pay a certain annual sum for tithe, and he would be free; then of course his lessee would have to pocket the whole value of the tithe during his whole lease; I do not recollect any provision to obviate that difficulty; I think in many cases this Bill would operate most capriciously ; for instance, it is a premium for bad farming and a penalty on good farming, immediately, if the Bill comes into operation. If the landlord has been kind to that tenant, and the tenant has been just to his landlord in cultivating the estate, the landowner will have to pav an increased tithe under the commutation for the land in future; and a man who has nothing but thistles upon his land will have to pay the smallest possible rate, as a reward for his indolence. Nothing can be so monstrous, in my mind, as that consequence of the Bill.

5011. If the object was to give relief to agriculture in a fair way by a Tithe Bill, in what way do you think that ought to be arranged?-I am of opinion that we can have no substantial relief to agriculture by a Tithe Bill, such as may be considered a just Tithe Bill to tithe-owners as well as tithe-payers, unless the whole law be considered, and the whole fund from which it is paid is altered; that there cannot be the same amount raised from the land, and yet the land relieved; I think also that the present system of tithes is most grievous.

5012. In what way?-My idea is, that there ought to be a review of the whole 
whole law of tithes, and that the whole property of the country should contribute to a new mode of supporting the church of the country, and that without that there can be no relief to the agricultural interest in this matter of tithes worth mentioning in comparison; I think the present state of the tithe system is very grievous, owing to the way in which it operates under the present taxation of the country.

5013. Do you think there is the most rigrorous exaction when the tithes are in the hands of the clergy or in the hands of the laity particularly? - I think, as far as my own experience goes, tithes are gencrally exacted less rigorously when in the hands of the clergy.

5014. Have you any means of forming a comparison how far the land tithed by the clergy is less injured or deteriorated by the system of tithes than when it is in the hands of the laity?-No; I know nany instances where clergymen do not get half the value of their tithe.

5015. Should you conceive that where land was under tithe in the hands of the clergy, that it would have such an injurious influence on agriculture as is now stated? - It would not have so injurious an effect, but I think it would still have an injurious effect, and that there would be constantly occurring instances where some clergymen would take as much as they have a legal right to do, and even take tithes in kind; I know some who take it in kind always.

5016. Do you know any instances of clergymen who take tithes in kind who are not forced to it?-Yes; I know those who will not give the parish a composition, and I know one who is on very good terms with his parish too.

5017. Then they do not feel it injurious to them?-I do not know that; he is a very pleasant man, and they are on good terms ; but still they feel it an injury, I apprehend.

5018. Are those persons landowners or land-occupiers?-They are chiefly land-occupiers.

5019. If the tithe were removed altogether, would there not be a very great addition in point of rent? - 1 have no doubt there would.

5020. Would that not be more than equal to the tithe they pay, even in the way in which it is taken?-No, I do not think it would; but I think the tithe system at present, in many cases, operates to prohibit cultivation, and must in a year or two still more; I think that in paying tithe they are now paying, in some instances, more than the value of the land.

5021 . Do you think a person would forbear to improve nine parts of his land because the improvement on the tenth part goes to another, he at the same time paying rent for the whole?-Yes, because the tenth part is, in many instances, more than the amount of his profit ; he must make a return for his capital laid out, and must pay his rent; this tenth would take away that portion which might enable him to do that, and then the land ceases to be cultivated.

5022. The tenth part of the produce you consider practically about one-fifth? -Yes, I have heard it estimated so ; but that must depend on circumstances; in some cases it is much more; it must depend on the expense of cultivation; and this tenth of the produce, when it is estimated for composition paid in lieu of it, has increased in value by the amount of taxation, and consequently is a more grievous payment to the landowner and the land-occupier. There can be no doubt taxation raises the price and value of all the articles of produce; they would be produced so mucl cheaper without the taxes;-- this rise in prices is a rise in value of this tenth part of the produce, for which the farmer gets no return.

5023. It does not strike you that there can be any equitable course pursued to make any alteration with respect to tithes, so as to be beneficial to the farmer, unless by totally altering the system of the taxes and the subject-matter on which the payment of tithes should attach?-I do not quite say that, but I do not think any thing will be complete and satisfactory that does not do that.

5024. It is what the land has always paid?-No, it has not always paid it; it is paying more and more every year; I have no doubt the hardship of tithes becomes greater every year.

5025. You do not mean to say the land has not always exclusively paid the tithe?-They have paid what has been called the tithe, but not the: same comparative amount in value; not in the same proportion to their profits.

5026. They are the only persons who have paid tithes hitherto?-Yes, in the common acceptation of those words. 
B. S. Fiscott, Esq. 5027. Your proposal is to make persons pay who never have paid, and who have other burthens? - Yes, according to your Lordship's acceptation of those terms, but I would not, after all, add to their burthens more than has been added to others.

502S. Do you consider that the introduction of Irish produce is injurious to the agriculture of this country? - I have no doubt it is injurious to the agriculture of England, in the same way as the introduction of other corn cheaper grown would be injurious to the farmers in a particular country; it overstocks their market. One thing I wish to mention. It is very commonly said that all that is wanted for agriculture is a reduction of rents, and that is an opinion which has been very much circulated among the landholders in my neighbourhood, and I believe generally in England, that the reduction of rents is all which is requisite. Speaking about the landowners, I should say a much further reduction of rent, if they are in the situation in which $I$ believe them to be, would be ruinous to them; but it appears to me that it will be ruin to the present race of renting farmers as well. It operates in this way: many landowners, particularly the small landowners of $800 l$. or $1,000 l$. a year, if compelled to reduce their rents much more, will say, "It is not worth while to let the land; we must try to farm it ourselves," which some are doing already, and consequently the occupation of the renting farmers will be destroyed. Suppose there are 500 or 600 acres of land which has always been let, and the owner takes it into his hands to farm it, the occupation of the former tenant, however respectable, is gone, and he must look elsewhere; and that has another ruinous effect also, which I know has been in operation throughout the whole race of farmers; it creates a too great competition for farms. When a farmer is put out of his farm, he must get another farm, unless he is a rich man; the consequence of which is, they bid a great deal too high for farms; and I am perfectly certain there are farms now, which, if they were to be let, would be taken at enormous rents; and then some persons will say that agriculture is not distressed, when they see that farms will let at those rents; but, in fact, they are taken at rents which the farmer cannot pay, and then either they must be reduced, and it is puffed off as a great sacrifice of the landlord, or, if he will not abate, the farm is given up, or the tenant ruined.

5029. Has there been much change of tenants in your district?-Yes, considerable change.

5030. Have any of those who have gone within these few years gone away in prosperous circumstances? - I know of none; at least I know of no one who has gone away better than he came in; I know none who have made money of late years.

5031. Do you know any who have gone away ruined?-Yes, I know grierous instances; many who have been most respectable farmers, and their fathers before them.

5032. Men who have not been extravagant?-Yes; the farmers are not generally extravagant; and I know, too, that the landowners are obliged to part with their land. I was talking to a friend of mine upon this subject not long ago, and I said the people must be losing their land estates, and they must go to mortgagees, and so on; and he said he did not perceive that that was the case; that there appeared to be the same possessors of the land as he ever knew ; I recollected myself for five minutes, and I showed him, within a distance of not 15 miles frum where we were sitting, land to the amount of $500,000 \mathrm{l}$. which had been sold within the last three or four years, and all those the estates of old respectabite families.

5033. All of them sold, not from their buying land elsewhere, but from their losses? - Yes; I think none had purchased elsewhere, or certainly not to any amount. One of the persons, a man of family, was utterly ruined ; the castle was bought by an attorney, who pulled it down, and built a house in its place.

5034. Have you any other suggestion to offer?-No, I have not, at the present moment.

5035. You said you thought the taking off the malt-tax would benefit agriculture very much; do you not conceive it would benefit Ireland much more than England?-I do not know why.

5036: Are you not aware that barley is much more grown in Ireland than wheat? - I have no knowledge of the agriculture of Ireland.

5037. You stated that you conceived the importations from Ireland were a disadvantage 
disadvantage to the agriculturists of Fingland? - What I stated was, that I con- B. S. Escott, Esq. ceived that the importations of agricultural produce from Ireland must lave the effect of lowering the price here, just the same as importations from one county 21 March 1836 . into another, or one market into another.

5038. Ireland, by growing generally much more barley than England, would benefit in a greater proportion than Eingland?-Of course, wherever the greatest quantity of barley is grown more people would be benefited, but I do not think all the benefit would be given to the growers of barley, as I stated before ; I conceive that the expeuse of the malt consumed by the farmer is very considerable, and the cost and quality of the beer drunk by the labourers still more. There is one thing I wish to say with respect to the present rise of prices. I am aware it is said by a class of persons, that the bulk of agricultural distress is a mere nothing; that it will soon be right again. The price of stock has been good lately ; very good in niy neighbourhood. I have no doubt the price of fat stock has been raised to what it is by a circumstance which has not benefited the farmers at all, but from which they are materially suffering; that is, the total loss of turnips, except swedes.

5039. You talk of the high price of stock relatively to the price it generally bears, but not relatively to the manner in which the farmer has been able to feed it? - Certainly. There is another thing; supposing that the price of grain is, as it certainly is, very low, the price of stock being high, it is an encouragement to throw land into pasture, and keep more stock, particularly sheep; but a great number of labourers will be thrown out of employment by that step.

5040. You think that will be the general consequence of the prices continuing so low? - Yes, other things remaining the same.

[The Witness is directed to withdraw.

Ordered, That this Committee be adjourned till To-morrow, One o'clock.

Die Veneris, $25^{\circ}$ Martii, 1836.

The Lord WYNFORD in Ths ChaIR.

Bickham S. Escott, Esq., is called in ; and further Examined as follows :

5041. DO you wish to make any addition to your evidence?-I omitted to state, in enumerating what I conceive to be the causes of the present rise in prices, one which nevertheless I think has had a very material effect in producing it-I mean the increased circulation of money. I believe that within the last two or three months there has been an increase effected in the circulating medium of the country by some means; I think, probably by means of different speculations in canals and railroads, an increased circulation of paper has been effected; I derive that impression from having conversed with several persons of practical knowledge in the banking affairs of the country, who have confirmed the suggestion, and have stated that they knew that to be the case.

5042. The bankers state that a great deal of paper has been pushed out in consequence of the speculations going on?-Yes.

5043. Have you any joint-stock bank companies in your neighbourhood? Yes, one very large one.

5044. Have you the means of knowing whether those joint-stock bank companies have increased their circulation? - I do not know that they have increased their circulation within the last two or three months, but I have been informed that they have increased their circulation very much within the last two or three years.

5045. Can it be safe for any banker to increase his circulation very considerably, while there is nothing but gold to fall back upon?-I think it may ; I do not say that it would be under present circumstances.

5046. Do you think it would be safe for country banks in general to issue such a quantity of paper as the wants of the country require, when there is nothing but gold to fall back on at the present standard? - No; when that qualification is introduced into the question, I should say not.

464 .

Q Q 3

5047. Do

B. S. Escott, E.

25 March 1836 . 
B.S. Escott, Esq. 504i. Do you know that there has not been so great an importation from Ireland lately? - I have no means of knowing how the importations from Ireland have been going on lately; I know they have increased very greatly within the last few years. In some parts almost all that is consumed is Irish produce.

5048. What additions have you to make to your evidence?-I was asked as to any manufactures in the part of the country with which I was best acquainted; I stated that I was not aware of any manufactures in my neighbourhood, except some small ones of paper; if that is confined to a very small neighbourhood, that is correct; but if I am to speak of a neighbourhood of 20 or 30 miles, and that I apprehend was what was referred to in the question, there are other manufactories; there is a very extensive glove manufactory at Yeovil, and a very beautiful one.

5049. That has existed for a long time?-Yes.

5050. And at Chard there is a manufactory of lace and silk?-Yes, and at other places.

5051. How long has that existed?-I do not know for what time it has existed, but many years; there is also some little woollen manufacture, but I believe very little of the woollen left; and there are considerable manufactures of bricks in different parts of the county. Another thing I wish to correct is this; I was asked whether any of our labourers migrated at any part of the year; I mentioned that at some seasons of the year some few have migrated; it is principally at the mowing season and the harvest, but it is a very small number indeed who ever migrate in that way, and they go into some not very distant parts of the country, where they get rather better wages; and it is the young men who do it, rather, I think, out of a liking for the change of going into a new country for a short time, and they sometimes return with $3 l$. or $4 l$. in their pockets.

5052. Do they go to the Isle of Wight? - I think chiefly into Gloucestershire and Wales. Your Lordships did me the honour to ask me what remedies I should propose for the present state of agriculture, and I mentioned several things. There is one I did not mention. It appears to me, as I stated, that there are two classes of remedies, remedies over which the law can have no control, and legislative remedies. This is one which perhaps your Lordships may think quite out of your legislative jurisdiction, but it appears to me a very important one, that landowners, if they are in the distressed state in which many have been for some years past, should, as far as possible, alter their domestic and family arrangements, both present and to come, with a view to the altered value of their property. As regards the landowners, the greatest distress will no doubt arise where estates are subject to heavy incumbrances, and those who have it in their power to alter those incumbrances have it in their power very considerably to remedy the degree of distress to which they are subject.

5053 . Would they not naturally do that where they had the power:-I believe, in many instances, they do not ; it takes time; and I allude particularly to charging their estates in making a provision for the other members of the family, in proportion to the reduced amount of the rent out of which the money is to be paid, and the increased value of the money which is to be paid.

5054. There are many cases in which settlements have been made?-I think they should do it when they have the power; but where they have not the power, I think many old families will be reduced to beggary by the want of such an arrangement, which I think is a great national evil.

505. All settlements by deed must of course continue?-Yes; but not those by will, where the parties are living.

5056. Is there any thing else you wish to add ?-With respect to the state of the labourers: I stated the other day my own opinion, that a great deal of distress among labourers arises more from certain moral causes than any other; I am strongly of opinion that any thing which would tend to encourage the revival of those sports and amusements which the labouring population of this country used to enjoy, and of which they are now very much deprived, would do a great deal of good." I am quite confident I did not sufficiently explain myself to your Lordships on the subject of tithes. I wish very much to be allowed to state, if I can, more clearly what I meant, when I said that I considered the cost of tithes to the landowner and occupier both was very much raised by the 
present amount of taxation; your Lordships know that though the taxation of the country has been rery much reduced within the last 20 ycars, it is nevertheless now three times as much as it was before the last French war. It is the opinion of many persons, - I will not pretend to give an opinion on that point, that the increased cost of growing a quarter of wheat is at least $20 \mathrm{~s}$. on account of taxation; that is, it costs $20 \mathrm{~s}$. more to grow a quarter of wheat than it would if that taxation did not exist. The way in which this appears to me to apply to the burthen of tithes, and to increase it, is this : the grower of corn must charge that increased cost of production upon the article he sells, in order to reimburse himself for his expenditure, otherwise he must pay the taxation out of his capital, which he could not long do ; it nust he a dead loss to lim, unless he can charge it on his customers. In selling the nine-tenths of his produce he does this; and perhaps the tax is doing no larm at all, for he is receiving for that an increased price ; but in parting with the tithe he receives not one penny of it back again, so that by every penny the cost of production is raised, the comparative value of the tithe is raised too, and its burthen increased to the grower of corn.

5057. You are speaking of the case where tithe is taken in kind?-I am, first ; I will speak of the money payment afterwards.

505 . If the tithes are taken in kind, generally the person taking the tithe pays the tax of the proportion, does he not?-I do not see that he pays any thing at all ; at least he pays nothing in the way of cost of production, except rates. He says, this part of the crop is mine. The farmer has raised the crop and paid the taxes, which are a part of his expense. By the amount of these taxes the cost of production is raised, and there is no means by which the farmer can reimburse himself.

5059. It is an addition, perhaps, rather to the burthen of the tithe?-Yes, it is an addition to the cost of producing it, which increases its burthen to the grower, and its value when computed in money.

5060. He obtains the value of the tenth, whatever it may be, if he takes it in kind?-Yes.

5061. If he lets it, he gets as much as the clear profit on the tenth would amount to?-Yes. If there is a composition, the matter, I think, stands thus; the composition is fixed on the valuation of the tithe; how does the valuer proceed? he takes the market price, and deducts from the market price the cost of the outgoings.

5062. Does he deduct any outgoings at all, supposing the tithe-owner lets it to each occupier himself? - Yes, no doubt he does. In valuing the tithes for composition he takes the market price of the produce, and deducts from that the amount he would be obliged to lay out in bringing that corn to market.

5063. Against that, does, not the tithe-owner set the straw and the dung, which the occupier has? - If there is such an agreement between them.

5064 . In many cases the straw pays for the drawing of the tithe, does it not? -The straw is part of the tithe, unless under particular circumstances; but I do not think that affects my argument. What I wish to state is this, that in estimating the compensation to be paid in money, the market value must be taken into consideration. If your Lordships are right in that suggestion, that simplifies my statement; but how is the market valne made up? it is made up of this taxation amongst other things. If it is right to say that the taxation adds $20 \mathrm{~s}$. to the cost of growing the quarter, $20 \mathrm{~s}$. is added in estimating the composition the farmer is to pay for the quarter, so that, whether he pays in kind or in composition, he pays so much more in proportion to the taxes. This opinion I do not pretend to state with any confidence before your Lordships as to its results, but it appears to me deserving of consideration, for if this is the case, precisely as the taxation of the country has been advancing since the beginning of the French war, so has the burthen of the tithes been increasing along with it ; and it may account for a good deal of the clamour on the subject of tithe.

5065. Have not the burthens of the clergy increased?-No doubt their expenses have increased; whether they have increased in proportion or not, I do not pretend to say. I only state how that operates on the grower of corn. That may be so, and that may be an answer to it, though I do not see how. There is one other observation which I wish to make; it may be said, at all events, ever since taxes have been diminishing, this burthen of tithes has been diminishing too on the same principle; but then that opens the other question, whether, in point 
B. S. Escott, Esq. of fact, under the existing pecuniary circumstances of the country, the burthen of taxes may not be as great and greater now than it was in the times of the

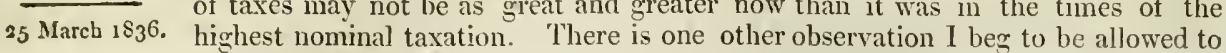
make. I was asked, in consequence of some remark of mine, whether I meant to make those pay tithes who never paid before; if the idea was, that in order to relieve the land from the burthen of tithes those must be made to pay who never paid before, that undoubtedly is a very serious consideration; but I am not sure that in any case those can be made to pay who never paid before; for where did all this money property come from? did it not all come from the land and the labour of the country? and if it has all been raised by the labour and taken from the land, when the land and labour formerly bore those tithes all that property had not been taken from it ; when it paid the tithe it had not to pay the taxes. There is one other circumstance that has occurred to me since. I am not sure that there is not a very high legislative precedent in this country for making the general property of the country contribute to the support of the church; if I am not misinformed, in the reign of George III. there were very large inoney contributions from the state to support the church; I believe nearly 2,000,000 of money were voted by Parliament for the augmentation of church property, which appears to me a most important precedent at all events. Then there is another observation I wish to make respecting the tithes, which escaped my memory the other day. It is said that the tithe commutation is to be a great relief to the land, and I think that if it is a proper one it may be a very great relief indeed; but see whether there is not a question of the greatest importance to be examined into before any Commutation Bill whatever, and we have had four or five, is worthy of being considered as a benefit to the land. I am told that some of the most able writers on political economy have laid it down as quite an axiom in their science that tithes are a tax, and a tax on the consumer; that, in point of fact, the consumer pays all the tithes of the country, because the produce is raised in price to the consumer by the amount of tithe subtracted from the grower; he must sell the nine-tenths for the same money for which he would have sold the whole.

5066. Do you recollect any particular writer who has laid down that position? -I do not; but I know the opinion has been maintained by able men.

5067. Do you propose to set aside all moduses and prescriptions in this case, and that all lands should pay in proportion, and all merchandise; you would not propose to tax the mercantile part of the community without setting aside all moduses and prescriptions? - I have the greatest hesitation in proposing any thing in such a matter, not only from my own inability, but that I do not know what is proposed to be done, and all must depend on what other measures are to be adopted. The present tithe system might, under some circumstances, not be oppressive. If we are to go on in other respects as at present, I do not think it is to be borne ; but I had rather not give an opinion upon that point.

5068. Can you set aside moduses, without, on the very same principle, taking the lands and every thing else; does not the modus secure the right?-I think so, under the present law.

5069. Consequently it cannot be set aside without destroying the right?That argument will apply to altering the present law on tithes at all; it appears to me to be equally valid against any commutation for money.

5070. Commutation may be very easily estimated; but if there is a modification of any part of the tithes, that will not apply? - I do not exactly understand that; but what I want to call your Lordships' attention to is this : supposing that opinion to prevail, as I know it does amongst many political economists, - I mean an opinion that tithes are a tax on the consumer,-then a commutation of tithe, which goes to fix a money payment on the land, will be in fact the imposing of a burthen on the land which it does not now bear, and this too under pretence of relieving the land from its burthens.

5071 . Will not that depend on whether the land rises or falls?-No, I think not at all.

5072. If the land rises, the landowner receives a considerable benefit?-Yes, in proportion to its increased value.

5073. If the land rises, and there is a fixed rent, the tithe-orwner will be the loser? - Certainly; which is a confirmation of the observation. I have made of the extreme difficulty, I should almost say absurdity, of pretending to devise any 
remedy for this evil, without knowing what other remedics are to be proposed or continued along with it.

5074. Have you any thing else to add?-I was not asked any questions on the subject of the corn law, or the present supply of corn. I wish to state, that it appears to me that any consideration with respect to the price of agricultural produce, and any remedies for it, must be ineffectual, unless the probable supply and demand of corn is taken into consideration, and the manner in which that supply and demand is effected by the present corn laws and the population.

5075. Do you suppose there is likely to be a deficient supply of corn?-I do not know, but I think not just at present.

5076 . Is it not likely to increase very much? - I should think that the supply of corn from foreign parts must be very likely to increase, as long as it is allowed to be sold to us, and the price there is so much lower than it is at home.

5077 . That must be the case as long as the national debt remains, must it not? - That I cannot say, but I do not see the necessary connexion between the propositions. Since I was last examined by your Lordships I have strengthened most of the opinions I then gave, and none more than that of the great danger of confidence in these matters. By referring to some notes I had formerly made, I have collected together a few sentences of certain men, considerable authorities in these matters, some not now living, and some who are,-Mr. Hume, Mr. Pitt, Mr. Baring (the present Lord Ashburton), Lord Brougham and Mr. Malthus.

5078 . Will you state what is the import of those opinions?-I have two or three short extracts, which I will beg to read. Mr. Hume says, in one of his Essays, "There is always an interval before matters be adjusted to their new situation, and this interval is as pernicious to industry when gold and silver are diminishing, as it is advantageous when these metals are increasing; the workman has not the same employment from the manufacturer and merchant, though he pays the same price for every thing in the market; the farmer cannot dispose of his corn or cattle, though he must pay the same rent to his landlord. The poverty and beggary and sloth which must ensue are easily foreseen." I wish to add to that, that it appears to me from the context that it is necessary, in order to make this applicable to the present time, to read "money" where Mr. Hume uses the words " silver and gold," in consequence of the alterations which have taken place since Mr. Hume wrote, or the phrase would be limited to gold and silver money only; I think paper money ought to be taken into the account also. In another place he states, not exactly in the words I am now about to read, but in substance, "It is the money which circulates that determines the prices, not the quantity of money in the country." He states afterwards, "One of these two events niust happen; either the nation must destroy public credit, or public credit will destroy the nation. It is impossible they can both subsist after the manner they have been hitherto managed." I wish upon that to make this observation, that it is a pity he did not begin that sentence by saying it was in consequence of the manner in which they have been managed that he apprehended the danger, rather than by stating the danger so positively, for, I apprehend, all he meant to say of public credit was, that it must be better managed in order to be preserved.

5079. What do you understand by being better managed? - That again would lead me into the whole question of the standard and the value of the currency ; but I will state presently, in a word, what I mean, after I have read these extracts. After glancing at what the House of Lords may do and what the House of Commons may do, he goes on in these words: "And perhaps, too, our foreign enemies may be so politic as to discover that our safety lies in despair, and may not therefore show the danger open and barefaced till it be inevitable. The balance of power in Europe our grandfathers, our fathers and we, have all decmed too unequal to be preserved without our attention and assistance; but our children, weary of the struggle, may sit down and see their neighbours oppressed and conquered, till at last they themselves and their creditors lie both at the mercy of the conqueror ; and this may be denominated the violent death of our public credit." Mr. Malthus says, "If the price of corn w'ere to fall to $50 \mathrm{~s}$. a quarter, and labour and other commodities nearly in proportion, there can be no doubt that the stockholder would be benefited unfairly at the expense of the industrious classes of society, and consequently at the expense of the wealth and prosperity of the whole country." That was in a pamphlet written by Mr. Malthus, I think in the year 1815. I will now read an extract from a speecls made by Lord Ashburton, in the 464. 
B. S. Escott, Esq. year 1822 or 1823 . "He did not think the noble marquis, who had stated in such forcible language the grievons injury which tampering with the currency

25 Nasch 18,36 . had inflicted on the aristocracy of the country, had at all over-rated it ; on that aristocracy he had no claim, but still he thought it ought to be upheld. There was not, he believed, a private family in the kingdom which had not been imporerished in some degree by the system; he himself knew instances in which large nominal fortunes were left to the elder sons of respectable families, which fortunes were not sufficient to discharge the incumbrances; and if that was the case with great fortunes, how stood the farmers throughout the country? Their situation was necessarily worse; many of them who had laid aside money to purchase land which they had partially mortgaged had been entirely ruined by the speculation; numerous families had been reduced to beggary, without perceiving the invisible hand which had struck them down." I wish to read the next extract, because it particularly supports my views in one suggestion I took the liberty of making to this Committee. "If the circulation was placed on the broader basis of two metals to the currency, there would be less danger of resorting again to the paper system. If, too, the Bank had two currencies to work with, it would greatly facilitate its operations in case of a demand for the precious metals, as there was no country in Europe in which silver may not be had, in the event of a run upon the Bank." It appears to me there is another reason in favour of a silver standard as well as guld. It is sometimes said that it might be difficult for the Bank to get silver in time, if they had to send across the sea for it; but then it is much more inconvenient to take away large sums in payment in silver than in gold, and that, I apprehend, would operate to prevent runs.

50 So. Would there not be a facility in obtaining silver, because if drafts are drawn on the Continent silver can be obtained, as the drafts are answered in silver and not in gold? - Yes. I think I ought to mention to your Lordships, that in the same speech Lord Ashburton, I think, uses the expression, that time is every thing in those matters; one in which I beg entirely to agree. The next extract I am about to read is from a speech of Lord Brougham's, delivered May the 9th, 1822. In his opinion, the first thing that ought to be considered was the means of escaping from the evil. It was immaterial whether taxation was admitted to be the only cause of the evil ; if it was allowed to occasion a part of it, a reduction of taxation was the only remedy within our reach. He thought this ought to be resorted to, in order to avoid the necessity of again interfering with the currency. Upon that $\mathbf{I}$ would observe, that the question is, according to Lord Brougham, whether, under the present circulation of the country, the taxation has been so far reduced as to enable us to bear it now, though we could not bear it then. He goes on, "That should be the ultimum remedium. If the return to cash payments had been accompanicd by measures which, in his opinion, were necessary, he should have considered it his most sacred duty to support that act of the Legislature which restored metallic currency. But it was never to be sufficiently deplored that, when that measure was resolved upon, Parliament did not sufficiently consider the state of the country, and the effect which it would produce upon a most important class of the people. In his opinion, any attempt to tamper with the currency after it had been placed on its present footing would show that we were reduced to something like extremity. He implored the House to avoid this evil, by having recourse to the only means by which it could be avoided, a reduction of taxation. l.et them afford every relief which it was practicable to afford to agriculture, by taking off those numerous and heavy duties by which it was now borne down. If all should prove unavailing, let them come to that which he would certainly fain avoid, if possible." There is another speech of Lord Brougham's, made in the same year, on the 12th of May 1822, from which I have not made any quotation, but I will beg of your Lordships to read the whole speech; that was a speech made in support of Mr. Western's motion for a committee to revise the currency, for whicli Lord Brougham voted. The speech sets out with stating, that "his doubt was, whether the standard ought not to have been fixed lower." There is also a speech of Lord Brougharn's on the former corn laws, which appears to me of the greatest possible importance. I would beg to state another opinion of mine, in which I am confirmed, within the last two or three days, by looking back at the speeches of Mr. Pitt, and reading the evidence given by Mr. Pitt before a certain Secret Committee, and endeavouring to take a view of the historical facts respecting Mr. Pitt's administration. One of the great causes of the evils under which we are labouring, I believe, is,

that 
that Mr. Pitt's policy, in the instance of the sinking fund, has not been acted on and followed up. If I am obliged to put my finger on any measure which I consider necessary to restore the prosperity of the land-owner, and do no injury, but add in the greatest possible degree to the security of public faith, I should say it would be for a government to act precisely on the principles laid down by Mr. Pitt, in re-establishing the sinking fund.

5081. By paying off the one per cent. ?-By constantly reducing the sum total of the debt; such a sinking fund as would enable us really and substantially to pay off debt. This appears to me the proper way to manage public credit.

5082 . Would not that oblige us to raise a larger amount of taxes? - Y Yes, it possibly might, though I do not know that; but 1 think one of the greatest evils to the country has been the taking off the taxes, and such taxes too, in the manner of late years, and violating the faith of Parliament by not keeping up the sinking fund, as Mr. Pitt promised for his successors. It is that which has brouglit us into our present situation more than any thing else.

5083. Have you made a calculation how much the national debt would have been reduced if the sinking fund had been kept up:-I have not such a calculation here; but it might have been reduced, I apprehend, at least a third already.

5084 . Do you think, in the state of the country, the sinking fund wonld have been kept up?-I think so; I am not aware why it should not; but that certainly depends on other questions. I think that if it was possible to keep up a strong government in the country it might have been donc; if it was possible there should be a government in the country strong enough to resist public clamour, and think of nothing but the utility of its measures. Lour Lordships know all these things much better than I do. But there is another matter upon which all the importance of these questions depends; it is a thing we have no sufficient experiment of as yet, but the immediate usefulness of all your Lordships' labours will depend upon it; I mean whether, under the present circumstances of the State, and new arrangements made and to be made, the land and the labour and the property of the country have a sufficient share in the system of its legislation. I will not venture to give an opinion to your Lordships on such a point, but it is at least very unsatisfactory to suggest legislative remedies without knowing all which is to be done, and the power of doing it ; it is like a stranger sitting down to regulate the economy of a family, without knowing what is the income of the pater-familias, or to what professions lie intends to bring up his children.

[The Witness is directed to aithdraw.

William Blamire, Esq., a Member of the House of Commons, attending, is Examined, as follows:-

L. S. Fiscull, Esq.

25 March $183 \%$.

5085. YOU are a Member of Parliament for the Eastern Division of the county of Cumberland?-I am.

5086. Are you acquainted with agriculture?-I have had considerable experience in all rural matters for upwards of 20 years past.

5087 . What sort of land is there in that county generally? - We have every variety of soil, from lands not worth more than $2 s .6 \mathrm{~d}$. an acre to lands worth $3 l$. an acre or upwards.

5088. What is the state of the farming interest in that part of the country?The state of the farming interest in the county of Cumberland is generally extremely depressed, more perhaps than in many other counties, from this circumstance, that very large tracts of common land have, in the last 15 years, been brought into cultivation, not containing in themselves a sufficient innate fertility to continue permanently to produce good crops; those crops have very much fallen off, and the tenants have become extremely depressed, and been driven to have recourse, in order to raise the rent for the landlord, to improper modes of cultivation, occasioning the exhaustion of the land.

5089. Cross-cropping, as it is called?-Ies, taking too large a quantity of corn.

50yo. What is the state of the farmers in other lands not of the description you have now mentioned? - The state of the farmers on the better land is not very materially different to that it has been for a number of years past. I conceive great exertions have bcen made in recent years to put the lands of the first quality into a high state of cultivation, from a greater quantity of draining, from the 464 .

Wm. Blamire, Esq. M: $P$. 


\section{MINUTES OF EVIDENCE BEFORE SELECT COMMITTEE}

$W m$. Blamire, Esq. purchase of more artificial manure, and that the product on those lands has not M.P. deteriorated; but on the inferior soils there is a very great difference indeed;

$=5$ March 1836 . and, generally speaking, the agricultural interest in the county of Cumberland is very much reduced.

509:. Which is the largest proportion, the poor lands or those of a better quality ?-The inferior land bears the largest proportion.

5092. Then you would say that, generally speaking, the agriculturists in that part of the country are depressed?-Yes.

5093. What is the state of the labourers?-The state of the labourers, more especially in the county of Cumberland, from various local circumstances, is better than it has usually been, from the accidental circumstances of railways and canals, the demand for an unusual quantity of labour; and that description of labourer has not felt the adversity of the farmers to the same degree one would suppose he might.

5094. Has the cultivation of land in Cumberland been decreased? - A considerable quantity of inferior land is thrown out of cultivation.

5095. How do the poor find employment in the country where that has taken place - We have in the county of Cumberland no surplus labour; we import, if I may so say, a quantity of labour at various seasons of the year; the demand for labour has been remarkably great, so much so, that if the farmer did not give emplayment to the people about him, they immediately found it elsewhere; but that is owing to the adventitious circumstance of railways and canals, and various demands for labour created there.

5096. Are the tenantry in general in a bad or a good state?-The tenantry are in a bad state, a very depressed state.

5097. Can they pay their rents except by cropping their lands in the way you speak of :-The tenants of inferior soils cannot pay their rents without giving up to their landlord a part of the fee simple every year.

5098. You mean by taking too much off?-Yes; if the estate were for sale it would probably sell for about as much less at the present moment as the difference as compared with what it would a few years ago when it was in a better state.

5099. Have rents been reduced in that county? - Rents have been reduced, but not to the great extent one might have supposed they ought to have been, and that they necessarily would have been, but for the great competition for farms.

5100. The competition for farms has kept up the rents?-Yes.

5101 . How do you account for that competition, when farming is so unprofitable a business? - I conceive it is solely to be accounted for in this way, that the pressure of the population against the cultivated lands of the country is so great, that it is not in every man's power to find a situation for himself to fix on ; and that makes a competition for lands greater than I ever before knew it.

5102. They will not quit their lands, although they can get nothing for the cultivation of them :-Although they are quite certain they must be ruined, or at all events certain they shall have no return for their labour, they are necessitated to have some place on which to live, and they have no means of turning themselves to any thing else.

5103. Do you know any instances of farmers being already ruined?-Great numbers.

5104. Reduced to the greatest distress?-Yes; and in that part of the country we have a great number of small estates men.

5105. You mean men who have a small farm of their own?-A small property of their own.

5106. They are yeomen, in fact?-Yes.

5107 . What is the condition of those persons? - The condition of those persons is, generally speaking, most pitiable at the present moment ; they are, as a body, in fact, ceasing to exist at all, the pressure of the times has been so great upon them; and from the unfortunate circumstance of the father of a family having settled a provision for his younger children upon the estate, in many instances an inducement, during the high prices of the war, was held out to them to improve their farms in every possible way; their condition at the present moment is truly lamentable; a vast number of those properties has passed from the possession of the yeomen, and there are others that must ere long pass away. 
5108. Have those who still retain possession of their lands incumbered them by $W \mathrm{~m}$. Blanire, Esy. mortgages?-There are very few men in that rank of life who have not, to a greater or less degree, incumbered their property.

$5 \mathrm{log}$. Is not that the case with the gentry and small frceholders?-It is.

5110 . Have any land-owners of the county gone to reside in more humble situations?.-There are some instances of yeomen having sold their properties and gone abroad ; but not in that part of the county many instances of gentlemen having done so.

5111. From your observation, is the emigration of those persons and their parting with their property the effect of any imprudence on their part, or merely the pressure of the times?-By no means the effect of any imprudence on their part, but solely from the pressure of the times; I believe there is no set of men in the world who live so poorly as that class of persons do, in comparison to the work they undergo.

5112. Do they manage their farms well?-They manage their farms as well as men so circumstanced can be expected to do, with as much reference to frugality and to every sort of management and desire to produce crops as can be seen any where; more capital might, no doubt, be advantageously expended in the farms.

5113. Is there any want of good management, or is that occasioned by the distress of their circumstances ?-Certainly, and not by the want of competence and knowledge; there is no man to be found who does not know how to make the utmost of his land under the circumstances, if he had the means.

5114. Do you state that many of the lands are over-cropped ?-Very much overcropped.

5115. Has the cultivation of other lands been given up in consequence of the poverty of the tenants?-In consequence of the poverty of the tenants some has ceased to be cultivated at all, and I conceive a much greater portion of land would cease to be, but that it is not unusual for the landlord to say to the tenant, "Instead of giving any greater reduction of rent, I will expend a certain amount of money in draining or in the purchase of artificial manure, which is to you equivalent to a reduction of rent; and from my pleasure in seeing my estate improved and looking better;" that has been done to a considerable extent by the more wealthy landlords.

5116. Has that been to such an extent as to account for the difference of rent now and formerly? - No, I do not think it has altogether; it has had a considerable effect; but I think the high proportion the rents at the present moment bear to the proportion they ought to have borne when compared with the price of produce, is to be attributed more to the pressure of the population than to that circumstance of the rents appearing nominally higher, which the landlord really does not put into his pocket.

5117. You say those improvements have been attended with considerable expense to the landlord? - No doubt.

5118 . That would justify some rise of rent, of course? - Not a rise of rent, but a continuance of the old rent, on an understanding on the part of the landlord that he will expend a part of that rent in the improvement of the land for the farmer.

5119. Since what time has the great depression in the agricultural interest taken place?-Since the year 1816 .

5120 . From what do you suppose that originated - The alteration of the currency was the first affecting cause, I conceive.

5121. Speaking from your own observation, can you take upon yourself to attribute it to that principally ?-I feel very confident that that was the case.

5122. Do you attribute it to any other cause; importations from other countries, for instance?-No doubt there was a very great importation in the year 1815, which had a very considerable effect, and the consumption has materially increased.

5123. From whence was that importation?-From various parts of the Continent.

5124. Do the Irish importations reach you?-On our side of the kingdom we are very materially affected by Liverpool being virtually the granary of Ireland.

5125. Have the importations from Ireland, in your opinion, depressed the prices of agricultural produce in the English market?-They have had a very 464 . R R 3 striking 
II $m$. Blamire, Esq. striking effect, and, perhaps, a more conspicuous effect on the price of animal M.P. food than on the price of corn.

$=5$ March 1836 .

5120 . Has it been great on the price of corn?-No doubt it has, since the passing of Sir Joln Newport's Act.

5127 . That was in 1826 ? - I think it was.

[Mr. Blamire withdraws.

Mr. William Summers is called in; and Examined, as follows:

Mr. Wm. Summers.

5128. YOU live at Ilton, in Somersetshire?-I do.

5129. You are a land-surveyor?-I am.

- 5130. Are you extensively employed in that line ?-I am.

5131. The land in that part of the county is, generally speaking, rery good, is it not:-Generally speaking, it is, but very variable.

5132. How long have you been acquainted witl agriculture?-Thirty years, or more; in fact, all my life.

5133. What is the state of agriculture in that county at this time?-It is in a depressed state, a very depressed state.

5134. Can the tenants pay their rents?-Not generally speaking.

5135. Is that the case in a great degree?-It is.

5136. Are the rents moderate?-They are more moderate than they have been.

5137. They have been reduced? - They have been.

5138 . To what extent have they been reduced?--There have been various reductions; I should say from 10 per cent. to 20 or 25 , in some instances.

5139. From what time - -W W ithin the last 20 years.

5140. Are they reduced as low as, considering the expense that the landlords liave been at in improvements, they can be fairly expected to be?-I think quite so.

5141. At those reduced rents, can the farmers go on with their business?Certainly not; it is principally so on arable land.

5142. Have there a great many thrown up their farms in your neighbourhood? - Not a great many, but there are some.

5143. Do you think they pay their rents out of their capital?-Yes, in many instances.

5144. For how long a time have they been paying their rents out of their capital ?-In some instances, I think, they have done so since 1822.

5145. Did the distress begin in 1 \$ 21 and 1822 ?-Yes.

5146. To what do you attribute that:-I think the first cause was the withdrawing of one-pound notes, and the diminution of the circulating medium.

5147. Has the distress continued uninterrupted up to the present time, or have there been suspensions of it - - There have beell suspensions of it.

5148. Do you recollect when those suspensions took place?-I think about 1824 or 1825 .

5149. When did the distress return again :-I think that the suspension was only for about two or three years, to any extent.

5150. Has it continued ever since?-Yes.

5151. Has it increased:-Certainly.

5152 . When was it greatest?-I think it was greatest in 1821 and 1822 ; that it was worse then than at present.

5153. Just at this present time the prices of corn and other things have risen? -Yes, a little.

5154. Do you think the tenants have more capital now than they had in 1821 and 1822 ? -O no, I think not.

5155. Of course, if the capital is decreased, they must be worse off now than they were then:-Certainly.

5156 . Though since that there has been a suspension of the depression of prices :-Certainly.

5157. They have never been relieved from the distress that was brought upon themin 1821 and I822? - Certainly not, though prices have got up since that.

5158. Have many farmers been broken up in your neighbourhood ?-Many.

5159. How far round are you acquainted with the state of the farmers :-For 25 miles round Taunton to Ilminster.

5160. A better 
5160 . A better part of the country, in point of land, there cannot be, can there? $\mathrm{Nr}$. Wm. Sumers. - 1 should think not.

5161. Yet, in that part of the country the tenantry are distressed? - Yes.

5162. Are poor-rates high in that part of the county --Some parishes are much more burthened with poor than others.

5163. Are the labourers pretty well employed in that part of the country? -Yes.

5164. How do you account for that, when the farmers are distressed? - They have got more into the habit of growing flax in the good soils.

5165. They grew more flax 20 or 30 years ago than now, did they not?-1 believe they grow about the same.

5166. Would it not relieve the furmers, and add to the market for labour, if the growth of flax in your county was cncouraged :-Certainly.

5167 . If foreign flax was shut out by duties?-Yes; flax has been very low till within the last two years.

5168. What has the rise been owing to?-I apprehend that the crops abroad have not been so good.

5169 . There is no crop that employs so great a number of labourers as flax, is there? - No.

5170. So that the increase of the growth of flax would be a great relief to the agriculturist?-Yes.

5171. Flax is a very impoverishing crop, is it not?-It is not so long in the ground, therefore I do not think it impoverishes so much as many other crops.

5172. It is sown in the spring?-Yes.

5173. Does it leave the ground dirty, or not?-No; we make our land particularly clean to get the flax in.

5174. You have hemp also in your county?-Ycs.

5175. There is no litter goes into the farm-yard?-No; I have here a statement of the expense of cultivating an acre of flax.

\section{[The same is delivered in, and read, and is as follows :]}

Expenses for the Cultivation of an Acre of Flax.

Rent and extra manure (being the best of his lands), and not paid the tenant $f . s . d$. the rent given the last two years - $-\quad-\quad-{ }_{-}-5_{-}-$

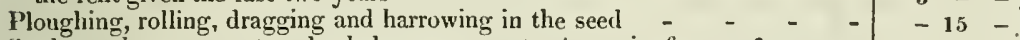

Seed, on the average, two bushels per acre, $10 s$. (once in four or five years

Russia Riga seed is sown, and costs almost always in cleaning, carriage, \&c.

1. per bushel)

Pulling and liquor per acre

Binding ditto and liquor

$\begin{array}{lllllllll}\text { Binding ditto and liquor } & - & - & - & - & - & - & - & - \\ \text { Threshing and winnowing } & - & - & - & - & - & - & - & -\end{array}$

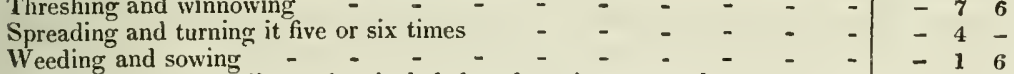

Dressing out the flax (liquor, \&c., included, and carriage to market), 35 dozen per acre, at $1 s .6 \mathrm{~d}$. per dozen

Tithes in general -

Parish rates -

(Cr.)

By 35 dozen per acre, at $6 s$. per dozen

By 10 bushels of seed, on the ayerage, $6 s$. per bushe

\begin{tabular}{|c|c|c|c|c|c|c|c|}
\hline Expenses & as above & - & - & - & - & $\begin{array}{l}13 \\
11\end{array}$ & $\begin{array}{r}10 \\
2\end{array}$ \\
\hline Profit & - & - & - & - & f. & 2 & 7 \\
\hline
\end{tabular}

No manure returned like a corn crop.

5176. There is a profit to the farmer paying rent at $2 l .7$ s. $6 d . ?-Y$-Yes.

5177. What was the price of flax at the time the importations came in from abroad? - I think about three years ago it was the lowest time; I recollect it was down to $3 l .15 s$. and $4 l$.

5178. That would pay no profit at all?-No; and then we did not grow so inuch.

464.

R $\ll 4$

5179. That 
Mr. $\mathrm{Km}$. Summers. 5179 . That prevented the growing of it?-Yes.

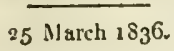

5180 . Would ground that will grow wheat do for flax? - Yes.

5181 . So that if there is too great a quantity of wheat, that quantity might be diminished if the farmer could profitably cultivate flax?-Yes, but not all wheat land; it is the best land; the cold soils which raise wheat will not raise flax.

5182. You do not consider it an exhausting crop ?-No; but it leaves nothing for the land.

$518_{3}$. It does not exhaust like potatoes?-No.

5184 . Do you generally manure for flax ?-Yes, unless it is after the breaking up, then we make the flax the first crop.

$5_{1} 8_{5}$. Is the price you have given for flax the present price?--Yes, the average present price; there has been some sold as high as $7 \mathrm{~s}$. per dozen, and some as low as $5 s$.

5186 . Is the price you have given that which you think may be reckoned on? - It is a very varying article; if there is an importation in this spring, which is talked of in the flax market, it will be $1 l$. or $2 l$. less.

5187 . Could you expect that price unless the import duties were raised?-No, I think not; I recollect when it was $10 l$.

5188 . Is any further process carried on in your neighbourhood with the flax?Within 20 miles round a great deal of it is manufactured.

5189 . Does that employ a great many people upon it?-Yes.

5190 . Do you think the country in general would be likely to benefit largely if encouragement were givell to the home produce of flax?-Yes, that is my opinion.

5191. Would that tend to improve the condition of the farmers by its effect on their neighbours? - Certainly.

5192. Are you aware what sum an acre of flax would set in motion?-No, I am not; that is a question a tradesman could answer better.

5193. The hackling is done in the neighbourhood?-Yes.

5194. What sort of soil is best calculated for it?-Fine rich loamy soil.

5195. Will it grow on clay?-Yes, but not so well.

5196 . On light sandy land?--No, not so well; it will grow on lime, but not so well as on a rich loamy soil.

5197. What quantity of wheat per acre do you think this land will grow, on which you calculate this product of flax? - That depends on the seasons; I have seen, on an average, on a farm from 20 to 30 , and, on an average, 15 bushels of wheat an acre.

5198 . Have you made a statement of the expense of the cultivation of corn, and the profits ?-I have; I have taken it on the four-course system.

\section{[The Account is delivered in, and read, and is as follows:]}

Statement of the Expense of the Cultivation of an Acre of Arable Land, on the Fourcourse System, and the Profit or Loss thereon.

1832 :

Average rent for an acre of arable land, $28 s$, say one year and a half

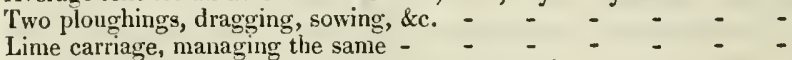

Seed wheat, two bushels (1832), cost $7 \mathrm{~s}$. per bushel

Weeding, $3 \mathrm{s.}$; tithe, about $15 \mathrm{~s}$. ; reaping, $7 \mathrm{~s}$.

Poor, church and highway rates, about

Interest of capital for a year and a half -

Produce, 21 bushels, at $6 s .6 d$., in 1833, is

Loss

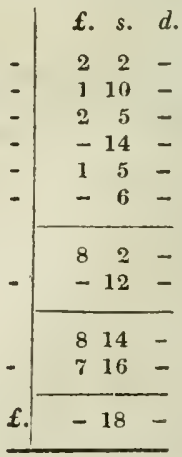




\section{3 :}

Ploughing and preparing the land for turnips, say four ploughings, at $7 \mathrm{~s}$. each, $1 \ell .8 \mathrm{~s}$.; rolling and harrowing, three times, each at $3 \mathrm{s.}, 9 \mathrm{~s}$. -

Manure with fold of sheep or dung -

Seed, 2 Jbs., $2 s$. ; hoeing, \&c., $5 s$.

Rent, half a year, as the above was taken at one year and a half; taxes, as above, 2 s. -

Tithes -

\section{Interest}

Value of the crop, if fed on the same

Loss $-\quad-\quad$ f. $13-$

f. s. $d$.

$117-$

$110-$

$-7-$

$-16-$ $-4-$
Ploughing, rolling, harrowing, \&e., for barley - - - -
Seed, five bushels, at $3 s .3 d$. per bushel, $16 s .3 d$. ; taxes, $4 \mathrm{~s}$. -

Rent, 1 l. $8 s$. ; tithes, $10 \mathrm{~s}$.

Interest

Straw of each crop to pay for threshing and harvesting.

Produce about 32 bushels, at $3 s .3 d$.

1835 :
Mr. $W m$. Summers.

25 March 1836 .

Grass seeds sown with the barley, 1 peck of rye or ever grass, at 1 s. $6 \mathrm{~d}$.;

$15 \mathrm{lbs}$. of white or red clover, at $7 d$. per lb., $8 s .9 d$.

Rent, 1 l. $8 \mathrm{~s}$. ; tithes, $4 s$. ; taxes, $4 s$; cutting, $7 \mathrm{~s}$.

Interest

Produce, one ton and a half of hay, at $2 l .10 \mathrm{~s}$. per ton

Outgoings for 1832

$$
\begin{array}{lrlrrr}
\text { tgoings for } 1832 & - & - & £ .8 & 14 & - \\
\text { Ditto } 1833 & - & - & 5 & 3 & - \\
\text { Ditto } 1834 & - & - & 4 & 17 & - \\
\text { Ditto } 1835 & - & - & 2 & 18 & 3 \\
& & & \\
\hline & & &
\end{array}
$$

5199. On what have you reckoned the price of wheat?-I have taken it in this account at the price of 1832 ; it is now worth only $5 s$.

5200 . Then the loss would be still greater?-Yes.

5201 . When you calculate the value of the crop at $4 l$. . in the account of 1833 , how do you use the produce?-Feeding sheep and bullocks.

5202. You think that is a fair calculation of profit from feeding three years? -It is sometimes more, and sometimes less; this year, I think, turnips, if we had grown them, would have been worth considerably more, but they failed altogether.

5203. Have you prepared any other paper:-I have also a paper stating what it would cost to stock 100 acres, the capital employed on live and dead stock.

5204. What description of land? - The average of land in our neighbourhood, taking arable and pasture.

[The same is delivered in, and read, and is as follows :] 


\subsection{MINUTES OF EVIDENCE BEFORE SELECT COMMITTEE}

Mr. $1 / m$. Simmers. Amount of Capital for purchasing the Live and Dead Stock employed on a Farm of 100 Acres of good Land, supposing to commence at Michaelmas, taking the Live and

25 March 1836 . Dead Stock at a valuation:-

16 acres of hay, at 30 cwt. per acre, at $2 s$. per cwt. -

3 horses, at $18 l$. each -

4 working oxen, at $12 l$. each

3 cows, at $10 l$. $10 \mathrm{~s}$. each

30 store ewes, at $30 \mathrm{~s}$. eac

30 one-year old sheep, at $25 \mathrm{~s}$. each

$1 \mathrm{ram}$

3 two-year old beasts, at $8 l$. each

3 yearlings, at $4 l$. each

1 yearling colt

1 sow pig -

6 store pigs

2 waggons -

2 carts, or putts -

2 ploughs

1 pair of drags

2 pair of harrows

2 rollers

Winnowing machine

2 dozen sacks, at $36 s$. per dozen

Winnowing sheet -

2 waggon lines

Horse harness, 2 breechings, and 3 single harness collars, halters, \&c.

Bridle and saddle -

Casks, dairy and brewing utensils, cider vats, \&c.

Forks, rakes, shovels and dung-forks

Yokes, bows and chains

Measures and seed lips, crow and iron bars - - -

Gate hurdles, for parting turnips, 10 dozen, at $10 \mathrm{~s}$. per dozen

Half-year's rent

Poor, church and lighway rates

Wages for manual labour, $s$ s. per week for three men, and $4 s$. per week for a strong lad, hay and corn harvest included ; also two women, hay-making, weeding, apple-picking, \&c., say three months, at $4 s$. per week each

Beer and cider for manual labour, including mowing, reaping in hay and corn harvest, 17 hogsheads, at 2 s. per hogshead -

Blackswith's bills

Carpenter's bills

Seed wheet, 46 bushels, at 5 s. $6 d$. per bushel

Seed lent corn, 56 bushels, at $4 s$. per bushel

300 hogsheads or quarters of lime, at $1 s .8 d$.

Farrier, $2 l .10 s$. ; harness man, $2 l$. 10 s. -

Market and fair expenses

Grass seeds -

5205. Have you prepared any other account of the produce of 100 acres of land :-I have.

[The same is delivered in, and read, and is as follows :]

The Produce of 100 Acres of the Average of the best Land in the Vale of Taunton, farmed as follows :-

23 acres of wheat, 25 bushels per acre, at $5 s$. per bushel

14 acres of lent corn, barley, beans and peas, 35 bushels per acre, at $4 s$. per

bushel

3 cows, at $8 \bar{l}$. each (one of which a heifer)

2 oxen, sold annually, at $18 l$. each

1 cow or heifer

30 fat sheep, at 100 pounds (ewes and wethers), at $4 \frac{1}{2} d$. per pound

1 pack and three quarters of wool, at $15 l$. per pack

5 acres orchard, at 8 hogsheads per acre on an average, $25 s$. per hogshead, for 40 hogshicads

1 colt, bred to keep up the horses once in two or three years -

1 acre of potatoes

10 acres of turnips, consumed by the keep of sheep, \&c.

Pigs, poultry, and a few grass seeds grown, on an average, say, -

Amount of earnings during the year, on an average, for labour done on the roads, and carriage of coal for burning lime, fc., say 
14 acres of young grass,

7 acres of second grass,

7 acres of pasture,

16 acres of meadow,

3 acres of mow, barton, fences,

homestead, wastes, \&c.

N.B.-About five acres of vetches, sown annually, are consumed by the sheep and afterwards sown to turnips; and if five or six acres of flax should be sown annually, there must be that less wheat or lent corn sown.

Expexses or Outgoings, \&c.

Tithes of 23 acres of wheat, at $15 s$. per acre - -

Tithes of 16 acres of hay mown, at $4 \mathrm{~s}$. per acre

Small tithes, lambs' wool, cows, apples, agistment, \&c.

Poor-rates, on the oxerage

Church-rates

Highway-rates

Wages, on an average, for mamul labour, say $8 \delta$. per week for 3 men, and $4 s$. per week a strong lad, mowing, reaping, hay and corn harvest included; also 2 women hay-making, weeding, apple-picking, \&c.; say three inonths, at $4 \mathrm{~s}$. per week each

Beer and cider for manual labour, including reaping, mowing, hay and corn harvest, 17 hogsheads, at $25 \mathrm{~s}$. per hogshead -

Blacksmith's bill -

Carpenter's bill

Seed wheat, 46 bushels, at $5 \mathrm{~s} .6 \mathrm{~d}$. per bushel -

Seed lent corn, 56 bushels, at $4 s$. per bushel

300 hogsheads or quarters of lime, at $1 s .8 d$. per quarter

Farrier, 2l. $10 \mathrm{~s}$; ; harness mender, $2 l .10 \mathrm{~s}$.

Market and fair expenses

Grass seeds, on the average

Female servant's wages

Thatching hay and corn

300 reed, generally found by the tenant at $21 \mathrm{~s}$. per 120 sheaves -

Sheap-shearing, washing, \&c., at 5 s. per score, including expenses

Corn for horses during the wheat sowing and harvest, say 40 bushels per year,

beans and oats, $3 \mathrm{~s}$. per bushel

Cooper's bill for casks, hoops, vats, pails, tubs, \&c.

15 bushels of vetches, sown annually, at $i s$. per bushel

'lumip seed -

Bull for cows, and horse for mare, say aunually -

Mole-catcher

Corn and milk for 3 calves, bred 16 weeks before they are turned out to grass,

at $1 s .6 d$. per week each

735l. capital employed on the farm, at $10 l$. per cent.

2 l. per cent. on $735 l$. for wear of implements, insurance, and risk of live and dead stock

\section{Expenses or outgoings}

Gross produce of 100 acres of the average of the best land

Outgoings or expenses, allowing for interest of the capital employed, \&c.

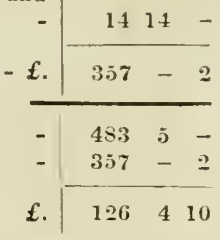

$$
\text { Remaining for rent, \&c. }
$$


Mr. $\mathrm{Wm}$. Summers. 5214. Have you any means of knowing the expense of growing corn in Ireland? - No.

25 March 1836 . 5215. Is the importation confined to corn?-No, there is a great deal of cattle and pigs, and so on.

5216 . Has the importation increased of late :-Yes, very rapidly within the last five or six years.

5217. Has it increased year by year since that time?-Yes, it has.

5218 . Have you any means of knowing whether our prices have gone down as the importations from Ireland have increased? - They have, certainly.

5219. When you have found a great importation from Ireland, has that depressed our price? - Yes, it has.

5220. Do you ever go to the Bristol market? -I never go to market there; I am frequently at Bristol.

5221. Have you the means of knowing that great quantities of Irish produce come to the market now, greater than formerly?-Yes.

5222. Do you visit Gloucester?--No.

5223. Do you visit any of the ports below Bristol ? - Yes.

5224. Bridgewater, for instance?-Yes, there is a great deal of Irish produce comes to Bridgewater.

5225. Does a much greater quantity of Irish produce come there than formerly-Yes.

5226. Is that the case lower down?--I cannot speak to Mineliead, but I believe it is so.

5227. Have you any doubt that it is the introduction of those articles from Ireland which has contributed to press down very considerably the price of all articles ? - No doubt of it ; particularly within the last two or three years.

5228. Has it pressed it down so much that it is difficult, if not impossible, if it presses further, to go on :-Certainly.

5229. Is there an increase in the quantity of wheat grown in your district?I think, with the exception of some large inclosures which lave caused wheat to be grown, otherwise I should say, there is less rather than more, latterly.

5230. When you state that $4 \frac{1}{2} d$. is the price which would be paid, at what time do you reckon upon those sheep being killed?-About Michaelmas; our average prices, between that and Ladyday, for our heavy sheep, have been about that.

5231. Is that about the time of the year you sell them?-Yes; from Michaelmas to Ladyday.

5232. That has been the average price?-Yes; it is rather more now.

5233. What is the price of beef now ?-About $9 s .6 d$. a score.

5234. About how much a pound?--They retail it at about $6 d$.

5235. Supposing the price of beef was higher, would not that give you a better price for your sheep?-Yes.

5236. Do not you conceive, that if an additional duty were imposed on foreign tallow, that would be a great advantage to the farmers?-Yes.

5237 . Since what time have the sheep sold as low as $4 \frac{x}{2} d$. - In 1821 and 1822 we sold our heavy sheep at $3 d$. a pound.

5238. Fat ones?-Yes.

5239. How do you account for mutton not having been under $6 d$. and $7 d$. in the market of late - I suppose we should not get now for our heavy sheep more than $5 \frac{1}{2} d$.

5240. That is taking the whole?-Yes, alive.

5241 . From your experience in farming, is it your opinion that the farmers can get their implements and other articles they want at a cheaper rate than formerly, or otherwise?-I do not think they can get any thing at a cheaper rate than formerly.

5242. Neither farming implements nor clothing?-I think that clothing is cheaper.

5243. Do you think there is much difference in the price of clothing? - Yes.

5244. Is there any alteration with respect to the durability of articles?-I think they are not so strong as they were in my recollcction.

5245 . What is your opinion of the cultivation of wheat in your neighbourhood? - It is very much lessened.

5246 . How do you account for that?-By the greatly increased growth of potatues.

5247 . Is 
5247 . Is that greatly increased growth of potatoes by farmers:-By small Mr. Wm Summers. farmers.

5248. What has inched them to make that change in their food now that 25 March 1836 . wheat has become so much cheaper?-It has been increasing, and has now become such a habit, I think the people are better satisficd with potatoes than bread, as they used it since my rccollection.

5249. Do they eat more meat :-I think they do; I think there is more bacon eaten, and more pigs killed by the poor people; in my recollection the labourer used to take his crust of bread in the morning, and live upon it for the day; and now the wife or some of the family bring them their potatoes twice or three times a day.

52.50. Hot potatoes :-Yes.

5251. Do they generally bring them with the potatoes any meat?-Sometimes they do; sometimes nothing but potatoes.

5252. Do you consider that the change has arisen from the labourer being in a more distressed situation?-Yes, I consider that the original cause; and perhaps it now operates in a measure.

5253. When you consider the price of wages now and the price of corn, do you think that they are in a worse situation than they were?-No, I think they are better off in the neighbourhood than I ever knew them.

5254. Then the change of food does rot arise from their being in a worse situation?-No, I think not.

5255. What do they do with the rest; do they put it into the savings banks? -No, they go to beer-shops with it.

5250 . Then the inference is, that there may be more barley consumed?I think there is.

5257. Can you estimate the proportion of the decreased consumption of wheat; suppose a labourer consumed before 12 bushels of wheat, what would he consume now? - I should think that it would be very nearly half the difference within my recollection.

5258 . Do you speak of a labourer, his wife and three children?-Yes; that they do not use half the quantity of wheat and flour they used in my recollection. 5259. Do you recollect their using any inferior article of corn than wheat?-

Yes, they used barley.

5260 . Do they use it now ?-No; I think that they use peas sometimes.

5261 . Peas are as dear as wheat, are they not.-Yes.

5262. Do peas go further than wheat?-I think they do; but that is merely matter of guess ; in some parts of our country we have very good fine white peas. 5263. How do they use them?-They boil them and make soup.

5264 . Do you think they have increased in the use of them?-No, I do not think they have.

5265. Do you remember when the lower orders of people in the western parts of England were chiefly fed on barley?-Yes, I recollect it perfectly well; in 1800 and 1801 , the dear times, they used a great deal of barley, and before that.

5266. They never touched wheaten bread, scarcely?-Not much.

$526 \%$. Do you think they eat a great deal more wheaten bread now than they did then ? - I do not think they do.

5268. You think the potato has supplied the use of barley -Yes.

5269 . Barley is scarcely eaten by them at all now ?-I think not.

5270 . The crop of potatoes is worth more than the crop of wheat :-Generally speaking, it is.

52.71. Is it not the interest of the farmer, if the landlord will let him, to grow potatoes rather than wheat?-Yes, they make a great deal more money.

5272. It injures the farm, does it not - -Very much indeed.

5273 . So that the tenant who pays his rent by growing potatoes instead of wheat, is paying the landlord out of his own money?-Yes; but still it is increasing.

5274. Do you think that increase is owing to the poverty of the tenants ?-In many instances it is.

5275 . Must not that have a very ruinous effect on the lands of this country?Yes, I think so.

5276 . Will it not be also injurious to the poor to reduce them to potato food?-I do not know that; I think that the poor are as bealthy as they were.

5277 . If the potato crop fails, is there any thing to retreat on ?-No.

464 .

s s 3

5278 . If 
Mr. Wm. Summers.

25 March 1836 .

5278 . If the wheat crop failed, they could resort to other grain?-Yes.

5279 . Is not there, therefore, more danger of distress in case of famine?-Yes.

52 So. You would not, as a land-surveyor, and assisting gentlemen in purchasing landed property, advise them to allow their tenants to grow potatoes to any great extent, would you?-Certainly not.

5281. Up to what period of the year do the old potatoes last?-.Till August; the new potatoes come in in plenty. They have different sorts of potatoes now; they have the apple potato, as they call it, in our county.

$52 S_{2}$. They are very much deteriorated at this season of the year $:-Y e s$, but still they keep them pretty good.

$52 \mathrm{~S}_{3}$. What effect have the beer-shops had in your neighbourhood?-A very bad one; I think they have demoralized the poorer classes very much.

5284 . Has the allotment system contributed to the growth of potatoes?-- Yes. hood.

5285 . To any great degree? - Yes, to a very great degree in our neighbour-

5286 . Is the greatest occasion for the cultivation of potatoes that you have alluded to the poverty of the farmers?-Yes.

5287 . Do they keep more pigs under the allotment system than they used to do?-Yes. I think it is not so much the allotment system as the taking half an acre or a quarter of an acre of potatoes of their masters; that is the way they do it there; they all keep a little pig, and some two or three.

5288 . Do they keep the pig for their own consumption or for sale?--Sometimes they consume it; sometimes they do not.

5289 . Sonsetimes perhaps they keep more than one pig?---Yes.

5290 . Would the beer-shops be prevented, in some measure, by getting rid of the duty on malt?-Yes, I should think they would; it is not so much the beer-shops as the cider-shops in our county.

5291 . Would that also increase the growth of barley ?-I think the consumption of barley is greater since the beer-shops have been established than before.

5292 . Is the consumption of barley diminished by the heavy tax on malt?-No doubt it must be so.

5293. Is that an injury to the farmers?-Certainly, it must be.

5294. Have you any practical experience of fatting stock with malt?-No; no such thing is done with us.

5295. Do you ever fat with damaged wheat or damaged barley?-No. I think damaged wheat has been consumed in some few instances, but not worth mentioning; we have very fine grazing land in our neighbourhood.

5296 . You do not buy much oil-cake in your neighbourhood ?-No; all we grow is mangel-wurzel and swede turnips for grazing stock.

5297. Do you think flax would be cultivated to any considerable extent if the importation of it was prevented :-I think it would.

5298 . You think that would be a great advantage to the farmer?-Yes.

5299. Do you say the same as to hemp?-Yes; but that does not produce so mucli labour as flax.

5300. Do you recollect when there was a bounty on the growth of flax? - Yes. 5301. Was there more flax grown then?-Yes.

5302 . That bounty is taken off?-Yes, it is.

[The Witness is directed to withdraw.

Ordered, that this Committee be adjourned to the Second day after the Recess.

Die Lunæ, 9॰ Maii, 1836.

The Lord WYNFORD in the ChaIr.

James Pattison, Esq., a Member of the House of Commons, attending, is called in; and Examined, as follows:

J. Pattison, Esq. M.P.

9 May 1836.
5303. YOU are member for the city of London?-I am.

5304. And governor of the Bank ? - I am.

5305. How long have you been a Bank Director?-Since the year 1813. 5306 . Were 
5306. Were you a director during the year 1816, when Lord Liverpool's Bill passed? - I do not recollect the year; I think I was out by rotation in that ycar.

5307. You were then connected with the city of London and with the Bank? -Yes.

530S. Do you know whether there were any complaints among the merchants, at the time of the bringing in that Bill, of the inconvenience arising from the double standard? - I cannot recollect.

5309. If there had been any great complaint, so as to warrant such an alteration, you would have heard of it?-I think so.

5310. Do you think if any particular complaint had been made of the double standard, and any wish expressed by any considerable number of persons in the city that an alteration should be made in that respect, you should have heard of it:- Such complaints may have been made, and may have escaped ny recollection.

5311. You hare no recollection of such a circumstance - None whatercr.

5312. During the time that the Bank Restriction Bill was in operation, the alteration that was made in 1816 was in fact a dead letter?-I do not precisely remember the alteration in 1816 .

5313. You are, of course, aware that in 1816 the silver standard was put an end to? - l am not aware the silver standard was put an end to in 1810 ; in that year an Act passed, I believe, for a new silver coinage.

5314. Taking away the silver standard as long as the Bank Restriction Act was in operation, of course it could have no effect one way or the other :--I should presume not.

5315. How long was it after the Bank Restriction Act was repealed before the Bank were in difficulties, in consequence of the drain upon it?-The Bank experienced a serious pressure in 1825 , which the public is pcrfectly acquainted with.

5316. The Comnittee do not mean to insinuate that the Bank was in any serious difficulty, except the difficulty of getting gold on that run; were not they in great difficulty from not being able to fund gold in 1825 :-Undoubtedly; the fact is well known, as given in evidence before former Parliamentary Committees.

5317 . Had not some millions of gold been drawn out of the Bank very shortly before that, and sent abroad?-There were very large drains from abroad, in addition to large drains from the country.

5318. You have not the means of knowing that very large quantities were sent abroad at that time?-There is no doubt there must have been.

5319. How many millions do you suppose went abroad:- It is difficult to ascertain the amount, as no return to be depended on is made of the exportation of bullion.

5320 . Was not the quantity of gold drawn out at that time drawn out by a very few individuals? - I am not aware of it.

5321. To what amount was the gold in the Bank, in bullion and in coin, at that time reduced? - To a very small sum.

5322. To what amount?-Under, perhaps, somewhere about half a million; perhaps less; I am not certain at this moment.

5323. Perhaps you know the individual by whom it was bronght back in this country; was not a large sum paid him for bringing it back?-I am aware of who was the individual you allude to; he made a considerable profit by the transaction entrusted to him.

5324. Did not that individual receive from the Bank, in the shape of profit and commission, above $100,000 \mathrm{l}$. on that transaction $\mathrm{r}-\mathrm{I}$ have no doubt he did.

5325. The fact is, he was obliged to purchase the gold he brought back ?-He bought from all parts of the Continent.

5326. He bought it as merchandize :-Yes; and, in fact, bullion is merchandize.

5327 . It is merchandize when it is out of the country ?-Yes; and in the country it is merchandize.

5328. Are you allowed to melt the coin in this country:-Yes, per Act 59 Géorge III.

5329. It may be taken abroad:- Yes; but it is merchandize, because we buy and we sell bullion.

5330. You do not buy and sell coin? -We buy and sell foreign coin.

5331. Not English coin?-No; it passes for its current ralue.

464 .

J. Pattison, E.sq. M. $P$

9 May 1836 . 
J. Pullisou, Esq. M. P.

9 May 1836 .

5332. You may send abroad English coin as much as you think proper? -Yes.

5333. Was not the Bank in difficulties merely from a run for gold in some subsequent years? - Not in difficulties. When Lord Grey resigned, in the year 1832, there was a run for gold, and the Bank lost at that time from a million and a half to two millions.

5334. When you use the expression lost, do you mean entirely lost?-I mean withdrawn from our possession.

5335. Were you under the necessity of purchasing gold on that occasion :We never purchased gold but at the standard price.

$533^{6}$. Did not you pay more than that price in the year $1825:-Y e s$; we always buy gold at $3 l .17 \mathrm{~s} .9 \mathrm{~d}$.

$533 \%$. And you send it out as coin at $3 l$. i $7 s .10 \frac{x}{2} d . ?-W e$ send bar gold to the mint, and it is returned to us in coin.

5338 . So that it is worth $1 \frac{1}{2} d$. more in coin than it is in bullion?-Yes.

5339. You purchased in 1825 , and did you not again purchase in 1832 at a higher rate than $3 l .17 s .9 d . ?-W e$ paid more than $3 l .17 s .9 d$. per ounce for gold in 1825 , as the party employed was entitled to a commission for procuring it. In 1832 the Bank did not pay more than $3 l .17 s .9 d$. per ounce for gold.

5340. In fact there was nothing but the price and the commission?-That may be said to have been the case ; it was a very liberal commission.

$534 \mathrm{I}$. By the price you mean $3 l .17 s .9 d$., and by commission extra of that? -Yes.

5342. What was the commission upon the purchase - - Really I forget.

5343 . Would you have been under the same difficulty if you had had a double standard upon those occasions? - I should say so.

5344. Could they have removed silver with the same facility they removed gold? - Most certainly so.

5345 . Is not the difference of weight an objection to that ?-None, for foreign demand.

5346 . Could you get back gold with the same facility as you could silver :If weight has any thing to do with it, we may suppose we should get gold easier in that mode; there is gold, but there is no silver to be had.

5347. Suppose a person had 100,000 livrès due in France, could not he require the payment in silver? - Yes.

5348 . Could he require the payment in gold? -No; he may generally procure gold by paying the agio.

5349. That agio is just what they please to put on, is it not?-The agio varies according to the supply and demand in foreign countries.

5350. What does that depend on ?-The demand for gold.

5351 . Consequentiy the debtor in France must pay the 1,000 livres in silver; but what he will have to pay in gold must depend upon the fluctuations of the exchange?-Certainly; or rather by the price of gold, which is known by the agio.

5352. Are you quite sure you can force him to pay in gold; have they not a right to say, "You may force me to pay in silver, but I will pay in goid if I please" ?- I believe he may force him to pay in gold.

5353. Supposing the fact to be that you cannot force him to pay in gold, the man owing his debt in silver, cannot you get the one more easily than you can the other ? - Yes.

5354. Is not it the case that the silver standard prevails all over Europe?I believe so.

53.5. Can you compel the payment of a debt in any country in Europe, from Gibraltar to the northern part of Sweden, in any thing but in silver?-I am not aware that you can.

5356. Then is it not self-evident that you can get the silver here with much greater facility than you can gold:-No, I do not allow that; for if I want gold I shall have that gold only in case it answers my purpose to pay for it; if I had a bill on Paris I should not bring home the amount either in silver or gold, because the exchanges are farourable to this country, therefore I should not have a return in either of these metals.

$535 \%$. You can enforce the payment of it in silver?-Yes.

5358 . Does not that also fluctuate according to the cxchange?-It does. 
5359. How is it possible, that being so, to say you can get the one with the same facility as the other?-There is, I believe, an agio upon the silver. The price of silver varies.

5360 . Has not that reason been given why a standard in silver here is desirable. by all the writers upon the subject, from Mr. Locke down to the present time?My own opinion is that it would be very unwise to change the standard.

5361 . Do you think it would be possible to go on witl a single gold standard for three weeks, if there was a bad liarvest or a war?-That is matter of opinion ; I should hope it would be possible to go on, but we have never yet been tried. I am pretty confident we should perhaps be put to sone inconvenience, but still I do not sce why we slrould not he able to meet the circumstances.

5362. Must you not be brought to a stoppage of payment?-I do not see why that should necessarily follow.

5363. What are your liabilities at this moment :-A bout $32,000,000 \mathrm{l}$.

5.364 . That does not include what you would be bound to pay, the $20,000,000 l$. for the savings banks? - We are not liable for the savings banks.

5365. The Government must find the money for them ?-The Bank has nothing to do with them.

5366. If there was a demand from the savings banks, and money was not ready to pay them by the Bank or the Government, would that not create very considerable alarm in the country ?-The Bank may just as well be called on to pay the whole national debt in gold ; the savings banks' money form a part of that debt. A change of the standard, in my opinion, would make no difference.

5367 . Only that you would have money to pay ?--I see no difference.

5368 . Would not your quantity of silver be very much increased if silver was the standard? - I see no reason why, unless the standard price was high.

$536 y$. How much silver had you in the Bank when silver was the standard? Silver has not been the standard in my recollection.

5370 . Was not it considerably greater than it is now ?-I have no recollection of the circumstance.

5371. It is of no use now but to find small change, is it?-The silver coin is used as small change. We are always glad to purchase silver bullion; from the year 1830 to 1834 the Bank bought from $3,000,000 l$. to $4,000,000 l$. of silver.

5372 . How much does it hold now ? - About lialf a million.

5373. It is found of no use but for any small transactions?-The silver coin is used for small transactions.

5374. Can you give a statement of the amount of silver the Bank held between 1830 and 1834?-Between the month of August 1830 and October 1834 the Bank purchased about 3,500,000 $\mathrm{l}$. of silver.

5375. How nuch did they hold at that time?-The amount must have varied.

5376 . What, at the same period, was the amount of your bullion?-I cannot recollect.

$537 \%$. In the year 1834 had you commenced the present system of publishing the accounts?-We commenced that, I think, in August 1834, under the present charter.

5378 . Can you state what is the amount of gold you have now? - I think we have about 7,600,000l. of bullion, of which $500,000 l$. is silver.

5379: You have about 7,000,000l. of bullion?-Yes.

73 So. That is to pay $32,000,000 l$. of liabilities? - To pay those notes for which payment may be demanded.

5381 . Have not the holders of those liabilities, whether in the shape of deposit or in the shape of notes, a right to call upon the Bank any day and say, "Give us gold"? - There is not the least doubt we are bound to pay our notes in gold; but as our liabilities decrease, and our notes become scarce, so will the demand for gold decrease.

5382 . Then will they become scarce without being paid off?-As the Bank's circulation is diminished the notes are paid off.

5383 . How are you to reduce the notes without paying them off?-By reducing our securities the notes are paid off.

5384 . You cannot get gold by the sale of them ?-The effect of a reduction of our circulation by the sale of securities will influence the exchanges and bring bullion.

5385 . Are you not every moment liable to be placed in the situation in which you must stop payment, and in which it is impossible for you to pay $4 s$. in the

J. Pattison, Esq. M. P.

9 May 1836 . 
J. Pattison, Esq. pound? - I should say certainly not, unless it could be contemplated that the

Y.P.

9 May 1836 . public would demand payment of the whole amount of the Bank's liabilities in a very short time; in such a case we must stop payment, but I should say such an event is impossible to occur.

5386. Could it increase its silver faster than its gold? - That depends on the supply and demand in the foreign markets; silver has varied much in value.

5387 . What has occasioned that variation ?-The demand for it.

5388 . Was not it usual for you to hold $10,000,000 \mathrm{l}$. of bullion, gold and silver?-There has been no regular system as to what amount we should keep.

53 $\mathrm{Sg}$. Was not it the practice of the Bank to keep about 10,000,000 l.?-No; there was never any practice determined on that might not be influenced by circumstances.

5390. Do not all bankers think it safe to hold about one-third of their liabilities in bank notes or in money?-I am not arware of it.

5391. Do you think any bank is safe without that?-The management of a private bank may be considered on a very different footing from that of a state bank like the Bank of England.

5392. Do you think any bank safe which had not that proportion in bank notes or gold? - I know nothing of the management of private banks.

53.93. Do they not profess to keep that proportion?-I am not aware of it.

5394. Are you aware that gold has been rendered much more scarce in Europe, in consequence of what has taken place in America?-I have no doubt that America has taken a considerable sum of gold from Europe; this has arisen from America altering the value of it.

5395. Do not you think America has taken to the extent of $3,000,000 l$. ? I have endeavoured to get information through various channels. I think it cannot amount to that sum.

5396. Has not Portugal had some operations which have diminished the quantity of gold in Great Britain?-So it has been stated. I have heard of gold being sent lately to Portugal, and returned by the next packet.

5397. That is the case with all countries?-Yes.

5398. Has not Portugal drawn away a great deal, which she has kept there for use in her coinage?-It may be so. The demand for silver from abroad got the price up materially.

5399. Did not what was done in America get up the price of gold more?-As long as the Bank pays in gold, and the present laws exist, the price in this country cannot well exceed $3 l .17 s .10 \frac{1}{2} l$. per ounce.

5400. Did you see the Report of the Committee of the American Congress, upon which that alteration was made?-I do not remember it at this moment.

5401 . Do you not know that all which was done in America was done with a view to the bringing gold there?-I am perfectly aware of it.

5402. You cannot pay more than $5 s .2 \mathrm{~d}$. per ounce for silver, and $3 l .17 \mathrm{s.10d}$. per ounce for gold?-There is no limit to the price the Bank may pay for bullion.

5403. The mint cannot?-I speak of the Bank.

5404. You do not take silver to be coined unless you take it there at $5 s .2 d$. an ounce - - We have never taken silver to be coined; the Government holds the silver coinage in its own hand.

5405. May not a great profit be made on gold by individuals coining?-No; it does not answer, or the dealer in bullion would send gold to be coined.

5406. Do you not know that they do it ? - I believe not.

5407. The merchant may get it minted, and get sovereigns for it?-Yes; but it does not answer to the merchant.

5408. Would it not answer very well, if the price of gold got up to $4 l$. an ounce, to send guineas out of the country and melt them down?-There is no doubt if the exchanges enhanced the price of gold to $4 l$. an ounce, gold would go out of this country.

5409. There would be a profit of something more than 10 per cent?-The profit would be in the difference between $3 l .17 s .10 \frac{1}{2} d$. and $4 . l$. per ounce.

5410. Altering the value of coin, for the purpose of enabling the trader to pay his debt, would be no doubt a scandalous fraud on the creditor; but would not the putting a proper seignorage on gold, to prevent that ever happening, be a wise thing? - It night be so, if it could be effected without altering the value of the coin. 
5411. Are you not aware that that has been recommended by a great number of persons? - It may have been so recommended.

J. Pattison, Esq. M. P.

9 May 1836 .

"Give me 100,000 sovereigns for them"? -No doubt.

5413. I suppose gold to be at the price of $4 l$. an ounce; would he not make a profit upon that of about 11 per cent., without any risk?-He would get the difference of the value between $3 l .17 \mathrm{~s} .10 \frac{1}{2} d$. and $4 l$.

5414. Does it not appear to you most absurd to have a practice which exposes the country to such fraud as that?-I do not see any absurdity in it ; on the contrary, I think it would be unwise to alter the system.

5415. What possible objection could there be to that?-The objection would be, that by increasing the value of gold you will enhance the value of every thing for a time, without rendering any lasting service to the state.

5416. Do you think we should suffer from rise of prices?-Any considerable rise in price is generally followed by a fall in the exchanges, and all may suffer in consequence.

5417. Is it possible that gold can get up above $3 \mathrm{l}$. $17 \mathrm{~s}$. $10 \mathrm{l} \mathrm{d}$. as long as the Bank is open for payment of gold?-It cannot.

5418. Has that never happened ?-I should say, not since the return to cash payments.

5419. It cannot happen as long as the Bank pays in specie ?-It cannot. The Bank pays its notes on demand in gold, the standard value of which is fixed by law at $3 l .17 s .10 \frac{1}{d} d$. In my time the exchange has much varied; I remember being in Paris when I only got $\mathbf{1 6}$ francs, or thereabouts, for my pound sterling.

5420 . Would it not happen to-morrow, if there was a great demand for gold on the the Continent? - If the exehanges are against this country there will be a demand for gold; quiet measures must then be taken to correct them.

5421. Did not those quiet measures operate very much to a diminution of the circulating medium of the country and a reduction of prices $:-$ Whenever circumstances require the Bank to take these measures the circulation would necessarily be diminished, and a reduction of prices most probably follow.

5422. Have not, in consequence of what you have done, the country banks also diminished their circulation; and has that not altogether occasioned a stagnation in the circulation of the country, which has very much lowered prices? -The returns to Parliament a few days ago prove the contrary; for during the last six months the increase has been a million in the country banks' circulation.

5423. Has not that been owing to the joint-stock banks ?-It appears that a part is to be attributed to the joint-stock banks, and a part to private bankers.

5424. Is it not to be attributed to the Bank of England ?-No.

5425. The Bank of England have been drawing in, have they not?-Our periodical returns show the transactions of the Bank.

5426. The Bank of England now are running counter to the joint-stock banks and country banks, are they not?-No. We are observing them with considerable anxiety, and as there is no legislative control over their issues as over those of the Bank of England, the Bank is cautious how it extends its issues at the present time, seeing the country circulation is increased by a million, and the bullion leaving the country.

5427. Has that fear of putting forth an increased circulation produced the present fluctuation of prices, and is not that injurious to the country ?-The action of the Bank is to prevent fluctuation.

5428 . Would not the mode for obtaining that regular system of prices be to have such a standard for the circulation of the country as the Bank of England may proceed upon without a continual fear of a run, and every other institution which issues paper may proceed upon with seeurity, under the present circumstances? - I am not at all aware what change of standard could possibly secure such a position.

5429. Would not adding silver increase the base on which the circulation rests?-I do not think the adding silver to the circulation would much facilitate this end.

5430. How do you account for the great fall in prices since 1820 ?-Owing to the change from a paper to a joint metallic and paper circulation.

5431. Though it would not be wise to return again to a paper circulation, would it not relieve the country from the difficulties under which it labours to 464. 
J. Puttisun, Esq. get back to that, as nearly as it can be done with safety?-I do not see how it ง. P. is to be effected.

5432. Do you not think it will add to the excitement if debtors are called 9 May 1336 upon to pay their debts in a coin they cannot get?-I cannot allow it is a coin they camnot get; the Bank can meet its engagements with a metallic currency.

5433. Is that circulation being contracted a great loss to the country? - It would cause a fall in prices.

5434. Do you not think that as far as you conld go, not meaning without limit, but as far as you could with safety enlarge our currency, having a circulating mediun to rest on, that would bring back the prices to the level that they ought to be ?-It is difficult to decide what the level of prices ought to be. In my opinion prices are now generally too high.

5435. You think the prices too high? -I do.

5436 . How long has it been so high ? - The rise has been most considerable since Christmas.

5437. What was it last year?-I think, upon the whole, we were then in a more satisfactory state; there was less to be apprehended from re-action.

5438 . You think it the more healthy the lower the prices?-A regular state of prices is most desirable.

5439. Do you think they were sufficiently high two or three years ago, or last year?-Last year I conceive the price of most articles was high enough; but prices must depend on the supply and demand.

5440. You are not acquainted with the price of agricultural articles?-I know little about agricultural articles. I had entertained an opinion that the cry of distress was exaggerated. This opinion was somewhat confirmed some months ago by a gentleman living in the centre of an agricultural district, who expressed the same doubts.

5441. Was he a considerable land-owner?-No; he was a country banker. He stated that distress, in his opinion, was exaggerated, and arose from various causes, and not enterely to be attributed to the distress of the farmer, caused by low prices.

5442. In what country did he live?-In Oxfordshire.

5443. You understood from him the farmers were there in a very flourishing condition?-He did not consider that there was so much distress among them as represented.

5444. Did he state that the bankers lent their money freely to farmers there? -I did not ask him the question.

5445. Would there be any limit to the excess to which paper currency might go, were it not for the liability to pay in some metallic standard?-There could be no limit whatever.

5446 . Nor consequently any limit to momentary prices arising therefrom?None whatever.

5447 . In the choice of a metallic standard, would not the value of that standard depend upon its certainty in holding its precise state ?-I imagine so.

5448 . The question is, whether a standard least liable to a fluctuating state would not be the best to regulate the currency?-I should say so.

5449. As the Bank is obliged to keep a certain proportion of gold locked up in its coffers, in reference to the amount of its currency, a part of that would be in silver if it were a joint cursency?-Certainly, as is the case now at times.

5450. Would not an increased importation of gold into this country take place without any exertion on the part of the Bank within a short limited time after any diminution of currency which affected the general rate of prices?-Undoubtedly, in ordinary times.

5451. Then such exertion upon the part of the Bank at a period of sudden emergency might be only an anticipation for its own convenience of that which would necessarily take place in the ordinary eourse of things? - Not for its own convenience, but its own security.

5452. Would the checking the excessive circulation of paper be better effected by a gold standard than by a silver standard?-I see no difference; all depends on the value of bullion.

5453. The general opinion is to the contrary; that there is more ease in obtaining silver:- That has not been the case of late; silver has varied in price during last year to the extent of $3 \frac{1}{4}$ per cent.

5454. When 
5454. When you say silver has varied in price, when you buy silver here you pay for it in gold ?- Yes.

5455. As it is silver which is bought, and a gold price paid for it, what means have you of knowing, the gold being in exchange for silver, whether it is the silver or the gold which has changed its value; it may be that the change has take place in the other metal, the exchange being of the one metal for the other? -It may be so.

5456 . Then there is no certainty when an alteration takes place in the price of silver that the alteration may not be in the metal given in exchange for it? - The relative price of the metals varies, and depends on the respective demand for each.

5457. That might appear by the price of silver in other countries, where the legal standard is not in gold ?-Prices vary every where. The merchant will export whichever metal answers his purpose best.

5458 . That will show what the variation in the price of silver is ?-Yes.

5459. Silver in countries where silver is the legal standard, and gold in countries where gold is the legal standard, cannot materially vary in price. Silver, for instance, at Hamburgh, cannot much alter in price?-That must depend on the demand.

5460. If in France a man buys silver, or if in Hamburgh a man buys silver, he pays for it in silver; if in England a man buys gold, for which he pays in gold, where the coin is upon a sound system, there is no possibility of such variation in any country of that metal which is the legal standard of that country :1 should say so.

5461 . 'That was the old standard of this country; gold and silver, at the option of the person paying? - That must have been at a very distant period.

546.2. Can you by any reasoning draw any inference, that what is supposed to have been the distressed state of agriculture through the country, can have originated from any circumstance connected with the currency ? - I cannot in any way see what effect that can have had upon it.

5463. You cannot by reasoning upon the subject see that it has originated from any peculiar state of the currency or the circulation ?-I am not aware of it.

5464. Do you think it probable if the circulation had done any mischief, it would have selected the operations of the farmers, and left in a state of prosperity other classes?-I think it would have affected all alike; if one class had been affected by its influence, it must have affected others.

5465 . Still more do you see any reason why, affecting the condition of the farmers, it should have left the wheat low, and wool and barley, and other things high?-I see none.

5466 . When articles generally rise or generally fall, do you not then naturally lonk for some possible causes in the state of the currency; but when some particular articles rise, and others are kept low, then is it not presumable that the variation is in circumstances connected with the articles themselves, and not referable to the circulating medium ?-Most certainly.

$546 \%$. If the fact turned out to be that in considering the condition of the farmer, the single article of the low price of which he has principally had to complain is wheat, and that of other articles some have maintained regular, and many of them fair prices, should not you come to the conclusion that the low price of wheat was something connected with the relative state of the consumption and production of the article, and not from any causes connected with the currency?-Such would be my conclusion.

5468 . You have stated that the great fall of prices in 1819 was owing to the change from a paper circulation to a sound metallic circulation; how do you reconcile that opinion, which applied to agricultural as well as to all commercial dealings, with the answers you have just given?-I conceive that the change in 1819 was a great state change, the object being to return to a metallic currency. A fall in prices was the consequence of the change. The answers just given have reference to the present time.

5469 . Do you think you have now any thing like a completely metallic currency - Our currency is a mixed one, metallic and paper; the latter convertible on demand into the former, which renders the currency as nearly a metallic one as could be well devised.

5470 . In point of fact, in 1819 there was a great fall of prices affecting articles of every description? - In 1819 and subsequent years.

464 .

T T 3

5471 . When 
J. Paltison, Esil. M. P.

9 May 1836 .

5471 . When you state, as you have stated, that at one period you might buy a pound sterling in France for 16 and 17 francs, and you now buy the same pound sterling for 26 francs, does not it necessarily follow that a depreciation, though not exactly corresponding, pretty generally corresponding, with that must have taken place in the value of all things for which the depreciated paper was exchanged?-Undoubtedly.

5472 . Do not you consider that, in a great financial country like this, nothing could be more fatal to its credit and its prosperity than changes in the standard of value by which every thing is measured?-Most assuredly.

5473. If any apprehension were entertained that Parliament would be disposed to such changes, would it not disturb the relations in this country, if not in every part of the world ?-Most undoubtedly it would.

5474. Do you not conceive that a change, even to any system you might think more perfect, is for that reason most undesirable ?-That is my opinion.

5475. Have you any objection to state your own private opinion, whether it was a mistake originally to have adopted the gold standard? - We have had the practical experience of the one and not of the other, and I do not see how an opinion adverse to a gold standard can be offered. Silver appears to vary much in value, perhaps more than gold; that would not occur to the same extent where silver was the standard, as a fixed value by law would be put on silver.

5476 . What reason have you to know that it is the one that varies least, when you exchange the one for the other?-I have already stated silver has varied during the last year $3 \frac{1}{4}$ per cent.

5477. Does not the greater proportion of silver from the mines pass through this country to those countries where it is used as a standard, with the exception of that used for ornamental articles:- - All depends upon the demand.

5478 . When you speak of the Bank holding so large a sum as $3,500,000 \ell$. of silver, it must necessarily be for the purpose of sending it abroad? - We retain our silver till the exchanges take a turn, and the demand for it occasioned thereby.

5479. The object of the Bank in holding it is for transactions on any turn of the exchanges against you?--Precisely so.

5480 . The return you make of bullion, which is published of course, includes both silver and gold ?-It does.

$54 \mathrm{~S}$. You say, in the year 1834 , you had as much as $3,500,000 \mathrm{l}$. in silver; are you generally holders of any thing like that amount:--I never stated, to the best of my recollection, that the Bank held, in $1834,3,500,000 \mathrm{l}$. of silver bullion; I believe I said we purchased that amount from 1830 to 1834 .

5482 . You state the present amount of bullion to be about $7,600,000 \mathrm{l}$. are you aware that it is, according to some of the returns, so low as $6,000,000 \mathrm{l}$. ?-()ur returns are correct; this time twelremonth we had about $6,000,000 l$. of bullion.

5483 . And that must have included a portion of silver bullion?-A very small portion at one time.

548 . When your whole amount of specie was reduced to $6,000,000 l$. had you as much as $500,000 l$. in silver?-I think not. We have about $500,000 l$. now.

5485 . That is distributed among all your various branches? - We have only silver coin at our branches, which is a small portion of our silver.

5486 . Suppose your whole bullion reduced to $6,000,000 /$. that would include whatever you had in London and all your branches:-Yes; in our branches we have generally about $1,000,000 \mathrm{l}$.

5487 . That reduces your amount in London to about $5,000,000 l$. which would undergo the reduction of any amount of silver you held, but which you say was small?-Yes.

$54 \mathrm{~S} 8$. Your deposit in London must be under $5,000,000 \mathrm{l}$. on which your basis of $32,000,000 \%$. of liabilities is built? - Not precisely so, A portion of our liabilities are the issues of our branches, therefore the bullion we have in our country establishments would meet those liabilities.

5489 . In case the Bank is under any apprehension that its stock of bullion is not in due proportion, they should wish to reduce the amount of its liabilities; you have explained the manner in which that difficulty is adjusted, by reducing your circulation and crcating what is called a scarcity?-Certainly.

5490. Is it not very desirable in a country like this that the fluctuations of money or those fluctuations of scarcity and plenty, should not be often produced by the operations of the Bank, over which the general mass of the industrious 
classes of the country can have no control?-Most assuredly. It is the anxious wish of the liank through their management to avoid fluctuation.

5491. Is it not desirable those operations upon the plenty or scarcity of money should be as little resorted to as possible?-Undoubterly, and would only be acted on by the Bank when it is forced on its management.

5492. Is it not the case, that while liabilitics exist, any operations arising from plenty, when they are suddenly drawn up by restrictive operations of the standard, do great injury?-They must cause a fall in prices.

5493. It is therefore desirable for tle country to kcep the amount of circulation, and consequently the value of money, as steadily as possible?-I should say it is highly desirable.

5494. Supposing the Bank's amount of bullion had come down to 5,000,000l, and you wanted to replenish it, do not you think you should have easier means of doing it, if it were open to you to do it by both metals, instead of being restricted to the one, the question not being applied to the propriety of making that alteration now; but would not those fluctuations of money be less intense and less frequent if you could have recourse to two metals instead of being restricted to one ?-In my opinion we cannot be said to be restricted to one metal, for though silver is not the standard by law in the country, it has an influence upon the exclianges when sold as bullion, and answers almost every purpose of a second metal.

5495. It becomes to you a merchandize, by which you can sell and purchase gold abroad ?-Precisely so.

5496 . Is not the gold sometimes to a very limited amount in different parts of the country. Supposing you had silver as a standard, you might use the identical silver for payment which you now use for procuring the metal with which you make payment?- - Silver might, assuredly, be used as stated; but I very much question whether the country would like to be embarrassed by large payments in silver. Silver bullion can generally purchase gold on the Continent.

5497. That is the case when the metal is wanted to ship abroad for the adjustment of the exchanges? - Yes.

$549^{8}$. When you had the $3,500,000 \mathrm{l}$. of silver, if your stock of gold had been low, though you had this amount of silver, not being able to reckon upon it as not being the legal standard, should you not have been obliged to make the same reduction of circulation as if you liad not any silver in your coffers at all?-Assuredly not. I cannot imagine a period to arrive when the Bank would hold a large stock of silver and a small stock of gold.

5499. You recollect the circumstances of the year 1825 ? - Yes.

5500 . Had you not then a very large amount of gold, and in addition to that a very considerable amount in silver?-In the early part of 1825 the Bank held a considerable amount of bullion.

5501. You had a larger amount in gold than in silver ?-Most assuredly.

5502. Are there not frequently political operations which draw gold, owing to its greater facility of conveyance as compared to silver; do not sudden wars in the east, for instance, cause it to be sent to those countries, or to countries in the condition in which the north of Spain is at present?-That may certainly happen.

5503. Whenever in any part of Europe a sudden demand arises for gold, the Bank of England is the only place to which they can have recourse for any quantity? - No. The price of gold on the Continent is the best criterion of the stock there; whenever the agio is high, it is to be presumed it is scarce in the place or country where that is the case.

5504. If matters are in a state of insecurity in any part of Europe, persons, you think, hoard gold in preference to silver?-Yes.

5505 . In that case, is not London the only market in which they would be quite sure of finding it? -I do no not see why this should be the case; a state of insecurity always causes hoarding.

5506 . If an individual has a bill in pounds sterling, and makes a demand for gold, the Bank, in those difficulties which exist, if it takes a bill on Paris or Hamburgh or Amsterdam, has no certainty of getting gold, but it has a certainty of getting silver for it?-Yes.

5507 . Do not you think that the Bank, under those circumstances of difficulty, if it took a bill on any foreign country, would feel a greater facility in the event of any difficulty in being able to take either metal for circulation?-The Bank 464 . 


\section{$33^{6}$ MINUTES OF EVIDENCE BEFORE SELECT COMMITTEE}

J. Paltison, Esq. N. P.

9 May 1836.

does not negociate foreign bills of exchange. It becomes the purchaser or the seller of bullion according to the state of the exchanges.

5508 . Were you not, in the year 1825 , though you did not take bills yourself, obliged to have recourse to an individual who took the Bank silver and bought the Bank gold; and did not the Bank get just as much or as little gold as it was the interest of that individual, with a certain profit to himself, to furnish? - After the crisis of 1825 the Bank made arrangements with the individual alluded to, and to facilitate the object in view, which was one of necessity, unusual means were resorted to. It was not to be expected that he would act as the Bank's agent without a liberal commission, particularly when it is considered he had to procure gold from every part of Europe.

5509. Would you have been so likely to have been in that state of necessity if you could have paid in silver :-During a panic a payment in silver would have retarded the drain, as a man cannot carry away with him so much silver as gold.

5510 . Has it not been found that it has saved the Bank in former times to your knowledge? -I never heard of it.

5511 . If you had $12,000,000 \mathrm{l}$. of gold in the Bank, you would be able to stand out longer than if you had $6,000,000 l$. ? - I suppose we should.

5512 . If you had $6,000,000 \mathrm{l}$. in silver, in addition to $6,000,000 \mathrm{l}$. of gold, if that silver could be paid instantly, without sending it round by France to alter the exchanges, would not it just as well answer as to have the 12,000,000l. in gold? - There is no doubt of it.

5513 . Now, if the $12,000,000 \mathrm{l}$. would save you longer than $6,000,000 \mathrm{l}$, would it be of any consequence in which metal it was, if each was a legal standard :None whatever.

5514. Will not the $12,000,000 \mathrm{l}$. be longer in drawing out than the $6,000,000 \mathrm{l}$ ? -Of course it would.

5515. Would you not be longer in paying in silver than gold, and has not silver sometimes been resorted to in consequence -There is not the least doubt that it would take longer time in paying in silver than gold. I do not believe silver was ever resorted to to prevent an internal run for gold.

$55 \mathrm{I} 6$. Have you any doubt that the contraction of the currency in the year 1819 reduced all prices? - I believe that the alteration of the currency had an effect on prices.

5517. Was not that effect, then, most injurious to the people of this country in general at that time?-I believe all classes sulfered. In my opinion it became imperative on the Legislature to effect the change. If the change had not been effected in 1819 , the state would have been called upon to do it at a later period, which would only have procrastinated the change, without any benefit to arise therefrom.

5518 . Would you not have been called upon to do it under nore difficult circumstances? - That might have been the case.

5519. Do you think that you could have been called upon to do it in more difficult circumstances than you were? - There was a preparation for it, and more difficult circumstances might have presented themselves.

5520 . Do you think there was the preparation there ought to have been when the debts of the country were increased to so enormous an extent?-The Legislature determined the course to be taken, and I am one who must think they determined wisely.

5521. Did they not find they had gone too far, and push out paper immediately afterwards, or call upon the Bank to do it, Lord Londonderry declaring in the House of Commons it was impossible to go on without?-I am not aware of it; I do not recollect the circumstance alluded to.

5522 . Has there been no departure from the metallic standard then established since?-No.

5523. Has not the effect of making that metallic standard been in some measure removed by issuing a great quantity of one-pound and two-pound notcs? -In England one-pound and two-pound notes are not issued.

5524. Was there not a box of one-pound and two-pound notes found in the Bank, and were not they pushed out?-That was in 1825 .

5525. That was an act of the Bank $;-$ Yes.

5526 . You stated that the effect of the panic you think has been done away; do not prices fluctuate up and down according to circuinstances?-Prices depend upon the supply and demand. 
5527. Is there any doubt that if there is a great scarcity of moncy that will lower the price of all articles? - lt would influence prices generally.

$552 \mathrm{~S}$. Will not the fall be counteracted with reference to particular articles if there be a great scarcity of that one article?-A scarcity of any one article might be excepted from the general influence.

5529. That will be counteracted by the deficiency of supply of any article?I think so.

5530. Though all other articles may keep down, that one will rise?-Yes; there may be a short supply and a large demand for that article.

5531. Was not that the reason why the prices of oats and barley and of cattle were apparently high when the prices of wheat were low, that there were bad crops of those articles when there were good crops of wheat?-I should say so.

5532. You have stated that deficiency of currency would lower the price of all articles?-A deficiency of circulation would, I conceive, have that influence on prices.

5533. Have you any doubt that the wheat and harley and oats bore different rates of prices in consequence of being depressed by the want of currency; but that in consequence of the deficiency of supply of barley and oats occasioned by bad harvests they fetched higher prices in proportion to wheat, of which there was a full supply? - The abundance or shortness of supply occasioned by good or bad harvests of different sorts of corn inust affect their prices; a want of currency would, of course, have its influence.

5534. Supposing there is a fair average quantity of wheat, will not the wheat, with a fair average quantity, be kept down by the want of currency, while barley and oats will rise in consequence of bad harvests?-That might occur.

5535. Is there any doubt that is always the case ?-It is the case with every article of prodnce.

55.36. Have you not found that all articles are pressed down by the diminution of the circulating medium, but some more than others, in consequence of deficient supply? - If the circulation is diminished, most, if not all, articles would be affected; some more than others, according to the supply and demand.

5537. If one article only is depressed whilst almost every article sustains its price, is not the inference that that particular article is affected entirely by the alteration of supply and demand?-I should say so.

$553 \mathrm{~S}$. Take the opposite side, that all articles are diminished, except a few, is not the price of those few kept up by the deficient supply, and should you argue that the price of others was kept down by the effect of the depression of the circulating medium?-I should say so.

5539. You state that if we had not done what we did in 1819 it must have been done since; do you think after the experiment has been made, supposing you had known what the effects would have been, the Bill of 1819 ought to have been carried into effect as strictly as it was at that time, or whenever the time came?-I conceive that, as the Legislature had determined on a return to a metallic currency, we were bound, in justice to the whole state, to carry that determination of the Legislature into its fullest effect. If that law had been altered, it would have only been tampering with the currency and trifling with the property of individuals.

5540. You think, from what you have seen, it ought not to have been nitigated? - I do not see how it could have been mitigated without doing acts, of injustice.

5541. You say the Legislature having determined; do you think that it was just in the Legislature so to determine without more preparation?-The Legislature determined what preparation it conceived was necessary, and having so determined, it would have been unjust to have altered that decision.

5542. You have stated that you were disposed to think, upon the whole, the measure of 1816 , for the establishment of a gold standard, was a wise measure :I think it was the best measure that could have been adopted.

5543. Was that always your opinion?-Many individuals were at first startled at the change, and I may have been among the alarmists; I may likewise have entertained doubts about the standard.

464 .

I U

5.544. Were
I'allison, lisin. M. $\mathrm{r}$.

9 May 1836 . 
J. Pattison, Esq. s. P.

9 May 1836 .

5544. Were you ever called upon to give evidence on that subject?-No, never.

5545. The directors, as directors, have never given any opinion on that subject? - They may have given an opinion, but I do not immediately recollect it.

[The Witness withdraws.

Ordered, That this Committee be adjourned to Thursday next, One o'clock.

Die Jovis, $2^{\circ}$ Junii, 1836.

The Lord WYNFORD in the ChaIk.

A. Attwood, Esq. M. P.

2 June 1836 .
Matthias Attwood, Esq., a Member of The House of Commons, attending, is Examined as follows :

5546. YOU are a Member of Parliament and a banker :-I am.

5547. Of course you are acquainted with the question of currency? -I have paid attention at various times to that subject.

5548 . Have you turned your attention to the effect of the restoration of a silver standard :- - The restoration, according to the old inetal coinage of the country, of a silver standard, would have the effect of producing an advance which may be taken at from four to six per cent. (to speak shortly, five per cent.) upon the rate of agricultural and all other prices. I apprehend upon that point there would be no difference of opinion whatever amongst parties who have paid attention to subjects of this nature. The old silver standard is silver money of $5 s .2 d$. an ounce. The price of silver in the market has been for the last ten years from $4 s .10 d$. to $5 s$., which, taking the average at $4 s .11 d$, gives a difference of $3 d$. in the ounce between silver in the market and silver in coin, which is precisely five per cent. 'l'he old standard, if now re-established, would give an advance corresponding with this difference, viz. an advance of six per cent. on agricultural and on all prices. It may be stated shortly, and I imagine would be universally admitted, that if in 1819 the old standard had been established, every bushel of wheat which has been sold since that time would have yielded an advance which may be taken at five per cent. above the price which it has actually produced; that in consequence of the Act of 1819 introducing a new standard, and not the old standard of the country which it professed to introduce, every bushel of wheat which has been since sold has sold for five per cent. less than it would have fetched if the old standard had been established.

5549. By the old standard you mean of silver at $5 s .2 d$. an ounce instead of what it is at present ; the cutting a pound of silver into $62 \mathrm{~s}$. instead of $66 \mathrm{~s}$. ?-By the old standard I mean silver coined at the rate of $5 s .2 d$. the ounce, and made a legal tender at that rate, which was the legal standard from the reign of Queen Elizabeth down to the two Acts of 1816 and 1829, which abolished silver money as a legal tender.

5.550. What difference would it make establishing again the silver standard, and taking $66 \mathrm{~s}$. out of each pound of silver instead of $62 \mathrm{~s}$. ?-It would make a difference of about six per cent. more. The present silver coin established as a legal tender would enhance the prices of agricultural produce, and all other prices, to the extent of about six per cent. beyond that which the old silver at $5 s .2 d$. would establish; it would thus give an advance altogether of 11 per cent. beyond that which can be sustained under the present monetary system.

5551 . How much were prices depressed by the law of 1819 ?-The law of 1819 , which substituted a gold standard alone, in the place of a conjoint gold and silver standard, which had been the original standard of the country, and also in the place of that paper standard which had then existed for more than 22 years, occasioned a fall of prices in agricultural produce far beyond that which I have stated as depending upon the difference between the silver standard and the gold standard. I apprehend that the law of 1819 has fixed in this country a permanent price for agricultural produce at least as low as any that it has yet 
reached, and probably one considerably lower. The law of 1819 introduced a description of money and a standard of value which had been suspended for more than 20 years. If it were desired to ascertain what rate of prices this money would sustain, and what measure of property that standard would give, I know no better method of arriving at a correct judgment upon those points than to have recourse to the guidance experience would give us. We have introduced a new species of money, a new standard of value; to know its effect we must look to the time when that standard existed before. It is money composed of the precious metals which we have now established. The value of the precious metals can never vary materially between one country and another. Unless we find the precious metals, then, to have altered on the Continent, and higher prices of agricultural produce to exist in the countries around us than cxisted 40 or 50 years back, there can be no reason for believing that higher prices of agricultural produce can exist in this country, measured in the money we have now established, than existed before the period of the Bank Suspension Act. Reasoning is worthless on a subject of this nature. I have here a table of the price of the principal articles of agricultural produce in this country (taken from a Report of a Committee of The House of Commons on the Corn Trade) for 30 years previous to the Bank Restriction Act, divided into average periods of five years, and I know no better guide. Corn particularly, and all agricultural produce, though subject to great variations in price from one year to another, and from year to year, is remarkably steady in money price, taken at short average periods. Even for periods so short as five years, corn rarely varies greatly, except when alterations have taken place in the standard of value in which it is measured. From this table, giving the experience of 30 years, ending in 1794, divided into average periods of five years, it will be seen that there is no period of five years in which the price of wheat fell below $40 s .9 d$. a quarter, or advanced above $47 \mathrm{~s}$. $10 \mathrm{~d}$. a quarter. There can be no valid reason for believing that, under the present system of cash payments, a higher price of wheat can obtain than this, nor indeed so high; because we have introduced, not the standard of value which gives those prices, but a standard of a higher character, namely, a gold standard, abolishing silver; and gold has become dearer in comparison with silver in the period which has since elapsed since the date of those prices.

\section{[The Slatement is read, as follows:]}

"Price of Wheats from the Report of the Committee of The Housc of Commons on the Corn Trade in 1813, page 6.

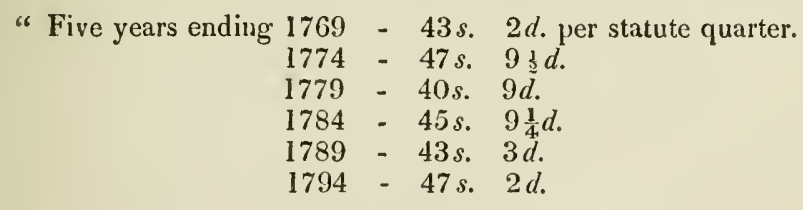

$267 s .11 d$.

\section{" Average per quarter $44 s$. $7 d$."}

5552. It is your opinion that, with the present standard of value, prices cannot rise so high again as they were before the suspension of cash payments? - That they cannot permanently maintain so high a level as before the suspension of cash payments. It may be perhaps better to explain how the present standard would operate upon prices differently from the old standard. The old standard of this country was silver money, coined after the rate of one ounce of silver into $5 s .2 d$. of money, and gold money, one ounce of gold standard into $3 \% .17 \mathrm{~s} .10 \frac{1}{2} \mathrm{~d}$. of money, either money being a legal tender, at the option of the party having money to pay. Silver has become cheaper than gold during the last 20 years. The proportions of the two metals in the old coins of this country were 15 ounces and one-fifth of silver to one ounce of gold; but the proportion between those two metals in the market, as they have prevailed for the last 20 years, are $15 \frac{7}{8}$ ounces of silver to an ounce of gold; silver in the market has therefore become cheaper, as compared with gold, than it is in the old coinage by the difference between $15 \frac{1}{5}$ and $15 \frac{7}{6}$, which is about five per cent. If I possess $3 \%$. $17 \mathrm{~s} .10 \frac{1}{2} d$. of money in gold, it is capable of discharging a debt of $3 l .17 \mathrm{~s} .10 \frac{1}{2} d$. as the lâw now stands, and

Attruood, Esq. M. P.

2 June 1836 . 
M. Atticood, Esq. no more. If the old law existed now, I could carry that $3 l .17 \mathrm{~s} .101$ to the bullion M. P. market, purchase with it at present prices 15 z ounces of silver, take that silver to 2 June 1836 . the Mint, and require it to be coined into silver money at a rate which would give me $3 l .17 s .10 \frac{1}{2}$. for $15 \frac{1}{3}$ ounces, and which would give me for 157 ounces 4.l. 1 s. $10 \mathrm{~d}$., and this according to those laws of the Mint which for more than two centuries gave to every subject of this realm the right of carrying his silver bullion to the Mint, and procuring it to be coined in this exact rate and proportion. I thus receive from the Mint silver money of the value of $4 \mathrm{l} .1 \mathrm{~s} .10 \mathrm{~d}$. which costs me to purchase $3 l .17 \mathrm{~s} .10 \frac{1}{2} d$. of gold money; the difference is five per cent. I therefore discharge my debt of $3 l .17 s$. 10 $\frac{1}{2} d$. in the lawful standard re-established, and have $4 s$. to spare. Thus a person having $100 \mathrm{l}$. of the present gold money exigible to discharge a debt of $100 \%$, or taxes to the amount of $100 l$. under the old law, could purchase with that $100 l$. as much silver in the market as, carried to the Mint, would yield in silver coins of the full ancient value $100 l$. ; he would therefore be able to discharge lis debt or his tax of $100 l$., demand an acquittance, and have $5 l$. of benefit left. Silver being in this manner and to this extent the cheapest money, if the old law were re-established, would be the money in which all debtors would discharge their engagements; it would drive the gold coins from circulation. Existing in circulation as the cheapest money, the channels of circulation would be more abundantly filled, all prices would be affected, and an advance in prices produced, which, reckoning permanently, may be taken at about five per cent; that would be the operation if our currency consisted entirely of metal money; consisting, as it does, of metal money with a large superstructure of paper founded upon it, the basis being extended would sustain a larger anount of paper money and paper credit in circulation, and a higher average rate of all prices; there would be no drain upon those silver coins, arising through the course of the exchanges out of an adverse balance of trade, before the exchanges had gone five per cent. against us below that rate of the exchanges which, under the present system, establishes through the medium of the exchanges, a drain of money from this country.

5553. Would not that be rather too great an advantage to the debtor?It would be an advantage to all debtors to the extent of five per cent.; no doubt it would vitiate all contracts which bear date since the introduction of the present standard to the extent of five per cent.; I do not know any other objection that could be made against the introduction of the old silver standard but this, and this is only to a certain extent a valid objection, because, though the cliange would produce a falsification in some contracts, it would rectify other contracts now existing to a great extent, which will be falsified unless such an alteration is made. Perhaps I had better, befure explaining how far the objection as to contracts is valid and how far not, state in more detail what would be the beneficial result of the introduction of silver money. First, it would give five per cent. of permanent advance on all prices. I assume it to be a matter generally agreed on that great distress prevails in the agricultural community, occasioned by the low scale of agricultural prices, and that to such distress it is a national object to afford relief. At the present low scale the general value of agricultural productions may perhaps be yet taken, speaking very vaguely for the mere purpose of exemplification, at $200,000,000 \mathrm{l}$. by the year; five per cent. upon that sum is $10,000,000 l$., which would thus be given in advanced prices to the agricultural community. If the Legislature should proceed to re-establish the old standard by adopting silver money, another proceeding would probably also at the same time be adopted, viz. to reinstate the old standard in the possession of those laws which for two centuries, down to the Act of 1819 , protected the coins of the country in circulation, and which laws acted as a seignorage upon the coins of the realm. I think that those laws which affixed penalties to the melting or cxportation of coin have been admitted by different Committees sitting on those subjects, to have operated in effect as a seignorage on the coin. I think the Committee of 1819 , on whose Report the present monetary system was founded, recognizes that this law operated as a seignorage upon the coin by preventing its exportation. The Bullion Committee of 1810 , a very great authority upon the abstract principles of these questions, on every thing relating to abstract principles, went into some examination of the extent to which those laws operated as a seignorage. They liave stated the result in their Report, and the conclusion to be drawn from that Report is, that those laws operated as an effectual seignorage to the extent of about two per cent. Now, if those laws operated in effect as a seignorage upon coin, they could not be taken away without falsifying contracts, 
unless by an actual seignorage being substituted in their place; and therefore if the determination of the Legislature should now be to re-establish that old and legitimate standard of value which the Legislature professed in 1819 it was its object to re-establish, it would be necessary to establish silver as a legal tender at $5 s .2 d$. an ounce, and either to re-enact the ancient laws, which prevented the exportation and melting of coin, or to establish a positive seignorage of two per cent. in their place, thus effecting an alteration in the standard, and an action on prices altogether of seven per cent.

5554. To whose benefit did that seignorage of two per cent. result?-lt prevented the coin being exported; it kept a larger quantity in circulation in the country, lowered in effect the standard, and maintained higher prices in the country; there is thus seven per cent. Seven per cent. of increased price on $200,000,000 l$. is $14,000,000 l$. of increased price given into the pockets of the owners and occupiers of land; and this annual 14,000,000 $\mathrm{l}$. the old standard would give them as effectually as if money were taken from the public creditor to that amount, and given to the agriculturists, with the drawback only of what they would pay out again in increased wages of labour in an increased cost of production, and in the cost of their own consumption. But upon all that description of land which is now over-rented, on which the wages of labour are higher than can be permanently sustained at present prices, on all estates on hich incumbrances exist of debts or settlements, on such lands and to such extent would this annual sum of $14,000,000 l$. be given in full proportion, without reduction or drawback.

555.5. What you call the establishing of the seignorage is again preventing by penal laws the exportation or melting of silver:-Yes; or, if we do not re-establish those laws, putting a depreciation to the extent which those laws effected upon the value of the coin. Now, if we establish seven per cent. advance on agricultural prices, - a self-evident benefit, I assume, as the landed interest now stands, - we may calculate in what manner (and the calculation is very casy) this result would operate on the rents of those estates which are now over-rented. The rent may be taken vaguely as one-third of the produce of an estate; an operation which should give to an estate a permanent advance of seven per cent. on all its produce, would give 21 per cent. upon the rent, if we take the production of the estate at three times its rent. A farmer now over-rented, on whose farm the wages of labour are yet too high, and who is subject to other outgoings not yet reduced to the scale of existing prices, could, under the proposed laws, the old laws of the country, sustain a rent of $100 \mathrm{l}$. as easily as under the present monetary system he could sustain a rent of $79 \mathrm{l}$. The change would prevent the necessity of a fall of rents on all this description of land, and I apprehend much land so circumstanced now exists to the extent of 20 or 21 per cent.; that is the advantage which would be produced ; first, by the re-establishing a silver standard, fire per cent., and next, an advantage by re-establishing a seignorage, of two per cent. more. Now the objection which has been suggested is, that these operations would vary contracts to the injury of that debtor; that is the only objection which can be raised; for the old standard of silver conjointly with gold, and both protected by a seignorage, would in no respect be inferior in point of security, or possess any other disadvantage, as compared with the single standard of gold. On the contrary, it would have many advantages; it would be more steady, quite as susceptible of limitation, altogether as incapable of being depreciated either by the efforts of individual issuers of money or the acts of a Government, and it would be safer than the single gold standard from the danger of any monetary convulsion. Doubtless every contract bearing date since the introduction of the present standard would be varied to the extent of five per cent. by the establishment of silver as a standard, and two per cent. more by the establishing the proposed seignorage; but it would there become a question what is the date which we should fix as the one since which contracts would be thus affected. We cannot fix the year 1816, for then there existed practically a cheaper standard than either gold or silver. We could not fix the date at 1819 , because the law of 1819 did not go into full operation for three or four years. I think the date could not be fixed in 1822 or 1823 , because it has been proved in evidence before a Committee of the House of Commons, and is indeed otherwise well known, that there commenced a period during which the standard established by the law of 1819 was virtually and effectually abolished by the efforts of the Government, and that it continued in a state of non-existence till the year 1826. We could not therefore fix the date further back than 1826 , and 464 . 
M. Attuood, Esq. M. P.

2 June 1836 .

it would be questionable whether we could fix that date, because from 1826 to the present period the currency has been repeatedly tampered with, and successive efforts have been made by the Government to relax the effects of that standard which the cxisting law established, and which standard has been thus effectively altered and relaxed from time to time. But fixing whatever date we please, 1830 or 1826 or 1823 , as the period from which all contracts since dated and now existing would be varied by an alteration of the law such as I have suggested, it is also equally certain that every contract now existing, which bears date before that period so fixed, is varied or falsified by the continuance of the present law. The public debt is a contract not founded in the present standard, but which has been varied by the present standard, and will be further varied by its continuance. All existing taxes, and taxes are of the nature of contracts (annual taxes excepted), and perhaps that exception ought not to be made, have been founded and imposed in a standard cheaper than the present, and cannot with justice be exacted in the present standard of value. Every existing debt contracted before the establishment of the present gold standard, and which should be paid off under the present standard, would be paid with injustice to the debtor to the extent of five per cent. or seven per cent., as the calculation may be made. No annual interest can be paid on any such debt without injustice being committed to an equal extent if the present standard be continued, and therefore the whole question between the old standard and the new becomes one of a balance between justice and injustice on the one side and on the other. If it be contended that the Legislature are bound to the present standard, and can make no alteration in it, because such alteration would vitiate all contracts dated since its introduction, that national faith and the security of contract prohibit to re-establish a silver standard or a seignorage, I apprehend it must then be admitted that it would be incumbent upon the Legislature, acting up to these principles, to cause a rectification or adjustment to be made in the amount of every existing contract which has its date before the introduction of the present gold standard. The Legislature would follow in that course the precedent they adopted, when in the Act which established an uniformity in weights and measures (I think that Act passed in 1824) it altered the quantity of existing weights and measures. Many contracts existed in all parts of the country expressed in various weights and measures, and the Act of 1824 provided for a rectification of all those contracts; it provided that an inquisition should be held in all principal towns, before which inquisition shonld be brought all contracts, rents or tolls expressed in bushels or in other weights or measures, of which there are great numbers; and to that inquisition was given the power of correcting such contract, and of substituting one quantity for another, in proportion to the change which the Legislature had made in the measure in which the contract was expressed.

$555^{\circ}$. You allude to the alteration from the Winchester to the imperial measure:-Yes; and which would vary contracts expressed in bushels precisely in the same manner and in no other manner than an alteration of the standard of value would vary contracts expressed in money.

5557. Have you any doubt about its effect, or only the question how far, in point of justice, in regard to the situation of parties under contract, you can go? It is certain, that in our situation we can render but an imperfect justice. By restoring the ancient law we should commit injustice to a certain extent, but we should prevent injustice to a certain other extent.

5558 . Which do you think would be the greatest?-It would be very difficult to calculate. The whole national debt, a large contract, is of that kind which sustains injustice from the permanence of the present standard. All the debt existing at the conclusion of the war was contracted either in the old standard of the country, viz. silver at $5 s .2 d$., as well as gold at $3 l .17 s .10 \frac{2}{2} d$. , or in a cheaper standard than that, namely, a paper standard. The debt prior to the war was founded on the old national standard. There is no part of the present national debt which can be paid in the present standird without injustice.

5559. The present standard never existed at any period while the debt was created :-No. Bearing on the question of justice is this consideration. I apprehend it is admitted that the Act of 1819 introduced a standard which was dearer, not by five or seven per cent. alone, but by 30 or 50 per cent., than the standard which existed during the war; that this measure occasioned great injustice to debtors, and, to the extent of from 30 to 50 per cent., a variation in contracts; that thus was causcd the ruin of immense numbers of persons, and that there still exist 
numerous contracts in which the variation or falsification thus effected has not been yet completed. It would therefore seem that the restoration of a silver standard and of a seignorage would be a kind of compromise between conflicting interests, between debtor and creditor, between justice and injustice on one side and on the other. There would be still an imperfect justice rendered, but perhaps the best which it is in the power of the Legislature, as things now stand, to give. I think that these considerations bear a stronger weight from a reference to the circumstances under which the present standard was introduced. It is perfectly clear that the Legislature acted in error, and luad no intention or belief when they abolished the silver standard, or when they abolished the seignorage upon the coin, that these measures would alter the standard of value, or cause a permanent action on the prices of commodities.

5560. Do you not remember what was stated at the time in Parliament on that subject, that it would not alter them more than four per cent., at the utmost?- It was never stated that the abolition of the silver standard would alter prices at all. It was stated, with relation to the Act of 1819, which abolished the paper standard, that this would alter prices to the extent of four or perhaps five per cent. A member of the Committee of 1819 stated, in his place' in the House of Commons, nine years after that time, that he as a member of the Committee was entirely misled as to the character of the measure which was founded on its recommendation and report. He stated that in his belief every member of that Committee was misled in the like manner; he believed that the Chairman of the Committee was similarly misled; he addressed himself to the Chairman to ask if this was not so; he stated that the Committee, entirely inexperienced in such matters, were misled by witnesses perfectly uninformed, who talked of a fall of prices of five or four or six per cent., when it was since rendered undeniable that a fall of prices had been produced, and an alteration in the value of money, not of four or six per cent., but of 20,30 or 40 per cent. ; that if the character of that measure, the Act of 1819, had been known to him, he would not have voted for such measure, or supported it in the House or the Committee; nor did he believe that any one member of the Committee, knowing the character of the measure, would have supported it, or that the Chairman of the Committee would have dune so.

5561. The Chairman was Sir Robert Peel?-Yes. He was present, and made no answer to that statement. It was Mr. Bankes made that statement. Another Member of the House of Commons, Sir James Graham, put a question to the Chairman of the Committee in the House immediately after the statcment of Mr. Bankes, whether he contradicted that statement, and he gave no contradiction.

5562. Was there any difference of opinion expressed by any member of that Committee as to the correctness of the statement that the understanding was, with respect to depreciation, that which you have stated $-\mathrm{N}_{0}$ one. With regard to the manner in which the old standard of silver has been abolished, and the views of the Legislature in making that change, it is certain they had no such intention as affecting any alteration in the value of money or any action upon the price of commodities by giving up silver. In fact, the whole proceeding is one of those almost incredible errors which have distinguished all our legislation for the last 40 years upon the subject of money, beginning with 1797, when the Legislature gave to the Bank of England and the issuers of paper money a power of augmenting the amount of money in circulation at their pleasure, without taking any precaution to secure that money from depreciation : going to 1810 , when a Committee of the House of Commons having ascertained that the paper money, become then the actual standard of value, had sustained a depreciation, adopted a recommendation that all existing debts formed in such depreciated paper should be paid in money of the old standard, and that cash payments should be resumed, in the midst of the war: proceeding to 1811 , when a solemn resolution of the House of Commons declared that no depreciation of paper money had taken place; then, in 1819, effecting an alteration in the standard of value and measure of property to the extent of from 30 to 50 per cent., believing that they were doing this to the extent of no more than four-and-a-half or five per cent.; and going, lastly, on to the year 1826, when the Legislature established joint-stock banks, for the purpose of serving as a protection against the recurrence of a panic such as had distinguished the close of 1825 , from which very joint-stock banks their authors now anticipate a recurrence of the evil against which they were ereated to guard.

5503 . Where was it stated that the joint-stock banks were established with that 464. 
M. Altrood, Esq. . view ?-It is to be found, I believe, in the Report of several Committees; it was M. P. stated in the speeches of those Members of the Legislature and of the Government who introduced and supported the Act for the Establishment of Joint Stock Banks. They ascribed the panic of 1825 to the bad system of banking which prevailed. That panic was established in evidence in 1832 to have had its origin entirely in measures of the Government itself tampering with the currency, and seeking to relieve the country from the pressure of the standard they had established. They ascribed the panic to the bad and insolvent state of the country banks, and thereupon proposed to establish a better description of banks for the purpose of guarding against future panics, not aware that the joint-stock bank system is in itself more insecure than any other; that although in Scotland such banks had supported a singular solvency, yet that in America, where the jcintstock bank system prevails, there have been greater failures among those banks than among the private banks in England. I have a list here, given by Mr. Gallatin, the American minister, of 163 chartered joint-stock banks that failed in America in 20 years - all chartered banks. Going back to the questions regarding silver, the manner in which we came to abolish silver as a legal tender appears to have been this. A Committee of Privy Council sat in 1816 for the purpose of establishing a silver coinage. They found that the silver coins of the country had, long anterior to the Bank Suspension Act, disappeared from circulation, that is, the silver coins of full weight. To remedy this evil in the proposed new coinage they devised a plan of a depreciated silver coin. They found that silver had assumed a high value as compared with gold, at a period beginning about the middle of the last century. Commencing with 1760, the price of standard silver appears frequently in the market as high as $5 s .4 d$. an onnce, $5 s .6 d$. an ounce, and $5 s .8 d$. an ounce. A crown piece of Queen Anne rould thus be worth $5 s .6 d$. to the silversmith to melt. The shilling was of the value of $13 \mathrm{~d}$. to the silversmith. The consequence was that all silver of full weight had been melted, and nothing remained in circulation but the worn silver coin that it was not profitable to melt. The Committee of Privy Council, to gnard against the danger of melting the new coin, proposed to coin the ounce of silver into a larger amount of money. Coining the ounce of silver into $5 s .6 \mathrm{~d}$., such money, if it had remained a legal tender, would have depreciated the standard and would have varied contracts. To prevent such depreciation and falsinication of contracts they recommended that silver should no longer be a legal tender, but that the new coin should circulate as tokens. Now, the Committee in taking this course guarded against a danger which had long ceased to exist, and fell into that very evil of falsifying the standard which they sought to avoid. If the Committee had examined more diligently the relative prices of silver and gold they would have found that silver, instead of maintaining those high prices which from 1760 to 1780 or 1790 had caused the coins to be melted, silver bullion had assumed, for 20 years before the sitting of the Committee, a low price as compared with gold. They were nisled by taking the price of silver during the war from the customary tables of prices, forgetting that those were the prices of silver bullion or paper money, and not the prices of silver valued against gold. If they had taken both prices together even during the war, the price of silver as valued in gold, they would have found that silver had become cheaper in comparison with gold; that valued in gold at $3 l .17 s .10 \frac{1}{2} d$. the price of silver would have been no higher than $4 s .11 \mathrm{~d}$. for many years; and that consequently wherever we should proceed to establish a gold money at $31.17 \mathrm{~s} .10 \frac{1}{2} d$. an ounce, in that money silver bullion would not reach the old Mint price of $5 \mathrm{~s} .2 \mathrm{~d}$., and that silver coinage would be as secure from melting, coined at $5 s .2 d$., the ancient stanclard of the country, as it would be coiried at $5 s .6 \mathrm{~d}$. or any higher rate.

5564. The silver now is below the Mint price ?-It is.

5565. Though the price of silver in the market is now below the Mint price, which is $5 s .2 d$, is there any law to get rid of the effect of the law of Charles II., by which a man could take silver to the Mint and require them to take it at $5 s .2 d$.? -I believe that cannot be done. I have not now the Act in my memory, but I believe that Act of Charles has been abrogated by the Act of 1816. The Mint will not coin silver at $5 s .2 d$.

5566 . A person can take gold, and require them to coin it at $3 l .17 \mathrm{~s} .10 \frac{1}{2} d$. an ounce?-Yes.

5567 . Has the price of gold differed of late? - Not of late years beyond $1 d$. or $2 d$. an ounce; it lias sustained its Mint price, or very nearly. 
5568. Ilas the price of silver varied much more than that of gold?-For the last ten years it has sustained a price from $4 s .10 \mathrm{~d}$. to $5 \mathrm{~s}$. an ounce; I take the average at $4 s$. Il $d$. an ounce, which is five per cent. below the old Mint price.

5569. The Government get great advantage from the new coin?-Yes; but they have had to sustain some loss. On one or two occasions, when the new coin has accumulated largrely in the coffers of the Bank, and the Bank has wanted hullion, they have applied to Government, proposing to melt their silver coin, the Government paying the loss of 10 per cent. upon it; and there have been long discussions, and $I$ apprehend there is still a discussion pending, as to who is to bear a loss thus arising, I believe, to the extent of $100,000 \%$.

5570 . If you restored the silver standard you would restore it at $5 s .2 d$. an ounce, that is $62 d$. an ounce? - Yes.

$55 \% 1$. Wonld vou take any other means of adjusting the value of silver to the value of gold:-I think, as the law now stands, which has abolished the penalty on the melting of coin, and on the selling of the coin at any rate the market will give, the establishment of a silver standard at $5 s .2 d$. would not necessarily occasion any further law than one which should enable the subjects of the realm to carry their silver bullion to the Mint to have it coined and delivered out to them at the rate of $5 s .2 d$. of money for the ounce of silver. Gold might be left. to find its level in the market. I take it the effect would be this; - silver would be carried to the Mint; there would be five per cent. profit upon the operation; it would come out in coin, and go into general circulation in the payment of debts; in the payment of wages, and all other transactions of money. Every man would find the advantage of paying in silver instead of gold; but many persons would find a great convenience in obtaining gold; they would ask for gold and offer a premium for it. The old law inflicted a penalty on the selling gold coin at a premium. That law is abolished. Persons would, as they do in France, pay a premium for gold coins; at a premium of five per cent. 100 sovereigns would discharge a debt of $105 \mathrm{l}$. as effectually and more conveniently than by being employed in the purchase of silver bullion, taking the same to the Mint, and obtaining $105 l$. in silver money; thus a premium of five per cent would be established on the present existing sovereign; we should find the sovereign continue in circulation at the rate of about $21 s$. for the sovereign in conjunction with silver at $5 s .2 d$. an ounce. Perhaps I should bring this operation more fully before your Lordships by explaining what has been done in regard to their gold and silver coins in the United States of America, circumstanced in many respects exactly as we were, and adopting that precisc course which it was fit we should have adopted. Gold coin as an exclusive standard I take not to be the standard of any country but this. In America the standard was originally a gold and a silver money, coined at certain proportions one to another (about 15 to 1 ), the payer of money having the option in which money he should discharge. his debt.

5572. Would it not be necessary, in order to have a double standard here, to adjust a certain proportion between the two metals? - I think the proportion and price would adjust itself, in consequence of the abrogation of the law which prevented gold coin being sold above the Mint price. Doubtless if we were to restore that old law, if we prevented the gold coin going at more than $20 \mathrm{~s}$. for a sovereign, it would be necessary to adjust the value of the coinage in order to prevent silver drawing away gold, and supplanting the gold money in circulation. That is what they experienced in the United States of America. They felt what we should have felt here if we had in 1819 re-established the old standard of the country, viz., a disappearance of gold from the circulation. Silver having become in America the cheaper metal, occupied the whole metallic currency of that country. There were no eagles in circulation, but abundance of dollars. The Congress was desirous to introduce a circulation of gold. They took the whole subject in all its bearings into very extensive deliberation and discussion. I think those discussions began in 1831 by a pamphlet of Mr. Gallatin, who had been much in this country, and had witnessed our proceedings and errors. He printed a very elaborate work in January 1831, in which he recommended the advantage of bringing back gold into the circulation of America, and took a general view of the bearings of the whole subject, and the effect of an alteration of the metals forming the coins on the debtor and creditor interest of the state. A Committee of Congress was appointed in that year, another in 1832 . They prepared a Bill for Congress, but it was not carried into effect. Other Committees 464. 
M. Attuood, Esq. were appointed. In the Reports of those Committees all the bearings of the M.P. measures in contemplation on the national interest are examined. They did not June ${ }_{1} 8_{3}$. confine themselves to the trifling details of the question, as our Committees on these matters have almost invariably done, such as the difficulty of the Bank of England; the period when, with more or less convenience to that body, could be effected a measure for altering the standard of value,few millions, more or less, to be kept in its coffers. The American Committees have uniformly rejected mere questions of convenience or detail, and directed their attention to the bearing on contracts, and on great public interests, of the alterations they were about to make. The object they had in view was that they should bring gold into circulation, gold having been driven out of circulation by silver becoming the cheaper metal. Different methods were considered for accomplishing that object; they might have done as we have done; abolish silver as a standard, and permit it to circulate only as a token, establishing a single standard of gold. That they decided would be a falsification of existing contracts. They might have made their silver dollar of greater weight; that would also be a falsification of existing contracts. The other modes suggested were, either the debasing the gold coin, to bring it on a level with the value of silver, or causing the existing coins to pass for a higher denomination in the discharge of debts.

5573. Can you state what the relative quantities of gold and silver were?The coinage laws in America regulated the coins in the proportion of 15 ounces of silver to one ounce of gold; but silver had become so cheap that an ounce of gold would purchase 16 ounces of silver in the market: therefore silver supplanted in circulation gold. The American Legislature adopted both the two latter courses which I have just described.

5574 . You say they raised the value of gold and lowered the value of silver? - They raised the value of gold in the coin which existed, and in the gold money which they were about to coin they diminished the quantity of the metal. The Act of Congress by which this has been effected is dated in June 1834; it enacts, "that the gold coins of the United States slıall contain the following quantities of metal, that is to say, each eagle shall contain 232 grains fine gold," the eagle, which before this Act existed contained 247 grains and five pennyweights of fine gold; it is a depreciation of about six per cent. The Act then goes on to proportion the half-eagle and the quarter-eagle in the same manner. The Act proceeds to deal with the gold coins then in circulation; it enacts, "that all gold coins of the United States minted anterior to the 31 st day of July next shall be receivable in all payments at the rate of $94 \frac{8}{10}$ of a cent. per pennyweight," that is at the rate, in their silver money, of 10 dollars and 66 cents for an eagle, the rate at which those monies were receivable before being 10 dollars for an eagle. They cansed the eagle to discharge a debt of 10 dollars and 66 cents. instead of a debt of 10 dollars, making an alteration of six per cent. Another Act which was passed at the same time, and seems collateral to it, deals with the English sovereigns current in the United States. Foreign coins are receivable by law in the United States according to their weight, as they were formerly in this country. It provides also for the gold coins of Portugal and Brazil, and fixes that the gold coins of Great Britain shall pass current as money in the United States at the rate of 94 cents. and $\frac{8}{10}$ of a cent. per pennyweight; that rate gives to an English sovereign the value of 4 dollars and 83 cents in American money. It had previously possessed the value of 4 dollars and 45 cents, being a difference of six per cent. A person having to discharge a debt or a duty at the treasury of the United States, and carrying an English sovereign there, will now discharge a debt of 4 dollars and 83 cents for the same sovereign with which he could before have discharged a debt of 4 dollars and 45 cents. The Americans have therefore depreciated not their own coins only but the English sovereign; and they have done this upon a full examination of the subject, and upon an entire demonstration that this measure was necessary to prevent injustice between debtor and creditor, to preserve the faith of contracts, and to render such faith consistent with the actual circulation of gold noney as a standard of value. See p. 354. I have here tables exhibiting the state of facts on which America has proceeded; one is a table which gives the relative prices of gold and silver in that country, valuing one metal against the other, from the year 1760 down to the year 1829, separated into average periods of five years; it is taken from the Appendix to the Report of a Committee of the American Congress, dated in June 1832; the other 
contains the relative prices of gold and silver in the market of this country, valued one against the other, commencing also in 1760 and ending in 1819 , divided into average periods of 10 years. T'lic results correspond, and show a like alteration in the value of silver as exchanged against gold in $\Lambda$ merica as here. In America, for the first 30 years of this period, viz., from 1760 to 1790 , the rate of silver as exchanged against gold was that an ounce of gold would purchase in America $14 \frac{1}{2}$ onnces of silver and no more; grold being thus the cheapest metal, and silver the dearest (an ounce of gold purchases at present $15 \frac{1}{2}$ or near 16 ounces of silver), the consequence was, that in $\Lambda$ merica, as in England, gold displaced the silver coins. It was taking the prices of this particular period which misled our Committce in $\mathbf{1 8 1 6}$ to think it necessary to take away weight from the silver coinage they were about to introduce; but from this period silver began to fall as compared with gold. In the next 10 years we find, ending with 1800, silver cxclianged at the rate of 15 ounces of silver against an ounce of gold. That fall in silver went on till it exchanged $15 \frac{\mathrm{s}}{2}$ ounces against an ounce of gold, taking the price for an average period of 30 years; so that $14 \frac{1}{3}$ ounces for the first 30 years of this period was the rate, and for the last 30 years $15 \frac{1}{2}$ ounces, silver having become cheaper as compared with gold during that time to the extent of 1 in 15 . The table I See p. 354 . now produce of the English prices of gold and silver shows a similar variation. During the first period of 30 years, commencing with 1760 , it exhibits a price of $14 \frac{1}{3}$ ounces of silver against 1 ounce of gold; in the last period, of $15 \frac{1}{3}$ ounces, precisely 1 ounce in 15 difference between the value of gold and silver in this period. The course we have adopted, therefore, is precisely the reverse of that which America, under similar circumstances, lias thought it right to adopt. Silver had become the cheapest metal; we have abolished that standard, and bound all contracts to the dearest metal, every subject of the realm having previously the right of discharging his debts in whichever metal should be the cheapest, by a law which had continued for two centuries. America, under similar circumstances, has retained silver as its immutable standard, has entrusted to silver the faith of contracts, and has altered the value of the grold coin to adjust it to the existing rate of silver. It perhaps may not be immaterial to this subject to state, that the course which has been thus adopted by America is exactly that which in former times was pursued in this country. America has followed precisely the precedents which we have formerly set; whilst we have abandoned now, under such circumstances as I have described, and in error, our former course of proceedings. It has been our custom to depreciate the gold coins, and that in the best times of our standard, those when its purity was most strictly preserved. Our standard was fixed in the 43d of Queen Elizabeth, the year 1601; a silver money, $5 s .2 d$. of money coined out of the ounce of silver, which money continued immutable from that time to the year 1816 a legal tender standard of value and measure of property in this country.

5575. You mean that at those prices it was first introduced then?-Yes; it was introduced first at those prices by that Act of the 43rd of Elizabeth which coined silver into $5 s .2 \mathrm{~d}$. an ounce, and coined gold into no more than $2 l .15 \mathrm{~s} .11 \mathrm{~d}$. an ounce, thus adapting the proportions between the two metals as 11 to 1 . Gold was at that time so cheap, or silver so dear, as that 11 ounces of silver would purchase an ounce of gold. The sovereign of the 43rd of Elizabeth, which was of the value of $20 \mathrm{~s}$., was of the weight in standard gold of seven pennyweights and four grains; the sovereign is now of the standard weight of five pennyweights and three grains; it has sustained a depreciation of about 39 per cent.; while silver continued still to be coined at $5 s .2 d$. an ounce till the Act of 1816 . Very shortly after this period of $43 d$ Elizabeth gold took that course which it has taken in Europe within the last 30 years; it became scarce, and advanced in price as compared with silver; instead of being worth 11 ounces of silver, in which proportion to silver it was coined, it became worth in the market 12 ounces of silver. The tendency of silver would be to drive gold from circulation. The Legislature of that time were placed therefore in the situation in which ourselves and the United States have been recently placed; they adopted the course which the United States have now pursued. In 1605, the first and second of the reign of James I., the gold coins were clebased; gold was coined into $3 l .2 s .1 d$. an ounce, being a debasement of 11 per cent. It is not immaterial to remark that the mode of adjustment of the two metals then first introduced, and which continued so long to be followed, was adopted by the advice of very able and distinguished statesmen,-Lord Cuke and Lurd Bacon. Gold continued to advance 

11. Atwrood, Esq. after that time; and in 1612, 9th James I., another debasement took place of 10
M.P.

2 June 1836 . per cent., gold being then coined at 3 l. $7 \mathrm{~s} .7 \mathrm{~d}$. an ounce. A small debasement in the 17th of James I. took place of one or two per cent. for the purpose of adjustment. We then proceed to 1663 , the 13 th of Charles II.; a debaseinent of gold took place at that time of eight and a half per cent.; gold coins were then coined at the rate of $3 l .14 s .2 d$. an ounce, being one ounce of gold to $14 \frac{1}{4}$ ounces of silver. In all those variations in the price of gold the Legislature appear uniformly to have considered silver coins as the paramount and predominant standard of value, immutable and invariable, on which was to be rested the faith of contracts and the security of men's property; altering the gold coins as gold should alter in value in relation to the price of silver; considering gold, as it in fact is, a metal more variable in its quantity than silver, and more unfit for the purposes of a standard.

$55-6$. Is there a less quantity of gold in England than there is of silver?-There is a greater amount of gold in value in the country than of silver.

$557 \%$. Then why should gold rise in price and silver fall ?-Though the absolute value of gold in England is greater than that of silver, it is less in its proportion to silver than it was formerly, viz., less than in the period from 1760 to 1780 and 1790 .

5578 . Though there is still more gold in point of value, they do not bear the same proportion to each other ---No. The absolute value of gold in England is much more than of silver; in France much less, I apprehend; much less in America. I think that one of the Reports of Congress states that there was not above $500,000 \mathrm{l}$. of gold money in circulation in America, and 5,000,000l. or $6,000,000 \mathrm{l}$. of silver dollars, reckoning in amount. There might be a question whether, if we were to adopt silver and bring it into circulation as a standard, the quantity required would not enhance the price of silver. I do not think it could permanently have that effect, because the alteration in value between the two metals which has taken place in England has been common to the two metals over the whole of Europe. In France the proportions between gold and silver in the coins are $15 \frac{x}{2}$ ounces of silver to an ounce of gold, but the gold coins are now at a premium of $1 \frac{5}{8}$ per cent. A person that should desire to get gold coin, which is in the proportion of $15 \frac{x}{2}$ ounces of silver in coin, would have to pay $1 \frac{5}{8}$ premium for it, which makes the relative market value about 16 ounces of silver to I of gold.

5579. Is that the situation of Europe generally:-I apprehend so, necessarily. Therefore, unless the new demand for silver should alter the relative value of silver to gold permanently throughout the world, it would not permanently alter the relative value in this country, supposing the law established to make the old silver coin a legal tender at $5 s .2 d$.

5.5 So. Are you contemplating silver now as the sole legal tender, or concurrently with gold?-I take it either way. If we were to establish silver as the main standard, our circulation would be mainly silver, but that would not raise the price of silver permanently. No doubt the first demand on the bullion market for silver would raise the price, but as silver got higher than the present proportional value, it would answer the purpose of the merchant to bring in his silver bullion and take out our gold bullion in exchange. As fast as silver thus came into the bullion market silver would fall, till at last the fluctuations would settle in silver maintaining its present relative value to gold; our circulation composed of silver; it not being at all probable that the quantity of silver that would go into circulation in this country would materially alter the relative value of the two metals throughout the world.

558 . In what way do you propose to continue both gold and silver in circulation, so as to have a joint standard?-Practically under the old laws, if they were re-established, we might, as in America, alter the value of the gold coin; or, retaining the present law, which suffers gold coins to find their value in the market, we might, by a simple enactment, establish a silver coin as a legal tender at $5 s .2 d$. an ounce, and leave the gold to find its value in the market. I apprehend the silver would then exist to the same extent in the current circulation as at present, and 'that gold coin would establish an agio of about five per cent.; that the sovereign would pass at about $21 \mathrm{~s}$. in discharge of debts, and that we should have both gold and silver in circulation.

5582 . It would not be necessary to alter the law further than merely to make silver a tender, saying that gold may be bought at whatever price it may fetch ?-The 
present law does admit of gold being bought at whatever price it will fetch, not only bullion, but in coin. I apprehend that the laws which prevented the exportation or selling of the gold coin at above its Mint price are altogether abolished, and that a person may now sell the sovereign at any price he can obtain for it; in the periods to which $I$ have referred, as affording examples of depreciations in the gold coin, no reproach lias been cast upon the Government of those times for the alterations they effected in the standard.

$55 \$_{3}$. Have not those alterations which brought reflections on the Government been alterations made expressly with a view to pay the creditor less than lie ought to have been paid? - Yes, but it is a matter more of argument than of evidence; I believe that most of the former debasements of our coin which preceded those to which I refer, and which have been generally ascribed to dishonest motives on the part of governments were not made to produce fraud, but to prevent fraud. I think a reference to the facts which bear upon the question would prove that point incontrovertibly. Every one knows that our silver coins originally contained one pound weight of silver to $20 \mathrm{~s}$. of money, and that a progressive depreciation took place in the size of those shillings from the period of William I. to the reign of Queen Elizabeth, when a pound in weight of silver came to be coined into $62 s$. instead of $20 \mathrm{~s}$; ; the question is, whether those successive debasements of the coin were made get rid of debts and defraud creditors, or to protect contracts faithfully. The fact appears to have been, that during this whole period the precious metals became progressively scarcer in this country and throughout Europe; population and productions progressively increased, and, unless the quantity of the precious metals increased also, they would undergo a change in their relative value to commodity, and the consequence would be a progressive fall in money prices if the coins were bound to contain the same quantity of metal at last as at first; the actual result on prices was this: taking the earliest accounts we have of the prices of bread corn at the time when the pound of silver was coined into $20 \mathrm{~s}$, the price of bread corn was about $20 \mathrm{~s}$. a quarter, on the average, in the money of that time ; bread corn did not advance as we proceeded to depreciate the silver coin, but fell in spite of that debasement. The best accounts we have of prices in those early times furnish the result that bread corn commenced with being $20 s$. a quarter in the reign of King William, and ended with being $10 s$. or $11 s$. a quarter in the reign of Elizabeth, those $10 s$. or $11 s$. being the small shillings of $62 \mathrm{~s}$. to the pound of silver, and the $20 \mathrm{~s}$. being large shillings which contained one pound of silver. Let it be then considered what the effect would have been if the coin had not been debased, but that the shilling of Elizabeth had continued of the same weight as that of King William, viz., $1 s$. of the weight of $3 \mathrm{~s}$.; the price of bread corn would have gone down to $4 \mathrm{~s}$. a quarter; a perpetual falling of prices going on for three centuries, and to the extent of five to one. How would this have effected the progress of population and industry - prices continually falling, every incuividual who contracted a debt or signcd a lease having to pay in money of a higher value, would do so to his own ruin; and it would seem to be that to prevent this consequence the coins were debased, in fact adjusted, according to the different value of the metal of which they were composed ; in fact, to prevent bad faith, and not to effect it. It is a corroboration of this view, to observe, that a similar alteration in the value of coins took place all over Europe at the same time, and was resorted to by all governments; this can be accounted for only by supposing a necessity to press on all governments alike, and that they were all compelled to alter the rate of the coin in order to adjust the coin to the altered value of the precious metals; this course begun, a Government might be apt to carry it too far. In the latter periods of our depreciations, in the reign of Henry VIII. and Edward VI., there can be no doubt depreciation and enhancement of the standard were both carried too far, and in France the depreciation in coins was carried much further than in this country. Still a great depreciation of the currency, I apprehend, was necessary to prevent the evil of an alteration of contracts arising from the scarcity of the metal in which contracts were to be discharged. The government must have left a watch on the fluctuations of the precious metals. It would be very difficult for a government to alter the coins justly on any trifling variation in the precious metals; but on any inportant variation they would bebound by justice to apportion the coin as would best serve the purpose of justice to the Government and to the people. At the time of the great influx into Europe of the precious metals, on the first discovery of America, which caused in 464 . 
11. Attword, Esq. England bread corn to rise from $11 s$. a quarter to $44 s$. a quarter in abont 70 years, M.P.

2 June 1836 . being 400 per cent., an advance which all writers npon the subject have ascribed to an increased abundance of money, the duty of the Government was to put larger quantities of metal into the coin instead of smaller; otherwise a lease dated in the first part of this period, and the rent paid when wheat rose to $44 \mathrm{~s}$., would give to the tenant the greatest part of the estate, and the lease be falsified.

$55^{8} 4$. Do you not find that money was raised in value when commodities became more abundant in this country, but when they were not it took a directly contrary course:-Necessarily. It corroborates the correctness of the opinion, that under the present system of cash payments, no higher average price of agricultural commodities can exist than the present, to find, looking to past experience, that no very great and permanent alteration has ever taken place in this country in the price of corn without that alteration having been afterwards aseribed, by all writers on the subject, not to a change in the quantity of corn affecting the supply and demand of corn, but to an alteration in the quantity or character of the money in which prices were measured. I have here a table of the price of corn, taken for 50 years, ending in 1794 ; the average is $39 s .3 d$. per quarter. In 1696 , just one century before, the average is $39 \mathrm{~s} .4 \mathrm{~d}$.; it has varied only $1 \mathrm{~d}$. in the century, and that was a fall of $1 d$., not a rise. There was an intervening period in the last century during which wheat underwent a considerable depression, and was under $33 s$. I think all writers upon that subject agree in ascribing that depression of wheat in England to a deficient supply of the precious metals from the mines; there was a similar depression throughout Europe at the same time; that fall was ascribed by the writers on political economy to a deficient supply of the precious metals. We came down to the Bank Restriction Act with a price not exceeding from $40 s$. to $50 \mathrm{~s}$. a quarter for wheat; that is the very price which existed immediately after the operation of the American mines had ccased upon the prices of Europe. Two centuries ago wheat rose to $2 l .7 s .5 d$. a quarter, viz., in the 40 years between 1561 and 1601 , and it appears to have undergone no advance in monied price in this country or in Europe at large down to the period of the Bank Restriction Act. This table shows that wheat never advanced beyond the price of from $40 s$. to $50 s$. for any average period of five years, frequently experiencing very high prices for a year or two in consequence of deficient harvests, but those prices, corrected by increased supplies, leaving an average nearly invariable. When we proceed to the years succeeding the Bank Restriction Act, it is found, that instead of bearing $44 \mathrm{~s}$. a quarter, we get, for five years ending in 1799 , to $64 s .5 d$. a quarter, then for five years, ending in 1804 , to $83 s .2 d$. a quarter, for five years, ending in 1809 , to $82 s .1 \mathrm{~d}$., and for five years, ending in 1814 , to $101 \mathrm{~s}$. $9 \mathrm{~d}$., for the quarter of wheat. I think it is impossible for any person, considering these prices, to doubt that the prices of the war were occasioned by the paper money of the war, that it would be absurd to expect that any such prices could be sustained when we returned to the old metal money, or any prices materially different from those which that metal money maintained when it previously existed.

5585. What is the difference in the prices of silver in Poland or Prussia, and other countries from which the corn comes into this country?-It would be necessary to state that in their monies; it could not be well stated without taking their monies.

5586. The ounce of silver and the ounce of gold do not differ much in Prussia and in England ?--No, not their relative proportions.

$55^{8} 7$. Then how do you account for corn being so much cheaper there than in England ? I I take it that we shall not find any material difference to have existed at any former time, nor in future to exist in the price of corn, as measured in metal money, between this country and the countries which immediately surround us. There would be little difference found in the price of corn here and in France. There are some countries in which corn can be produccd at a very low price, to a certain extent; it is not there the food of the people. The wages of labour do not depend upon the price of corn, and to a certain extent they can produce corn at a very low price. Corn cannot obtain a highier price there, because in those countries there is not a use for corn ; but there is no considerable manufacturing and commercial country in which a much lower price of corn can be found than has been maintained in this country. There has been a very great uniformity between the price of corn in this country and in France, estimatcd in the precious metals. 
5.588. What occasions the enormous difference which has always existed lietween Prussia and some other countries and this country?-That difference could not very long exist if we admitted the corn. The exporting corn to this country, and taking back our money, would fill those countries witl metal money. The value of money would thus equalize itself. Whilst we prohibit corn from arriving here from these countries, we ean for a time prevent the equalization of the value of money. There is also a permanent and natural disproportion, to a ccrtain extent, betiveen the value of money in this country and in other countries, the extent of which is controlled and settled by cireumstances over which governments have very little permanent control. Jmproved manufactures would draw the precious metals into those eountries where they flourished, and would sustain a higher average rate of prices. A country without manufactures to give in exchange for the precious metals would draw but a small quantity of those metals, and prices would be low in that country, to a certain extent.

5589 . An enlargement of the standard would of eourse operate on the prices of manufactures as well as the prices of corn?-Yes.

5590. Manufactures are protected by an ad-valorem duty, and the protection rises as the price rises; but that is not the ease with corn. Would it not be necessary to alter the law if the change in the currency you have proposed is made?-Not at all. The standard suggested would make no alteration of the corn laws necessary. In fact, no corn laws can permanently and materially enhance the value of agricultural produce in this country or any country. In sine of the Reports of the American Congress, to which I have referred, I observe that the corn laws in England are described as an attempt made by the Legislature to evade the consequences of the return to cash payments pressing on a particular class of the community ; and they describe it as one of those vain attempts which governments frequently resort to under similar difficulties, necessarily ending in disappointment; in which view I concur.

5591. The great corn law passed before the suspension of cash payments ended - -Yes; in 1815. But the first law which re-established cash payments provided that they should take place within six months after the signature of a definitive treaty of peace; so that, in fact, cash payments were provided for immediately on the conclusion of the war. Preparations were, in fact, made as early as the war appeared to be drawing to a close, and a great fall in prices took place in conscquence.

5592. What is the alteration you would recommend?-I should recommend, but it would be a question on which I do not speak with great positiveness, silver money of the present coinage of $5 s .2 d$. to be a legal tender. In my humble opinion, that course would best meet the ends of justice. I think that would be an imperfect compromise between conflicting interests and considerations, between the debtor on the one side and the creditor on the other; but I think it indisputable, that at least to return to a silver standard of $5 s .2 d$., with a seignorage proportionate to the amount the coin was depreciated in value by the old prohibiting laws, is imperative upon the Legislature. If they do not adopt that course, they are bound to rectify all contracts, public or private, dated before the establishment of the present standard and still existing, by an alteration of the amount expressed in those contracts.

5593. Leaving the letter of the contract, but restoring the spirit of it?-Yes.

5594. You have spoken of joint-stock banks; have you ever had jour attention called to any supposed improvement in them by requiring them to pay up their capital, and limiting the amount of responsibility :- If that regulation had been made in the Bill which provided for the establishment of joint-stock banks there can be no question it would have prevented much of the danger which is now thought to have arisen from the proceedings of those joint-stock banks; it would have prevented the too rapid increase of their numbers, and compelled them to aet with more caution, and avoid that eager competition which is decreasing the rate of banking profit and security. A bank commeneing with small capital, and trading almost entirely on borrowed capital, may make a considerable dividend, though with little actual banking profit on that small capital. I know joint-stock banks that trace with a eapital of $20,000 l$.

5595. What is the capital usually subscribed?-Perhaps $100,000 l$. or $200,000 l$., or from that to $1,000,000 l$. subscribed, sometimes with so small a sum 464 .

M. Attwood, Esq. M.P.

2 June 1836 . 
M. Attreod, Esq. as $20,000 l$. paid up. Now, if suclı a bank shall make $1,000 l$. of annual profit, s.P. besides the interest on its capital of $20,000 l$. paid up, which will yield three or

2 June 1836 . four per cent., such bank can make a dividend on that trifling capital of eight per cent. almost immediately on their establishment. $A$ profit of $1,000 l$. a year is not the usual profit a banker might be expected to make; but the profits of all banks are subject to a reverse in consequence of the bad debts, which do not show themselves perhaps for five or six years. Thus banks having a small profit can make a great dividend on their capital. The consequence is, that shares rise to a great price. If a shareholder gets seven or eight per cent. on the money he has paid up, he can sell his shares for $50 l$., $60 l$. or $70 l$. premium on the money he has paid. This operates as a bounty on the establishment of more joint-stock banks. Persons will take shares because they see the profits which have been made by those who have become shareholders in the first. Founded on that calculation active individuals contrive more banks; they find the shares immediately taken, and as long as shares continue to be taken and to bring premiums, there never will be wanting active men disposed to conduct banks. Those banks also have a profit, small in the whole amount though considerable on the shares, and at last there rises a body of men whose business it is to run from town to town to induce persons to set up these banks. Now, provided they were compelled to pay up the whole capital of $1,000,000 l$. or $100,000 l$. before commencing business, they would, for obvious reasons, be enabled to give a much smaller rate of dividend; one that would not bring them up probably to five per cent.; the shares would not adrance; no shareholder's profit could be large from such a bank; and if this had been provided for in the first Act, probably not one bank in five of those now established would have existed, It would be a very different question now, the compelling those banks to pay up their capital; it would be doubtful whether they could pay up their capital; I should be afraid such an attempt would canse great embarrassments among the joint-stock banks. I anticipate that wherever any one considerable joint-stock bank shall fail there will be considerable alarm respecting joint-stock banks generally. There has been of late in private banks as well as in joint-stock banks a great confidence; credit is cheap. At such times bankers are given credit to without inquiry; it is enough that they are bankers. One failure taking place throws distrust on others. If at such a time the money market is straitened, and other failures follow, distrust becomes general. Hitherto no joint-stock bank has been kuown to fail in England, and none in Scorland. There is a credit in joint-stock banks, without any reference to their means to meet their emergencies. They all have credit as being joint-stock bankers. If any one fails with a considerable extent of operation, that would induce sume distrust in the whole body. Many may fail, one after another; credit may be withdrawn from them to a great extent. The test of their security would be the prudence with which their affairs have been conducted; and the best conducted, if they have not guarded against the probability of an emergency such as this, would be exposed to difficulties very serious, from the ruin of their neighbours.

5596. Do you think they are more secure in consequence of the number of partners:- I recollect that questions bearing on that subject were put to more than one of the witnesses before the Bank Committee in 1832, who stated that the number of partners gave an indisputable security to the creditors of those banks, because a creditor could sue any one of liundreds of partners. The question was put to those gentlemen. Suppose one of your neighbours to have been a shareholder in one of those banks; the bank to fail, and the party to be sued ior $10,000 l$., $20,000 l$, or $50,000 l$. by a creditor of the bank, which might be the whole he was worth; would he feel and act with respect to that debt in the way he would as to a private debt, which, as an honest man, he would make every effort to pay? Would he make the same effort to pay this debt due from the bank, or would he seek to defeat the creditor by any stratagem the law would afford him : They each said he would seek to defeat it. They were asked, "Would a debtor think himself justified in selling his property and learing the country, rather than pay such a debt?" The answer was, "Yes;" the debtor certainly would not deal with a debt due from a bank in which he was a shareholder as he would with a common debt contracted by himself.

5.597. In what Committee was that stated? - The Committee on the Bank in 153:.

5.5yS. Hould 
5598 . Would there be any thing to prevent a creditor getting hold of the property of one of the sharcholders? - That would take some time, and might be defeated in various ways. $\Lambda$ case which actually occurred was stated before that committee in respect of a joint-stock company, not a bank, but an insurance com-

M. Attwond, Esq. M. $\boldsymbol{t}$.

2 June $1 \varepsilon_{3} 6$. pany, in Ireland; I think the St. Patrick's lusurance Company, which lad then been recently established, had experienced great losses, and become insolvent ; and it appeared that the individual shareholders of that insurance company did, in fact, all in their power to defeat the creditors of the company ; that many sold up their property and went to America in order to defeat their creditors; and this, 1 apprehend, would be what a person who found himself in danger of utter ruin from such a circumstance would be very apt to do.

5599. Would it not be very desirable, particularly in the present state of the agricultural interest, to which this Committee is to direct its attention, that banks should be established with paid-up capital and limited responsibility, the responsibility being limited to the capital subscribed?-That might be a better system than the present; but it cannot be effected without the consent of the Bank of England. The Bank of England has purchased for money (and paid the consideration) the privilege of being for the term of their charter the only joint-stock bank that shall have a limited liability applicable to its partners.

5600 . Supposing the thing can be done, would it not be very desirable that in different parts of the country large landed proprietors and owners should be induced by limited responsibility, which would be a great temptation, to establish such banks as that?-It might be beneficial.

560 . Do you not conceive that so far as panics are to be apprehended in consequence of the alterations which have been made in the law of 1819 , the circumstance of establishing silver as a conjoint standard would tend very much to lessen the apprehension of such panics?-There can be no doubt upon that point; a silver standard would give a security to the present monetary system in times of pecuniary pressure, or in a commercial or political crisis in pecuniary affairs, beyond any security which the present system promises.

5602. As far as accommodation is beneficial in agriculture, as well as mercantile and manufacturing concerns, would not this be likely to increase the disposition to afford such accommodation?-It would.

5603. Do you not conceive, if there was to be a large demand for corn from Prussia, the tendency would be very materially to raise the prices of corn in that district?-I should think indisputably so ; I imagine no large supply permanently could be drawn from that district without a great advance in price.

[The Witness is directed to withdraw.

Ordered, That this Committee be adjourned to the 13th instant. 
M. Attuood, Esq. M.P.

2 June 1836 .
ApPendix to Evidence of the $2 d$ of June 1836.

The Ratios of Gold to Silver from 1760 to 1829 , with the Averages for each Ten Years, and the Total Mean Average for Severty Years.

(Taken from Appendix to a Report of a Select Committee of Congress on Coins, 3oth Junc 1832.)

\begin{tabular}{|c|c|c|c|c|c|c|c|}
\hline & Years. & & $\begin{array}{c}\text { Pure Gold } \\
\text { to } \\
\text { Pure Silver. }\end{array}$ & $\begin{array}{c}\text { Average for } \\
\text { Ten } \\
\text { Years. }\end{array}$ & Years. & $\begin{array}{l}\text { Pure Gold } \\
\text { to } \\
\text { Pure Silver. }\end{array}$ & $\begin{array}{c}\text { Average for } \\
\text { Ten } \\
\text { Years. }\end{array}$ \\
\hline 1760 & - & - & 14.29 to 1 & & 1795 - & 14.77 to 1 & \\
\hline $17^{61}$ & - & - & 13.94 to 1 & & $1796-$ & 14.77 to 1 & \\
\hline $1 ; 62$ & - &. & 14.63 to 1 & & 1797 - & 15.45 to 1 & \\
\hline 763 & - & - & 14.71 to 1 & & $179^{8}-$ & 15.45 to 1 & \\
\hline $1 ; 64$ & - & - & 14.91 to 1 & & $17 \subseteq 9-$ & 14.29 to 1 & 14.94 to 1 \\
\hline 1765 & - & - & 14.69 to 1 & & $1800=$ & 14.81 to 1 & \\
\hline 1766 & $\cdot$ & - & $14.4^{1}$ to 1 & & $1801-$ & 14.47 to 1 & \\
\hline $1 ; 67$ & - & - & 14.45 to 1 & & $1802=$ & 15.23 to 1 & \\
\hline 1768 & - & - & $14.5^{8}$ to 1 & & $1803-$ & 14.47 to 1 & \\
\hline 1769 & - & - & 14.45 to 1 & 14.51 to 1 & 1804 - & 14.67 to 1 & \\
\hline $177^{\circ}$ & - & - & 14.35 to 1 & & $1805-$ & 15.14 to 1 & \\
\hline $177^{1}$ & - & $\cdot$ & 14.36 to 1 & & 1806 & 14.25 to 1 & \\
\hline 1772 & - & - & 14.19 to 1 & & $1807-$ & 14.46 to 1 & \\
\hline 1773 & - & $\cdot$ & 14.73 to 1 & & 1808 & 14.79 to 1 & \\
\hline 1774 & - & $\cdot$ & 15.05 to 1 & & 1809 & 16.25 to 1 & 14.85 to 1 \\
\hline 1775 & - & - & 14.62 to 1 & 14.3 & $1810-$ & 16.15 to 1 & \\
\hline $177^{6}$ & - & - & 14.34 to 1 & & $1811=$ & 15.72 to 1 & \\
\hline 1777 & - & - & 14.04 to 1 & & $1812=$ & 15.04 to 1 & \\
\hline 1778 & - & - & 14.34 to 1 & & $1813-$ & 14.53 to 1 & \\
\hline 1779 & - & - & 14.89 to 1 & 14.49 to 1 & $1814-$ & 15.85 to 1 & \\
\hline 1780 & - & - & 14.43 to 1 & & $1815-$ & 16.30 to 1 & \\
\hline 1781 & - & - & 13.33 to 1 & 13.9 & 1816 & 13.64 to 1 & \\
\hline 1782 & - & - & 13.54 to 1 & 14.8 & $1817=$ & $15.5^{8}$ to 1 & \\
\hline 1783 & $\cdot$ & $\cdot$ & 13.78 to 1 & - & 1818 & 15.42 to 1 & \\
\hline 1784 & - & - & $14.9^{\circ}$ to 1 & 28.7 & $1819-$ & $15.8 \mathrm{a}$ to 1 & 15.41 to 1 \\
\hline 1785 & - & - & 15.21 to 1 & 14.3 & $1820=$ & 15.71 to 1 & \\
\hline 1786 & - & - & 14.89 to 1 & & $1821=$ & 15.98 to 1 & \\
\hline 1787 & - & - & 14.83 to 1 & & $1822=$ & 15.91 to 1 & \\
\hline 1788 & - & - & 14.71 to 1 & & $1823-$ & 15.91 to 1 & \\
\hline 1789 & - & - & 14.89 to 1 & 14.45 to 1 & $1824=$ & 15.64 to 1 & \\
\hline 1790 & - & - & 15.01 to 1 & 14.7 & $1825=$ & 15.69 to 1 & \\
\hline $179^{1}$ & - & - & 14.95 to 1 & 14.9 & $1826=$ & 15.69 to 1 & \\
\hline $179^{2}$ & - & - & 14.43 to 1 & $\longrightarrow$ & $1827=$ & 15.77 to 1 & \\
\hline 1793 & - & - & 15.01 to 1 & 29.6 & $1828=$ & 15.77 to 1 & \\
\hline 1794 & - & - & 15.32 to 1 & 14.8 & $1829=$ & 15.95 to 1 & 15.80 to 1 \\
\hline
\end{tabular}


A Table of the Prices in the Market of Gold and Silver from 1760 to 1819 , taken from Wittenlrall's Lists, and exhibiting the relative Prices of Gold and Silver to each other.



M. Allroool, Esq. M.1'.

2 June 1836 .

Bills relating to Gold and Silver Corss, passed in June 1834.

A BiLl concerning the Gold Coins of the United States, and for other purposes.

BE it enacted by the Senate and House of Representatives of the United States of America in Congress assembled, That the gold coins of the United States shall contain the following quantities of metal; that is to say, each cagle shall contain two-hundred and thirty-two grans fine gold and two hundred and fifty-eight grains standard gold; each half eagle one hundred and sixteen grains fine gold, and one hundred and twenty-nine grains standard gold ; each quarter eagle shall contain fifty-eight grains fine gold and sixty-four grains and a half standard gold; every such eagle shall be of the value of ten dollars; every such half eagle shall be of the value of five dollars, and every such quarter eagle shall be of the value of two dollars and fifty cents; and the said gold coins shall be receivable in all payments, when of such weight, according to their said respective values; and when of less than such weight at less values, proportioned to their respective actual weights.

Sect. 2. And be it further enacted, That all standard gold and silver deposits for coinage after the thirty-first day of July next shall be paid for in coin under the direction of the Secretary of the Treasury within five days from the making such deposit, deducting from the amount of said deposit of gold and silver one-half of one per centum; provided that no deduction shall be made unless said advance be required by sucli depositor within forty days.

Sect. 3. And be it furller enacted, That all gold coins of the United States minted anterior to the thirty-first day of $J$ uly next shall be receivable in all payments at the rate of ninety-four and eight-lenths of a cent per pennyweight.

Sect. 4. And be it further enacted, That this Act shall be in force from and after the thirty-first day of July in the year one thousand eight hundred and thirty-four.

As AC'r regulating the value of certain foreign Gold Coins within the United States.

Be it enacted, \&ic. That from and after the thirty-first day of July next the following gold coins shall pass current as money within the United States, and be receivable in all payments by weight for the payment of all debts and demands, at the rates following; that is to say, the gold coins of Great Britain, Portugal and Brazil, of not less than twenty-two carats fine, at the rate of ninety-four cents and eight-tenths of a cent per pennyweight; the gold coins of France, nine-tenths fine, at the rate of ninety-three cents and one-tenth of a cent 464 .

$$
\text { Y Y } 2
$$


M. Attwood, Est. per pennyweight; and the gold coins of Spain, Mexico and Colombia, of the fineness of M.P. $\quad$ twenty carats three grains and seven-sixteenths of a grain, at the rate of eighty-nine cents and nine tenths of a cent per pennyweight.

2 June 1836. Sect. 2. And be it further enacted, That it shail be the duty of the Secretary of the Treasury to cause assays of the aforesaid gold coins made current by this Act to be had at the mint of the United States at least once in every year, and to make report of the result thereof to Congress.

An Act regulating the value of certain foreign Silver Coins within the United States.

Be it ellacted by the Senate and House of Representatives of the United States of America in Congress assembled, That from and after the passage of this Act the following silver coins shall be of the legal value and shall pass current as money within the United States, by tale, for the payment of all debts and demands, at the rate of one hundred cents the dollar ; that is to say, the dollars of Mexico, Peru, Chili and Central America, of not less weight than four hundred and fifteen grains each, and those re-stamped in Brazil of the like weight, of not less fineness than ten ounces fifteen pennyweights of fine silver in the Troy pound of twelve ounces of standard siiver; and the five-franc pieces of France, when of not less fineness than ten ounces and sixteen pennyweights in twelve ounces Troy weight of standard silver, and weighing not less than three hundred and eighty-four grains each, at the rate of ninety-three cents each.

Sect. 2. And be it further enacted, That it shall be the duty of the Secretary of the Treasury to cause assays of the aforesaid silver coins made current by this Act to be had at the Mint of the United States at least once in every year, and to make report of the result thereof to Congress.

Die Lune, $13^{\circ}$ Junii, 1836.

\section{The Lord WYNFORD in the Ciair.}

\section{Mr. William Blacker is called in ; and Examined, as follows :}

Mr. W. Blacker.

13 June 1836 .
5604. YOU reside in the North of Ireland?-I reside in the town of Armagh. 5 tio5. How long have you been acquainted with agriculture in Ireland?-I have been in the management of different landed properties 22 years.

5606 . To a large extent ?-To a very considerable extent.

5607 . What is the state of agriculture now in Ireland?-I think agriculture itself is improving; the farmer s skill is improving very much.

5608 . Is the market improving?-No; that is falling, and has been for many years back; but the skill and exertions of the people are improving.

5609 . Can you state the prices of wheat in the different markets of Ireland ?$\mathrm{No}$; I cannot give a detailed account of them.

5610 . Have you any thing to state which could be done by Parliament in any respect to ameliorate the condition of the agriculturists in Ireland, or are they at present in a prosperous condition :-I think the best thing I can do is to mention the points I have endeavoured to establish in favour of agriculture in a late publication of mine, entitled "The Claims of the Landed Interest to Legislative Protection," published by Ridgway. I have endeavoured to show that the produce of the soil is the great source of the riches of the state, that manufactures are then most important to the wealth and prosperity of the nation when the national produce supports and employs the operative, and according as this ceases to be the case the importance of manufactures diminishes in a like ratio. I have likewise endeavoured to show that the burthens of a country are felt like the burthens of an individual, according to the income he has to meet them; and therefore that the national income, in the present state of Great Britain, ought to be kept up to the utmost practicable point, let that income consist in what it may; and as an incumbered landlord cannot afford to lower the rents of his estate, so neither can an incumbered nation afford to lower the rents of its territory, which, with the other branches of income, forms the source from which the revenue of the state is raised. I have likewise endeavoured to slow, that to keep up the income of the community it is absolutely necessary to make money as plenty as it can be made, without departing from a metallic basis; and I contend that an obligation to pay in specie is a sufficient and undoubted check to over-issue, and all the evils formerly produced by the Bank Restriction Act, of which Scotland and Ireland are examples, where joint-stock banks and one-pound notes have been of incalculable benefit, checked by the gold circulation of England; and I endeavoured to show that the same benefits would be conlerred by the same system on the empire at large, 
large, and would be checked by the continental markets, which regulate the prices of the exports of the empire in like mamner as England regulates the prices of the exports of Scotland and Ireland. I have therefore come to the conclusion, that

Mr. W. Blucker.

13 June 1836 . the prices of agricultural produce (upon which all kinds of fixed income, of whatever kind it may be, mainly depends) shall be kept up to that point which will swell the income of the community to the greatest possible amount, at the same time keeping prices under that point which would prevent our manufactures from successfully competing in foreign markets; and I liave further endeavoured to show that the obligation to pay in specie will always accomplish this; for, should the cost of manufacture at any time exceed the price the continental markict afforded, there must, in the natural course of things, be a stop to export, and of consequence the exchanges will be immediately affected. This will produce dircctly a drain upon the banks for specie, which will at once cause them to reduce the extent of the circulating medium to the point required; and although the suggestion I have offcred, of affording assistance to the banker by enabling him to procure a discount for the securities he possesses by Exchequer bills, would, as it appears to me, effectually secure the public and the banker from any panic or sudden shock to commercial credit, yet the safety valve which this affords is so wrought that it is made the interest of the banker gradually to confine his issues to that account which the circumstances of the country require. I have also endeavoured to show that the present graduated scale of duty on corn, although affording a good protection in years of plenty, affords none in years of scarcity; and as there is no advantage in keeping up a prohibition to a scale of prices that home competition in ordinary seasons will not allow prices to arrive at, 1 recomInend (in case a fixed duty of $20 \mathrm{~s}$. in all cases is not agreed to) that the prohibitory duty shall not extend to the high rate it does at present, and that a fixed duty should be adopted when prices reached the height contemplated; which fixed duty, I contend, would be levied off the foreigner, and would not be paid by the English consumer. I further contend that home competition has of late lowered wheat to a non-remunerating price, and that to lessen that redundancy of produce which has occasioned that result, other kinds of agricultural produce ought to be equally protected, so as to enable the farmer to cultivate other crops; and I show that by protecting flax and butter, land would be turned to their cultivation in Ireland and Scotland which now inundate the English markets with at least $2,000,000$ of quarters of grain ; and I maintain that such a moderate duty as would be necessary to give this protection would be paid by the foreigner, and not by the English consumer; and I further contend that home competition will inevitably reduce the price of all agricultural produce to the lowest price it can be produced at, and that the interest of the community at large is, that we shall not be reduced to depend on foreigners for any thing which our own soil and climate is suited to. The truth of the above is shown by the low price wheat has fallen to since the prohibition arising from the present corn laws took place, and also by the butter trade, the duty on which yields a large revenue to the state, which is so much levied off the foreigner; and it is also proved by the advance which has taken place in the price of rape-seed since the protecting duty has been taken off, which has destroyed almost entirely the growth in Ireland of a crop the best suited of any to the bogs of that country, and has at the same time raised the price upon the English consumer, the whole profit going to the foreigner; and the very same thing would happen as I have stated in grain or butter if sufficient protection is not afforded; if that is not afforded, for a short time (whilst the home producer is gradually ruining himself in the contest with the foreigner) the prices will go lower and lower until he is broke, and when we are thereby left dependent upon the foreign supply the prices will advance higher than ever. The Emperor of Russia levies a duty of about $2 \% 10 \mathrm{~s}$. per ton as the export of tallow now, in like manner as the King of Prussia attempted to do on corn ; this could not be done, only for our giving the advantage of our market without proper protection; and the Emperor of Russia is now pocketing, at the expense of the British consumer, that which, if laid on in this country, would be paid into the British treasury at the expense of Russia.

5611 . Do you know that fact? - I was told it by a Russian merchant, and I have no doubt whatever of it.

5612. What is the price of labour in Ireland?-The price of labour in the county of Armagh is 1 s. a day in summer, and reduced to $10 d$. in winter.

464 . 
Mr. IV. Blacker. 13 June $18{ }_{3} 6$.
5613. Is not that a high price in Ireland ?-It is higher than in the south of Ireland.

5614. What is the price of labour in the soutl of Ireland ?-Last year I saw people working on the roads in the south of Ireland, and breaking stones, at a price at which I was told that they would not realize above $6 d$. a day.

5615. Is there any thing clse you would wish to add to your evidence? - I do not know any thing that would be so efficient as allowing us to cultivate flax in Ireland, which we are not able to do without a protecting duty. We cannot compete with Russia, for Russia can send flax cheaper to Dundee market than we can from Armagh. The principle for which I contend is, that all produce, whether grain or flax, will always go to the best market, and the English market will be better than any other market the continental growers can send one or the other to, even supposing we levy a regular fixed duty on the importation into this country to any moderate extent. I also strongly recommend that the session shall not be allowed to terminate without a permanent duty on corn being adopted, to take place when prices shall have arrived at whatever rate may be deemed most advisable. The short quantity of wheat now in the ground, and the appearance of the crop, together with the fact that all the low qualities are almost out of the market, lead me to apprehend that prices may, in case of a bad harvest, rise to the rate at which free importation would be permitted, which I should consider most ruinous to the community. I also beg to add, that the Exchequer bill issue, which I have already alluded to, and which I propose should be made a legal tender in discharge of deposits by the banker, would even be a great advantage without being made a legal tender, in case the said Exchequer bills were received as cash at the public offices, because the banker could then be secure of turning them into cash whenever his occasions required, and by this accommodation 110 possible injury could arise to any one, and the assistance in this way to the banker is in fact only another mode of assisting the mercantile and manufacturing interests through lim, which was formerly given directly to themselves upon a deposit of goods. Without some such relief as this, to enable the banker to keep up his issues when there is an export of gold, I do not see how any steady amount of circulating medium can, under such circumstances, be maintained, and I think all objections to the plan I have proposed are successfully answered, page 237 of the publication I have alluded to.

5616. You are of opinion the present duty on those articles, flax and hemp and butter, is not sufficient to protect the growers, even in Ireland?-Certainly not. There is no duty on flax; there is a duty on butter, which has produced a great revenue to the country without raising the price to the consumer, and that is a direct proof of that which $I$ assert.

5617 . What is the nature of the culture about Armagh? - It is almost entirely arable land; there is but little thrown into pasture. Latterly it has become pretty generally the practice to cut the grass, and bring it to the cattle in the house. There is no pasture at all on a number of farms; there is not the breadth of this roon in pasture sometimes on a small farm.

5618. The grasses you cut are artificial grasses ?-Yes; clover and rye grass.

5619 . Is it a country of rich soil generally ?-The soil is very varions; some is very poor, and other exceedingly good; but there is no soil that, if the cattle are fed in the house, the manure will not enrich in a few years.

5620. You find stall-feeding the cattle is a great benefit?-Yes; that the making of manure is the great secret of farming.

5621 . Is that a new practice with you? - It is a new practice almost entirely, though it has been long insisted on by agricultural writers. I have been instrumental a good deal myself in bringing it into effect by offering to the tenants encouragement, and lending them assistance in every thing they require, if they will follow the advice of an agriculturist that I bring for the purpose of instructing them. His business is to go round from one farmer's house to another from Monday morning to Saturday night, pointing out where any one lias been going wrong, and showing him what is right.

5622. All your cattle are stall-fed?- It is coming to that. I allude particularly to Lord Gosford's estate and Colonel Close's.

5623 . Is that in small farms or in large farms?-In very small farms.

5024. Averaging how many acres:- Not above eight, and many so low as four and five acres.

5625. What are the largest :- In the low lands we should consider 40 acres a very 
very large farm; in the mountainous part of the comtry there are still larger farms of a pasture nature.

5626. Is that cultivated with spade husbandry or the plough? - Partly with one and partly with the other. Generally a small farmer is anxious to get the assistance of a plough to save his spade labour, and if he can get that in the proper season he is glad to avail himself of it; if not, he takes to the spade.

5627. Unless they club together to keep cart-horses, it is not worth while for only one to kecp a team?-The practice is, on the townlands, for one or two of the principal tenants to join and keep a horse each and a plough in partnership for the rest of the tenantry.

5628. What are generally the rents in that part of the country ?-The rents in the county of Armagh are higher, I think, than in any other part of Ireland. The population is calculated to be about five souls to four acres, a more dense population than perhaps any other agricultural county; but nevertheless we are a very large exporting county, and have a very large proportion of the surface which is unprofitable land.

5629. What does the land let at?-I think for land in the low lands the average would be fully a guinea an English acre; the mountainous lands are a little cheaper.

5630. Do you mean to say that good land in the neighbourhood of Armagh does not let higher than a guinea an acre?-It lets a great deal higher in the neighbourhood of Armagh.

5631. The question does not refer to land used for accommodation purposes, but the land at a distance from the town ?-It depends a good deal upon the nature of the estate, whether it is the property of a large proprietor; they generally let their land on more moderate terms; but there are instances of lands let by the landed proprietors at a guinea an acre that were set afterwards at $35 \mathrm{~s}$. and $2 l$. to under-tęnants again.

5632. You have the system of middlemen between the landlord and the tenant?-In some cases it still remains, but as fast as the old leases fall out, the landlord in the north of Ireland takes the cottier into his own hands, and I attribute a great deal of the prosperity of that part of the country to that circumstance.

5633 . Is there a tendency to great subdivision, or are the small farms run together?-The landlord generally wishes to run the small farms together, but he cannot do that without turning out the population, and I think, generally speaking, that is not resorted to in the north now.

5634. You yourself do not much approve of that :-No, I do not. For the purpose of trying an experiment upon my own principles, I took the agency of a small property in the county of Tyrone which was under very bad circumstances, just to try what could be made of it; and I took all the cottiers, and allocated them upon the edges of a large bog which was in the property, and they are doing well there. I think I was never in advance more than 127l., and out of that I have realized a well-paid rental of $66 l$. a year, and the most part of that loan is. paid up.

5635. You know what the rents are in England, generally speaking? - I have inquired here and there in passing through the country.

5636 . Do you not think the rents in Ireland are as high as they are in England?-I do.

5637. Are they higher?-I think, in many instances, they are higher for the same quality of land.

$5^{6} 3^{8}$. And well paid? - Yes. I was furnishing my accounts the other day to Lord Gosford, and there was only an arrear of $10 \mathrm{l}$. upon one of his manors, which was near $4,000 \mathrm{l}$. a year; and this tenant was originally, when I got the management of the property, in debt $60 l$. or $70 \mathrm{l}$., but he has paid it all up now but that $10 l$, and that will be paid this year, I hope.

5639 . Is not the quantity of corn land increased very much in Ireland ?-I should think it was.

5640. Your lrish acres are larger in Ireland, are they not?-We have the statute acre now in Armagh.

5041 . Is it the case in the county of Armagh generally, or only nearer towns, that the land lets at a guinea an acre?-I think that would be the average rent of arable farms; perhaps from $22 \mathrm{~s}$. to $23 \mathrm{~s}$. would be nearer to the average of the low lands.

404.

Y $\times 4$

5642. You

Mr. W. Blacker.

23 June 1836 . 
Mr. W. Blachcr. 5642. You say there is a great exportation from Armagh ?-Yes; there is a very considerable exportation of wheat and butter, and oats and pork.

5643. That is sent to the English market?-Yes.

5644. Can you form any opinion what quantity of those articles comes to the English market in the course of the year?-I cannot. The only mode of estimating the quantity is by the shipments at the several ports.

5645 . Have not those exports increased very much of late years ? - 1 think they were increasing very much within the last two years; and I rather think the growth of flax, which has been revived by the failure of the flax crop on the Continent, has checked, in a great measure, the increase of the exports in corn from the north of Ireland; 1 think it is scarcely so much as it was ; but this year, in the whole north of Ireland, in the flax-growing country, there is not the eighth part of the wheat crop sown that there was two year ago.

5646. It is applied to flax?-Yes.

5647 . Will that continue to be the case if there is a good crop of flax on the Continent?-Certainly not. We were formerly driven out of that crop altogether, and shall be again, no doubt.

5648 . There was a very bad crop of flax the year before last on the Continent? -Yes.

5649. Where does your flax go? - The great demand is from Dundee.

5650. You have suggested, as an encouragement to agriculture, a duty on the raw materials. Are you not aware that if a Dundee manufacturer has his price of flax enhanced to him he may run the risk of not being able to stand the competition of other countries? - Yes, I am perfectly aware of that; but, talking as a flax grower, I know that it is not my interest to ruin the flax-spinner or the linen trade generally, for that is the market we look to for the sale of our flax, and I would not contemplate it. Even if there was a complete prohibition put on foreign flax the price of the home-grown flax would keep within 25 per cent. of what it has been the last 18 months, and during the last 18 months the prosperity, not only of the flax-grower but of the flax-spinner and the linen manufacturer, has been very great, so that that shows they are not incompatible; but suppose it was incompatible with the foreign export of linen, I think I have shown in my publication that the national wealth and prosperity would be more increased by the value of the home growth of flax than it could be five times over by all the profit derived from foreign export; therefore, if they were incompatible, that must be preferred which is most for the interest of the community; but I assert that they are not incompatible; and that, under a proper protection, home competition would have the price so as to enable the flax-spinner and the linen manufacturer to carry on a prosperous trade.

5651 . Do you save your own seed in flax? - That is coming into practice at present, but generally we have it from America, and Holland and Russia; a great deal from Rigra.

5652. An opinion has prevailed generally that the climate of Ireland will not ripen the seed? - It will ripen the seed, and as fine seed as can be put into the ground.

5653. Then why do yon import it?-It gives a good deal of trouble, and people sowing small quantities do not think it worth while to be at the trouble of it.

5654 . Should you think that the grower of flax would be benefited by putting a duty on the importation of foreign flaxseed ? - I think that would tend to increase the value of the produce of the land, for different flax growers, who have made it the practice of saving the seed, have gained from $8 l$. to $9 l$. an acre by the seed, and without having the flax very little, if at all, deteriorated.

565.5. Can it be desirable so far to reduce the price of home-grown flax as to prevent its being grown at home merely for the purpose of promoting manufactures? - I should say decidedly not, and that any person who goes into a calculation of that will see that the home growth is five times over more important to the nation than any profit on the foreign trade. The linen manufacture at present has a complete monopoly of the home consumption of linen, because there is a duty of 40 per cent. on the import of foreign linen, therefore the only question is as to the foreign trade.

5656 . There is a protecting duty of $3 l$. on the import of flax, is not there?-I am not aware of that; it is quite free.

5657. While the manufacturer is protected by the duty of 40 per cent.?-Yes; and 1 strongly pift forward, that the only reason that the manufacturer can give for 
calling on the country to give him that protection is on account of the cheap rent and the cheap labour of the Continent, that cnables the foreigner to undersell him; that cheap rent and cheap labour just operate on the growth of flax as much as it does on the linen manufacturer's trade; therefore, if one is entitled to protection from that circumstance, the other is also. In my publication I have given the extent of labour which would be required for the cultivation of flax as vastly above the entire labour that is employed in the whole manufacture of linen, both for home and foreign consumption.

\section{[The Witness is directed to withdraw.}

Mr. Carter Fairbrother is called in ; and Examined, as follows:

5658. YOU are a bailiff to Lord Salisbury? - I am.

5659. Have you prepared a table of what flour might be produced from five Mr. C. Fairlirother, bushels of wheat, and what quantity of bread may be made from it 24 hours after baking?-I have.

[The same is read, and is as follows:]

Price and Produce of Five Bushels of Wheat, 31 st May 1836.

\begin{tabular}{|c|c|c|c|c|c|c|c|c|c|}
\hline \multirow{2}{*}{$\begin{array}{c}\text { Price of } \\
\text { Five Bushels of } \\
\text { Wheat. }\end{array}$} & \multirow{2}{*}{$\begin{array}{c}\text { Weight of } \\
\text { Five Bushels of } \\
\text { Wheat. }\end{array}$} & \multirow{2}{*}{$\begin{array}{l}\text { Cost of } \\
\text { grinding. }\end{array}$} & \multicolumn{4}{|c|}{ Produce of Wheat. } & \multicolumn{3}{|c|}{$\begin{array}{l}\text { Weight of Brad Twenty-four } \\
\text { Hours alter babing. }\end{array}$} \\
\hline & & & Firsts. & Scconds. & Pollard. & Bran. & Firsts. & Seconds. & $\begin{array}{l}\text { Waste in } \\
\text { grinding. }\end{array}$ \\
\hline \multirow[t]{2}{*}{$33 s}$. & \multirow[t]{2}{*}{315 lbs. } & \multirow[t]{2}{*}{$2 s .6 d$} & \multirow[t]{2}{*}{$84 \mathrm{lbs}}$. & \multirow[t]{2}{*}{$141 \mathrm{lbs}$. } & \multirow[t]{2}{*}{$26 \mathrm{lbs}}$. & \multirow[t]{2}{*}{$54 \mathrm{lbs}}$. & \multirow[t]{2}{*}{$11.3 \frac{1}{2}$} & $\begin{array}{l}174 \\
113 \frac{1}{2}\end{array}$ & \multirow[t]{2}{*}{$10 \mathrm{lbs}}$. \\
\hline & & & & & & & & $287 \frac{1}{2}$ & \\
\hline
\end{tabular}

5660 . What is the price of flour a sack?-I think about $2 l$. or $2 l .2 s$.

$566 \mathrm{~s}$. Is the price of flour double the price of wheat?-No; wheat in Hertfordshire is sold by the load, that is five bushels; the quarter is eight bushels. I have the produce of flour from five bushels, which is $225 \mathrm{lbs}$; that is one pound more than a sack. It appears the price of flour in London is $2 l$. per sack, or $10 s$. a bushel.

5662. Can you state the price of the bread?-The value of bread is somewhere about $7 d$. a quartern, four pounds five or six ounces.

5663 . How much would the bread be worth? -Nearly $1 \frac{1}{2} d$. a pound. The amount of bread is $287 \frac{1}{2}$ pounds, $1 / .15 \mathrm{~s} .10 \mathrm{~d}$.; then there is the bran and pollard, $1 s .6 d$. ; it is generally about $1 s$. a bushel, and there is a bushel and a half, making $1 l .17 \mathrm{~s} .4 \mathrm{~d}$.; but I imagine the bread is dearer here than $1 \frac{1}{2} d$. a pound; I believe it is here $2 d$.; that will make $2 l .3 s .4 d$.

5664 . What is the worth of a sack of the best flour? -I think the price of the best flour is $40 \mathrm{~s}$.

5665. What is the price of second flour ? - I believe it varies from about $4 s$. to $5 s$. a sack less.

5666. At what is wheat selling in Hertfordshire :-In Hertfordshire this week wheat sold at $33 \mathrm{~s}$.; I believe it is from $33 \mathrm{~s}$. to $35 \mathrm{~s}$. per lcad, that is five bushels. Not being prepared with any calculation, I cannot answer to these questions correctly, but merely filled up the table sent under the several heads as stated.

[The Witness is directed to withdraw.

The Lord Kenyon (a member of the Committee) communicated to the Committee information he had received from his bailifl, that five families of labourers in his Lordship's employ, all of them having allotments of land, consumed one half bushel of wheat weekly, one family being three in number, two families four in number, and two families five in number; the wages of the labourers being some $10 s$. and some $12 s$. a week.

[Committee adjourned. 


\section{LIST OF THE APPENDIX.}

No. 1.-Statement showing the Average Rate per Pound of the Land Tax in certain Places, upon the Rental assessed to the inhabited House Tax - - - - - $-{ }_{-} \mathrm{C}_{3}$

No. 2.-Statemext showing the Average Rate in the Pound at which the Land Tax is charged in the sereral Counties in England and Wales, and in Scotland; taking the Value at three-fourtlss of the $\Lambda$ mount assessed to the Property Duty in $1815 \quad-\quad$ - $\quad 3^{6} 6_{4}$

No. 3.-Return to an Order of the House for an Account of the Number of Stock (distinguishing the various kinds), and of the Amount of Butter, Beef, Pork, Bacon, and Hams, brought into Great Britain from Ireland, from 1826 to 1835, both years inclusive $-\quad-\quad-\quad-\quad--_{-}-{ }_{-}-365$

No. 4.-Return to an Order of the House fur an Account of the Number of Stock 'distinguishing the various kinds), and of the Amount of Butter, Beef, Pork, Bacon, and Hams, brought into Great Britain from Ireland, from 1826 to 1835, both years inclusive

No. 5.-Av Accoust of the several Quantities of Foreign Grain, Wheat, Barley, Oats, Rye, Beans and Peas, Meal and Flour, imported into His Majesty's Colonies in America, the Islands of Guernsey, Jersey, Alderney and Sark, and the Isle of Man, from Foreign Parts, in each of the years from 1815 to 1835, both inclusive - $\quad$ - 366

No. 6.-As Accoust of the annual Average Prices of Wheat, Barley, Oats, Rye, Beans, and Peas, in the Narket of Mark-lane, in each year from $181 j$ to 1835 , buth inclusive - 370

No. 7.-As Account of Foreign Grain, Wheat, Barley, Oats, Rye, Beans and Peas, Flour and Meal, brought into Consumption in Great Britain, in each year from 1815 to 1835, both inclusive - - _ - _ - - - _ - - - - 39

No. 8.-Av Accoux $\mathrm{T}$ of Grain, Wheat, Barley, Oats, Rye, Beans and Peas, Flour and Meal (other than Foreign), brought into Consumption in Great Britain from Ireland, His Majesty's Colonies in America, the Islands of Guernsey, Jersey, Alderney and Sark, and the Isle of Man, specifying the Quantity of each Sort of Grain, Flour and Meal, brought from each of the afore-mentioned places, in each of the years from 1815 to $\mathbf{1 8 3 5}$, both inclusive, and in the last year the Importation being detailed by month -393

No. 9.-An Account of the Prices of Beef, Mutton, Veal, Pork, Cheese and Butter, at Smithfield and Leadenhall Markets, for each of the years from 1815 to 1835 , buth inclusive

No. 10.-Av Account of the Quantities and Prices of Irish salted Beef and Pork contracted for from 1813 to 1836 .

No. 11. An Account of the several Articles of Clothing, and the Prices of eacl, in Greenwich, Bethlem, and Chclsea Hospitals, in each year, from 181.5 to 1835 , both inclusive

No. 12.-AN Account of the Number of Stock (distinguishing the various kinds), and of the Amount of Butter, Beef, Pork, Bacon, and Hams, brought into Great Britain from Ireland, from 1815 to 1825 .

No. 13.-A Returx (so far as the same can be furnished), of the Notes of Private and JointStock Banks, in each Quarter, from the year 1825 to the year 1835, buth inclusive - 406

No. 14.-A Return of the Amount of the Liabilities of the Bank of England, distinguishing Bank Notes from Deposits, and the Bank Notes under $5 l$. from those above that Amount, also of Coin and Bullion, distinguishing eacl, in the Bank, and distinguishing Gold from Silver, in eacl Quarter, from the year 1825 to the year 183j, both included 


\section{A P P E N D I X.}

No. 1.

Statement showing the Average Rate per Pound of the Land-Tax in the undermentioned Places upon the Rental assessed to the Inliabited House Tax.

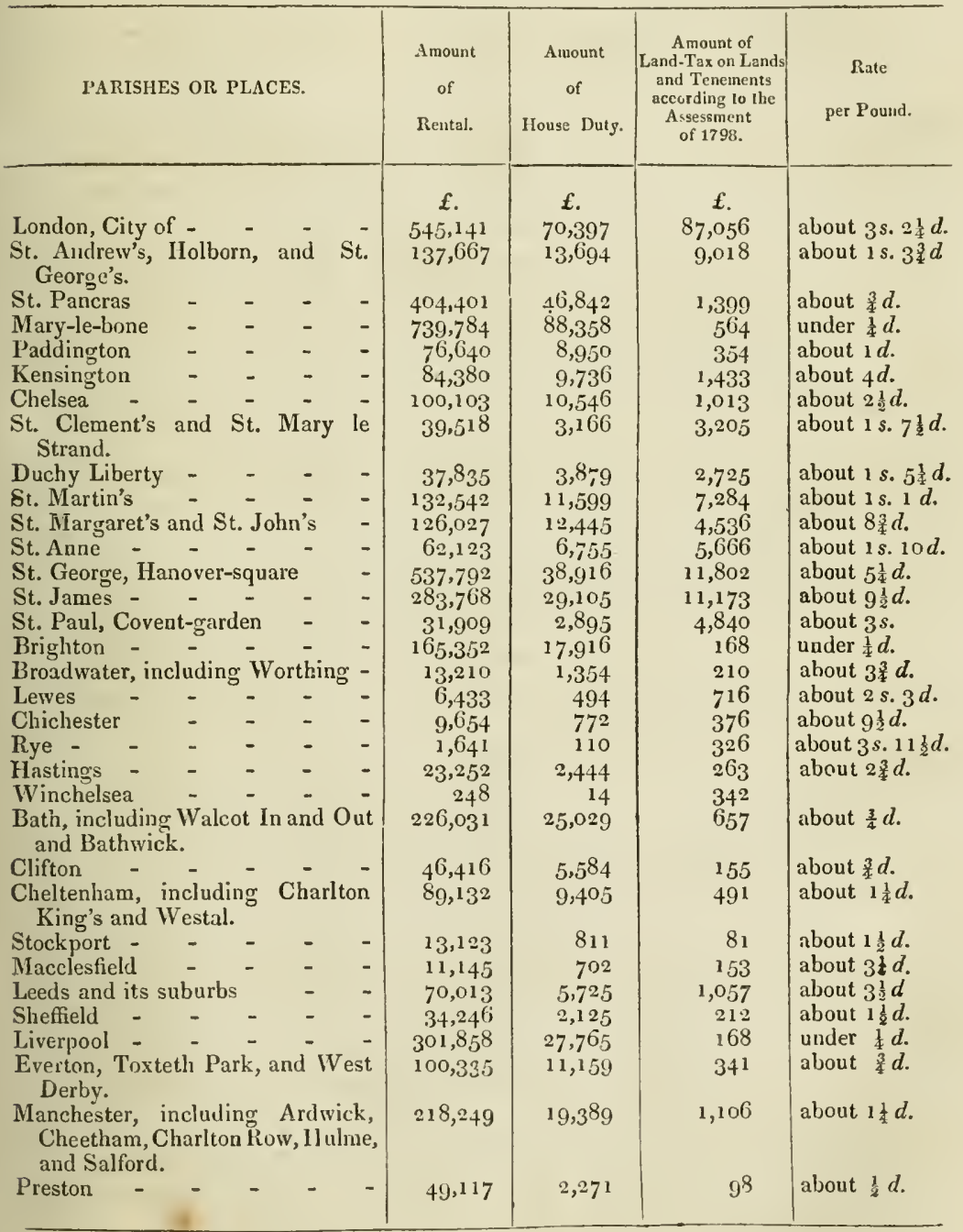


No. 2.

Appendix, No. 2. Statement slowing the Average Rate in the Pound at which the Land Tax is charged in the several Counties in England and Wales, and in Scotland; taking the Value at Three-fourths of the Amount assessed to the Property Duty in 1815.

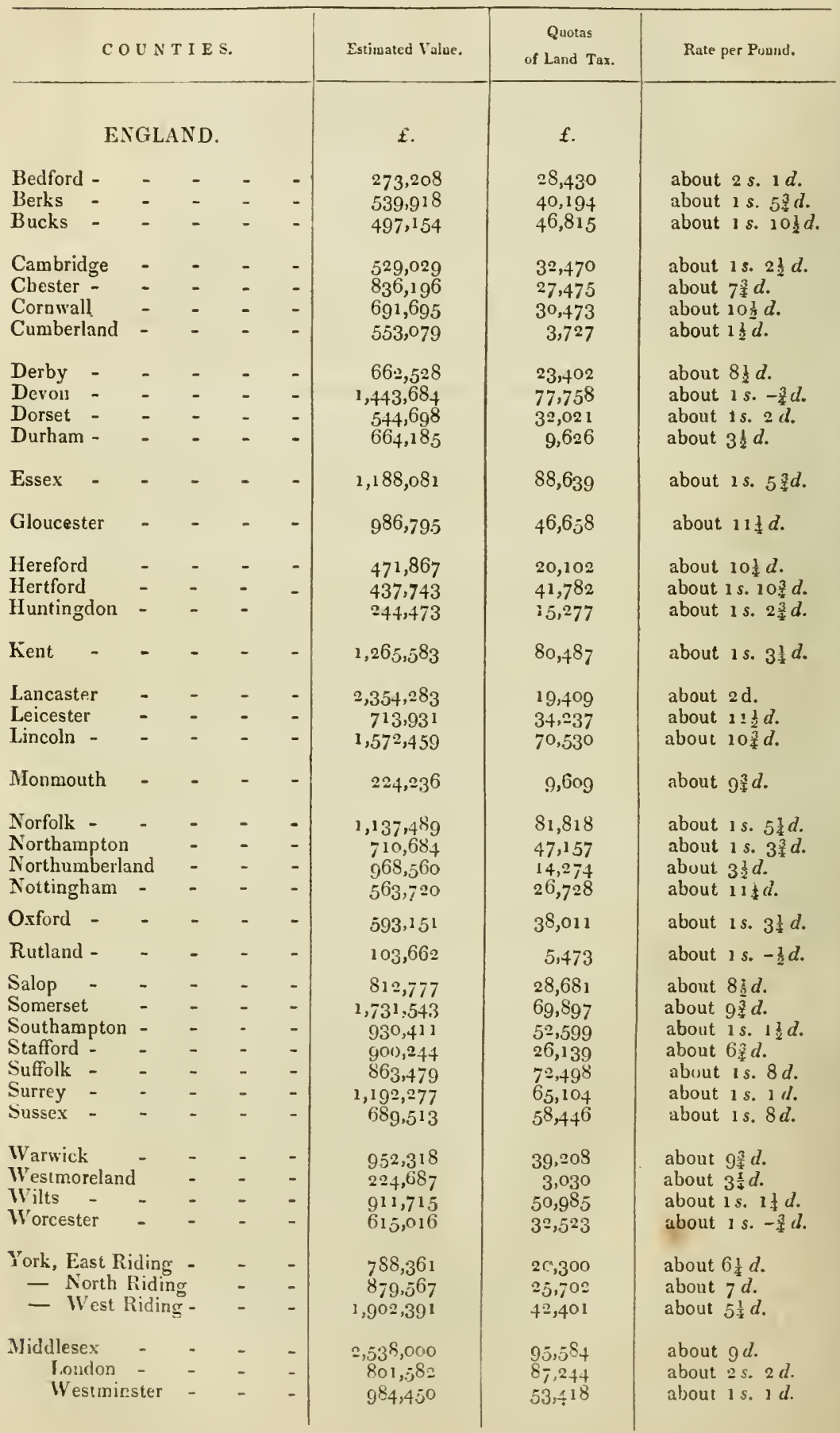


No. 2.-Average Rate at which the Lan D TAx is charged in Linglund, \&c.-continued.

\begin{tabular}{|c|c|c|c|c|c|c|}
\hline \multicolumn{4}{|c|}{ C OUN T I ES. } & \multirow{2}{*}{$\frac{\text { Estimaled Value. }}{f .}$} & \multirow{2}{*}{$\begin{array}{c}\text { Quulas } \\
\text { of Land Tax. } \\
\qquad .\end{array}$} & \multirow[t]{2}{*}{ Rate per Pound. } \\
\hline & VALES. & & & & & \\
\hline Anglesea & - & - & - & 71,075 & 1,536 & about $5 \downarrow d$. \\
\hline Brecon - & - & - & - & $121,49^{2}$ & 2,953 & about $5 \frac{3}{4} d$. \\
\hline Cardigan & - & - & - & 110,112 & 1,278 & about $23 \mathrm{~d}$. \\
\hline Carmarthen & - & - & - & 211,569 & 4,147 & abont $4 \frac{3}{4} d$. \\
\hline Carnarvon & - & - & - & 98,409 & $2,17^{2}$ & about 5$\} d$ \\
\hline Denbigh & - & - & & $234,43^{2}$ & 6,722 & about $7 \mathrm{~d}$. \\
\hline Flint - & - & - & - & $13^{1,337}$ & 2,247 & about $4 d$ \\
\hline Glamorgan & - & - & - & 279,453 & $7,67^{\circ}$ & about $6 \frac{1}{2} d$. \\
\hline Merioneth & - & - & - & $84,3^{87}$ & 2,423 & about $7 d$ \\
\hline Montgomery & - & - & - & 159,063 & 5,804 & about $8 \frac{1}{4}$ \\
\hline Pembroke & - & - & - & 165,181 & 2,903 & about $4 \frac{1}{4} d$. \\
\hline Radnor - & - & - & - & $7^{6,467}$ & 2,652 & about $8 \frac{1}{4} d$. \\
\hline \multicolumn{2}{|c|}{ SCOTLAND } & - & - & $4,9^{8} 9,49^{1}$ & 47,954 & about $2 \frac{1}{4} d$ \\
\hline \multicolumn{2}{|r|}{ Total. } & - & - & $45,222,890$ & $1,906,802$ & average about lod. \\
\hline
\end{tabular}

\section{No. 3.}

RETURN to an Order of The House for an Account of the NumBER of Stock (distinguishing the various Kinds), and of the Amount of Butter, BeEF, PoRK, BacoN

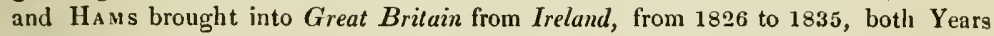
inclusive.

THE Account called for cannot be supplied from the records of this department, nor is there any other official source from which it can be obtained. From the commencement of the period which the Order embraces, the trade between Great Britain and Ireland has been assimilated to a coasting traffic (having been placed upon that footing by the Act ${ }_{4}$ Geo. IV. cap. 30), and goods of the production or manufacture of either division of the United Kingdom, with the exception of the single article of corn, have consequently been allowed to pass from the one country to the other without being subject to any specific entry at the Custom House.

Inspector General's Office,

Custom House, London, 3 oth March 1836 .

\section{William Irving,}

Inspector General of Imports and Exports.

Appendix, No. 3 .

No. 4.

RETuRn to an Order of The House for an Account of the Number of Stock (distinguishing the various Kinds), and of the Amount of ButTer, BeEF, Pork, BAcoN and HAMs brought into Great Britain from Ireland, from 1826 to 1835, hoth Years inclusive.

T'uERE is not any source from which the information thus required can be obtained.

Since the time (1826) when the traffic between Great Britain and Ireland was placed npon the footing of a coasting trade, not any official record lias been taken of the shipments of produce and manufactures from one division of the United Kingdom to the other, with the exception of grain and meal passing to Great Britain from Ireland.

A Return was made from this department in May 1833 to the Select Corrmittee of the House of Commons on Agriculture, and inserted in the Appendix to the Report of that Committee (page 630), stating the quantity of each description of agricultural produce imported into the single port of Liverpool from Ireland, in each of the years 1831 and 1832 . At that time it was explained that the return was not official, but was compiled from papers collected by the managers of a private company. Applications have since been made from this department to the same parties for a continuation of the Accourt, but without success, and no other means have presented themselves for obtaining the desired information.

Statistical Department, Board of Trade, Whitehall, 8th April 1836 . 
No. 5.

AN aCCOUNT of the several Quantities of Foreign Grain, Wileat, Barley, Oats, Rre, Beans Jersey, Alderney and Sark, and the Isle of MIan, from ForEig N

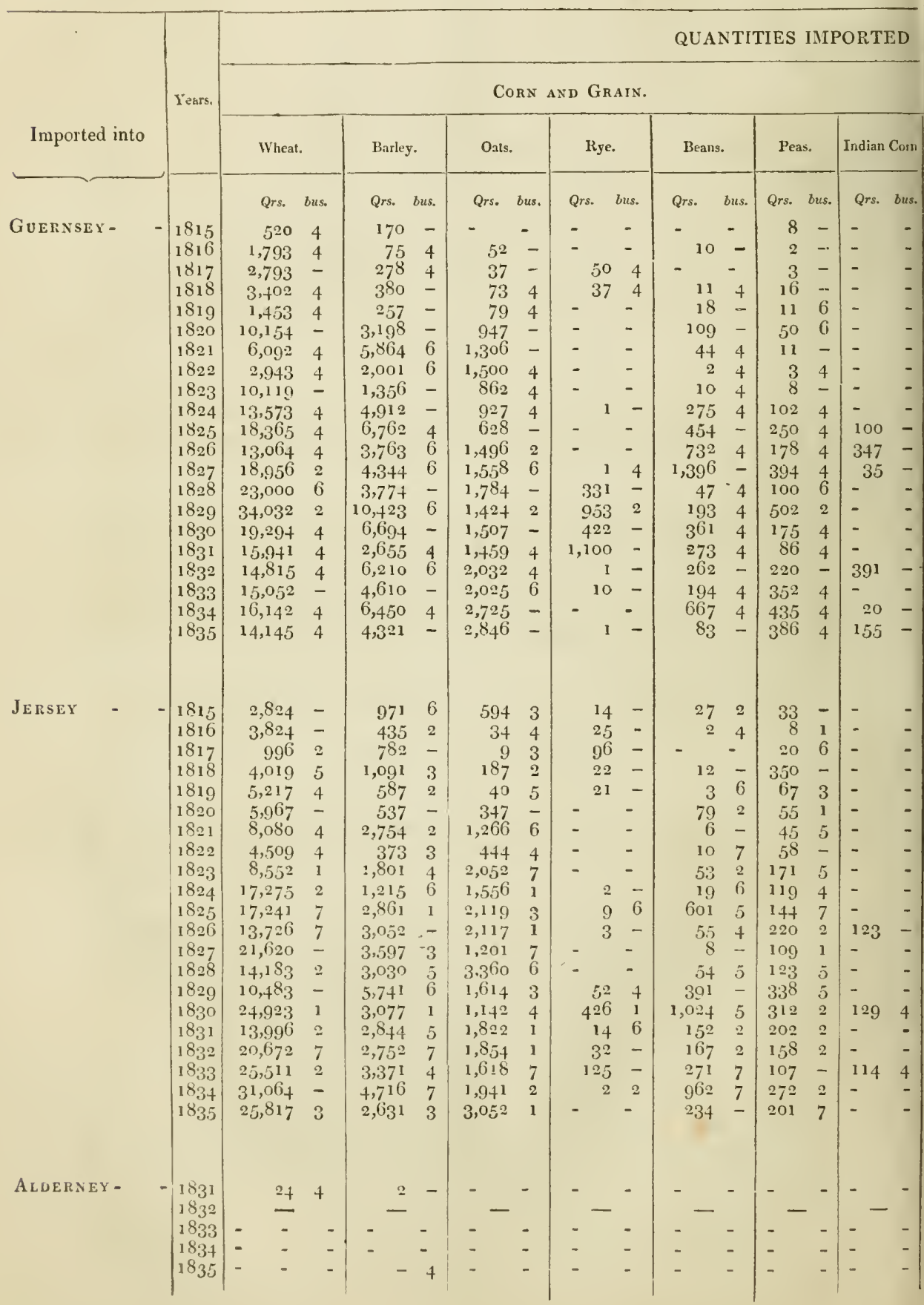


No. 5.

and Peas, Meal and Flour, Imported into His Majesty's Colonies in America, the Islands of Guernsey, PArTs, in each of the Years from 1815 to 1835 , both inclusive.

\section{FROM FOREIGN PARTS.}

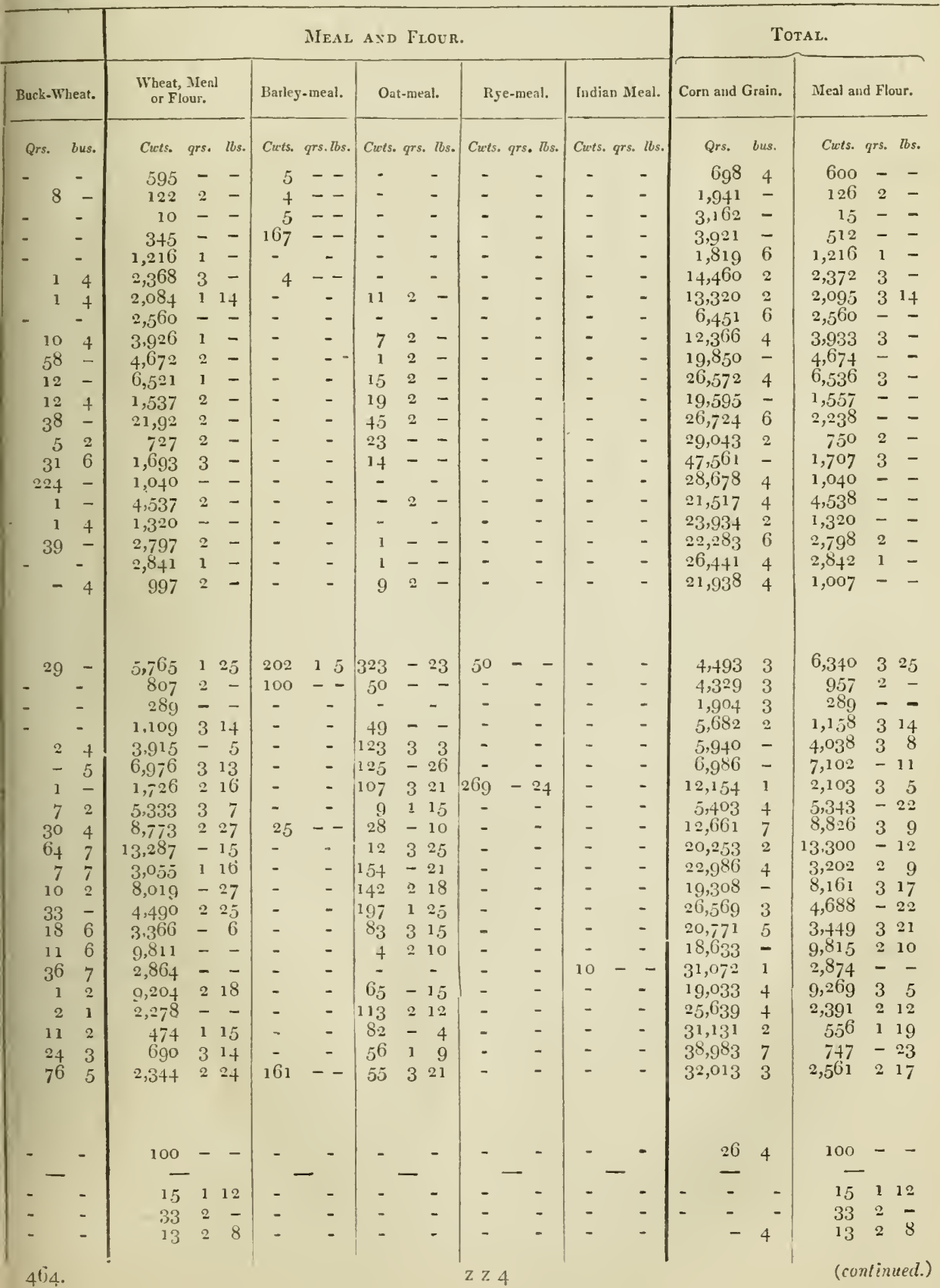


No. 5.-Quantities of Foreign Grain, Sc. imported into His Majesty's Colonies in America, the Istands

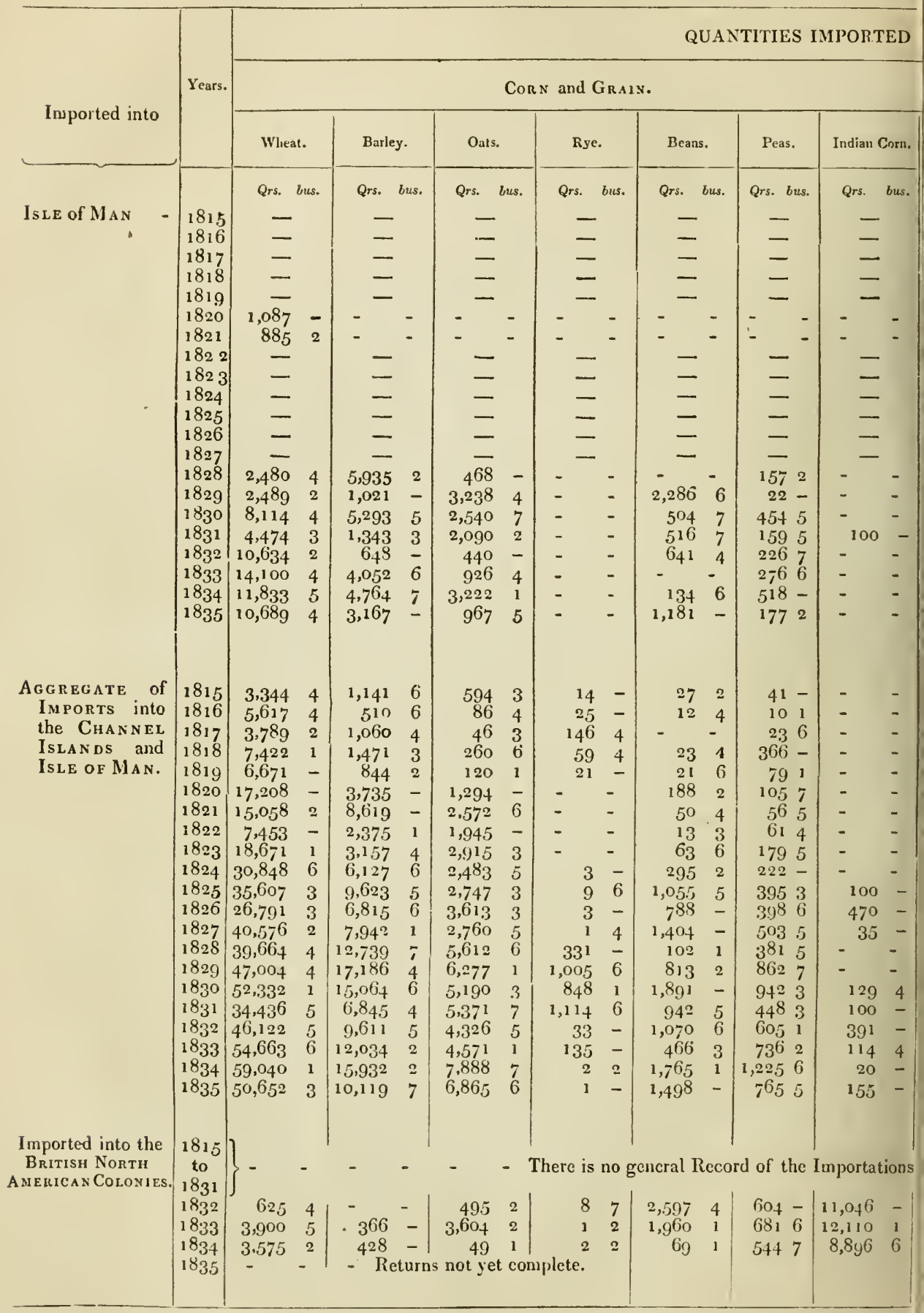

Inspector General's Office, Custom Ilouse, ?

London, 28 th March 1836 . 
of Guernsey, Jersey, \&c., from Foreign Parts, in each Year from 1815 to 1835, both inclusive-continued.

FROM FOREIGN PARTS.

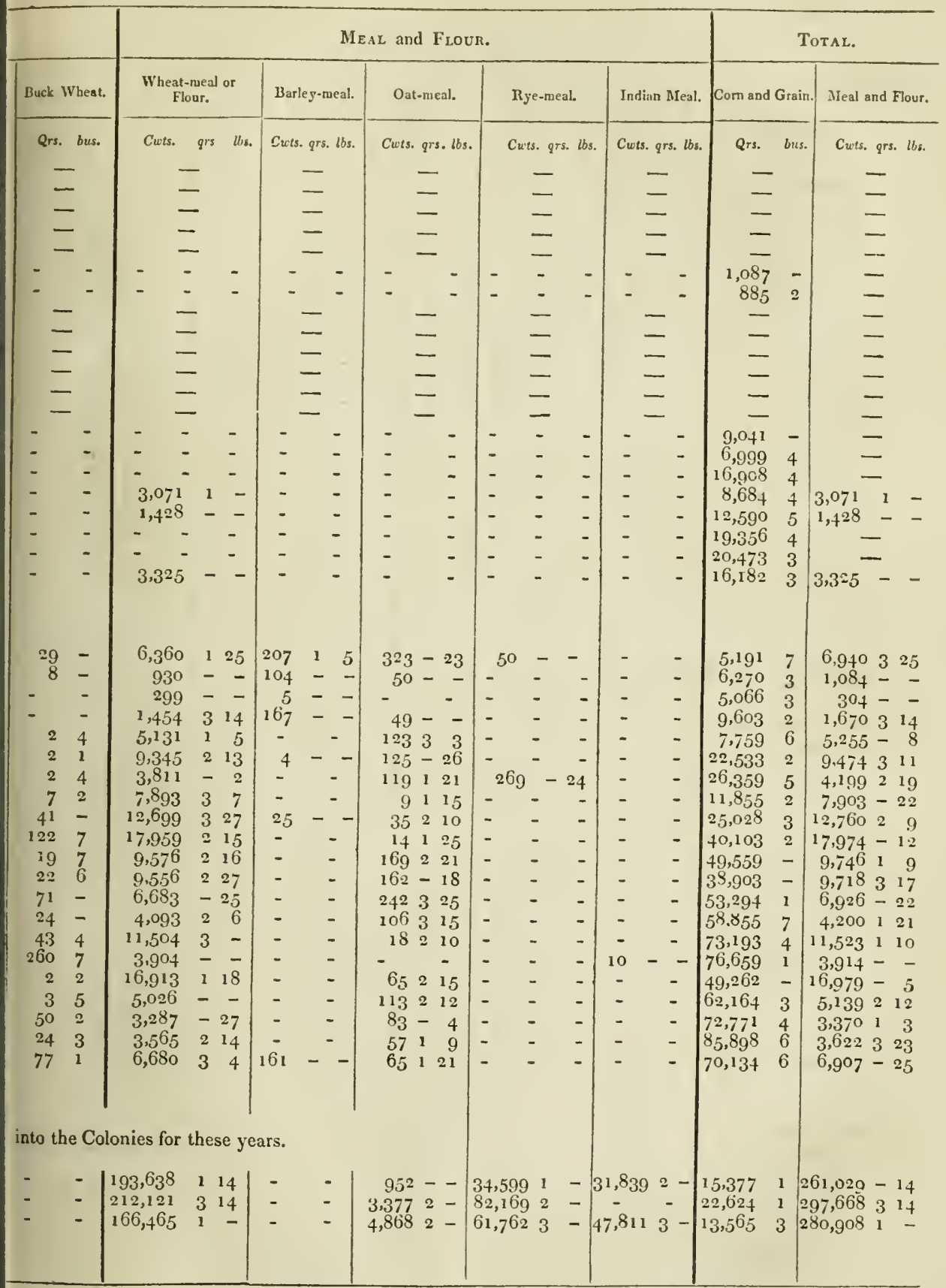

William Irving,

Inspector General of Imports and Exports.

464 
No. 6.

Appendix, No.6. AN aCCOUNT of the Annual Average Prices of. Wueat, Bariey, Oats, Rye, BeANs, and PEAS, in the Market of MARK-LANE, in each year from 1815 to 1835 both inclusive.

1815.

\begin{tabular}{|c|c|c|c|c|c|c|c|c|c|c|c|c|c|c|}
\hline \multicolumn{4}{|c|}{ The Week ending } & WHEAT. & \multicolumn{2}{|c|}{ BARLEY. } & \multicolumn{2}{|c|}{ OATS. } & \multicolumn{2}{|c|}{ RYE. } & \multicolumn{2}{|c|}{ BEANS. } & \multicolumn{2}{|c|}{ PEAS. } \\
\hline 7 & anuary & 1815 & - & $\begin{array}{cc}\text { s. } & d . \\
59 & 5\end{array}$ & $\begin{array}{r}s . \\
34\end{array}$ & $\begin{array}{l}d \\
1\end{array}$ & $\begin{array}{c}s . \\
251\end{array}$ & $d$ & $-^{s .}$ & $d$ & $\begin{array}{r}s . \\
36\end{array}$ & $\begin{array}{l}d . \\
6\end{array}$ & $\begin{array}{r}s \\
4^{8}\end{array}$ & $d$ \\
\hline 14 & - & - & - & $58 \quad 2$ & & 10 & 22 & 5 & - & - & 34 & 7 & 44 & 2 \\
\hline 21 & - & - & - & 584 & 291 & 11 & 23 & 4 & 27 & - & 3210 & 10 & 40 & 8 \\
\hline 28 & 一 & - & - & 558 & 28 & - & 21 & 7 & & - & 301 & 10 & 39 & 3 \\
\hline & Tebruary & & - & 597 & 291 & 11 & 22 & 4 & - & - & 31 & & $3^{8}$ & - \\
\hline 11 & - & - & - & 629 & $3^{2}$ & - & 22 & 3 & 29 & 7 & 311 & & 39 & - \\
\hline 18 & - & - & - & 6710 & $3^{2}$ & 1 & 24 & 7 & 33 & - & 33 & 9 & 39 & 2 \\
\hline 25 & - & - & - & $68 \quad 6$ & 31 & 5 & 23 & 3 & 33 & 10 & 34 & & 40 & 1 \\
\hline 4 & Iarch & - & - & 703 & 29 & 8 & 22 & 8 & - & - & 39 & 2 & 37 & 7 \\
\hline 11 & - & - & - & $64 \quad 4$ & 28 & 6 & 21 & 7 & - & - & $3^{2}$ & 1 & 37 & 3 \\
\hline 18 & - & - & - & 6311 & 29 & 2 & 22 & 11 & - & - & 29 & 9 & $3^{8}$ & 5 \\
\hline 25 & - & - & - & $65 \quad 10$ & 31 & 1 & 22 & 11 & - & - & 30 & 5 & 34 & 4 \\
\hline & pril & - & - & $69 \quad 5$ & $3^{2}$ & - & 23 & 1 & $3^{6}$ & - & 32 & 9 & $3^{8}$ & 9 \\
\hline 8 & - & - & - & $70 \quad 2$ & $3^{1}$ & 8 & 24 & 5 & & - & $3^{2} 1$ & 11 & 42 & 8 \\
\hline 15 & - & - & - & $68 \quad 1$ & 32 & 2 & 24 & 1 & 33 & 11 & $3^{2}$ & 7 & 44 & 9 \\
\hline 22 & - & - & - & 6711 & $3^{1}$ & 8 & 23 & 3 & 33 & - & $3^{2}$ & - & 53 & 4 \\
\hline 29 & - & - & - & 6610 & 31 & 6 & 221 & 11 & 36 & - & 33 & - & 53 & 9 \\
\hline & Iay & - & - & 671 & $3^{2}$ & 1 & 25 & 11 & 35 & 8 & 33 & 5 & 50 & 9 \\
\hline 13 & - & - & - & $\begin{array}{ll}67 & 4\end{array}$ & 33 & 10 & 26 & 1 & $3^{6}$ & $\bar{c}$ & 33 & 3 & 51 & - \\
\hline 20 & - & - & - & 658 & 33 & 10 & 26 & 6 & 35 & 6 & 34 & 6 & 45 & 11 \\
\hline 27 & - & - & - & 677 & $3^{2}$ & 1 & 24 & 4 & - & - & 34 & 1 & 44 & 4 \\
\hline & une & - & - & $65 \quad 5$ & 30 & ] & 25 & 6 & - & - & 33 & 7 & 44 & - \\
\hline 10 & - & - & - & 645 & 29 & 2 & 24 & 7 & $3^{2}$ & - & 33 & 4 & 42 & 5 \\
\hline 17 & - & - & - & 665 & 29 & 1 & 24 & 8 & - & - & 33 & 4 & 49 & 1 \\
\hline 24 & - & - & - & 647 & 28 & 7 & 23 & 8 & 33 & 2 & $3^{2}$ & 4 & 51 & 11 \\
\hline & uly & - & - & $64-$ & 291 & 10 & 23 & 7 & 35 & - & 33 & 7 & 50 & 2 \\
\hline 8 & - & - & - & 625 & 28 & 4 & 24 & 3 & - & - & 33 & 6 & 42 & 8 \\
\hline 15 & - & - & - & 652 & 271 & 10 & 24 & $\delta$ & - & - & 33 & - & $3^{8}$ & 8 \\
\hline 22 & - & - & - & 658 & 29 & 11 & 261 & 10 & 34 & - & 33 & 9 & $3^{8}$ & 3 \\
\hline 29 & - & - & - & $69 \quad 1$ & 31 & 8 & 28 & 1 & 35 & - & 34 & 2 & 39 & 8 \\
\hline 5 & ugust & - & - & 6711 & 33 & 8 & 28 & 1 & - & - & 34 & 4 & 40 & 4 \\
\hline 12 & - & - & - & 658 & 31 & 10 & $37^{1}$ & 10 & - & - & 34 & - & 38 & 3 \\
\hline 19 & - & - & - & $64 \quad 6$ & $3^{0}$ & 7 & 26 & - & 36 & - & 33 & - & $3^{8}$ & - \\
\hline 26 & - & - & - & 616 & 29 & 5 & 25 & - & 36 & - & $3^{2}$ & 11 & $3^{8}$ & 3 \\
\hline & ptemb & & - & $59 \quad 1$ & 28 & 7 & 25 & 9 & 34 & 3 & 32 & 4 & 37 & 5 \\
\hline 9 & - & - & - & $6_{1}-$ & 29 & 2 & 24 & 7 & 33 & 11 & $3^{2}$ & 2 & 37 & 4 \\
\hline 16 & 一 & - & - & $\begin{array}{ll}61 & 4\end{array}$ & 28 & 4 & 241 & 11 & 33 & 4 & 31 & - & $3^{8}$ & 10 \\
\hline 23 & - & - & - & $\begin{array}{ll}62 & 3\end{array}$ & 30 & 4 & 25 & 5 & 33 & 2 & $3^{0}$ & 5 & 37 & 8 \\
\hline 30 & - & - & - & $62 \quad 3$ & 30 & 9 & 25 & 4 & $3^{\circ}$ & - & 29 & 11 & 37 & 9 \\
\hline 7 & tober & - & - & 631 & 31 & 5 & 26 & 3 & 35 & 7 & $3^{\circ}$ & - & 37 & 6 \\
\hline 14 & - & - & - & $60 \quad 2$ & 291 & 10 & 26 & 2 & 35 & - & 30 & 7 & 37 & 9 \\
\hline 21 & - & - & - & 5910 & 28 & 5 & 27 & - & - & - & 31 & 1 & 39 & 7 \\
\hline 20 & - & - & - & 6o 3 & 27 & 9 & 261 & 11 & - & - & 31 & 3 & 39 & 6 \\
\hline 4 & ovemb & & - & $60-$ & 28 & - & 26 & 6 & - & - & 31 & 6 & $3^{8}$ & - \\
\hline 11 & - & - & - & 597 & 29 & 3 & 25 & 9 & $3^{\circ}$ & 9 & 31 & 11 & $3^{8}$ & 2 \\
\hline 18 & - & - & - & $61-$ & 29 & 6 & 25 & - & $3^{2}$ & - & $3^{1}$ & 6 & 39 & 2 \\
\hline 25 & - & - & - & $62 \quad 2$ & $3^{\circ}$ & - & 24 & 8 & $3^{1}$ & - & 31 & 11 & 37 & 8 \\
\hline 2 & ecembe & & - & $61-$ & 29 & 7 & 23 & 1 & 30 & 5 & 31 & 9 & 36 & 9 \\
\hline 9 & - & - & - & 6o 7 & 29 & 6 & 23 & 7 & - & - & 30 & 6 & 36 & 11 \\
\hline 16 & - & - & - & $60 \quad 2$ & 29 & 6 & 24 & - & 30 & - & 30 & 6 & $3^{6}$ & 9 \\
\hline 23 & - & - & - & 597 & 28 & 9 & 23 & 1 & 28 & - & 30 & 5 & $3^{6}$ & 4 \\
\hline 30 & - & - & - & 5710 & 27 & 2 & 23 & 7 & - & - & $2 S$ & 2 & 35 & 3 \\
\hline & $\begin{array}{l}\text { gate } \\
\text { the } 5^{2} \\
\text { quart } \\
\text { ster }\end{array}$ & $\begin{array}{l}\text { weeks } \\
\text { er Win. }\end{array}$ & & $\begin{array}{ll}63 & 6\end{array}$ & $3^{\circ}$ & 3 & 24 & 7 & 33 & 2 & $3^{2}$ & 3 & $4^{0}$ & 11 \\
\hline
\end{tabular}


Annual Average Prices of Wheat, \&c., in Mark-lane-continued.

Appendix, No. 6.

1816.

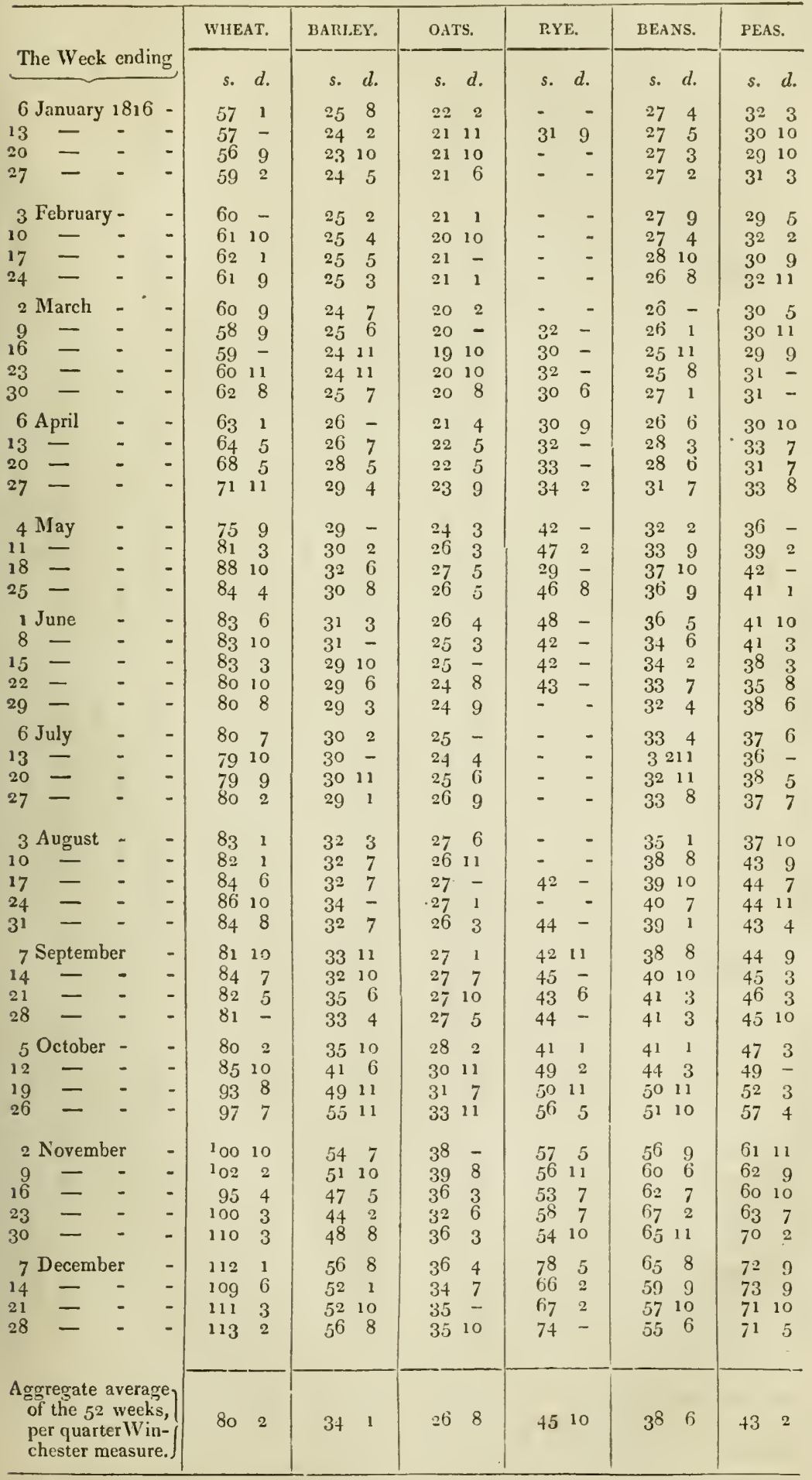


1817.

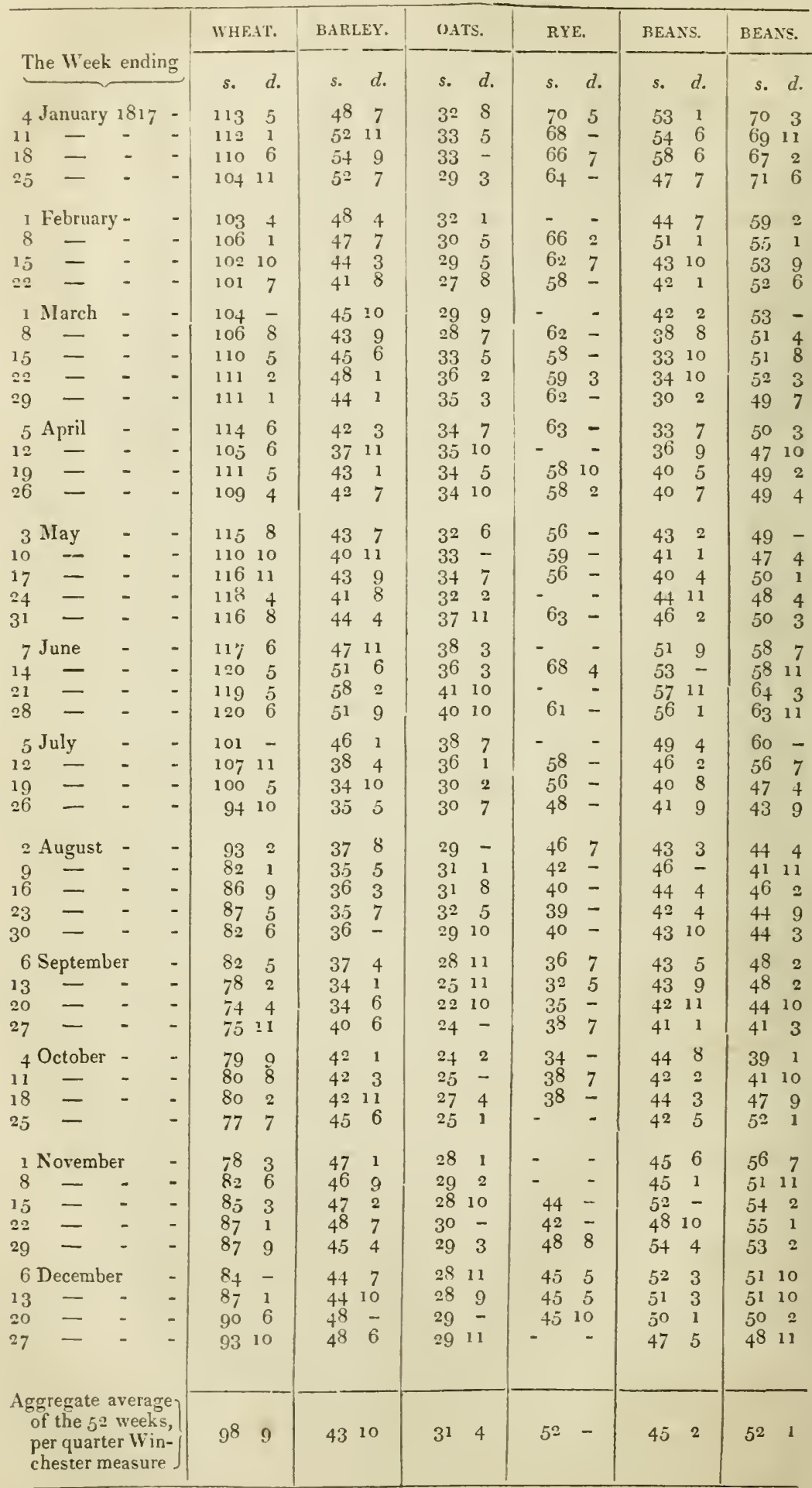


Annual Average Prices of Wheat, \&c., in Mark-lane-continued.

1818.

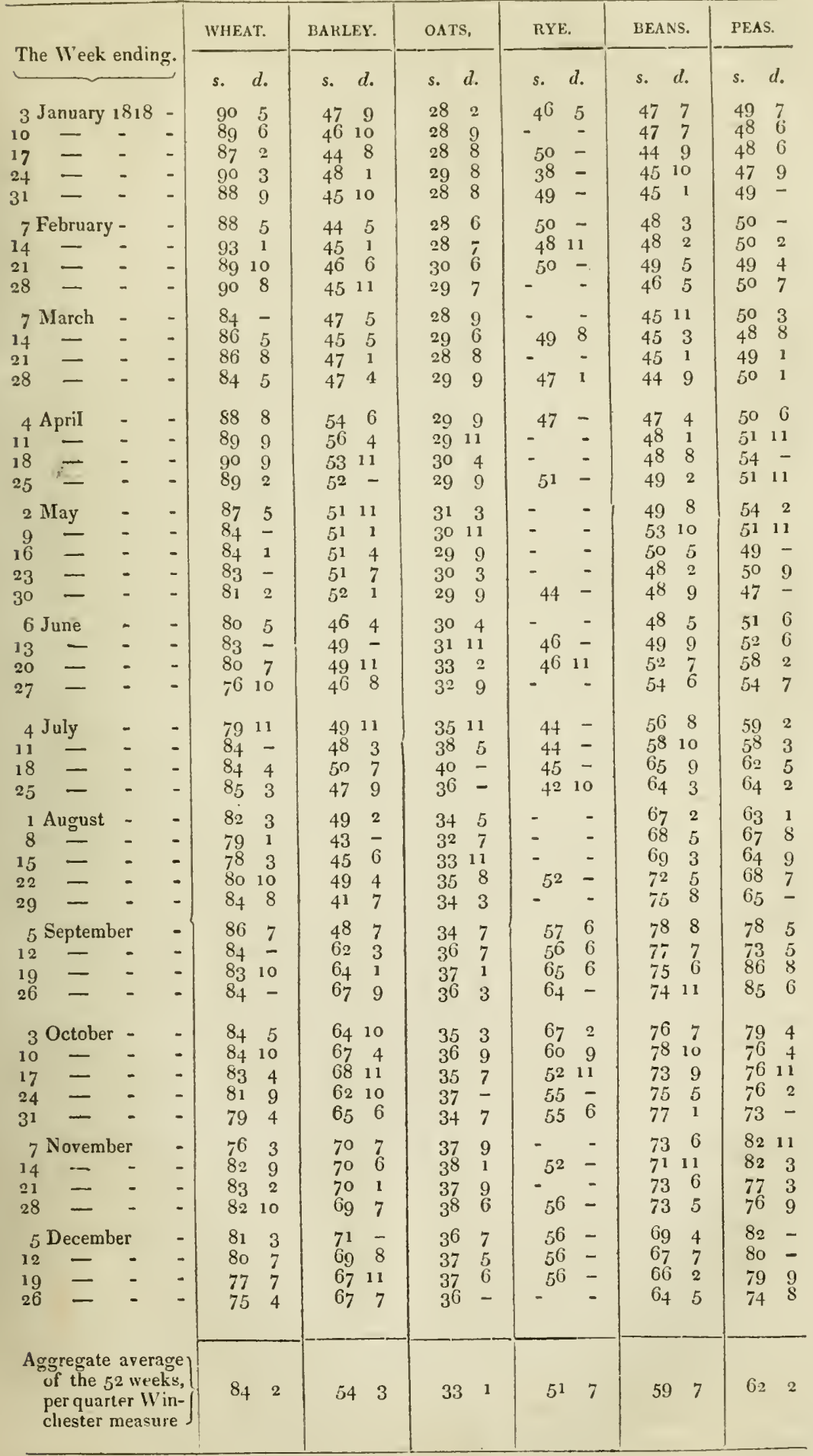


Annual Average Prices of Wheat, \&c., in Mark-lane-continued.

1819 .

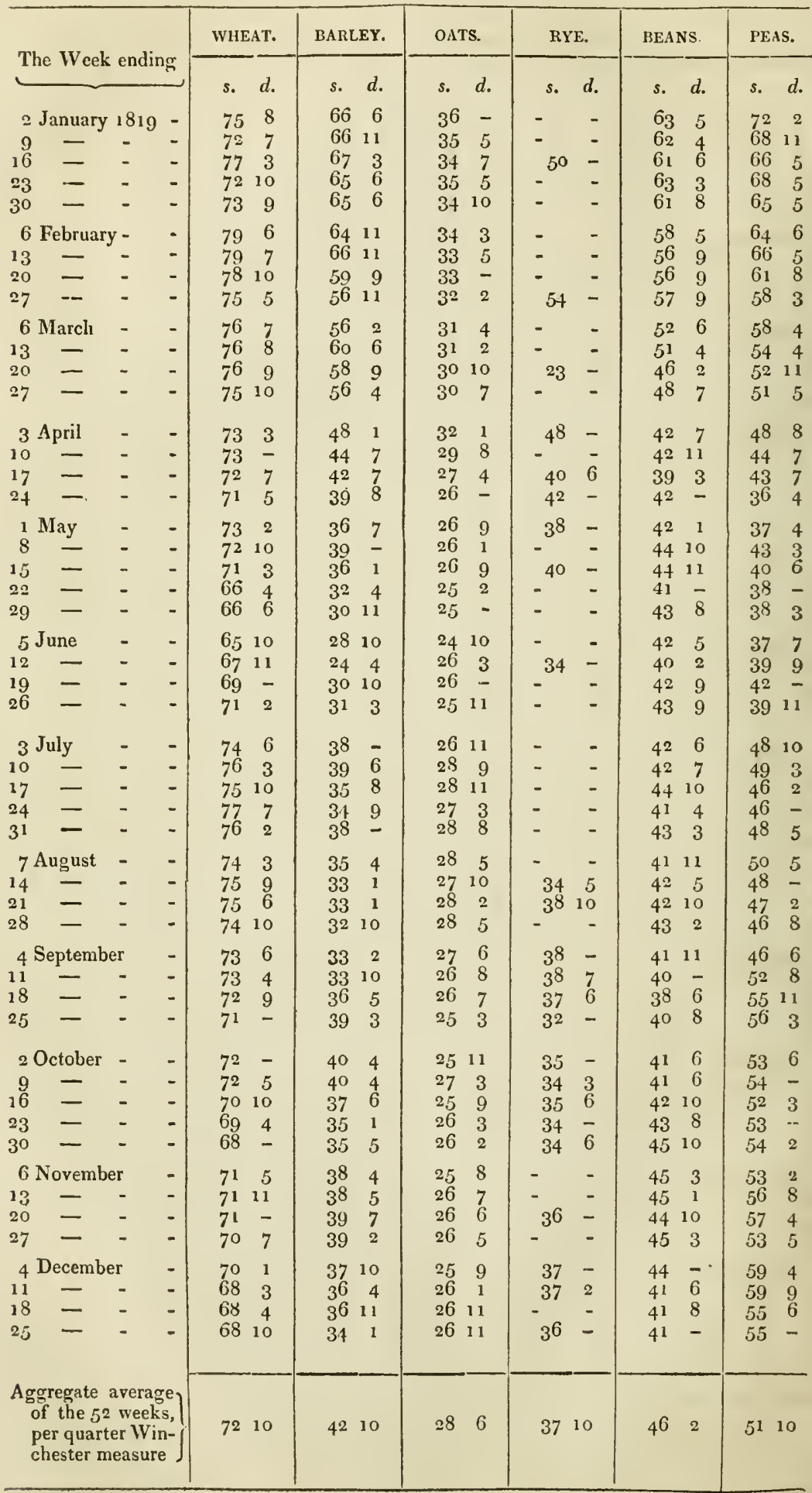


Annual Average Prices of Wheat, \&ic., in Mark-lane-continued.

1820.

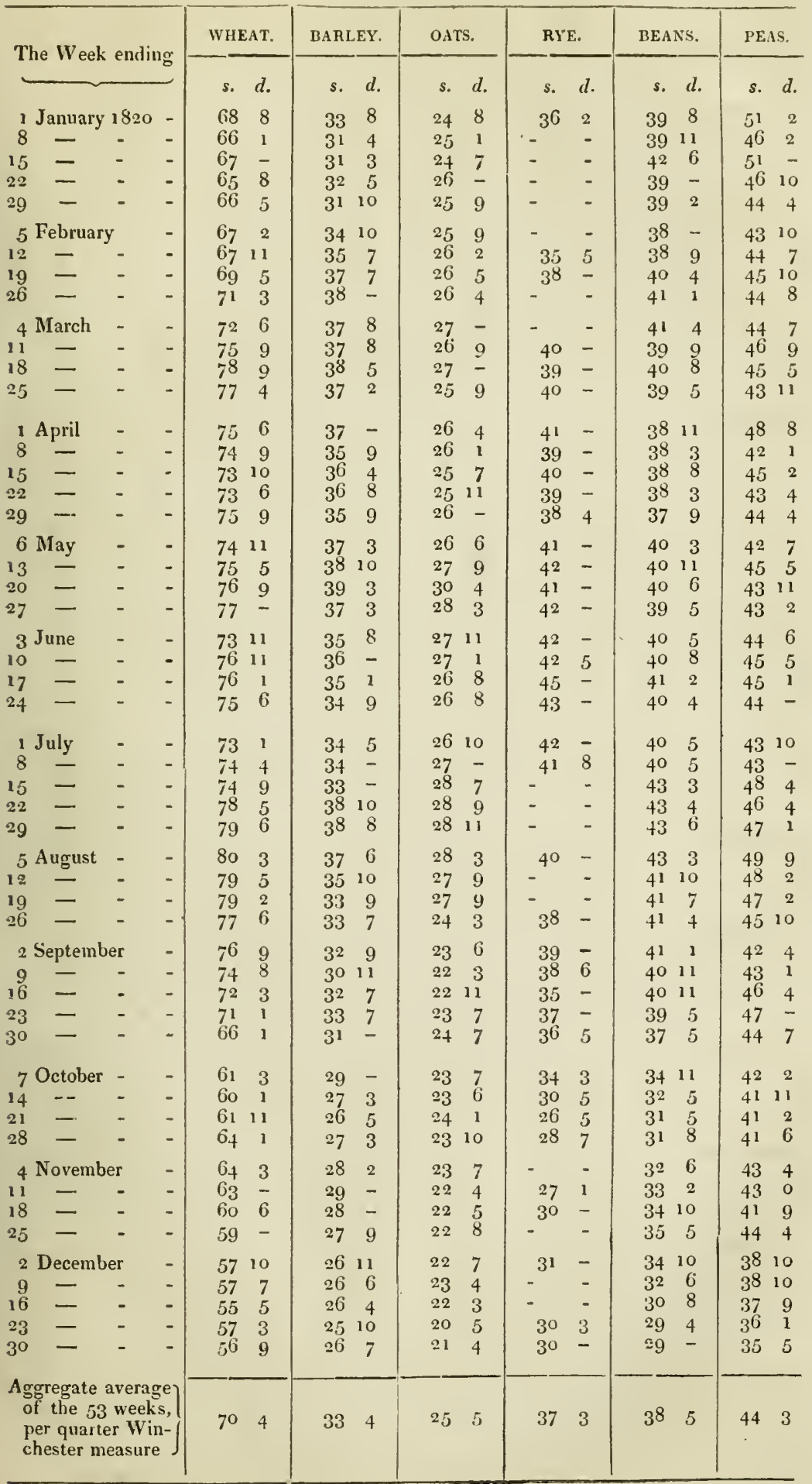


Appendix, No, 6 .

Annual Average Prices of Wheat, \&c., in Mark-lane--continued.

1821.

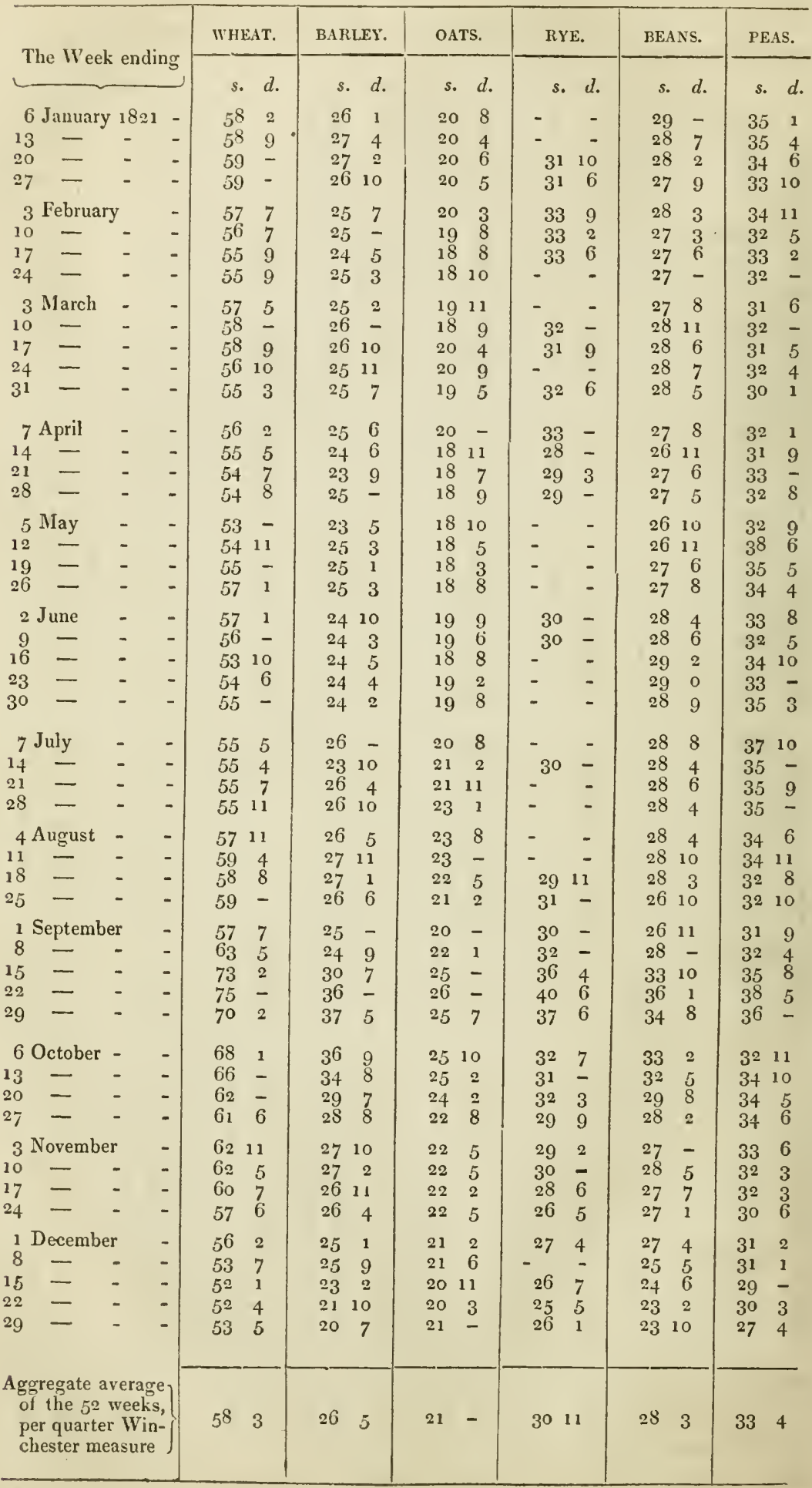


Annual Average Prices of Wheat, Sc., in Mark-lane-continued.

1822.

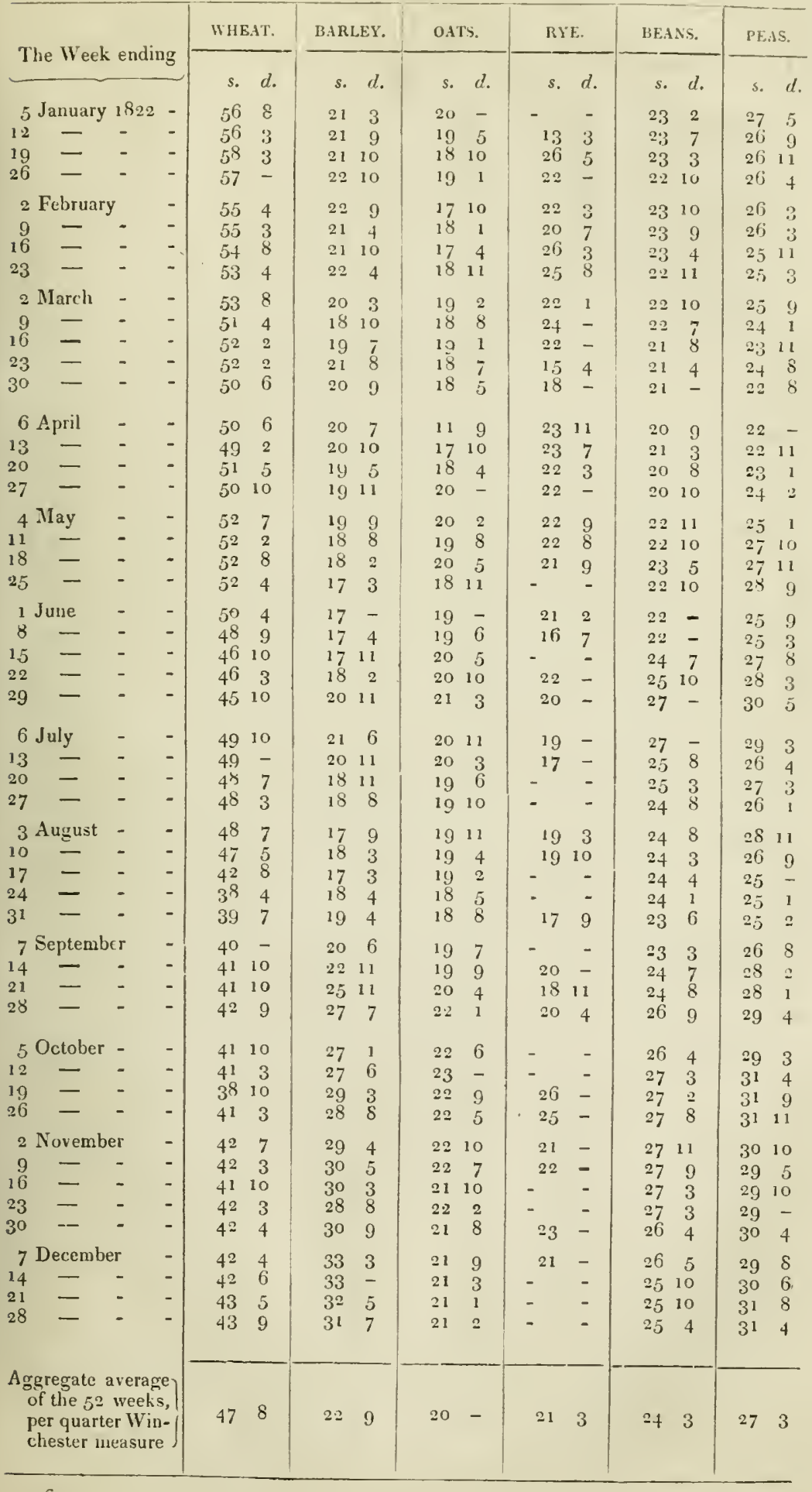


Annual Average Prices of Wheat, \&c., in Mark-lane-continued.

1823.

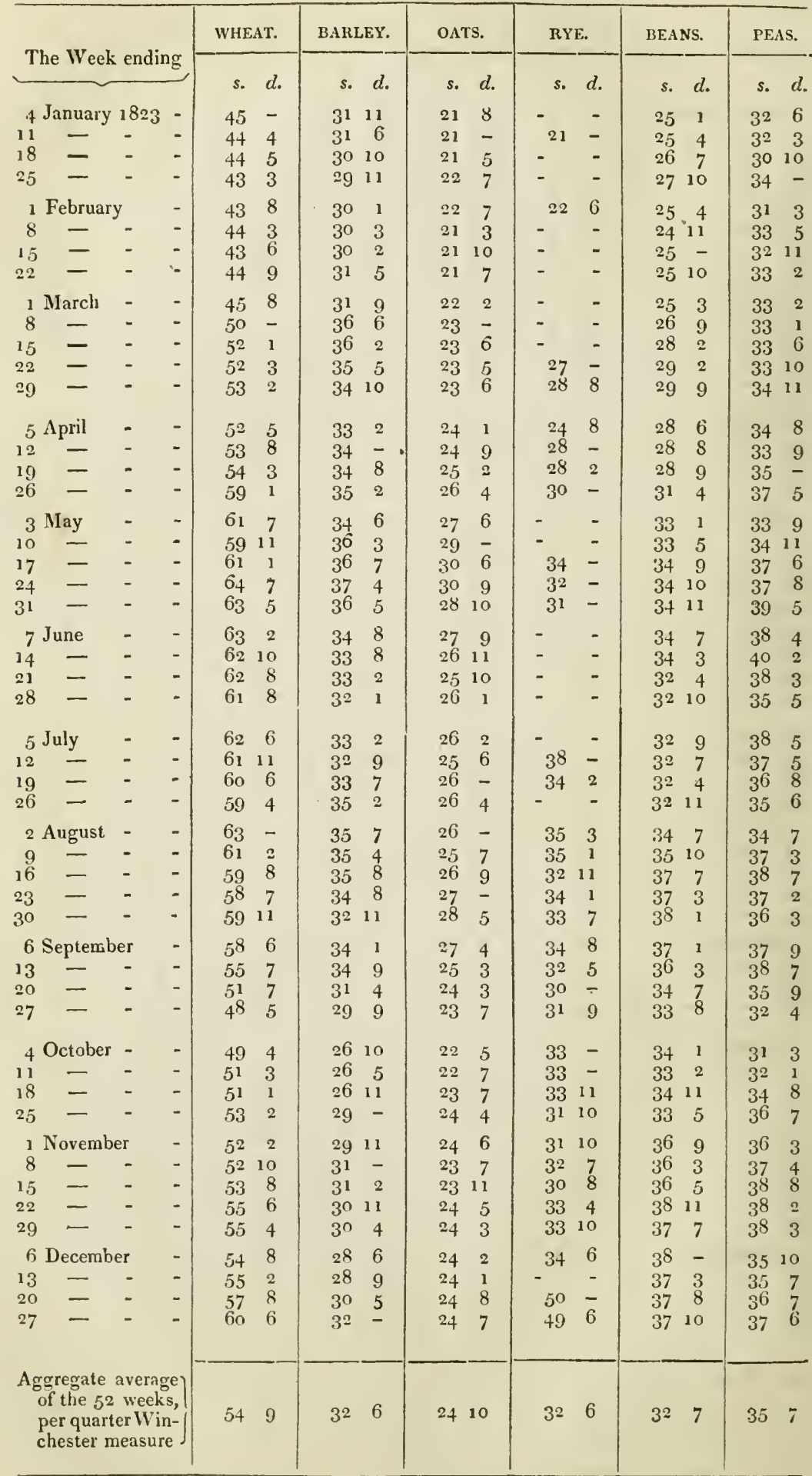


Annual Average Prices of Wheat, \&c., in Mark-lane-contimued.

1824.

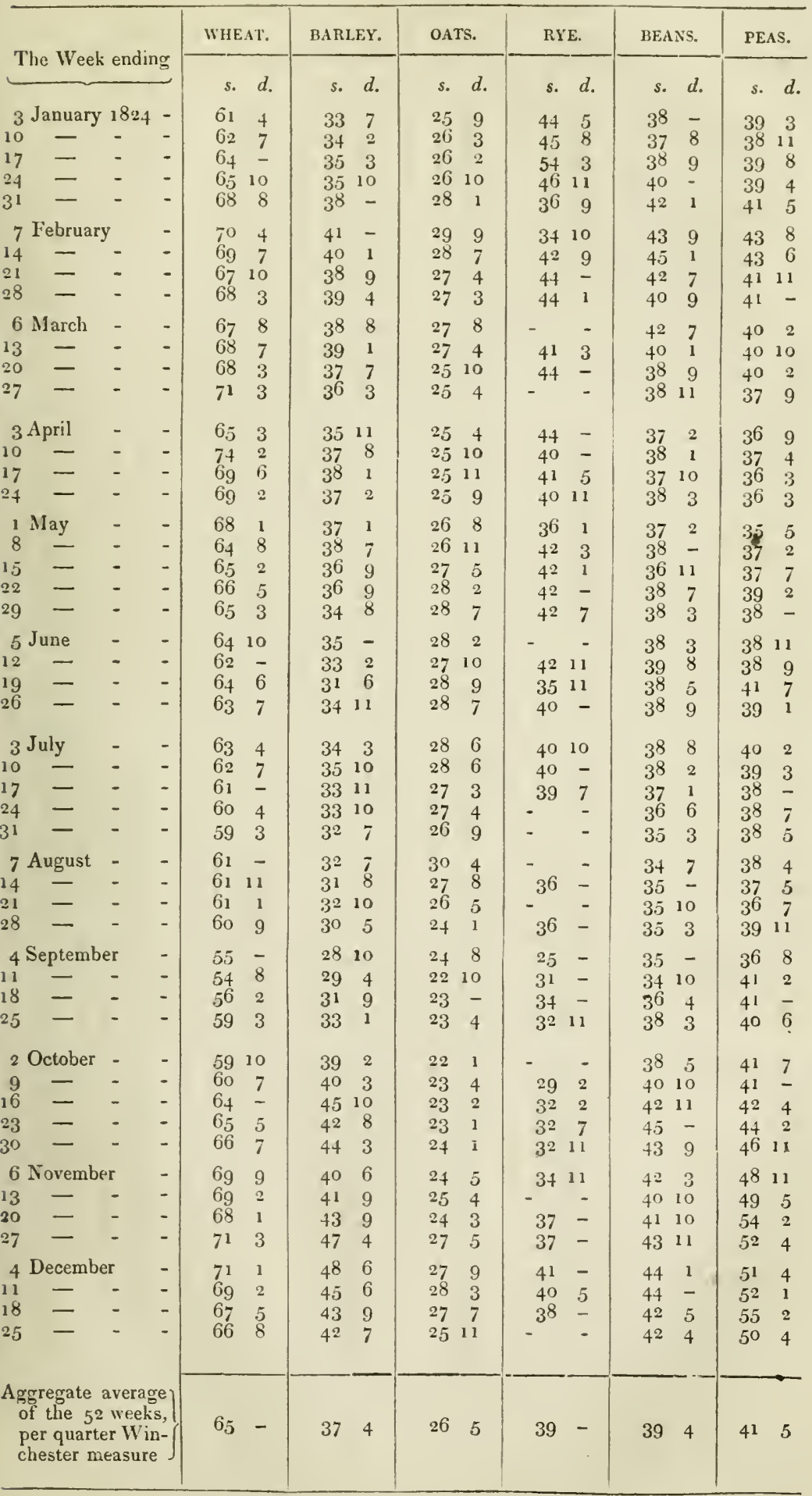


Appendix, No.6.

Annual Avcrage Prices of Wheat, Sic., in Mark-lane-continued.

1825.

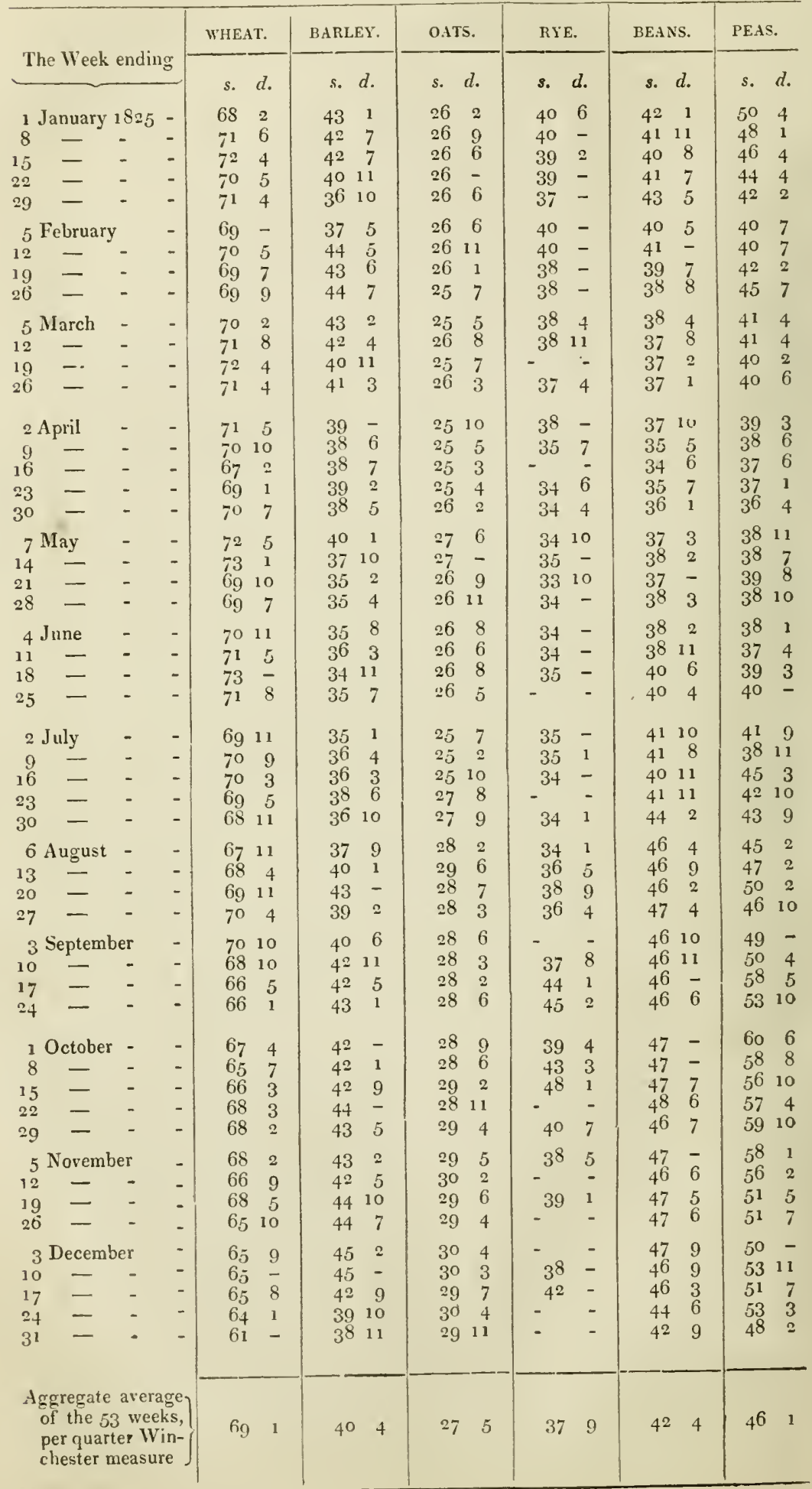


Annual Average Prices of Wheat, \&c., in Mark-lane-continued.

1826.

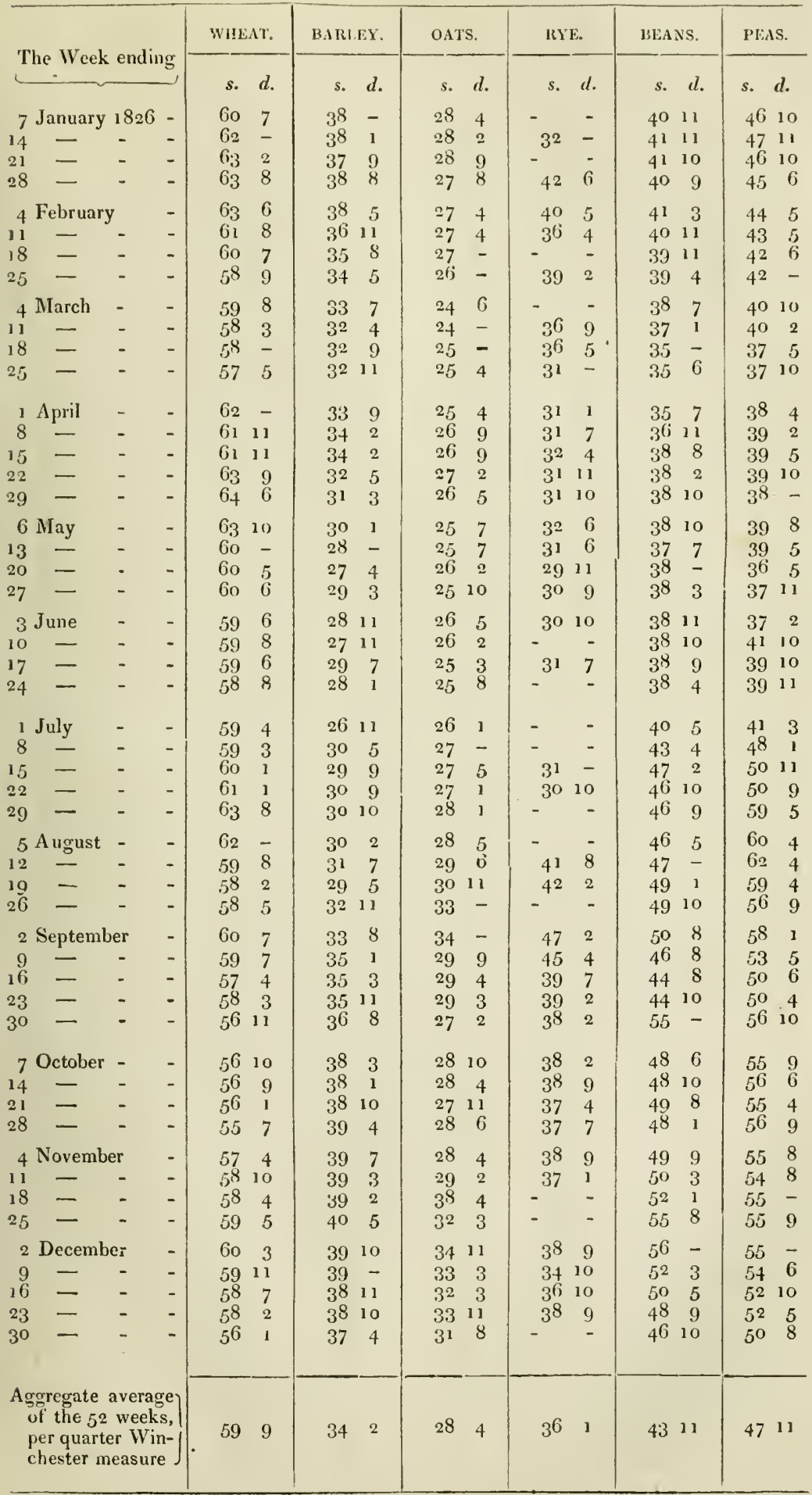


Annual Average Prices of Wheat, \&c., in Mark-lane-continued.

1827.

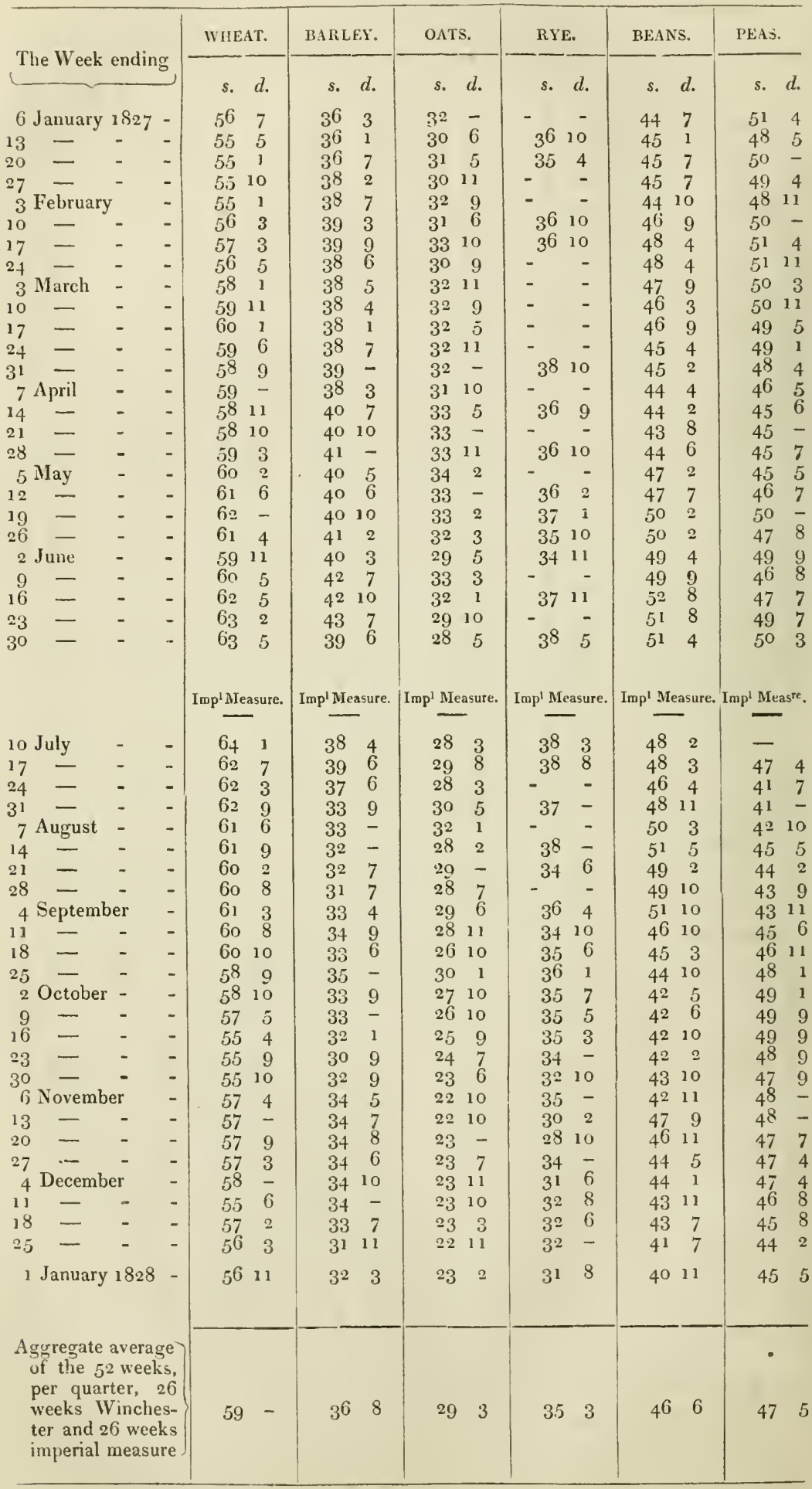


Annual Average Prices of Wheat, Sic., in Mark-lane-contimued.

1828.

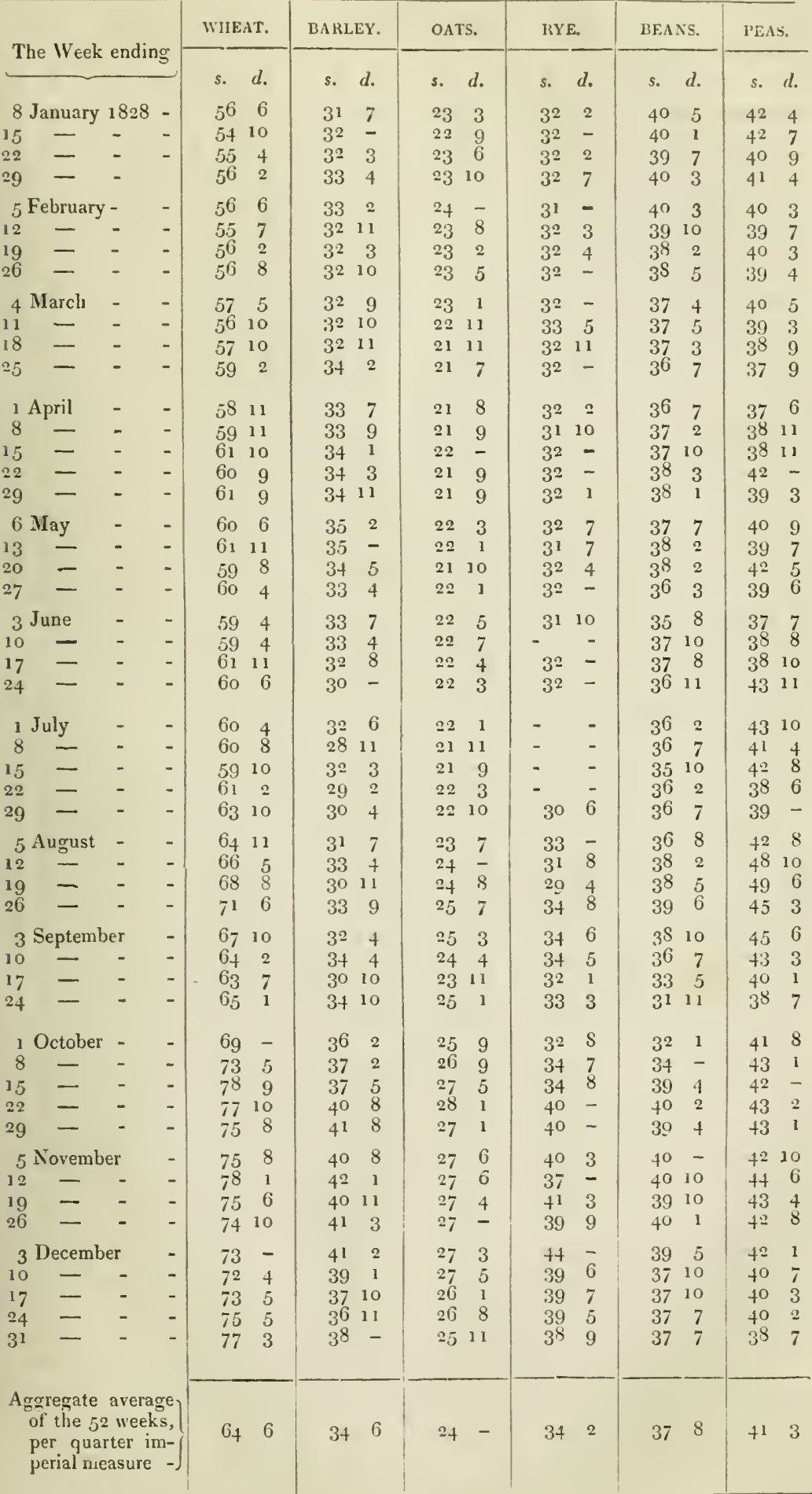


Annual Average Prices of Wheat, Sc., in Mark-lane-continued.

1829.

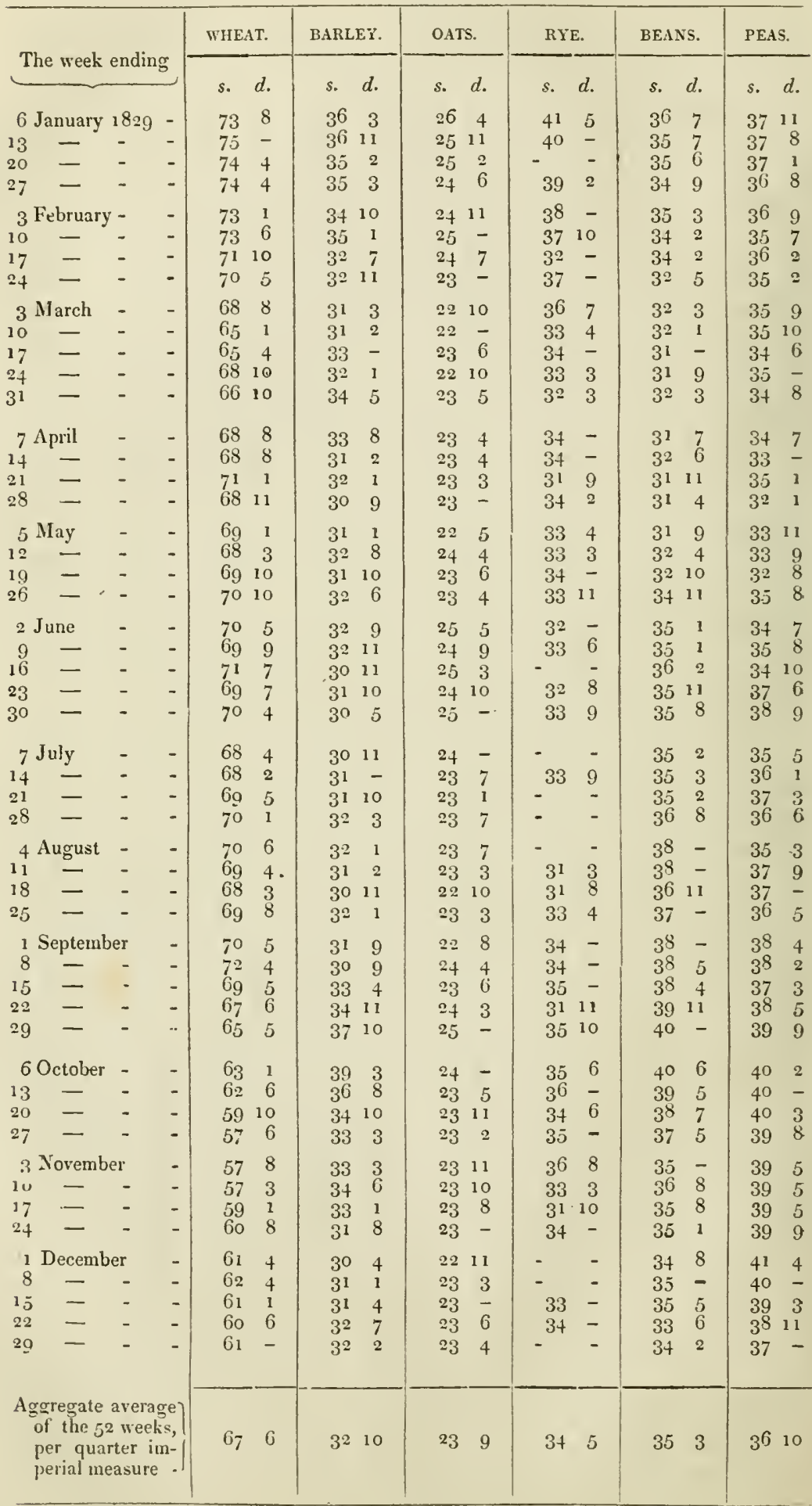


Annual Averuge P'rices of Wheat, sic., in Mark-lane-contimued.

1830.

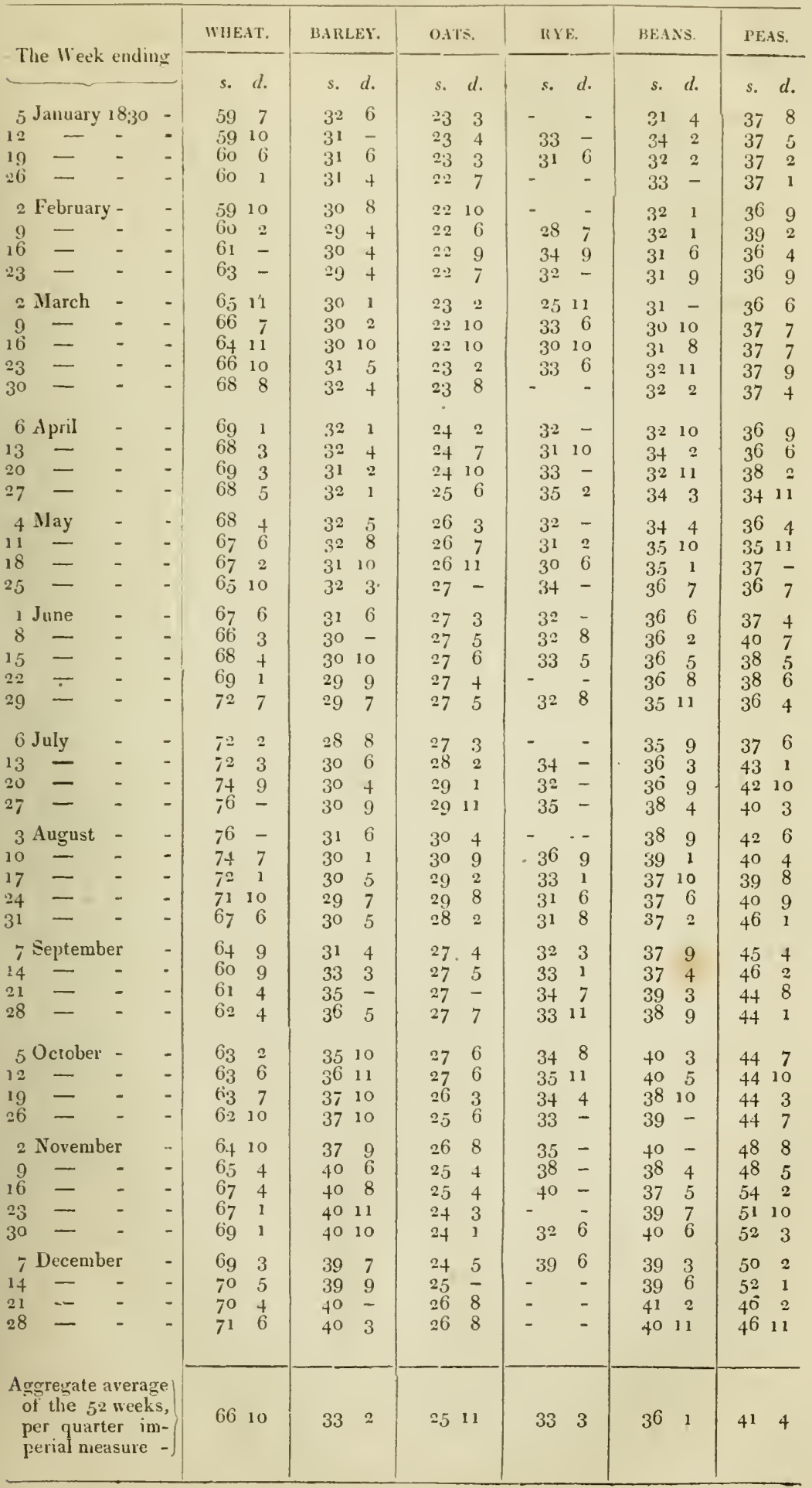


1831 .

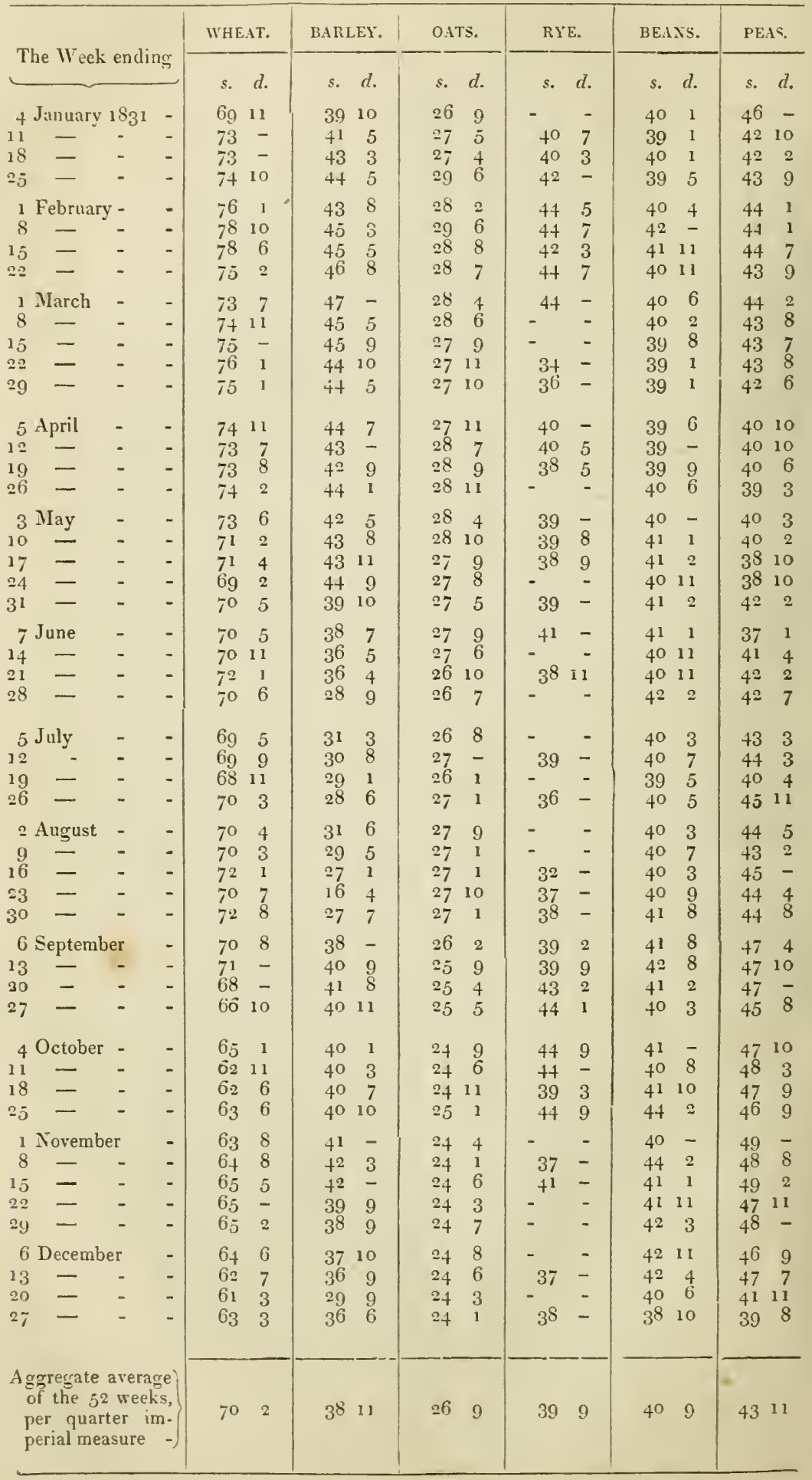


Annual Average Prices of Wheat, scc, in Mark-lane-continued.

1832.

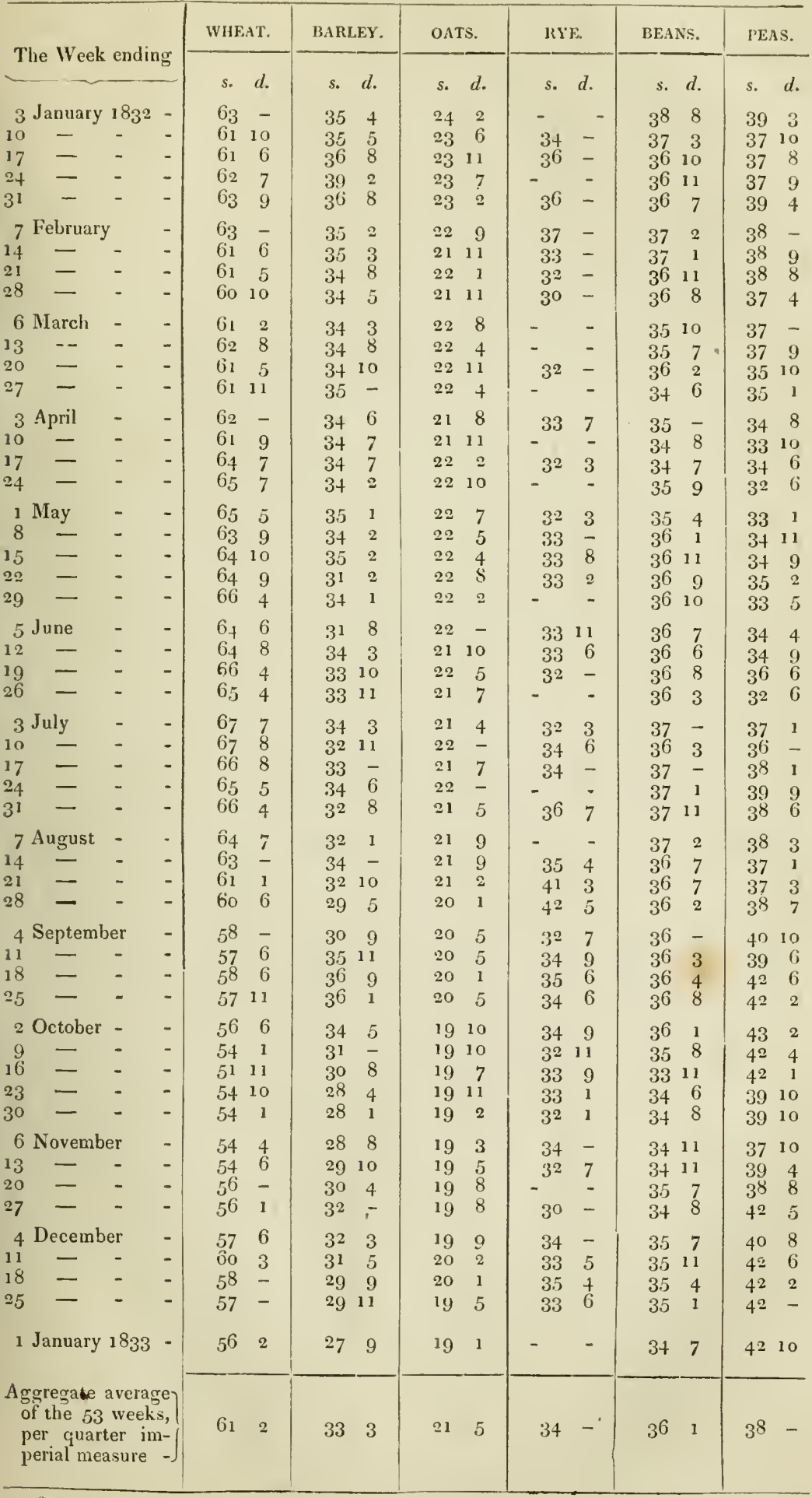


Annual Average Prices of Wheat, \&c., in Mark-lane-continued.

1833.

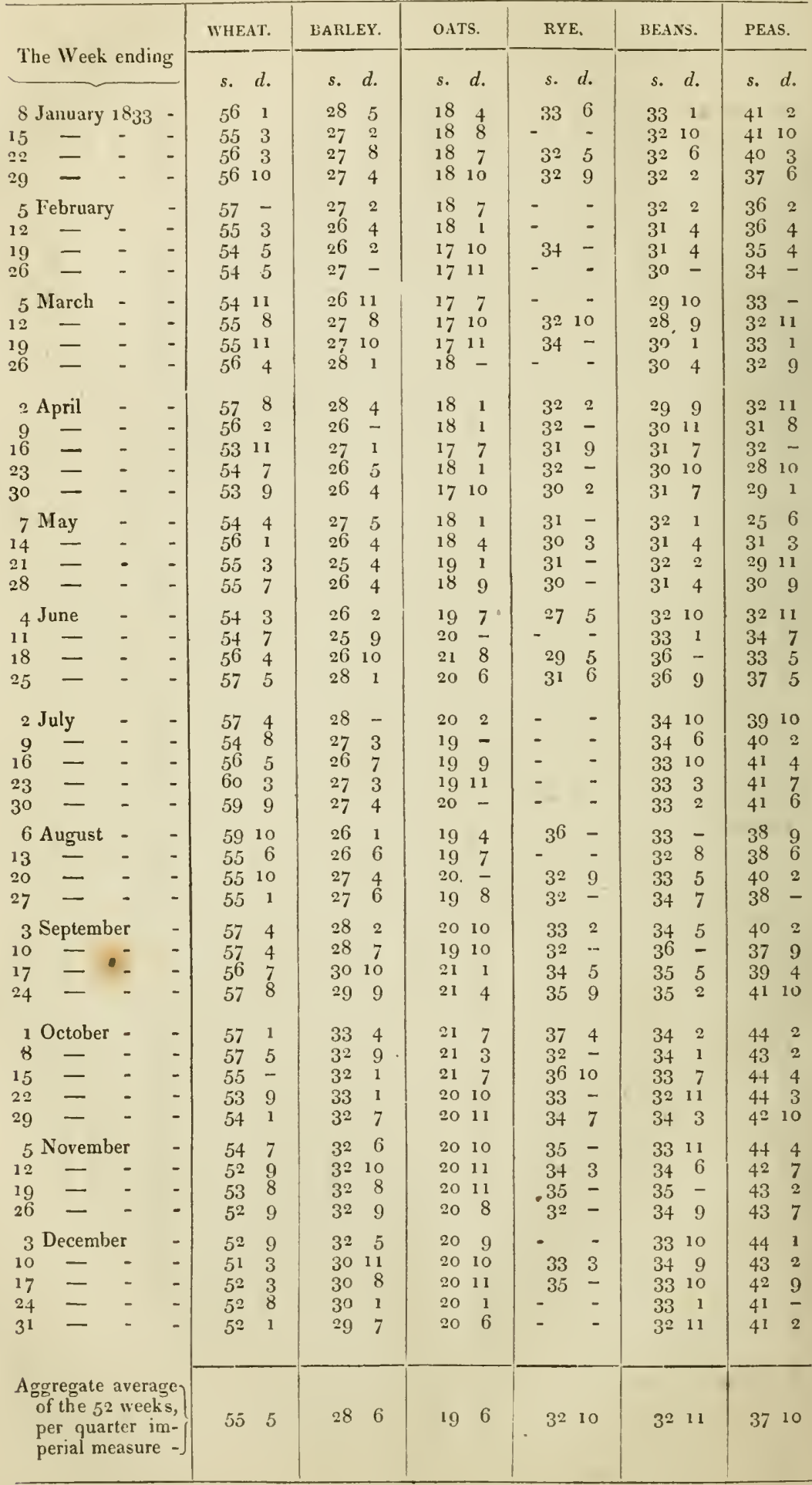


Annual Average Prices of Wheat, \&c., in Mark-lane--contimned.

1834.

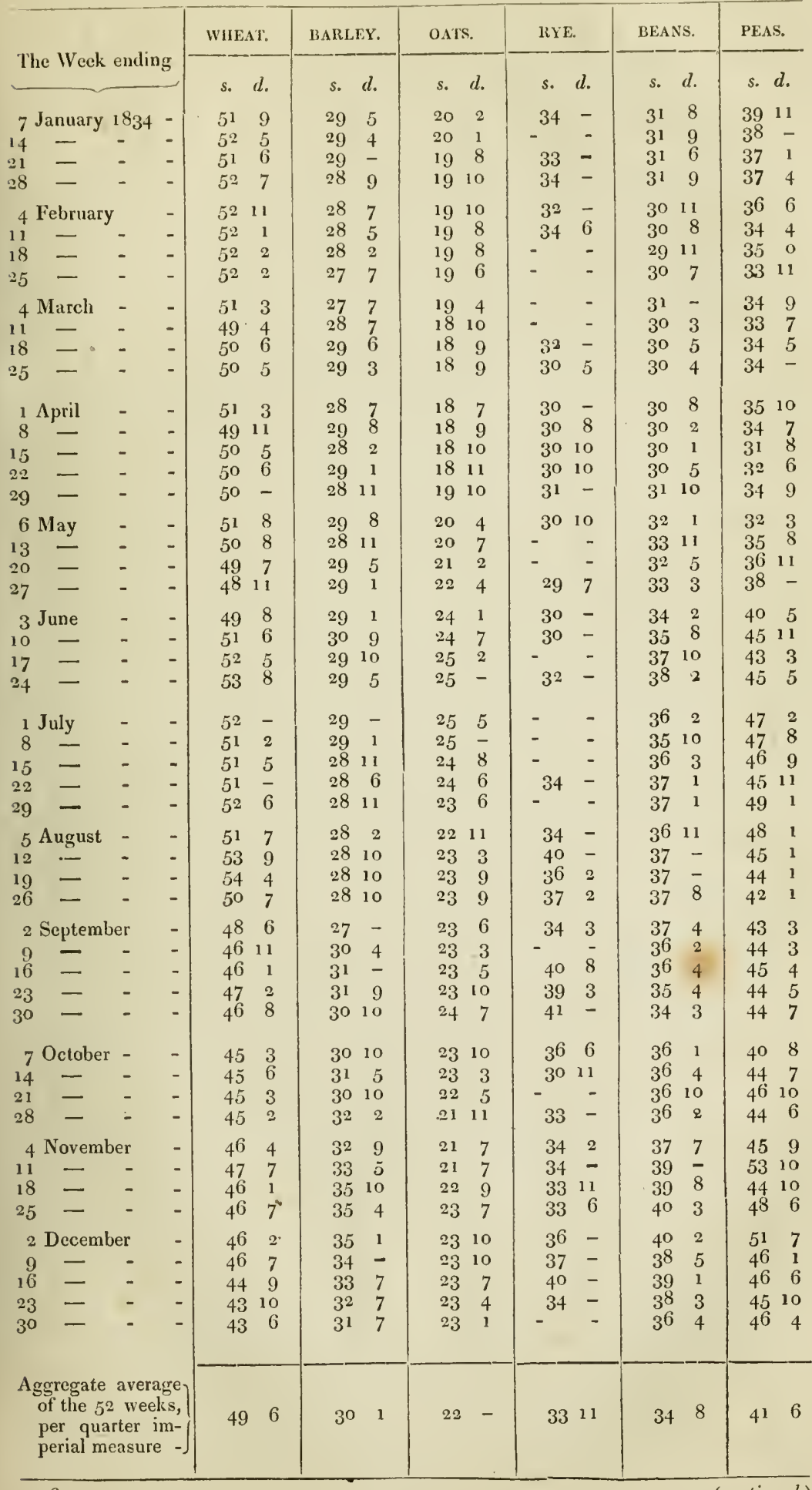


Average Annual Prices of Wheat, \&c., in Mark-lane--continued.

1835.

\begin{tabular}{|c|c|c|c|c|c|c|c|c|c|c|c|c|c|c|c|}
\hline \multirow{2}{*}{\multicolumn{4}{|c|}{ The Week ending }} & \multicolumn{2}{|c|}{ WHEAT. } & \multicolumn{2}{|c|}{ BARLEY. } & \multicolumn{2}{|c|}{ OATS. } & \multicolumn{2}{|c|}{ RYE, } & \multicolumn{2}{|c|}{ BEANS. } & \multicolumn{2}{|c|}{ PEAS. } \\
\hline & & & & \multirow{2}{*}{\multicolumn{2}{|c|}{$\begin{array}{lr}\text { s. } & d . \\
43 & 8\end{array}$}} & \multirow{2}{*}{\multicolumn{2}{|c|}{$\begin{array}{ll}\text { s. } & d . \\
3^{2} & 2\end{array}$}} & \multirow{2}{*}{\multicolumn{2}{|c|}{$\begin{array}{cc}\text { s. } & d . \\
22 & 11\end{array}$}} & \multicolumn{2}{|c|}{ s. $d$. } & \multicolumn{2}{|c|}{ s. $\quad d$} & \multirow{2}{*}{\multicolumn{2}{|c|}{$\begin{array}{ll}\text { s. } & d \\
44 & \end{array}$}} \\
\hline 6 & January & 1835 & - & & & & & & & & - & 36 & 11. & & \\
\hline 13 & - & - & - & 44 & 9 & $3^{2}$ & 3 & 23 & 6 & 33 & - & 35 & 11 & 45 & 2 \\
\hline 20 & - & - & - & 44 & 10 & 33 & 5 & 23 & 3 & & - & 36 & 4 & 42 & 4 \\
\hline 27 & - & - & - & 45 & 2 & 33 & 8 & 23 & 6 & & - & 36 & 5 & 39 & 9 \\
\hline & February & & - & 45 & 1 & 331 & 10 & 23 & 7 & 33 & - & 36 & 4 & $3^{9}$ & 2 \\
\hline 10 & - & - & - & +5 & 1 & 35 & 6 & 23 & 8 & & - & 37 & 1 & 39 & 8 \\
\hline 17 & - & - & - & 43 & 4 & 35 & 8 & 23 & 10 & - & - & 37 & 3 & 38 & 6 \\
\hline 24 & - & - & - & 43 & 11 & 34 & 1 & 23 & 8 & & - & 36 & 3 & $3^{8}$ & 4 \\
\hline & March & - & - & $4^{2}$ & 9 & 33 & 7 & 23 & 7 & 31 & 10 & 35 & 6 & 37 & 2 \\
\hline 10 & - & - & - & 42 & 10 & 34 & 2 & 23 & 4 & & - & $3^{8}$ & 1 & 39 & - \\
\hline 17 & - & - & - & $4^{2}$ & 9 & 331 & 11 & 23 & 4 & 29 & 8 & 37 & 6 & 36 & 7 \\
\hline 24 & - & - & - & 43 & 3 & 35 & 2 & 23 & 5 & 23 & - & 37 & 6 & $3^{8}$ & 2 \\
\hline 31 & - & - & - & 42 & 10 & 34 & 10 & 23 & 8 & $3^{2}$ & - & 35 & 8 & 34 & - \\
\hline & April & - & - & 41 & 11 & 34 & 3 & 23 & 8 & & - & 37 & 1 & 33 & - \\
\hline 14 & - & - & - & 41 & 10 & 34 & 2 & 24 & - & 31 & 11 & 36 & 11 & 35 & 11 \\
\hline 21 & - & - & - & 41 & 3 & $3^{2}$ & 10 & 24 & 6 & 31 & - & 36 & 2 & 34 & 6 \\
\hline 28 & - & - & - & 401 & 11 & $3^{2}$ & 4 & 24 & 11 & - & - & $3^{6}$ & 9 & 34 & 9 \\
\hline & May & - & - & 40 & 11 & $3^{2}$ & 5 & 24 & 4 & $3^{1}$ & 4 & 37 & 3 & 36 & 8 \\
\hline 12 & - & - & - & 42 & 9 & 31 & 10 & 24 & 4 & $3^{2}$ & - & $3^{8}$ & 4 & 33 & 7 \\
\hline 19 & - & - & - & $4^{2}$ & 2 & 28 & 7 & 24 & 2 & $3^{2}$ & - & 39 & 9 & 35 & 6 \\
\hline 26 & - & - & - & $4^{2}$ & - & 28 & 7 & 23 & 10 & 30 & - & 39 & 11 & 34 & 6 \\
\hline & June & - & - & $4^{2}$ & - & 27 & 9 & 24 & 2 & 31 & - & 39 & 10 & $3^{6}$ & 7 \\
\hline 9 & - & - & - & 42 & 9 & 301 & 10 & 24 & 5 & 30 & - & $3^{8}$ & - & 36 & 1 \\
\hline 16 & - & - & - & 43 & 6 & 28 & 7 & 24 & 4 & 31 & $\bar{c}$ & 40 & 6 & 37 & 9 \\
\hline 23 & - & - & - & $4^{2}$ & 6 & 26 & 1 & 23 & 5 & $3^{2}$ & 6 & 39 & 5 & 38 & 6 \\
\hline 30 & - & - & - & 43 & 7 & 29 & 4 & 23 & 5 & & - & 39 & 8 & $3^{8}$ & 9 \\
\hline & July & - & - & 44 & 7 & 281 & 10 & 23 & 7 & 32 & 6 & 40 & 11 & $3^{8}$ & 1 \\
\hline 14 & - & - & - & 46 & - & 291 & 10 & 23 & 9 & & - & 40 & 1 & 40 & 10 \\
\hline 21 & - & - & - & 47 & 2 & 271 & 11 & 25 & 1 & & - & 40 & 5 & 39 & 7 \\
\hline 28 & - & - & - & 47 & 7 & 28 & 4 & 24 & 4 & 28 & - & 39 & 2 & $3^{8}$ & 6 \\
\hline 4 & August & - & - & $4^{6}$ & 5 & 28 & - & 24 & 9 & - & - & 39 & 3 & 35 & 8 \\
\hline & - & - & - & 44 & 9 & 27 & 4 & 25 & 6 & 32 & - & 39 & - & $3^{2}$ & 4 \\
\hline 18 & - & - & - & 43 & 2 & 26 & - & 24 & 2 & 33 & 2 & $3^{8}$ & 7 & $3^{2}$ & 11 \\
\hline 25 & - & - & - & $4^{2}$ & 4 & 26 & 4 & 22 & 1 & 27 & 3 & 39 & 7 & 34 & 11 \\
\hline & Septemb & & -1 & $4^{2}$ & - & 27 & 1 & 21 & 2 & 34 & 3 & $3^{6}$ & 4 & 39 & 1 \\
\hline 8 & - & - & - & 41 & 4 & 251 & 11 & 20 & - & 34 & 1 & 34 & 5 & 37 & 5 \\
\hline 15 & - & - & - & 40 & 4 & 28 & - & 20 & 3 & 32 & - & $3^{2}$ & 11 & $4^{\circ}$ & 4 \\
\hline 22 & - & - & - & 391 & 11 & 28 & 2 & 21 & 3 & 36 & 2 & $3^{2}$ & 5 & 39 & 8 \\
\hline 29 & - & - & - & 40 & 3 & 29 & 3 & 21 & 2 & 33 & 7 & $3^{1}$ & 11 & $3^{8}$ & 4 \\
\hline 6 & October & - & - & 41 & - & 30 & 9 & 22 & 1 & 34 & 10 & $3^{\circ}$ & 3 & 39 & 1 \\
\hline 13 & - & - & - & to 1 & 10 & 31 & 6 & 21 & - & 34 & 7 & $3^{1}$ & 1 & $3^{8}$ & 3 \\
\hline 20 & - & - & - & 39 & 9 & 301 & 11 & 21 & - & 34 & 3 & $3^{1}$ & 1 & 36 & 8 \\
\hline 27 & - & - & - & 39 & 3 & $3^{\circ}$ & 6 & 20 & 5 & $3^{2}$ & 11 & $3^{2}$ & 11 & $3^{8}$ & 1 \\
\hline & Novembe & & - & & 6 & 28 & 4 & 19 & 9 & 29 & - & 34 & 11 & $3^{९}$ & 7 \\
\hline 10 & - & - & - & 40 & 0 & $3^{1}$ & 3 & 19 & 7 & - & - & 35 & 1 & 37 & 6 \\
\hline 17 & - & - & - & 39 & 6 & 30 & 8 & 19 & 11 & 30 & - & 35 & 5 & $3^{8}$ & 2 \\
\hline 24 & - & - & - & 391 & 11 & $3^{1}$ & 4 & 19 & 7 & 34 & - & $3^{6}$ & 7 & 39 & - \\
\hline & Decembe & & - & 391 & 10 & 29 & 9 & 19 & 3 & 39 & 5 & & - & 36 & 6 \\
\hline 8 & - & - & - & $3^{8}$ & 9 & 28 & 9 & 19. & 6 & $3^{\circ}$ & 2 & 33 & 8 & 37 & 6 \\
\hline 15 & - & - & - & 44 & - & 29 & 2 & 19 & 11 & $3^{\circ}$ & - & 34 & 2 & $3^{6}$ & 6 \\
\hline 22 & - & - & - & $3^{8}$ & 2 & 28 & 6 & 20 & 3 & - & - & 31 & 5 & 37 & 7 \\
\hline 29 & - & - & - & $3^{8}$ & 9 & 28 & 1 & 19 & 9 & 30 & 8 & & 10 & 37 & - \\
\hline & $\begin{array}{l}\text { gregate a } \\
\text { of the } 52 \\
\text { per quart } \\
\text { perial me: }\end{array}$ & $\begin{array}{l}\text { averag } \\
\text { week } \\
\text { ter in }\end{array}$ & & $4^{2}$ & 3 & 30 & 7 & 22 & 7 & 31 & 6 & $3^{6}$ & 5 & 37 & 7 \\
\hline
\end{tabular}


ANNUAL AVERAGE PRICES of Wheat, Barley, OAts, Rye, Beans and Peas in the Market of MARK-LANE, in each Year from 1815 to 1835, both inclusive.

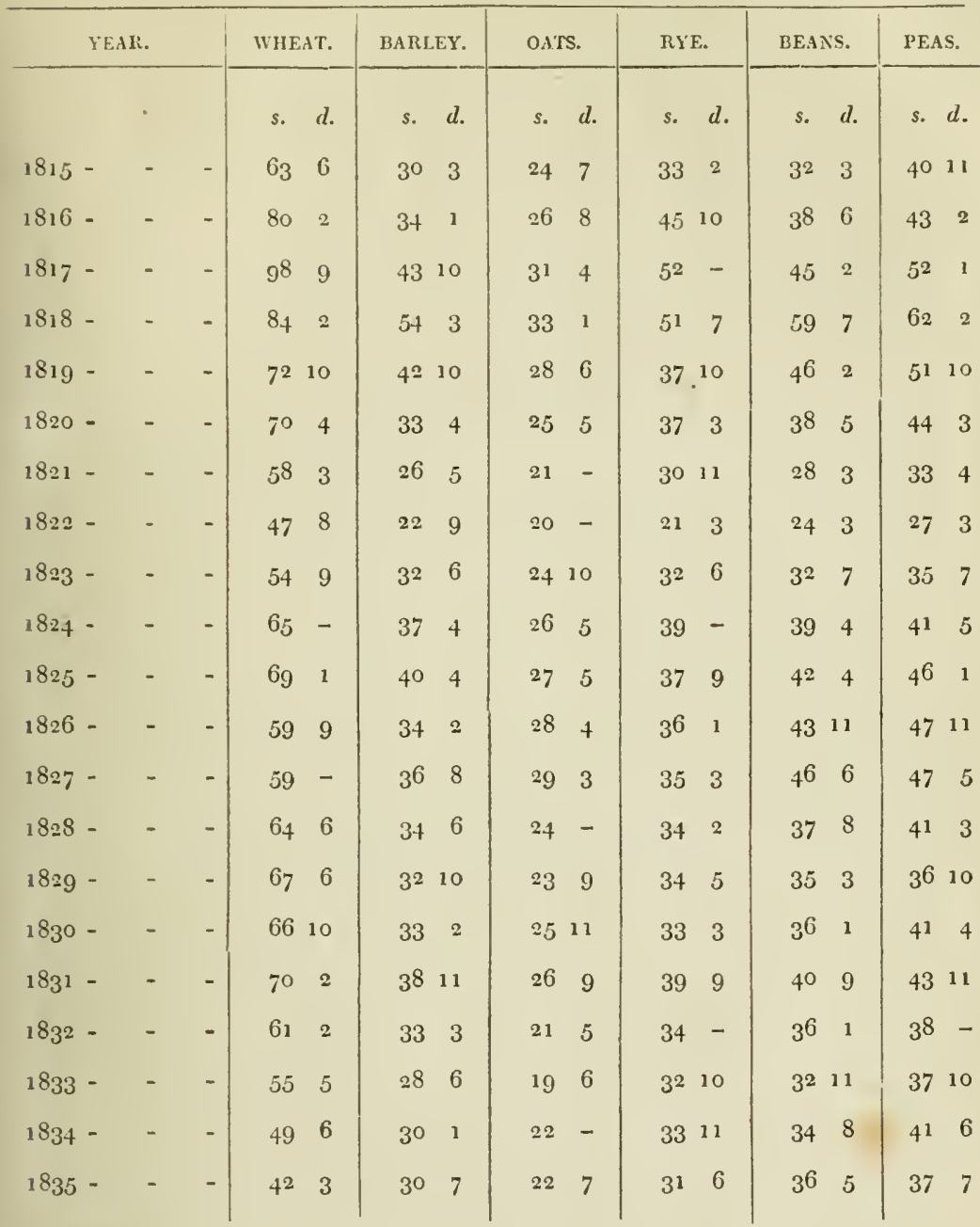

Per quarter Winchester measure, to the 30 th June 1827.

Per quarter Imperial measure, to the 29 th December 1835 .

5, Fowke's Buildings, Great Tower-street, ] London, $15^{\text {th }}$ March 1836 .
Geo. Levick,

Inspector of Corn Returns. 
Appendix, No. 7 .

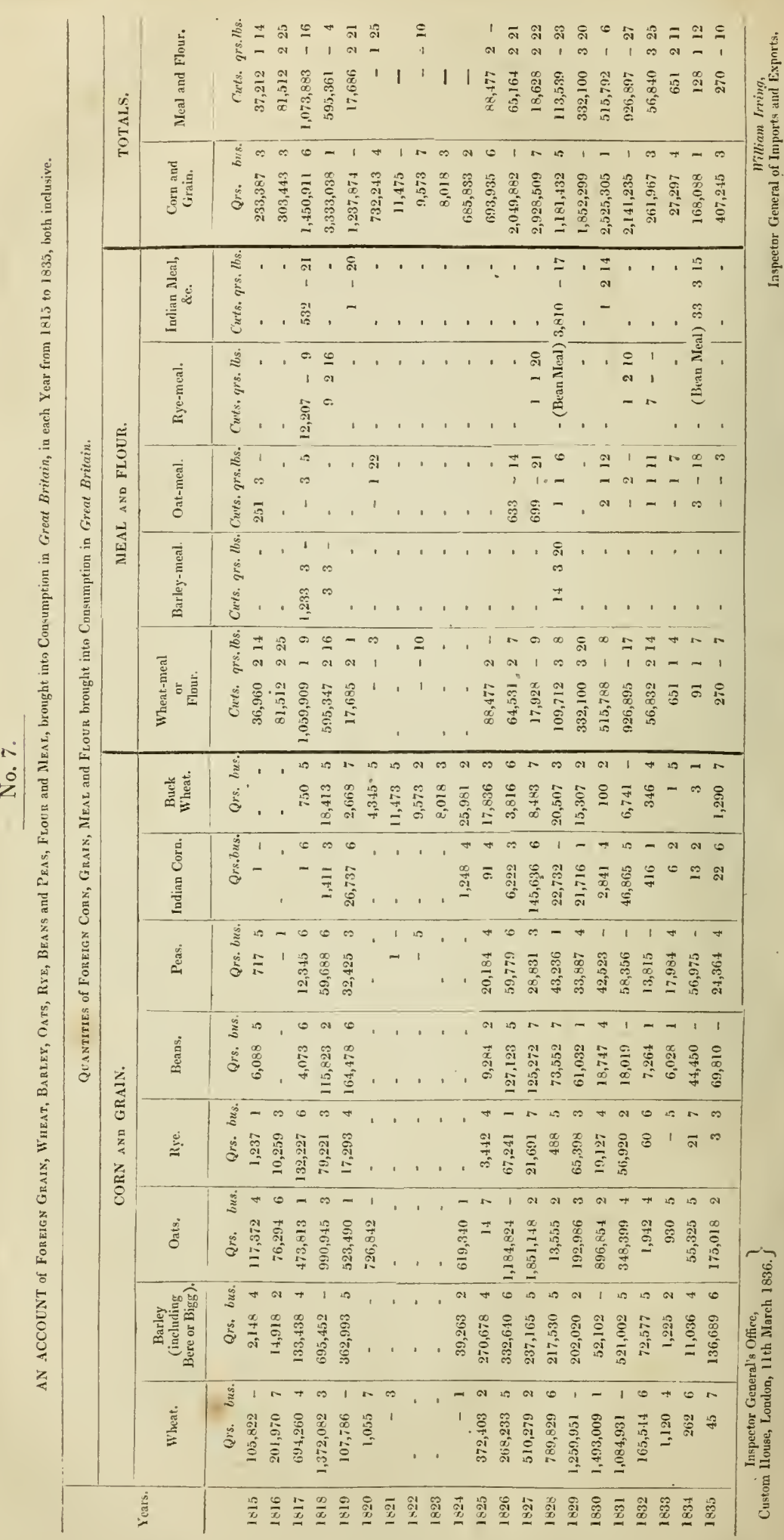


No. 8.

An Account of Grais, Whelt, Barley, Oats, Rye, Beass and Peas, Floun and Meal (other than Foreign), brught into Consumption in Greal Britain from Ireland, His Majesty's Colonies in America, the Islands of Guernsey, Jerscy, Aldcrney and Sark, and the Isle of Man, specifying the Quantity of eacl Sort of Grain, llour and Meal brought from each of the afore-mentioned Places, in each of the Years from 1815 to 1835, both inclusive, and in the last Year the Importation being detailed by Month.

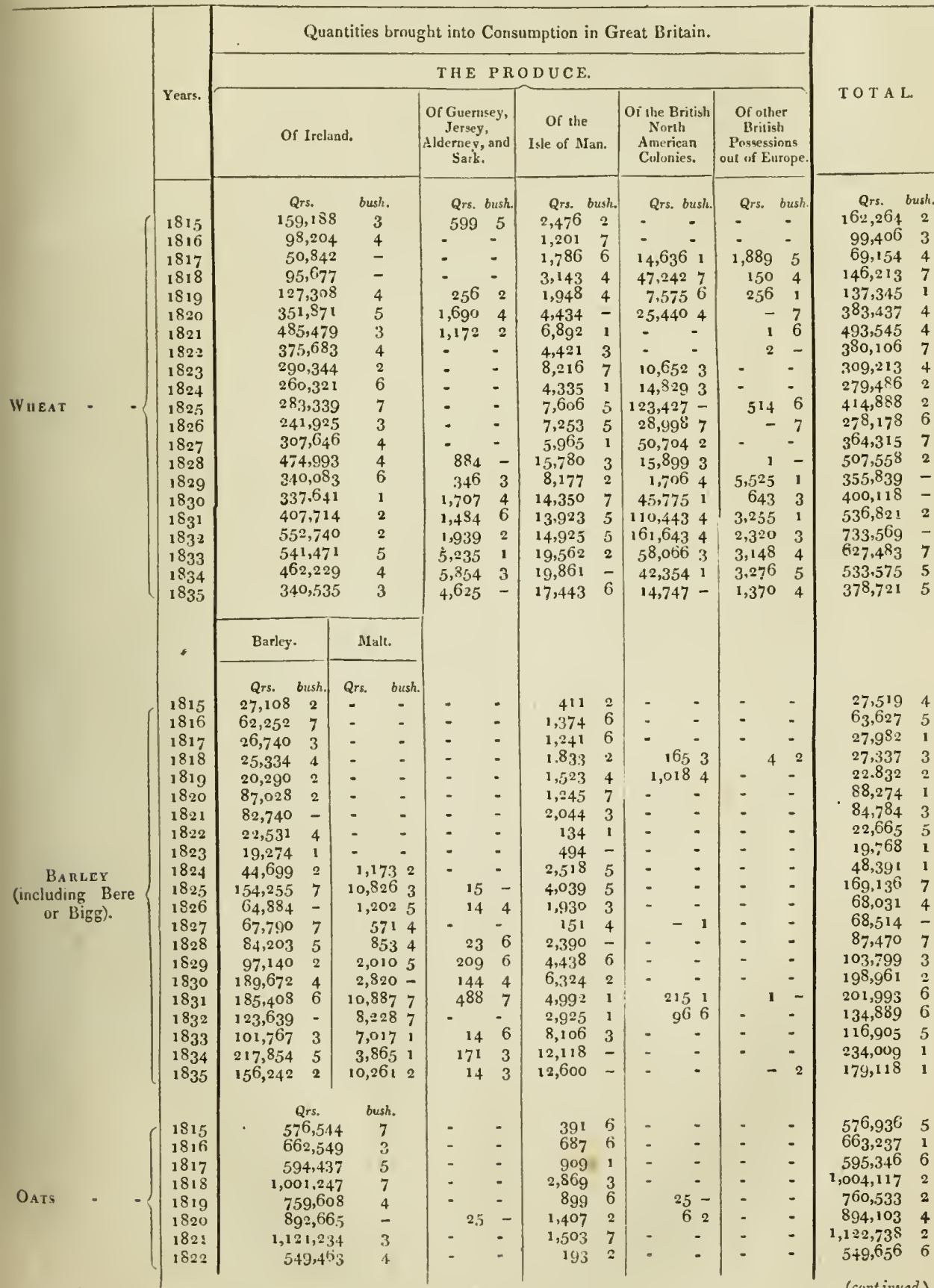


No. 8.-An Account of Grain, Wheat, Barley, Oats, Rye, \&c., brought into Consumption in Great Brituin from Ireland, His Majesty's Colonies in America, \&c., \&c.-continued.

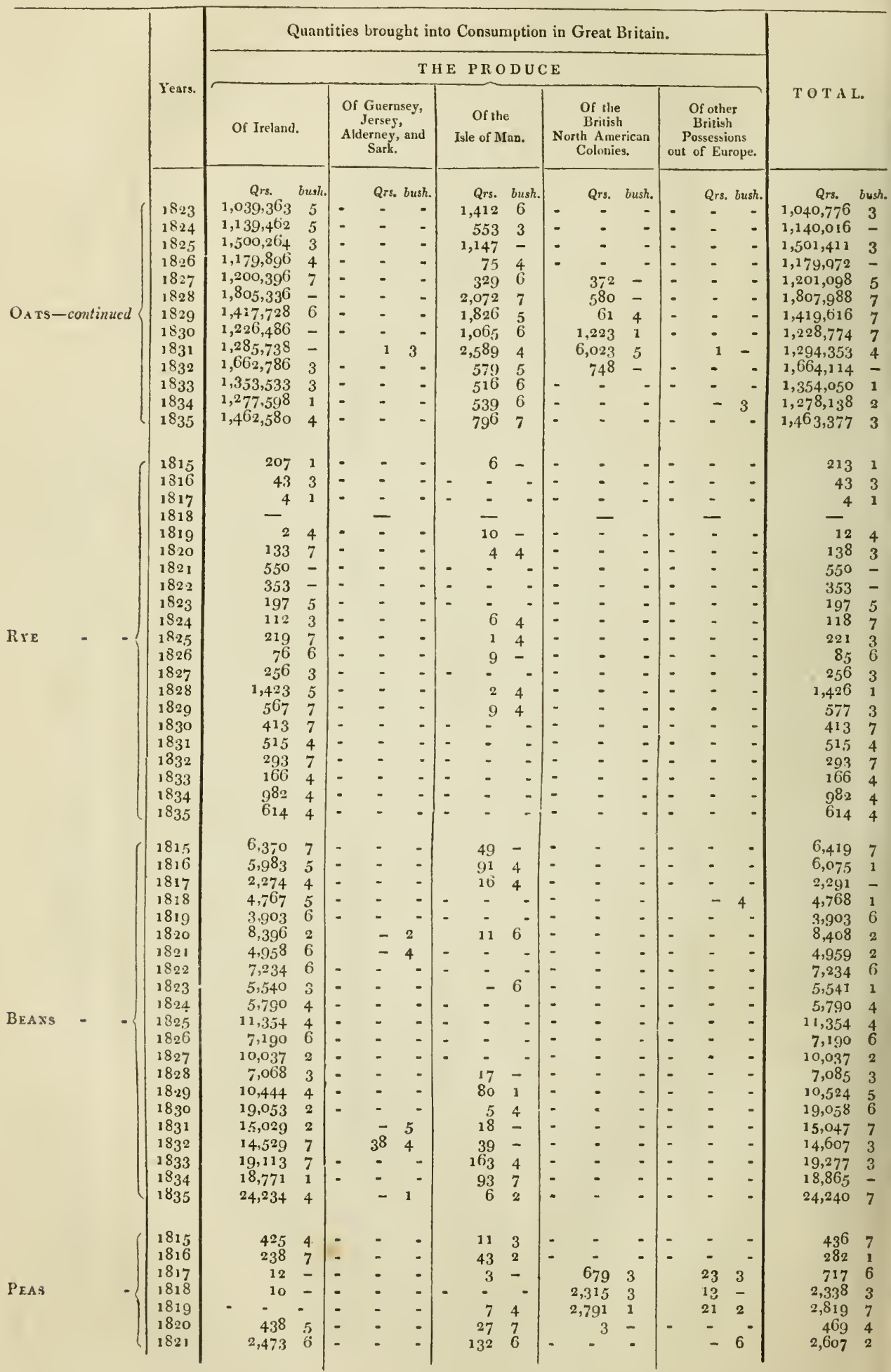


No.8.-Ax Accous t of Grain, Wheat, Barley, Oats, Rye, sc., brought into Consumption in Great Brituin from Ireland, llis Majesty's Colonies in Americu, \&e., Sc.-continued.

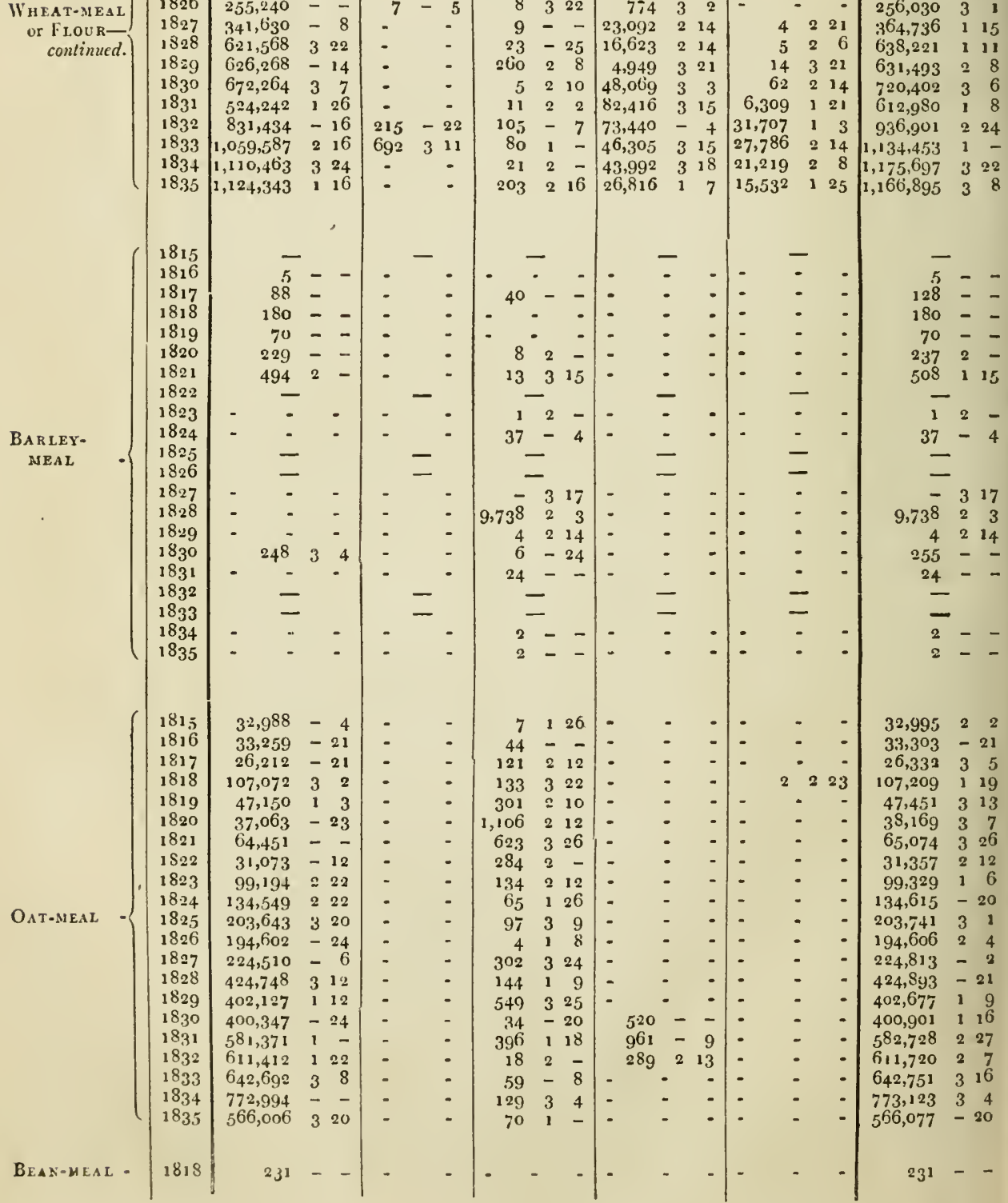


No. 8. -Ax Accoun t of Grain, Wheat, Barley, Oats, Rye, \&c., brought into Consumption in Great Britain from Ireland, His Majesty's Colonies in America, \&c., \&c.-continued.

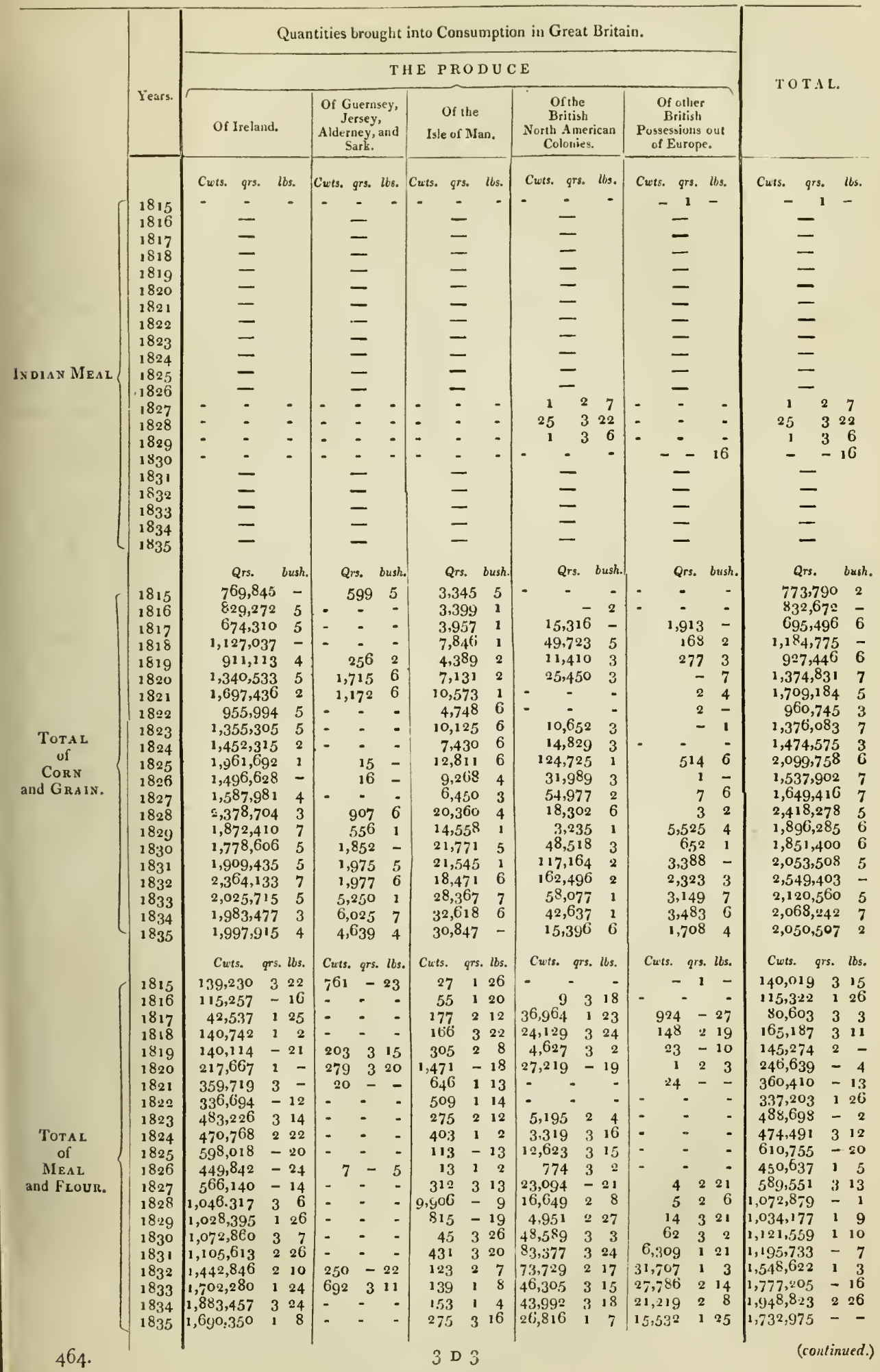


No. 8. -An Account of Grain, Wheat, Barley, Oats, R ye, Sc., brought into Consumption in Great Brituin from Ireland, His Majesty's Colonies in America, Sic., \&c.-continued.

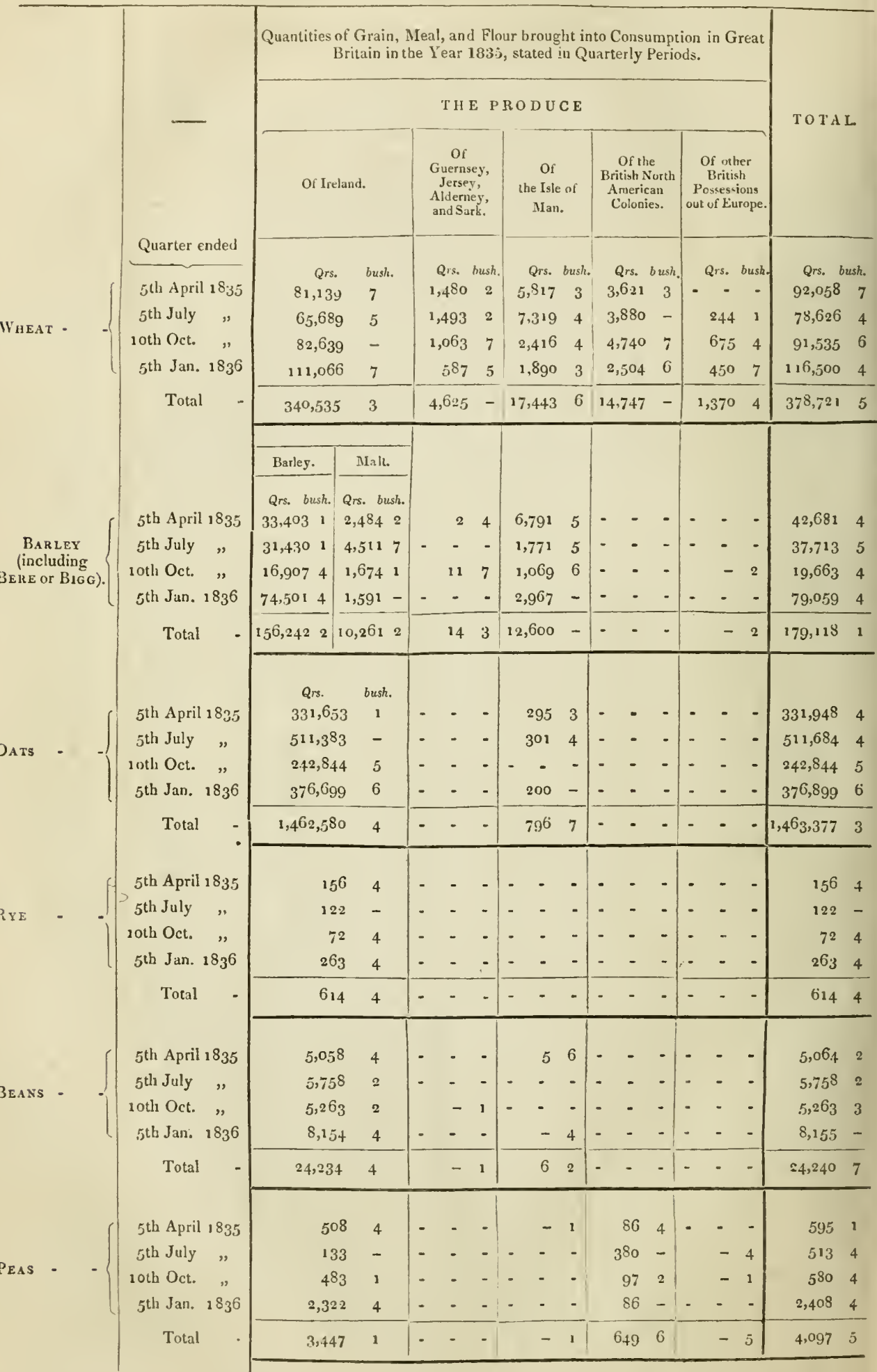


Nu. 8.-An Accoust of Grain, Wheat, Barley, Oats, Rye, \&c., brought into Consumption in GreatBritain from Irclund, His Majesty's Colonies in America, \&.c., \&. c.-cuntinued.

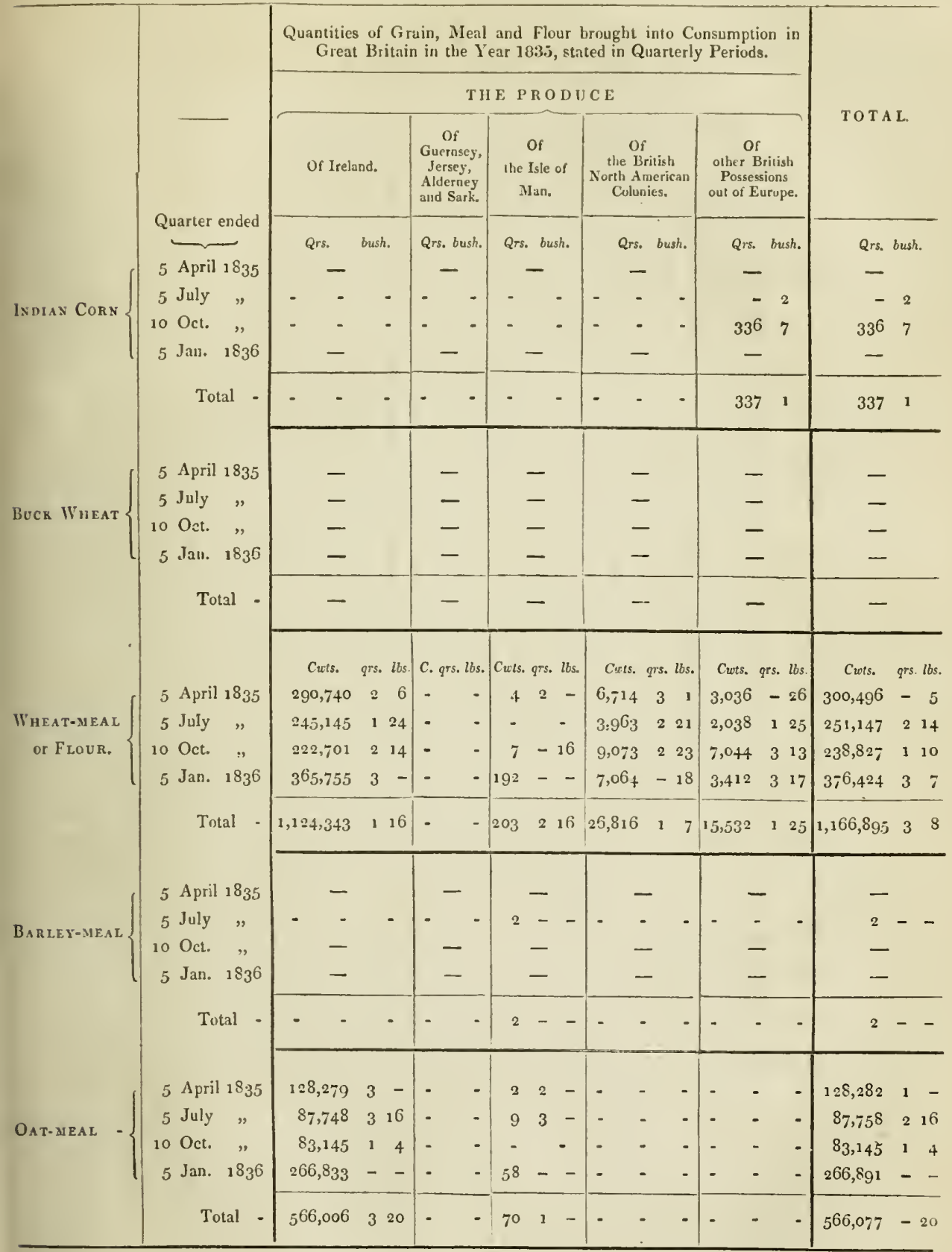

The records of this department do not supply the means of exbibiting the consumption of grain (nther than foreign) in monthly periods, as required by the order. The furegning statement, which shows the consumption in quarterly periods, is therefore respectfully submitted.

Inspector General's Office,
Custom House, London,

11 March 1836 .
William Irving,

Inspector General of Imports and Export6. 
No. 9.

Appendix, No. 9. An Accuust of the Prices of Beef, Muttux, Veal, Pork, Cueese and Butter, at Smithifield and Leadenhall Markets, for each of the Years from 1815 to 1835 , both inclusive.

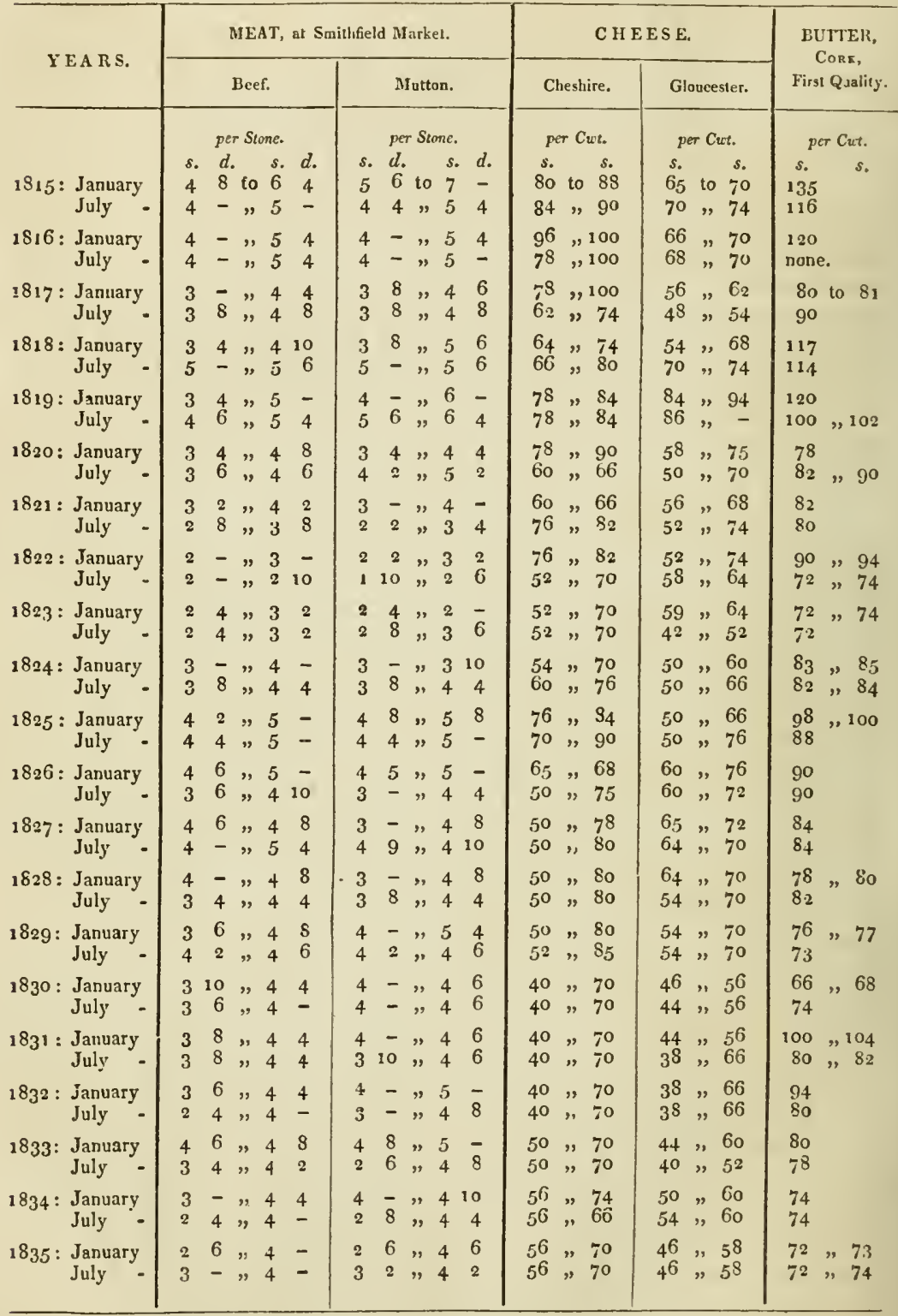

Mem.-There are not any documents in this department which record the prices of veal or pork, nor the prices of beef and mutton, in Leadenhall Market. The prices of cheese and butter, as given above, are those which were current in the different London mankets at the dates specified.

Statistical Department,

Board of Trade, Whitehall,

G. R. Purter.

14 . March 1836. 
No. 10.

An Account of the Quantities and Prices of frisil Salted Begf and Pork contracted for from 1813 to 1836 .

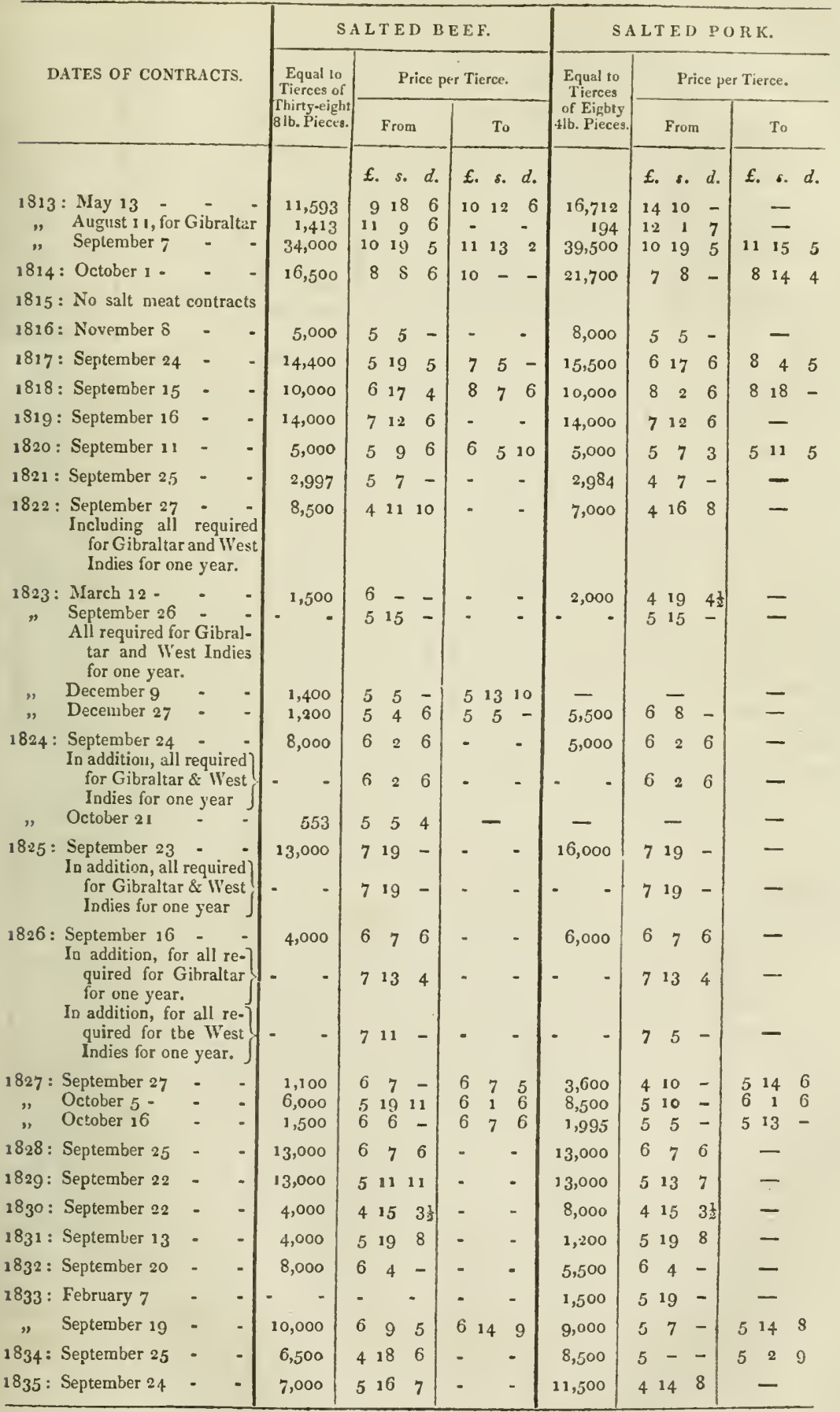

Statistical Department,

Board of Trade, Whitehall,

G. R. Porter. 
No. 11.

Ax Account of the several Articles of Clothixg, and the Prices nf each, in Greentich,

GREENWICH

\begin{tabular}{|c|c|c|c|c|c|c|c|c|c|c|c|c|c|c|c|c|}
\hline & & & & 181 & & 181 & & 1817 & & 1818 & & 1819. & 1820. & 1821. & 1822. & 1823. \\
\hline & & & & & & & & & & & & s. $\quad d$. & $\begin{array}{ll}\text { s. } & d .\end{array}$ & s. d. & s. $\quad$ l. & s. d. \\
\hline Shoes & - & - & per pair & 4 & 7 & & 7 & & 10 & 31 & & $4 \quad 2 \frac{3}{3}$ & $4 \quad 4 \frac{1}{2}$ & 43 & $\begin{array}{ll}4 & 2 \frac{1}{2}\end{array}$ & $4 \quad 7 \frac{3}{4}$ \\
\hline Slockings & s- & - & - dito & 3 & 3 & 2 & 9 & 2 & 9 & 21 & 11 & 211 & $2 \quad 9 \frac{1}{2}$ & 28 & 25 & 22 \\
\hline Hats & - & - & - each & 3 & - & 3 & - & 3 & - & 3 & - & $3-$ & $3-$ & $3-$ & $3-$ & $3-$ \\
\hline Blankets & - & - & - ditto & 11 & 3 & 9 & $4 \frac{1}{2}$ & 9 & $4 \frac{1}{2}$ & 9 & $4 \frac{1}{2}$ & $\left.\begin{array}{l}\begin{array}{l}\text { Suits of } \\
\text { Bedding }\end{array}\end{array}\right\} 59 \quad 10 \frac{1}{2}$ & $\begin{array}{ll}59 & 10 \frac{1}{3}\end{array}$ & $59 \begin{array}{ll}50 & 10 \\
\frac{1}{2}\end{array}$ & $59 \quad 10 \frac{1}{2}$ & $5910 \frac{1}{2}$ \\
\hline Suits of $\mathrm{C}$ & Cloth & & - ditto & & - & - & - & - & - & & - & $41-\frac{1}{2}$ & $41 \quad 7 \frac{1}{4}$ & $43 \quad 3 \frac{1}{4}$ & 419 & $40 \quad 2 \frac{3}{3}$ \\
\hline Coats & - & - & - ditto & 24 & 9 & 24 & 9 & 20 & 7 & 20 & 7 & $21 \quad 10 \frac{1}{2}$ & 227 & 2111 & $21 \quad 3 \mid$ & $21 \quad 1 \frac{1}{2}$ \\
\hline
\end{tabular}

BETHLEM

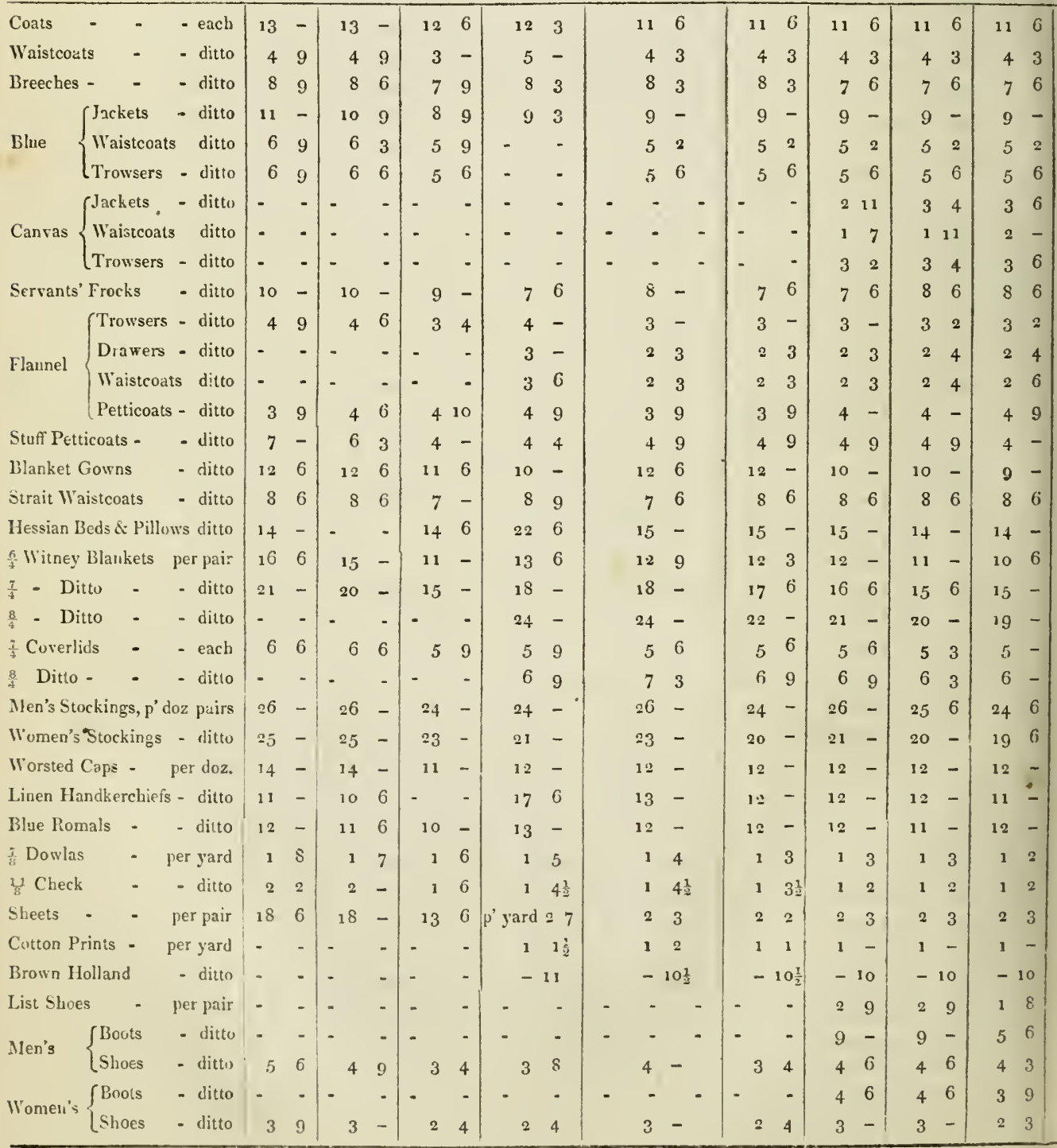


No. 11.

Bethlem and Chelsea Hospitais, in each Year, from 1815 to 183j, both inclusive.

HOSPITAL.

\begin{tabular}{|l|l|l|l|l|l|l|l|l|l|l|l|}
\hline 1824. & 1825. & 1826. & 1827. & 1828. & 1829. & 1830. & 1831. & 1832. & 1833. & 1834. & 1835. \\
\hline
\end{tabular}

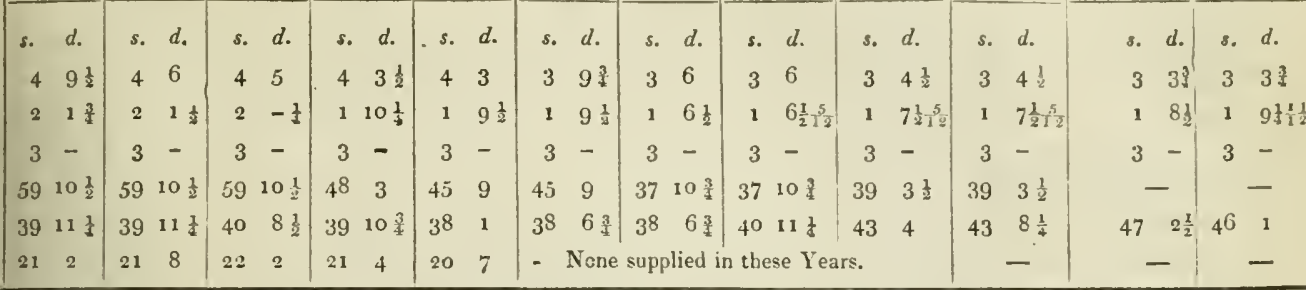

\section{HOSPITAL.}

\begin{tabular}{|c|c|c|c|c|c|c|c|c|c|c|c|c|c|c|c|c|c|c|c|c|c|}
\hline 103 & 116 & 11 & 3 & 11 & 3 & 11 & 3 & 11 & 2 & I 1 & 2 & - & - & - & - & - & - & 16 & - & 16 & - \\
\hline $4-$ & 43 & 4 & 3 & 4 & 3 & 4 & 3 & 4 & 2 & 4 & 2 & - & - & - & - & - & - & 6 & - & 6 & - \\
\hline $\begin{array}{ll}6 & 9\end{array}$ & $\begin{array}{ll}6 & 3\end{array}$ & 6 & - & 5 & 10 & 5 & 10 & 5 & 8 & 5 & 8 & - & - & - & - & - & - & 12 & - & 12 & - \\
\hline $8-$ & $8-$ & 7 & 9 & 7 & 9 & 7 & 9 & 7 & 8 & 7 & 8 & & 一 & & - & & - & - & & - & - \\
\hline 46 & 46 & 5 & - & 4 & 10 & 4 & 10 & 4 & 9 & 4 & 9 & & - & & - & & - & - & & - & - \\
\hline 411 & 411 & 4 & 9 & 4 & 9 & 4 & 9 & 4 & 8 & 4 & 8 & & - & & 一 & & - & - & & - & - \\
\hline 310 & 38 & 3 & - & 2 & 10 & 2 & 10 & 2 & 9 & 2 & 9 & 2 & 8 & 2 & 4 & - & - & 3 & 6 & 3 & \\
\hline 24 & 22 & 1 & 9 & 1 & 8 & 1 & 8 & 1 & $7 \frac{1}{2}$ & 1 & $7 \frac{1}{2}$ & 1 & 8 & 1 & 4 & - & - & 1 & 6 & 1 & \\
\hline $4-$ & 38 & 3 & - & 2 & 10 & 2 & 10 & 2 & 9 & 2 & 9 & 2 & 8 & 2 & 4 & - & - & 4 & 6 & & \\
\hline $7-$ & 76 & 6 & 3 & 6 & 3 & 6 & 3 & 6 & 3 & 6 & 3 & 6 & $1 \frac{1}{2}$ & & - & & - & - & & - & - \\
\hline $\begin{array}{ll}3 & 1\end{array}$ & 31 & 3 & 4 & 3 & 3 & 3 & 3 & 3 & 2 & 3 & 2 & & - & & - & & - & - & & - & - \\
\hline 25 & 25 & 2 & 3 & 2 & 2 & 2 & 2 & 2 & 1 & 2 & 1 & - & - & - & • & - & - & 3 & - & 3 & \\
\hline 31 & $3-$ & 2 & 5 & 2 & 4 & 2 & 4 & 2 & 3 & 2 & 3 & - & $\cdot$ & - & - & - & - & 3 & - & 3 & \\
\hline 311 & $4-$ & 3 & 8 & 3 & 8 & 3 & 8 & 3 & 8 & 3 & 8 & - & - & - & - & - & - & 4 & 6 & 4 & \\
\hline $4-$ & 43 & 3 & 8 & 3 & 8 & 3 & 8 & 3 & 8 & $3^{\prime}$ & 8 & - & - & - & - & - & & 3 & 6 & 3 & 6 \\
\hline 89 & - & 8 & 6 & 8 & 6 & 8 & 6 & 8 & 3 & 8 & 3 & & - & & - & & - & - & & - & - \\
\hline 79 & $7-$ & 6 & 6 & 6 & 6 & 6 & 6 & 6 & 6 & 6 & 6 & & $4 \frac{1}{2}$ & & - & & - & - & & - & - \\
\hline- & - & - & - & & - & & - & & - & & - & & - & & - & & - & - & & - & - \\
\hline $10-$ & $11-$ & 9 & - & 9 & - & 9 & 0 & 9 & - & 9 & - & 8 & 9 & 8 & 8 & 9 & & each 5 & 11 & 5 & \\
\hline $13-$ & $15-$ & 11 & 6 & 11 & 6 & 11 & 6 & $1^{1}$ & 6 & 11 & 6 & 10 & 6 & 11 & 4 & 12 & & 7 & 6 & 7 & \\
\hline 186 & $19-$ & 14 & - & 14 & - & 14 & - & 13 & 6 & 13 & 6 & 14 & - & 14 & 4 & 15 & 4 & 9 & 6 & 9 & 3 \\
\hline 32 & $4 \quad 2$ & 3 & 9 & - & - & - & - & - & - & - & - & - & - & 3 & 2 & 3 & 6 & 3 & 9 & 3 & 9 \\
\hline 43 & 56 & 4 & 9 & 4 & 9 & 4 & 9 & 4 & 6 & 4 & 6 & 4 & 6 & 4 & 4 & 4 & 8 & 5 & - & 5 & \\
\hline $19-$ & $25-$ & 21 & - & 21 & - & 21 & - & 21 & - & 21 & - & 13 & - & 21 & - & 21 & 6 & $\begin{array}{l}\text { per } \\
\text { pair }\}_{1}\end{array}$ & 10 & 1 & 10 \\
\hline 123 & $20-$ & 17 & - & 17 & - & 17 & - & 17 & - & 17 & - & 12 & - & 16 & 6 & 18 & - & 1 & 8 & 1 & 8 \\
\hline 56 & 106 & 10 & - & 10 & - & 10 & - & 9 & - & 9 & - & 6 & - & 7 & - & 7 & 6 & each - & $7 \frac{1}{2}$ & - & 8 \\
\hline io 3 & $\begin{array}{ll}11 & 6\end{array}$ & 9 & - & 9 & - & 9 & - & 9 & - & 9 & - & 8 & - & 8 & - & 8 & - & - & 8 & - & 8 \\
\hline $\begin{array}{ll}8 & 3\end{array}$ & 910 & 9 & - & 8 & - & 8 & - & 7 & 6 & 7 & - & 5 & - & 7 & - & 7 & - & - & 7 & - & 8 \\
\hline $1-$ & $1 \quad 2 \frac{1}{2}$ & 1 & - & 1 & $-\frac{1}{2}$ & 1 & $-\frac{1}{2}$ & 1 & $-\frac{1}{4}$ & 1 & $-\frac{1}{4}$ & & $10 \frac{1}{2}$ & & II $\frac{3}{4}$ & 1 & - & 1 & $-\frac{x}{3}$ & 1 & $1 \frac{1}{2}$ \\
\hline-10 & $-10 \frac{1}{2}$ & - & 11 & - & $10 \frac{1}{2}$ & - & $10 \frac{1}{2}$ & - & $10 \frac{1}{2}$ & & $10 \frac{1}{2}$ & & 7 & - & 8 & - & 8 & - & 8 & - & 9 \\
\hline 18 & 19 & 1 & $5 \frac{1}{2}$ & 1 & $5 \frac{1}{2}$ & 1 & $5 \frac{1}{2}$ & 1 & 5 & 1 & 5 & 1 & 3 & 1 & $2 \frac{1}{2}$ & 1 & $2 \frac{3}{x}$ & 1 & 3 & 1 & 4 \\
\hline-10 & -11 & & 10 & - & 9 & - & 9 & - & $8 \frac{3}{4}$ & - & $8 \frac{3}{4}$ & - & $5 \frac{1}{2}$ & - & 5 & - & $5 \frac{1}{4}$ & - & $5^{3}$ & - & $6 \frac{1}{4}$ \\
\hline-7 & -8 & - & $8 \frac{1}{2}$ & - & $8 \frac{1}{2}$ & - & $8 \frac{1}{2}$ & - & $8 \frac{1}{4}$ & - & $8 \frac{x}{4}$ & - & $6 \frac{1}{2}$ & & 8 & - & 8 & - & 8 & - & 8 \\
\hline 110 & - & - & - & 2 & - & 2 & - & 1 & 8 & - & - & - & - & - & & - & - & 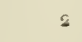 & - & 2 & - \\
\hline 56 & - & - & - & 5 & 6 & 5 & 6 & 4 & 10 & - & - & - & - & - & - & - & - & 6 & - & - & \\
\hline 44 & 48 & 4 & 8 & 4 & - & 4 & 2 & 4 & - & 4 & 1 & - & & & & - & - & 4 & 6 & & - \\
\hline 310 & - & - & - & 3 & 9 & 3 & 9 & 3 & 8 & & - & & - & & -- & & - & - & & - & - \\
\hline 211 & $\begin{array}{ll}3 & 1\end{array}$ & 3 & 1 & 2 & 9 & 2 & 9 & 2 & 11 & & II & - & - & - & - & - & - & - & -1 & 4 & - \\
\hline
\end{tabular}


No. 11.-An Account of the several Articles of Clothing, and the Prices of

Officers -

Coats Light Horsemen Serjeants

Privates -

Officers

Great Coats $\left\{\begin{array}{l}\text { Light Horsemen } \\ \text { Serjearts }\end{array}\right.$ Serjearts

Privates

Gown and Petticoat, Matron $\begin{array}{lllllll}1 & 17 & 3 & 1 & 17 & 3\end{array}$

\begin{tabular}{l|lll|llll} 
Coat and Breeches, servant & 1 & 14 & 4 & 1 & 14 & 4
\end{tabular}

Hats, Shoes and Stockings, ?

porter .

$$
-\}-
$$

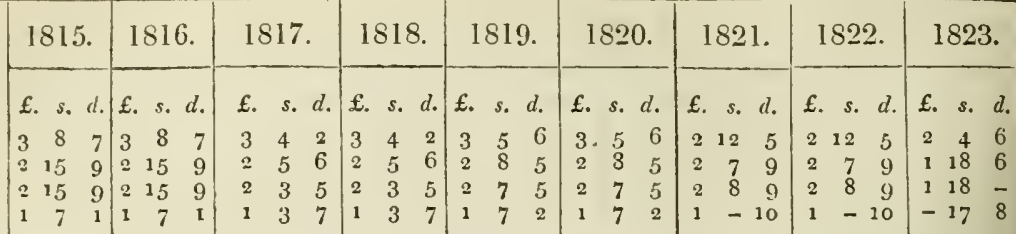

Waistcoat - - Officers - 11116

Breeches - - ditto - $1-11-1$

Hat - - - ditto - $-1711-1711$

3 Shirts, 2 Rollers ditto - $\begin{array}{llllll}1 & 2 & 2 & 1 & 2 & 2\end{array}$

2 Night Caps - - ditto -

2 Pairs Stockings ditto - $-\begin{array}{lllll}6 & 3 & -6 & 3\end{array}$

A Pair of Gaiters

A Pair of Shues -

ditto

A Pair of Mitts - ditto

Waistcoat, Light Horsemen

Breeches - - ditto - $-14 \quad 9-149$

\begin{tabular}{rrr|rrr|rrr|rr}
18 & 4 & 1 & 18 & 4 & 1 & 17 & - & 1 & 17
\end{tabular}

Hat

3 Shirts, 2 Rollers ditto - -\begin{tabular}{ll|lll}
-18 & 10 & -18 & 10
\end{tabular}

2 Night Caps - ditto -

2 Pairs Stockings ditto - $-\begin{array}{llll}-6 & 3 & -6 & 3\end{array}$

1 Pair Shoes - - ditto -

1 Pair Gaiters - ditı -

1 Pair Mitts - - ditto -

Waistcoat - Serjeants - $-18--18-$

Breeches - - - ditto - \begin{tabular}{ll|lll}
-14 & 9 & -14 & 9
\end{tabular}

\begin{tabular}{ll|ll|ll|ll|ll}
-12 & 4 & -12 & 4 & -13 & 1 & -13 & 1
\end{tabular}

\begin{tabular}{lll|lll|lll|lll|lll|lll|lll}
1 & 7 & 6 & 1 & 7 & 6 & 1 & 17 & 11 & 1 & 17 & 11 & 1 & 5 & $8 \frac{1}{4}$ & 1 & 5 & $8 \frac{1}{2}$ & 1 & -3
\end{tabular}

$-1410-1410-156-156-14--14--106$

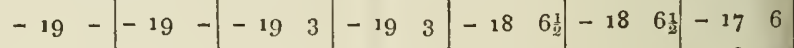

\begin{tabular}{ll|ll|ll|ll|ll|llll}
-17 & 9 & -17 & 9 & -18 & 1 & -18 & 1 & -12 & 11 & -12 & 11 & -18 & $4 \frac{1}{2}$
\end{tabular}

Hat - - - ditto - $\begin{array}{lllll}-11 & 3 & -11 & 3\end{array}$

3 Shirts, 2 Rollers ditto - $\mid$\begin{tabular}{ll|ll}
-18 & 10 & -18 & 10
\end{tabular}

3 Night Caps

Pairs Stoching

2 Pairs Stockings ditto
1 Pair Shoes - -

1 Pair Gaiters - ditto -

1 Pair Mitts - - ditto -

Waistcoat - Privates - $\mid$\begin{tabular}{ll|ll}
-11 & 7 & -117 & 7
\end{tabular}

Breeches - - ditto - - 94 - 94

Hat - - - ditto - $-\begin{array}{lll}4 & 2 \\ -4 & 2\end{array}$

3 Shirts, 2 Rollers ditto - $\begin{array}{llll}-18 & 2 & -18 & 2\end{array}$

2 Night Caps - - ditto - $-2 \quad-\begin{array}{lll}-2 & -2\end{array}$

2 Pairs Stockings ditto - $-510-510$

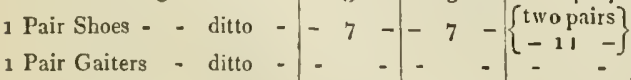

1 Pair Mitts - - ditio 
each, in Greenwich, Bethlem, and Chelsea Hosjita's - continued.

\section{HOSPITAL.}

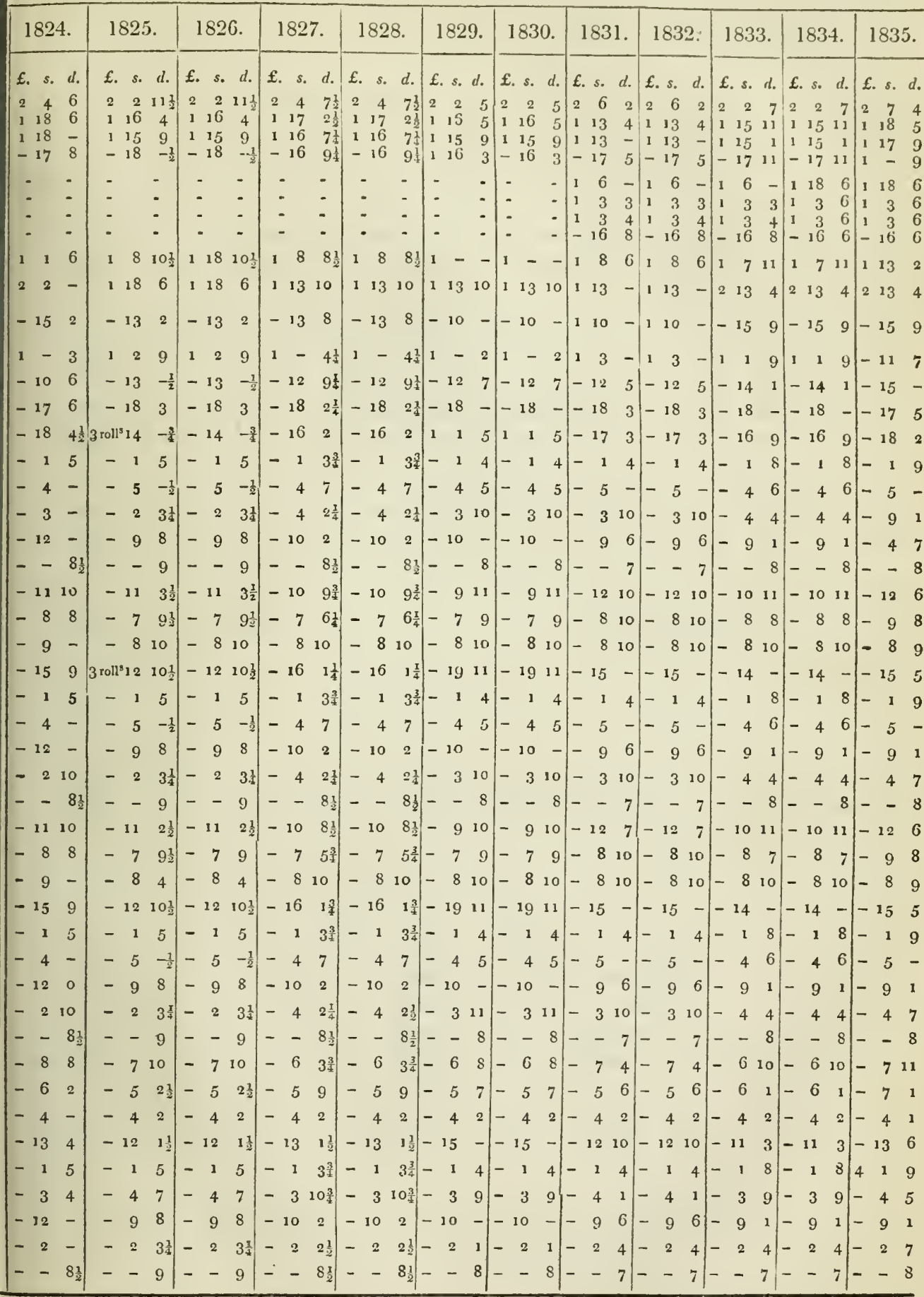


No. 12 .

Appendix, No. 12. Ax Account of the Number of Stock (distinguishing the various kinds), and of the Anovnt of Butter, Beef, Pork, Bacon, und Hasis, brought into Great Britain from Ireland from 1815 to 1825 .

\begin{tabular}{|c|c|c|c|c|c|c|c|c|}
\hline \multirow{2}{*}{ Yeurs. } & \multicolumn{4}{|c|}{ S T O C K. } & \multirow{2}{*}{ BUTTER. } & \multirow{2}{*}{ BEEF. } & \multirow{2}{*}{ PORK. } & \multirow{2}{*}{$\begin{array}{l}\text { BACON } \\
\text { and } \\
\text { HAMS. }\end{array}$} \\
\hline & $\begin{array}{c}\text { Cows and } \\
\text { Oxe12. }\end{array}$ & Horses. & Sheep. & Swine. & & & & \\
\hline 1815 & $\begin{array}{c}\text { Number. } \\
33,809\end{array}$ & $\begin{array}{r}\text { Numbcr. } \\
1,283\end{array}$ & $\begin{array}{l}\text { Number. } \\
26,502\end{array}$ & $\begin{array}{l}\text { Number. } \\
127,570\end{array}$ & $\begin{array}{c}\text { Cwts. } \\
337,378\end{array}$ & $\begin{array}{l}\text { Barrels. } \\
60,307\end{array}$ & $\begin{array}{l}\text { Barrels. } \\
105,766\end{array}$ & $\begin{array}{c}C w t s . \\
213,569\end{array}$ \\
\hline 1816 & 31,752 & 801 & 34,483 & 83,618 & 303,964 & 39,495 & 59,284 & $219,99^{8}$ \\
\hline 1817 & 45,301 & 848 & 29,460 & 24,193 & 320,180 & $105: 555$ & 89,941 & 179,093 \\
\hline 1818 & $5^{8,165}$ & 2,142 & 25,152 & 23,960 & $3^{81,554}$ & 80,587 & 87,992 & 212,740 \\
\hline 1819 & 52,175 & 2,944 & 19,710 & 61,759 & 433,174 & 60,361 & 86,650 & 221,309 \\
\hline 1820 & 39,014 & 2,552 & 24,159 & 99,107 & 490,845 & $5^{2}, 591$ & 105,973 & 260,549 \\
\hline 1821 & 26,725 & 2,392 & 25,310 & 104,501 & 413,088 & 65,905 & $9^{6,449}$ & $3^{62,846}$ \\
\hline 1822 & 34,659 & 1,089 & 35,685 & 65,037 & 377,651 & 43,139 & 72,148 & $23^{8,985}$ \\
\hline 1823 & 46,351 & 2,277 & $55,15^{8}$ & 82,789 & 466,834 & 69,079 & 84,442 & 341,515 \\
\hline 1824 & 62,314 & 2,081 & 61,137 & 73,027 & 431,175 & 54,840 & 75,525 & 3 I 2,000 \\
\hline 1825 & 63,519 & 3,130 & 72,161 & $65,9^{19}$ & 425,670 & 63,507 & 83,783 & $3^{61,139}$ \\
\hline
\end{tabular}

In: ector General's Office, Custum House, London 11 . . Iarch 1836 .
William Irving,

Inspector General of Imports and Exports.

No. 13.

Appendix, No. 13. A Keturn (so far as the same can be furnished) of the Notes of Private and Joint-Stock BANKs, in each Quarter, from the Year 1825 to the Year 1835, both inclusive.

\begin{tabular}{|c|c|c|c|c|c|}
\hline & & & PRIVATE BANKS. & $\begin{array}{l}\text { JOINT_STOCK } \\
\text { BANKS. }\end{array}$ & TOTAL. \\
\hline & & & f. & $f$. & f. \\
\hline & ( 28 December 1833 & - & $8,836,803$ & $1,315,301$ & $10,15^{2,104}$ \\
\hline & 29 March $\quad 1834$ & - & $8,733,400$ & $1,45^{8,427}$ & $10,191,827$ \\
\hline & 28 June & - & $8,875,795$ & $1,642,887$ & $10,518,682$ \\
\hline & 27 September , & - & $8,370,423$ & $1,783,689$ & $10,154,112$ \\
\hline Quarter ending & 28 December ", & - & $8,537,655$ & $2,122,173$ & $10,659,828$ \\
\hline & 28 March $\quad 1835$ & - & $8,231,206$ & $2,188,954$ & $10,420,160$ \\
\hline & 27 June & - & $8,455: 114$ & $2,484,687$ & $10,939,801$ \\
\hline & 26 September & - & $7,912,587$ & $2,508,03^{6}$ & $10,420,623$ \\
\hline & (26 December , & - & $8,334,863$ & $2,799,55^{1}$ & $11,134,414$ \\
\hline
\end{tabular}

N. B. - These Returns are made in pursuance of the Act $3 \& 4$ IV. 4 . cap. 83 , which only came into operation on the 28 th December 1833 , and consequently no Returns exist previous to that period. 
No. 14.

A Return of the Anount of the Liabizities of the Baxk of Englnnd, distinguishing Baxk Notes from Derosits, and the BANk Nores under $f .5$ from those above that Anount; also of Cors and Bulcros, distinguishing each, in the Bank, and distinguishing Gold from SiLver, in each ( $u a r t e r$, from the Year 1825 to the Yeur 1835, both included.

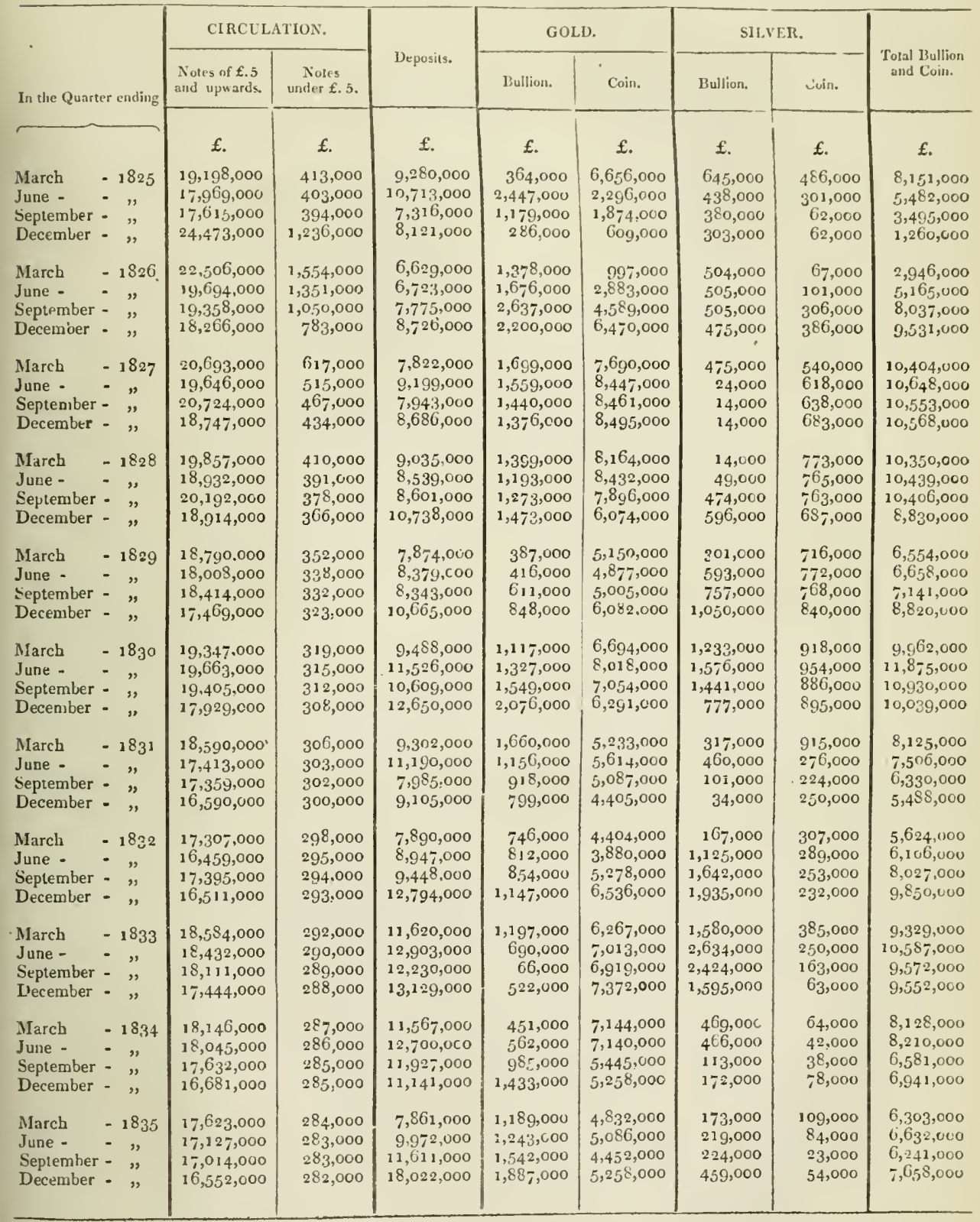

Bank of England, ?

15 March 1836 .
N. Murshall,

Chief Cashier. 
<smiles>C[13CH3]</smiles> 


\section{ANALYSIS OF INDEX.}

LIST of the Principal Headings referred to in the following Index, witl the Page of the Index at which they will be respectively found.

AgRICULTURAL DISTRESS-EXTENT THEREOF:

1. Generally

2. In particulur C'ounties

ALLOTMENT SYSTEM :

1. Its Effects upon the Consumption and Price of Wheat - $-{ }_{-}{ }_{2}$ A rable Farms

\section{BANKERS :}

2. Accommodation to Farmers

\section{Bill Brokers}

Butter

\section{CAPITAL:}

Exhanstion of Agricultural Capital - _ - _ - _ -

Cash Payments Bill

Clay Lands

Competition for Farms

Corn Crops

Corn Lazss

Cultivation

Currency

Failures

Farmers

Freeholders -

Importations

Ireland

Joint Standard

JOINT STOCK BANKS :

1. Accommodation to Farmers and Mamufacturers - $\quad$ - $\quad$ - $\quad-32$

Labour

Labourers

Land

Land Tax

Landowners

Malt Tax

Manure

Over-cropping

Parliament

Potatoes

Prices

Rents

Settlements on Estates -

Sheep

Sheep Farmer's

Silver Standard

Stock

464 .

Tallow 
Report, 1837 -continned.

Agricultural Distress:-JoINT Stock BaNks-continued.

Taxation

Tithe Bill -

Tithes

Wages

Wheat

Wool -

Yeomen

Agricultural Population

ALLOTMENT SYSTEM :

1. Its Effects upon the Consumption and Price of Wheat -

2. System in parlicular Counties

Potatoes

America

American Mines

Artificers

AVERAGES :

1. Accuracy thereof

2. Proposed Improvements

Bank of England

Branch Banks

Currency

BANKERS

1. Generally

2. Accommodation to Furmers

Bank Notes

Branch Banks

Joint Stock Banks -

\section{BARLEY :}

I. Growth and Consumption

2. Prices; whether remunerating or otherwise - _ _ _ _ _

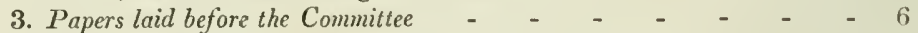

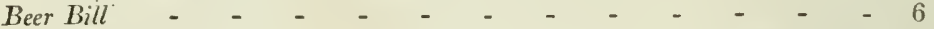

Chevalier Barley - -

Malt-tux - - - - - -

Beuns

Beef

Beer-shops

Birmingham

Bone Manure

Branch Banks

Bread

CAPITAL: Exhaustion of Agricultural Capital:

1. In England generally

2. In particular Countics

Cultivation

Interest -

Cash Payments Bill -

Contracts

Currency

Cattle

Circulation

CLAY LANDS:

1. Generally

2. In particular Connties 
Report, 18:37-contimued.

Clothing

Contracts

Corn

Corn Crops

Barley

Wheat

CORN LAWS:

1. Generally

2. Warehousing System

3. Proposed Alterations

Fixed Duty

Collage Rents

Crops

CULTIVATION:

1. Improvements therein - - - - - - - - -17

2. Deterioration: Causes and Extent thereof - _ _ _ _ $\quad-17$

3. Effects of diminishing the Cultivation of Corn - $\quad{ }_{-} \quad{ }_{-} \quad-17$

4. Expenses - - - - - - - - - - - - - 17

5. Systems pursued in different Counties - _ - _ _ - _ $\quad-18$

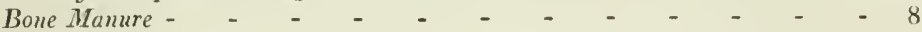

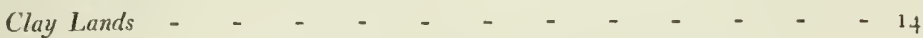

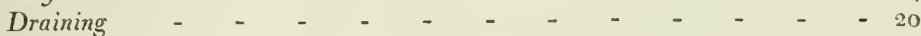

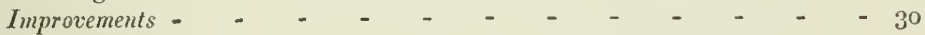

Inferior Lands -

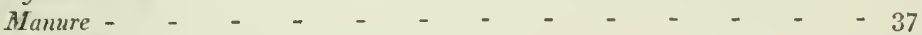

Over-cropping - $\quad$ - $\quad$ - $\quad$ - $\quad$ - $\quad$ - $\quad$ - $\quad$ - -38

CURRENCY:

1. Its Effects upon Prices and Agricultural Interests - $\quad-\quad{ }_{-} \quad 18$

2. How far Depreciation would relieve Disiress .. $\quad$ - $\quad$ - $\quad$ - $\quad$ - 18

3. Nature of the Alterations proposed - $\quad$ - $\quad-\quad-\quad-\quad-19$

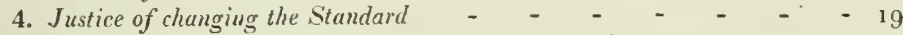

Bank of Eugland - - $\quad$ - $\quad$ - $\quad$ - $\quad$ - $\quad$ - $\quad$ - 5

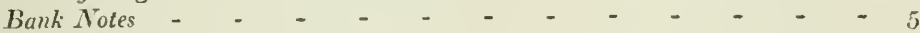

Bankers - - - - - - - - - - - -

Circulation - - - - - - - - - - - - 15

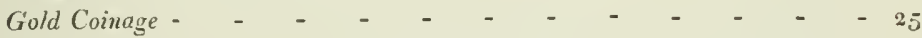

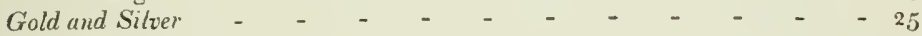

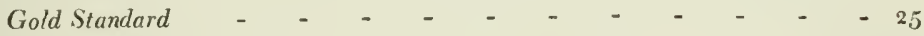

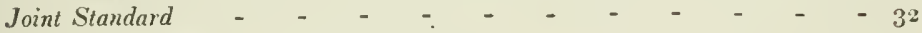

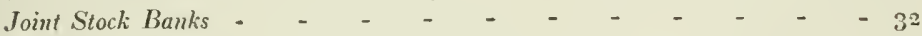

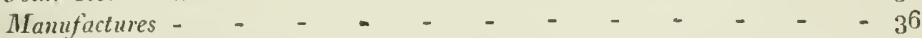

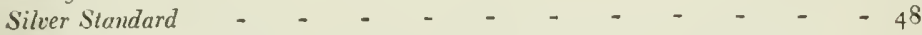

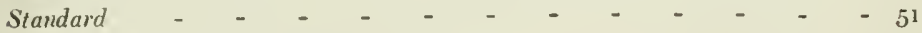

Draining

Employment

Labourers

Poor

Failures

Poor Lav Act - _ _ _ _ - _ _ _ - -

FARMERS :

1. Their Distress generally - - _ - - - - - -22

2. Classes more peculiarly affected - _ _ - _ _ _

3. Their Distress doubted or denied - - - - - fo - $\quad 23$

4. Whether they will profit by a Rise in the Price of Wheat " - - 23

5. Their mode of Lizing

464 . 
Report, 1837 --continued.

FARMERS-continued.

Agricultural Distress - $\quad-\quad-\quad-\quad-\quad-\quad-\quad-\quad-\quad-1$

Competition for Fnrms - - - - - - - - -

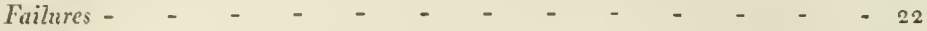

Graziers - - $\quad$ - $\quad$ - $\quad$ - $\quad$ -

Fires

Gold Standard - - $\quad$ - $\quad$ - $\quad$ - $\quad$ - $\quad$ -

IMPORTATIONS :

1. Effect of Importutions of Irish Produce upon Prices - - - - 30

2. Amount and Nature of the Imports - - - - - $\quad$ - $\quad 30$

3. Foreign Importations: their Effect on the English Markets - - - 30

4. Fraudulent Importations of Forcign Grain - - - - - - 30

IRELAND :

1. Expenses of Cultication therein - - - - - - - - 31

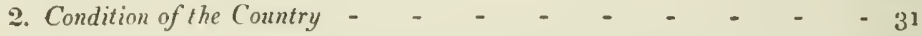

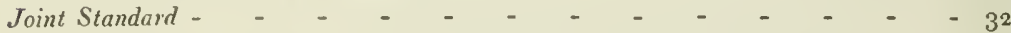

Currency - $-\quad-\quad-\quad-\quad-\quad-\quad-\quad-\quad-\quad-\quad-18$

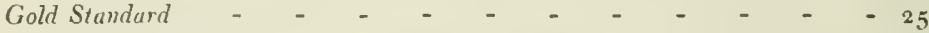

Silver Stundard - $\quad-\quad-\quad-\quad-\quad-\quad-\quad-\quad-\quad-\quad-48$

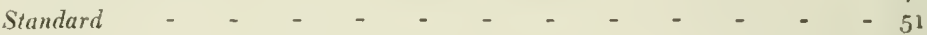

JOINT STOCK BANKS:

1. Accommodation to Farmers and Manufacturers - $-\quad$ - $\quad-32$

2. Their Constitution, \&c. - - - - - - - - - -32

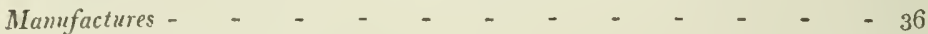

Labour

LABOURERS :

1. Their Condition generally - - - - - - - - - 33

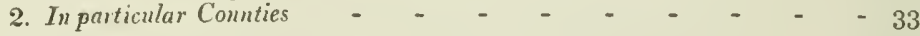

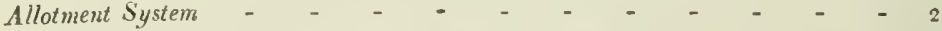

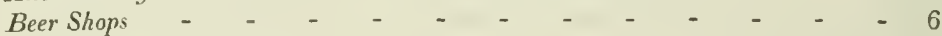

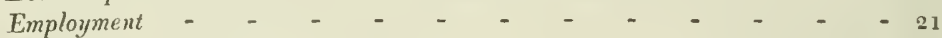

Malt Tax, I., 3 - $\quad$ - $\quad-\quad-\quad-\quad-\quad-\quad-\quad-\quad-\quad-\quad-36$

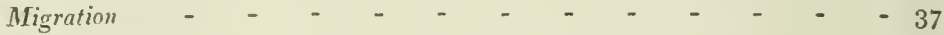

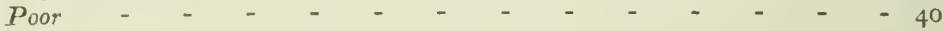

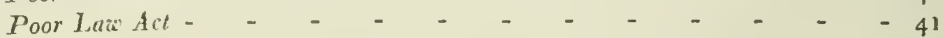

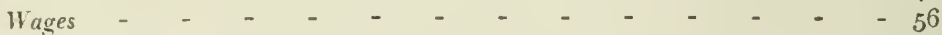

Land Tax - $-\quad-\quad-\quad-\quad-\quad-\quad-\quad-\quad-\quad-\quad-\quad-33$

Machinery - $\quad$ - $\quad-\quad-\quad-\quad-\quad-\quad-\quad-\quad-\quad-\quad-\quad-35$

MALT TAA:

1. Advantages in repealing the Malt Tax:

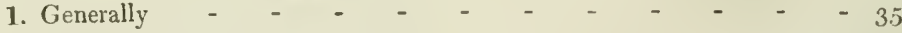

2. Farmers - - - $\quad-\quad-\quad-\quad-\quad-\quad-\quad-\quad-\quad-35$

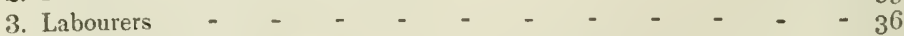

II. Advantages to Farmers in being enabled to malt their oz'n Grain for Cattle - 36

III. Substitutes for Taxation in case of the Repeal of the Malt I'ax - - $\quad 36$

IV. Alterations in Duty or Mode of collecting - - - - - - $\quad$ - 36

MANUFACTURES:

1. Couses of their Prosperity - - - - - - - - 36

2. Extent thereof - - - - - - - - - - - 36

3. Influence of a Change of Currency upon their Condiion - $\quad-\quad-36$

Manure

Outs

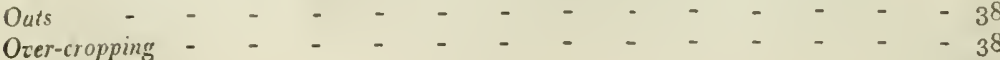


Report, 1837 -continued.

Pook

Employment

Labourers

POOR LAW ACT:

1. Generally

2. Beneficial Effects thereof - _ _ _ _ _ _ -

3. Injurious Eiffects thereof -

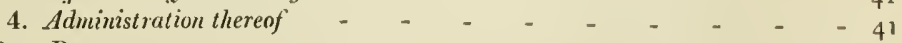

Poor Rates - - - - - - - - - - - - 41

Poor Laws (Ireland)

POOR RATES :

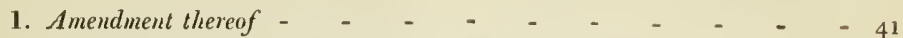

2. Proportions borne by Manufacturers and Agriculturists
-

\section{Potatoes:}

1. Cultization thereof, whether increased or diminished - $\quad-\quad-\quad-42$

2. Effects upon the Consumption of Wheat by Labourer - $\quad-\quad-\quad-42$

3. Consumption of a Family estimated - - - - - - -42

Allotment System - - $\quad$ - $\quad$ - $\quad$ - $\quad$ - $\quad$ - $\quad$ - $\quad$ - 2

\section{PRICES:}

I. High Prices :

1. Comparative Periods of - - - - - - - - -43

2. Effects of Appointment of Committees on - - - - $\quad-43$

3. High, on account of bad Crops - $\quad$ - $\quad$ - $\quad$ - $\quad$ - $\quad-43$

4. Effected by Currency and Corn Laws - _ - - - $\quad$ - 43

II. Low Prices:

1. Generally - - - - - - - - - - - 43

2. Caused by forced Sales of Agricultural Produce - - - - 43

3. Caused by Foreign and Irish Importations - - - - - - 43

4. Caused by the State of the Currency - - - - - - 43

5. Caused by over Supply - - - $\quad$ - $\quad-\quad-\quad-44$

6. Effect of Low Prices on Cultivation of Land - - - - - 44

7. High Prices of other Produce no compensation for Low Price of Wheat 44

III. Prices of Agricultural Produce Wheal roould remunerate - - $\quad 44$

RENTS:

1. Rate per Acre - - - - - - - - - - - - - 45

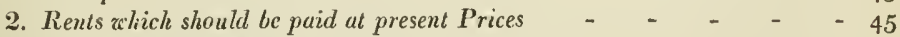

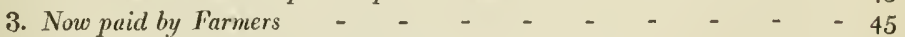

4. Amount of Reduction already made - - - $\quad$ - $\quad-\quad-\quad-45$

5. Evil Consequences of further Reduction - - - - - - $\quad-45$

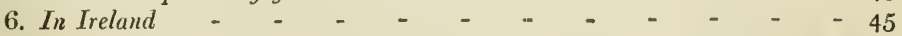

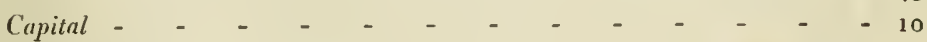

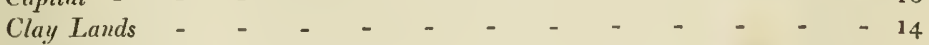

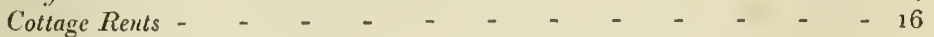

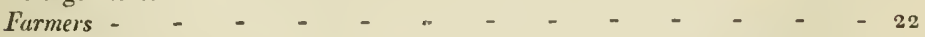

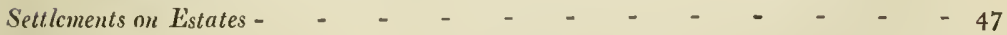

Sheep - - - - - - - - - - - - - - - 48

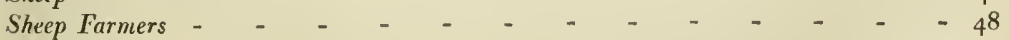

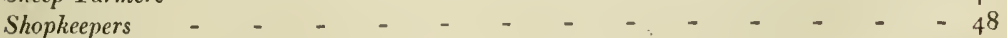

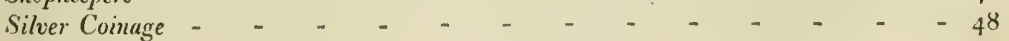

Silver Standard - 
Report, 1837 -continued.

SPECULATION:

1. Generally

2. In Corn -

Canals and Railroads

Corn Lats

Standard

STOCK :

1. Prices thereof, and by whut Circumstances infuenced - - - 51

2. How far profituble to the Furmer - $\quad$ - $\quad$ - $\quad$ - $\quad$ - $\quad$ - 51

3. Pupers laid before the Committee - $\quad$ - $\quad$ - $\quad$ - $\quad$ - $\quad$ - 51

TALLOW:

1. Duty on Foreign Tallow - - $\quad$ - $\quad$ - $\quad$ - $\quad$ - 52

2. Low Prices of British Tallow - $\quad$ - $\quad$ - $\quad$ - $\quad$ - $\quad$ - $\quad$ - 52

TAXATION :

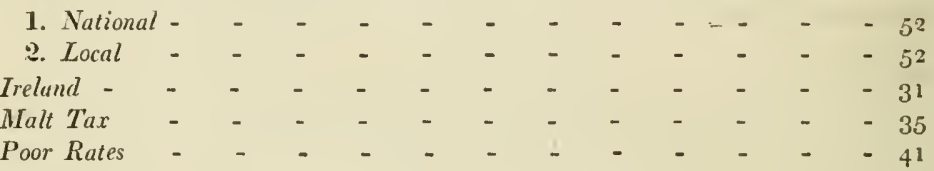

TITHES :

1. In Kind - - - - - - - - - - - - - 54

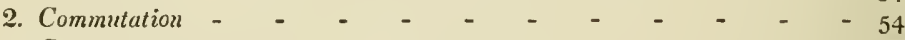

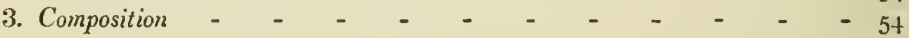

WAGES :

1. Generally - - - - - - - - - - - 56



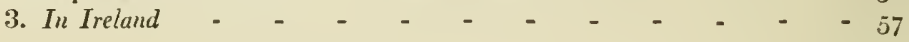

WIEAT:

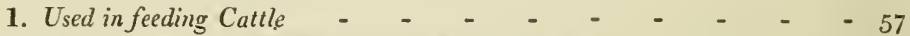

2. Prices of Wheat in England, Ireland and France - - - - 57

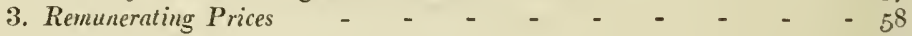

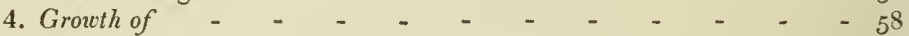

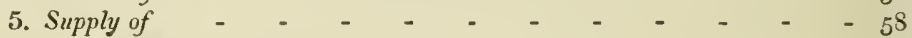

6. Consumption of - $\quad-\quad-\quad-\quad-\quad-\quad-\quad-\quad-\quad-58$

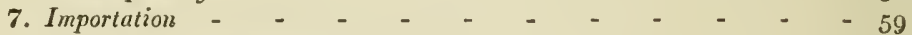

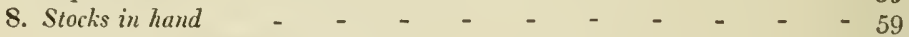

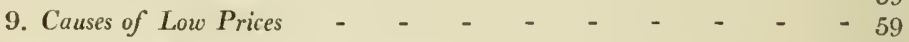

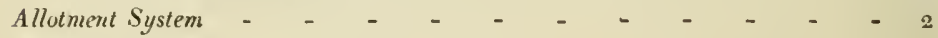

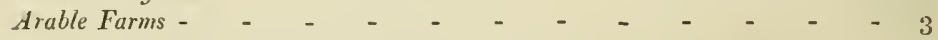

Corn - - - - - - - - - - - - - 15

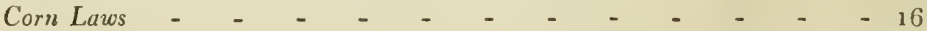



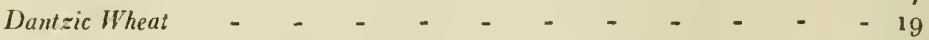

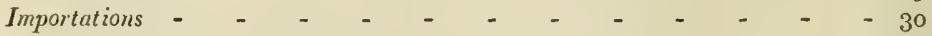

Liverpool - $-\quad-\quad-\quad-\quad-\quad-\quad-\quad-\quad-\quad-\quad-35$

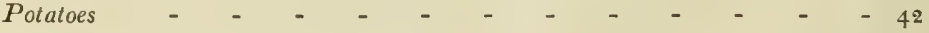

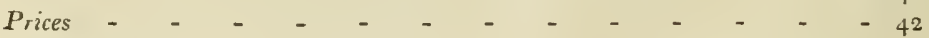

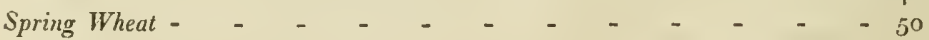

Swansea

WOOL:

1. Prices thereof - - - - - - - - - - - - 60

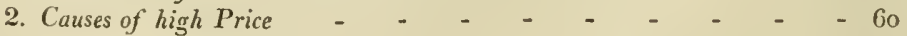

Yeomen 


\section{N D E X.}

N. B.-In the following Index, the Figures following the Names refer to the Number of the Questions of the Evidence; and $A_{p p} . p$. to the page of the Appendix.

A.

ACCOMmODATION. See Bankers. Bill Brokers. Branch Banks. Joint Stock Banks.

Accounts of the Bant of England. Publication of accounts of the Bank of England commenced in 1834, under the present charter, Pattison 5377.

Adjustment of Contracts. See Contracts.

Adjustment of Metals. See Standard.

\section{AGRICULTURAL Distress-EXTENT THEREOF:}

1. Generally.

2. In particular Counties.

\section{Generally.}

The whole egricultural body, including noblemen as well as farmers, are insolvent, Bernard 1615-1620-The agricultural counties were never in such distress as at the present time, Wilson 1701-1703-C - State of agriculture is very mucl depressed in all the southern counties, Trumper 3118-3120-Estimated loss to the agricultural interest in the drought of 1826 , and in the rot in sheep in 1831 and 1832 , Sandars 4073,4074

Great depression has taken place since 1816 ; the alteration of the currency was the first affecting cause, Blamire 5119, 5120; Summers 5146-_- The amount of agricultural distress has been greatly exaggerated, Pattison $544^{\circ}$.

\section{In particular Counties.}

In Bedfordshire the farming interest is much depressed; strong lands cannot by any system of farming be cultivated with profit at the present prices, Bennett 385,386 Table exhibiting the annual gain or loss, for 10 years, upon a farm of 163 acres in Berkshire, with explanations, Allnatt 774-791_- Statement of the produce of wheat in 1834 , in a whole parish, showing an excess in poor-rates and labour over the value of the wholc produce, Allnatt 792-797. 805-813- East Cumberland generally depressed; causes Blamire 5088, 5090-5092 - Less severe in Dorsetshire than in any other county, Taylor 3259-3263 - In Hampshire the state of agriculture is distressed, particularly in stronir clay lands, Twynam 562-564_The state of agriculture near Elthim is very distressed, Green 150-The state of the farms near Hounslow is not flourishing, but they are well cultivated, and there are not more changes amongst the tenantry than usual, Sherborne $4785-4789$ — In Suffolk, began in 1815; decreased in 1816 , but increased in 1821 and 1822 , Lewin 920-924-In South Wilts the state of agriculture has never been depressed so much as at present, except in 1822, Hughes 2994-2996-Complaints were first made in 1822 , but no improvement took place until 1826 , when country one-pound notes were withdrawn, Hughes 2997-3002.

See also Allotment System, 1. Arable Farms. Bankers, 2. Bill Brokers. Butter. Capital. Cash Payments Bill. Clay Lands. Competition for Farms. Corn Crops. Corn Laws. Cultivation. Currency. Failures. Farmers. Freeholders. Importations. Ireland. Joint Standard. Joint Stock Banks. Labour. Labourers. Land. Land Tax. Landowners. Malt Tax. Manure. Over-eropping. Parliament. Potatoes. Prices. Rents. Settlements on Estates. Sheep. Sheep Farmers. Silver Standard. Siock. Tallow. Taxation. Tithe Bill. Tithes. Wages.

Wheat. Woul. Yeomen.

Agricultural Labourers. See Labourers.

Agricultural Population. Although the per centage of agricultural families appears, from the Population Returns, to have decreased since 1811 , the apparent decrease arises only from a different mode of conducting the inquiry, Rickman $368,3^{69}$ - Tables and calculations to ascertain the real proportion of agriculturists to other classes, Rickman 370$37^{2}$ - Calculation of the number of males engaged in the cultivation of land, Rickman 375-377.

See also Population Returns. $4^{6} 4$. 
Report, 1837 -continued.

Allnatt, John Joseph. (Analysis of his Evidence.)-Resides at Wallingford, in Berkshire, and has occupied land, 767,768 - $A$ land-surveyor and agent, $769-$ The great mass of farmers are much distressed; their condition las been getting worse and worse for the last 10 years, $770-773$ - Table exhibiting the annual gain or loss for 10 years upon a farm of 163 acres, $774-778$ - It is impossible for any farm to be better cultivated, 779781 - Explanations of the account, $782-786$ - Amount of poor-rates and labour, $787-791$ - Statement of the produce of wheat in 1834 in a whole parish, showing an excess in poor-rates and labour over the value of the whole produce, 792-Explanations of the same, 793-797. $805-813$ - The farmers, in almost all cases, are paying the expenses of their farms out of capital, 798-800-It is impossible that they can be making profits, 801,802 - There is a profit on stock, but not sufficient, when brought into the general account, to save the farmer from loss, 803,804 .

The success of a farmer cannot be inferred from the price of wheat alone, 814,815

There has been much rot amongst the sheep, 816,817 - In the year $1823^{-24}$, the farm before alluded to produced a profit of nearly $400 l$., 818-826-All land is overrented at the present prices, 827,828 With the present rents, wheat should sell at 16 $l$. a load to make a profit, $829-831$ - - The four-course system of husbandry is used at Wallingford, 832,833 The wages are from $8 s$. to $12 s .6 d ., 835,836$ - The whole of the labour on the aforesaid farm is profitably employed, $837-841$ - It is in a very high state of cultivation, 842 - There has been a large crop of wheat for some years, as the seasons have been favourable, $843^{-84} 8$ - In 1819 the farm would have been worth 10 per cent. more than the present rental, $849-853$ - Now a bonus ought to be given for cultivating it, $854-856$ - Yet it would let again for its present rent, as farmers must have an occupation,' and always hope that times will mend, $857-863-$ Much land would be converted into pasture, if it could be done with less difficulty, 864,865 .

The market is overstocked with wheat of our own produce, and the prices are depreciated, $866-878$ - The reduction of the price of labour has borne no proportion to the reduction in the price of wheat, $879,880-$ - It would not be safe to reduce the one to the level of the other, $881-884-$ Blacksmiths, wheelwrights, \&c., charge very nearly as much as when prices were high, $88_{5}-887 \ldots$ The farmers approve of the principle of the new Poor Law, but think there is not sufficient discrimination between good and bad characters, $888-895$ - The poor will be excited unless their treatment, in some places, be altered, $896-898$ - Beer-houses have a tendency to demoralize, 899,900 - In a moral point of view, it would be beneficial to transfer the duty from malt to beer, 901 , $902-M u c h$ wheat has been used in feeding cattle, $903,904-$ It would be very beneficial to farmers to permit them to malt their own barley for their cattle, 905-907-The removal of the malt-tax would be a great relief; it would stimulate the barley trade by increasing consumption, 908-913.

\section{ALLOTMENT SYSTEM:}

1. Its Effects upon the Consumption and Price of Wheat.

2. System in particular Counties.

\section{Its Effects upon the Consumption and Price of Wheat.}

Has a tendency to substitute garden produce for wheat, as the food of labourers, Bennett $545-547$ - Its effects in supplying labourers with garden produce and diminishing their consumption of bread, Jacob $351,352-$ Has introduced the use of bread and meat amongst the labourers near Windsor, Kendall 1145-1152 - It encourages the growth of potatoes, Escott 4910 - Has greatly increased the cultivation of potatoes, Summers 5285 .

Is much encouraged in Wiltshire, and is beneficial to the poor, but reduces the consumption of wheat one-third, Hughes $3016,301 \% \cdot 3057-3060$-The cottagers live upon the produce of their gardens, and consume more pork and bacon, Hughes 3035-3037 - Is beneficial to labourers, but has had the effect of depreciating the price of wheat, Twynam 624- Is not sufficiently prevalent to liave affected the price of wheat, Howard $2169-2175$ - It improves the condition of the labourers; half an acre of potatoes will serve a family twice as long as half an acre of wheat, Kendall $11 \$_{5}-1191$.

\section{System in particular Counties.}

Dorsetshive. The system of giving labourers a piace of land in a field, and manuring it for them, is preferable to the usual system, Taylor $3284-3287$.

Wiltshire. The system has been carried to a greater extent than in any other county; a quarter of an acre is the largest allotment, Hughes $3054-3056$.

East Riding of York. The system has been introduced upon the larger estates, where the landlords reside, Howard 2168.

See also Potatoes.

America. Evidence as to quantity of gold taken from Europe by America, Pattison 5394,5395 - The United States have depreciated their gold standard six per cent., to bring it on a par with their silver, Cayley $3^{671-C o p y ~ o f ~ a ~ B i l l ~ c o n c e r n i n g ~ G o l d ~ C o i n s ~}$ for the United Statcs, Attwood, p. 355-Copy of an Act regulating the value of certain 
Report, 1837 -comtimuct.

\section{America-continued.}

foreign Silver Coins within the United States, Attwood, $p .356$ - Conduct of the American Congress on the subject of currency; method pursued by them, witli a view to bring back a gold circulation, Attwood 5i572- Plan adopted by Fingland as to currency precisely the reverse of that which America, under similar circumstances, $h_{1}$ as thought right to adopt, Attuood 5574 .

American Corn and Flour. The price of wheat in America is higher than in England, IJodgson 2028-2031- Corn could not be imported from that country until the home price exceeded $70 \mathrm{~s}$. the quarter, Hodyson 2038-2043- Some may have been surreptitiously introduced into England through Canada, IIodgson 2044-2048- American flour is more highly dried than our own; the wheat undergoes the process of kiln-drying before it is ground, Levin 978,979 .

See also Canada.

American Mines. The price of wheat, which had been ins, a quarter for a century, rose to 40 s. On the opening of the American mines, Cayley 3642 - Influx into Europe of the precious metals on the first discovery of America; its effect on prices and the coinage, Attwood 5583 .

See also Precious Metals.

Amesbury. Nature of the soil and rent per acre, Hughes 3030, 3031-Quantity of wheat, barley and oats that can be produced per acre, Hughes 3032-3034.

Animal Food. Effect of Irish importation on the price of animal food in the north of England, Blamire 5124,5125 .

See also Importations.

Arable Farms. The arable farmer could not go on but for his grass farms in connexion with his corn land, Cayley 3528-3530-In Glamoryanshire there is more arable land than there was in 1790 , David 1252-1257.

Armagh. About Armagh almost entirely arable land, but little thrown into pasture, Blacker 5617 Considerable exportation of wheat, butter, oats and pork from Armagh to England, Blacker 5642 .

Artificers. Blacksmiths, wheelwrights, \&c., charge the farmers very nearly as much as when prices were high, Allnatt $885-887$ - There has been very little difference in their charges since the war, Peyton 1536-1539--In Sussex their charges not much reduced, Hudson 3459 - They charge high prices to cover bad debts; the large farmer can get his work done more cheaply, Cayley 3599, 3600.

See also Shopkeepers.

Artificial Food. See Cattle. Sheep.

Artificial Manure. See Bone Manure. Manure.

Attwood,Matthias, esq., M.P. (Analysis of bis Evidence.)-Member of Parliament and banker, 5546 - Effect which would be produced by the restoration of a silver standard, 5548 Extent to which prices were depresed by the law of 1819,5551 - Table showing the price of corn in periods of five years, $1769-1794,555^{1}$ — Reasons why, with the present standard of value, prices cannot permanently maintain so high a level as before the suspension of casli payments, 5552- Proposed alteration to a silver standard would no doubt vitiate all contracts which bear date since the introduction of the present standard to the extent of fire per cent., 5553 - Beneficial results of the introduction of silver currency, 5553 Old laws regulating coin acted as a seignorage to the extent of two per cent., by preventing the melting and exportation of the coin of the realm, 5553, 55.54-Further presumed adrantages of a silver currency, 5555- If the present standard cannot be varied, it would be incumbent on the legislature to cause an adjustment in the amount of every existing contract which has its date before the introduction of the present gold standard, 5.555 .

Manner in which contracts were adjusted when the law regulating weights and measures was passed, 5555,5556 - Restoration of a silver standaid and a seignorage would be a compromise between conflicting interests, between debtor and creditor, 5559 .

Statement made in the House of Commons by a menber of the Committee of 1819 as to the mamer in which the Committee were misled as to the operation of the Act for returning to cash payments in its extent of altering prices, 5560 - Statement made by the bankers unanswered by the chairman, Sir R. Peel, $55^{6} 61$.

Errors which have been committed by the House of Commons in its regulations of the currency from $1797,5.562$ - Joint-stock banks, established in 1826 as a guarantee against future panics, now considered as the probable cause of an expected crisis, 5562,5563 Committee of the Privy Council, 1816 , sat for the purpose of establishing a silver coinage; results of their labuurs ; fallacy of their reasoning, 5563 - Discussion between the Bank and Gorernment as to which party should bear the loss on the silver coin accimulatcel in the coffers of the Bank, 5569 .

${ }_{2} 64$. 
Report, 1837 -continued.

Attwood, Matthias, esq., м. P. (Analysis of his Evidence)-continued.

To adjust the value of silver and gold, no other law necessary than one which should enable the subjects of the realm to carry their silver bullion to the Mint and have it coined and delivered at the rate of $5 \mathrm{~s} .2 \mathrm{~d}$. of money for the ounce of silver, $557 \mathrm{i}$ - Conduct of the American Congress on the subject of currency ; mode pursued by them, with a view to bring back a gold circulation, $557_{2}$ - Notice of a pamphlet, written by Mr. Gallatin, on the subject of currency, 5572_-Plan adopted by England precisely the reverse of that which America, under similar circumstances, has thonght right to adopt, 5.574 Standard was fixed in 43 d Elizabeth, 1601 ; this standard continued immutable to 1816 , 5574 - Narrative of the alterations in gold coins from Queen Elizabeth to Charles Il., 5575 - Adjustment of value of metals, which took place in the reign of James, was adopted by the advice of very able and distinguished statesmen, Lord Coke and Lord Bacon, 5575 .

Manmer in which they might be continued in circulation so as to have a joint standard, 5581 - Proofs that former debasements of the coin on the part of Government were not made to produce but to prevent frauds, 5583- Inflnx into Enrope of the precious metals on the first discovery of America ; its effects on prices and the coinage, $55^{8} 3$.

Average price of corn for 50 years ending $1794,55^{8}+$ Which demonstrates that the prices during the war were occasioned by the paper money; that such prices could not be maintained when returning to metal money, $55^{8}+$ - Reasons why the price of corn may not be so affected by the price of the precions metals in some countries as others, 5587 , $55^{88}$ - A great uniformity between the price of corn in this conntry and in France, estimated in the precious metals, 5587 - Cause of the great difference which has always existed in the price of corn between Prussia and some other countries and this country, 5588 - An enlargement of the standard would operate on the prices of manufactures as well as prices of corn, $55^{8} 9$.

In an American Congress Report the Corn Laws of England are described as an attempt made by the legislature to evade the consequences of the return to cash payments pressing on one part of the community; vanity of the attempt; concurrence of witness in the opinion, 5590.

Imperative on the legislature to return to a silver standard of $5 s .2 d$., with a proportionate seignorage to the amount the coin was depreciated in value by the old prohibitory laws, $559^{2}$.

Extent to which it might be an improvement in joint-stock banks to require them to pay up their capital, and limit the amount of responsibility, 5594-Opinion as to the additional security caused by the number of partners, 5596 - Conduct of many shareholders in the St. Patrick's Assurance Company on being threatened with actions for the debts of the company, $559^{8}$.

Value of a silver standard in times of panic, in giving security to the monetary system, beyond any security which the present system promises, 5601 .

No large supply of com could be permanently drawn from Prussia without a great advance in price, 5603 .

Ratios of gold to silver from 1760 to 1829 , with the averages of each 10 years, and the total mean average for to years, $p$. 354.

Table of prices in the market of gold and silver from 1760 to 1819 , taken from Wittenhall's Lists, and exhibiting the relative prices of gold and silver to each other, $p .355$.

A Bill concerning Gold Coins for the United States, p. 355-An Act regulating the value of certain foreign Silver Coins within the United States, p. 356 .

AVERAGES :

\section{Accuracy thcrenf. \\ 2. Proposed Improvements.}

\section{Accuracy thereof.}

Are ninre correct in England than in France; in the latter they are below the real prices, Jacob 298-300-Are fairly taken; millers generally have no interest in making unfair returns, and are better accountants than farmers, Jacob 329-333 - Are very inaccurate at Mark-lane, Bradley, 2495_- Scotch and English corn sold in the English markets was the average taken, but with the expense of carriage added to the price, Jacob $323-328$

\section{Proposed Improvements.}

Should be taken in Ireland as well as in England, and should be received from the farmer, Lewin 982 - A greater number of returns should be made, and the principal millers and maltsters should be required to make them by the quarter sessions, David $1333^{-1} 336$.

\section{B.}

Bacon. Nuch Irish bacon is consumed in Wiltshire, Hughes 3067, 3068-Quantity brought into Great Britain from Ireland, 1815 to 1825 , App.p. 406.

Bad Debts. See Artificers. Furmers. 
lieport, 18:37-continued.

Bank of England. Should be permitted to issue one-pound notes, and to pay their notes at

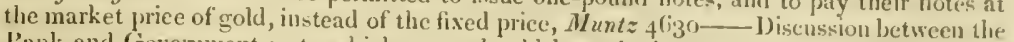
liank and Govenment as to which party should bear the loss on silver coin acemmulated in the coffers of the Bank, Attwood $556 \mathrm{~g}$-Amount of the liabilities of the bank about 32,000,000/., Pattison 5363.

Return of the amount of the liabilities of the Bank of Fngland, distinguishing bank notes from deposits, and the bank notes under $5 /$. from those above that amount; also of coin and bullion, distinguishing each in the Bank, and distinguishing gold fron silver in each quarter, fo: the year's 1825 to 1835 , both inchusive, App. $\% \cdot 407$.

See also Accounts. Bills of Elchange. Branch Banks. Bullion. Circnlation. Currency.

Bank Nates. Advantages of a free circulation of notes from 21. to 5 l. value, which should be on the same security as that upou which $5 l$. notes now rest, Escott $498+-$ R c.turn of the notes of private and joint-stock loanks in pach quarter from the yeir $18_{25}$ to the year 1835 , both.inclusive, $A p p \cdot p \cdot 406$.

See also Bankers, 1. Circulation. Currency.

Bank Restriction Act was followed by a general increace of prices in 1797 , Cayley 3642.

BANKERS:

\section{Generally. \\ 2. Accommodation to Farmers.}

\section{Generally.}

Are not anxious to increase their circulation, Langhorne $3766-3769-$ They would prefer Bank of England one-pound notes to an issue of their own, Langhorne $3847,3{ }_{4} 4$ Partners in banks should be required to give seenrity to the amount of their subscriptions, David 1279-1282_. The country bankers would very much object to give security for the amount of their issues, Langliorne 3834,3835 .

\section{Accommodation to Furmers.}

Freeholders can get accommodation from their bankers more readily than farmers, who are so distressed that they have no security, Wilson 1,$8 ;-1796-$ Farmers cannot give good security; persons in trade can indorse over their property, Cayley $4144-4146-$ Bankers will not trust famers, because they know they are needy, and on the verge of insolvency, Kendall 1128-1130; Spooner 4348-4350; Cayley 3661, 3662-In Cambridgeshire, Thurnall $2272-$ In Glamorganshire, Bradley $2484-2486-$ Farmers can get assistance for a month or two when prices are low, Bradley 25 - In Northumberland the farmers overdraw their accounts, giving bonds with two securities, Langhorne 37093711 _ Bankers will not advance money so readily in the East Riding of Yorkshire as they formerly did, as farmers have no personal security, Hoxard 2127-2129.

Scotland. Scotch tenants not immediately swept away, as they have been in the south, because they can procure accommodation from the banks, Grey $47^{2} 4$.

See also Bauk Notes. Branch Banks. Joint Stock Barks.

Baring, Mr. Quotations from his speeches supporting the view of two currencies, gold and silver, on account of the facilities which the Bank would experience in getting silver, when there might be difficulties in procuring gold, Escott 5079 .

\section{BARLEI' :}

1. Grouth and Consumption.

2. Prices, uhether remunerating or otheruise.

3. Papers laid before the Committee.

\section{Grouth and Consumption.}

The consumption has not increased in proportion to the population, Sharpe 3918,3919 There are no counties in which more could not be grown, sharpe 3920-3923Consumption of barley greatly increased since the establishment of beer-shops, Summers 5291 - In case of an increased consumption, farmers could produce double the quantity that is now grown, Firchild $1400-1+03$ - The price would improve if the malt duty were removed, Douling 2825-2827--And the consumption greatly increase, Dourling 2905,2906 - Farmers could afford to graw it at a lower price than $35 s$., so as to exclude foreign barley, Dowling $2907-2911$.

Evidence as to quantity of barley grown to an acre, Escott $486 \overline{7}$ - Produce of barley per acre in Glamorganshire, Bradley $2528-2532$ - - The erops were deficient iu 1834 and 1835, Thurnall $2331-2336$.

\section{Prices, whether remunerating or otherisise.}

Prices of barley in 1831 and February 1836 ; difference between cheralier and conımon barley, Bennett $455-46.7-$ fhe present prices are not remunerating, Bennett 522-527The price (28.s.) is fair, Tuynam 687,688_-But will not compensate for that of wheat, Tuynam 709-The price has been fair, but the crops deficient, Hudson 3414-3416-Four shillings a bushel is a fair price, if the quantities are average, Bradley $2553^{-2555}$. $257^{8-2583-R e m u n e r a t i n g}$ price in a rerage seasons, Sharpe 3900-Atter four years 464 . 
Report, 1837 -continued.

Barley:-2. Prices, whether remunerating or otherwise-continued.

bad crops, $40 \mathrm{~s}$. would be a fair price, Levin 1037-1043-The price of barley has been higher than that of wheat, only because the crops were bad, Carter 2950-2952; Hughes 3005 ; Bradley $2528-2532$.

3. Papers laid before the Committee.

Qunutities imported from foreign parts in cach of the years from 1815 to 1835 , both inclusive, $A_{p p} \cdot p \cdot 366,367$ - Average prices of, at Mark-lane, from 1815 to 1835 , both yeirs inclusive, App $\cdot p \cdot 37^{0-391}$ - Account of foreign barley brought into consumption in Great Britain, from 1815 to 1835 , both inclusive, $\boldsymbol{A} p p \cdot p \cdot 392$ - Similar return of barley other than foreign for the same term, $A p p \cdot p \cdot 393-399$.

See also Beer Bill. Chevalier Barley. Malt Tax.

Beans. Fetch a better price than usual, in consequence of the failure of turnips, Bennett $480-486$ — In Glamorganshire beans are very little cultivated, Bradley $25^{6} 4_{4-2568}$.

Quantities imported into His Majesty's colonies from different parts, in each of the years from 1815 to 1835 , inclusive, $A p p \cdot p \cdot 366,367$ - Arerage prices of, in the market at Mark-lane, from 1815 to 1835 , both inclusive, App.p. 370-391- - Account of foreign beans brought into consumption in Great Britain in each year from 1815 to 1835 , App. p. 392-Similar return for beans other than foreign during the same years, App. p. 393-399.

Beef. Account of the prices of beef at Smithfield and Leadenhall Markets, for each of the years from 1815 to 1835 , both inclusive, App. p. 400-Account of the quantities and prices of Irish salted beef and pork contracted for from 1813 to $1836, A p p . p .401$ - Quantity brought into Great Britain from Ireland, 1815 to $1825, A p p \cdot p \cdot 406$.

Beer Bill. Raiscd the price of barley; the repeal of the malt-tax would raise it more, Cayley $4169-4171$.

Beer Duty. In a moral point of view it would be beneficial to transfer the daty from malt to beer, Allnatt 901, 902 - The malt-tax should be transferred to beer; proposed regulations for granting licenses and permitting private consumption duty-free, Spooner 4303-4310. 4330, 4331.

Beer Shops. Evil effects of beer-shops; present system very ruinous to the condition of the people, Escott 4940 .

In Berkshire have caused demoralization, Allnatt 899, 900-In Essex, Comport 4263 - In Hertfordshire, Sharpe 3907, 3908-In Kent, the beer-shops and small publichonses, Dowling 2902-2904 - There are many in the Isle of Thanet; their effect very demoralizing, Cramp 752,753 .

Somersetshire; are more frequented by labourers than formerly, Summers $5255-$ Their bad effect; have contributed very much to the demoralization of the lower classes, Summers 5283-In Staffordshire are very pernicious, Firchild 1396-1399- In Suffolk, Cooper 2710 - In South Wilts, Hughes 3105 - In East Riding of Yorkshire, Howard $2198-2200$.

In Cambridgeshire have not injured the morals of the people in the manner described, Thurnall 2397 .

Bennett, William. (Analysis of his Lvidence.)-Has been engaged in the cultivation of land since 1813; first in Norfolk, now in Bedfordshire, $378-3^{8}+\ldots$ The farming interest is much depressed; strong lands cannot by any system of farming be cultivated with profit at the present prices, $385,38 \mathrm{C}$ - l'rices are lower than they were in 1833,387 , 388 - Wages have been reduced $1 s$. a week; they are now $8 s$. or $9 s ., 389,390-$ This is not more than sufficient to maintain a laboures's family, but cannot be continued with the present prices, 391, 392- - Rents liave been generally reduced in witness's neighbourhood; he holds his land under lease, $393-397$ - The difference between the price of wheat and barley in 1832 and now is equal to his whole rental, supposing an equal produce, 398-405-- Nature of the soil on witness's farm, 406-412- The years 1822 and 1823 were not so bad as last year, $4^{1} 3^{-117}$ - Notwithstanding the reduction of rents, furmers are unable to meet their engagements, $418-422$ - They were better off in $182+$ and 1825 , in consequence of an issue of paper money; prices fell in 1827 , when the notes were called in, 423-430--Causes of the present rise in corn (February) $43^{1}, 432$.

Great improvements have been made on convertible lands in Bedfordshire, 433-437$\Lambda$ greater quartity of corn has been grown, $438-44_{2}$ - The last harvest was an average crop, and the two years preceding rather above the average, 443-446- The great lulk of corn has already been sent to marhet, $447,+48$ — The four-course system of farming described, 449-451- Number of sheep bred by witness; proportions of wheat and barley grown, $452-454-\ldots$ Prices of barley in 1831 and at the present time; difference betriecn chevalier and common barley, $455-464$ - The price of wool has improred about onc-shird since $1831,465-475-$-The price of stock remains the same, but all grain is lower, $776-479--$ Beans fetcls a better price than usual this year, in conscquence 
Report, 1837 -continued.

Bennett, William. (Analysis of his Evidence)-continued.

of the failure of turnips, $480-486$ _ Poor-rates in witness's parish are lower than in former years, $487-490-$ - Reduction of the weekly expenses in watres, 491-493.

There is still competition for farms as the number of farmers increases, $41,4,415-$ With the present burthens upon land, some of which are unfair, wheat should be (j+ $s_{\text {. a }}$ quarter and barley 40 s., $496-499$ - The poverty of farmers lias compelled then to part with their corn, which has forced down prices, $500-502$ - Canses of the rise in the price of wool, 503, 506__ Railroads have relieved the county from the pressure of surplus labour, 507-510-Che total repeal of the malt-tax would be of great benefit, 513,514

Chevalier barley makes the best malt; its growth, culture, \&c., 515-519-1] 1 would be the best food for fattening cattle, 520,521 - The present price of barley is not remunerating, $522-527$ - Wheat is the staple article of the farmer; good crops of other descriptions of corn will not make up any deficiency in it, 528,529 - When trade is bad in the straw-plait business the poor-rates in witness's neighbourhood are increased, 530-534-Wages of men employed on railroads, $535-538$.

Causes of the depression in the price of wheat; good crops; increased consumption of potatoes and meal, 539-544-The allotment system has a tendency to substitute garden produce for wheat as food for labourers, $545-547$ Bread is too dear according to the price of corn; the bad debts of the poor have raised it, $54^{8}, 5+9$ - Labourer's generally are in debt to the bakers, and cannot buy corn of the farnicrs, $550-552$.

\section{Berkshire. See Agricultural Distress. Farmers' Wages, \&c.}

Bernard, J. B. (Analysis of his Evidence.)-Lives at Sidmouth, 1567, 1568 -Accounts were furnished to witness in 1822 , which show that half the rent of the kingdom is paid out of capital instead of protit, $1569-1576$ - Wheat was then $7 \mathrm{~s} .6 \mathrm{~d}$. a bushel, and is now $5 \mathrm{~s} . ;$ the distress is therefore greater, $1577^{-1} 582$ - The former price was occasioned by a succession of wet seasons, the present is the natural price, $15^{8} 3,15^{8}+$ - The dininution of the circulating medium has been the principal cause of distress; variations of prices, with the extension and contraction of the currency since $1822,1585-1605-$ Importations from Ireland are another cause, 1606, 1607--The expenses of farmers have very much increased in the last 20 years, $1608-161+$ - The whole agricultural body, including noblemen as well as farmers, are insolvent, 1615-1620--CThe price of barley and oats is high, on account of bad crops, 1621-1623.

The diminution of the currency has reduced prices, except when there has been a scarcity of produce, 1624,1625 Effects of Peel's Bill, 1626, 1627- The currency is more fluctuating since the adoption of the gold standard, $1628-1630-$ An extension of the circulating medimm would remore distress to a certain extent, 1631-1633Reason why new tenants can be found without difficulty, 1634-1636- Farms on which there is not much arable land are not so distressed as others, 1639,1640 - Witness's rents have been reduced 40 per cent., $1641-16+5$ - The price of butter has been depreciated, $1646-1651$ - Burthens imposed on witness's estate during the ligh prices, $165_{2-}$ $1654-$ Nature of the land and produce, $1655-1658$ Making allowances for improvements, the rental of land is much the same as before the war, 1659-1663-The labourers are hetter off in Devonshire than in most other counties, although wages are low, $1664-1667$.

Beruick-upon-Tueed. The land is exceedingly good, and the local burthens altogether only $2 s$. in the pound, Langhorne $3683-3692$ The tenantry are the best farmers in the kingdom, and of large capital, Langhorne 3693,3694 .

See also Furmers.

Bethlem Hospital. Account of the several articles of clothing, and the prices of each, supplied to Bethlem Hospital, in each year, from 1815 to $1835, A_{\Gamma} p \cdot p \cdot 402$.

Bexley, Lord. Statement of expenses and returns of a farm rented of his lordship in Kent, Douling 2781-2803.

Bill Brohers. In Essex the farmers can only get accommodation from bill brokers, which is the sure forerunner to their ruin, Compori $4253-4259$.

Bills of Exchange. Bank of England does not negociate foreign bills of exchange, but becomes the purchaser or seller of bullion, according to the rates of exchange, $F$ at/ison 5507 .

Birmingham. Average wages of workmen; they have remained stationary for three years, Muntz 4567-4575--The deposits in the savings bank have greatly increased, Muntz $4576-4577$ - The moral condition of the people is improved ; there is less drunkenness, Muntz 4578, 4579 - Their employment is generally healthy; they live in separate houses ; their rent, Muntz 4587-4590-Many articles of Paris manufacture excel those of Birmingham, particularly such as require much manual labour, Muntz $460,3-4607 \ldots$ Wages are from 30 to 50 per cent. lower at Paris than at Birminglam, Muntz $4609-$ 4611 .

464 .

Blacher, 
Report, 1837 -continued.

Blacker, William. (Analysis of his Evidence.)-Resides in the north of Ireland, 5604 Ilas liad the management of Irish landed properties for 22 years, $560 z-\mathrm{Agricul}-$ ture improving; farmers' skill inproving very much, 5607- Extent to which Parliament uight amelionte the condition of agriculturists in Ireland, $5610-$ By actions on the currency; alterations in the corn laws, 5610- Price of labour in the county of Armagh, $1 \mathrm{~s}$. a day in summer, and reduced to $10 \mathrm{~d}$. in winter, 5612 - These wages are higher than in the south of Ireland, 5613 - Witness last year saw a man breaking stones in the south of Ireland at a price which would not realize $6 \mathrm{~d}$. per dày, 5614 Falue attached to the permission to cultivate flax in Ireland, which cannot be done withont a protecting duty, 5615-- Russia can send flax to Dunder cheaper than it conld be sent from Armagh, 5615_- Strong recommendation that a permanent duty on corn be adopted, to take at a particular price, 5615-Issue of Exchequer bills to baukers on securities, recommended, $5_{61} 5$ - Alteration of the duty on flax, hemp and butter necessary, 5616 .

Nature of the culture about Armagh, 5617-Almost entirely arable land, but little thrown into pasture, 5617 - Soil varions; some poor, some very good, 5619 - - Stallfeeding the cattle is a great benefit, 5620 -The country generally divided into very small farms, few above eight and niany so low as four and five acres, 5623,5624 _. In the low lands 40 acres considered a very large farm; in the mountainous countries there are larger farms of a pasture nature, 5625 - A great deal of the husbandry conducted by the spade, 5626 - Tenants join together to keep a horse each, and a plough, in partnership, $5627-$ Rents higher in Arnagh than in other parts of Ireland, 5628 system of middlemen decreasing, 5632 - Ejectment of cottiers, or a landlord taking an estate into his own hands, not resorted to in the north, 5633- Scttlement of cottiers by witness, on an estate in Tyrone, 5634 - Rents in Ireland as high as they are in England, 5635- - In many instances higher for the same quality of land, 5637 - Considerable exportation of wheat, butter, oats and pork from Armagh, 5642 - Growth of flax, which has much revived, owing to the failure of the crop on the Continent; less breadth of wheat in consequence thereof, 5645-Evidence concerning proposed duty on foreign flax, $5650-5657$.

Blacksmiths. See Artificers.

Blamire, William, esq., M. P. (Analysis of his Evidence.)-Member of Parliament for East Cumberland, $508,5-\mathrm{Had}$ considerable experience in rural matters for upwards of 20 years, $5086-$ Generally depressed state of the farming interest in Cumberland, 5088 -Great exertions made to keep lands of the first quality in a high state of cultivation, 5090-General good state of the labourers from rarious causes, 5093 - Considerable quantity of inferior land thrown out of cultivation, 5094-Demand for labour remarkably great, 5095 - Tenantry generally in a bad state, 5096 - Rents cannot be paid without exhausting the lands, 5097,5098 - Rents not reduced to the extent they should have been, owing to the competition for farms, 5099-Great numbers of yeomen reduced to the greatest distress, owing to the pressure of the times, 5102-5103-Assistance given by wealthy landlords in draining and manuring, in lieu of reduction of rent, $5115 \frac{0}{-}$ - reat depression in the agricultural interests has taken place since 1816,5119 The alteration of the currency was the first affecting cause, 5119,5120 - Also the great foreign importation of corn, 5122 - The lrish importation, more particularly as to price of animal food, 5124,5125 .

Blythburgh (Suffolk). Population and acreage of the parish, Cooper 2614-2618Number of acres of each description of land, arable, pasture, \&c., Cooper 2632-2634Many labourers have been ont of emplovment for several years; profitable labour could not be found for all, Cooper $2607-2613$-Per centage of poor-rate in the pound, Cooper $2636-2642$.

The parochial expenses have increased since 1823, Cooper 2597-2601 — Rates and expenses at different periods since 1793, Cooper $260: 2604$ - Price of wheat at those periods, Cooper $2605,2606$.

The poor are suffering, as many are out of employment, and out-door relief has been withdrawn; number out of employment, Cooper $2723-2727$.

\section{Bonding System. See Corn Lau's, 2.}

Bone Manure. Has been introduced with great profit into the East Riding of Yorkshire, Howard 2190-2197_- The use of bone manure since 1820 has raised the value of land in the Wolds of Yorkshire from $i s$. to $20 s$. an acre, Cayley 3545-Cost of bone manure; very good manure for raising a crop of turnips, and also for succeeding grasses, Grey 4679 .

Boroughbridge. Account of the cost of growing wheat and other crops upon good soils near Boroughbridge by the four-course and three-course systems, Cayley 3555-3560.

Bradley, Edward. (Analysis of his Evidence.)-Steward to gentleman near Cowbridge, in Glamorganshire, $2+27-2+31-$ Farmers have been very backward with their rents, and 
Report, 1837 -continued.

Bradley, Edward. (Analysis of his Lividence)-continucd.

have not paid them out of profits, $2432-2435$ —There are not many really solvent there lave been many failures, $2436-2438$-Their distress ariscs from the low prices of corn and other produce, $2439-244^{2}$-The inportation of Irish corn lias been the cause of low prices in Glamorganshire; imports in 1833,1834 and 1835 , and price of wheat each year, 2443-2454-The produce of Glamorganshire is not enough for its consumption, $2455-2+68$ - The farmers cannot compete with the Irish, as their burthens on land and wages are much greater, $2469-2477$ - It is impossible for them to go on unless their expenses be diminished or prices raised; they expect assistance from Parliament, $2478-2483-$ Country banks will not give them so much assistance as they formerly did, $2484-2486$.

Many farmers are living harder than their labourers, and have not been reduced by imprudence, 2487,2458 - Average rent of land; it has been reduced from 10 to 25 per cent., 2489-2490-Comparison of the prices of corn at Sivansea and Mark-lane; incorrectness of the averages, $249 t-2500$-The freeholders occupying their own land and the smaller gentry are distressed and reduced, 2501-2505_ An equalization of the taxes in England and Ireland would be an advantage to the English farmer, 2506-2508-The price of stock is low; much is imported from Ireland, 2509-2513-The Irish breed less cattle than they did, and are bringing more land into cultivation, 2514-2519-The land is worse cultivated, and produces less than it did, in consequence of the distressed state of the farmers, $25^{20-2524}$ - Price of wheat that would be remunerating, 2525-2527 - Produce of barley per acre; causes of its high price, 2528-2532- System of cropping in Glamorganshire, 2533-2535-The crops have been falling off; average amount thereof, $2536-2541$.

Properties are generally small, $2542-2545-U$ se and advantages of the instrument called the presser, 2547 - Witness's land is not deteriorated; he feeds much cattle and has a breeding flock of sheep, 2548-2552- - Four shillings a bushel is a fair price for barley, if the quantities are average, 2553-2555- Many farms which were in a tlourishing state have been reduced by over-cropping, 2556-2560-Witness's crop has been better than that of his neighbours, on account of better cultivation, 2561-2563-Beans are not generally cultivated, $2564-2568$ - Farmers can get assistance from bankers for a month or two when prices are low, 2574_-Examination as to the prices of wool and barley, $2576-2583$ - Further evidence on the practice of cropping, fallow and manure, $2584-2587$.

Branch Banks. The Bank of England branch banks have contracted the circulation of other banks by taking their notes in for cash, Langhorne $3819-3_{31}^{8}$ - They will not give accommodation to farmers on any security they have to offer, Langhorne 3832,3833 .

Breud. Is cheaper in Paris than in London; the London floul trade is a monopoly, Jacob 303,304 Is too dear according to price of corn; the bad debts of the poor have raised it, Bennett 548,549- Labourers are generally in debt to the bakers, and cannot buy corn of the farmers, Bennett 550-552- Evil caused by the price of bread not bearing its proper proportion to the price of wheat, Escott 4907 - The competition of the London millers and bakers has made bread proportionately cheaper than in the country, Dowling 2876-2880-Table laid before the Committee of the quantity of flour which might be produced from five bushels of wheat, and what weight of bread may be made from it, taken 24 hours after baking, Fairbrother 5659 .

Bricks. Notice of the extent to which brickmaking is carried on in Somersetshire, Escott 5051.

Bristles. Quantity thereof, of foreign production, consumed in the United Kingdom in each year, 1833-1835, Ev. p. 59 .

Bristol. See Importations, 1.

Brougham, Lord. Extract from a speech of Lord Brougham's, 1822, on the subject of the state of currency and distress in the country; reduction of taxation recommended as the best means of meeting the difficulty, Escott 5080 .

Brunton. See Land.

Bullion. Bank always glad to purchase silver bullion, Pattison 5371 - The Bank purchased, between 1830 and $1834,3,500,000 l$. of silver, Pattison $5374-$ - Amount of bullion, May 1836, in the Bank, 7,600,000 l., of which 500,000 l. was silver, Pattison 5378,5379 Evidence as to amount of bullion held by the Bank at different dates; proportion of gold and silver, Pattison 5478-5489.

Bullocks. See Cattle.

Burke, Mr. His opinion that the issue of one-pound notes would drive the gold out of the country, Escott 4991.

764. 
Report, 1837 -continucd.

Butter. The price has bcen depreciated, Bernard 1646-1651-Importations from Ireland and Holland have depressed the prices of English butter, Taylor 3303-3306-Duty on butter has produced a great revenue to Govermment without raising the price to the consuner, Blacker 5616.

Account of the prices at Smithfield and Leadenhall Markets from 1815 to 1835 , both inclusive, App. p. 400.-Quantity brought into Great Britain from Ireland, from 1815 to $825, A p p . p .406$.

Calves. See Cattle.

C.

Canada. Some United States wheat may have been surreptitiously introduced into England through Cunada, but importations have been small, Hodgson 2044-2048-Quantity of Canadian corn imported; much American wheat cannot be brought through Canada, as the price is generally higher than in Europe, Sandars $4087-4098$.

Canals and Railroads. Effect of the general speculation in these schemes in increasing the quantity of money in circulation, Escott $50+1$ - Bankers state that a great deal of paper money has been issued in consequence of these schemes, Escott 5042.

CaPITAL: Exhaustion of Agricultural Capital.

1. In England generally.

2. In particular Counties.

\section{In England generally.}

The large farmer is sinking his capital; the small farmer has already sunk it, Green $189,190-$ Accounts were furnished to witness in 1822 , which show that half the rent of the kingdon is paid out of capital instead of profit, Bernard 1569-1576-. Wheat was then $7 s .6 d$. a bushel, and is now $5 s$.; the distress is therefore greater, Bernard

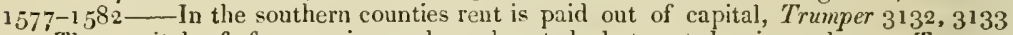
The capital of farmers is nearly exhausted, but not by imprudence, Trumper $3^{162-3164 . ~}$

\section{In particular Counties.}

In Berkshire the farmers, in almost all cases, are paying the expenses of their farms out of capital, Allnatt $79^{8} 800$ - In Cambridgeshire capital has been reduced one-half by the low prices, Thurnall $2287-2289$ - In Glamorganshire the capital of the tenantry has been gradually diminished for 15 years, and the land not well managed for want of means, David 1203-1208-In Hampshire the capital of farmers has been much diminished, Tu'ynam 608-610.

In Hertfordshire rents are paid out of capital, Sharpe $3^{870}, 3^{871}$ - In Kent, Waring 118, 1 19-Until lately the farmers near Canterbury have paid their rents out of capital, Nererne 1441-1444-C The farmer has no interest for his eapital in cultivating corn lands in Kent, Waring 14, 15-Near Eltham farmers are paying wages and other expenses out of capital, Green 161, 162_- In Staffordshire rents are paid out of capital, Firchild 1372-1374-In Suffolk the farmers are generally spending their capital, Cooper $2594^{-2596-1}$ - In the East Riding of Yorkshire, Howard $2130,213^{1}$.

See also Clay Lands. Cultivation. Interest.

Capitalists. The present tendency, both in manufactures and agriculture, is to break up the smaller capitalists, Cayley 3663,3664 .

Capron, Mr. Particulars of a farm in Suffolk mortgaged to, which cannot be sold at half the price for which it was purchased in 1813 , Cooper $2650-2655$.

Carter, John Thomas. (Analysis of his Evidence.)-A farnier at Hunstanton, in Norfolk, and agent to Mr. Styleman, 2915-2921_- The present state of the tenantry is ruinous, $2922-2924$ - The rents were reduced last year ; they were always noderate, $29^{2} 5^{-2927}$ The tenants cannot pay their rents off the farms, but are not in arrear, $2928-2930$ - None have been broken up, 2931, 2932_-The large supply has affected prices, 2933 - Some land farmed by witness made a profit from Michaelmas 1822 to Michaelmas 1825 , but has since occasioned an annual loss, 2934-2939- Statement of the annual losses since Michaelmas $18,50,2940-2946$ The farm was equally well managed at both periods; causes of the different results, 2947 - There have been bad crops since 1830 , yet the prices have been reduced, 2948,2949 The price of wheat has been lower than that of barley, because the crop was better, 2950-2952- - Price of wheat and barley in the Lynn market, 1823,1824 and $1825,2953,2954-$ In 1833 and 1834 ; the harvests of 1833 and 1835 were bad, $2955^{-2958}$.

In some parts of Norfolk many of the poor are out of employment, and are much distressed, 2959-2961_Wages are reduced from $10 \mathrm{~s}$. $6 \mathrm{~d}$. to $9 \mathrm{~s}$. a week; if prices were improved, employment would be found, 2962-2968-The poor are discontented, but are becoming reconciled to the new Poor Law, 2969 - The farmers are afraid to lower wages, lest their property should be destroyed, 2970-2974-Advantage of employing the London police in the country, 2975-The repeal of the nalt-tax would be of great benefit both to the farmers and labonrers, $2976-2980$ - Cattle are very much fed with wheat in Norfolk, 2991, 2982 The land is deteriorated in value, for want of manure and cleaning, $2983-2988$. 
Report, 1837 -continued.

Cash Payments Bill. It had very little effeet in reducing prices, Sandars 4057-4060. $4068-4070$ - It has not yet hal its full effect upon landowners, whose estates are charged with fixed payments, Sandars 4071,4072 - Eflicet of Mr. Peel's 13 ill upon prices; successive contractions of paper currency from 1814 to 1819 , in anticipation of the resumption of cash payments, Cayley 3629,3630 - Variations of issues and prices subsequent to 1829, Cayley $3630-3633$ Agricultural and manufacturing prices fell equally in 1819 , Cayley 3643,3644 .

Extent to which contracts have adjusted themselves thereto; consequences of that measure, without reference to debtor and creditor, Cayley 4111,4112 - The effects on manufactures have passed, but still operate on agriculture, Cayley 4113 - They are most severely felt by freeholders who cultivate their own land, Cayley $411,4-4121$ Its political consequences; effect of distress ir producing political discontent and a desire for change, Cayley 3665-3666_- it las operated most injuriously to the small proprietors or yeomanry who had contracted engagements in depreciated money, C'ayley $3667-3669$ - Its injury has only been in full operation for two years, Cayley 3673-3675. 3677 - Successive departures from the Bill in issuing notes, Langlorne 3783-3791; Spooner 4418-There has been no departure from the metallic currency since that period, Pattison 5522-Had the State not effected the change in 1819 , they would have been called upon to do so at a later period, Pattison 5517 _ Statement made by Mr. Bankes, in the House of Commons, complaining of the manner in which the Conmittee of 1819 had been deceired as to the true operation and extent of the Act for resuming Cash Payments, Attuood 5560, 5561.

See also Currency.

Cattle. Much fed with wheat in Norfolk, Carter 2981, 2982_-Much oil-cake and corn are used in feeding cattle in Suffolk, Cooper $2704-2707$.

Quantity of bullocks, cows, sheep, pigs, horses, nrules, calves and lambs imported into Liverpool from Ireland and coastwise, from 1829 to 1835 inclusive, Sandars 3950 .

See also Malt Tax, II. Wheat, 1.

Cayley, Edward Stillingfleet, esq., M. P. (Analysis of his Evidence.)-Member for the North Riding of Yorkshire, and has made agriculture his study for many years, $3518-3520$ Was a member of the Commons' Committee of 1833 ; the farmers at that time were deeply distressed, 3521-3525_-The lowland farmers were suffering from wet seasons and short crops, while the upland farmers, whose crops were good, enjoyed the scarcity price, 3526 In the last two years the condition of upland farmers has been worse, while that of the lowland farmer has improved, 3527 - The arable farmer could not go on but for his grass farms in connexion with his corn-land, 3528-3530-The upland farmers have been preserved, until lately, from the effects of low prices, 3531_-Abundant harvests have made the state of the lowland farmer better than in 1833 , but these cannot be expected to continue, 3532,3533 .

Account of the expenses and produce of a farm in witness's occupation for the years 1833,1834 and 1835 ; nature of the soil, \&c., 3534-3540-The four-shift system prevails, and artificial manure is used with greac effect, $354^{1-35+5-D e t a i l e d ~ s t a t e m e n t ~ o f ~ t h e ~}$ mode of working one acre of land cultivated on the improved or four-course system, 3545 , 3546 - Account of receipts and expenses, for six years, of a farm held at a corn-rent near York, showing a loss, 3547-3550-Variations in the expenditure explained, 3551 , $355^{2}$ - This farm has a larger proportion of grass, and the poor-rates are light, 3553 , 35.54 - Accounts from a farmer near Boroyghbridge of the cost of growing wheat and other crops upon good soils, on the four-course system, 3555-3558-Account from the same farmer of the cost of growing wheat, \&c., on the three-course system, 3559,3560 .

In many counties the proportion of heavy land to lighter soils is one-half, $35_{61}$ Until lately it was peculiarly the wheat land, 3564 The product of the heavy soils generally determines the abundance or scarcity of wheat; influence of wet and dry seasons upon the upland and lowland farms, 3565_-The harvest of 1833 was scarcely an average ; 1834 very abundant, and 1835 deficient: 3566,3567 - Circumstances which occasioned the deficiency, $3568-3571$ - Rents are better paid than they ought to be, for the tenants pay them out of capital and leave their bills unpaid, 3572, 3573Tradesmen who were anxious for a repeal of the com laws are now desirous of sustaining the price of corn, 3574_- If landlords pressed for arrears few tenants could pay them, 3575 - Rents have, in some instances, been reduced from $400 \mathrm{l}$. to $100 \mathrm{l}$. a year; in others a sum has been paid a tenant to take a farm, paying no rent, 3576-3578.

Wages are high in witness's district, as much new land has been brought into cultivation,

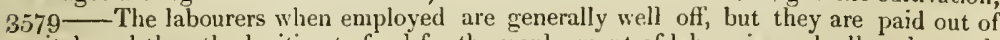
capital, and thus the legitimate fund for the employment of labour is gradually exhausted, $35^{80}, 358 \mathrm{r}$ — With the present prices wages must be reduced and the labourer eventually thrown altogether out of employment, $3582 \ldots$ The Poor Law Amendment Act scarcely operates in the north, $35^{8} 3,35^{8} 4$ - It cannot come into full operation while the present prices continue, $35^{8} 5$ - In the north the effects of the new law of settlement are not apparent; uncertain benefits of migration, 3586 - Many of the tradesmen in towns surrounded by agricultural districts have been bankrupt; they all complain of the want of the farmer's custom, $35^{8} 7,35^{58}$ - Many labourers have left poor law unions and $t^{f i}$. 
Report, 1837 -continued.

Cayley, Edward Stillingfleet, esq., M.P. (Analysis of his Evidence)-continued. sought employment elsewhere; the reduction of rates is not a proof of more emplovment, $3589-3592-$ The absorption of agricultural labourers in manufactures and railroads may render agricultural labour dearer than the farmer can afford to purchase, 3593, 3594 - Incompatibility of high wages with low prices; difficulty of adjusting them, $3595-3598$.

The artisans charge high prices to cover bad delsts ; the large farmer can get his work done more cheaply, 3599,3600 - All persons who have farmers for their debtors are in distress, 3601,3602 The manufacturers are said to be very prosperous ; their prosperity arises from the large issues of joint-stock banks, who accommodate them, but refuse assistance to the farmers, $3603-3605$ - There is not an identity of interest between the manufacturers and agriculturists; neither are exports a criterion of the prosperity of either, 3606 - Iniportance of the home trade is greater than the export trade, 3607 _ Calculation of the number of persons in the United Kingdom dependent upon agriculture and upon the export trade, 3608 .

Natural dependence of agriculture and manufactures upon each other; their interests may be opposed, $3609-3611$ - The condition of the manufacturing interest in connexion with the export trade should not be taken as a criterion of the condition of the agricultural interest, 3612,3613 - Importance to the manufacturer of being able to supply himself from the growth of his own country, 3614 - The present corn law is nearly perfect, and has given the farmcr, of late years, all the protection he can derive from any corn law, 3615 - Estimated value of the gross annual produce of land, 3616 - The manufacturer derives as much benefit from it as the agriculturist, $3617,3^{618}$.

Distress is the result of low prices, 3619 The prices of all agricultural produce are really low; but in the case of barley, wool and meal have been artificially raised by scarcity, 3620-3622_ Effect of supply and demand, and of abundance or scarcity of money upon the prices of articles, $3623-3627$ - An average of seasons may be calculated upon for a long series of years, 3628 - Effect of Mr. Peel's Bill of 1819 upon prices; statement of the successive contractions of paper currency from 1814 to 1819 , in anticipation of the resumption of cash payments, $3629-3635$ The reduced issues caused the adverse years of 1820,1821 and 1822 , in which the prices of manufactures, as well as agricultural produce were depressed, 3630-3632-Increased issues between the years 1822 and 1825 produced the prosperous years of 1823,1824 and $1825,363^{2}$, 3633 - The panic was occasioned by an over-issue of paper upon too contracted a standard of value, 3634 - In consequence of the panic a law was passed to prevent the issue of one-pound notes after $1829,3634-363^{8}$.

Since 1815 extension and contraction of the currency have been invariably followed by high or low prices, 3639,3640 - A general increase of prices followed the Bank Restriction Act and continued until 1819 , since which time prices have declined; the price of wheat, which had been $10 s$. a quarter for a century, was quadrupled by the opening of the American mines, 3641,3642 Manufacturing and agricultural prices fell equally in $1819,3643,3644$ - The manufacturers are in a state of prosperity, principally in consequence of the over-issues of joint-stock banks, 3645, 3646_-Tabular statement of wool imported and woollen manufactured goods exported, with calculations to prove that the prosperity of the woollen trade did not cause the rise in the price of wool, 3647 Circumstances which contribute to the prosperity of manufactures during the depression


of issuing five-pound notes on advantageous terms may be equivalent, $3^{65} 5^{1-3653-}$ The war did not occasion high prices; statement showing that in all the wars of the last century prices rose at the peace, 3654 .

Authorities in proof of the position that depreciation of currency affects prices, and that the restoration of a former standard is then unjust, 3654 - Principle adopted by Austria, France and Russia of paying debts in the same depreciated money in which they had been contracted, 3655 - Importations from Ireland bave not in the least affected prices in England, 3655,3656 - Low prices cause a greater export from Ireland, unless they fall too low for any profit, 3657 - Farmers find great difficulty in obtaining accommodation from bankers, 3661,3662 - The present tendency, both in manufactures and agriculture, is to break up the smaller capitalists, 3663,3664 - Political consequences of Mr. Peel's Bill ; effect of distress in producing political discontent and a desire for change, 3665,3666 - The change in the value of money has operated most injuriously to the smaller proprietors or yeomanry who had contracted engagements in depreciated money, $3667-3669$.

The principles on which cash payments were resumed were unjust to the public; the addition of silver is an optional standard proposed, 3670-Advantages of a silver currency, in conjunction with an issue of one-pound notes by country barker's; it would raise prices 20 per cent., $3671-$ The landowner would gain by the depreciation of money, in all his fixed payments, and manufacturers and labourers would not have to pay a price for articles corresponding with their increased receipts, 3672 - The injury of Mr. Peel's Bill has only been in full operation for two year's, $3673-3675$ - A change in the currency would be injurious to fixed annuitants; reasons which would render it not unjust, $3676-$ Changes in the currency and extraordinary seasons have suspended the operation of Mr. Peel's Bill until the last few years, 3677 . 
Report, 1837 -continucd.

Cayley, Eduard Stillingfect, esq., M. P. (Analysis of his Evidence)-continucd.

[Second Examination.]-Extent to which contracts have adjusted themselves to the Bill of 1819 ; other consequences of that measure, without reference to the relation of debtor and creditor, 4111, 4112-Its effects on manufactures have passed; those on agriculture continue; necessity of a general reduction of rent, unless prices are raised, 4113- Its effects have becu most severely felt by the frecholders who cultivate their own land, 4114-4116 The small mortgagees still continue to pay the old rate of interest, in many instances, 4117-4121_Taxation and pror-rates have been reduced only nominally, and there are less means of paying them, 4122, 4123-Node in which currency operates upon prices explained, 4124 -Advantages of a silver standard, 41254128.

Extract from Montesquieu on the effects of contraction and expansion of the currency upon the Roman empire, $4129-$ Deprcciation of old coins in Eugland, 4130, 4131 Di. Franklin's opinion of the effect of ruising the value of colonial currency, upon the revolt of the American provinces, 4131 - Silver being the standard of other countries is more accessible in panics, $413^{2-4134-T h e ~ o l d ~ s t a n d a r d ~ s h o u l d ~ b e ~ r e s o r t e d ~ t o ~ o f ~}$ gold, silver and one-pound notes, 4135-4139-This would not raise prices sufficiently high to admit foreign corn; the present corn laws should not be altercd, 4140-4143 - In seeking accommodation from bankers, farmers cannot give good seeurities, 4144 - Persons in trade can give better security by indorsing over their property, 4145 , 4146 - Many landlords have been paying tlieir own reuts, by the land being run out, $4147,4^{1} 48$ An equitable commutation of tithe will afford relief to the farmer, 4149 Beneficial effects of repealing the malt-tax, 4150,4151 -Objections to an inconetax; the land-tax should be equalized, $4152-4155$.

Doubtful expediency of an Irish poor law, and of equalizing the taxation of both countries, $4156-4161$ Tendency of wages to find a level in both countries, $4162-4164$ - Effect of Irish produce on prices, 4165-4168-The Beer Bill raised the price of barley; the repeal of the malt-tax would raise it more, 4169-4171 Much drainage has been done by landlords instead of reducing rent, 4172,4173 -Difficulty of effecting sales of land; the number of years' purchase is not reduced, 4174,4175 - To raise the price of wheat by reducing the quantity grown is not profitable to the farmer, 4176 Importance of encouraging the growth of flax, 4177,4178 - To raise the duty on foreign flax and tallow would be a recompense for the malt-tax, 4179-4181_-The labourer would be benefited by a rise in prices, as the fund from which he is now paid must soon be exhausted, $4184-4186$ - Danger of reducing wages, 4187,4188 - The Northumberland system of paying them in kind is advantageous to the occupier, $4189-$ Comparative comforts of the labourer during high and low prices, $4190-4195$.

Chalk Lands. Had more than average crops in 1835 , Peyton 1528-1530.

Chard. Notice of a lace and silk manufactory at Chard, Escott 5050.

Cheese. Account of the prices of, at Snithfield and Leadenhall markets, from 1815 to 2835 , both inclusive, App. p. 400.

Chelsea Hospital. Account of the several articles of clothing, and the prices of each, supplied to Chelsea Hospital in each year, from 1815 to $1835, A$, Ap. p. 40 .

Chevalier Barley. Chcralier barley makes the best malt; its growth, culture, \&c., Bennett $515-519$ - It does not yield so much as other kinds, and is more liable to injury in wet seasons, Sharpe 3924, 3925.

See also Barley.

Chevint Hills. Sheep farms on the Clıeviot hills have often less than one sheep to an acre, Grey 4687 .

Children. Are employed by the manufacturers in Leicestershire; there is no mmployment for them in agriculture, Wilson $1769-1771$ - In Sussex labourers are willing to let their children work, which, under the system of head-money, they often refused to do, Hudson 3500-3502.

See also Poor Law Act.

Churches, Building. Importance of the precedent, when considering the question whether the general property of the country is answerable for chulch support; of the large sums of money contributed by the Legislature towards building cliurches, Escott 5065 .

Circulation. Comparative circulation of notes by the Bank of England and country bankers at different periods, Langhorne $3836-3839$ - The amount of gold in circulation is much over-rated, Langhorne $3^{8} 40-3^{8} 46$.

See also Bank Notes. Bankers. Branch Bank. Bullion. Canals and Railroads. Currency. Joint Stock Banks. Munufactures. Sarings Banks. 464. 
Report, 1837 -continued.

\section{CLAY LANDS:}

1. Generally.

2. In particular Counties.

\section{Generally.}

Strong clay lands cannot, by any system of farming, be cultivated with profit at the present prices, Bennett 385,386 - The farmers on cold clay lands are the most distressed; many, on the most heavy lands, have failed in the southern counties, Trumper $3118-312 S$ - Some of the poorest clay lands require a reduction of 100 per cent. in rent, Trumper 3207-3212_-Little improvement has been made in cultivating them; some will not produce so much as they did in 1793, Trumper 3213-3217-In many counties the proportion of heavy land to lighter soils is one-half, Cayley 3561 - Until lately it was peculiarly the wheat land, Cayley $35^{6} 4$ _- The product of heavy soils generally determines the abundance or scarcity of wheat, Cayley $3565-$ Cold clay lands, which form about one-fourth of the cultivated land of the kingdom, could not be cultivated with profit, if rent-frce, Howard 2216-2221 - Are the most expensive to cultivate, Peyton 1533,1534 - Are not favourable to the breeding of sheep, Green $207-209$.

\section{In particular Counties.}

Distress in Hampshire applies more particularly to strong clay lands, Twynam $562-564$ - In Herefordshire the farmers of cold clay lands have wasted their capital, Turner 4105-4106- The farmers near Berwick-upon-Tweed, on strong clay lands, are losing money, and paying rent out of capital, Langhorne $3695-3699$ - The stiffer lands in the

Weald of Sussex will hardly pay any rent, IIudson 3453,3454 .

See also Agricultural Distress. Clover.

Clotking. Price of cotton goods is much reduced, but the woollen clothes, once worn by the poor, were the product of this country, and their own manufacture, Spooner 4359 4364 - Is certainly cheaper than formerly, Escott 4901 - The only article which is cheaper to a farmer, Summers 5243 - Account of the several articles of clothing, and the prices of each, in Greenwich, Bethlem and Chelsea Hospitals, in each year, from 1815 to 1835 , both inclusive, App. p. 402 .

Clover. Average quantity that can be grown on an acre of clay land, Waring 19.

Coin. The export of coin could not be prevented, but might be restrained by prohibition, Spooner 4400 Causes which led to debasements, on the part of Government, of the coin of the realm; the object was not to produce but to prevent fraud, Attwood $55^{83}$ The coin of the country may be melted, by the Act 59 Geo. III., Pattison 5328.

See also Seignorage.

Common Land. Large tracts have been brought into cultivation in Cumberland in the last 15 years; bad state of the land, Blamire 5088 .

Competition for Farms. Reasons why new tenants can be found without difficulty; although the farms are not profitable, Bernard $1634^{-16} 3_{6}$ - There is still competition for furms in Bedfordshire, as the number of farmel's increases, Bennett 494,495 - A farm in Berkshire, for which a bonus should be given for cultivating it, would let again at its present rent, as farmers must have an occupation, and always hope that times will mend, Allnatt $854-863$ - Great competition for farms in East Cumberland, Blumire 5099 — In Middlesex there is no difficulty in obtaining tenants when farms are worth anything, Sherborne 4849 .

In Glamorganshire many farms are out of occupation, David 1342-1344-Many tenants in Berkshire, Essex, Middlesex, Surrey, Sussex and Kent, liave thrown up their farms, and there is difficulty in getting new tenants, Peyton $1543^{-1} 54^{8}$.

Comport, Michael. (Analysis of his Evidence.)-An attorney at Rochford, in Essex, 41974199 - The small proprictors of land are much distressed, 4200, 4201- They have contracted engagements in better times, which they cannot discharge, 4202-4205-The land is good, 4206 - The tenantry are worse off; they are paying rent out of capital; the capital of most is reduced, of some entirely gone, 4207-4212-Number of acres of land in the hundred of Rochford in the landlords' hands, where the tenantry have thrown up their farms or failed, 4213 The poor are well employed, and the land is in a gond state of cultivation, $4214-4222$ - The rents are moderate, and the tenants prudent and skilful, $4223-4226$ Their distress is caused by the low price of wheat, $4227-422 \mathrm{~S}$ The price of barley and oats will not compensate for that of wheat; the quantity produced has been average, $423^{1-4233-P r o d u c e ~ o f ~} 90$ acres of arable and 10 of pasture land in Rochford hundred, in 1833,1834 and 1835 , upon the six-course system, 4234, $4235 \ldots$. Nothing but the interest of capital is left for the farmer's subsistence, $4236-4240-$ Many failures, to a large amount, have taken place, 4241-4251- Rochford hundred is considered the garden of Essex, 4252 - The farmers can only get accommodation from bill brokers, which is the sure forerunner to their ruin, 4253-4259-They live scarcely better than well-employeá labourers, 4260,4261 _ The beer-shops have had a very bad effect, 4263 .

The new Poor Law will reduce the rates, and is popular with the well-disposed and industrious labourers, $4264-4270$-Children have never been taken away without the 
Report, 1837-continucd.

Comport, Michael. (Analysis of his Evidence)-continued.

consent of the parents, 4271 - The Poor Law has the effect of employing the poor, $427^{2}-4274$ - There is not more labour than is sufficient for the demands of the farmer, 4275,4276 - Amount of poor-rates; it will be reduced one-third without iujuring the poor, $4277-4287$ - The tendency of the law is to give independence to the able-bodied and industrious, 7288 - There has not been over-production at Rochford, 4289-4202 The reduction of poor-rates will not compensate the farmer for the losses he is suffering, 4293,4294 .

Contracts. Proposed adoption of a silver standard would vitiate all contracts which bear date since the introduction of the present standard to the extent of 5 per cent, Attwood 5553-5555-- If the present standard cannot be varied, it would be incumbent on the Legislature to cause an adjustment in the amount of every existiner contract which has its date before the introduction of the present standard, Attwood 5555-Manner in which contracts were adjusted when the law regulating wcights and measures was passed, Attwood 5555 .

See also Cash Payments Bill.

Cooper, J. G. (Analysis of his Evidence.)-Farmer at Blythburgh, in Suffolk. Has been a tenant of Sir Charles Blois since $1823,2588-2593-T h e$ farmers are, gencrally, spending their capital, $2597^{-25} 96$ - The parochial expenses have increased since 1823 , $2597-2601$ Rates and expenses at different periods since 1703, 2602-260.4_- Price of wheat at those periods, 2605, 2606-Many labourers have been out of employment for several years; profitable labour could not be found for all, $2607-2613$. - Population and acreage of the parish, 2614-2618 The land is not quite as well cultivated as in $1823,2619-2620$ - The farmers would not continue to cnltivate, unless they expected an improvement in prices, $2621-2626$ - They are, generally, in a ruinons state, 26262629 - Average wages $9 s$. a week, 2630,2631 - Number of acres of arable, pasture, and other land in Blythburgh, $2632-2634-$ Per centage in the pound of poor-rates, $2636-2642$.

Rents have been generally reduced from 12 to 18 per cent., 2643-2649-Particulars of an estate mortgaged to Mr. Capron, which cannot be sold for lalf the surn at which it was purchased in $1813,2650-2655$-The land is not so well cultivated, and produces less corn, $2656-2658$ - The average price of wheat and oats shonld be $60 s$. and $34 \mathrm{~s}$. respectively, to make a profit, $2659-2665$ - Reduction of witness's rent, $2666-2668$ - Cultivation of his farm; his sheep, \&c., 2669-2679-Wool was very low from 1826 to 1830 ; the price is fair at present, $2680-2682$ - Less artificial manure is now used, and the cultivation is less perfect, by reason of the low prices, $268_{3}-268 \mathrm{y}$ - Average crops of wheat and barley per acre, 2690-2703-Much oil-cake and corn are nsed in feeding cattle, $2704-2707-$ The repeal of the malt-tax would be advantageons to the farmer and to the labouring classes, $2708,2709-$ Beer-shops have a very bad effect, 2710 .

Poor-law unions have been used in Suffolk for many years; the rates were generally higher in the unincorporated hundreds, $2717-2719$-Reduction of rates is expected from the new Poor Law, $2720-2722$ - The poor are suffering, as many are out of employment, and out-door relief has been withdrawn, $2723-2727$ Rents are higher than they were in 1793; they are too high, as tenants hope to gain the profits of unexhansted improvements, 2728,2729 - Rents should be higher than at that period, as landlords have expended capital in improved drainage, fencing, \&c., 2730-2735- Steady and industrions people are now refused out-door relief, and forced iuto the workhouse, $2736-2742$.

Corn. Rise of corn in the reign of King Willian and Elizabeth, Attwood $55^{8} 3$ - Table, showing the price of corn in periods of five years, 1769-1794, $A$ ttwood 5551-Average price of corn for 50 years, ending 1794 , demonstrating that the prices during the war were occasioned by paper money, and could not be maintained when returning to metal money, Attwood $55^{8}$.

Account of the several quantities of foreign grain, wheat, barley, oats, rye, beans and peas, meal and flour inported into His Majesty's colonies in America, the lslands of Guernsey, Jersey, Aldemey and Sark and the Isle of MIan, from foreign parts, in each of the years from 1815 to 1835 , both inclusive, App. p. 366-369-Account of the annual average prices of wheat, barley, oats, rye, peas and beans in the market of Mark-lane in each year, from 1815 to 1835 , both inclusive, App. p. 370-391- Account of foreign grain, wheat, barley, oats, rye, beans and peas, flour and meal bronght into consumption in Great Britain in each year, from 1815 to 1835 , both inclusive, $A p p \cdot p \cdot 392$.

Account of grain, wheat, barley, oats, rye, beans and peas, flonr and meal (other than foreign) bronght into consumption in Great Britain frum Ireland, His Majesty's colonies in America, the Islands of Guernsey, Jersey, Alderney and Sark and the Isle of Man, specifying the quantity of each sort of grain, flour and meal in each of the years from 1815 to 1835 inclnsive, and in the last year the importation detailed by month, A pp. p. 393-399.

See also American Corn and Flour. Barley. Clay Lands. French Corn. Oats. Prussia. Wheat. 464. 
Report, 1837-continued.

\section{Corn Averages. See Averages.}

Corn Crops. It is impossible for a farmer to make a profit by the cultivation of land for corn, Waring 7-9-Calculation of the expense of cultivation and the value of produce, Waring 10-12_- Statement of the expenditure and receipts of corn crops for five years, on an acre of land near Eltham, Grcen 151-154.

See also Cultiration. Wheat.

CORN LAWS:
1. Generally.
2. Warehousing System.
3. Proposed Alterations.

\section{Generally.}

Advantage of the present restrictions on the importation of foreign corn, Jacob 249-251 - They maintain a certain equilibrium in prices, Jacob $34^{8-350-T h e ~ p r e s e n t ~ c o r n ~}$ law is nearly perfect, and has given the farmer, of late years, all the protection he can derive from any corn law, Cayley 3615 .

They impose upon the landed interest the odium of a monopoly, witlout affording any protection, Spooner 4518 - In a Report to the American Congress, the corn laws are described as an attempt to evade the consequence of a return to cash payments pressing on one part of the community; vanity of the attempt, Attwood 5590 .

\section{Warehousing System.}

The bonding system is very injurious; it encourages speculation in foreign corn; and when we have a small surplus of English corn the prices are reduced still more, David 1329-1332; Lewin 990-1008; Sharpe 3876-3878-The bonding system encourages speculation in foreign corn, and the duty is not sufficiently high, Thurnall 2277-2281 The evil of the corn laws consists in making foreign com always ready to come into consumption, when the price is rising, rather than in the actual consumption, Thurnall $2366-2372$ - If foreign corn paid duty on entering the ports, it would afford some protection to the farmer, Thurnall 2373-2382_Warehousing system is injurious both to the farmer and merchant in English corn, Douling 2771-2776- Foreign corn is generally brought into consumption by the high prices at harvest time, and enters into competition with English corn after the harvest, Dowling $2806.2835-28+0.2844-28+6$ - It cannot compete with our own until the price rises to 65 s. or $70 s$., Dowling $2830-2834$.

If the corn were not permitted to be warehoused in England, English merchants would not speculate in it, Dowling 2862-2873 - If corn was warehoused abroad, speculation would not be restrained; warehousing would be cheaper, Sandars 4042-4047--. Men speculate in foreign corn because it is cheaper, and they take the chance of duty, Sandars 4048-4054-An alteration in the warehousing system would not restrain speculation; corn would be warehoused abroad, employing foreign labour, Spooner $43^{86-4389}$.

\section{Proposed Alterations.}

Proposed alterations for the protection of farmers, Lewin $967-981$ - The minimum duty should be raised to $8 s$., to be paid on entering the ports, Sharpe $3879-3898$ Alterations recommended in the present corn laws as a means of mitigating the agricultural distress, Blacker 5610.5615 .

See also Fixed Duty. Prices I. 4.

Corn Returns. Returns from inspectors of corn returus in Scotland and England have ceased ; their inutility, $J a c o b 319-322$.

Cottage Rents have generally fallen when they belong to estates, but not if the property of speculators, Peyton 1560, 1561 Vary very much in different counties; in some places they do not exceed 1 l. or $30 s$., Trumper 3185,3186 - Average rents in Sussex, Hudson $3474-3476$ - In East Kiding of Yorkshire, 50s. a year, with a garden, Howard 2166,2167 .

Cotticrs. Fjectment of cottiers on a landlord taking an estate into his own hands not much resorted to in the north of Ireland, Blucker 5633-Results of a settlement of cottiers by witness on an estate in Tyrone, Blacker, 5634 .

Cotton. See Malt Tax, III.

County Rates. See Taxation.

Cous. See Cattle. Dairymen.

Cramp, Mr. John Mockett. (Analysis of his Evidence.)-Occupies 120 acres of arable land

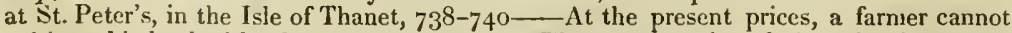
cultivate his land with advantage, $741-743$-The average price of wheat for six months has been $38 s$.; nothing less than $60 s$. would be remunerating, $744-746$ - The wages of able-bodied men are from $10 s$. to $12 s$.; this rate cannot be continued if prices remain the same, 747,748 - The men are in a better state than in many other places; the Isle of Thanet is not orerburthened by surplus population, 749-751-There are many beer- 
Report, 1837 -continued.

Cramp, Mr. Jolın Mockett. (Analysis of his Evidence)-contimued.

shops, the effect of which is very demoralizing, 752, 753-The only instance of a fire for a year or two occurred last week (February), 754,756 - The prices of other articles ure not such as to remunerate for the low prices of wheat, 757,758 -Very few farmers keep sheep in witness's neighbourhood, 759,760 - The food of the people is chiefly bread, 761 - The growth of potatoes in the Isle of Thanet has decreased, $762-766$.

Crops. Rota of crops on the hill farms in Kent, Waring 13- Examination in detail as to the expenses and profits of successive erops, Waring 16-32_- System of cropping in Glamorganshire, Brnclley 2533-2535-The crops have been falling off lately; average

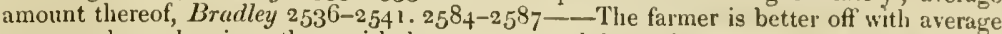
crops and good prices than with large crops and low prices, Hudson 3436-3439Average crops per acre in Suftolk, Cooper 2690-2703.

See also Corn Crops. Cross C'ropping. Cultivation. Prices, I., 3. Whent.

Cross Cropping. System pursued by farmers in East Cumberland on the cominon lands lately enclosed, Blamire 5088-5114.

CULTIVATION :

1. Improvements therein.

2. Deterioration, Causes and Extent thereof.

3. Effects of diminishing the Cultivation of Corn.

4. Expenses.

5. Systems pursued in particular Counties.

\section{Improvements therein.}

The system of agriculture has improved, and a larger proportion of corn can be grown, Jacob $232-238$ - Great improvements have been made on convertible lands in Bedfordshire, and a greater quantity of corn has been grown, Bertnett $43^{8-44^{2}}-$ - In Hampshire, Twynam 678-681_Little improvement has been made in cultivating the poor clay lands, Trumper $3213-3215$.

\section{Deterioration, Causes and Extent thereof.}

Whenever a farmer is needy, his land is not well cultivated, Dowling 2804, 2805 The condition of the land has been improved by dry summers, but less manure and labour are employed upon it, Trumper 3140-3145_- In Cambridgeshire land is less highly cultivated than it was; farmers cannot affurd manure, Thurnall $2383-2386$ _- In Glamorganshire land not so well cultivated as it was, Bradley 2520-2524 The distress of the farmers has deteriorated the cultivation ; less corn is grown, David 1308-1312_- In Hertfordshire, where there is want of capital, cultivation has deteriorated, Sharpe 3929 , 3930.

In Leicestershire tenants have scourged the land to save themselves from ruin, Wilson 1822-1 825 - Much grass land has been broken up, with the consent of landlords, for the payment of rent, Wilson $1826-1837-$ Norfolk : the land near Hunstanton is deteriorated in value for want of manure and cleaning, Carter 2983-2988_- Somersetshire: many farms are deteriorating in the mode of cultivation, Escott 4860 -_-Staffordshire : lands have been thrown out of cultivation; they are poor soils, Firchild 1426-1432Suffolk : land not so well eultivated at Blythburgh, Cooper 2619-2620. 2656-2658

Less artificial manure is used, as the prices are so low, Cooper $2683-2689-$ Sussex: the Down farmers cultivate their land well when they have capital, Hudson $3491,349^{2}$ Wilts : when farmers have capital, the land is well cultivated, but not when they are poor, Hughes 3079, 3080.

\section{Effects of diminishing the Cultization of Corn.}

Land cannot be cultivated at the present prices, and, if laid down, the poor will be deprived of their labour, Trumper 3138,3139 - Farmers are diminishing the cultivation of corn; this practice will increase the poor-rates, Waring 128-137- And make it necessary to use more artificial food for sheep in winter, Waring 140, 141-Although cultivation is deficient, there is a superabundance of wheat, Kendall 1164-117c-There is more arable land in Glamorganshire than there was in 1790, David 1252-1257.

\section{Expenses.}

It is impossible for arable farmers near Eltham to bear their expenses with the present prices, Green 156 - The expenses have very much increased in the last 20 years, $B \in r-$ nard 1608-1614; Nearne 1472-1477- Statement of the expense of the cultivation of an acre of arable land on the four-course system, and the profit and loss thereon, Summers 5198 - Average rent, tithes, wages, rates and taxes, and all other outgoings, for each year for four years, of an acre of land in Dorsetshire, and the value of the produce, Taylor $3289-3298$ - Statement of the comparative expenses of cultivation in 1790,1813 and 1835 , on a farm in Glamorganshire, with explanations, David 1232-1238, 1248-1251.

Expense per acre, in Kent, of labour, ploughings, carting, manure, \&c., Waring, 49-58 - Calculation of expenses, and of the value of produce, Haring 10-15- Prcduce of wheat in low lands in Kent, and quantity of seed; the expense of cultivation camiot be repaid, Waring 108-113. 
Report, 1837 -contimued.

Cultiration:- -4 Expenses-continued.

Northumberland: Estimate of the proceeds of a farm of 300 acres of turnip-soil managed under the fitth-course rotation, Langhorue 3743-3755-Yurkshire: statement of the expenses and profits of cultivation of land on the four-course and threeconrse sytems of husbandry, in Yorkshire, Cayley 353+-3560.

Comparative expense of growing corn in England and lreland, David 1327-1338.13521354 .

\section{Systems pursued in particular Counties.}

Land may be cultivated on the four-course system without fallow, Peyton 1535-The four-course system of husbandry, as pursued in Bedfordshire, described, Bennett 449$45+$ - The four-conrse system is used at Wallingford, Allnatt $832,833 \ldots-$ In Hampshire the five-course system prevails, Twynam 672-677--Near Hounslow two-thirds of the land are in corn every year, which is the best mode of farming when there is sufficient manule, Sherborne ${ }_{4}^{8} 31-4835$.

Sce also Bone Manure. Clay Lands. Common Lands. Crops. Cross Cropping.

Draining. Improvements. Inferior Lands. Manure. Over-cropping. Prices, 11., 6.

CURRENCY:

1. Its Effects upon Prices and Agricultural Interests.

2. How far Depreciation would relieve Distress.

3. Nature of the Alterations proposed.

4. Justice of changing the Standard.

1. Its Effects upon Prices and Agricultural Interests.

Alteration in the currency luas not affected agriculture, Waring 91_-_Corn fell in 1822 in consequence of the abundant crops of $18: 20$ and 1821, Sandars 4061, 4062-It rose again in 1823 , as an increased issue of paper by the Bank and a continuance of one-pound notes encouraged specnlation, Sandars t063-4066- Agricultural distress cannot have originated in any circumstance connected with the currency, Pattison 5+62-Farmers were better off in 1824 and 1825 , in consequence of an issue of paper money ; prices fell in 1827 , when the notes were called in, Bennett 423-430-The alteration in the currency was the commencement of agricultural distress, Tuynam 625-630; Cayley 3643-The withdrawal of paper money restrained speculation, Trcynam $631-633$.

Examination as to the prices of wheat since 1822 , and the effects of the currency thereupon, Tuynam 634-664; Cayley 3630-3633-The contraction of the currency has caused the depression of prices, Lewin 964-966- Erery expansion of the currency since 1796 has been succeeded by a rise in prices, Lexin 1016-1023-The Bank of England regulates the circulation of other banks and affects prices, Lewin 1028-1036_-Whent has been more affected than other articles, because there have been full crops, Leuin 1048-1051.

Part of the agricultural distress arises from the resumption of cash payments in 1819 ; prices rose in 1825 with the increased circulation, David 1239-1244 The diminution of the circulating medium has been the principal cause of distress; variations of prices with the extension and contraction of the currency since 1822, Bernard 1585-1605; Thurnall 2252-2264; Cayley 3632-3633; Spooner $+3+6-1347 \cdot 4390$ - Fluctuation in the price of wheat at different periods since 1815 , with reference to the currency, Houcard $2176-2189$ - Prices fell as soon as the Bill (1825) for the suppression of country onepound notes was passed, Escott 4907 _ Since the withdrawal of one-pound notes from circulation there have never been fair prices except when the crops were deficient, Thurnall $234+-2365$ - The farmers think they were better off when one-pound notes were issued; variation of prices in 1822,1823 and i 824 , Dowling $2765-2770.2883-2897$.

Since 1815 extension and contraction of the currency have been universally followed by high and low prices, Cayley 3639,3640 - Prices before and since the Bank Restriction Act, Cayley $36+1,36+2$ Mode in which currency operates upon prices, Cayley 4124 Ratio of the contraction of the currency in Berwick, Langhorne 3758-3765When the small notes were called in, in 1829 , bad seasons delayed the fall of prices, Langhorne 3792-3794- The state of the farmer has been depressed with each restriction of the currency; since 1819 it has been getting worse and worse, Langhorne 3795$3804-$ Alteration of, in 1816 , a great affecting cause of agricultural depression, Blamire $5119,5120--$ First cause of agricultural distress the withdrawal of one-pound notes and the diminution of the circulating medium, Summers $51+6$ - How far alterations in the currency affected prices, Estcoti 4907 .

\section{How far Depreciation would relieve Distress.}

Any measure that would increase the circulation would be beneficial to the agricultural interest, David 1272-1275; Cayley 3672-The expansion of the currency would afford the greatest relief; all other measures are comparatively useless, Thurnall 2392 _-Action on the currency recommended as a means of alleviating agricultural distress, Blacker 5610 - Mode in which a depreciation of the currency would assist the agriculturist who owes nothing, Munt $\approx 4547-4557-$ One half of the landed proprietors have no real interest in the land, Muntz $4558,+559$ - An alteration of the standard was the only measure that could have continued the prosperity of $182+$ and 1825 , Nunt $z 4628,4629$ - If the currency were much extended there would soon be a panic unless the standard were changed, Sandars, 4075-4079.

3. Suture 
Report, 1837 -continued.

\section{Currency-continued.}

\section{Nature of the Alterations proposed.}

One-pound notes slould be issned convertible into bank notes in the country and into gold at the Bank of England, Darid 1283-1287---Tlie old standard of gold, silver and one-pound notes should be resorted to, Cayley 4135-7139-Advantage of one-pound notes for circulation, Cayley $3651-3653$.

A large portion of the circulation should consist of national irredeenable paper, Spooner $4457-4464 \cdot 4473-4477-1$ - 1 would be liable to depreciation as compared with gold, but should still be a legal tender, Spooner $4465-4467$ The payment of dividends to foreigners in this money would not aflect the credit of the country, Spooner $4482-4484$ -There should be no irredeemable pajer, Muntz 4612-4615-Series of errors committed by the Legislature on the subject of currency, from 1797 to 1826 , Atturood 5,562 .

\section{Justice of changing the Standard.}

Injustice of reverting to a former standard; principle adopted by France, Austria and Russia, of paying debts in the same depreciated money in which they had been contracted, Cayley 3654,3655 - A depreciation is a matter of justice to the debtor and safety to the creditor, Spooner $4+88$ - In considering the relation between debtor and creditor, the advantage which the latter has gained should not be forgotten, Munt $24560-4562$ Seventy-five per cent. of the community would derive advantage from a depreciation of the currency, and their interest should be preferred to that of the minority, Muntz 4628 .

See also Bank of England. Bank Notes. Bankers. Circulation. Gold Coinage. Gold and Silver. Gold Standard. Joint Stock Banks. Joint Standard. Mamufactures. Paper Currency. Prices, I. 4. Standard.

\section{D.}

Dairymen. System on which farmers in Dorsetshire let cows to dairymen, rate of hire, disposal of the calves, \&c., Taylor $3307-3324 \cdot 3364,3365$.

Dantzic Wheat. Can be easily distinguished from English, Hodgson 2020-2023.

David, Mr. Evan. (Analysis of his Evidence.)-A farmer at Radyr Court, in the Vale of Glamorgan, $1192-1197-$ Director of a joint-stock bank, $1198-$ His experience as a farmer, 1199-1202- The capital of the tenantry has been gradually diminished for 15 years, and the land not well managed, in consequence of the want of means, 1203-1208 -Cattle farmers are not suffering so much as corn farmers; sheep farms require less labour, 1209-1213-There has sometimes been a surplus of labour, 1214-1217Wages are $10 s$. a week; it would be dangerous to reduce them, and with present prices they cannot be continued, 1218-1222_Rents have been much reduced, and land has been sold at a great loss, 1223-1225-These reduced rents cannot be paid, 1226-1228

Rents are in some cases barely sufficient to pay the settlements on younger branclies of the family, 1229-1231-Statements of the comparative expenses of cultivation in 1790, 1813 and 1835, on a farm in Glamorganshire, with explanations, 1232-1238. $12+8-1251$.

Part of the agricultural distress arises from the resumption of cash payments in 1819 ; prices rose in 1825 , with the increased circulation, 1239-1244-Increased importation from Ireland has reduced prices, $1245^{-1247}$ - There is more arable land than there was in $1790,125^{2-1257-T}-$ There is an improvement in stock, \&c., but not equal to the expenses, 1258-1262 Notwithstanding all improvements, the farmer was better off in 1790, 1263-1266_-Before the introduction of machinery the women were generally clothed in clothes of their own making, 1267-1271-Any measure that would increase the circulation would be beneficial, 1272-1275 Joint-stock banks have given accommodation upon moderate terms, 1276 - Savings banks have withdrawn money from circulation and placed it in the funds, 1277, 1278--Partners in banks should be required to give security to the amount of their subscriptions, 1279-1282 - One-pound notes should be issued, convertible into Bank notes in the country and into gold at the Bank of England, 1283-128\%.

The malt duty should be withdrawn; the value of all agricultural produce would be improved, 1288-1291—-The nanufacturers do not contribute their just proportion of poor-rates, $1292-1296$ - Nor of county-rates, road-rates or land-tax, 1297-1300The population has increased, and the manufacturers employ more men and capital, 1301-1303-Comparative sufferings of freelolders and tenants, $1304-1307$ - Che distress of the farmers has deteriorated the cultivation ; less corn is grown, $1308-1312$ There was not so much land broken up in 1790 as at present, $1313-1318$ Much corn has been imported into Glamorganshire from Ireland, 1319-1324-Much produce is exported to Bristol, 1325-1328 - Evils of the poor laws; alterations suggested; mode of taking averages, $1329^{-1} 336-$ Comparative expense of growing corn in England and Ireland, 1327,1328 . 1352-1354-Average produce of wheat and barley per acre in Glamorganshire, $1339^{-1} 341-$ Many farms are out of occupation, $13+2-134+-2$ Number of labourers employed by witness; difficulty of reducing it, $1345^{-1} 3+7-$ Rent of land, $134^{8-1} 351$.

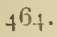


Report, $18_{37}$-continued.

\section{Debasement of Coin. See Coin.}

Debts. Proposed alteration to a silver standard would vitiate all contracts which bear date since the introduction of the present standard, to the extent of five per cent., Attwood $5553-5555$.

Dorsetshire. The down lands are superior to those in Wiltshire or Hampshire; average rent thereof, Taylor 3333-3336-They will feed cows, but the situation is too high for corn, Taylor $3337-3341$.

See also Allotment System.

Dowling, R. H. (Analysis of his Evidence.)-Corn-factor, farmer and miller, at Bexley, in Kent, and a tenant of Lord Bexley, 2743-2745-The farmers cannot generally pay their rent, except out of their own capital, or by over-cropping, 2746-2751- - They are in great distress; many must inevitably come to the workhouse in a few years, unless they get relief, $275^{2-2754-T h e y ~ c a n n o t ~ p a y ~ t h e i r ~ d e b t s, ~} 2755,2756$ - They are highly honourable and industrious men; their distress arises from low prices, $2757,275^{8}$ Importations from lreland is one cause of the depression, $2759-2762$ - It is impossible to compete with the Irish farmer, whose expenses are so inconsiderable, 2763,2764 The farmer's think they were better off when one-pound notes wele issued; variation of prices in 1822,1823 and $1824,2765^{-2770}$ - The warehousing of foreign corn in this country is injurious to the farmer and the merchant in English corn, 2771-2776.

A partial remission of the malt duty would be useless to the farmer, 2777 - A total repeal would bc a great benefit, $2778-2780$ _ Statement and examination concerning the expenses and returns of a farm rented by witness of Lord Bexley, 2781-2803Whenever a farmer is needy, his land is not well cultivated, 2804, 2805-Mamner in which the bonding system is jnjurious to the farmer, 2806 - Prices of all corn are low, $2807-2813$ - The price of stock is good, but the turnip crop failed, and artificial food must be used, 2814-2820_— Wool is selling well ; wheat is the main cause of complaint, $2821-2824$ The price of barley would improve if the malt duty were removed; advantage of being able to malt, 2825-2827.

The foreign corn camnot compete with our own until the price rises to $65 \mathrm{~s}$. or $70 \mathrm{~s}$, $2830-2834-$ The corn laws afford no protection to the farmer; manner in which they operate injuriously, 2835-2840- They have not reduced the price of wheat, which is rather to be referred to the glut of oats from Ireland, $2841-2843$ - The price of corn invariably rises a few weeks before the harvest, which enables foreign corn to enter into competition with us after the harvest, $2844-2846$ - It has been a very bad year for breeding lambs, and the price of lean stock has been low, $2850-2852$ - Unless the whole malt-tax be repealed, the excise jurisdiction continues, 2853 - When wheat is higher than $70 s$. it is necessary for the population of London to have a supply from abroad, 2854-2859-Witness's objection to the corn laws does not apply to the introduction of wheat when prices are high, but to the warehousing system, $2860,2861-$ The English merchant would not speculate in foreign corn, if warehoused abroad, 2862, 2869 - He does not like to advance his money, unless the corn is at command, $2870-$ 2873 - In case a fixed duty should be proposed, it should not be less than $20 s$. a quarter, 2874,2875 .

The competition of the London millers and bakers has made bread proportionately lower than in the country, $2876-2880-A$ laboujer in constant employment is better off than he ever was, 2881,2882 — Further examination respecting the effect of the currency upon the price of wheat, $2883-2897$ The breeding of cattle would have been more profitable, if the turnips had not failed, 2899,2900 - Malt, half made, would have been very useful for fattening them, 2901-The beer-shops and small public-houses have tended to demoralize the labourers, 2902-2904-- - The consumption of barley would be greatly increased by the repeal of the malt duty; farmers would supply their labourers with beer, 2905,2906 - They could afford to grow barley at a lower price than 35 s., so as to exclude foreign barley, 2907-2911.

Draining. Much draining has been done in the southern counties at the expense of landlords, which has given employment to the poor, Trumper 3134-3137-Much drainage has been done by landlords, instead of reducing rent, Cayley 4172, 4173-Assistance rendered by landlords in Cumberland to farmers, by draining and manuring instead of reduction of rent, Blamire 5115 - Much improvement has been made in drainage in Leicestershire; generally at the expense of the landlord, Wilson 1808-1821 - The drainage of land has made it capable of producing more corn, Trumper $3203-3206$.

See also Improvements.

Drilling. Is done by the Suffolk machine at is. $6 \mathrm{~d}$. an acre, Green 191-192.

Duddo. See Land.

Duxford (Cambridgeshire). Statement of receipts and outgoings of a farm of 400 acres, in the occupation of $\mathrm{W}$. Thurnall, $1834,1835, p .128$ - Statement of proceeds and expenses attending the cultivation of an off-hand farm of 657 acres, from 1831 to 1835 , in the occupation of Mr. Peter Grain, at a coril-rent, Thuruall $2422-2426$. 
East Lillum. See Land.

E.

Elthum. Is not much burthened with poor-rates; employnent is found for the labourers, Green 158-160.

Employment. Many of the poor, near Windsor, are not employed, from want cf capital, Kendall 1203-1104-On Ilampshire all the labourers would have employnent, if prices were remunerating, Tuyum $714-716-$ In Suffolk many of the poor are out of employment, Leuin g6o.

See also Labourers. Poor. P'oor Law Act.

Iiscolt, Bichliam,S., esq. (Analysis of his Evidence.)-Distressed state of agriculture as regards landowners, renting farmers and agricultural labourers; more depressed than the condition of any other class of the subjects of this country, $4^{8} 51$ - More severely felt l,y persons with small property than large estates, 4851 _- Labourers not too many for the proper cultivation of the land, but unemployed through the poverty of farmers, $48,3-\ldots$ Nature of cultivation generally in Somersetshire, $4^{8} 54$. Many farms are deteriorating in their mode of cultivation, $4860 \ldots$ Growth of wheat must materially deerease, if the prices do not improve, 4862 A much smaller breadth of wheat has been sown this year than formerly, 4864 - Owing to the low prices as compared with the expenses, 4865 - Evidence as to quantity of wheat grown to an acre, 4866 - Of barler, 4867 - Of turnips, 4868 - Rate of rent in Somersetshire from 11 . to 11 . $10 \mathrm{~s}$. per acre; but varies very much, 4869 _ Extent of reduction in rent which has taken place as compared with dear times; on witness's property, to the extent of 50 per cent., 4870 - Pasture farms bear a mucli ligher rent; if good land, from $2 l$. to $3 l ., 487 i$ - Rate of wages given to labourers in Somersetshire about $7 \mathrm{~s}$. or $8 \mathrm{~s}$. per week, 4885 - Wares in Somersetshire low as compared with other counties, 4889 - No decrease in blacksmiths" and other tradesmen's bills to farmers, 4900 - Clothing is certainly cheaper, 4901 _. Shoes not cheaper, but better made than formerly, 4903-Causes of distress, 4,05-4908.

Fall of prices was immediately consequent on the withdrawal of the paper money and the removal of the Bank restriction, $49^{\circ} 7$ - Prices rose as soon as mcasures were taken to obviate the contraction of the circulating medium, 490 - Effect of the Bill of $\$_{25}$ for suppression of one-pound notes, 4907 - Evil caused by the price of bread not bearing its proper proportion to the price of wheat, 4907 - Potatoes being much used instead of bread, owing to its price, 4908 - Enconragement of the allotment system to the growth of potatoes, 4910 - Working of the system in Somersetshire, $4911-49^{2.1}$ Witness's opinion as to probable working of the new Poor Law Bill; formerly felt strongly against it, but now in favour of its operation, 4925- - Evil effeets of the old system of poor laws, 4927-_Labonrers in full employ consume more potatoes and less bread than formerly, 4938 - Evil effects of beer-shops; present system very rumous to the condition of the people, 4940 - Bad consequences of the present game laws; they act with beer-shops, the latter as meeting-places for poachers, while drunkards frequenting them turn poachers, 4949-4955.

Anecdote as to the working of the new Poor Law Bill; its kencficial effect in reducing rates and angmenting the amount paid by farmers for wages of labour, $497 \mathcal{C}$ - Advantages which would result from a circulation of notes from $2 l$. to $5 l$., which should rest on the same security as that on which 5 l. notes now rest, 4984 .

Evidence as to the alteration of currency and standard of value, $4991-4997$ - Repeal of the malt-tax would afford very substantial relief to the agriculturist, 4998-Opinion as to probability of grain being largely applied to feeding cattle, 5001-Duty being taken off malt would be useful to the lower descriptions of wheat, 5003-Farmers would be more inclined to provide labourers with malt liquor, 5005 - Relief which the present Tithe Bill is calculated to afford agriculturists, 5008 - Grievous state of the present tithe law, 5011, 5012-Tithes generally less rigorously exacted when in the hands of the clergy, 5013 -Witness knows many instances in which elergymen do not get half the value of their tithe, 5014 - Witness knows clergy who always take their tithes in kind, and who will not give the parish a composition, 5015, 5016-Hardship of tithes on the land, 5019-5024.

Introduction of Irish produce to this comntry injurious to the agriculturist, 5028 Effeet of any further reduction of rents upon small or moderate landholders, 5028 Great alterations in the holders of estates; many families have sold their properties, 5032 -Price of live stock, occasioned by the total loss of turnips, except Swedes, $503 \varepsilon-$ Present price of stock an encouragement to throw land into pasture; a great number of labourers would be thrown out of employ by that step, Escott 5039 .

[Second Examination.]-Effect of the increased circulation of money as a cause of the rise in prices, 5041_ Caused probably by different speculations in canals and railroads, 5041-Bankers state that a great deal of paper lias been issued in consequence of these speculations, 5042-Joint-stock banks have materially increased their cirenlation in the last few years, 5,44-Corrections of former evidence as to manufactures in Somersetshire; notice of the glove manufactory at Yeovil, 5048-Oof the manufactory of lace and silk at Chard, 5050 - Of woollen manufactures, 5051—Uf brickmaking in different parts of the county, 5051- Explanation in answer to former queries 464 . 
Report, 1837 -continued.

Lscott, Bickham S., esq. (Analysis of his Evidence)-continued.

on the subject of migration of labourers, 5051 -Reduction of domestic establishments recommended to gentry, 5052-Greater care in settling payments and annuity charges on their estates, 5053-Revival and encouragement of those sports and amusements which the labouring population of this country used to enjoy, recommended, 5056 Explanation of former evidence on the proposed commutation of tithes, and of the principle on which titlues now act oneronsly on the land, 5056-Explanation as to evidence concerning tithes taken in kind, 5056-5059.

Under composition, in estimating the compensation to be paid in money, the market value must be taken into consideration, 5064_- inportance of the precedent, when viewing the question, whether the general property of the country is answerable for church support; of the large sums of money already contributed by the Legislature for building churches, 5065 - If tithes are a tax on consumers, a commutation will be inposing a burthen on the land which it does not now bear, 5070- - Opinions of Mr. Hume, Mr. Pitt, Mr. Baring, Lord Brougham and Mr. Malthus, on currency, and the operation of various changes proposed or effected, and their hearing on the condition of the agriculturists, $5077-5080$ - The reduction of taxes, instead of keeping up the sinking-fund, lias been a great evil, 5081,5082 - The national debt might have been reduced one-third, $508_{3}$ C The sinking-fund could have been maintained by a strong goverument, 5084 .

Exchanges. When exchanges are against this country, there will he a demand for gold, Pattison 5420-- Measures necessary to be taken by the Bank would diminish the circulation, and a reduction of prices would follow, Pattison 5421 .

See also Manufacturers.

Exchequer Bills. Extent to which the issue of Exchequer bills to bankers by Govemment, on securities, might be useful in cases of drains for specie, Blacker 5610-5615.

Excise. See Malt Tax, IV.

Exports. A depreciation of the currency would stimulate exports, Spooner 4495,4496 - The amount of exports is no criterion of agricultural or manufacturing prosperity, Cayley 3606.

See also Manufactues.

F.

Failures. There have been many failures in Glamorganshire, Bradley 2436-2438 - In Hertfordshire some farms have been given up by prudent men, Sharpe $386+-3869-$ In Leicestershire many prudent farmers have failed, Wilson 1753-1756- - Sume farms have been given up in Sussex, and the dividends have been small, Hudson $3461-3464$ -In South Wilts many small farmers have been broken up, and if prices do not improve, the large farmers must ultimately be ruined, Hughes 3006-3009.

Fairbrother, Carter. (Analysis of his Evidence.)-Bailiff to Lord Salisbury, 5658 Table laid before the Committee, of what flour might be produced from five bushels of wheat, and what quantity of bread may be made from it in 24 hours after baking, 5659 .

Fallow. See Cultivation.

FARMERS :

1. Their Distress generally.

2. Classes more peculiarly affected.

3. Their Distress doubted or denied.

4. Whether they will profit by a Rise in the Price of Wheat.

5. Their morle of Living.

1. Their Distress generally.

Although rents have been reduced, farmers have been losing for the last 20 years, Peyton 1551-1556-All persons who have farmers for their debtors are in distress, Cayley 3601,3602 - Notwithstanding the reduction of rent in Bedfordslire, farmers cannot meet their engagements, Bennett 418-422 - In Berkshire the great mass are much distressed; their condition has been getting worse and worse for the last 10 years, Allnatt $770-773$.

In almost all cases they are paying the expenses of their farms out of capital, Allnatt $798-800$ - It is impossible that they can be making profit, Allnatt 801-804-Many near Windsor have left the country for America, Kendall 1182-1184- Near Windsor they cannot make up more than two-thirds of their rent, Keadall 1094-1098_- For some years they have been paying rent and other expenses out of capital, Kendall 1099-1102.

In Cambridgeshire: farmers are in a most deplorable state, not from imprudence, but from the state of the times, Thurnall 2241-2243- They cannot pay their debts, Thurnall 2270, 2271 - Some who are living on their own lands cannot pay their poor-rates, Thurnall $2282-228+$ - Ln Essex: the capital of most is reduced, of some 
Farmers:-1. Their Distress generally-continued.

entirely gone, Comport 4207-4212-In Glamorganshire, notwithstanding the improveinents which have since been mate, the farmer's were better off' in 1790 , David 1263-1266 _-_'l'here are not many really solvent; there have been many failures, Bradley $2436-243^{8}$.

On Greenwich Ilospital Estates: farmers are very much reduced; their capital has considerably diminished, Grey 4635-Reasons why many of the farms were thrown up by the tenants, Grey 4649-4655-Farms belonging to Greenwich Hospital more worked out and worse nianaged than the general farms in the country, Grey 4704-In Ilerefordshire many cannot pay their rents although they lave been reduced; some who have been fortunate as breeders have made a profit, Turner 4098, 4104.

Kent: Near Bexley many must inevitably come to the workhouse in a few years, unless they get relief, Dowling 2752-2754-They cannot pay their debts, Dowling 2755,2756 -.They are highly honourable and industrious men; their distress arises from low prices, Dowling, 2757, 2758_-They are redueing tleir expenses by diminishing the cultivation of corn, Waring 128-131-Near Eltham they are paying wages and other expenses ont of capital, Green, 101,162 .

Northumberland: Cannot go on unless prices are raised, Langhorne 3758 .

Norfolk: The tenantry near Hunstanton cannot pay their rents off their farms, but are not in arrear; none have been broken up, Carter $2928-2932$.

Suffolk: Could not continue to cultivate unless they expected an improvement in prices, Cooper 2621-2626-They are in a ruinous state, Cooper 2626-2629-Their state is dreadful, Lewin 943-945-They cannot pay their rent and wages if prices remain the same, Lewin 954-There are many cases in which opulent and prudent men have become paupers, Lewin 955-959-For the last eight years their condition has been growing worse and worse, Lewin $1009-1015$ - Statement as to the condition of farms in Norfolk and Suffolk, Wilson 1849 .

Weald of Sussex: Are in a very bad state; prices do not remunerate them; they must pay rent out of capital, Hudson 3374-3380 - In the East Riding of Yorkshire are in great distress, although their rents have been reduced; many have failed, Howard $2089-2093$.

\section{Classes more peculiarly affected.}

Farmers who have not much arable land are not so distressed as others, Bernard 1639 , 1640 - Are generally insolvent, except on the best lands, which are only one-fourth of the country, Spooner 4338-4343-The occupiers of poor soils are in a very bad conclition; they pay rent out of capital ; many have been mined, Peyton 1497-1502_- Their failure arises from their expenses and the low price of produce; scmetimes from want of skill, Peytou 1503-1507-The occupiers of good land can make a profit, Peyton $1508-$ 1511 - Those on cold clay lands are the most distressed in the southern counties, Trumper $3121-3128$.

The small farmers are more distressed than others; they once performed the greater part of the work on their farms, but surplus labour has discontinued this system, Trumper 3187,3188 - The poor farmers are in the greatest distress; they are obliged to bring their corn to market, and thus depress the prices, II aring 79, 80.

In Hertfordshire they are much distressed, particularly those on inferior lands, Sharpe $3^{860-3863}$ _ On corn lands in Kent farniers make no profit, and receive no interest for their eapital, Waring 7-9.14, 15-Near Canterbury the oceupier of poor land is better off than the occupier of good land, Nearne 1438-1440-When they have depended upon the growth of corn they have suffered much, Nearne 1445-1447- Their condition is generally very bad; they are in want of capital, Nearne $144^{-1}+51$ - Last year they made enough to pay their rent, labour and the interest of capital, Nearne $1453^{-1456 .}$

Relative condition of upland and lowland farmers in 1833 and now, Cayley 3526,3527 . 3531-3533-Influence of wet and dry seasons upon upland and lowland farms, Cuyley 3565 - State of renting farmers more depressed than the condition of any other class of subjects in this country, Escott 4851 .

\section{Their Distress doubted or denied.}

Are in a prosperous state, except in so far as the price of wheat affects them, IIodgson $1905^{-1911-T h r o u g h o u t ~ t h e ~ c o u n t r y ~ t h e r e ~ i s ~ n o ~ e x c e p t i o n ~ f r o m ~ t h e ~ g e n e r a l ~ a p p e a r-~}$ ance of comfort in the case of farmers, Hodgson 1964-1968-There are no external signs of distress, Sandars 4067 - In Dorsetshire they are in a good state; they are men of opulence and have large farms, with much down land, Taylor 3329-3332Their condition is better in Hampshire than in other counties, but they cannot continue to grow wheat at the present priees, Tuynam 562-573.

\section{Whether they will profit by a Rise in the Price of Wheat.}

Cannot profit by a rise in price, as they lave been obliged to part with their produce, Waring 85-87; Spooner 4430-4432-Corn seldom rises until the farmer has disposed of it to the corn factor, Hulson 3426 - A large stock of wheat is in the liands of the farmers, and any rise in price will be of great benefit to the agricultural interest, Hodgson 1931,1932 . 
Report, 1837 -continued.

Farmers-continued.

\section{Their mode of Living.}

The present race of farmers are living very economically; many have not comforts, and certainly not luxuries, Trumper $3165-3167-$ In Essex they live scarcely better than well-cmployed labourers, Comport 4260, 4261-In Glamorganshire many are living harder than their labourers, and have not been reduced by imprudence, Bradley 2487 , 2488 _ In Sussex they do not live extravagantly now ; their distress has arisen not from imprudence, but the state of the times, Hudson 3465-3468—They live very well, but have reduced their expenses, Hudson 3479-348.

See also Agricultural Distress. Competition for Farms. Failures. Graziers. Malt Tax, 1. 2.

Farms. In the southern counties there is rather a disposition to subdivide than consolidate farms, Trumper 3189-3192- Armagh county generally divided into small furms, few above eight, many as low as four or five acres, Blacker 5623,5624 - In the lowlands 40 acres is considered a very large farm; in the mountainous countries there are larger pasture farms, Blacker 5625 .

See also Competition for Farms.

Firclild, G. W. (Analysis of his Evidence.)-Farmer and cow-keeper at Harborne, in Staffordshire, 1355-1358-Tenants are not able to pay their rents, and many have left their farms, $1359^{-1365}$ _- Rents have been lowered, 3366,1367 - Local burthens liave been somewhat reduced, $1368-1371-\ldots$ With the present prices, rent must be paid out of capital, $1372-1374$ - One-third less wheat has been sown this year; consumption has increased; this will account for the rise in price, $1375^{-1} 37^{8}$ - The surplus labour is gener ally absorbed by the manufacturers, $1379^{-1} 385-$ Causes of the late low prices; diminished consumption, large crops and importations from Ireland, $1386-1392$ Advantages of removing the malt-tax, 1393-1395.1411-1420-Beer-shops are very pernicious, and if the malt were free of duty, labourers would brew their own beer, 1396-1399- The consumption of barley would be increased, and farmers could provide it, 1400-1403 - The severity of the excise laws, rather than the duty, prevents farmers from malting, 1404-1410-In Worcestershire county rates are charged as highly on property in towns as in the country, 1423-1425-The lands which have been thrown out of cultivation are poor soils, 1426-1432.

Fires. There have been several nea: Canterbury, but none lately, Nearne 1482- - In Hampshire rick-burning ceased when employment was found in 1831, Twynam 579,580 In Kent either less labour would be employed or wages reduced, were it not for the fear of incendiary fires, Waring 92-99-There have been several in North Wilts, Hughes 3027 .

\section{See also Wages.}

Fixcd Duty. In case a fixed duty should be imposed on foreign corn, it should not be less than $20 s$. a quarter, Dowling 2874,2875 .

See also Corn Laws.

Flax. Importance of encouraging its growth, Cayley $4177,41,8$ - The growth of flax would impoverish the land, Truniper 3230,3231 - Hemp cannot be grown to any extent in Wiltshire; more is grown in Somersetshire and Dorsetshire, Hughes 3069-3071 Encouragement of the growth of flax in Somersetshire would be a great relief to farmers, Summers 5166_- Statement of expense of cultivating an acre of Hax, Summers 5175 -Cannot be raised on the cold soil on which wheat will grow, Summers 5181 Cultivation of, would be greatly increased if importation were prevented, Summers 5297 .

Value attaclied to the cultivation of flax in Ireland, which cannot be done without a protecting duty, Blacker 5615,5616 - Russia conld send flax cheaper to Dundee than it could be shipped from Amagh, Blacker 5615--Growth of flax has much revived, owing to the failure of the crop on the Continent; evidence concerning proposed duty on foreign flax, Blacker $5650-5657$ - Quantity of foreign flax consumed in the United Kingdom in each year, 1833-1835, p. 59 .

See also Malt Tax, III.

\section{Flemish Farm. See King's Farms.}

Flour. It is quite impossible for foreign flour to come through Ireland as Irish flour, Sanciars 4093 .

Flour and Meal. Quantities imported into His Majesty's colonies, \&c., and from foreign parts, in each of the years from 1815 to 1835 , both inclusive, $A p p \cdot p .366,367$ - Account of foreign flour and meal brought into consumption in Great Britain, from 1815 to 1835 , inclusive, App. p. 392 - Similar return of flour and meal, other than foreign, during the same years, $\Lambda p p \cdot p \cdot 393-399$. 
Report, 1837 -continucd.

Flour Trade. In Londun the Hour trade is a monopoly, Jacob 303, 304-This arises from the wealth of millers and the poverty of bakers, and from the piucity of mill-streams, which reduces competition, Jacol 312-3is.

Flushing. Corn could be brought to the London market from Flushing as soon as from Lyun, Thurnall $2388-2390$.

Forced Sales. Sec Prices, II, 2،

I'orcign Importations. See Importations, 3. Prices, II. 3 .

Iranklin, Dr. His opinion of the effect of raising the value of the colonial currency, upon the revolt of the American colonies, Cayley +131 .

Irecholders. Distress prevails amongst freeholders occupving their own land, Kondall $1171,1172-$ In Essex they have contracted engagements on better tems, which thev camnot discluarge, Comport $4200-4205$ - Comparative distress of freeliolders and tenants in Glamorganshire, Darid $1304^{-1} 307$ - The freeloolders occupying their own land, and the smaller gentry, are distressed and reduced, Brudley 2501-2505.

See also Yeomen.

French Corn. Is inferior to the English, Jacob 288-292_Calculating the relative qualities of each, the former is the dearer, Jacob 293-297 - A great uniformity between the price of corn in this conntry and in France, estimated in precious metals, Attwood 5587 .

Paper prepared by Mr. Jacob, of the prices of wheat in French markets, $p .64$.

G.

Gallatin, Mr. Notice of a pamphlet written by Mr. Gallatin, on the subject of the currency, of the value of gold and silver standard, Attuood $557^{2}$.

Games. Revival and encouragement of those sports and amusements which the labouring population of the country used to enjoy, recommended, Escott 5056 .

Game Laus. Bad consequences of the present game laws; beer-shops much frequented by poachers, Escott $49+9-4955$.

Gaols. A larger proportion of manufacturers are committed to gaols in Leicestershire than of agricultural labourers, Wilson $1766,1,67$.

Glamorganshire. A comparative statement of corn grown in certain parishes therein for two years prior to 1830 , and in 1834 and 1835 , David $1309-$-Average produce of wheat and barley per acre, David 1339-1341_ Imports from Ireland into Glamorganshire in 1833,1834 and 1835 , and price of wheat each year, Bradley $2443-2454$ - The produce of the county is not enough for its own consumption, Bradley $2455-2468$ - The properties are generally small, Bradley $2542-2545$.

See also Cultivation. Farmers.

Glore Trade. See Lcicestershire. Yeoril.

Gold. See Exchanges. Portugal.

Gold Coinage. Narrative of the alterations in gold coins from Queen Elizabeth to Charles II., Attuood 5575 - Profit cannot be made on gold by indiriduals coining, Pattison 54055407 .

United States: Copy of a Bill concerning gold coins for the United States, Attwood, p. 355 .

Gold Seignorage. Seignorage on gold might be useful, if it could be effected without altering the value of the coin, Pattison 5410.

Gold and Silver. Ratios of gold and silver, $1760-1829$, with the averages of each 10 vears, and the total mean average for 70 years, Attu:ood, p.35t-Table of prices in the market of goold and silver, $1760-1819$, taken from Wettenlrall's List, and exhibiting the relative prices of gold and silver to each other, Attuood, $p .355-$ Copy of an Act regulating the value of certain foreign silver coins in the United States, Attwood, p. $35^{6}$.

see also Bullion.

Gold Standard. The currency is more fluctuating since the adoption of the grold standard, Bernard 1631-1633-C The gold standard of 1819 never existed before that time, Spooner 4441-4442- Gold was not the practical standard previous to 1797, Spooner $445^{2}-4+57^{-}$- Danger of founding a large paper circulation upon a small quantity of gold wbich nay be suddenly withdrawn, Spoomer $+468-4+70-$ Pressure on the Bank of England from the drain for gold, Pattison 5315-532.2_ Bank parted with $1,500,000 l$. or $2,000,000 \mathrm{l}$. at the time of the resignation of Lord (irey in 1832 , Pattison 5333.

See also Currency. Joint Stundard. Silandard.

Goswick. see Land.

Gruin, Peter. See Duxford. $t^{l i}$. 
Report, 1837 -continutd.

Gruziers. Calculations of their losses upon sheep and cattle, on account of the low price of tallow, Wilson 1838 - Have more resources than other farmers, Trumper 3236,3237 -Their complaints in Ieicestershire; low price of tallow and hides, Wilson $1671-16-6$ - The low price of tallow prevents the grazier from getting the same price for his cattle, Wilson 1677-1679-Chey are better off than they were some years since, as the price of wool has risen, Wilson $1696-1700$.

Green, John, esq. (Analysis of his Evidence.) - Resides at Eltham; has been an occupier of land 43 years, $142-149--D e l i v e r s$ in a statement of the expenditure and receipts of corn crops for five years, 150,151 - Nineteen shillings and nine-pence is the whole profit on an acre of land, without allowance for capital, trouble or risk, $15^{2-1} 54$ - Eight years since the price of wheat was as low as in the present year, 15.5- - It is impossible for arable farmers to bear their expenses with the present prices, $156-$ - Eltham is not much burthened with poor rates; employment is found for the labourers, 158-160_-Farmers are now paying wages and other expenses out of their capital, 161, 162-Explanation of the statement delivered in by witness, $163-165--\mathrm{He}$ has reduced the wages of his Jabourers from $15 \mathrm{~s}$. to $12 \mathrm{~s}$. a week, but will raise them again, $166-175-\mathrm{He}$ holds crown lands under a lease from Sir John Shaw, $776-184-$ Manure is obtained from London and Woolwich, $185^{-187}$ - Poor and other rates have not much increased in the last five years, 188 - The large farmer is sinking his capital; the small farmer has alseady sunk it, 189,190 .

Drilling is done with the! Suffolk machine, at $1 \mathrm{s.} 6 \mathrm{~d}$. an acre, $191,192-$ Number of slieep usually kept by witness; the price of wool has been good, but that of mutton bad, $193^{-198--H e ~ b u y s ~ t h e m ~ a s ~ l a m b s, ~ a n d ~ o u g h t ~ t o ~ m a k e ~} 1 l$. a head profit on the two years, independent of the wool, 199-201_- The present reduced prices of tallow raise the price of meat, 202-206-Witness's land is strong clay, and not favourable to the breeding of sheep, 207-209- - He is paying a very high rent for the crown lands; he purchased the lease during the war, $210-215-$ He is obliged to cultivate the land, as it would be sacrificed for 10 or 12 years if laid down for pasture, $216-219-$ Old sheep produce seven or eight pounds of wool; the younger about five pounds, 220- -1 ligh prices of wool during the last two years, 221-224- At the present prices of corn the land is not worth any rent, $225-227$.

Greenwich IIospital. Account of the several articles of clothing, and the prices of each, in Greenwich Hospital, from 1815 to 1835 , both inclusive, App. $p .402$.

Greenwich IIospital Estates. State of the property; amount of rental; reductions of rent; mode of management; distress of farmers, Grey $4633-468_{3}$.

Grey, John. (Analysis of his Evidence.) - Lives in Northumberland, $4631-$ - Receiver of the Greenwich Hospital estates for the northern counties, 4632 - - Rental amounting to $30,000 l$. per annum, 4633 - Farmers on the estate very much reduced; their capital has considerably diminished, 4635 - Rental of farms varying from $500 l$. to 1,300l. per annum, 4636- - State of farmers on the Tweed much reduced as to capital, 4639 Farms have been much run out, in consequence of distress, $46+1$ - Reductions which have taken place in the rent of Greenwich Hospital estates, $4646-4648$ - Reasons why a great proportion of the farms were thrown up by the tenants, $4649-4655$ - Evidence as to management, production of land, $4656-4666$ - Rate of rents, and produce of land, $4667-4683$ - Cost of bone manure; very good manure for raising a crop of turnips, and also for succeeding grasses, 4679- Stock has lately been selling well, and wool very high, $4680-4682$ Many farms where large flocks are kept lately let at high rents, in consequence of the high price of wool, 4684- - Sheep farms generally in mountainous districts; not more than a sheep to an acre; on the Cheviot hills much less, 4687.

Wages in Northumberland generally from $10 \mathrm{~s}$. to $12 \mathrm{~s}$. per week, 4691 --Regularly hired servants are paid in kind; generally have means to keep their families comfortable, 4692 - Not overburthened with poor, 4695_- Population equal to agricultural wants, cxcept in harvest, when there is an influx of lrish labourcrs, 4696 - Rate of wages paid to Irish labourers $2 s$. $6 d$. a day, $4607-$ Reduction of rent the most important mode of relief, 4702 - Alterations in the Poor Law are improving the state of the agricultural districts, 4702 .

Farms belonging to Greenwich Hospital more worked ont and worse managed than the general farms in the country, 4704-Nature of leases granted by Greenwich Hospital, $4705-4709-$ Present low prices attributable to the great produce, 4713 .

Scotch notes come over the border and are instantly sent back again, 4717- - The pressure less where Scotch notes were in circulation, and where the Scotch system of banking prevails, 4724--Scotch tenantry better off than English, from their production of wool, 4726 - Extent to which a repeal of the malt-tax would be beneficial to the farmers, $4729-4732$ - If the 'Tithe Bill were settled on just grounds, it would remove the impediment to the employment of capital on agricultural inprovements, 4735 - - Land in Northumberland in a worse state than it was, 4736-4738-_-Evidence as to growth and price of wheat, $1837,4741-4748$ - Amount on tenants' outgoings as rent and taxation, $4749-475^{2}-$ Immense extent of inclosures in Northumberland; different class of persons who aspire to be farmers, 4757 - Willingness of persons to pay high rent, 4758 Price of land in Northumberland, $4761-4763$ _- Low prices the result of goud crops, not of increased cultivation, 4769 - Condition of labourers as good now as in i 815,4773 .

Girindon. 
Report, 1837-contimed.

Grindon. See Land.

Guernsey, importation of foreign grain to. See Corn.

II.

IIams. Quantity bronght into Great Britain from Ireland, 1815 to $1825, A p p \cdot p \cdot 406$.

Hare, Colonel. See Sutton Estute.

Harman, Mr. Jeremiah. Statement before the Committee of the House of Commons on eash payments in 1819 ; respecting the removal of distress, in 1815 and 1816 , by an issue of bank notes, Cayley 3630 .

Harrests. Each year, from 1832 to 1835 inclusive, have been good years for wheat, Trimper $3250-3252$ - An average of seasons may be ealculated upon for a long series of years, Cayley, 3628 .

See also Crops.

Hemp. Quantity of hemp of foreign production consumed in the United Kingdom in each year, $1833^{-18} 35, A p p . p .59$ Cultivation of, would be much increased if importation were prevented, Summers 5299-Alteration of duty on hemp reconmended, in orcier to protect the home growth from foreign competition, Blacker 5616 .

See also Flax. Malt Tax, III.

Hides. The reduced prices of hides and fat are a positive loss to the farmer, Wilson 17751781 - Their price has fallen, Wilson 1676 .

Highcay Rates. See Taxation.

Hinchley (Leicestershire). Acreage of the parish; agricultural and manufacturing population; proportion of rates contributed by land and houses, Ev. p. 15.5 .

Hodgson, Darid. (Analysis of his Evidence.)-Merchant at Liverpool, \&.e., 1850-1853The importations of corn from Ireland have been increasing and varying since $18_{20}$, 1.854-1862 - No foreign con has been elandestinely inported in the form of Irish flour, $1863-1867$ - The price of no agricultural produce is depressed except wheat, $1868-1869$ The cause of this depression is superabundant production for three or four years, 1870-1877- Large importations of oats from Ireland have led to the increased cultivation of wheat, $1878-1884$ - Witness's firm send two persons through the country each year to report on the crops, $1885-1892$ - Whether the present price of wheat be renunerating ean he best ascertained by the average price for 20 years, as the article would not have been produced at a loss, $1893^{-1904}$ - The farmers are in a prosperous state, except in so far as the price of wheat affects them, 1905-1911-Over production occasioned the low prices, and less wheat has been sown in the present year, 1912-1918.

The difference in the prices of wheat in the English and Irish markets must be the same, taking into consideration the quality, with the expense of carriage, 1919-1927If there should be another prodnctive harrest, and the same quantity of wheat sown, prices must be lower still, $1928-1930$ - A large stock is in the hands of the farmers, and any rise in price will be of great benefit to the agricultural interest, 1931, 1932Manner in which witness's traveller proceeds to estimate and measure the crops, $1933^{-}$ 1949. 2049-2052-All agricultural produce, except wheat, bears the sane exchangeable value as it bore 40 years ago ; all articles are cheaper, 1950-1955-Wages and poorrates have not fallen, 1956 - Examination as to comparative productiveness of spring and autumn wheat, $1957^{-1} 963$ - There is no exception from the general appearance of confort throughout the country, in the case of farmers, 1964-1968- Many tenants have changed their farms, but there are no farms without tenants; the landowners are distressed by the altered ralue of money, $1969-1981$.

Advance in the price of wheat in the Lirerpool market, $1982-1988$ - The prospect of a diminished supply has encouraged speculation, $19^{8} 9-199^{1}$ - Time which wheat may be kept without injury; best mode of preservation, 1992-199f - No foreigu wheat has been snuggled from Ireland; the quality could be imniediately distinguished, 1997-2003 - The traud was more difficult to detect with respect to the Isle of Man, 2004,2005 - Extreme difficulty of applying the same fraud to Ireland to any great extent, 2006 2019 - The quality of English wheat has improved; that of Dantzic lias not deteriorated; they can be easily distinguished, $2000-2023$ - There has been an unusual constimption of wheat for farming purposes as a substitute for other food, 2024-2027:- The price of wheat in America is higher than in England, 2028-2031.

Irish wheat is generally consumed at Liverpool; white wheat is nore used in London, $2032-2034-$ Effects of kceping wheat upon its value, 2035-2037-Con wonld not be imported from America unti] the home price exceeded 7os. the quarter, 2u38-2043 - Some may have been surreptitiously intrcduced into England through Canada, 2044-2048.

Holderness Conntry (East Riding, York). Arerage rent was $40 \mathrm{~s}$. an acre; it has been reduced to 20 s., Houvel $2235,2: 36$.

4 fis. 
Report, 1837 -contimued.

Horses. See Cattle.

Horton. See Land.

Hosiery. Sce Leicestershire.

Houghton Regis. Sec Poor-rates.

Hounslou. Is tithe-free; there was an allotment for small and great tithes, Sherborne 4778 , 4779 .

Hounslow Heath. Mode of cultivation pursued thereon, Sherborne 4825-4827. 4832-4835.

IIoward, C., esq. (Analysis of his Evidence).-Resides at Melbourne (York, East Riding), and is manager of two estates; their extent, 2053-2058— The produce of the Sutton estate (Colonel Hare's) has been diminishing for some years, 2059-2061_-Nuch of the Scoreby estate (Mr. Wood's) has beeu laid down in grass, on account of the cultivation of com being unprofitable, 2062-2071 - The rents have been reduced 30 per cent., and insprovements made by the landlords, making the whole equivalent to a reduction of 45 per cent., 2072-2074-C The tenants cannot pay the reduced rent; every tenant of Mr. Wood has given notice to quit, 2075-2079-Colonel Hare's rents have been reduced 50 per cent., and the tenants have paid them by over-cropping, 2080-2085The estate is not in so good a condition as it was, so the landlord has in fact paid his own rent, 2086-2088-C The farmers in the East Riding, although rents have been reduced, are in great distress; many have failed, 2089-2093--Average produce of the Sutton estate per acre, and the nature of the land and cultivation, 209+-2102-Much pasture has been ploughed up and cropped, 2103-2109-Successive reductions of rent since $1816,2110-2120$ - Nature of the land on the Sicoreby estate, 2121-2126.

Country bankers will not advance money to farmers as readily as they formerly did, as they have no personal sccurity, 2127-2129-Rents have been paid out of capital for many years, 2130-2131_-The condition of the poor has improved lately; many have emigrated to America, and others have employment in manufactures, 2132-2139Reduction of rates during the last 10 years, 2139-2143 — The Poor Law Act has operated, although not put into execution; it is popular, with the exception of the bastardy clause, which will increase expenses, 2144-2151-Average rate of wages throughout the year from $10 s$. to $12 s ., 2152,2153$ - The tenauts who have given Mr. Wood notice to quit, undertook their farms with sufficient capital, $2154-2158$ Wages have been reduced, but the price of the common necessaries of life has been proportionately diminished, 2159-2165-Cottage rents $50 \mathrm{~s}$. a year, with a garden, 2166 , 2167 - The allotment system has caused libourers to eat less wheat, and more regetables and meat; nevertheless the general consumption of wheat has increased, $2168-2175$ Opinion that the currency has affected prices; fluctuation of the price of wheat at different periods since $1815,2176-2189-$-The use of artificial manure, bones, \&c., has been introduced with great profit, $2190-2197$ - - The beer-shops have produced much mischief amongst the labouring classes, $2198-2200-$ - State of agriculture in the district called Howdenshire; depreciation of the value of land; quantity thrown out of cultivation, 2201-2206-Much less wheat than usual has been sown this year, 2207-2210_Sheep farmers are not in a bad coudition, 2211-2215.

Cold clay lands, which form about one-fourth of the cultivated part of the kingdom, could not be cultivated with profit, if rent-free, 2216-2221 - Many landlords have been paying their own rent by the improved cultivation of their tenants, 2222-2224If the average price of wheat were $60 \mathrm{~s}$. a quarter, and other produce in proportion, $17 \mathrm{~s}$. an acre rent could be paid, 2225-2229-The distress has not been great amongst sheep farmers, as the price of wool and mutton has been good, 2230-2234- The average rent in the Holderness country was 40 s. an acre; it has been reduced to 20 s., $2235-2237$.

Howdenshire (East Riding, York). State of agriculture in that district; depreciation of the value of land, Howard 2201-2206.

IIudson, James. (Analysis of his Evidence.) - Has been 35 years a farmer in Sussex, 3372,3373 - The farmers are in a rery bad state in the Weald of sussex, $3374-3376$ L'rices do not remunerate them; they must pay rent out of capital, $3377-3380-$ The profit of stock has not made up for the loss on coln, $3381-3383$ - The poor are generally employed, $33^{\$} 4-33^{8} 7$-The farmers do not employ then profitably to themselves, 3388-3390- The great crops of wheat have been the cause of the low price, $3391-3395$ The Irish corn enters into competition with our own; much Irish oats are imported into Brighton, 3396-3399- - The poor-rates have been reduced by the new law, $3+00-3+04-W$-Wages $3+05,3406.3+60$.

Produce per acre of wheat, barley, oats and beans in the Weald and in the Down country, $3+07-3+11$ - Prices of wheat, oats and barley which would be remunerating, $34^{12}, 3+^{13}$ The price of barley and oats is fair, but the crops deficient, $34^{1}+-3+19-$ The price of wheat is nore than one-third less than the remunerating price, while there is one-fourth morc than the average produce, $3+20-3+25-$ Corn seldom rises until the farmer has disposcu of it to the corn-factor, 3420-2-The small farmers arc more 
Report, 18:37-continued.

Ifulsor, Jumes. (Analysis of his Evidence)-contimued.

benefited than the large ones, by the greater produce of wheat, $34^{27}-3429$ - For the last three years there lave becin abundant crops; previously they were deficient, $3+30-$ 3435 - The fitmer is better off with average crops and good prices than with large crops and low prices, 3436-3439-C-The Weald larmers are more distressed than those on the hills, $3440-3+43$-The price of shcep stock was very bad last year, $3+4+4-344^{6}$ - The wool has improved ; its price, $34+7-3+48$.

Rents have been reduced, in many instinces, in the Weald, more than half since 1814 , 3449-3452- Yet at present prices the stiffer land will hardly pay any rent, 3453,3454 On the Down farms, rents have been reduced one-third, 345.5- The furners are not making a profit even on the Downs, 3456-3458-The charge for the work of artisans has not been much reducel, 3450 - Some farms have been given up, and the dividends liave been small, $3461-3464$ - This lias arisen not from imprudence, but the state of the times; farmers do not live extravagantly now, $3465-3468$ - The rate of wages is not influenced by any fear of destruction to property, 3469-3473--Cottage rents; labourers never lived so well as at present, $3474-3478$ - The farmers live very well, but have reduced their expenses, $3479-3482 \frac{-V a l u e}{}$ of wool and sheep; size of flocks, \&c., $34^{8} 3-3487$ - With the exception of last season, a greater breadth of wheat has been sown, and larger crops produced, 3488-3490- C The Down farmers cultivate their land well when they have capital, 3491,3492 .

The poor-rates will be recluced one-third, and in some cases one-half, under the new system, withont any severity to the poor, 3493-3498-The workhouse is offered for children when there are more than three, 3499--Labourers are willing to let their children work, which, under the old system of liead-money, they often refused to do, 3500-3502

-Rate in the pound, 3503,3504 - The children are well provided for in the workhonse, and are educated, 3505-3507-Parents are, in most instances, unwilling to part with their children, 3508-3510--Those in the workhouse are generally bastards or orphans; they are kept until they can get into service, $3511-3517$.

Hughes, Robert. (Analysis of his Evidence.)-Lives at Woodford, near Salisbury; steward to several gentlemen in the county, $29^{8} 9-2903$ - The state of agriculture has never becu depressed so much as at present, except in 1822, 2994-2996-Complaints were first made in 1822 , but an improvement took place until 1826 , when country onepound notes were withdrawn, 2997-3002-.. Prices improved in consequence of three wet seasons; in 1832 , and since, there were fine barvests of wheat, and the price has fallen more than that of barley and oats, 3003-3005- - Many small farmers have been broken up, and if prices do not inprove the large farmers must iltimately be ruined, 3006-3009.

Causes of the low prices; importations from abroad and from Ireland, and good crops, 3010-3012_The agricultural produce of Ireland has affected the price of cattle, pirss, xo., 3013 The price of wheat has risen lately in the Wiltshire markets, in consequence of the demand at Bristol not having been supplied from Ireland, 3014,3015- The allotment system is much encouraged in Wiltshire and is beneficial to the poor, but reduces the consumption of wheat, 3016,3017 The poor have suffered much, but their comforts have been increased by the new Poor Law, 3018-In North Wiltshire they objected to receive their allowance in bread, 3019, 3020-- Wages have been raised since the introduction of the new Poor Law, and are still on the increase, 3021,3022 The farmers cannot continue their wages unless prices improve; the poor would not generally subnit to a reduction, and the poor-rates would be increased, 3023-3026 - There have been rick-burnings in North Wiltshire, 3027.

Nature of the soil near Amesbury, and rent per acre, 3030, 3031-Quantity of wheat, barley and oats that can be produced per acre, $3032-3034$ The cottagers live upon the produce of their gardens; they consume more pork and bacon, 3035-3037-The labourers are better paid now, with reference to the price of provisions, than at any time in witness's recollection, 3038-3040- They are allowed ovens; they used to pay the baker and small tradesmen 20 or 25 per cent. too much, 3042, 3043- Wages have been rediced since 1820 , but poor-rates are ligher, $3044-3048$ - Rents have been lowered from 10 to 25 per cent., 3049,3050 .

The consumption of bread corn in Wiltshire has decreased, 3051-3053- The allotment system has been carried to a greater extent than in any other county; a quarter of an acre is the largest allotment, $305+-3056$ - The consumption of wheat by the labourers lias been reduced une-third, $3057-3060$ - Twenty sacks of potatoes are sufficient for the consumption of a family and for tattening pigs, 3061-3063-Potatoes are much grown by farmers, $3064-3066$ - Quantities of Irish bacon are consumed, 3067,3068 - Flax and hemp cannot be growa to any extent in Wiltshire : more is grown in Somersetshire and Dorsetshire, 3069-3071 — More wheat has been sown in order to make up in quantity for the low prices, 3072-3075-Little spring wheat is sown; it is of inferior quality, $3076-3078$ - When farmers have capital the land is well cultivated, but not when they are poor, 3079,3080 - . The last season was unfarourable for sowing wheat un the wet clay lands, $3081-308, \ldots$ The South Wiltshire farmers are generally sheep farmers, and the prices of sheep and wool have been good, $308_{5}, 3086$ - If the price of wheat bore a proportion to that of other agriculumal produce, the farmers would not complain, 3087-3090- - With average crups the price of barley and oats would be remune464 . 
Report, $18_{37}$-continited.

Hughes, Robert. (Analysis of his Evidence)-continued. rating at a reut of $1 l$. per acre, $3091-3104$ The effect of the Beer Bill has been very bad, 3105 - If the malt-tax were repealed the poor would brew their own beer, as they did many years ago, $3106.3109-3111$ - It would be very adrantageous to the farmer to malt his own barley for consumption on his farm, 3107,3108 .

Hume, David. Extract from his works on the operation of changes in the currency, on workmen, manufacturers, farmers and landowners, Escott 5078 .

\section{IMPORTATIONS:}
1. Effect of Importations of Irish Produce upon Prices.
2. Amount and Nature of the Imports.
3. Foreign Importations; their Effect on the English Markets.
4. Fraudulent Importations of Foreign Corn.

1. Effect of Importations of Irish Produce upon Prices.

Increased impoitations from Ireland have reduced prices, David 1245-1247; Bernard, 1606, 1607; Douling 2763, 2764; Langhorne 3812-3816; Sandars 3942-3946-The price of wheat has risen (March) in the Wiltshire markets, in consequence of the demands at Bristol not having been supplied from Ireland, Hughes 3014,3015 - Effect of introduction of Irish produce in Bristol on prices of agricultural produce, Strmmcrs 5213-5227 The produce of Ireland, both in stock and corn, is a great injury to the farmers in this country; annual value thereof, Kendall $1123-1127-$ The agricultural produce of Ireland has affected the price of cattle, pigs, \&c., Hughes 3013-Importation of corn and pork one of the main causes of distress, Trumper 3155-3161_-Injurious effect of the introduction of Irish produce into this country to the agriculturists, Escott 5028 .

Importations from Ireland and the Channel islands in 1834 to the extent of $1,000,000$ quarters will not account for the depression of prices, Twynam 707, 708-Importations from Ireland hare not eflected prices in England, Cayley $3655,3656.4165-4168$ - Low prices cause an increased export from Ireland, unless they fall too low for any profit, Cayley 3657.

\section{Amount and Wature of the Imports.}

Annual value of Irish agricultural produce imported into Lirerpool, Sandars 395!-3054 - Importatious from Ireland have been increasing since 1820 , Hodgson $1857^{-1} 862-$ The importation of Irish wheat lias not increased during the last two years, Sandars 3933-3935- - Imports at several periods since 1808, Sandars 3937-39+1 - Imports of corn from lreland into Glamorganshire in 1833,1834 and 1835 , and the prices of whent in each vear, Bradley $24+3-24.4$ - Large quantities of oats, beef, pork and bacon have been imported from Ireland, as well as wheat, Peyton $1562-1566$-Imports decrease when prices are low, but inerease immediately prices rise again, Spooner $4365-4367$.

\section{Forcign Importations; their Effect upon the English Marhets.}

Effect of importation of foreign corn in 1829,1830 and 1831 , upon the present prices, Tuymam 665-671_The importation of foreign corn when prices are high keeps English corn from the market, Lcuin $9^{8} 3-989 \ldots$ Ctatement of the respective quantities of hemp, flax, tallow and bristles of foreign production consumed in the United Kingdom, 1833$1835, p \cdot 59$.

\section{Fraudulent Importations of Foreign Corn.}

It is the general opinion that there have been fraudulent importations of foreign com, Sharpe 3911 - No foreign corn has been clandestinely insorted in the form of Irish flonr, Hodgson 1863-1867.1997-2003-The frand was more difficult to detect witl respect to the Isle of Man, Hodgson 2004, 2005-Extreme difficulty of applying the same frand to Ireland to any great extent, Hodgson 2006-2019.

See also American Corn and Flour. Canada. Ireland. Prices, II. 3. Heat, 7.

Improvements. In Leicestershire great improvements have been made in cultivation and draining, generally at the expense of the landlord, Wilson 1808-1821.

See also Draining.

Incendiary Fires. See Fires.

Inclosures. Inmense extent of inclosures in Northumberland during the last 30 years, Grey +757 .

Income Tax. Would not be submitted to, unless rery light, Cayley $4152-4155$.

Inferior Lands. Effect of an extension of the currencr, and of Irish importations, upon the cultivation of bad land, Sandars 4084-4086_- In East Cumberland considerable quantities of inferior land thrown out of cuitivation, Blamive 5094.

Intcrest. The low rate of interest in England has a tendency to make other countries trade with our eapital; but this is not done by the U'nited States, nor so much as formerly by other countries, Spooner $+4^{8} 9-\frac{1}{1} 494$.

sere also Mortgagres. 
Report, 1837 -continued.

IRELAND:

1. Fxpenses of Cultivation therein.

2. Condition of the Country.

1. Expenses of Cultivation therein.

The price of labour is half that paid in lingland, and taxes are lighter, Sandars $3955^{-}$ 3962 - Comparative expeuse of growing corn in England and Ireland, David 13271338. 1352-1354 - The competition of Irish produce, while the labourers of that country receive small wages, is a great cause of distress to the English famer, Thurnall $2265-2269$ - The furners camot compete with the Irish, while the burthens on their land and wages are so much higher, Brodley $2469-2477$; Dowling 2763,2764 - An equalization of the taxes in England and Ireland would be an advantage to the English firmer, Bradley $2506-2508$.

\section{Condition of the Country.}

The condition of the agricultural population has improved, Sandurs 398:2-3988-.. The appearance of the Irish labourers, who come to England, is better than it was, Sandars 3993-3996_Cultivation is improving, Sandars 3975-The farmers are improving rapidly in skill, Blacker 5607 - Wages will not increase with prosperity, as the population will increase too rapidly, Sandars 4002,4003 -Could not supply the whole of England with corn, Sandar's 3997-4001_Can grow corn as cheap as France and Holland, Sandars $4004-4006$ - The quantity of corn grown is not indicated by the exports, as during the low prices much has been used, by distillers, Saudars 4011 - The late prices have not remunerated the Irish grower, Sondars 4012-4015Less cattie is bred now, and more land is brought into cultivation, Bralley 2514-2519 -There has been extensive emigration; many Protestants have left the country, Sandurs 3991, $399^{2}$.

See also Armagle. Bacon. Butter. Cattle. Cottiers. Importations. Middlemen. Rents. Spule Lalsour. Stall-feeding. W'ages.

Irish Flour. Is not so good as English flour, Lewin 972-975.

Irish Labourers. Northumberland: population equal to agricultural wants, except in harvest, when there is an influx of Irish labourers, who receive $2 s .6 d$. per diem and meat, Grey 4697 .

Irish Produce See Importations, 1, 2.

Iron. Great rise which has taken place in the price of iron, Escott 4968.

Isle of Man. See Importations, 4 -

Isle of Thanet. The poor are in a better state than in many other places; there is not a surplus population, C'ramp 749-751.

$J a c o b, W$. (Analysis of his Evidence.)-Has been compt roller of corn returns 14 or 15 years, 228, 229-Was for some time a practical larmer, 230,231 - The system of agriculture has improved and a larger proportion of corn can he grown on the same lands, $232-23^{8}$ - The quantity grown cannot be safely diminished; we should pay higher prices for foreign corn, $239-242$ - For several year's we have not produced corn enough for our population, $243-248$ - Advantages of the present corn laws, 249-251

There is not much disposition to speculate in English corn, 252-255- Speculation in foreign corn is injurious to the farmer, $256,257-$ The inhabitants of the Continent eat very little wheat; it is a drug in their markets, $258-262$ — There is a general complaint of low prices, $263-265$ The farmers in France are to be compared with our small farmers, who are generally in distress, $266-268$ - In many parts of lingland the poor have changed their food from wheat to potatoes; but wheat lias been substituted for barley and rye, $269-282$.

Estimated average consumption of wheat in England, 283,284 - Imports from the Continent and from Ireland, $285-287$ - French corn and bread are inferior to the English, $288-292$ - Caleulating the relative qualities of French and English wheat, the former is the deares, $293-297$ - The corn averages are nore correct in England than in France; in the latter they are below the real prices, $298-300-$ The variation in the price of wheat in different districts is greater in Franes than in England, 301, 302Bread is cheaper in Paris than in London; the Iondon flour trade a monopoly, 303 , 304-The increased cultivation of potatoes is observed all over England; witness does not consider them an exhausting crop, $305-310$ - The monopoly of the London flour trade caused by the wealth of millers and the poverty of bakers; paucity of millstreams reduces competition, 312-318- Returns from inspectors of corn leturns in Scotland and England have ceased; their inutility, 319-322- Scotch and English corn sold in the English market has the averages taken, but with the expense of carriage, $323-328$ The averages are fairly taken, 329-333- The quantity sold in the markets is no criterion of consumption; speculation causes frequent re-sales, which cannot be estimated, $334-347$ The present corn law maintains a certain equilibrium in prices, $34^{8-350-}$ - Eflects of the allotment system in supplying labourers with garden produce instead of bread, 351,352 . 
Report, 1837 -continued.

Jumes, Mr. Evtract from his work, showing how the manufacturers and labourers would derive alvantage from the depreciation of money, Cayley 3672.

Jersey. Importation of foreign grain, Sc., to. See Corn.

Joint Standard. Would improve the condition of the agricultural interest, afford security against panics, and extend the circulation, Langhorne $3770,3771.3775-3782-A$ return to the mixed gold and silver standard of 1797 would be an advantage to the public debtor of 15 per cent., spooner 4391-4399.4404-4409- - The difference of 15 per cent. calculated, Spooner $44+3-4+49-\mathrm{A}$ larger issue of paper might be made with safety with that standard, Spooner $4410-4413$ Justice requires the adoption of the standard of 1797 , as that of 1819 never existed before, Spooner $4+41,44+2$ - It would give the agriculturists from 10 to 15 per cent,; it would not affect the manufacturers, as the exchanges will adjust themselves, Muntz $4536-4546$.

To adjust the value of silver and gold no other law necessary than one which should enable the subjects of the realm to carry themselves bullion to the mint, and have it coined and delivered, at 5 s. $2 d$. to the ounce, Attzrood 5571 .

See also Currency. Gold Standard. Silver Standard. Standard.

\section{JOINT STOCK BANKS:}

1. Accommodation to Farmers and Mamufacturers.

2. Their Constitution, \&c.

1. Accommolation to Farmers aul Mannfacturers.

In Glamorganshire, have given accommodation to farmers upon moderate terms, David 1276 - They accommodate the manufacturers, but refuse assistance to the farmers, Cayley 3603-3605- Reasons why they give assistance to the manufacturing and not to the agricultural interest, Spooner 4419.4504-4506- - They circulate credit freely

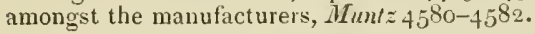

\section{Their Constitution, \&c.}

Have materially increased their circulation in the last few years, Escott 5044Established 1826 for the purpose of serving as a protcction against the recurrence of a panic such as had distinguished 1825 ; a recurrence of the same evils now anticipated fiom that source by the authors of the measure, Attwood 5562 - Extent to which it might be an improvement in joint-stock banks to require them to pay up their capital and limit the amount of responsibility, Attwood 5.594-Such a system cannot be effective without the consent of the Bank of England, Attrood 5599-C.-Opinion as to the amount of additional security occasioned by the number of partners, Attwood 5596 .

See also Mamufactures.

K.

Kendall, Samuel. (Analysis of his Evidence.)-Manages His Majesty's farms, 1075-1077 - Names thereof and quantity of land, $1078,1079-$ They will not make a profit, nor conld any rent be paid, 1080-1088_ The prices of oats and barley do not compensate for the luw prices of wheat, 1089-1093 The farmers are in a very bad state; they cannot make up more than two-thirds of their rent, $1094^{-1098}$ _ For some years they have been paying rent, \&c., out of capital, 1099-1102_-Many of the poor are not employed for want of eapital, 1103,1104 - These observations apply to the country 20 miles round Windsor, $1105^{-1109-A}$ tcnant cannot pay rent upon the best land, $1110-1113$ - The poor are dissatisfied; wages $12 \mathrm{~s}$. a week; have not been reduced for fear of damage to property, $1114-1122$ - The produce of Ireland, both in stock and corn, is a great injury to this country; annual value thereof, 1123-1127.

Bankers will not irust farmers, because they know they are needy, $1128-1130-$ Labourers perform less work than they once did; evils of beer-shops, 1131-1137-The contraction of the circulating mediun in 1829 had some effects on prices, 1138,1139 Much land which grew oats now grows wheat, on account of the importation of oats from Irelaid, and wheat is now imported from that country also, 1140-1 +4 - The allotment system has introduced potatoes and meat instead of bread for food, $1145^{-1} 15^{2}$ -In Sussex the large farmers have much wheat; the poorer have brought it to market and depressed the prices, $1153^{-1} 159$ - The vexations of the excise on malt should be removed, and the duty paid on taking it out of bond for consumption, 1160-1163Cultivation is deficient, and yet there is a superabundance of wheat, 1164-11-0Distress prevails anongst freeholders nccupying their own land, $1171-1172$ - The new Poor Law has reduced the rates in many places, but has driven away the labourers, $1173-1179$ Less wheat nill be grown; farmers will try something more profitable, 1180,1181 . Nlany farmers have left this country for America, $1182-118_{4}$ - The allotment system makes the condition of the labourers much better; half an acre of potatoes will serve a family twice as long as half an acre of wheat, $1185-1191$.

ficuyon, Lord. Conmunicates to the Committee information as to the consumption of wheat of five families on his estate, each having allotments of land; rages of the labourers, $p \cdot 3^{61}$. 
Report, 1837 -continued.

King's Farms. The Flemish and Norfolk farms, near Windsor, will not make a profit, nor could any rent be paid, Kendull $1080-1088$.

L.

Iabour. There would be a less surplus of labour, if agriculture were in a better state, Trumper $317^{1-3174}$; Lscott 4853 -The absorption of labour in manulactures and railroads may render ayricultural labour dearer than the farmer can afford to purchase, Cayley $359.3,3594$ - In Lissex there is not more labour than the farmer requires, Comport 4275 , $427^{6}$.

See also Employment.

\section{LABOURERS :}

1. Their Condition generally.

2. In particular Counties.

1. Their Condition generully.

The effect of dininishing the cultivation of corn will be to throw many out of employment and increase the poor-rates, Waring 128-137- In the soutlueris counties, the labourers, when regularly employed, are better off than they ever were, Thamper $3168-$ $31 ; 0$ - Labourers in full employment are better off now than witness has ever knowu them, Escott 4851 - When emploved are generally well off; but they are paid out of capital, which must be exhausted, Cayley 35800,3581 - Are better paid than they uere during the high prices, when within the influence of manufacturing wages, Spooner $4350-$ 4358 Would be benefited by a rise in prices, Cayley 4184-4186. 4190-4195Condition of labourers as good now as in 1815, Grey 4773- Difliculty of asccrtaining their real condition, Escott $7^{851}$ —-Perform less work than they once did, Kendall 11311137 .

\section{In particular Counties.}

In East Cumberland, better off than others, from various local circumstances, Blamire 5093 .

Devnoshire: Are better off in Devonshire than in most other counties, although wages are low, Bernard $1664-1667$.

Kent: Near Canterbury are better off than they were 30 years ago, Nearne $1468-1471$ - Since the peace many have been out of employment, for whom the farmers were obliged to find work, Nearne $1478-1481$ - If the state of agriculture were improved, the farmers would find employment for all, Nearme $1483,1484-\mathrm{A}$ labourer in constant employment is better off now than he ever was, Douling $288_{1}, 288_{2}$ - The poor farmers have been obliged to reduce the number of their labourers, Waring $13^{8}$.

In Sussex, never lived so well as at present, Hudson 3477,3478 .

In Wilts they are better paid, with reference to the price of provisions, than they ever were, Hughes 3038-3040-- They are allowed orens; they used to pay the baker and small tradesmen 20 or 25 per cent. too much, Hughes 3042,3043 .

See also Allotment System. Beer Shops. Employment. Labour. Malt Tax, I. 3. Migration. Poor. Wages.

Lace and Silk. See Chard.

Lambs. See Cattle.

Land. Acreage of each of the following farms in Northumberland, with the depreciated value of each; viz., Grindon, Gosu ick, Norham Mains, Duddo, Melkington, East Lilburn, Horton, North Earl and Brunton, Langhorme 3729-3737- Difficulty of effecting sales of land; the number of years' purchase is not reduced, Cayley $4 \mathbf{i} 74$, 4175 .

See also Cultivation. Produce. Rents.

Landowners. Are much distressed by the altered value of money, Hodgson 1969-1981 -More distressed in their condition than any other class in this country, Escott 4851 .

Land Tax. Very unequal; land on which towns have been built pay no more than when in cultivation, Spooner 4519__ Should be equalized, Cayley 4153 .

Statement, showing the average rate per pound of the lasid-tax in certain places, upon the rental assessed to the inhabiled house-tax, App. p. 363- Statement, showing the average rate in the pound at which the land-tax is charged in the several counties in England and $\mathrm{W}$ ales, and in Scotland; taking the value at three-fourths of the amount assessed to the property duty in $1815, A p p \cdot p \cdot 364$.

See also Taxation.

Langhome, John. (Analysis of his Evidence.)-A banker at Berwick-upon-Tweed, and has the managenent of a large estate, $36-8-368.2$ The land is exceedngly good, and the local burthens altogether only $2 s$. in the 1 ound on real value, $3683-3692-$ The tenantry ale the best faimers in the kingdom, and of Jarge capital, 3693,3694 - (in 464. 
Report, 1837 -continued.

Langhorme, John. (Analysis of his Evidence)-continued.

strong clay soils they are losing money, and paying rent out of capital, $3695-3699-$ WIitness never advances money for the payment of rent, as the landlord can distrain, and he cannot, $3700-3703$ The arrears are about one-fourth of the rent, $3704-3708$ The famers overdraw their accounts, according to the extent of their farms, giving bonds, with two securities, 3709-3711- The Scotch notes increase the general circulation, and do good to the public, $3712-3728$.

Names of several farms in Northumberland which have been depreciated in value, 3720-3734 - The land has not been deteriorated, during the leases, to any extent, 3735-3737- When the leases were granted prices were three times as high as they now are, $373^{8}, 3739$ - Produce of the land per acre, $3740-374 ?$ - Estimate of the proceeds of a farm of 300 acres of turnip-soil, manazed under the fifth-course rotation of husbandry, 37+3-37+5- Examination relative thereto, $37+6-3755$ - There is no surplus population, 3756,3757 -Unless prices are raised the farmer cannot go on, 3758 .

The main cause of low prices is the contraction of the currency; ratio of this contraction in Berwick, 3758-3765-Bankers are not anxious to increase their circulation, $3766-3769-$ A donble currency of gold and silver would improve the condition of the agricultural interest, 3770,3771 - The failure of Mr. Mowbray's bank was caused by lending large sums to speculators in mines, $377^{2-377+}$ - The adopion of the joint standard would afford security against panics, and extend the circulation, $3775-3782$ Departures from the Bill of 1819 , in issuing notes, $3783-3791-$ When the small notes were called in, in 1829 , bad seasons delayed the fall of prices, 3792-379.4-The state of the farmer has been depressed since 1815 , with each restriction of the currency; since 1819 it has been getting worse and worse, $3795-3804---1$ hether seasous have been good or bad, there has been the same result, which shows that some other cause than production must be in operation, $3805-3811$.

Importations from Ireland contribute to increase the depression of prices, $3812-3816$

The corn laws for the present are a dead letter, $3^{817}, 3^{518}$ - The Bank of Fngland branch banks bave contracted the circulation of other banks, by taking their notes in for cash, $3819-3831$ - They will not give accommodation to farmers on any security which they have to offer, $383^{2}, 3^{8} 33$ - There would be vely great objection on the part of country bankers to give security for their issues, $383+, 3835$-Comparative circulation of notes by the Bank and country bankers, at different periods, $3^{8} 3^{6}-3^{8} 39$ - The amount of gold in circulation is much overrated, $38+0-38+6$ - The country bankers would prefer Bank of England one-pound notes to an issue of their own, $38+7$, $38+8$ - Wages are $10 \mathrm{~s}$. a week in Northumberland; the farmers' servants are paid in kind; conditions upon which Lord Tankerville hires bis labourers, $3^{8}+9^{-} 3^{8} 51$ - There lias been no discontent; the system gives the labourer an interest in the produce of the farm, $385^{2}-3^{8} 54$.

\section{Leadenhall Market. See Beef. Butter. Cheese. Mutton. Pork. Veal.}

Leases of Greenwich Hospital Estates. Description of leases granted to tenants by Greenwich Hospital, Grey $+705-7709$.

Leicestershire Statement from Parliamentary Returns of the comparative contributions to local taxation of the agriculturists and manufacturers, Wilson 1757-1 763 - Paper, showing the unequal assessment of mamufacturing and agricultural property therein, Ev.p. 154 _ Statement of the number of machines engaged in the hosiery and glove trade in Leicestershire; also the number of persons employed and their average clear earnings, if in full work, $E_{v} \cdot p \cdot 156$.

Lezin, John. (Analysis of his Evidence.)-A farmer and miller, at Wickham Market, in Suffolk, 914-917_-The state of agriculture in that part of the country is very much distressed, 918, 919 - The distress began in 1815 ; was not so great in 1816, but increased in 1821 and $1822,920-924-$ Prices rose in 1823 ; variations until 1828 , 925 - Average from 1828 to 1831 ; the seasons and crops were good, 926-930- Prices fell in the following years; there were good crops of wheat, but a scarcity in other corn, 931-935-C Years in which Woodbridge and Framlingham markets were glutted, $936-9.12$-The state of the farmers is dreadful; their poverty has driven them to the markets, and has depressed prices, 943-945_Rents have been reduced from 20 to 40 per cent. in the last 15 years, $9+6-949$ - They are not higher than they were in $1793,950,951-$ Farmers cannot pay their rent and wages if prices remain the same, $95+$ - There are masy instances in which opulent and prudent rate-payers have becone paupers, 955-959-Nany of the poor are out of employment; rate of wages, $960-063$.

The depression of prices arises from the contraction of the currency, 964-966Proposed alterations in the corn laws for the protection of farmers, 967-981 The avelages should be taken in Ireland, and from the farmer, 982 - The importation of foreign corm, whou prices are ligh, keeps English corn from the market, $983-989-$ Disadvantages of the warelousing system to the farmers, 990-1008-For the last eight years the condition of farniers has becn growiln worse and worse, $1009-1015$ 


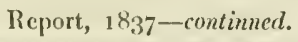

Lewin, Jolin. (Analysis of his Fvidence)-contiuued.

Every expansion of the currency since $179^{6}$ has been suceceded by a rise of prices, 1016-1023-There is always capital for speculation when prices are low, 1024-1027 The Bank of England regulates the circulation of other banks, and affects prices, 1028-1036- - After four year's' bad crops, $40 \mathrm{~s}$. would be a fiar price for barley, 1037 1043 - Neiller the price of batley nor meat is satisfactory, $1044-1046$ - The price of wool is fair, 1047_-Currency has affected wheat more than other articles, because there has been a full crop, 1048-1051_L_ L rish corn will reduce the price of our own, and the allotment system and the poor laws will make our poor live upon potatoes, $1052-105^{8}$ - Injurious operation of the new Poor law upon the labouring clisses, 10.59-1063 _. The rates liave not been reduced in some parishes; reductions were effected by giving employment, before the new system was introduced, 1064-1074.

Liabilities of the Bank. See Bank of England.

Liverpool. Price of wheat in the market, Hodgson 1982-1988-_-Irish wheat is of the most general consumption, Hodgson 2032-2034- Irish corn is geuerally consumed there, Saudars $3978-3981$.

See also Cattle. Importations.

London Police. Beneficial effects of employing the London police in repressing disturbances in Norfolk, Carter 2975 .

Lowland Farmers. See Farmers, 2.

Luton. See Poor Rates.

Lym. Price of wheat and barley in the Lynn market in 1823,1824 and 1825, Carter 2953 , $2954-$ In 1833 and 1834 , Carter $2055^{-2958 .}$

M.

Machinery. Effects of the introduction of machinery upon the rural population; in Glamorganshire women were generally clothed in stuff of their own making, David $1267-$ 1271 - Has taken away the employment of women and children in spinning in Leicestershire, Wilson $177^{2-1} 774$.

MALT TAX :

I. Advantages in repealing the Malt Tax.

1. Generally.

2. Farmers.

3. Labourers.

II. Advantages to Farmers in being enabled to malt their own Grain for Cattle.

1II. Substitutes for Taxation in case of the Repeal of the Malt Tax.

IV. Alterations in Duty or Mode of Collecting.

I. Advantages in repealing the Malt Tax.

1. Generally.

Advantages of repealing the malt-tax, Bennett 513,$514 ;$ Allnatt 908; David $1288-$ 1291; Firchild 1393-1395. 1411-1420; Wilson 1805; Cooper 2708; Dorcling 2777-2780. 2825-2S27. 2853; Thurnall 2393-2396; Carter 2976; Hughes 3107, 3108 ; Trumper 3224 ; Taylor 3366, 3367; Cayley 4150,4151; Grey 4729; Sherbome 4846; Escott 4998 The repeal of the malt duty would improve the value of all agricultural produce, Duvid 1288-1291 The advantages would be increased consumption of barley, and the removal of the monopoly occasioned by the excise laws, Firchild 1393-1395.1411-1420-_Unless the whole be repealed, the excise jurisdiction contiuues, Dowling 2853-Beneficial effects of repealing the duty, or permitting the farmers to malt for lome consumption, Thurnall $2393^{-2396}$; Hughes $3107,3108-$ No other article is taxed so bighly; the maltster will only buy the finest barley, Trumper 3228,3229 - Would be a benefit to the landlord, the tenant and the public, Taylor 3366 , 3367 .

2. Farmers.

The total repeal of the malt-tax would be of great benefit to the farmers, Bemett 513 , 514 - The removal of the malt-tax would be a great relief to famers; it would stimulate the barley trade, by increasing consumption, Allnatt 908-913- - The severity of the excise laws, rather than the amount of duty, prevents farmers from malting, Firchild $1404-$ 1410 - To enable the farmer to malt for his own consumption would aflord great relief, Wilson ${ }_{1} \mathrm{SO}_{5-1807}$ - Partial remission would be useless to the farmer; a total repeal would be a great benefit, Dozeling $2777-2780.2825-2827$ Would be a benefit both to the farmer and labourer, Cooper 2708, 2709; Carter 2976-2980; Trumper 3224-3227Extent to which the repeal of the malt-tax would be bencficial to farmers, Grey $4729-4732$ - Repeal of the malt-tax would afford very substantial relief to the agricuhurist, Escott 4998-5003.

3. Labourers. 
Report, 1837 -continued.

Malt Tax: I. Adrantages in repealing the Malt Tax-continued.

3. Labourers.

If malt were free of duty labourers would brew their own beer, Firchild, 1396-1 399 Would induce farmers to supply their labourers with beer and increase the consumption, Doxling 2905, 2906 — The poor would brew their own beer, Hughes 3106 Would enable farmers to supply their labourcrs with beer, and their cattle with inferior barley malted, Sharpe 3902-3910 - Farmers would find it useful to provide their labcurers with beer, if the malt duty was repealed, Escott 5005 .

\section{Adrantages to Farmers in being enabled to malt their oz"n Grain for Cattle.}

NIalt would be the best food for fattening cattle, Bennett 520,521 - It would be very beneficial to farmers to permit them to nalt their own barley for their cattle, Allnatt $905-907$ Advantage to the farmer in malting his own grain as food for cattle, Spooner 4295-4301.

\section{I. Substitutes for Taxation in case of the Repeal of the Malt Tax.}

The revenue might be compensated by a duty on foreign flax and tallow, Cayley 41794181 - A sufficient duty might be raised on cotton, hemp, flax ind tallow to supply the deficiency to the revenue, Spooner $4311-4322$.

\section{V. Alterations in Duty or Mode of collecting.}

The vexations of the excise on malt should be removed, and the duty be paid on taking it out of bond for consumption, Kendall 1160-1163 Should be transterred to beer brewed for sale by retail, Spooner 4303-431

See also Barley. Bcer Bill. Beer Duty.

Malthus, Mr. His opinion (1815) that when corn should fall to $50 s$. a quarter and labour in proportion, that the stock-holder would be benefited unfairly at the expense of the prosperity of the whole country, Escott 5079, 5080.

Maltsters. Do not trade with the capital of duty; there is not much competition in the trade, Sharpe $3916,3917$.

See also Averages.

Man, 1sle of. Importation of foreign grain, Sc., to. See Corn.

\section{MANUFACTURES :}

1. Causes of their Prosperity.

2. Ertent thereof.

3. Influence of a Change of Currency upon their Condition.

\section{Causes of their Prosperity.}

The mutual interests and dependence of manufactures and agriculture examined, Cayley 3606-3614 - Their prosperity ( $\mathrm{March}$ ) arises from the large issues of joint-stock banks, Cayley $3603-3605.3645,3646$ - Have been prosperous while agriculture was distressed, Spooner $4+97-4503$ - Joint-stock banks operate directly upon the former, and only indirectly upon the latter, Spooner $4504-4506$ - Circumstances which coutribute to their prosperity during the depression of agriculture, Cayley $36+8-3650$ - The advance in price (March) arises from the increased issues of the Bank and of joint-stock banks, Spooner $4420-4+23$ - Causes of the rise of prices; it is confined to the raw materials, Munt $\approx$ 4526-4530 - Grounds for anticipating a short continuance of manufacturing prosperity, Munt $z 5591$.

\section{Extent thereof.}

The condition of the workmen is very good; the master manufacturer is making very moderate profits, Munt $z 523,45^{2} 4-$ The manufacturer has lately been able to dispose of his stock very readily, but profits have not been large, Mluntz $4596-4601$ -The advance in the raw materials will affect many trades, Munt 4602 .

\section{Influence of a Change of Currency upon their Condition.}

An increased price of agricultural produce (by an extension of the currency) would not affect the export of manufactures, Spooner 4414- -The goods would be sold abroad as cheaply as before; their nominal price in this country only would be changed, Spooner 4415-4417 No depreciation of the currency would affect them; the advanced prices of the goods abroad would be counterbalanced by the exchange falling in proportion, Munt 4626,4627 - When there is a general rise in the prices of inanufactures exports cease and prices are depressed, Muntz 4593-An enlargement of the standard would operate on the price of manufactures as well as prices of corn, 1 tt wood $55^{8} 9$.

See also Birmingham. Pour-rates, 2. Taxation. 
Report, 1837 -continued.

Manure. The farmers in Suffolk cannot afford to buy so much artificial manure as their lands require at the present price of produce, Cooper $2683-2680$ - Cost of manure per acre in Niddlesex, Sherborne $+823,4924-$ - Manner in which it is procured from London; cost of each cart or waggon load, Sherborne $4836-4840.4844$ The use of artificial manure, bones, \&c., las been introduced with great profit into the East lidingr of Yorkshire, Hoz"urd 2190-2197.

See also Bone Manure. Cultiration.

Maık-lane. See Averages.

Meal. See Flour and Meal.

Meat. The price is raiser by the low price of tallow, Grcen 202-206-The improved price is cansed by the failure of the tumip crop, Caylen $3620 \ldots$ The prices in the London market have not been remunerating to the yraziers, Wilsun 1720-172,j.

Melkington. See Land.

Middlemen. System of middlemen much on the decrease in Armagh, Blacker 5632 .

Migration. The fluctuations of trade render the migration of labonrers to the manufacturing districts a questiomable advantage, Cayley 3586 - Many have left the poor-law unions to seek emplovment elsewhere; the reduction of rates is not a proof of more employment, Cayley 3589-3592- - Evidence as to migration of labourers from Somersetshire, Liscutt 4935 - Explanation of former evidence on the subject of migration of labourers, Escott 5051.

Millers. See Averages.

Montesquicu. Extract concerning the depreciation of money by the Romans during the first and second Punic wars, Cayley 3654 - Extract on the effects of contraction and expansion of the currency upon the Koman empire, with reference to Lixation, Cayley +129 .

Mortgagees. The small mortgagees still continue to pay the old rate of interest in many instances, Cayley 4117-4121.

Mowbray, Mr. Causes of the failure ol his bank, Langhorne 3772-3774.

Mules. See Cattle.

Muntz, George Frederick. (Analysis of his Evidence.)-Amerchant in Birmingham, 4521, 4522 - The condition of the workmen is better Ihan witness lias ever known it, lhough the master manufacturers are making very moderate profits, $45^{23}, 45^{24}$ - - The merchants are embarrassed by orders from abroad for goods, the prices of which have risen since the patterns were sent out, $45^{2} 5$ - Causes of the late rise of prices, $4526,45^{27}-$ The price of raw materials, not of manufactured articles, has risen, $4528-4530$ - After the panic most manufactured articles were reduced in price, 4531 - The prices of provisions have never fallen in proportion, except, of late, wheat and potatoes, 4532 - The consumption of these has not diminished, 4533,4534 -Explanation of the causes of the low price of corn, 453.5 .

The effect of a inixed standard of gold and silver at the present standard wonld be to give to the agriculturists from 10 to 15 per cent.; it woukd not affect the manufacturers, $453^{6}-453^{8}$ — There should be a silver standard alone; but payments might be made in gold, 4539-4543- Any elevation of the standard which is best for the agricultural interest will not be injurious to the manufacturers, as the exchanges will adjust themselves, $4544-4546$ - Mode in which a depreciation of money would assist the agriculturist who owes nothing, $4547-4557-$ One half of the landed proprietors have no real interest in the land, but have to pay the interest of their debts, $455^{8}, 4559$ - In considering the relation between debtor and rreditor, the advantage which the latter has gained by the improved value of money should be taken into account, $4560-4562$ - The intermediate tradesmen who sell articles to farmers have not reduced their prices, although the manufacturer supplies them at 50 per cent. less than he did, 4563 .

The burthen of taxation is greater now than during the war, $45^{6}+-$ The taxes which press most heavily are those on bread, malt, tea and other necessaries of life, 4565,4566 - Average wages of workmen at Birmingham; they have remained nearly stationary for three years, $456,-4575$ - The deposits in the savings bank have greatly increased, 4576,4577 - The moral condition of the people of Birmingham is improved; there is less drunkenness, 4578,4579 - The joint stock banks circulate credit freely amongst the manufacturers, $4580-4582$ - There is inuch greater facility than at the time of irredeemable paper, $4583-4585$ _ Since the alteration in the usury laws, many transactions have taken place at seren-and-a-half per cent. interest, $45^{86}$ - The employments of workmen at Birmingham are generally healthy; they live in separate houses, $45^{8} 7$, $45^{88}$ - Average rent, $45^{89}, 4590$.

Grounds for anticipating no long continuance of manufacturing prosperity, 4591A rise in the price of provisions is of no consequence, if provided for by an alteration of the standard, 4592 When there is a general rise in the price of manufactures, exports 464 . 
Report, 1837-contimued.

Muntz, George Frederick. (Analysis of his Evidence)-contimued.

cease and prices are depressed, 4593-Examination of the comparative effects of the corn law and of a depreciated currency in raising prices, $4593-4595$ - The manufacturer has lately been able to dispose of his stock very readily; but profits have not been large, 4596-4601 - The advance of the raw material will affect many trades, 4602 - Many articles of Paris manufacture excel those of Birmingham, particularly such as require much manual labour, $4603-4607$ - Cutlery is manufactured at st. Etienne, 4608 Wages at Paris are from 30 to 50 per cent. lower than at Birmingham, $4609-4611$.

There should be no irredeemable paper, 4612-4615-If Parliament think fit that wheat should be $\delta s$. a bushel, the silver standard should be $8 \mathrm{~s}$. an ounce, and the corn laws would be virtually repealed, $4616-4625$ - This would make no difference to the manufacturers; the advanced price of their manufacture on the Continentwould be counterbalanced by the exchange falling in proportion, 4626,4627 -Seventy-five persons out of the hundred would derive benefit from the change in the currency, and their interest shonld be preferred to that of the minority, 4628-An alteration of the standard was the only measure that could have continued the prosperity of 1824 and $1825,4628,4629$ - The Bank should be permitted to issue one-pound notes, and to pay their notes at the market price of goid, instead of a fised price, 4630 .

Mutton. Account of the prices of mutton at Smithfield and Leadenhall Markets for each of the years from 1815 to 1835 , both inclusive, $A p p \cdot p \cdot f 00$.

National Debt. See Sinking Fund.

Nearne, Mr. Jolm. (Analysis of his Evidence.) Has been for some years steward to several noblemen and gentlemen near Faversham and Canterbury, 1433-1437-- The occupier of poor land has lately been better off than the occupier of good laud, $1438-1440-$-Until lately they paid their tents out of capital, 1441-1444-- When they have depended upon the growth of corn, they have suffered much, $1445^{-1}+47$ Their condition is generally very bad; they are in want of capital, $1448-1451$ Tithes are frequently taken in kind, $145^{2}$ - Last year the farmers made enough 10 pay their rent, labour and the interest of capital, $1453^{-1} 456$ - Prices have been progressively lower; injury to farmers of good wheat land, 1457,1458 - Rents have been reduced from 10 to 20 per cent. since $1822,1459-1467$ - Average wages; labourers are better off than they were 30 years ago, $1468-1471$ - The expenses of the farmers have increased in the last 20 years, $1472-1477$ - Since the peace niany labourers liave been out of employment, for whom the farmers were obliged to find work, $1478-1481$ - There have been several fires in witness's neighbourhood, $148: 2$ _ If the state of agriculture were improved, the farmers would find employment for all the labourers, $1483,1484-$ Variation in the price of wheat since $1822,14^{8} 5-149^{2}$.

Norfolk Farm. See King's Farms.

Norham Mains. See Land.

North Earl. See Land.

O.

Outs. Remunerating price in average seasons, Sharpe 3901 Should be 34 s. a quarter to make their growth profitable to the farmer in Suffolk, Cooper $2659-2665$ - In Sussex the price has been fair but the crops deficient, IIudson $3+17-3+19$ - Great quantities of Irish oats are imported into Brighton, Hudson 3396-3399-Large importations of oats from Ireland haveled to an increased cultivation of wheat in England, Hodgsom 1878-1884 -Will be used in Ireland for distillation when the price of wheat rises, Sandars 4036,4037 .

Quantities imported into His Majesty's colonies in America, \&c., from foreign parts in each of the years from 1815 to 1835 , both inclusive, App.p. 366,367 - Average prices of, at Mark-lane, from 1815 to 1835 , both years inclusive, App. p. 370-391-Account of foreign oats brought into consumption in Great Britain from 1815 to 1835 , App.p. $39^{2}$ - Similar return for oats, other than foreign, for the same years, App.p. 393-399.

Oil-cake. See Cattle.

One-pound Notes. See Burke, Mr. Currency.

Orpington. The poor are very discontented, and there have been many incendiary fires, Waring 114-117.

Over-cropping. Many landlords have been paying their own rent by the land being run out, Cayley 4147,4148 - In the southern counties the land has been too much forced in order to grow wheat, Trumper $3146-3149$ - This was occasioned by the distress of the farmers, Trumper 3150-3154-Many farms in Wales which were in a flourishing state have been reduced by over-cropping, occasioned by the distrcss of the tenants, Bradley $2556-2560$. 
Report, 1837-contimued.

Over-production. Whether seasons have been good or bad the farmers have bcen equally listressed; some other cause than production must therefore be in operation, Langhorne $3805-3811$.

See also Prices, 11. 5 .

Orfordshire. See Wages.

\section{P.}

Panic. The panic of 1825 was caused by an over-issue of paper upon too contracted a standard of valuc, and was the occasion of the law restraining the issue of one-pound notes, Cayley $3634-3638$ - Value of a silver currency in protecting the Bank during a panic, Cayley 3671 - A silver standard would give sccurity in times of panic to the monetary system, beyond any security which the present system promises, Attwood 5601 .

Paper Currency. No limit to the extent to which paper currency might go, were it not for the liability to pay in some metallic standard, Pattison, $5+45$.

See also C'urrency.

Parliament. Relief is expected from the Parliamentray inquiries, and if nothing be done the farmers will be in a state of desperation and despondencv, Thurnall 2285, 2286 In Glamorganshire the farmers are in great expectations of assistance from Parliament; they cannot hold their farms unless their expenses be diminished or prices raised, Bradiley $2478-2483$.

Pasture. In Berkshire much land would be converted into pasture if it conld be done with less difficulty and expense, Allnat 864,865 .

Pasture Farms (Somerset). Bear a much higher rent than arable; if good land, from $2 l$. to 3 l. per acre, Escott 4877 .

See also Farmers.

Patrick, St., Assurance Cumpary. Conduct of many shareholders of St. Patrick's Assurance Company on being threatened with actions for the debts incurred by the company, Attwood $559^{8}$.

Pattison, James, esq., ı. P. (Analysis of his Evidence.)-Member of Parliament for the City of London, 5303 - Governor of the Bank, 5304-Evidence as to the Act for the new silver coinage, $1816,5306-5314$ - Pressure on the Bank in 1825 from the drain for gold, 5315-5322-Considerable profit made by the person who brought back gold to the Bank, 5323-5325 - Run for gold on the resignation of Lord Grey, 1832, 5333 - Evidence on the subject of foreign payments by a silver standard, $5347-5359-$ Unwise in this country to ehange the standard, 5360 - Amount of the liabilities of the Bank, 5363-..-Silver coin now used as small ehange; Bank always glad to purchase silver butlion, 5371 - Bank purchased, between 1830 and $1834,3,500$, o0o $l$. of silver, 5374 - Publication of Bank accounts commenced 1834 , under the present charter, 5377 Amount of bullion, May $183^{6}$, in the Bank 7,600,000. , of which $500,000 /$. is silver, 5375-5379 — Evidence as to the amount of bullion in the Bank at former periods, 5388-5393-Quantity of gold taken from Europe by America, 5394, 5395-Operation of the shipment of gold for Portugal, which was often returned by the next packet, 5396 - Government holds the silver coinage in its own hands, 5404 - Profit cannot be made on gold by individuals coining, 5405-5407_- Seignorage on gold might be useful, could it be effected without altering the value of the coin, 5410 -Evils of altering the currency, 5415 .

Price of gold can uever rise as long as the Bank continues cash payments, 5417-5419 When exchanges are against this country there will be a demand for gold, $5420-1$ Measures necessary to be taken by the Bank would diminish the circulation, and a reduction of prices would follow, $54^{21}$ - Effect on country and juint-stock banks of the operation of the Bank of England, 5422-5426_- Fall of prices since 1820 accounted for by the change from a paper to a metallic currency, 5430 - Prices now generally too high; in a more satisfactury state last year, $5434-5439$ - Witness has entertained an opinion that the cry of agricultural distress has been greatly exaggerated, 5440 - Further evidence as to the value of gold or silver as a standard, 5447 .

Agricultural distress cannot have originated fiom any circumstance connected with the currency, 5462_- Present currency mixed, metallic and paper; latter convertible on demand into the former, which renders the currency as nearly a metallic one as could well be devised, 5469-- Evils which would arise from any change in the currency; change even for a more perfect system not desirable, 5472--Evidence as to amount of bullion held by the Bank, at different dates; proportion of silver and gold, $5478-5489$ -Great anxiety on the part of the Bank to avoid fluctuation, 5490-5493--Bank are not now restricted to gold only; the silver is not the standard by law, it has an inflnence upon the exchanges when sold as bullion, and answers almost every purpose of a second metal, 5494. 
Report, 1837 -contimued.

I'ultison, James, esqi., 1. 1.-(Analysis of his Evidence)-contimuerl.

Further evidence as to comparative advantages of gold or silver currency, 5495-5506 - Bank of England does not negociate foreign bills of exchange, 5507-Beconies the purchaser or seller of bullion according to the rates of exchanges, 5507 - Alteration of currency in 1810 had an effect on prices, 5.5 16 - - Had the state not effected the change in $1 \mathrm{~S}_{10}$, they would have been called upon to do so at a later period, 5517 There has been no departure from the metallic standard since 1819,5522 - - How far prices of agricultural prodnce might be effected by supply, independent of currency, $5.5-9-5537$ - The establishment of a gold standard (1816) was the best measure that could have been arlopted, $55+2$.

l'eas. Consumption thereof in Somersetshire, Summers $5260-$ Quantities imported into Hlis Majesty's colonies from different parts, in each of the years from 1815 to 1835 , both inclusive, A pp. p. 366, 367- Average prices of, at the market in Mark-lane, from 1815 to 1835 , both inclusive, App. p. 370-391- - Accomnt of foreign peas brought into consumption in Great Britain, from 1815 to $18_{35}$. App. p. 392--CSimilar return for peas, other than foreign. during the same years, App.p.393-399.

I'ecl's Bill. See Cash Payments Bill.

Peyton, Mr. R. (Analysis of his Evidence.)-Concerned in the valuation of land, and has the management of estates in several counties, 1493-1496-The occupiers of poor soils are in a very had condition; they pay rent out of capital; many have been ruined, $1497^{-}$ 1502 - Their failures arise from their expenses and the low price of produce; sometimes from want of skill, $1503^{-1507-T h e ~ o c c u p i e r s ~ o f ~ g o o d ~ l a n d ~ c a n ~ m a k e ~ a ~ p r o f i t, ~} 1508$ 1511 The causes of low prices of wheat are excess of cultivation and importations from Ireland, $1512-1526$ - The chalk lands had more than an average crop last year, 1528-1530- The farmers of the South Downs are better off than they were in 1822 , 1531,1532 -Clay lands are the most expensive to cultivate, 1533,1534 - Good land may be cultivated on the four-course system without fallow, 1535 - There is very little difference in the tradesmen's and artificers' bills, compared with the war time, $1536-$ $1539-$ Average rate of wages $10 s$. a week, 1540-15 $57^{2}$.

Many tenants have thrown up their farms of late, and the value of land is depreciated, 1543-1545- - There is a difficulty in getting tenants, $154^{-1}-154^{8}$ - Nature of valuations taken on a tenant quitting his farm in Kent, Sussex, Sc., 1549, 1550-Although rates have been reduced, farmers have been losing for the last 20 years, $1551-155_{6}$ The poor rlo not live more on potatoes than they did, but they consume more wheat, 1557 -Cattle have been fed on wheat during the low prices, 1558,1559 - Rents of cottages have fallen when they belong to estates, but not if the property of speculators, 1560,1561 Large quantities of oats, beef, pork and bacon have been imported from Ireland, as well as wheat, $1562-1566$.

Pigs. Have been sold in the London market at a loss of 15 per cent., Thumall 2408 . See also Allotmient System. Cattle.

Pilkington, Mr. Assistant Poor-law Commissioner.-Extracts from his report in 1833 , on the unequal assessment of agricultural and manufacturing property in Leicestershire, Liv. p. 1.55 .

Pitt, Mr. Reference to his opinion given in evidence before a secret committee, Spooner 4391. 4509 ; Escott 5080.

Ploughs. In Armagh tenants join together and have ploughs in partnerslip, Blacker 5627 .

Foucling. Increase of poaching in Somersetshire; extent to which poachers are aided by beer-shops; evil consequences of the present game laws, Escott $4049-4955$.

See also Game Laz's.

Poor. In the southern counties the poor have been well employed for the last three or four years by draining, which has been done at the expense of landlords, Trumper 3134-3137 Are dissatisfied near IVindsor, Kendall $111,-1122$ - In Hertfordshire are well off when employed, Sharpe $38,2-3875$ - At Chelsfield (Kent) the poor are tolerably satisficd, as a new turupike-road gives employment, Waring 36,37 - Nany have been out of employment, and work was found on the roads, WFaring $38-42$ - lin some parts of Norfolk many of the poor are out of employment and much distressed, Carter 2959-2961 They are discontented, but are becoming reconciled to the new Poor Law, Carter 2969 .

In the Weald of Sussex, are generally employed, but not with profit to the farmers, Hudson 3388-3390 — In York (East Riding) their condition has improved; many have einigrated to Ameriea, and others have employment in manufactures, Iloward $2132-213$ b.

See also Employnent. Lnbourers.

Soor Iaw (Old System). Abuses of the old Poor Law very materially contributed to the present distressed state of agriculture, Escott 4927. 
Report, 1837-rontinued.

POOK LAW ACT:
1. Generally.
2. Beneficial Effects thereof.
3. Injurious Effects.
4. Administration thereof.

1. Generally.

Caunot be brought into full operation while the present prices continue, Cayley $35^{8} 5$ - Alterations in the Poor Law arc improving the state of the agricultural districts, Grey 4702 The reduction of rates will not compensate the farmer for the losses he is suffering, Comport 4293,4294 .

\section{Beneficial Effects thereof.}

The Poor Law has compelled labourers to seek employment, Treynain $711-713-\ln$ Rochfoud IIundred (Essex) will reduce the rates, and is popular with the well-disposed and industrious labourers, Comport 4264-4270. 4277-4287-It has the effect of giving employment to the poor, and of making then independent, Comport 4272-4274.4288 - In Suffolk a reduction of rates is expected, Cooper $2720-2722-$ - Rates reduced in the Weald of Sussex, Hulson 3400-3404-- In Sussex the poor-rates will be reduced one-third, and in some cases one-half, under the new system, without any severity to the poor, Hudson 3493-3498.

In South Wilts the poor have suffered mucl, but their comforts have been increased hy the new Poor Law, Hugles 3018_-In North Wilts they objected to receive their allowance in bread, Hugles 3019,3020 - - IVitne:ss's opinion as to probable working of the new Poor Law Bill in Somersetshire; formerly felt strongly against it, but now in favour, Escott 4925-Anecdote as to the working of the new Poor Law; its beneficial effects in reducing rates and augmenting the amount paid by farmers for wages of labour Liscott 4976.

3. Iijurious Effects.

It has reduced the rates in many places near Windsor, but has driven away the labourers, Kendall 1173-1179-Injurions operation of the new Poor Law upon the labouring classes in Suffolk, Lewin 1059-1063-The rates were reduced by giving employment before the new system was introduced, Lewin 106.4-1074- In Berkshire the farmers approve of the principle of the new law, but think there is not sufficient discrimination between good and bad characters, Allualt 888-895-The poor will be excited unless their treatment in some places be altered, Allnatt $896-898-$ - ls popular in the East Riding of Yorkshire, with the exception of the bastardy clause, which will increase expenses, Howard 2144-2151.

\section{Administration thereof.}

Suffolk: Steady and industrious people at Blythburgh (Suffolk) are now refused outdoor retief and forced into the workhouse, Cooper $2736-2742$.

Sussex: The workhouse is offered for children when there are more than three, Hudson 3499-They are well fed and educated in the workhouse, Hudson 3505-3507Parents are generally unwilling to part with them; those in the workhouse are mostly orphans and bastards, Hudson $3508-3517$.

See also Poor Rates. Settlentent, Law' of.

Poor Law Unions. Have been used in Suffolk for many years; the rates were generally higher in the unincorporated hundreds, Cooper 2714-2719.

See also Poor Rates.

Pour Laws (Ireland). Doubtful expediency thereof, Cayley 4156-4161-Unless Ireland has poor laws, the condition of the English labourer will be reduced to that of the Irish, Spooner 4368-4374-The tendency of an Irish poor law would be to raise wages and put the labourers in a condition to consume their own corn, Spooner $4375-4381$.

\section{POOR RATES:}

\section{Amount thereof.}

2. Proportions borne by Manufacturers and A griculturists.

\section{Amount thereof.}

The reduction of poor-rates is not a proof of more employment, as many labourers have nigrated from the poor law unions, Cayley 3589-3592-Charge per acre on land in Kent, Waring 59-Difference in the rates since 1823 , when the prices were luw, Wariug $81-84-A$ re $3 s$. in the pound at Whitchurch in Ilampshire $6 d$. will be saved by the union under the poor law, T'zynam 691-698-Amount levied in Somersetshire; Escott 4929 .

\section{Proportions borue by Mamefacturers and Agriculturists.}

Manufacturers do not contrihute their fair proportion, as their stock in trade is not assessed, Bennett 496-499--In Glamorganshire the wanufucturers are not rated in 46.4 .

proportion 
Report, 18:37-continued.

Poor Rates:-2. Properlies boine by Manufacturers and Agriculturists-continued.

proportion to their property, David 1292-1296-Unequal proportion borne by manafucturers in Leicestershire; case of the parish of Wigstin, Wilson 1757-1763- In Leicestershire the wages of manufacturers have been made up out of poor-rates, Wilson $1-68---$ heduced in Luton, Toddington and Haughton Regis, Bennelt, 487-490When trade is bad in the straw-plait business the poor-rates are increased, Bennett $530-534$.

See also Poor Law Act. Poor Law Unions. Taxation, 2.

Population. Calculation of the number of persons in the United Kingdom dependent upon agriculture and upon the export trade, Cuyley 3608.

Population Returns. In agricultural parishes none are described as agriculturists who are not employed in the cultivation of the soil, Rickman 356-359-The column, "all other families," includes the clergyman, the landlord and persons not engaged in trade, Rickman $3^{60-362-D v e r y ~ k i n d ~ o f ~ m e c h a n i c ~ i s ~ c l a s s e d ~ a s ~ e m p l o y e d ~ i n ~ t r a d e, ~ R i c k m a n ~}$ 363,364 - This arrangement does not show accurately the number of families dependent upon agriculture, Rickman $365-3^{67}$ - Distinction between manufacturers and artisans and persons employed in handicraft, Rickman 373, 374-Explanation of the uses and results of the three classes into which persons employed in agriculture are divided, Rickman 375-377.

Portugul. Operation of the shipment of gold for Portugal, which was often returned by the next packet, Pattison 5396.

Pork. Account of the prices of, at Smithfield and Leadenhall Markets, from 1815 to 1835 , App. p. 400- Account of the quantities of, and prices of Irish salted pork contracted for, from 1813 to 1836 , App.p. 401 - Quantity of, bronght into Great Britain from Ireland, 1815 to 1825 , App. p. 406 .

Potatoes:

1. Cullivaiion thereof, whether increased or diminished.

2. Effects upon the Consumption of Wheat by Labourers.

3. Consumption of " Famly estimuted.

1. Cultization thereof, whether increased or diminished.

The increased cultivation of potatoes is observed all over England; witness does not consider them an exhausting crop, Jacob 305-310-_-In Wiltshire are much grown by farmers, Hughes 3064-3066 - Their growth has decreased in the Isle of Thanet, Cramp $762-766$ - Growth of, greatly increased in Somersetshire; people now better satisfied with potatoes than bread, Summers 5246-5250.

\section{Effects upon the Consumption of Wheat by Labourers.}

In many parts of England the poor have changed their food from wheat to potatoes, $J a c o b 269-282$ - The growth of potatoes has increased very considerably, and diminished the consumption of wheat. Benmett 540- - The increased culture of the potato is one cause of the depreciation of wheat, Twynum 622,623-The poor in the counties of Berks, Essex, Middlesex, Surrey, Sussex and Kent, do not live more upon potatoes than they did, Peyton 1557 - Price of bread has very much driven the poorer classes to the consumption of potatoes, Escott 4908.

\section{Consumption of a Family estimated.}

Half an acre of potatoes will serve a family twice as long as half an acre of wheat, Kendall 1185-1 191 - Twenty sacks are sufficient for the consumption of a labourer's family, and for fattening pigs, Hughes $3061-3063$.

See also Allotment System.

Precious Metals. Influx into Europe of the precious metals on the first discovery of America ; its effect on prices and the coinage, Attwood $55^{8} 3-$ Reasons why the prices of corn may not be so affected by the prices of precious metals in some countries as in others, Attwood 5587,5588 .

Presser, The. Description of the implement of husbandry so called; its uses and advantages, Bradley 2547.

PRICES:

I. High Prices.

1. Comparative Periods of.

2. Effect of Appointment of Committees on.

3. High on account of bad Crops.

4. Effected by Currency and Corn Laws. 
Report, 1837 -contimued.

Prices-continued.

1I. Low Prices.

1. Generally.

2. Caused by forced Sales of Agricultural Produce.

3. Cansed by Foreign and Irish Importation.

4. Caused by the State of the Currency.

5. C'ansed by over Supply.

6. Effect of Low Prices on Cultivation of Land.

7. High Price of other Produce no Compensation for Low Price of Wheat.

III. Prices of Agricultural Produce which would remunerate.

1. Iligh Prices.

1. Comparative Periods of.

The difference between the price of wheat and barley in 18.32 and now is equal to witness's whole rental, supposing an equal produce, Benuct 398-405-C-Prices high in 1823 ; variations until 1828 , Lezin 925 -Average from 1828 to 1831 , Lewin 926-930.

2. Effect of Appointment of Committees on.

The appointment of Committees of hoth Houses lıas tended to improve prices, Benuelt 431,432 .

3. High on account of bad Crops.

Barley and oats are high, on account of bad crops, Beruard 1621-1623-CThere were three wet seasons, 1828,1829 and 1830 , in consequence of which prices rose; since $183^{2}$ there have been fine harrests of wheat, and the price has fallen more than that of barley and outs, Hughes 3003-3005.

4. Effected by Currency and Corn Laws.

Comparatise effects of a corn law and a depreciated currency in raising prices, $M u n z$ 4593-4595-Price rose as soon as measures were taken to obviate the coutraction of the circulating medium, Escott 4907 - Effect of the increased circulation of money as a cause of the rise of prices, Escott 5041-Any considerable rise in prices is cenerally followed by a fall in the exchanges, and all may suffer in consequence, Pattison $5+16$ Prices are now generally too high; they were in a more satisfactory state last year, Pattison 5434-5439.

\section{I. Low Prices.}

1. Generally.

The distressed state of agriculture is occasioned chiefly by the low prices, Waring $65-78$ -The complaint of low prices is general, Jarob $263-265$ - All agricultural produce, except wheat, bears the same exchangeable value as it bore 40 years ago; all articles are cheaper, Hodgson 1950-1955- Effect of supply and demand, and of abundance and scarcity of money upon prices, Cayley $3623-3627$-C Causes of the late low prices, diminished consumption, large crops and importation from Ireland, Firchild $13^{\mathrm{S} 6-1392}$ How far agricultural produce night he $\in$ ffected by supply independent of currency, Pattison 5529-5537.

2. Caused by forced Sales of Agricultural Produce.

The porerty of farmers, which has compelled them to part with their wheat, has forced down prices in Bedfordshire, Bennett 500-502_ In Hampshire, Ticynam 608-610_In Suffolk, Letin $943-945$ - The poor farmers are obliged to bring their corn to market, which reduces the prices, Waring 79,80 .

3. Caused by Foreign and Irish Importation.

Effects of the importation of foreign wheat in 1829,1830 and 1831 upon the present prices, Twynain $665-671$; Lewin $983-989$.

Causes importations from abroad and from Ireland, and good crops, Hughes 301 0-3012 - Importations from Ireland, David 1245-1247; Firchild 1386-1392; Bernard 1606; Dowling 2763; Langhorne 3812-3816; Sandur's 39+2-39t6.

4. Caused by the Stale of the Currency.

Fall of prices since 1820 accounted for by the change from a paper to a metallic currency, Pattison 5430-5516-Fall of prices was immediately consequent on the witldrawal of the paper money and the removal of the Bank restriction, Escott 4907-Extent to which prices were depressed by the law of 1819 , Attuood 55.51 - Reasons why, with the present standard of value, prices cannot permanently naintain so bigh a level as before the suspension of eash payments, Attwond 5552 .

The prices of wool, cattle, barley, oats and beans are low, as regards the farmer, by reason of the currency, but high as regards the consumer, in consequence of scarcity Spouner 4427-4429 - The depression of prices arises from the contraction of the currency, licuin $96+-966$. 
Report, 1837 -continued.

Prices-II. Low Prices-continued.

5. Caused by over Supply.

The immense supply canse of low prices, Carter $2934 \longrightarrow$ Good crops a cause of low prices, Hughes 3010 - Attributable to the great produce, Grey 4713 - The present low prices are the result of good crops, not of increased cultivation, Grey 4769 .

6. Effect of Low Prices on Cultivation of Land.

At the present prices land cannot be cultivated with profit in Kent, even in the valleys, Waring 43-47 - Land must be thrown out of cultivation, rents reduced and employment diminished, Spooner 4344,4345 - Strong lands cannot by any system of farming be cultivated with profit at the present prices, Benmett 385,386 - Have been progressively lower; injury to farmers of good wheat land, Nearne $1457,145^{8}$.

7. High Price of other Produce no Compensation for low Price of Wheat.

The prices of other articles are not such as to remunerate for the low price of wheat, Cramp $757-758$ The prices of oats and barley do not compensate for the low price of wheat, Kendall 1089-1093-No agricultural produce is depressed except wheat, Hodgson 1868,1869 .

If the price of wheat bore a proportion to that of other agricultural produce the farmers would not complain, Hughes 3087-3090-IVith average crops the price of barley and oats would be remunerating at a rent of $1 l$. an acre, Hughes $3091-3104$ - The farmers complain of the price of all agricultural produce except wool, Thurnall $2337-23+1-$ The prices of all agricultural produce are really low, but some have been artificially raised by scarcity, Cayley $3620-3622$ - Barley and oats will not compensate for wheat; the quantity produced lias been average, Comport 4231-4233.

III. Prices of Agricultural Praduce vhich would Remunerate.

Wheat should be $64 \mathrm{~s}$. a quarter and barley $40 \mathrm{~s}$, with the existing burthens upon land, Bennett 496-499 - Prices of wheat, oats and barley which would be remunerating, Hudson 3412,3413-Remunerating price of wheat, barley and oats, Sharpe 3899-3901.

See also Beef. Butter. ('ash Payments Bill. Cattle. Cheese. Corn. Currency.

Importations. Mutton. Pork. Sheep. Stock. Veal. Wheat, 2-9. Wool.

Privy Council. Committee of the Privy Council sat in 1816 , for the purpose of establishing a silver coinage ; results of their labours; fallacy of their reasonings, Attwood $55^{6} 3$.

Produce. Estimated value of the gross annual produce of land in England, Cayley 3616 Statement of the produce of wheat in 1834 , in a whole parish in Berkshire, showing an excess of poor-rates and labour over the value of the whole produce, Allnatt 792797. $805-813$.

See also Cultiration.

Prussia. Cause of the great difference which has always existed in the price of corn between Prussia and some other countries and this country, Attwood 5588 .

Punic Wars. See Muntesquien.

Quarter Sessions. See Averages.

Q.

R.

Railroads. Have relieved Bedtordshire from the pressure of surplus labour, Bennett $5^{n} 7^{-}$ 510 - Wages of men emplcyed, Bennett 535-538-Number of persons employed on railroads between London and Liverpool, Sundars 4040, 4041.

See also Canals and Railroads.

Remunerating Prices. See Prices, 3. Wheat, 3 .

RENTS :

1. Rate per Acre.

2. Rents which should be paid at the present Prices.

3. How puid by Farmers.

4. Amount of Reduction already made.

5. Evil Consequences of further Reduction.

6. In Ireland.

1. Rate per Acre.

Average rent of intermediate and good lands in the southern countics, Trumper $3129-$ 3131 - In Glamorganshire 20s. an acre, David $134^{8-1} 35^{1}$; Bradley $2489-2490-$ Average rent in Kent 15 s. an acre, Waring 48. 100-107--In Somersetshire, rate of rent for arable farms, from $1 l$. to $30 s$. per acre, but varies very much, Escott 4869 .

2. Rents which should be puid at the present Prices.

The number of rents which should be made by the gross produce of a farm is an imperfect criterion of profit; four is the general estimate, Thurnall $2342,23+3$ - Land 
Report, 1837 -continued.

Rents:-2. Rents which should be paid at the present Prices-continued.

is not woth any rent at the present prices of corn, Green 225-227-In Bcrkshire all land is over-rented at the present prices, Allmatt 827,828 - A tenaut cannot pay rent for the best lands near Windsor, Kendall 1110-1113-Have been reduced in Cambridgeshire, in some instances, but no farms are worth any rent whatever, Thurnall $2244-2248$ - In East Cumberland have not been reduced to the extent they should have been, owing to the competition for farms, Blamire 5099- - Seventeen shillings an acre could be paid in the East Riding of York, if wheat were 60s. a quarter, and other produce in proportion, Hozard 2225-2229.

\section{How paid by Farmers.}

Although rents have been reduced, farmers have been losing for the last 20 years in mauy counties, Peyton 1551-15.56-Glamorganshire: the tenants have been very backward with their rents, and have not paid then out of profits, Bradley 2432-2435 - The reduced rents cannot be paid, Darid 1226-1228_They are, in some cases barely sufficient to pay the settlements on younger branches of the family, David 12291231 Kent: near Bexley, can only be paid out of capital or by over-cropping, Dowling 2746-2751-Northumberland: the arrears are about one-fourth of the rent, Langhorre $3704-3708$ - Somersetshire: tenants cannot pay rents ; notwithstanding reductions, have been paying from capital, Summers 5134-5144-Staffordshire: tenants are not able to pay their rents, which have been lowered, and many have left their farms, Finchild $1359^{-1367-\ldots}$ Yrkshire: are better paid than they ought to be, for tenants pay them out of capital, and leave their bills unpaid, Cayley $357^{2}, 3573$ - - If landlords pressed for arrears, few tenants could pay them, Cayley 3575 .

\section{Amount of Reduction already made.}

Have been reduced, in some cases, from $400 l$. to $100 l$. a year; in others, tenants bave been paid to take a farm, Cayley 3576-3578-In the southern counties have been reduced, since 1812 , from 30 to 40 , and in some cases 50 per cent., Trumper 3193,3194 Prices at which rents have been settled, Trumper $3195,3196-$ If prices remain the same, a further reduction of 15 per cent. will be necessary, Trumper $3200-3202$. 3219,3220 - Some of the poorest clay lands require a reduction of 100 per cent. Trumper 3207-3212-Have been reduced from 10 to 20 per cent. since 1822 , Nearne $1459-1467$.

Bedfordshire: have been generally reduced, Bemett $393-397$ _ But farmers cannot meet their engagements, Bennett 418-422 - Dezonshire: witness's rents bave been reduced 40 per cent., Bermard $1641-1645-1]$ aking allowances for improvements, the rental is much the same as before the war, Bernard 1659-1663 Dursetshire: have not been much reduced, Taylor 32;2-32;6-Glamorganshire: have been reduced from 10 to 25 per cent., Daxid $1223^{-1225}$; Bradley $2489,2490$.

Greemich Hospital: rental amounts to $30,000 /$ per annum, Grey 4633 - Farms varying from $500 l$, to $1,300 l$. per annum, Girey +636 - Reductions which have taken place in the rent of the farms, Grey $4645-4648$ Hampshire: Twynam $562-573$.

Leicestershire: have been reduced from 10 to 15 per cent., and the farmers still complain, Wilson 1742-1752.

Somersetshire : extent of reduction in rent which has taken place generally in Somersetshire, as conipared with dear times; on witness's property to the extent of 50 per cent. Escott $4870-S u f f o l k$ : have been reduced from 20 to 40 per cent. in the last 15 years, Leuin 946-949-Are not ligher than they were in 1793, Lexin 950,951 - From 12 to 18 per cent., Cooper $2643-2649$ - Are ligher than they were in 1793 ; they are too high, as tenants hope to gain the profits of unexhausted improvements, Cooper 2728 2729 Rents ought to be higher than at that period, as landlords have expended capital, improsed drainage, fencing, \&c, Cooper $2730-2735-$ Sussex : have been reduced, in many instances more than half, since 1814, in the Weald, Hudson 3449-3452 On the down farms one-third. Hudson 3455- South Hilts: fron 10 to 25 per cent., Hughes 3049, 3050-East Riding of Yorkshire: in some estates rents have been reduced 30 per cent., and improveusents made by landlords, making the whole equivalent to a reduction of 45 per cent., Howard 2072-2074.

\section{Ezil Consequences of further Reduction.}

Further reductions of rent will diminish the means of the landlord to make improvements, and increase the poor rates, 'Tuylor 3368, 3369- Evil effects of any attempt to relieve agriculturists by a further reduction of rents on small and moderate landholders,
Escolt 5028 .

\section{In Ireland.}

Have not fallen in lreland, Sandars 3976,3977 - Are as bigh as in England; the Jandlord has a large proportion of the produce, Sandars 3963-3982-In many instances higher for the same quality of land, Blacker 5635-5637-Rents in Armagh higher tlian in other parts of Ireland, Blacker 5628.

See also Capital. Clay Lands. Cotlage Rents. Farmers. Holderness Country.

464 .

Rick-burining, 
lieport, 1837 -continued.

Rick-luming. See Fires.

Rickman, John. (Analysis of his Evidence.)-Prepared a table of the population, divided in to the agricultural and manufacturing classes, 353- It was collected from the answers of overseers, $354,355-$ In agricultural parishes none are described as agriculturists who are not employed in the cultivation of the soil, 356-359-The column, " all other families," includes the clergyman, the landlord, and persons not engaged in trade$360-362$ - Every kint of mecbanic is classed as employed in trade, 363,364 — This arrangement does not show accurately the number of families dependent upon agriculture, 365-367- Although the per centage of agricultural families appears to have decreased since 1811 , it arises only from a different mode of conducting the inquiry, $368,369-\ldots$ Tables and calculations to ascertain the real proportion of agriculturists to other classes, $370-372-$ Distinction between manufacturers and artisans, or persons employed in handicraft, 373,374 - Explanation of the uses and results of the three classes into which persons enployed in agriculture are divided; calculation of the number of males engaged in the cultivation of land, $375-377$.

Rochford Hundred (Essex). Number of acres of land in the landlords' hands whose tenantry have thrown up farms or failed, Comport 4213 - The poor are well employed; the land in a good state of cultivation; rents moderate and tenants prudent and skilful, Comport 4214-4226-It is considerer the garden of Essex, Compori $4252 \ldots$ Produce of 90 acres of land in 1833,1834 and 1835 upon the six-course system, Comport 4234,4235 .

Rot. See Shrep. Wool.

Russia. Extract from Dr. Pinkerton's work, showing the state of Russian serfs, in referemse to the cheapness of foreign labour, Sandars 4096.

Rye. Quantities imported into His Majesty's colonies from different parts in each of the years from 1815 to 1835 inclusive, App.p. 366, 367-Average prices of, in the market at Mark-lane, from 1815 to 1835 , both inclusive, App. p. 370-391 Account of foreign oats brought into consumption in Great Britain from 1815 to 1835 , App. p. 392 Similar return of rye other than foreign during the same years, App. p. 393-399.

\section{S.}

St. Etienne. Cutlery is manufactured there, Muntz 4608.

Sandars, Joseph. (Analysis of his Evidence.)-Corn-merchant at Liverpool, 3931, $393^{2}$ - The inportation of Irish wheat has not increased during the last two years, 39333935-CThe quantity grown has increased; imports at several periods since 1808 , 3937-3941 — These importations have had great effcct in depressing prices, 39423946 - Quantities of cattle, sheep, pigs, \&c., imported into Liverpool fiom 1829 to 1835 inclusive, $3947-3950$ - The annual value of Irish agricultural produce imported into Liverpool is about $8,000,000 \mathrm{l}, 3,395^{1-3954-C}$ - The price of labour in Irelard is lialf that paid in England, and their taxes are lighter, 3955-3962-Rents are as higlu as in England; the landlord has a lirger proportion of the produce, as taxes and labour do not diminish it, $3963-3967$ - Relative prices of Irish and English wheat; expense of transport; difference in quality, 3968-3974_-The Irish are insproving their cultivation, 3975 - Rents have not fallen in Ireland, $3976,3977$.

The greater quantity of corn consumed at Liverpool is Irish, $397^{8-3981}$ - The condition of the agricultural population of Ireland has improved generally within the last 20 years ; in England they are poorer, 3982-3990 - There has been extensive emigration from Ireland; many Protestants have left the country, 3991, 3992 - - The appearance of the Irish labourers who come to this country is improved, 3993-3996Ireland could not supply the whole of England with com, but can depress prices very much, 3997-4001 - W IV ages will not rise with prosperity as the population will increase too rapidly, 4002, 4003-C. Ireland can grow corn as cheap as France and Holland, 4004-4006--She can undersell the English grower in the market, 4007-4010- The quantity grown in Ireland is not indicated by the exports, as during the low prices unch has been used by distillers, 4011 - The late prices have not remunerated the Irish grower, as corn is not yet produced so cheaply as it might be, and rent is ligh, $4012-4015$.

The farmer was in great distress in 1833 ; wheat is the only article which is lower now, 4016-4018- There were abundant crops of spring corn in 1835 . except in some parts of Scotland, $4019-4024$ - The loss of sheep by rot in 1831 and 1832 obligred the farmer to grow more wheat, which has caused over-production, 4025-4028- - Less wheat has been sown this year, which will raise prices; lrish wheat will no longer be used for distillation, but will be exportecl, 4029-4035-And oats used instead, 4036 , 4037 - Much land will be laid down in grass, and the labourers must seek employment in the manufacturing districts, 4038,4039 - The railroads give work to great numbers, 4040, 404l- If com were warehoused abroad, speculation would not be restruined; warehousing would be cheaper, fo42-4047--Nen speculate in foreign 
Report, 1837 -continued.

Sandars, Joseph. (Analysis of his Evidence)-continued.

corn because it is cheaper, and they take the chance of the duty, 4048-4054Lowest prices at which foreign corn has been imported into Liverpool; freight from the Baltic, $4055,4056$.

The Cash Payments Bill of 1819 had very little effect in reducing prices, 4057-406o Corn fell in 1822, in consequence of the extraordinary crops of 1820 and 1821,4061 , 4062 - It rose again at the end of 1823 , as an increased issue by the lank and a continuance of one-pound notes encouraged speculation, 4063-4066-C'There are no external sigus of the distress of furmers, 4067 - Peel's Bill had an effect in depressing prices, 4068-4070-lt has not yet had its full effect upon landowners whose estates are charged with payments, 4071,4072 - Estimated loss to the agricultural interest in the drought of 1826 , and in the rot in the slieep in 1831 and $1832,4073,4074$

-If the currency were much extended there would soon be a panic, unless the standard were changed, 4075-4079- The adopition of a silver standard would raise prices 10 per cent., and enable debtors to pay $18 \mathrm{~s}$. in the pound, $40 \mathrm{OO}-4083$ - Effect of in extension of the currency and of Irish importations upon the cultivators of bad land, 4084-4086- Quantity of Canadian corn imported; much American corn cannot be brought through Canada, as the price is generally higher than in Europe, 40874092 - It is quite impossible for foreign flour to come through Ircland as Irish Hour, 4093 - Causes of wheat being grown cheaper on the Continent than in England; extract from Dr. Pinkerton's Past and Present State of Russia, 4094-4096.

Savings Banks. Have withdrawn money from circulation and placed it in the funds, Darid 1277,1278

Say, Mr. His opinion concerning the restoration of the gold standard in 1819 , Cayley 3654 .

Scoreby Estate (York, East Riding). Belongs to Mr. Wood; much land has been laid down in grass, on account of the cultivation of corn being unprofitable, Howard 20622071 - The tenants cannot pay their rent; every one has given notice to quit, Howard 2075-2079- Nature of the soil, Howard 2121-2126- - They undertook their farms with sufficient capital, Howard 2154-2158.

Scotch Notes. Increase the general circulation and do good to the public, Langhorne 3712-3728 — Scotch notes come over the border, but are immediately sent back again, Grey 4717 - Pressure less where Scotch notes are in circulation, and where the Scotch system of banking prevails, Grey 4724 .

Scotch Tenantry. Are better off than English, from their production of wool, Grey 4724 .

Scourging of Land. See Ocer-cropping.

Seignorage. Laws prior to 1819 regulating coin, by preventing the melting and exportation of coin, acted as a seignorage to the extent of two per cent., Attzood 5553, 5554.

Setllement, Lazo of. The aiteration in the law of settlement has been very beneficial, Twynam 731-737.

Settlements on Estates. Burthens imposed on witness's estate during the high prices, Bernard $1652-1654$ - Recommendation to landowners to use greater caution than is now observed in placing fixed charges or annuities ou their estates, Escott 5053 .

See also I,andowners. Rents.

Sharpe, Ahel. (Analysis of his Evidence.)-Lives at Mạidencroft, Hertfordshire, a farmer, and steward to Mr. D. Ratcliff, $3855-3859$ - The farmers are in great distress, particularly those on inferior lands, 386o-3863- Some prudent men have given up their farms, $3^{864-3869-R e n t s ~ a r e ~ p a i d ~ o u t ~ o f ~ c a p i t a l, ~} 3^{870}, 3^{871}$ — Rate of warres; the poor when employed are well off, $3^{872-3875-T h e ~ c o r n ~ l a w s ~ e n c o u r a g e ~ s p e c u l a t i o n ~ i n ~}$ forcign corn, $3^{8} 76-3878$ - The mininum duty should be raised to $8 s$., to be paid on entering the ports, 3879,3880 - British corn would then be warehoused in abundant seasons and distributed over seasons of scarcity, $3881-3885$ - Importers and speculators endeavour to force up the market, and then take their foreign corn out of bond at a nominal duty, 3886,3887 . When wheat is high the foreign grower could afford to pay 8 s. duty, which would be paid by the consumer in the form of price, if there were no duty, $3888-3898$.

Remunerating prices of wheat, barley and oats, $3^{899-3901-T h e ~ r e p e a l ~ o f ~ t h e ~ m a l t-~}$ tax would enable the farmers to supply their labourers with beer and their cattle with inferior barley malted; the beer-shops are demoralizing, 3902-3910-It is the general opinion that there have been fraudulent importations of foreign corn, 3911-Importations from Ireland, together with the presence of foreign corn in bond, depress prices, 3912-3915- - Maltsters do not trade with the capital of duty; there is not much competition in the trade, 3916,3917 .

The consumption of barley has not increased in proportion to the population, 391 8 , 3919-_-Barley is less grown in some counties than in others, but there are notie in which more could not be grown, 3920-3923 Chevalier barley is not so much nsed as 464 . 
Report, 1837 -continued.

Sharpe, Aliel. (Analysis of his Evidence)-continued.

it was, 3924, 3925-Much wheat has been used in feeding cattle, which would liave been warehoused if speculation had been directed to English corn, 3926-3928 - When there is a want of capital the cultivation of farms has deteriorated, $3929,393^{\circ}$.

Shaz, Sir John. Particulars respecting a lease of Crown lands held of, near Eltham, Green $17^{6-184} \cdot 210-215$.

Shecp. Estimated loss to the agricultural interest by the rot in sheep in 1831 and 18.32 , Sandars 4073- In Berkshire there has been rot, Allnatt 816,817 - The price of store slieep declined 30 or 40 per cent. from Narch 1835 to March 1836 , Thurnall $2338-2340$ -Value of slieep and lambs, including contingencies, Thurnall $2409-2421$.

In buying them as lambs, 1 . a head profit should be made on the two years, independent of the wool, Green 199-201-C Proportion of sheep to an acre of land, in Kent; several have been sold when the sale was not profitable, for want of food, and because their owners a anted money, Waring 120-127- In Dorsetshire have been selling well until this year, Taylor 3349-3353-The price is not satisfactory, as the turnip crops failed, Taylor 3361-3363 - The price of sheep-stock was very bad lust year in Sussex, Iludson $3444-3446$.

Advantages of keeping sheep for farming, Waring 88-90_-The effect of ploughing less land will be the necessity of using more artificial food for sheep in winter, Waring $140-1+1$.

See also Cattle.

Sheep Farmers. Are not in a bad condition in East Riding of Yorkshire, as the price of wool and mutton has been good, Hozard 2211-2215.223c-2234-Many farms where large flocks are kept lately let at high rents, in consequence of the high price of wool, Grey 4684 - Sheep farms generally in mountainous districts not nore than a sheep to an acre; on the Cheviot Hills much less, Grey 4687.

See also Stock Farms.

Sherborne, Mr. (Analysis of his Evidence.)-A farmer, near Hounslow; number of acres in lis occupation, rent, \&c., 4774-4779- Produce per acre, $4780-4784-$ The state of the farms near Hounslow is not flourishing, 'but they are well cultivated, and there are not more changes amongst the tenantry than usual, $4785-4789-$ Rent and quality of a farm held by witness at Harmondsworth, 4790-4797- The produce per acre, 47984800 - Uxbridge, the market is not so good as it was, 4801,4802 - Malıure procured from London; produce sent there, $4803-4806$ - Rate of wages, 4808 - Amount of poor rates; they have been reduced lately, $4809-4813$.

Witness has calculated the amount of produce in paying his rent, $4814-4816$ _ Wheat should be $7 s .6 d$. a bushel to pay a fair rent and profit to the farmer, $4817-4822-$ Cost of manure per acre, 4823,4824 - Cultivation of Hounslow Heath, $4825-4827--$ Sheep arc bought in the west of England, and fattened for the London market, $4828-4831$ - Two-thirds of the land are in corn every year, which is the best mode of farming, both for the land and the farmer, when there is plenty of manure, $4831-4835$ - Manner in which manure is procured from London; cost of each load, $4836-4840.4844$-There is the usual quantity of wheat in the farmers' stack yards, $4841,4842-$ - And the usual quantity has been sown, 4943 - The farmers complain of no particular burthen, but the repeal of the malt-tax would be a relief, $4845 \cdot 4846--$ They complain of low prices; but there is no difficulty in obtaining tenants, $4847-4849$.

Shoes. Are not cheaper, but are better made than formerly, Escott 4903 .

Shopkeepers. Do not supply farmers more cheaply, althongh they receive their goods from the manufacturers at 50 per cent. less than they did, Muntz 4563- - Suffer from agricultural distress; many who were anxious for the repeal of the corn laws are now desirous of sustaining the price of corn, Cayley 3574- - Nany have been bankrupt; they all complain of the want of the farmers' custom, Cayley $35^{87}, 3588$ - In Cambridgeshire are getting into a deplorable state; the farmers do not buy so much as they did, and do not pay their debts, Thurmall $2398-2407$.

Silver. See Bullion.

Silver Coinage. Evidence as to the Act of Parliament for the new silver coinage in 1816 , Pattison 5306-5314-Government holds the silver coinage in its own hands, Pattison $5+04$.

See also Privy Council.

Silver Standard. The adoption of silver, as an optional standard, proposed, Cayley 3670 This, in conjunction with the issue of one-pound notes by country bankers, would raise prices 20 per cent., Cayley 3671 - The landowner would gain in all his fixed payments; manufacturers and labourers would not have to pay a price for articles corresronding with their receipts, Cayley 3672 - Reasons why it would not be unjust to fixed anmuitants, Cayley $3674 \cdot$ Its advantages, Cayley $4125-4128$ - Being the staindard 
Report, 1837-continued.

\section{Silver Standard-continued.}

standard of other countries, is more accessible in panics, Cayley $4142-4144-\mathrm{W}^{\mathrm{T}}$ ould raise prices 10 per cent., and enable debtors to pay $18 \mathrm{~s}$. in the pound, Sandars $4080-$ 4083 - Would cause a rise in prices of six per cent., Attwood $554^{8}$.

Silver is less liable to fluctuation than gold, Spooner 4450,4451 - Silver should be the only standard, but pavments might be made in gold, Muntz 4539-4543_- If Parliament think fit that wheat should be $8 \mathrm{~s}$. a bushel, the silver standard should be $8 \mathrm{~s}$. an ounce, and the corn laws would be virtually repealed, Muntz 4616-4625.

Imperative on the Legislature to return to a silver standard of $5 s$. $2 d$., with a proportionate seignorage to the amount coin was depreciated in value by the old prohibitory laws, Altwood $559^{2}$ - Restoration of a silver standard and a seignorage would be a compromise between conflicting interests, between debtor and creditor, Attzood 5559 .

Sinking Fund. The reduetion of taxes, instead of keeping up the sinking fund, has been a great evil, liscott 5081,5082_- The national debt night have been reduced one-third, Escott 5083,5084 .

Smithfield Market. See Bcef. Butter. Cheese. Mutton. Pork. Veal.

Soap Duty. Doubts as to the expediency of repealing the duty, Spooner 4507,4508 .

South Downs. The farmers are better off than they were in 1822, Peyton'1531, 1532.

Spade Labour. A great deal of husbandry on farms in Armagh conducted by spade-labour Blacker 5626 .

SPECULATION :

\section{Generally.}

2. In Corn.

\section{Generally.}

Improvident speculation is the result of a defective currency, which accumulates capital, Spooner $443^{8-4440-W h e n ~ p r i c e s ~ a r e ~ l o w ~ t h e r e ~ i s ~ a l w a y s ~ c a p i t a l ~ f o r ~ s p e c u-~}$ lation, Letin $1024-1027$.

\section{In Corn.}

There is not much disposition to speculate in English corn, Jacob 252-255- Speculation in foreign corn is injurious to the farmer, Jacob 256,257 There has not been much disposition to speculate in corn until lately (February), Twynam 614-621_-The withdrawal of paper money restrained it, Trynam 631-633-The prospect of a diminished supply of wheat has encouraged speculation, Hodgson 1989-1991.

\section{Sec also Canals and Railroads. Corn Laws.}

Spooner, Richard. (Analysis of his Evidence.)-Advantages to the farmer in malting his own grain as food for cattle, $4295-4301$ - ' l he duty on malt should be transferred to beer brewed for sale by retall, $4303-4310$ - A sufticient duty night be raised Ipon cotton, hemp, flax and tallow, to supply the deficiency to the revenue, $4311-4322$ Towns dependent upon the supply of the agriculturists suffer much from their distress, $4323-4328$ - Birmingham felt this too, but its foreign trade has increased, 4329,4330 - Permission should be granterl to retail beer, to be consumed off the premises, dutyfree, and licenses should be given only to persons paying a certain amount of taxes, $4330-4331$.

Witness farms land of the first quality, near Worcester, which is very unprofitable, 4332-4:337 - T'he farmers are generally insolvent, except on the best lauds, which are unly one fourth of the country, $4338-4343$ - Much land must be thrown out of cultivation, rents reduced, and employment diminished, 4344,4345 - - The currency is the chief moving cause of distress, 4346,4347 - Accommodation is not extended to farmers as it was formerly, $4348-4350$ - The labourers are better paid than they were during the high prices; in Glamorganshire the farmer has to pay high wages, while his produce is depreciated by Irish exports, $435^{0-4355-T h i s ~ a p p l i e s ~ o n l y ~ t o ~ t h o s e ~ d i s t r i c t s ~ w i t h i n ~}$ the influence of manufacturing wages; in some counties wages are very low, $4356-435^{8}$ - The price of cotton goods is much reduced, but the woollen clothes once worn by the labouring classes were the product of this country, and their own manufacture, $4359-4364$.

Imports from Ireland have been diminished since prices wcre low, but will increase directly prices improve aqain, $4365-4367$ Unless lreland has poor laws, the condition of the Linglish labourer will be reduced to that of the Irish, $4368-4374$ - The tendency of Irish poor laws would be to raise wages, and put the labourers in a condition to consume their own corn, 4375-4381-CThere is no method of equalizing the lncal burthens upon manufucturing and agricultural property but a mational assessment, $4382-$ $43^{8} 5$ _ An alteration in the warehousing system would not restrain speculition in foreign corn; it would be warehoused abroad, employing foreign labour, $4386-4380$.

464 . 
Report, 1837 -continued.

Spooner, Richard. (Analysis of his Evidence)-continued.

[Second Examination.] - The main cause of low prices is our present monetary system, 4390 - History of the standard of this country; a return to the mixed gold and silver standard of 1797 would be an advantage to the public debtor of 15 per cent., $4391-4399$ - The export of coin could not be prevented, but might be restrained by prohibition, 4400- - There has been an increased import of gold (March), which has raised prices; when prices rise enough to make gold the most profitable export we shall lose it again, 4401 - Bad harrests would reuder an import of corn necessary, which must be paid for in gold, and still further diminish the circulating medium; dangerous consequences of sucli an event, $4401-4403$.

In adopting silver as the standard it should be $5 \mathrm{s.} 6 \%$. an ounce, which would raise prices 15 per cent., $4404-4406$ - This would be a bounty on the export of manufactures and the import of silver, $4407-4409$ - A larger issue of paper might also safely be made upon this more extended standard, 4410-4+13_-An increased price of agricultural produce would not affect the export of manufactures, for the returns would be measured by the same standard as the exports, 4414- - The goods would be sold abroad as cheaply as before; their value would remain the same, the nominal price only in this country would be changed, $4+15-4417$ - Departures which bave been made from the Cash Payments Bill of $1819,4+18$ - Reasons why the joint-stock banks grive assistance to the manufacturing and not to the agricultural interest, 4419 - The present advance of price in manufactures arises from the increased issues of the Bank and of jointstock banks ; it will not be permanent, 4420-4423.

The prices of wool, cattle, barley, oats and beans are high only on account of scarcity; the causes of scarcity enmmerated, $4424-4426$ - All these articles are low, as regards the fatmer, by reason of the currency, but high as regards the consumer, in consequence of scarcity, 4427-4429- The farmer cannot avail himself of a rise in price, as the difficulties of former years have obliged hin to sell his produce, $+430-4432-$ The operation of the currency is universal; the increased price of manufactures is caused by increased issues, and agriculturul produce is aiso rising, $4433-4437$ Improvident speculation is the result of our defective currency, which accumulates capital and withdraws it from the wholesome circulation of the country, $443^{8}-4+40$.

Justice requires the adoption of the standard of 1797 , as that of 1719 never existed before, 4441,4442 — The difference of 15 per cent. between the two standards calculated; present price of silver; legality of exporting cnin, 4443-4449--Silver is less liable to fuctuation, $4450,445 \mathrm{l}$ - Gold was not the practical standard previous to 1797 , $4452-4454-$ At $5 s .2 d$. an ounce silver would be aken largely to the Bank to be coined, $4455,4456-A$ large portion of the circulation should consist of national irredeemable paper, $4+57-4461$ - It should be compulsory to receive it, $4462-4464-$ It would be liable to depreciation as compared with gold, but should still be a legal tender, $4465-4467$ The danger of founding so large a circulation as our own upon $7,000,000 i$. of gold, which may be suddenly withdrawn, renders irredeemable paper necessary, 4468 4470 - The Bank has been placed under circumstances which rendered sound discretion, in regulating their issues impossible; if there were an irredeemable paper they might act with judgnuent, $4471,447^{2}$.

This national paper should be regulated by the amount of dividends; the foreign fundholder wust receive it, $4473-4475$ - It should be issived by Government and not by the Bank, 4476-Government is responsible to Parliament, and more to be depended upun, 4477 -There are not many foreigners possessing money in our funds, as the rate of interest is lower than abroad, $4478-4481$ - The payment of the dividends of fureigners in paper would not affect the credit of the country, but would avert those shocks to which it is liable, $44^{82}-44^{8}+$-Depreciation is in jtself bad, but that has been effected, and we are suffering from the attempt to revert to a higher standard, $4485-44^{8} 7$ - Another depreciation is a matter of justice to the debtor and safety to the creditor, 4488 - The Jow rate of interest in this country has a tendency to make other countries trade with our capital; this is not done by the United States of America, nor so much by other countries as formerly, $44^{8} 9-4494 \ldots$ A depreciation of the currency would enable the foreigner to pay us less, but would stimulate exports, 4495,4496 .

The manufacturing class have been in great prosperity for two years, and particularly for the last six months, while the agriculturists have been in distress, $+497-4503$ - Jointstock banks operate directly upon the former, and indirectly only upon the latter, who require long credit and cannot give negociable securities, $4504-4506$ - A duty on foreign tallow would be very beneficial to agriculture; doubts as to the expediency of repealing the duty on soap, 4507,4508 - A commutation of titlse, which would reliere the farmer from additional charges on improvements, would be raluable, $4509-4511$ _- Objections to certain parts of the Tithe Bill, $4512-4514$ - If practicable, poor and county rates should be paid out of the Exchequer, 4515-4517--The corn laws impose upon the Ianded interest the odium of a monopoly without affording them any protection, 4518 The land tax is very unequal; lands on which towns have been buit pay no more than they did before, 4519 .

Spring Wheal. Examination as to the comparative productiveness of spring and autumn wheat, Hodgson 1957-1963.

See also itheut, 4 . 
Report, 18:37-continued.

Stall-feeding. Stall-feeding the cattle has been much introduced, and with good effect, into the north of Ireland, Blacker 5620 .

Standard. Was fixed in 43 Eliz., 1601 , and continued immutable to 1816 , Attuood 5574 -Adjustment of the value of metals, which took place in the reign of James, was adopted by the advice of Lord Coke and Lord Bacon, Attwood 5575 - Unwise in this country to make any alteration in the staudard, Pattison 5360 - Present currency mixed; metallic and paper; latter convertible on demand into the former, which renders the currency as nearly metallic as could well be devised, Pattison 5469, 5542_-Banks are not restricted to gold only; silver is not the stundard by law, but has an influence upon the exchanges when sold as bullion, and answers almost every purpose of a second metal, Pattison 5494 .

See also Cash Payments Bill. Currency. Gold Standard. Joint Standard. Silcer Standard.

STOCK:

1. Prices thereof, and by what Circumstances infuenced.

2. How far profitable to the Farmer.

3. Papers laid before the Committee.

1. Prices thereof, and by what Circumstances infuenced.

The price of stock remains the same as in 1831 , Bennett $476-+79$ - Prices of lean and fat stock for the last few years, Wilson 1712-1719-The prices of lean stock are lower than they were some years since, Wilson $1782-1786$-II as lately been selling very well, Grey 4680-4682 - The price is good, by reason of the demand occasioned by the prosperity of the manufacturers, Tuynam 586-591-CThere is an improvement in the quality of stock, but not equal to the expenses, David 1258-1262.

Although the price is good, the turnip crop failed, and artificial food must be used, Dowling 2814-28:20 - The byeeding of cattle would have been more profitable if the turnips had not failed, Dowling 2899,2900 - Price of stock has lately been much higher, caused by the total loss of turnips, except Swedes, Escott 5038-Price low in Glamorganshire; much imported into Bristol from Ireland, Bradley 2509-2513.

2. How far profitable to the Farmer.

The profit on stock has not made up for the loss on corn, Taylor 3269-3271; Hudson $33^{81-33} 83$ - The profit on stock is not sufficient, when brought into the general account to save the farmer from loss, Allnatt 803,804 .

\section{Papers laid before the Committee.}

Return to an order of The House for an account of the number of stock (distinguishing the various kinds), and of the amount of butter, beef, pork, bacon and hams brought into Great Britain from Ireland, from 1826 to 1835 , both years inclusive, App. $p .365$

Account of the number of stock (distinguishing the various kinds), and of the amount of butter, beef, pork, bacon and hams brought into Great Britain from Ireland, from 1815 to 1825, App. p. 406 .

See also Cattle. Sheep.

Stock Farms. Cattle farmers in Glamorganshire are not suffering so much as corn farmers; sheep farms require less labour, David $1209^{-1} 213$ - Employ less labourers than arable farms, Twynam 592, 593- Present price of stock an encouragement to throw land into pasture; a great number of labourers will be thrown out of employ by that step, Escott 5039 - Amount of capital for purchasing the live and dead stock employed on a farm of 100 acres of good land, taking the stock at a valuation, Summers, $p .3^{22}$.

See also Sheep Farmers.

Strong Lands. See Clay Lands.

Styleman, Mr. Some land at Hunstanton belonging to him made a profit from Michaelmas 1822 to Michaelmas 1825, hut has since occasioned an annual loss, Carter 2934-2939 Statement of the annual losses since Michaelmas 1830 , Carter 2940-2946-The farm was equally well managed at both periods; causes of the different results, Carter 2947.

Suffolh Machine. See Drilling.

Summers, William. (Analysis of his Evidence.)--Land surveyor, residing at Ilton, Somersetshire, 5128 - All his life acquainted with agriculture, $5132-$ Agricultural interest at present in a very depressed state, 5133 - Generally speaking, tenants cannot pay rent, 5134 - Although more moderate than they have been, 5137 - Farmers have been paying their rents out of their capital, 5144 - First cause of distress was the withdrawing one-pound notes and the diminution of the circulating medium, $5^{146-\text { Although }}$ prices have varied since 1822 , tenantry have never been relieved from the depression of that period, 5157 - Labourers well employed, 5163- Farmers would be much relieved, and the market for labour added to, if the growth of flax was encouraged, $5166-5170 \cdots-$

Statement of the expense of cultivation of an an acre of flax, 5175 Statement of the 464 . 
Report, 1837-continued.

Shummers, William. (Analysis of his Evidence)-continned.

expense of cultivation of an acre of arable land, on the four-course system, and the profit or loss thereon, $519^{8}$ - Amount of capital for purchasing the live and dead stock employed on a farm of 100 acres of good land, taking the live and dead stock at a valuation, p.322- Produce of 100 acres of the average of the best land in the vale of Tauntun, p. 322 - Effect of the introdnction of Irish produce at Bristol on prices of agricultural produce, 5213-5227.

It would be a great advantage to farmers if an additional duty were imposed on tallow, 5236 - Farmers can get nothing, except clothing, at a cheaper rate than formerly, 52 $41-$ 5243 - Cultivation of wheat much lessened, 5245-Accounted for by the greatly increased growth of potatoes, 5246 - People better satisfied with potatoes than bread, $52+7-5251$ Little more than half the wheat consumed by labourers, as compared with former times, 5257,5258 - Incrcased consumption of pease, 5260 -Allotment system has contributed very much to the increased growth of potatoes, 5284 -Bad effect of beer-shops, which have contributed very much to demoralize the poor, 5283 - Might be decreased in number by taking off the duty on malt, 5290-Consumption of barley greatly increased since the establishment of beer-shops, 5291_Cultivation of flax would be considerably increased if the importation were prevented, 5297-5302.

Sussex. Produce per acre of wheat, barley, oats and beans, in the Weald and in the Down country, Hudson 3407-3411-The Weald farmers are more distressed than those on the hills, Hudson 3440-3443-But the Down farmers are not making a profit, Hudson $345^{6-3458 .}$

See also Capital. Farmers. Rents.

Sutton Estate (York, East Riding). Belongs to Colonel Hare. The produce has been diminishing for some years, Howurd 2059-2061 The rents have been reduced 50 per cent., and tenants have paid them by over-cropping, Howard $2080-2085$ - The estate is not in so good a condition as it was, so the landlord has, in fact, been paying his own rent, Howard 2086-2088_- Successive reductions of rent since 1816, Houcid 2110-2120 - Average produce per acre; nature of the land, and how cultivated, Howard $2094^{-}$ 2102 - Much pasture has been ploughed up and cropped, Howard 2103-2109.

Swansea. Comparison of the prices of corn at Swansea and Mark-iane; incorrectness of the averages, Bradley 2491-2500.

See also Averages.

Low :

1. Duty on Foreigu T'allow.

2. Low Prices of British Tallow.

1. Duty on Foreign 'Fallow.

Duty on foreign tallow would be very beneficial, Spooner 4507,4508 -Advantageous to farmers that an additional duty should be imposed on tallow, Summers $5256-\mathrm{A}$ higher duty on foreign tallow would increase the price of our own produce, and would not diminish the price of meat, Trumper 3232-3235-Price of tallow in 1812 and at the presellt time, Trumper 3238-3243-Quantity of foreign tallow consumed in the United Kingdom in each year, 1833 to $1835, p .59$.

\section{Low Prices of British Tallow.}

Calculations of losses to the yraziers upon sheep and bullocks, on account of the low prices of tallow, Wilson 1838 - Time at which the fat was equal in value to the meat, Wilson 1839 -The low price prevents the grazier from getting the same price for lis cattle, Wilson 1677-1679-It arises from the importations from Russia; amount thereof from 1828 to 1835 , Wilson $1680-1693$ - Prices since 1830 ; cattle have been less fat, Wilson 1726-1741 -The low price of tallow raises the price of meat, Green 202-206.

See also Graziers. Hides. Malt Tax, III.

Tankerville, Earl of. See Wages.

TAXATION :

\section{National. \\ 2. Local.}

1. National.

Has only been reduced nominally, and there are less means of paying it, Cayley 4122 , 4123 - T'he burthen is greater than during the war, Muntz $456.4-$ The taxes which press most heavily are those on bread, malt, tea, and other necessaries of life, Muntz $+565,4566$.

\section{Local.}

A national assessment is the only method of equalizing the local burthens upon agricultural and manufacturing property, Spooner $4382-43^{8} 5$ - The poor and comnty rate shou!d, 
Report, 1837-continued.

Taxation:-2. Local-continued.

should, if practicable, be paid out of the Exchequer, Spooner $4515-4517$ - The manufacturers du not contribute their just proportion of poor-rates, county-rates, road-rates or land-tax, David 1297-1300-The population has increased, and they employ more men and capital, David 1301-1303-Cliarge per acre on land in Kent for poor-rates, highway-rates and land-tax, Waring 59-6+-Paper on the unequal assessment of manufacturing and agricultural property in Lcicestershire, $p .154-\ln$ Worcestershire county rates are charged as highly on property in towns as in the country, Firchild $14^{23-1425}$.

Sce also Irelund. Leicestershive. Malt Tax. Poor Rales.

Taylor, James. (Analysis of his Evidence.) - A large farmer at Littlebury, in Dorsetshire, 3253-3258— There has been less distress in Dorsetshire than in any other county; the poor-rates are not heavy, and the lalsourers have cottiges and potito ground provided for them, 3259-3263- There is a loss on the cultivation of corn; on the fourcourse system the other crops do not compensate for the loss, $3264-3268$ - Nor does the price of stock, $3269-3271$ - Rents lave not been reduced to any anount, $3272-3276$ The present wages camot be continued unless the price of wheat rises, and labourers cannet live upon less, $3277-3283$ - The system of giving them a piece of land in a ficld, and manuring it for them, is preferable to the allotment system, $3284-3287$.

Average rent, tithes, wages, rates and taxes, and all otlier outgoings for each year for four years, of an acre of land, and the value of the produce, $3289-$ Lxplanations of this statement, $3290-3298$ — There is a loss upon all agricultural produce except wool, 32993302 - Butter fiom Ireland and Holland has ciepressed the price of English butter, 33033306 - System on which the farmers let cows to dairymen; rate of hire, disposal of the calves, \&c., 3307-3324-All agricultural produce comes from Ireland, to the injury of the farmers, $3325-3326$ - The quantity of corn land has not been increased lately, 3327, 3328 - The farmers are in a good state; they are nien of opulence, and have large farms with much down land, 3329-3332 - Average rent; the down lands are superior to those in Wiltshire or Hampshire, $3333-3336$-They will feed cows, but the situation is too high for corn; the last four seasons have been productive, 3337-33+1.

Number of sheep and cows kept by witness, $334^{2}-3348$ - The sheep stock have been selling well until this year; wool is at a great price, 3349-3354- Barley has been $26 \mathrm{~s}$., 3355,3356 - This has been a bad year; wimess would not feel satisfied that he could pay his rent at the present prices, $3357-3360$ - The price of sheep is not satisfactory, as the turnips failed, $3361-3363$ Highest price at which cows bave been let to dairymen, 3364,3365 - The repeal of the malt-tax would be a benefit to the landlord, the tenant and the public, $3366,3367 \ldots$ Rents have been reduced one-third within tlie last few years; further reduction will diminish the neans of the landlord to make improvements and will increase the poor-1ates, 3368,3369 .

Thanet, Isle of. See Isle of Thanet.

Thurnall, William. (Analysis of his Evilence.)-Occupier of land and chairman of the Agricultural Association of Cambridge, 2258-2240- - The farmers are in a most deplorable state, not from imprudence, but from the state of the times, 2241-2243- Rents have been reduced in some instances, but no farm in witness's neighbourhood is worth any rent whatever, $2244^{-2248}$ - He has a lease of a farm at Duxford, and lost more than the whole rent last year, 2249-2251-The abridgment of the circulating medium has been one cause, of distress; variations in the price of wheat since $1822,2252-2264$ - The competition of Irish produce, while the labourers of that country receive less wages, is another cause, 2265-2269-The farmers cannot pay their debts, $2270,2271-$ - Bankers will not trust them, because they know they are on the verge of insolvency, 2272_- The wages are 40 per cent. higher than can be afforded, but are continued as a kind of insurance of property, $2273^{-2276}$.

Objections to the corn laws: the bonding system encourages speculation in foreign corn, and the duty is not sufficiently high, $2277-2281$ - Some farmers living on their own lands camot pay their pool'rates, $2282-2284$ - The farmers expect relief from Parliament, 2285,2286 -CCapital has been reduced one-half by the low prices, 228-2289 - Nature of farming, of the soil, \&e., 2291-2302—— Produce of witness's farn in 1834 , in detail ; proportion of wheat, barley, stock, \&c., with the amount for which each was sold, 2303-2331_Deficient crops of barley, 2331-2336-The farmers complain of the price of all agricultural produce except wool, $2337-23 t^{1}$ - Since the withdra wal of one-pound notes from circulation there have never been fair prices, except when the crops were deficient, $2344-2365$.

The evil of the corn laws consists in making foreign com always ready to come into consumption when the price is rising rather than in the actual con-umption, $2366-237^{2}$ - If foreign corn paid duty on entering the ports it would afford sonie protection to the farmer, $2373^{-2} 3^{8}$ — The land is now less cultivated; farmers cannot afford the manure, 2383-2386-- - Statement of receipts and outgoings upon a farm of 400 acres at Duxford, in witness's occupation, 2388 - Corn could be brought to London from Flushing as soon as from Lynn, 2388-2390- An expansion of the currency would be a great relief, 2391-2392 The repeal of the malt-tax would benefit the farmer to a certain degree, $2393-2396 \frac{-39}{4}$ The
$4^{6} 4$. 
Report, 1837-continued.

Thurnall, Milliam. (Analysis of his Evidence)-continued.

The beer-shops have not injured the morals of the people in the manner described, 2397 .

The shopkeepers are getting into a deplorable state; the farmers do not buy so much and do not pay their debts, $2398-2407-$ - Pigs have sold in the London market at a loss of 15 per cent., $240 S$ - Value of sheep and lambs, including contingencies, 2409-2421 - Statement of the proceeds and expenses attending the cultivation of an off-land farm of 657 acres in the parish of Duxford, from 1831 to 1835 , in the occupation of Mr. Peter Grain, on a corn rent, $2422-2426$.

Statement of the receipts and outgoings upon a farm of 400 acres at Duxford, in his occupation from Michaelmas 1834 to Michuelinas $1835, p .128$.

Tierney, Mr. Extract from his speceh, in 1819 , on the removal of distress in 1816 , by increased issues of bank-notes, Cayley $3^{6} 3^{\circ}$.

Tithe Bill. Objections to celtain parts thereof, Spooner 4512-4514-If the tithe were settled on just grounds, it would remove the impediment to the employment of capital on agricultural improvements, Grey 4735 - Relief which the present Tithe Bill is calculated to afford to agriculturists, Escott 5008-_ Explanations, Escott 5056-Rentingfarmer would not be benefited; his rent would be increased in proportion to the tithe which he would not have to pay, Escott 5008.

See also Tithes, infra.

TITHES :

\section{In Kind. \\ 2. Commutation. \\ 3. Composition.}

\section{In Kind.}

Are frequently taken in kind near Faversham and Canterbury, Nearne 1452 - Witness knows clergymen who always take their tithes in kind, and who will not give the parish a composition, Escott 5015,5016-Explanations of former evidence as to tithes taken in kind, Escott 5056-5059-Generally less rigorously exacted when in the hands of the clergy, Escott 5013 -Wituess knows many instances in which elergymen do not get half the value of their tithes, Escott 5014 .

\section{Commutation.}

An equitable commutation will be a relief to farmers, Cayley $4149-A$ commutation of tithe, that would relieve the farmer from additional charges on improvements, would be very valuable, Spooner 4509-4511 - If tithes are a tax on consumers, a commutation will be enforcing a burthen on the land which it does not now bear, Escott 5070 .

\section{Composition.}

Under composition, in estimating the compensation to be paid in money, the market value must be taken into consideration, Escott 5064 .

Toddington. See Poor Rates.

Tradesmen. See Shopkecpers.

Trumper, George. (Analysis of his Evidence.)-Lives at Norwood; has been a landsurveyor for 25 years, 3113-3117- The state of agriculture is very much depressed in all the southem counties, 3118-3120- The farmers on cold clay lands are the most distressed ; they pay their rents out of capital, 3121-3125-Many on the worst heary lands have failed, $3126-3128$ - Average rent of intermediate and good land, 31293131 - It cannot be paid without infringing on capital, 3132, 3133 - The poor have been well employed for three or four years, by the draining which has been done at the expense of landlords, 3134-3137 - The land cannot be cultivated at the present prices, and if laid down the poor will be deprived of their labour, $3^{1} 38,3139$.

The condition of the land has been improved within the last three years by dry summers, 3140-3142- Less labour and manure is employed upon it, 3143-3145-There has been a very large growth of wheat for the last four years; land has been too mich forced, 3146-3149- This was occasioned by the distress of the farmers, and is very injurious to the land, $3150-315 t$ - The importation of corn and pork from Ireland

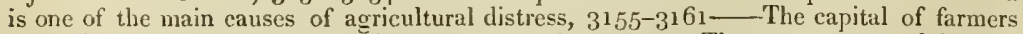
is nearly exhausted, but not by imprudence, $3162-316_{4}-$ The present race of farmers are living very economically; many have not comforts, and certainly not luxuries, $3165-$ 3167 .

The labourers, when regularly employed, are better off than they ever were, 3168$3170-M a n y$ are emigrating; there would be a less surplus of labour if agriculture were in a better state, $3171-3174-$ Variations in the rate of wages in different counties; in Lincolnshire, when the population is thin, wages are high; they are very low in Hamp- 
Reporl, 18:37-continucd.

Trumper, George. (Analysis of his Evidence)-continued.

shire, $3175-3184$ Cottage rents vary very much in different counties, 3185,3186 The small farmers are the nost distressed; their families once performed the greater part of the work, but the surplus population has discontinued this system, 3187, 3188There is rather a disposition to subdivide than consolidate farms, $3189^{-}-319^{2}-$ Rents have bcen recluced, since 1812 , from 30 to 40 , and in some cases 50 per cent., 3193,3194 .

Calculation of prices on which rents lave been settled, 3195,3196 - Price of wheat and barley at Uxbriclge (March), 3197-3199_- If prices remain the same, a further reduction of 15 per ccut. will be necessary, $3200-3202,3219,3220$ - The drainage of land has made it capable of producing more corn, $3203-3206$ - Some of the poorest clay lands require a reduction of 100 per cent. in rent, 3207-3212-little improvement. has been made in cultivating them, 321:3-3215- Some will not produce so much as they did in $1793,3216,3217-$ On the Hertfordshire side of Essex wages are only 8 s., 3218 - Wages are lower where the supply of fuel is cheap, as at the New Forest, $3221-$ 3223 .

The repeal of the malt-tax would benefit the farmer, and the labourer still more, 3224 , 3227 -No other article, the produce of the farmer, is taxed so highly; the maltster will only buy the finest barley, 3228,3229 - The growth of flax would impoverish the land, 3230,3231 - A higher duty on foreign tallow would increase the price of our own produce, 3232,3233 - And would not diminish the price of meat, 3234,3235 - The graziers have more resources than other farmers, 3236,3237 -Tallow was $9 d$. a pound in 1812 , and is now only $3 \frac{1}{2} d$.; the price of hides lias also fallen, $323^{8}-3243$ - Wages must be reduced if there are not better prices, $3244-3246$ - In some places much wheat is on the farmers' hands, but not more than usual, 3247-3249- Each of the years from 1832 to 1835 inclusive, have been good years for wheat, $3^{2} 5^{0-3252}$.

Turner, John Beresford. (Analysis of his Evidence.)-Farms his own estate in Herefordshire, 4097 - The state of the farmers is very indifferent; many cammot pay their rents, although they have been reduced; some who have been fortunate as traders have made a profit, $4098-4104$ - Those on cold clay lands must have wasted their capital, 4105-4106-Witness cannot let some of his farms at a very low rent, in consequence of low prices, $4107-4110$.

Turnips. Evidence as to quantity of tumips grown to an acre, Escott 4868 . See also Sheep. Stock.

Twynam, J. T. (Analysis of his Evidence.)-A farmer at Whitchurch, in Hampshire, 553-561 - The state of agriculture is distressed, particularly in strong clay lands, 562564 - Rents have been reduced, and the condition of the farmers is better than in other counties, but they cannot continue to grow wheat at the present prices, $562-573-$ The poor have been generally employed since $1831,574-578$-Rick-burnings ceased when employment was found, 579,580 - With the present wages wheat should be $60 s$. the quarter to remunerate the farmer, $581-583$ - The wages are nearly equal to the rent, 594,585 - The price of stock is good, by reason of the demand occasioned by the prosperity of the manufacturers, $586-591$ - Fewer labourers are employed on a stock farm, 592, 593-Calculation that the produce of wheat in England and Ireland and importations exceed the consumption by two-fifths; depression of the warket attributed to this excess, $594-607$.

The capital of farmers has been much diminished; they are obliged to bring their corn to market, and thus depress prices, 608-610-Much business is done with borrowed capital, 611-613 - There has not been much disposition to speculate in corn until lately, 614-621 The increased culture of the potato is one cause of the depreciation of wheat, 622,623 - The allotment system, though beneficial to the labourers, has had the same effect, 624_- The change in the currency was the commencement of agricultural distress, $625-630-$ The withdrawal of paper money restrained speculation, $631-633$ - Examination as to the prices of wheat since 1822 , and the effects of the currency thereupon, $634-664$ - Effect of the importations of wheat in 1829,1830 and 1831 11pon the present prices, $665-671$ - The five-course system of farming prevails in Hampshire, $672-677$ Great improvements have been made; more corn is grown, 678-681-Wool and sheep are both selling well, $68_{2}-686$ - And the price of barley is fair, 687,688 .

Wages were reduced at Michaelmas from $9 s$. to $8 s, 680-C 90$ - The poor-rates are $3 s$. in the pound; $6 d$. will be saved by the union under the Poor law, 6g1-6gs_- The price of wheat has improved 15 per cent., 699-701. - The tithes are paid under composition, and are higher than they fairly should be, $702-706$ - Importations from Ireland and the Channel islands in 1834 , to the extent of $1,000,000$ quarters, will not account for the depression of prices, 707,708 - The price of barley will not compensate for that of wheat, 709-The present wages cannot be continued, 710-C The Poor Law has compelled the labourers to seek employment, $711-713$ - They would be all employed, if prices were remunerating, 714-716_- Witness does not recollect so many good year's for wheat in succession as there have been since $1828,717-722$ - The Poor Law and public works have relieved the union of surplus labour, $723-730$ - The alteration of the law of settlement has been very beneficial, $731-737$. 
Report, $1837-c o n t i n u e d$.

I.

Usury Laus. Since the usury laws have been altered, many transactions have taken place at. 7 这 per cent. interest, Muntz 4586 .

United States. See America. Gold Coinage. Interest.

Upland Farmers. See Farmers, 2.

Uxbridye. Is a good market, but not so good as it used to be, Sherborne $4801-4802$.

V.

Valuations. Nature thereof, taken on a tenant quitting his farm in certain counties, Peyton 1549-1550.

$V$ eal. Account of the prices of, at Smithfield and Leadenhall markets, from 1815 to 1835 , App. p. 400.

$W_{A G E S}:$

W:
1. Generally.
2. In particular Counties.
3. In Ireland.

1. Generally.

Average $10 \mathrm{~s}$. a week in Berkshire, Essex, Middlesex, Surrey, Sussex and Kent, Peyton $1540-1542 \longrightarrow$ Variatious in the rate of wages in different counties; in Lincolnshire, where the population is thin, wages are high; they are low in Hampshire, Berkshire and Oxfordshire, and in parts of Essex, Trumper 3175-3184.3218- Wages are low where fuel is cheap, as at the New Forest, Trumper 3221-3223-They must be reduced, Trumper $3244-3246$ - The reduction in the price of labour has borne no proportion to the price of wheat; it would not be safe to reduce the one to the level of the other, Allnatt 879-884_-Danger of a general reduction of wages, Cayley $4187-4188$.

\section{In particular Counties.}

In Bedfordshire: they have been reduced $1 \mathrm{~s}$. a week; they are now $8 \mathrm{~s}$. or $9 \mathrm{~s}$., Bennet $389,390--$ This is not more than sufficient to maintain a labourer's family, hut cannot be continued with the present prices, Bennett 391, 392-Berkshire: At Wallingford, from $8 s$. to $12 s$. $6 \mathrm{~d}$., Alnatt $865-836-$ Near Windsor they have not been reduced from fear of damage to property, Kendall 1114-1122—Cambridgeshire: are 40 per cent. higher in Cambridgeshire than can be afforded, but are continued as a kind of insurance of property, Thurnall 2273-2276_- In Dorsetshire: the present rate of wages cannot be continued, and labourers cannot live upon less, Taylur $3277-32 S_{3}$.

Glamorganshire: ten shillings in Glamorganshire; it would be dangerons to rednce them, bnt they cannot be continued, David 1218-1222- In Hampshire: are nearly equal to the rent, Twynam 584,585 -Were reduced at Whitchurch, in Hampshire, from $9 \mathrm{~s}$. to $8 s$. at Michaelmas, Twywam 689,690 - The present rate camnot be continued, T'wynam $710-$ In Mertfordshire, $3873-$ Kent: are the same in Kent as they were 45 years ago; it will be impossible to continue them if prices do not improve, Waring 33-35Near Canterbury, Nearne $1468-1471$ - In the Isle of Thanet from $10 \mathrm{~s}$. to $12 \mathrm{~s}$.; this rate cannot be continued, unless prices improve, Cramp 747,748 .

In Norfolk: are reduced from $10 s .6 d$. to $9 s$. a week, Carter $2962-2968$ _ The farmers are afraid to make further reductions lest their property should be destroyed, Carter 2970-2974-In Northumberland: the farmers' servants are paid in; kind; conditions upon which Lord Tankerville hires his labourers, Langhorne $3^{8}+9^{-38} 5_{1}$ - This system gives the labourer an interest in the produce of the farm, Langhorne $385^{2}-3854-$ WVages are generally from $10 \mathrm{~s}$. to $12 \mathrm{~s}$. per week; regularly hired servants are paid in kind; generally have means to keep their families comfortable, Grey $469^{2}$ - Rate of wages : mode of payment, Grey 4691,4692 - The Northumberland system is advalltageons to the occupier, Cayley 4189-In Suffolk: Lewin 961, 962-In Blythburgh (Suffolk), 9s. a week, Cooper 2630, 2631 - Somersetshire: rate of wages given to labourers in Somersetshire about $7 \mathrm{~s}$. or $8 \mathrm{~s}$. per week, Escott 4885 - Wages in Somersetshire low, as compared with other counties, Escott 4839 .

In Sussex: the rate of wages is not influenced by any fear of destruction to property, Hudson 3469-3473 - In the Weald of Sussex, Hudson $3405,3406.3460-$ In Wiltshire: have been raised since the introduction of the new Poor Law, and are still on the increase, Hughes 3021,3022 - The poor would not quietly submit to a reduction, which must be made unless prices improve, and then the poor rates would be increased, Hughes $3023-3026-Y o r k s h i r e:$ from $10 s$. to $12 s$. throughont the year in the East Riding of Yorkshire, Howard 2152, 2153 - They have been reduced, but the price of the common necessaries of life has been proportionately diminished, Hovard 2159-2165Are high in the North Riding of Yorkshire, as much new land has been bronght into cultivation, Cayley 3579 They nust be reduced if prices do not improve, Cayley 3.58 ? 
[Report, 1837 -contimued.

ITages-continued.

3. In Trelaikb.

Price of labour in Armagh $1 \mathrm{~s}$. per diem in summer, and reduced to $10 d$. in winter, Blacker 5612 - Lower in the sonth of Ireland than in the northern counties, Blacker 5613 - Witness last year saw a man breaking stones in the south of Ireland at a price which would not realize $6 d$. per day, Blacker 5614 .

See also Fires. Labourers.

War Prices. The war did not occasion high prices; statement, showing that in all the wars of the last century prices rose at the peace, Cayley 3654 .

See also Prices.

Ward, Mr. Extract from lis Evidence in 1832 , ou the reduced issues of country banks subsequent to the Cash Payments Bill of 1819 , Cayley $3^{6} 3^{\circ}$.

Warchousing System. See Corn Laus, 2.

Waring, Thomas. (Analysis of his Evidence.)-A considerable occupier of land at Chelsfield, in Kent, 1-4- Has been connected with agriculture 45 years, 5-6--It is impossible for a farmer to make much profit by the cultivation of land for corn, 7-9-Calculation of the expense of cultivation and the value of produce, 10-12- - Rota of crops on the hill farms, 13-The farmer has no interest for his capital, 14, 15- Examination in detail as to the expenses and profits of successive crops, 16-32_-Wages are the same as they were 45 years ago; it will be impossible to employ labourers long at the present prices, $33-35-$ The poor are now tolerably satisfied, as a new turnpike-road gives employment, 36,37 Many were out of employment, and work was found upon the roads, $38-42$ - At the present prices land cannot be cultivated witl profit, even in the valleys, $43-47$ The average rent is $15 \mathrm{~s}$. an acre, 48 - Expense per acre of labour, ploughing, carting, manure, \&c., 49-58-Charge per acre for poor-rates, highway-rates and land-tax, $59-64-$ The distressed state of agriculture is occasioned cliefly by the low prices, $65-78$ - The poor farmers suffer the most; they are obliged to bring their corn to market, which reduces the prices, $79,80-$ Difference in the rate of poor-rates since $18_{23}$, when prices were low, $81-84$ - The small farmers will not be able to avail themselves of the rise in wheat, $8_{5}-87-$ Advantages of keeping slieep, 88-90.

Witness does not believe that the alteration in the currency affected agriculture, $91-$ Either less labour would be employed, or wages reduced, were it not for the fear of fires, 92-99-The average of rent on hill and low lands is 15 s. per acre, 100-107-_- Produce of wheat on lowlands, and quantity of seed, 108-113--In Orpington the poor are very discontented, and there have been many fires, 114-127-CThe present rents are paid out of capital, and not out of profits, 118, 119--Proportion of sheep to an acre of land; several have been sold, when it was not profitable, for want of food, and becanse the owners wanted money, 120-127-C The farmers are reducing their expenses by diminishing the cultivation of corn; witness has reduced his expenses in this manner, 128-131 The consequence of this practice will be the increase of poor-rates; witness employs fewer men, $132-137$ - The poor farmers have been obliged to reduce the number of their labourers, 138 - Witness has employed many in planting, 139-C-The effect of ploughing less is the necessity of using more artificial food for the sheep in winter, 140, 141.

Weights and Measures. Manner in which contracts were adjusted when the law regulating weights and measures was passed, Attwood 5555 .

WHEAT:

1. Used in feeding Cattle.

2. Prices of Wheat at different periods in England, Ireland and France.

3. Remunerating Prices.

4. Growth of.

5. Supply of.

6. Consumption of.

7. Inportation.

8. Stocks in hand.

9. Causes of Low Prices.

1. Used in feeding Cattle.

In Berkshire much wheat has been used in feeding cattle, Allnatt 903, 904 C- Cattle lave been fed upon it in Berks, Essex, Middlesex, Surrey, Sussex and Kent during the low prices, Peyton 1558, 1559--There has been an unusual consumption of wheat for farming purposes as a substitute for other food, Hodgson 2024-2027-Much wheat has been used in feeding cattle which would have been warehoused, if speculation had been directed to English corn, Sharpe 3926-3928.

\section{Prices of Wheat at different periods.}

Eight years since the price of wheat was as low as in the present year, Green $155-$ Variations in the price of wheat in different districts is greater in France than in England, 464 . 
Report, 1837 -confinued.

Wheat-2. Prices of Wheat at different Periods-continued.

Jacob 301,302 The average price for six months has been $3^{8 s}$.; nothing less than $60 s$. would be remunerating, $\mathscr{C}_{\text {ramp }} 744-746-V$ Variations of price since 1822 , Vearne $14^{8} 5^{-1} 492$ - In 1822 , the price was $7 s$. $6 \mathrm{~d}$. a bushel, and is now $5 \mathrm{~s}$.; the former was occasioned by a succession of wet seasons, the present is the natural price, Bernard $1,583,158_{4}$ The difference in the price of wheat in the English and Irish markets must be the same, taking into consideration the quality, with the expense of carriage, Hodgson 1919-1927-C Relative prices of Irish and English wheat; expense of transport; difference of quality, Sandars 3968-3974_L Lowest prices at which foreign corn has been imported into Liverpool ; freight from the Baltic, Sandirs 4055,4056 - Average prices of wheat in Mark-lane from 1815 to 1835 , both inclusive, App.p.370-391.

\section{Remunerating Prices.}

Is the staple article of the farmer; good crops of other descriptions of corn will not make up any deficiency in it, Bennett $528,529-$ With the present rate of wages, wheat should be $60 s$. a quarter to remunerate the farmer, Twynam 581-583-- With present rents, should be $16 l$. a load to make a profit, Allnatt $829-831$ - Whether the price be remunerating can be best ascertained by taking the average price for 20 years, as the article would not have been produced at a loss, Hodgson 1893-1904_- In Glamorganshire cannot be grown for less than $7 s$. a bushel; and on land cultivated upon the fallowing system, no price less than $9 s$. would be remunerating, Bradley $25^{25} 5-2527-$ Should be $60 \mathrm{~s}$. a quarter for Suffolk farmers to make a profit, Cooper $2659-2665$ - The price is more than one-third less than the remunerating price, while there is one-fourth more than the average produce, Hudson $3420-3425-$ In average seasons $56 \mathrm{~s}$. a quarter would be a remunerating price, Sharpe $3899-$ Should be $7 s .6 d$. a bushel to pay a fair rent, and leave a profit to the farmer, Sherborne $4817-4822$.

\section{Growth of.}

Less wheat than usual will now be grown; farmers will try something more profitable, Kendall 1180, 1181-Large importations of oats from Ireland have led to the increased cultivation of wheat, Hodgson 1878-1884-—Less sown this year in the East Riding of York, Howard 2207-2210--In Wiltshire little spring wheat is sown; it is of inferior quality, Hughes $3076-3078$ - In Dorsetshire there is a loss on the cultivation of corn ; on the four-course system the other crops do not compensate for the loss, Taylor 3264-3268- In Dorsetshire the quantity of corn land has not been increased lately, Taylor 3327,3328 - In Sussex, with the exception of last season, a greater breadth of wheat has been sown and larger crops produced, Hudson 3491, 3492-Less has been sown this year, Sundars 4029-4035- - In Wiltshire more has been sown in order to make up in quantity for the low price, Hughes $3072-3075$.

Causes of wheat being grown cheaper on the Continent than in England, Sandars $4094-4096$ - The usual quantity has been sown this year near Hounslow, Sherborne $48+3$ - Growth of wheat must materially decrease if the prices do not improve, Escott 4862 - Much smaller breadth of wheat this year than formerly, Escott 4864_Evidence as to quantity of wheat grown to an acre, Escott 4866 .

5. Supply of.

The quantity grown cannot safely be diminished; we should pay higher prices for foreign corn, $J_{a c o b} 239-242$ - For several years we have not grown sufficient for our population, $J a c o b 2+3^{-248}$ - The harvest of 1835 was an average crop, and the two preceding years rather above the average, Bennett $443-446$ - The markets are overstocked with wheat of our own growth, and thus the price is low, Allnatt 866-878 - The cause of the depression is superabundant production for three or four years, Hodgson 1870-_Over-production caused the low prices, and less wheat has been sown in the present year, Hodgson 1912-1918- If there should be another productive harvest, and the same quantity of wheat sown, prices must be lower still, IIodgson 19281930 - The spring corn was abundant in 1835 , except in some parts of Scotland, Sandars 4019-4024-The loss of sheep by rot in 1831 and $183^{2}$ obliged the farmers to grow more wheat, which has caused over-production, Sandars 4025-4028.

\section{Consumption.}

The inhabitants of the Continent consume very little wheat; it is a drug in their markets, Jacob 258-262_- In many parts of England the poor have changed their food from wheat to potatoes; but wheat has been substituted for barley and rye, Jacob $269-$ 282 - Estimated average consumption in England, Jacob 283, 284 - The quantity sold in the markets is no criterion of consumption; speculation causes frequent re-sales, the amount of which cannot be estimated, Jacob 334-347-The great bulk of the harvest of 1835 has already (February) been sent to market, Bennett 447, 448 - Calculation that the produce of wheat in England and Ireland, and importations, exceed the consumption by two-fifths; depression of the market attributed to this excess, Tuynam 595-607 - One-third less wheat has been sold this year, while consumption lias increased ; this will account for the rise in price, Firchild $1375^{-13} 7^{-8}$-Communication from Lord Kenyon to the Committee, as to the consumption of wheat of five families on 
Report, $1837-c o n t i m u e d$.

Wheat-6. Consumption-continued.

his estate, each laving allotments of land; wages of labourers, $p .361$ - Account of foreign wheat brought into consumption in Great Britain fiom 1815 to 1835 , both inclusive, App. p. $39^{2}$ _ Similar return for wheat, not foreign, during the sane years, App. p. 393-399.

\section{Importation.}

Imports from the Continent and from Ireland, Jaoob $285-287$ - The introduction of Irish corn will reduce the price of our own, and the allotment system and the poor laws will make the poor live upon potatoes, Lewin 1052-1058-Much land which orew oats was forced by large importations from Ireland to grow wheat; and then wheat was also imported from that country, Kendall 1140-1144-Foreign wheat lias not reduced the price of our own produce, which is rather to be referred to the glut of oats from Ireland, Dowling 28+1-28+3-Importations from I reland and the presence of foreign corn in bond, sharpe 3912-3915-Quantity imported from foreign parts in each of the years from 815 to 1835 , both inclusive, App. p. $366,3^{67}$.

\section{Stocks in hand.}

Time wheat may be kept without injury; best mode of preservation, Hodyson 19921996 - Effects of keeping wheat, upon its value, IIodgson 2035-2037 — In Sussex the large farmers have much wheat; the poorer have brought all theirs to market and depressed the prices, Kendall 1153-1159--In some places there is much in the farmers' hands, but not more than usual, Trumper 3247-3249-Near Ilounslow, there is (March) as much wheat as usual in the farmers stack-yards, Sizerborne 4841,4842 .

\section{Causes of Low Prices.}

Causes of the depression in the price; good crops; increased consumption of potatoes and meat, Bennet $539-5+4-$ The causes of low prices are excess of cultivation and importations from Ireland, Peyton 1512-1526_Explanation of the causes of the low price, Muntz 4535 .

See also Allotment System. American Corn and Flour. American Mines. Arable Farms. Corn. Corn Laws. Cultivation. Dantzic Wheat. Importations. Liverpool. Potatoes. Prices. Spring ITheat. Swansea.

\section{Wheelwrights. S'ee Artificers.}

Wigston (Leicestershire). Agricultural and manufacturing population thereof, and unequal contribution of the latter to the pogr-rates, $1 /$ ilson 1768 - Average of each description of land in the parish; agricultural and manufacturing population; proportion of rates contributed by land and houses; the land thrown out of cultivation by the rates, $p .155$.

See also Taxation.

Wilson, $H . W$. (Analysis of his Evidence.)-Resides in the grazing country at Allerton, in Leicestershire, 1668-1670-C Comploints of the graziers; low prices of tallow, 1671-1675

The price of hides has also fallen, 1676 _- The low price of tallow prevents the graziers from getting the same price for his cattle, $1677^{-1679^{\circ}}$ - It arises from importation from Russia; amount thereof from 1828 to $1835,1680-1693$ - The graziers are better off than they were some years since, as the price of wool has risen, 1696-1 700The agricultural counties were never in so much distress as at present, 1701-1703-C Improvements in the price of wool since 1828, 1704-1709--Number of pounds to a fleece, $1710,1711-$ - Prices of lean and fat stock, 1712-1710-C Prices of meat in the London market have not been remunerating, 1720-1725-Prices of tallow since 18:30; cattle have been less fat, $1726-1741-$ - Rents have been reduced from 10 to 15 per cent. and the farmers still complain, 1742-1752_- Many prudent persons have failed, $1753-1756$.

Unequal proportion of poor rates borne by the manufacturers in Leicestershire; case of the parish of Wigston, $1757^{-1} 7_{3}$ - The land-tax is generally redeemed, 1764,1765 - A larger proportion of manufacturers are committed to gaol than of agricultural labourers, 1766,1767 - The wages of manufacturers have leen made up ont of poorrates, 1768 - Children are employed; there is no employment for them in agriculture, $1769-1771$ - Machinery has taken away the employment of women and children in spinning, 1772-1774-The reduced prices of hides and fat are a positive loss to the farmer, $1775^{-17} 781$ The price of lean stock is lower than it was some years since, 1782-1 786 - Freeholders can get accommodation from their bankers more readily than farmers, who are so distressed, that they have no security, $17^{8} 7^{-1} 796$ - Evidence as to the growth of flax, hemp and rape, 1797-1804- Repeal of the malt duty would be a great relief, $1805^{-1807-G r e a t ~ i m p r o v e m e n t s ~ h a v e ~ t a k e n ~ p l a c e ~ i n ~ c a l t i v a t i o n ~ a n d ~}$ draining generally, at the expense of the landlord, 1808-1821_-Tenants have scourged the land, to save themselves from ruin, 1822-1825-Much grass land has been broken up, with the consent of landlords, for the payment of rent, $1826-1837$ - Calculations of lose to the grazier upon sheep and bullocks, on account of the low price of tallow, 1839 -Time at which the fat was equal in value to the meat, 1840-1848-Statement as to the condition of farmers in Norfolk and Suffolk, 1849 . 
Report, 1837 -continued.

Wilson, H. W. (Analysis of his Evidence)-contimued.

[Second Examination.]-Delivers in a paper containing statements of the unequal assessment of manufacturing and agricultural property in Leicestershire, 2912, 2913

Necessity of attending ta this injustice, and of revising the duties on foreign tallow, liides, \&c., 2914 .

Wood, Mr. Sce Scorcby Esiate.

WOOL:

1. Prices.

2. Causes of High Price.

1. Prices.

Quantity produced by sheep, Green 220 - The prices have been very high during the last two years, Green 221-224-Price good, Lewin 1047; Taylor 3299-3302; Hudson 3447,3448 ; Grey $4680-4682$ _ The price was very low from 1826 to 1830 , but is fair at present, Cooper $2680-2682$ _The price has improved about one-third since 1831 , Bennett 465-475-Improvements in the price since 1828 , Wilson 1704-1709-Number of pounds to a fleece, Wilson 1710,1711 .

\section{Causes of High Price.}

The improved price arises from the rot in sheep and the rise in the price of them, Bennett 503-506- The high price occasioned by the rot in sheep, Cayley 3620,3621

- Tabular statement of wool imported, and woollen goods exported, with calculations to prove that the prosperity of the woollen trade did not cause the rise in the price of wool, Cayley 3647.

See also Sheep.

Yeomen. Great numbers of, in East Cumberland, reduced to the greatest distress, owing to the pressure of the times, Blamire 5102-5113.

See also Freeholders.

Yeovil. Notice of a glove manufactory at Yeovil, Escott 5048.

Yorkshire. Statements of the expenses and profits of cultivation of land on the four-course and three-course systems of husbandry, Cayley 3534-3560. 



HD Gt. Brit. Parliament. House

1921 of Lords. Select Committee

A2'? to Inquire into the State of

1837 Agriculture in Finglend and Wales

Report 


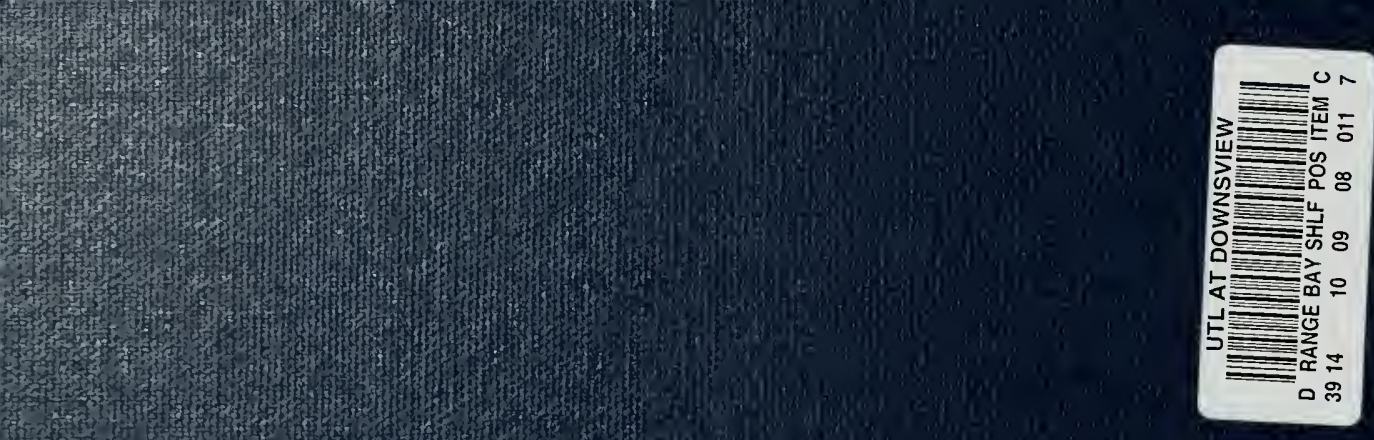
G 3.1. 3 Non

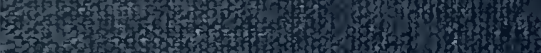

If

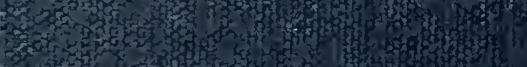

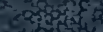

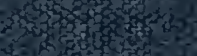

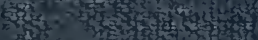

int

A (x)

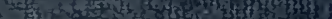

(y)

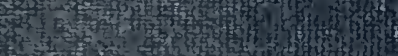

Thin

Hot

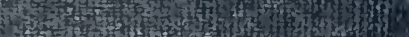

thon

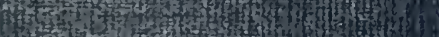

4t

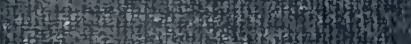

Mons 